\title{
Asymmetric Syntheses and Applications of Propargylic
} Alcohols and Amines

\author{
Jun Ying \\ Fenghua, Zhejiang, China
}

B.S. Pharmacy

East China University of Science and Technology, 2011

A Dissertation presented to the Graduate Faculty of the University of Virginia in Candidacy for the Degree of Doctor of Philosophy

Department of Chemistry

University of Virginia

August, 2016 


\begin{abstract}

\section{Asymmetric Syntheses and Applications of Propargylic Alcohols and Amines}

Chiral propargylic alcohols and amines are important building blocks for the synthesis of numerous pharmaceuticals, biologically active compounds and natural products. A number of catalytic systems have been reported for the highly enantioselective alkynylation of aldehydes and imines to access chiral propargylic alcohols and amines.
\end{abstract}

Using the chiral propargylic alcohols prepared from the asymmetric alkyne addition to aldehydes catalyzed by the $\mathrm{BINOL}-\mathrm{Ti}\left(\mathrm{O}^{i} \mathrm{Pr}\right)_{4}-\mathrm{Et}_{2} \mathrm{Zn}-\mathrm{Cy}_{2} \mathrm{NH}$ catalyst system, we have prepared a series of chiral propargylic triene-ynes with high enantiomeric purity (up to $92 \%$ ee). We have found that these compounds can undergo an efficient one-pot $\mathrm{Rh}(\mathrm{I})$-catalyzed domino $\mathrm{PK} / \mathrm{DA}$ cycloaddition to generate the multicyclic products with high chemoselectivity and stereoselectivity (up to $94 \%$ ee). These products contain the core structure of mangicol A, a natural product possessing significant anti-inflammatory activity.

A series of chiral propargyl 2,4-hexadienyl ethers are also found to undergo a highly chemo- and stereoselective PK/DA cycloaddition to generate the tetracyclic products (up to $88 \%$ ee). This strategy is very efficient for the asymmetric synthesis of polycyclic compounds such as polyquinanes.

A 3,3'-di(1-diphenylmethylpiperazinyl)methyl $\mathrm{H}_{8} \mathrm{BINOL}$ compound has been developed to catalyze the asymmetric reaction of both alkyl and aryl alkynes with 
$N$-(diphenylphosphinoyl)imines in the presence of $\mathrm{Et}_{2} \mathrm{Zn}$ and $\mathrm{Ti}\left(\mathrm{O}^{i} \mathrm{Pr}\right)_{4}$. It exhibits unprecedented high enantioselectivity (up to $85 \%$ ee) for the alkyl alkyne addition to the $N$-(diphenylphosphinoyl)imines.

A $\mathrm{Au}(\mathrm{III})$-catalyzed regiospecific hydration of $N$-(diphenylphosphinoyl) propargylic amines has been developed to produce various $\beta$-amino ketones under mild conditions. The high enantiomeric purity of a chiral $N$-(diphenylphosphinoyl) propargylic amine $(85 \%$ ee) is maintained after the hydration which makes method useful for the asymmetric synthesis of chiral $\beta$-amino ketones. 


\section{Acknowledgements}

I would like to thank Prof. Pu for providing me the opportunity to pursue my graduate studies. I greatly appreciate his guidance and training during my graduate career. I would also like to thank Prof. Gunnoe, Prof. Harman and Prof. McGarvey for serving on my committee. I greatly appreciate all that they taught me in and out of class. I especially appreciate Prof. Wu's willingness to serve as the outside member of my committee.

I also am thankful for my labmates and friends who have helped me a lot, especially Wei Chen, Shanshan Yu, Chao Wang, Shifeng Nian, Xuedan Wu and Gengyu Du.

I am grateful for my family for supporting me and praying for me during my graduate career. I could not have made it through without their endless love, encouragement, trust and support. 


\section{Table of Contents}

Abstract

Chapter 1. Introduction to Asymmetric Syntheses and Applications of Propargylic Alcohols

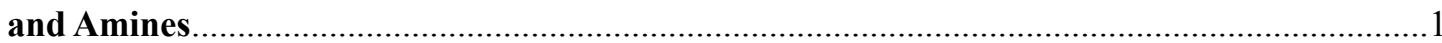

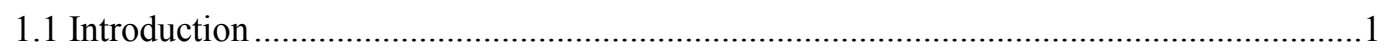

1.2 Asymmetric alkynylzinc addition to aldehydes.........................................................

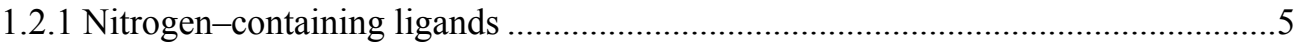

1.2.2. BINOL/ $\mathrm{H}_{8} \mathrm{BINOL}$ ligands ...................................................................... 14

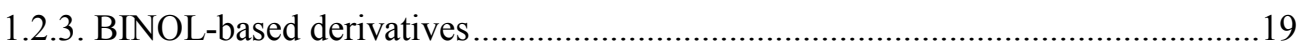

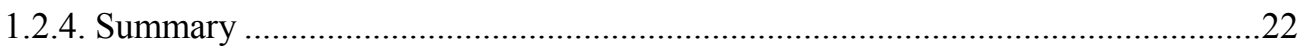

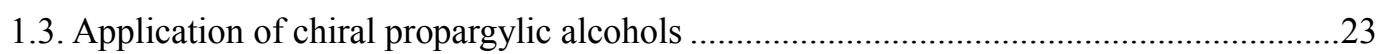

1.3.1 Diverse transformations of chiral propargylic alcohols.....................................23

1.3.2 Application in total synthesis ......................................................................27

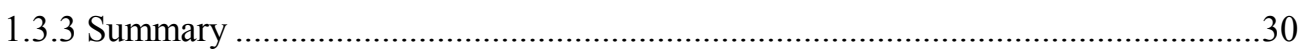

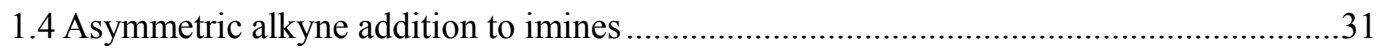

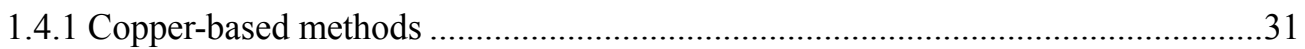

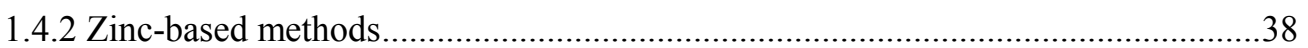

1.4.3 Other metals-based methods ....................................................................41

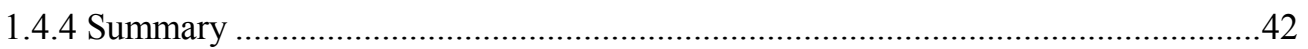

1.5. Application of chiral propargylic amines ...........................................................43

1.5.1 Diverse transformations of chiral propargylic amines......................................43

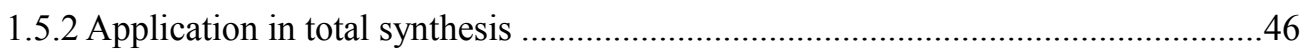

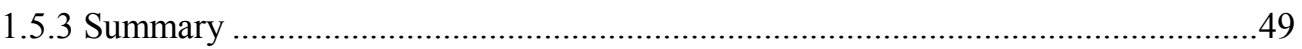

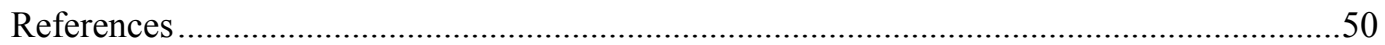

Chapter 2. A Facile Asymmetric Approach to the Multicyclic Core Structure of Mangicol A

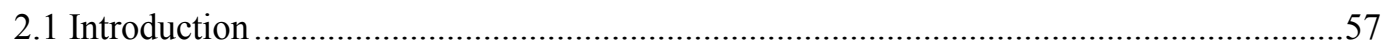

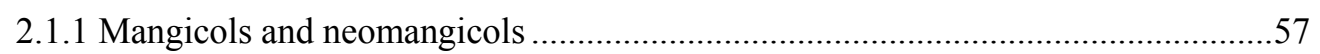

2.1.2. Biosynthesis of mangicols and neomangicols ...............................................5. 58

2.1.3. Approaches to mangicols and neomangicols..................................................60

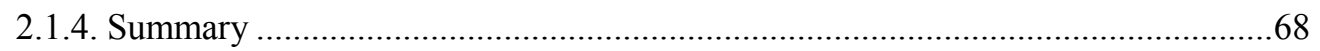

2.2 Construction of the core structure of mangicol A .......................................................69

2.2.1 Preliminary investigation of PK/DA strategy ................................................... 71

2.2.2 Asymmetric approach to the multicyclic core structure of mangicol A ................72

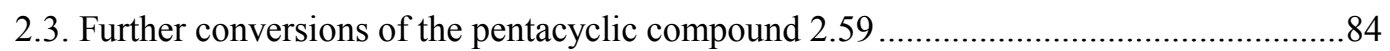

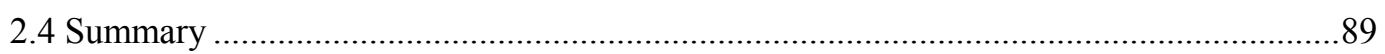




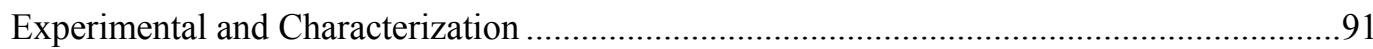

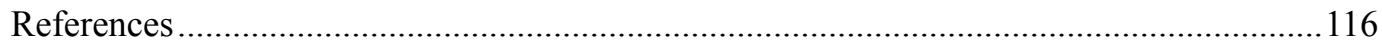

Chapter 3. Rh(I)-Catalyzed Chemo- and Stereoselective Domino Cycloaddition of Optically

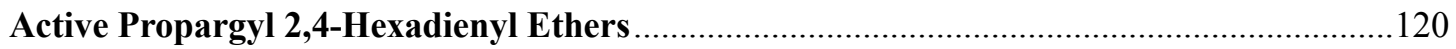

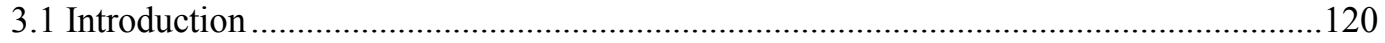

3.1.1 Co-catalyzed Pauson-Khand-based domino reactions ........................................121

3.1.2 Rh-catalyzed Pauson-Khand-based domino reactions .......................................123

3.2 $\mathrm{Rh}(\mathrm{I})$-catalyzed domino PK/DA cycloaddition of optically active propargyl

2,4-hexadienyl ethers 125

3.2.1 Preparation of chiral propargylic alcohols by the catalytic asymmetric alkyne addition to aldehydes.

3.2.2 Preparation of the chiral propargylic ether-based dienediynes.

3.2.3 Catalytic domino PK/DA cycloaddition of the chiral propargylic ether-based dienediynes.

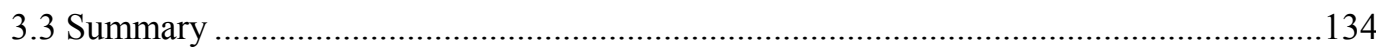

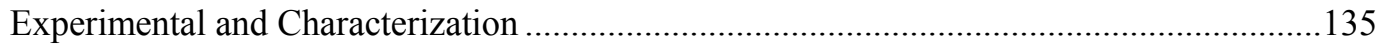

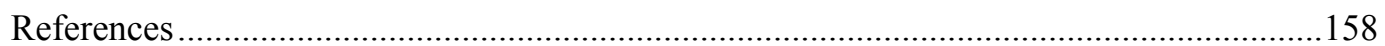

Chapter 4. Asymmetric Addition of Both Alkyl and Aryl Alkynes to

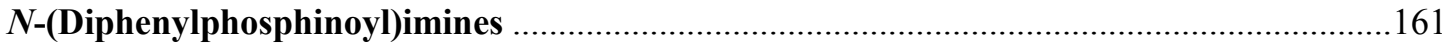

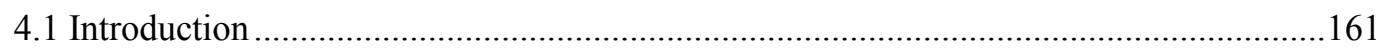

4.2 Catalytic asymmetric addition of both alkyl and aryl alkynes to

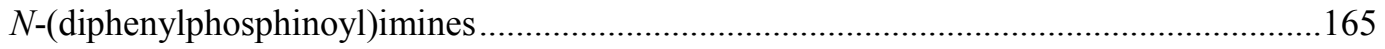

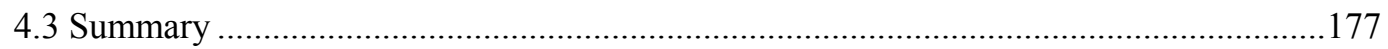

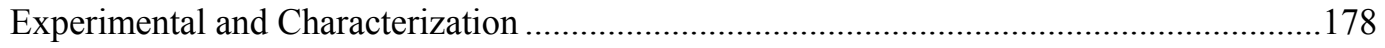

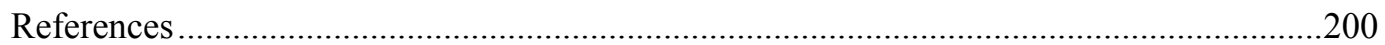

Chapter 5. Gold-catalyzed Regiospecific Hydration of Propargylic $N$-(diphenylphosphinoyl)

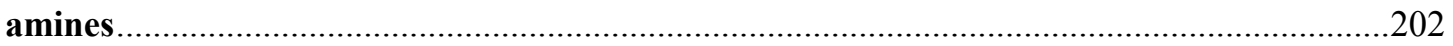

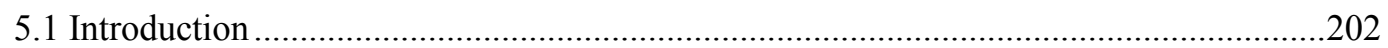

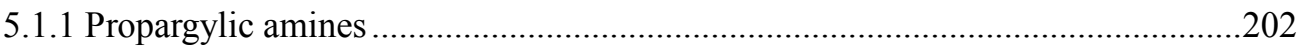

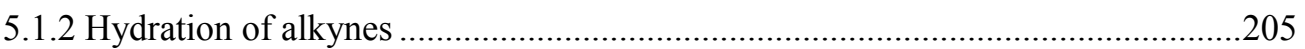

5.2. Gold-catalyzed regiospecific hydration of propargylic $N$-(diphenylphosphinoyl) amines

209

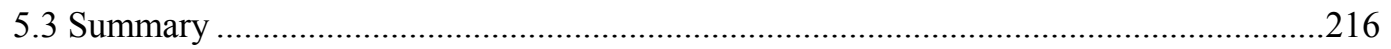

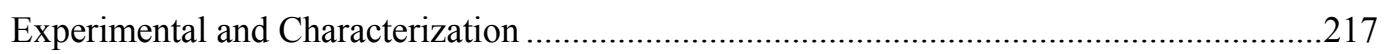

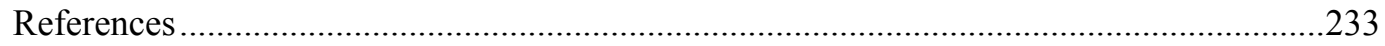

Chapter 6. Attempted Research: Asymmetric Reformatsky Reaction Catalyzed by the

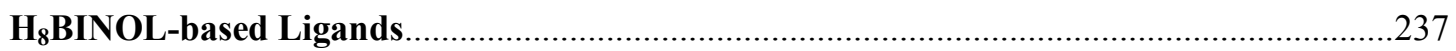

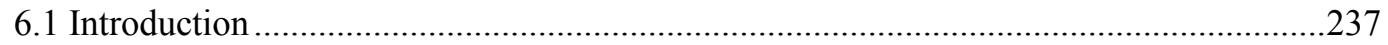

6.2 Asymmetric reformatsky reaction catalyzed by the $\mathrm{H}_{8} \mathrm{BINOL-based} \mathrm{ligands} \mathrm{.................242}$

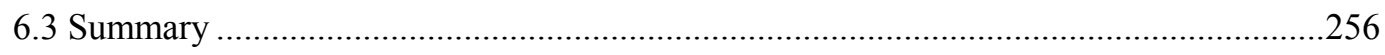

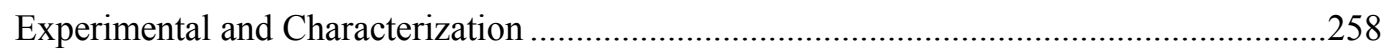

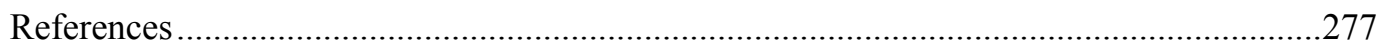

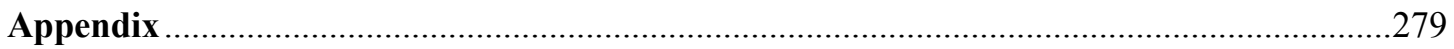




\section{List of Figures}

Figure 1.1. Chiral propargylic alcohols

Figure 1.2. Various transformations from the chiral propargylic alcohol 1.1

Figure 1.3. Two methods to access chiral propargylic alcohols

Figure 1.4. Proposed intermediate A1 for alkyne addition to aldehydes by using Carreria's catalytic system

Figure 1.5. Proposed mechanism for the ProPhenol-catalyzed alkyne addition to aldehydes

Figure 1.6. Other amino alcohol ligands and sulphur-containing ligands

Figure 1.7. Other amide ligands

Figure 1.8. Pyridyl and alkaloid ligands

Figure 1.9. $\mathrm{BINOL}$ and $\mathrm{H}_{8} \mathrm{BINOL}$

Figure 1.10. Proposed intermediate $\mathbf{B}$ for the $\mathrm{BINOL} / \mathrm{Et}_{2} \mathrm{Zn} / \mathrm{Ti}\left(\mathrm{O}^{i} \mathrm{Pr}\right)_{4}$ catalyzed alkyne addition to aldehydes

Figure 1.11. 3,3'-substituted BINOL ligands 1.46-1.52

Figure 1.12. Diverse transformations of chiral propargylic alcohols

Figure 1.13. Polyacetylenic compounds

Figure 1.14. Polymer-bound Pybox ligands

Figure 1.15. Proposed mechanism for alkyne addition to imines catalyzed by the binaphthyl-imine ligand $\mathbf{1 . 9 8}$ 
Figure 1.16. Proposed mechanism for alkyne addition to imines catalyzed by Quinap

\subsection{7}

Figure 1.17. HIV reverse transcriptase inhibitors

Figure 2.1. Mangicols A-G

Figure 2.2. Neomangicols A-C

Figure 2.3. ${ }^{1} \mathrm{H}$ NMR signal assignment of compound 3a

Figure 2.4. ${ }^{1} \mathrm{H}$ NMR signal assignments of compound 3c

Figure 2.5. Diastereoselective alkene hydrogenation and carbonyl reduction

Figure 3.1. Examples of polyquinanes containing rings jointed by a quaternary carbon

Figure 3.2. ${ }^{1} \mathrm{H}$ NMR signal assignments of compound 4a

Figure 3.3. Observed NOE effects of compound $\mathbf{4 a}$ and a molecular modeling structure

Figure 3.4. Structure of compound $\mathbf{4 d}$ determined by X-ray analysis

Figure 3.5. Additional dienediyne substrates studied

Figure 4.1. Chiral $\mathrm{H}_{8} \mathrm{BINOL}$ derivatives containing monomorpholinylmethyl substitutents

Figure 4.2. The structure of intermediate $\mathbf{A}$

Figure 4.3. Chiral $\mathrm{H}_{8} \mathrm{BINOL}$ derivatives containing 3,3'-piperazinyl substituents

Figure 5.1. Proposed 6-endo-dig cyclized intermediate 5.27

Figure 5.2. Proposed 6-endo-dig cyclized intermediate $\mathbf{5 . 2 8}$ 


\section{List of Schemes}

Scheme 1.1. Sharpless's expoxidation, Noyori's hydrogenation and Knowles's hydrogenation

Scheme 1.2. The first catalytic enantioselective alkynylzinc addition to aldehydes

Scheme 1.3. Alkyne addition to aldehydes catalyzed by Tombo's ligand $\mathbf{1 . 1 4}$

Scheme 1.4. Alkyne addition to aldehydes catalyzed by Li’s amino alcohol ligand

\subsection{6}

Scheme 1.5. Alkyne addition to aldehydes by using Carreira's amino alcohol ligand

\subsection{8}

Scheme 1.6. Alkyne addition to aldehydes by using Jiang's amino alcohol 1.19

Scheme 1.7. Alkyne addition to aldehydes catalyzed by ProPhenol 1.20

Scheme 1.8. Phenylacetylene and methyl propiolate addition to aldehydes catalyzed by ligand $\mathbf{1 . 2 6}$

Scheme 1.9. TMS-acetylene addition to aldehydes catalyzed by ligand $\mathbf{1 . 2 7}$

Scheme 1.10. Alkyne addition to aldehydes catalyzed by Wang's sulfonamide ligands

Scheme 1.11. Chan's BINOL catalytic system for the alkynylzinc addition

Scheme 1.12. Pu's BINOL catalytic system for the alkynylzinc addition

Scheme 1.13. Pu's BINOL catalytic systems employing HMPA or $\mathrm{Cy}_{2} \mathrm{NH}$ as an additive

Scheme 1.14. Pu's BINOL catalytic systems employing Zn powder 
Scheme 1.15. 3,3'-substituted BINOL ligands $\mathbf{1 . 5 3 - 1 . 5 4}$ catalyzed alkynylzinc addition

Scheme 1.16. BINOL-imine ligands $\mathbf{1 . 5 5 - 1 . 5 6}$ catalyzed alkynylzinc addition

Scheme 1.17. Pauson-Khand reactions of the chiral enynes 1.70-1.72

Scheme 1.18. Asymmetric synthesis of the 5,5,7,6-polycyclic compound $\mathbf{1 . 7 9}$

Scheme 1.19. $\mathrm{Rh}(\mathrm{I})$-catalyzed domino intramolecular Pauson-Khand reaction and [4+2] cycloaddition

Scheme 1.20. Total synthesis of aspergillide B by using the ProPhenol-catalyzed alkyne addition strategy

Scheme 1.21. Total synthesis of (+)-spirolaxine methyl ether by using the ProPhenol-catalyzed alkyne addition strategy

Scheme 1.22. The first enantioselective copper-catalyzed alkyne addition to imines

Scheme 1.23. Alkyne addition to imines catalyzed by Pybox $\mathbf{1 . 9 5}$

Scheme 1.24. Alkyne addition to imines catalyzed by the binaphthyl-imine ligand

\subsection{8}

Scheme 1.25. Addition of phenylacetylene to $N$-benzylideneaniline catalyzed by binaphthyl-amine ligands

Scheme 1.26. Reaction of alkynes, aldehydes and amines catalyzed by $\mathrm{CuBr}$ and Quinap 1.107

Scheme 1.27. Asymmetric synthesis of the terminal propargylic amines $\mathbf{1 . 1 1 4}$

Scheme 1.28. Reaction of alkynes, aldehydes and amines catalyzed by $\mathrm{CuBr}$ and Pinap 
Scheme 1.29. Reaction of alkynes, aldehydes and 4-piperidone hydrochloride catalyzed by $\mathrm{CuBr}$ and Pinap

Scheme 1.30. Addition of cyclopropylacetylene to the cyclic acylimine $\mathbf{1 . 1 1 8}$

Scheme 1.31. Enantioselective three-component reaction catalyzed by $\mathbf{1 . 1 2 0}$

Scheme 1.32. Addition of alkynes to $N$-sulfonyl aldimines by using $\mathrm{Me}_{2} \mathrm{Zn}$ and $\mathbf{1 . 1 2 1}$

Scheme 1.33. Addition of terminal alkynes to $N$-(diphenylphosphinoyl) aldimines by using $\mathrm{Me}_{2} \mathrm{Zn}$ and $\mathbf{1 . 1 2 2}$

Scheme 1.34. Addition of terminal alkynes to $N$-(diphenylphosphinoyl) aldimines by using $\mathrm{Et}_{2} \mathrm{Zn}$ and 1.123-1.125

Scheme 1.35. Addition of mixed alkynylzinc reagents to $N$-arylimines by using ligand

$$
\text { 1.126 and } \mathrm{Zr} \text { complex }
$$

Scheme 1.36. Addition of the BINOL-based alkynylboronates 1.127 to $N$-acylaldimines

Scheme 1.37. Diverse transformations of the chiral propargylic amines $\mathbf{1 . 1 2 9}$

Scheme 1.38. Diverse transformations of chiral propargylic amines $\mathbf{1 . 1 3 3}$

Scheme 1.39. Diverse transformations of the chiral propargylic amine $\mathbf{1 . 1 3 8}$

Scheme 1.40. Total synthesis of $(S)-(+)$-coniine using an imine alkynylation strategy

Scheme 1.41. Total synthesis of (S)-homolaudanosine 1.145

Scheme 1.42. Total synthesis of a small-molecule inhibitor $\mathbf{1 . 1 4 6}$

Scheme 1.43. Total synthesis of (-)- $N$-acetylcolchinol

Scheme 2.1. Proposed biosynthesis of the mangicol core

Scheme 2.2. Transformation from the mangicol core to the neomangicol core

Scheme 2.3. Retrosynthetic analysis of the mangicol core 
Scheme 2.4. Synthesis of the Stille coupling partners 2.5 and 2.11

Scheme 2.5. Synthesis of the Nozaki-Hiyama-Kishi coupling precursor $\mathbf{2 . 1 4}$

Scheme 2.6. Transannular Diels-Alder reaction to form the mangicol core

Scheme 2.7. Retrosynthetic analysis of mangicol A

Scheme 2.8. Paquette's first strategy

Scheme 2.9. Retrosynthetic analysis of the tricyclic compounds

Scheme 2.10. First synthetic route

Scheme 2.11. Second synthetic route

Scheme 2.12. Synthesis of the side chain $\mathbf{2 . 3 5}$

Scheme 2.13. Retrosynthetic analysis of the neomangicol core

Scheme 2.14. Synthesis of the boronic ester $\mathbf{2 . 3 8}$

Scheme 2.15. Synthesis of the vinyl triflate $\mathbf{2 . 3 7}$

Scheme 2.16. Synthesis of the neomangicol core $\mathbf{2 . 5 0}$

Scheme 2.17. Rh(I)-catalyzed domino intramolecular Pauson-Khand and Diels-Alder cycloaddition

Scheme 2.18. A proposed approach to the multicyclic core structure of mangciol A

Scheme 2.19. Preparation of the racemic triene-yne $\mathbf{2 . 5 8}$

Scheme 2.20. Domino intramolecular PK/DA cycloaddition of the triene-yne $\mathbf{2 . 5 8}$

Scheme 2.21. Catalytic asymmetric alkyne addition to aldehydes to form the chiral propargylic alcohols $(R)-\mathbf{1 a - e}$

Scheme 2.22. Preparation of the chiral propargylic ether-based triene-ynes $(R)-\mathbf{2 a - e}$

Scheme 2.23. Catalytic conversion of $(R)-2 a$ to generate 3a 
Scheme 2.24. Catalytic conversion of $(R)-2 b$

Scheme 2.25. Catalytic conversion of $(R)-2 \mathrm{c}$

Scheme 2.26. Catalytic conversion of $(R)-2 d$

Scheme 2.27. Catalytic conversion of $(R)-2 \mathrm{e}$

Scheme 2.28. Catalytic conversions of the racemic propargylic ethers $\mathbf{2 f - h}$

Scheme 2.29. A proposed mechanism for the formation of $\mathbf{3 a}$

Scheme 2.30. Proposed intermediates for the $\mathrm{Rh}(\mathrm{I})$-catalyzed domino reaction

Scheme 2.31. Further conversions of 2.59

Scheme 2.32. Test of ring cleavage of $\mathbf{2 . 6 7}$

Scheme 2.33. Test of various conditions for the ring cleavage of $\mathbf{2 . 6 6}$

Scheme 2.34. Synthesis of compound 2.69

Scheme 2.35. Test of the ring cleavage of $\mathbf{2 . 6 9}$

Scheme 2.36. Test of the ring cleavage of $\mathbf{2 . 5 9}$

Scheme 2.37. $\mathrm{NaBr} / \mathrm{TBABr}$-promoted ring cleavage of $\mathbf{2 . 5 9}$

Scheme 3.1. Co-catalyzed domino $[2+2+1]$ and $[2+2+2]$ cycloaddition

Scheme 3.2. Co-catalyzed domino $[2+2+1]$ and $[4+2]$ cycloaddition

Scheme 3.3. One-pot Co-catalyzed domino Pauson-Khand and Diels-Alder reaction

Scheme 3.4. One-pot synthesis of fenestrane derivatives from dienediynes

Scheme 3.5. Synthesis of the tetracyclic compounds 3.10 from the dienediynes $\mathbf{3 . 9}$

Scheme 3.6. Synthesis of the tetracyclic compounds 3.12 from the triynes $\mathbf{3 . 1 1}$

Scheme 3.7. $\mathrm{Rh}(\mathrm{I})$-catalyzed domino intramolecular Pauson-Khand and Diels-Alder cycloaddition 
Scheme 3.8. Construction of the core structure of mangicol A via the domino PK/DA cycloaddition

Scheme 3.9. Catalytic conversion of $(R)-3 \mathbf{a}$ to generate 4a

Scheme 3.10. A proposed mechanism for the chemoselective and stereoselective domino PK/DA cycloadditions

Scheme 4.1. First $\mathrm{Cu}$-catalyzed enantioselective alkyne addition to $N$-arylimines

Scheme 4.2. An example for the removal of the $N$-aryl group

Scheme 4.3. An example for the removal of the $N$-diphenylphosphinoyl group

Scheme 4.4. The enantioselective alkyne addition to the $N$-(diphenylphosphinoyl)imines by using Wang's ligands

Scheme 4.5. The enantioselective alkyne addition to the $N$-(diphenylphosphinoyl)imines by using Pedro's ligands

Scheme 4.6. An aliphatic alkyne addition to the $N$-(diphenylphosphinoyl)imine 4.10

Scheme 4.7. Synthesis of 3,3'-di(aminomethyl) $\mathrm{H}_{8} \mathrm{BINOLs}$

Scheme 4.8. Screening of the nitrogen-containing acyclic and cyclic bases as the additive

Scheme 4.9. Reaction of aliphatic alkynes with $N$-(diphenylphosphinoyl)imines catalyzed by $(S)-\mathbf{4 . 1 1}$

Scheme 4.10. Reaction of aromatic alkynes with $N$-(diphenylphosphinoyl)imines catalyzed by $(S)-\mathbf{1 1}$

Scheme 5.1. Direct nucleophilic 1,2-addition of alkynes to imines

Scheme 5.2. First zinc-catalyzed addition of alkynes to imines 
Scheme 5.3. $\mathrm{Et}_{2} \mathrm{Zn}$-promoted alkynylation of nitrones

Scheme 5.4. An example for the removal of the $N$-diphenylphosphinoyl group

Scheme 5.5. $\mathrm{Me}_{2} \mathrm{Zn}$-promoted addition of alkynes to $N$-(diphenylphosphinoyl) amines

Scheme 5.6. Hydration of internal alkynes

Scheme 5.7. Regiospecific hydration of the $\gamma$-hydroxy- $\alpha, \beta$-acetylenic esters $\mathbf{5 . 7}$

Scheme 5.8. Regioselective hydration of the 3-alkynoates $\mathbf{5 . 1 0}$

Scheme 5.9. Regioselective hydration of the propargyl acetates $\mathbf{5 . 1 3}$

Scheme 5.10. Regioselective hydration of the terminal halo-substituted propargyl carboxylate $\mathbf{5 . 1 6}$

Scheme 5.11. Regioselective hydration of the $\gamma$-acetoxy- $\alpha, \beta$-alkynoates $\mathbf{5 . 1 9}$

Scheme 5.12. Regioselective hydration of the alkynes $\mathbf{5 . 2 2}$

Scheme 5.13. $\mathrm{Hg}$ (II)-catalyzed regioselective hydration of the $\mathrm{N}$-acetyl compound $\mathbf{5 . 2 5}$

Scheme 5.14. Synthesis of $\beta$-amino ketones

Scheme 5.15. Preparation of the propargylic $N$-(diphenylphosphinoyl) amines 1

Scheme 5.16. Gold-catalyzed hydration of the propargylic $N$-(diphenylphosphinoyl) amines 1

Scheme 5.17. Gold-catalyzed hydration of the chiral propargylic $N$-(diphenylphosphinoyl) amine $(S)-\mathbf{1 a}$

Scheme 5.18. Diastereoselective reduction of the racemic $\beta$-amino ketones $2 \mathbf{i}$

Scheme 6.1. The $\mathrm{Me}_{2} \mathrm{Zn}$-mediated Reformatsky reaction catalyzed by $[\mathrm{MnCl}(\mathrm{salen})] \mathbf{6 . 1}$

Scheme 6.2. The enantioselective three-component imino-Reformatsky reaction

Scheme 6.3. The Reformatsky reaction of aldehydes catalyzed by the 3, 3'-BINOL 
derivative ligand $\mathbf{6 . 3}$

Scheme 6.4. Proposed mechanism for the air-promoted Reformatsky reaction

Scheme 6.5. The Reformatsky reaction of aldehydes catalyzed by the chiral bisoxazolidine 6.4

Scheme 6.6. The ${ }^{t} \mathrm{BuOOH}$-promoted enantioselective Reformatsky reaction

Scheme 6.7. The Reformatsky reaction by using the BINOL/ $\mathrm{H}_{8} \mathrm{BINOL}-$ based bifunctional ligands L1-L9

Scheme 6.8. A new procedure for the Reformatsky reaction catalyzed by $\mathbf{L 1}$

Scheme 6.9. Extending the reaction time of step 1 and step 2

Scheme 6.10. Screening of the reaction conditions for the Reformatsky reaction catalyzed by $\mathbf{L} \mathbf{1}$

Scheme 6.11. The Reformatsky reaction catalyzed by ligands A1-A9

Scheme 6.12. The Reformatsky reaction catalyzed by ligands B1-B9

Scheme 6.13. The Reformatsky reaction catalyzed by ligands C1-C8

Scheme 6.14. The Reformatsky reaction catalyzed by ligands D1-D6

Scheme 6.15. Screening of nitrogen-containing additives

Scheme 6.16. Proposed mechanism for the Reformatsky reaction catalyzed by $\mathbf{C} \mathbf{1}$ 


\section{List of Tables}

Table 3.1. Catalytic asymmetric alkyne addition to aldehydes to form chiral propargylic alcohols

Table 3.2. Preparation of the chiral propargylic ether-based dienediynes

Table 3.3. Synthesis of more tetracyclic products 4 from the $\mathrm{Rh}(\mathrm{I})$-catalyzed domino PK/DA cycloaddition

Table 4.1. Results for the reaction of phenylacetylene with 4.10 catalyzed by $(S)-4.1$ $-(S)-4.3^{\text {a }}$

Table 4.2. Results for the reaction of phenylacetylene with 4.10 catalyzed by $(S)-4.4$ $-(S)-4.7^{\mathrm{a}}$

Table 4.3. Results for the reaction of phenylacetylene with 4.10 catalyzed by the piperazine derivatives $(S)-\mathbf{4 . 8}-(S)-4.11^{\text {a }}$

Table 4.4. Results for the reaction of phenylacetylene with $\mathbf{4 . 1 0}$ catalyzed by $(S)-\mathbf{4 . 1 1}{ }^{\mathrm{a}}$

Table 4.5. Results for the reaction of 1-hexyne with 4.10 catalyzed by $(S)-4.11^{\text {a }}$

Table 5.1. Screening of catalysts and solvents 


\section{Chapter 1. Introduction to Asymmetric Syntheses and}

\section{Applications of Propargylic Alcohols and Amines}

\subsection{Introduction}

Recent trends in pharmaceutical industry in the past decade demonstrate that drug discovery and development has moved away from the racemic drugs to single enantiomer drugs. ${ }^{1}$ The enantiomers show significant different properties in biological activity, pharmacokenetics and toxicity. ${ }^{2}$ The tragedy of thalidomide makes the pharmaceutical industry aware of the importance of introducing stereochemistry in drug development. Indeed, more than $50 \%$ of commercial drugs are enantiomers currently and nine of top ten best-selling drugs contain stereogenic centers. ${ }^{3}$ The demand for enantiomerically pure drugs has promoted the development of asymmetric synthesis, which is one of the most important methods to introduce stereochemistry. Asymmetric synthesis is composed of various synthetic methodologies employing chiral auxiliary, chiral reagent and chiral pool. ${ }^{3-5}$

Among the various strategies developed to conduct asymmetric synthesis, asymmetric catalysis has a prominent position. This chemical approach uses a small amount of enantiomerically pure catalysts to transform prochiral substances into valuable enantioenriched synthetic building blocks in large quantities. ${ }^{6}$ There are three general categories of the catalysts: transition metal complexes (organomettalic catalysis), enzymes (biocatalysis) and organic compounds (organocatalysis). Since the first report of the homogeneous $\mathrm{Cu}$-catalyzed asymmetric cyclopropanation, transition 
metal catalysis has seen an exponential growth in the last four decades. ${ }^{7}$ The tremendous progress in the field of transition metal-based asymmetric catalysis ultimately culminated in the award of Nobel Prize to K. Barry Sharpless, Ryoji Noyori and William S. Knowles in 2001. Sharpless's asymmetric expoxidation ${ }^{8}$, Noyori's asymmetric hydrogenation ${ }^{9}$ and Knowles's asymmetric hydrogenation ${ }^{10}$ have found broad application in asymmetric synthesis (Scheme 1.1).

Scheme 1.1. Sharpless's expoxidation, Noyori's hydrogenation and Knowles's hydrogenation

Sharpless Asymmetric Expoxidation

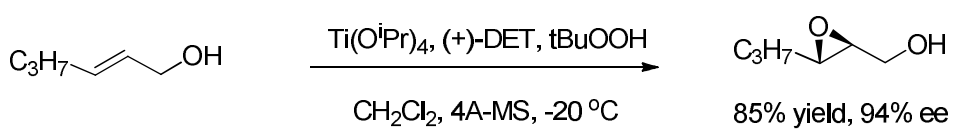

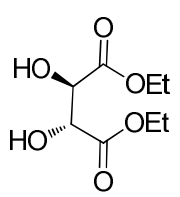

$(+)$-DET

Noyori Asymmetric Hydrogenation<smiles>COC(=O)CC(C)=O</smiles>

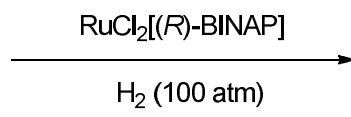<smiles>COC(=O)C[C@@H](C)O</smiles>

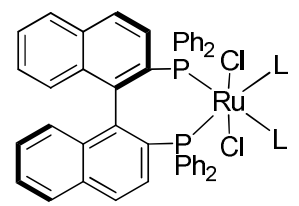

$\mathrm{RuCl}_{2}[(R)-\mathrm{BINAP}]$

\section{Knowles Asymmetric Hydrogenation}
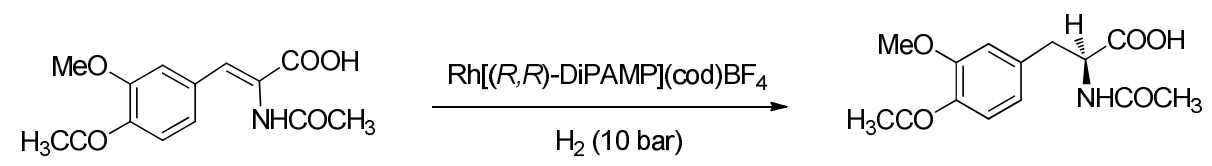

$90 \%$ yd, $95 \%$ ee

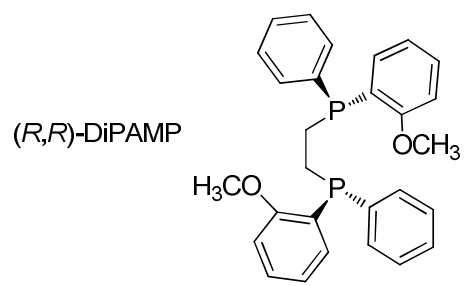




\subsection{Asymmetric alkynylzinc addition to aldehydes}

A propargylic alcohol is defined as an alkyne unit connected to a carbon bearing a hydroxyl group. Chiral propargylic alcohols, possessing chirality at the propargylic carbon, are useful building blocks in asymmetric synthesis (Figure 1.1). ${ }^{11} \mathrm{~A}$ variety of transformations can be achieved with the use of optically active propargylic alcohols as precursors due to the reactions of the alcohol and alkyne functionalities (Figure 1.2). This is demonstrated in the case of the chiral propargylic alcohol 1.1. The reaction of $\mathbf{1 . 1}$ with nucleophiles can lead to the optically active allenes $\mathbf{1 . 2}$. Selective hydrogenation can afford the alkanes $\mathbf{1 . 3}$ or the alkenes 1.4. Metal-catalyzed hydrostannation, hydroboration and hydrosilyation can produce the vinyl stannanes 1.5, the vinyl borates $\mathbf{1 . 6}$ and the vinyl silanes 1.7 , which can be further converted to the functionalized olefins $1.8 .^{12-14}$ Metal-catalyzed $[2+2+2]$ cycloaddition can generate the benzylic alcohol 1.9. ${ }^{15}$

Figure 1.1. Chiral propargylic alcohols

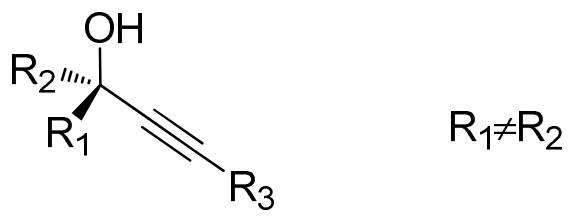

Chiral propargylic alcohols 
Figure 1.2. Various transformations from the chiral propargylic alcohol $\mathbf{1 . 1}$

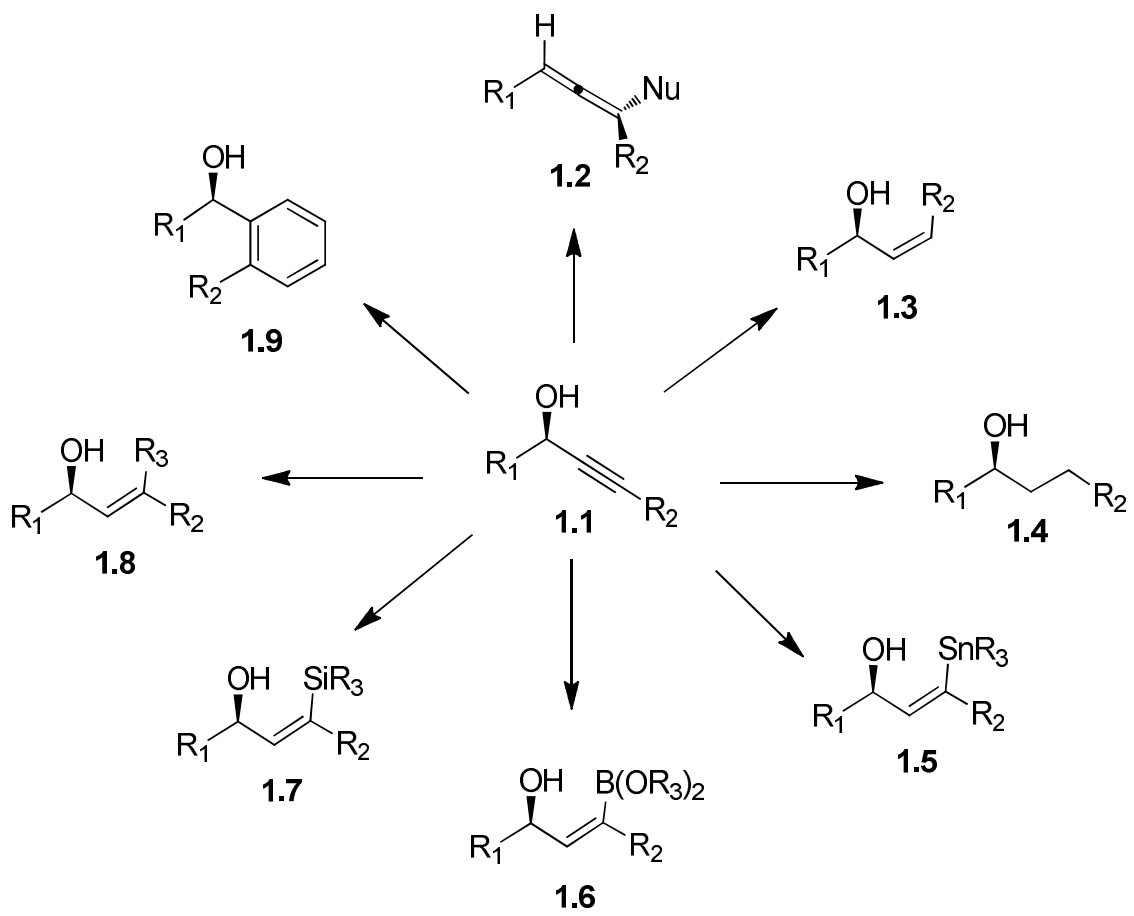

There are two traditional methods to produce optically active propargylic alcohols: asymmetric ynone reduction and asymmetric metal-catalyzed alkyne addition to carbonyl compounds (Figure 1.3). ${ }^{11}$ Although asymmetric ynone reduction has been widely studied, the application of this method is limited by the accessibility of ynone starting materials. In addition, tertiary propargylic alcohols cannot be obtained through ynone reduction. However, a carbon-carbon bond and a new stereogenic center can be formed in one step via asymmetric metal-catalyzed alkyne addition, which is more convenient to access chiral propargylic alcohols. Moreover, tertiary propargylic alcohols can be prepared when ketones are treated with alkynyl metal reagents. 
Figure 1.3. Two methods to access chiral propargylic alcohols<smiles>[R]C#CC([R])=O</smiles>

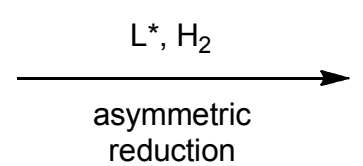<smiles>[R]C#CC([R])O</smiles><smiles>[R]C([R])=O</smiles>

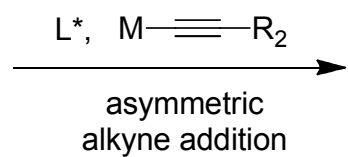<smiles>[R]C#CC([R3])([R3])O</smiles>

Among the asymmetric alkyne addition to aldehydes, using alkynylzinc reagents is the most studied. ${ }^{16-18}$ Unlike other metal reagents, alkynylzinc reagents can tolerate many functional groups such as esters, amides, nitro groups, halogens, silyl groups and nitriles. In addition, alkynylzinc reagents can be conveniently prepared in-situ under mild conditions. Also, alkynylzinc reagents show a slow rate of addition to carbonyl compounds in the absence of a catalyst and minimize the non-enantioselective background reaction. A series of representative catalyst systems are discussed below.

\subsubsection{Nitrogen-containing ligands}

\section{a. Amino alcohol ligands}

In the asymmetric alkynylzinc addition to aldehydes, chiral amino alcohols are the most studied ligands. The first catalytic enantioselective alkynylzinc addition to aldehydes was reported by Soai and Niwa in $1990 .{ }^{19}$ The highest ee (43\%) was observed when $20 \mathrm{~mol} \%$ of the chiral amino alcohol 1.13 was used in the reaction of benzaldehyde with the alkynylzinc derived from phenylacetylene and $\mathrm{Et}_{2} \mathrm{Zn}$ (Scheme 1.2). Other ligands gave much lower enantioselectivity 
Scheme 1.2. The first catalytic enantioselective alkynylzinc addition to aldehydes<smiles>[R]N([R])C(O)c1ccccc1</smiles>

1.10

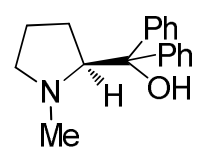

1.11<smiles>[R]C1CNCC([R])N1</smiles>

1.12<smiles>CC(c1ccccc1)C(O)N(C)C(C)(C)C</smiles>

In the same year, Tombo used stoichimetric amounts of the chiral amino alcohol lithium salt $\mathbf{1 . 1 4}$ in the asymmetric alkynylzinc addition to aldehydes and up to $88 \%$ ee was observed (Scheme 1.3.). ${ }^{20}$ The reaction was conducted at $0-5{ }^{\circ} \mathrm{C}$ in toluene in the presence of 1 equiv of ligand $\mathbf{1 . 1 4}$ and 2 equiv of the alkynylzinc reagent 1.15.

Scheme 1.3. Alkyne addition to aldehydes catalyzed by Tombo's ligand $\mathbf{1 . 1 4}$<smiles>O=Cc1ccc(F)c(Oc2ccccc2)c1</smiles>

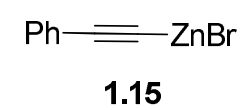
1.15<smiles>CC(C(O)c1ccccc1)C(O)C(C)N(C)C</smiles><smiles>O=S(=O)(O)c1ccc(C(O)C#CPc2ccccc2)cc1Oc1ccccc1</smiles>

$88 \%$ ee

In 1999, Li reported the use of the amino alcohols $\mathbf{1 . 1 6}$ and $\mathbf{1 . 1 7}$ in the addition of terminal alkynes to aromatic aldehydes (Scheme 1.4). ${ }^{21}$ When 10 mol \% ligand $\mathbf{1 . 1 6}$ was employed to catalyze the addition of phenylacetylene to 2-methoxy benzaldehyde at $-20{ }^{\circ} \mathrm{C}$, the expected propargylic alcohol was achieved with $74 \%$ yield and $82 \%$ ee. $\mathrm{Me}_{2} \mathrm{Zn}$ was used to form the alkynylzinc reagent in this reaction. 
Scheme 1.4. Alkyne addition to aldehydes catalyzed by Li's amino alcohol ligand 1.16<smiles>OC(c1ccccc1)C(c1ccccc1)N1CCCC1</smiles>

1.16

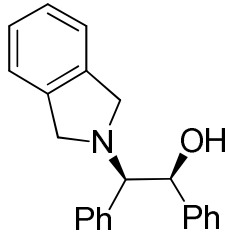

1.17

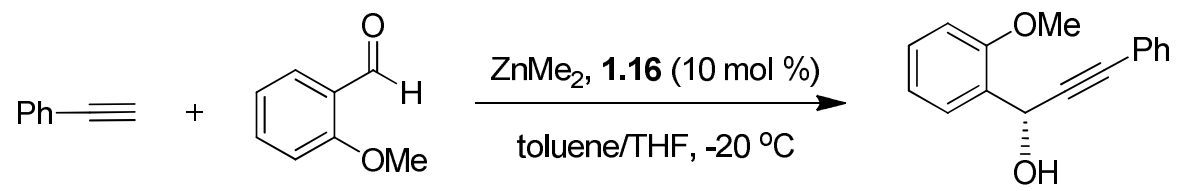

$74 \%$ yield, $82 \%$ ee

In 2000, Carreira and co-workers made great progress in asymmetric alkynylzinc addition to aldehydes. They used stoichiometric amounts of the chiral amino alcohol 1.18 in the asymmetric reaction of alkynes with a broad range of aldehydes (Scheme $1.5) .^{22}$ The reaction was conducted at room temperature in the presence of 1.1 equiv $\mathrm{Zn}(\mathrm{OTf})_{2}$ and 1.2 equiv $\mathrm{Et}_{3} \mathrm{~N}$ to produce propargylic alcohols with up to $99 \%$ ee. The mild conditions were applicable to both aromatic and aliphatic aldehydes and high enantioselectivity was observed. In these reactions, the alkynylzinc reagents were readily prepared from the reactions of terminal alkynes, $\mathrm{Zn}(\mathrm{OTf})_{2}$ and an amine base. In 2001, Carreria found the reaction could be carried out using a catalytic amount of $1.18(22 \mathrm{~mol} \%)$ and $\mathrm{Zn}(\mathrm{OTf})_{2}(20 \mathrm{~mol} \%)$ when increasing the temperature to 60 ${ }^{\circ} \mathrm{C} \cdot{ }^{23}$

Besides the high enantioselectivity this catalytic system provides, several advantages can be highlighted. First, alkynylzinc reagents are generated from alkynes and $\mathrm{Zn}(\mathrm{OTf})_{2}$. Expensive and reactive alkylzinc reagents $\left(\mathrm{Me}_{2} \mathrm{Zn}\right.$ and $\left.\mathrm{Et}_{2} \mathrm{Zn}\right)$ are avoided. Secondly, the system has been proved effective for a variety of alkynes and 
aldehydes. Finally, these reactions are conducted under mild conditions and the system is robust. The major drawback of the system is that Cannizaro reactions compete with the asymmetric reactions and result in reduced yields of the products when benzaldehyde is involved.

Scheme 1.5. Alkyne addition to aldehydes by using Carreira's amino alcohol ligand

\subsection{8}

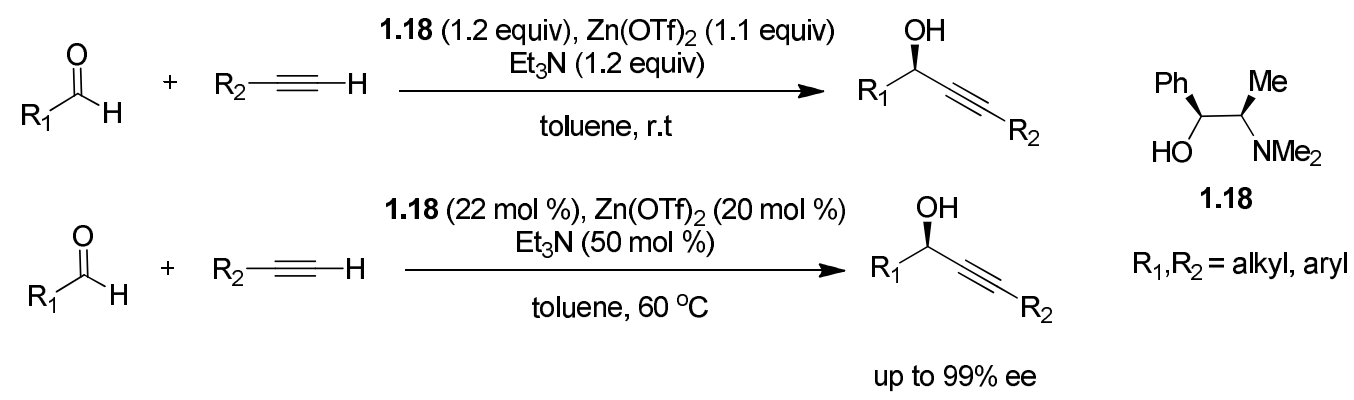

The intermediate $\mathbf{A 1}$ has been proposed to illustrate the enantioselective alkyne addition to aldehydes by using Carreria's catalytic system (Figure 1.4). Due to the interaction between the $R_{1}$ group of the aldehyde and the OTf group of the $\mathrm{Zn}$ complex, the intermediate $\mathbf{A 1}$ is more favorable than A2. The alkynyl group of $\mathbf{A 1}$ attacks the $s i$ face of the aldehyde forming the observed $(R)$-product.

Figure 1.4. Proposed intermediate A1 for alkyne addition to aldehydes by using Carreria's catalytic system

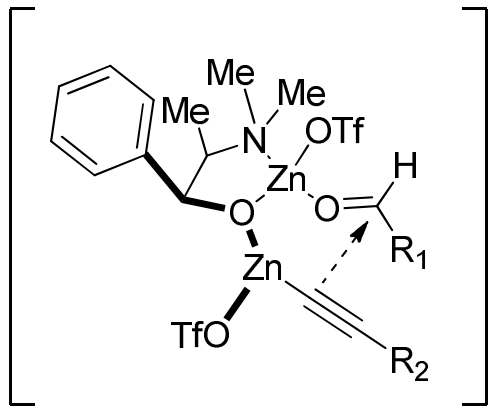

A1

favored

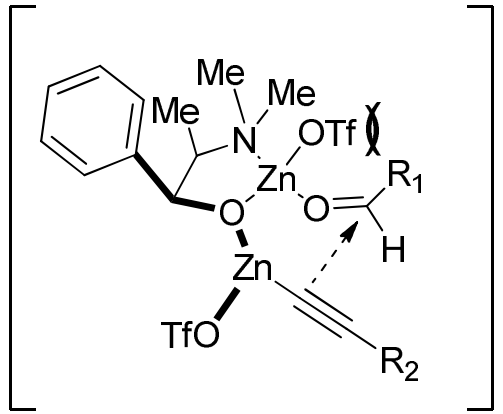

A2 disfavored 
On the basis of Carreria's catalytic system, Jiang prepared a new zinc reagent, $\mathrm{Zn}\left(\mathrm{OSO}_{2} \mathrm{CF}_{2} \mathrm{H}\right)$ and the amino alcohol $\mathbf{1 . 1 9}$ that has similar structure to ligand $\mathbf{1 . 1 8}$ in 2002..$^{24,25}$ The amino alcohol $\mathbf{1 . 1 9}$ was employed in the addition of alkynes to various aldehydes in the presence of $\mathrm{Zn}\left(\mathrm{OSO}_{2} \mathrm{CF}_{2} \mathrm{H}\right)$ and $\mathrm{Et}_{3} \mathrm{~N}$, producing the desired propargylic alcohols with high enantioselectivity (up to 99\% ee) (Scheme 1.6).

Scheme 1.6. Alkyne addition to aldehydes by using Jiang's amino alcohol 1.19

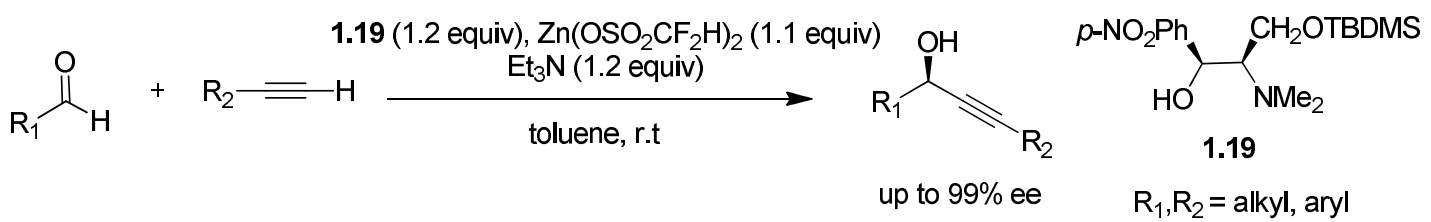

Besides Carreria's catalytic system, Trost's ProPhenol ligand is quite attractive as well. In 2006, Trost reported that the proline-derived ligand 1.20 (ProPhenol) was used in the alkynylation of aromatic and $\alpha, \beta$-unsaturated aldehydes to afford chiral propargylic alcohols with high enantioselectivity (Scheme 1.7). ${ }^{26}$ The reaction proceeded in the presence of $10 \mathrm{~mol} \% \mathbf{1 . 2 0}$ and $\mathrm{Me}_{2} \mathrm{Zn}$ ( 3 equiv). The efficiency and application of the ProPhenol-catalyzed addition have been illustrated by several total syntheses of natural products including asteriscunolide $\mathrm{D},{ }^{27}$ aspergillide $\mathrm{B},{ }^{28}$ $(+)$-spirolaxine methyl ether ${ }^{29}$ and a series of polyacetylenic compounds ${ }^{30-32}$.

Scheme 1.7. Alkyne addition to aldehydes catalyzed by ProPhenol 1.20

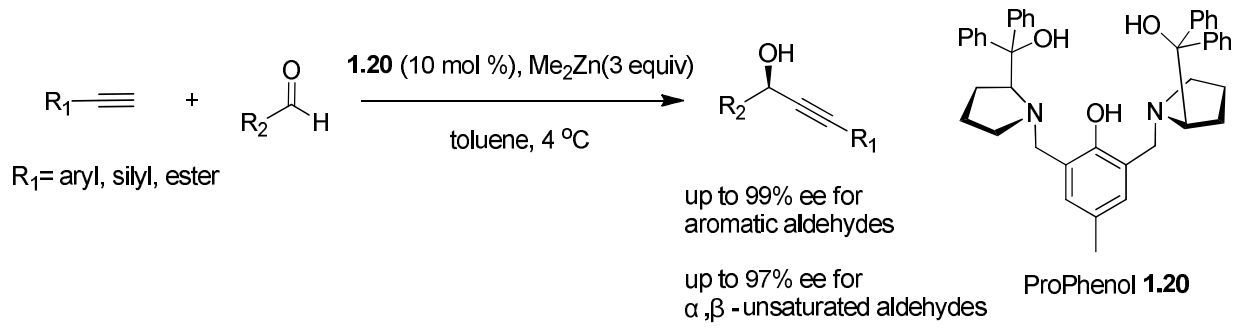

The proposed mechanism for the ProPhenol-catalyzed alkyne addition involves the formation of the dinuclear zinc complex $\mathbf{1 . 2 1}$ containing both Bronsted basic and 
Lewis acidic sites. The complex $\mathbf{1 . 2 1}$ then activates a terminal alkyne to give the alkynylzinc complex 1.22, which incorporates with an aldehyde to form the intermediate 1.23. The nucleophilic attack of the acetylide on the si face of the aldehyde coordinated with the second zinc atom generates the intermediate 1.24. Subsequent metal exchange converts $\mathbf{1 . 2 4}$ to the addition product $\mathbf{1 . 2 5}$ and regenerates the active catalyst $\mathbf{1 . 2 1}$ (Figure 1.5). ${ }^{30}$

Figure 1.5. Proposed mechanism for the ProPhenol-catalyzed alkyne addition to aldehydes

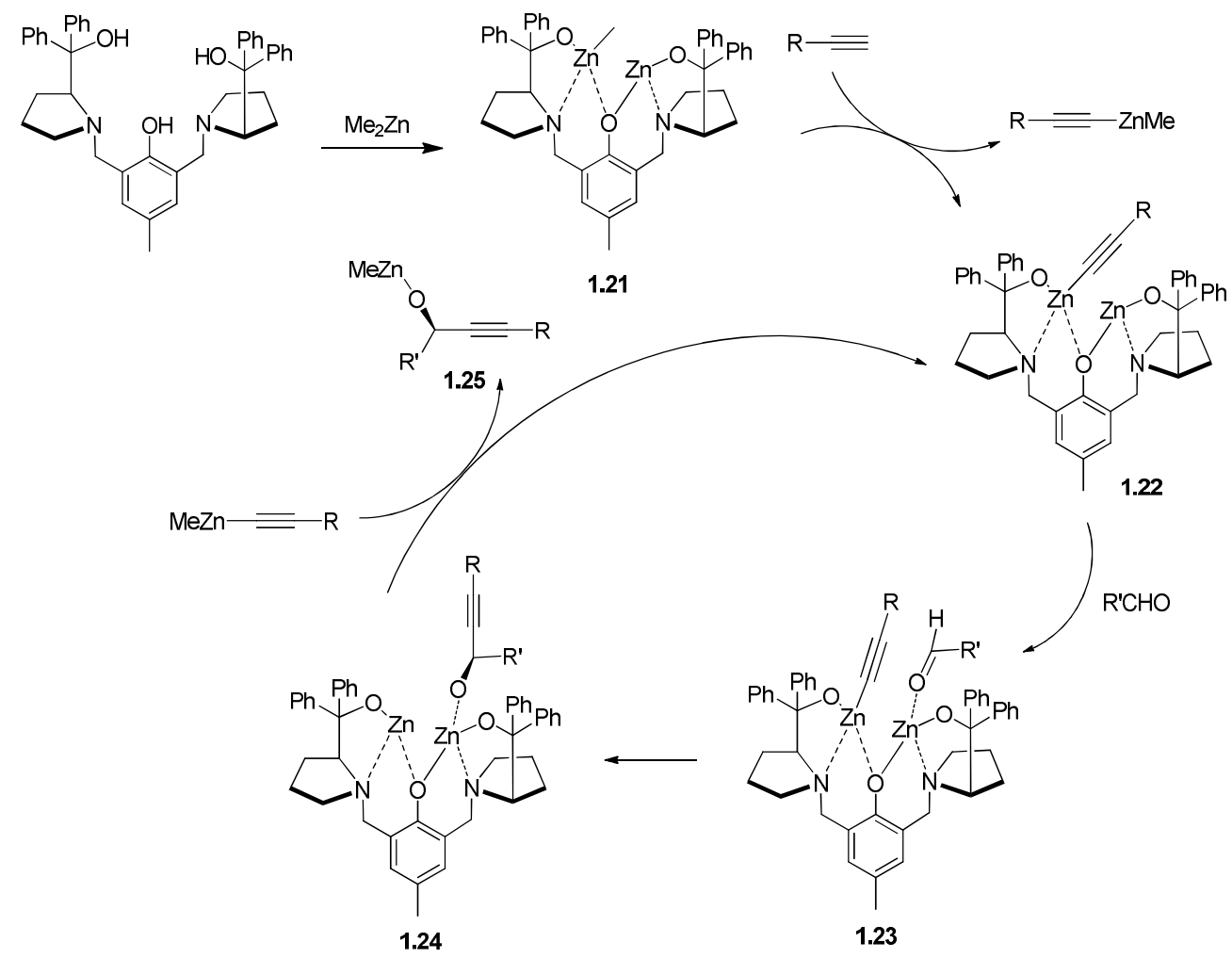

In 2009, the cyclopropane-based amino alcohol 1.26 was used in the addition of phenylacetylene and methyl propiolate to various aldehydes with high enantioselectivity (up to $95 \%$ ee) (Scheme 1.8$).^{33}$ 
Scheme 1.8. Phenylacetylene and methyl propiolate addition to aldehydes catalyzed by ligand $\mathbf{1 . 2 6}$

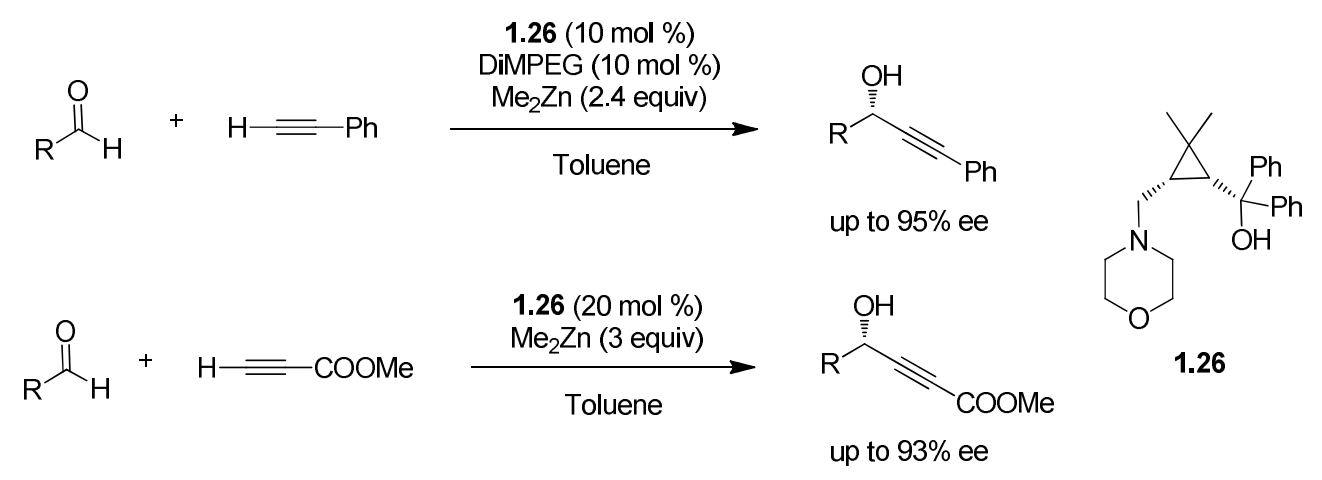

Later, the structure of ligand $\mathbf{1 . 2 6}$ was further modified. The morpholinyl substituent was replaced with a $(S)$-prolinol derived one to give a new ligand 1.27. Ligand 1.27 was shown to be effective for the highly enantioselective addition of TMS-acetylene to aldehydes with up to $97 \%$ ee (Scheme 1.9$){ }^{34}$

Scheme 1.9. TMS-acetylene addition to aldehydes catalyzed by ligand $\mathbf{1 . 2 7}$

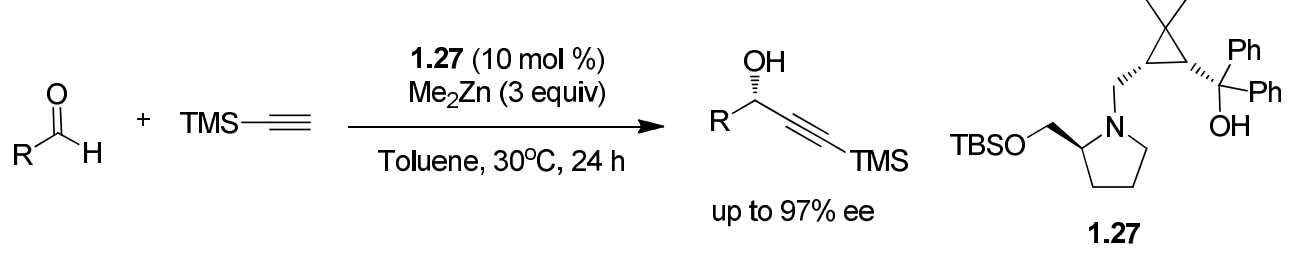

Many other amino alcohol based ligands 1.28-1.31 were developed and examined in the asymmetric alkyne addition to aldehydes. ${ }^{35-38}$ Most of these ligands were only efficient for the addition of aromatic aldehydes. Compared with the ligands mentioned before, the reaction of alkynes with both aromatic and aliphatic aldehydes gave lower enantioselectivity (Figure 1.6).

Sulphur-containing ligands are promising alternatives for amino alcohols. However, ligand $\mathbf{1 . 3 2}$ and $\mathbf{1 . 3 3}$ delivered products with moderate ee. ${ }^{39}$ The amino thio ligands $\mathbf{1 . 3 4}$ and $\mathbf{1 . 3 5}$ showed much better results while the enantioselectivity still remained below $90 \%$ (Figure 1.6). ${ }^{40,41}$ 
Figure 1.6. Other amino alcohol ligands and sulphur-containing ligands

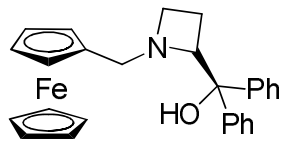

1.28

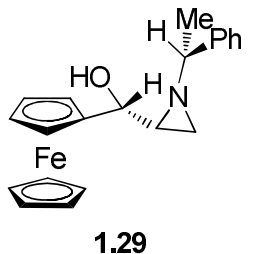

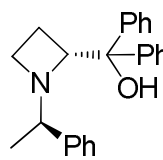

1.30<smiles></smiles>

1.31<smiles>OCC(CSSCC(CO)NCc1ccccc1)NCc1ccccc1</smiles>

1.32<smiles>c1ccc(CN2COCC2CSSCC2COCN2Cc2ccccc2)cc1</smiles>

1.33<smiles>O=C(OC[C@H](C(S)c1ccccc1)N1CCCCC1)c1ccccc1</smiles>

1.34

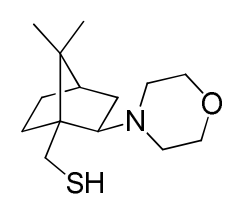

1.35

\section{b. Amide ligands}

Chiral amide compounds were recently reported as a class of efficient ligands in the asymmetric alkyne addition to aldehydes.

In 2004, Wang developed the camphorsulfonamide ligand $\mathbf{1 . 3 6}$ for the reaction of phenylacetylene with aromatic aldehydes in the presence of $\operatorname{Ti}\left(\mathrm{O}^{i} \mathrm{Pr}\right)_{4}$ and $\mathrm{Et}_{2} \mathrm{Zn}$. The reaction proceeded under mild conditions with up to $98 \%$ ee. ${ }^{42}$ Later, the same group prepared another sulfonamide ligand $\mathbf{1 . 3 7}$ and used it at a loading of $4 \mathrm{~mol} \%$ in the same reaction. High enantioselectivity $(83-97 \%$ ee) was obtained for various aromatic aldehydes (Scheme 1.10). ${ }^{43}$

Scheme 1.10. Alkyne addition to aldehydes catalyzed by Wang's sulfonamide ligands

$$
\begin{aligned}
& \begin{array}{l}
1.36 \text { (10 mol \%) } \\
\text { Ti(O'Pr) }{ }_{4}(40 \mathrm{~mol} \%)
\end{array}
\end{aligned}
$$

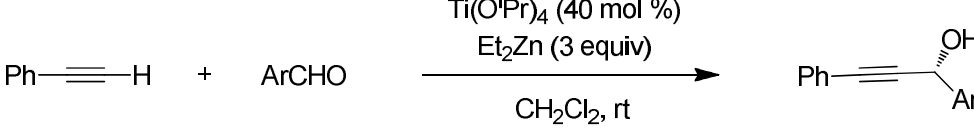

$$
\begin{aligned}
& \text { up to } 98 \% \text { ee } \\
& \overbrace{1.36}^{\mathrm{NHT}} \\
& \mathrm{Ph}=\mathrm{H}+\mathrm{ArCHO} \quad \frac{\begin{array}{c}
1.37(4 \mathrm{~mol} \%) \\
\mathrm{Ti}(\mathrm{O} \operatorname{Pr})_{4}(24 \mathrm{~mol} \%) \\
\mathrm{Et}_{2} \mathrm{Zn}(3 \text { equiv) }
\end{array}}{\text { Toluene }}
\end{aligned}
$$
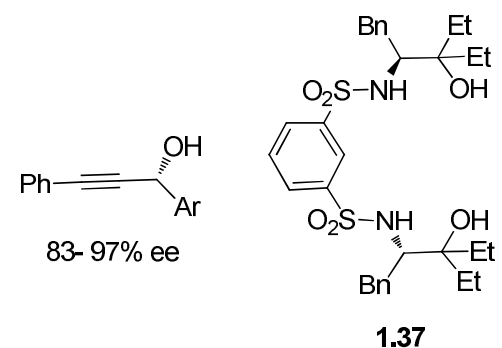
The amide ligand $\mathbf{1 . 3 8}$ reported by $\mathrm{Xu}$ in 2005 was used in the addition of phenylacetylene to aromatic aldehydes and up to $92 \%$ ee was observed. ${ }^{44}$ But the reaction with aliphatic aldehydes gave inferior results. Also, ligand 1.39 was only applicable to aromatic aldehydes to achieve high enantioselectivity. ${ }^{45}$ Ligand $\mathbf{1 . 4 0}$ was one of few amide ligands giving good results for both aromatic and aliphatic aldehydes (Figure 1.7). ${ }^{46}$

Figure 1.7. Other amide ligands<smiles>O=C(NC(c1ccccc1)c1ccccc1)c1cc(C(=O)NC(c2ccccc2)[C@H](O)c2ccccc2)cc(C(=O)NC(c2ccccc2)[C@H](O)c2ccccc2)c1</smiles>

1.38

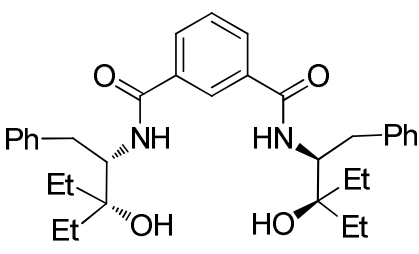

1.39

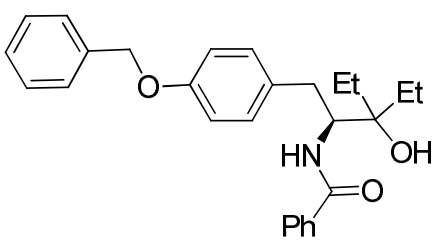

1.40

\section{c. Pyridyl and alkaloid ligands}

Nitrogen-containing ligands like pyridyl and alkaloid ligands are less studied for the asymmetric alkyne addition to aldehydes.

In 1991, Falorni used the pyridyl amine ligand $\mathbf{1 . 4 1}$ to catalyze the addition of $\left({ }^{n} \mathrm{BuCC}\right)_{2} \mathrm{Zn}$ to benzaldehyde and afforded the corresponding propargylic alcohol with $16 \%$ ee. $^{47}$ In 1994, Ishizaki reported the highly enantioselective addition of alkynylzinc to aromatic aldehydes with up to $95 \%$ ee by using the pyridyl alcohol ligand 1.42. ${ }^{48}$ But the reaction with aliphatic aldehydes gave much lower enantioselectivity. Wangelin developed the fenchone-based ligand $\mathbf{1 . 4 3}$ for the enantioselctive alkynylation of aldehydes in 2007. The reaction of various alkynes with aldehydes produced propargylic alcohols in good yield and with up to $85 \%$ ee 
(Figure 1.8).

In 2003, Kamble and Singh found that the alkaloid ligand $\mathbf{1 . 4 4}$ catalyzed the addition of phenylacetylene to aromatic and aliphatic aldehydes with $62-85 \%$ ee in the presence of $\mathrm{Ti}\left(\mathrm{O}^{i} \mathrm{Pr}\right)_{4}$ and $\mathrm{Et}_{2} \mathrm{Zn}$ (Figure 1.8). ${ }^{49}$

Figure 1.8. Pyridyl and alkaloid ligands<smiles>c1ccc([C@H]2CCCN2)nc1</smiles>

1.41<smiles>CC(C)(C)[C@H](OCC(O)(Br)Br)c1ccccn1</smiles>

Ar= $\alpha-$ naphthyl

1.42

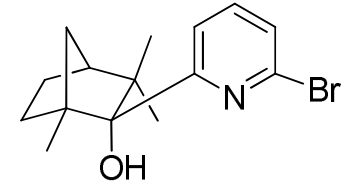

1.43<smiles>C=CC1CC2CCN1C([C@H](O)c1ccnc3ccccc13)C2</smiles>

1.44

\subsubsection{BINOL/ $\mathrm{H}_{8} \mathrm{BINOL}$ ligands}

Chiral 1,1'-bi-2-naphthol (BINOL) and its partially hydrogenated derivative $\mathrm{H}_{8} \mathrm{BINOL}$ have been studied and widely used in asymmetric synthesis (Figure 1.9). ${ }^{50-52}$ Catalytic systems using optically active BINOL and $\mathrm{H}_{8} \mathrm{BINOL}$ in the alkynylzinc addition to aldehydes have also been investigated over the past decade. ${ }^{17}$ Simple BINOL was successfully used in the $\operatorname{Ti}\left(\mathrm{O}^{i} \operatorname{Pr}\right)_{4}$ system, while the substituted BINOL derivatives were mostly used in the absence of the titanium(IV) complex. 
Figure 1.9. $\mathrm{BINOL}$ and $\mathrm{H}_{8} \mathrm{BINOL}$<smiles>Oc1ccc2ccccc2c1-c1c(O)ccc2ccccc12</smiles>

(S)-BINOL<smiles>Oc1ccc2c(c1-c1c(O)ccc3c1CCCC3)CCCC2</smiles>

(S)- $\mathrm{H}_{8} \mathrm{BINOL}$<smiles>Oc1ccc2ccccc2c1-c1c(O)ccc2ccccc12</smiles>

(R)-BINOL<smiles>Oc1ccc2c(c1-c1c(O)ccc3c1CCCC3)CCCC2</smiles>

$(R)-\mathrm{H}_{8} \mathrm{BINOL}$

In 2002, Pu's group ${ }^{53,54}$ and Chan's group ${ }^{55,56}$ independently reported the work on the use of BINOL for the asymmetric alkynylzinc addition. In their study, the BINOL-Ti $\left(\mathrm{O}^{i} \mathrm{Pr}\right)_{4}$ catalytic systems were introduced to catalyze the alkynylzinc addition to aldehydes with high enantioselectivity. Different alkylzinc precursors and experimental procedures were employed in their work.

Chan used $(S)$-BINOL or $(S)-\mathrm{H}_{8} \mathrm{BINOL}$ in combination with $\mathrm{Ti}\left(\mathrm{O}^{i} \mathrm{Pr}\right)_{4}$ and $\mathrm{Me}_{2} \mathrm{Zn}$ for the asymmetric addition of phenylacetylene to aromatic aldehydes with up to $99 \%$ ee (Scheme 1.11). ${ }^{55}$ High enantioselectivity was achieved for the addition to para and meta-substituted aromatic aldehydes, but reduced enantioselectivity for ortho-substituted aromatic and aliphatic aldehydes. It was later found that the use of the sulfonamide $\mathbf{1 . 4 5}$ as a co-catalyst improved the enantioselectivity for all aldehydes. $^{56}$ 
Scheme 1.11. Chan's BINOL catalytic system for the alkynylzinc addition

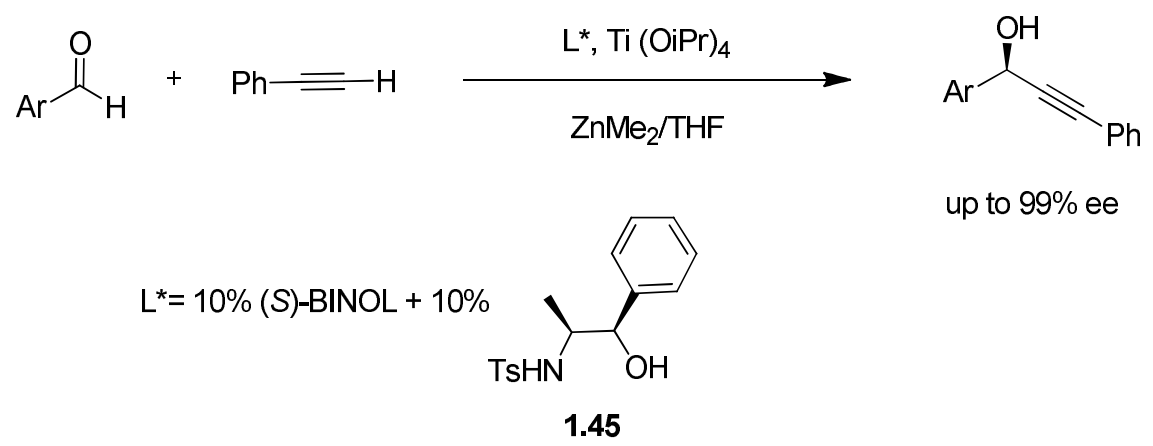

$\mathrm{Et}_{2} \mathrm{Zn}$ was utilized to form the alkynylzinc reagent in Pu's work. ${ }^{53}$ High ee up to $98 \%$ was achieved for the addition of phenylacetylene to various aromatic aldehydes including ortho, meta and para-substituted aromatic aldehydes. Using a different procedure, high ee up to $99 \%$ was observed for the addition of alkynylzinc to aliphatic and $\alpha, \beta$-unsaturated aldehydes (Scheme 1.12). ${ }^{54}$

Scheme 1.12. Pu's BINOL catalytic system for the alkynylzinc addition

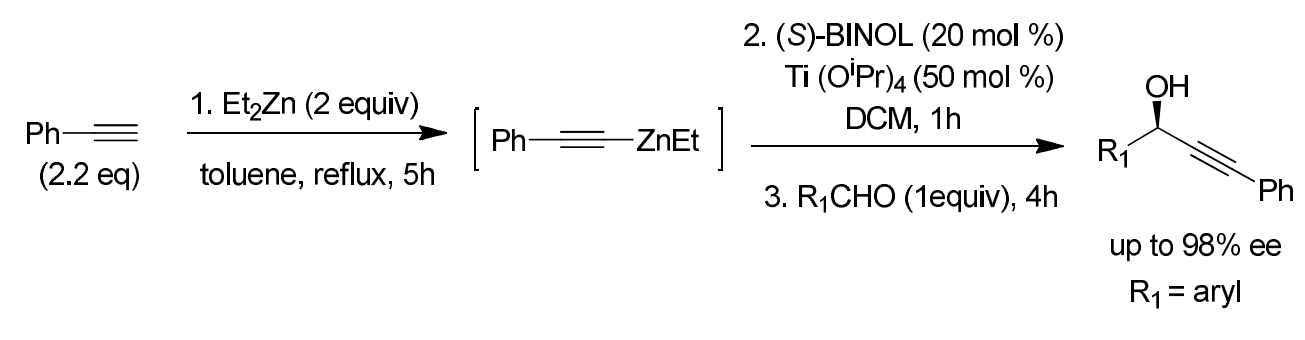

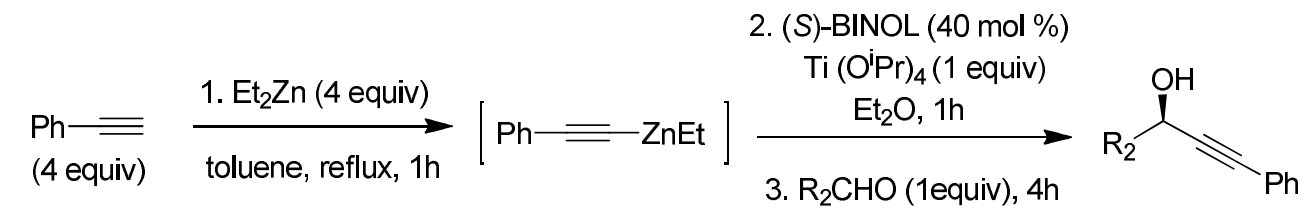

$$
\begin{aligned}
& \text { up to } 99 \% \text { ee } \\
& \mathrm{R}_{2}=\text { alkyl, vinyl }
\end{aligned}
$$

Although the method is applied to various aldehydes with high yield and enantioselectivity, a high temperature is required for the formation of the alkynylzinc intermediate. In 2004, Pu developed a mild condition to form the alkynylzinc 
intermediate, which extended the generality in the asymmetric alkynylzinc addition to aldehydes. $^{57}$ HMPA as a Lewis base additive was employed in the BINOL-Et 2 Zn-Ti( $\left(\mathrm{O}^{i} \mathrm{Pr}\right)_{4}$ system which catalyzed the reaction at room temperature with up to $95 \%$ ee for aromatic aldehydes. Later, a more efficient Lewis base dicyclohexylamine $\left(\mathrm{Cy}_{2} \mathrm{NH}\right)$ was used in the asymmetric addition of alkynes to aliphatic aldehydes and high ee (81-89\%) was obtained (Scheme 1.13). ${ }^{58}$

Scheme 1.13. Pu's BINOL catalytic systems employing HMPA or $\mathrm{Cy}_{2} \mathrm{NH}$ as an additive

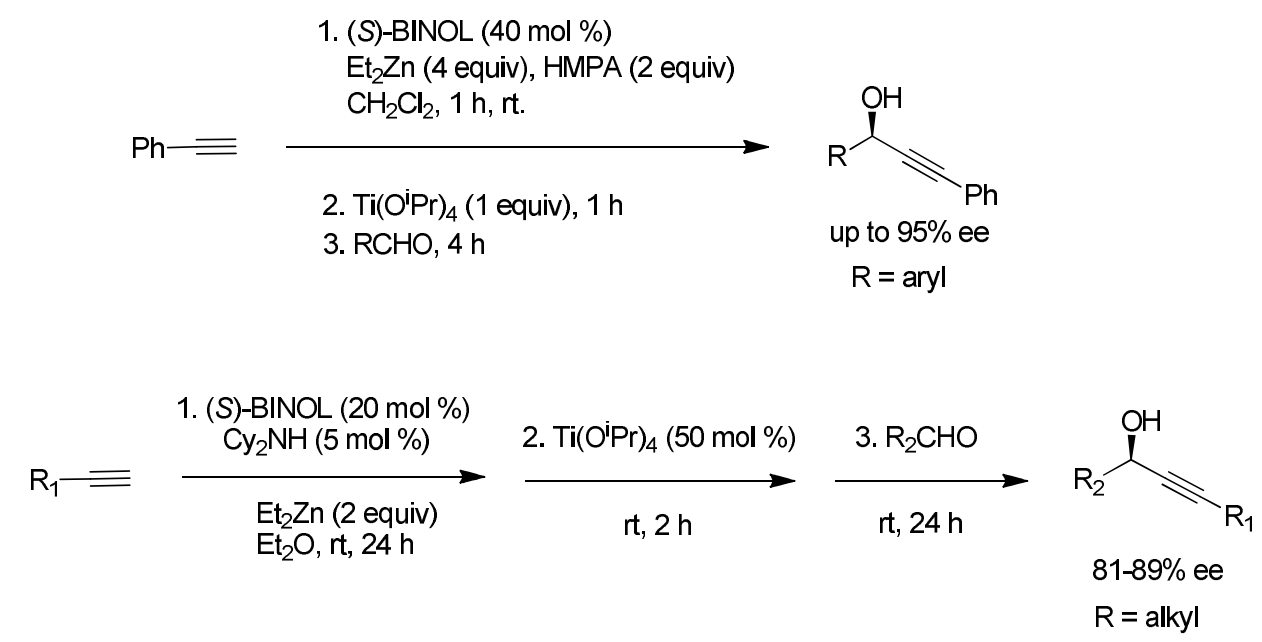

Recently, $\mathrm{Pu}$ reported that a BINOL-Ti( $\left(\mathrm{O}^{i} \mathrm{Pr}\right)_{4}$ catalyst system was found to activate the reaction of $\mathrm{Zn}$ powder with EtI for the asymmetric alkyne addition to aromatic aldehydes with up to $96 \%$ ee. ${ }^{59}$ This method avoided the direct use of $\mathrm{Et}_{2} \mathrm{Zn}$, a combustible and reactive liquid. In the same year, a new catalytic system based on $\mathrm{Zn},{ }^{\mathrm{i}} \mathrm{PrI}, \mathrm{H}_{8} \mathrm{BINOL}$ and $\mathrm{Ti}\left(\mathrm{O}^{i} \mathrm{Pr}\right)_{4}$ was developed to catalyze the addition of various alkynes to aromatic, aliphatic and vinyl aldehydes with up to $98 \%$ ee (Scheme 1.14$){ }^{60}$ 
Scheme 1.14. Pu's BINOL catalytic systems employing Zn powder

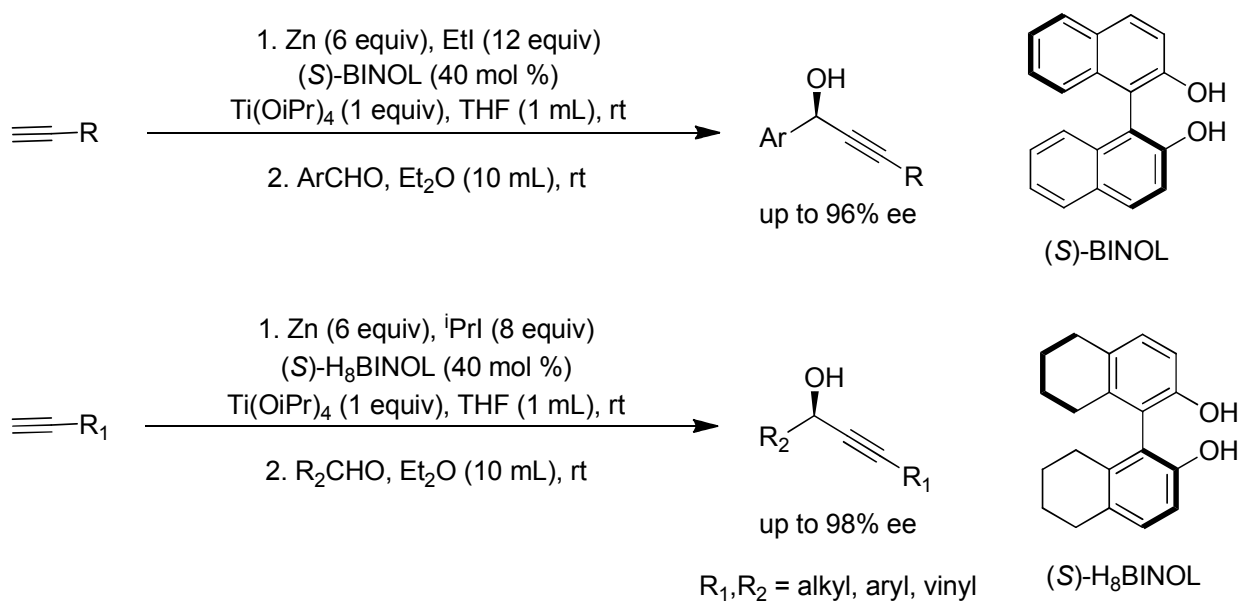

$\mathrm{Pu}$ proposed the intermediate $\mathbf{B}$ for the $\mathrm{BINOL} / \mathrm{Et}_{2} \mathrm{Zn} / \mathrm{Ti}\left(\mathrm{O}^{i} \mathrm{Pr}\right)_{4}$ catalyzed alkyne addition to aldehydes (Figure 1.10). In this intermediate, the ethyl group of the ethylalkynylzinc is at the back position due to less steric hindrance with $(S)$-BINOL. The larger $R_{1}$ group of the aldehyde is away from the ethyl group of the ethylalkynylzinc in order to avoid interaction. The isoproxy groups on $\operatorname{Ti}\left(\mathrm{O}^{i} \mathrm{Pr}\right)_{4}$ are oriented away from the aromatic rings of $(S)$-BINOL to minimize their interactions. Resultantly, the alkynyl group attacks the si face of the aldehyde forming the observed $(R)$-product.

Figure 1.10. Proposed intermediate $\mathbf{B}$ for the $\mathrm{BINOL} / \mathrm{Et}_{2} \mathrm{Zn} / \mathrm{Ti}\left(\mathrm{O}^{i} \mathrm{Pr}\right)_{4}$ catalyzed alkyne addition to aldehydes

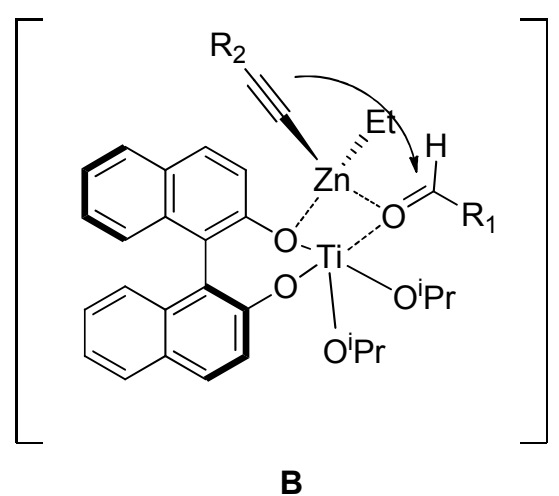




\subsubsection{BINOL-based derivatives}

\section{a. 3,3'-substituted BINOL ligands}

$\mathrm{Pu}$ and co-workers also conducted a significant amount of research to explore the use of 3,3'-substituted BINOL ligands in the asymmetric alkynylation addition. Ligand 1.46 was found highly effective for the addition of dialkylzincs to various aldehydes including aromatic and aliphatic aldehydes. ${ }^{61}$ In 2002, ligand $\mathbf{1 . 4 6}$ and other derivatives were prepared and investigated for the asymmetric addition of alkylnylzinc to aldehydes (Figure 1.11). ${ }^{62}$ The report showed that ligand $\mathbf{1 . 4 6}$ and a series of derivatives with electron-withdrawing groups on benzene rings were not good for the reaction of phenylacetylene with benzaldehyde in the presence of $\mathrm{Et}_{2} \mathrm{Zn}$. However, ligand $\mathbf{1 . 4 7}$ was found to catalyze the asymmetric addition more effectively with $80 \%$ ee. The steric effect was examined by synthesizing and testing another two ligands 1.48 and 1.49. The ligand 1.48 with the bulkier ${ }^{t} \mathrm{Bu}$ group at the para position of the 3,3'-anisyl group improved the enantioselectivity to $89 \%$. The ligand $\mathbf{1 . 4 9}$, which has smaller methyl group substituents, gave lower ee in comparison with the use of ligand 1.48. Interestingly, ligand $\mathbf{1 . 4 8}$ could facilitate the formation of the alkynylzinc at room temperature without Lewis base additives, which would become a feature of the 3,3'-substituted BINOL ligands. Later, ligand $\mathbf{1 . 4 8}$ was further modified and a series of 3,3'-substituted BINOL, $\mathrm{H}_{4} \mathrm{BINOL}$ and $\mathrm{H}_{8} \mathrm{BINOL}$ derivatives 1.50-1.52 were prepared and examined. ${ }^{63} 1.50$ showed much lower enantioselectivity than the $\mathrm{C}_{2}$ symmetric ligand $\mathbf{1 . 5 1}$, which was found to be a generally enantioselective catalyst for the addition of diverse alkynes to various 
aldehydes (up to $95 \%$ ee for aromatic aldehydes and up to $99 \%$ ee for aliphatic aldehydes). Ligand $\mathbf{1 . 5 2}$ performed much better than other ligands in the reaction of aldehydes and various alkynes except TMS-acetylene.

Figure 1.11. 3,3'-substituted BINOL ligands 1.46-1.52

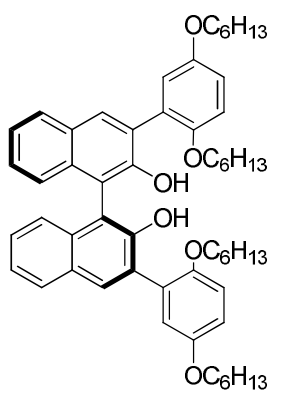

1.46

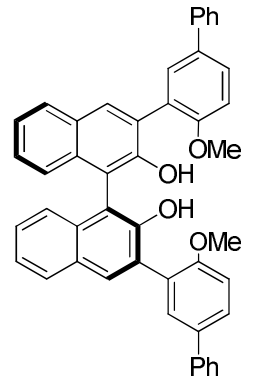

1.47

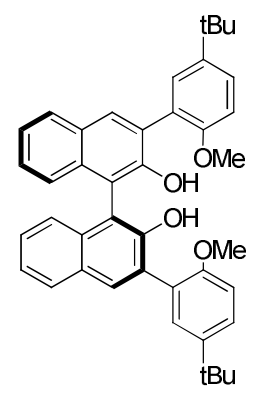

1.48

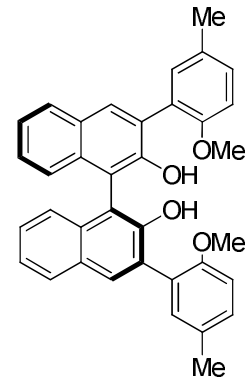

1.49

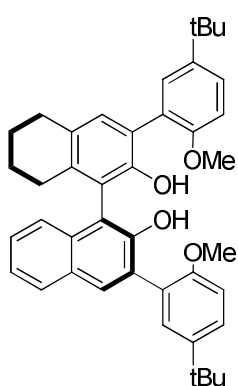

1.50

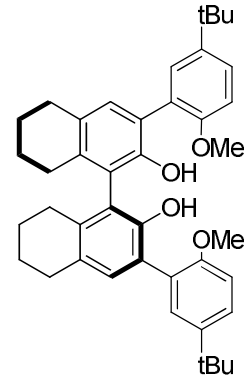

1.51

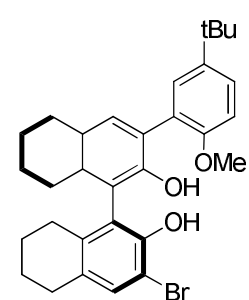

1.52

Encouraged by previous results, the more bulkier adamantyl group was introduced to the para position of the $3,3^{\prime}$-anisyl group and ligand 1.53 was synthesized. It was found to catalyze the reaction of terminal alkynes with various aromatic aldehydes under mild conditions to generate chiral propargylic alcohols with up to $94 \%$ ee. ${ }^{64} \mathrm{Ti}\left(\mathrm{O}^{i} \mathrm{Pr}\right)_{4}$ was not required and an alkynylzinc could be formed at room temperature in this procedure. It was hypothesized that the catalytic efficiency could be improved if the bulky group was closer to the chiral center. With that in mind, ligand 1.54 was synthesized and tested. It showed high enantioselectivity ( $86-94 \%$ ee) without using $\operatorname{Ti}\left(\mathrm{O}^{i} \operatorname{Pr}\right)_{4}$ and a Lewis base additive for the reaction of phenylacetylene 
with aromatic aldehydes in the presence of $\mathrm{Et}_{2} \mathrm{Zn}$ (Scheme 1.15). ${ }^{65}$

Scheme 1.15. 3,3'-substituted BINOL ligands $\mathbf{1 . 5 3 - 1 . 5 4}$ catalyzed alkynylzinc addition
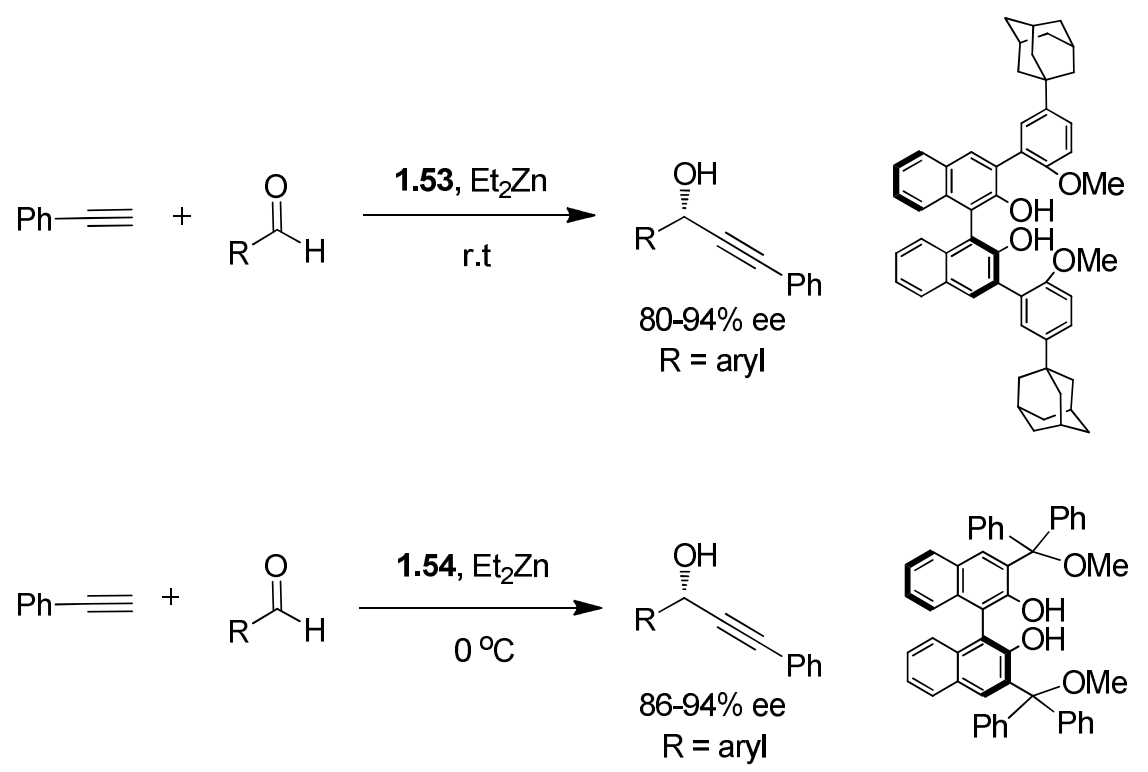

\section{b. BINOL-imine ligands}

BINOL-imine ligands have also been employed in the asymmetric alkynylzinc addition to aldehydes. In 2004, the BINOL-imine ligand $\mathbf{1 . 5 5}$ designed by $\mathrm{Pu}$ catalyzed the addition of terminal alkynes to aromatic aldehydes at room temperature with up to $97 \%$ ee (Scheme 1.16$).{ }^{66}$ However, low enantioselectivity was observed for the addition of aliphatic aldehydes. The catalytic system featured the mild conditions and no addition of $\operatorname{Ti}\left(\mathrm{O}^{i} \mathrm{Pr}\right)_{4}$.

In 2007, $\mathrm{Pu}$ reported that the BINOL-imine macrocycle ligand $\mathbf{1 . 5 6}$ could improve enantioselectivity for the addition of aliphatic aldehydes (Scheme 1.16). ${ }^{67} \mathrm{~A}$ range of $89-96 \%$ ee's were obtained when ligand $\mathbf{1 . 5 6}$ and $\mathrm{Me}_{2} \mathrm{Zn}$ were used in the reaction of phenylacetylene with aliphatic aldehydes. The reaction was conducted at room temperature without the use of $\mathrm{Ti}\left(\mathrm{O}^{i} \mathrm{Pr}\right)_{4}$. 
Scheme 1.16. BINOL-imine ligands $\mathbf{1 . 5 5 - 1 . 5 6}$ catalyzed alkynylzinc addition
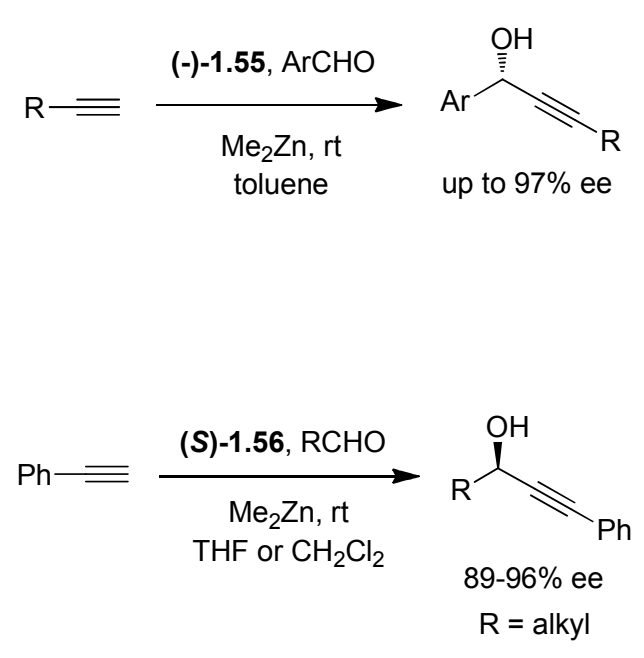

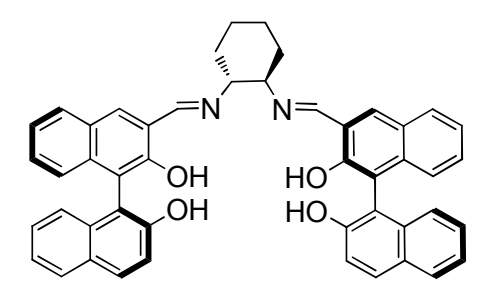

$(-)-1.55$

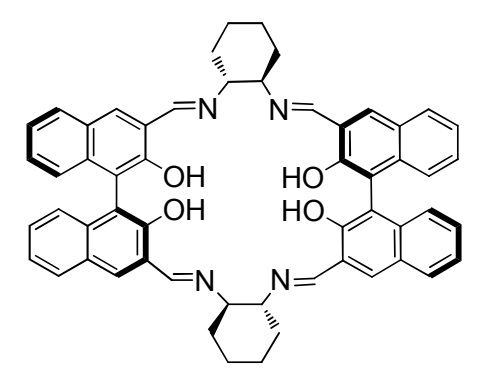

(S)-1.56

\subsubsection{Summary}

Many highly effective catalytic systems for asymmetric alkynylzinc addition to aldehydes have been developed over the decades. Chiral amino alcohols and BINOLs represent two important classes of catalytic systems. Among these methods, Carreira's $\mathrm{N}$-methylephedrine system, Trost's ProPhenol catalyst and Pu's BINOL-based system are the most effective and attractive in their practical use. However, no catalytic system is suitable for all types of alkynes and aldehydes. Traditionally, the alkynylation of aliphatic aldehydes is a great challenge in this area. The extensive application of chiral propargylic alcohols in organic synthesis will continue to promote the exploration of more effective and general catalytic systems. 


\subsection{Application of chiral propargylic alcohols}

\subsubsection{Diverse transformations of chiral propargylic alcohols}

As significant progress has been made on the asymmetric addition of alkynes to aldehydes in recent years, diverse chiral propargylic alcohols are readily available for the synthesis of chiral organic compounds.

$\mathrm{Pu}$ and co-workers developed a number of BINOL-based catalytic systems for the asymmetric alkyne addition to access chiral propargylic alcohols with high yield and enantioselectivity. To show the application of chiral propargylic alcohols, various transformations were studied (Figure 1.12). ${ }^{68}$

A type of functionalized propargylic alcohols $\mathbf{1 . 5 7}$ were converted to the optically active tetronic acids $\mathbf{1 . 5 8}^{37}$ and the aminofuranones $\mathbf{1 . 5 9}{ }^{69}$ Also, a domino ring closing metathesis/hydrogenation of $\mathbf{1 . 6 0}$ afforded the cycloalkenes $\mathbf{1 . 6 1}{ }^{63}$ The propargylic alcohol-based enynes $\mathbf{1 . 6 2}$ underwent an intramolecular Pauson-Khand reaction to access the bicyclic products $\mathbf{1 . 6 3 - 1 . 6 5}$. $^{70}$ The polycyclic compounds $\mathbf{1 . 6 7}$ were constructed via a Pauson-Khand reaction of the propargylic alcohol-based dienediynes $\mathbf{1 . 6 6}$ followed by an enyne ring closing metathesis and intermolecular $\left[4+2\right.$ cycloaddition. $^{71}$ Finally, a domino Pauson-Khand and Diels-Alder reaction was used to generate the tetracyclic compounds $\mathbf{1 . 6 9}$ from the propargylic alcohol based trienynes $\mathbf{1 . 6 8} .^{72,73}$ 
Figure 1.12. Diverse transformations of chiral propargylic alcohols

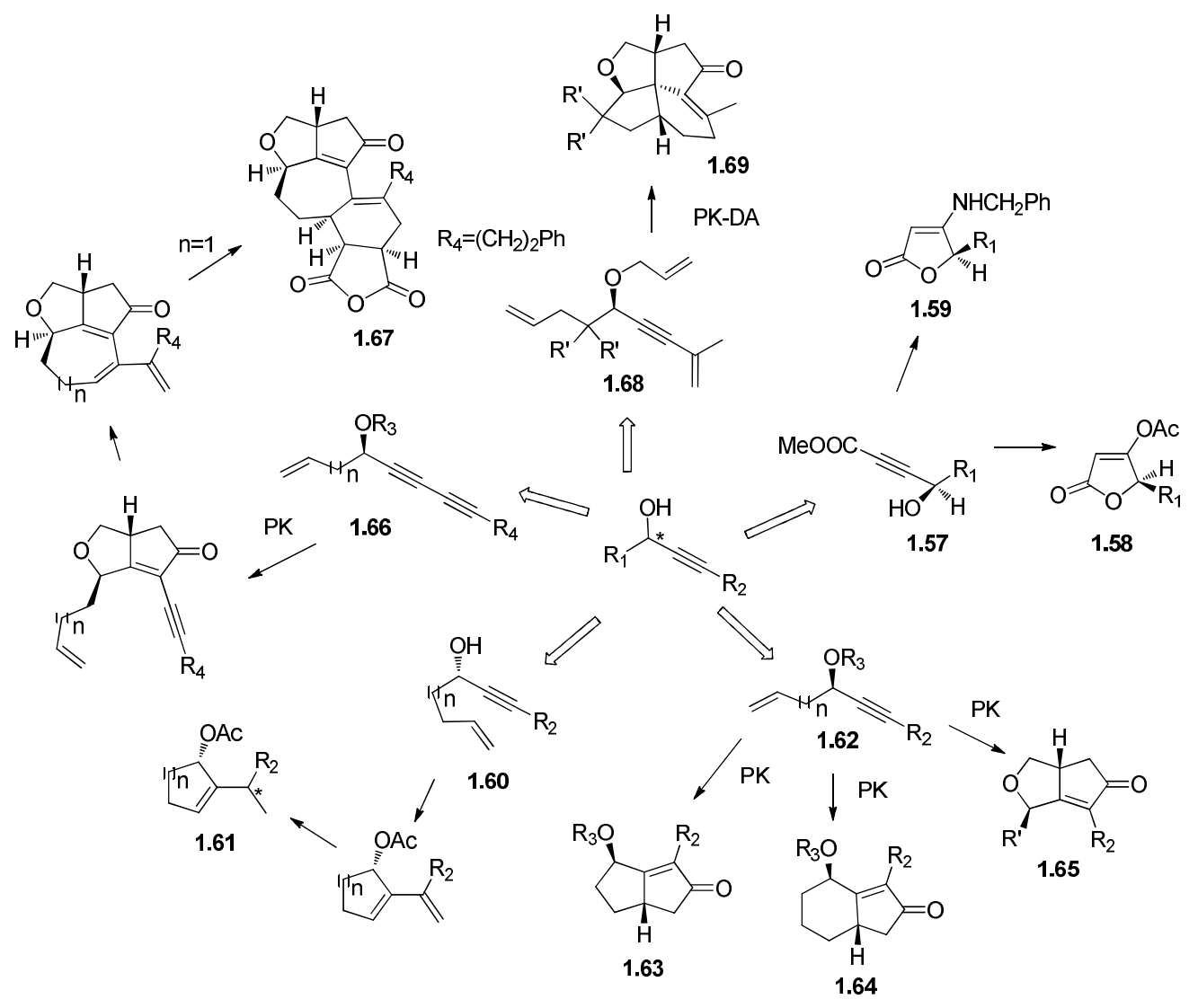

Among all these transformations, Pauson-Khand-based reaction is one of the most attractive methods for the construction of polycyclic ring systems. More details will be discussed below.

The chiral enynes $\mathbf{1 . 7 0 - 1 . 7 2}$ were readily prepared from the corresponding chiral propargylic alcohols. When the enynes 1.70 and 1.71 were treated with $\mathrm{Co}_{2}(\mathrm{CO})_{8}$ in dichloromethane, followed by the addition of $N$-methylmorpholine $N$-oxide (NMO) at room temperature, the fused 5,5-bicyclic products $\mathbf{1 . 7 3}$ and the 6,5-bicyclic products 1.74 were obtained with high yield and diastereoselectivity. A new class of 5,5-bicyclic products $\mathbf{1 . 7 5}$ were formed with excellent diastereoselectivity when the chiral allyl propargylic ethers $\mathbf{1 . 7 2}$ were subjected to the similar conditions (Scheme $1.17)^{70}$ 
Scheme 1.17. Pauson-Khand reactions of the chiral enynes 1.70-1.72

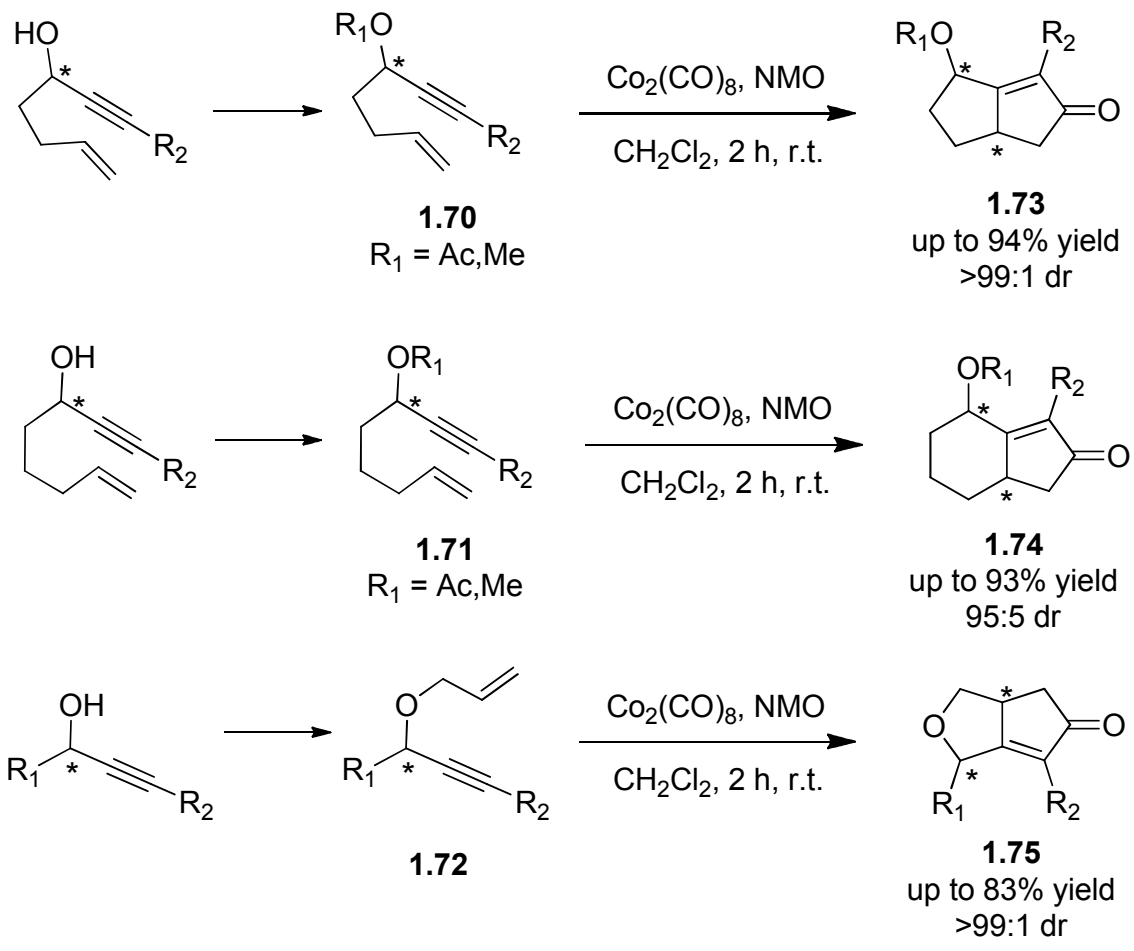

In 2011, $\mathrm{Pu}$ reported a new synthetic strategy to readily access polycyclic compounds from chiral propargylic alcohols (Scheme 1.18). ${ }^{71}$ The chiral propargylic alcohol 1.76 was obtained with $80 \%$ yield and $92 \%$ ee in the asymmetric addition of diyne to 4-pentenal by using Pu's BINOL-Ti( $\left(\mathrm{O}^{i} \mathrm{Pr}\right)_{4}-\mathrm{Et}_{2} \mathrm{Zn}-\mathrm{Cy}_{2} \mathrm{NH}$ system. Allylation of 1.76 gave the dienediyne 1.77 , which underwent the $\mathrm{Rh}(\mathrm{I})$-catalyzed Pauson-Khand cycloaddition to generate the 5,5-bicyclic product 1.78. Ring closing metathesis of $\mathbf{1 . 7 8}$ followed by the intermolecular Diels-Alder reaction with maleic anhydride afforded the 5,5,7,6-polycyclic compound $\mathbf{1 . 7 9}$ with five stereocenters with high chemo- and diastereoselectivity. This work provides a novel and efficient synthetic route from chiral propargylic alcohols to the framework of many biologically active compounds. 
Scheme 1.18. Asymmetric synthesis of the 5,5,7,6-polycyclic compound $\mathbf{1 . 7 9}$
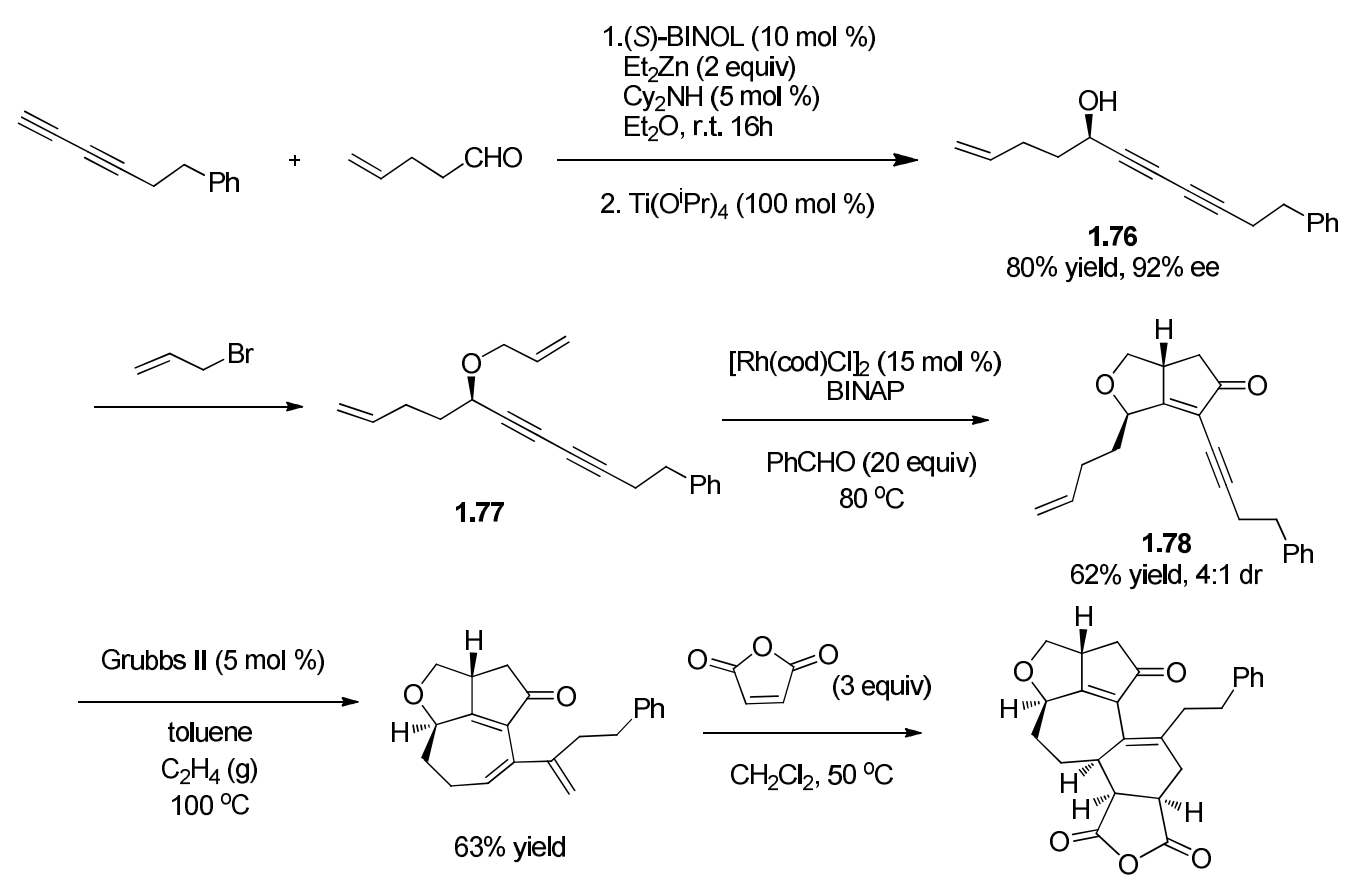

1.79, $70 \%$ yield

Recently, the same group developed an efficient $\mathrm{Rh}(\mathrm{I})$-catalyzed domino intramolecular Pauson-Khand reaction and [4+2] cycloaddition to access spirotricyclic compounds. ${ }^{72,73} \mathrm{BINOL}-\mathrm{Ti}\left(\mathrm{O}^{i} \mathrm{Pr}\right)_{4}-\mathrm{Et}_{2} \mathrm{Zn}-\mathrm{Cy}_{2} \mathrm{NH}$ system was employed to produce the chiral propargylic alcohol 1.80 with $75 \%$ yield and $82-90 \%$ ee. The chiral trieneyne $\mathbf{1 . 8 1}$, readily prepared from allylation of $\mathbf{1 . 8 0}$, was treated with $\left[\left[\mathrm{RhCl}(\mathrm{CO})_{2}\right]_{2}(10 \mathrm{~mol} \%)\right.$ under $1 \mathrm{~atm} \mathrm{CO}$ in refluxing 1,2-dichloroethane (DCE) to generate the tetracyclic compound $\mathbf{1 . 8 2}$ with $\mathbf{7 5 \%}$ yield and $90 \%$ ee (Scheme 1.19 ). Compound 1.82 represents an analogue of the core fragment of mangicol A after the opening of its hydrofuran ring. 
Scheme 1.19. $\mathrm{Rh}(\mathrm{I})$-catalyzed domino intramolecular Pauson-Khand reaction and [4+2] cycloaddition

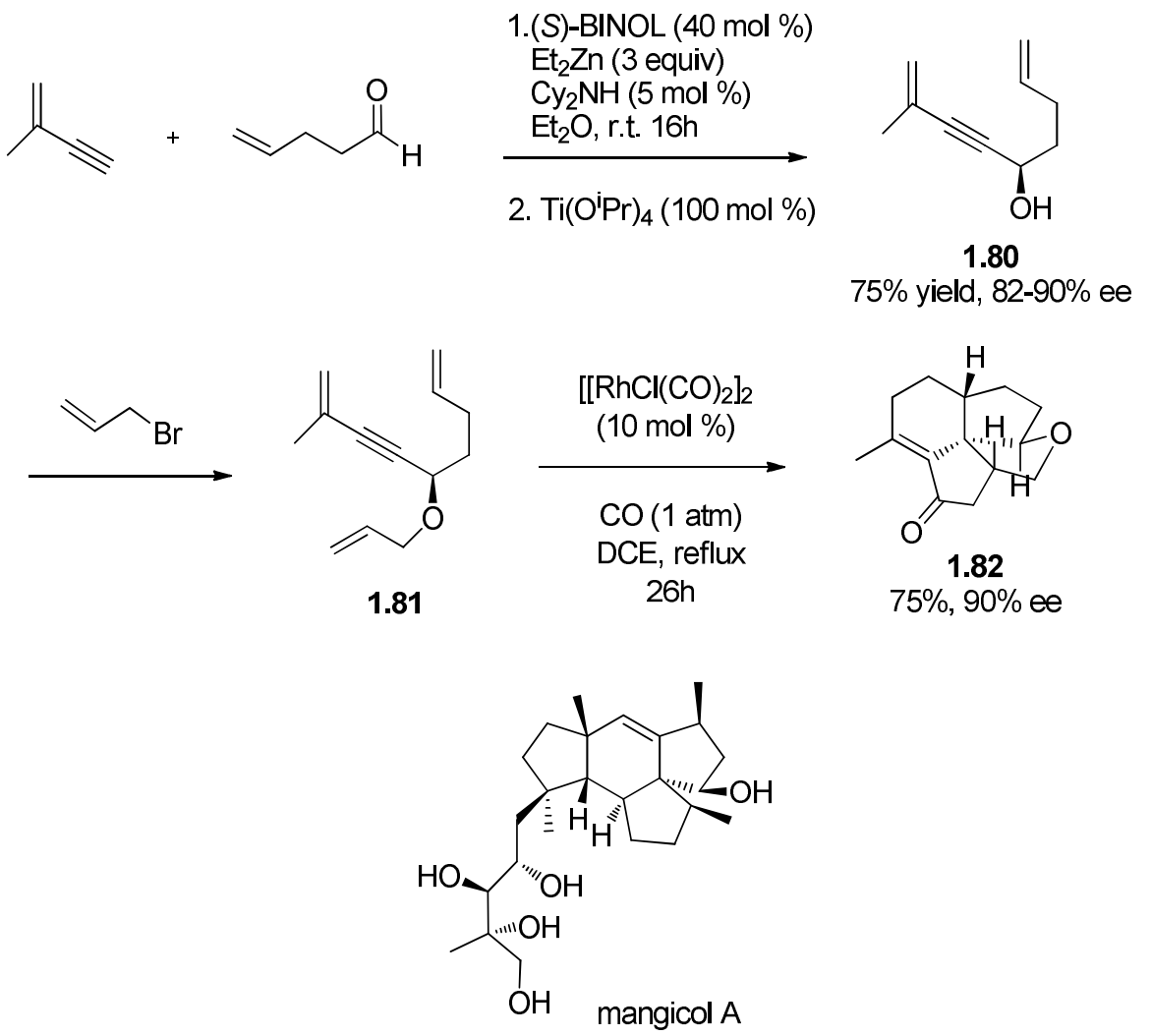

\subsubsection{Application in total synthesis}

Trost employed the ProPhenol-catalyzed alkyne addition methodology in several total syntheses of natural products including aspergillide $\mathrm{B},{ }^{28}(+)$-spirolaxine methyl ether $^{29}$ and a series of polyacetylenic compounds ${ }^{30-32}$.

As shown in Figure 1.13, a propargylic alcohol moiety is present in a number of polyacetylenic compounds ${ }^{30-32}$ (adociacetylene $\mathrm{B}$, strongylodiols $\mathrm{A}$ and $\mathrm{B}$, $(3 R, 9 R, 10 R)$-panaxytriol, minquartynoic acid), which was installed directly through asymmetric alkyne addition by using ProPhenol catalyst. 
Figure 1.13. Polyacetylenic compounds

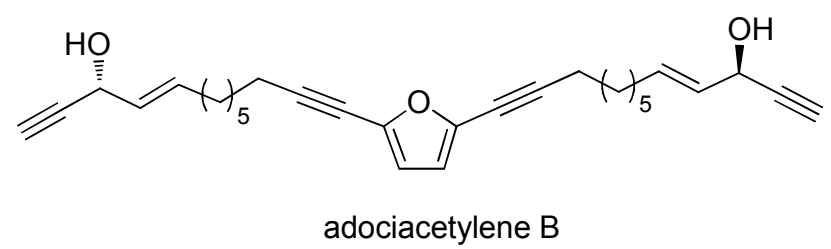

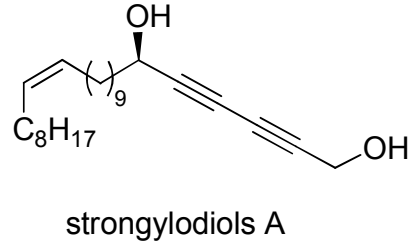

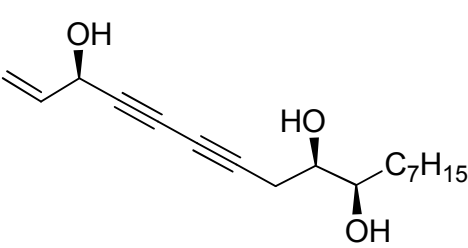

$(3 R, 9 R, 10 R)$-panaxytriol

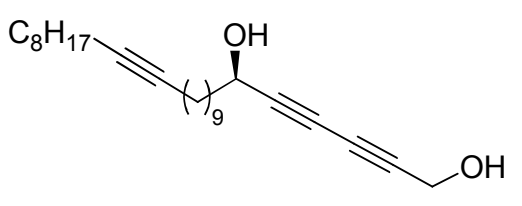

strongylodiols B

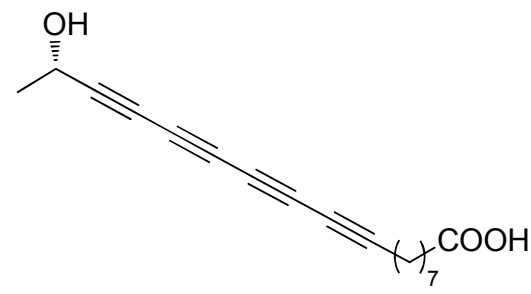

minquartynoic acid

In the total synthesis of aspergillide B, the propargylic alcohol $\mathbf{1 . 8 5}$ was obtained with $82 \%$ yield and 19:1 dr in the ProPhenol-catalyzed addition of $(S)$-hept-6-yn-2-yl benzoate $\mathbf{1 . 8 3}$ to fumaraldehyde dimethylacetal 1.84. Further functionalizations of 1.85 in four steps led to the formation of the aldehyde $\mathbf{1 . 8 6}$, which was then treated with methyl propiolate to undergo another ProPhenol-catalyzed addition and generate the propargylic alcohol $\mathbf{1 . 8 7}$ with $71 \%$ yield and 5.2:1 dr. The total synthesis of aspergillide B was completed in six steps from 1.87. This alkyne addition strategy leads to a straightforward total synthesis (Scheme 1.20). ${ }^{28}$ 
Scheme 1.20. Total synthesis of aspergillide B by using the ProPhenol-catalyzed alkyne addition strategy

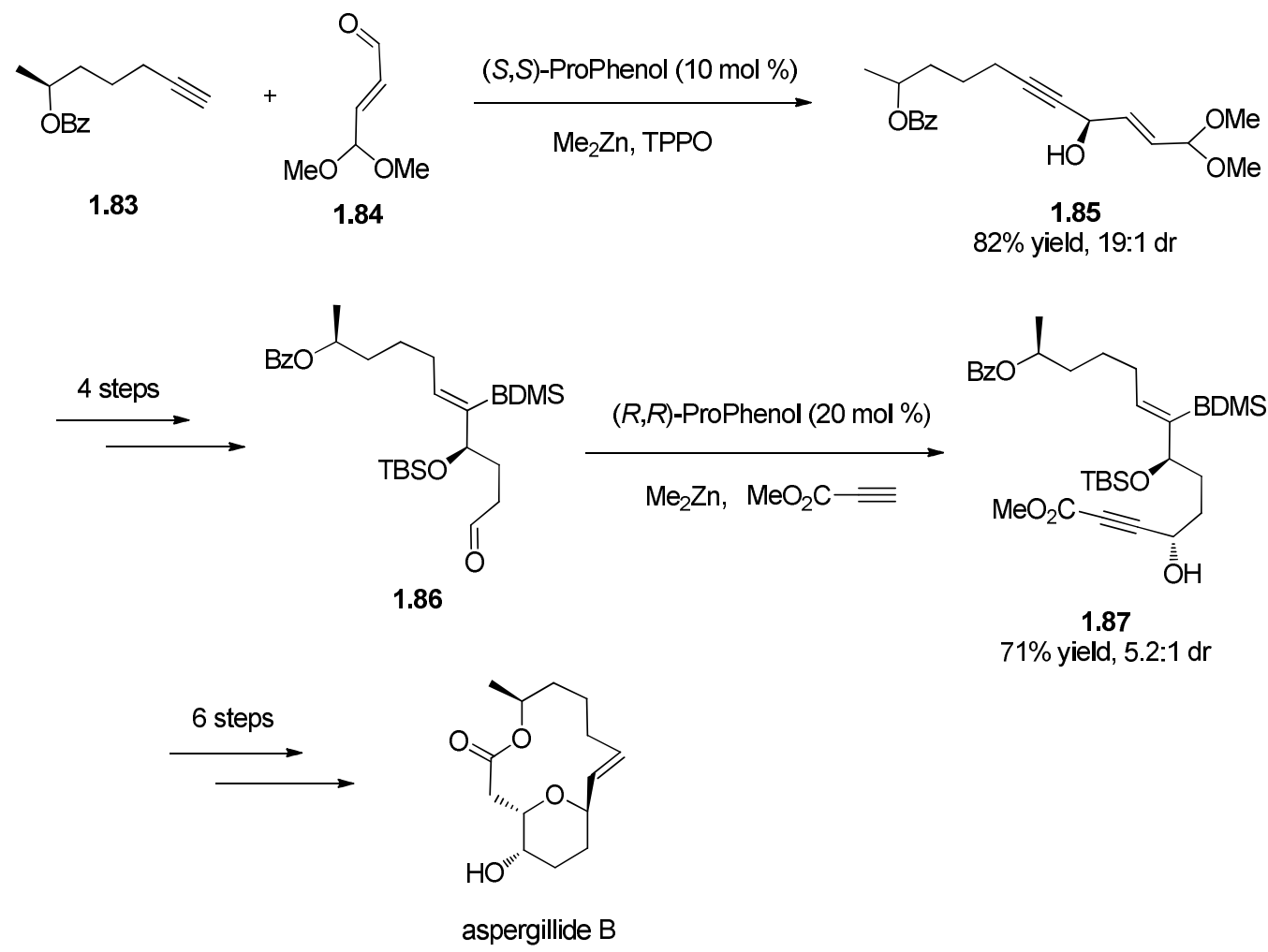

The ProPhenol catalyzed alkyne addition also showed great efficiency in the total synthesis of $(+)$-spirolaxine methyl ether (Scheme 1.21). ${ }^{29}$ The asymmetric addition of the alkyne $\mathbf{1 . 8 8}$ to 3,5-dimethoxylbenzaldehyde $\mathbf{1 . 8 9}$ produced the chiral propargylic alcohol 1.90 with $82 \%$ yield and $90 \%$ ee. An additional asymmetric alkyne addition of the alkyne $\mathbf{1 . 9 2}$ to the aldehyde $\mathbf{1 . 9 1}$ provided the propargylic alcohol 1.93 with 52\% yield and 5:1 dr. The total synthesis of (+)-spirolaxine methyl ether was accomplished in 13 linear steps highlighted by the alkyne addition strategy. 
Scheme 1.21. Total synthesis of $(+)$-spirolaxine methyl ether by using the ProPhenol-catalyzed alkyne addition strategy

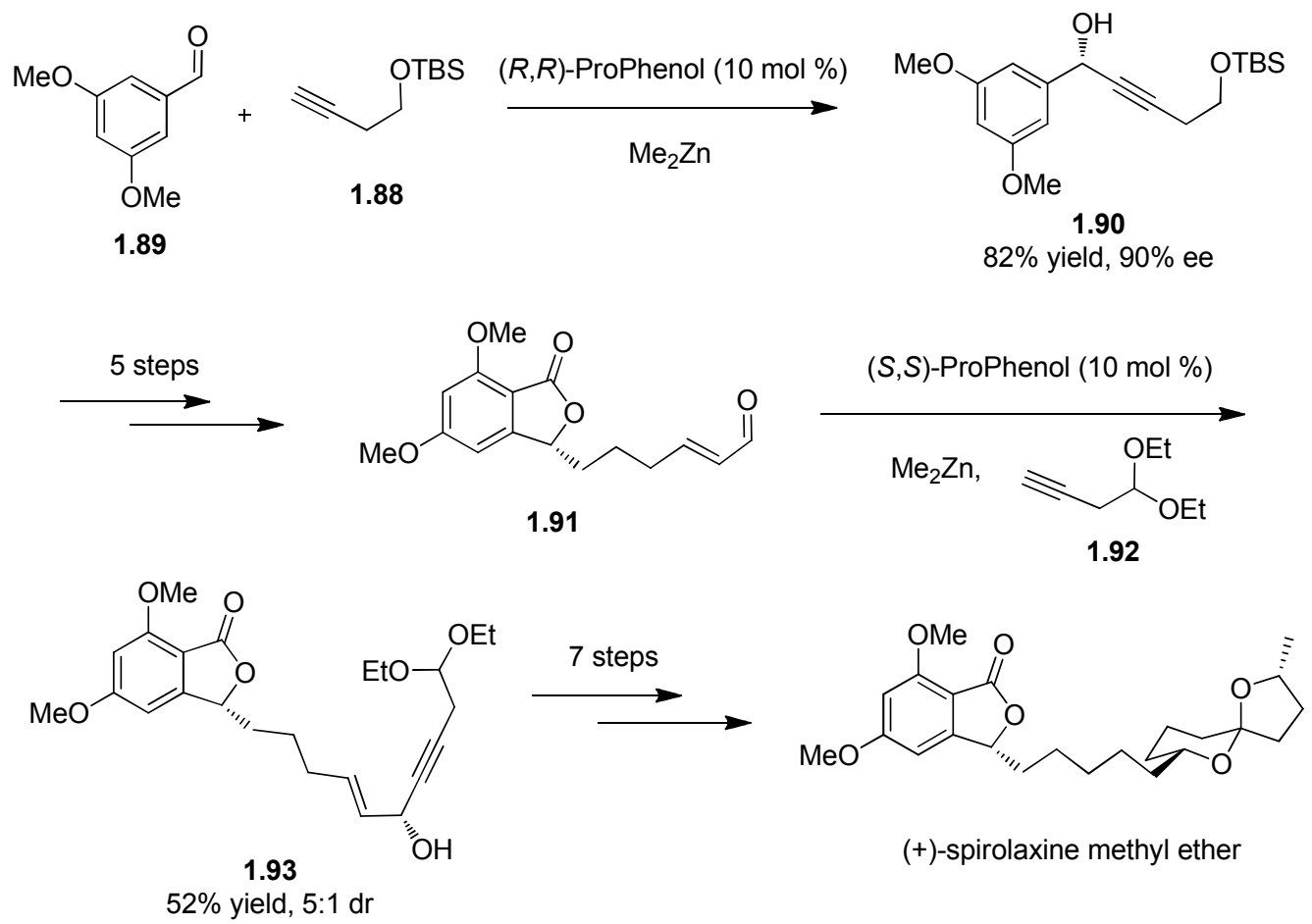

\subsubsection{Summary}

Chiral propargylic alcohols are versatile and useful building blocks in organic chemistry. A variety of chiral propargylic alcohols are readily available through asymmetric alkyne addition to aldehydes by using Pu's BINOL-based systems and Trost's ProPhenol catalyst.

The synthetic utility of the chiral propargylic alcohols was demonstrated by $\mathrm{Pu}$ through numerous transformations. Pauson-Khand-based reactions from chiral propargylic alcohol derivatives produced a series of optically active polycyclic compounds that are potentially useful in biological study. Trost's method found broad application in the total synthesis of various natural products including aspergillide B, $(+)$-spirolaxine methyl ether and polyacetylenic compounds. 


\subsection{Asymmetric alkyne addition to imines}

Chiral propargylic amines are important building blocks in the synthesis of numerous pharmaceuticals, biologically active compounds and natural products. ${ }^{74}$ While a substantial amount of work on alkyne addition to imines without stereocontrol have been reported, the enantioselective version of this reaction has not yet been fully developed. ${ }^{75}$

\subsubsection{Copper-based methods}

Among all the methods for the enantioselective alkynylation of imines, copper-based reactions have a prominent position. ${ }^{75}$ The first enantioselective copper-catalyzed alkyne addition to imines was introduced by Li and Wei in 2002 (Scheme 1.22). ${ }^{76}$ They employed Pybox 1.94 in combination with CuOTf to catalyze the addition of phenylacetylene to aromatic imines with excellent yield and enantioselectivity. The aromatic imines were generated in-situ via dehydration of the aldehyde and amine and the reaction was performed in either toluene or water with good results. Later on, the same group applied this method to aliphatic alkynes, which gave poorer results than phenylacetylene. ${ }^{77}$

Scheme 1.22. The first enantioselective copper-catalyzed alkyne addition to imines

$$
\begin{aligned}
& \mathrm{Ar}_{1}^{\mathrm{O}}+\mathrm{H}_{2} \mathrm{~N}-\mathrm{Ar}_{2}+\equiv \mathrm{Ph} \underset{\begin{array}{c}
1.94(10 \mathrm{~mol} \%) \\
\text { r.t. to } 35^{\circ} \mathrm{C} \\
\text { toluene or water }
\end{array}}{\mathrm{CuOTf}(10 \mathrm{~mol} \%)}
\end{aligned}
$$

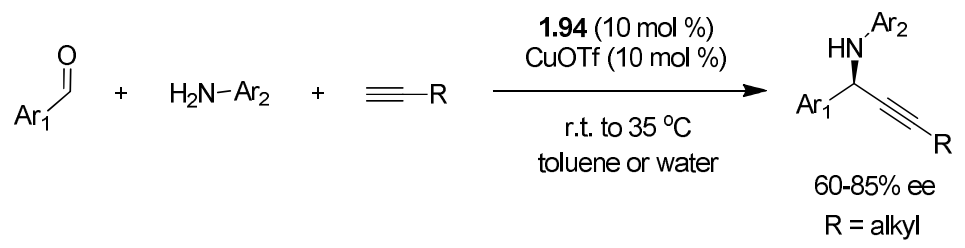

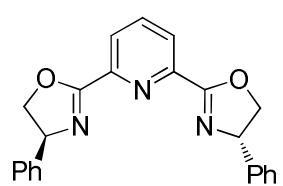


In 2006, Singh and Bisai prepared the highly substituted Pybox ligand 1.95 and used it with $\mathrm{CuPF}_{6}$ in the copper-catalyzed alkynylation of imines (Scheme 1.23). ${ }^{78}$ This method was applicable to a broad scope of substrates. Excellent yield and enantioselectivity (up to $99 \%$ ee) were observed in the reaction of various alkynes with aromatic imines. The reaction with aliphatic alkynes furnished with slightly lower enantioselectivity (84-93\% ee).

Scheme 1.23. Alkyne addition to imines catalyzed by Pybox 1.95

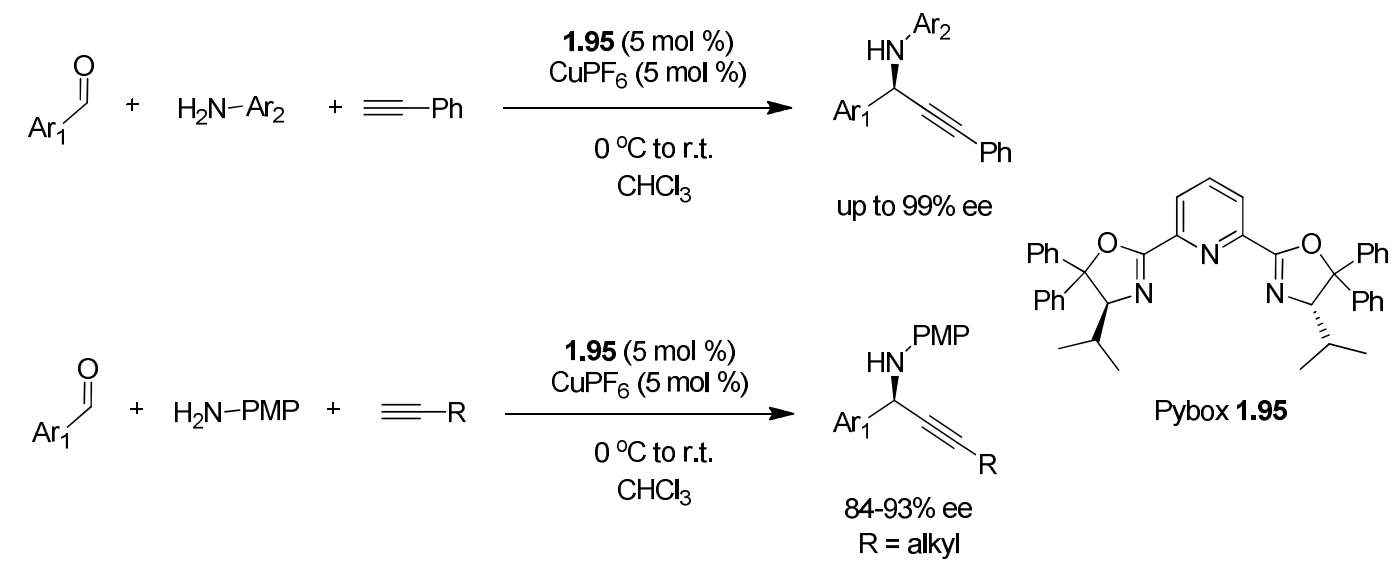

A couple of polymer-bound Pybox ligands were prepared and examined in the copper-catalyzed asymmetric addition of alkynes to imines (Figure 1.14). In 2005, Portnoy reported that the Pybox ligand $\mathbf{1 . 9 6}$ was prepared in 5 steps on a solid phase and catalyzed the reaction of phenylacetylene with $N$-benzylideneaniline in the presence of CuOTf with $83 \%$ ee. ${ }^{79}$ Another polymer-bound Pybox ligand 1.97, developed by Moberg and Levacher in 2007, was used with CuOTf in the enantioselective addition of phenylacetylene to aromatic imines, affording the corresponding propargylic amines with high enantioselectivity (up to $90 \%$ ee). ${ }^{80}$ 
Figure 1.14. Polymer-bound Pybox ligands

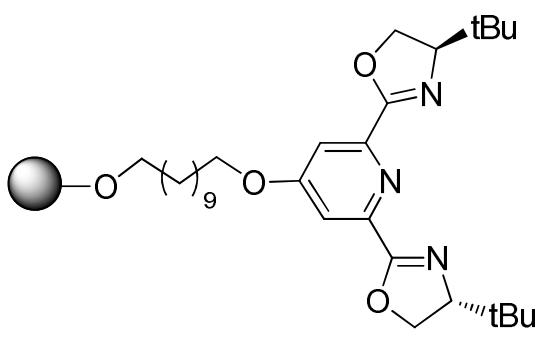

1.96

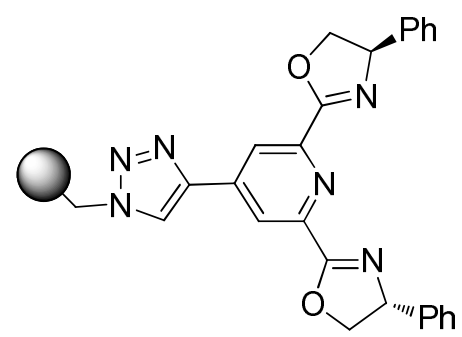

1.97

In 2004, Benaglia developed a new class of ligands for copper-catalyzed enantioselective alkynylation of imines (Scheme 1.24). ${ }^{81}$ The binaphthyl-imine ligand 1.98 was found to catalyze the reaction of phenylacetylene with aromatic imines, producing the desired propargylic amines with up to $85 \%$ ee. The reaction was conducted in the presence of CuOTf at room temperature. This method was also applied to aliphatic alkynes and lower enantioselectivity (up to $73 \%$ ee) was observed. It represents the first example of enantioselective addition of aliphatic alkynes to imines.

Scheme 1.24. Alkyne addition to imines catalyzed by the binaphthyl-imine ligand

\subsection{8}
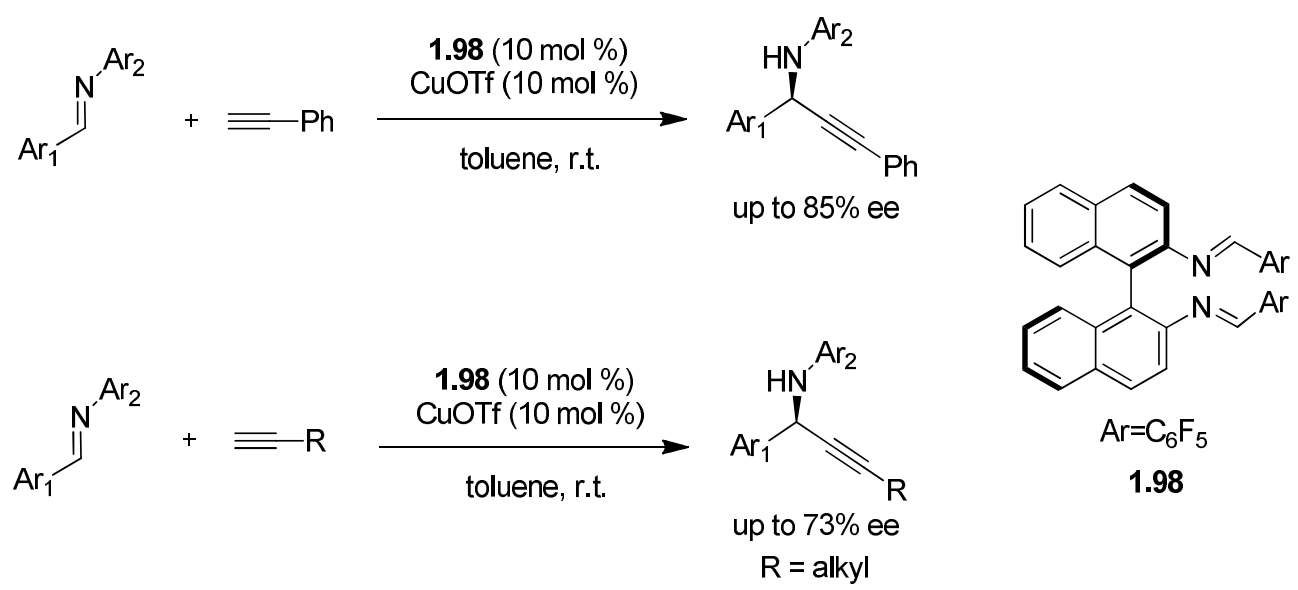

The author also proposed a tentative mechanism as shown in Figure 1.15. The chiral copper complex $\mathbf{1 . 9 9}$ coordinates with the imine to form the intermediate $\mathbf{1 . 1 0 0}$, 
which incorporates with phenylacetylene to generate the complex 1.101. Activation of the terminal alkyne in $\mathbf{1 . 1 0 1}$ leads to the formation of 1.102. After the intramolecular addition of the alkyne to the imine, the propargylic amine product $\mathbf{1 . 1 0 4}$ is released, regenerating the catalytic species 1.99 by decomplexation of $\mathbf{1 . 1 0 3}$.

Figure 1.15. Proposed mechanism for alkyne addition to imines catalyzed by the binaphthyl-imine ligand $\mathbf{1 . 9 8}$

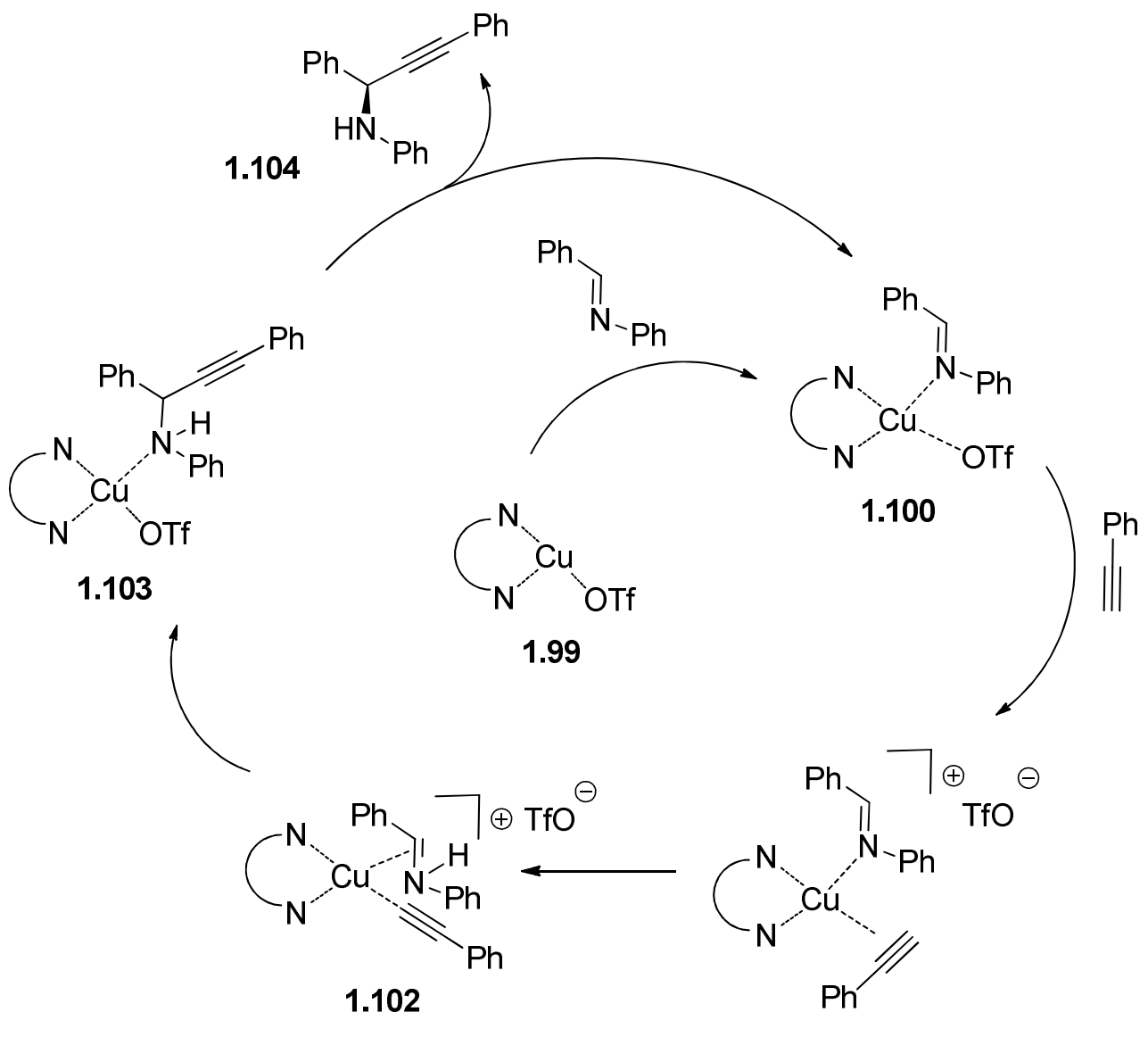

1.101

Later on, a series of binaphthyl-amine ligands were prepared and tested in the enantioselective addition of phenylacetylene to $N$-benzylideneaniline, producing the expected propargylic amines with high yield but moderate enantioselectivity. Ligand 1.105 and $\mathbf{1 . 1 0 6}$ gave the best results as shown in Scheme $1.25{ }^{82}$ 
Scheme 1.25. Addition of phenylacetylene to $N$-benzylideneaniline catalyzed by binaphthyl-amine ligands

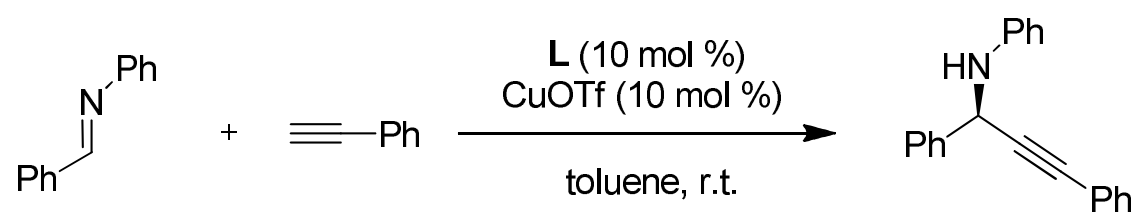<smiles>Nc1ccc2ccccc2c1-c1c(N)ccc2ccccc12</smiles>

1.105

$99 \%, 67 \%$ ee<smiles>Nc1ccccc1Oc1ccc2ccccc2c1-c1c(Oc2ccccc2N)ccc2ccccc12</smiles>

1.106

$73 \%, 82 \%$ ee

Simultaneously to Li's work, Knochel reported a highly enantioselective reaction of alkynes, aldehydes and amines catalyzed by $\mathrm{CuBr}$ and Quinap 1.107 (Scheme 1.26). ${ }^{83}$ The reaction has a broad substrate scope in all three components and gave the corresponding propargylic amines with high yield (43-99\%) and good enantioselectivity (32-96\% ee). It was noteworthy that the methodology was suitable for both aromatic and aliphatic alkynes and aldehydes. The amines were limited to dibenzylamine and diallylamine that could be removed by reported methods.

Scheme 1.26. Reaction of alkynes, aldehydes and amines catalyzed by $\mathrm{CuBr}$ and Quinap 1.107

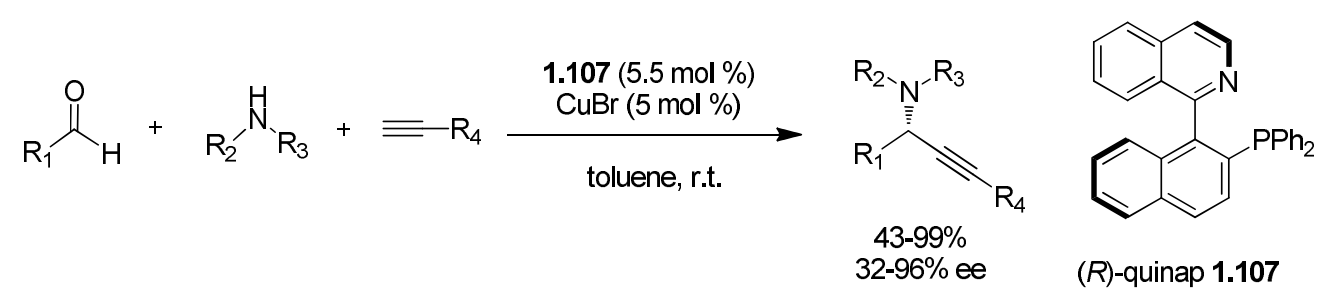

The author suggested a proposed mechanism in Figure 1.16. The dimeric chiral copper complex $\mathbf{1 . 1 0 8}$ reacts with the alkyne, giving the side-on complex $\mathbf{1 . 1 0 9}$. 
Complexation of $\mathbf{1 . 1 0 9}$ with the aminal $\mathbf{1 . 1 1 0}$ formed by the reaction of the aldehyde with the secondary amine leads to the complex 1.111. Deprotonation of the coordinated alkyne and elimination of water generates the complex 1.112, an end-on copper acetylide with a coordinated iminium ion. The addition of the acetylide to the iminium salt in the coordination sphere of copper forms the chiral propargylic amine 1.113 and regenerates the catalyst $\mathbf{1 . 1 0 8}$.

Figure 1.16. Proposed mechanism for alkyne addition to imines catalyzed by Quinap

\subsection{7}

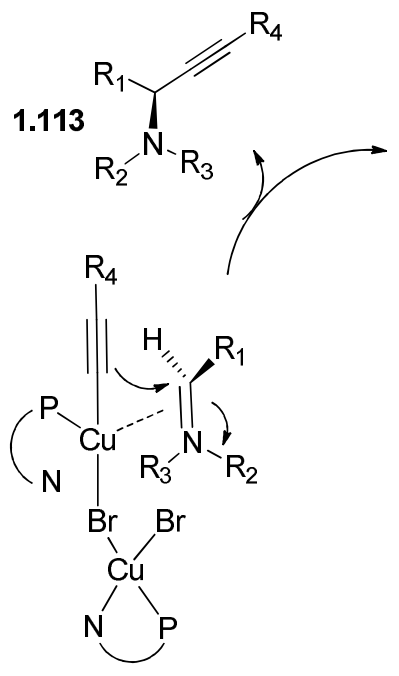

1.112

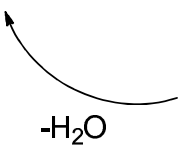<smiles>Br[Ge]1(Br)NCCP1</smiles>
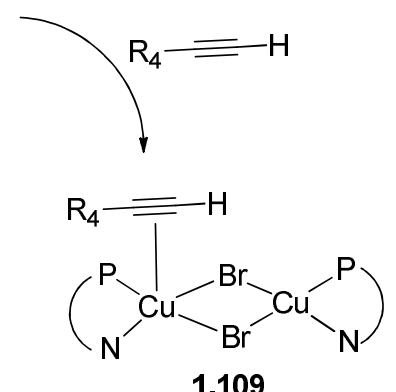

1.109
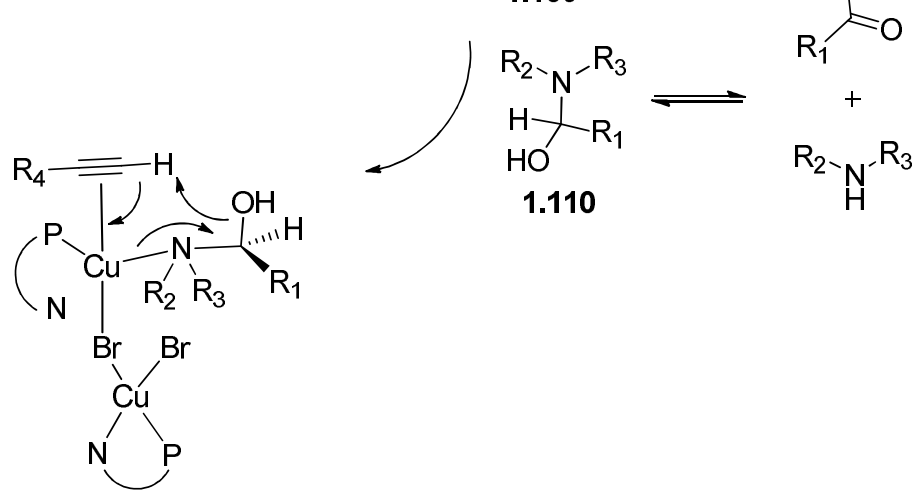

1.110

1.111

The same group also described an asymmetric synthesis of propargylic amines via three-component reaction using trimethylsilylacetylene. The terminal propargylic amines 1.114 were achieved after removal of the TMS group (Scheme 1.27). ${ }^{84}$ 
Scheme 1.27. Asymmetric synthesis of the terminal propargylic amines $\mathbf{1 . 1 1 4}$

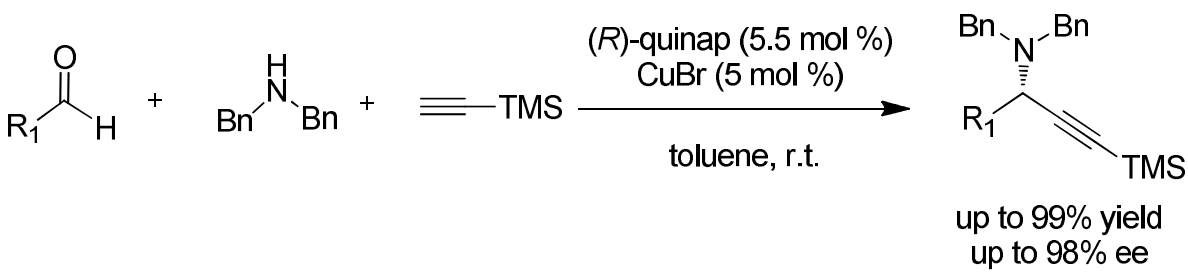

$$
\begin{aligned}
& \underset{\begin{array}{c}
\mathrm{K} \text { or }(1.2 \text { equiv }) \\
\text { MeOH, r.t. }
\end{array}}{\stackrel{\mathrm{Bu}_{4} \mathrm{NF}(0.3 \text { equiv) }}{\mathrm{THF}, 0^{\circ} \mathrm{C}}}
\end{aligned}
$$

Although Quinap is efficient in the asymmetric alkyne addition to imines, its synthesis requires many steps. In 2004, Carreira developed a pair of new $P, N$-ligands Pinap 1.115 and $1.116 .{ }^{85}$ These ligands are readily prepared in four steps with simpler purification. When Pinap 1.115 and $\mathbf{1 . 1 1 6}$ were utilized in Knochel's three-component method for a few substrates, higher enantioselectivity was obtained in comparison with the reaction using Quinap (Scheme 1.28).

Scheme 1.28. Reaction of alkynes, aldehydes and amines catalyzed by $\mathrm{CuBr}$ and Pinap

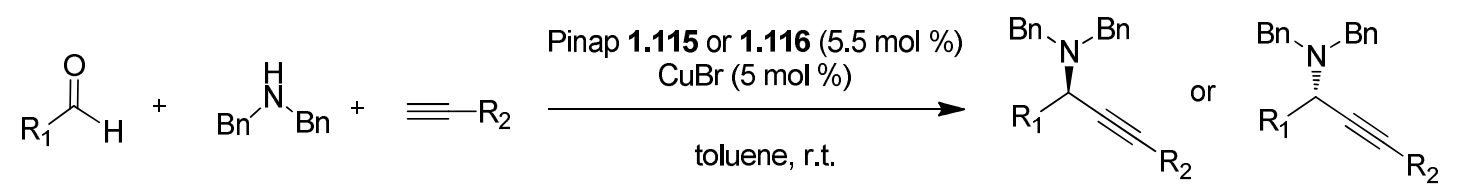<smiles>CC(Nc1nnc(-c2cccc3ccccc23)c2ccccc12)c1ccccc1</smiles>

Pinap 1.115<smiles>C[C@H](Nc1nnc(-c2c(-c3ccccc3)ccc3ccccc23)c2ccccc12)c1ccccc1</smiles>

Pinap 1.116

$\begin{array}{lcc} & \text { Pinap 1.115 } & \text { Quinap } \\ \mathrm{R}_{1}=\mathrm{P} P \mathrm{Pr}, \mathrm{R}_{2}=\mathrm{TMS} & 98 \% \text { ee } & 92 \% \text { ee } \\ \mathrm{R}_{1}=\mathrm{Pr}, \mathrm{R}_{2}=\mathrm{Ph} & 90 \% \text { ee } & 84 \% \text { ee } \\ \mathrm{R}_{1}=\mathrm{B} \mathrm{Bu}, \mathrm{R}_{2}=\mathrm{nBu} & 91 \% \text { ee } & 82 \% \text { ee }\end{array}$


Later on, Carreira used 4-piperidone hydrochloride instead of dibenzylamine for the same reaction (Scheme 1.29). ${ }^{86}$ Various aliphatic aldehydes were examined and the reactions gave the corresponding tertiary propargylic amines with good yield (up to $88 \%$ ) and enantioselectivity (up to $96 \%$ ee). The $N$-substituted piperidone protecting group could be removed using ammonia/EtOH to give free propargylic amines.

Scheme 1.29. Reaction of alkynes, aldehydes and 4-piperidone hydrochloride catalyzed by $\mathrm{CuBr}$ and Pinap

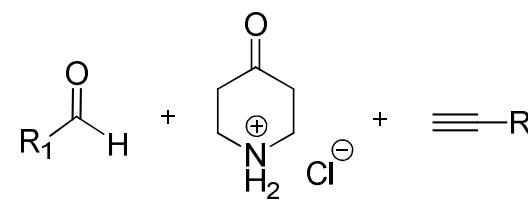

Pinap $1.116(5.5 \mathrm{~mol} \%)$ $\mathrm{CuBr}(5 \mathrm{~mol} \%)$

$\mathrm{Et}_{3} \mathrm{~N}$ (1.1 equiv)

$4 \mathrm{AMS}, \mathrm{CH}_{2} \mathrm{Cl}_{2}$<smiles>[R]C#CC([R])N</smiles>

\subsubsection{Zinc-based methods}

Besides copper-based methods, zinc-based enantioselective alkynylation of imines have become more intriguing recently.

In 2004, Jiang described a highly enantioselective addition of cyclopropylacetylene to the cyclic acylimine $\mathbf{1 . 1 1 8}$ in the presence of $\mathrm{Zn}(\mathrm{OTf})_{2}, \mathrm{Et}_{3} \mathrm{~N}$ and a stoichiometric chiral amino alcohol 1.117, furnishing the propargylic amine 1.119 with excellent yield (96\%) and enantioselectivity $\left(99.1 \%\right.$ ee) (Scheme 1.30). ${ }^{87}$ The $p$-methoxybenzyl (PMB) group was removed in the treatment of ceric ammonium nitrate (CAN) to give DPC 961, a second generation HIV non-nucleoside reverse 
transcriptase inhibitor with enhanced potency compared to Efavirenz (Sustiva).

Scheme 1.30. Addition of cyclopropylacetylene to the cyclic acylimine $\mathbf{1 . 1 1 8}$<smiles>C#CC1CC1</smiles>

Recently, Bolm reported a first $\mathrm{Me}_{2} \mathrm{Zn}$-mediated addition of terminal alkynes to imines in the absence of ligands. ${ }^{88}$ The author also developed an enantioselective three-component reaction in the presence of the chiral amino alcohol $\mathbf{1 . 1 2 0}$ and $\mathrm{Me}_{2} \mathrm{Zn}$ (Scheme 1.31). ${ }^{89} \mathrm{~A}$ variety of propargylic amines were obtained with good yield (up to 93\%) and enantioselectivity (up to 97\% ee) in the reaction of different alkynes, aromatic aldehydes and o-methoxyaniline. However, the reaction with aliphatic alkynes gave much lower enantioselectivity (13-73\% ee).

Scheme 1.31. Enantioselective three-component reaction catalyzed by $\mathbf{1 . 1 2 0}$

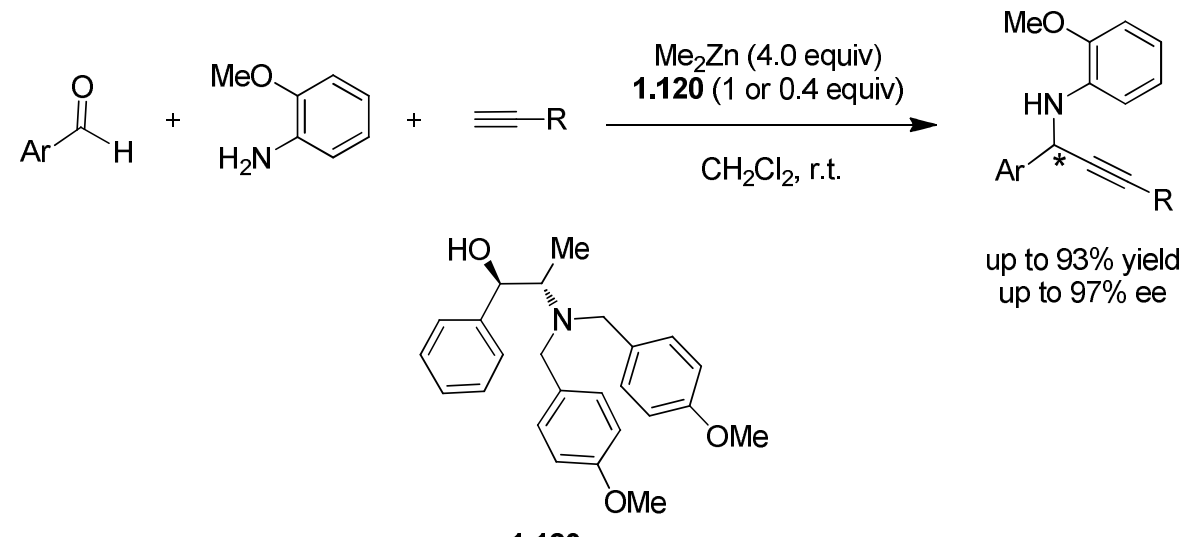


Based on the findings reported by Bolm, alkylzinc reagents have been studied in the enantioselective alkynylation of $N$-activated imines recently. In 2008, Pedro developed a highly enantioselective addition of alkyne to $N$-sulfonyl aldimines by using $\mathrm{Me}_{2} \mathrm{Zn}$ and the 3,3'-substituted BINOL ligand 1.121 (Scheme 1.32). ${ }^{90}$ The reaction of various alkynes with aromatic $N$-sulfonyl aldimines afforded the desired products with good yield (70-86\%) and high enantioselectivity (76-100\% ee). The $N$-sulfonyl-protected propargylic amines could be converted to free propargylic amines by treatment with $\mathrm{SmI}_{2}$.

Scheme 1.32. Addition of alkynes to $N$-sulfonyl aldimines by using $\mathrm{Me}_{2} \mathrm{Zn}$ and $\mathbf{1 . 1 2 1}$
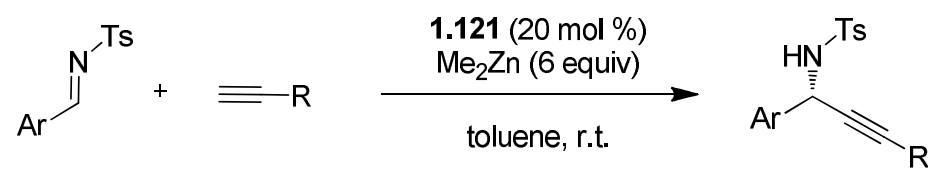

$\mathrm{R}=\mathrm{aryl}, \mathrm{alkyl}$ $70-86 \%$ yields $76-100 \%$ ee

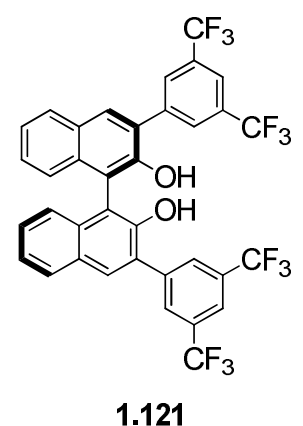

Later on, Pedro described an enantioselective addition of terminal alkynes to $N$-(diphenylphosphinoyl) aldimines in the presence of $\mathrm{Me}_{2} \mathrm{Zn}$ and the 3,3'-dibromo-BINOL 1.122 (Scheme 1.33). ${ }^{91}$ The reaction of aromatic alkynes with various aromatic $N$-(diphenylphosphinoyl) aldimines provided the corresponding propargylic amines with good yield and high enantioselectivity (up to $96 \%$ ee).

Scheme 1.33. Addition of terminal alkynes to $N$-(diphenylphosphinoyl) aldimines by using $\mathrm{Me}_{2} \mathrm{Zn}$ and $\mathbf{1 . 1 2 2}$

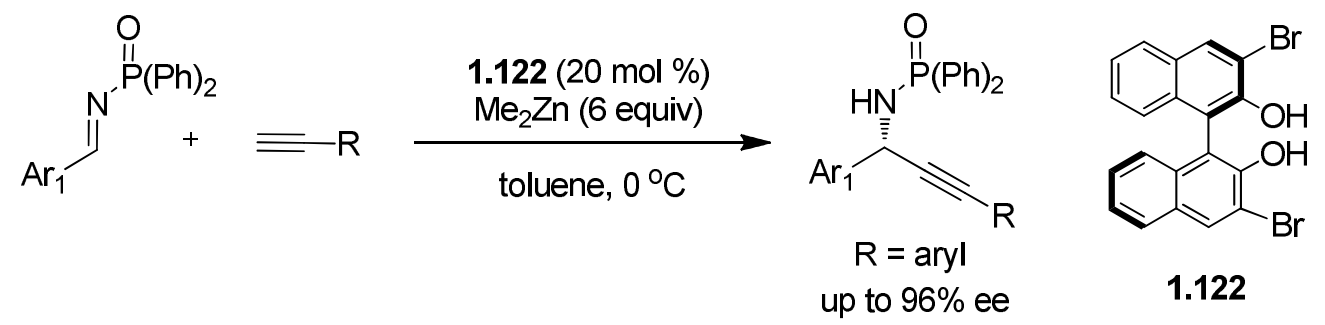


In 2009, Wang used stoichiometric amounts of the proline-derived $\beta$-amino alcohol ligand $\mathbf{1 . 1 2 3}$ in combination with $\mathrm{Et}_{2} \mathrm{Zn}$ for the enantioselective alkynylation of aromatic $N$-(diphenylphosphinoyl)aldimines, producing the expected $N$-protected propargylic amines with high yield and excellent enantioselectivity. ${ }^{92}$ Later, the tridentate ligand $\mathbf{1 . 1 2 4}$ (35 mol \%) was employed to catalyze the reaction with good results by the same group. ${ }^{93}$ The author also studied the enantioselective addition of trimethylsilylacetylene to $N$-(diphenylphosphinoyl)aldimines catalyzed by the $C_{2}$-symmetric proline-derived $\beta$-amino alcohol ligand $\mathbf{1 . 1 2 5}$ (Scheme 1.34). ${ }^{94}$

Scheme 1.34. Addition of terminal alkynes to $N$-(diphenylphosphinoyl) aldimines by using $\mathrm{Et}_{2} \mathrm{Zn}$ and 1.123-1.125

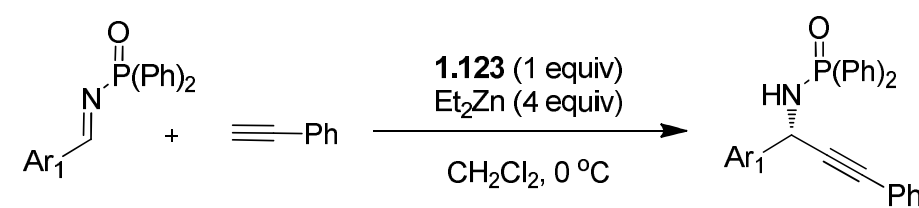
up to $96 \%$ ee<smiles>[R]C=N[P+](=O)N=C[R]</smiles>

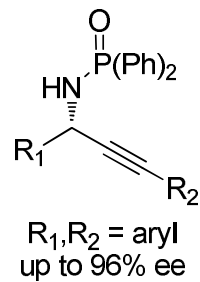

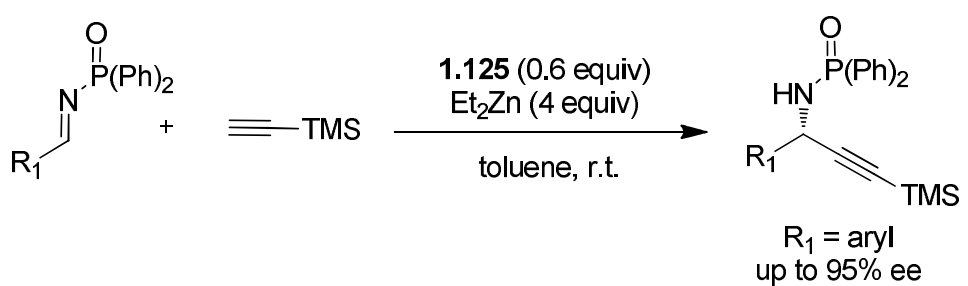<smiles>OC[C@H]1CCCN1Cc1ccc2ccccc2c1</smiles>

1.123<smiles>OCC1CCCN1Cc1cccs1</smiles>

1.124<smiles>Cc1cc(CN2CCCC2CO)cc(CN2CCC[C@H]2CO)c1</smiles>

1.125

\subsubsection{Other metals-based methods}

Hoveyda and Snapper reported that ligand $\mathbf{1 . 1 2 6}$ and Zr complex were employed to catalyze the enantioselective addition of mixed alkynylzinc reagents to various 
$N$-arylimines with up to $90 \%$ ee (Scheme 1.35$).{ }^{95}$

Scheme 1.35. Addition of mixed alkynylzinc reagents to $N$-arylimines by using ligand 1.126 and Zr complex<smiles>COc1ccccc1/N=C/c1ccccc1</smiles>

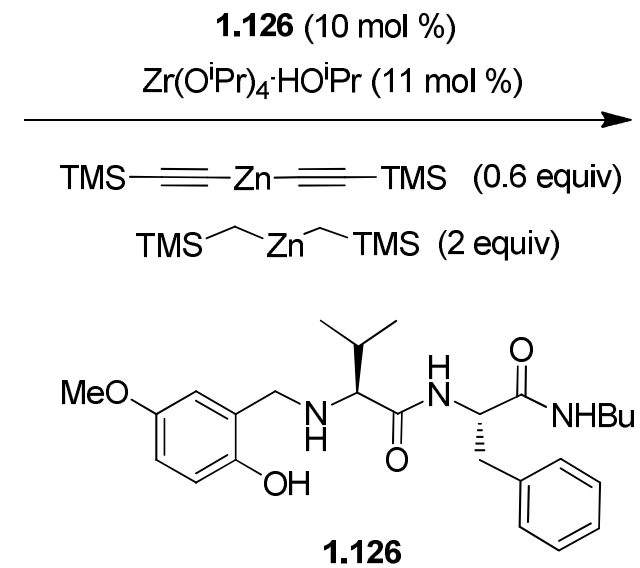<smiles>COc1ccccc1NC(C#CC(C)(C)C)c1ccccc1</smiles>

In 2006, Chong developed a highly enantioselective addition of the BINOL-based alkynylboronates $\mathbf{1 . 1 2 7}$ to $\mathrm{N}$-acylaldimines (Scheme 1.36). ${ }^{96}$ The reaction produced chiral propargylic amides with up to $99 \%$ ee.

Scheme 1.36. Addition of the BINOL-based alkynylboronates 1.127 to $N$-acylaldimines

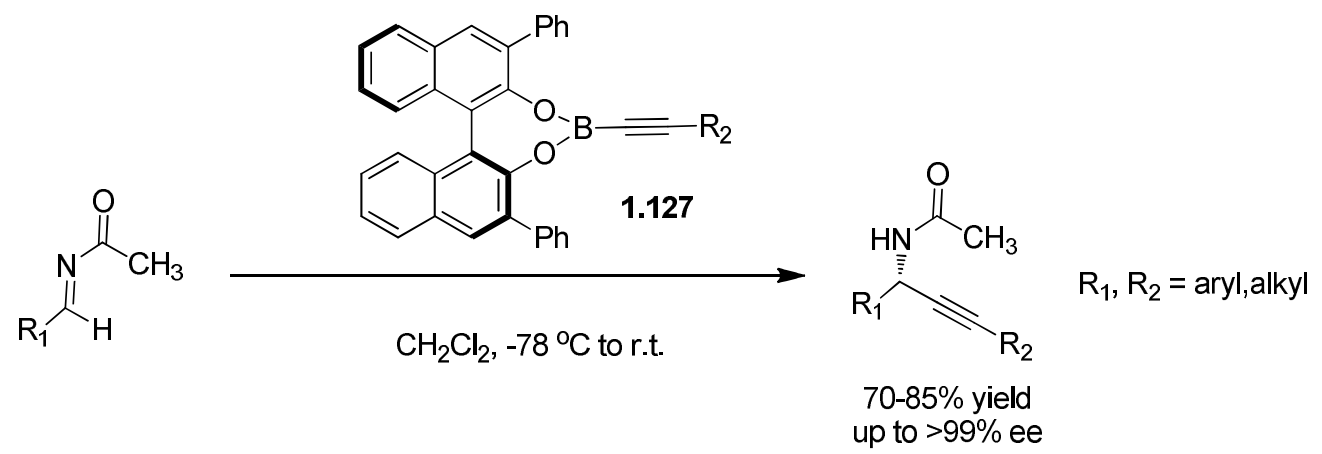

\subsubsection{Summary}

A number of excellent protocols for asymmetric addition of alkynes to imines have been developed in the last decade. Copper-based methods, first introduced by Li, are widely studied and employed in the enantioselective alkynylation of $N$-arylimines 
to access chiral propargylic amines. Zinc-based methods have been proved effective in the asymmetric alkynylation of the $N$-protected imines. The $N$-protecting groups can be easily removed under mild conditions to give free chiral propargylic amines. The methods based on other metals, such as zirconium and chiral boronates, have also been reported. But, all these methods lack generality and some of them employ stoichiometric amounts of chiral ligands or metal complexes. Further developments are necessary to find more effective catalysts and general procedures.

\subsection{Application of chiral propargylic amines}

\subsubsection{Diverse transformations of chiral propargylic amines}

Chiral propargylic amines obtained from the enantioselective alkynylation of imines described above have found broad application in organic synthesis. A number of powerful enantioselective transformations were demonstrated by Knochel group and Benaglia group.

Knochel employed $(S)$-Quinap and $\mathrm{CuBr}$ to catalyzed the enantioselective addition of trimethylacetylene to imines, affording a variety of the TMS-substituted propargylic amines $\mathbf{1 . 1 2 8}$ with up to $98 \%$ ee. After removal of the TMS group, the propargylic amines $\mathbf{1 . 1 2 9}$ with terminal triple bond underwent diverse transformations to access functionalized amines. ${ }^{97}$ For instance, deprotonation of 1.129 with ${ }^{n} \mathrm{BuLi}$ followed by alkylation with either paraformaldehyde or ethylene oxide and silylation with TIPSCl produced the protected amino alcohols $\mathbf{1 . 1 3 0}$ with $58-71 \%$ yield and up 
to $98 \%$ ee. In addition, the chiral alkynyl esters $\mathbf{1 . 1 3 1}$ were obtained with $85-96 \%$ yield and up to $97 \%$ ee when compounds $\mathbf{1 . 1 2 9}$ were treated with ${ }^{n} \mathrm{BuLi}$ and ethyl chloroformate. Finally, Sonogashira cross-coupling of $\mathbf{1 . 1 2 9}$ with iodobenzene in combination with $\mathrm{PdCl}_{2}\left(\mathrm{PPh}_{3}\right)_{2}$ and $\mathrm{CuI}$ generated the phenylacetylene derivatives 1.132 with $87-90 \%$ yield and up to $98 \%$ ee (Scheme 1.37 ).

Scheme 1.37. Diverse transformations of the chiral propargylic amines $\mathbf{1 . 1 2 9}$
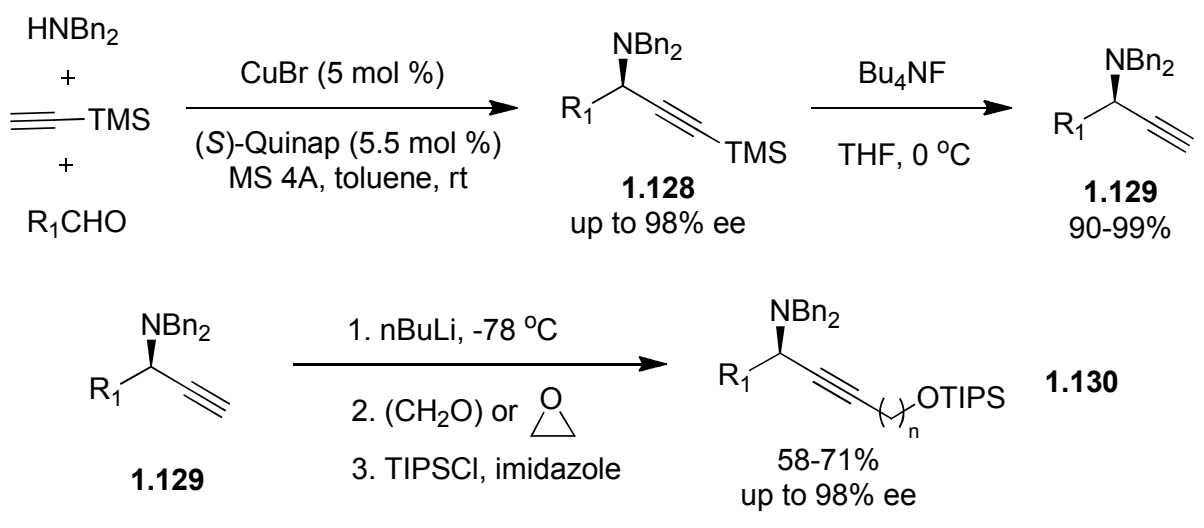<smiles>[R]C(C#C)[NH2+]CCCC</smiles>

1.129<smiles>[R]C([NH2+])C#C</smiles>

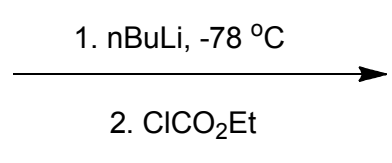

up to $98 \%$ ee

1.131

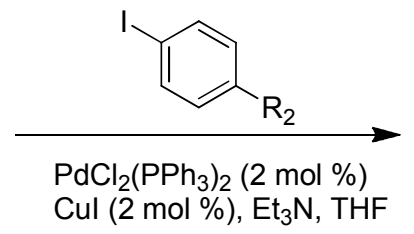

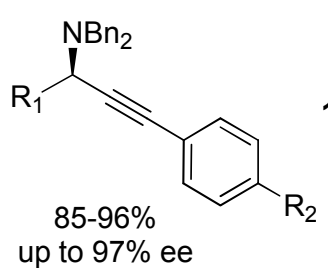

$(R)$-Quinap was utilized to produce the enantiomer 1.133. A range of the a-aminoalkylpyrimidines $\mathbf{1 . 1 3 6}$ were prepared with $73-98 \%$ yields and up to $98 \%$ ee's by successive reactions of $\mathbf{1 . 1 3 3}$ with the acid chlorides $\mathbf{1 . 1 3 4}$ and the amidines 1.135. ${ }^{98}$ Pyrimidines have found potential biological activity and are of great interest in pharmaceutical industry. Treatment of $\mathbf{1 . 1 3 3}$ with functionalized azides in the 
presence of copper provided various chiral $\alpha$-aminoalkyl-1,2,3-triazoles $\mathbf{1 . 1 3 7}$ in $73-98 \%$ yields without a loss of stereochemistry (Scheme 1.38). ${ }^{99}$ These products show a high synthetic potential towards natural products and biologically active compounds.

Scheme 1.38. Diverse transformations of chiral propargylic amines $\mathbf{1 . 1 3 3}$

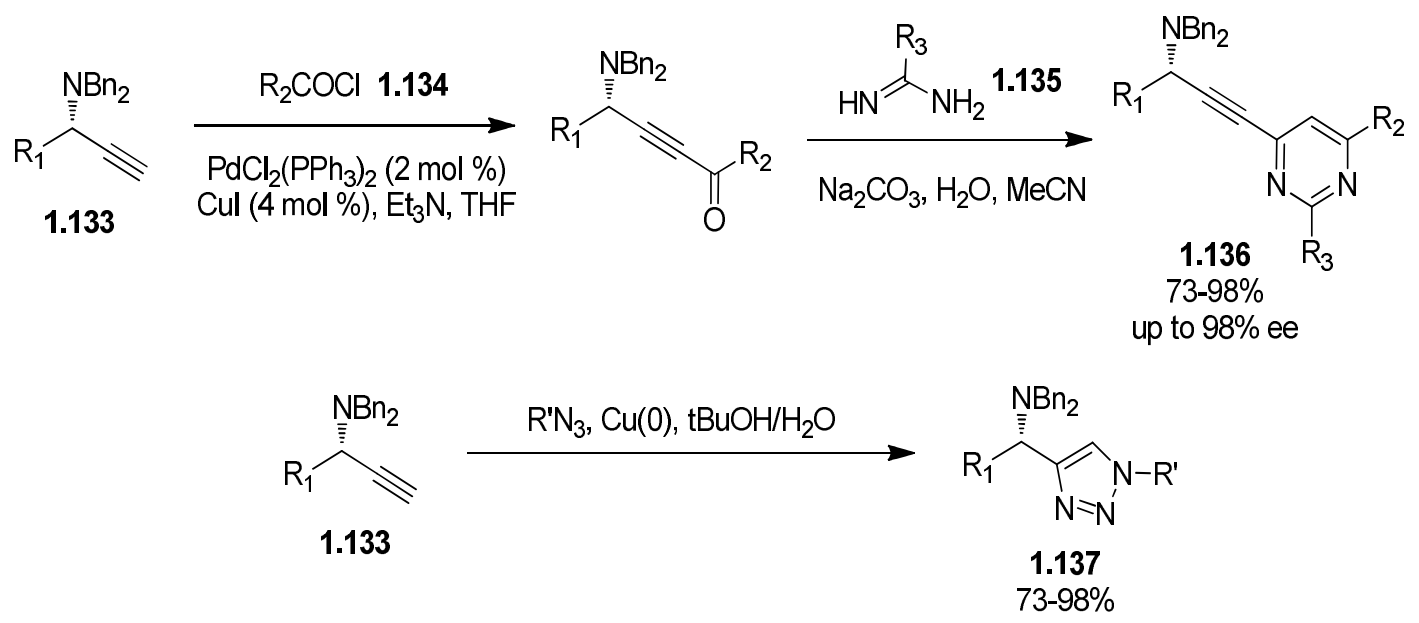

Benaglia used the binaphthyl-imine ligand $\mathbf{1 . 9 8}$ in combination with CuOTf for the enantioselective addition of phenylacetylene to $\mathrm{N}$-benzylideneaniline, furnishing the desired propargylic amine $\mathbf{1 . 1 3 8}$ with $98 \%$ yield and $81 \%$ ee. Partial or complete hydrogenation of $\mathbf{1 . 1 3 8}$ produced the highly functionalized allylic amine $\mathbf{1 . 1 3 9}$ or the saturated amine 1.140, respectively. Treatment of 1.138 with $\mathrm{AcCl}$ and $\mathrm{Et}_{3} \mathrm{~N}$ gave the $N$-acetyl compound 1.141, which was converted to the $\beta$-amino ketone $\mathbf{1 . 1 4 2}$ in $37 \%$ yield via $\mathrm{Hg}$ (II)-catalyzed hydration. Compound $\mathbf{1 . 1 4 2}$ is an attractive precursor for the synthesis of chiral 1,3-amino alcohol derivatives (Scheme 1.39). ${ }^{81 \mathrm{a}}$ 
Scheme 1.39. Diverse transformations of the chiral propargylic amine $\mathbf{1 . 1 3 8}$

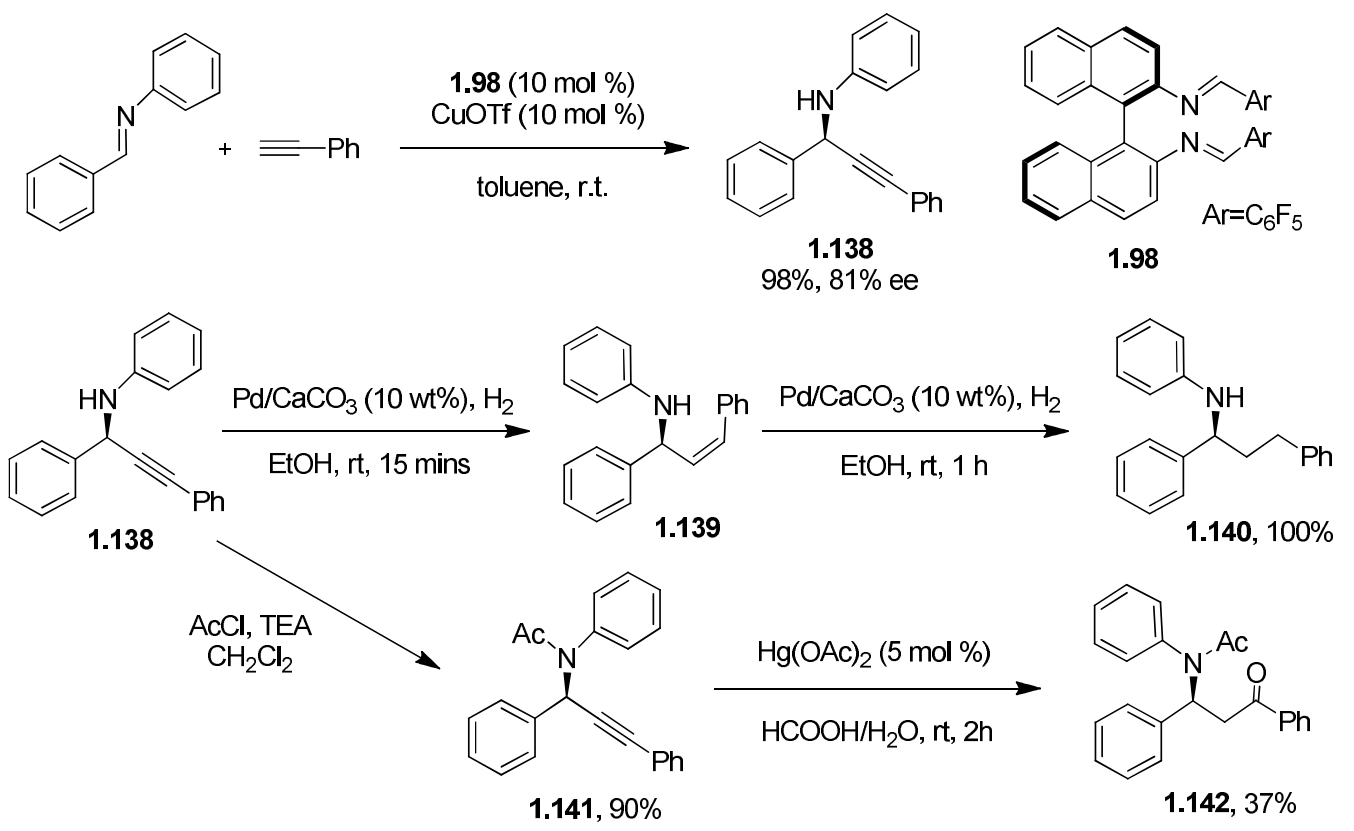

\subsubsection{Application in total synthesis}

The synthetic utility of chiral propargylic amines was also demonstrated by several total syntheses of natural products and pharmaceuticals.

Knochel accomplished an expeditious synthesis of $(S)-(+)$-coniine using an imine alkynylation strategy (Scheme 1.40). ${ }^{100}$ The chiral propargylic amine $\mathbf{1 . 1 4 3}$ was obtained with $88 \%$ yield and $90 \%$ ee via the $(R)$-Quinap/CuBr catalyzed enantioselective three-component reaction and desilylation. Deprotonation of $\mathbf{1 . 1 4 3}$ with ${ }^{n} \mathrm{BuLi}$ followed by alkylation with ethylene oxide and silylation with TIPSCl led to the formation of the TIPS-protected derivative $\mathbf{1 . 1 4 4}$ in $70 \%$ overall yield. $\mathrm{Pd} / \mathrm{C}$ hydrogenation of $\mathbf{1 . 1 4 4}$ gave a primary amine which was desilylated with $\mathrm{Bu}_{4} \mathrm{NF}$ and underwent Mitsunobu reaction to generate $(S)-(+)$-coniine in $65 \%$ yield. 
Scheme 1.40. Total synthesis of $(S)-(+)$-coniine using an imine alkynylation strategy

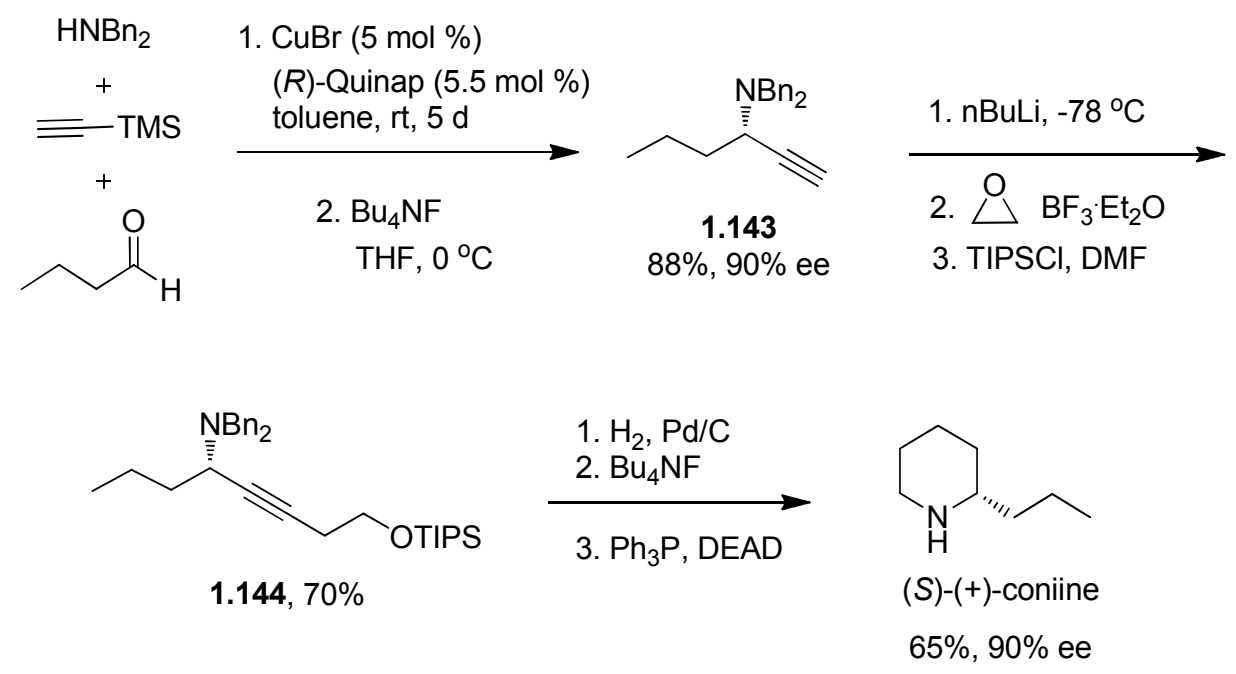

Schreiber also used Quinap/CuBr system in the enantioselective addition of alkynes to isolated isoquinoline iminium ions. This methodology displayed important utility in the synthesis of (S)-homolaudanosine $\mathbf{1 . 1 4 5}$ (Scheme 1.41), an isoquinoline-based natural product from a family of alkaloids with neurologic activity, and the synthesis of a small-molecule inhibitor $\mathbf{1 . 1 4 6}$ of yeast proliferation (Scheme $1.42) .^{101}$

Scheme 1.41. Total synthesis of $(S)$-homolaudanosine $\mathbf{1 . 1 4 5}$
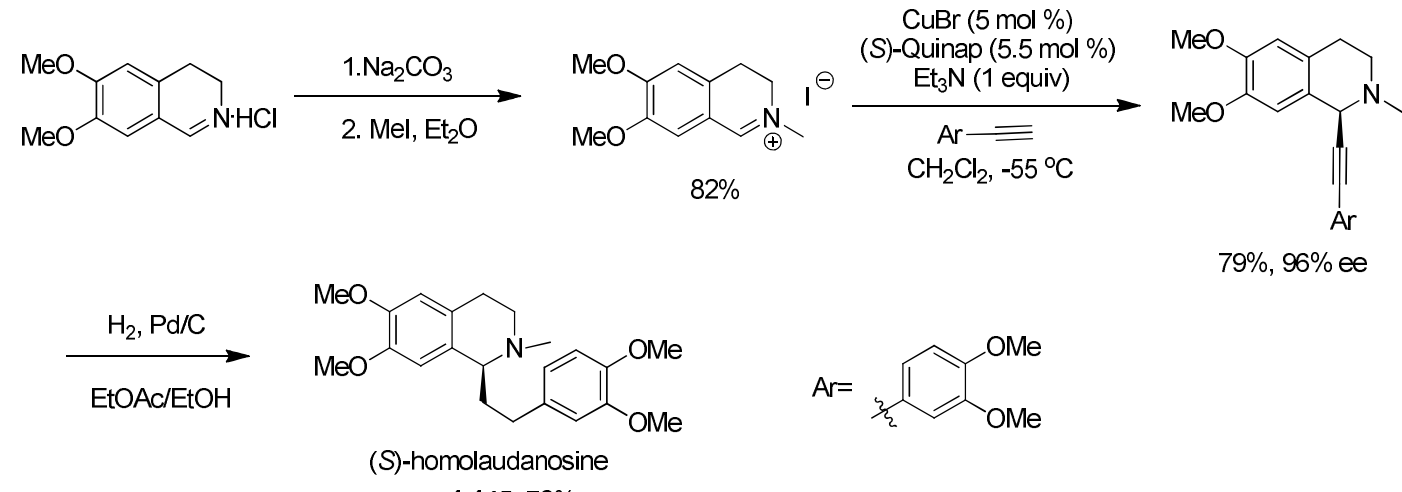

$79 \%, 96 \%$ ee 1.145, $76 \%$ 
Scheme 1.42. Total synthesis of a small-molecule inhibitor $\mathbf{1 . 1 4 6}$

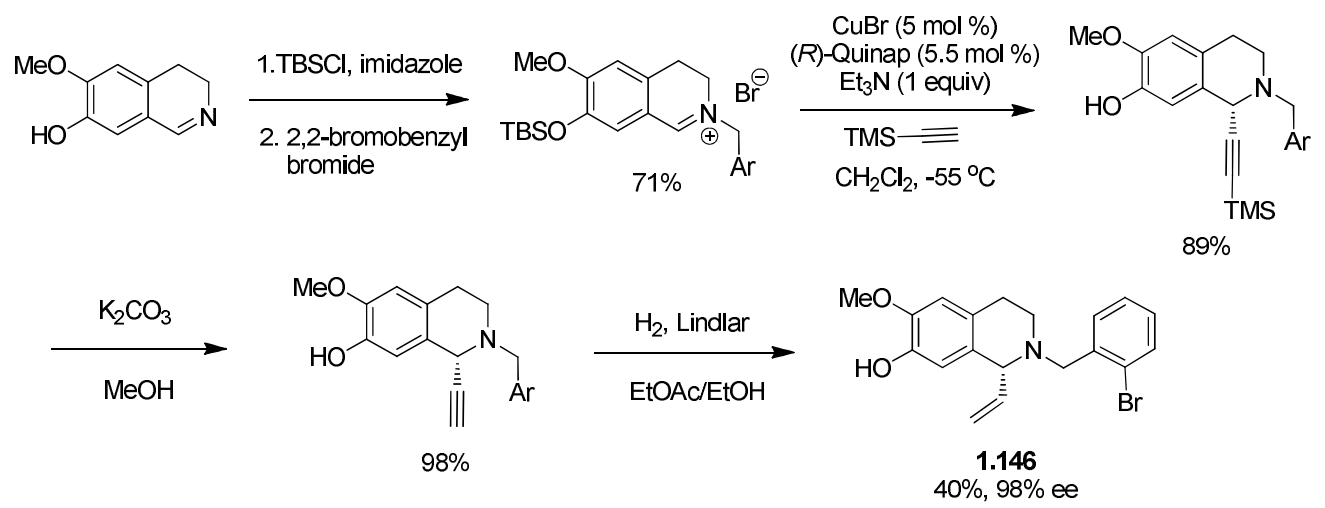

Chong employed the BINOL-based alkynylboronates in the enantioselective alkynylation of $N$-acylaldimines to give the corresponding chiral $N$-Acyl propargylic amides with good yield and high enantioselectivity. The synthetic utility of this protocol was demonstrated by the synthesis of (-)- $N$-acetylcolchinol, whose $O$-phosphate, known as ZD6126, is useful in the treatment of cancer (Scheme 1.43). ${ }^{96}$ The crude imine, converted from TBS-protected 3-hydroxybenzaldehyde, was reacted with $(R)$-diphenylbinaphthol alkynylboronate $\mathbf{1 . 1 4 7}$ to give the desired $(R)$ - $N$-Acyl propargylic amide $\mathbf{1 . 1 4 8}$ with $72 \%$ yield and $94 \%$ ee. $\mathrm{Pd} / \mathrm{C}$ hydrogenation of $\mathbf{1 . 1 4 8}$ led to the saturated amide $\mathbf{1 . 1 4 9}$, which was treated with $\left(\mathrm{CF}_{3} \mathrm{COO}\right)_{3} \mathrm{Tl}$, TFA, TFAA and $\mathrm{BF}_{3}-\mathrm{Et}_{2} \mathrm{O}$ to afford (-)- $N$-acetylcolchinol in $53 \%$ yield.

Scheme 1.43. Total synthesis of (-)- $N$-acetylcolchinol

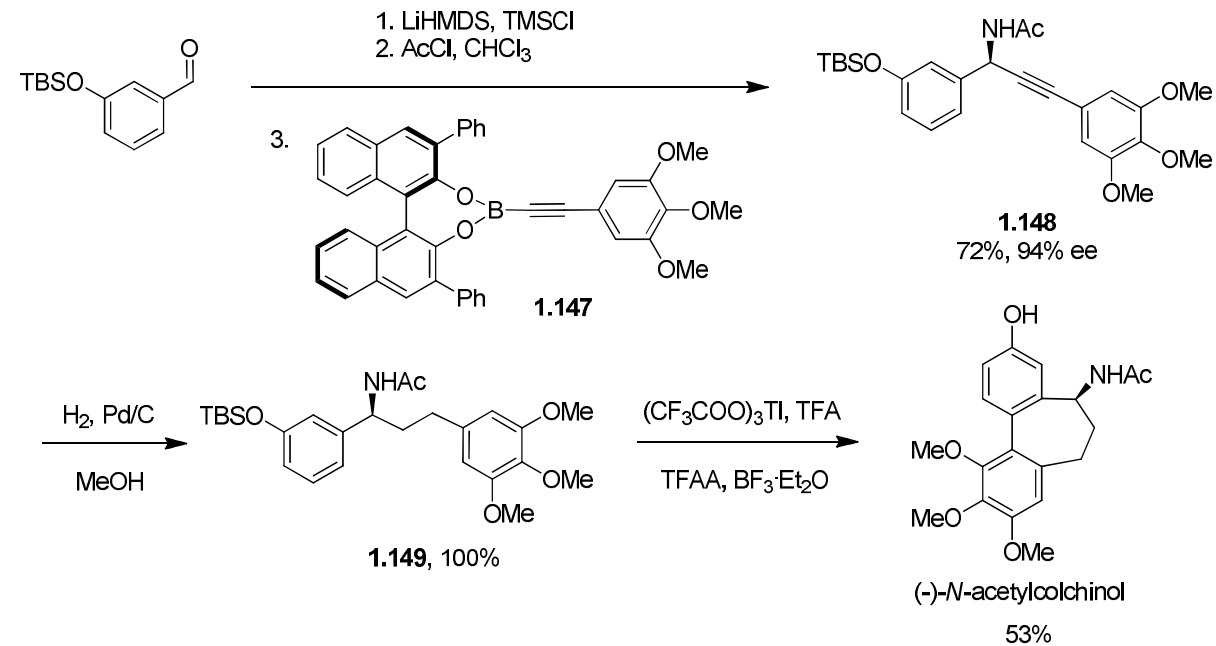


A series of HIV reverse transcriptase inhibitors, 1.150, DPC 963 and DPC 961, were synthesized via the Li-mediated enantioselective alkynylation of imines by Merck Laboratories (in 1995) ${ }^{102}$ and DuPont Pharmaceuticals Company (in 2000) (103 $^{103}$ (Figure 1.17). In 2004, Jiang developed a Zn-mediated highly enantioselective addition of alkynes to imines under mild conditions for the synthesis of DPC $961 .^{87}$

Figure 1.17. HIV reverse transcriptase inhibitors<smiles>O=C1Nc2ccc(Cl)cc2[C@](C#Cc2ccccn2)(C2CC2)N1</smiles>

1.150<smiles>C[C@]1(C#CC2CC2)NC(=O)Nc2ccc(F)c(F)c21</smiles>

DPC 963<smiles>C[C@]1(C#CC2CC2)NC(=O)Nc2ccc(Cl)cc21</smiles>

DPC 961

\subsubsection{Summary}

Metal-mediated asymmetric alkynylation of imines has been proved a powerful way to construct chiral propargylic amines that are useful building blocks in the synthesis of numerous pharmaceuticals, biologically active compounds and natural products.

Knochel and Benaglia groups described various transformations of chiral propargylic amines to access other functionalized amines. In addition, several groups demonstrated a remarkable synthetic utility of chiral propargylic amines in the total syntheses of natural products and pharmaceuticals including $(S)-(+)$-coniine, (S)-homolaudanosine, (-)- $\mathrm{N}$-acetylcolchinol and HIV reverse transcriptase inhibitors 1.150, DPC 963 and DPC 961. 


\section{References}

1. Walsh, P. J.; Kozlowski, M. C. Fundamentals of Asymmetric Catalyst, 2009.

2. Clayden, J.; Moran, W. J.; Edwards, P. J.; LaPlante, S. R. Angew. Chem. Int. Ed. 2009, 48, 6398-6401.

3. Gawroński, J. Acta. Pol. Pharm. 2006, 63, 331-351.

4. Hawkins, J. M.; Watson, T. J. N. Angew. Chem. Int. Ed. 2004, 43, 3224-3228.

5. Ager, D. J.; East, M. B. Asymmetric Synthetic Methodology, 1996.

6. Noyori, R. Asymmetric Catalysis in Organic Synthesis, 1994.

7. Nozaki, H.; Moriuti, S.; Takaya, H.; Noyori, R. Tetrahedron 1966, 43, 5239-5244.

8. Gao, Y.; Klunder, J. M.; Hanson, R. M.; Masamune, H.; Ko, S. Y.; Sharpless, K. B. J. Am. Chem. Soc. 1987, 109, 5765-5780.

9. Noyori, R.; Okhuma, T.; Kitamura, M.; Takaya, H.; Sayo, N.; Kumobayashi, H.; Akuragawa, S. J. Am. Chem. Soc. 1987, 109, 5856-5858.

10. (a) Vineyard, B. D.; Knowles, W. S.; Sabacky, M. J.; Bachman, G. L.; Weinkauff, D. J. J. Am. Chem. Soc. 1977, 99, 5946-5952. (b) Knowles, W. S. Acc. Chem. Res. 1983, $16,106-112$.

11. Trost, B. M.; Weiss, A. H. Adv. Synth. Catal. 2009, 351, 963-983.

12. Vogels, C. M.; Westcott, S. A. Curr. Org. Chem. 2005, 9, 687-699.

13. Smith, N. D.; Mancuso, J.; Lautens, M. Chem. Rev. 2000, 100, 3257-3282.

14. Trost, B. M.; Ball, Z. T. Synthesis 2005, 853-887.

15. Witulski, B.; Zimmermann, A.; Gowans, N. D. Chem. Commun. 2002, 2984-2985. 
16. Turlington, M.; Pu. L. Synlett 2012, 23, 649-684.

17. Pu, L. Tetrahedron 2003, 59, 9873-9886.

18. (a) Bauer, T. Coord. Chem. Rev. 2015, 299, 83-150. (b) Pu, L.; Yu, H.-B. Chem. Rev. 2001, 101, 757-824.

19. Niwa, S.; Soai, K. J. Chem. Soc. Perkin Trans. 1 1990, 937-943.

20. Tombo, G. M. R.; Didier, E.; Loubinoux, B. Synlett 1990, 547-548.

21. Li, Z.; Upadhyay, V.; DeCamp, A. E.; DiMichele, L.; Reider, P. Synthesis 1999, $1453-1458$.

22. Frantz, D. E.; Fässler, R.; Carreira, E. M. J. Am. Chem. Soc. 2000, 122, 1806-1807.

23. Anand, N. K.; Carreira, E. M. J. Am. Chem. Soc. 2001, 123, 9687-9688.

24. Jiang, B.; Chen, Z.-L.; Xiong, W.-N. J. Chem. Soc. Chem. Commun. 2002, $1524-1525$.

25. Chen, Z.-L.; Xiong, W.-N.; Jiang, B. Chem. Commun. 2002, 2098-2099.

26. Trost, B. M.; Weiss, A. H. J. Am. Chem. Soc. 2006, 128, 8-9.

27. Trost, B. M.; Burns, A. C.; Bartlett, M. J.; Tautz, T.; Weiss, A. H. J. Am. Chem. Soc. 2012, 134, 1474-1477.

28. Trost, B. M.; Bartlett, M. J. Org. Lett. 2012, 14, 1322-1325.

29. Trost, B. M.; Weiss, A. H. Angew. Chem. Int. Ed. 2007, 46, 7664-7666.

30. Trost, B. M.; Bartlett, M. J.; Weiss, A. H.; von Wangelin, A. J.; Chan, V. S. Chem. Eur. J. 2012, 18, 16498-16509.

31. Trost, B. M.; Chan, V. S.; Yamamoto, D. J. Am. Chem. Soc. 2010, 132, 5186-5192. 
32. Trost, B. M.; Quintard, A. Angew. Chem. Int. Ed. 2012, 51, 6704-6708.

33. Zhong, J.; Hou, S.; Bian, Q.; Yin, M.; Na, R.; Zheng, B.; Li, Z.; Liu, S.; Wang, M. Chem. Eur. J. 2009, 15, 3069-3071.

34. Li, Z.; Wang, M.; Bian, Q.; Zheng, B.; Mao, J.; Li, S.; Liu, S.; Wang, M.; Zhong, J.; Guo, H. Chem. Eur. J. 2011, 17, 5782-5786.

35. Wang, M.; Zhang, Q.; Zhao, W.; Wang, X.; Ding, X.; Jing, T.; Song, M. J. Org. Chem. 2008, 73, 168-176.

36. Koyuncu, H.; Dogan, Ö. Org. Lett. 2007, 9, 3477-3479.

37. Niu, J.; Wang, M.; Lu, L.; Ding, G.; Lu, H.; Chen, Q.; Song, M. Tetrahedron: Asymmetry 2009, 20, 2616-2621.

38. Lu, G.; Li, X. -S.; Zhou, Z. -Y.; Chan, W. L.; Chan, A. S. C. Tetrahedron: Asymmetry 2001, 12, 2147-2152.

39. Braga, A. L.; Appelt, H. R.; Silveira, C. C. Wessjohann, L. A.; Schneider, P. H. Tetrahedron 2002, 58, 10413-10416.

40. Subirats, S.; Jimeno, C.; Pericàs, M. A. Tetrahedron: Asymmetry 2009, 20, 2616-2621.

41. Wu, P. -Y.; Wu, H. -L.; Shen, Y. -Y.; Uang, B. -J. Tetrahedron: Asymmetry 2009, $20,1837-1841$.

42. Xu, Z.; Chen, C.; Xu, J.; Miao, M.; Yan, W.; Wang, R. Org. Lett. 2004, 6, 1193-1195.

43. Ni, M.; Wang, R.; Han, Z.; Mao, B.; Da, C.; Liu, L.; Chen, C. Adv. Synth. Catal. 2005, 347, 1659-1665. 
44. Fang, T.; Du, D. -M.; Lu, S. -F.; Xu, J. Org. Lett. 2005, 7, 2081-2084.

45. Hui, X. -P.; Yin, C.; Chen, Z. -C.; Huang, L. -N.; Xu, P. -F.; Fan, G. -F. Tetrahedron 2008, 64, 2553-2558.

46. Li, Y. -M.; Tang, Y. -Q.; Hui, X. -P.; Huang, L. -N.; Xu, P. -F.; Tetrahedron 2009 , $65,3611-3614$

47. Chelucci, G.; Conti, S.; Falorni, M.; Giacomelli, G. Tetrahedron 1991, 47, $8251-8258$.

48. Ishizaki, M.; Hoshino, O. Tetrahedron: Asymmetry 1994, 5, 1901-1904.

49. Kamble, R. M.; Singh, V. K. Tetrahedron Lett. 2003, 44, 5347-5349.

50. Pu, L. Chem. Rev. 1998, 98, 2405-2494.

51. Kočovský, P.; Vyskočil, Š.; Smrčina, M. Chem. Rev. 2003, 103, 3213-3246.

52. Brunel, J. M. Chem. Rev. 2005, 105, 857-898.

53. Moore, D.; Pu, L. Org. Lett. 2002, 4, 1855-1857.

54. Gao, G.; Moore, D.; Xie, R.-G.; Pu, L. Org. Lett. 2002, 4, 4143-4146.

55. Lu, G.; Li, X.-S.; Chan, W. L.; Chan, A. S. C. J. Chem. Soc. Chem. Commun. 2002, 172-173.

56. Li, X.-S.; Lu, G.; Kwok, W. H.; Chan, A. S. C. J. Am. Chem. Soc. 2002, 124, 12636-12637.

57. Gao, G.; Xie, R.-G.; Pu, L. Proc. Natl. Acad. Sci. U.S.A. 2004, 101, 5417.

58. Du, Y.; Turlington, M.; Zhou, X.; Pu, L. Tetrahedron Lett. 2010, 51, 5024-5027.

59. Chen, S. -Y.; Liu, W.; Wu, X. -D.; Ying, J.; Yu, X. -Q.; Pu, L. Chem. Commun. 2015, 51, 358-361. 
60. Huang, W. -C.; Liu, W.; Wu, X. -D.; Ying, J.; Pu, L. J. Org. Chem. 2015, 80, $11480-11484$.

61. Huang, W.-S.; Hu, Q.-S.; Pu, L. J. Org. Chem. 1998, 63, 1364-1365.

62. Moore, D.; Huang, W.-S.; Xu, M.-H.; Pu, L. Tetrahedron Lett. 2002, 43, 8831-8834.

63. Yue, Y.; Turlington, M.; Yu, X. -Q.; Pu, L. J. Org. Chem. 2009, 74, 8681-8689.

64. Xu, M.-H.; Pu, L. Org. Lett. 2002, 4, 4555-4557.

65. Wang, Q.; Chen, S.-Y.; Yu. X.-Q.; Pu, L. Tetrahedron. 2007, 63, 4422-4428.

66. Li, Z.-B.; Pu, L. Org. Lett. 2004, 6, 1065-1068.

67. Li, Z.-B.; Liu, T.-D.; Pu, L. J. Org. Chem. 2007, 72, 4340-4343.

68. Wang, Q.; Pu, L. Synlett 2013, 24, 547-548.

69. Zhou, L.-H.; Yu, X.-Q.; Pu, L. J. Org. Chem. 2009, 74, 2013-2017.

70. Turlington, M.; Yue, Y.; Yu, X.-Q.; Pu, L. J. Org. Chem. 2010, 75, 6941-6952.

71. Turlington, M.; Du, Y.-H.; Ostrum, S. G.; Santosh, V.; Wren, K.; Lin, T.; Sabat, M.; Pu, L. J. Am. Chem. Soc. 2011, 133, 11780-11794.

72. Chen, W.; Tay, J.-H.; Ying, J.; Sabat, M.; Yu, X.-Q.; Pu, L. Chem. Commun. 2013, $49,170-172$.

73. Chen, W.; Tay, J.-H.; Ying, J.; Yu, X.-Q.; Pu, L. J. Org. Chem. 2013, 78, $2256-2265$

74. Reviews: (a) Cozzi, P. G.; Hilgraf, R.; Zimmermann, N. Eur. J. Org. Chem. 2004, 4095-4105. (b) Zani, L.; Bolm, C. Chem. Commun. 2006, 4263-4275. (c) Trost, B.M.; Weiss, A.H. Adv. Synth. Catal. 2009, 351, 963-983. (d) Blay, G.; Monleón, 
A.; Pedro, J. R. Curr. Org. Chem. 2009, 13, 1498-1539.

75. Yamada, K.; Tomioka, K. Chem. Rev. 2008, 108, 2874-2886.

76. Wei, C.; Li, C. J. Am. Chem. Soc. 2002, 124, 5638-5639.

77. Wei, C.; Mague, J; Li, C. Proc. Natl. Acad. Sci. U.S.A. 2004, 101, 5749-5754.

78. Bisai, A.; Singh, V. K. Org. Lett. 2006, 8, 2405-2408.

79. Weissberg, A.; Halak, B.; Portnoy, M. J. Org. Chem. 2005, 70, 4556-4559.

80. Tilliet, M.; Lundgren, S.; Moberg, C.; Levacher, V. Adv. Synth. Catal. 2007, 349, 2079-2084.

81. (a) Colombo, F.; Benaglia, M.; Orlandi, S.; Usuelli, F.; Celentano, G. J. Org. Chem. 2006, 71, 2064-2070. (b) Benaglia, M.; Negri, D.; Dell'Anna, G. Tetrahedron Lett. 2004, 45, 8705-8708.

82. Orlandi, S.; Colombo, F.; Benaglia, M. Synthesis, 2005, 1689-1692.

83. Gommermann, N.; Koradin, C.; Polborn, K.; Knochel, P. Angew. Chem. Int. Ed. 2003, 42, 5763-5766.

84. Gommermann, N.; Knochel, P. Chem. Eur. J. 2006, 12, 4380-4392.

85. Knöpfel, T. P.; Aschwanden, P.; Ichikawa, T.; Carreira, E. M. Angew. Chem., Int. Ed. 2004, 43, 5971-5973.

86. Aschwanden, P.; Stephenson, C. R. J.; Carreira, E. M. Org. Lett. 2006, 8, $2437-2440$.

87. Jiang, B.; Si, Y. G. Angew. Chem., Int. Ed. 2004, 43, 216-218.

88. Zani, L.; Alesi, S.; Cozzi, P. G.; Bolm, C. J. Org. Chem. 2006, 71, 1558-1562.

89. Zani, L.; Eichhorn, T.; Bolm, C. Chem. Eur. J. 2007, 13, 2587-2600. 
90. Blay, G.; Cardona, L.; Climent, E.; Pedro, J. R. Angew. Chem., Int. Ed. 2008, 47, 5593-5596.

91. Blay, G.; Ceballos, E.; Monleón, A.; Pedro, J. R. Tetrahedron 2012, 68, 2128-2134.

92. Yan, W.; Mao, B.; Zhu, S.; Jiang, X.; Liu, Z.; Wang, R. Eur. J. Org. Chem. 2009, $3790-3794$

93. Zhu, S.; Yan, W.; Mao, B.; Jiang, X.; Wang, R. J. Org. Chem. 2009, 74, 6980-6985.

94. Yan, W.; Li, P.; Feng, J.; Wang, D.; Zhu, S.; Jiang, X.; Wang, R. Tetrahedron: Asymmetry 2010, 21, 2037-2042.

95. Traverse, J. F.; Hoveyda, A. H.; Snapper, M. L. Org. Lett. 2003, 5, 3273-3275.

96. Wu, T. R.; Chong, J. M. Org. Lett. 2006, 8, 15-18.

97. Gommermann, N.; Knochel, P. Tetrahedron 2005, 61, 11418-11426.

98. Dube, H.; Gommermann, N.; Knochel, P. Synthesis, 2004, 12, 2015-2025.

99. Gommermann, N.; Gehrig, A.; Knochel, P. Synlett, 2005, 18, 2796-2798.

100. Gommermann, N.; Knochel, P. Chem. Commun. 2004, 2324-2325.

101. Taylor, A. M.; Schreiber, S. L. Org. Lett. 2006, 8, 143-146.

102. Huffman, M. A.; Yasuda, N,; De Camp, A. E.; Grabowski, E. J. J. J. Org. Chem. 1995, 60, 1590-1594.

103. Kauffman, G. S.; Harris, G. D.; Dorow, R. L.; Stone, B. R. P.; Parsons, R. L.; Pesti, J. A.; Magnus, N. A.; Fortunak, J. M.; Confalone, P. N.; Nugent, W. A. Org. Lett. 2000, 2, 3119-3121 


\section{Chapter 2. A Facile Asymmetric Approach to the Multicyclic Core Structure of Mangicol A}

\subsection{Introduction}

\subsubsection{Mangicols and neomangicols}

Mangicols represent a novel class of multicyclic natural products that could potentially be made by using the transformations of chiral propargylic alcohols. Mangicol A-G (Figure 2.1), isolated from the marine fungus Fusarium heterosporum by Fenical and coworkers in 2000, are new type of sesterterpenoid metabolites with unprecedented spirotricyclic skeletal components. ${ }^{1}$ In a test against the National Cancer Institutes 60 cell line panel, mangicols showed weak to modest cytotoxicities with no specificity towards any particular cancer cell evaluation. However, mangicol $\mathrm{A}$ and $\mathrm{C}$ displayed significant anti-inflammatory activity in a phorbol myristate acetate-induced edema assay ( $81 \%$ and $57 \%$ reduction in edema, respectively), which was comparable to a commercially available anti-inflammatory reagent, indomethacin (71\% reduction). ${ }^{1}$ Therefore, mangicols may be potentially promising in this therapeutic application.

Figure 2.1. Mangicols A-G

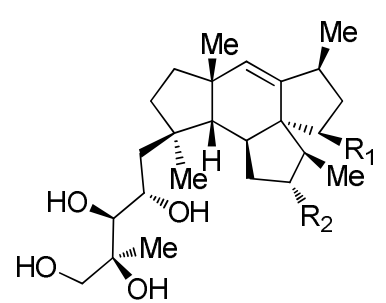

Mangicol $A, \mathrm{R}_{1}=\mathrm{OH}, \mathrm{R}_{2}=\mathrm{H}$ Mangicol $B, R_{1}=H, R_{2}=O H$ Mangicol $D, R_{1}=H, R_{2}=H$

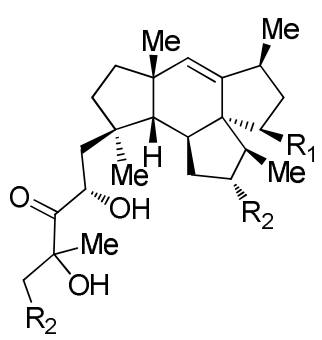

Mangicol C, $\mathrm{R}_{1}=\mathrm{OH}, \mathrm{R}_{2}=\mathrm{H}$ Mangicol $E, R_{1}=H, R_{2}=\mathrm{OH}$ Mangicol $F, R_{1}=H, R_{2}=H$

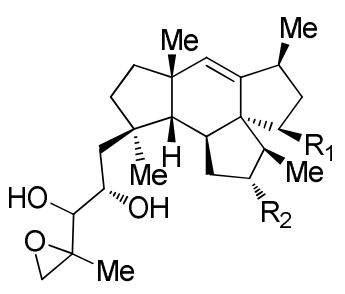

Mangicol G 
Neomangicols A-C (Figure 2.2), isolated from the same organism, also represent a new class of sesterterpenenes possessing a related and intriguing framework to the mangicols. ${ }^{2}$ Neomangicol $\mathrm{A}$ and $\mathrm{B}$ are the first examples of halogenated sestererpenoids natural products although halogenated terpenoid natural products are ubiquitous. It was found that neomangicol A was active against MCF-7 (human breast carcinoma) $\left(\mathrm{IC}_{50}=4.9 \mathrm{uM}\right)$ and CACO-2 (human colon carcinoma) $\left(\mathrm{IC}_{50}=5.7 \mathrm{uM}\right)$ cell lines. Neomangicol B showed less potent towards cancer cell lines but significant antibacterial activity against the gram-positive bacterium Bacillus subtilus, which was comparable to the known antibiotic, gentamycin. Neomangicol C, an isolation artifact from aromatization of neomangicol A or B, had no specific biological activities.

Figure 2.2. Neomangicols A-C

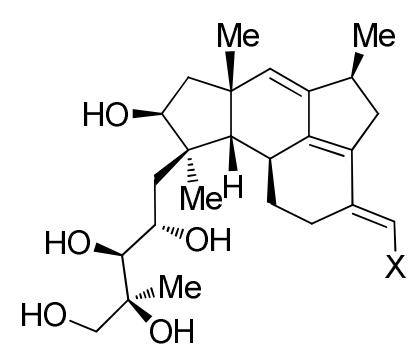

Neomangicol $\mathrm{A}, \mathrm{X}=\mathrm{Cl}$ Neomangicol $\mathrm{B}, \mathrm{X}=\mathrm{Br}$

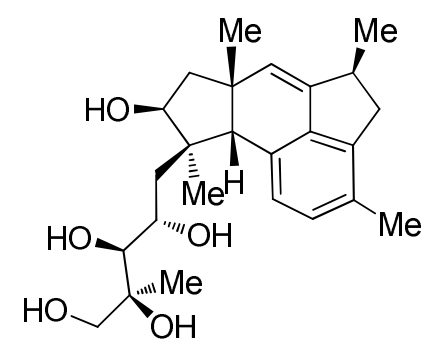

Neomangicol C

\subsubsection{Biosynthesis of mangicols and neomangicols}

Mangicols and Neomangicols belong to terpenoid family that consists of isoprene units. $^{3}$ On the basis of feeding experiments, Fenical proposed geranylfarnesyl diphosphate as a biogenetic precursor for $\mathrm{C}_{25}$ sesterterpenes. ${ }^{1}$ Three of the five isoprene units kept intact and the remaining two isoprene units were rearranged through two 1,2-alkyl shift. Similar to the biosynthesis of the humulene skeleton in another fungal terpenoid, the 11-membered ring was formed by the initial 
cyclolization of geranylfarnesyl diphosphate (Scheme 2.1). ${ }^{4}$ A 1,2-alkyl shift generated a secondary carbocation, followed by another 1,2-alkyl shift to give a new 5-membered ring with a new secondary carbocation. This macrocyclic carbon cation underwent two intramolecular cycloadditions to alkenes, two 1,2-hydride shifts and a deprotonation to give the mangicol core.

Scheme 2.1. Proposed biosynthesis of the mangicol core

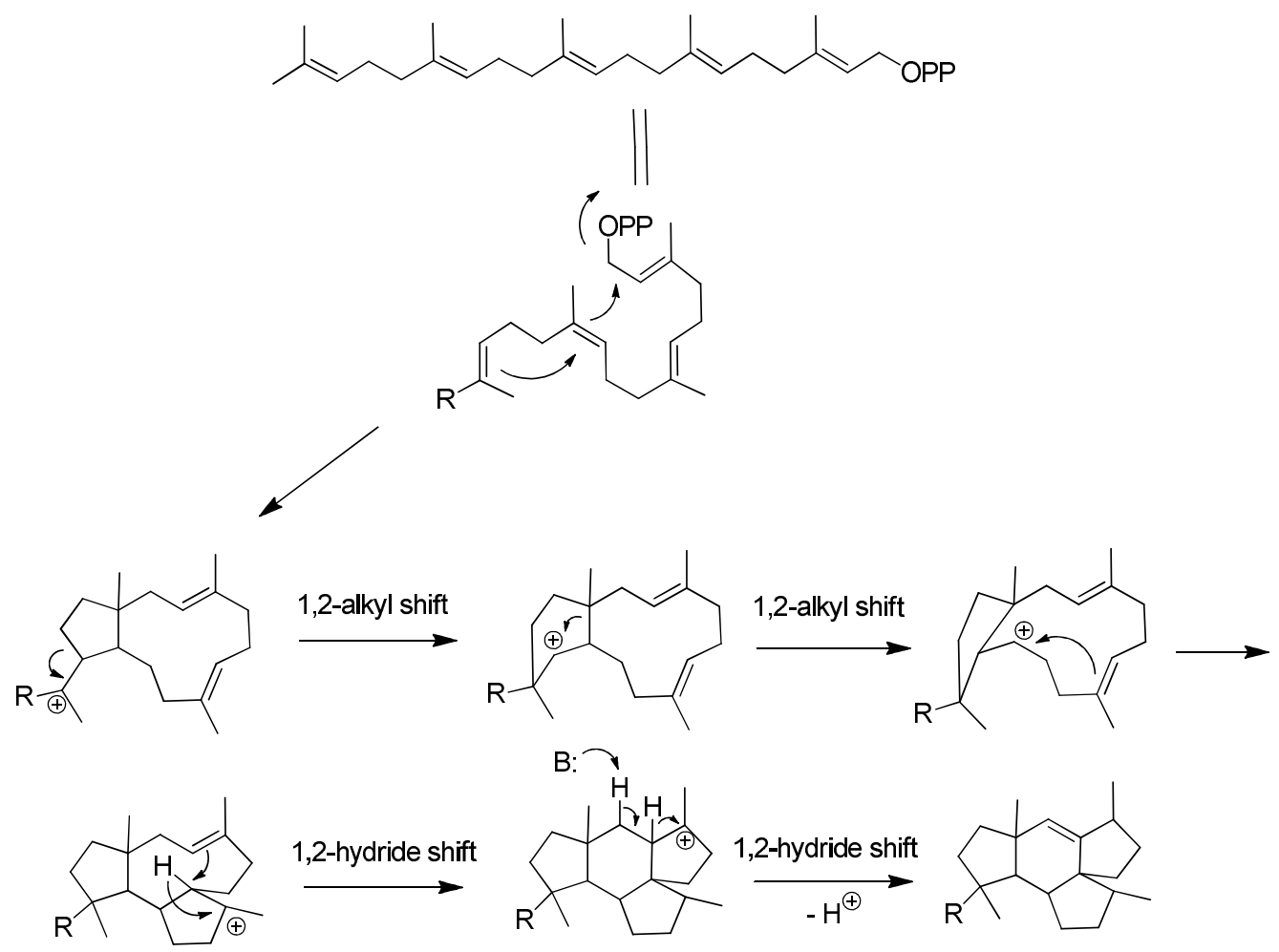

The labeling patterns observed also indicated that the neomangicol carbon skeleton was derived from a mangicol skeleton precursor (Scheme 2.2). ${ }^{1}$ It would be a reasonable explanation that a C-7 carbocation in the mangicol skeleton initiated a 1,2-alkyl migrations to generate a more stable tertiary carbocation at C-6 and completed the establishment of the neomangicol core. Subsequent modifications including halogenation could afford neomangicol A and B. 
Scheme 2.2. Transformation from the mangicol core to the neomangicol core

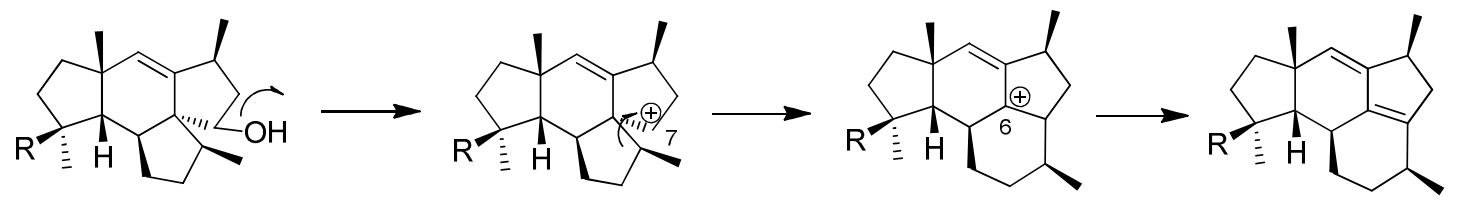

\subsubsection{Approaches to mangicols and neomangicols}

\section{a. Uemura's approach to mangicols}

In 2004, Uemura reported an effective synthetic way to establish the core fragment of mangicols by employing a transannular Diels-Alder (TADA) reaction. ${ }^{5}$ The strategy featured reductive aldol cyclization, Stille coupling and intramolecular Nozaki-Hiyama-Kishi coupling for the preparation of the precursor of TADA reaction (Scheme 2.3).

Scheme 2.3. Retrosynthetic analysis of the mangicol core

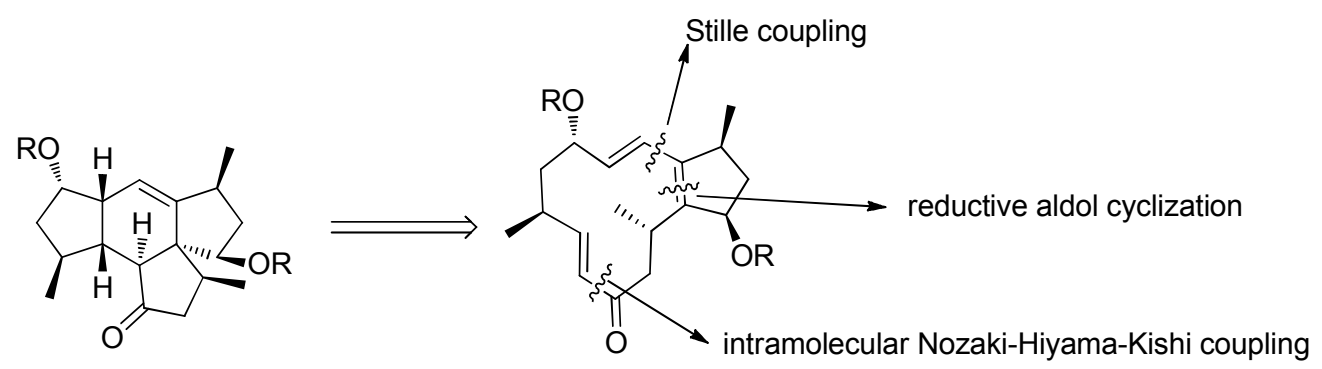

The chiral alcohol 2.1 served as the starting material for the Stille coupling partners 2.5 and 2.11 (Scheme 2.4). Tosylation of 2.1 and substitution with cyanide generated the nitrile, which was reduced with DIBAL-H to give the aldehyde 2.2. The ketone 2.3 was formed by the addition of ethylnylmagnesium bromide to the aldehyde 2.2 and subsequent $\mathrm{MnO}_{2}$ oxidation. Diastereoselective reduction and benzylation of 2.3 gave the benzyl ether 2.4, which underwent bromination and hydrostannylation to afford the vinyl stannane $\mathbf{2 . 5}$.

The aldehyde 2.2 was also used for the synthesis of another partner 2.11. It was 
reduced with $\mathrm{NaBH}_{4}$ and substituted by TBDPS group to form the ether $\mathbf{2 . 6}$. Subsequent removal of the trityl protecting group, elaboration of sulfide and oxidation led to the sulfone 2.7. Deprotonation of 2.7, nucleophilic addition to the aldehyde $\mathbf{2 . 2}$, removal of the trityl protecting group and Dess-Martin oxidation gave the ketoaldehyde 2.8. Reductive aldol cyclization of $\mathbf{2 . 8}$ mediated by $\mathrm{SmI}_{2}$ and treatment with $\mathrm{Al}_{2} \mathrm{O}_{3}$ afforded the cyclopentenone 2.9. Michael addition of 2.9 with thiophenol led to the thioester 2.10. Partner 2.11 was obtained through oxidative chlorination of 2.10 with trichloroisocyanuric acid.

Scheme 2.4. Synthesis of the Stille coupling partners 2.5 and 2.11

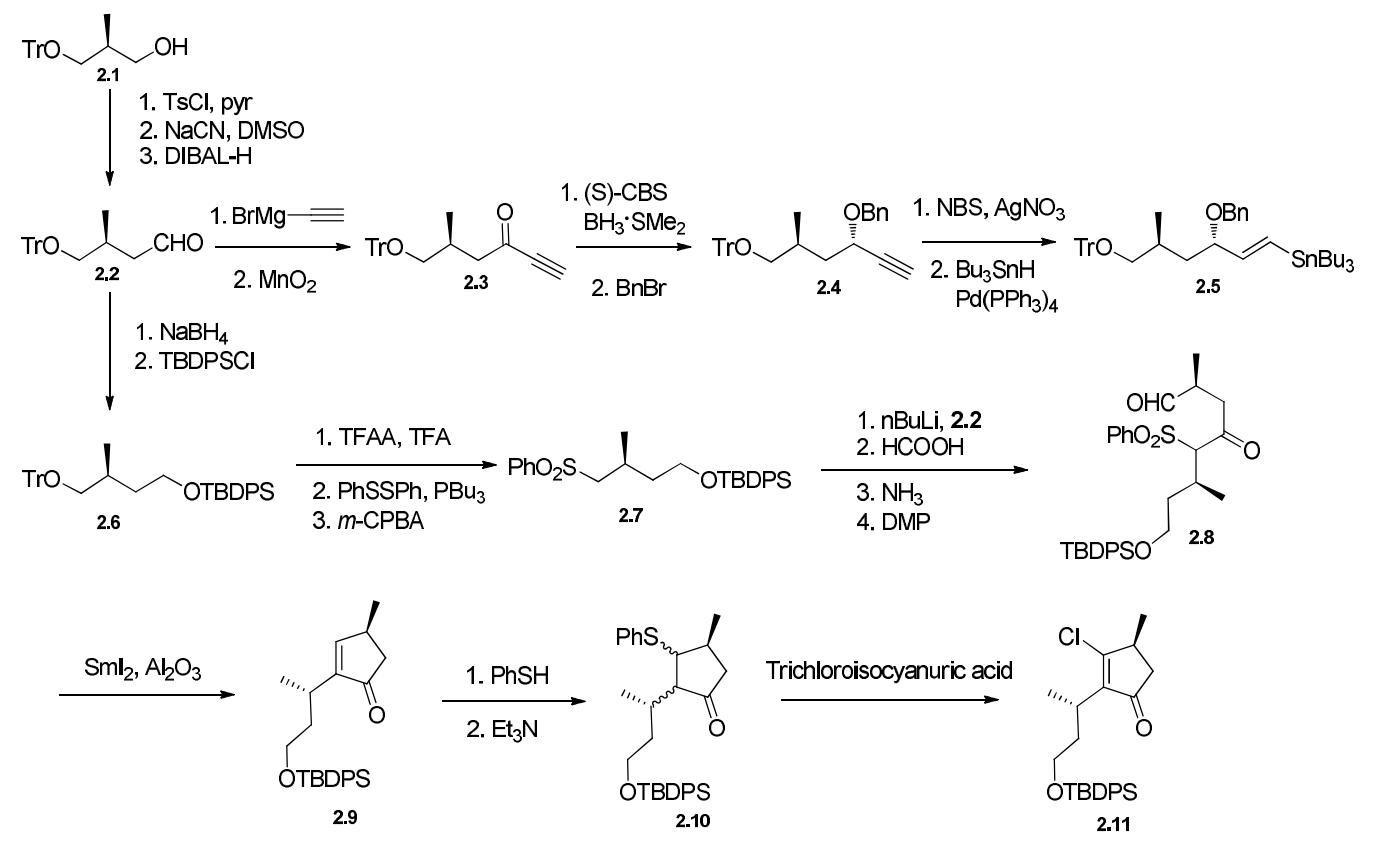

Stille coupling of partner 2.5 and $\mathbf{2 . 1 1}$ gave the dienone 2.12 in excellent yield. After the trityl group was removed with $\mathrm{ZnBr}_{2}$, subsequent Dess-Martin oxidation and Takai olefinantion afforded the vinyl iodide $\mathbf{2 . 1 3}$. Then TBDPS group was removed with TBAF and the resultant alcohol was oxidized by PDC to generate the aldehyde 2.14 (Scheme 2.5). 
Scheme 2.5. Synthesis of the Nozaki-Hiyama-Kishi coupling precursor 2.14
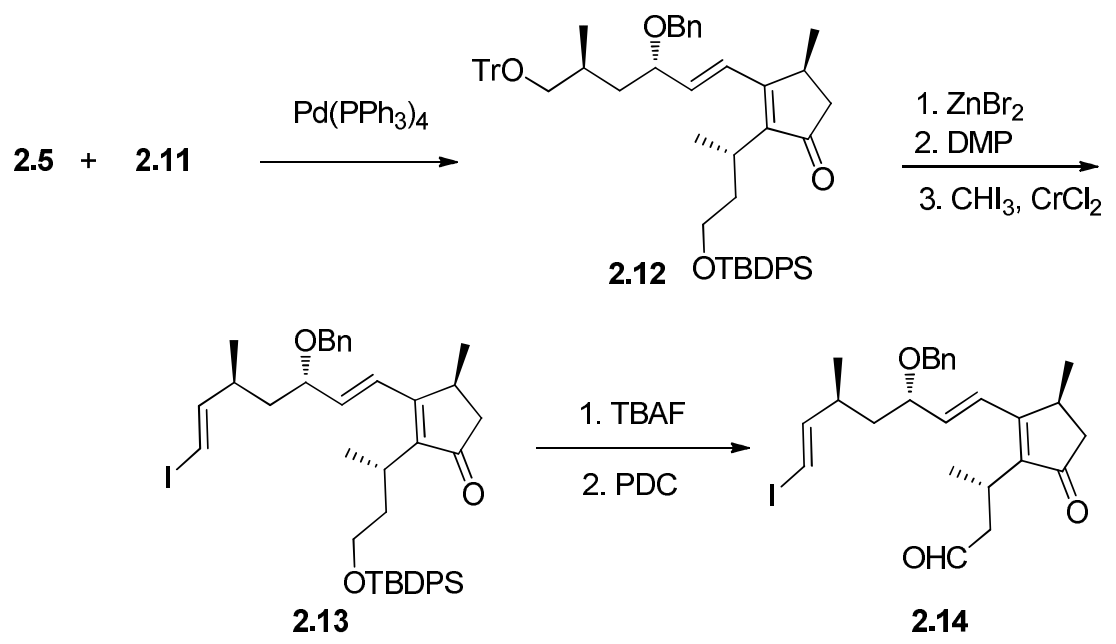

The aldehyde $\mathbf{2 . 1 4}$ was prepared in 27 steps. Intramolecular Nozaki-Hiyama-Kishi coupling of $\mathbf{2 . 1 4}$ generated two diastereomeric macrocycles $2.15(3 S)$ and $2.16(3 R)$. The minor diastereomer $2.15(3 S)$ underwent the thermal transannular Diels-Alder reaction to produce a single diastereomer $\mathbf{2 . 1 7}$ quantitatively. The major diastereomer 2.16 (3R) was converted to compounds 2.18 and 2.19 each in $42 \%$ yield under the same conditions (Scheme 2.6).

Compounds 2.18 and 2.19 contain many structural features of the core fragment of mangicol A. However, many more synthetic steps are required to elaborate the chiral centers such as $\mathrm{C} 3, \mathrm{C} 7, \mathrm{C} 12, \mathrm{C} 13, \mathrm{C} 15$ and introduce a polyol side chain.

Scheme 2.6. Transannular Diels-Alder reaction to form the mangicol core

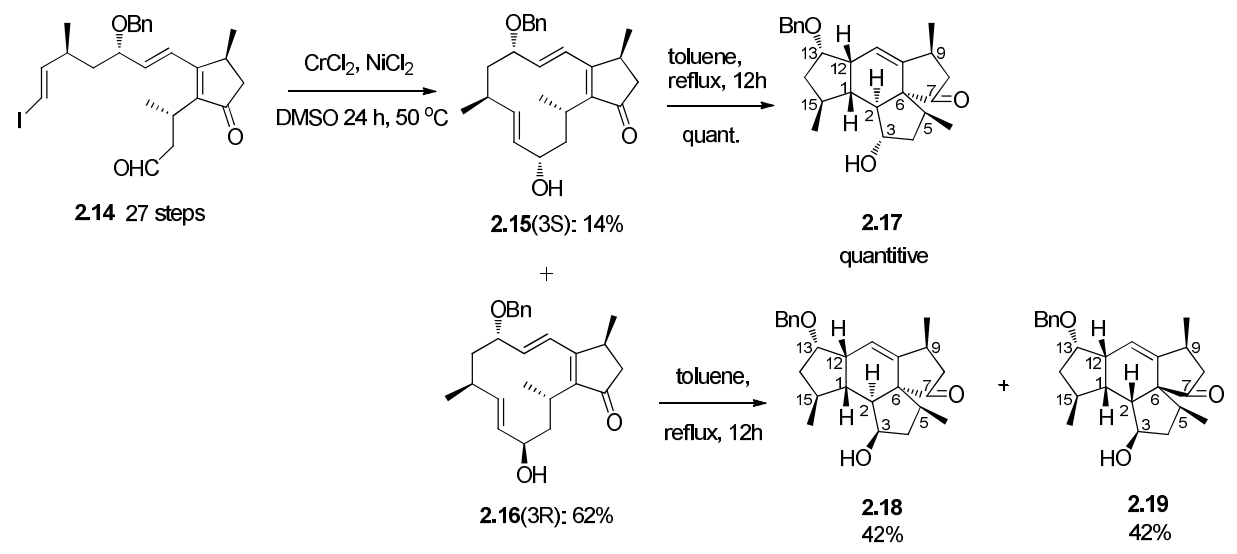




\section{b. Paquette's approaches to mangicols}

In 2006, Paquett reported two attempted syntheses of mangicol A, ${ }^{6,7}$ but both of the strategies were unsuccessful to access the natural product skeleton.

As shown in Scheme 2.7, the first strategy was keyed to the availability of a tricyclic compound through Diels-Alder reaction, which could undergo [2+2] photocyclization and radical fragmentation to access the fundamental skeleton of mangciols. ${ }^{6}$

Scheme 2.7. Retrosynthetic analysis of mangicol A

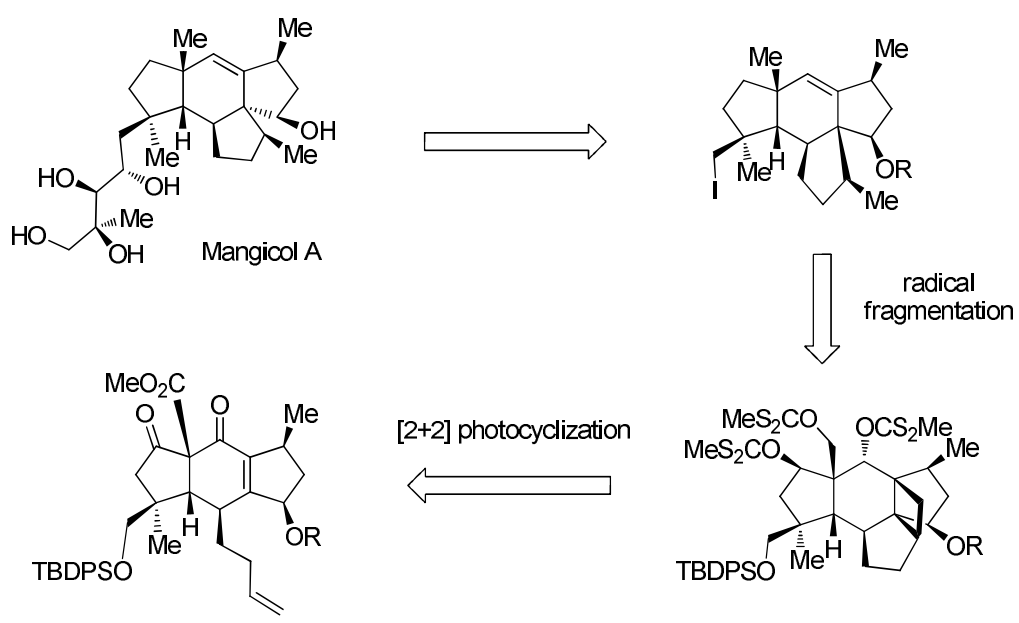

The dienophile $\mathbf{2 . 2 2}$ and the diene $\mathbf{2 . 2 3}$ were synthesized in nine steps from the $\beta$-ketoester $\mathbf{2 . 2 0}$ and twenty-two steps from the ascorbic acid 2.21, respectively. The precursor 2.24 was formed through DCC-mediated esterification with excellent yield. But subsequent attempts to promote intramolecular Diels-Alder reaction were unsuccessful under many classical conditions. The reactivity of dienophile and diene components was also investigated and optimized. Unfortunately, no desired Diels-Alder cycloadducts were obtained (Scheme 2.8). 
Scheme 2.8. Paquette's first strategy<smiles>CCOC(=O)C12CCCCC1ONC21CNO1</smiles>

2.20

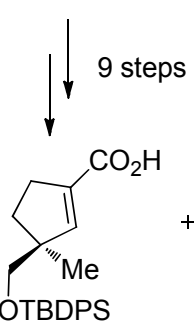

2.22<smiles></smiles>

2.21
DCC, DMAP

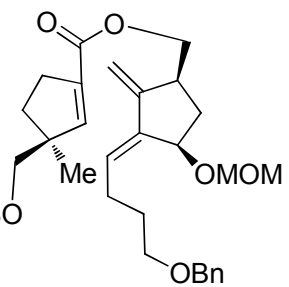

2.24

2.23

Diels-Alder reaction

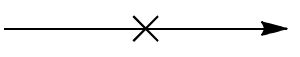

TBDPSO

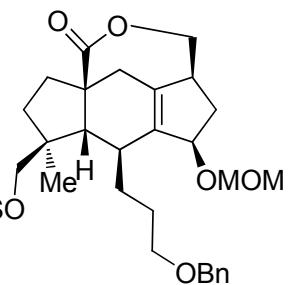

The second strategy attempted to use alternative routes to access the tricyclic compound that featured several conjugate additions and aldol condensation. ${ }^{7}$ They proposed two synthetic routes which were different in the order of alkylation and aldol condensation (Scheme 2.9).

Scheme 2.9. Retrosynthetic analysis of the tricyclic compounds
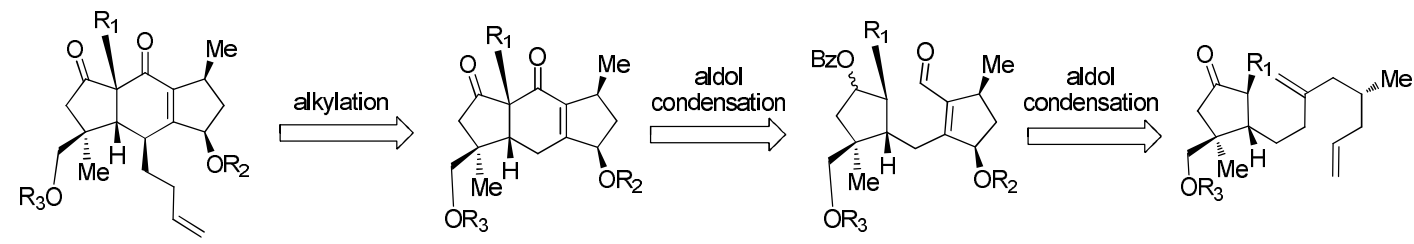

$$
\begin{aligned}
& \text { conjugate } \\
& \text { addition }
\end{aligned}
$$<smiles>[R10]CC1(C[Y])C=C([R])C(=O)C1</smiles>

$\mathrm{R}_{1}=\mathrm{COOMe}$ $\mathrm{R}_{2}=\mathrm{PMB}$
$\mathrm{R}_{3}=\mathrm{TBDPS}$

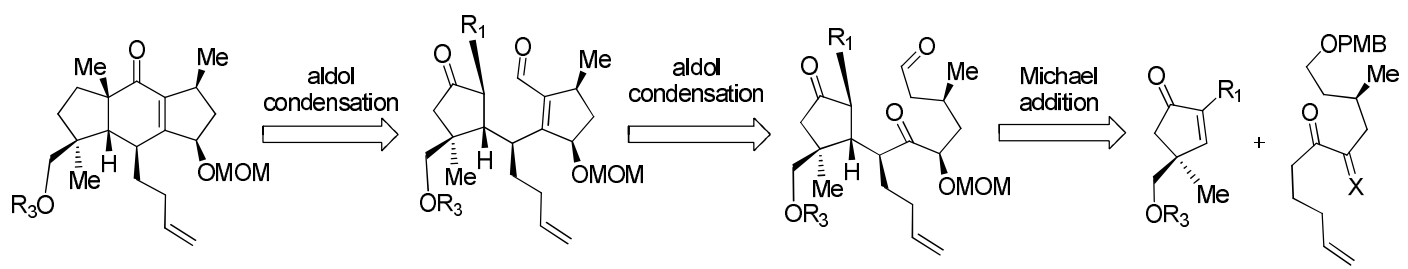

The first route was to construct the tricyclic structure via sequence aldol 
condensation and incorporate the side chain at late stage via alkylation. Compound 2.26 was prepared in 22 steps from the commercially available 1,4-butanediol $\mathbf{2 . 2 5}$. After the benzoyl group was cleaved, DMP oxidation and subsequent cyclization gave the tricycilic compound 2.27 with high stereoselectivity. Elaboration over 3 steps generated compound $\mathbf{2 . 2 8}$, which failed to undergo alkylation due to the instability under basic conditions (Scheme 2.10).

Scheme 2.10. First synthetic route

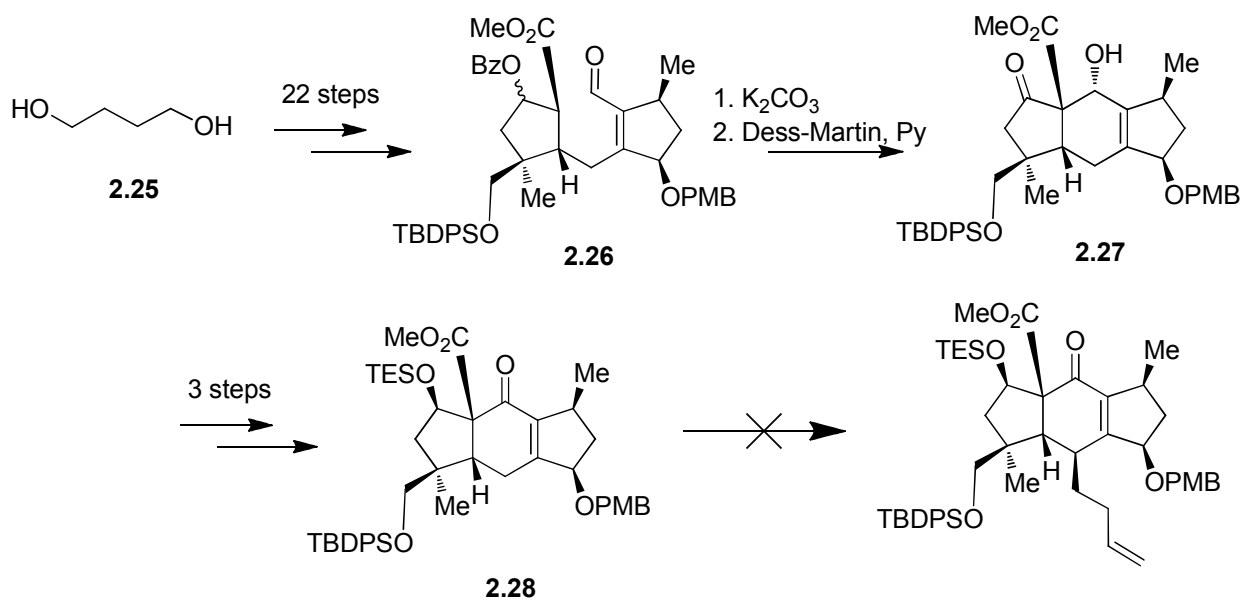

The second route was then examined. It involved 13 steps from $(S)-(-)$-citronellol 2.29 to generate the highly functionalized diketo aldehyde $\mathbf{2 . 3 0}$. Unfortunately, no desired tricyclic compound was obtained via aldol condensation of $\mathbf{2 . 3 0}$ under a variety of conditions (Scheme 2.11).

Scheme 2.11. Second synthetic route

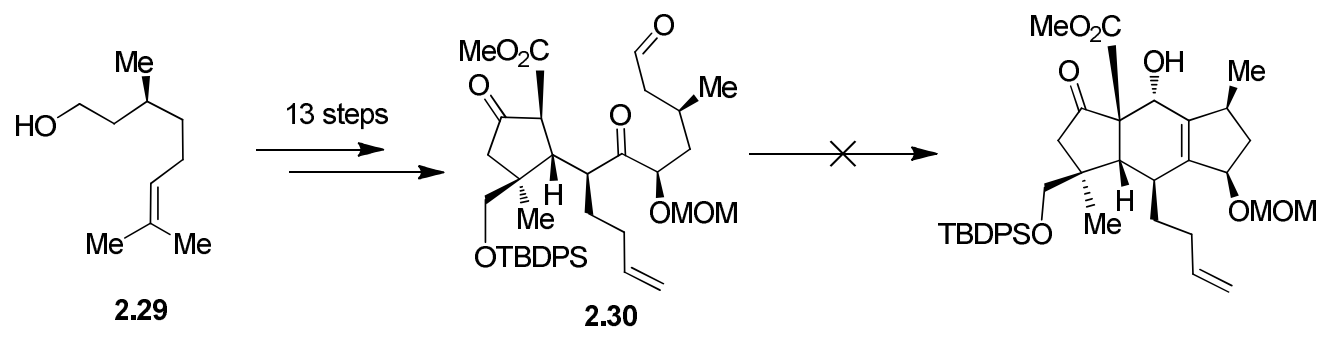

Although the construction of the mangicol core fragment was unsuccessful, they 
developed an efficient way to access the side chain. Oxidation of the commercially available prenyl acetate $\mathbf{2 . 3 1}$ by $\mathrm{SeO}_{2}$ oxidaiton followed by $\mathrm{MOM}$ protection afforded compound $\mathbf{2 . 3 2}$, which was transformed to $\mathbf{2 . 3 3}$ via deacetylation followed by benzylation. Sharpless asymmetric dihydroxylation of $\mathbf{2 . 3 3}$ with AD-mix- $\alpha$ led to the formation of 2.34. TIPS protection, chemoselective debenzylation and Dess-Martin oxidation generated the final protected aldehyde 2.35 (Scheme 2.12).

Scheme 2.12. Synthesis of the side chain $\mathbf{2 . 3 5}$

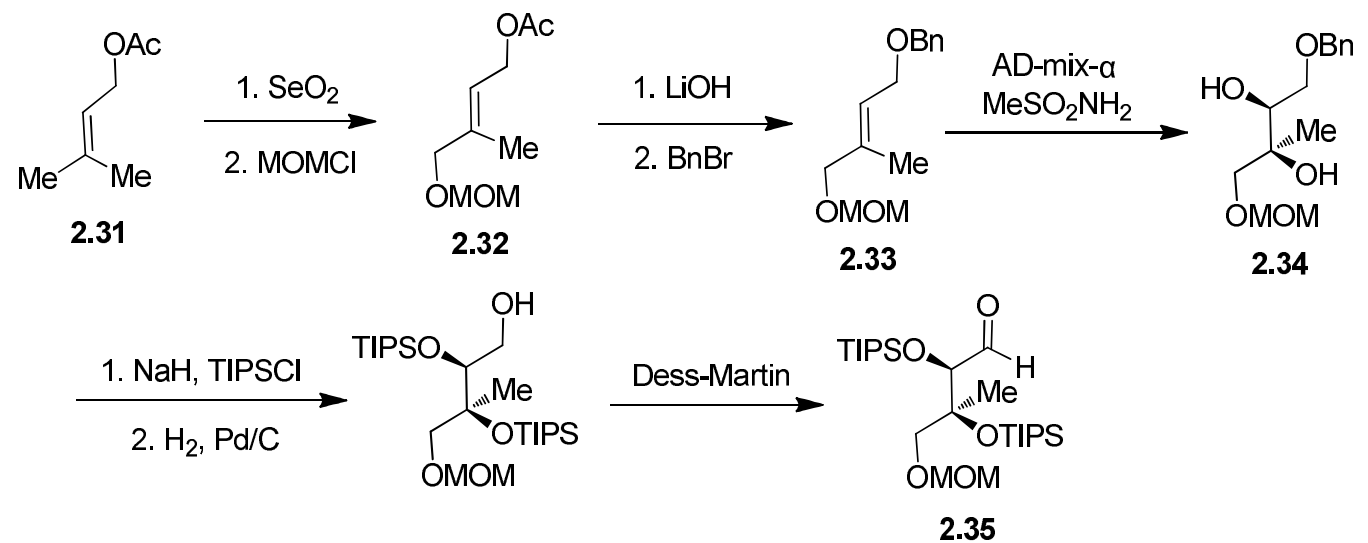

\section{c. Sarpong's approach to neomangicols}

In 2009, Sarpong reported the first approach to the tetracyclic core of the neomangicols via a late-stage indene alkylation reaction. ${ }^{8}$ As neomangicol carbon skeleton may derive from a mangicol skeleton precursor, the establishment of the core fragment of neomangicol $\mathrm{C}$ will promote the synthesis of neomangicols and mangicols.

The strategy features a late-stage alkylation of the indene $\mathbf{2 . 3 6}$, which could led to the construction of the tetracyclic core fragment. Compound 2.36 could be synthesized through Suzuki cross-coupling of the vinyl triflate $\mathbf{2 . 3 7}$ with the boronic ester 2.38 (Scheme 2.13). 
Scheme 2.13. Retrosynthetic analysis of the neomangicol core
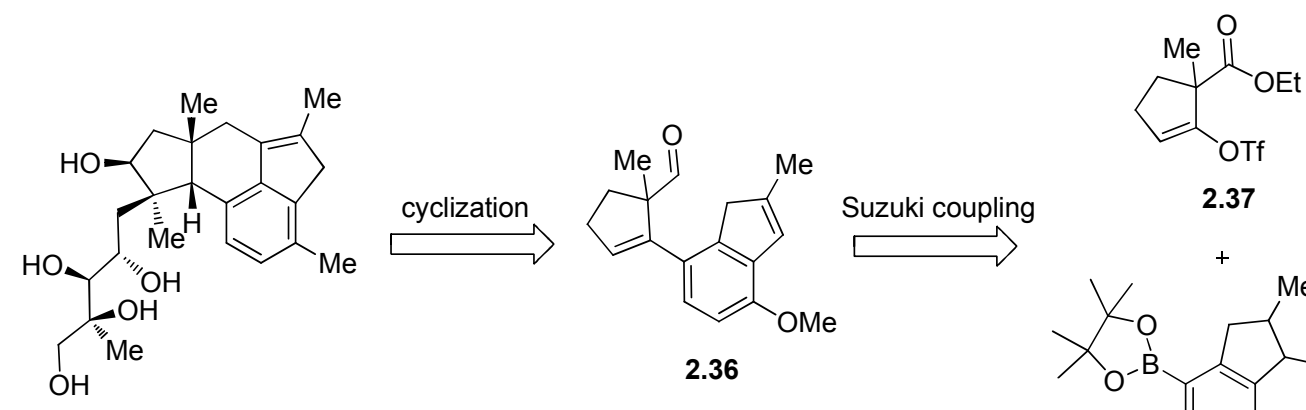

2.37

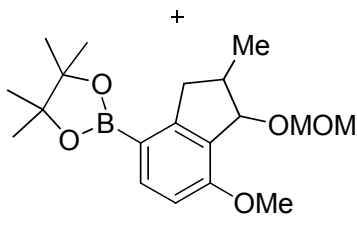

2.38

The boronic ester $\mathbf{2 . 3 8}$ was prepared in seven steps starting from 2-bromo-5-methoxybenzaldehyde $\mathbf{2 . 3 9}$ (Scheme 2.14). Knoevenagel condensation of 2.39 and the sodium salt $\mathbf{2 . 4 0}$ afforded compound $\mathbf{2 . 4 1}$, which underwent sequential conjugate reduction, methylation and Friedel-Crafts acylation to access the indanone 2.42. The ether $\mathbf{2 . 4 3}$ was obtained via DIBAL-H reduction and MOM protection. Halogen-metal exchange with tBuLi followed by reacting with the dioxaborolane $\mathbf{2 . 4 4}$ gave the boronic ester $\mathbf{2 . 3 8}$.

Scheme 2.14. Synthesis of the boronic ester $\mathbf{2 . 3 8}$<smiles>COc1ccc(Br)c(C=O)c1</smiles>

2.39<smiles>CCC1(C)OC(=O)C=C(O[Na])O1</smiles><smiles>COc1cccc(/C=C2/COC(C)(C)OC2=O)c1</smiles>
2.41<smiles>COc1ccc(Br)c(C=C2C(=O)OC(C)(C)OC2=O)c1</smiles>

2.42

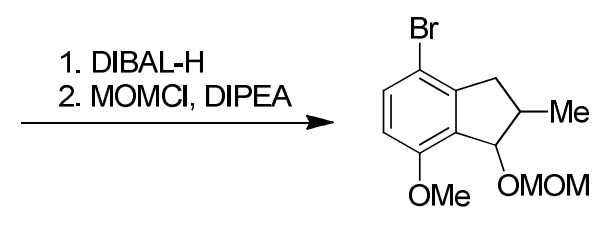

2.43

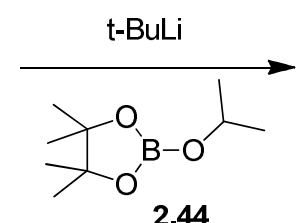

2.44<smiles>COc1ccc(B2OC(C)(C)C(C)(C)O2)c2c1C(C)C(C)C2</smiles>

2.38

Another partner the vinyl triflate $\mathbf{2 . 3 7}$ was easily available from the $\beta$-ketoester 2.45 via enolate formation and triflation (Scheme 2.15). 
Scheme 2.15. Synthesis of the vinyl triflate 2.37<smiles>CCOC(=O)C1(C)CCCC1=O</smiles>

2.45
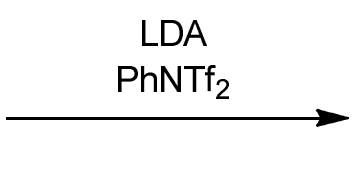

Suzuki cross-coupling of the vinyl triflate vinyl $\mathbf{2 . 3 7}$ and the boronic ester $\mathbf{2 . 3 8}$ gave compound 2.46. Reduction of $\mathbf{2 . 4 6}$ upon treatment with DIBAL-H and elimination with pyridinium $p$-toluenesulfonate (PPTS) led to the alcohol 2.47 . Dess-Martin oxidation of $\mathbf{2 . 4 7}$ provided the precursor $\mathbf{2 . 4 8}$ for cyclization. After the screening of a series of base conditions for indene alkylation, they found triton B effectively converted 2.48 to the tetracyclic compound 2.49. Subsequent Dess-Martin oxidation of $\mathbf{2 . 4 9}$ generated compound $\mathbf{2 . 5 0}$ possessing the core structure of neomangicol C (Scheme 2.16).

Scheme 2.16. Synthesis of the neomangicol core 2.50

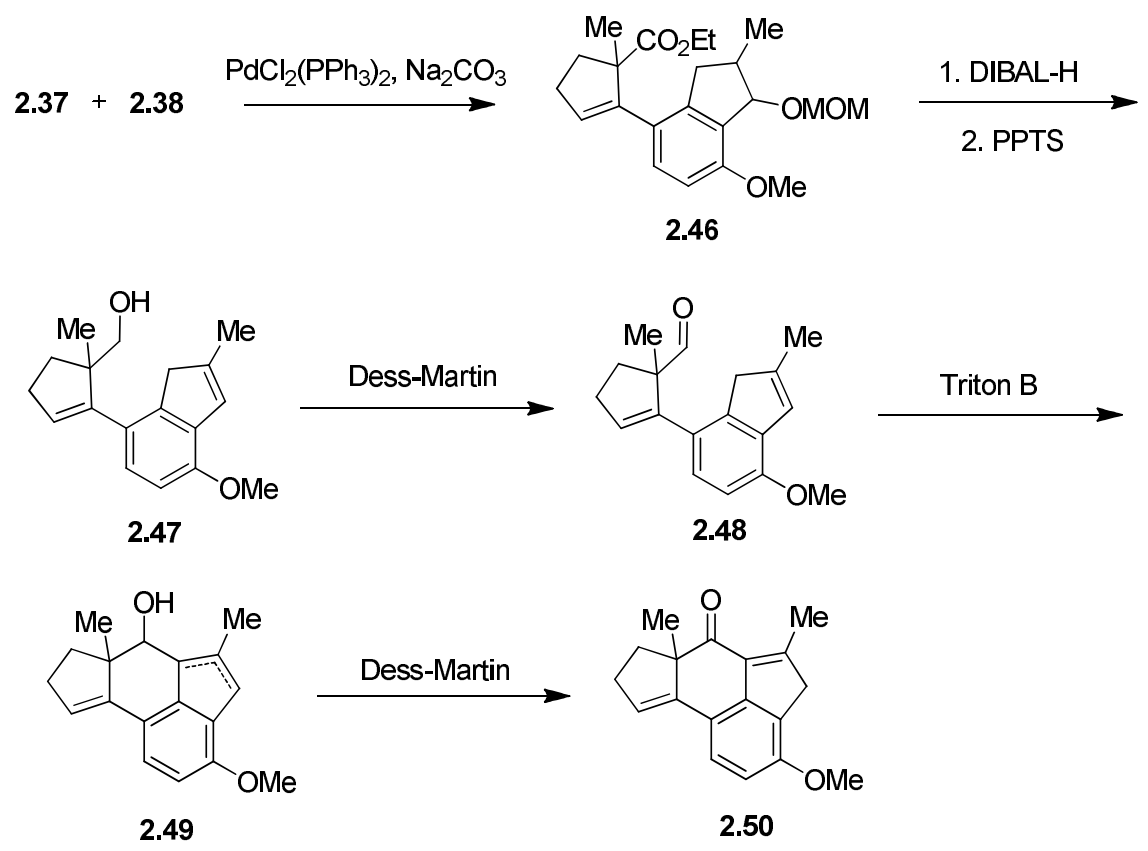

\subsubsection{Summary}

Several approaches have been described here to review the previous synthetic 
work towards mangicols and neomangicols. Uemura reported a synthesis of the core structure of mangicols in 29 steps employing a transannular Diels-Alder reaction. Paquett reported two synthetic strategies for the synthesis of mangicol A but neither of them could access the core fragment. Sarpong successfully completed the synthesis of core structure of neomangicols. No total synthesis of mangicols and neomangicols has been achieved to date while substantial progress has been made toward their preparation.

\subsection{Construction of the core structure of mangicol A}

In our laboratory, we have developed a number of BINOL-based catalytic systems for highly enantioselective alkyne addition to aldehydes, affording various chiral propargylic alcohols. ${ }^{9}$ Diverse transformations of chiral propargylic alcohols have been studied. ${ }^{10,11}$ For instance, Pauson-Khand-based reaction provided an efficient way to construct polycyclic compounds from chiral propargylic alcohol derivatives. $^{10}$

Recently, we reported that in the presence of a $\mathrm{Rh}(\mathrm{I})$ catalyst and $\mathrm{CO}$, the chiral propargylic ether-based triene-ynes $\mathbf{2 . 5 1}$ are found to undergo a domino Pauson-Khand (PK) and Diels-Alder (DA) reaction to generate the optically active tetracyclic compounds $\mathbf{2 . 5 2}$ or $\mathbf{2 . 5 3}$ with excellent chemoselectivity and stereoselectivity (Scheme 2.17). ${ }^{12,13}$ This is an initial test of PK/DA approach for the construction of the tetracyclic compounds containing a quaternary chiral carbon center. 
Scheme 2.17. Rh(I)-catalyzed domino intramolecular Pauson-Khand and Diels-Alder cycloaddition

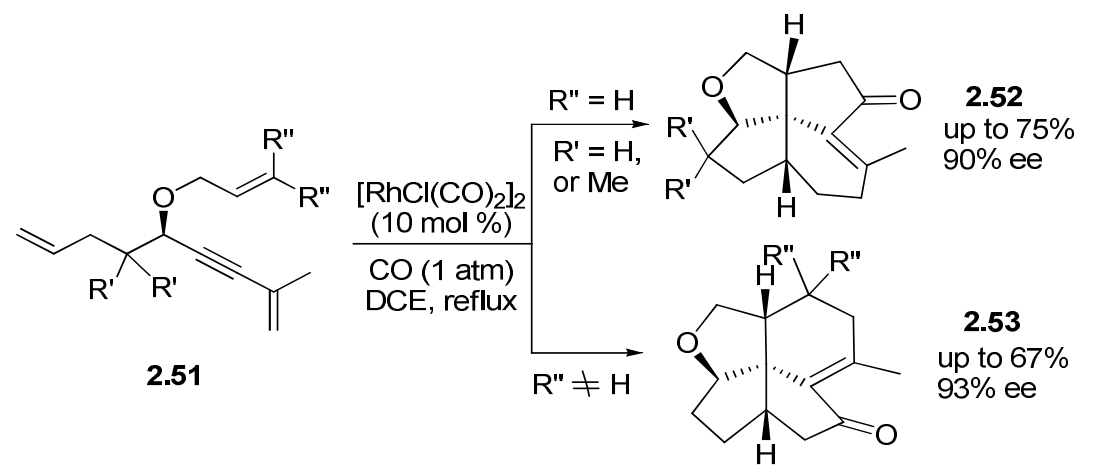

Encouraged by the success of PK/DA strategy, we further explored a facile synthetic route to the tetracyclic core structure of mangicol A. As shown in Scheme 2.18, a catalytic PK cycloaddition of a chiral propargylic ether-based triene-yne followed by an intramolecular DA reaction will be conducted to generate a pentacyclic product. Cleavage of the $\mathrm{C}-\mathrm{O}$ bond of the hydrofuran ring of the pentacyclic product followed by functional group modification could eventually lead to mangicol A and its analogs. Since the chiral propargylic ether starting material containing three alkene functions could give more than one possible PK cyclization products, high chemoselectivity is required for the PK cycloaddition in the first step. After the PK/DA reactions, new chiral centers are generated. Thus, high stereoselectivity is also necessary in order to obtain the desired product.

Scheme 2.18. A proposed approach to the multicyclic core structure of mangciol A

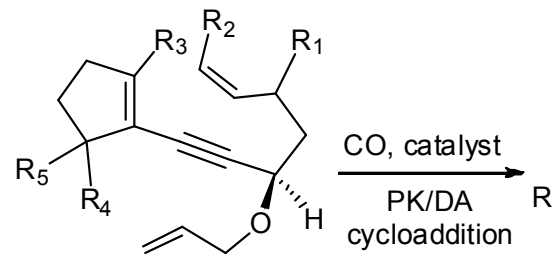

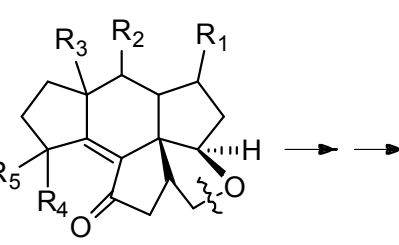

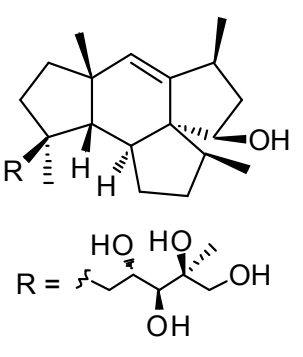

Mangicol A 


\subsubsection{Preliminary investigation of PK/DA strategy}

To test the domino PK/DA cycloaddition, the racemic triene-yne $\mathbf{2 . 5 8}$ was prepared in 5 steps from cyclopentanone (Scheme 2.19). Deprotonation of trimethylsilylacetylene with ${ }^{n} \mathrm{BuLi}$ followed by the reaction with cyclopentanone led to the racemic alcohol $\mathbf{2 . 5 4}$ in $99 \%$ yield. Treatment of the alcohol 2.54 with phosphorus oxychloride and pyridine at $0{ }^{\circ} \mathrm{C}$ gave the enyne 2.55 in $76 \%$ yield. Desilylation of the enyne $\mathbf{2 . 5 5}$ with TBAF produced the terminal enyne $\mathbf{2 . 5 6}$, which was then reacted with $\mathrm{nBuLi}$ and 4-pentenal to give the propargylic alcohol 2.57 in $63 \%$ yield over 2 steps. The racemic triene-yne $\mathbf{2 . 5 8}$ was obtained in $90 \%$ yield when the alcohol 2.57 was treated with $\mathrm{NaH}$ and allyl bromide.

Scheme 2.19. Preparation of the racemic triene-yne $\mathbf{2 . 5 8}$

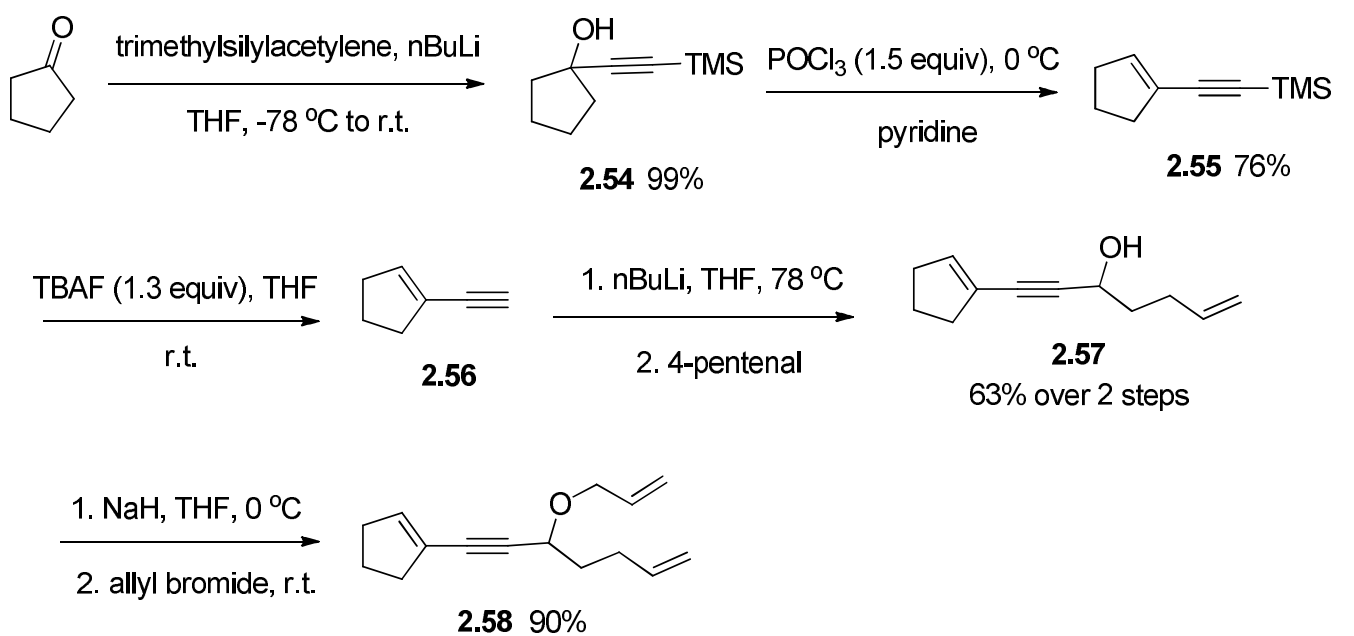

With the racemic triene-yne $\mathbf{2 . 5 8}$ in hand, we examined the domino PK/DA cycloaddition. When the triene-yne $\mathbf{2 . 5 8}$ was treated with $\left[\mathrm{Rh}(\mathrm{CO})_{2} \mathrm{Cl}\right]_{2}(10 \mathrm{~mol} \%)$ under 1 atm $\mathrm{CO}$ in refluxing 1,2-dichloroethane (DCE), a domino intramolecular PK/DA cycloaddition took place chemoselectively and stereoselectively to give the pentacyclic product $\mathbf{2 . 5 9}$ in $62 \%$ yield within 25 h (Scheme 2.20). Lower yield (44\%) 
was observed when reduced catalyst loading $(2 \%)$ was employed. This strategy gives a quick access to the fundamental ring structure of mangicol A in short steps.

Scheme 2.20. Domino intramolecular PK/DA cycloaddition of the triene-yne 2.58

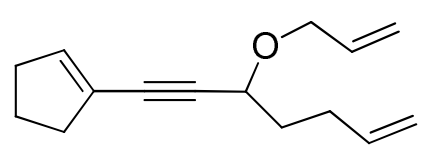

2.58

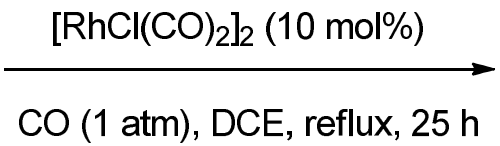

CO (1 atm), DCE, reflux, $25 \mathrm{~h}$

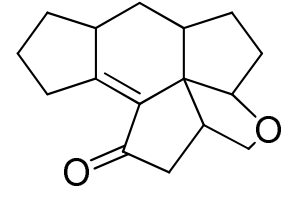

2.59

$62 \%$

\subsubsection{Asymmetric approach to the multicyclic core structure of mangicol A}

a. Preparation of the chiral propargylic alcohols by the catalytic asymmetric alkyne addition to aldehydes

Encouraged by the results from preliminary study on PK/DA strategy, we turn to the preparation of the nonracemic chiral propargylic ether-based triene-ynes, which are readily converted from chiral propargylic alcohols. The enantioselective addition of alkynes to aldehydes have been proved highly effective for the synthesis of chiral propargylic alcohols

In the past decade, our laboratory has worked on the development of BINOL-based catalytic systems for the asymmetric alkyne addition to aldehydes. ${ }^{9}$ Recently, we reported that the asymmetric reaction of terminal alkynes with aldehydes can be conducted at room temperature to generate chiral propargylic alcohols with high enantioselectivity by using a catalytic amount of BINOL in combination with $\mathrm{Ti}\left(\mathrm{O}^{i} \mathrm{Pr}\right)_{4}, \mathrm{ZnEt}_{2}$ and dicyclohexylamine $\left(\mathrm{Cy}_{2} \mathrm{NH}\right) .{ }^{14,15}$ We made a slight modification of the procedure and utilized it in the preparation of a series of the chiral propargylic 
alcohols $(R)$-1a-e. All these reactions were conducted in diethyl ether at room temperature under nitrogen in a three-step-one-pot process. In the first step, an enyne was treated with $\mathrm{ZnEt}_{2}$ and $\mathrm{Cy}_{2} \mathrm{NH}$, which presumably generated a nucleophilic alkynylzinc reagent. In this step, it is proposed that coordination of $\mathrm{Cy}_{2} \mathrm{NH}$ with $\mathrm{Et}_{2} \mathrm{Zn}$ could increase the basicity of the Et group on $\mathrm{Zn}$ to facilitate the deprotonation of the enyne. (S)-BINOL (40 mol \%) was also added in the first step, which should be deprotonated by $\mathrm{ZnEt}_{2}$. In the second step, $\mathrm{Ti}\left(\mathrm{O}^{i} \mathrm{Pr}\right)_{4}$ was added. In this step, the combination of the deprotonated $(S)$-BINOL with $\mathrm{Ti}\left(\mathrm{O}^{i} \mathrm{Pr}\right)_{4}$ could generate a chiral Lewis acid complex to catalyze the reaction. In the third step, an aldehyde was added and the asymmetric alkyne addition proceeded. After aqueous workup, a chiral propargylic alcohol product was obtained. In the second step, after the addition of $\mathrm{Ti}\left(\mathrm{O}^{i} \mathrm{Pr}\right)_{4}$, additional time $(3 \mathrm{~h})$ was required in order to generate the BINOL-Ti(IV) complex to control the stereochemistry of the next step. When the addition of $\mathrm{Ti}\left(\mathrm{O}^{i} \mathrm{Pr}\right)_{4}$ was immediately followed with the addition of the aldehyde, enantioselectivity was much lower. As shown in Scheme 2.21, these catalytic asymmetric enyne additions to the aliphatic aldehydes were accomplished with $57-89 \%$ yield and $90-92 \%$ ee. The configurations of the chiral propargylic alcohols were determined on the basis of our previous studies. ${ }^{14}$ 
Scheme 2.21. Catalytic asymmetric alkyne addition to aldehydes to form the chiral propargylic alcohols $(R)$-1a-e

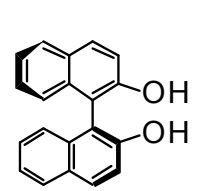

(S)-BINOL

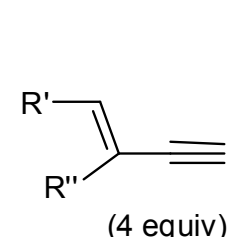

(4 equiv) 3. R'"CHO (1 equiv)
1. $\mathrm{ZnEt}_{2}$ (4 equiv)

$\mathrm{Cy}_{2} \mathrm{NH}(5 \mathrm{~mol} \%)$

(S)-BINOL (40 mol \%)

2. $\mathrm{Ti}\left(\mathrm{O}^{\mathrm{i}} \mathrm{Pr}\right)_{4}$ (1 equiv)

CHO (1 equiv)

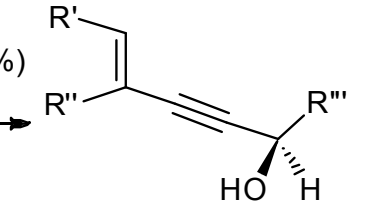

$(R)-1$

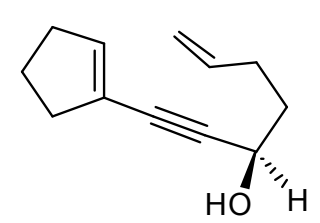

$(R)-1 \mathrm{a}$

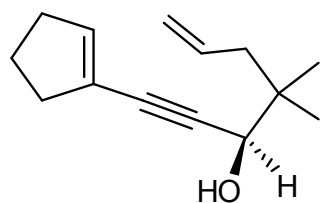

(R)-1b

$71 \%, 90 \%$ ee

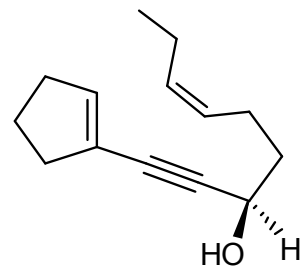

$(R)-1 \mathrm{c}$

$70 \%, 90 \%$ ee

$71 \%, 92 \%$ ee<smiles>CC/C=C\CC[C@H](O)C#CC1=CCCC1</smiles>

$(R)-1 \mathrm{~d}$

$57 \%, 92 \%$ ee<smiles>C=CCC[C@H](O)C#CC1=CCCCC1</smiles>

$(R)-1 \mathrm{e}$

$89 \%, 90 \%$ ee

b. Preparation of the chiral propargylic ether-based triene-ynes from the chiral

\section{propargylic alcohols}

The chiral propargylic alcohols $(R)$-1a-e are converted to the corresponding allylic ethers as shown in Scheme 2.22. Treatment of the chiral propargylic alcohols with $\mathrm{NaH}$ at $0{ }^{\circ} \mathrm{C}$ followed by reactions with allyl bromide at $50{ }^{\circ} \mathrm{C}$ gave the desired propargylic ether-based triene-ynes $(R)$-2a-e in 69-92\% yields. 
Scheme 2.22. Preparation of the chiral propargylic ether-based triene-ynes $(R)-\mathbf{2 a - e}$

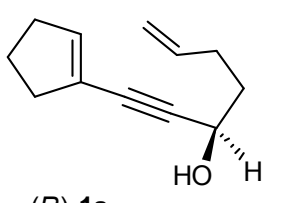

$(R)-1 \mathbf{a}$

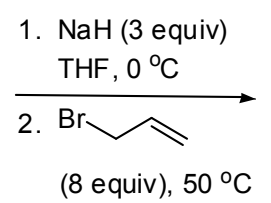

(8 equiv), $50^{\circ} \mathrm{C}$

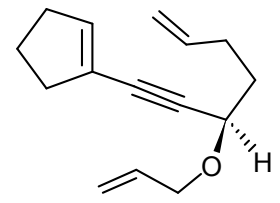

(R)-2a, $92 \%$

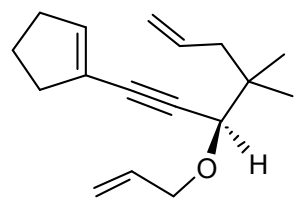

(R)-2b, 69\%

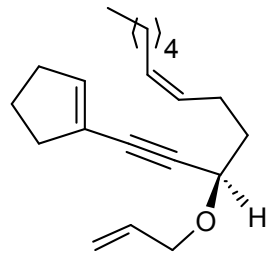

$(R)-2 d, 80 \%$

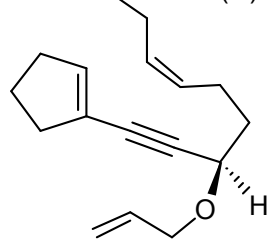

(R)-2c, $69 \%$

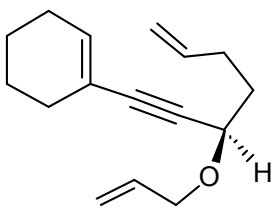

$(R)-2 \mathrm{e}, 88 \%$

\section{c. Catalytic domino PK/DA cycloaddition}

When the solution of $(R)-\mathbf{2 a}$ in 1,2-dichloroethane (DCE) was heated in the presence of $10 \mathrm{~mol} \%\left[\mathrm{RhCl}(\mathrm{CO})_{2}\right]_{2}$ under 1 atm $\mathrm{CO}$, a domino PK/DA cycloaddition occurred to generate the pentacyclic product 3a with $60 \%$ yield and $94 \%$ ee (Scheme 2.23). ${ }^{16-18}$ Thus a highly chemoselective and stereoselective transformation has taken place. The enantiomeric purity of the original propargylic alcohol generated by the catalytic asymmetric enyne addition to aldehydes has been preserved in this domino cycloaddition process. In this conversion, the original propargylic chiral center has directed the formation of four additional chiral centers.

Scheme 2.23. Catalytic conversion of $(R)-\mathbf{2 a}$ to generate $\mathbf{3 a}$

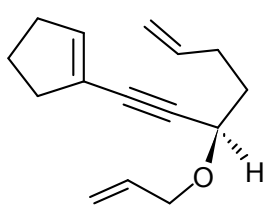

$(R)-2 a$

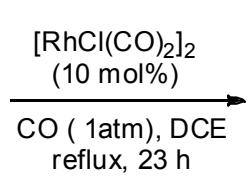

reflux, $23 \mathrm{~h}$

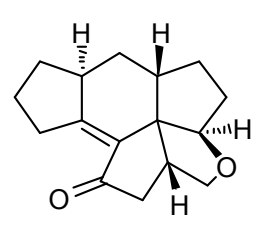

3a $60 \%$ yield $94 \%$ ee 
The structure of 3a was established by high-resolution mass spectroscopic analysis and various ${ }^{1} \mathrm{H}$ and ${ }^{13} \mathrm{C}$ NMR spectroscopic analysis including COSY, NOESY, HSQC and DEPT-135. The ${ }^{1} \mathrm{H}$ NMR signal assignments for compound 3a are shown in Figure 2.3. The signal at $\delta 4.15$ was assigned to be $\mathrm{H}_{1}$ on the basis of DEPT-135 and HSQC. The signal at $\delta 1.75$ was assigned to be $\mathrm{H}_{20}$ since it showed stronger NOE effect with $\mathrm{H}_{1}$ than the signal at $\delta 1.67$ which was assigned to be $\mathrm{H}_{19}$. The signals at $\delta 4.08$ and 3.85 were assigned to be $\mathrm{H}_{2}$ and $\mathrm{H}_{3}$ on the basis of DEPT-135, HSQC and stronger NOE effect $\left(\mathrm{H}_{2}\right)$ with $\mathrm{H}_{1}$. The signal at $\delta 2.54$ was assigned to be $\mathrm{H}_{4}$ because of COSY correlation with $\mathrm{H}_{2} / \mathrm{H}_{3}$ and HSQC. The configuration of $\mathrm{H}_{4}$ was assigned to be up based on its NOE effect with $\mathrm{H}_{3}$. The signals at $\delta 2.28$ and 2.50 were assigned to be $\mathrm{H}_{6}$ and $\mathrm{H}_{5}$ on the basis of COSY correlation with $\mathrm{H}_{4}, \mathrm{HSQC}$ and $\mathrm{NOE}$ effect $\left(\mathrm{H}_{6}\right)$ with $\mathrm{H}_{3}$. The signal at $\delta 2.12$ was assigned to be $\mathrm{H}_{18}$ since it showed stronger NOE effect with $\mathrm{H}_{2}$ than the signal at $\delta$ 1.57 which was assigned to be $\mathrm{H}_{17}$. The signal at 2.30 was assigned to be $\mathrm{H}_{16}$ according to COSY correlation with $\mathrm{H}_{17} / \mathrm{H}_{18}$, HSQC and DEPT-135. The configuration of $\mathrm{H}_{16}$ was assigned to be up based on its strong NOE effect with $\mathrm{H}_{4}$. The signal at 2.25 was assigned to be $\mathrm{H}_{13}$ on the basis of HSQC and DEPT-135. The configuration of $\mathrm{H}_{13}$ was assigned to be down due to its strong NOE effect with $\mathrm{H}_{1}$. The signals at $\delta 1.05$ and 1.92 were assigned to be $\mathrm{H}_{15}$ and $\mathrm{H}_{14}$ on the basis of COSY correlation with $\mathrm{H}_{16}, \mathrm{HSQC}$ and $\mathrm{NOE}$ effect $\left(\mathrm{H}_{14}\right)$ with $\mathrm{H}_{13}$. Tracing the COSY, HSQC and NOE correlation with $\mathrm{H}_{13}$ allowed the assignment of $\mathrm{H}_{11}$ and $\mathrm{H}_{12}$ at $\delta 2.07$ and at 1.09. On the basis of COSY correlation with $\mathrm{H}_{11} / \mathrm{H}_{12}$ and HSQC, the signal at $\delta$ 
1.82 was assigned to be $\mathrm{H}_{9}$ as it showed strong NOE effect with $\mathrm{H}_{20}$ and the signal at $\delta 1.62$ was assigned to be $\mathrm{H}_{10}$. The signals at $\delta 2.83$ and 2.64 were assigned to be $\mathrm{H}_{8}$ and $\mathrm{H}_{7}$ on the basis of COSY correlation, HSQC and NOE effect $\left(\mathrm{H}_{8}\right)$ with $\mathrm{H}_{10}$.

Figure 2.3. ${ }^{1} \mathrm{H}$ NMR signal assignment of compound 3a

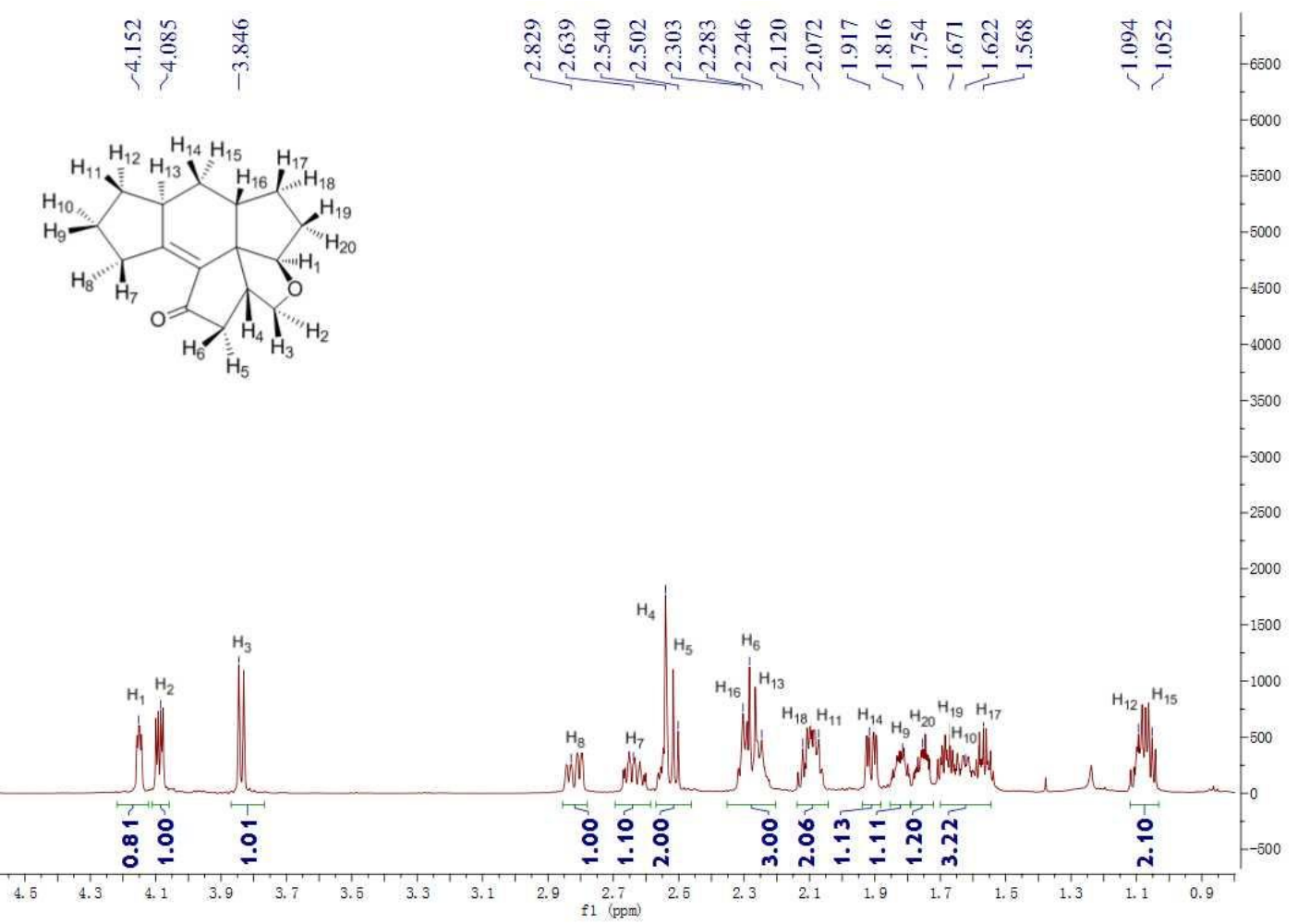

Similar to the conversion of $(R)-\mathbf{2 a}$ to $\mathbf{3 a}$, when the triene-yne $(R)-\mathbf{2} \mathbf{b}$ was treated with $\left[\mathrm{RhCl}(\mathrm{CO})_{2}\right]_{2}$ and $\mathrm{CO}$, compound $3 \mathbf{b}$ was obtained with $54 \%$ yield and $91 \%$ ee (Scheme 2.24). The geminal dimethyl groups in $(R)-\mathbf{2 b}$ did not have much effect on the cycloaddition. The stereochemistry of $\mathbf{3 b}$ was assigned by comparing its NMR spectra with those of $\mathbf{3 a}$.

Scheme 2.24. Catalytic conversion of $(R)-\mathbf{2 b}$

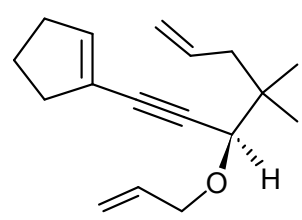

$(R)-\mathbf{2 b}$

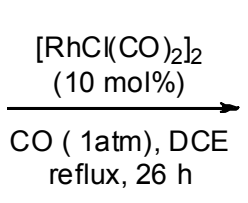

( $1 \mathrm{~atm}), \mathrm{DC}$
reflux, $26 \mathrm{~h}$

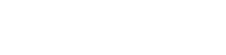

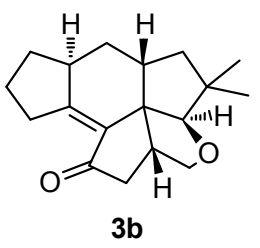

$54 \%$ yield $91 \%$ ee 
The propargylic ether $(R)-2 \mathrm{c}$ contains a cis double bond in the alkyl chain. When this compound was subjected to the same catalytic conditions, the pentacyclic product 3c was obtained as a single diastereomer with $47 \%$ yield and $91 \%$ ee (Scheme 2.25). The ethyl group on the cis double bond of $(R)-2 \mathrm{c}$ is located on the $\alpha$ face of the six-membered ring of $\mathbf{3 c}$.

Scheme 2.25. Catalytic conversion of $(R)-2 \mathrm{c}$

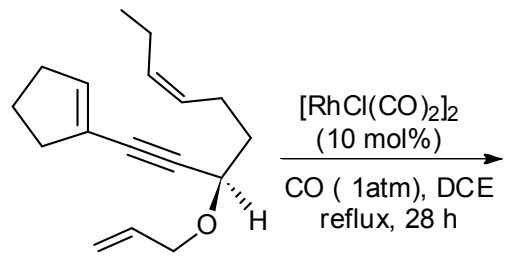

$(R)-2 \mathrm{c}$

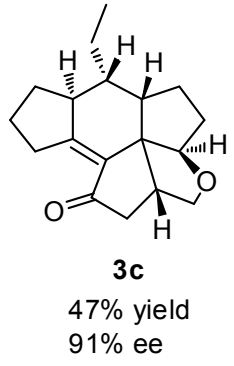

$91 \%$ ee

The structure of 3c was determined by high-resolution mass spectroscopic analysis and various ${ }^{1} \mathrm{H}$ and ${ }^{13} \mathrm{C}$ NMR spectroscopic analysis including COSY, NOESY, HSQC and DEPT-135. The ${ }^{1} \mathrm{H}$ NMR signal assignments for compound 3c are shown in Figure 2.4. The configurations of $\mathrm{H}_{1}, \mathrm{H}_{15}, \mathrm{H}_{4}$ and $\mathrm{H}_{13}$ were same as compound 3a. The signal at $\delta 4.21$ was assigned to be $\mathrm{H}_{1}$ on the basis of DEPT-135 and HSQC. The signal at $\delta 1.82$ was assigned to be $\mathrm{H}_{18}$ since it showed stronger NOE effect with $\mathrm{H}_{1}$ than the signal at $\delta 1.61$ which was assigned to be $\mathrm{H}_{19}$. The signals at $\delta$ 1.83 and 1.48 were assigned to be $\mathrm{H}_{17}$ and $\mathrm{H}_{16}$ on the basis of DEPT-135, HSQC and stronger NOE effect $\left(\mathrm{H}_{16}\right)$ with $\mathrm{H}_{1}$. The signal at $\delta 2.28$ was assigned to be $\mathrm{H}_{15}$ because of COSY correlation with $\mathrm{H}_{17} / \mathrm{H}_{16}$ and HSQC. The configuration of $\mathrm{H}_{15}$ was assigned to be up based on the analysis of compound 3a. The signal at $\delta 2.46$ was 
assigned to be $\mathrm{H}_{14}$ on the basis of COSY correlation with $\mathrm{H}_{15}$ and HSQC. The configuration of $\mathrm{H}_{14}$ was assigned to be $u p$ because of strong NOE effect with $\mathrm{H}_{15}$. It was also supported by the strong NOE effect between $\mathrm{H}_{14}$ and $\mathrm{H}_{4} / \mathrm{H}_{2}$. The signals at $\delta$ 1.28 and $\delta 1.66$ were assigned to be $\mathrm{H}_{20}$ and $\mathrm{H}_{21}$ based on COSY and HSQC. The signal at 2.08 was assigned to be $\mathrm{H}_{4}$ according to HSQC and DEPT-135. The configuration of $\mathrm{H}_{4}$ was assigned to be $u p$ based on the analysis of compound 3a. The signals at $\delta 1.05$ and 2.13 were assigned to be $\mathrm{H}_{5}$ and $\mathrm{H}_{6}$ on the basis of COSY correlation, HSQC and NOE effect $\left(\mathrm{H}_{5}\right)$ with $\mathrm{H}_{4}$. The signals at $\delta 4.04$ and $\delta 3.85$ were assigned to be $\mathrm{H}_{2}$ and $\mathrm{H}_{3}$ on the basis of ${ }^{1} \mathrm{H}$ NMR and NOESY. The signal at $\delta$ 1.01 was assigned to be $\mathrm{H}_{13}$ and the configuration was down based on the analysis of compound 3a. The signals at $\delta 1.55$ and 1.88 were assigned to be $H_{11}$ and $H_{12}$ on the basis of COSY correlation with $\mathrm{H}_{13}$, HSQC and NOE effect $\left(\mathrm{H}_{12}\right)$ with $\mathrm{H}_{13}$. Tracing the COSY, HSQC and NOE correlation with $\mathrm{H}_{11} / \mathrm{H}_{12}$ allowed the assignment of $\mathrm{H}_{9}$ and $\mathrm{H}_{10}$ at $\delta 2.52$ and at 2.33. On the basis of COSY correlation with $\mathrm{H}_{9} / \mathrm{H}_{10}$ and HSQC, the signal at $\delta 2.86$ was assigned to be $\mathrm{H}_{7}$ as it showed strong NOE effect with $\mathrm{H}_{9}$ and the signal at $\delta 2.56$ was assigned to be $\mathrm{H}_{8}$. The signal at $\delta 0.94$ was assigned to be Me. 
Figure 2.4. ${ }^{1} \mathrm{H}$ NMR signal assignments of compound $\mathbf{3 c}$

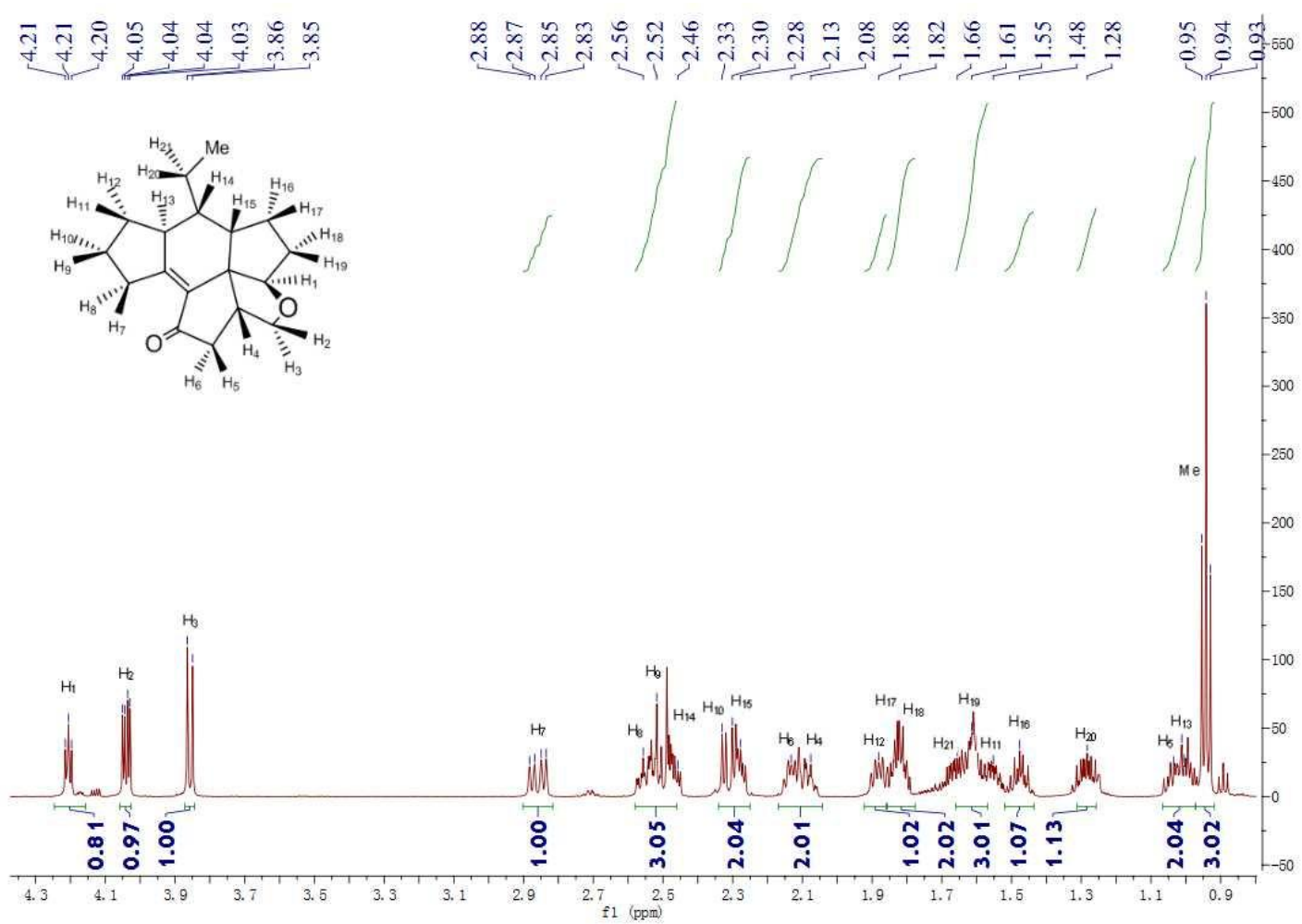

Compound (R)-2d contains a longer chain alkyl substituent on the cis double bond than $(R)-2 \mathrm{c}$. When $(R)-\mathbf{2 d}$ was treated with $\left[\mathrm{RhCl}(\mathrm{CO})_{2}\right]_{2}$ under $\mathrm{CO}$, two diastereomers (9:1) were formed in $45 \%$ yield (Scheme 2.26$)$. The major product $3 \mathbf{d}$ contains a pentyl group on the $\alpha$ face of the six-membered ring. The factors contributed to the reduced enantiomeric purities of $\mathbf{3 d}$ and $\mathbf{3 d}$ ' relative to the propargylic alcohol starting material are not clear at this stage. The more extended reaction time might be partially responsible.

Scheme 2.26. Catalytic conversion of $(R)-2 d$

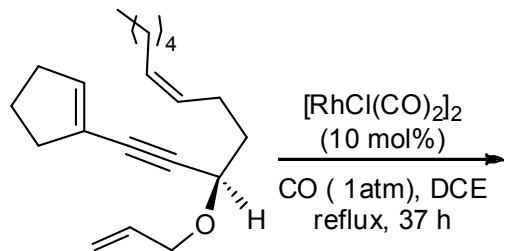

$(R)-2 \mathbf{d}$

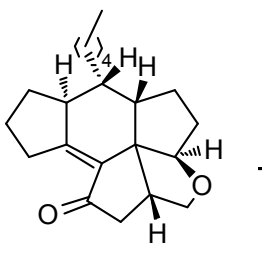

$3 d$ $72 \%$ ee $9: 1$
$45 \%$ yield

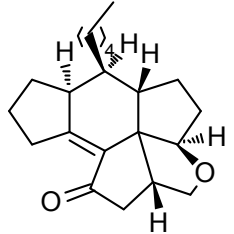

3d' $78 \%$ ee 
Unlike compounds $(R)$-2a-d, the chiral propargylic ether $(R)-\mathbf{2 e}$ contains a cyclohexene unit rather than a cyclopentene unit. This compound undergoes the same domino PK/DA reaction smoothly to give $3 \mathrm{e}$ with $71 \%$ yield and $90 \%$ ee (Scheme 2.27).

Scheme 2.27. Catalytic conversion of $(R)-2 \mathrm{e}$<smiles>C=CCC[C@H](C)OC#CC1=CCCCC1</smiles>

$(R)-2 e$

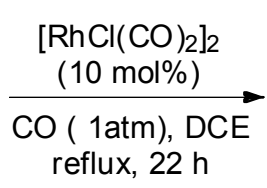

reflux, $22 \mathrm{~h}$

$$
90 \% \text { ee }
$$

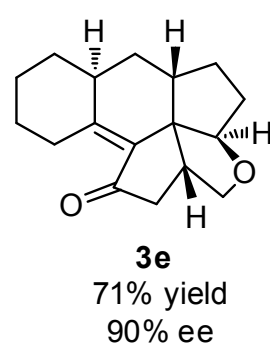

We also prepared the cyclohexene-containing racemic propargylic ethers $\mathbf{2 f}, \mathbf{2 g}$ and $\mathbf{2 h}$. When these compounds were subjected to the conditions of the $\mathrm{Rh}(\mathrm{I})$ catalysis in the conversion of $(R)-\mathbf{2 e}$ to $\mathbf{3 e}$, only the PK cycloaddition products $\mathbf{3 f}, \mathbf{3 g}$ and $\mathbf{3 h}$ were obtained in $57 \%, 44 \%$ and $64 \%$ yields, respectively (Scheme 2.28). No intramolecular DA reaction took place. When the isolated 3g was treated with $\left[\mathrm{Rh}(\mathrm{CO})_{2} \mathrm{Cl}\right]_{2}(10 \mathrm{~mol} \%)$ under $\mathrm{N}_{2}$ in refluxing toluene, there was still no DA reaction. Apparently, the intramolecular DA reaction is very sensitive to the sterics of the dienophiles in these compounds. This is in sharp contrast to the cyclopentene-containing substrates $(R)-\mathbf{2 a - d}$. 
Scheme 2.28. Catalytic conversions of the racemic propargylic ethers $\mathbf{2 f - h}$<smiles>C=CCOC(C#CC1=CCCCC1)C(C)(C)CC=C</smiles>

$2 f$<smiles>C=CCOC(C#CC1=CCCCC1)CC/C=C/CC</smiles>

$2 \mathrm{~g}$

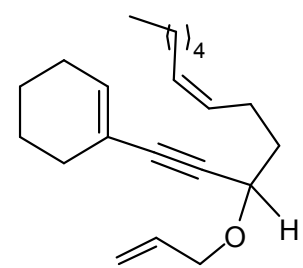

$2 \mathrm{~h}$

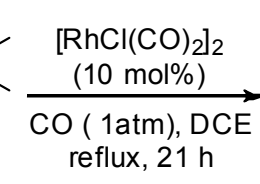

reflux, $21 \mathrm{~h}$

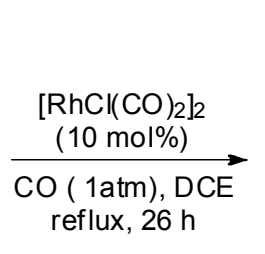$$
3 g, 44 \% \text { yield }
$$
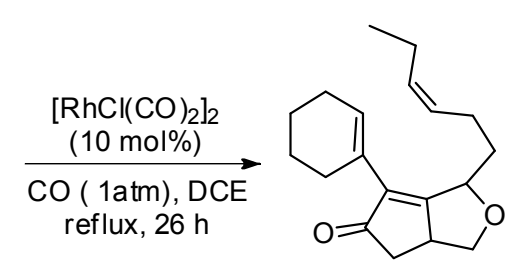

$3 \mathrm{~h}, 64 \%$ yield

On the basis of the previous studies on the Rh-catalyzed PK/DA cycloaddition, a mechanism has been proposed to illustrate the formation of $\mathbf{3 a}$ (Scheme 2.29). ${ }^{13,16-18}$ The chiral triene-yne $(R)$-2a can coordinate with the metal center of the catalyst to generate the chair-like intermediate $\mathbf{2 . 6 0}$. The oxidative coupling of the coordinated triple bond and double bond of $\mathbf{2 . 6 0}$ gives 2.61. In this step, the newly formed bridgehead hydrogen $\mathrm{H}_{2}$ is trans with respect to the proton $\mathrm{H}_{1}$ from the chiral triene-yne (R)-2a. CO insertion of $\mathbf{2 . 6 1}$ and reductive elimination give the $\mathrm{PK}$ cyclization intermediate $\mathbf{2 . 6 2}$. The coordination of the diene unit and alkene unit to the $\mathrm{Rh}$ center in $\mathbf{2 . 6 3}$ could promote an exo DA cycloaddition to generate the pentacyclic product 3a. In this step, the newly formed bridgehead hydrogen $\mathrm{H}_{3}$ is cis with respect to $\mathrm{H}_{2}$, whereas $\mathrm{H}_{4}$ is trans with respect to $\mathrm{H}_{2}$.

When $(R)-\mathbf{2 a}$ is treated with the catalyst, 2.64 is another possible intermediate in 
which the double bond $b$ is coordinated instead of the double bond $a$. The intermediate 2.64 is less favorable probably due to the greater 1,3,-diaxial interaction. The difference of the electronic effect in the formation of an ether ring verses a carbocycle should be an important factor for the reaction pathway.

Scheme 2.29. A proposed mechanism for the formation of $\mathbf{3 a}$<smiles>C=CCCC(C#CC1=CCCC1)OCC=C</smiles>

$(R)-2 \mathrm{a}$

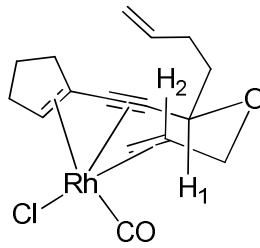

2.60

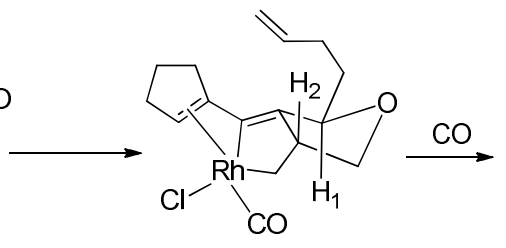

2.61

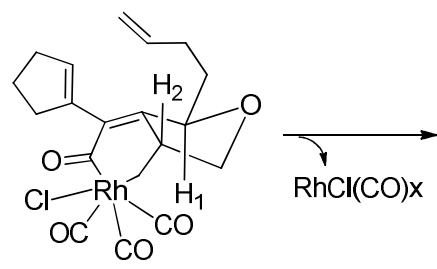<smiles>C=CCCC12COCC1(CCC=C)C(C1=CCCC1)C(=O)C2</smiles>

2.62

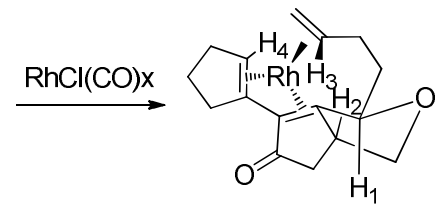

2.63

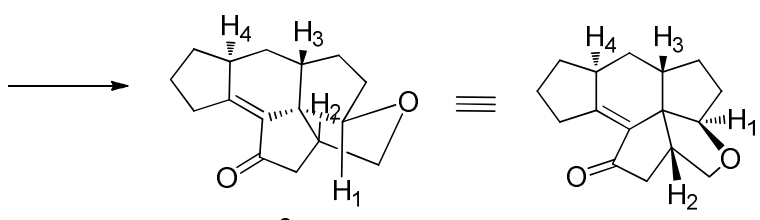

$3 a$

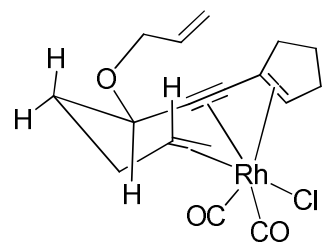

2.64

For compounds 1c,d that contains an ethyl or pentyl group on the dienophile double bond, the intermediates $\mathbf{4 c , d}$ could form. The Rh(I)-mediate exo DA cycloaddition of $\mathbf{4 c , d}$ would give the obtained products $3 \mathbf{c}, \mathbf{d}$ with the R group of the major diastereomer trans to $\mathrm{H}_{3}$ (Scheme 2.30).

Scheme 2.30. Proposed intermediates for the Rh(I)-catalyzed domino reaction

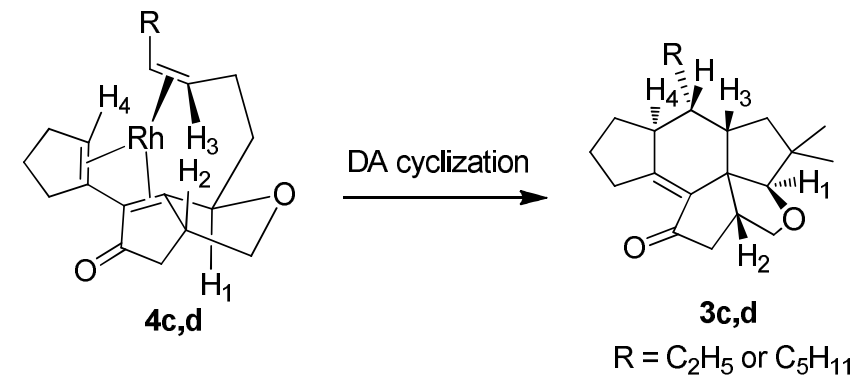




\subsection{Further conversions of the pentacyclic compound 2.59}

With the pentacyclic compound $\mathbf{2 . 5 9}$ in hand, the next work was to open its hydrofuran ring. Considering the functional groups in 2.59 (C-C double bond and carbonyl group) might be sensitive to ring opening reagents, further elaborations were made before the cleavage of the hydrofuran ring (Scheme 2.31). Pd/C hydrogenation of compound 2.59 in the presence of $1 \mathrm{~atm} \mathrm{H}_{2}$ gave compound $\mathbf{2 . 6 5}$ in $76 \%$ yield. Treatment of $\mathbf{2 . 6 5}$ with $\mathrm{NaBH}_{4}$ afforded compound $\mathbf{2 . 6 6}$ in $85 \%$ yield. ${ }^{19}$ Excellent diastereoselectivity was achieved in these two steps. It was found that $\mathrm{H}_{2}$ and $\mathrm{NaBH}_{4}$ attacked the C-C double bond and carbonyl group from the backside of ring system respectively and generated $\mathrm{H}_{\mathrm{a}}, \mathrm{H}_{\mathrm{b}}, \mathrm{H}_{\mathrm{c}}$ that are cis with respect to $\mathrm{H}_{1}$ (Figure 2.5). Compound $\mathbf{2 . 6 7}$ was obtained in $87 \%$ yield via silylation of $\mathbf{2 . 6 6}$.

Scheme 2.31. Further conversions of $\mathbf{2 . 5 9}$

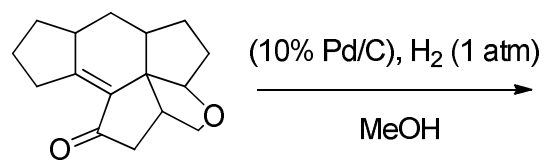

2.59

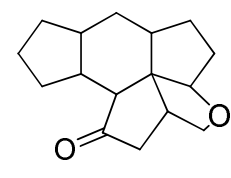

2.65

$76 \%$
$\mathrm{NaBH}_{4}$ (2 equiv)

$\mathrm{MeOH}$

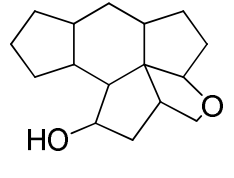

2.66

$85 \%$

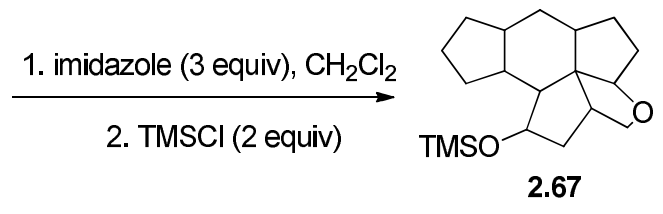

$87 \%$ 
Figure 2.5. Diastereoselective alkene hydrogenation and carbonyl reduction

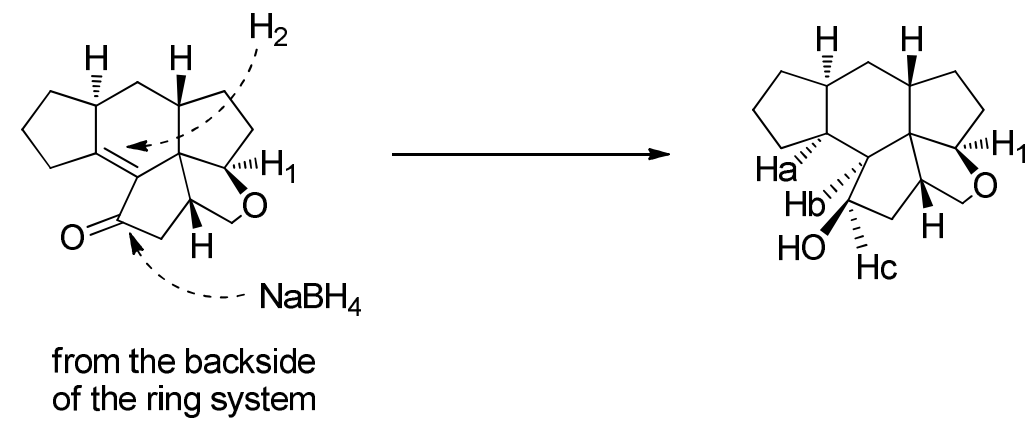

We envisioned that after the hydrofuran ring of $\mathbf{2 . 6 7}$ was cleaved, a polyol side chain could be introduced to TMS position to access an analogue of mangciol A which might have potential biological activities. To test the ring opening reaction, compound 2.67 was reacted with $\mathrm{Me}_{2} \mathrm{BBr}$ (2 equiv) and $\mathrm{Et}_{3} \mathrm{~N}\left(0.2\right.$ equiv) ${ }^{20}$ Instead of giving the desired product, the TMS group came off to regenerate the alcohol $\mathbf{2 . 6 6}$ (Scheme 2.32).

Scheme 2.32. Test of ring cleavage of $\mathbf{2 . 6 7}$

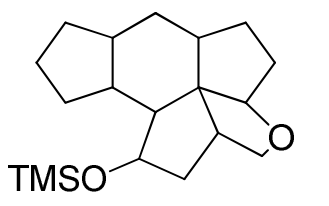

2.67

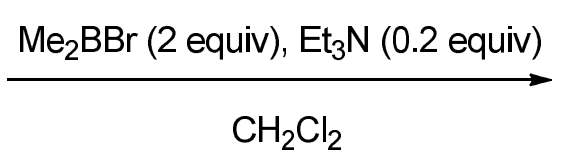

$\mathrm{CH}_{2} \mathrm{Cl}_{2}$

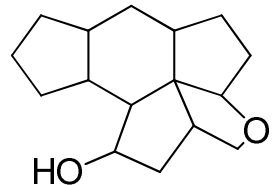

2.66

Jatczak and co-workers disclosed that simple ethers could undergo ring opening reaction. ${ }^{21}$ Thus, a variety of conditions with different Lewis acids and nucleophiles were examined for the ring cleavage of compound 2.66. (Scheme 2.33). ${ }^{21-29}$ 
Scheme 2.33. Test of various conditions for the ring cleavage of $\mathbf{2 . 6 6}$

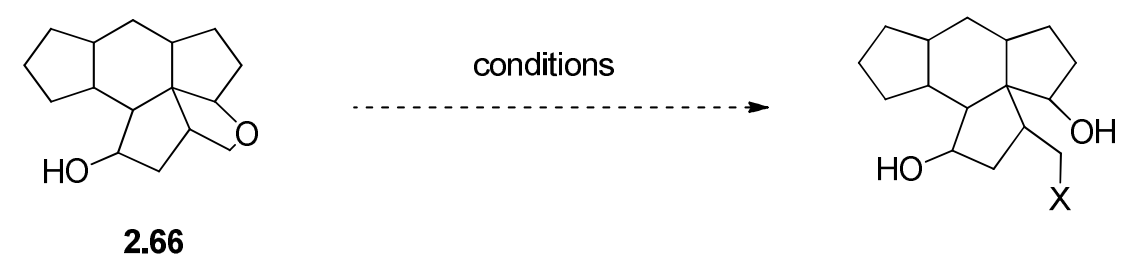

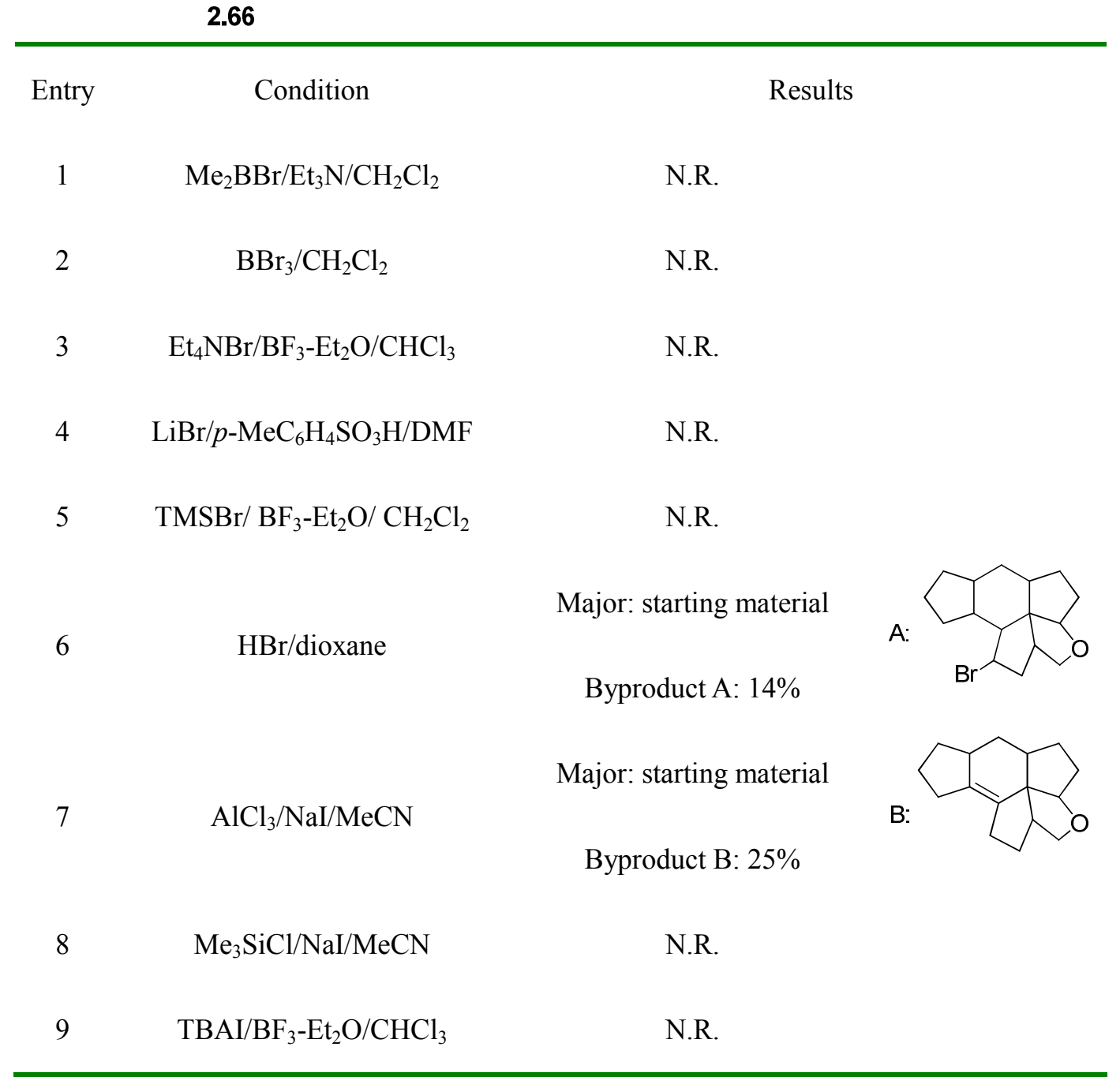

$\mathrm{Br}$ nucleophiles were examined first (entry 1-6). No reaction occurred under the conditions in entry 1-5. In entry 6, a small amount of possible byproduct A (14\% yield) was obtained when compound 2.66 was treated with $\mathrm{HBr}$ in dioxane at $85^{\circ} \mathrm{C}$ overnight. With the failure of $\mathrm{Br}$ nucleophiles, we turned to stronger I nucleophiles. The conditions in entry $8-9$ were unable to cleave the hydrofuran ring. In entry 7 , compound 2.66 was reacted with $\mathrm{AlCl}_{3} / \mathrm{NaI} / \mathrm{MeCN}$ at $95{ }^{\circ} \mathrm{C}$ to give a possible elimination byproduct $\mathbf{B}$ in $25 \%$ yield. 
As no methods were able to cleave the hydrofuran ring of 2.66, it was hypothesized that Lewis acids might be trapped by the hydroxyl group. Removal of the hydroxyl group could promote the ring opening reaction. Then compound 2.69 was synthesized through sulfonylation of $\mathbf{2 . 6 6}$ with $\mathrm{MsCl}$ followed by elimination under DBU condition (Scheme 2.34). ${ }^{30,31}$

Scheme 2.34. Synthesis of compound 2.69

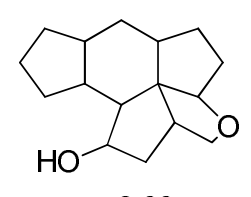

2.66

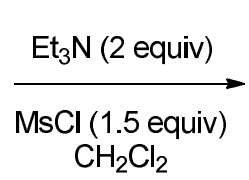

$\mathrm{CH}_{2} \mathrm{Cl}_{2}$

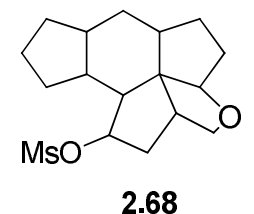

$66 \%$

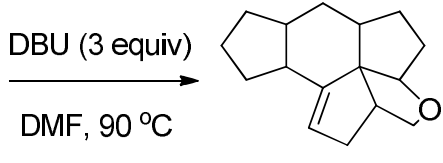

2.69 $81 \%$

Then compound 2.69 was investigated under the $\mathrm{Et}_{4} \mathrm{NBr} / \mathrm{BF}_{3}-\mathrm{Et}_{2} \mathrm{O} / \mathrm{CHCl}_{3}$ conditions which had been proved effective for the opening of simple tetrahydrofurans previously. Disappointingly, this method failed to convert compound 2.69 to the desired product $\mathbf{2 . 7 0}$. No reaction occurred when the temperature was gradually raised to refluxing (Scheme 2.35).

Scheme 2.35. Test of the ring cleavage of $\mathbf{2 . 6 9}$

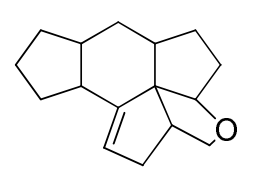

2.69

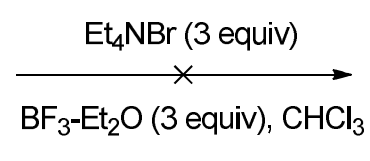

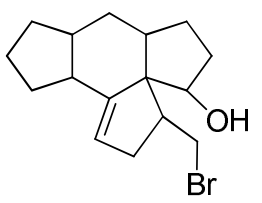

2.70

After many methods were tested to be unsuccessful to open the hydrofuran ring of compounds 2.66, 2.67 and 2.69, we went back to test compound 2.59 without any modification. Excess $\mathrm{BBr}_{3}\left(10\right.$ equiv) was reacted with 2.59 at $-78^{\circ} \mathrm{C}$ for $2 \mathrm{~h}$. Then the system was warmed to $0{ }^{\circ} \mathrm{C}$ for $3 \mathrm{~h}$ and to room temperature overnight. Encouragingly, another type of ring opening product $\mathbf{2 . 7 1}$ was obtained in low yield 
(8\%) although it was not the desired product 2.72 . Besides, $46 \%$ starting material was recovered and some unidentified byproducts were formed (Scheme 2.36). The structure of 2.71 was determined by ${ }^{1} \mathrm{H},{ }^{13} \mathrm{C}$ NMR and high-resolution mass spectroscopic analysis. We were pleased that $\mathrm{BBr}_{3}$ didn't affect two functional groups (C-C double bond and carbonyl group) in the ring system. Compared to $\mathbf{2 . 7 2}$, more steps are required for $\mathbf{2 . 7 1}$ to construct the chiral centers C5 and C7. However, compound $\mathbf{2 . 7 1}$ is still useful in the synthesis if a high yield could be achieved.

Scheme 2.36. Test of the ring cleavage of $\mathbf{2 . 5 9}$

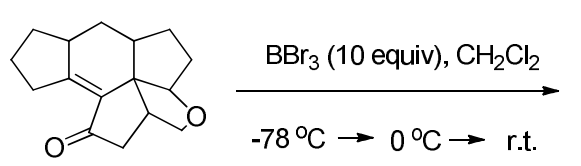

2.59

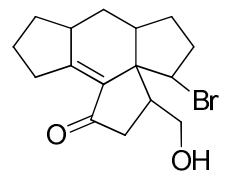

$2.718 \%$

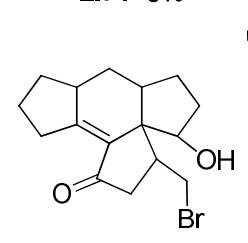

2.72

desired product

Our next task was to improve the yield by optimizing the $\mathrm{BBr}_{3}$ conditions. This reaction was limited to the incomplete conversion of starting material and side reactions. We were trying to improve the conversion and inhibit the side reactions.

When $\mathrm{BBr}_{3}$ (10 equiv) was employed, extending the reaction time at room temperature didn't help the conversion. Gradually increasing the temperature to $50{ }^{\circ} \mathrm{C}$ promoted the decomposition of compounds. Decreasing the temperature to $0{ }^{\circ} \mathrm{C}$ lowered the conversion and the side reactions still occurred. Reducing the amount of $\mathrm{BBr}_{3}$ (1 equiv) were unable to inhibit the side reactions while some product was formed. $\mathrm{NaBr}$ with catalytic tetrabutylammonium bromide (TBABr) had been 
reported to promote the ring opening reaction and improve the conversion. ${ }^{32}$ After $\mathrm{NaBr}$ ( 3 equiv) and $\mathrm{TBABr}(0.2$ equiv) were introduced to the system at room temperature, more products were obtained while the yield was still not high $(26 \%)$ (Scheme 2.37). No further conversion was observed when increasing temperature to $45{ }^{\circ} \mathrm{C}$. Adding extra $\mathrm{BBr}_{3}$ (1 equiv) to the system also failed to improve the conversion.

Scheme 2.37. $\mathrm{NaBr} / \mathrm{TBABr}$-promoted ring cleavage of $\mathbf{2 . 5 9}$
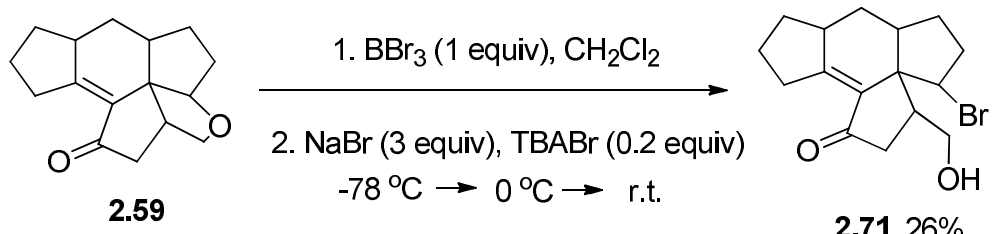

recovered starting material: $30 \%$

The formation of compound $\mathbf{2 . 7 1}$ indicated that the reaction might undergo $\mathrm{S}_{\mathrm{N}} 1$ process. The resulting secondary carbocation combined with $\mathrm{Br}^{-}$to give 2.71. In addition, some side reactions such as elimination might have occurred.

\subsection{Summary}

Using the chiral propargylic alcohols prepared from the asymmetric enyne addition to aliphatic aldehydes catalyzed by the $\mathrm{BINOL}-\mathrm{Ti}\left(\mathrm{O}^{i} \mathrm{Pr}\right)_{4}-\mathrm{Et}_{2} \mathrm{Zn}-\mathrm{Cy}{ }_{2} \mathrm{NH}$ catalyst system, we have prepared a series of chiral propargylic ether-based triene-ynes with high enantiomeric purity. We have found that these compounds can undergo an efficient one-pot $\mathrm{Rh}(\mathrm{I})$-catalyzed domino $\mathrm{PK} / \mathrm{DA}$ cycloaddition to generate the multicyclic products 3a-e with high chemoselectivity and 
stereoselectivity. These products contain the core structure of mangicol A which could facilitate the synthesis and study of this class of natural products.

Further conversions of the racemic pentacyclic product 2.59 have also been studied. After extensive exploration and optimization of the ring cleavage conditions, another type of ring opening product $\mathbf{2 . 7 1}$ was obtained in a low yield. This compound may be useful in the synthesis of the analogues of mangicol A. 


\section{Experimental and Characterization}

\section{Analytical instruments}

NMR: Bruker $600 \mathrm{MHz}$.

HPLC: Water 600 Pump and Waters 486 Tunable Absorbance Detector, Chiralcel OD, OD-H, or Chiralpak AD, AD-H column.

Polarimeter: Jasco Digital Polarimeter P-2000.

High resolution mass spectra were obtained by EI [70-VSE(C)] or ESI (Q-TOf) analysis.

\section{General data}

Reactions were carried out under nitrogen. All commercial chemicals were used without further purification unless otherwise noted. Zinc reagents and catalysts were purchased and stored in dry nitrogen atmosphere. THF and toluene were distilled over sodium and benzophenone under nitrogen. $\mathrm{DCM}$ and $\mathrm{Et}_{2} \mathrm{O}$ were dried by passing through activated alumina columns under nitrogen. All the NMR spectra were obtained in $\mathrm{CDCl}_{3}$ unless indicated otherwise.

\section{Preliminary investigation of PK/DA strategy}

a. Synthesis of the racemic triene-yne 2.58
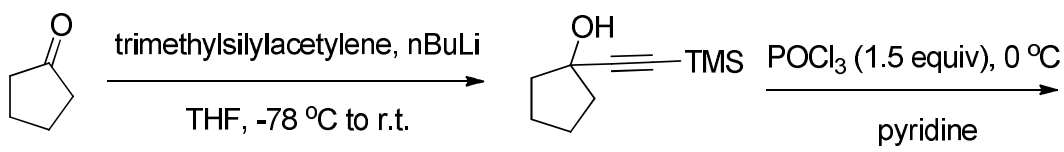

pyridine

$2.5499 \%$

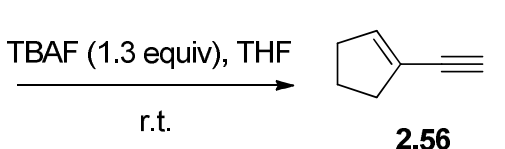

2.56
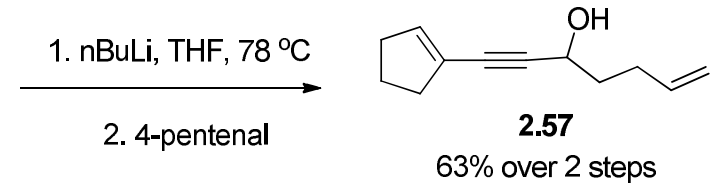

$\underset{\text { 2. allyl bromide, r.t. }}{\stackrel{\text { 1. } \mathrm{NaH}, \mathrm{THF}, 0^{\circ} \mathrm{C}}{\longrightarrow}}$

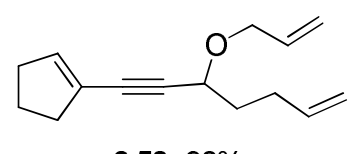

$2.5890 \%$

$63 \%$ over 2 steps

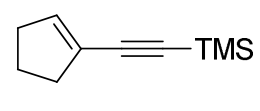

$2.5576 \%$ 


\section{1-((trimethylsilyl)ethynyl)cyclopentanol, 2.54}

Trimethylsilylacetylene (15 g, $153 \mathrm{mmol}, 1.5$ equiv) was dissolved in THF (20 $\mathrm{mL}$ ) and cooled to $-78{ }^{\circ} \mathrm{C}$ under nitrogen. ${ }^{n} \mathrm{BuLi}(48.9 \mathrm{~mL}, 122.4 \mathrm{mmol}, 2.5 \mathrm{M}$ in hexane, 1.2 equiv) was added and the mixture was stirred for $30 \mathrm{~min}$. Then cyclopentenone ( $9 \mathrm{~mL}, 102 \mathrm{mmol}, 1$ equiv) was added and the system was warmed to room temperature. After $4 \mathrm{~h}$, the reaction was quenched with saturated aqueous ammonium chloride solution and extracted with $\mathrm{CH}_{2} \mathrm{Cl}_{2}$ three times. The organic layer was washed with brine, dried with $\mathrm{Na}_{2} \mathrm{SO}_{4}$, concentrated by rotary evaporation and purified by flash column chromatography (hexane:EtOAc=15:1) to furnish compound 2.54 (18.3 g, 99\%). ${ }^{1} \mathrm{H}$ NMR $\left(300 \mathrm{MHz}, \mathrm{CDCl}_{3}\right) \delta 1.93(\mathrm{~m}, 4 \mathrm{H}), 1.73(\mathrm{~m}$, 4H), $0.16(\mathrm{~s}, 9 \mathrm{H}) .{ }^{13} \mathrm{C} \mathrm{NMR}\left(75 \mathrm{MHz}, \mathrm{CDCl}_{3}\right) \delta 109.8,87.3,75.0,42.8,23.8,0.21$.

\section{(cyclopent-1-en-1-ylethynyl)trimethylsilane, 2.55}

To a solution of the alcohol 2.54 (18.3 g, $100.5 \mathrm{mmol}, 1$ equiv) in $\mathrm{CH}_{2} \mathrm{Cl}_{2}(20 \mathrm{~mL})$ was added pyridine $(20 \mathrm{~mL})$ under nitrogen. The system was cooled to $0{ }^{\circ} \mathrm{C}$ and phosphoryl chloride (13.8 mL, $150.8 \mathrm{mmol}, 1.5$ equiv) was added dropwise. Then the mixture was kept at $0{ }^{\circ} \mathrm{C}$ for $30 \mathrm{~min}$ and warmed to room temperature for $2 \mathrm{~h}$. The reaction was quenched with small pieces of ice at $0{ }^{\circ} \mathrm{C}$, neutralized by $2 \mathrm{M} \mathrm{HCl}$ and extracted with $\mathrm{CH}_{2} \mathrm{Cl}_{2}$ three times. The organic layer was washed with brine, dried with $\mathrm{Na}_{2} \mathrm{SO}_{4}$, concentrated by rotary evaporation and purified by flash column

chromatography eluted with hexanes to give $\mathbf{2 . 5 5}$ as yellow oil $(12.5 \mathrm{~g}, 76 \%) . \quad{ }^{1} \mathrm{H}$ NMR $\left(300 \mathrm{MHz}, \mathrm{CDCl}_{3}\right) \delta 6.11(\mathrm{t}, 1 \mathrm{H}, \mathrm{J}=3 \mathrm{~Hz}), 2.46-2.41(\mathrm{~m}, 4 \mathrm{H}), 1.88(\mathrm{~m}, 2 \mathrm{H})$, $0.19(\mathrm{~s}, 9 \mathrm{H}) .{ }^{13} \mathrm{C} \mathrm{NMR}\left(75 \mathrm{MHz}, \mathrm{CDCl}_{3}\right) \delta 139.6,124.8,102.8,95.5,36.6,33.5,25.6$, 
0.26 .

\section{1-(cyclopent-1-en-1-yl)hept-6-en-1-yn-3-ol, 2.57}

To a solution of $\mathbf{2 . 5 5}(0.89 \mathrm{~g}, 5.42 \mathrm{mmol}, 1$ equiv $)$ in THF (10 ml) was added TBAF ( $7 \mathrm{~mL}, 7 \mathrm{mmol}, 1 \mathrm{M}$ in THF, 1.3 equiv) dropwise at room temperature under nitrogen. The mixture was stirred for $4 \mathrm{~h}$. The reaction was quenched with saturated aqueous ammonium chloride solution and extracted with $\mathrm{Et}_{2} \mathrm{O}$ three times. The organic layer was washed with brine, dried with $\mathrm{Na}_{2} \mathrm{SO}_{4}$, concentrated by rotary evaporation at $0{ }^{\circ} \mathrm{C}$ and purified by flash column chromatography eluted with n-hexanes to furnish compound $\mathbf{2 . 5 6}$ (498 $\mathrm{mg})$.

The enyne 2.56 (498 mg, $5.4 \mathrm{mmol}, 1.25$ equiv) was dissovled in THF (10 mL) and cooled to $-78^{\circ} \mathrm{C}$ under nitrogen. ${ }^{n} \mathrm{BuLi}(1.94 \mathrm{~mL}, 4.86 \mathrm{mmol}, 2.5 \mathrm{M}$ in hexane, 1.13 equiv) was added and the mixture was stirred for $30 \mathrm{~min}$. Then 4-pentenal (425.6 $\mathrm{uL}, 4.32 \mathrm{mmol}, 1$ equiv) was added and stirred for $2 \mathrm{~h}$. The reaction was quenched with saturated aqueous ammonium chloride solution and extracted with $\mathrm{CH}_{2} \mathrm{Cl}_{2}$ three times. The organic layer was washed with brine, dried with $\mathrm{Na}_{2} \mathrm{SO}_{4}$, concentrated by rotary evaporation and purified by flash column chromatography (hexane:EtOAc=15:1) to give compound 2.57 (480.4 mg, 63\% over two steps). ${ }^{1} \mathrm{H}$ NMR (300 MHz, $\left.\mathrm{CDCl}_{3}\right) \delta 6.03(\mathrm{t}, 1 \mathrm{H}, \mathrm{J}=3 \mathrm{~Hz}), 5.84(\mathrm{~m}, 1 \mathrm{H}), 5.06(\mathrm{~m}, 1 \mathrm{H}), 4.98(\mathrm{~d}$, 1H, J=12 Hz), $4.52(\mathrm{t}, 1 \mathrm{H}, \mathrm{J}=6 \mathrm{~Hz}), 2.42(\mathrm{~m}, 4 \mathrm{H}), 2.23(\mathrm{~m}, 2 \mathrm{H}), 2.03(\mathrm{~s}, 1 \mathrm{H})$, 2.03-1.80 (m, 4H). ${ }^{13} \mathrm{C}$ NMR $\left(75 \mathrm{MHz}, \mathrm{CDCl}_{3}\right) \delta 138.5,138.0,124.1,115.4,91.2$, $82.7,62.7,37.1,36.6,33.4,29.7,23.5$. 


\section{1-(3-(allyloxy)hept-6-en-1-yn-1-yl)cyclopent-1-ene, 2.58}

To a solution of $\mathrm{NaH} 60 \% \mathrm{w} / \mathrm{w}(3.5 \mathrm{~g}, 87.6 \mathrm{mmol}, 3$ equiv) in THF $(20 \mathrm{~mL})$ was added the alcohol 2.57 (5.14 g, $29.2 \mathrm{mmol}, 1$ equiv) in THF $(10 \mathrm{~mL})$ at $0{ }^{\circ} \mathrm{C}$ under nitrogen and stirred for $30 \mathrm{~min}$. Then allyl bromide $(20.2 \mathrm{~mL}, 233.6 \mathrm{mmol}, 8$ equiv) was added and the mixture was warmed to room temperature overnight. The reaction was quenched with saturated aqueous ammonium chloride solution and extracted with $\mathrm{CH}_{2} \mathrm{Cl}_{2}$ three times. The organic layer was washed with brine, dried with $\mathrm{Na}_{2} \mathrm{SO}_{4}$, concentrated by rotary evaporation and purified by flash column chromatography (hexane:EtOAc=25:1) to give compound 2.58 (5.68 g, 90\%). ${ }^{1} \mathrm{H}$ NMR (300 MHz, $\left.\mathrm{CDCl}_{3}\right) \delta 6.03(\mathrm{t}, 1 \mathrm{H}, \mathrm{J}=3 \mathrm{~Hz}), 5.86(\mathrm{~m}, 2 \mathrm{H}), 5.30(\mathrm{dd}, 1 \mathrm{H}, \mathrm{J}=18,3 \mathrm{~Hz}), 5.17(\mathrm{~d}, 1 \mathrm{H}$, $\mathrm{J}=9 \mathrm{~Hz}), 5.04(\mathrm{dd}, 1 \mathrm{H}, \mathrm{J}=18,3 \mathrm{~Hz}), 4.96(\mathrm{~d}, 1 \mathrm{H}, \mathrm{J}=18 \mathrm{~Hz}), 4.25(\mathrm{~m}, 2 \mathrm{H}), 3.95(\mathrm{dd}, 1 \mathrm{H}$, $\mathrm{J}=12,6 \mathrm{~Hz}), 2.42(\mathrm{~m}, 4 \mathrm{H}), 2.23(\mathrm{~m}, 2 \mathrm{H}), 1.86(\mathrm{~m}, 4 \mathrm{H}) .{ }^{13} \mathrm{C} \mathrm{NMR}\left(75 \mathrm{MHz}, \mathrm{CDCl}_{3}\right)$ $\delta 138.2,138.0,134.8,124.3,117.4,115.2,89.3,83.5,69.8,68.9,36.7,35.2,33.4$, 29.8, 23.5. HRMS (ESI) for $\mathrm{C}_{15} \mathrm{H}_{19} \mathrm{O}(\mathrm{MH}+)$ Cacld: 215.14360, Found: 215.14395.

\section{b. Synthesis of the racemic PK-DA product 2.59}
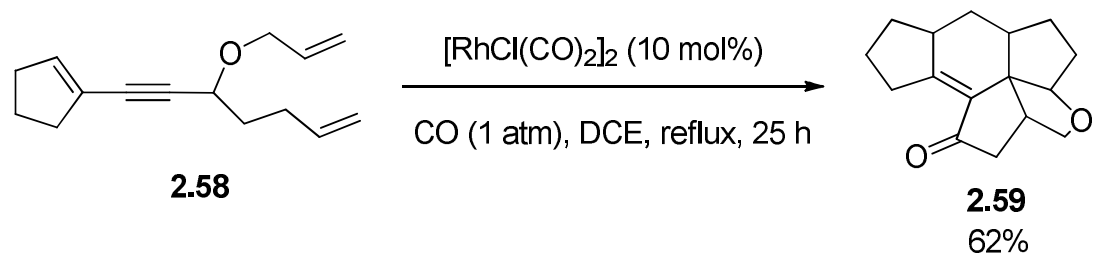

Under nitrogen, compound $\mathbf{2 . 5 8}$ (58.5 $\mathrm{mg}, 0.272 \mathrm{mmol}, 1$ equiv) and $\left[\mathrm{Rh}(\mathrm{CO})_{2} \mathrm{Cl}\right]_{2}(10.5 \mathrm{mg}, 0.10$ equiv) were weighed into a tared two-necked round bottom flask and dissolved in DCE $(5 \mathrm{~mL})$. The flask was fitted with reflux condenser fit with a septum and the side arm of the flask was also fitted with septum. The solution was bubbled with $\mathrm{CO}$ gas for 2 minutes through the side arm fitted with 
septum and a vent needle in the septum of the reflux condenser. Then, the solution was placed under $\mathrm{CO}$ atmosphere by using a balloon. After the reaction mixture was heated at $70^{\circ} \mathrm{C}$ to reflux temperature for $25 \mathrm{~h}$, it was cooled to room temperature and the $\mathrm{CO}$ was released cautiously in the hood. The reaction mixture was concentrated and the crude product was purified by column chromatography on silica gel (hexane:EtOAc=20:1 to 8:1) to give compound $2.59(40.7 \mathrm{mg}, 62 \%) .{ }^{1} \mathrm{H}$ NMR $(600$ $\left.\mathrm{MHz}, \mathrm{CDCl}_{3}\right) \delta 4.15(\mathrm{~m}, 1 \mathrm{H}), 4.09(\mathrm{dd}, 1 \mathrm{H}, \mathrm{J}=6,3 \mathrm{~Hz}), 3.84(\mathrm{~d}, 1 \mathrm{H}, \mathrm{J}=6 \mathrm{~Hz}), 2.82(\mathrm{dd}$, 1H, J=9, $3 \mathrm{~Hz}), 2.64(\mathrm{~m}, 1 \mathrm{H}), 2.52(\mathrm{~m}, 1 \mathrm{H}), 2.28(\mathrm{~m}, 3 \mathrm{H}), 2,09(\mathrm{~m}, 2 \mathrm{H}), 1.91(\mathrm{dd}, 1 \mathrm{H}$, $\mathrm{J}=6,3 \mathrm{~Hz}), 1.82(\mathrm{~m}, 1 \mathrm{H}), 1.75(\mathrm{~m}, 1 \mathrm{H}), 1.71-1.54(\mathrm{~m}, 3 \mathrm{H}), 1.07(\mathrm{~m}, 2 \mathrm{H}) .{ }^{13} \mathrm{C} \mathrm{NMR}$ $\left(150 \mathrm{MHz}, \mathrm{CDCl}_{3}\right) \delta 205.0,160.6,132.4,91.2,73.0,62.9,47.5,43.1,42.4,39.8,35.7$, 32.8, 32.6, 32.0, 31.6, 24.9. HRMS (ESI) for $\mathrm{C}_{16} \mathrm{H}_{21} \mathrm{O}_{2}(\mathrm{MH}+$ ) Cacld: 245.1542, Found: 245.1544 .

\section{Asymmetric approach to the multicyclic core structure of mangicol A}

\section{a. General procedure for the preparation of the racemic propargylic alcohols from enyne addition to aldehydes}

Under nitrogen, an enyne (1.5 equiv) was dissolved in THF $(5 \mathrm{~mL})$ and cooled to $-78{ }^{\circ} \mathrm{C} .{ }^{n} \mathrm{BuLi}$ ( $2.5 \mathrm{M}$ in hexane, 1.2 equiv) was added and the mixture was stirred for $30 \mathrm{~min}$. Then an aldehyde $(0.5 \mathrm{mmol}, 1$ equiv) was added and the mixture was stirred for $3 \mathrm{~h}$. Then, the reaction mixture was warmed up to room temperature and quenched with the addition of saturated aqueous ammonium chloride solution. After extraction with $\mathrm{CH}_{2} \mathrm{Cl}_{2}$ for three times, the combined organic layer was washed with brine, dried with $\mathrm{Na}_{2} \mathrm{SO}_{4}$, concentrated by rotary evaporation and purified by column 
chromatography on silica gel eluted with hexanes/ethyl acetate to give the product.

Characterizations of the racemic propargylic alcohols 1f-h

1-(cyclohex-1-en-1-yl)-4,4-dimethylhept-6-en-1-yn-3-ol, 1 f<smiles>C=CCC(C)(C)C(O)C#CC1=CCCCC1</smiles>

Colorless oil, $173.2 \mathrm{mg}, 79 \%$ yield. ${ }^{1} \mathrm{H}$ NMR $\left(300 \mathrm{MHz}, \mathrm{CDCl}_{3}\right) \delta 6.08(\mathrm{~m}, 1 \mathrm{H}), 5.83$ $(\mathrm{m}, 1 \mathrm{H}), 5.08(\mathrm{~m}, 1 \mathrm{H}), 5.03(\mathrm{~m}, 1 \mathrm{H}), 4.16(\mathrm{~s}, 1 \mathrm{H}), 2.10(\mathrm{~m}, 6 \mathrm{H}), 1.04(\mathrm{~s}, 1 \mathrm{H}), 1.59(\mathrm{~m}$ 4H), $0.96(\mathrm{~m}, 3 \mathrm{H}), 0.95(\mathrm{~m}, 3 \mathrm{H}) .{ }^{13} \mathrm{C} \mathrm{NMR}\left(75 \mathrm{MHz}, \mathrm{CDCl}_{3}\right) \delta$ 135.3, 135.2, 120.4, $117.8,88.1,86.1,70.8,43.0,39.1,29.4,25.8,22.9,22.8,22.5,21.7$.

(Z)-1-(cyclohex-1-en-1-yl)non-6-en-1-yn-3-ol, 1 g

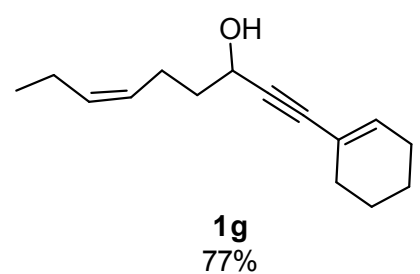

Colorless oil, $167.8 \mathrm{mg}, 77 \%$ yield. ${ }^{1} \mathrm{H}$ NMR (300 MHz, $\left.\mathrm{CDCl}_{3}\right) \delta 6.07(\mathrm{~m}, 1 \mathrm{H}), 5.35$ (m, 2H), $4.46(\mathrm{~m}, 1 \mathrm{H}), 2.18(\mathrm{~m}, 3 \mathrm{H}), 2.07(\mathrm{~m}, 6 \mathrm{H}), 1.74(\mathrm{~m}, 2 \mathrm{H}), 1.58(\mathrm{~m}, 4 \mathrm{H}), 0.94(\mathrm{t}$, $3 \mathrm{H}, \mathrm{J}=7.5 \mathrm{~Hz}) . \quad{ }^{13} \mathrm{C} \mathrm{NMR}\left(75 \mathrm{MHz}, \mathrm{CDCl}_{3}\right) \delta 135.3,132.9,128.1,120.3,87.5,87.0$, $62.7,38.0,29.4,25.8,23.2,22.5,21.7,20.8,14.6$.

(Z)-1-(cyclohex-1-en-1-yl)dodec-6-en-1-yn-3-ol, $1 \mathrm{~h}$

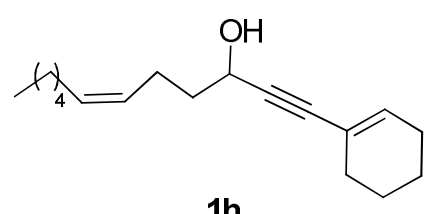

$1 \mathrm{~h}$

Colorless oil, $205 \mathrm{mg}, 79 \%$ yield. ${ }^{1} \mathrm{H}$ NMR $\left(300 \mathrm{MHz}, \mathrm{CDCl}_{3}\right) \delta 6.06(\mathrm{~m}, 1 \mathrm{H}), 5.35$ 
$(\mathrm{m}, 2 \mathrm{H}), 4.45(\mathrm{~m}, 1 \mathrm{H}), 2.34(\mathrm{~d}, 1 \mathrm{H}, \mathrm{J}=5.1 \mathrm{~Hz}), 2.18(\mathrm{~m}, 2 \mathrm{H}), 2.06(\mathrm{~m}, 6 \mathrm{H}), 1.73(\mathrm{~m}$, 2H), $1.57(\mathrm{~m}, 5 \mathrm{H}), 1.27(\mathrm{~m}, 6 \mathrm{H}), 0.85(\mathrm{t}, 3 \mathrm{H}, \mathrm{J}=6.6 \mathrm{~Hz}) .{ }^{13} \mathrm{C} \mathrm{NMR}\left(75 \mathrm{MHz}, \mathrm{CDCl}_{3}\right)$ $\delta 135.2,131.3,128.6,120.4,87.6,87.0,62.7,38.0,31.8,29.6,29.4,25.8,23.4,22.8$, $22.5,21.7,14.3$.

b. General procedure for the (S)-BINOL-catalyzed enantioselective enyne addition to aldehydes

Under nitrogen, $(S)$-BINOL (40\%) was weighted into a tared flask and dissolved in $\mathrm{Et}_{2} \mathrm{O}$ (3 mL). An enyne (4 equiv), $\mathrm{Cy}_{2} \mathrm{NH}(5 \%)$ and $\mathrm{Et}_{2} \mathrm{Zn}$ (4 equiv) were added and the mixture was stirred at room temperature for $16 \mathrm{~h}$. Then, $\operatorname{Ti}\left(\mathrm{O}^{i} \mathrm{Pr}\right)_{4}(100 \%)$ was added and the stirring continued for $3 \mathrm{~h}$. An aldehyde ( $0.25 \mathrm{mmol}, 1$ equiv) was added and the mixture was stirred for another $4 \mathrm{~h}$. The reaction was quenched with saturated aqueous ammonium chloride and extracted three times with $\mathrm{CH}_{2} \mathrm{Cl}_{2}$. The organic layer was dried with anhydrous $\mathrm{Na}_{2} \mathrm{SO}_{4}$ and concentrated by rotary evaporation. The resultant oil was purified by flash column chromatography on silica gel eluted with hexanes/ethyl acetate to give the product in $57-89 \%$ yield and $90-92 \%$ ee.

Characterizations of the optical active propargylic alcohols generated from the enyne addition to aldehydes

(R)-1-(cyclopent-1-en-1-yl)hept-6-en-1-yn-3-ol, $(R)-1 \mathrm{a}$.

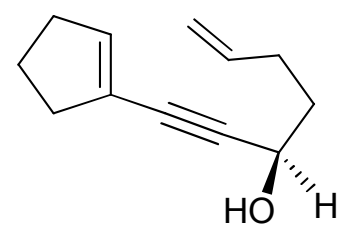

$(R)-1 \mathrm{a}$

$71 \%, 92 \%$ ee 
Yellow oil, $31.1 \mathrm{mg}, 71 \%$ yield. $92 \%$ ee determined by HPLC analysis: Chiralpak OD column, 98:2 hexanes: ${ }^{i} \mathrm{PrOH}$, flow rate $=1.0 \mathrm{~mL} / \mathrm{min}, \lambda=254 \mathrm{~nm}$, retention time: $\mathrm{t}_{\text {major }}=11.0 \mathrm{~min}, \mathrm{t}_{\text {minor }}=13.1 \mathrm{~min} . \quad[\alpha]_{\mathrm{D}}^{24}=-19.0\left(\mathrm{c}=0.455, \mathrm{CHCl}_{3}\right) . \quad{ }^{1} \mathrm{H}$ NMR $(300$ $\left.\mathrm{MHz}, \mathrm{CDCl}_{3}\right) \delta 6.03(\mathrm{t}, 1 \mathrm{H}, \mathrm{J}=2.1 \mathrm{~Hz}), 5.84(\mathrm{~m}, 1 \mathrm{H}), 5.06(\mathrm{dd}, 1 \mathrm{H}, \mathrm{J}=17.1,1.8 \mathrm{~Hz})$ $4.98(\mathrm{~d}, 1 \mathrm{H}, \mathrm{J}=10.2 \mathrm{~Hz}), 4.52(\mathrm{t}, 1 \mathrm{H}, \mathrm{J}=6.3 \mathrm{~Hz}), 2.42(\mathrm{~m}, 4 \mathrm{H}), 2.23(\mathrm{~m}, 2 \mathrm{H}), 2.03(\mathrm{~s}$, 1H), 2.03-1.80 (m, 4H). ${ }^{13} \mathrm{C}$ NMR $\left(75 \mathrm{MHz}, \mathrm{CDCl}_{3}\right) \delta 138.5,138.0,124.1,115.4$, 91.2, 82.7, 62.7, 37.1, 36.6, 33.4, 29.7, 23.5. HRMS [EI(TOF)] for $\mathrm{C}_{12} \mathrm{H}_{16} \mathrm{O}(\mathrm{M}+)$ Cacld: 176.1201, Found: 176.1199.

(R)-1-(cyclopent-1-en-1-yl)-4,4-dimethylhept-6-en-1-yn-3-ol, $(R)-1 b$.

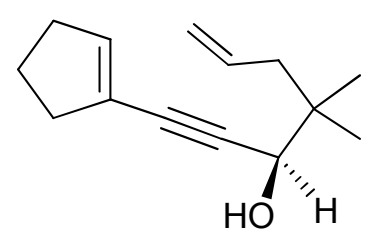

$(R)-1 \mathbf{b}$

$71 \%, 90 \%$ ee

Colorless oil, $36 \mathrm{mg}, 71 \%$ yield. $\quad 90 \%$ ee determined by HPLC analysis: Chiralpak AD-H column, 98:2 hexanes: ${ }^{i} \mathrm{PrOH}$, flow rate $=1.0 \mathrm{~mL} / \mathrm{min}, \lambda=225 \mathrm{~nm}$, retention time: $\mathrm{t}_{\text {major }}=8.4 \mathrm{~min}, \mathrm{t}_{\text {minor }}=9.4 \mathrm{~min} . \quad[\alpha]^{27}{ }_{\mathrm{D}}=-20.3\left(\mathrm{c}=1.300, \mathrm{CHCl}_{3}\right) . \quad{ }^{1} \mathrm{H} \mathrm{NMR}$ $\left(300 \mathrm{MHz}, \mathrm{CDCl}_{3}\right) \delta 6.02(\mathrm{t}, 1 \mathrm{H}, \mathrm{J}=1.8 \mathrm{~Hz}), 5.84(\mathrm{~m}, 1 \mathrm{H}), 5.08(\mathrm{dd}, 1 \mathrm{H}, \mathrm{J}=5.4,0.6$ Hz), $5.04(\mathrm{~s}, 1 \mathrm{H}), 4.19(\mathrm{~d}, 1 \mathrm{H}, \mathrm{J}=6 \mathrm{~Hz}), 2.42(\mathrm{~m}, 4 \mathrm{H}), 2.14(\mathrm{~m}, 2 \mathrm{H}), 1.90(\mathrm{~m}, 3 \mathrm{H})$, $0.97(\mathrm{~s}, 3 \mathrm{H}), 0.96(\mathrm{~m}, 3 \mathrm{H}) .{ }^{13} \mathrm{C} \mathrm{NMR}\left(75 \mathrm{MHz}, \mathrm{CDCl}_{3}\right) \delta 138.2,135.2,124.2,117.9$, 90.0, 83.7, 70.9, 43.0, 39.1, 36.6, 33.4, 23.5, 22.9, 22.8. HRMS [EI(TOF)] for $\mathrm{C}_{14} \mathrm{H}_{20} \mathrm{O}(\mathrm{M}+)$ Cacld: 204.1514, Found: 204.1513. 
$(R, Z)-1-(c y c l o p e n t-1-e n-1-y l) n o n-6-e n-1-y n-3-o l,(R)-1 c$.

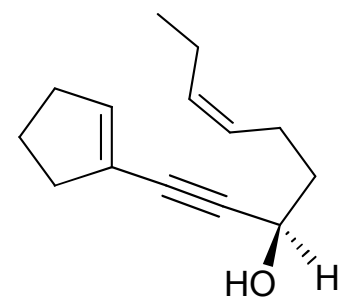

$(R)-1 \mathrm{c}$

$70 \%, 90 \%$ ee

Colorless oil, $35.5 \mathrm{mg}, 70 \%$ yield. $\quad 90 \%$ ee determined by HPLC analysis: Chiralpak OD column, 97:3 hexanes: ${ }^{i} \mathrm{PrOH}$, flow rate $=1.0 \mathrm{~mL} / \mathrm{min}, \lambda=220 \mathrm{~nm}$, retention time: $\mathrm{t}_{\text {major }}=10.8 \mathrm{~min}, \mathrm{t}_{\text {minor }}=12.5 \mathrm{~min} . \quad[\alpha]_{\mathrm{D}}^{27}=-28.7\left(\mathrm{c}=1.275, \mathrm{CHCl}_{3}\right) . \quad{ }^{1} \mathrm{H} \mathrm{NMR}(300$ $\left.\mathrm{MHz}, \mathrm{CDCl}_{3}\right) \delta 6.02(\mathrm{~m}, 1 \mathrm{H}), 5.37(\mathrm{~m}, 2 \mathrm{H}), 4.51(\mathrm{~m}, 1 \mathrm{H}), 2.41(\mathrm{~m}, 4 \mathrm{H}), 2.20(\mathrm{~m}, 2 \mathrm{H})$, $2.04(\mathrm{~m}, 3 \mathrm{H}), 1.88(\mathrm{~m}, 2 \mathrm{H}), 1.76(\mathrm{~m}, 2 \mathrm{H}), 0.95(\mathrm{t}, 3 \mathrm{H}, \mathrm{J}=7.5 \mathrm{~Hz}) .{ }^{13} \mathrm{C}$ NMR $(75$ $\left.\mathrm{MHz}, \mathrm{CDCl}_{3}\right) \delta 138.4,133.0,128.0,124.2,91.3,82.6,62.8,37.9,36.6,33.4,23.5$, 23.2, 20.8, 14.6. HRMS [EI(TOF)] for $\mathrm{C}_{14} \mathrm{H}_{20} \mathrm{O}(\mathrm{M}+)$ Cacld: 204.1514, Found: 204.1512.

(R,Z)-1-(cyclopent-1-en-1-yl)dodec-6-en-1-yn-3-ol, $(R)-1 \mathrm{~d}$.

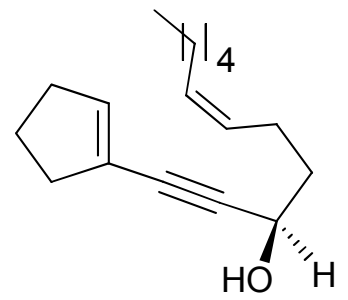

$(R)-1 \mathbf{d}$

$57 \%, 92 \%$ ee

Colorless oil, $35.2 \mathrm{mg}$, 57\% yield. $\quad$ 92\% ee determined by HPLC analysis: Chiralpak OD column, 97:3 hexanes: ${ }^{i} \mathrm{PrOH}$, flow rate $=1.0 \mathrm{~mL} / \mathrm{min}, \lambda=225 \mathrm{~nm}$, retention time: 
$\mathrm{t}_{\text {major }}=10.7 \mathrm{~min}, \mathrm{t}_{\text {minor }}=12.8 \mathrm{~min} . \quad[\alpha]^{27}{ }_{\mathrm{D}}=-25.4\left(\mathrm{c}=1.760, \mathrm{CHCl}_{3}\right) . \quad{ }^{1} \mathrm{H} \mathrm{NMR}(300$ $\left.\mathrm{MHz}, \mathrm{CDCl}_{3}\right) \delta 6.03(\mathrm{~s}, 1 \mathrm{H}), 5.39(\mathrm{~m}, 2 \mathrm{H}), 4.51(\mathrm{~m}, 1 \mathrm{H}), 2.42(\mathrm{~m}, 4 \mathrm{H}), 2.21(\mathrm{~m}, 2 \mathrm{H})$, $2.06(\mathrm{~m}, 2 \mathrm{H}), 1.89(\mathrm{~m}, 3 \mathrm{H}), 1.78(\mathrm{~m}, 2 \mathrm{H}), 1.29(\mathrm{~m}, 6 \mathrm{H}), 0.88(\mathrm{t}, 3 \mathrm{H}, \mathrm{J}=5.7 \mathrm{~Hz}) .{ }^{13} \mathrm{C}$ NMR $\left(75 \mathrm{MHz}, \mathrm{CDCl}_{3}\right) \delta 138.4,131.5,128.5,124.1,91.3,82.6,62.9,38.0,36.6$, 33.4, 31.8, 29.6, 27.4, 23.5, 23.3, 22.8, 14.3. HRMS [EI(TOF)] for $\mathrm{C}_{17} \mathrm{H}_{26} \mathrm{O}(\mathrm{M}+)$ Cacld: 246.1984, Found: 246.1980.

(R)-1-(cyclohex-1-en-1-yl)hept-6-en-1-yn-3-ol, $(R)-1$ e.

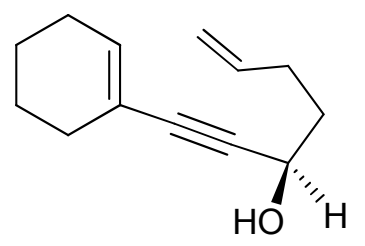

$(R)-1 \mathrm{e}$

$89 \%, 90 \%$ ee

Colorless oil, $42.4 \mathrm{mg}$, 89\% yield. $\quad 90 \%$ ee determined by HPLC analysis: Chiralpak OD column, 95:5 hexanes: ${ }^{i} \mathrm{PrOH}$, flow rate $=1.0 \mathrm{~mL} / \mathrm{min}, \lambda=225 \mathrm{~nm}$, retention time: $\mathrm{t}_{\text {major }}=8.5 \mathrm{~min}, \mathrm{t}_{\text {minor }}=9.8 \mathrm{~min} . \quad[\alpha]^{24}=-14.6\left(\mathrm{c}=2.120, \mathrm{CHCl}_{3}\right) .{ }^{1} \mathrm{H}$ NMR $(300$ $\left.\mathrm{MHz}, \mathrm{CDCl}_{3}\right) \delta 6.09(\mathrm{~m}, 1 \mathrm{H}), 5.83(\mathrm{~m}, 1 \mathrm{H}), 5.08(\mathrm{dd}, 1 \mathrm{H}, \mathrm{J}=18.9,1.8 \mathrm{~Hz}), 4.98(\mathrm{dd}$, 1H, J=10.2, $1.8 \mathrm{~Hz}), 4.49(\mathrm{t}, 1 \mathrm{H}, \mathrm{J}=6.6 \mathrm{~Hz}), 2.22(\mathrm{~m}, 2 \mathrm{H}), 2.08(\mathrm{~m}, 4 \mathrm{H}), 2.00(\mathrm{~s}, 1 \mathrm{H})$, $1.80(\mathrm{~m}, 2 \mathrm{H}), 1.59(\mathrm{~m}, 4 \mathrm{H}) .{ }^{13} \mathrm{C} \mathrm{NMR}\left(75 \mathrm{MHz}, \mathrm{CDCl}_{3}\right) \delta 138.0,135.5,120.3$ 115.4, 87.4, 87.2, 62.6, 37.2, 29.7, 29.4, 25.8, 22.5, 21.7. HRMS [EI(TOF)] for $\mathrm{C}_{13} \mathrm{H}_{18} \mathrm{O}(\mathrm{M}+)$ Cacld: 190.1358 , Found: 190.1360 . 


\section{c. General procedure for the preparation of the chiral propargylic alcohol-based triene-ynes}

To a solution of $\mathrm{NaH} 60 \% \mathrm{w} / \mathrm{w}$ (3 equiv) in THF was added a chiral propargylic alcohol ( 1 equiv) in THF at $0{ }^{\circ} \mathrm{C}$ under nitrogen and stirred for $30 \mathrm{~min}$. Then allyl bromide ( 8 equiv) was added and the mixture was warmed to $50{ }^{\circ} \mathrm{C}$ overnight. The reaction was quenched with saturated aqueous ammonium chloride solution at room temperature and extracted with $\mathrm{CH}_{2} \mathrm{Cl}_{2}$ three times. The organic layer was washed with brine, dried with $\mathrm{Na}_{2} \mathrm{SO}_{4}$, concentrated by rotary evaporation and purified by flash column chromatography on silica gel eluted with hexanes/ethyl acetate to give the product in $69-92 \%$ yield.

\section{Characterization of the optical active triene-ynes}

(R)-1-(3-(allyloxy)hept-6-en-1-yn-1-yl)cyclopent-1-ene, $(R)-2 a$.

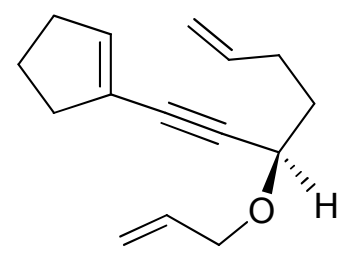

$(R)-2 \mathrm{a}, 92 \%$

Prepared from $(R)-1 \boldsymbol{a}(21.3 \mathrm{mg}, 0.12 \mathrm{mmol})$, Colorless oil, $24 \mathrm{mg}, 92 \%$ yield. ${ }^{1} \mathrm{H}$ NMR (300 MHz, $\left.\mathrm{CDCl}_{3}\right) \delta 6.03(\mathrm{t}, 1 \mathrm{H}, \mathrm{J}=1.8 \mathrm{~Hz}), 5.86(\mathrm{~m}, 2 \mathrm{H}), 5.30(\mathrm{dd}, 1 \mathrm{H}, \mathrm{J}=17.4$, $1.5 \mathrm{~Hz}), 5.18(\mathrm{~d}, 1 \mathrm{H}, \mathrm{J}=9.3 \mathrm{~Hz}), 5.04(\mathrm{dd}, 1 \mathrm{H}, \mathrm{J}=17.1,1.5 \mathrm{~Hz}), 4.96(\mathrm{~d}, 1 \mathrm{H}, \mathrm{J}=11.1$ Hz), 4.25 (m, 2H), $3.95(\mathrm{dd}, 1 \mathrm{H}, \mathrm{J}=12.6,6.3 \mathrm{~Hz}), 2.42(\mathrm{~m}, 4 \mathrm{H}), 2.23(\mathrm{~m}, 2 \mathrm{H}), 1.86(\mathrm{~m}$,

4H). ${ }^{13} \mathrm{C} \mathrm{NMR}\left(75 \mathrm{MHz}, \mathrm{CDCl}_{3}\right) \delta 138.2,138.0,134.8,124.3,117.4,115.2,89.3$, 83.5, 69.8, 68.9, 36.7, 35.2, 33.4, 29.8, 23.5. HRMS [ESI(TOF)] for $\mathrm{C}_{15} \mathrm{H}_{19} \mathrm{O}(\mathrm{MH}+)$ 
(R)-1-(3-(allyloxy)-4,4-dimethylhept-6-en-1-yn-1-yl)cyclopent-1-ene, $(R)-2 b$.

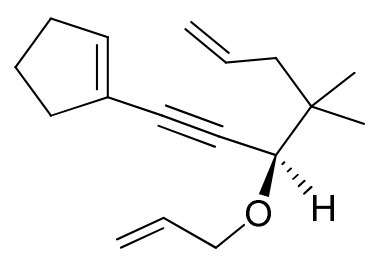

$(R)-\mathbf{2 b}, 69 \%$

Prepared from $(R)-1 \boldsymbol{b}(27 \mathrm{mg}, 0.13 \mathrm{mmol})$, Colorless oil, $21.5 \mathrm{mg}, 69 \%$ yield. ${ }^{1} \mathrm{H}$ $\operatorname{NMR}\left(300 \mathrm{MHz}, \mathrm{CDCl}_{3}\right) \delta 6.03(\mathrm{~m}, 1 \mathrm{H}), 5.86(\mathrm{~m}, 2 \mathrm{H}), 5.30(\mathrm{~m}, 1 \mathrm{H}), 5.17(\mathrm{~m}, 1 \mathrm{H})$, $5.04(\mathrm{~m}, 2 \mathrm{H}), 4.30(\mathrm{ddt}, 1 \mathrm{H}, \mathrm{J}=12.9,4.8,1.8 \mathrm{~Hz}), 3.93(\mathrm{~m}, 1 \mathrm{H}), 3.87(\mathrm{~s}, 1 \mathrm{H}), 2.45(\mathrm{~m}$, 4H), $2.16(\mathrm{~m}, 2 \mathrm{H}), 1.90(\mathrm{~m}, 2 \mathrm{H}), 0.99(\mathrm{~s}, 3 \mathrm{H}), 0,97(\mathrm{~s}, 3 \mathrm{H}) .{ }^{13} \mathrm{C}$ NMR $(75 \mathrm{MHz}$ $\left.\mathrm{CDCl}_{3}\right) \delta 137.8,135.3,135.0,124.5,117.6,117.0,88.3,84.3,77.2,70.3,43.4,38.7$ 36.7, 33.4, 29.9, 23.5, 23.2. GCMS (EI) for $\mathrm{C}_{15} \mathrm{H}_{19} \mathrm{O}(\mathrm{M}+)$ Found: 244.

$(R, Z)-1-(3-($ allyloxy)non-6-en-1-yn-1-yl)cyclopent-1-ene, $(R)-2 \mathrm{c}$.

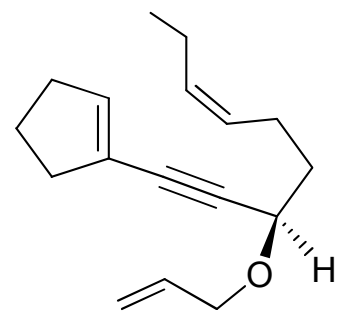

(R)-2c, $69 \%$

Prepared from (R)-1c (26 mg, $0.13 \mathrm{mmol}$ ), Colorless oil, $24.4 \mathrm{mg}, 80 \%$ yield. ${ }^{1} \mathrm{H}$ NMR (300 MHz, $\left.\mathrm{CDCl}_{3}\right) \delta 6.03(\mathrm{~m}, 1 \mathrm{H}), 5.92(\mathrm{~m}, 1 \mathrm{H}), 5.36(\mathrm{~m}, 3 \mathrm{H}), 5.16(\mathrm{~m}, 1 \mathrm{H})$, $4.23(\mathrm{~m}, 2 \mathrm{H}), 3.97$ (ddt, 1H, J=12.6, 6.3, $1.2 \mathrm{~Hz}), 2.42(\mathrm{~m}, 4 \mathrm{H}), 2.20(\mathrm{~m}, 2 \mathrm{H}), 2.06(\mathrm{~m}$, 2H), $1.89(\mathrm{~m}, 2 \mathrm{H}), 1.79(\mathrm{~m}, 2 \mathrm{H}), 0.95(\mathrm{t}, 3 \mathrm{H}, \mathrm{J}=7.5 \mathrm{~Hz}) .{ }^{13} \mathrm{C} \mathrm{NMR}\left(75 \mathrm{MHz}, \mathrm{CDCl}_{3}\right)$ $\delta 138.1,134.8,132.8,128.1,124.3,117.4,89.5,83.4,69.8,69.0,36.6,36.0,33.4$, 
23.5, 23.3, 20.7, 14.6. HRMS [EI(TOF)] for $\mathrm{C}_{17} \mathrm{H}_{24} \mathrm{O}(\mathrm{M}+)$ Cacld: 244.1827, Found: 244.1818.

$(R, Z)-1-(3-($ allyloxy)dodec-6-en-1-yn-1-yl)cyclopent-1-ene, $(R)-2 \mathrm{~d}$.

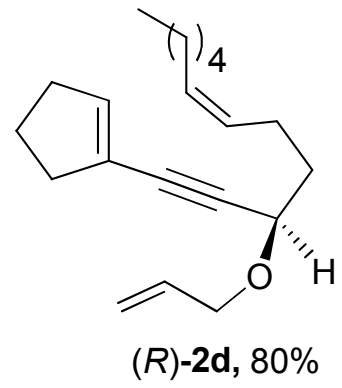

Prepared from (R)-1d (35.2 mg, $0.14 \mathrm{mmol})$, Colorless oil, $27.8 \mathrm{mg}, 69 \%$ yield. ${ }^{1} \mathrm{H}$ NMR (300 MHz, $\left.\mathrm{CDCl}_{3}\right) \delta 6.03(\mathrm{~m}, 1 \mathrm{H}), 5.92(\mathrm{~m}, 1 \mathrm{H}), 5.36(\mathrm{~m}, 3 \mathrm{H}), 5.18(\mathrm{~m}, 1 \mathrm{H})$, $4.23(\mathrm{~m}, 2 \mathrm{H}), 3.97$ (ddt, 1H, J=12.6, 6.3, $1.2 \mathrm{~Hz}), 2.43(\mathrm{~m}, 4 \mathrm{H}), 2.21(\mathrm{~m}, 2 \mathrm{H}), 2.03(\mathrm{~m}$, 2H), $1.90(\mathrm{~m}, 2 \mathrm{H}), 1.79(\mathrm{~m}, 2 \mathrm{H}), 1.29(\mathrm{~m}, 8 \mathrm{H}), 0.88(\mathrm{t}, 3 \mathrm{H}, \mathrm{J}=6 \mathrm{~Hz}) .{ }^{13} \mathrm{C}$ NMR $(75$ $\left.\mathrm{MHz}, \mathrm{CDCl}_{3}\right) \delta 138.1,134.8,131.2,128.6,124.3,117.3,89.5,83.4,69.8,69.1,36.7$ 36.0, 33.4, 31.8, 29.6, 27.4, 23.5, 23.4, 22.8, 14.6. HRMS [ESI(TOF)] for $\mathrm{C}_{20} \mathrm{H}_{30} \mathrm{ONa}(\mathrm{MNa}+)$ Cacld: 309.2194, Found: 309.2191.

(R)-1-(3-(allyloxy)hept-6-en-1-yn-1-yl)cyclohex-1-ene, $(R)-2 \mathrm{e}$.

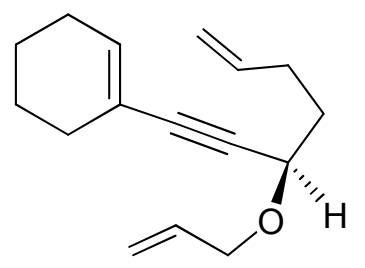

$(R)-2 e, 88 \%$

Prepared from (R)-1e (42.4 mg, $0.22 \mathrm{mmol})$, Colorless oil, $45.1 \mathrm{mg}, 88 \%$ yield. ${ }^{1} \mathrm{H}$ NMR (300 MHz, $\left.\mathrm{CDCl}_{3}\right) \delta 6.09(\mathrm{~m}, 1 \mathrm{H}), 5.93(\mathrm{~m}, 1 \mathrm{H}), 5.79(\mathrm{~m}, 1 \mathrm{H}), 5.30(\mathrm{~m}, 1 \mathrm{H})$, 
$5.17(\mathrm{~m}, 1 \mathrm{H}), 5.04(\mathrm{~m}, 1 \mathrm{H}), 4.97(\mathrm{~m}, 1 \mathrm{H}), 4.22(\mathrm{~m}, 2 \mathrm{H}), 3.97$ (ddt, 1H, J=12.6, 6.3, $1.2 \mathrm{~Hz}), 2.22(\mathrm{~m}, 2 \mathrm{H}), 2.09(\mathrm{~m}, 4 \mathrm{H}), 1.84(\mathrm{~m}, 2 \mathrm{H}), 1.60(\mathrm{~m}, 4 \mathrm{H}) .{ }^{13} \mathrm{C}$ NMR $(75$ $\left.\mathrm{MHz}, \mathrm{CDCl}_{3}\right) \delta 138.1,135.1,134.9,120.4,117.4,115.2,88.0,85.4,69.7,68.9,35.2$, 29.8, 29.5, 25.8, 22.5, 21.7. HRMS [CI(TOF)] for $\mathrm{C}_{16} \mathrm{H}_{21} \mathrm{O}$ (MH-) Cacld: 229.1592, Found: 229.1592.

\section{Characterization of the racemic triene-ynes $2 \mathrm{f}-\mathrm{h}$}

1-(3-(allyloxy)-4,4-dimethylhept-6-en-1-yn-1-yl)cyclohex-1-ene, 2 f.

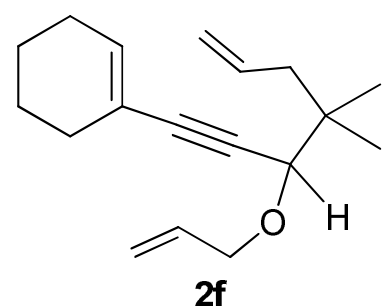

Prepared from 1f $(173.2 \mathrm{mg}, 0.79 \mathrm{mmol})$ Colorless oil, $187 \mathrm{mg}, 91 \%$ yield. ${ }^{1} \mathrm{H}$ NMR (300 MHz, $\left.\mathrm{CDCl}_{3}\right) \delta 6.10(\mathrm{~m}, 1 \mathrm{H}), 5.87(\mathrm{~m}, 2 \mathrm{H}), 5.30(\mathrm{~m}, 1 \mathrm{H}), 5.17(\mathrm{~m}, 1 \mathrm{H})$, $5.03(\mathrm{~m}, 2 \mathrm{H}), 4.29(\mathrm{ddt}, 1 \mathrm{H}, \mathrm{J}=12.9,4.8,1.5 \mathrm{~Hz}), 3.90(\mathrm{~m}, 1 \mathrm{H}), 3.85(\mathrm{~s}, 1 \mathrm{H}), 2.13(\mathrm{~m}$, $6 \mathrm{H}), 1.60(\mathrm{~m}, 4 \mathrm{H}), 0.98(\mathrm{~s}, 3 \mathrm{H}), 0.96(\mathrm{~s}, 3 \mathrm{H}) .{ }^{13} \mathrm{C} \mathrm{NMR}\left(75 \mathrm{MHz}, \mathrm{CDCl}_{3}\right) \delta$ 135.3, $135.1,134.7,120.7,117.5,116.9,88.8,84.4,77.1,70.2,43.4,38.7,29.9,29.6,25.8$, 23.5, 23.2, 22.5, 21.7. HRMS [ESI(TOF)] for $\mathrm{C}_{18} \mathrm{H}_{27} \mathrm{O}(\mathrm{MH}+)$ Cacld: 259.2062, Found: 259.2066.

(Z)-1-(3-(allyloxy)non-6-en-1-yn-1-yl)cyclohex-1-ene, 2g.

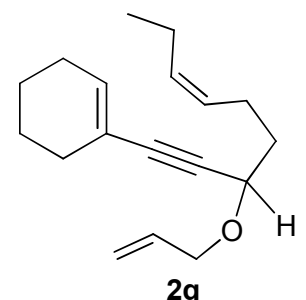

Prepared from $1 \mathrm{~g}$ (167.8 mg, $0.77 \mathrm{mmol})$, Colorless oil, $181.5 \mathrm{mg}, 91 \%$ yield. ${ }^{1} \mathrm{H}$ 
NMR (300 MHz, $\left.\mathrm{CDCl}_{3}\right) \delta 6.09(\mathrm{~m}, 1 \mathrm{H}), 5.91(\mathrm{~m}, 1 \mathrm{H}), 5.35(\mathrm{~m}, 2 \mathrm{H}), 5.29(\mathrm{~m}, 1 \mathrm{H})$, $5.17(\mathrm{~m}, 1 \mathrm{H}), 4.27$ (ddt, 1H, J=12.6, 5.1, $1.5 \mathrm{~Hz}), 4.18(\mathrm{t}, 1 \mathrm{H}, \mathrm{J}=6.6 \mathrm{~Hz}), 3.96(\mathrm{ddt}, 1 \mathrm{H}$, $\mathrm{J}=12.6,6.3,1.5 \mathrm{~Hz}), 2.21(\mathrm{q}, 2 \mathrm{H}, \mathrm{J}=7.2 \mathrm{~Hz}), 2.08(\mathrm{~m}, 6 \mathrm{H}), 1.78(\mathrm{~m}, 2 \mathrm{H}), 1,61(\mathrm{~m}, 4 \mathrm{H})$, $0.95(\mathrm{t}, 3 \mathrm{H}, \mathrm{J}=7.5 \mathrm{~Hz}) .{ }^{13} \mathrm{C} \mathrm{NMR}\left(75 \mathrm{MHz}, \mathrm{CDCl}_{3}\right) \delta 135.1,134.9,132.8,128.1$, $120.5,117.3,87.9,85.6,69.8,69.0,36.1,29.5,25.8,23.3,22.5,21.7,20.7,14.6$. HRMS [ESI(TOF)] for $\mathrm{C}_{18} \mathrm{H}_{27} \mathrm{O}(\mathrm{MH}+)$ Cacld: 259.2062, Found: 259.2061.

\section{(Z)-1-(3-(allyloxy)dodec-6-en-1-yn-1-yl)cyclohex-1-ene, $2 \mathrm{~h}$.}

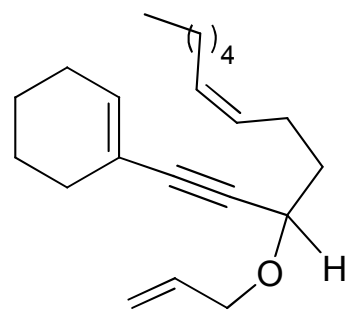

$2 h$

Prepared from $1 \mathbf{h}$ (205 mg, $0.79 \mathrm{mmol})$, Light yellow oil, $157.8 \mathrm{mg}, 67 \%$ yield. ${ }^{1} \mathrm{H}$ NMR (300 MHz, $\left.\mathrm{CDCl}_{3}\right) \delta 6.10(\mathrm{~m}, 1 \mathrm{H}), 5.92(\mathrm{~m}, 1 \mathrm{H}), 5.38(\mathrm{~m}, 2 \mathrm{H}), 5.30(\mathrm{~m}, 1 \mathrm{H})$, $5.17(\mathrm{~m}, 1 \mathrm{H}), 4.27(\mathrm{ddt}, 1 \mathrm{H}, \mathrm{J}=12.6,5.1,1.5 \mathrm{~Hz}), 4.18(\mathrm{t}, 1 \mathrm{H}, \mathrm{J}=6.6 \mathrm{~Hz}), 3.96(\mathrm{ddt}, 1 \mathrm{H}$, $\mathrm{J}=12.3,6,1.2 \mathrm{~Hz}), 2.21(\mathrm{q}, 2 \mathrm{H}, \mathrm{J}=6.9 \mathrm{~Hz}), 2.10(\mathrm{~m}, 6 \mathrm{H}), 1.78(\mathrm{~m}, 2 \mathrm{H}), 1,59(\mathrm{~m}, 4 \mathrm{H})$, $1.29(\mathrm{~m}, 6 \mathrm{H}), 0.88(\mathrm{t}, 3 \mathrm{H}, \mathrm{J}=6 \mathrm{~Hz}) .{ }^{13} \mathrm{C} \mathrm{NMR}\left(75 \mathrm{MHz}, \mathrm{CDCl}_{3}\right) \delta 135.2,134.9$, $131.2,128.7,120.5,117.3,88.0,85.6,69.7,69.0,36.1,31.8,29.7,29.5,27.4,25.8$, 23.4, 22.8, 22.5, 21.7, 20.7, 14.3. HRMS [ESI(TOF)] for $\mathrm{C}_{21} \mathrm{H}_{33} \mathrm{O}(\mathrm{MH}+)$ Cacld: 301.2531, Found: 301.2532. 


\section{d. General procedure for the domino PK/DA cycloaddition}

Under nitrogen, a triene-yne (1 equiv) and $\left[\mathrm{Rh}(\mathrm{CO})_{2} \mathrm{Cl}\right]_{2}(0.1$ equiv) were weighed into a tared two-necked round bottom flask and dissolved in DCE (3 mL). The flask was fitted with a reflux condenser fitted with a septum and the side arm of the flask was also fitted with a septum. The solution was bubbled with $\mathrm{CO}$ gas for 2 minutes through the side arm fitted with septum and a vent needle in the septum of the reflux condenser. Then, the solution was placed under $\mathrm{CO}$ atmosphere by using a balloon. After the reaction mixture was heated at $70^{\circ} \mathrm{C}$ to reflux temperature for $21-37$ $\mathrm{h}$, it was cooled to room temperature and the $\mathrm{CO}$ was released cautiously in the hood. The reaction mixture was concentrated and the crude product was purified by column chromatography on silica gel eluted with hexanes/ethyl acetate to give the product in $45-71 \%$ yield and $71-94 \%$ ee.

\section{Characterizations of the domino PK/DA cycloaddition products 3a-e}

3a.

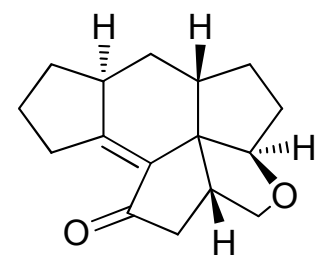

3a $60 \%$ yield $94 \%$ ee

Prepared from (R)-2a (24 mg, $0.11 \mathrm{mmol}$ ), Colorless oil, $16.3 \mathrm{mg}, 60 \%$ yield. $\quad 94 \%$ ee determined by HPLC analysis: Chiralpak AD-H column, 98:2 hexanes: ${ }^{i} \mathrm{PrOH}$, flow rate $=1.0 \mathrm{~mL} / \mathrm{min}, \lambda=254 \mathrm{~nm}$, retention time: $\mathrm{t}_{\text {major }}=22.8 \mathrm{~min}, \mathrm{t}_{\text {minor }}=14.6 \mathrm{~min}$. 
$[\alpha]^{23}=-103.6\left(\mathrm{c}=0.815, \mathrm{CHCl}_{3}\right) . \quad{ }^{1} \mathrm{H} \mathrm{NMR}\left(600 \mathrm{MHz}, \mathrm{CDCl}_{3}\right) \delta 4.15(\mathrm{~m}, 1 \mathrm{H})$, 4.09 (dd, 1H, J=9, $4.2 \mathrm{~Hz}), 3.84$ (d, 1H, J=9 Hz), 2.82 (dd, 1H, J=19.2, 8.4 Hz), 2.64 (m, 1H), $2.52(\mathrm{~m}, 1 \mathrm{H}), 2.28(\mathrm{~m}, 3 \mathrm{H}), 2,09(\mathrm{~m}, 2 \mathrm{H}), 1.91(\mathrm{dd}, 1 \mathrm{H}, \mathrm{J}=13.2,4.8 \mathrm{~Hz})$ $1.82(\mathrm{~m}, 1 \mathrm{H}), 1.75(\mathrm{~m}, 1 \mathrm{H}), 1.71-1.54(\mathrm{~m}, 3 \mathrm{H}), 1.07(\mathrm{~m}, 2 \mathrm{H}) .{ }^{13} \mathrm{C} \mathrm{NMR}(150 \mathrm{MHz}$ $\left.\mathrm{CDCl}_{3}\right) \delta 205.0,160.6,132.4,91.2,73.0,62.9,47.5,43.1,42.4,39.8,35.7,32.8,32.6$, 32.0, 31.6, 24.9. HRMS [ESI(TOF)] for $\mathrm{C}_{16} \mathrm{H}_{21} \mathrm{O}_{2}(\mathrm{MH}+)$ Cacld: 245.1542, Found: 245.1544 .

$3 b$.

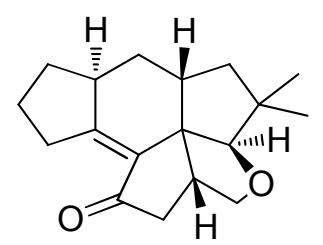

$3 \mathbf{b}$

$54 \%$ yield

$91 \%$ ee

Prepared from (R)- $2 \boldsymbol{b}(21.5 \mathrm{mg}, 0.09 \mathrm{mmol})$, Light yellow oil, $13 \mathrm{mg}, 54 \%$ yield. 91\% ee determined by HPLC analysis: Chiralpak AD-H column, 95:5 hexanes: ${ }^{i} \mathrm{PrOH}$, flow rate $=1.0 \mathrm{~mL} / \mathrm{min}, \lambda=254 \mathrm{~nm}$, retention time: $\mathrm{t}_{\text {major }}=7.1 \mathrm{~min}, \mathrm{t}_{\mathrm{minor}}=6.4 \mathrm{~min}$. $[\alpha]^{26}=-79.7\left(\mathrm{c}=0.650, \mathrm{CHCl}_{3}\right) .{ }^{1} \mathrm{H} \mathrm{NMR}\left(600 \mathrm{MHz}, \mathrm{CDCl}_{3}\right) \delta 4.05(\mathrm{~m}, 1 \mathrm{H}), 3.87$ $(\mathrm{d}, 1 \mathrm{H}, \mathrm{J}=9 \mathrm{~Hz}), 3.76(\mathrm{~s}, 1 \mathrm{H}), 2.83(\mathrm{dd}, 1 \mathrm{H}, \mathrm{J}=19.2,8.4 \mathrm{~Hz}), 2.61(\mathrm{~m}, 1 \mathrm{H}), 2.46(\mathrm{~m}$, 3H), $2.26(\mathrm{~m}, 1 \mathrm{H}), 2.11(\mathrm{~m}, 1 \mathrm{H}), 1.91(\mathrm{~m}, 2 \mathrm{H}), 1.84(\mathrm{~m}, 1 \mathrm{H}), 1.63(\mathrm{~m}, 1 \mathrm{H}), 1,58(\mathrm{~m}$, 1H), $1.51(\mathrm{~m}, 1 \mathrm{H}), 1.25(\mathrm{~m}, 1 \mathrm{H}), 1.06(\mathrm{~s}, 3 \mathrm{H}), 0.93(\mathrm{~s}, 3 \mathrm{H}) .{ }^{13} \mathrm{C}$ NMR $(150 \mathrm{MHz}$ $\left.\mathrm{CDCl}_{3}\right) \delta 204.8,158.7,134.2,96.2,72.6,64.0,47.6,45.9,43.0,40.9,40.2,38.3,32.9$, 32.7, 31.7, 29.1, 24.8, 24.5. HRMS [ESI(TOF)] for $\mathrm{C}_{18} \mathrm{H}_{25} \mathrm{O}_{2}(\mathrm{MH}+)$ Cacld: 273.1855, Found: 273.1850. 
3c.

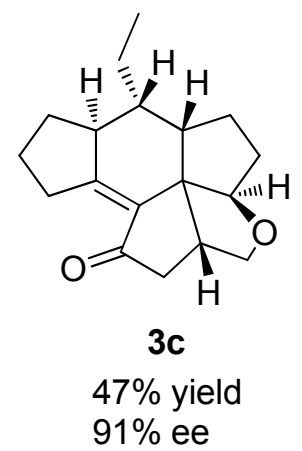

Prepared from $(R)-2 c(24.4 \mathrm{mg}, 0.10 \mathrm{mmol})$, Light yellow oil, $12.7 \mathrm{mg}, 47 \%$ yield. 91\% ee determined by HPLC analysis: Chiralpak AD-H column, 98:2 hexanes: $\mathrm{MeOH}$, flow rate $=1.0 \mathrm{~mL} / \mathrm{min}, \lambda=254 \mathrm{~nm}$, retention time: $\mathrm{t}_{\text {major }}=9.9 \mathrm{~min}, \mathrm{t}_{\text {minor }}=$ 12.9 min. $[\alpha]^{24}=-84.2\left(\mathrm{c}=0.635, \mathrm{CHCl}_{3}\right) . \quad{ }^{1} \mathrm{H} \mathrm{NMR}\left(600 \mathrm{MHz}, \mathrm{CDCl}_{3}\right) \delta 4.21(\mathrm{t}$, 1H, J=5.4 Hz), $4.04(\mathrm{dd}, 1 \mathrm{H}, \mathrm{J}=4.5,3.6 \mathrm{~Hz}), 3.86(\mathrm{~d}, 1 \mathrm{H}, \mathrm{J}=9 \mathrm{~Hz}), 2.86(\mathrm{dd}, 1 \mathrm{H}$, $\mathrm{J}=20.4,9 \mathrm{~Hz}), 2.52(\mathrm{~m}, 3 \mathrm{H}), 2.30(\mathrm{~m}, 3 \mathrm{H}), 2.11(\mathrm{~m}, 2 \mathrm{H}), 1.88(\mathrm{~m}, 1 \mathrm{H}), 1.82(\mathrm{~m}, 2 \mathrm{H})$, $1.61(\mathrm{~m}, 3 \mathrm{H}), 1.48(\mathrm{~m}, 1 \mathrm{H}), 1,28(\mathrm{~m}, 1 \mathrm{H}), 1.01(\mathrm{~m}, 2 \mathrm{H}), 0.94(\mathrm{t}, 3 \mathrm{H}, \mathrm{J}=7.2 \mathrm{~Hz}) .{ }^{13} \mathrm{C}$ NMR (150 MHz, $\left.\mathrm{CDCl}_{3}\right) \delta 205.4,159.3,133.9,91.4,72.3,64.2,47.3,46.3,44.9$, 44.7, 43.5, 32.4, 32.3, 31.4, 25.3, 24.9, 24.5, 12.5. HRMS [ESI(TOF)] for $\mathrm{C}_{18} \mathrm{H}_{25} \mathrm{O}_{2}$ (MH+) Cacld: 273.1855, Found: 273.1855.

3d.

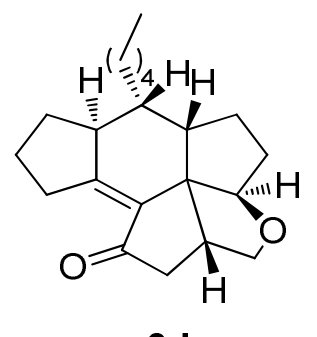

$3 d$

$45 \%$ yield $72 \%$ ee 
Prepared from $(R)-2 \boldsymbol{d}(27.8 \mathrm{mg}, 0.10 \mathrm{mmol})$, Colorless oil, $13.6 \mathrm{mg}, 45 \%$ yield, $\mathrm{dr}=$ 9:1. 72\% ee determined by HPLC analysis: Chiralpak AD-H column, 99:1 hexanes: $\mathrm{MeOH}$, flow rate $=1.0 \mathrm{~mL} / \mathrm{min}, \lambda=254 \mathrm{~nm}$, retention time: $\mathrm{t}_{\text {major }}=13.9 \mathrm{~min}, \mathrm{t}_{\text {minor }}=$ 9.0 min. $[\alpha]^{24}=-105.3\left(\mathrm{c}=0.530, \mathrm{CHCl}_{3}\right) .{ }^{1} \mathrm{H} \mathrm{NMR}\left(600 \mathrm{MHz}, \mathrm{CDCl}_{3}\right) \delta 4.20(\mathrm{t}$, 1H, J=10.2 Hz), 4.03 (m, 1H), 3.84 (d, 1H, J=18 Hz), 2.86 (dd, 1H, J=40.8, 17.4 Hz), $2.47(\mathrm{~m}, 3 \mathrm{H}), 2.26(\mathrm{~m}, 2 \mathrm{H}), 2.11(\mathrm{~m}, 2 \mathrm{H}), 1.83(\mathrm{~m}, 3 \mathrm{H}), 1.53(\mathrm{~m}, 5 \mathrm{H}), 1.28(\mathrm{~m}, 6 \mathrm{H})$ $1.05(\mathrm{~m}, 2 \mathrm{H}), 0.89(\mathrm{t}, 3 \mathrm{H}, \mathrm{J}=13.2 \mathrm{~Hz}) .{ }^{13} \mathrm{C} \mathrm{NMR}\left(150 \mathrm{MHz}, \mathrm{CDCl}_{3}\right) \delta$ 204.7, 158.6, 133.2, 90.7, 71.6, 63.5, 46.6, 44.5, 44.2, 43.7, 42.8, 32.0, 31.8, 31.7, 30.9, 30.6, 26.7, 24.5, 24.3, 22.5, 14.0. HRMS [ESI(TOF)] for $\mathrm{C}_{21} \mathrm{H}_{31} \mathrm{O}_{2}(\mathrm{MH}+)$ Cacld: 315.2297, Found: 315.2323.

$3 \mathbf{e}$

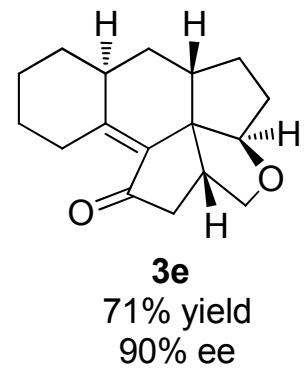

Prepared from $(R)-2 e(45.1 \mathrm{mg}, 0.20 \mathrm{mmol})$, Light yellow solid, $36 \mathrm{mg}, 71 \%$ yield. 90\% ee determined by HPLC analysis: Chiralpak AD-H column, 95:5 hexanes: ${ }^{i} \mathrm{PrOH}$, flow rate $=1.0 \mathrm{~mL} / \mathrm{min}, \lambda=254 \mathrm{~nm}$, retention time: $\mathrm{t}_{\text {major }}=13.7 \mathrm{~min}, \mathrm{t}_{\text {minor }}=11.1 \mathrm{~min}$. $[\alpha]^{25}=-81.4\left(\mathrm{c}=1.800, \mathrm{CHCl}_{3}\right) . \quad \mathrm{Mp}: 74-75^{\circ} \mathrm{C} .{ }^{1} \mathrm{H}$ NMR $\left(600 \mathrm{MHz}, \mathrm{CDCl}_{3}\right) \delta$ $4.21(\mathrm{~d}, 1 \mathrm{H}, \mathrm{J}=4.8 \mathrm{~Hz}), 3.97(\mathrm{dd}, 1 \mathrm{H}, \mathrm{J}=9,4.2 \mathrm{~Hz}), 3.82(\mathrm{~m}, 1 \mathrm{H}), 3.76(\mathrm{~d}, 1 \mathrm{H}, \mathrm{J}=9$ Hz), $2.66(\mathrm{dd}, 1 \mathrm{H}, \mathrm{J}=19.2,10.2 \mathrm{~Hz}), 2.46(\mathrm{~m}, 1 \mathrm{H}), 2.18(\mathrm{~m}, 3 \mathrm{H}), 2.01(\mathrm{~m}, 2 \mathrm{H}), 1.85$ $(\mathrm{m}, 2 \mathrm{H}), 1.74(\mathrm{~m}, 3 \mathrm{H}), 1.61(\mathrm{~m}, 1 \mathrm{H}), 1.50(\mathrm{~m}, 2 \mathrm{H}), 1.28(\mathrm{~m}, 3 \mathrm{H}) .{ }^{13} \mathrm{C}$ NMR $(150$ 
$\left.\mathrm{MHz}, \mathrm{CDCl}_{3}\right) \delta 206.7,154.0,132.6,90.0,72.3,62.6,45.7,44.7,40.4,37.6,35.2,34.4$, 32.8, 32.7, 28.8, 27.5, 25.8. HRMS [ESI(TOF)] for $\mathrm{C}_{17} \mathrm{H}_{23} \mathrm{O}_{2}(\mathrm{MH}+)$ Cacld: 259.1698, Found: 259.1699.

\section{Characterization of the PK cycloaddition products $3 f-h$}

3f.

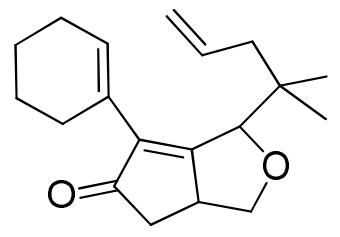

3f, $57 \%$ yield

Prepared from 2f (187 mg, $0.73 \mathrm{mmol})$, Light yellow solid, $117.4 \mathrm{mg}$, 57\% yield. Mp: 67-68 ${ }^{\circ} \mathrm{C} . \quad{ }^{1} \mathrm{H}$ NMR $\left(300 \mathrm{MHz}, \mathrm{CDCl}_{3}\right) \delta 5.79(\mathrm{~m}, 1 \mathrm{H}), 5.69(\mathrm{~s}, 1 \mathrm{H}), 5.06(\mathrm{~s}$, 1H), $5.01(\mathrm{~d}, 1 \mathrm{H}, \mathrm{J}=8.4 \mathrm{~Hz}), 4.54(\mathrm{~s}, 1 \mathrm{H}), 4.30(\mathrm{t}, 1 \mathrm{H}, \mathrm{J}=6.9 \mathrm{~Hz}), 3.14(\mathrm{~m}, 2 \mathrm{H}), 2.61$ (dd, 1H, J=18, $6 \mathrm{~Hz}), 2.40(\mathrm{~d}, 1 \mathrm{H}, \mathrm{J}=16.8 \mathrm{~Hz}), 2.05(\mathrm{~m}, 5 \mathrm{H}), 1.61(\mathrm{~m}, 4 \mathrm{H}), 1.23(\mathrm{~s}$, 1H), $0.89(\mathrm{~s}, 3 \mathrm{H}), 0.87(\mathrm{~s}, 3 \mathrm{H}) .{ }^{13} \mathrm{C} \mathrm{NMR}\left(75 \mathrm{MHz}, \mathrm{CDCl}_{3}\right) \delta 208.3,176.8,140.5$, $134.7,130.1,128.6,118.0,82.8,71.7,43.6,43.5,39.5,29.9,27.4,25.4,23.5,23.4$, 22.6, 22.0. HRMS [ESI(TOF)] for $\mathrm{C}_{19} \mathrm{H}_{27} \mathrm{O}_{2}(\mathrm{MH}+)$ Cacld: 287.2011, Found: 287.2006.

$3 g$.

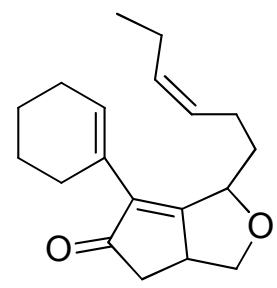

$3 g, 44 \%$ yield 
Prepared from $2 \mathrm{~g}$ (90.8 mg, $0.35 \mathrm{mmol})$, Colorless oil, $44 \mathrm{mg}, 44 \%$ yield. $\quad{ }^{1} \mathrm{H}$ NMR $\left(300 \mathrm{MHz}, \mathrm{CDCl}_{3}\right) \delta 6.17(\mathrm{~m}, 1 \mathrm{H}), 5.37(\mathrm{~m}, 2 \mathrm{H}), 4.74(\mathrm{~m}, 1 \mathrm{H}), 4.31(\mathrm{~m}, 1 \mathrm{H}), 3.19(\mathrm{~m}$, 2H), $2.65(\mathrm{dd}, 1 \mathrm{H}, \mathrm{J}=17.7,6 \mathrm{~Hz}), 2.28-2.00(\mathrm{~m}, 9 \mathrm{H}), 1.82-1.57(\mathrm{~m}, 6 \mathrm{H}), 0.95(\mathrm{t}, 3 \mathrm{H}$, $\mathrm{J}=7.5 \mathrm{~Hz}) .{ }^{13} \mathrm{C} \mathrm{NMR}\left(75 \mathrm{MHz}, \mathrm{CDCl}_{3}\right) \delta 208.3,176.7,137.1,133.2,130.4,129.2$, $127.9,76.1,71.7,42.4,40.0,35.9,29.9,27.8,25.7,23.4,22.8,22.0,20.8,14.5$. HRMS [ESI(TOF)] for $\mathrm{C}_{19} \mathrm{H}_{27} \mathrm{O}_{2}(\mathrm{MH}+)$ Cacld: 287.2011, Found: 287.2007.

$3 \mathbf{h}$.

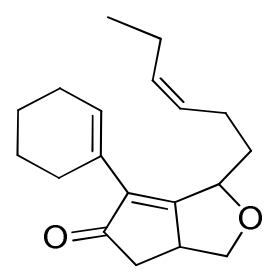

$3 \mathrm{~h}, 64 \%$ yield

Prepared from $2 \mathbf{h}(78.9 \mathrm{mg}, 0.30 \mathrm{mmol})$, Colorless oil, $55 \mathrm{mg}, 64 \%$ yield. ${ }^{1} \mathrm{H}$ NMR $\left(300 \mathrm{MHz}, \mathrm{CDCl}_{3}\right) \delta 6.18(\mathrm{~m}, 1 \mathrm{H}), 5.39(\mathrm{~m}, 2 \mathrm{H}), 4.74(\mathrm{~m}, 1 \mathrm{H}), 4.31(\mathrm{~m}, 1 \mathrm{H}), 3.19(\mathrm{~m}$, 2H), 2.65 (dd, 1H, J=17.7, $6 \mathrm{~Hz}), 2.27-2.09$ (m, 6H), 2.01 (m, 2H), 1.80-1.59 (m, 6H), 1.34-1.24 (m, 7H), $0.87(\mathrm{t}, 1 \mathrm{H}, \mathrm{J}=6.6 \mathrm{~Hz}) .{ }^{13} \mathrm{C} \mathrm{NMR}\left(75 \mathrm{MHz}, \mathrm{CDCl}_{3}\right) \delta 208.3$, $176.7,137.1,131.6,130.4,129.2,128.4,76.1,71.7,42.4,40.0,35.9, \quad 31.7,29.9$, 29.6, 27.8, 27.4, 25.7, 23.5, 22.8, 22.0, 14.3. HRMS [ESI(TOF)] for $\mathrm{C}_{22} \mathrm{H}_{33} \mathrm{O}_{2}$ $(\mathrm{MH}+)$ Cacld: 329.2481, Found: 329.2480 .

\section{Further conversions and explorations}

a. Ring-opening reaction

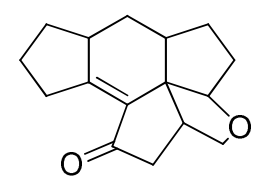

2.59

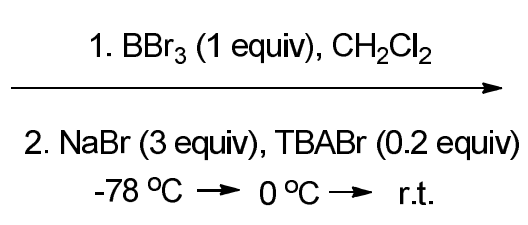

$-78^{\circ} \mathrm{C} \rightarrow 0^{\circ} \mathrm{C} \rightarrow$ r.t.

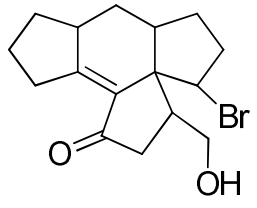

$2.7126 \%$ 


\section{Ring-opening product, 2.71}

To a solution of 2.59 (43.7 $\mathrm{mg}, 0.179 \mathrm{mmol}, 1$ equiv) in $\mathrm{CH}_{2} \mathrm{Cl}_{2}(10 \mathrm{~mL})$ was added $\mathrm{BBr}_{3}\left(17 \mathrm{uL}, 1\right.$ equiv) in $\mathrm{CH}_{2} \mathrm{Cl}_{2}(5 \mathrm{~mL})$ dropwise at $-78^{\circ} \mathrm{C}$ under nitrogen. The mixture was kept at $-78^{\circ} \mathrm{C}$ for $2 \mathrm{~h}$ and warm to $0{ }^{\circ} \mathrm{C}$ overnight. Then $\mathrm{NaBr}(55.2 \mathrm{mg}, 3$ equiv) and $\mathrm{TBABr}\left(13 \mathrm{mg}, 0.2\right.$ equiv) in $\mathrm{CH}_{2} \mathrm{Cl}_{2}(5 \mathrm{~mL})$ were added at room temperature and stirred overnight. The reaction was quenched by slow addition of saturated sodium bicarbonate solution and extracted with $\mathrm{CH}_{2} \mathrm{Cl}_{2}$ three times. The organic layer was washed with brine, dried with $\mathrm{Na}_{2} \mathrm{SO}_{4}$, concentrated by rotary evaporation and purified by column chromatography on silica gel $\left(\mathrm{CH}_{2} \mathrm{Cl}_{2}: \mathrm{MeOH}=150: 1\right)$ to give compound $2.71(15 \mathrm{mg}, 26 \%) .{ }^{1} \mathrm{H}$ NMR (300 MHz, $\left.\mathrm{CDCl}_{3}\right) \delta 4.56(\mathrm{t}, 1 \mathrm{H}, \mathrm{J}=6 \mathrm{~Hz}), 3.91(\mathrm{dd}, 2 \mathrm{H}, \mathrm{J}=6,3 \mathrm{~Hz}), 2.94(\mathrm{~m}, 1 \mathrm{H}), 2.63(\mathrm{~m}, 2 \mathrm{H})$, $2.33(\mathrm{~m}, 3 \mathrm{H}), 2.10(\mathrm{~m}, 2 \mathrm{H}), 1.90(\mathrm{~m}, 6 \mathrm{H}), 1.67(\mathrm{~m}, 2 \mathrm{H}), 1.04(\mathrm{~m}, 2 \mathrm{H}) .{ }^{13} \mathrm{C} \mathrm{NMR}$ $\left(150 \mathrm{MHz}, \mathrm{CDCl}_{3}\right) \delta 203.5,161.9,135.9,62.8,57.4,57.3,55.8,46.1,41.3,39.8,38.9$, 34.9, 32.4, 31.7, 29.4, 24.7. HRMS (ESI) for $\mathrm{C}_{16} \mathrm{H}_{22} \mathrm{O}_{2} \mathrm{Br}(\mathrm{MH}+)$ Cacld: 325.0803, Found: 325.0805 .

\section{b. Further conversions of 2.59 before ring-opening}

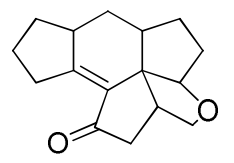

2.59

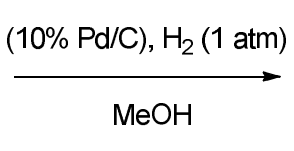

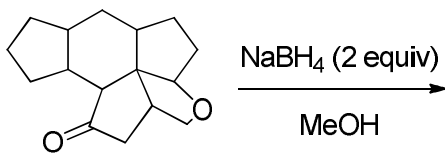

2.65

$76 \%$

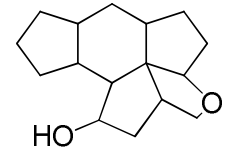

2.66

$85 \%$

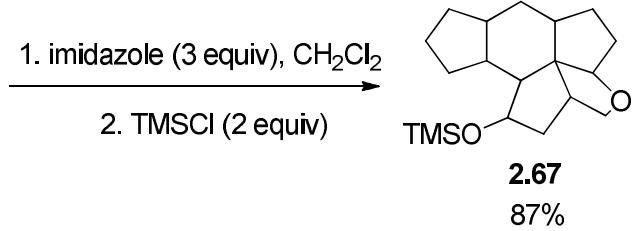




\section{Compound 2.66}

A suspension of 2.59 (73.2 $\mathrm{mg}, 0.3 \mathrm{mmol}, 1$ equiv) and 10\% $\mathrm{Pd} / \mathrm{C}(7.3 \mathrm{mg})$ in $\mathrm{MeOH}(3 \mathrm{~mL})$ was hydrogenated with $\mathrm{H}_{2}(1 \mathrm{~atm})$ for $18 \mathrm{~h}$. The reaction mixture was filtrated over Celite and the residue was concentrated by rotavapor and purified by column chromatography on silica gel (hexanes:EtOAc $=15: 1$ to 10:1) to give compound $2.65(55.8 \mathrm{mg}, 76 \%)$.

A solution of 2.65 (55.8 mg, 0.230 mmol, 1 equiv) and $\mathrm{NaBH}_{4}(17.4 \mathrm{mg}, 2$ equiv) in $\mathrm{MeOH}(3 \mathrm{~mL})$ was stirred for $11 \mathrm{~h}$ at room temperature. The reaction was quenched by water and extracted with $\mathrm{CH}_{2} \mathrm{Cl}_{2}$ three times. The organic layer was washed with brine, dried with $\mathrm{Na}_{2} \mathrm{SO}_{4}$, concentrated by rotary evaporation and purified by flash column chromatography (hexanes:EtOAc=5:1 to 3:1) to afford compound $\mathbf{2 . 6 6}(47.9$ mg, 85\%). ${ }^{1} \mathrm{H}$ NMR (600 MHz, $\left.\mathrm{CDCl}_{3}\right) \delta 4.54$ (q, 1H, J=6 Hz), 4.09 (dd, 1H, J=6, 3 Hz), $3.92(\mathrm{dd}, 1 \mathrm{H}, \mathrm{J}=12,6 \mathrm{~Hz}), 3.68(\mathrm{dd}, 1 \mathrm{H}, \mathrm{J}=12,6 \mathrm{~Hz}), 2.28(\mathrm{~m}, 1 \mathrm{H}), 2.23(\mathrm{t}, 1 \mathrm{H}$, $\mathrm{J}=6 \mathrm{~Hz}), 2.16(\mathrm{~m}, 1 \mathrm{H}), 2.08(\mathrm{~m}, 1 \mathrm{H}), 1.99(\mathrm{~m}, 1 \mathrm{H}), 1.95(\mathrm{~m}, 1 \mathrm{H}), 1.91(\mathrm{~m}, 1 \mathrm{H}), 1.83$ (m, 2H), $1.77(\mathrm{~m}, 4 \mathrm{H}), 1.59(\mathrm{~m}, 1 \mathrm{H}), 1.41(\mathrm{~m}, 3 \mathrm{H}), 1.31(\mathrm{~m}, 1 \mathrm{H}), 1.24(\mathrm{~m}, 1 \mathrm{H}), 1.17$ (m, 1H). ${ }^{13} \mathrm{C}$ NMR $\left(75 \mathrm{MHz}, \mathrm{CDCl}_{3}\right) \delta 94.5,76.6,74.9,62.3,49.7,47.8,41.3,41.1$, 37.2, 34.4, 32.6, 32.2, 32.0, 30.8, 30.0, 25.5. HRMS (ESI) for $\mathrm{C}_{16} \mathrm{H}_{25} \mathrm{O}_{2}(\mathrm{MH}+)$ Cacld: 249.1855, Found: 249.1681.

\section{Compound 2.67}

To a solution of 2.66 (105.2 $\mathrm{mg}, 0.424 \mathrm{mmol}, 1$ equiv) in $\mathrm{CH}_{2} \mathrm{Cl}_{2}(5 \mathrm{~mL})$ was added imidazole ( $86.5 \mathrm{mg}, 3$ equiv) and $\mathrm{TMSCl}\left(73 \mathrm{uL}, 2\right.$ equiv) at $0{ }^{\circ} \mathrm{C}$ sequentially. The reaction mixture was stirred at $0{ }^{\circ} \mathrm{C}$ for $1 \mathrm{~h}$ and warmed to room temperature. 
After $2.5 \mathrm{~h}$, the reaction was quenched by water, neutralized by $2 \mathrm{M} \mathrm{HCl}$ and extracted with $\mathrm{CH}_{2} \mathrm{Cl}_{2}$ three times. The organic layer was washed with brine, dried with $\mathrm{Na}_{2} \mathrm{SO}_{4}$, concentrated by rotary evaporation and purified by flash column chromatography (hexanes:EtOAc=25:1) to give compound $2.67(117.8 \mathrm{mg}, 87 \%) .{ }^{1} \mathrm{H}$ NMR (300 MHz, $\left.\mathrm{CDCl}_{3}\right) \delta 4.46(\mathrm{q}, 1 \mathrm{H}, \mathrm{J}=6 \mathrm{~Hz}), 4.09(\mathrm{dd}, 1 \mathrm{H}, \mathrm{J}=9,3 \mathrm{~Hz}), 3.92(\mathrm{dd}$, 1H, J=9, $6 \mathrm{~Hz}), 3.68$ (d, 1H, J=9 Hz), $2.24(\mathrm{~m}, 1 \mathrm{H}), 2.12(\mathrm{~m}, 2 \mathrm{H}), 1.97(\mathrm{~m}, 3 \mathrm{H}), 1.86$ $(\mathrm{m}, 2 \mathrm{H}), 1.63(\mathrm{~m}, 5 \mathrm{H}), 1.39(\mathrm{~m}, 3 \mathrm{H}), 1.21(\mathrm{~m}, 3 \mathrm{H}), 0.08(\mathrm{~s}, 9 \mathrm{H}) .{ }^{13} \mathrm{C}$ NMR $(150$ $\left.\mathrm{MHz}, \mathrm{CDCl}_{3}\right) \delta 94.7,76.5,74.8,61.9,49.6,48.5,41.5,41.3,37.7,34.4,32.7,32.2$, $32.1,30.8,29.6,25.4,0.32$.

\section{c. Further conversions of $\mathbf{2 . 6 6}$ before ring-opening}

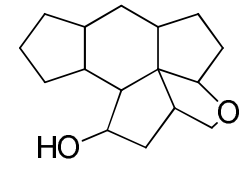

2.66

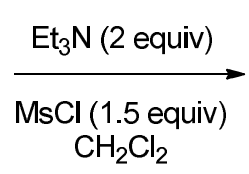
$\mathrm{CH}_{2} \mathrm{Cl}_{2}$

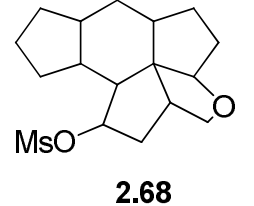

$66 \%$

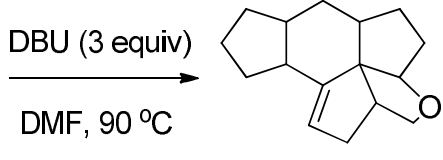

2.69 $81 \%$

\section{Compound 2.68}

To a solution of 2.66 (110.8 $\mathrm{mg}, 0.447 \mathrm{mmol}, 1$ equiv) in $\mathrm{CH}_{2} \mathrm{Cl}_{2}(5 \mathrm{~mL})$ was added $\mathrm{Et}_{3} \mathrm{~N}\left(124 \mathrm{uL}, 2\right.$ equiv) and $\mathrm{MsCl}\left(51.8 \mathrm{uL}, 1.5\right.$ equiv) at $0^{\circ} \mathrm{C}$ sequentially. The reaction mixture was stirred at $0{ }^{\circ} \mathrm{C}$ for $2 \mathrm{~h}$ and warmed to room temperature overnight. Then the reaction was quenched by water, neutralized by $2 \mathrm{M} \mathrm{HCl}$ and extracted with $\mathrm{CH}_{2} \mathrm{Cl}_{2}$ three times. The organic layer was washed with brine, dried with $\mathrm{Na}_{2} \mathrm{SO}_{4}$, concentrated by rotary evaporation and purified by flash column chromatography (hexanes:EtOAc=10:1) to give compound $\mathbf{2 . 6 8}(96.8 \mathrm{mg}, 66 \%) .{ }^{1} \mathrm{H}$ NMR (300 MHz, $\left.\mathrm{CDCl}_{3}\right) \delta 5.24(\mathrm{q}, 1 \mathrm{H}, \mathrm{J}=6 \mathrm{~Hz}), 4.16(\mathrm{dd}, 1 \mathrm{H}, \mathrm{J}=6,3 \mathrm{~Hz}), 3.92(\mathrm{dd}$, $1 \mathrm{H}, \mathrm{J}=9,6 \mathrm{~Hz}), 3.72(\mathrm{~d}, 1 \mathrm{H}, \mathrm{J}=9 \mathrm{~Hz}), 3.01(\mathrm{~s}, 3 \mathrm{H}), 2.12(\mathrm{~m}, 2 \mathrm{H}), 2.54(\mathrm{t}, 1 \mathrm{H}, \mathrm{J}=6 \mathrm{~Hz})$, 
$2.28(\mathrm{~m}, 2 \mathrm{H}), 2.17(\mathrm{~m}, 2 \mathrm{H}), 2.00(\mathrm{~m}, 4 \mathrm{H}), 1.78(\mathrm{~m}, 4 \mathrm{H}), 1.61(\mathrm{~m}, 1 \mathrm{H}), 1.44(\mathrm{~m}, 3 \mathrm{H})$, $1.25(\mathrm{~m}, 3 \mathrm{H}) . \quad{ }^{13} \mathrm{C} \mathrm{NMR}\left(75 \mathrm{MHz}, \mathrm{CDCl}_{3}\right) \delta 94.2,83.5,76.1,61.6,48.6,46.8,40.8$, $38.3,38.1,37.5,34.2,32.6,32.2,31.9,30.4,29.3,25.2$.

\section{Compound 2.69}

To a solution of $\mathbf{2 . 6 8}$ (24.2 $\mathrm{mg}, 0.074 \mathrm{mmol}, 1$ equiv) in DMF (3 mL) was added DBU (22.1 uL, 2 equiv) under nitrogen. The mixture was heated to $90{ }^{\circ} \mathrm{C}$ and stirred for $19 \mathrm{~h}$. Then the system was cooled to room temperature, quenched by water, neutralized by $2 \mathrm{M} \mathrm{HCl}$ and extracted with $\mathrm{CH}_{2} \mathrm{Cl}_{2}$ three times. The organic layer was washed with brine, dried with $\mathrm{Na}_{2} \mathrm{SO}_{4}$, concentrated by rotary evaporation and purified by flash column chromatography (hexanes:EtOAc=15:1) to give compound 2.69 (13.7 mg, 81\%). ${ }^{1} \mathrm{H}$ NMR (300 MHz, $\left.\mathrm{CDCl}_{3}\right) \delta 5.21(\mathrm{~m}, 1 \mathrm{H}), 4.26(\mathrm{~m}, 1 \mathrm{H}), 4.06$ $(\mathrm{dd}, 1 \mathrm{H}, \mathrm{J}=9,6 \mathrm{~Hz}), 3.54(\mathrm{dd}, 1 \mathrm{H}, \mathrm{J}=9,3 \mathrm{~Hz}), 2.53(\mathrm{~m}, 3 \mathrm{H}), 2.14(\mathrm{~m}, 3 \mathrm{H}), 1.92(\mathrm{~m}$, 2H), $1.82(\mathrm{~m}, 2 \mathrm{H}), 1.66(\mathrm{~m}, 4 \mathrm{H}), 1.49(\mathrm{~m}, 3 \mathrm{H}), 1.16(\mathrm{~m}, 1 \mathrm{H})$. GCMS (EI) for $\mathrm{C}_{16} \mathrm{H}_{22} \mathrm{O}(\mathrm{M}+)$ Found: 230 . 


\section{References}

1. Renner, M. K.; Jensen, P. R.; Fenical, W. J. Org. Chem. 2000, 65, 4843-4852.

2. Renner, M. K.; Jensen, P. R.; Fenical, W. J. Org. Chem. 1998, 63, 8346-8354.

3. Dewick, P. M. Nat. Prod. Rep. 2002, 19, 181-222.

4. Dewick, P. M. Nat. Prod. Rep. 1997, 14, 111-144.

5. Araki, K.; Saito, K.; Arimoto, H.; Uemura, Daisuke. Angew. Chem. Int. Ed. 2004, $43,81-84$.

6. Pichlmair, S.; Basu, Kallol; Paquette, L. Tetrahedron 2006, 62, 5178-5194.

7. Pichlmair, S.; Vilotijevic, I.; Paquette, L. Tetrahedron 2006, 62, 5791-5802.

8. Wood, J. L.; Pujanauski, B. G.; Sarpong, R. Org. Lett. 2009, 11, 3128-3131.

9. (a) Moore, D.; Pu, L. Org. Lett. 2002, 4, 1855-1857. (b) Gao, G.; Moore, D.; Xie, R. -G.; Pu, L. Org. Lett. 2002, 4, 4143 - 4146. (c) Gao, G.; Xie, R. -G.; Pu, L. Proc. Nat. Acad. Sci. 2004, 101, 5417-5420. (d) Gao, G.; Wang, Q.; Yu, X. -Q.; Xie, R. -G.; Pu, L. Angew. Chem. Int. Ed. 2006, 45, 122-125. (e) A review: Turlington, M.; Pu, L. Synlett. 2012, 23, 649-684.

10. (a) Rajaram, A. R.; Pu, L. Org. Lett. 2006, 8, 2019-2021. (b) Yue, Y.; Turlington, M.; Yu, X. -Q.; Pu, L. J. Org. Chem. 2009, 74, 8681-8689. (c) Zhou, L. -H.; Yu, X. -Q.; Pu, L. J. Org. Chem. 2009, 74, 2013-2017. (d) Turlington, M.; Yue, Y.; Yu, X. -Q.; Pu, L. J. Org. Chem. 2010, 75, 6941-6952. (e) Turlington, M.; Du, Y. -H.; Ostrum, S. G.; Santosh, V.; Wren, K.; Lin, T.; Sabat, M.; Pu, L. J. Am. Chem. Soc. 2011, 133, 11780-11794. (f) Turlington, M.; Pu, L. Org. Lett. 2011, 13, 4332-4335. 
11. Wang, Q.; Pu, L. Synlett. 2013, 11, 1340-1363.

12. Chen, W.; Tay, J. -H.; Ying, J.; Sabat, M.; Pu, L. Chem. Commun. 2013, 49, $170-172$.

13. Chen, W.; Tay, J. -H.; Ying, J.; Yu, X. -Q.; Pu, L. J. Org. Chem. 2013, 78, 2256-2265.

14. (a) Du, Y. -H.; Turlington, M.; Zhou, X.; Pu, L. Tetrahedron Lett. 2010, 51, 5024-5027. (b) Frantz, D. E.; Fässler, R.; Tomooka, C. S.; Carreira, E. M. Acc. Chem. Res. 2000, 33, 373-381. (c) Pu, L. Tetrahedron. 2003, 59, 9873-9886.

15. (a) Cozzi, P. G.; Hilgraf, R.; Zimmermann, N. Eur. J. Org. Chem. 2004, 4095-4105. (b) Lu, G.; Li, Y.-M.; Li, X.-S.; Chan, A. S. C. Coord. Chem. Rev. 2005, 249, 1736-1744. (c) Trost, B. M.; Weiss, A. H. Adv. Synth. Catal. 2009, 351, 963-983.

16. Selected reviews on PK cycloadditions: (a) Fletcher, A.J.; Christie S.D.R. J. Chem. Soc., Perkin Trans. 1. 2000, 1657-1668. (b) Brummond, K. M.; Kent J. L. Tetrahedron, 2000, 56, 3263-3283. (c) Blanco-Urgoiti, J.; Añorbe, L.; Pérez-Serrano L.; Domínguez, G.; Pérez-Castells, J. Chem. Soc. Rev. 2004, 33, 32-42. (d) Gibson, S. E.; Stevenazzi, A. Angew. Chem. Int. Ed. 2003, 42, 1800-1810. (e) Lee, H.-W.; Kwong, F.-Y. Eur. J. Org. Chem. 2010, 789-811.

17. Rh-catalyzed PK cycloadditions: (a) Jeong, N.; Lee, S.; Sung, B. K. Organometallics 1998, 17, 3642-3644. (b) Jeong, N.; Sung, B. K.; Choi, Y. K. J. Am. Chem. Soc. 2000, 122, 6771-6772. (c) Evans, P. A.; Robinson, J. E. J. Am. Chem. Soc. 2001, 123, 4609-4610. (d) Kobayashi, T.; Koga, Y.; Narasaka, K. J. Organomet. Chem. 2001, 624, 73-87. (e) Fan, B. M.; Xie, J. H.; Li, S.; Tu, Y. Q.; 
Zhou, Q. L. Adv. Syn. Cat. 2005, 347, 759-762. (f) Shibata,T.; Toshida, N.; Takagi, K. Org. Lett. 2002, 4, 1619-1621. (g) Shibata, T.; Toshida, N.; Takagi, K. J. Org. Chem. 2002, 67, 7446-7450.

18. Rh-catalyzed intramolecular [4+2] cycloaddition of alkenes with conjugated dienes: (a) Jolly, R. S.; Luedtke, G.; Sheehan, D.; Livinghouse, T. J. Am. Chem. Soc. 1990, 112, 4965-4966. (b) McKinstry, L.; Livinghouse, T. Tetrahedron 1994, 50, 6145-6154. (c) Wender, P. A.; Jenkins, T. E.; Suzuki, S. J. Am. Chem. Soc. 1995, 117, 1843-1844. (d) Gilbertson, S. R.; Hoge, G. S. Tetrahedron Lett. 1998, 39, 2075-2078. (e) Gilbertson, S. R.; Hoge, G. S.; Genov, D. G. J. Org. Chem. 1998, 63, 10077. (f) Wang, B.; Cao, P.; Zhang, X. Tetrahedron Lett. 2000, 41, 8041-8044.

19. Vischer, H. F.; Hulshof, J. W.; Hulscher, S.; Fratantoni, S. A.; Verheij, M. H. P.; Victorina, J.; Smit, M. J.; Leurs, R. Bioorg. Med. Chem. 2010, 18, 675-688.

20. Guindon, Y.; Therien, M.; Girard, Y.; Yoakim, C. J. Org. Chem. 1987, 52, $1680-1686$.

21. Jatczak, M.; Amouroux, R.; Chastrette, M. Tetrahedron Lett. 1985, 26, 2315-2316.

22. Pasquarello, C.; Picasso, S.; Demange, R.; Malissard, M.; Berger, E. G.; Vogel, P. J. Org. Chem. 2000, 65, 4251-4260.

23. Baran, A.; Kazaz, C.; Seçen, H.; Sütbeyaz, Y. Tetrahedron 2003, 59, 3643-3648.

24. Yadav, V. K.; Fallis, A. G. J. Org. Chem. 1986, 51, 3372-3374.

25. Cooke, N. G.; Jones, D. A.; Whiting, A. Tetrahedron 1992, 48, 9553-9560.

26. Hadžić, P.; Vukojević, N. Popsavin, M.; Čanadi, J. J. Serb. Chem. Soc. 2001, 66, 
$1-8$

27. Node, M.; Kajimoto, T.; Nishide, K.; Fujita, E.; Fuji, K. Tetrahedron Lett. 1984, $25,219-222$.

28. Lauzon, S.; Tremblay, F.; Gagnon, D.; Godbout, C.; Chabot, C.; Mercier-Shanks, C.; Perreault, S.; DeSève, H.; Spino, C. J. Org. Chem. 2008, 73, 6239-6250.

29. Mehta, G.; Ramesh, S. S. Tetrahedron Lett. 2003, 44, 3105-3108.

30. Gouin, S. G.; Gestin, J.-F.; Joly, K.; Loussouarn, A.; Reliquet, A.; Meslin, J. C.; Deniaud, D. Tetrahedron 2002, 58, 1131-1136.

31. Abraham, E.; Claridge, T. D. W.; Davis, S. G.; Odell, B.; Roberts, P. M.; Russell, A. J.; Smith, A. D.; Smith, L. J.; Storr, H. R.; Sweet, M. J.; Thompson, A. L.; Thomson, J. E.; Tranter, G. E.; Watkin, D. J. Tetrahedron: Asymmetry 2011, 22, 69-100.

32. Cabarat, D.; Adediran, S. A.; Gonzalez, M. J. G.; Pratt, R. F.; Wakselman, M. J. Org. Chem. 1999, 64, 713-720. 


\section{Chapter 3. Rh(I)-Catalyzed Chemo- and Stereoselective Domino Cycloaddition of Optically Active Propargyl 2,4-Hexadienyl Ethers}

\subsection{Introduction}

Terpenoids constitute the largest class of natural products that have been widely studied in organic synthesis and drug discovery. Polyquinanes represent a class of terpenoids containing multiple fused five or six-membered rings and other types of rings. ${ }^{1-4}$ Figure 3.1 gives a few examples of polyquinane natural products with a quaternary chiral carbon center shared by the muticyclic ring system. Intrigued by the unusual assemblage of rings and the wide ranging biological activities, synthetic chemists have conducted extensive work on the construction of these complex molecules.

Figure 3.1. Examples of polyquinanes containing rings jointed by a quaternary carbon

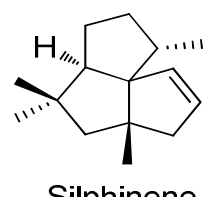

Silphinene

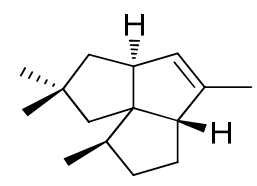

Pentalenene

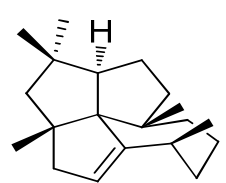

Laurenene

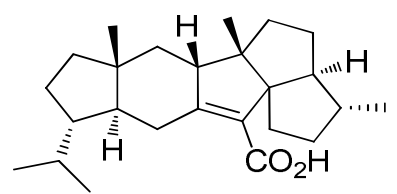

Retigeranic acid

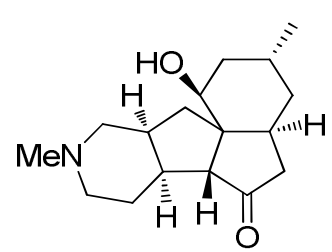

Paniculatine

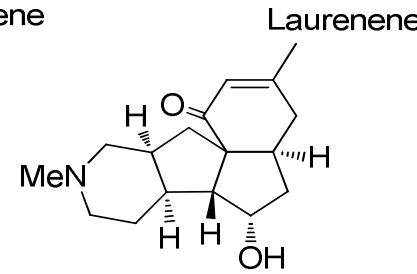

Magellanine

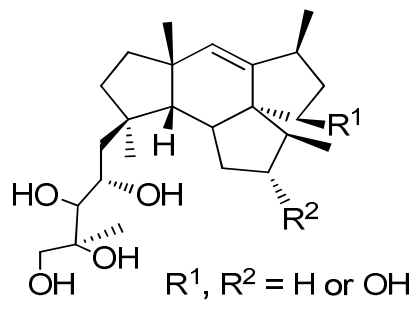

Mangicol 
Over the past several decades, transition metal-mediated domino reactions have been developed and adopted as a more general strategy for the rapid assembly of complex ring systems. ${ }^{5-9}$ Among all the transformations, Pauson-Khand-based domino reactions have been proved highly effective to construct polycyclic ring systems containing cyclopentenone unit.

\subsubsection{Co-catalyzed Pauson-Khand-based domino reactions}

Chung and co-workers have been active for decades in the area of the Pauson-Khand-based domino reactions. A variety of complex polycyclic compounds have been readily synthesized by their catalytic system.

In 2000, they reported a Co-catalyzed domino [2+2+1] and $[2+2+2]$ cycloaddition reaction of diynes with two phenylacetylenes in the presence of $30 \mathrm{~atm}$ CO (Scheme 3.1). ${ }^{10}$ The first $[2+2+1]$ cycloaddition is a Co-catalyzed Pauosn-Khand type reaction employing 1,6-diyne 3.1 as substrate, whose product is trapped through the second Co-catalyzed $[2+2+2]$ cycloaddition with phenylacetylene to generate the tricyclic compound 3.2.

Scheme 3.1. Co-catalyzed domino $[2+2+1]$ and $[2+2+2]$ cycloaddition

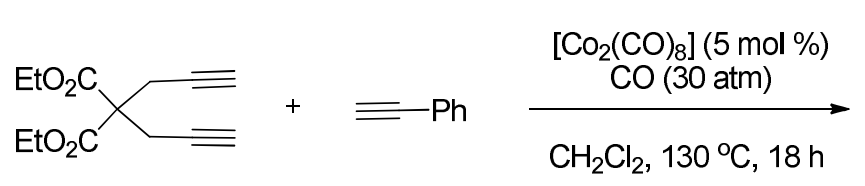

3.1

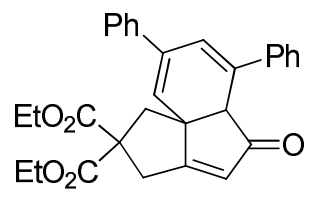

$3.2,68 \%$

Chung also studied the Co-catalyzed domino [2+2+1] and [4+2] cycloaddition reaction between a diyne and a diene (Scheme 3.2). ${ }^{11}$ Treatment of the diyne 3.3 and dimethyl-1,3-butadiene with $\mathrm{Co}_{2}(\mathrm{CO})_{8}(5 \mathrm{~mol} \%)$ in $\mathrm{CH}_{2} \mathrm{Cl}_{2}$ at $110^{\circ} \mathrm{C}$ under $30 \mathrm{~atm}$ CO for $18 \mathrm{~h}$ afforded the tricyclic compound $\mathbf{3 . 4}$ (Scheme 3.2). 
Scheme 3.2. Co-catalyzed domino $[2+2+1]$ and $[4+2]$ cycloaddition

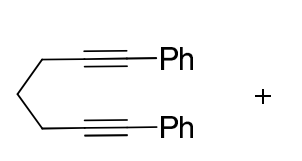

3.3

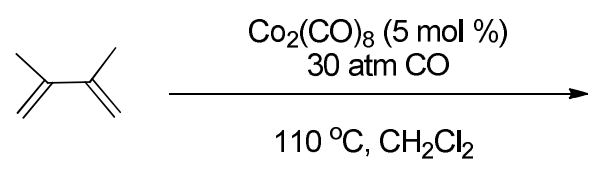

$110^{\circ} \mathrm{C}, \mathrm{CH}_{2} \mathrm{Cl}_{2}$

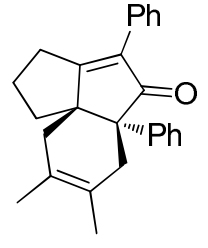

$3.4,80 \%$

In 2005, they demonstrated a one-pot Co-catalyzed domino Pauson-Khand and Diels-Alder reaction to access complex compounds from three components. ${ }^{12}$ The enyne 3.5 was treated with norbornene, maleic anhydride and $\mathrm{Co}_{2}(\mathrm{CO})_{8}(5 \mathrm{~mol} \%)$ in $\mathrm{CH}_{2} \mathrm{Cl}_{2}$ at $130{ }^{\circ} \mathrm{C}$ under $30 \mathrm{~atm} \mathrm{CO}$ for $21 \mathrm{~h}$ to generate the polycyclic compound $\mathbf{3 . 6}$ in $47 \%$ yield (Scheme 3.3 ).

Scheme 3.3. One-pot Co-catalyzed domino Pauson-Khand and Diels-Alder reaction

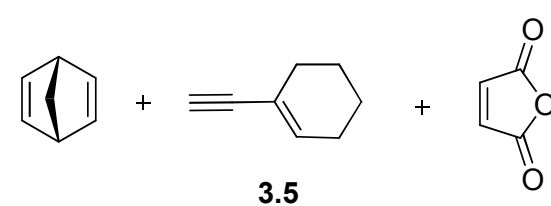

3.5

$$
\underset{\mathrm{CH}_{2} \mathrm{Cl}_{2}, 130^{\circ} \mathrm{C}, 21 \mathrm{~h}}{\stackrel{\mathrm{Co}_{2}(\mathrm{CO})_{8}(5 \mathrm{~mol} \%)}{\mathrm{CO}(30 \mathrm{~atm})}}
$$

3.6, $47 \%$

In 2002, Chung developed a one-pot synthesis of fenestrane derivatives from dienediynes by the Co-catalyzed domino intramolecular Pauson-Khand-type reaction and [4+2] cycloaddition. ${ }^{13}$ The dienediynes 3.7 was treated with $\mathrm{Co}_{2}(\mathrm{CO})_{8}(5 \mathrm{~mol} \%)$ in $\mathrm{CH}_{2} \mathrm{Cl}_{2}$ at $130^{\circ} \mathrm{C}$ in the presence of $30 \mathrm{~atm} \mathrm{CO}$ for $18 \mathrm{~h}$ to form the fenestrane derivatives 3.8 (Scheme 3.4). Later they reported the synthesis of the new tetracyclic compounds 3.10 from another type of dienediynes 3.9 by using the same method (Scheme 3.5). ${ }^{14}$ 
Scheme 3.4. One-pot synthesis of fenestrane derivatives from dienediynes

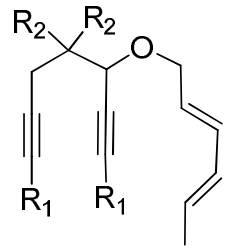

3.7

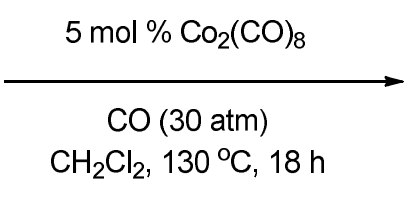

$\mathrm{CH}_{2} \mathrm{Cl}_{2}, 130^{\circ} \mathrm{C}, 18 \mathrm{~h}$

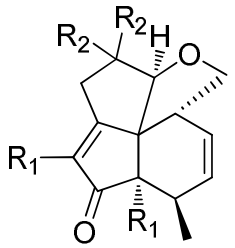

3.8

$\mathrm{R}_{1}=\mathrm{Ph}, \mathrm{R}_{2}=\mathrm{Me} \quad 84 \%$

$\mathrm{R}_{1}=\mathrm{Ph}, \mathrm{R}_{2}=\mathrm{H} \quad 74 \%$

$\mathrm{R}_{1}=\mathrm{R}_{2}=\mathrm{H} \quad 51 \%$

Scheme 3.5. Synthesis of the tetracyclic compounds 3.10 from the dienediynes 3.9

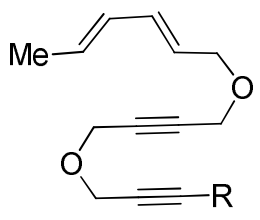

3.9

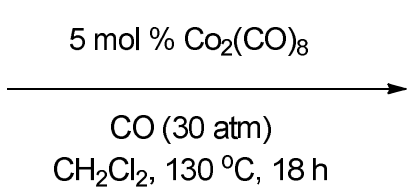

$\mathrm{CH}_{2} \mathrm{Cl}_{2}, 130^{\circ} \mathrm{C}, 18 \mathrm{~h}$

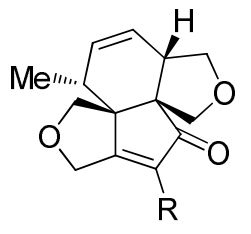

3.10

$\mathrm{R}=\mathrm{H}, \quad 19 \%$

$\mathrm{R}=\mathrm{Me}, \quad 64 \%$

$\mathrm{R}=\mathrm{nBu}, \quad 57 \%$

$\mathrm{R}=\mathrm{Ph}, \quad 73 \%$

Triynes could also be appropriate precursors to the construction of tetracycles through intramolecular Pauson-Khand-based domino reactions. $\mathrm{Co}_{2}(\mathrm{CO})_{8}(2.5 \mathrm{~mol} \%)$ catalyzed the triynes $\mathbf{3 . 1 1}$ under $30 \mathrm{~atm} \mathrm{CO}$ at $130{ }^{\circ} \mathrm{C}$ for $18 \mathrm{~h}$ to give the tetracyclic compounds 3.12 in poor to good yields (Scheme 3.6). ${ }^{15}$

Scheme 3.6. Synthesis of the tetracyclic compounds 3.12 from the triynes 3.11<smiles>[X]C(C#C[In]S)CC#C</smiles>

3.11

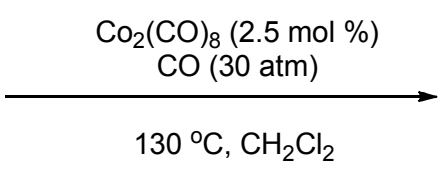

$30{ }^{\circ} \mathrm{C}, \mathrm{CH}_{2} \mathrm{Cl}_{2}$

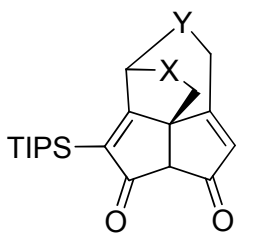

3.12

\subsubsection{Rh-catalyzed Pauson-Khand-based domino reactions}

Recently, our lab developed an efficient Rh(I)-catalyzed domino intramolecular 
Pauson-Khand and Diels-Alder cycloaddition to access spirotetracyclic compounds with excellent chemoselectivity and stereoselectivity (Scheme 3.7). ${ }^{16,17}$ The optically active trieneynes 3.13 were treated with a catalytic amount of $\left[\operatorname{RhCl}(\mathrm{CO})_{2}\right]_{2}$ in the presence of 1 atm $\mathrm{CO}$ to generate the multicyclic products 3.14 or 3.15 .

Scheme 3.7. $\mathrm{Rh}(\mathrm{I})$-catalyzed domino intramolecular Pauson-Khand and Diels-Alder cycloaddition<smiles>[R7]C(=CCO[C@H](C#CC(=C)C)C([R])([R])CC=C)CC</smiles>

3.13

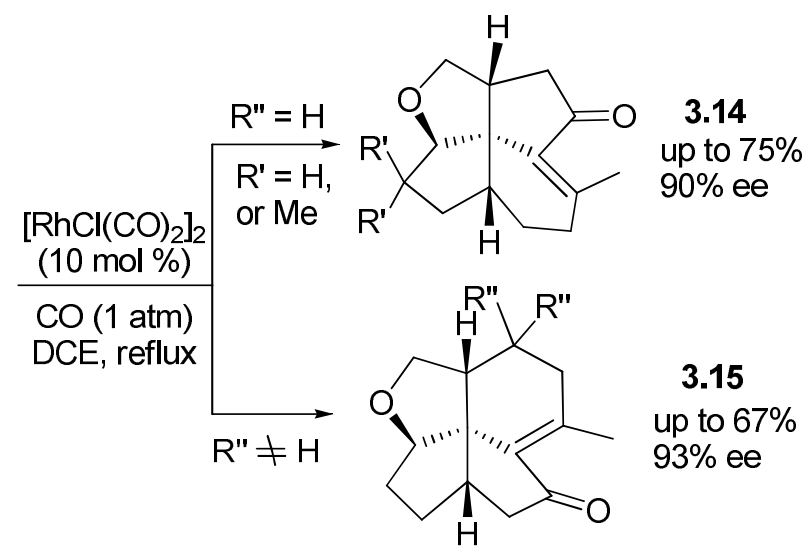

As described in Chpater 2, we further expanded this strategy to prepare the pentacyclic compound 3.17 from the trieneyne 3.16 via the domino PK/DA cycloaddition (Scheme 3.8). ${ }^{18}$ This product contains the multicyclic core structure of mangicol A. Cleavage of the $\mathrm{C}-\mathrm{O}$ bond of the hydrofuran ring of the pentacyclic product followed by functional group modification could eventually lead to mangicol A and its analogs.

Scheme 3.8. Construction of the core structure of mangicol A via the domino PK/DA cycloaddition

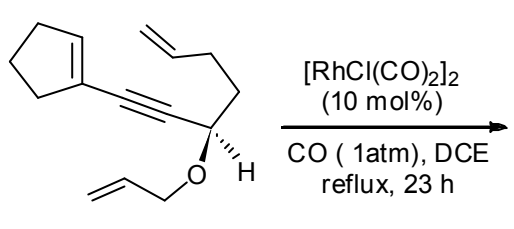

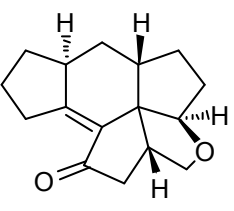

3.17 $60 \%$ yield $94 \%$ ee

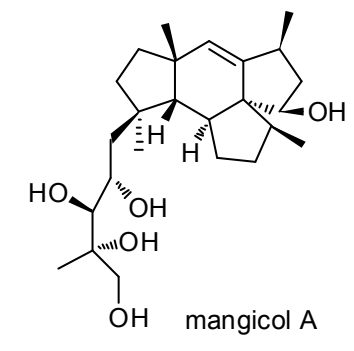




\subsection{Rh(I)-catalyzed domino PK/DA cycloaddition of optically active propargyl 2,4-hexadienyl ethers}

Recently, we have reported a few examples of $\mathrm{Rh}(\mathrm{I})$-catalyzed domino PK/DA reactions of chiral propargylic alcohol derivatives to prepare muticyclic products. To further show the utility of this strategy, we employed the Rh catalyst in a domino PK/DA cycloaddition of chiral propargyl 2,4-hexadienyl ethers. This process could efficiently generate muticyclic products with high chemo- and stereoselectivity.

\subsubsection{Preparation of chiral propargylic alcohols by the catalytic asymmetric}

\section{alkyne addition to aldehydes}

Over the past decade, significant progress has been made on the catalytic asymmetric alkyne addition to aldehydes to generate chiral propargylic alcohols. ${ }^{19-21}$ For example, in our laboratory, we have discovered that the readily available 1,1'-bi-2-naphthol (BINOL) in combination with $\mathrm{ZnEt}_{2}$ and $\mathrm{Ti}\left(\mathrm{O}^{i} \mathrm{Pr}\right)_{4}$ can catalyze the highly enantioselective reaction of a broad range of alkynes with aldehydes. ${ }^{21}$ Addition of a catalytic amount of dicyclohexylamine $\left(\mathrm{Cy}_{2} \mathrm{NH}\right)$ allows the entire catalytic process to be conducted at room temperature. ${ }^{21 \mathrm{c}, \mathrm{d}}$ Using the BINOL-based catalytic system can quickly produce structurally diverse chiral propargylic alcohols with high enantiomeric purity. This has promoted us to explore the application of these chiral propargylic alcohols in the asymmetric synthesis of multicyclic organic compounds. $^{17,18,22}$

We have conducted the asymmetric alkyne addition to 5-trimethylsilanyl-pent-5-ynal to synthesize a series of chiral propargylic alcohols 
containing two alkyne functions. As shown in Table 3.1, in the presence of (S)-BINOL, $\mathrm{ZnEt}_{2}, \mathrm{Cy}_{2} \mathrm{NH}$ and $\mathrm{Ti}\left(\mathrm{O}^{i} \mathrm{Pr}\right)_{4}$, the reaction of various terminal alkynes with the ynal gave the corresponding diynols $(R)-\mathbf{1 a - g}$ with good yield (69-95\%) and high enantioselectivity (86-92\% ee). Both the aromatic alkynes and aliphatic alkynes show similar high stereoselectivity. These reactions were conducted in diethyl ether solution at room temperature under nitrogen in a three-step-one-pot process. In the first step, an alkyne was treated with $\mathrm{ZnEt}_{2}, \mathrm{Cy}_{2} \mathrm{NH}$ and $(S)$-BINOL, which presumably generated a nucleophilic alkynylzinc reagent. The Lewis base $\mathrm{Cy}_{2} \mathrm{NH}$ could increase the basicity of $\mathrm{Et}_{2} \mathrm{Zn}$ for the deprotonation of the alkyne. In the second step, the deprotonated $(S)$-BINOL in the first step was combined with $\mathrm{Ti}\left(\mathrm{O}^{i} \mathrm{Pr}\right)_{4}$ to generate a chiral Lewis acid catalyst. In the third step, an aldehyde was added and the asymmetric alkyne addition proceeded. After aqueous workup, the desired chiral propargylic alcohol product was obtained.

Table 3.1. Catalytic asymmetric alkyne addition to aldehydes to form chiral propargylic alcohols

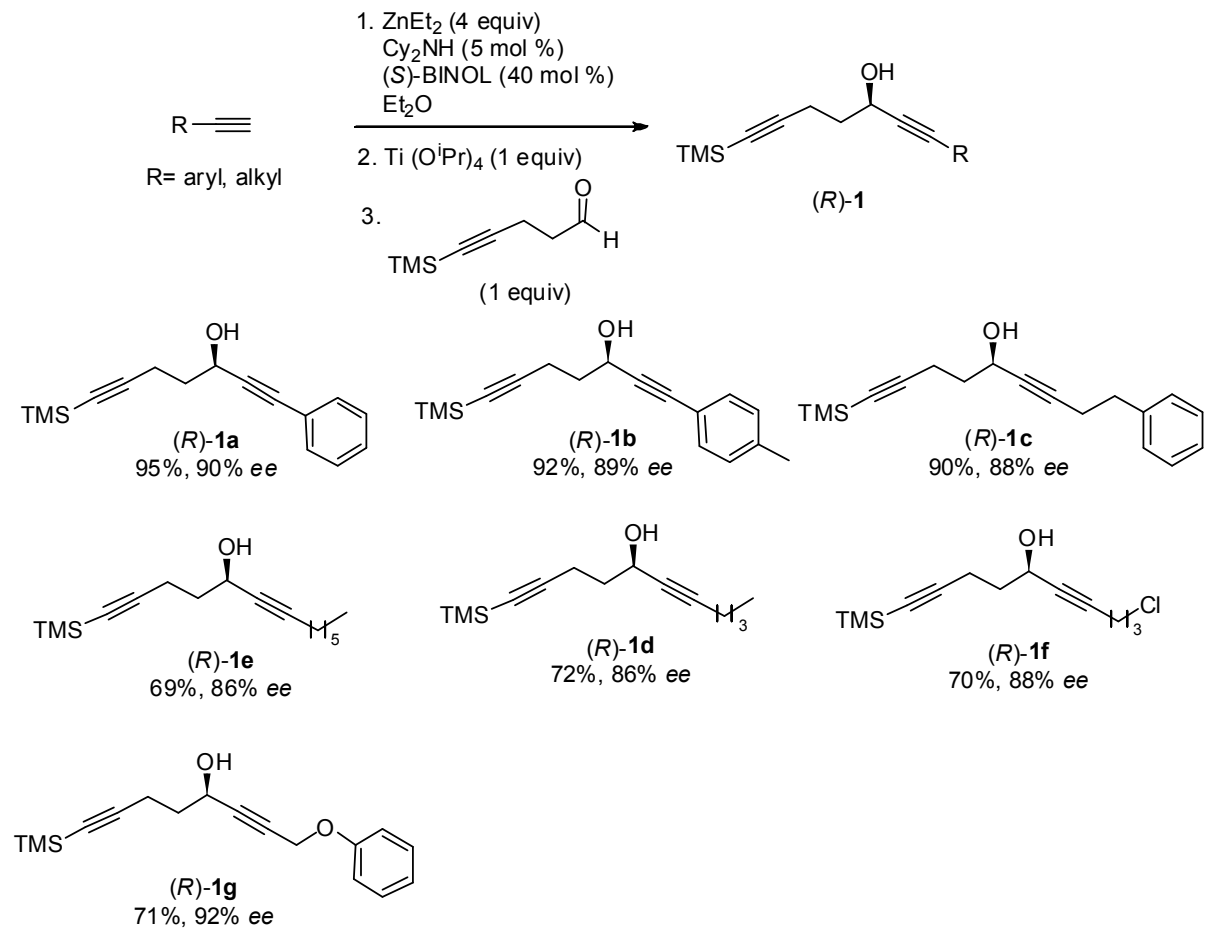




\subsubsection{Preparation of the chiral propargylic ether-based dienediynes}

We have introduced conjugated diene unit into the above optically active diynols by reacting with 1-bromo-2,4-hexadiene under basic conditions. As shown in Table 3.2, treatment of $(R)-\mathbf{1 a - g}$ with ${ }^{t} \mathrm{BuOK}$ followed by addition of 1-bromo-2,4-hexadiene at room temperature gave the corresponding ether products (R)-2a-g in 50-86\% yield. In this step, the TMS group was also removed. This allows the introduction of other groups on the alkyne unit. For example, treatment of $(R)-\mathbf{2 a}$ with $\mathrm{nBuLi}$ followed by addition of MeI gave the methylated product $(R)-3-\mathrm{Me}$. The TMS group was also placed back on the alkyne unit to obtain compounds $(R)-\mathbf{3 a - g}$ in good yields. Compounds ( $R$ )-3 are optically active propargyl 2,4-hexadienyl ethers containing two alkyne and a conjugated diene functions. These compounds are designed to undergo a metal-promoted domino PK/DA cycloaddition.

Table 3.2. Preparation of the chiral propargylic ether-based dienediynes

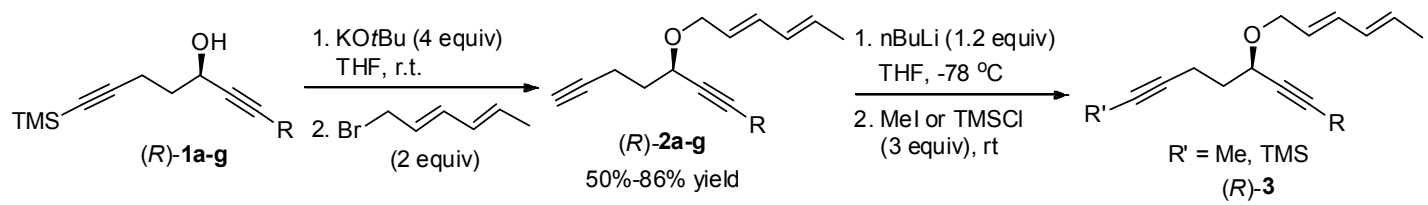<smiles>CC#CCCC(C#Cc1ccccc1)OC/C=C/C=C/C</smiles><smiles>CC#CCCC(C#Cc1ccccc1)OCC=CC=CC</smiles><smiles>CC#CCCC(C#Cc1ccc(C)cc1)OC/C=C/C=C/C</smiles><smiles>CC#CCCC(C#CCCc1ccccc1)OCC=CC=CC</smiles><smiles>CC#CCCC(C#CC)OC/C=C/C=C/C</smiles><smiles>CC#CCCC(OCC#CC)OC/C=C/C=C/C</smiles><smiles>CC#CCCC(C#CCCl)OCC=CC=CC</smiles>

(R)-3f, $76 \%$<smiles>CC#CCCC(C#CCOc1ccccc1)OCC=CC=CC</smiles> 


\subsubsection{Catalytic domino PK/DA cycloaddition of the chiral propargylic ether-based}

\section{dienediynes}

With the synthesis of the chiral propargylic ether-based dienediynes, we studied their catalytic conversions in the presence of a $\mathrm{Rh}(\mathrm{I})$ catalyst and $\mathrm{CO}$. When the optically active dienediyne $(R)-3 \mathbf{a}$ was treated with $10 \mathrm{~mol} \%\left[\mathrm{RhCl}(\mathrm{CO})_{2}\right]_{2}$ under 1 atm $\mathrm{CO}$ in refluxing 1,2-dichloroethane (DCE), a highly chemoselective and stereoselective domino $\mathrm{PK} / \mathrm{DA}$ cycloaddition occurred to generate the tetracyclic product $4 \mathbf{a}$ as a single diastereomer with $64 \%$ yield and $87 \%$ ee (Scheme 3.9). This demonstrates that the enantiomeric purity of the original chiral propargylic alcohol $(R)$-1a generated by the catalytic asymmetric alkyne addition to aldehydes is almost completely maintained. There is little change in the enantiomeric purity in the ether formation step as well as in the domino cyclization step. In this domino cycloaddition process, four new chiral centers including a quaternary chiral carbon core are formed.

Scheme 3.9. Catalytic conversion of $(R)-3 \mathbf{a}$ to generate 4a

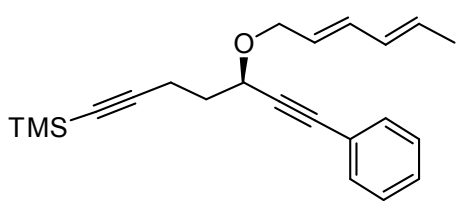

$(R)-3 a$

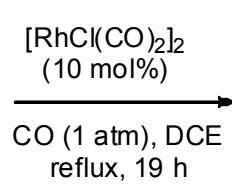
reflux, $19 \mathrm{~h}$

(a)

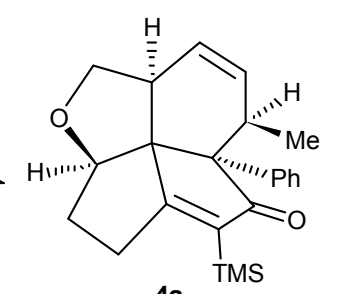

$4 a$

$64 \%$ yield $87 \%$ ee

The structure of 4a was established by high-resolution mass spectroscopic analysis and various ${ }^{1} \mathrm{H}$ and ${ }^{13} \mathrm{C}$ NMR spectroscopic analysis including COSY, NOESY, HSQC and DEPT-135 (Figure 3.2). The ${ }^{1} \mathrm{H}$ NMR signal assignments for compound 4a are shown below. The signal at $\delta 3.62$ was assigned to be $\mathrm{H}_{1}$ on the 
basis of DEPT-135 and HSQC. The signals at $\delta 3.75$ and $\delta 4.16$ were assigned to be $\mathrm{H}_{2}$ and $\mathrm{H}_{3}$ on the basis of DEPT-135, HSQC and a strong NOE effect of $\mathrm{H}_{2}$ with $\mathrm{H}_{8}$. The signal at $\delta 3.11$ was assigned to be $\mathrm{H}_{4}$ because of COSY correlation with $\mathrm{H}_{2} / \mathrm{H}_{3}$ and HSQC. The configuration of $\mathrm{H}_{4}$ was assigned to be down on the basis of its stronger NOE effect with $\mathrm{H}_{3}$ than with $\mathrm{H}_{2}$. The signals at $\delta 5.89$ and $\delta 5.84$ were assigned to be $\mathrm{H}_{5}$ and $\mathrm{H}_{6}$ on the basis of ${ }^{1} \mathrm{H}$ NMR and COSY correlation with $\mathrm{H}_{4}$. The signal at $\delta 2.99$ was assigned to be $\mathrm{H}_{7}$ according to COSY correlation with $\mathrm{H}_{6}$ and the configuration of $\mathrm{H}_{7}$ was assigned to be down on the basis of its strong NOE effect with $\mathrm{H}_{4}$. NOE effect is also observed between $\mathrm{Ph}$ and $\mathrm{H}_{7}$. The signals at $\delta 2.09$ and $\delta$ 1.08 were assigned to be $\mathrm{H}_{10}$ and $\mathrm{H}_{11}$ because of COSY correlation. The NOE effect of $\mathrm{H}_{11}$ with $\mathrm{H}_{1}$ is stronger than that of $\mathrm{H}_{10}$ with $\mathrm{H}_{1}$. The signals at $\delta 2.53$ and $\delta 2.60$ were assigned to be $\mathrm{H}_{8}$ and $\mathrm{H}_{9}$ according to COSY and HSQC. The NOE effect of $\mathrm{H}_{10}$ with $\mathrm{H}_{8}$ is greater than it with $\mathrm{H}_{9}$.

Figure 3.2. ${ }^{1} \mathrm{H}$ NMR signal assignments of compound $4 \mathbf{a}$

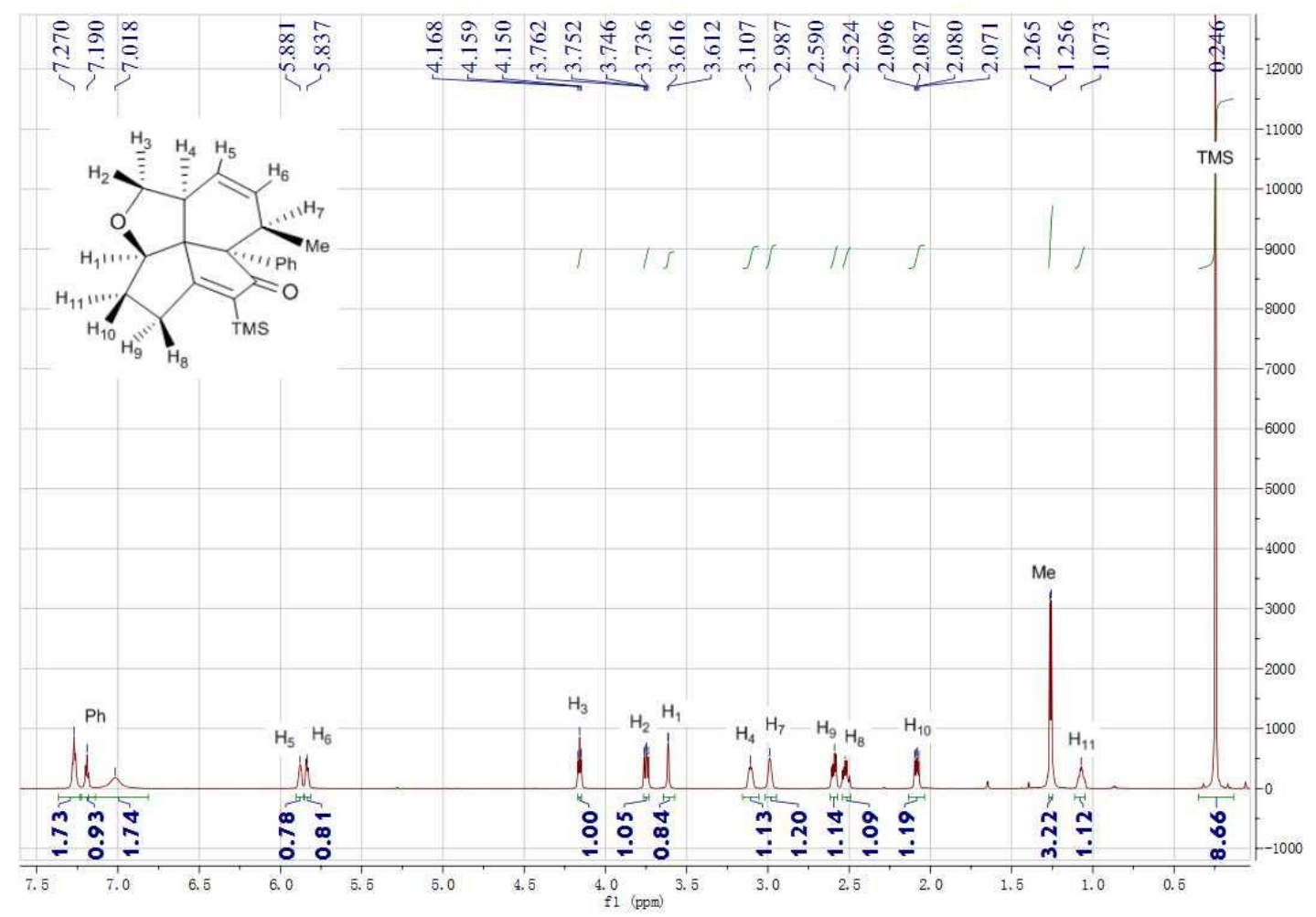


Figure 3.3 shows the observed NOE effects between the proton signals which have allowed the determination of its stereo structure and a molecular modeling structure of 4a obtained by using Spartan-Semiemperical-PM3 program.

Figure 3.3. Observed NOE effects of compound 4a and a molecular modeling structure
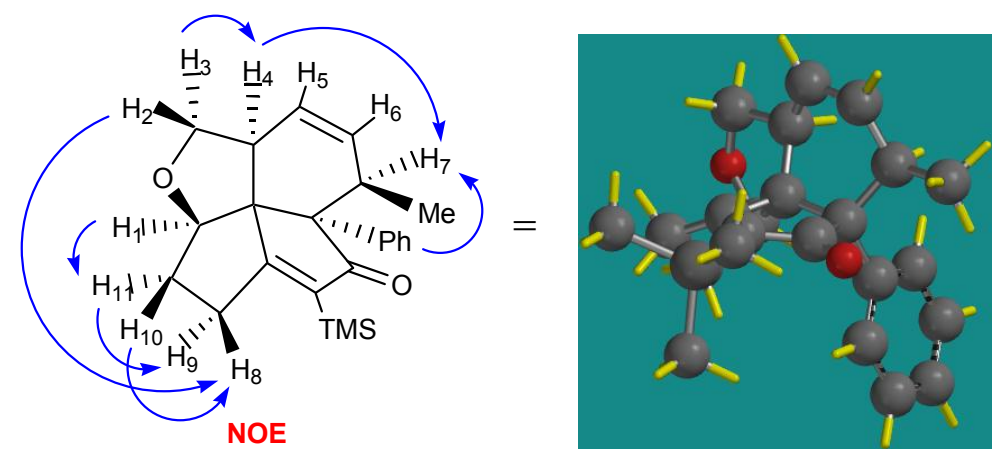

Previously, Chung reported a Co-catalyzed cyclization of racemic dienediynes to give racemic tetracyclic products similar to $4 \mathbf{a} .{ }^{13}$ The use of the Co catalyst required higher temperature $\left(130{ }^{\circ} \mathrm{C}\right)$ and higher pressure $(30 \mathrm{~atm})$ of $\mathrm{CO}$ than the use of the $\mathrm{Rh}$ catalyst reported here. In Chung's work, the stereostructure of the product is also different from 4a which could be due to either a different reaction mechanism or a possible error in assignment.

When the aliphatic alkyne-derived propargylic ether $(R)-3 \mathbf{c}$ was treated with the $\mathrm{Rh}(\mathrm{I})$ catalyst under the same conditions as the reaction of $(R)-\mathbf{3 a}$, a similar tetracyclic product $4 \mathbf{c}$ was also obtained as a single diastereomer with $60 \%$ yield and $88 \%$ ee (Table 3.3). Thus, the enantiomeric purity of the starting chiral propargylic alcohol $(R)-1 \mathrm{c}$ is completely maintained in this product. In a similar fashion, the other propargylic ethers $(R)-\mathbf{3}$ are also converted to the corresponding cyclic products $\mathbf{4}$ in the presence of $\left[\mathrm{RhCl}(\mathrm{CO})_{2}\right]_{2}$ and $\mathrm{CO}$ with high chemoselectivity and stereoselectivity. 
It is expected that these products should also maintain the enantiomeric purity of their corresponding propargylic alcohol starting materials, similar to the case for $\mathbf{4 a , c}$.

Table 3.3. Synthesis of more tetracyclic products 4 from the $\mathrm{Rh}(\mathrm{I})$-catalyzed domino PK/DA cycloaddition<smiles>CC#CCCC(C#CCCc1ccccc1)OC/C=C/C=C/C</smiles>

$(R)-3 c$
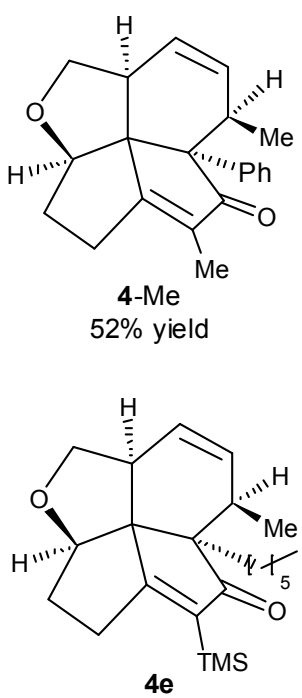

$57 \%$ yield

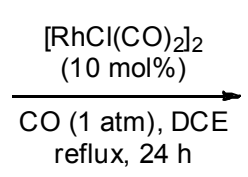

reflux, $24 \mathrm{~h}$

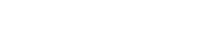
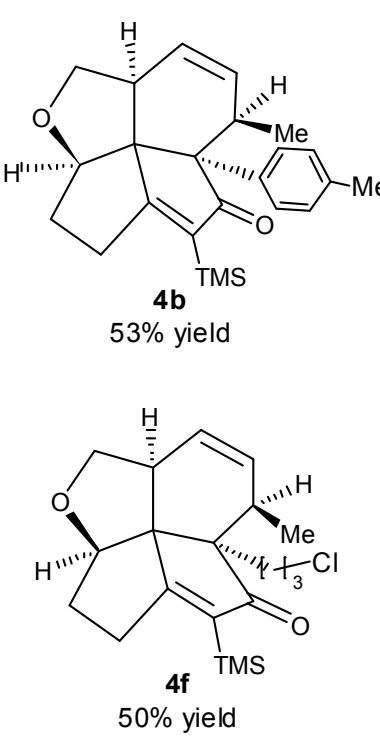

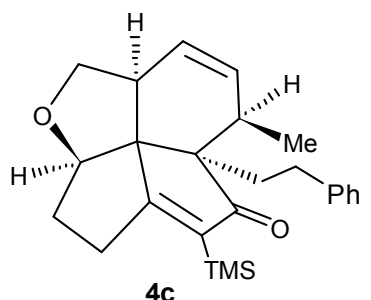

$60 \%$ yield $88 \%$ ee
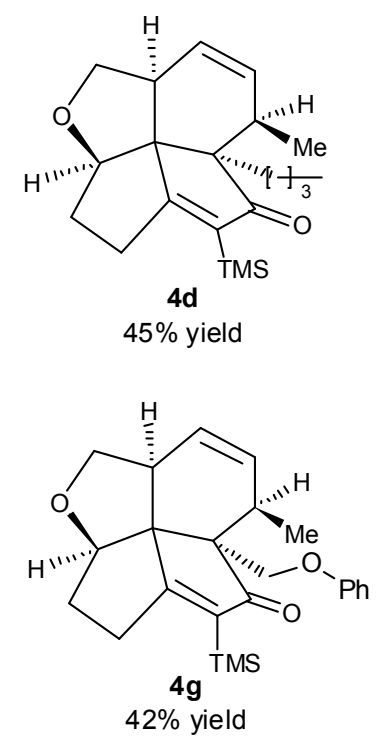

Single crystals of compound $\mathbf{4 d}$ were obtained by slow evaporation of its hexane/isopropyl alcohol solution. An X-ray analysis of these single crystals has allowed us to determine the structure of $\mathbf{4 d}$, as shown in Figure 3.4. This confirms the structural assignment derived by analogy with that of $\mathbf{4 a}$ determined by NMR analysis. The bond angles around the central quaternary carbon of $\mathbf{4 d}$ are found to be $100.0-116.6^{\circ}$ with the angle $\mathrm{C}(2)-\mathrm{C}(1)-\mathrm{C}(9)$ being the largest and the angle $\mathrm{C}(2)-\mathrm{C}(1)-\mathrm{C}(12)$ being the smallest. These data are very close to those calculated for 4a. 
Figure 3.4. Structure of compound $\mathbf{4 d}$ determined by X-ray analysis

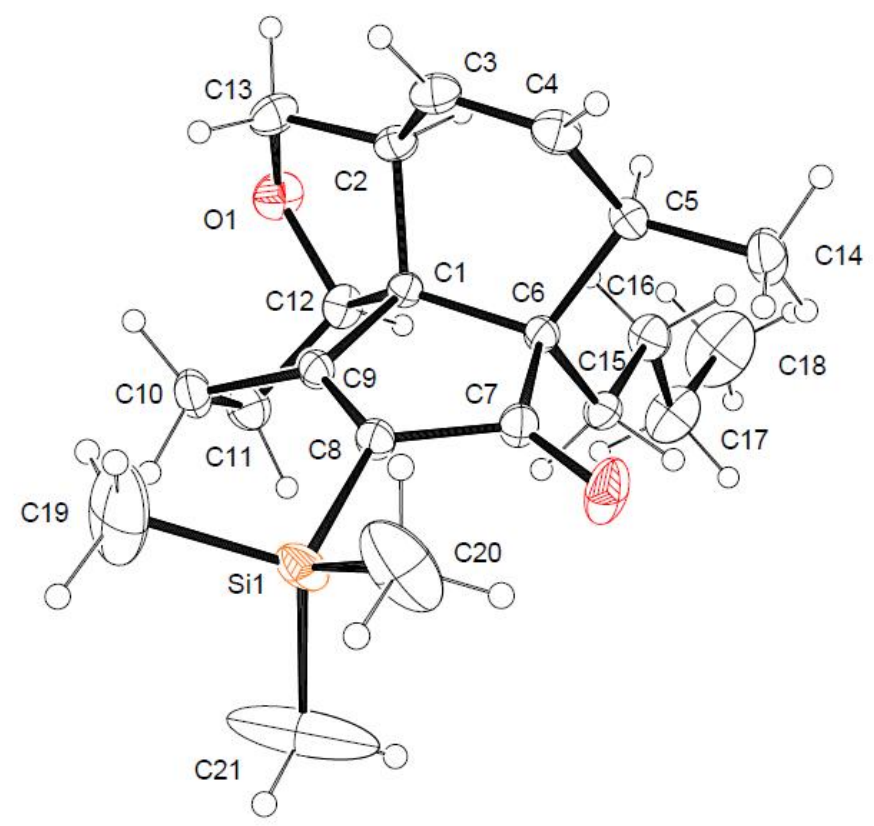

The reactions of additional racemic propargylic ether substrates in the presence of $\left[\mathrm{RhCl}(\mathrm{CO})_{2}\right]_{2}$ and $\mathrm{CO}$ were also studied (Figure 3.5). Under the same conditions, compound 2a with a terminal alkyne group gave a complicated product mixture. Apparently other reactions also occurred to the terminal alkyne. Compound $\mathbf{3 i}$ was observed to undergo the domino PK/DA cycloaddition in the presence of $\left[\mathrm{RhCl}(\mathrm{CO})_{2}\right]_{2}$ and $\mathrm{CO}$. However, unlike $(R)-3-\mathrm{Me}$, which gave 4-Me as a single diastereomer, $3 \mathbf{i}$ gave a mixture of two inseparable diastereomers in about 1.6:1 ratio. When the bis-TMS compound $\mathbf{3} \mathbf{j}$ was subjected to the reaction conditions, an enyne PK cycloaddition took place to give $\mathbf{4 j}$ in $51 \%$ yield. That is, the PK cycloaddition of the two TMS group substituted alkyne units might be too sterically hindered to occur. This shows that it is possible to control the direction of the cycloaddition by varying the substituents of the alkyne units to generate diverse products. The formation of $\mathbf{4} \mathbf{j}$ from $\mathbf{3 j}$ also suggests that the intramolecular DA reaction of the alkyne unit with the 
conjugated diene should not occur prior to the PK cycloaddition of the diyne. That is, the PK cycloaddition of compounds 3 should be more facile than the DA cycloaddition under the reaction conditions.

Figure 3.5. Additional dienediyne substrates studied

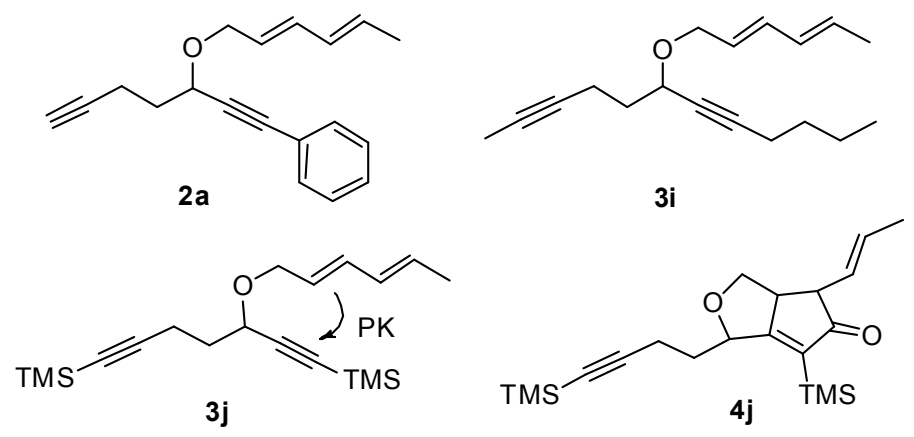

On the basis of the previous studies on the Rh-catalyzed PK reactions, ${ }^{17,18,23}$ a mechanism is proposed to illustrate the formation of compound 4a from $(R)-\mathbf{3 a}$ (Scheme 3.10). Coordination of $(R)-\mathbf{3 a}$ with $\left[\mathrm{RhCl}(\mathrm{CO})_{2}\right]_{2}$ can generate the intermediate 3.18. Oxidative coupling of the coordinated triple bonds of $\mathbf{3 . 1 8}$ gives 3.19. Migratory insertion of $\mathbf{3 . 1 9}$ with $\mathrm{CO}$ followed by reductive elimination should give the PK cycloaddition product 3.20. When both of the alkyne units contain a TMS group, as in $\mathbf{3} \mathbf{j}$, it should be more difficult to generate a corresponding intermediate similar to 3.18 due to the steric interaction of the two bulky TMS groups in the intermediate, and thus no PK cycloaddition of the two alkyne units of $\mathbf{3} \mathbf{j}$ was observed. The cyclopentadienone unit of the intermediate $\mathbf{3 . 2 0}$ is expected to be highly reactive, which readily undergoes an intramolecular endo-DA cycloaddition to give the tetracyclic product $\mathbf{4 a}$. In this step, the cis $\mathrm{H}_{\beta}$ and $\mathrm{H}_{\gamma}$ atoms on the newly formed chiral centers are cis with respect to $\mathrm{H}_{\alpha}$ on the propargylic chiral center, whereas $\mathrm{Ph}$ and $\mathrm{Me}$ are trans with respect to each other. The stereochemistry of the isolated product 
supports this mechanism.

Scheme 3.10. A proposed mechanism for the chemoselective and stereoselective domino PK/DA cycloadditions

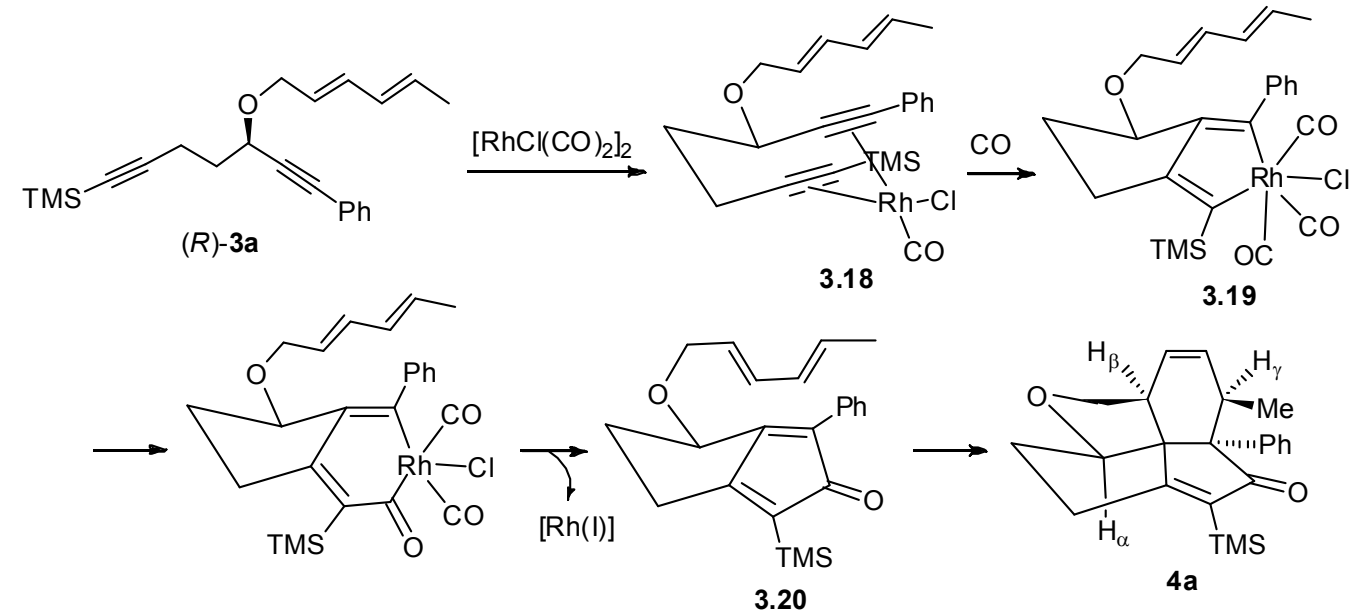

\subsection{Summary}

Using the chiral propargylic alcohols prepared from the catalytic asymmetric alkyne addition to aldehydes, we have synthesized a series of optically active propargyl 2,4-hexadienyl ethers. These compounds are found to undergo a one-pot $\mathrm{Rh}$ (I) catalyzed intramolecular domino PK/DA cycloaddition under mild reaction conditions to generate optically active tetracyclic products with high chemoselectivity and stereoselectivity. We have demonstrated that the high enantiomeric purity of the propargylic alcohols generated from the catalytic asymmetric alkyne addition is maintained in the domino cycloaddition products. This strategy is very efficient for the asymmetric synthesis of polycyclic compounds such as polyquinanes. 


\section{Experimental and Characterization}

\section{Analytical instruments}

NMR: Bruker $600 \mathrm{MHz}$.

HPLC: Water 600 Pump and Waters 486 Tunable Absorbance Detector, Chiralcel OD, OD-H, or Chiralpak AD, AD-H column.

Polarimeter: Jasco Digital Polarimeter P-2000.

High resolution mass spectra were obtained by EI [70-VSE(C)] or ESI (Q-TOf) analysis.

\section{General data}

Reactions were carried out under nitrogen. All commercial chemicals were used without further purification unless otherwise noted. Zinc reagents and catalysts were purchased and stored in dry nitrogen atmosphere. THF, Toluene and 1,4-dionaxe were distilled over sodium and benzophenone under nitrogen. DCM, $\mathrm{Et}_{2} \mathrm{O}$ and hexanes were dried by passing through activated alumina columns under nitrogen. All the NMR spectra were obtained in $\mathrm{CDCl}_{3}$ unless indicated otherwise.

\section{General procedure for the catalytic asymmetric alkyne addition to aldehydes}

Under nitrogen, $(S)$-BINOL (40 mol \%) was weighted into a tared flask and dissolved in $\mathrm{Et}_{2} \mathrm{O}(9 \mathrm{~mL})$. An alkyne (4 equiv), $\mathrm{Cy}_{2} \mathrm{NH}\left(5 \mathrm{~mol} \%\right.$ ) and $\mathrm{Et}_{2} \mathrm{Zn}$ (4 equiv) were added and the mixture was stirred at room temperature for $16 \mathrm{~h}$. Then, $\operatorname{Ti}\left(\mathrm{O}^{i} \mathrm{Pr}\right)_{4}$ ( 1 equiv) was added and stirring continued for $3 \mathrm{~h}$. An aldehyde (0.75 mmol, 1 equiv) was added and the mixture was stirred for another $4 \mathrm{~h}$. The reaction was quenched 
with saturated aqueous ammonium chloride and extracted three times with $\mathrm{CH}_{2} \mathrm{Cl}_{2}$. The organic layer was dried with anhydrous $\mathrm{Na}_{2} \mathrm{SO}_{4}$ and concentrated by rotary evaporation. The resultant oil was purified by flash column chromatography on silica gel with hexanes/ethyl acetate to give the propargylic alcohol products with $69-95 \%$ yield and $86-92 \%$ ee.

Characterizations of the chiral propargylic alcohol products $(R)-1$ a-g generated from the alkyne addition to aldehydes

(R)-1-Phenyl-7-(trimethylsilyl)hepta-1,6-diyn-3-ol, $(R)-1$ a.<smiles>CSC#CCCC(O)C#Cc1ccccc1</smiles>

Light yellow oil, $182.4 \mathrm{mg}$, 95\% yield. 90\% ee determined by HPLC analysis: CHIRALCEL OD column, 98:2 hexanes: ${ }^{i} \mathrm{PrOH}$, flow rate $=1.0 \mathrm{~mL} / \mathrm{min}, \lambda=254 \mathrm{~nm}$, retention time: $\mathrm{t}_{\text {minor }}=8.8 \mathrm{~min}, \mathrm{t}_{\text {major }}=10.2 \mathrm{~min} . \quad[\alpha]^{22}=-36.3\left(\mathrm{c}=0.88, \mathrm{CHCl}_{3}\right) .{ }^{1} \mathrm{H}$ NMR (300 MHz, $\left.\mathrm{CDCl}_{3}\right) \delta 7.43(\mathrm{~m}, 2 \mathrm{H}), 7.32(\mathrm{~m}, 3 \mathrm{H}), 4.75(\mathrm{t}, 1 \mathrm{H}, \mathrm{J}=6.3 \mathrm{~Hz}), 2.51$ $(\mathrm{m}, 2 \mathrm{H}), 2.03(\mathrm{~m}, 3 \mathrm{H}), 0.16(\mathrm{~s}, 9 \mathrm{H}) .{ }^{13} \mathrm{C} \mathrm{NMR}\left(75 \mathrm{MHz}, \mathrm{CDCl}_{3}\right) \delta 131.9,128.7$, $128.5,122.6,106.3,89.4,85.9,85.6,62.2,36.6,16.2,0.3$. HRMS [ESI(TOF)] for $\mathrm{C}_{16} \mathrm{H}_{20} \mathrm{ONaSi}\left[\mathrm{M}+\mathrm{Na}^{+}\right]$: m/z: calcd for: 279.1181; found: 279.1186 .

(R)-1-(p-Tolyl)-7-(trimethylsilyl)hepta-1,6-diyn-3-ol, $(R)-1 b$.<smiles>Cc1ccc(C#CC(O)CCC#CSC(C)(C)C)cc1</smiles> 
Light yellow oil, $186.3 \mathrm{mg}$, 92\% yield. $89 \%$ ee determined by HPLC analysis: CHIRALPAK AD-H column, 93:7 hexanes: ${ }^{i} \mathrm{PrOH}$, flow rate $=1.0 \mathrm{~mL} / \mathrm{min}, \lambda=254$ $\mathrm{nm}$, retention time: $\mathrm{t}_{\text {minor }}=5.7 \mathrm{~min}, \mathrm{t}_{\text {major }}=6.9 \mathrm{~min} . \quad[\alpha]^{23}=-37.1\left(\mathrm{c}=3.34, \mathrm{CHCl}_{3}\right)$. ${ }^{1} \mathrm{H}$ NMR $\left(300 \mathrm{MHz}, \mathrm{CDCl}_{3}\right) \delta 7.31(\mathrm{~d}, 2 \mathrm{H}, \mathrm{J}=8.1), 7.11(\mathrm{~d}, 2 \mathrm{H}, \mathrm{J}=8.4), 4.74(\mathrm{t}, 1 \mathrm{H}, \mathrm{J}$ $=6.6 \mathrm{~Hz}), 2.48(\mathrm{~m}, 2 \mathrm{H}), 2.34(\mathrm{~s}, 3 \mathrm{H}), 2.02(\mathrm{~m}, 2 \mathrm{H}), 0.16(\mathrm{~s}, 9 \mathrm{H}) .{ }^{13} \mathrm{C} \mathrm{NMR}(75 \mathrm{MHz}$, $\left.\mathrm{CDCl}_{3}\right) \delta 138.9,131.8,129.3,119.6,106.4,88.7,85.8,85.7,62.2,36.7,21.7,16.2$ 0.3. HRMS [ESI(TOF)] for $\mathrm{C}_{17} \mathrm{H}_{22} \mathrm{ONaSi}\left[\mathrm{M}+\mathrm{Na}^{+}\right]$: m/z: calcd for: 293.1338; found: 293.1352.

(R)-9-Phenyl-1-(trimethylsilyl)nona-1,6-diyn-5-ol, (R)-1c.<smiles>CSC#CCCC(O)C#CCCc1ccccc1</smiles>

Colorless oil, $191.7 \mathrm{mg}, 90 \%$ yield. $88 \%$ ee determined by HPLC analysis: CHIRALPAK AD-H column, 99:1 hexanes: ${ }^{i} \mathrm{PrOH}$, flow rate $=1.0 \mathrm{~mL} / \mathrm{min}, \lambda=254$ $\mathrm{nm}$, retention time: $\mathrm{t}_{\text {minor }}=11.8 \mathrm{~min}, \mathrm{t}_{\text {major }}=13.3 \mathrm{~min} . \quad[\alpha]^{22}{ }_{\mathrm{D}}=-14.7(\mathrm{c}=3.20$, $\left.\mathrm{CHCl}_{3}\right) . \quad{ }^{1} \mathrm{H} \mathrm{NMR}\left(300 \mathrm{MHz}, \mathrm{CDCl}_{3}\right) \delta 7.26(\mathrm{~m}, 5 \mathrm{H}), 4.48(\mathrm{~m}, 1 \mathrm{H}), 2.82(\mathrm{~m}, 2 \mathrm{H})$, $2.51(\mathrm{~m}, 2 \mathrm{H}), 2.35(\mathrm{~m}, 2 \mathrm{H}), 1.85(\mathrm{~m}, 3 \mathrm{H}), 0.15(\mathrm{~s}, 9 \mathrm{H}) .{ }^{13} \mathrm{C} \mathrm{NMR}\left(75 \mathrm{MHz}, \mathrm{CDCl}_{3}\right)$ $\delta 140.7,128.7,128.6,126.6,106.5,85.6,85.5,81.4,61.9,36.8,35.2,21.1,16.1,0.3$. HRMS [ESI(TOF)] for $\mathrm{C}_{18} \mathrm{H}_{25} \mathrm{OSi}\left[\mathrm{M}+\mathrm{H}^{+}\right]$: $\mathrm{m} / \mathrm{z}$ : calcd for: 285.1675; found: 285.1681. 
(R)-1-(Trimethylsilyl)undeca-1,6-diyn-5-ol, $(R)-1 \mathrm{~d}$.

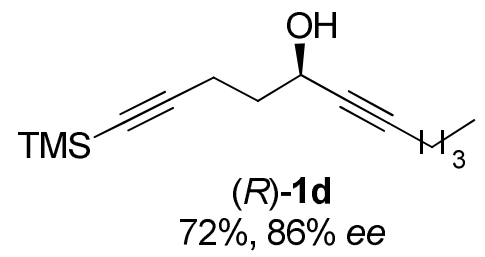

Light yellow oil, $127.4 \mathrm{mg}, 72 \%$ yield. $\quad 86 \%$ ee determined by ${ }^{1} \mathrm{H}$ and ${ }^{19} \mathrm{~F}$ NMR analyses of the corresponding $(R)$-Mosher ester. $[\alpha]^{22}=-12.2\left(\mathrm{c}=0.64, \mathrm{CHCl}_{3}\right)$. ${ }^{1} \mathrm{H}$ NMR (300 MHz, $\left.\mathrm{CDCl}_{3}\right) \delta 4.49(\mathrm{~m}, 1 \mathrm{H}), 2.41$ (m, 2H), $2.20(\mathrm{~m}, 2 \mathrm{H}), 1.87(\mathrm{~m}, 3 \mathrm{H})$, $1.43(\mathrm{~m}, 4 \mathrm{H}), 0.91(\mathrm{t}, 3 \mathrm{H}, \mathrm{J}=7.2 \mathrm{~Hz}), 0.14(\mathrm{~s}, 9 \mathrm{H}) .{ }^{13} \mathrm{C} \mathrm{NMR}\left(75 \mathrm{MHz}, \mathrm{CDCl}_{3}\right) \delta$ $106.5,86.4,85.6,80.5,62.0,36.9,30.9,22.1,18.6,16.2,13.8,0.3$. HRMS [ESI(TOF)] for $\mathrm{C}_{14} \mathrm{H}_{25} \mathrm{OSi}\left[\mathrm{M}+\mathrm{H}^{+}\right]$: m/z: calcd for: 237.1675; found: 237.1680.

(R)-1-(Trimethylsilyl)trideca-1,6-diyn-5-ol, $(R)-1$ e.<smiles>CCC#CC(O)CCC#CSC(C)(C)C</smiles>

Light yellow oil, $136.6 \mathrm{mg}, 69 \%$ yield. $\quad 86 \%$ ee determined by ${ }^{1} \mathrm{H}$ and ${ }^{19} \mathrm{~F}$ NMR analyses of the corresponding $(R)$-Mosher ester. $[\alpha]^{22}=-15.3\left(\mathrm{c}=0.65, \mathrm{CHCl}_{3}\right)$. ${ }^{1} \mathrm{H}$ NMR $\left(300 \mathrm{MHz}, \mathrm{CDCl}_{3}\right) \delta 4.49(\mathrm{~m}, 1 \mathrm{H}), 2.39(\mathrm{~m}, 2 \mathrm{H}), 2.19(\mathrm{~m}, 2 \mathrm{H}), 1.95(\mathrm{~s}, 1 \mathrm{H})$, $1.87(\mathrm{~m}, 2 \mathrm{H}), 1.49(\mathrm{~m}, 2 \mathrm{H}), 1.37(\mathrm{~m}, 2 \mathrm{H}), 1.28(\mathrm{~m}, 4 \mathrm{H}), 0.88(\mathrm{t}, 3 \mathrm{H}, \mathrm{J}=6.9 \mathrm{~Hz}), 0.14$ (s, 9H). ${ }^{13} \mathrm{C} \mathrm{NMR}\left(75 \mathrm{MHz}, \mathrm{CDCl}_{3}\right) \delta 106.5,86.4,85.5,80.6,62.0,36.9,31.5,28.8$, 28.7, 22.8, 18.9, 16.2, 14.3, 0.3. HRMS [ESI(TOF)] for $\mathrm{C}_{16} \mathrm{H}_{29} \mathrm{OSi}\left[\mathrm{M}+\mathrm{H}^{+}\right]: \mathrm{m} / \mathrm{z}$ : calcd for: 265.1988; found: 265.1994. 
(R)-10-Chloro-1-(trimethylsilyl)deca-1,6-diyn-5-ol, (R)-1f.

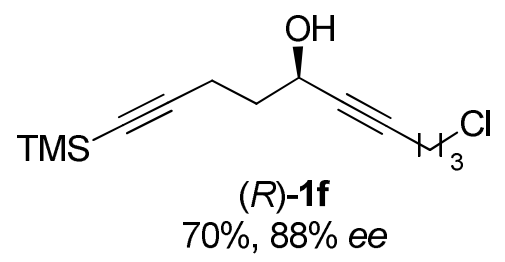

Light yellow oil, $134.4 \mathrm{mg}, 70 \%$ yield. $88 \%$ ee determined by ${ }^{1} \mathrm{H}$ NMR analyses of the corresponding $(R)$-Mosher ester. $[\alpha]^{22}=-15.3\left(\mathrm{c}=0.87, \mathrm{CHCl}_{3}\right) . \quad{ }^{1} \mathrm{H}$ NMR $\left(300 \mathrm{MHz}, \mathrm{CDCl}_{3}\right) \delta 4.49(\mathrm{~m}, 1 \mathrm{H}), 3.63(\mathrm{t}, 2 \mathrm{H}, \mathrm{J}=6.3 \mathrm{~Hz}), 2.40(\mathrm{~m}, 4 \mathrm{H}), 2.08(\mathrm{~s}, 1 \mathrm{H})$, $1,91(\mathrm{~m}, 4 \mathrm{H}), 0.13(\mathrm{~s}, 9 \mathrm{H}) .{ }^{13} \mathrm{C} \mathrm{NMR}\left(75 \mathrm{MHz}, \mathrm{CDCl}_{3}\right) \delta 106.3,85.7,84.2,81.7$, 61.9, 43.8, 36.8, 31.4, 16.3, 16.2, 0.3. HRMS [ESI(TOF)] for $\mathrm{C}_{13} \mathrm{H}_{22} \mathrm{OSiCl}\left[\mathrm{M}+\mathrm{H}^{+}\right]$: m/z: calcd for: 257.1128 ; found: 257.1129 .

(R)-1-Phenoxy-8-(trimethylsilyl)octa-2,7-diyn-4-ol, $(R)-1 g$.<smiles>CS(C)(=O)=O</smiles>

Light yellow oil, $152.3 \mathrm{mg}, 71 \%$ yield. $\quad 92 \%$ ee determined by ${ }^{1} \mathrm{H}$ NMR analyses of the corresponding $(R)$-Mosher ester. $[\alpha]^{22}=-15.0\left(\mathrm{c}=1.07, \mathrm{CHCl}_{3}\right) . \quad{ }^{1} \mathrm{H}$ NMR $\left(300 \mathrm{MHz}, \mathrm{CDCl}_{3}\right) \delta 7.30(\mathrm{~m}, 2 \mathrm{H}), 6.98(\mathrm{~m}, 3 \mathrm{H}), 4.72(\mathrm{~d}, 2 \mathrm{H}, \mathrm{J}=1.5 \mathrm{~Hz}), 4.56(\mathrm{~m}$, 1H), $2.34(\mathrm{~m}, 3 \mathrm{H}), 1.90(\mathrm{q}, 2 \mathrm{H}, \mathrm{J}=6.6 \mathrm{~Hz}), 0.15(\mathrm{~s}, 9 \mathrm{H}) .{ }^{13} \mathrm{C}$ NMR $(75 \mathrm{MHz}$ $\left.\mathrm{CDCl}_{3}\right) \delta 157.8,129.7,121.8,115.1,106.1,87.8,85.9,80.4,61.6,56.2,36.3,16.1$, 0.3. HRMS [ESI(TOF)] for $\mathrm{C}_{17} \mathrm{H}_{23} \mathrm{O}_{2} \mathrm{Si}\left[\mathrm{M}+\mathrm{H}^{+}\right]$: $\mathrm{m} / \mathrm{z}$ : calcd for: 287.1467 ; found: 287.1468. 
4. General procedure for the preparation of the unsubstituted diene-diynes $(R)-2 a-g$

Under nitrogen, $\mathrm{KO}^{t} \mathrm{Bu}$ (4 equiv) was weighed into a flask and dissolved in THF $(10 \mathrm{~mL})$. Then a propargylic alcohol (1 equiv) and 1-bromo-2,4-hexadiene (2 equiv) was added sequentially. The mixture was stirred at room temperature for $15 \mathrm{~h}$. The reaction was quenched with saturated aqueous ammonium chloride and extracted three times with $\mathrm{CH}_{2} \mathrm{Cl}_{2}$. The organic layer was dried with anhydrous $\mathrm{Na}_{2} \mathrm{SO}_{4}$ and concentrated by rotary evaporation. The resultant oil was purified by flash column chromatography on silica gel with hexanes/dichloromethane to give the product (R)-2a-g in $50-86 \%$ yield.

\section{Characterizations of compounds $(R)-2 a-g$}

((R)-3-((2E,4E)-Hexa-2,4-dien-1-yloxy)hepta-1,6-diyn-1-yl)benzene, $(R)-2 a$.<smiles>C#CCC[C@H](C#Cc1ccccc1)OC/C=C/C=C/C</smiles>

Prepared from $(R)-\mathbf{1 a}(184.8 \mathrm{mg}, 0.722 \mathrm{mmol})$, light yellow oil, $123.0 \mathrm{mg}, 65 \%$ yield. $[\alpha]^{22}=95.0\left(\mathrm{c}=1.71, \mathrm{CHCl}_{3}\right) . \quad{ }^{1} \mathrm{H} \mathrm{NMR}\left(600 \mathrm{MHz}, \mathrm{CDCl}_{3}\right) \delta 7.43(\mathrm{~m}, 2 \mathrm{H}), 7.30$ $(\mathrm{m}, 3 \mathrm{H}), 6.25(\mathrm{~m}, 1 \mathrm{H}), 6.06(\mathrm{~m}, 1 \mathrm{H}), 5.72(\mathrm{~m}, 1 \mathrm{H}), 5.65(\mathrm{~m}, 1 \mathrm{H}), 4.44(\mathrm{~m}, 1 \mathrm{H}), 4.32$ $(\mathrm{dd}, 1 \mathrm{H}, \mathrm{J}=12,6 \mathrm{~Hz}), 4.05(\mathrm{dd}, 1 \mathrm{H}, \mathrm{J}=12,6 \mathrm{~Hz}), 2.43(\mathrm{~m}, 2 \mathrm{H}), 2.03(\mathrm{~m}, 2 \mathrm{H}), 1.96(\mathrm{t}$, 1H, $3 \mathrm{~Hz}), 1.75(\mathrm{~d}, 3 \mathrm{H}, \mathrm{J}=6 \mathrm{~Hz}) .{ }^{13} \mathrm{C} \mathrm{NMR}\left(150 \mathrm{MHz}, \mathrm{CDCl}_{3}\right) \delta$ 133.7, 131.7, $130.8,130.2,128.4,128.3,126.2,122.6,87.5,86.1,83.5,69.3,68.7,67.5,34.6,18.1$, 14.7. 
(R)-2b.<smiles>C#CCCC(C#Cc1ccc(C)cc1)OC/C=C/C=C/C</smiles>

Prepared from $(R)-\mathbf{1 b}(227.7 \mathrm{mg}, 0.843 \mathrm{mmol})$, yellow oil, $125.8 \mathrm{mg}, 54 \%$ yield. $[\alpha]^{22}=95.5\left(\mathrm{c}=1.23, \mathrm{CHCl}_{3}\right) . \quad{ }^{1} \mathrm{H}$ NMR $\left(600 \mathrm{MHz}, \mathrm{CDCl}_{3}\right) \delta 7.32(\mathrm{~d}, 2 \mathrm{H}, \mathrm{J}=8.4$ Hz), $7.10(\mathrm{~d}, 2 \mathrm{H}, 7.8 \mathrm{~Hz}), 6.25(\mathrm{~m}, 1 \mathrm{H}), 6.06(\mathrm{~m}, 1 \mathrm{H}), 5.72(\mathrm{~m}, 1 \mathrm{H}), 5.65(\mathrm{~m}, 1 \mathrm{H})$, $4.43(\mathrm{t}, 1 \mathrm{H}, \mathrm{J}=6 \mathrm{~Hz}), 4.31(\mathrm{dd}, 1 \mathrm{H}, \mathrm{J}=12,6 \mathrm{~Hz}), 4.04(\mathrm{dd}, 1 \mathrm{H}, \mathrm{J}=12,6.6 \mathrm{~Hz}), 2.42$ (m, 2H), $2.34(\mathrm{~s}, 3 \mathrm{H}), 2.02(\mathrm{~m}, 2 \mathrm{H}), 1.96(\mathrm{t}, 1 \mathrm{H}, \mathrm{J}=2.4 \mathrm{~Hz}), 1.75$ (d, 3H, J=6 Hz). ${ }^{13} \mathrm{C} \mathrm{NMR}\left(150 \mathrm{MHz}, \mathrm{CDCl}_{3}\right) \delta 138.5,133.6,131.6,130.8,130.1,129.0,126.2,119.5$, $86.7,86.2,83.6,69.2,68.7,67.5,34.6,21.5,18.1,14.7$

((R)-5-((2E,4E)-Hexa-2,4-dien-1-yloxy)nona-3,8-diyn-1-yl)benzene, $(R)-2 c$.<smiles>C#CCCC(C#CCCc1ccccc1)OC/C=C/C=C/C</smiles>

Prepared from $(R)-1 \mathrm{c}(211.5 \mathrm{mg}, 0.745 \mathrm{mmol})$, light yellow oil, $178.8 \mathrm{mg}, 82 \%$ yield. $[\alpha]^{22}{ }_{\mathrm{D}}=64.7\left(\mathrm{c}=0.79, \mathrm{CHCl}_{3}\right) . \quad{ }^{1} \mathrm{H} \mathrm{NMR}\left(600 \mathrm{MHz}, \mathrm{CDCl}_{3}\right) \delta 7.29(\mathrm{~m}, 2 \mathrm{H}), 7.22$ (m, 3H), $6.17(\mathrm{~m}, 1 \mathrm{H}), 6.04(\mathrm{~m}, 1 \mathrm{H}), 5.71(\mathrm{~m}, 1 \mathrm{H}), 5.59(\mathrm{~m}, 1 \mathrm{H}), 4.17(\mathrm{~m}, 2 \mathrm{H}), 3.89$ (m, 1H), $2.82(\mathrm{t}, 2 \mathrm{H}, \mathrm{J}=7.2 \mathrm{~Hz}), 2.52(\mathrm{t}, 2 \mathrm{H}, \mathrm{J}=7.2 \mathrm{~Hz}), 2.30(\mathrm{~m}, 2 \mathrm{H}), 1.93(\mathrm{~s}, 1 \mathrm{H})$, $1.90(\mathrm{~m}, 1 \mathrm{H}), 1.85(\mathrm{~m}, 1 \mathrm{H}), 1.75(\mathrm{~d}, 3 \mathrm{H}, \mathrm{J}=6.6 \mathrm{~Hz}) .{ }^{13} \mathrm{C} \mathrm{NMR}\left(150 \mathrm{MHz}, \mathrm{CDCl}_{3}\right) \delta$ 
$140.5,133.4,130.8,129.9,128.4,128.3,126.4,126.3,85.9,83.7,79.2,68.9,68.5$, $67.2,35.0,34.7,20.8,18.1,14.5$.

$(R)-5-((2 \mathrm{E}, 4 \mathrm{E})-H e x a-2,4-d i e n-1-y l o x y)$ undeca-1,6-diyne, $(R)-2 \mathrm{~d}$.

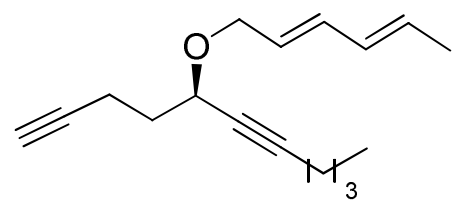

$(R)-2 d, 50 \%$

Prepared from $(R)-1 d(50.0 \mathrm{mg}, 0.212 \mathrm{mmol})$, colorless oil, $26.1 \mathrm{mg}, 50 \%$ yield. $[\alpha]^{21}=78.8\left(\mathrm{c}=0.53, \mathrm{CHCl}_{3}\right) . \quad{ }^{1} \mathrm{H}$ NMR $\left(600 \mathrm{MHz}, \mathrm{CDCl}_{3}\right) \delta 6.20(\mathrm{~m}, 1 \mathrm{H}), 6.04$ $(\mathrm{m}, 1 \mathrm{H}), 5.68(\mathrm{~m}, 1 \mathrm{H}), 5.60(\mathrm{~m}, 1 \mathrm{H}), 4.22(\mathrm{dd}, 1 \mathrm{H}, \mathrm{J}=12.6,6 \mathrm{~Hz}), 4.17(\mathrm{t}, 1 \mathrm{H}, \mathrm{J}=6.6$ Hz), $3.94(\mathrm{dd}, 1 \mathrm{H}, \mathrm{J}=12.6,6.6 \mathrm{~Hz}), 2.34(\mathrm{~m}, 2 \mathrm{H}), 2.21(\mathrm{~m}, 2 \mathrm{H}), 1.89$ (m, 3H), $1.73(\mathrm{~d}$, $3 \mathrm{H}, \mathrm{J}=6.6 \mathrm{~Hz}), 1.48(\mathrm{~m}, 2 \mathrm{H}), 1.40(\mathrm{~m}, 2 \mathrm{H}), 0.90(\mathrm{t}, 3 \mathrm{H}, \mathrm{J}=7.2 \mathrm{~Hz}) .{ }^{13} \mathrm{C}$ NMR $(150$ $\left.\mathrm{MHz}, \mathrm{CDCl}_{3}\right) \delta 133.3,130.8,129.9,126.4,86.8,83.7,78.3,68.9,68.4,67.3,34.8$, $30.7,21.9,18.3,18.0,14.6,13.5$.

$(R)-5-((2 \mathrm{E}, 4 \mathrm{E})-H e x a-2,4-d i e n-1-y l o x y)$ trideca-1,6-diyne, $(R)-2 \mathrm{e}$.

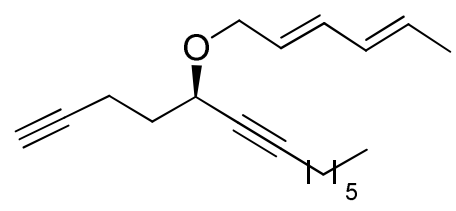

$(R)-\mathbf{2 e}, 71 \%$

Prepared from $(R)-1 \mathrm{e}(95.1 \mathrm{mg}, 0.360 \mathrm{mmol})$, colorless oil, $69.5 \mathrm{mg}, 71 \%$ yield. $[\alpha]^{21}=66.1\left(\mathrm{c}=1.47, \mathrm{CHCl}_{3}\right) . \quad{ }^{1} \mathrm{H} \mathrm{NMR}\left(600 \mathrm{MHz}, \mathrm{CDCl}_{3}\right) \delta 6.20(\mathrm{~m}, 1 \mathrm{H}), 6.04$ (m, 1H), $5.70(\mathrm{~m}, 1 \mathrm{H}), 5.61(\mathrm{~m}, 1 \mathrm{H}), 4.22(\mathrm{dd}, 1 \mathrm{H}, \mathrm{J}=12,5.4 \mathrm{~Hz}), 4.18(\mathrm{~m}, 1 \mathrm{H}), 3.95$ 
$(\mathrm{dd}, 1 \mathrm{H}, \mathrm{J}=12.6,7.2 \mathrm{~Hz}), 2.34(\mathrm{~m}, 2 \mathrm{H}), 2.20(\mathrm{~m}, 2 \mathrm{H}), 1.89(\mathrm{~m}, 3 \mathrm{H}), 1.74(\mathrm{~d}, 3 \mathrm{H}, \mathrm{J}=$ $6 \mathrm{~Hz}), 1.49(\mathrm{~m}, 2 \mathrm{H}), 1.37(\mathrm{~m}, 2 \mathrm{H}), 1.28(\mathrm{~m}, 4 \mathrm{H}), 0.88(\mathrm{t}, 3 \mathrm{H}, \mathrm{J}=6.6 \mathrm{~Hz}) .{ }^{13} \mathrm{C} \mathrm{NMR}$ $\left(150 \mathrm{MHz}, \mathrm{CDCl}_{3}\right) \delta 133.4,130.8,129.9,126.4,86.9,83.7,78.3,68.9,68.4,67.3$, $34.8,31.3,28.6,28.5,22.5,18.7,18.1,14.6,14.0$.

(R)-10-Chloro-5-((2E,4E)-hexa-2,4-dien-1-yloxy)deca-1,6-diyne, $(R)-2 f$.<smiles>C#CCCC(C#CCCl)OC/C=C/C=C/C</smiles>

$(R)-2 f, 75 \%$

Prepared from $(R)$-1f $(95.0 \mathrm{mg}, 0.371 \mathrm{mmol})$, colorless oil, $73.3 \mathrm{mg}, 75 \%$ yield. $[\alpha]^{19}{ }_{\mathrm{D}}=63.3\left(\mathrm{c}=0.60, \mathrm{CHCl}_{3}\right) . \quad{ }^{1} \mathrm{H} \mathrm{NMR}\left(600 \mathrm{MHz}, \mathrm{CDCl}_{3}\right) \delta 6.21(\mathrm{~m}, 1 \mathrm{H}), 6.04$ (m, 1H), $5.71(\mathrm{~m}, 1 \mathrm{H}), 5.60(\mathrm{~m}, 1 \mathrm{H}), 4.20(\mathrm{~m}, 2 \mathrm{H}), 3.94(\mathrm{~m}, 1 \mathrm{H}), 3.63(\mathrm{~m}, 2 \mathrm{H}), 2.41$ $(\mathrm{m}, 2 \mathrm{H}), 2.33(\mathrm{~m}, 2 \mathrm{H}), 1.94(\mathrm{~m}, 4 \mathrm{H}), 1.87(\mathrm{~m}, 1 \mathrm{H}), 1.74(\mathrm{~d}, 3 \mathrm{H}, \mathrm{J}=6.6 \mathrm{~Hz}) .{ }^{13} \mathrm{C}$ NMR $\left(150 \mathrm{MHz}, \mathrm{CDCl}_{3}\right) \delta 133.5,130.8,130.1,126.2,84.6,83.6,79.5,69.1,68.6$, $67.2,43.6,34.7,31.3,18.1,16.2,14.6$.

(((R)-4-((2E,4E)-Hexa-2,4-dien-1-yloxy)octa-2,7-diyn-1-yl)oxy)benzene, $(R)-2 \mathrm{~g}$.<smiles>C#CCC[C@H](C#CCOc1ccccc1)OC/C=C/C=C/C</smiles>

Prepared from $(R)-\mathbf{1 g}(112.0 \mathrm{mg}, 0.392 \mathrm{mmol})$, colorless oil, $99.4 \mathrm{mg}, 86 \%$ yield. $[\alpha]^{20}{ }_{\mathrm{D}}=74.8\left(\mathrm{c}=1.75, \mathrm{CHCl}_{3}\right) . \quad{ }^{1} \mathrm{H}$ NMR $\left(600 \mathrm{MHz}, \mathrm{CDCl}_{3}\right) \delta 7.30(\mathrm{~m}, 2 \mathrm{H}), 7.00$ (m, 3H), $6.15(\mathrm{~m}, 1 \mathrm{H}), 6.02(\mathrm{~m}, 1 \mathrm{H}), 5.67(\mathrm{~m}, 1 \mathrm{H}), 5.56(\mathrm{~m}, 1 \mathrm{H}), 4.73(\mathrm{~s}, 2 \mathrm{H}), 4.25$ 
(m, 1H), $4.18(\mathrm{~m}, 1 \mathrm{H}), 3.92(\mathrm{~m}, 1 \mathrm{H}), 2.32(\mathrm{~m}, 2 \mathrm{H}), 1.90(\mathrm{~m}, 3 \mathrm{H}), 1.74(\mathrm{~d}, 3 \mathrm{H}, \mathrm{J}=6.6$

Hz). ${ }^{13} \mathrm{C} \mathrm{NMR}\left(150 \mathrm{MHz}, \mathrm{CDCl}_{3}\right) \delta 157.5,133.8,130.7,130.3,129.4,125.9,121.5$, $115.0,85.9,83.3,81.0,69.3,68.8,66.8,56.0,34.3,18.1,14.5$.

5. General procedure for the preparation of the optically active propargyl

\section{2,4-hexadienyl ethers $(R)-3$.}

Under nitrogen, $(R)$-2 (1 equiv) was dissolved in THF $(5 \mathrm{~mL})$ and cooled to -78 ${ }^{\circ} \mathrm{C}$ under nitrogen. ${ }^{n} \mathrm{BuLi}$ (2.5 $\mathrm{M}$ in hexane, 1.2 equiv) was added and the mixture was stirred for $30 \mathrm{~min}$. Then TMSCl or MeI (3 equiv) was added and the system was stirred for $18 \mathrm{~h}$ at room temperature. The reaction was quenched with saturated aqueous ammonium chloride solution and extracted with $\mathrm{CH}_{2} \mathrm{Cl}_{2}$ three times. The organic layer was washed with brine, dried with $\mathrm{Na}_{2} \mathrm{SO}_{4}$, concentrated by rotary evaporation and purified by column chromatography on silica gel with hexanes/dichloromethane to give the products $(R)-3$ in $70-91 \%$ yield.

\section{Characterizations of the optically active diene-diynes $(R)-3$}

((R)-3-((2E,4E)-Hexa-2,4-dien-1-yloxy)octa-1,6-diyn-1-yl)benzene, $(R)-3-M e$.<smiles>CC#CCCC(C#Cc1ccccc1)OC/C=C/C=C/C</smiles>

Prepared from $(R)-2 a(172.0 \mathrm{mg}, 0.652 \mathrm{mmol})$, colorless oil, $144.5 \mathrm{mg}, 80 \%$ yield. $[\alpha]^{22}=77.5\left(\mathrm{c}=1.30, \mathrm{CHCl}_{3}\right) . \quad{ }^{1} \mathrm{H}$ NMR $\left(600 \mathrm{MHz}, \mathrm{CDCl}_{3}\right) \delta 7.43(\mathrm{~m}, 2 \mathrm{H}), 7.30$ $(\mathrm{m}, 3 \mathrm{H}), 6.25(\mathrm{~m}, 1 \mathrm{H}), 6.06(\mathrm{~m}, 1 \mathrm{H}), 5.72(\mathrm{~m}, 1 \mathrm{H}), 5.66(\mathrm{~m}, 1 \mathrm{H}), 4.43(\mathrm{t}, 1 \mathrm{H}, \mathrm{J}=6.6$ 
Hz), $4.32(\mathrm{dd}, 1 \mathrm{H}, \mathrm{J}=12,5.4 \mathrm{~Hz}), 4.05(\mathrm{dd}, 1 \mathrm{H}, \mathrm{J}=12,6.6 \mathrm{~Hz}), 2.35(\mathrm{~m}, 2 \mathrm{H}), 1.97$ $(\mathrm{m}, 2 \mathrm{H}), 1.77(\mathrm{~s}, 3 \mathrm{H}), 1.75(\mathrm{~d}, 3 \mathrm{H}, \mathrm{J}=6 \mathrm{~Hz}) .{ }^{13} \mathrm{C} \mathrm{NMR}\left(150 \mathrm{MHz}, \mathrm{CDCl}_{3}\right) \delta$ 133.6, $131.7,130.8,130.1,128.3,128.2,126.3,122.7,87.9,85.9,78.1,76.0,69.2,67.7,35.2$, 18.1, 15.0, 3.5. HRMS [ESI(TOF)] for $\mathrm{C}_{20} \mathrm{H}_{23} \mathrm{O}\left[\mathrm{M}+\mathrm{H}^{+}\right]$: m/z: calcd for: 279.1749; found: 279.1749 .

((R)-5-((2E,4E)-Hexa-2,4-dien-1-yloxy)-7-phenylhepta-1,6-diyn-1-yl)trimethylsila ne, $(R)-3 a$.<smiles>CC#CCCC(C#Cc1ccccc1)OCC=CC=CC</smiles>

Prepared from $(R)-\mathbf{2 a}(123.0 \mathrm{mg}, 0.466 \mathrm{mmol})$, colorless oil, $127.6 \mathrm{mg}, 82 \%$ yield. $[\alpha]^{22}=69.3\left(\mathrm{c}=1.92, \mathrm{CHCl}_{3}\right) . \quad{ }^{1} \mathrm{H}$ NMR $\left(600 \mathrm{MHz}, \mathrm{CDCl}_{3}\right) \delta 7.44(\mathrm{~m}, 2 \mathrm{H}), 7.30$ $(\mathrm{m}, 3 \mathrm{H}), 6.25(\mathrm{~m}, 1 \mathrm{H}), 6.06(\mathrm{~m}, 1 \mathrm{H}), 5.72(\mathrm{~m}, 1 \mathrm{H}), 5.65(\mathrm{~m}, 1 \mathrm{H}), 4.43(\mathrm{t}, 1 \mathrm{H}, \mathrm{J}=7.2$ Hz), $4.31(\mathrm{dd}, 1 \mathrm{H}, \mathrm{J}=12,6 \mathrm{~Hz}), 4.06(\mathrm{dd}, 1 \mathrm{H}, \mathrm{J}=12,7.2 \mathrm{~Hz}), 2.46(\mathrm{~m}, 2 \mathrm{H}), 2.01(\mathrm{~m}$, 2H), $1.75(\mathrm{~d}, 3 \mathrm{H}, \mathrm{J}=6.6 \mathrm{~Hz}) .{ }^{13} \mathrm{C} \mathrm{NMR}\left(150 \mathrm{MHz}, \mathrm{CDCl}_{3}\right) \delta 133.7,131.7,130.8$ $130.1,128.3,128.2,126.2,122.6,106.3,87.7,86.0,85.0,69.2,67.4,34.8,18.1,16.1$ 0.1. HRMS [ESI(TOF)] for $\mathrm{C}_{22} \mathrm{H}_{29} \mathrm{OSi}\left[\mathrm{M}+\mathrm{H}^{+}\right]$: $\mathrm{m} / \mathrm{z}$ : calcd for: 337.1988 ; found: 337.1995 . 

ane, $(R)-3 b$.<smiles>CC#CCC[C@H](C#Cc1ccc(C)cc1)OC/C=C/C=C/C</smiles>

Prepared from $(R)-\mathbf{2 b}(125.8 \mathrm{mg}, 0.453 \mathrm{mmol})$, colorless oil, $111.2 \mathrm{mg}, 70 \%$ yield. $[\alpha]^{22}=63.6\left(\mathrm{c}=1.89, \mathrm{CHCl}_{3}\right) . \quad{ }^{1} \mathrm{H} \mathrm{NMR}\left(600 \mathrm{MHz}, \mathrm{CDCl}_{3}\right) \delta 7.32(\mathrm{~d}, 2 \mathrm{H}, \mathrm{J}=8.4$ Hz), $7.10(\mathrm{~d}, 2 \mathrm{H}, 7.8 \mathrm{~Hz}), 6.25(\mathrm{~m}, 1 \mathrm{H}), 6.06(\mathrm{~m}, 1 \mathrm{H}), 5.72(\mathrm{~m}, 1 \mathrm{H}), 5.65(\mathrm{~m}, 1 \mathrm{H})$, $4.42(\mathrm{~m}, 1 \mathrm{H}), 4.31(\mathrm{dd}, 1 \mathrm{H}, \mathrm{J}=12.6,6 \mathrm{~Hz}), 4.05(\mathrm{dd}, 1 \mathrm{H}, \mathrm{J}=12,6.6 \mathrm{~Hz}), 2.46(\mathrm{~m}$, 2H), $2.34(\mathrm{~s}, 3 \mathrm{H}), 2.00(\mathrm{~m}, 2 \mathrm{H}), 1.75(\mathrm{~d}, 3 \mathrm{H}, \mathrm{J}=6 \mathrm{~Hz}), 0.15(\mathrm{~s}, 9 \mathrm{H}) . \quad{ }^{13} \mathrm{C}$ NMR $(150$ $\left.\mathrm{MHz}, \mathrm{CDCl}_{3}\right) \delta 138.4,133.6,131.6,130.9,130.1,129.0,126.3,119.6,106.3,86.9$, 86.1, 84.9, 69.2, 67.5, 34.8, 21.5, 18.1, 16.1, 0.1. HRMS [ESI(TOF)] for $\mathrm{C}_{23} \mathrm{H}_{31} \mathrm{OSi}$ $\left[\mathrm{M}+\mathrm{H}^{+}\right]: \mathrm{m} / \mathrm{z}$ : calcd for: 351.2144 ; found: 351.2141 .

((R)-5-((2E,4E)-Hexa-2,4-dien-1-yloxy)-9-phenylnona-1,6-diyn-1-yl)trimethylsila ne, $(R)-3 c$.<smiles>CC#CCCC(C#CCCc1ccccc1)OC/C=C/C=C/C</smiles>

Prepared from $(R)-\mathbf{2 c}(178.8 \mathrm{mg}, 0.612 \mathrm{mmol})$, colorless oil, $203.8 \mathrm{mg}, 91 \%$ yield. $[\alpha]^{22}=45.7\left(\mathrm{c}=1.02, \mathrm{CHCl}_{3}\right) . \quad{ }^{1} \mathrm{H}$ NMR $\left(600 \mathrm{MHz}, \mathrm{CDCl}_{3}\right) \delta 7.29(\mathrm{~m}, 2 \mathrm{H}), 7.21$ $(\mathrm{m}, 3 \mathrm{H}), 6.17(\mathrm{~m}, 1 \mathrm{H}), 6.04(\mathrm{~m}, 1 \mathrm{H}), 5.69(\mathrm{~m}, 1 \mathrm{H}), 5.58(\mathrm{~m}, 1 \mathrm{H}), 4.15(\mathrm{~m}, 2 \mathrm{H}), 3.89$ $(\mathrm{dd}, 1 \mathrm{H}, \mathrm{J}=12.6,7.2 \mathrm{~Hz}), 2.82(\mathrm{t}, 2 \mathrm{H}, \mathrm{J}=7.2 \mathrm{~Hz}), 2.52(\mathrm{t}, 2 \mathrm{H}, \mathrm{J}=7.2 \mathrm{~Hz}), 2.33(\mathrm{~m}$, 
2H), $1.86(\mathrm{~m}, 2 \mathrm{H}), 1.75(\mathrm{~d}, 3 \mathrm{H}, \mathrm{J}=6.6 \mathrm{~Hz}), 0.14(\mathrm{~s}, 9 \mathrm{H}) .{ }^{13} \mathrm{C} \mathrm{NMR}(150 \mathrm{MHz}$, $\left.\mathrm{CDCl}_{3}\right) \delta 140.5,133.4,130.9,129.9,128.4,128.3,126.4,126.3,106.5,85.7,84.7$, 79.4, 68.8, 67.1, 35.0, 34.9, 20.9, 18.0, 16.0, 0.1. HRMS [ESI(TOF)] for $\mathrm{C}_{24} \mathrm{H}_{33} \mathrm{OSi}$ $\left[\mathrm{M}+\mathrm{H}^{+}\right]$: $\mathrm{m} / \mathrm{z}$ : calcd for: 365.2301 ; found: 365.2298 .

((R)-5-((2E,4E)-Hexa-2,4-dien-1-yloxy)undeca-1,6-diyn-1-yl)trimethylsilane, (R)-3d.<smiles>CC#CCC(C#CC)OC/C=C/C=C/C</smiles>

$(R)-3 d, 86 \%$

Prepared from $(R)$-2d (26.1 mg, $0.091 \mathrm{mmol})$, colorless oil, $29.1 \mathrm{mg}, 86 \%$ yield. $[\alpha]^{20}{ }_{\mathrm{D}}=48.3\left(\mathrm{c}=1.46, \mathrm{CHCl}_{3}\right) . \quad{ }^{1} \mathrm{H} \mathrm{NMR}\left(600 \mathrm{MHz}, \mathrm{CDCl}_{3}\right) \delta 6.20(\mathrm{~m}, 1 \mathrm{H}), 6.04$ (m, 1H), $5.69(\mathrm{~m}, 1 \mathrm{H}), 5.60(\mathrm{~m}, 1 \mathrm{H}), 4.21(\mathrm{dd}, 1 \mathrm{H}, \mathrm{J}=12.6,6 \mathrm{~Hz}), 4.16(\mathrm{t}, 1 \mathrm{H}, \mathrm{J}=6$ Hz), $3.95(\mathrm{dd}, 1 \mathrm{H}, \mathrm{J}=12.6,6.6 \mathrm{~Hz}), 2.36(\mathrm{~m}, 2 \mathrm{H}), 2.20(\mathrm{t}, 2 \mathrm{H}, \mathrm{J}=5.4 \mathrm{~Hz}), 1.87(\mathrm{~m}$, 2H), $1.73(\mathrm{~d}, 3 \mathrm{H}, \mathrm{J}=6.6 \mathrm{~Hz}), 1.48(\mathrm{~m}, 2 \mathrm{H}), 1.40(\mathrm{~m}, 2 \mathrm{H}), 0.90(\mathrm{t}, 3 \mathrm{H}, \mathrm{J}=7.2 \mathrm{~Hz})$, $0.12(\mathrm{~s}, 9 \mathrm{H}) . \quad{ }^{13} \mathrm{C} \mathrm{NMR}\left(150 \mathrm{MHz}, \mathrm{CDCl}_{3}\right) \delta 133.4,130.9,129.9,126.4,106.5,86.6$, $84.7,78.4,68.8,67.2,35.0,30.7,21.9,18.4,18.1,16.0,13.6,0.1$. HRMS [ESI(TOF)] for $\mathrm{C}_{20} \mathrm{H}_{33} \mathrm{OSi}\left[\mathrm{M}+\mathrm{H}^{+}\right]$: m/z: calcd for: 317.2301; found: 317.2298.

((R)-5-((2E,4E)-Hexa-2,4-dien-1-yloxy)trideca-1,6-diyn-1-yl)trimethylsilane, (R)-3e.<smiles>CC#CCC(C#CC)OC/C=C/C=C/C</smiles>

(R)-3e, $76 \%$ 
Prepared from $(R)-2 \mathrm{e}(69.5 \mathrm{mg}, 0.256 \mathrm{mmol})$, colorless oil, $66.6 \mathrm{mg}, 76 \%$ yield. $[\alpha]^{20}{ }_{\mathrm{D}}=48.0\left(\mathrm{c}=1.65, \mathrm{CHCl}_{3}\right) . \quad{ }^{1} \mathrm{H}$ NMR $\left(600 \mathrm{MHz}, \mathrm{CDCl}_{3}\right) \delta 6.20(\mathrm{~m}, 1 \mathrm{H}), 6.04$ (m, 1H), $5.69(\mathrm{~m}, 1 \mathrm{H}), 5.60(\mathrm{~m}, 1 \mathrm{H}), 4.20(\mathrm{dd}, 1 \mathrm{H}, \mathrm{J}=12,5.4 \mathrm{~Hz}), 4.16(\mathrm{t}, 1 \mathrm{H}, \mathrm{J}=6$ Hz), $3.95(\mathrm{~m}, 1 \mathrm{H}, \mathrm{J}=12.6,6.6 \mathrm{~Hz}), 2.37(\mathrm{~m}, 2 \mathrm{H}), 2.20(\mathrm{t}, 2 \mathrm{H}, \mathrm{J}=6 \mathrm{~Hz}), 1.88(\mathrm{~m}, 2 \mathrm{H})$, $1.73(\mathrm{~d}, 3 \mathrm{H}, \mathrm{J}=6.6 \mathrm{~Hz}), 1.49(\mathrm{~m}, 2 \mathrm{H}), 1.37(\mathrm{~m}, 2 \mathrm{H}), 1.28(\mathrm{~m}, 4 \mathrm{H}), 0.88(\mathrm{t}, 3 \mathrm{H}, \mathrm{J}=6.6$ $\mathrm{Hz}), 0.13(\mathrm{~s}, 9 \mathrm{H}) . \quad{ }^{13} \mathrm{C} \mathrm{NMR}\left(150 \mathrm{MHz}, \mathrm{CDCl}_{3}\right) \delta 133.4,130.9,129.9,126.4,106.5$, $86.7,84.7,78.4,68.8,67.2,35.0,31.3,28.6,28.5,22.5,18.7,18.1,16.0,14.0,0.1$. HRMS [ESI(TOF)] for $\mathrm{C}_{22} \mathrm{H}_{37} \mathrm{OSi}\left[\mathrm{M}+\mathrm{H}^{+}\right]$: $\mathrm{m} / \mathrm{z}$ : calcd for: 345.2614; found: 345.2619 .

((R)-10-Chloro-5-((2E,4E)-hexa-2,4-dien-1-yloxy)deca-1,6-diyn-1-yl)trimethylsila ne, $(R)-3 f$.<smiles>CC#CCCC(C#CCCl)OCC=CC=CC</smiles>
$(R)-3 f, 76 \%$

Prepared from $(R)$-2f $(31.5 \mathrm{mg}, 0.119 \mathrm{mmol})$, colorless oil, $30.3 \mathrm{mg}, 76 \%$ yield. $[\alpha]^{20}{ }_{\mathrm{D}}=48.1\left(\mathrm{c}=1.52, \mathrm{CHCl}_{3}\right) . \quad{ }^{1} \mathrm{H}$ NMR $\left(600 \mathrm{MHz}, \mathrm{CDCl}_{3}\right) \delta 6.20(\mathrm{~m}, 1 \mathrm{H}), 6.04$ (m, 1H), $5.70(\mathrm{~m}, 1 \mathrm{H}), 5.59(\mathrm{~m}, 1 \mathrm{H}), 4.20(\mathrm{~m}, 1 \mathrm{H}), 4.16(\mathrm{~m}, 1 \mathrm{H}), 3.95(\mathrm{~m}, 1 \mathrm{H}), 3.63(\mathrm{t}$, $2 \mathrm{H}, \mathrm{J}=6.6 \mathrm{~Hz}), 2.41(\mathrm{~m}, 2 \mathrm{H}), 2.35(\mathrm{~m}, 2 \mathrm{H}), 1.95(\mathrm{t}, 2 \mathrm{H}, \mathrm{J}=6.6 \mathrm{~Hz}), 1.87(\mathrm{~m}, 2 \mathrm{H})$, $1.74(\mathrm{~d}, 3 \mathrm{H}, \mathrm{J}=6.6 \mathrm{~Hz}), 0.13(\mathrm{~s}, 9 \mathrm{H}) .{ }^{13} \mathrm{C} \mathrm{NMR}\left(150 \mathrm{MHz}, \mathrm{CDCl}_{3}\right) \delta 133.5,130.8$ $130.1,126.2,106.3,84.9,84.4,79.7,69.0,67.1,43.6,34.9,31.3,18.1,16.2,16.0,0.1$. HRMS [ESI(TOF)] for $\mathrm{C}_{19} \mathrm{H}_{30} \mathrm{OSiCl}\left[\mathrm{M}+\mathrm{H}^{+}\right]$: m/z: calcd for: 337.1754; found: 
((R)-5-((2E,4E)-Hexa-2,4-dien-1-yloxy)-8-phenoxyocta-1,6-diyn-1-yl)trimethylsila ne, $(R)-3 g$.<smiles>CC#CCC[C@@H](C#CCOc1ccccc1)OC/C=C/C=C/C</smiles>

Prepared from $(R)-2 \mathrm{~g}(99.4 \mathrm{mg}, 0.338 \mathrm{mmol})$, colorless oil, $94.6 \mathrm{mg}, 76 \%$ yield. $[\alpha]^{20}{ }_{\mathrm{D}}=57.8\left(\mathrm{c}=0.78, \mathrm{CHCl}_{3}\right) . \quad{ }^{1} \mathrm{H} \mathrm{NMR}\left(600 \mathrm{MHz}, \mathrm{CDCl}_{3}\right) \delta 7.30(\mathrm{t}, 2 \mathrm{H}, \mathrm{J}=7.2$ Hz), $6.98(\mathrm{~m}, 3 \mathrm{H}), 6.13(\mathrm{~m}, 1 \mathrm{H}), 6.01(\mathrm{~m}, 1 \mathrm{H}), 5.68(\mathrm{~m}, 1 \mathrm{H}), 5.56(\mathrm{~m}, 1 \mathrm{H}), 4.73(\mathrm{~s}$, 2H), $4.23(\mathrm{t}, 1 \mathrm{H}, \mathrm{J}=6 \mathrm{~Hz}), 4.17(\mathrm{dd}, 1 \mathrm{H}, \mathrm{J}=12.6,6 \mathrm{~Hz}), 3.92(\mathrm{dd}, 1 \mathrm{H}, \mathrm{J}=12,7.2 \mathrm{~Hz})$, $2.35(\mathrm{~m}, 2 \mathrm{H}), 1.89(\mathrm{~m}, 2 \mathrm{H}), 1.73(\mathrm{~d}, 3 \mathrm{H}, \mathrm{J}=6.6 \mathrm{~Hz}), 0.13(\mathrm{~s}, 9 \mathrm{H}) .{ }^{13} \mathrm{C}$ NMR $(150$ $\left.\mathrm{MHz}, \mathrm{CDCl}_{3}\right) \delta 157.5,133.8,130.7,130.2,129.4,125.9,121.4,115.0,106.0,86.0$ 85.1, 80.8, 69.2, 66.8, 56.0, 34.4, 18.1, 15.9, 0.1. HRMS [ESI(TOF)] for $\mathrm{C}_{23} \mathrm{H}_{31} \mathrm{O}_{2} \mathrm{Si}$ $\left[\mathrm{M}+\mathrm{H}^{+}\right]: \mathrm{m} / \mathrm{z}$ : calcd for: 367.2093 ; found: 367.2099 .

\section{General procedure for the catalytic domino PK/DA cycloaddition}

Under nitrogen, a propargyl 2,4-hexadienyl ether (1 equiv) and $\left[\mathrm{Rh}(\mathrm{CO})_{2} \mathrm{Cl}\right]_{2}$ (0.1 equiv) were weighed into a tared two-necked round bottom flask and dissolved in 1,2-dichloroethane (DCE, $5 \mathrm{~mL}$ ). The flask was fitted with reflux condenser fitted with a septum and the side arm of the flask was also fitted with a septum. The solution was bubbled with CO gas for 2 minutes through the side arm fitted with septum and a vent needle in the septum of the reflux condenser in a well-vented fuming hood. 
Then, the solution was placed under CO atmosphere by using a balloon. After the reaction mixture was heated at $80{ }^{\circ} \mathrm{C}$ to reflux temperature for $19-26 \mathrm{~h}$, it was cooled to room temperature and the $\mathrm{CO}$ was released cautiously in the fuming hood. The reaction mixture was concentrated and the crude product was purified by column chromatography on silica gel with hexanes/ethyl acetate to give the tetracyclic products 4 with $42-64 \%$ yield and 87 - $88 \%$ ee.

\section{Characterizations of the domino PK/DA cycloaddition products 4}

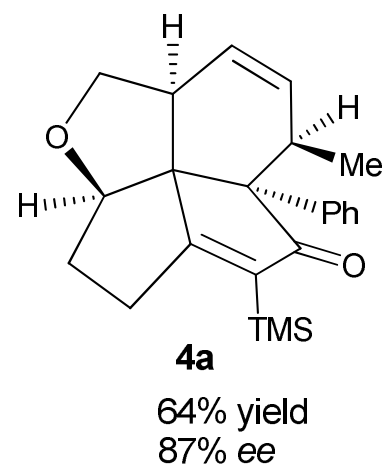

4a. Prepared from $(R)-3 \mathbf{a}(127.6 \mathrm{mg}, 0.380 \mathrm{mmol})$, colorless oil, $88.7 \mathrm{mg}, 64 \%$ yield. $\quad 87 \%$ ee determined by HPLC analysis: CHIRALPAK AD-H column, 100:0.5 hexanes: ${ }^{i} \operatorname{PrOH}$, flow rate $=1.0 \mathrm{~mL} / \mathrm{min}, \lambda=254 \mathrm{~nm}$, retention time: $\mathrm{t}_{\text {major }}=7.6 \mathrm{~min}$, $\mathrm{t}_{\text {minor }}=9.4 \min . \quad[\alpha]^{22}{ }_{\mathrm{D}}=371.3\left(\mathrm{c}=1.18, \mathrm{CHCl}_{3}\right) . \quad{ }^{1} \mathrm{H} \mathrm{NMR}\left(800 \mathrm{MHz}, \mathrm{CDCl}_{3}\right) \delta$ $7.27(\mathrm{~m}, 2 \mathrm{H}), 7.19(\mathrm{~m}, 1 \mathrm{H}), 7.02(\mathrm{br}, 2 \mathrm{H}), 5.88(\mathrm{~m}, 1 \mathrm{H}), 5.84(\mathrm{~m}, 1 \mathrm{H}), 4.16(\mathrm{t}, 1 \mathrm{H}, \mathrm{J}=$ $7.2 \mathrm{~Hz}), 3.75(\mathrm{dd}, 1 \mathrm{H}, \mathrm{J}=12.8,8 \mathrm{~Hz}), 3.61(\mathrm{~d}, 1 \mathrm{H}, \mathrm{J}=3.2 \mathrm{~Hz}), 3.11(\mathrm{~m}, 1 \mathrm{H}), 2.99(\mathrm{~m}$, 1H), $2.59(\mathrm{~m}, 1 \mathrm{H}), 2.52(\mathrm{~m}, 1 \mathrm{H}), 2.08(\mathrm{dd}, 1 \mathrm{H}, \mathrm{J}=12.8,7.2 \mathrm{~Hz}), 1.26(\mathrm{~d}, 3 \mathrm{H}, \mathrm{J}=7.2$ $\mathrm{Hz}), 1.07(\mathrm{~m}, 1 \mathrm{H}), 0.25(\mathrm{~s}, 9 \mathrm{H}) .{ }^{13} \mathrm{C} \mathrm{NMR}\left(150 \mathrm{MHz}, \mathrm{CDCl}_{3}\right) \delta$ 211.5, 192.6, 143.7, $139.7,136.4,128.5,127.0,126.5,124.5,80.9,74.2,69.7,65.6,51.5,39.8,37.9,32.0$, 15.3, 0.9. HRMS [ESI(TOF)] for $\mathrm{C}_{23} \mathrm{H}_{29} \mathrm{O}_{2} \mathrm{Si}\left[\mathrm{M}+\mathrm{H}^{+}\right]$: $\mathrm{m} / \mathrm{z}$ : calcd for: 365.1937 ; 
found: 365.1939 .

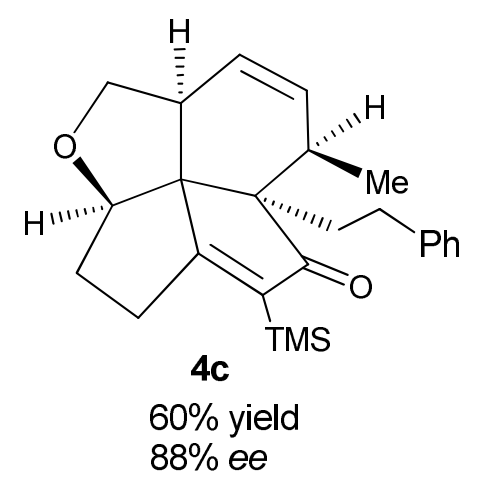

4c. Prepared from $(R)-3 c(203.8 \mathrm{mg}, 0.560 \mathrm{mmol})$, colorless oil, $131.7 \mathrm{mg}, 60 \%$ yield. $88 \%$ ee determined by HPLC analysis: CHIRALPAK AD-H column, 100:0.5 hexanes: ${ }^{i} \operatorname{PrOH}$, flow rate $=1.0 \mathrm{~mL} / \mathrm{min}, \lambda=254 \mathrm{~nm}$, retention time: $\mathrm{t}_{\text {major }}=8.9 \mathrm{~min}$, $\mathrm{t}_{\text {minor }}=10.9 \min . \quad[\alpha]_{\mathrm{D}}^{22}=147.4\left(\mathrm{c}=0.58, \mathrm{CHCl}_{3}\right) . \quad{ }^{1} \mathrm{H} \mathrm{NMR}\left(600 \mathrm{MHz}, \mathrm{CDCl}_{3}\right) \delta$ $7.27(\mathrm{~m}, 2 \mathrm{H}), 7.18(\mathrm{~m}, 3 \mathrm{H}), 5.82(\mathrm{~m}, 1 \mathrm{H}), 5.66(\mathrm{~m}, 1 \mathrm{H}), 4.69(\mathrm{~d}, 1 \mathrm{H}, \mathrm{J}=4.2 \mathrm{~Hz}), 4.17$ $(\mathrm{t}, 1 \mathrm{H}, \mathrm{J}=7.8 \mathrm{~Hz}), 3.84(\mathrm{dd}, 1 \mathrm{H}, \mathrm{J}=12.6,7.8 \mathrm{~Hz}), 2.90(\mathrm{~m}, 1 \mathrm{H}), 2.64(\mathrm{dd}, 1 \mathrm{H}, \mathrm{J}=$ 13.8, $7.2 \mathrm{~Hz}), 2.56(\mathrm{~m}, 3 \mathrm{H}), 2.42(\mathrm{dd}, 1 \mathrm{H}, \mathrm{J}=13.2,7.2 \mathrm{~Hz}), 2.34(\mathrm{~m}, 1 \mathrm{H}), 2.09(\mathrm{~m}$, 1H), $1.70(\mathrm{~m}, 2 \mathrm{H}), 1.37(\mathrm{~d}, 3 \mathrm{H}, \mathrm{J}=7.2 \mathrm{~Hz}), 0.16(\mathrm{~s}, 9 \mathrm{H}) .{ }^{13} \mathrm{C}$ NMR (150 MHz, $\left.\mathrm{CDCl}_{3}\right) \delta 211.1,192.0,142.5,142.1,136.2,128.7,128.3,126.2,124.7,79.9,71.6$ 69.6, 58.8, 52.2, 39.6, 38.7, 33.5, 32.2, 31.0, 15.3, 0.8. HRMS [ESI(TOF)] for $\mathrm{C}_{25} \mathrm{H}_{33} \mathrm{O}_{2} \mathrm{Si}\left[\mathrm{M}+\mathrm{H}^{+}\right]$: m/z: calcd for: 393.2250; found: 393.2250 .

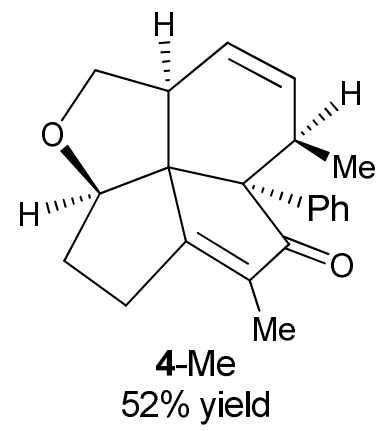


4-Me. Prepared from $(R)-3-M e(144.5 \mathrm{mg}, 0.520 \mathrm{mmol})$, light yellow oil, $82.7 \mathrm{mg}$, $52 \%$ yield. $[\alpha]^{22}{ }_{\mathrm{D}}=328.8\left(\mathrm{c}=1.14, \mathrm{CHCl}_{3}\right) . \quad{ }^{1} \mathrm{H}$ NMR $\left(600 \mathrm{MHz}, \mathrm{CDCl}_{3}\right) \delta 7.27$ (m, 3H), $7.03(\mathrm{~m}, 2 \mathrm{H}), 5.89(\mathrm{~m}, 1 \mathrm{H}), 5.83(\mathrm{~m}, 1 \mathrm{H}), 4.17(\mathrm{t}, 1 \mathrm{H}, \mathrm{J}=7.8 \mathrm{~Hz}), 3.75(\mathrm{dd}$, $1 \mathrm{H}, \mathrm{J}=12,7.8 \mathrm{~Hz}), 3.59(\mathrm{~d}, 1 \mathrm{H}, \mathrm{J}=3 \mathrm{~Hz}), 3.11(\mathrm{~m}, 1 \mathrm{H}), 3.03(\mathrm{~m}, 1 \mathrm{H}), 2.56(\mathrm{dd}, 1 \mathrm{H}$, $\mathrm{J}=20.4,7.2 \mathrm{~Hz}), 2.43(\mathrm{~m}, 1 \mathrm{H}), 2.07(\mathrm{dd}, 1 \mathrm{H}, \mathrm{J}=13.2,7.2 \mathrm{~Hz}), 1.82(\mathrm{~s}, 3 \mathrm{H}), 1.27(\mathrm{~d}$, $3 \mathrm{H}, \mathrm{J}=7.2 \mathrm{~Hz}), 1.08(\mathrm{~m}, 1 \mathrm{H}) .{ }^{13} \mathrm{C} \mathrm{NMR}\left(150 \mathrm{MHz}, \mathrm{CDCl}_{3}\right) \delta 208.1,178.4,139.6$, $139.1,136.3,128.7,127.2,126.8,125.2,81.2,71.6,69.9,64.7,51.3,40.2,38.2,29.8$, 15.4, 9.5. HRMS [ESI(TOF)] for $\mathrm{C}_{21} \mathrm{H}_{23} \mathrm{O}_{2}\left[\mathrm{M}+\mathrm{H}^{+}\right]$: $\mathrm{m} / \mathrm{z}$ : calcd for: 307.1698; found: 307.1693 .

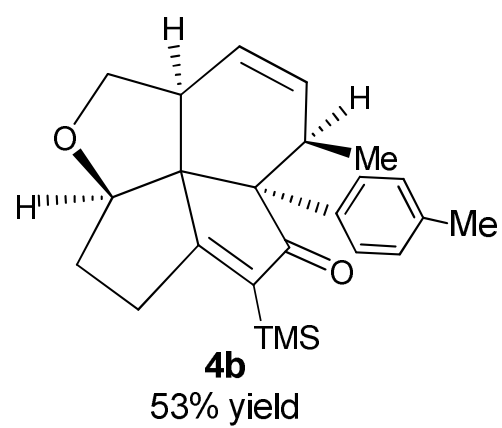

4b. Prepared from $(R)-3 \mathbf{b}(111.2 \mathrm{mg}, 0.318 \mathrm{mmol})$, colorless oil, $63.2 \mathrm{mg}, 53 \%$ yield. $[\alpha]^{22}{ }_{\mathrm{D}}=370.6\left(\mathrm{c}=1.17, \mathrm{CHCl}_{3}\right) . \quad{ }^{1} \mathrm{H} \mathrm{NMR}\left(600 \mathrm{MHz}, \mathrm{CDCl}_{3}\right) \delta 7.07(\mathrm{~d}, 2 \mathrm{H}$, $\mathrm{J}=7.2 \mathrm{~Hz}), 6.89(\mathrm{~s}, 2 \mathrm{H}), 5.86(\mathrm{~m}, 1 \mathrm{H}), 5.83(\mathrm{~m}, 1 \mathrm{H}), 4.15(\mathrm{t}, 1 \mathrm{H}, \mathrm{J}=7.2 \mathrm{~Hz}), 3.74(\mathrm{~m}$, 1H), $3.64(\mathrm{~s}, 1 \mathrm{H}), 3.09(\mathrm{~m}, 1 \mathrm{H}), 2.95(\mathrm{~s}, 1 \mathrm{H}), 2.58(\mathrm{~m}, 1 \mathrm{H}), 2.52(\mathrm{~m}, 1 \mathrm{H}), 2.28(\mathrm{~s}, 3 \mathrm{H})$, $2.08(\mathrm{~m}, 1 \mathrm{H}), 1.25(\mathrm{~d}, 3 \mathrm{H}, \mathrm{J}=6 \mathrm{~Hz}), 1.07(\mathrm{~m}, 1 \mathrm{H}), 0.24(\mathrm{~s}, 9 \mathrm{H}) .{ }^{13} \mathrm{C}$ NMR $(150$ $\left.\mathrm{MHz}, \mathrm{CDCl}_{3}\right) \delta 211.6,192.5,143.6,136.6,136.5,136.0,129.2,126.9,124.4,81.0$ $74.1,69.7,65.3,51.5,39.8,37.9,32.0,20.9,15.3,0.9$. HRMS [ESI(TOF)] for $\mathrm{C}_{24} \mathrm{H}_{31} \mathrm{O}_{2} \mathrm{Si}\left[\mathrm{M}+\mathrm{H}^{+}\right]$: m/z: calcd for: 379.2093; found: 379.2091 . 


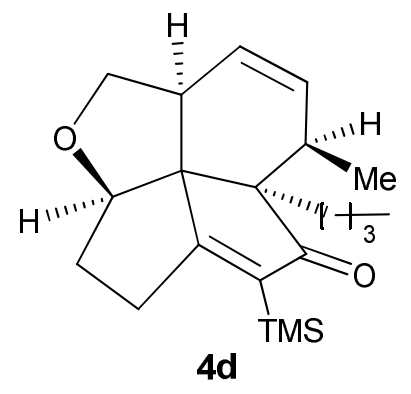

$45 \%$ yield

4d. Prepared from $(R)-3 d$ (29.1 mg, $0.092 \mathrm{mmol})$, light yellow oil, $14.1 \mathrm{mg}, 45 \%$ yield. $[\alpha]^{21}=101.3\left(\mathrm{c}=0.51, \mathrm{CHCl}_{3}\right) . \quad{ }^{1} \mathrm{H} \mathrm{NMR}\left(600 \mathrm{MHz}, \mathrm{CDCl}_{3}\right) \delta 5.77(\mathrm{~m}, 1 \mathrm{H})$, $5.62(\mathrm{~m}, 1 \mathrm{H}), 4.48(\mathrm{~d}, 1 \mathrm{H}, \mathrm{J}=4.2 \mathrm{~Hz}), 4.12(\mathrm{t}, 1 \mathrm{H}, \mathrm{J}=7.8 \mathrm{~Hz}), 3.79(\mathrm{dd}, 1 \mathrm{H}, \mathrm{J}=12.6$, $7.8 \mathrm{~Hz}), 2.82(\mathrm{~m}, 1 \mathrm{H}), 2.60(\mathrm{dd}, 1 \mathrm{H}, \mathrm{J}=13.8,7.2 \mathrm{~Hz}), 2.51(\mathrm{~m}, 1 \mathrm{H}), 2.36(\mathrm{dd}, 1 \mathrm{H}, \mathrm{J}=$ 13.2, 7.2 Hz), $2.27(\mathrm{~m}, 1 \mathrm{H}), 1.79(\mathrm{~m}, 1 \mathrm{H}), 1.63(\mathrm{~m}, 1 \mathrm{H}), 1.29$ (d, 3H, J = 7.2 Hz), 1.27 $(\mathrm{m}, 5 \mathrm{H}), 0.89(\mathrm{t}, 1 \mathrm{H}, \mathrm{J}=6.6 \mathrm{~Hz}), 0.15(\mathrm{~s}, 9 \mathrm{H}) . \quad{ }^{13} \mathrm{C} \mathrm{NMR}\left(150 \mathrm{MHz}, \mathrm{CDCl}_{3}\right) \delta 211.5$, $191.7,142.1,136.1,124.3,79.6,71.4,69.4,58.6,52.0,39.3,38.2,31.9,30.8,26.5$, 23.5, 15.0, 13.9, -1.0. HRMS [ESI(TOF)] for $\mathrm{C}_{21} \mathrm{H}_{33} \mathrm{O}_{2} \mathrm{Si}\left[\mathrm{M}+\mathrm{H}^{+}\right]$: $\mathrm{m} / \mathrm{z}$ : calcd for: 345.2250; found: 345.2245 .

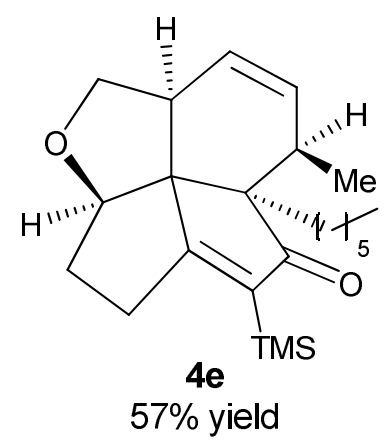

4e. Prepared from $(R)-3 e(26.7 \mathrm{mg}, 0.078 \mathrm{mmol})$, light yellow oil, $16.6 \mathrm{mg}, 57 \%$ yield. $[\alpha]^{21}=134.7\left(\mathrm{c}=0.83, \mathrm{CHCl}_{3}\right) . \quad{ }^{1} \mathrm{H} \mathrm{NMR}\left(600 \mathrm{MHz}, \mathrm{CDCl}_{3}\right) \delta 5.77(\mathrm{~m}, 1 \mathrm{H})$, $5.62(\mathrm{~m}, 1 \mathrm{H}), 4.47(\mathrm{~d}, 1 \mathrm{H}, \mathrm{J}=4.2 \mathrm{~Hz}), 4.12(\mathrm{t}, 1 \mathrm{H}, \mathrm{J}=7.8 \mathrm{~Hz}), 3.79(\mathrm{dd}, 1 \mathrm{H}, \mathrm{J}=12.6$, $7.8 \mathrm{~Hz}), 2.82(\mathrm{~m}, 1 \mathrm{H}), 2.60(\mathrm{dd}, 1 \mathrm{H}, \mathrm{J}=13.8,6.6 \mathrm{~Hz}), 2.52(\mathrm{~m}, 1 \mathrm{H}), 2.36(\mathrm{dd}, 1 \mathrm{H}, \mathrm{J}=$ 
13.2, 7.2 Hz), $2.26(\mathrm{~m}, 1 \mathrm{H}), 1.78(\mathrm{~m}, 1 \mathrm{H}), 1.64(\mathrm{~m}, 1 \mathrm{H}), 1.30$ (d, 3H, J = 7.8 Hz), 1.25 $(\mathrm{m}, 9 \mathrm{H}), 0.87(\mathrm{t}, 3 \mathrm{H}, \mathrm{J}=6 \mathrm{~Hz}), 0.15(\mathrm{~s}, 9 \mathrm{H}) .{ }^{13} \mathrm{C} \mathrm{NMR}\left(150 \mathrm{MHz}, \mathrm{CDCl}_{3}\right) \delta 211.7$, $191.9,142.3,136.4,124.5,79.9,71.7,69.6,58.9,52.2,39.5,38.5,32.1,31.8,31.3$, 30.3, 24.6, 22.8, 15.2, 14.2, -0.7. HRMS [ESI(TOF)] for $\mathrm{C}_{23} \mathrm{H}_{37} \mathrm{O}_{2} \mathrm{Si}\left[\mathrm{M}+\mathrm{H}^{+}\right]: \mathrm{m} / \mathrm{z}$ : calcd for: 373.2563 ; found: 373.2561 .

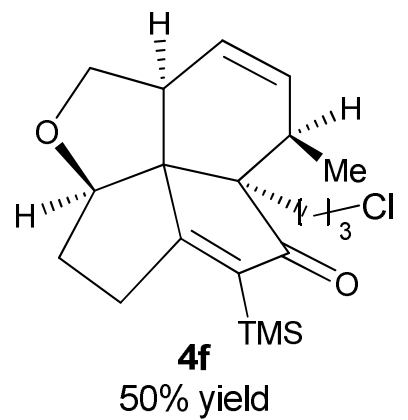

4f. Prepared from $(R)$-3f $(30.3 \mathrm{mg}, 0.090 \mathrm{mmol})$, colorless oil, $16.4 \mathrm{mg}, 50 \%$ yield. $[\alpha]^{21}=182.0\left(\mathrm{c}=0.35, \mathrm{CHCl}_{3}\right) . \quad{ }^{1} \mathrm{H}$ NMR $\left(600 \mathrm{MHz}, \mathrm{CDCl}_{3}\right) \delta 5.78(\mathrm{~m}, 1 \mathrm{H}), 5.62$ (m, 1H), $4.55(\mathrm{~d}, 1 \mathrm{H}, \mathrm{J}=3 \mathrm{~Hz}), 4.12(\mathrm{t}, 1 \mathrm{H}, \mathrm{J}=7.2 \mathrm{~Hz}), 3.79(\mathrm{dd}, 1 \mathrm{H}, \mathrm{J}=13.2,9 \mathrm{~Hz})$, $3.50(\mathrm{~m}, 2 \mathrm{H}), 2.79(\mathrm{~m}, 1 \mathrm{H}), 2.61(\mathrm{dd}, 1 \mathrm{H}, \mathrm{J}=13.8,7.2 \mathrm{~Hz}), 2.51(\mathrm{~m}, 1 \mathrm{H}), 2.37(\mathrm{dd}$, $1 \mathrm{H}, \mathrm{J}=13.2,7.2 \mathrm{~Hz}), 2.22(\mathrm{~m}, 1 \mathrm{H}), 1.91(\mathrm{~m}, 1 \mathrm{H}), 1.72(\mathrm{~m}, 2 \mathrm{H}), 1.65(\mathrm{~m}, 1 \mathrm{H}), 1.57$ $(\mathrm{m}, 1 \mathrm{H}), 1.29(\mathrm{~d}, 3 \mathrm{H}, \mathrm{J}=7.2 \mathrm{~Hz}), 0.15(\mathrm{~s}, 9 \mathrm{H}) .{ }^{13} \mathrm{C} \mathrm{NMR}\left(150 \mathrm{MHz}, \mathrm{CDCl}_{3}\right) \delta$ $210.7,191.9,142.2,135.8,124.6,79.4,71.3,69.3,57.9,51.9,45.3,39.3,38.5,31.9$ 28.3, 27.6, 15.0,-1.0. HRMS [ESI(TOF)] for $\mathrm{C}_{20} \mathrm{H}_{30} \mathrm{O}_{2} \mathrm{SiCl}\left[\mathrm{M}+\mathrm{H}^{+}\right]$: m/z: calcd for: 365.1704; found: 365.1704 . 


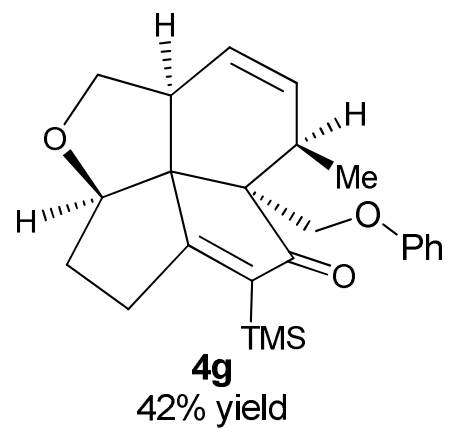

4g. Prepared from $(R)-3 g(94.6 \mathrm{mg}, 0.258 \mathrm{mmol})$, light yellow oil, $42.8 \mathrm{mg}, 42 \%$ yield. $[\alpha]^{21}{ }_{\mathrm{D}}=190.4\left(\mathrm{c}=0.66, \mathrm{CHCl}_{3}\right) . \quad{ }^{1} \mathrm{H} \mathrm{NMR}\left(600 \mathrm{MHz}, \mathrm{CDCl}_{3}\right) \delta 7.24(\mathrm{t}, 2 \mathrm{H}$, $\mathrm{J}=7.2 \mathrm{~Hz}), 6.92(\mathrm{t}, 1 \mathrm{H}, \mathrm{J}=7.8 \mathrm{~Hz}), 6.80(\mathrm{~d}, 1 \mathrm{H}, \mathrm{J}=8.4 \mathrm{~Hz}), 5.85(\mathrm{~m}, 1 \mathrm{H}), 5.66(\mathrm{~m}$, 1H), $4.51(\mathrm{~s}, 1 \mathrm{H}), 4.15(\mathrm{dd}, 2 \mathrm{H}, \mathrm{J}=15.6,7.2 \mathrm{~Hz}), 4.08(\mathrm{~d}, 1 \mathrm{H}, \mathrm{J}=9 \mathrm{~Hz}), 3.81(\mathrm{dd}, 1 \mathrm{H}$, $\mathrm{J}=12.6,8.4 \mathrm{~Hz}), 2.97(\mathrm{~m}, 1 \mathrm{H}), 2.66(\mathrm{dd}, 1 \mathrm{H}, \mathrm{J}=13.8,6.6 \mathrm{~Hz}), 2.58(\mathrm{~m}, 1 \mathrm{H}), 2.52(\mathrm{~m}$, 1H), $2.32(\mathrm{dd}, 1 \mathrm{H}, \mathrm{J}=12.6,7.2 \mathrm{~Hz}), 1.75(\mathrm{~m}, 1 \mathrm{H}), 1.37(\mathrm{~d}, 3 \mathrm{H}, \mathrm{J}=6.6 \mathrm{~Hz}), 0.18(\mathrm{~s}$, 9H). ${ }^{13} \mathrm{C} \mathrm{NMR}\left(150 \mathrm{MHz}, \mathrm{CDCl}_{3}\right) \delta 208.7,193.1,158.3,142.8,135.6,129.4,124.9$, $121,1,114.3,79.9,70.4,69.3,67.7,59.5,51.5,39.0,36.8,32.2,15.1,-1.0$. HRMS [ESI(TOF)] for $\mathrm{C}_{24} \mathrm{H}_{31} \mathrm{O}_{3} \mathrm{Si}\left[\mathrm{M}+\mathrm{H}^{+}\right]$: m/z: calcd for: 395.2042; found: 395.2039 .

\section{Characterizations of additional dienediyne substrates and a PK Product}

6-((2E,4E)-Hexa-2,4-dien-1-yloxy)dodeca-2,7-diyne, $3 i$.

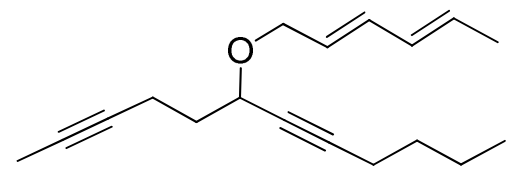

3i

Colorless oil, $72 \mathrm{mg}, 74 \%$ yield. ${ }^{1} \mathrm{H}$ NMR $\left(600 \mathrm{MHz}, \mathrm{CDCl}_{3}\right) \delta 6.20(\mathrm{~m}, 1 \mathrm{H}), 6.04$ $(\mathrm{m}, 1 \mathrm{H}), 5.69(\mathrm{~m}, 1 \mathrm{H}), 5.61(\mathrm{~m}, 1 \mathrm{H}), 4.22(\mathrm{dd}, 1 \mathrm{H}, \mathrm{J}=12,5.4 \mathrm{~Hz}), 4.16(\mathrm{t}, 1 \mathrm{H}, \mathrm{J}=6$ Hz), $3.95(\mathrm{dd}, 1 \mathrm{H}, \mathrm{J}=12.6,7.2 \mathrm{~Hz}), 2.27(\mathrm{~m}, 2 \mathrm{H}), 2.20(\mathrm{t}, 2 \mathrm{H}, \mathrm{J}=7.2 \mathrm{~Hz}), 1.86(\mathrm{~m}$, 1H), $1.80(\mathrm{~m}, 1 \mathrm{H}), 1.75(\mathrm{~s}, 3 \mathrm{H}), 1.73(\mathrm{~d}, 3 \mathrm{H}, \mathrm{J}=7.2 \mathrm{~Hz}), 1.48(\mathrm{~m}, 2 \mathrm{H}), 1.40(\mathrm{~m}, 2 \mathrm{H})$, 
$0.90(\mathrm{t}, 3 \mathrm{H}, \mathrm{J}=7.8 \mathrm{~Hz}) . \quad{ }^{13} \mathrm{C} \mathrm{NMR}\left(150 \mathrm{MHz}, \mathrm{CDCl}_{3}\right) \delta 133.2,130.9,129.8,126.6$ $86.5,78.6,78.3,75.7,68.8,67.5,35.4,30.8,21.9,18.4,18.0,14.9,13.5,3.4$. HRMS [ESI(TOF)] for $\mathrm{C}_{18} \mathrm{H}_{27} \mathrm{O}\left[\mathrm{M}+\mathrm{H}^{+}\right]$: m/z: calcd for: 259.2062; found: 259.2064.

(3-((2E,4E)-Hexa-2,4-dien-1-yloxy)hepta-1,6-diyne-1,7-diyl)bis(trimethylsilane), $3 \mathbf{3}$.<smiles>CC#CC(CCC#CS(C)(=O)=O)OC/C=C/C=C/C</smiles>

Colorless oil, $120.2 \mathrm{mg}, 87 \%$ yield. ${ }^{1} \mathrm{H}$ NMR $\left(600 \mathrm{MHz}, \mathrm{CDCl}_{3}\right) \delta 6.20(\mathrm{~m}, 1 \mathrm{H})$, $6.04(\mathrm{~m}, 1 \mathrm{H}), 5.70(\mathrm{~m}, 1 \mathrm{H}), 5.60(\mathrm{~m}, 1 \mathrm{H}), 4.22(\mathrm{dd}, 1 \mathrm{H}, \mathrm{J}=12,5.4 \mathrm{~Hz}), 4.17(\mathrm{t}, 1 \mathrm{H}, \mathrm{J}$ $=7.2 \mathrm{~Hz}), 3.96(\mathrm{dd}, 1 \mathrm{H}, \mathrm{J}=12.6,7.2 \mathrm{~Hz}), 2.37(\mathrm{~m}, 2 \mathrm{H}), 1.90(\mathrm{~m}, 2 \mathrm{H}), 1.74(\mathrm{~d}, 3 \mathrm{H}, \mathrm{J}$ $=6.6 \mathrm{~Hz}), 0.16(\mathrm{~s}, 9 \mathrm{H}), 0.13(\mathrm{~s}, 9 \mathrm{H}) .{ }^{13} \mathrm{C} \mathrm{NMR}\left(150 \mathrm{MHz}, \mathrm{CDCl}_{3}\right) \delta 133.6,130.8$, $130.0,126.2,106.3,104.1,90.7,84.8,69.0,67.3,34.6,18.0,15.9,0.09,-0.10$. HRMS [ESI(TOF)] for $\mathrm{C}_{19} \mathrm{H}_{33} \mathrm{OSi}_{2}\left[\mathrm{M}+\mathrm{H}^{+}\right]$: $\mathrm{m} / \mathrm{z}$ : calcd for: 333.2070; found: 333.2069 .

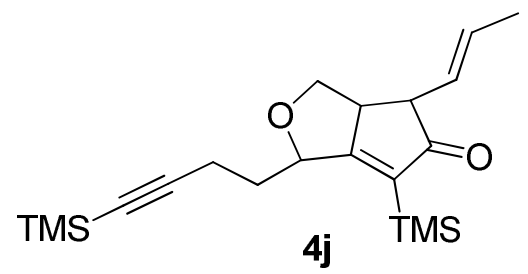

PK product 4j, light yellow oil, $58.7 \mathrm{mg}, 51 \%$ yield. ${ }^{1} \mathrm{H}$ NMR $\left(600 \mathrm{MHz}, \mathrm{CDCl}_{3}\right) \delta$ $5.56(\mathrm{~m}, 2 \mathrm{H}), 5.00(\mathrm{~d}, 1 \mathrm{H}, \mathrm{J}=10.2 \mathrm{~Hz}), 4.24(\mathrm{t}, 1 \mathrm{H}, \mathrm{J}=8.4 \mathrm{~Hz}), 3.29(\mathrm{~m}, 1 \mathrm{H}), 3.15$ (m, 1H), $2.79(\mathrm{~d}, 1 \mathrm{H}, \mathrm{J}=5.4 \mathrm{~Hz}), 2.46(\mathrm{~m}, 2 \mathrm{H}), 1.79(\mathrm{~m}, 1 \mathrm{H}), 1.72(\mathrm{~d}, 3 \mathrm{H}, \mathrm{J}=6 \mathrm{~Hz})$ 
$1.63(\mathrm{~m}, 1 \mathrm{H}), 0.24(\mathrm{~s}, 9 \mathrm{H}), 0.13(\mathrm{~s}, 9 \mathrm{H}) .{ }^{13} \mathrm{C} \mathrm{NMR}\left(150 \mathrm{MHz}, \mathrm{CDCl}_{3}\right) \delta$ 211.7, $193.3,134.1,129.2,126.6,105.4,86.1,75.1,68.3,56.3,55.1,33.2,18.1,17.2,0.03$, -0.77. HRMS [ESI(TOF)] for $\mathrm{C}_{20} \mathrm{H}_{33} \mathrm{O}_{2} \mathrm{Si}_{2}\left[\mathrm{M}+\mathrm{H}^{+}\right]$: m/z: calcd for: 361.2019 ; found: 361.2021. 


\section{References}

1. Paquette, L. A. Top. Curr. Chem. 1979, 79, 41-165.

2. Trost, B. M. Chem. Soc. Rev. 1982, 11, 141-170.

3. Paquette, L. A. Top. Curr. Chem. 1984, 119, 1.

4. Mehta, G.; Srikrishna, A. Chem. Rev. 1997, 97, 671-719.

5. Lautens, M.; Klute, W.; Tam, W. Chem. Rev. 1996, 96, 49-92.

6. Ajamian, A.; Gleason, J. L. Angew. Chem. Int. Ed. 2004, 43, 3754-3760.

7. Meijere, A.; Bräse, S. J. Organomet. Chem. 1999, 576, 88-110.

8. Malacria, M. Chem. Rev. 1996, 96, 289-306.

9. Molander, G. A.; Harris, C. R. Chem. Rev. 1996, 96, 307-338.

10. Son, S. U.; Choi, D. S.; Chung, Y. K. Org. Lett. 2000, 2, 2097-2100.

11. Son, S. U.; Chung, Y. K. J. Org. Chem. 2000, 65, 6142-6144.

12. Kim, D. H.; Chung, Y. K. Chem. Commun. 2005, 1634-1636.

13. Kim, D. H.; Son, S. U.; Chung, Y. K.; Lee, S.-G. Chem. Commun. 2002, 56-57.

14. Kim, D. H.; Chung, Y. K. Synlett 2005, 1889-1892.

15. Son, S. U.; Yoon, Y. A.; Choi, D. S.; Park, J. K.; Kim, B. M.; Chung, Y. K. Org. Lett. 2001, 3, 1065-1067.

16. Chen, W.; Tay, J. -H.; Ying, J.; Sabat, M.; Pu, L. Chem. Commun. 2013, 49, $170-172$.

17. Chen, W.; Tay, J. -H.; Ying, J.; Yu, X. -Q.; Pu, L. J. Org. Chem. 2013, 78, 2256-2265. 
18. Ying, J.; Pu, L. Chem. Eur. J. 2014, 20, 16301-16307.

19. (a) Frantz, D. E.; Fässler, R.; Tomooka, C. S.; Carreira, E. M. Acc. Chem. Res. 2000, 33, 373-381. (b) Pu, L. Tetrahedron 2003 59, 9873-9886. (c) Cozzi, P. G.; Hilgraf, R.; Zimmermann, N. Eur. J. Org. Chem. 2004, 4095-4105. (d) Lu, G.; Li, Y.-M.; Li, X.-S.; Chan, A. S. C. Coord. Chem. Rev. 2005, 249, 1736-1744. (e) Trost, B. M.; Weiss, A. H. Adv. Synth. Catal. 2009, 351, 963-983.

20. Selected reports on the catalytic asymmetric alkyne addition to aldehydes: (a) Frantz, D. E.; Fässler, R.; Carreira, E. M. J. Am. Chem. Soc. 2000, 122, 1806-1807. (b) Anand, N. K.; Carreira, E. M. J. Am. Chem. Soc. 2001, 123, 9687-9688. (c) Li, X.-S.; Lu, G.; Kwok, W. H.; Chan, A. S. C. J. Am. Chem. Soc. 2002, 124, 12636-12637. (d) Xu, Z. Q.; Wang, R.; Xu, J. K.; Da, C.-S.; Yan, W. J.; Chen, C. Angew. Chem., Int. Ed. 2003, 42, 5747-5749. (e) Takita, R.; Yakura, K.; Ohshima, T.; Shibasaki, M. J. Am. Chem. Soc. 2005, 127, 13760-13761. (f) Wolf, C.; Liu, S. J. Am. Chem. Soc. 2006, 128, 10996-10997. (g) Trost, B. M.; Weiss, A. H.; von Wangelin, A. J. J. Am. Chem. Soc. 2006, 128, 8-9. (h) Blay, G.; Cardona, L.; Fernandez, I.; Marco-Aleixandre, A.; Muñoz, M.C.; Pedro J.R. Org. Biomol. Chem. 2009, 7, 4301-4308.

21. (a) Moore, D.; Pu, L. Org. Lett. 2002, 4, 1855-1857. (b) Gao, G.; Moore, D.; Xie, R.-G.; Pu, L. Org. Lett. 2002, 4, 4143-4146. (c) Du, Y. -H.; Turlington, M.; Zhou, X.; Pu, L. Tetrahedron Lett. 2010, 51, 5024-5027. (d) Turlington, M.; Du, Y. -H.; Ostrum, S. G.; Santosh, V.; Wren, K.; Lin, T.; Sabat, M.; Pu, L. J. Am. 
Chem Soc. 2011, 133, 11780-11794. (e) Pu, L. Acc. Chem. Res. 2014, 47, $1523-1535$.

22. Wang, Q.; Pu, L. Synlett. 2013, 11, 1340-1363.

23. Rh-catalyzed PK cycloadditions: (a) Jeong, N.; Lee, S.; Sung, B. K. Organometallics 1998, 17, 3642-3644. (b) Jeong, N.; Sung, B. K.; Choi, Y. K. J. Am. Chem. Soc. 2000, 122, 6771-6772. (c) Evans, P. A.; Robinson, J. E. J. Am. Chem. Soc. 2001, 123, 4609-4610. (d) Kobayashi, T.; Koga, Y.; Narasaka, K. J. Organomet. Chem. 2001, 624, 73-87. (e) Fan, B. M.; Xie, J. H.; Li, S.; Tu, Y. Q.; Zhou, Q. L. Adv. Syn. Cat. 2005, 347, 759-762. (f) Shibata, T.; Toshida, N.; Takagi, K. Org. Lett. 2002, 4, 1619-1621. (g) Shibata, T.; Toshida, N.; Takagi, K. J. Org. Chem. 2002, 67, 7446-7450. 


\section{Chapter 4. Asymmetric Addition of Both Alkyl and Aryl Alkynes to $N$-(Diphenylphosphinoyl)imines}

\subsection{Introduction}

Chiral propargylic amines are important building blocks for the synthesis of numerous pharmaceuticals, biologically active compounds and natural products. ${ }^{1}$ The enantioselective alkyne addition to imines represents a very efficient process to produce chiral propargylic amines and a number of highly enantioselective catalytic systems have been developed. ${ }^{1-3}$ For example, extensive work has been conducted by using the $\mathrm{Cu}(\mathrm{I})$-catalyzed reaction of terminal alkynes with $N$-arylimines that could be generated in-situ from an aldehyde and an arylamine, and excellent enantioselectivity has been achieved for a number of substrates in the presence of various nitrogen-containing chiral ligands. ${ }^{2}$

Among these Cu-based catalytic systems, PyBOX compounds, introduced by $\mathrm{Li}$ and Wei in 2002, represent the first as well as one of the most effective ligands for the Cu-catalyzed enantioselective alkyne addition to $N$-arylimines. ${ }^{2 a}$ PyBOX 4.1 was employed to catalyze the reaction of phenylacetylene with aromatic imines in the presence of CuOTf, affording the corresponding propargylic amines with $82-86 \%$ enantioselectivity. The aromatic imines were generated in-situ via dehydration of the aldehydes and amines and the reactions were performed in either toluene or water with good results. Later, this method was applied to aliphatic alkynes to give the desired products with $60-85 \%$ enantioselectivity (Scheme 4.1). ${ }^{2 \mathrm{i}}$ 
Scheme 4.1. First $\mathrm{Cu}$-catalyzed enantioselective alkyne addition to $N$-arylimines

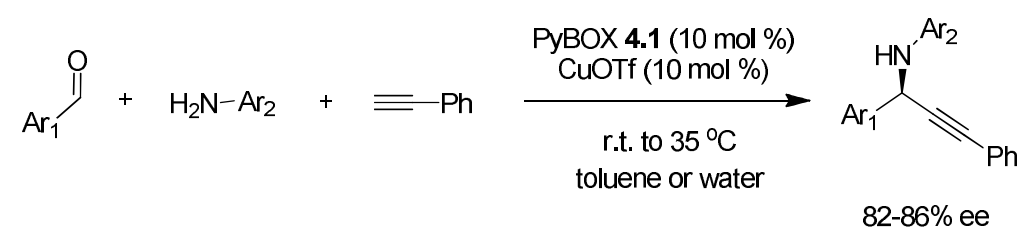

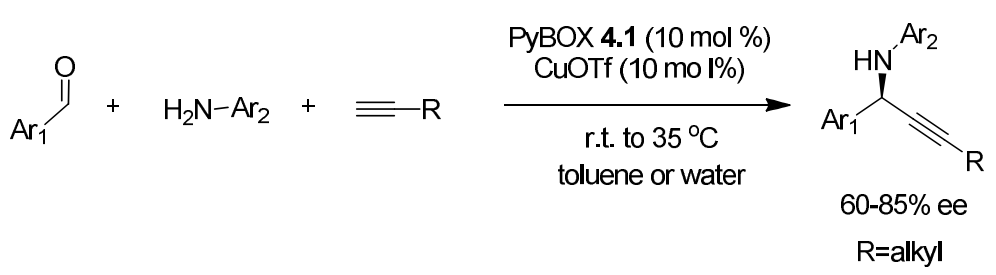

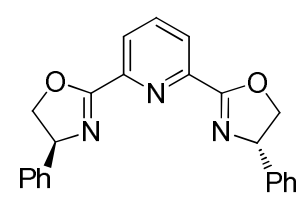

In many of these reactions, however, the $N$-protecting groups of the propargylic amine products, such as the aryl groups, are not easily removable for further transformation. Scheme 4.2 shows one of few examples reported for the removal of the $N$-aryl groups. When compound 4.2 was treated with $\mathrm{PhI}(\mathrm{OAc})_{2}$ and $\mathrm{Ac}_{2} \mathrm{O}$, the optically active propargylic amine $\mathbf{4 . 3}$ was obtained in $71 \%$ yield by oxidative removal of the $o$-anisidyl activating group and acylation. The high enantiomeric purity of 4.2 was maintained in the transformation. ${ }^{3 a}$

Scheme 4.2. An example for the removal of the $N$-aryl group<smiles>C#CC(Nc1ccccc1OC)c1ccccc1</smiles>

4.2

$90 \%$ ee

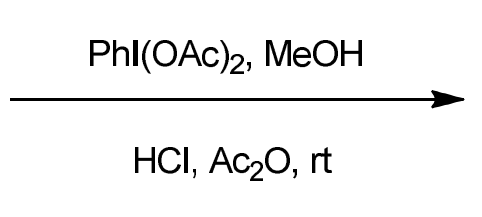

$\mathrm{HCl}, \mathrm{Ac}_{2} \mathrm{O}, \mathrm{rt}$<smiles>C#CC(NC(C)C)c1ccccc1</smiles>

\section{3}

$71 \%, 90 \%$ ee

Among the imine substrates studied in the asymmetric alkyne addition to generate propargylic amines, the use of $\mathrm{N}$-(diphenylphosphinoyl)imines is particularly interesting because the $\mathrm{N}$-diphenylphosphinoyl activating/protecting group can be easily removed under very mild conditions after the reaction. ${ }^{4-6}$ For example, when a 
methanol solution of an optically active $N$-(diphenylphosphinoyl) propargylic amine 4.4 was treated with aqueous $\mathrm{HCl}$ at room temperature for $2 \mathrm{~h}$, the resulting propargylic amine 4.5 was obtained in $92 \%$ yield with retention of the enantiomeric purity (Scheme 4.3). ${ }^{6}$

Scheme 4.3. An example for the removal of the $N$-diphenylphosphinoyl group

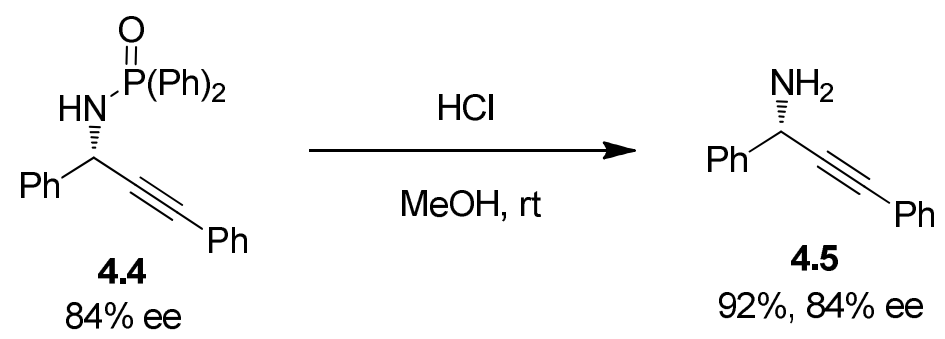

Several reports have appeared for the catalytic asymmetric alkyne addition to the $N$-(diphenylphosphinoyl)imines and high enantioselectivity has been observed for certain substrates. $^{5,6}$

In 2009, Wang used stoichiometric amounts of the proline-derived $\beta$-amino alcohol ligand 4.6 in combination with $\mathrm{Et}_{2} \mathrm{Zn}$ for the enantioselective alkynylation of aromatic $N$-(diphenylphosphinoyl)aldimines, providing the expected $N$-protected propargylic amines in high yield and with excellent enantioselectivity (up to $96 \%$ ee). ${ }^{5 \mathrm{a}}$ Later, a novel tridentate ligand $4.7(35 \mathrm{~mol} \%)$ was employed to catalyze the reaction with good results by the same group..$^{5 \mathrm{c}}$ The authors also studied the enantioselective addition of trimethylsilylacetylene to $N$-(diphenylphosphinoyl)aldimines catalyzed by the $C_{2}$-symmetric proline-derived $\beta$-amino alcohol ligand 4.8 (Scheme 4.4). ${ }^{5 b}$ 
Scheme 4.4. The enantioselective alkyne addition to the $N$-(diphenylphosphinoyl)imines by using Wang’s ligands

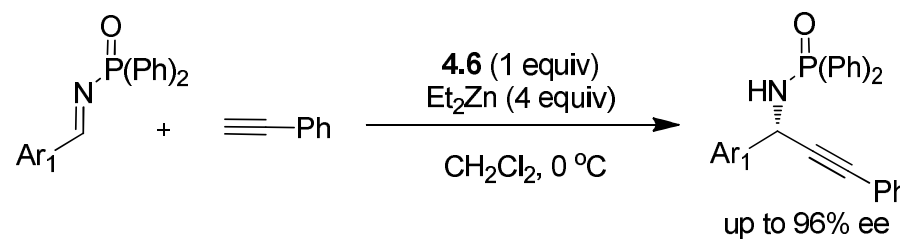<smiles>OCC1CCCN1Cc1ccc2ccccc2c1</smiles><smiles>[R]C=N[P+](=O)[PH2+]C#[R]</smiles><smiles>OCC1CCCN1Cc1cccs1</smiles>

4.7

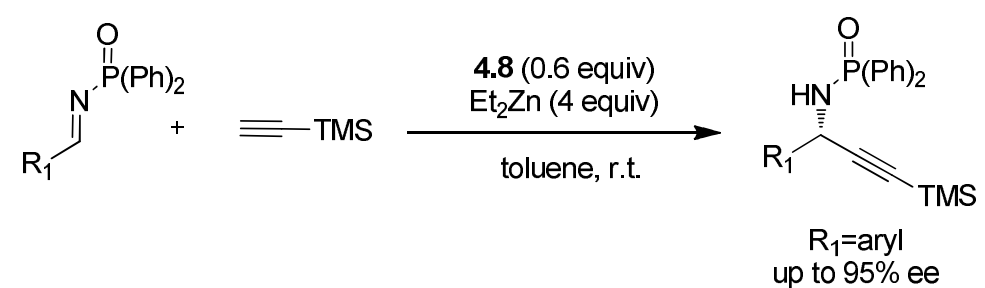<smiles>Cc1cc(N2CCCC2CO)cc(N2CCCC2CO)c1</smiles>

In 2012, Pedro described an enantioselective addition of terminal alkynes to $N$-(diphenylphosphinoyl) aldimines in the presence of $\mathrm{Me}_{2} \mathrm{Zn}$ and 3,3'-dibromo-BINOL 4.9 (Scheme 4.5). ${ }^{6}$ The reaction of aromatic alkynes with various aromatic $N$-(diphenylphosphinoyl) aldimines provided the desired propargylic amines with good yield and high enantioselectivity (up to $96 \%$ ee).

Scheme 4.5. The enantioselective alkyne addition to the $N$-(diphenylphosphinoyl)imines by using Pedro's ligands

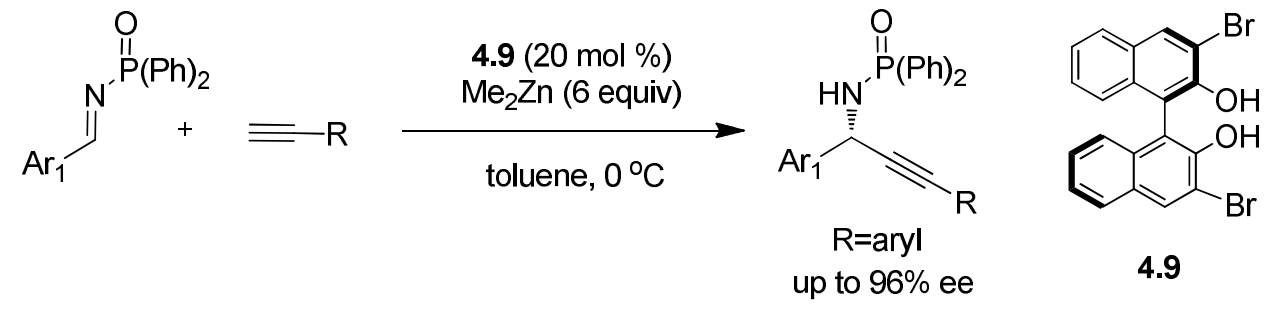

In spite of the progresses described above, however, there are still limitations in 
these methods. For example, no highly enantioselective simple alkyl alkyne addition to $N$-(diphenylphosphinoyl)imines was reported. As shown in Scheme 4.6, although the 1,1'-bi-2-napthol (BINOL) compound 4.9 showed high enantioselectivity for the reaction of aryl alkynes with $N$-(diphenylphosphinoyl)imines, it gave only $14 \%$ ee and $22 \%$ yield for the reaction of 1-hexyne with $N$-(diphenylphosphinoyl)benzaldimine (4.10). ${ }^{6}$ Thus, more efficient catalytic systems are required for the enantioselective addition of both alkyl and aryl alkynes to $N$-(diphenylphosphinoyl)imines.

Scheme 4.6. An aliphatic alkyne addition to the $N$-(diphenylphosphinoyl)imine 4.10

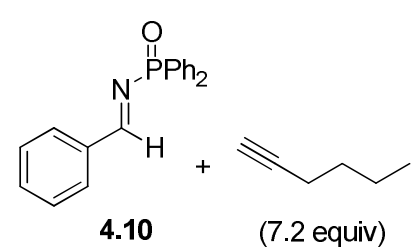

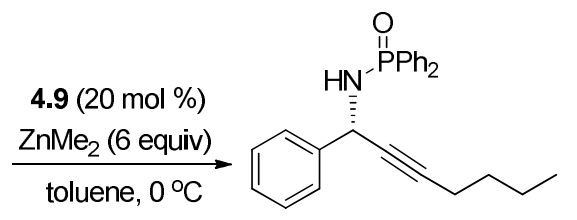

$22 \%, 14 \%$ ee

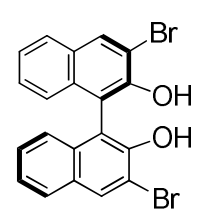

4.9

\subsection{Catalytic asymmetric addition of both alkyl and aryl alkynes to $N$-(diphenylphosphinoyl)imines}

In our laboratory, we have discovered that the 3,3'-di(aminomethyl) substituted partially hydrogenated BINOL $\left(\mathrm{H}_{8} \mathrm{BINOL}\right)$ derivatives exhibit high enantioselectivity for the asymmetric alkyne, aryl and vinyl additions to aldehydes. ${ }^{7,8}$ This class of compounds can be synthesized in one-step from the Mannich-type reaction of $\mathrm{H}_{8} \mathrm{BINOL}$ with paraformaldehyde and a secondary amine (Scheme 4.7). Thus, we have explored the use of these compounds in the enantioselective alkyne addition to $N$-(diphenylphosphinoyl)imines. 
Scheme 4.7. Synthesis of $3,3^{\prime}$-di(aminomethyl) $\mathrm{H}_{8} \mathrm{BINOLs}$

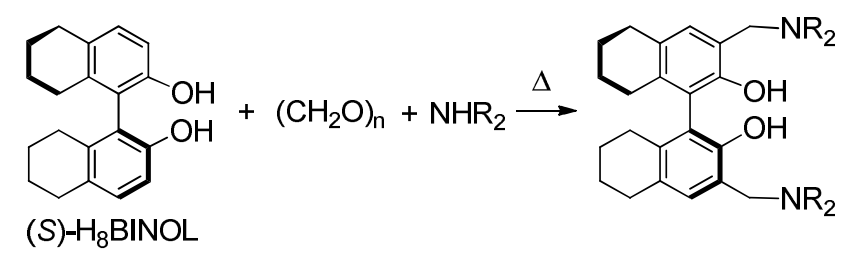

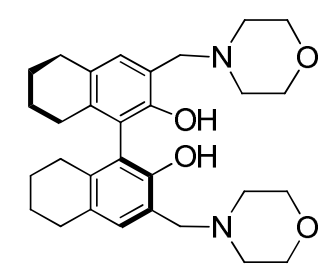

(S)-4.1

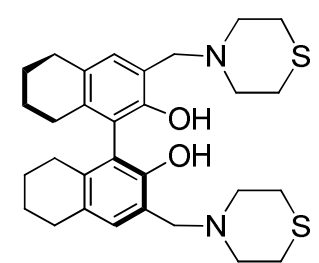

(S) -4.2

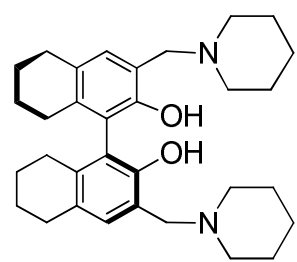

(S)-4.3

Previously, we reported the use of the 3,3'-di(morpholinylmethyl) $\mathrm{H}_{8} \mathrm{BINOL}$ (S)-4.1 in combination with $\mathrm{Et}_{2} \mathrm{Zn}$ and $\mathrm{Ti}\left(\mathrm{O}^{i} \mathrm{Pr}\right)_{4}$ to catalyze the phenylacetylene addition to aldehydes with high enantioselectivity. ${ }^{7 a}$ Therefore, we first tested the use of this compound to catalyze the reaction of phenylacetylene with 4.10 in the presence of $\mathrm{Et}_{2} \mathrm{Zn}$ and $\mathrm{Ti}\left(\mathrm{O}^{i} \mathrm{Pr}\right)_{4}$ and the results are given in Table 4.1. As shown in entry 1 of Table 4.1, in the presence of $30 \mathrm{~mol} \%(S)-4.1$, the $N$-(diphenylphosphinoyl) propargylic amine product 4.4 was obtained with $58 \%$ yield and $50 \%$ ee. We found that addition of pyridine (30 mol \%) as an additive improved both the yield and ee of the product (entry 2). Compound (S)-4.2 is a sulfur-substituted analog of $(S)-\mathbf{4 . 1}$ and it gave the same enantioselectivity as $(S) \mathbf{- 4 . 1}$ (entry 3). However, when $(S) \mathbf{- 4 . 3}$, an analog of $(S)$-4.1 without the oxygen atom in the morpholinyl ring, was used, the enantioselectivity was significantly decreased (entry 4). 
Table 4.1. Results for the reaction of phenylacetylene with 4.10 catalyzed by $(S)-\mathbf{4 . 1}$ $-(S)-4.3^{\mathrm{a}}$

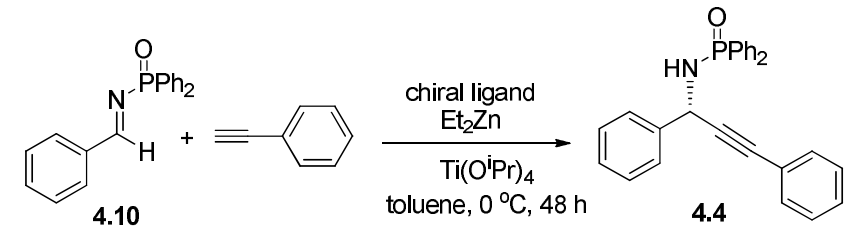

\begin{tabular}{|c|c|c|c|c|}
\hline Entry & Chiral ligand & Additive & Yield (\%) & ee (\%) \\
\hline 1 & $(S)-\mathbf{4 . 1}$ & none & 58 & 50 \\
\hline 2 & $(S)-\mathbf{4 . 1}$ & pyridine & 70 & $58(S)$ \\
\hline 3 & $(S)-\mathbf{4 . 2}$ & pyridine & 58 & 59 \\
\hline 4 & $(S)-\mathbf{4 . 3}$ & pyridine & 62 & 49 \\
\hline
\end{tabular}

a. Alkyne $/ \mathrm{Et}_{2} \mathrm{Zn} / \mathrm{Ligand} / \mathrm{Ti}\left(\mathrm{O}^{i} \mathrm{Pr}_{4}\right) /$ imine $=4: 4: 0.3: 1: 1 . \quad$ Pyridine $(30 \mathrm{~mol} \%)$ was added in entries 2-4.

In addition, we also prepared the monomorpholinylmethyl substituted $\mathrm{H}_{8} \mathrm{BINOL}$ derivatives (S)-4.4-(S)-4.7 (Figure 4.1), but these compounds gave much lower enantioselectivity (Table 4.2, entries 1-4). Especially, compound (S)-4.6 with a bulky TBS group and compound (S)-4.7 with a 2-morpholinylmethyl substituent gave almost no enantioselectivity at all (entry 3 and 4). These results demonstrate that both of the 3,3'-aminomethyl groups are important for the chiral induction.

Figure 4.1. Chiral $\mathrm{H}_{8} \mathrm{BINOL}$ derivatives containing monomorpholinylmethyl substitutents

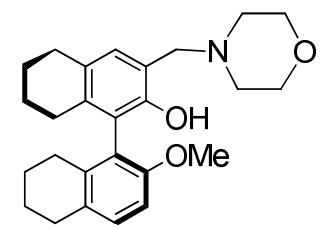

(S) -4.4

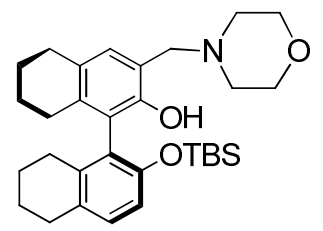

(S)-4.6

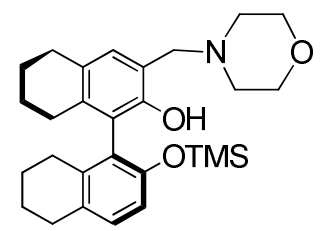

(S)-4.5

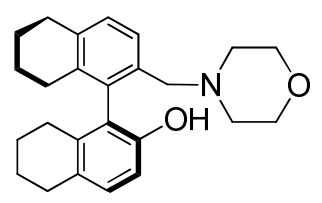

$(S)-4.7$ 
Table 4.2. Results for the reaction of phenylacetylene with 4.10 catalyzed by $(S)-4.4-$ $(S)-4.7^{\mathrm{a}}$

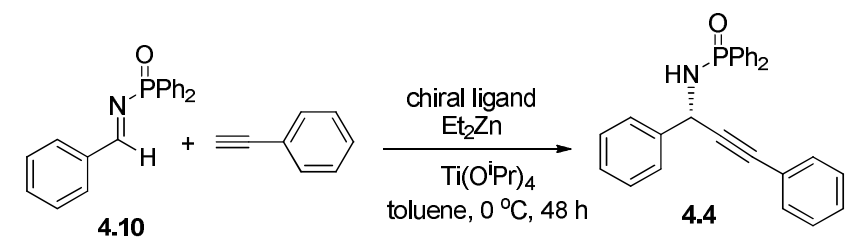

\begin{tabular}{|c|c|c|c|c|}
\hline Entry & Chiral ligand & Additive & Yield (\%) & ee (\%) \\
\hline 1 & $(S)-4.4$ & pyridine & 62 & 43 \\
\hline 2 & $(S)-4.5$ & pyridine & 65 & 12 \\
\hline 3 & $(S)-4.6$ & pyridine & 60 & 3 \\
\hline 4 & $(S)-4.7$ & pyridine & 68 & 5 \\
\hline
\end{tabular}

a. Alkyne $/ \mathrm{Et}_{2} \mathrm{Zn} / \mathrm{Ligand} / \mathrm{Ti}\left(\mathrm{O}^{i} \mathrm{Pr}_{4}\right) /$ imine $=4: 4: 0.3: 1: 1 . \quad$ Pyridine $(30 \mathrm{~mol} \%)$ was added in entries 1-4.

The study of $(S)$-4.1, $(S)-4.2$ and $(S)$-4.3 indicates that the hetero atoms in the cyclic amine groups of these compounds should play a role in the asymmetric induction. The intermediate $\mathbf{A}$ is proposed to guide our exploration of this catalytic system (Figure 4.2). In $\mathbf{A}$, the zinc acetylide is coordinated to the Lewis base additive (B) and the heterocyclic substituent of the $\mathrm{H}_{8} \mathrm{BINOL}$ ligand. On the basis of this hypothesis, changing the hetero atom $\mathrm{X}$ and the additive $\mathrm{B}$ should allow us to tune the catalytic properties of this system.

Figure 4.2. The structure of intermediate $\mathbf{A}$

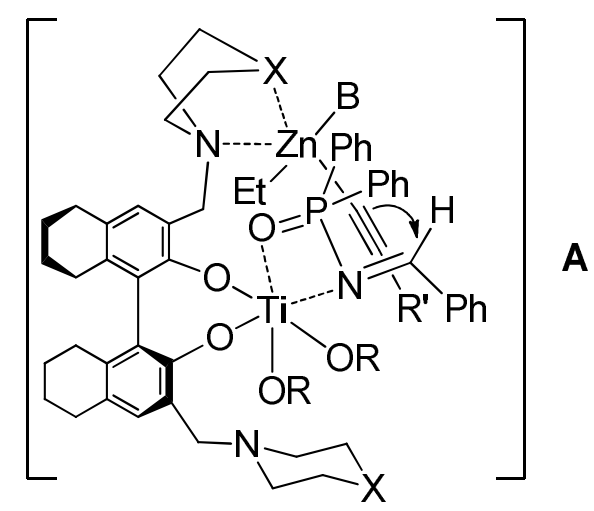


We thus designed a new type of catalyst for this reaction by incorporating an additional nitrogen atom into the cyclic amine substituents to give $(S)-\mathbf{4 . 8}$ (Figure 4.3). This compound was prepared from the condensation of 1-methyl piperazine with $\mathrm{H}_{8} \mathrm{BINOL}$ and paraformaldehyde. This compound represents an interesting class of $\mathrm{H}_{8} \mathrm{BINOL}$ derivatives in which the terminal nitrogen atom could be easily modified by using various $N$-substituents. This should allow us to systematically modify the steric and electronic properties of the heteroatom $\mathrm{X}$ coordinated to the zinc acetylide as shown in the proposed intermediate $\mathbf{A}$.

When $(S)-\mathbf{4 . 8}$ was used to catalyze the reaction of phenylacetylene with $\mathbf{4 . 1 0}$ under the same conditions as the use of $(S)-4.1$, it gave $47 \%$ ee for the addition product as shown in entry 1 of Table 4.3. In order to improve the enantioselectivity of this reaction, we have used various $N$-substituted piperazines to prepare compounds $(S)-4.9-(S)-4.11$ and examined their catalytic properties. As shown in entries 2-4 of Table 4.2, among these compounds, (S)-4.11 with a bulky 1-(diphenyl)methyl substituent on each piperazine ring gave the best enantioselectivity (64\% ee, entry 4$)$. When the solvent of the reaction was changed from toluene to $\mathrm{CH}_{2} \mathrm{Cl}_{2}$, THF and $\mathrm{Et}_{2} \mathrm{O}$, the yield and/or ee decreased (entries 5-7).

Figure 4.3. Chiral $\mathrm{H}_{8} \mathrm{BINOL}$ derivatives containing 3,3'-piperazinyl substituents

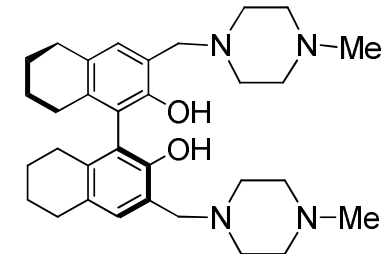

(S) $-\mathbf{4 . 8}$

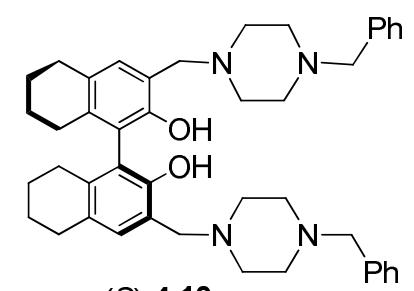

(S) -4.10

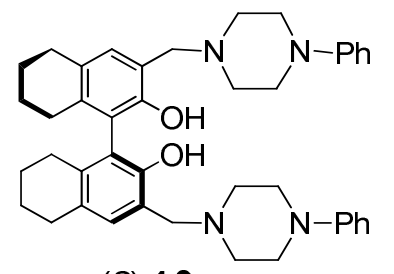

(S) -4.9

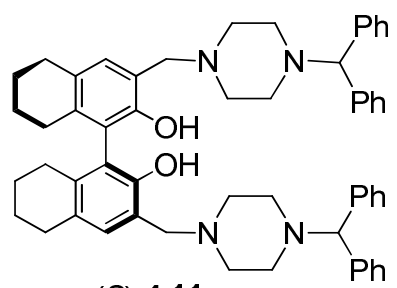

(S) -4.11 
Table 4.3. Results for the reaction of phenylacetylene with $\mathbf{4 . 1 0}$ catalyzed by the piperazine derivatives $(S)-4.8-(S)-4.11^{\text {a }}$

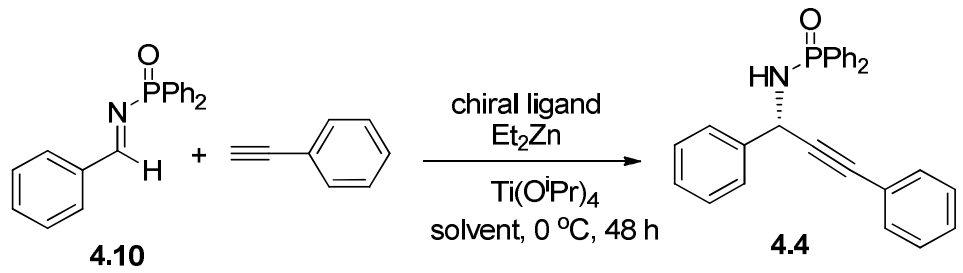

\begin{tabular}{|c|c|c|c|c|}
\hline Entry & Chiral ligand & Solvent & Yield (\%) & ee (\%) \\
\hline 1 & $(S)-\mathbf{4 . 8}$ & Toluene & 67 & 47 \\
\hline 2 & $(S)-\mathbf{4 . 9}$ & Toluene & 42 & 56 \\
\hline 3 & $(S)-\mathbf{4 . 1 0}$ & Toluene & 48 & 50 \\
\hline 4 & $(S)-\mathbf{4 . 1 1}$ & Toluene & 63 & 64 \\
\hline 5 & $(S)-\mathbf{4 . 1 1}$ & $\mathrm{CH}_{2} \mathrm{Cl} l_{2}$ & $10 \mathrm{w}$ & - \\
\hline 6 & $(S)-\mathbf{4 . 1 1}$ & $\mathrm{THF}$ & 45 & 35 \\
\hline 7 & $(S)-\mathbf{4 . 1 1}$ & $\mathrm{Et}_{2} \mathrm{O}$ & 60 & 51 \\
\hline
\end{tabular}

a. Alkyne/Et $2 \mathrm{Zn} / \mathrm{Ligand} / \mathrm{Ti}\left(\mathrm{O}^{i} \mathrm{Pr}_{4}\right) /$ imine $=4: 4: 0.3: 1: 1 . \quad$ Pyridine $(30 \mathrm{~mol} \%)$ was added in entries 1-7.

Since (S)-4.11 shows improved enantioselectivity than the other $\mathrm{H}_{8} \mathrm{BINOL}$ compounds, we further explored the reaction conditions for the use of this compound.

The results are summarized in Table 4.4. As shown in entry 2, without the additive, the enantioselectivity significantly decreased for the reaction of phenylacetylene with 
4.10. We tested the use of imidazole in place of pyridine as the additive, the enantioselectivity was improved to $72 \%$ ee (entry 3 ). Increasing the concentration of the reaction by reducing the solvent volume, the enantioselectivty was further increased to $77 \%$ ee (entry 4). Further increasing the concentration reduced the enantioselectivity (entry 5). Lowering the reaction temperature to $-20{ }^{\circ} \mathrm{C}$ greatly decreased the reaction yield and also with small reduction in enantioselectivity (entry 6). Increasing the reaction temperature to room temperature increased the yield but greatly reduced the enantioselectivity (entry 7). In the absence of $\operatorname{Ti}\left(\mathrm{O}^{i} \mathrm{Pr}\right)_{4}$, there was significant reduction of ee (entry 8). When $\mathrm{Et}_{2} \mathrm{Zn}$ was replaced with $\mathrm{Me}_{2} \mathrm{Zn}$, lower enantioselectivity was observed (entry 9). At $0{ }^{\circ} \mathrm{C}$, when the amount of $\mathrm{Et}_{2} \mathrm{Zn}$ was increased to 6 equiv, the enantioselectivity was further enhanced to $81 \%$ ee (entry 10 ). Further increasing the amount of $\mathrm{Et}_{2} \mathrm{Zn}$ decreased the enantioselectivity (entry 11). Either increasing or decreasing the amount of $(S)$-4.11 reduced the enantioselectivity (entry 12,13). The configuration of the product was determined to be $S$ by comparing the HPLC retention time with those in the literature. ${ }^{5 \mathrm{a}, 6}$ 
Table 4.4. Results for the reaction of phenylacetylene with 4.10 catalyzed by $(S)-4.11^{\text {a }}$

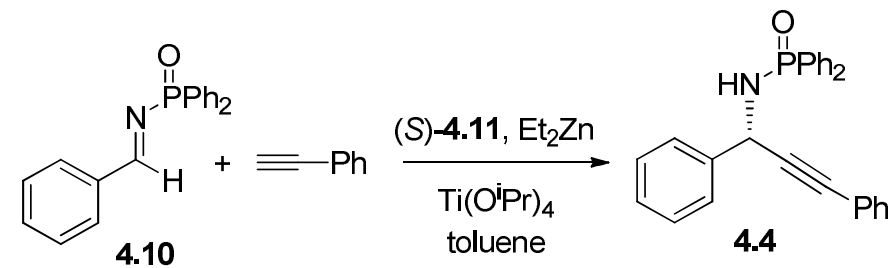

\begin{tabular}{|c|c|c|c|c|c|c|c|}
\hline Entry & $\mathrm{RC} \equiv \mathrm{CH}$ & Additive & Toluene $(\mathrm{mL})$ & $\mathrm{T}\left({ }^{\circ} \mathrm{C}\right)$ & $\mathrm{R}_{2} \mathrm{Zn}$ & Yield (\%) & ee $(\%)$ \\
\hline 1 & $\mathrm{Ph}$ & pyridine & 1.0 & 0 & $\mathrm{Et}_{2} \mathrm{Zn}$ (4 equiv) & 63 & 64 \\
\hline 2 & $\mathrm{Ph}$ & none & 1.0 & 0 & $\mathrm{Et}_{2} \mathrm{Zn}$ (4 equiv) & 60 & $47(S)$ \\
\hline 3 & $\mathrm{Ph}$ & imidazole & 1.0 & 0 & $\mathrm{Et}_{2} \mathrm{Zn}$ (4 equiv) & 72 & 72 \\
\hline 4 & $\mathrm{Ph}$ & imidazole & 0.70 & 0 & $\mathrm{Et}_{2} \mathrm{Zn}$ (4 equiv) & 75 & 77 \\
\hline 5 & $\mathrm{Ph}$ & imidazole & 0.50 & 0 & $\mathrm{Et}_{2} \mathrm{Zn}$ (4 equiv) & 70 & 67 \\
\hline 6 & $\mathrm{Ph}$ & imidazole & 0.70 & -20 & $\mathrm{Et}_{2} \mathrm{Zn}$ (4 equiv) & 24 & 74 \\
\hline 7 & $\mathrm{Ph}$ & imidazole & 0.70 & r.t. & $\mathrm{Et}_{2} \mathrm{Zn}$ (4 equiv) & 82 & 37 \\
\hline $8^{\mathrm{b}}$ & $\mathrm{Ph}$ & imidazole & 0.70 & 0 & $\mathrm{Et}_{2} \mathrm{Zn}$ (4 equiv) & 67 & 60 \\
\hline $9^{c}$ & $\mathrm{Ph}$ & imidazole & 0.70 & 0 & $\mathrm{Me}_{2} \mathrm{Zn}$ (4 equiv) & 70 & 68 \\
\hline $10^{\mathrm{d}}$ & $\mathbf{P h}$ & imidazole & 0.70 & $\mathbf{0}$ & $\mathrm{Et}_{2} \mathrm{Zn}$ (6 equiv) & 80 & 81 \\
\hline $11^{\mathrm{e}}$ & $\mathrm{Ph}$ & imidazole & 0.70 & 0 & $\mathrm{Et}_{2} \mathrm{Zn}$ (8 equiv) & 68 & 73 \\
\hline $12^{\mathrm{f}}$ & $\mathrm{Ph}$ & imidazole & 0.70 & 0 & $\mathrm{Et}_{2} \mathrm{Zn}$ (6 equiv) & 73 & 68 \\
\hline $13^{\mathrm{g}}$ & $\mathrm{Ph}$ & imidazole & 0.70 & 0 & $\mathrm{Et}_{2} \mathrm{Zn}$ (6 equiv) & 78 & 62 \\
\hline
\end{tabular}

a. Unless noted otherwise, the following reagent ratio was used: Alkyne $/ \mathrm{Et}_{2} \mathrm{Zn} /(S)-\mathbf{4 . 1 1} /$ additive $/ \operatorname{Ti}\left(\mathrm{O}^{i} \mathrm{Pr}_{4}\right) / \mathbf{4 . 1 0}=$ 4:4:0.3:0.3:1:1, and $\mathbf{4 . 1 0}(0.1 \mathrm{mmol})$. The reaction was allowed to proceed for $48 \mathrm{~h}$.

b. $\operatorname{Ti}\left(\mathrm{O}^{i} \mathrm{Pr}_{4}\right)$ was not added.

c. $\mathrm{Me}_{2} \mathrm{Zn}$ was used in place of $\mathrm{Et}_{2} \mathrm{Zn}$.

d. Alkyne/Et ${ }_{2} \mathrm{Zn} /(S)-\mathbf{4 . 1 1} /$ additive $/ \mathrm{Ti}\left(\mathrm{O}^{i} \mathrm{Pr}_{4}\right) / \mathbf{4 . 1 0}=7.2: 6: 0.3: 0.3: 1: 1$

e. Alkyne $/ \mathrm{Et}_{2} \mathrm{Zn} /(S)-\mathbf{4 . 1 1} /$ additive $/ \operatorname{Ti}\left(\mathrm{O}^{i} \mathrm{Pr}_{4}\right) / \mathbf{4 . 1 0}=12: 8: 0.3: 0.3: 1: 1$

f. Alkyne/Et $2 \mathrm{Zn} /(S)-\mathbf{4 . 1 1} /$ additive $/ \mathrm{Ti}\left(\mathrm{O}^{i} \mathrm{Pr}_{4}\right) / \mathbf{4 . 1 0}=7.2: 6: 0.6: 0.6: 1: 1$

g. Alkyne/Et ${ }_{2} \mathrm{Zn} /(S)-\mathbf{4 . 1 1} /$ additive/Ti( $\left(\mathrm{O}^{i} \mathrm{Pr}_{4}\right) / \mathbf{4 . 1 0}=7.2: 6: 0.1: 0.3: 1: 1$ 
Besides imidazole, we also screened the use of a broad range of nitrogen-containing acyclic and cyclic bases as the additive, but they all gave lower enantioselectivity ( $52-70 \%$ ee) (Scheme 4.8$)$ under the same conditions of entry 10 in Table 4.4 .

Scheme 4.8. Screening of the nitrogen-containing acyclic and cyclic bases as the additive<smiles>O=[P+](N=Cc1ccccc1)c1ccccc1</smiles><smiles>c1ccc(Nc2ccccc2)cc1</smiles>

$68 \%$ ee<smiles>Oc1ccccc1N(c1ccccc1)c1ccccc1</smiles>

$70 \%$ ee<smiles>CCN(CC)CC</smiles>

$70 \%$ ee
(S)-4.11, $\mathrm{Et}_{2} \mathrm{Zn}$, additive $\mathrm{Ti}(\mathrm{O} \mathrm{Pr})_{4}$ toluene<smiles>c1ccc(CNCc2ccccc2)cc1</smiles>

$68 \%$ ee<smiles>Oc1ccc(CN(Cc2ccccc2)Cc2ccccc2)cc1</smiles><smiles>c1cncnc1</smiles>

$52 \%$ ee<smiles>O=[PH](N[C@@H](C#Cc1ccccc1)c1ccccc1)c1ccccc1</smiles><smiles>C1CCC(CNCC2CCCCC2)CC1</smiles>

$53 \%$ ee

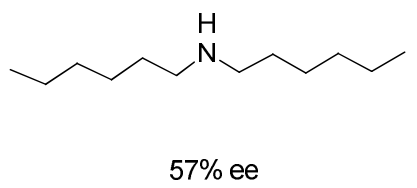

When the reaction conditions of entry 10 in Table 4.4 were applied to the reaction of 1-hexyne 4.11 with 4.10, we were pleased to obtain the desired product 4.12 from this aliphatic alkyne addition with good enantioselectivity (74\% ee) (entry 1, Table 4.5). As described earlier in Scheme 4.6, the previous catalytic system gave very low enantioselectivity for the aliphatic alkyne addition. The enantioselectivity was enhanced to $85 \%$ ee when the amount of $\mathrm{Et}_{2} \mathrm{Zn}$ was reduced to 4 equiv (entry 2). Further decreasing the amount of $\mathrm{Et}_{2} \mathrm{Zn}$ reduced the enantioselectivity (entry 3). 
Increasing the reaction temperature to $10{ }^{\circ} \mathrm{C}$ or room temperature decreased the yield and the enantioselectivity (entry 4,5). As shown in entry 6 and 7, there was significant reduction of ee without either imidazole or $\operatorname{Ti}\left(\mathrm{O}^{i} \mathrm{Pr}\right)_{4}$. When $\mathrm{Et}_{2} \mathrm{Zn}$ was replaced with $\mathrm{Me}_{2} \mathrm{Zn}$, very low conversion was observed (entry 8).

Table 4.5. Results for the reaction of 1-hexyne with 4.10 catalyzed by $(S)-4.11^{\text {a }}$

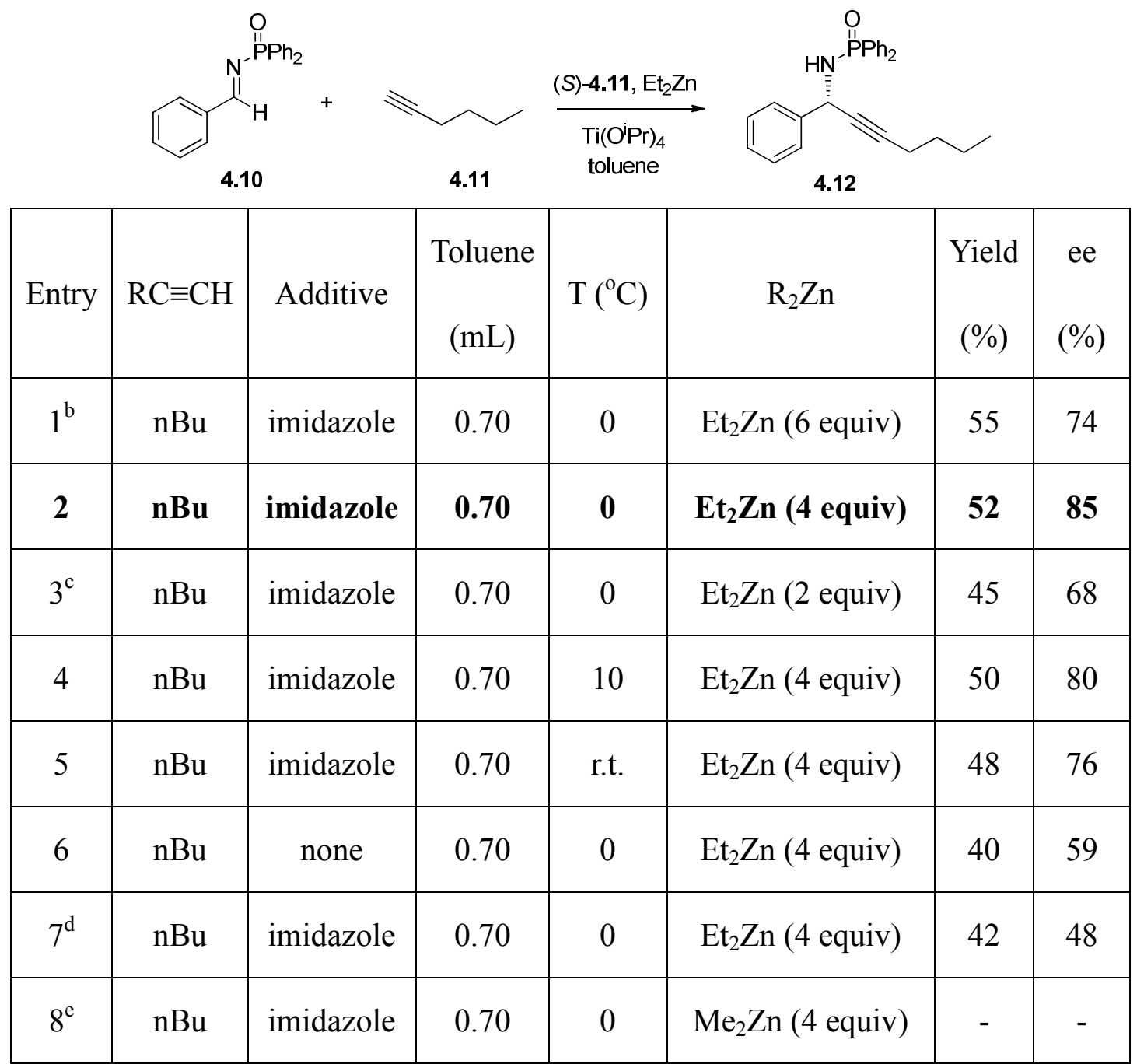

a. Unless noted otherwise, the following reagent ratio was used: Alkyne/Et $2 \mathrm{Zn} /(S)-\mathbf{4 . 1 1} /$ additive $/ \operatorname{Ti}\left(\mathrm{O}^{i} \mathrm{Pr}_{4}\right) / \mathbf{4 . 1 0}=$ 4:4:0.3:0.3:1:1, and $\mathbf{4 . 1 0}(0.1 \mathrm{mmol})$. The reaction was allowed to proceed for $48 \mathrm{~h}$.

b. Alkyne $/ \mathrm{Et}_{2} \mathrm{Zn} /(S)-\mathbf{4 . 1 1} /$ additive $/ \mathrm{Ti}\left(\mathrm{O}^{i} \mathrm{Pr}_{4}\right) / \mathbf{4 . 1 0}=7.2: 6: 0.3: 0.3: 1: 1$

c. Alkyne/Et $2 \mathrm{Zn} /(S)-\mathbf{4 . 1 1} /$ additive $/ \operatorname{Ti}\left(\mathrm{O}^{i} \mathrm{Pr}_{4}\right) / \mathbf{4 . 1 0}=2: 3: 0.3: 0.3: 1: 1$

d. $\operatorname{Ti}\left(\mathrm{O}^{i} \mathrm{Pr}_{4}\right)$ was not added.

e. $\mathrm{Me}_{2} \mathrm{Zn}$ was used in place of $\mathrm{Et}_{2} \mathrm{Zn}$.

The high enantioselectivity observed for the reaction of 1-hexyne with $\mathbf{4 . 1 0}$ catalyzed by $(S)-\mathbf{4 . 1 1}$ prompted us to apply these conditions for the reaction of various 
alkyl alkynes with various $N$-(diphenylphosphinoyl)imines. As the results summarized in Scheme 4.9 show, when 1-hexyne was reacted with the aldimines containing electron donating $\mathrm{Me}$ group or the electron-withdrawing $\mathrm{Br}$, the corresponding products 4.13 and 4.14 were obtained with good yields and ee's. The addition of other aliphatic alkynes to $N$-(diphenylphosphinoyl)imines also gave good results to make compounds $4.15-\mathbf{4 . 1 8}$. The lower yields in the isolation of compounds $4.15,4.16$ and 4.18 could be attributed to the sensitivity of the functional groups on the alkyl alkynes. The reaction of the conjugated enynes with $N$-(diphenylphosphinoyl)imines was also studied which gave the products 4.19 and 4.20 with good results.

Scheme 4.9. Reaction of aliphatic alkynes with $N$-(diphenylphosphinoyl)imines catalyzed by $(S)-\mathbf{4 . 1 1}$
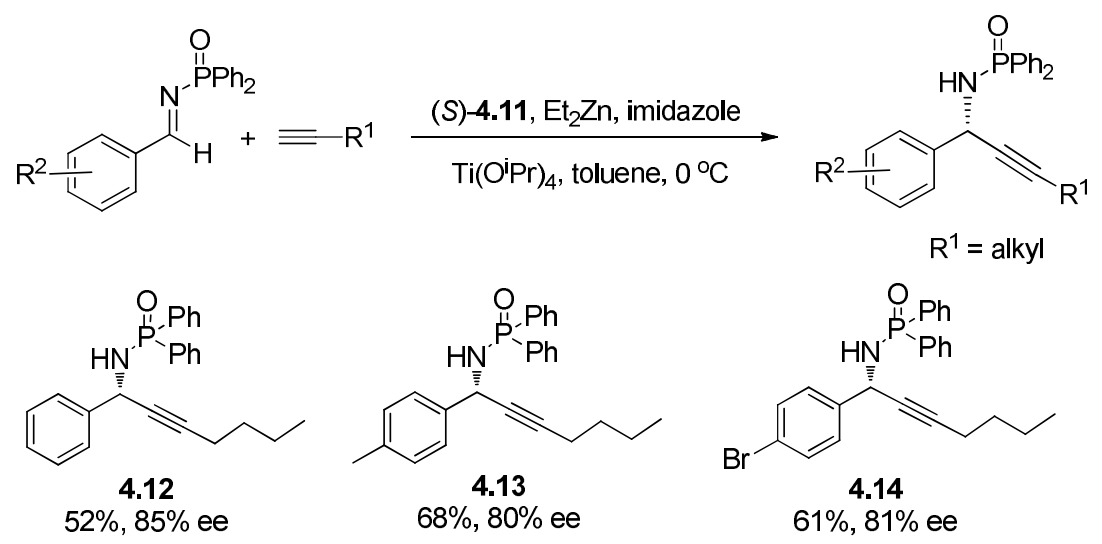

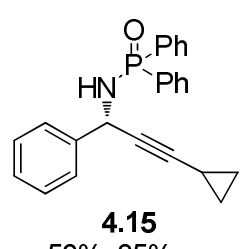

$50 \%, 85 \%$ ee

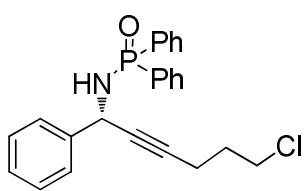

4.18
$46 \%, 77 \%$ ee
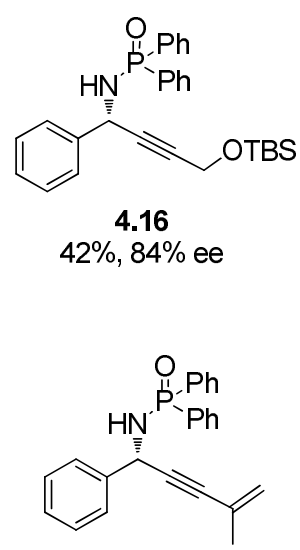

4.19

$64 \%, 81 \%$ ee
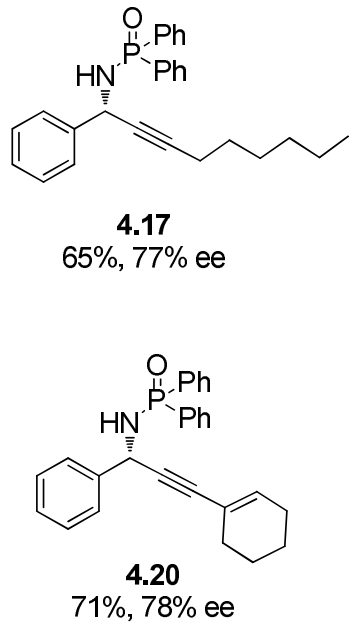
We applied the conditions of entry 10 in Table 4.4 for the asymmetric addition of aryl alkynes to $N$-(diphenylphosphinoyl)imines. The results are summarized in Scheme 4.10. Similar enantioselectivity was observed for the phenylacetylene addition to $N$-(diphenylphosphinoyl)benzaldimines containing an electron-donating Me group or an electron-withdrawing $\mathrm{Br}$ for the formation of compounds $\mathbf{4 . 2 1}$ and 4.22. Addition of other aryl alkynes to $N$-(diphenylphosphinoyl)imines was studied. It was found that the more electron rich aryl alkynes gave higher enantioselectivity for the formation of products $\mathbf{4 . 2 3}-\mathbf{4 . 2 5}$ than the more electron deficient aryl alkynes which gave the products 4.26 and 4.27. The lower yields of 4.26 and 4.27 could be attributed to their corresponding less nucleophilic zinc acetylides.

Scheme 4.10. Reaction of aromatic alkynes with $N$-(diphenylphosphinoyl)imines catalyzed by $(S)-\mathbf{1 1}$
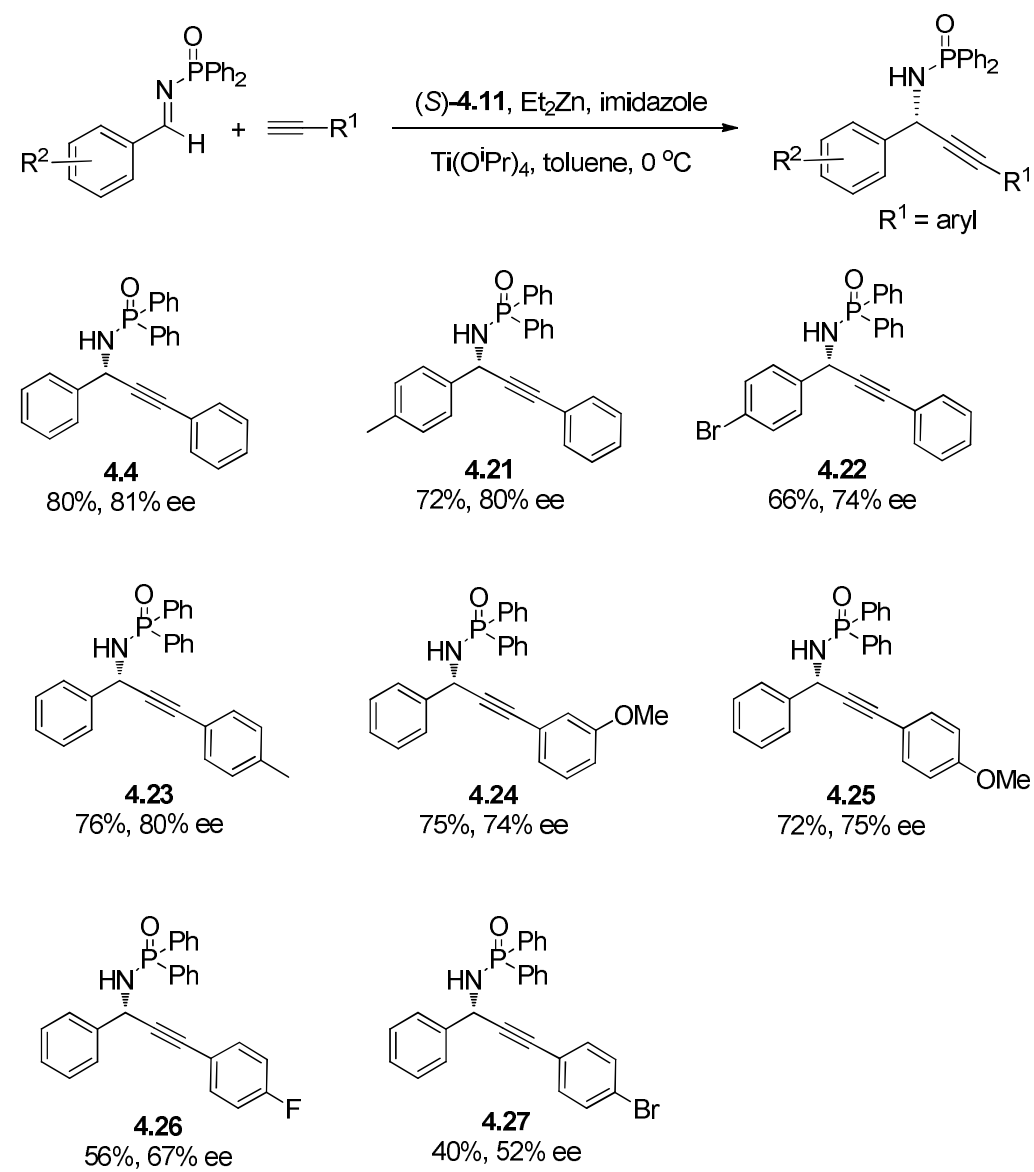

Reagents: Alkyne/ $\mathrm{Et}_{2} \mathrm{Zn} / /(S)-4.11 /$ additive/Ti $\left(\mathrm{O}^{i} \mathrm{Pr}_{4}\right) /$ imine $=7.2: 6: 0.3: 0.3: 1: 1$, imine $(0.1 \mathrm{mmol})$ 


\subsection{Summary}

We have discovered that a new 3,3'-di(1-diphenylmethylpiperazinyl)methyl $\mathrm{H}_{8}$ BINOL compound $(S)$-4.11 can catalyze the asymmetric reaction of alkynes with $N$-(diphenylphosphinoyl)imines in the presence of $\mathrm{Et}_{2} \mathrm{Zn}$ and $\mathrm{Ti}\left(\mathrm{O}^{i} \mathrm{Pr}\right)_{4}$. Especially, it exhibits unprecedented high enantioselectivity for the alkyl alkyne addition to the $N$-(diphenylphosphinoyl)imines. The easy removal of the $N$-(diphenylphosphinoyl) protecting groups of the propargylic amine products makes this method practically useful for the synthesis this class of important chiral compounds. Because this catalyst system utilizes two metallic reagents in combination with a multifunctional chiral ligand, more detailed study of the reaction mechanism is necessary in order to gain better understanding of this reaction and further improve the catalytic efficiency. 


\section{Experimental and Characterization}

\section{Analytical instruments}

NMR: Bruker $600 \mathrm{MHz}$.

HPLC: Water 600 Pump and Waters 486 Tunable Absorbance Detector, Chiralcel OD, OD-H, or Chiralpak AD, AD-H column.

Polarimeter: Jasco Digital Polarimeter P-2000.

High resolution mass spectra were obtained by EI [70-VSE(C)] or ESI (Q-TOf) analysis.

\section{General data}

Asymmetric reactions were carried out under nitrogen in vials. All commercial chemicals were used without further purification unless otherwise noted. Zinc reagents and catalysts were purchased and stored in dry nitrogen atmosphere. THF, Toluene and 1,4-dionaxe were distilled over sodium and benzophenone under nitrogen. DCM, $\mathrm{Et}_{2} \mathrm{O}$ and hexanes were dried by passing through activated alumina columns under nitrogen. All the NMR spectra were obtained in $\mathrm{CDCl}_{3}$ unless indicated otherwise.

\section{Synthesis and characterization of ligands $(S)-4.1-(S)-4.11$}

Compounds $(S)-4.1{ }^{7 \mathrm{~d}}(S)-\mathbf{4 . 2}{ }^{7 \mathrm{e}}$ and $(S)-4.3^{7 \mathrm{e}}$ were known compounds and prepared according to literature procedures. 


\section{Characterization of $(S)-4.1$}

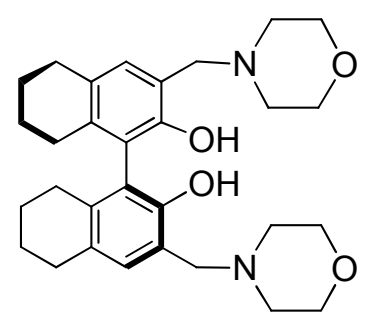

(S)-4.1

${ }^{1} \mathrm{H}$ NMR (600 MHz, $\left.\mathrm{CDCl}_{3}\right) \delta 10.34$ (s, 2H), 6.72 (s, 2H), 3.79 (d, 2H, J=13.8 Hz), $3.67(\mathrm{~s}, 8 \mathrm{H}), 3.58(\mathrm{~d}, 2 \mathrm{H}, \mathrm{J}=13.8 \mathrm{~Hz}), 2.70(\mathrm{~m}, 4 \mathrm{H}), 2.54(\mathrm{~s}, 8 \mathrm{H}), 2.32(\mathrm{~m}, 2 \mathrm{H}), 2.16$ $(\mathrm{m}, 2 \mathrm{H}), 1.68(\mathrm{~m}, 8 \mathrm{H}) .{ }^{13} \mathrm{C} \mathrm{NMR}\left(150 \mathrm{MHz}, \mathrm{CDCl}_{3}\right) \delta 152.0,135.9,128.7,127.6$, $123.9,117.7,66.7,61.9,52.9,29.2,27.0,23.2,23.1$.

\section{Characterization of $(S)-4.2$}

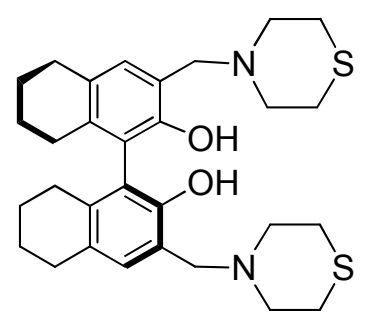

(S)-4.2

${ }^{1} \mathrm{H}$ NMR (600 MHz, $\left.\mathrm{CDCl}_{3}\right) \delta 10.34(\mathrm{~s}, 2 \mathrm{H}), 6.70(\mathrm{~s}, 2 \mathrm{H}), 3.77$ (d, 2H, J=13.8 Hz), $3.60(\mathrm{~d}, 2 \mathrm{H}, \mathrm{J}=13.8 \mathrm{~Hz}), 2.81(\mathrm{~s}, 8 \mathrm{H}), 2.70(\mathrm{~m}, 4 \mathrm{H}), 2.65(\mathrm{~m}, 4 \mathrm{H}), 2.34(\mathrm{~m}, 2 \mathrm{H}), 2.14$ (m, 2H), $1.69(\mathrm{~m}, 8 \mathrm{H}) .{ }^{13} \mathrm{C}$ NMR $\left(150 \mathrm{MHz}, \mathrm{CDCl}_{3}\right) \delta 152.1,135.9,128.7,127.5$, $124.0,117.9,62.3,54.3,29.2,27.7,27.0,23.25,23.18$.

\section{Characterization of $(S)-4.3$}

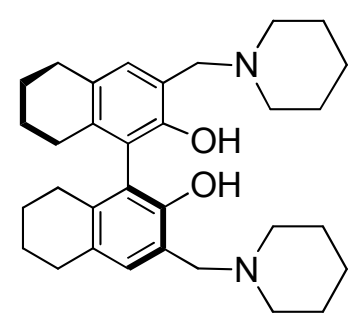

(S) -4.3

${ }^{1} \mathrm{H}$ NMR (600 MHz, $\left.\mathrm{CDCl}_{3}\right) \delta 11.0(\mathrm{~s}, 2 \mathrm{H}), 6.67$ (s, 2H), $3.75(\mathrm{~d}, 2 \mathrm{H}, \mathrm{J}=13.8 \mathrm{~Hz})$, 
$3.50(\mathrm{~d}, 2 \mathrm{H}, \mathrm{J}=13.8 \mathrm{~Hz}), 2.70(\mathrm{~m}, 4 \mathrm{H}), 2.63-2.14(\mathrm{~m}, 12 \mathrm{H}), 1.68(\mathrm{~m}, 8 \mathrm{H}), 1.55(\mathrm{~m}$, $8 \mathrm{H}), 1.43(\mathrm{~s}, 4 \mathrm{H}) .{ }^{13} \mathrm{C} \mathrm{NMR}\left(150 \mathrm{MHz}, \mathrm{CDCl}_{3}\right) \delta 152.6,135.4,128.2,126.9,124.0$, $118.7,62.3,53.8,29.3,26.9,25.6,24.1,23.32,23.26$.

\section{Synthesis and characterization of $(S)-4.4$}

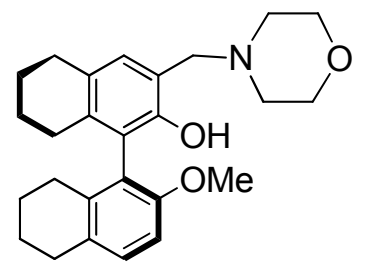

(S)-4.4

(a) To a solution of $(S)-\mathrm{H}_{8} \mathrm{BINOL}\left(2.04 \mathrm{mmol}, 600 \mathrm{mg}, 1\right.$ equiv) and $\mathrm{K}_{2} \mathrm{CO}_{3}(10.2$ mmol, $1.4 \mathrm{~g}, 5$ equiv) in $20 \mathrm{~mL}$ THF was added MeI (2.04 mmol, $127.1 \mu \mathrm{L}, 1$ equiv) at room temperature under nitrogen. Then the reaction was heated to $50{ }^{\circ} \mathrm{C}$ and stirred for $24 \mathrm{~h}$. After cooled to room temperature, the mixture was quenched with water (10 $\mathrm{mL})$ and extracted with $\mathrm{CH}_{2} \mathrm{Cl}_{2}(3 \times 15 \mathrm{~mL})$. The organic layer was then dried over anhydrous $\mathrm{Na}_{2} \mathrm{SO}_{4}$ and concentrated by rotary evaporation. The crude mixture was purified by flash column chromatography on silica gel eluted with hexanes $/ \mathrm{CH}_{2} \mathrm{Cl}_{2}$ $(5 / 1)$ to give $O-\mathrm{Me}-(S)-\mathrm{H}_{8} \mathrm{BINOL}$ as a white powder in $70 \%$ yield $(440 \mathrm{mg})$. The NMR spectra match those reported. ${ }^{8 a}$

(b) Paraformaldehyde (5.0 mmol, $150 \mathrm{mg}, 5$ equiv) was added to a 2-neck round bottom flask fitted with condenser under nitrogen. The flask was then charged with dioxane $\left(10 \mathrm{~mL}\right.$, degassed), and the mixture was cooled to $0{ }^{\circ} \mathrm{C}$. Morpholine $(5.0$ mmol, $431 \mathrm{uL}, 5$ equiv) was added dropwise into the mixture over $20 \mathrm{~min}$. After the addition was completed, the ice bath was removed and the mixture was warmed to room temperature for $2 \mathrm{~h}$. It was then heated at $65^{\circ} \mathrm{C}$ for $18 \mathrm{~h}$. After the solution was 
cooled to room temperature, $O-\mathrm{Me}-(S)-\mathrm{H}_{8} \mathrm{BINOL}(1.0 \mathrm{mmol}, 308 \mathrm{mg}, 1$ equiv) dissolved in dioxane $(5 \mathrm{~mL})$ was added, and the resulting solution was reheated to 95 ${ }^{\circ} \mathrm{C}$ for $20 \mathrm{~h}$. Upon completion of the reaction, the mixture was diluted with ethyl acetate $(15 \mathrm{~mL})$ and washed with saturated $\mathrm{NaHCO}_{3}(3 \times 15 \mathrm{~mL})$ and $\mathrm{H}_{2} \mathrm{O}(3 \times 15$ $\mathrm{mL}$ ). The organic layer was then dried over anhydrous $\mathrm{Na}_{2} \mathrm{SO}_{4}$ and concentrated by rotary evaporation. The crude mixture was purified by flash column chromatography on silica gel eluted with hexanes/ethyl acetate $(20 / 1$ to $10 / 1)$ to give pure $(S)-4.4$ as a white powder in 65\% yield (265 mg). ${ }^{1} \mathrm{H}$ NMR $\left(600 \mathrm{MHz}, \mathrm{CDCl}_{3}\right) \delta 10.31(\mathrm{~s}, 1 \mathrm{H})$, $7.12(\mathrm{~d}, 1 \mathrm{H}, \mathrm{J}=8.4 \mathrm{~Hz}), 6.87(\mathrm{~d}, 1 \mathrm{H}, \mathrm{J}=8.4 \mathrm{~Hz}), 6.81(\mathrm{~s}, 1 \mathrm{H}), 3.83(\mathrm{~d}, 1 \mathrm{H}, \mathrm{J}=13.8$ $\mathrm{Hz}), 3.76(\mathrm{~m}, 7 \mathrm{H}), 3.70(\mathrm{~d}, 1 \mathrm{H}, \mathrm{J}=13.8 \mathrm{~Hz}), 2.83(\mathrm{~m}, 4 \mathrm{H}), 2.62(\mathrm{~s}, 4 \mathrm{H}), 2.38(\mathrm{~m}, 2 \mathrm{H})$, $2.20(\mathrm{~m}, 2 \mathrm{H}), 1.76(\mathrm{~m}, 8 \mathrm{H}) .{ }^{13} \mathrm{C}\left\{{ }^{1} \mathrm{H}\right\} \mathrm{NMR}\left(150 \mathrm{MHz}, \mathrm{CDCl}_{3}\right) \delta$ 154.8, 152.0, $136.5,136.2,129.6,129.0,128.6,127.5,125.7,124.3,117.7,109.2,66.7,61.9,56.1$ 53.0, 29.5, 29.3, 27.2, 27.1, 23.4, 23.35, 23.32, 23.2. HRMS [ESI(TOF)] for $\mathrm{C}_{26} \mathrm{H}_{34} \mathrm{NO}_{3}\left[\mathrm{M}+\mathrm{H}^{+}\right]: \mathrm{m} / \mathrm{z}$ : calcd for: 408.2539; found: 408.2536 .

\section{Characterization of $(S)-4.5$}

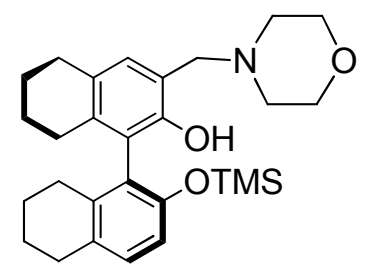

(S)-4.5

Prepared according to the similar procedure as $(S)-\mathbf{4 . 6}$

${ }^{1} \mathrm{H}$ NMR $\left(600 \mathrm{MHz}, \mathrm{CDCl}_{3}\right) \delta 10.2(\mathrm{~s}, 1 \mathrm{H}), 6.93(\mathrm{~d}, 1 \mathrm{H}, \mathrm{J}=7.8 \mathrm{~Hz}), 6.71(\mathrm{~s}, 1 \mathrm{H}), 6.66$ (d, 1H, J=8.4 Hz), 3.74 (d, 1H, J=13.2 Hz), 3.68 (s, 4H), 3.57 (d, 1H, J=13.2 Hz), 2.77 (m, 2H), $2.71(\mathrm{t}, 2 \mathrm{H}, \mathrm{J}=6 \mathrm{~Hz}), 2.55(\mathrm{~s}, 4 \mathrm{H}), 2.45(\mathrm{~m}, 2 \mathrm{H}), 2.14(\mathrm{~m}, 2 \mathrm{H}), 1.68(\mathrm{~m}, 8 \mathrm{H})$, 
$-0.03(\mathrm{~s}, 9 \mathrm{H})$.

\section{Synthesis and characterization of $(S)-4.6$}

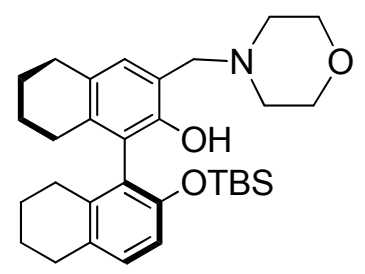

(S)-4.6

(a) To a solution of $(S)-\mathrm{H}_{8}$ BINOL (1.7 mmol, $500 \mathrm{mg}, 1$ equiv) in $10 \mathrm{~mL}$ THF was added ${ }^{n} \mathrm{BuLi}$ (2.0 mmol, $2.5 \mathrm{M}$ in hexanes, $0.8 \mathrm{~mL}, 1.2$ equiv) at $0{ }^{\circ} \mathrm{C}$ under nitrogen. The reaction was stirred for $20 \mathrm{~min}$. Then $\mathrm{TBSCl}(2.0 \mathrm{mmol}, 306 \mathrm{mg}, 1.2$ equiv) in 5 $\mathrm{mL}$ THF was added and the resulting solution was warmed to room temperature. After $20 \mathrm{~h}$, the reaction was quenched with saturated $\mathrm{NH}_{4} \mathrm{Cl}$ solution $(10 \mathrm{~mL})$ and extracted with $\mathrm{CH}_{2} \mathrm{Cl}_{2}(3 \times 15 \mathrm{~mL})$. The organic layer was then dried over anhydrous $\mathrm{Na}_{2} \mathrm{SO}_{4}$ and concentrated by rotary evaporation. The crude mixture was purified by flash column chromatography on silica gel eluted with hexanes/ $\mathrm{CH}_{2} \mathrm{Cl}_{2}(8 / 1$ to $5 / 1)$ to give $O$-TBS- $(S)-\mathrm{H}_{8} \mathrm{BINOL}$ as a white powder in $74 \%$ yield $(512 \mathrm{mg})$. The NMR spectra match those reported. ${ }^{8 b}$

(b) Paraformaldehyde (6.25 mmol, $188 \mathrm{mg}, 5$ equiv) was added to a 2-neck round bottom flask fitted with condenser under nitrogen. The flask was then charged with dioxane $\left(10 \mathrm{~mL}\right.$, degassed), and the mixture was cooled to $0{ }^{\circ} \mathrm{C}$. Morpholine $(6.25$ mmol, $548 \mathrm{uL}, 5$ equiv) was added dropwise into the mixture over $20 \mathrm{~min}$. After the addition was completed, the ice bath was removed and the mixture was warmed to room temperature for $2 \mathrm{~h}$. It was then heated at $65^{\circ} \mathrm{C}$ for $18 \mathrm{~h}$. After the solution was cooled to room temperature, $O$-TBS- $(S)-\mathrm{H}_{8} \mathrm{BINOL}(1.25 \mathrm{mmol}, 512 \mathrm{mg}, 1$ equiv) 
dissolved in dioxane $(5 \mathrm{~mL})$ was added, and the resulting solution was reheated to 95 ${ }^{\circ} \mathrm{C}$ for $20 \mathrm{~h}$. Upon completion of the reaction, the mixture was diluted with ethyl acetate $(15 \mathrm{~mL})$ and washed with saturated $\mathrm{NaHCO}_{3}(3 \times 15 \mathrm{~mL})$ and $\mathrm{H}_{2} \mathrm{O}(3 \times 15$ $\mathrm{mL}$ ). The organic layer was then dried over anhydrous $\mathrm{Na}_{2} \mathrm{SO}_{4}$ and concentrated by rotary evaporation. The crude mixture was purified by flash column chromatography on silica gel with hexanes/ethyl acetate $(25 / 1$ to $15 / 1)$ to give pure $(S)-\mathbf{4 . 6}$ as a white powder in 59\% yield (374 mg). ${ }^{1} \mathrm{H}$ NMR $\left(600 \mathrm{MHz}, \mathrm{CDCl}_{3}\right) \delta 10.21(\mathrm{~s}, 1 \mathrm{H}), 6.97(\mathrm{~d}$, $1 \mathrm{H}, \mathrm{J}=8.4 \mathrm{~Hz}), 6.71(\mathrm{~m}, 2 \mathrm{H}), 3.79(\mathrm{~d}, 1 \mathrm{H}, \mathrm{J}=13.2 \mathrm{~Hz}), 3.70(\mathrm{~s}, 4 \mathrm{H}), 3.54(\mathrm{~d}, 1 \mathrm{H}$, $\mathrm{J}=13.8 \mathrm{~Hz}), 2.78(\mathrm{~m}, 2 \mathrm{H}), 2.71(\mathrm{~m}, 2 \mathrm{H}), 2.60(\mathrm{~m}, 4 \mathrm{H}), 2.48(\mathrm{~m}, 2 \mathrm{H}), 2.16(\mathrm{~m}, 2 \mathrm{H})$, $1.70(\mathrm{~m}, 8 \mathrm{H}), 0.70(\mathrm{~s}, 9 \mathrm{H}), 0.16(\mathrm{~s}, 3 \mathrm{H}),-0.01(\mathrm{~s}, 3 \mathrm{H}) .{ }^{13} \mathrm{C}\left\{{ }^{1} \mathrm{H}\right\}$ NMR $(150 \mathrm{MHz}$ $\left.\mathrm{CDCl}_{3}\right) \delta 152.1,150.1,137.0,136.4,129.6,128.8,128.08,128.06,127.5,124.7$ $117.6,116.0,66.7,61.9,52.9,29.5,29.4,27.3,27.0,25.3,23.4,23.33,23.30,23.2$, 17.7, -4.1, -4.8. HRMS [ESI(TOF)] for $\mathrm{C}_{31} \mathrm{H}_{46} \mathrm{NO}_{3} \mathrm{Si}\left[\mathrm{M}+\mathrm{H}^{+}\right]$: $\mathrm{m} / \mathrm{z}$ : calcd for: 508.3247; found: 508.3253 .

\section{Characterization of $(S)-4.7$}

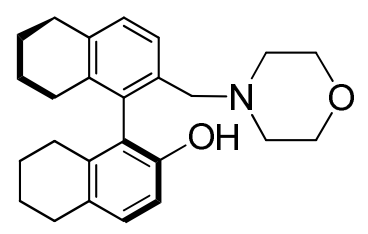

(S)-4.7

Prepared according to the literature procedure. ${ }^{9}$

$[\alpha]^{22}=61.3\left(\mathrm{c}=3.0, \mathrm{CHCl}_{3}\right) .{ }^{1} \mathrm{H}$ NMR $\left(600 \mathrm{MHz}, \mathrm{CDCl}_{3}\right) \delta 8.97(\mathrm{~s}, 1 \mathrm{H}), 7.02(\mathrm{q}$, 2H, J=4.2 Hz), 6.97 (d, 1H, J=7.8 Hz), 6.87 (d, 1H, J=8.4 Hz), 3.70 (m, 2H), 3.59 (m, 2H), 3.32 (d, 1H, J=12 Hz), $2.96(\mathrm{~d}, 1 \mathrm{H}, \mathrm{J}=12 \mathrm{~Hz}), 2.80(\mathrm{~m}, 2 \mathrm{H}), 2.74(\mathrm{~m}, 2 \mathrm{H}), 2.57$ 
(m, 2H), $2.22(\mathrm{~m}, 2 \mathrm{H}), 2.17(\mathrm{~m}, 1 \mathrm{H}), 2.13(\mathrm{~m}, 1 \mathrm{H}), 2.05(\mathrm{~m}, 1 \mathrm{H}), 1.95(\mathrm{~m}, 1 \mathrm{H}), 1.68$ $(\mathrm{m}, 8 \mathrm{H}) .{ }^{13} \mathrm{C}\left\{{ }^{1} \mathrm{H}\right\}$ NMR $\left(150 \mathrm{MHz}, \mathrm{CDCl}_{3}\right) \delta 151.5,138.1,137.9,136.8,135.1$, $132.0,130.0,129.6,129.3,127.8,127.4,117.4,66.4,62.4,52.9,30.0,29.4,27.6,27.3$, $23.3,23.2,23.1,22.7$.

Compounds $(S)-\mathbf{4 . 8},(S)-\mathbf{4 . 9}$ and $(S)-\mathbf{4 . 1 0}$ were prepared in the same way as $(S)$-4.11 by using the corresponding commercially available 1-substituted piperazine as the starting material.

\section{Characterization of $(S)-4.8$}

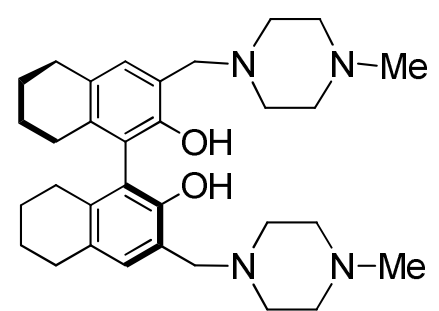

$(S)-4.8$

${ }^{1} \mathrm{H}$ NMR $\left(600 \mathrm{MHz}, \mathrm{CDCl}_{3}\right) \delta 6.69(\mathrm{~s}, 2 \mathrm{H}), 3.77(\mathrm{~d}, 2 \mathrm{H}, \mathrm{J}=13.2 \mathrm{~Hz}), 3.58(\mathrm{~d}, 2 \mathrm{H}, \mathrm{J}=$ $13.8 \mathrm{~Hz}), 2.70(\mathrm{~m}, 4 \mathrm{H}), 2.59-2.43(\mathrm{~m}, 16 \mathrm{H}), 2.36(\mathrm{~m}, 2 \mathrm{H}), 2.25(\mathrm{~s}, 6 \mathrm{H}), 2.15(\mathrm{~m}, 2 \mathrm{H})$, $1.69(\mathrm{~m}, 8 \mathrm{H}) .{ }^{13} \mathrm{C}\left\{{ }^{1} \mathrm{H}\right\} \operatorname{NMR}\left(150 \mathrm{MHz}, \mathrm{CDCl}_{3}\right) \delta$ 152.2, 135.7, 128.5, 127.3, 124.0, 118.2, 61.4, 54.7, 52.4, 45.8, 29.2, 27.0, 23.3, 23.2. HRMS [ESI(TOF)] for $\mathrm{C}_{32} \mathrm{H}_{47} \mathrm{~N}_{4} \mathrm{O}_{2}\left[\mathrm{M}+\mathrm{H}^{+}\right]:$m/z: calcd for: 519.3699; found: 519.3701 .

\section{Characterization of $(S)-4.9$}

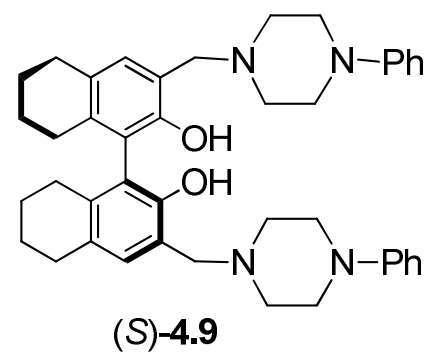


${ }^{1} \mathrm{H}$ NMR $\left(600 \mathrm{MHz}, \mathrm{CDCl}_{3}\right) \delta 10.45(\mathrm{~s}, 2 \mathrm{H}), 7.25(\mathrm{~m}, 4 \mathrm{H}), 6.89(\mathrm{~m}, 6 \mathrm{H}), 6.76(\mathrm{~s}, 2 \mathrm{H})$, $3.87(\mathrm{~d}, 2 \mathrm{H}, \mathrm{J}=13.8 \mathrm{~Hz}), 3.66(\mathrm{~d}, 2 \mathrm{H}, \mathrm{J}=13.8 \mathrm{~Hz}), 3.19(\mathrm{~s}, 8 \mathrm{H}), 2.74(\mathrm{~m}, 12 \mathrm{H}), 2.38$ (m, 2H), $2.19(\mathrm{~m}, 2 \mathrm{H}), 1.72(\mathrm{~m}, 8 \mathrm{H}) .{ }^{13} \mathrm{C}\left\{{ }^{1} \mathrm{H}\right\}$ NMR $\left(150 \mathrm{MHz}, \mathrm{CDCl}_{3}\right) \delta$ 152.2, $151.0,135.9,129.1,128.6,127.5,124.0,120.0,118.1,116.4,61.5,52.5,49.1,29.2$ 27.0, 23.3, 23.2. HRMS [ESI(TOF)] for $\mathrm{C}_{42} \mathrm{H}_{51} \mathrm{~N}_{4} \mathrm{O}_{2}\left[\mathrm{M}+\mathrm{H}^{+}\right]$: $\mathrm{m} / \mathrm{z}$ : calcd for: 643.4012; found: 643.4015 .

\section{Characterization of $(S)-4.10$}

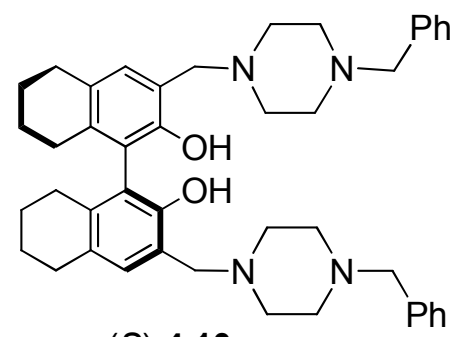

(S)-4.10

${ }^{1} \mathrm{H}$ NMR $\left(600 \mathrm{MHz}, \mathrm{CDCl}_{3}\right) \delta 10.67(\mathrm{~s}, 2 \mathrm{H}), 7.30(\mathrm{~m}, 10 \mathrm{H}), 6.73(\mathrm{~s}, 2 \mathrm{H}), 3.83(\mathrm{~d}, 2 \mathrm{H}$, $\mathrm{J}=13.8 \mathrm{~Hz}), 3.59(\mathrm{~d}, 2 \mathrm{H}, \mathrm{J}=13.8 \mathrm{~Hz}), 3.48(\mathrm{~s}, 4 \mathrm{H}), 2.74-2.16(\mathrm{~m}, 28 \mathrm{H}), 1.72(\mathrm{~m}$, 8H). ${ }^{13} \mathrm{C}\left\{{ }^{1} \mathrm{H}\right\}$ NMR $\left(150 \mathrm{MHz}, \mathrm{CDCl}_{3}\right) \delta 152.3,138.0,135.6,129.0,128.4,128.2$, $127.2,127.1,124.0,118.2,62.8,61.5,52.7,52.5,29.2,27.0,23.3,23.2$. HRMS [ESI(TOF)] for $\mathrm{C}_{44} \mathrm{H}_{55} \mathrm{~N}_{4} \mathrm{O}_{2}\left[\mathrm{M}+\mathrm{H}^{+}\right]$: m/z: calcd for: 671.4325; found: 671.4324 .

\section{Synthesis and characterization of $(S)-4.11$}

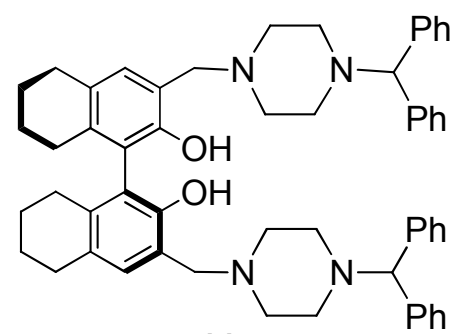

(S)-4.11

$\mathrm{Ph}$ 
Paraformaldehyde (23.8 mmol, $714.3 \mathrm{mg}, 4$ equiv) was added to a 2-neck round bottom flask fitted with condenser under nitrogen. The flask was then charged with dioxane (20 mL, degassed), and the mixture was cooled to $0{ }^{\circ} \mathrm{C}$. 1-(diphenylmethyl)piperazine ( $23.8 \mathrm{mmol}, 6.0 \mathrm{~g}, 4$ equiv) was added dropwise into the mixture over $20 \mathrm{~min}$. After the addition was completed, the ice bath was removed and the mixture was warmed to room temperature for $2 \mathrm{~h}$. It was then heated at $65^{\circ} \mathrm{C}$ for $18 \mathrm{~h}$. After the solution was cooled to room temperature, $(S)-\mathrm{H}_{8} \mathrm{BINOL}$ ( $6.0 \mathrm{mmol}$, $1.76 \mathrm{~g}, 1$ equiv) dissolved in dioxane $(10 \mathrm{~mL})$ was added, and the resulting solution was reheated to $65^{\circ} \mathrm{C}$ for $18 \mathrm{~h}$. Upon completion of the reaction, the mixture was diluted with ethyl acetate $(20 \mathrm{~mL})$ and washed with saturated $\mathrm{NaHCO}_{3}(3 \times 20 \mathrm{~mL})$ and $\mathrm{H}_{2} \mathrm{O}(3 \times 20 \mathrm{~mL})$. The organic layer was then dried over anhydrous $\mathrm{Na}_{2} \mathrm{SO}_{4}$ and concentrated by rotary evaporation. The crude solid was washed with EtOH to give pure $(S)$-4.11 as a white powder in 90\% yield (4.44 g). ${ }^{1} \mathrm{H}$ NMR $\left(600 \mathrm{MHz}, \mathrm{CDCl}_{3}\right)$ $\delta 10.46(\mathrm{~s}, 2 \mathrm{H}), 7.42(\mathrm{~m}, 8 \mathrm{H}), 7.28(\mathrm{~m}, 8 \mathrm{H}), 7.20(\mathrm{~m}, 4 \mathrm{H}), 6.74(\mathrm{~s}, 2 \mathrm{H}), 4.27(\mathrm{~m}, 2 \mathrm{H})$ $3.87(\mathrm{~d}, 2 \mathrm{H}, \mathrm{J}=13.8 \mathrm{~Hz}), 3.58(\mathrm{~d}, 2 \mathrm{H}, \mathrm{J}=13.8 \mathrm{~Hz}), 2.76-2.33(\mathrm{~m}, 22 \mathrm{H}), 2.17(\mathrm{~m}, 2 \mathrm{H})$, $1.72(\mathrm{~m}, 8 \mathrm{H}) .{ }^{13} \mathrm{C}\left\{{ }^{1} \mathrm{H}\right\} \mathrm{NMR}\left(150 \mathrm{MHz}, \mathrm{CDCl}_{3}\right) \delta$ 152.4, 142.6, 142.5, 135.6, $128.6,128.5,128.4,127.9,127.3,127.1,127.0,124.0,118.2,76.0,61.6,52.8,51.5$, 29.3, 27.0, 23.4, 23.3, $[\alpha]^{24}{ }_{\mathrm{D}}=16.5\left(\mathrm{c}=1.10, \mathrm{CHCl}_{3}\right) . \quad \mathrm{Mp} 182-185^{\circ} \mathrm{C} . \quad \mathrm{HRMS}$ [ESI(TOF)] for $\mathrm{C}_{56} \mathrm{H}_{63} \mathrm{~N}_{4} \mathrm{O}_{2}\left[\mathrm{M}+\mathrm{H}^{+}\right]$: m/z: calcd for: 823.4951; found: 823.4950 .

\section{General procedure for the alkyne addition to $N$-(diphenylphosphinoyl)imines} catalyzed by $(S)-4.11$

Under nitrogen, $(S)-4.11(30 \mathrm{~mol} \%, 24.8 \mathrm{mg})$ and imidazole $(30 \mathrm{~mol} \%, 2 \mathrm{mg}$ ) 
were added into a vial and dissolved in toluene $(0.3 \mathrm{~mL})$. An alkyne (4 equiv or 7.2 equiv), and $\mathrm{Et}_{2} \mathrm{Zn}$ ( 4 equiv or 6 equiv) were then added and the mixture was stirred at room temperature for $5 \mathrm{~h}$. Then, $\operatorname{Ti}\left(\mathrm{O}^{i} \mathrm{Pr}\right)_{4}$ (1 equiv) was added and the stirring continued at room temperature for $3 \mathrm{~h}$. A $N$-(diphenylphosphinoyl)imine $(0.1 \mathrm{mmol}, 1$ equiv) was added and the mixture was cooled to $0{ }^{\circ} \mathrm{C}$ and stirred for $48 \mathrm{~h}$. The reaction was quenched with the addition of water $(2 \mathrm{~mL})$ and extracted with ethyl acetate $(3 \times 4 \mathrm{~mL})$. The organic layer was dried with anhydrous $\mathrm{Na}_{2} \mathrm{SO}_{4}$, filtered and then concentrated by rotary evaporation. The crude mixture was purified by flash column chromatography on silica gel with hexanes/ethyl acetate (1/1) to give the propargyl phosphonamide products with 40 - $80 \%$ yield and 52 - $85 \%$ ee.

Characterization of the propargyl phosphonamides prepared from the asymmetric alkyne addition to $N$-(diphenylphosphinoyl)imines

(S)-P,P-diphenyl- $N$-(1-phenylhept-2-yn-1-yl)phosphinic amide, 4.12<smiles>CCCCC#C[C@H](NP(=O)(c1ccccc1)c1ccccc1)c1ccccc1</smiles>

4.12

$52 \%, 85 \%$ ee

White solid, Mp $116-118{ }^{\circ} \mathrm{C}, 20.1 \mathrm{mg}, 52 \%$ yield. $85 \%$ ee determined by HPLC analysis: CHIRALPAK AD-H column, 90:10 hexanes: ${ }^{i} \mathrm{PrOH}$, flow rate $=1.0 \mathrm{~mL} / \mathrm{min}$, $\lambda=225 \mathrm{~nm}$, retention time: $\mathrm{t}_{\text {minor }}=14.8 \mathrm{~min}, \mathrm{t}_{\text {major }}=16.3 \mathrm{~min} .[\alpha]^{24}=-16.3(\mathrm{c}=$ 0.705, $\left.\mathrm{CHCl}_{3}\right) .{ }^{1} \mathrm{H}$ NMR (600 MHz, $\left.\mathrm{CDCl}_{3}\right) \delta 8.03(\mathrm{~m}, 2 \mathrm{H}), 7.82(\mathrm{~m}, 2 \mathrm{H}), 7.60(\mathrm{~d}, 2 \mathrm{H}$, $\mathrm{J}=7.8 \mathrm{~Hz}), 7.52(\mathrm{t}, 1 \mathrm{H}, \mathrm{J}=7.2 \mathrm{~Hz}), 7.46(\mathrm{~m}, 3 \mathrm{H}), 7.37(\mathrm{~m}, 2 \mathrm{H}), 7.32(\mathrm{t}, 2 \mathrm{H}, \mathrm{J}=7.2 \mathrm{~Hz})$, 
$7.25(\mathrm{t}, 1 \mathrm{H}, \mathrm{J}=6.6 \mathrm{~Hz}), 5.13(\mathrm{t}, 1 \mathrm{H}, \mathrm{J}=10.2 \mathrm{~Hz}), 3.41(\mathrm{t}, 1 \mathrm{H}, \mathrm{J}=9 \mathrm{~Hz}), 2.21(\mathrm{t}, 2 \mathrm{H}$, $\mathrm{J}=7.2 \mathrm{~Hz}), 1.48(\mathrm{~m}, 2 \mathrm{H}), 1.41(\mathrm{~m}, 2 \mathrm{H}), 0.91(\mathrm{t}, 3 \mathrm{H}, \mathrm{J}=7.8 \mathrm{~Hz}) .{ }^{13} \mathrm{C}$ NMR $(150 \mathrm{MHz}$ $\left.\mathrm{CDCl}_{3}\right) \delta 141.0(\mathrm{~d}, \mathrm{~J}=4.7 \mathrm{~Hz}), 132.7(\mathrm{~d}, \mathrm{~J}=9.8 \mathrm{~Hz}), 131.9,131.8,128.5,128.4(\mathrm{~d}$, $\mathrm{J}=11.9 \mathrm{~Hz}), 127.7,127.2,86.2,79.7(\mathrm{~d}, \mathrm{~J}=6.2 \mathrm{~Hz}), 46.8,30.7,22.0,18.5,13.6$. These data are consistent with those reported. ${ }^{6}$

\section{(S)-P,P-Diphenyl-N-(1-(p-tolyl)hept-2-yn-1-yl)phosphinic amide, 4.13}

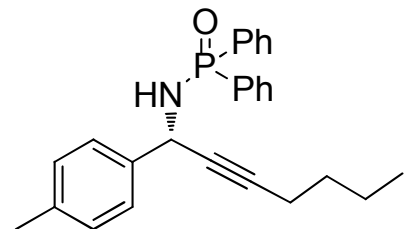

4.13

$68 \%, 80 \%$ ee

White solid, Mp $138-140{ }^{\circ} \mathrm{C}, 27.2 \mathrm{mg}, 68 \%$ yield. $80 \%$ ee determined by HPLC analysis: CHIRALPAK AD-H column, 90:10 hexanes: ${ }^{i} \mathrm{PrOH}$, flow rate $=1.0 \mathrm{~mL} / \mathrm{min}$, $\lambda=225 \mathrm{~nm}$, retention time: $\mathrm{t}_{\text {minor }}=16.6 \mathrm{~min}, \mathrm{t}_{\text {major }}=20.0 \mathrm{~min} . \quad[\alpha]_{\mathrm{D}}^{25}=-13.7(\mathrm{c}=$ 0.96, $\left.\mathrm{CHCl}_{3}\right) . \quad{ }^{1} \mathrm{H}$ NMR $\left(600 \mathrm{MHz}, \mathrm{CDCl}_{3}\right) \delta 8.02(\mathrm{~m}, 2 \mathrm{H}), 7.82(\mathrm{~m}, 2 \mathrm{H}), 7.52(\mathrm{~m}$, 1H), $7.47(\mathrm{~m}, 5 \mathrm{H}), 7.38(\mathrm{~m}, 2 \mathrm{H}), 7.12(\mathrm{~d}, 2 \mathrm{H}, \mathrm{J}=7.8 \mathrm{~Hz}), 5.09(\mathrm{t}, 1 \mathrm{H}, \mathrm{J}=9.6 \mathrm{~Hz})$, $3.37(\mathrm{t}, 1 \mathrm{H}, \mathrm{J}=9 \mathrm{~Hz}), 2.31(\mathrm{~s}, 3 \mathrm{H}), 2.19(\mathrm{t}, 2 \mathrm{H}, \mathrm{J}=7.2 \mathrm{~Hz}), 1.47(\mathrm{~m}, 2 \mathrm{H}), 1.40(\mathrm{~m}$, 2H), $0.91(\mathrm{t}, 3 \mathrm{H}, \mathrm{J}=7.2 \mathrm{~Hz}) .{ }^{13} \mathrm{C}\left\{{ }^{1} \mathrm{H}\right\} \mathrm{NMR}\left(150 \mathrm{MHz}, \mathrm{CDCl}_{3}\right) \delta 138.2(\mathrm{~d}, \mathrm{~J}=4.7$ $\mathrm{Hz}), 137.4,132.7$ (d, J = 9.8 Hz), 131.9, 131.8, 129.1, 128.4 (d, J = 12.6 Hz), 127.1, 86.0, $79.8(\mathrm{~d}, \mathrm{~J}=6 \mathrm{~Hz}), 46.6,30.7,22.0,21.1,18.5,13.6$. HRMS [ESI(TOF)] for $\mathrm{C}_{26} \mathrm{H}_{29} \mathrm{NOP}\left[\mathrm{M}+\mathrm{H}^{+}\right]: \mathrm{m} / \mathrm{z}$ : calcd for: 402.1987; found: 402.1985. 


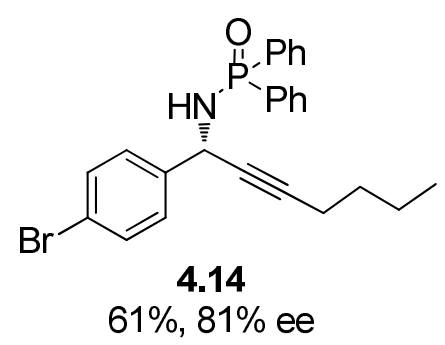

White solid, Mp $140-143{ }^{\circ} \mathrm{C}, 28.5 \mathrm{mg}, 61 \%$ yield. $81 \%$ ee determined by HPLC analysis: CHIRALPAK AD-H column, 90:10 hexanes: ${ }^{i} \mathrm{PrOH}$, flow rate $=1.0 \mathrm{~mL} / \mathrm{min}$, $\lambda=225 \mathrm{~nm}$, retention time: $\mathrm{t}_{\text {minor }}=14.9 \mathrm{~min}, \mathrm{t}_{\text {major }}=20.2 \mathrm{~min} . \quad[\alpha]^{23}=-10.9(\mathrm{c}=$ 1.175, $\left.\mathrm{CHCl}_{3}\right) . \quad{ }^{1} \mathrm{H} \mathrm{NMR}\left(600 \mathrm{MHz}, \mathrm{CDCl}_{3}\right) \delta 8.01(\mathrm{~m}, 2 \mathrm{H}), 7.79(\mathrm{~m}, 2 \mathrm{H}), 7.53(\mathrm{~m}$, 1H), $7.48(\mathrm{~m}, 5 \mathrm{H}), 7.43(\mathrm{~m}, 2 \mathrm{H}), 7.38(\mathrm{~m}, 2 \mathrm{H}), 5.08(\mathrm{t}, 1 \mathrm{H}, \mathrm{J}=9 \mathrm{~Hz}), 3.44(\mathrm{t}, 1 \mathrm{H}, \mathrm{J}=$ $7.8 \mathrm{~Hz}), 2.21(\mathrm{~m}, 2 \mathrm{H}), 1.48(\mathrm{~m}, 2 \mathrm{H}), 1.40(\mathrm{~m}, 2 \mathrm{H}), 0.91(\mathrm{t}, 3 \mathrm{H}, \mathrm{J}=7.2 \mathrm{~Hz}) .{ }^{13} \mathrm{C}\left\{{ }^{1} \mathrm{H}\right\}$ $\operatorname{NMR}\left(150 \mathrm{MHz}, \mathrm{CDCl}_{3}\right) \delta 140.1(\mathrm{~d}, \mathrm{~J}=3.8 \mathrm{~Hz}), 132.6(\mathrm{~d}, \mathrm{~J}=9.9 \mathrm{~Hz}), 132.0(\mathrm{~d}, \mathrm{~J}=$ $10.5 \mathrm{~Hz}), 131.7$ (d, J = 9.8 Hz), 131.5, 129.1, 128.4 (d, J = 12.9 Hz), 121.7, 86.6, 79.1 $(\mathrm{d}, \mathrm{J}=6.9 \mathrm{~Hz}), 46.4,30.6,22.0,18.4$, 13.6. HRMS [ESI(TOF)] for $\mathrm{C}_{25} \mathrm{H}_{26} \mathrm{NOPBr}$ $\left[\mathrm{M}+\mathrm{H}^{+}\right]: \mathrm{m} / \mathrm{z}$ : calcd for: 466.0935; found: 466.0932 .

(S)-N-(3-cyclopropyl-1-phenylprop-2-yn-1-yl)-P,P-diphenylphosphinic amide,

\subsection{5}

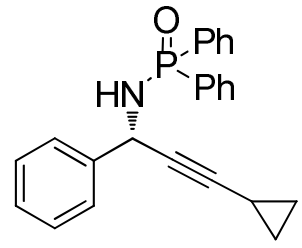

4.15

$50 \%, 85 \%$ ee

White solid, $\mathrm{Mp} 178-180{ }^{\circ} \mathrm{C}, 18.5 \mathrm{mg}, 50 \%$ yield. $85 \%$ ee determined by HPLC 
analysis: CHIRALPAK AD-H column, 90:10 hexanes: ${ }^{i} \mathrm{PrOH}$, flow rate $=1.0 \mathrm{~mL} / \mathrm{min}$, $\lambda=210 \mathrm{~nm}$, retention time: $\mathrm{t}_{\text {minor }}=19.1 \mathrm{~min}, \mathrm{t}_{\text {major }}=21.3 \mathrm{~min} .[\alpha]^{24}=-11.1(\mathrm{c}=0.54$, $\left.\mathrm{CHCl}_{3}\right) .{ }^{1} \mathrm{H} \mathrm{NMR}\left(600 \mathrm{MHz}, \mathrm{CDCl}_{3}\right) \delta 8.01(\mathrm{~m}, 2 \mathrm{H}), 7.80(\mathrm{~m}, 2 \mathrm{H}), 7.56(\mathrm{~d}, 2 \mathrm{H}, \mathrm{J}=7.8$ Hz), $7.53(\mathrm{t}, 1 \mathrm{H}, \mathrm{J}=7.2 \mathrm{~Hz}), 7.47(\mathrm{~m}, 3 \mathrm{H}), 7.38(\mathrm{~m}, 2 \mathrm{H}), 7.31(\mathrm{t}, 2 \mathrm{H}, \mathrm{J}=7.8 \mathrm{~Hz}), 7.25(\mathrm{t}$, $1 \mathrm{H}, \mathrm{J}=5.4 \mathrm{~Hz}), 5.10(\mathrm{t}, 1 \mathrm{H}, \mathrm{J}=9.6 \mathrm{~Hz}), 3.38(\mathrm{t}, 1 \mathrm{H}, \mathrm{J}=8.4 \mathrm{~Hz}), 1.24(\mathrm{~m}, 1 \mathrm{H}), 0.74(\mathrm{~m}$, 2H), $0.63(\mathrm{~m}, 2 \mathrm{H}) .{ }^{13} \mathrm{C}$ NMR $\left(150 \mathrm{MHz}, \mathrm{CDCl}_{3}\right) \delta 140.9(\mathrm{~d}, \mathrm{~J}=4.7 \mathrm{~Hz}), 132.7(\mathrm{~d}$, $\mathrm{J}=9.8 \mathrm{~Hz}), 131.9(\mathrm{~d}, \mathrm{~J}=8.7 \mathrm{~Hz}), 131.8(\mathrm{~d}, \mathrm{~J}=9.8 \mathrm{~Hz}), 128.5,128.4(\mathrm{~d}, \mathrm{~J}=12.6 \mathrm{~Hz})$, 127.7, 127.2, 89.2, $74.8(\mathrm{~d}, \mathrm{~J}=6 \mathrm{~Hz}), 46.8,8.1,-0.5$. These data are consistent with those reported. ${ }^{6}$

\section{(S)-N-(4-((tert-butyldimethylsilyl)oxy)-1-phenylbut-2-yn-1-yl)-P,P-diphenylphos}

phinic amide, 4.16

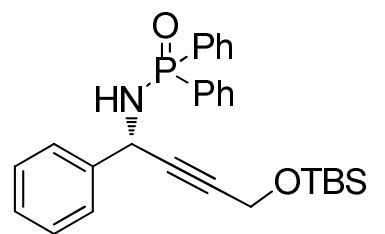

\subsection{6}

$42 \%, 84 \%$ ee

White solid, Mp $109-111^{\circ} \mathrm{C}, 20.0 \mathrm{mg}, 42 \%$ yield. $84 \%$ ee determined by HPLC analysis: CHIRALPAK AD column, 90:10 hexanes: ${ }^{i} \mathrm{PrOH}$, flow rate $=1.0 \mathrm{~mL} / \mathrm{min}, \lambda$ $=225 \mathrm{~nm}$, retention time: $\mathrm{t}_{\text {minor }}=9.1 \mathrm{~min}, \mathrm{t}_{\text {major }}=10.2 \min .[\alpha]_{\mathrm{D}}^{24}=-19.5(\mathrm{c}=0.565$, $\left.\mathrm{CHCl}_{3}\right) .{ }^{1} \mathrm{H} \mathrm{NMR}\left(600 \mathrm{MHz}, \mathrm{CDCl}_{3}\right) \delta 8.01(\mathrm{~m}, 2 \mathrm{H}), 7.82(\mathrm{~m}, 2 \mathrm{H}), 7.59(\mathrm{~d}, 2 \mathrm{H}, \mathrm{J}=7.2$ Hz), $7.51(\mathrm{~m}, 1 \mathrm{H}), 7.47(\mathrm{~m}, 3 \mathrm{H}), 7.38(\mathrm{~m}, 2 \mathrm{H}), 7.31(\mathrm{~m}, 2 \mathrm{H}), 7.25(\mathrm{~m}, 1 \mathrm{H}), 5.16(\mathrm{t}$, $1 \mathrm{H}, \mathrm{J}=9.6 \mathrm{~Hz}), 4.35(\mathrm{~s}, 2 \mathrm{H}), 3.48(\mathrm{t}, 1 \mathrm{H}, \mathrm{J}=9 \mathrm{~Hz}), 0.90(\mathrm{~s}, 9 \mathrm{H}),-0.10(\mathrm{~s}, 6 \mathrm{H}) .{ }^{13} \mathrm{C}$ NMR (150 MHz, $\left.\mathrm{CDCl}_{3}\right) \delta 140.2(\mathrm{~d}, \mathrm{~J}=4.2 \mathrm{~Hz}), 132.6$ (d, J=9.8 Hz), 132.0 (d, J=9.5 Hz), 131.9 (d, J=9.8 Hz), 128.5, 128.4 (d, J=12.8 Hz), 127.9, 127.2. 84.2 (d, J=6.8 Hz), 
$84.1,51.8,46.8,25.8,18.3,-5.1(\mathrm{~d}, \mathrm{~J}=2.7 \mathrm{~Hz})$. These data are consistent with those reported. ${ }^{5 \mathrm{a}}$

(S)-P,P-diphenyl- $N$-(1-phenylnon-2-yn-1-yl)phosphinic amide, 4.17

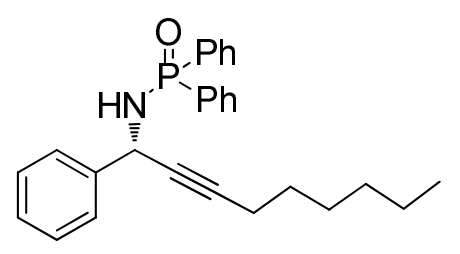

4.17

$65 \%, 77 \%$ ee

White solid, Mp 110-112 ${ }^{\circ} \mathrm{C}, 27.0 \mathrm{mg}, 65 \%$ yield. $77 \%$ ee determined by HPLC analysis: CHIRALPAK AD-H column, 90:10 hexanes: ${ }^{i} \mathrm{PrOH}$, flow rate $=1.0 \mathrm{~mL} / \mathrm{min}$, $\lambda=225 \mathrm{~nm}$, retention time: $\mathrm{t}_{\text {minor }}=10.4 \mathrm{~min}, \mathrm{t}_{\text {major }}=11.5 \mathrm{~min} . \quad[\alpha]_{\mathrm{D}}^{24}=-13.4(\mathrm{c}=$ 0.95, $\left.\mathrm{CHCl}_{3}\right) . \quad{ }^{1} \mathrm{H} \mathrm{NMR}\left(600 \mathrm{MHz}, \mathrm{CDCl}_{3}\right) \delta 8.03(\mathrm{~m}, 2 \mathrm{H}), 7.82(\mathrm{~m}, 2 \mathrm{H}), 7.60(\mathrm{~d}$, 2H, J=8.4 Hz), $7.52(\mathrm{~m}, 1 \mathrm{H}), 7.46(\mathrm{~m}, 3 \mathrm{H}), 7.37(\mathrm{~m}, 2 \mathrm{H}), 7.32$ (t, 2H, J=7.2 Hz), 7.25 $(\mathrm{m}, 1 \mathrm{H}), 5.13(\mathrm{t}, 1 \mathrm{H}, \mathrm{J}=9.6 \mathrm{~Hz}), 3.41(\mathrm{t}, 1 \mathrm{H}, \mathrm{J}=9 \mathrm{~Hz}), 2.20(\mathrm{~m}, 2 \mathrm{H}), 1.49(\mathrm{~m}, 2 \mathrm{H})$, $1.38(\mathrm{~m}, 2 \mathrm{H}), 1.29(\mathrm{~m}, 4 \mathrm{H}), 0.88(\mathrm{t}, 3 \mathrm{H}, \mathrm{J}=7.2 \mathrm{~Hz}) .{ }^{13} \mathrm{C}\left\{{ }^{1} \mathrm{H}\right\}$ NMR $(150 \mathrm{MHz}$, $\left.\mathrm{CDCl}_{3}\right) \delta 141.0(\mathrm{~d}, \mathrm{~J}=4.7 \mathrm{~Hz}), 132.7(\mathrm{~d}, \mathrm{~J}=9.9 \mathrm{~Hz}), 131.9(\mathrm{~d}, \mathrm{~J}=7.4 \mathrm{~Hz}), 131.8(\mathrm{~d}, \mathrm{~J}$ $=9.6 \mathrm{~Hz}), 128.5,128.4(\mathrm{~d}, \mathrm{~J}=12.8 \mathrm{~Hz}), 127.7,127.2,86.3,79.7(\mathrm{~d}, \mathrm{~J}=6.2 \mathrm{~Hz}), 46.8$, 31.3, 28.6, 28.5, 22.5, 18.8, 14.0. HRMS [ESI(TOF)] for $\mathrm{C}_{27} \mathrm{H}_{31} \mathrm{NOP}\left[\mathrm{M}+\mathrm{H}^{+}\right]: \mathrm{m} / \mathrm{z}$ : calcd for: 416.2143; found: 416.2141 .

(S)-N-(6-Chloro-1-phenylhex-2-yn-1-yl)-P,P-diphenylphosphinic amide, 4.18

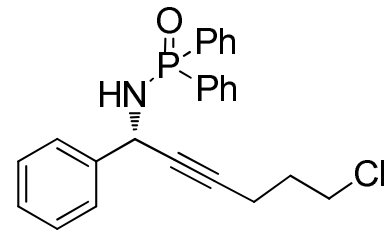

4.18

$46 \%, 77 \%$ ee 
White solid, Mp 107-109 ${ }^{\circ} \mathrm{C}, 18.7 \mathrm{mg}, 46 \%$ yield. $77 \%$ ee determined by HPLC analysis: CHIRALPAK AD-H column, 90:10 hexanes: ${ }^{i} \mathrm{PrOH}$, flow rate $=1.0 \mathrm{~mL} / \mathrm{min}$, $\lambda=225 \mathrm{~nm}$, retention time: $\mathrm{t}_{\text {minor }}=21.6 \mathrm{~min}, \mathrm{t}_{\text {major }}=25.2 \mathrm{~min} . \quad[\alpha]^{24}=-11.5(\mathrm{c}=$ 0.605, $\left.\mathrm{CHCl}_{3}\right) . \quad{ }^{1} \mathrm{H} \mathrm{NMR}\left(600 \mathrm{MHz}, \mathrm{CDCl}_{3}\right) \delta 8.00(\mathrm{~m}, 2 \mathrm{H}), 7.82(\mathrm{~m}, 2 \mathrm{H}), 7.56(\mathrm{~d}$, 2H, J = 7.8 Hz), $7.52(\mathrm{~m}, 1 \mathrm{H}), 7.47(\mathrm{~m}, 3 \mathrm{H}), 7.39(\mathrm{~m}, 2 \mathrm{H}), 7.33(\mathrm{t}, 2 \mathrm{H}, \mathrm{J}=7.8 \mathrm{~Hz})$, $7.26(\mathrm{t}, 1 \mathrm{H}, \mathrm{J}=7.2 \mathrm{~Hz}), 5.14(\mathrm{t}, 1 \mathrm{H}, \mathrm{J}=9.6 \mathrm{~Hz}), 3.61(\mathrm{t}, 2 \mathrm{H}, \mathrm{J}=6.6 \mathrm{~Hz}), 3.42(\mathrm{t}, 1 \mathrm{H}, \mathrm{J}$ $=8.4 \mathrm{~Hz}), 2.39(\mathrm{~m}, 2 \mathrm{H}), 1.92(\mathrm{~m}, 2 \mathrm{H}) .{ }^{13} \mathrm{C}\left\{{ }^{1} \mathrm{H}\right\} \mathrm{NMR}\left(150 \mathrm{MHz}, \mathrm{CDCl}_{3}\right) \delta 140.7$ $(\mathrm{d}, \mathrm{J}=4.8 \mathrm{~Hz}), 132.5$ (d, J = 9.8 Hz), $132.0(\mathrm{~d}, \mathrm{~J}=6.9 \mathrm{~Hz}), 131.8(\mathrm{~d}, \mathrm{~J}=9.8 \mathrm{~Hz})$, 128.6, $128.4(\mathrm{~d}, \mathrm{~J}=12.6 \mathrm{~Hz}), 127.9,127.1,84.1,80.8(\mathrm{~d}, \mathrm{~J}=5.6 \mathrm{~Hz}), 46.7,43.7,31.2$, 16.2. HRMS [ESI(TOF)] for $\mathrm{C}_{27} \mathrm{H}_{24} \mathrm{NOPCl}\left[\mathrm{M}+\mathrm{H}^{+}\right]$: $\mathrm{m} / \mathrm{z}$ : calcd for: 408.1284; found: 408.1280 .

(S)-N-(4-methyl-1-phenylpent-4-en-2-yn-1-yl)-P,P-diphenylphosphinic amide, 4.19<smiles>C=C(C)C#C[C@H](NP(=O)(c1ccccc1)c1ccccc1)c1ccccc1</smiles>

\subsection{9}

$64 \%, 81 \%$ ee

White solid, Mp $140-142{ }^{\circ} \mathrm{C}, 23.0 \mathrm{mg}, 64 \%$ yield. $81 \%$ ee determined by HPLC analysis: CHIRALPAK AD-H column, 93:7 hexanes: ${ }^{i} \mathrm{PrOH}$, flow rate $=1.0 \mathrm{~mL} / \mathrm{min}$, $\lambda=210 \mathrm{~nm}$, retention time: $\mathrm{t}_{\text {minor }}=22.1 \mathrm{~min}, \mathrm{t}_{\text {major }}=24.7 \mathrm{~min} .[\alpha]_{\mathrm{D}}^{23}=-21.3(\mathrm{c}=0.5$, $\left.\mathrm{CHCl}_{3}\right) .{ }^{1} \mathrm{H} \mathrm{NMR}\left(600 \mathrm{MHz}, \mathrm{CDCl}_{3}\right) \delta 8.03(\mathrm{~m}, 2 \mathrm{H}), 7.81(\mathrm{~m}, 2 \mathrm{H}), 7.61(\mathrm{~d}, 2 \mathrm{H}, \mathrm{J}=7.8$ $\mathrm{Hz}), 7.53(\mathrm{~m}, 1 \mathrm{H}), 7.47(\mathrm{~m}, 3 \mathrm{H}), 7.38(\mathrm{~m}, 2 \mathrm{H}), 7.33(\mathrm{t}, 2 \mathrm{H}, \mathrm{J}=7.2 \mathrm{~Hz}), 7.27(\mathrm{t}, 1 \mathrm{H}$, $\mathrm{J}=7.2 \mathrm{~Hz}), 5.27(\mathrm{~m}, 3 \mathrm{H}), 3.47(\mathrm{t}, 1 \mathrm{H}, \mathrm{J}=9.6 \mathrm{~Hz}), 1.87(\mathrm{~s}, 3 \mathrm{H}) .{ }^{13} \mathrm{C} \mathrm{NMR}(150 \mathrm{MHz}$ 
$\left.\mathrm{CDCl}_{3}\right) \delta 140.4(\mathrm{~d}, \mathrm{~J}=4.4 \mathrm{~Hz}), 132.7$ (d, J=9.8 Hz), 132.0 (d, J=9.3 Hz), 131.8 (d, $\mathrm{J}=9.8 \mathrm{~Hz}), 128.6,128.4(\mathrm{~d}, \mathrm{~J}=12.8 \mathrm{~Hz}), 127.9,127.2,126.3,122.1,87.7$ (d, J=6.2 Hz), 86.7, 46.9, 23.3. These data are consistent with those reported. ${ }^{5 \mathrm{a}}$

\section{(S)-N-(3-(Cyclohex-1-en-1-yl)-1-phenylprop-2-yn-1-yl)-P,P-diphenylphosphinic}

amide, 4.20

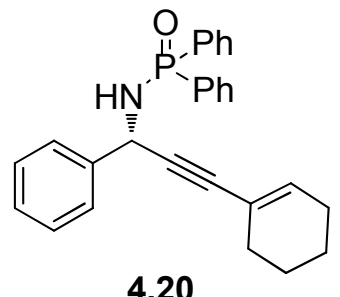

$71 \%, 78 \%$ ee

White solid, Mp 154-156 ${ }^{\circ} \mathrm{C}, 29.2 \mathrm{mg}, 71 \%$ yield. $78 \%$ ee determined by HPLC analysis: CHIRALCEL OD-H column, 93:7 hexanes: ${ }^{i} \mathrm{PrOH}$, flow rate $=1.0 \mathrm{~mL} / \mathrm{min}$, $\lambda=225 \mathrm{~nm}$, retention time: $\mathrm{t}_{\text {minor }}=10.7 \mathrm{~min}, \mathrm{t}_{\text {major }}=8.3 \mathrm{~min} . \quad[\alpha]^{24}{ }_{\mathrm{D}}=-26.7(\mathrm{c}=1.21$, $\left.\mathrm{CHCl}_{3}\right) . \quad{ }^{1} \mathrm{H} \mathrm{NMR}\left(600 \mathrm{MHz}, \mathrm{CDCl}_{3}\right) \delta 8.04(\mathrm{~m}, 2 \mathrm{H}), 7.81(\mathrm{~m}, 2 \mathrm{H}), 7.61(\mathrm{~d}, 2 \mathrm{H}$, $\mathrm{J}=7.2 \mathrm{~Hz}), 7.52(\mathrm{~m}, 1 \mathrm{H}), 7.46(\mathrm{~m}, 3 \mathrm{H}), 7.37(\mathrm{~m}, 2 \mathrm{H}), 7.32(\mathrm{~d}, 2 \mathrm{H}, \mathrm{J}=7.8 \mathrm{~Hz}), 7.25(\mathrm{~m}$, 1H), $6.09(\mathrm{~s}, 1 \mathrm{H}), 5.26(\mathrm{t}, 1 \mathrm{H}, \mathrm{J}=9.6 \mathrm{~Hz}), 3.46(\mathrm{t}, 1 \mathrm{H}, \mathrm{J}=9 \mathrm{~Hz}), 2.09(\mathrm{~d}, 4 \mathrm{H}, \mathrm{J}=6 \mathrm{~Hz})$, $1.62(\mathrm{~m}, 4 \mathrm{H}) .{ }^{13} \mathrm{C}\left\{{ }^{1} \mathrm{H}\right\} \mathrm{NMR}\left(150 \mathrm{MHz}, \mathrm{CDCl}_{3}\right) \delta 140.7(\mathrm{~d}, \mathrm{~J}=4.4 \mathrm{~Hz}), 135.1$, $132.8(\mathrm{~d}, \mathrm{~J}=9.8 \mathrm{~Hz}), 131.9(\mathrm{~d}, \mathrm{~J}=7.8 \mathrm{~Hz}), 131.8(\mathrm{~d}, \mathrm{~J}=9.8 \mathrm{~Hz}), 128.5,128.4(\mathrm{~d}$, $\mathrm{J}=12.8 \mathrm{~Hz}), 127.8,127.3,120.2,87.4,86.0(\mathrm{~d}, \mathrm{~J}=6.3 \mathrm{~Hz}), 47.1,29.1,25.6,22.2,21.5$. HRMS [ESI(TOF)] for $\mathrm{C}_{27} \mathrm{H}_{27} \mathrm{NOP}\left[\mathrm{M}+\mathrm{H}^{+}\right]$: $\mathrm{m} / \mathrm{z}$ : calcd for: 412.1830; found: 412.1829 . 
(S)-N-(1,3-diphenylprop-2-yn-1-yl)-P,P-diphenylphosphinic amide, 4.4<smiles>CC(C#Cc1ccccc1)(NP(=O)(c1ccccc1)c1ccccc1)c1ccccc1</smiles>

$80 \%, 81 \%$ ee

White solid, Mp $160-162{ }^{\circ} \mathrm{C}, 32.6 \mathrm{mg}, 80 \%$ yield. $81 \%$ ee determined by HPLC analysis: CHIRALPAK AD-H column, 93:7 hexanes: ${ }^{i} \mathrm{PrOH}$, flow rate $=1.0 \mathrm{~mL} / \mathrm{min}$, $\lambda=254 \mathrm{~nm}$, retention time: $\mathrm{t}_{\text {minor }}=28.2 \mathrm{~min}, \mathrm{t}_{\text {major }}=31.2 \mathrm{~min} .[\alpha]^{24}=-36.3(\mathrm{c}=$ 0.715, $\left.\mathrm{CHCl}_{3}\right) .{ }^{1} \mathrm{H}$ NMR $\left(600 \mathrm{MHz}, \mathrm{CDCl}_{3}\right) \delta 8.08(\mathrm{~m}, 2 \mathrm{H}), 7.84(\mathrm{~m}, 2 \mathrm{H}), 7.69(\mathrm{~d}, 2 \mathrm{H}$, $\mathrm{J}=7.2 \mathrm{~Hz}), 7.51(\mathrm{~m}, 1 \mathrm{H}), 7.46(\mathrm{~m}, 3 \mathrm{H}), 7.41-7.34(\mathrm{~m}, 6 \mathrm{H}), 7.30(\mathrm{~m}, 4 \mathrm{H}), 5.40(\mathrm{t}, 1 \mathrm{H}$, $\mathrm{J}=10.2 \mathrm{~Hz}), 3.70(\mathrm{t}, 1 \mathrm{H}, \mathrm{J}=9 \mathrm{~Hz}) .{ }^{13} \mathrm{C} \mathrm{NMR}\left(150 \mathrm{MHz}, \mathrm{CDCl}_{3}\right) \delta 140.4(\mathrm{~d}, \mathrm{~J}=4.5 \mathrm{~Hz})$ 132.8 (d, J=9.9 Hz), 132.0 (d, J=8.0 Hz), 131.8 (d, J=9.8 Hz), 131.7, 128.6, 128.5 (d, $\mathrm{J}=12.8 \mathrm{~Hz}), 128.4,128.2,127.9,127.3,122.7,88.9(\mathrm{~d}, \mathrm{~J}=6 \mathrm{~Hz}), 85.6,47.1$. These data are consistent with those reported. ${ }^{6}$

(S)-P,P-diphenyl- $N$-(3-phenyl-1-(p-tolyl)prop-2-yn-1-yl)phosphinic amide, 4.21

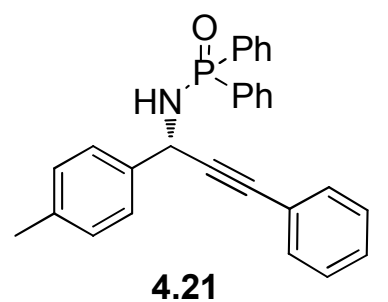

$72 \%, 80 \%$ ee

White solid, $\mathrm{Mp} 148-150{ }^{\circ} \mathrm{C}, 30.3 \mathrm{mg}, 72 \%$ yield. $80 \%$ ee determined by HPLC analysis: CHIRALPAK AD-H column, 90:10 hexanes: ${ }^{i} \mathrm{PrOH}$, flow rate $=1.0 \mathrm{~mL} / \mathrm{min}$, $\lambda=254 \mathrm{~nm}$, retention time: $\mathrm{t}_{\text {minor }}=25.1 \mathrm{~min}, \mathrm{t}_{\text {major }}=27.7 \mathrm{~min} .[\alpha]^{24}=-13.5(\mathrm{c}=0.55$, $\left.\mathrm{CHCl}_{3}\right) .{ }^{1} \mathrm{H} \mathrm{NMR}\left(600 \mathrm{MHz}, \mathrm{CDCl}_{3}\right) \delta 8.07(\mathrm{~m}, 2 \mathrm{H}), 7.85(\mathrm{~m}, 2 \mathrm{H}), 7.56(\mathrm{~d}, 2 \mathrm{H}, \mathrm{J}=8.4$ 
Hz), $7.51(\mathrm{~m}, 1 \mathrm{H}), 7.46(\mathrm{~m}, 3 \mathrm{H}), 7.39$ (m, 4H), 7.29 (m, 3H), 7.16 (d, 2H, J=7.8 Hz), $5.36(\mathrm{t}, 1 \mathrm{H}, \mathrm{J}=9.6 \mathrm{~Hz}), 3.58(\mathrm{t}, 1 \mathrm{H}, \mathrm{J}=9 \mathrm{~Hz}), 2.33(\mathrm{~s}, 3 \mathrm{H}) .{ }^{13} \mathrm{C} \mathrm{NMR}\left(150 \mathrm{MHz}, \mathrm{CDCl}_{3}\right)$ $\delta$ 137.7, 137.5 (d, J=4.5 Hz), 132.8 (d, J=9.8 Hz), 132.0 (d, J=8.3 Hz), 131.8 (d, J=9.8 Hz), 131.7, 129.3, 128.5 (d, J=12.9 Hz), 128.3, 128.2, 127.2, 122.8, 89.1 (d, J=6.2 Hz), 85.4, 46.9, 21.1. These data are consistent with those reported. ${ }^{6}$

\section{(S)-N-(1-(4-bromophenyl)-3-phenylprop-2-yn-1-yl)-P,P-diphenylphosphinic}

amide, 4.22

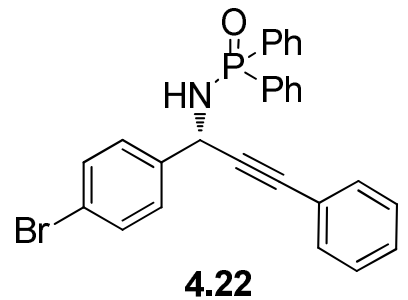

$66 \%, 74 \%$ ee

White solid, $\mathrm{Mp} 181-183{ }^{\circ} \mathrm{C}, 32.0 \mathrm{mg}, 66 \%$ yield. $74 \%$ ee determined by HPLC analysis: CHIRALPAK AD-H column, 90:10 hexanes: ${ }^{i} \mathrm{PrOH}$, flow rate $=1.0 \mathrm{~mL} / \mathrm{min}$, $\lambda=254 \mathrm{~nm}$, retention time: $\mathrm{t}_{\text {minor }}=17.9 \mathrm{~min}, \mathrm{t}_{\text {major }}=26.0 \mathrm{~min} .[\alpha]_{\mathrm{D}}^{23}=-30.8(\mathrm{c}=1.1$, $\left.\mathrm{CHCl}_{3}\right) .{ }^{1} \mathrm{H}$ NMR $\left(600 \mathrm{MHz}, \mathrm{CDCl}_{3}\right) \delta 8.06(\mathrm{~m}, 2 \mathrm{H}), 7.82(\mathrm{~m}, 2 \mathrm{H}), 7.57(\mathrm{~d}, 2 \mathrm{H}, \mathrm{J}=8.4$ Hz), $7.52(\mathrm{~m}, 1 \mathrm{H}), 7.47(\mathrm{~m}, 5 \mathrm{H}), 7.40(\mathrm{~m}, 4 \mathrm{H}), 7.32(\mathrm{~m}, 3 \mathrm{H}), 5.34(\mathrm{t}, 1 \mathrm{H}, \mathrm{J}=10.2 \mathrm{~Hz})$, $3.55(\mathrm{t}, 1 \mathrm{H}, \mathrm{J}=9.6 \mathrm{~Hz}) .{ }^{13} \mathrm{C} \mathrm{NMR}\left(150 \mathrm{MHz}, \mathrm{CDCl}_{3}\right) \delta 139.4$ (d, J=3.6 Hz), 132.7 (d, $\mathrm{J}=9.9 \mathrm{~Hz}), 132.1$ (d, J=10.2 Hz), 131.7 (d, $9.8 \mathrm{~Hz}), 131.6$ (d, J=4.1 Hz), 129.1, 128.6, $128.5(\mathrm{~d}, \mathrm{~J}=6.2 \mathrm{~Hz}), 128.4$ (d, J=6.2 Hz), 128.3, 122.4, 122.0, 88.1 (d, J=6.5 Hz), 85.9, 46.7. These data are consistent with those reported. ${ }^{5 \mathrm{a}}$ 


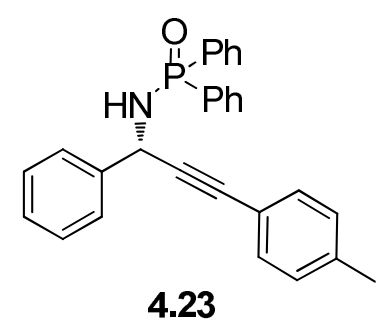

$76 \%, 80 \%$ ee

White solid, Mp $172-174{ }^{\circ} \mathrm{C}, 32.0 \mathrm{mg}, 76 \%$ yield. $80 \%$ ee determined by HPLC analysis: CHIRALPAK AD-H column, $93: 7$ hexanes: ${ }^{i} \mathrm{PrOH}$, flow rate $=1.0 \mathrm{~mL} / \mathrm{min}$, $\lambda=254 \mathrm{~nm}$, retention time: $\mathrm{t}_{\text {minor }}=28.6 \mathrm{~min}, \mathrm{t}_{\text {major }}=32.7 \mathrm{~min} .[\alpha]^{23}{ }_{\mathrm{D}}=-46.8(\mathrm{c}=1.1$, $\left.\mathrm{CHCl}_{3}\right) .{ }^{1} \mathrm{H}$ NMR $\left(600 \mathrm{MHz}, \mathrm{CDCl}_{3}\right) \delta 8.08(\mathrm{~m}, 2 \mathrm{H}), 7.84(\mathrm{~m}, 2 \mathrm{H}), 7.68(\mathrm{~d}, 2 \mathrm{H}, \mathrm{J}=$ $7.8 \mathrm{~Hz}), 7.52(\mathrm{~m}, 1 \mathrm{H}), 7.46(\mathrm{~m}, 3 \mathrm{H}), 7.40-7.34(\mathrm{~m}, 4 \mathrm{H}), 7.29(\mathrm{~m}, 3 \mathrm{H}), 7.11(\mathrm{~d}, 2 \mathrm{H}$, $\mathrm{J}=7.8 \mathrm{~Hz}), 5.38(\mathrm{t}, 1 \mathrm{H}, \mathrm{J}=9.6 \mathrm{~Hz}), 3.53(\mathrm{t}, 1 \mathrm{H}, \mathrm{J}=8.4 \mathrm{~Hz}), 2.35(\mathrm{~s}, 3 \mathrm{H}) .{ }^{13} \mathrm{C}\left\{{ }^{1} \mathrm{H}\right\}$ NMR (150 MHz, $\left.\mathrm{CDCl}_{3}\right) \delta 140.4(\mathrm{~d}, \mathrm{~J}=4.2 \mathrm{~Hz}), 138.5,132.8(\mathrm{~d}, \mathrm{~J}=9.9 \mathrm{~Hz}), 132.0$ $(\mathrm{d}, \mathrm{J}=8.9 \mathrm{~Hz}), 131.8(\mathrm{~d}, \mathrm{~J}=9.8 \mathrm{~Hz}), 131.5,129.0,128.6,128.5(\mathrm{~d}, \mathrm{~J}=12.9 \mathrm{~Hz})$ 127.9, 127.3, 119.6, 88.1 (d, J=6 Hz), 85.7, 47.2, 21.5. HRMS [ESI(TOF)] for $\mathrm{C}_{28} \mathrm{H}_{25} \mathrm{NOP}\left[\mathrm{M}+\mathrm{H}^{+}\right]: \mathrm{m} / \mathrm{z}$ : calcd for: 422.1674; found: 422.1660 .

\section{(S)-N-(3-(3-Methoxyphenyl)-1-phenylprop-2-yn-1-yl)-P,P-diphenylphosphinic}

amide, 4.24

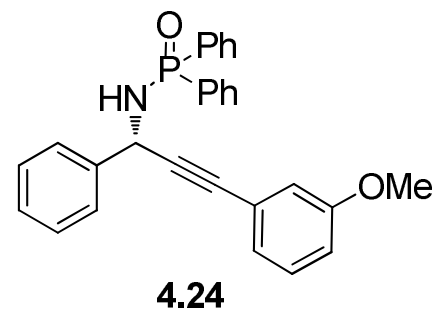

$75 \%, 74 \%$ ee 
Colorless oil, $32.8 \mathrm{mg}, 75 \%$ yield. $74 \%$ ee determined by HPLC analysis: CHIRALPAK AD-H column, 90:10 hexanes: ${ }^{i} \mathrm{PrOH}$, flow rate $=1.0 \mathrm{~mL} / \mathrm{min}, \lambda=254$ $\mathrm{nm}$, retention time: $\mathrm{t}_{\text {minor }}=22.2 \mathrm{~min}, \mathrm{t}_{\text {major }}=26.3 \mathrm{~min} . \quad[\alpha]_{\mathrm{D}}^{23}=-38.9(\mathrm{c}=0.65$, $\left.\mathrm{CHCl}_{3}\right) . \quad{ }^{1} \mathrm{H} \mathrm{NMR}\left(600 \mathrm{MHz}, \mathrm{CDCl}_{3}\right) \delta 8.07(\mathrm{~m}, 2 \mathrm{H}), 7.84(\mathrm{~m}, 2 \mathrm{H}), 7.67(\mathrm{~d}, 2 \mathrm{H}, \mathrm{J}=$ $7.8 \mathrm{~Hz}), 7.51(\mathrm{~m}, 1 \mathrm{H}), 7.47$ (m, 3H), 7.39-7.35 (m, 4H), 7.29 (t, 1H, J = 7.8 Hz), 7.21 (t, 1H, J = $7.8 \mathrm{~Hz}), 7.00(\mathrm{~d}, 1 \mathrm{H}, \mathrm{J}=7.2 \mathrm{~Hz}), 6.92(\mathrm{~s}, 1 \mathrm{H}), 6.87(\mathrm{~d}, 1 \mathrm{H}, \mathrm{J}=8.4 \mathrm{~Hz})$, $5.39(\mathrm{t}, 1 \mathrm{H}, \mathrm{J}=9.6 \mathrm{~Hz}), 3.79(\mathrm{~s}, 3 \mathrm{H}), 3.54(\mathrm{t}, 1 \mathrm{H}, \mathrm{J}=9 \mathrm{~Hz}) .{ }^{13} \mathrm{C}\left\{{ }^{1} \mathrm{H}\right\} \mathrm{NMR}(150$ $\left.\mathrm{MHz}, \mathrm{CDCl}_{3}\right) \delta 159.2,140.3(\mathrm{~d}, \mathrm{~J}=4.4 \mathrm{~Hz}), 132.8(\mathrm{~d}, \mathrm{~J}=9.9 \mathrm{~Hz}), 132.0(\mathrm{~d}, \mathrm{~J}=6.9$ Hz), 131.8 (d, J=9.8 Hz), 129.3, 128.7, 128.5 (d, J = 12.8 Hz), 128.0, 127.3, 124.2, 123.7, 116.6, 114.9, 88.6 (d, J=6.2 Hz), 85.4, 55.3, 47.1. HRMS [ESI(TOF)] for $\mathrm{C}_{28} \mathrm{H}_{25} \mathrm{NOP}\left[\mathrm{M}+\mathrm{H}^{+}\right]: \mathrm{m} / \mathrm{z}$ : calcd for: 438.1623; found: 438.1631 .

(S)-N-(3-(4-methoxyphenyl)-1-phenylprop-2-yn-1-yl)-P,P-diphenylphosphinic amide, 4.25

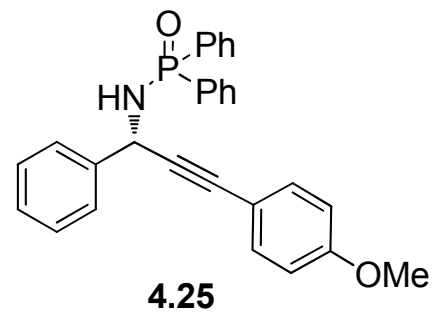

$72 \%, 75 \%$ ee

White solid, Mp $168-170{ }^{\circ} \mathrm{C}, 31.5 \mathrm{mg}, 72 \%$ yield. $75 \%$ ee determined by HPLC analysis: CHIRALPAK AD-H column, 90:10 hexanes: ${ }^{i} \mathrm{PrOH}$, flow rate $=1.0 \mathrm{~mL} / \mathrm{min}$, $\lambda=254 \mathrm{~nm}$, retention time: $\mathrm{t}_{\text {minor }}=28.7 \mathrm{~min}, \mathrm{t}_{\text {major }}=32.6 \mathrm{~min} .[\alpha]^{24}{ }_{\mathrm{D}}=-44.8(\mathrm{c}=1.5$, $\left.\mathrm{CHCl}_{3}\right) .{ }^{1} \mathrm{H} \mathrm{NMR}\left(600 \mathrm{MHz}, \mathrm{CDCl}_{3}\right) \delta 8.07(\mathrm{~m}, 2 \mathrm{H}), 7.84(\mathrm{~m}, 2 \mathrm{H}), 7.67(\mathrm{~d}, 2 \mathrm{H}, \mathrm{J}=7.8$ Hz), $7.52(\mathrm{t}, 1 \mathrm{H}, \mathrm{J}=7.2 \mathrm{~Hz}), 7.47(\mathrm{~m}, 3 \mathrm{H}), 7.39(\mathrm{~m}, 2 \mathrm{H}), 7.34(\mathrm{~m}, 4 \mathrm{H}), 7.28(\mathrm{t}, 1 \mathrm{H}$, $\mathrm{J}=7.8 \mathrm{~Hz}), 6.82(\mathrm{~d}, 2 \mathrm{H}, \mathrm{J}=8.4 \mathrm{~Hz}), 5.37(\mathrm{t}, 1 \mathrm{H}, \mathrm{J}=9.6 \mathrm{~Hz}), 3.81(\mathrm{~s}, 3 \mathrm{H}), 3.53(\mathrm{t}, 1 \mathrm{H}$, 
$\mathrm{J}=9 \mathrm{~Hz}) .{ }^{13} \mathrm{C}$ NMR $\left(150 \mathrm{MHz}, \mathrm{CDCl}_{3}\right) \delta 159.7,140.5(\mathrm{~d}, \mathrm{~J}=4.2 \mathrm{~Hz}), 133.1,132.8(\mathrm{~d}$, $\mathrm{J}=9.8 \mathrm{~Hz}), 132.0(\mathrm{~d}, \mathrm{~J}=7.1 \mathrm{~Hz}), 131.8(\mathrm{~d}, \mathrm{~J}=9.8 \mathrm{~Hz}), 128.6,128.5$ (d, J=12.8 Hz), 127.9, 127.3, 114.8, 113.8, $87.4(\mathrm{~d}, \mathrm{~J}=6.3 \mathrm{~Hz}), 85.5,55.3,47.2$. These data are consistent with those reported. ${ }^{6}$

(S)-N-(3-(4-fluorophenyl)-1-phenylprop-2-yn-1-yl)-P,P-diphenylphosphinic

amide, 4.26

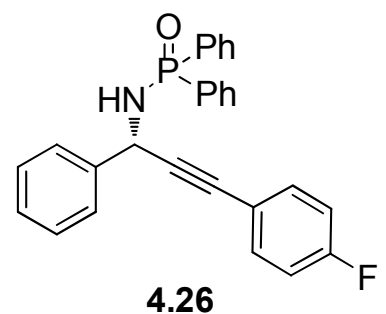

$56 \%, 67 \%$ ee

White solid, Mp $143-145{ }^{\circ} \mathrm{C}, 23.8 \mathrm{mg}, 56 \%$ yield. $67 \%$ ee determined by HPLC analysis: CHIRALPAK AD-H column, 90:10 hexanes: ${ }^{i} \mathrm{PrOH}$, flow rate $=1.0 \mathrm{~mL} / \mathrm{min}$, $\lambda=254 \mathrm{~nm}$, retention time: $\mathrm{t}_{\text {minor }}=20.6 \mathrm{~min}, \mathrm{t}_{\text {major }}=23.4 \mathrm{~min} .[\alpha]^{23}{ }_{\mathrm{D}}=-16.8(\mathrm{c}=0.7$, $\left.\mathrm{CHCl}_{3}\right) .{ }^{1} \mathrm{H} \mathrm{NMR}\left(600 \mathrm{MHz}, \mathrm{CDCl}_{3}\right) \delta 8.05(\mathrm{~m}, 2 \mathrm{H}), 7.84(\mathrm{~m}, 2 \mathrm{H}), 7.65(\mathrm{~d}, 2 \mathrm{H}, \mathrm{J}=7.8$ Hz), 7.52 (t, 1H, J=7.2 Hz), 7.47 (m, 3H), 7.40-7.34 (m, 6H), 7.29 (t, 1H, J=7.2 Hz), $6.99(\mathrm{t}, 2 \mathrm{H}, \mathrm{J}=8.4 \mathrm{~Hz}), 5.38(\mathrm{t}, 1 \mathrm{H}, \mathrm{J}=9.6 \mathrm{~Hz}), 3.57(\mathrm{t}, 1 \mathrm{H}, \mathrm{J}=9 \mathrm{~Hz}) .{ }^{13} \mathrm{C}$ NMR $(150$ $\left.\mathrm{MHz}, \mathrm{CDCl}_{3}\right) \delta 163.4,161.7,140.2(\mathrm{~d}, \mathrm{~J}=4.8 \mathrm{~Hz}), 133.5(\mathrm{~d}, \mathrm{~J}=8.4 \mathrm{~Hz}), 132.7(\mathrm{~d}$, $\mathrm{J}=9.8 \mathrm{~Hz}), 132.0(\mathrm{t}, \mathrm{J}=2.4 \mathrm{~Hz}), 131.8(\mathrm{~d}, \mathrm{~J}=9.9 \mathrm{~Hz}), 128.7,128.5(\mathrm{~d}, \mathrm{~J}=12.6 \mathrm{~Hz}), 128.0$, 127.2, 118.7 (d, J=3.5 Hz), 115.5 (d, J=22.1 Hz), 88.5 (d, J=5.6 Hz), 84.5, 47.1. These data are consistent with those reported. ${ }^{6}$ 
amide, 4.27

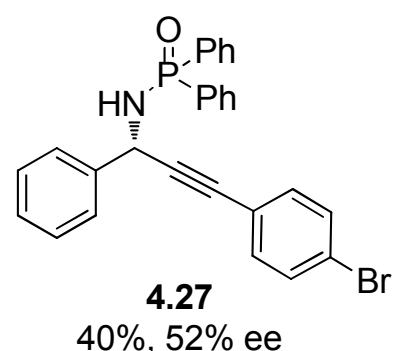

White solid, Mp 175-178 ${ }^{\circ} \mathrm{C}, 19.5 \mathrm{mg}, 40 \%$ yield. 52\% ee determined by HPLC analysis: CHIRALPAK AD-H column, 90:10 hexanes: ${ }^{i} \mathrm{PrOH}$, flow rate $=1.0 \mathrm{~mL} / \mathrm{min}$, $\lambda=254 \mathrm{~nm}$, retention time: $\mathrm{t}_{\text {minor }}=26.2 \mathrm{~min}, \mathrm{t}_{\text {major }}=29.0 \mathrm{~min} . \quad[\alpha]_{\mathrm{D}}^{25}=-12.2(\mathrm{c}=$ 0.475, $\left.\mathrm{CHCl}_{3}\right) . \quad{ }^{1} \mathrm{H} \mathrm{NMR}\left(600 \mathrm{MHz}, \mathrm{CDCl}_{3}\right) \delta 8.04(\mathrm{~m}, 2 \mathrm{H}), 7.84(\mathrm{~m}, 2 \mathrm{H}), 7.64(\mathrm{~d}$, $2 \mathrm{H}, \mathrm{J}=7.2 \mathrm{~Hz}), 7.52(\mathrm{~m}, 1 \mathrm{H}), 7.46-7.35(\mathrm{~m}, 9 \mathrm{H}), 7.29(\mathrm{~m}, 1 \mathrm{H}), 7.22(\mathrm{~d}, 2 \mathrm{H}, \mathrm{J}=7.8$ $\mathrm{Hz}), 5.38(\mathrm{t}, 1 \mathrm{H}, \mathrm{J}=9 \mathrm{~Hz}), 3.56(\mathrm{t}, 1 \mathrm{H}, \mathrm{J}=8.4 \mathrm{~Hz}) .{ }^{13} \mathrm{C} \mathrm{NMR}\left(150 \mathrm{MHz}, \mathrm{CDCl}_{3}\right) \delta$ $140.1(\mathrm{~d}, \mathrm{~J}=4.4 \mathrm{~Hz}), 133.1,132.7(\mathrm{~d}, \mathrm{~J}=9.6 \mathrm{~Hz}), 132.0,131.8(\mathrm{~d}, \mathrm{~J}=9.5 \mathrm{~Hz}), 131.5$, 128.7, $128.5(\mathrm{~d}, \mathrm{~J}=12.5 \mathrm{~Hz}), 128.1,127.2,122.6,121.6,90.0(\mathrm{~d}, \mathrm{~J}=5.0 \mathrm{~Hz}), 84.5,47.1$. HRMS [ESI(TOF)] for $\mathrm{C}_{27} \mathrm{H}_{22} \mathrm{NOPBr}\left[\mathrm{M}+\mathrm{H}^{+}\right]$: m/z: calcd for: 486.0622; found: 486.0636 . 


\section{References}

1. Reviews: (a) Cozzi, P. G.; Hilgraf, R.; Zimmermann, N. Eur. J. Org. Chem. 2004, 4095-4105. (b) Zani, L.; Bolm, C. Chem. Commun. 2006, 4263-4275. (c) Trost, B.M.; Weiss, A.H. Adv. Synth. Catal. 2009, 351, 963-983.

2. (a) Wei, C.; Li, C. J. J. Am. Chem. Soc. 2002, 124, 5638-5639. (b) Ji, J. X.; Wu, J.; Chan, A. S. C. Proc. Natl. Acad. Sci. U.S.A. 2005, 102, 11196-11200. (c) Bisai, A.; Singh, V. K. Org. Lett. 2006, 8, 2405-2408. (d) Colombo, F.; Benaglia, M.; Orlandi, S.; Usuelli, F.; Celentano, G. J. Org. Chem. 2006, 71, 2064-2070. (e) Gommermann, N.; Koradin, C.; Polborn, K.; Knochel, P. Angew. Chem. Int. Ed. 2003, 42, 5763-5766. (f) Knöpfel, T. P.; Aschwanden, P.; Ichikawa, T.; Carreira, E. M. Angew. Chem., Int. Ed. 2004, 43, 5971-5973. (g) Aschwanden, P.; Stephenson, C. R. J.; Carreira, E. M. Org. Lett. 2006, 8, 2437-2440. (h) Lu, Y.; Johnstone, T. C.; Arndtsen, B. A. J. Am. Chem. Soc. 2009, 131, 11284-11285. (i) Wei, C.; Mague, J; Li, C. Proc. Natl. Acad. Sci. U.S.A. 2004, 101, 5749-5754.

3. Other work on the asymmetric alkyne addition to imines: (a) Traverse, J. F.; Hoveyda, A. H.; Snapper, M. L. Org. Lett. 2003, 5, 3273-3275. (b) Jiang, B.; Si, Y. G. Angew. Chem., Int. Ed. 2004, 43, 216-218. (c) Gonzalez, A. Z.; Canales, E.; Soderquist, J. A. Org. Lett. 2006, 8, 3331-3334. (d) Zani, L.; Eichhorn, T.; Bolm, C. Chem. Eur. J. 2007, 13, 2587-2600. (e) Rueping, M.; Antonchick, A. P.; Brinkmann, C. Angew. Chem., Int. Ed. 2007, 46, 6903-6906. (f) Blay, G.; Cardona, L.; Climent, E.; Pedro, J. R. Angew. Chem., Int. Ed. 2008, 47, 5593-5596. (g) De 
Armas, P.; Tejedor, D.; García-Tellado, F. Angew. Chem., Int. Ed. 2010, 49, 1013-1016.

4. A review on using $N$-diphenylphosphinoylimines in stereoselective synthesis: Weinreb, S. M.; Orr, R. K. Synthesis 2005, 8, 1205-1227.

5. (a) Yan, W.; Mao, B.; Zhu, S.; Jiang, X.; Liu, Z.; Wang, R. Eur. J. Org. Chem. 2009, 3790-3794; (b) Zhu, S.; Yan, W.; Mao, B.; Jiang, X.; Wang, R. J. Org. Chem. 2009, 74, 6980-6985. (c) Yan, W.; Li, P.; Feng, J.; Wang, D.; Zhu, S.; Jiang, X.; Wang, R. Tetrahedron: Asymmetry 2010, 21, 2037-2042.

6. Blay, G.; Ceballos, E.; Monleón, A.; Pedro, J. R. Tetrahedron 2012, 68, $2128-2134$.

7. (a) Liu, L.; Pu, L. Tetrahedron 2004, 60, 7427-7430. (b) Qin, Y. -C.; Pu, L. Angew. Chem. Int. Ed. 2006, 45, 273-277. (c) Qin, Y. -C.; Liu, L.; Sabat, M.; Pu, L. Tetrahedron 2006, 62, 9335-9348. (d) Turlington, M.; Pu, L. Org. Synth. 2010, 87, 59-67. (e) DeBerardinis, A. M.; Turlington, M.; Ko, J.; Sole, L.; Pu, L. J. Org. Chem. 2010, 75, 2836-2850. (f) DeBerardinis, A. M.; Turlington, M.; Pu, L. Angew. Chem. Int. Ed. 2011, 123, 2416 -2418. (g) Gu, S. -X.; Huang, W. -C.; Wu, X. -D.; Ying, J.; Pu, L. Syn. Comm. 2015, 45, 1541-1545. (h) Pu, L. Acc. Chem. Res. 2014, 47(5), 1523-1535.

8. (a) McDougal, N. T.; Schaus, S. E. J. Am. Chem. Soc. 2003, 125, 12094-12095.

(b) Sattely, E. S.; Meek, S. J., Malcolmson, S. J.; Schrock, R. R. Hoveyda, A. H. J. Am. Chem. Soc 2009, 131, 943-953.

9. Ko, D. -H.; Kim, K. H.; Ha, D. -C. Org. Lett. 2002, 4, 3759-3762. 


\section{Chapter 5. Gold-catalyzed Regiospecific Hydration of Propargylic $N$-(diphenylphosphinoyl) amines}

\subsection{Introduction}

\subsubsection{Propargylic amines}

Propargylic amines are synthetically important intermediates for nitrogen-containing pharmaceuticals, natural products and biologically active compounds. ${ }^{1}$ Direct nucleophilic 1,2-addition of alkynes to imine double bond via $\mathrm{C}-\mathrm{H}$ activation of terminal alkynes is a general and straightforward method for the synthesis of propargylic amines (Scheme 5.1). ${ }^{2}$ While extensive work on the addition of alkynes to aldehydes have been reported, the use of imines as substrates has been much less developed due to the reduced reactivity of these compounds compared to aldehydes. ${ }^{3}$ Thus, activated substrates such as nitrones and iminium ions instead of simple imines are often used in the alkyne addition.

Scheme 5.1. Direct nucleophilic 1,2-addition of alkynes to imines

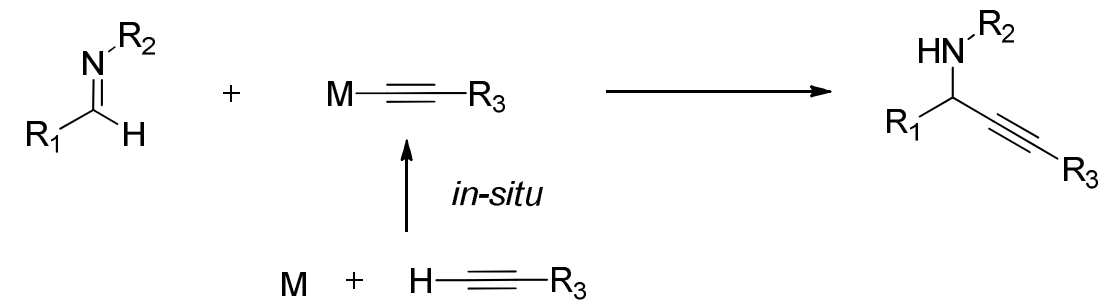

In 1999, Carreira reported the first zinc-catalyzed addition of alkynes to imines (Scheme 5.2). ${ }^{4}$ The nitrones $\mathbf{5 . 1}$ was employed as $\mathrm{C}=\mathrm{N}$ electrophiles and the reaction was performed in the presence of $\mathrm{Zn}(\mathrm{OTf})_{2}$ and $\mathrm{iPr}_{2} \mathrm{NEt}$ at room temperature, affording the corresponding $N$-hydroxy propargylic amines $\mathbf{5 . 2}$ in moderate to good 
yields (43-99\%). Later, it was found that $\mathrm{ZnCl}_{2}$ could also promote the addition of alkynes to nitrones or $\mathrm{N}$-alkylimines. ${ }^{5}$

Scheme 5.2. First zinc-catalyzed addition of alkynes to imines

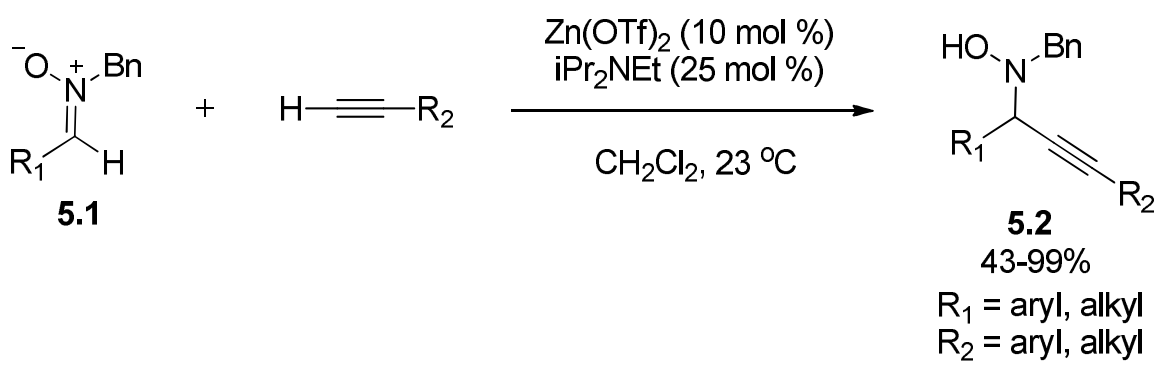

Besides zinc salts, a dialkylzinc reagent, $\mathrm{Et}_{2} \mathrm{Zn}$, was also used in the alkynylation of nitrones in 2002 by Vallée (Scheme 5.3). ${ }^{6}$ The zinc alkynylides were generated in-situ by mixing terminal alkynes with $\mathrm{Et}_{2} \mathrm{Zn}$. It was noteworthy that the reaction didn't require an additional base.

Scheme 5.3. $\mathrm{Et}_{2} \mathrm{Zn}$-promoted alkynylation of nitrones<smiles>[R]C#C[CH]CC</smiles><smiles></smiles>

Among various propargylic amine substrates prepared from the alkyne addition, propargylic $\mathrm{N}$-(diphenylphosphinoyl) amines have attracted more attention of organic chemists because the $N$-diphenylphosphinoyl activating/protecting group can be easily removed under very mild conditions after the reaction. ${ }^{7,8}$ For example, when a methanol solution of the optically active $N$-(diphenylphosphinoyl) propargylic amine 5.3 was treated with aqueous $\mathrm{HCl}$ at room temperature for $2 \mathrm{~h}$, the resulting 
propargylic amine $\mathbf{5 . 4}$ was obtained in $92 \%$ yield with retention of the enantiomeric purity (Scheme 5.4). ${ }^{8}$

Scheme 5.4. An example for the removal of the $N$-diphenylphosphinoyl group<smiles>O=[PH+](NC(C#Cc1ccccc1)c1ccccc1)c1ccccc1</smiles>

5.3

$84 \%$ ee

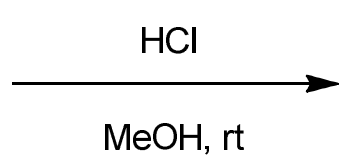

$\mathrm{MeOH}, \mathrm{rt}$<smiles>NC(C#CC#P)c1ccccc1</smiles>

5.4

$92 \%, 84 \%$ ee

Recently, Bolm reported an efficient and facile addition of terminal alkynes to $N$-(diphenylphosphinoyl) amines $\mathbf{5 . 5}$ mediated by $\mathrm{Me}_{2} \mathrm{Zn}$, providing the expected propargylic $N$-(diphenylphosphinoyl) amines 5.6 in good yields (up to 95\%) (Scheme 5.5). ${ }^{9}$ No additional base was required in this reaction.

Scheme 5.5. $\mathrm{Me}_{2} \mathrm{Zn}$-promoted addition of alkynes to $N$-(diphenylphosphinoyl) amines

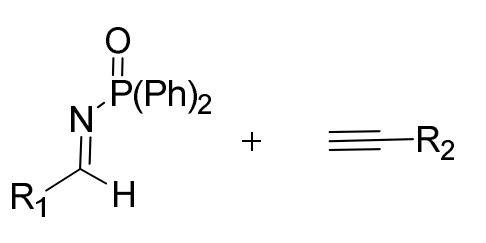

5.5

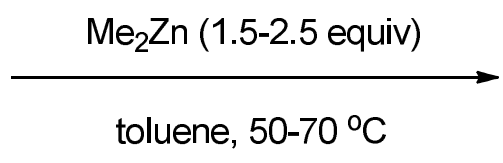

toluene, $50-70^{\circ} \mathrm{C}$<smiles>[R]C#CC([R])N[P+](=O)c1ccccc1</smiles>

up to $95 \%$

$\mathrm{R}_{1}=$ aryl, alkyl

$\mathrm{R}_{2}=$ aryl, alkyl

It has previously been reported that $\mathrm{Me}_{2} \mathrm{Zn}$ is unable to deprotonate terminal alkynes and react with aldehydes in the absence of proper ligands. ${ }^{10}$ In the $\mathrm{Me}_{2} \mathrm{Zn}$-promoted alkynylation of imines, the author suggested that the substrate could behave in a "ligand-like" fashion, coordinating with $\mathrm{Me}_{2} \mathrm{Zn}$ and activating the terminal alkyne. 


\subsubsection{Hydration of alkynes}

Functionalization of alkynes is one of the most attractive research areas in organic synthesis. ${ }^{11 \mathrm{a}}$ Alkyne hydration reactions provide a straightforward and atom-economical approach to obtain carbonyl compounds. ${ }^{11 \mathrm{~b}}$ The $\mathrm{Hg}(\mathrm{II})$-catalyzed hydration of alkynes has been studied for more than a century since its first discovery by Kutscheroff in $1881 .^{11 \mathrm{c}}$ To avoid the use of toxic $\mathrm{Hg}(\mathrm{II})$ salts, various catalysts such as Bronsted acids and other metals such as $\mathrm{Rh},{ }^{12} \mathrm{Ir},{ }^{13} \mathrm{Pd},{ }^{14} \mathrm{Pt},{ }^{15} \mathrm{Cu},{ }^{16} \mathrm{Au}{ }^{17}$, etc., have been developed. In particularly, gold catalysts show higher affinity toward alkynes, becoming more efficient for hydration of alkynes. Although these methods are favorable, there is a major issue: hydration of internal alkynes gave very low regioselectivity (Scheme 5.6).

Scheme 5.6. Hydration of internal alkynes

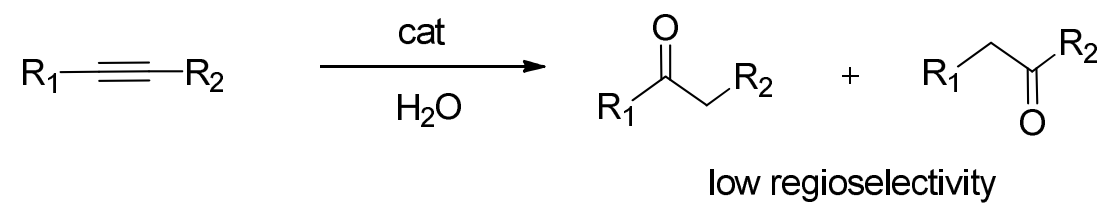

Recently, a few examples of the highly regioselective hydration of internal and terminal alkynes have been reported. ${ }^{18-23}$ In these cases, a directing group (like carbonyl group) assists the coordination of metal center to form a more favorable intermediate, resulting in the regioselective nucleophilic attack of water.

In 2006, Pu reported that the optically active $\gamma$-hydroxy- $\alpha, \beta$-acetylenic esters $\mathbf{5 . 7}$ could undergo a regiospecific hydration in the presence of Zeise's dimer to form the optically active tetronic acids $\mathbf{5 . 8}$ in moderate to good yields (Scheme 5.7). ${ }^{18}$ The intermediate 5.9 is proposed to explain the observed results. The author suggested that 
in 5.9, the regiospecific hydration could be attributed to the electron-withdrawing effect of the ester group, the Lewis acidity of the Pt(II) center and the chelate effect in the coordination of the acetyleneic ester to the Pt(II) center.

Scheme 5.7. Regiospecific hydration of the $\gamma$-hydroxy- $\alpha, \beta$-acetylenic esters $\mathbf{5 . 7}$<smiles>[R]C([2H])(O)C#CC(=O)OC</smiles>

5.7

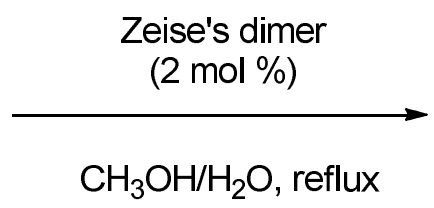

$\mathrm{CH}_{3} \mathrm{OH} / \mathrm{H}_{2} \mathrm{O}$, reflux<smiles>[R]C(O)C1C(CO)=C(OC)OC1C</smiles><smiles>[R][C@]1([2H])OC(=O)C=C1O</smiles>

5.8

$41-78 \%$

$\mathrm{R}=$ aryl, alkyl

5.9

In 2009, Hammond developed an effective hydration of the 3-alkynoates $\mathbf{5 . 1 0}$ in the presence of a gold catalyst at room temperature to give the $\gamma$-keto esters $\mathbf{5 . 1 1}$ in high yield and with excellent regioselectivity (Scheme 5.8). ${ }^{19}$ The carbonyl group of the 3-alkynoates $\mathbf{5 . 1 0}$ participates in a favored 5-endo-dig cyclization to form the intermediate 5.12, which is attacked by water to give the final product 5.11.

Scheme 5.8. Regioselective hydration of the 3-alkynoates $\mathbf{5 . 1 0}$<smiles>[R]C#CC([R])([R])O[R]</smiles>

5.10

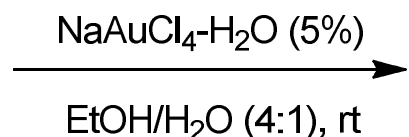

$\mathrm{EtOH} / \mathrm{H}_{2} \mathrm{O}$ (4:1), rt

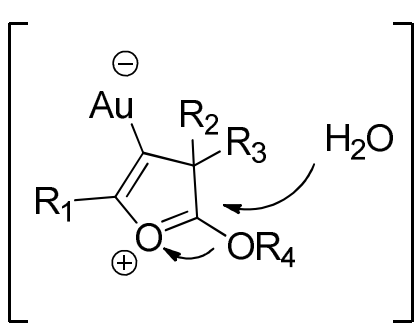

5.12<smiles>[R4]OC([R])([R])CC([R])=O</smiles>

5.11

58-93\%

$\mathrm{R}_{1}=$ aryl, alkyl

$\mathrm{R}_{2}, \mathrm{R}_{3}=$ alkyl 
A gold-catalyzed regioselective hydration of the propargyl acetates $\mathbf{5 . 1 3}$ was described by Sahoo in $2011 .^{20}$ The reaction proceeded in the presence of $1 \mathrm{~mol} \%$ $\mathrm{Ph}_{3} \mathrm{PAuCl}$ and $1 \mathrm{~mol} \% \mathrm{AgSbF}_{6}$ at room temperature, affording the $\alpha$-acyloxy methyl ketones $\mathbf{5 . 1 4}$ in good to excellent yields (Scheme 5.9). The author proposed that the reaction proceeds through the addition of water to the favored 5-exo-dig cyclized intermediate 5.15. The utility of this strategy was also demonstrated by the total synthesis of actinopolymorphol B.

Scheme 5.9. Regioselective hydration of the propargyl acetates $\mathbf{5 . 1 3}$<smiles>[R]C(C)[CH]C#CC([R])OC(C)=O</smiles>

5.13

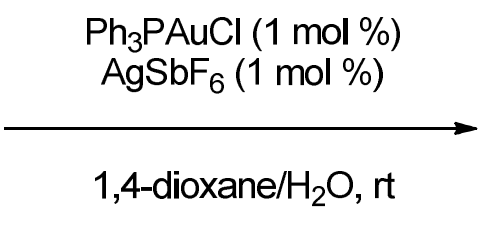<smiles>[R]C1OC(C)=CC1=CCCC</smiles>

5.15

Later, the same group reported a regioselective hydration of the terminal halo-substituted propargyl carboxylate $\mathbf{5 . 1 6}$ in the presence of $3 \mathrm{~mol} \% \mathrm{Ph}_{3} \mathrm{PAuCl}$ and $3 \mathrm{~mol}^{\%} \mathrm{AgSbF}_{6}$, furnishing a variety of the $\alpha$-acyloxy $\alpha$ '-halo ketones $\mathbf{5 . 1 7}$ in good yields (up to 94\%) (Scheme 5.10). ${ }^{21}$ A similar 5-exo-dig cyclized intermediate $\mathbf{5 . 1 8}$ is proposed to illustrate the observed single regiomer. 
Scheme 5.10. Regioselective hydration of the terminal halo-substituted propargyl carboxylate $\mathbf{5 . 1 6}$<smiles>[X]C#CC([R])OC([R])=O</smiles>

5.16

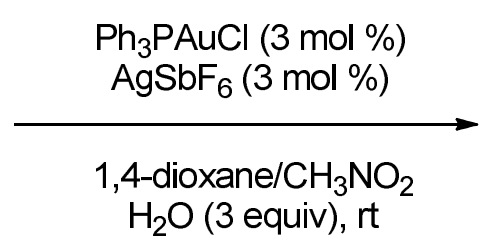

$\mathrm{H}_{2} \mathrm{O}$ (3 equiv), rt<smiles>[Y]C(C)=C1OC([R])(CC)OC1[R2]</smiles>

5.18<smiles>[X]CC(=O)C([R2])OC([R])=O</smiles>

5.17

$$
\begin{gathered}
\text { up to } 94 \% \\
\mathrm{R}_{1}, \begin{array}{l}
\mathrm{R}_{2}=\text { aryl, alkyl } \\
\mathrm{X}=\mathrm{I}, \mathrm{Br}, \mathrm{Cl}
\end{array}
\end{gathered}
$$

Recently, Mohapatra demonstrated that a wide variety of the $\gamma$-acetoxy $\beta$-keto esters $\mathbf{5 . 2 0}$ were readily prepared through a $\mathrm{Au}(\mathrm{I})$-catalyzed regioselective hydration of the $\gamma$-acetoxy- $\alpha, \beta$-alkynoates $\mathbf{5 . 1 9}$ (Scheme 5.11). ${ }^{22}{ }^{18} \mathrm{O}$ labeling experiments disclose that the oxygen transposition occurs from water to the carboxylate group and the carboxylate group to the triple bond simultaneously, which favors the proposed intermediate 5.21.

Scheme 5.11. Regioselective hydration of the $\gamma$-acetoxy- $\alpha, \beta$-alkynoates 5.19<smiles>[R]OC(=O)C#CC([R])([R])OC([R])=O</smiles>

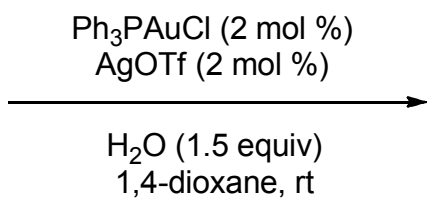<smiles>[R]OC(=O)CC(=O)C([R2])([R])OC([R])=O</smiles>

up to $94 \%$

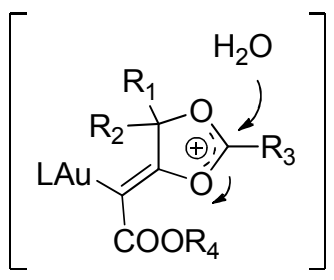

$\mathrm{R}_{1}, \mathrm{R}_{2}=$ aryl, alkyl, $\mathrm{H}$

$\mathrm{R}_{3}=$ aryl, alkyl, vinyl

$\mathrm{R}_{4}=$ methyl, ethyl, tbutyl, benzyl 
It was recently found that an amide oxygen could assist a Pd-catalyzed regioselective hydration of the alkynes $\mathbf{5 . 2 2}$ through an oxypalladation pathway (Scheme 5.12). ${ }^{23}$ The reaction proceeded under mild conditions, producing the $o$-acylacetanilide derivatives $\mathbf{5 . 2 3}$ in good yield (up to 94\%) and with excellent regioselectivity. The reaction is proposed to precede through the 6-exo-dig cyclized intermediate 5.24.

Scheme 5.12. Regioselective hydration of the alkynes $\mathbf{5 . 2 2}$<smiles>[R]C#Cc1cc[R]([R6])cc1NC([R2])=O</smiles>
5.22

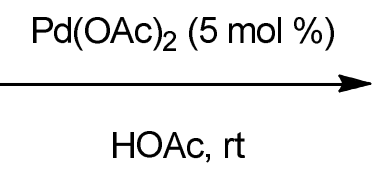

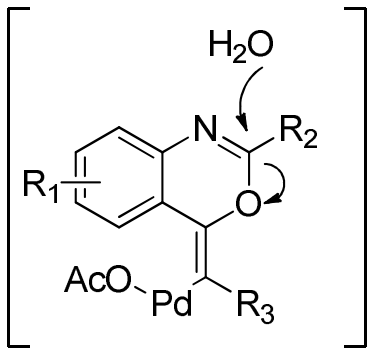

5.24<smiles>[R3]CC(=O)c1cc[R]([R])cc1NC([R])=O</smiles>

5.23

up to $94 \%$ $\mathrm{R}_{2}, \mathrm{R}_{3}=$ aryl, alkyl

\subsection{Gold-catalyzed regiospecific hydration of propargylic}

\section{$N$-(diphenylphosphinoyl) amines}

Propargylic amines are synthetically useful building blocks for numerous nitrogen-containing pharmaceuticals, biologically active compounds and natural products. Various transformations of propargylic amines have been studied. ${ }^{24-26}$ However, regioselective hydration of propargylic amines is still rarely reported. 
Benaglia found that the $N$-acetyl compound $\mathbf{5 . 2 5}$ could undergo the $\mathrm{Hg}(\mathrm{II})$-catalyzed regioselective hydration to generate the $\beta$-amino ketone $\mathbf{5 . 2 6}$ in $37 \%$ yield (Scheme 5.13). ${ }^{27}$ Compound $\mathbf{5 . 2 6}$ is an attractive precursor for the synthesis of chiral 1,3-amino alcohol derivatives.

Scheme 5.13. $\mathrm{Hg}(\mathrm{II})$-catalyzed regioselective hydration of the $\mathrm{N}$-acetyl compound

\subsection{5}<smiles>CN(c1ccccc1)C(C#Cc1ccccc1)c1ccccc1</smiles>

5.25

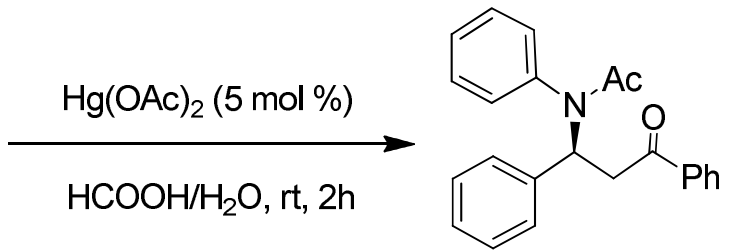

5.26, $37 \%$

On the basis of the previous mechanistic investigation, ${ }^{19-23}$ the 6-endo-dig cyclized intermediate $\mathbf{5 . 2 7}$ could be proposed for this reaction (Figure 5.1).

Figure 5.1. Proposed 6-endo-dig cyclized intermediate $\mathbf{5 . 2 7}$

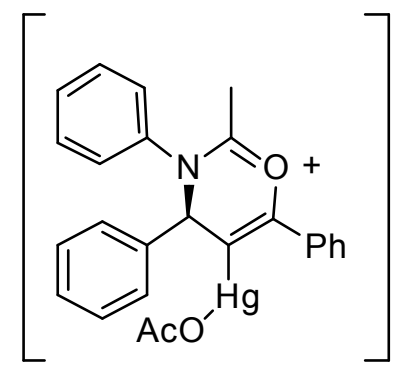

5.27

Inspired by Benaglia's work, we envision that a neighboring phosphinoyl group could assist in a regioselective hydration of propargylic $N$-(diphenylphosphinoyl) amines in the presence of a suitable catalyst to give $\beta$-amino ketones, which are key intermediates in the synthesis of pharmaceuticals and natural products. ${ }^{28}$ It could be an alternative strategy to access functionalized $\beta$-amino ketones that are generally prepared by Mannich-type reactions (Scheme 5.14). ${ }^{28-30}$ 
Scheme 5.14. Synthesis of $\beta$-amino ketones

$$
\mathrm{R}_{1} \mathrm{NH}_{2}+\mathrm{R}_{2} \mathrm{CHO}+\overbrace{\mathrm{R}_{3}}^{\text {Mannich-type reaction }}
$$

To test the hydration, the $N$-(diphenylphosphinoyl) amine 1a was chosen as an initial substrate. A variety of metal catalysts were investigated under different conditions as shown in Table 5.1. No reaction occurred when $\mathrm{AgNO}_{3}$ or $\mathrm{Cu}(\mathrm{OAc})_{2}$ were used (entry 1,2). The reaction with $\mathrm{Hg}(\mathrm{OAc})_{2}$ gave trace product (entry 3). Previously, we reported that Zeise's dimer was very effective in the regiospecific hydration of $\gamma$-hydroxy- $\alpha, \beta$-acentylenic esters. ${ }^{18}$ When 1a was treated with Zeise's dimer at room temperature, there was no reaction (entry 4). Raising the temperature to $50{ }^{\circ} \mathrm{C}$ or refluxing at $85{ }^{\circ} \mathrm{C}$, the reactions turned messy (entry 5,6). Gratifyingly, the desired product $\mathbf{2} \mathbf{a}$ as a single regiomer was obtained in 50\% yield in the presence of a gold(III) salt, $\mathrm{NaAuCl}_{4}-2 \mathrm{H}_{2} \mathrm{O}$. When DCM was combined with $\mathrm{EtOH} / \mathrm{H}_{2} \mathrm{O}$ as solvents, the yield was improved to $62 \%$ due to the better solubility of starting material $1 \mathbf{a}$. 
Table 5.1. Screening of catalysts and solvents<smiles>CCCCC#CC(NP(=O)(c1ccccc1)c1ccccc1)c1ccccc1</smiles><smiles>CCCCCCCCO</smiles><smiles>CCCCC(=O)CC(NP(=O)(c1ccccc1)c1ccccc1)c1ccccc1</smiles>

\begin{tabular}{|c|c|c|c|c|c|}
\hline entry & catalyst $(10 \%)$ & solvent & temp. $\left({ }^{\circ} \mathrm{C}\right)$ & time (h) & yield $(\%)$ \\
\hline 1 & $\mathrm{AgNO}_{3}$ & $\mathrm{MeOH} / \mathrm{H}_{2} \mathrm{O}(4: 1)$ & R.T. & 20 & N.R. \\
\hline 2 & $\mathrm{Cu}(\mathrm{OAc})_{2}$ & $\mathrm{MeOH} / \mathrm{H}_{2} \mathrm{O}(4: 1)$ & R.T. & 20 & N.R. \\
\hline 3 & $\mathrm{Hg}(\mathrm{OAc})_{2}$ & $\begin{array}{c}\mathrm{CH}_{3} \mathrm{CN} / \mathrm{H}_{2} \mathrm{O} / \mathrm{DCM} \\
(4: 1: 1)\end{array}$ & R.T. & 20 & trace \\
\hline 4 & Zeise's dimer & $\mathrm{MeOH} / \mathrm{H}_{2} \mathrm{O}(3: 1)$ & R.T. & 20 & N.R. \\
\hline 5 & Zeise's dimer & $\mathrm{MeOH} / \mathrm{H}_{2} \mathrm{O}(3: 1)$ & 50 & 20 & messy \\
\hline 6 & Zeise's dimer & $\mathrm{MeOH} / \mathrm{H}_{2} \mathrm{O}(3: 1)$ & 85 & 12 & messy \\
\hline 7 & $\mathrm{NaAuCl}_{4}-2 \mathrm{H}_{2} \mathrm{O}$ & $\mathrm{EtOH} / \mathrm{H}_{2} \mathrm{O}(4: 1)$ & R.T. & 20 & 50 \\
\hline 8 & $\mathrm{NaAuCl}_{4}-2 \mathrm{H}_{2} \mathrm{O}$ & $\begin{array}{c}\mathrm{EtOH} / \mathrm{H}_{2} \mathrm{O} / \mathrm{DCM} \\
(4: 1: 1)\end{array}$ & R.T. & 20 & 62 \\
\hline
\end{tabular}

Alkyne (0.1 mmol), EtOH/ $\mathrm{H}_{2} \mathrm{O} / \mathrm{DCM}(4: 1: 1,3 \mathrm{~mL})$

With the optimal reaction conditions in hand, we then examined the substrate scope of the hydration reactions. The propargylic $N$-(diphenylphosphinoyl) amines $\mathbf{1}$ were synthesized via direct addition of terminal alkynes to $N$-(diphenylphosphinoyl) imines. Treatment of terminal alkynes with $\mathrm{Me}_{2} \mathrm{Zn}$ followed by the addition of $N$-(diphenylphosphinoyl) imines afforded the corresponding propargylic $N$-(diphenylphosphinoyl) amines 1 in 70-90\% yields (Scheme 5.15). 
Scheme 5.15. Preparation of the propargylic $N$-(diphenylphosphinoyl) amines 1

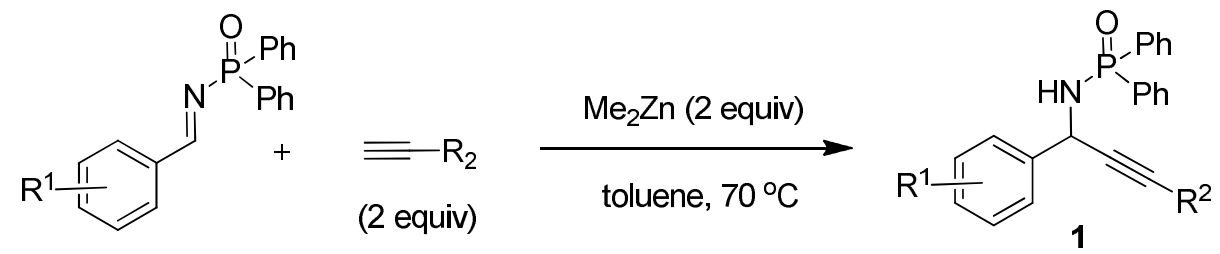<smiles>CN(C)C(NP(=O)(c1ccccc1)c1ccccc1)c1ccccc1</smiles>

$1 \mathrm{a}, 85 \%$<smiles>CC(C)CC(NP(=O)(c1ccccc1)c1ccccc1)c1ccccc1</smiles>

1d, $78 \%$<smiles>O=P(NC(C#CC1CCCC1)c1ccccc1)(c1ccccc1)c1ccccc1</smiles>

$1 \mathrm{~g}, 72 \%$<smiles>O=P(NC(C#CCl)c1ccccc1)(c1ccccc1)c1ccccc1</smiles>

1 j, $90 \%$<smiles>CC#CC(NP(=O)(c1ccccc1)c1ccc(C)cc1)c1ccccc1</smiles>

$1 b, 87 \%$<smiles>CC(C)(C)CNP(=O)(c1ccccc1)c1ccccc1</smiles>

$1 e, 80 \%$<smiles>O=P(NC(C#CC1CCCCC1)c1ccccc1)(c1ccccc1)c1ccccc1</smiles>

1h, $75 \%$<smiles>O=P(NC(C#CCCc1ccccc1)c1ccccc1)(c1ccccc1)c1ccccc1</smiles>

1k, $75 \%$<smiles>CN(C)C(NP(=O)(c1ccccc1)c1ccc(Br)cc1)c1ccccc1</smiles>

1c, $80 \%$<smiles>O=P(NC(C#CC1CC1)c1ccccc1)(c1ccccc1)c1ccccc1</smiles>

1f, $70 \%$<smiles>O=P(NC(C#CC1=CCCCC1)c1ccccc1)(c1ccccc1)c1ccccc1</smiles>

$1 i, 82 \%$

The results of the hydration reactions are summarized in Scheme 5.16. When the electron donating Me-substituted propargylic $N$-(diphenylphosphinoyl) amine $\mathbf{1 b}$ was treated with the gold catalyst, the product $\mathbf{2 b}$ was obtained in $60 \%$ yield. The reaction with the electron-withdrawing Br-substituted amine 1c gave the product 2c in moderate yield (48\%). The hydration of other linear propargylic amines led to the 
formation of the products $\mathbf{2 d}$ and $\mathbf{2 e}$ with good results. The reaction with the propargylic amines containing 3-membered, 5-membered or 6-membered ring also provided the corresponding products $\mathbf{2 f}, \mathbf{2} \mathbf{g}$ and $\mathbf{2 h}$ in good yields. When the amine $\mathbf{1 i}$ containing a conjugated enyne motif was subjected to the same condition, the $\alpha, \beta$-unsaturated ketone product $\mathbf{2} \mathbf{i}$ was formed in $65 \%$ yield. The hydration of other propargylic amines gave the desired products $\mathbf{2} \mathbf{j}$ and $\mathbf{2 k}$ in moderate to good yields.

Scheme 5.16. Gold-catalyzed hydration of the propargylic $N$-(diphenylphosphinoyl) amines 1<smiles>[R]C#CC(NP(=O)(c1ccccc1)c1ccc([R1])cc1)c1ccc(C)cc1</smiles>

$2 a, 62 \%$

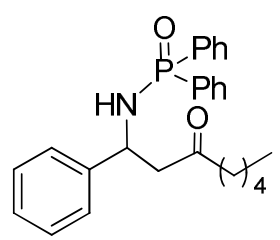

2d, $65 \%$<smiles>O=C(CC(NP(=O)(O)c1ccccc1)c1ccccc1)C1CCCC1</smiles>

$2 \mathrm{~g}, 50 \%$<smiles>O=C(Cl)CC(NP(=O)(O)c1ccccc1)c1ccccc1</smiles>

2j, $45 \%$

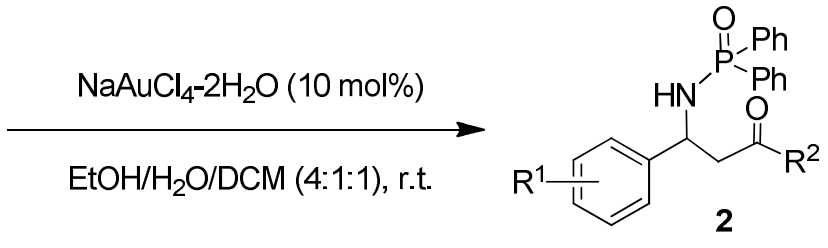<smiles>Cc1ccc(C(CC(=O)O)NP(=O)(c2ccccc2)c2ccccc2)cc1</smiles>

2b, $60 \%$<smiles>CC(C)CC(NP(=O)(c1ccccc1)c1ccc(Br)cc1)c1ccccc1</smiles>

2c, $48 \%$<smiles>O=C(CC(NP(=O)(O)c1ccccc1)c1ccccc1)c1ccccc1</smiles>

2f, $71 \%$<smiles>O=C(CC(NP(=O)(O)c1ccccc1)c1ccccc1)C1=CCCCC1</smiles>

2i, $65 \%$<smiles>O=C(CC(NP(=O)(O)c1ccccc1)c1ccccc1)C1CCCCC1</smiles>

2h, $53 \%$<smiles>O=C(CCc1ccccc1)CC(NP(=O)(c1ccccc1)c1ccccc1)c1ccccc1</smiles>

$2 k, 58 \%$ 
Next, we investigated the gold-catalyzed hydration of the chiral propargylic $N$-(diphenylphosphinoyl) amine (S)-1a. Recently, we developed an asymmetric addition of aliphatic alkynes to $N$-(diphenylphosphinoyl) imines, affording the propargylic $\mathrm{N}$-(diphenylphosphinoyl) amines with high enantioselectivity. The chiral propargylic $N$-(diphenylphosphinoyl) amine $(S)$-1a was prepared with $85 \%$ ee. The hydration of $(S)$-1a under optimal catalytic conditions gave the product $(R)$-2a with $60 \%$ yield and $85 \%$ ee (determined by chiral HPLC) (Scheme 5.17). The results shows that the high enantiomeric purity of $(S)$-1a is maintained in the gold-catalyzed hydration. This strategy is useful in the synthesis of the chiral $\beta$-amino ketone derivatives.

Scheme 5.17. Gold-catalyzed hydration of the chiral propargylic $N$-(diphenylphosphinoyl) amine $(S)-\mathbf{1 a}$

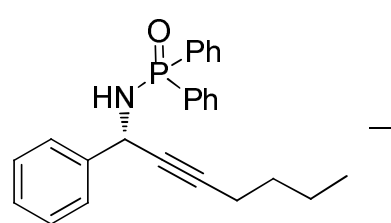

$(S)-1 a$

$85 \%$ ee

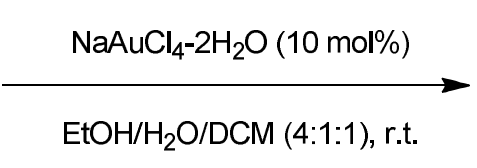

(4:1:1), r.t.

In addition, we examined the diastereoselective reduction of the racemic $\beta$-amino ketones $2 \mathbf{i}$. When $2 \mathbf{i}$ was treated with $\mathrm{Zn}\left(\mathrm{BH}_{4}\right)_{2}$ in THF solution, two diastereomers $3 \mathbf{i}$ $(\mathrm{dr}=2.3: 1)$ were achieved in $86 \%$ yield (Scheme 5.18$)$.

Scheme 5.18. Diastereoselective reduction of the racemic $\beta$-amino ketones $2 \mathbf{i}$<smiles>O=P(O)(NC(CC(=C1CCCCC1)c1ccccc1)c1ccccc1)c1ccccc1</smiles>

2i

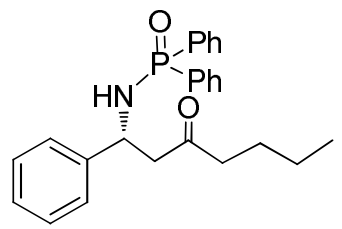

$(R)-2 \mathbf{a}$

$60 \%, 85 \%$ ee

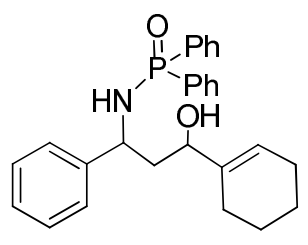

3i, $86 \%, d r=2.3: 1$ 
On the basis of the previous studies on the neighboring group assisted regioselective hydration, ${ }^{19-23}$ the 6-endo-dig cyclized intermediate $\mathbf{5 . 2 8}$ is proposed to illustrate the formation of compound 2a from 1a (Figure 5.2). The gold (III) catalyst coordinates with the triple bond of compound 1a and then the phosphinoyl oxygen attacks the $\beta$-carbon of the triple bond via 6-endo-dig process to form the intermediate 5.28. Nucleophilic attack of water, proto-deauration and tautomerization leads to the final product $\mathbf{2 a}$.

Figure 5.2. Proposed 6-endo-dig cyclized intermediate $\mathbf{5 . 2 8}$<smiles>CCCCCCCCCCC1=C(CCC)[O+]=P(c2ccccc2)(c2ccccc2)NC1c1ccccc1</smiles>

5.28

\subsection{Summary}

In summary, we have developed a neighboring phosphinoyl group assisted regiospecific hydration of propargylic $N$-(diphenylphosphinoyl) amines in the presence of a gold(III) catalyst. These reactions produce various $\beta$-amino ketones in moderate to good yields. We also have demonstrated that the high enantiomeric purity of the chiral propargylic $N$-(diphenylphosphinoyl) amine is maintained in the hydration. This strategy is very useful in the asymmetric synthesis of chiral $\beta$-amino ketone derivatives. 


\section{Experimental and Characterization}

\section{Analytical instruments}

NMR: Bruker $600 \mathrm{MHz}$.

HPLC: Water 600 Pump and Waters 486 Tunable Absorbance Detector, Chiralcel OD, OD-H, or Chiralpak AD, AD-H column.

Polarimeter: Jasco Digital Polarimeter P-2000.

High resolution mass spectra were obtained by EI [70-VSE(C)] or ESI (Q-TOf) analysis.

\section{General data}

Reactions were carried out under nitrogen. All commercial chemicals were used without further purification unless otherwise noted. Zinc reagents and catalysts were purchased and stored in dry nitrogen atmosphere. Toluene and tetrahydrofuran were distilled over sodium and benzophenone under nitrogen. Dichloromethane was dried by passing through activated alumina columns under nitrogen. All the NMR spectra were obtained in $\mathrm{CDCl}_{3}$ unless indicated otherwise.

\section{General procedure for the syntheses of the propargylic}

\section{$N$-(diphenylphosphinoyl) amines 1}

Under nitrogen, an alkyne ( 2 equiv) was added into a dry $100 \mathrm{~mL}$ flask and dissolved in toluene $(30 \mathrm{~mL}) . \mathrm{Me}_{2} \mathrm{Zn}(1.67 \mathrm{~mL}, 1.2 \mathrm{M}$ in toluene, 2 equiv) was then added and the mixture was stirred at room temperature for $30 \mathrm{~min}$. Then, a solution of $\mathrm{N}$-(diphenylphosphinoyl) imine (1 mmol, 1 equiv) in $5 \mathrm{~mL}$ Toluene was added and the 
reaction system was raised to $70{ }^{\circ} \mathrm{C}$ and stirred for $18 \mathrm{~h}$. The reaction was quenched with the addition of water $(20 \mathrm{~mL})$ and extracted with dichloromethane $(3 \times 20 \mathrm{~mL})$. The organic phase was washed with brine $(20 \mathrm{~mL})$ and dried with anhydrous $\mathrm{Na}_{2} \mathrm{SO}_{4}$, filtered and then concentrated by rotary evaporation. The crude mixture was purified by flash column chromatography on silica gel with hexanes/ethyl acetate (1/1) to give the propargylic $N$-(diphenylphosphinoyl) amine products 1 in $70-90 \%$ yields.

Characterization of the propargylic $N$-(diphenylphosphinoyl) amines 1

$P, P$-diphenyl- $N$-(1-phenylhept-2-yn-1-yl)phosphinic amide, 1 a.<smiles>CC#CC(NP(=O)(c1ccccc1)c1ccccc1)c1ccccc1</smiles>

1a, $85 \%$

White solid, Mp $116-118^{\circ} \mathrm{C}, 329 \mathrm{mg}$ (prepared from $1 \mathrm{mmol}$ imine), $85 \%$ yield. ${ }^{1} \mathrm{H}$ NMR (600 MHz, $\left.\mathrm{CDCl}_{3}\right) \delta 8.03(\mathrm{~m}, 2 \mathrm{H}), 7.82(\mathrm{~m}, 2 \mathrm{H}), 7.60$ (d, 2H, J=7.8 Hz), $7.52(\mathrm{t}$, 1H, J=7.2 Hz), $7.46(\mathrm{~m}, 3 \mathrm{H}), 7.37(\mathrm{~m}, 2 \mathrm{H}), 7.32(\mathrm{t}, 2 \mathrm{H}, \mathrm{J}=7.2 \mathrm{~Hz}), 7.25(\mathrm{t}, 1 \mathrm{H}, \mathrm{J}=6.6$ Hz), $5.13(\mathrm{t}, 1 \mathrm{H}, \mathrm{J}=10.2 \mathrm{~Hz}), 3.41(\mathrm{t}, 1 \mathrm{H}, \mathrm{J}=9 \mathrm{~Hz}), 2.21(\mathrm{t}, 2 \mathrm{H}, \mathrm{J}=7.2 \mathrm{~Hz}), 1.48(\mathrm{~m}$, 2H), $1.41(\mathrm{~m}, 2 \mathrm{H}), 0.91(\mathrm{t}, 3 \mathrm{H}, \mathrm{J}=7.8 \mathrm{~Hz}) .{ }^{13} \mathrm{C}\left\{{ }^{1} \mathrm{H}\right\} \mathrm{NMR}\left(150 \mathrm{MHz}, \mathrm{CDCl}_{3}\right) \delta 141.0$ (d, J=4.7 Hz), 132.7 (d, J=9.8 Hz), 131.9, 131.8, 128.5, 128.4 (d, J=11.9 Hz), 127.7, 127.2, 86.2, 79.7 (d, J=6.2 Hz), 46.8, 30.7, 22.0, 18.5, 13.6.

$P, P$-Diphenyl- $N$-(1-(p-tolyl)hept-2-yn-1-yl)phosphinic amide, 1 b.<smiles>CC#CC(NP(=O)(c1ccccc1)c1ccc(C)cc1)c1ccccc1</smiles>

1b, $87 \%$ 
White solid, Mp $138-140{ }^{\circ} \mathrm{C}, 153 \mathrm{mg}$ (prepared from $0.44 \mathrm{mmol}$ imine), $87 \%$ yield. ${ }^{1} \mathrm{H}$ NMR $\left(600 \mathrm{MHz}, \mathrm{CDCl}_{3}\right) \delta 8.02(\mathrm{~m}, 2 \mathrm{H}), 7.82(\mathrm{~m}, 2 \mathrm{H}), 7.52(\mathrm{~m}, 1 \mathrm{H}), 7.47(\mathrm{~m}, 5 \mathrm{H})$, $7.38(\mathrm{~m}, 2 \mathrm{H}), 7.12(\mathrm{~d}, 2 \mathrm{H}, \mathrm{J}=7.8 \mathrm{~Hz}), 5.09(\mathrm{t}, 1 \mathrm{H}, \mathrm{J}=9.6 \mathrm{~Hz}), 3.37$ (t, 1H, J = 9 Hz), $2.31(\mathrm{~s}, 3 \mathrm{H}), 2.19(\mathrm{t}, 2 \mathrm{H}, \mathrm{J}=7.2 \mathrm{~Hz}), 1.47(\mathrm{~m}, 2 \mathrm{H}), 1.40(\mathrm{~m}, 2 \mathrm{H}), 0.91(\mathrm{t}, 3 \mathrm{H}, \mathrm{J}=7.2$ Hz). ${ }^{13} \mathrm{C}\left\{{ }^{1} \mathrm{H}\right\} \operatorname{NMR}\left(150 \mathrm{MHz}, \mathrm{CDCl}_{3}\right) \delta 138.2(\mathrm{~d}, \mathrm{~J}=4.7 \mathrm{~Hz}), 137.4,132.7(\mathrm{~d}, \mathrm{~J}=$ $9.8 \mathrm{~Hz}), 131.9,131.8,129.1,128.4(\mathrm{~d}, \mathrm{~J}=12.6 \mathrm{~Hz}), 127.1,86.0,79.8$ (d, J = $6 \mathrm{~Hz})$, 46.6, 30.7, 22.0, 21.1, 18.5, 13.6. HRMS [ESI(TOF)] for $\mathrm{C}_{26} \mathrm{H}_{29} \mathrm{NOP}\left[\mathrm{M}+\mathrm{H}^{+}\right]: \mathrm{m} / \mathrm{z}$ : calcd for: 402.1987; found: 402.1985 .

N-(1-(4-Bromophenyl)hept-2-yn-1-yl)-P,P-diphenylphosphinic amide, $1 \mathrm{c}$.<smiles>CC#CC(NP(=O)(c1ccccc1)c1ccc(Br)cc1)c1ccccc1</smiles>

1c, $80 \%$

White solid, Mp $140-143^{\circ} \mathrm{C}, 145.4 \mathrm{mg}$ (prepared from $0.39 \mathrm{mmol}$ imine), $80 \%$ yield. ${ }^{1} \mathrm{H}$ NMR $\left(600 \mathrm{MHz}, \mathrm{CDCl}_{3}\right) \delta 8.01(\mathrm{~m}, 2 \mathrm{H}), 7.79(\mathrm{~m}, 2 \mathrm{H}), 7.53(\mathrm{~m}, 1 \mathrm{H}), 7.48(\mathrm{~m}, 5 \mathrm{H})$, $7.43(\mathrm{~m}, 2 \mathrm{H}), 7.38(\mathrm{~m}, 2 \mathrm{H}), 5.08(\mathrm{t}, 1 \mathrm{H}, \mathrm{J}=9 \mathrm{~Hz}), 3.44(\mathrm{t}, 1 \mathrm{H}, \mathrm{J}=7.8 \mathrm{~Hz}), 2.21(\mathrm{~m}$, 2H), $1.48(\mathrm{~m}, 2 \mathrm{H}), 1.40(\mathrm{~m}, 2 \mathrm{H}), 0.91(\mathrm{t}, 3 \mathrm{H}, \mathrm{J}=7.2 \mathrm{~Hz}) .{ }^{13} \mathrm{C}\left\{{ }^{1} \mathrm{H}\right\} \mathrm{NMR}(150 \mathrm{MHz}$ $\left.\mathrm{CDCl}_{3}\right) \delta 140.1(\mathrm{~d}, \mathrm{~J}=3.8 \mathrm{~Hz}), 132.6(\mathrm{~d}, \mathrm{~J}=9.9 \mathrm{~Hz}), 132.0(\mathrm{~d}, \mathrm{~J}=10.5 \mathrm{~Hz}), 131.7(\mathrm{~d}$, $\mathrm{J}=9.8 \mathrm{~Hz}), 131.5,129.1,128.4(\mathrm{~d}, \mathrm{~J}=12.9 \mathrm{~Hz}), 121.7,86.6,79.1(\mathrm{~d}, \mathrm{~J}=6.9 \mathrm{~Hz})$ 46.4, 30.6, 22.0, 18.4, 13.6. HRMS [ESI(TOF)] for $\mathrm{C}_{25} \mathrm{H}_{26} \mathrm{NOPBr}\left[\mathrm{M}+\mathrm{H}^{+}\right]: \mathrm{m} / \mathrm{z}$ : calcd for: 466.0935; found: 466.0932. 
$P, P$-diphenyl- $N$-(1-phenyloct-2-yn-1-yl)phosphinic amide, $1 \mathrm{~d}$.<smiles>CC#CC(NP(=O)(c1ccccc1)c1ccccc1)c1ccccc1</smiles>

$1 \mathrm{~d}, 78 \%$

White solid, Mp 120-122 ${ }^{\circ} \mathrm{C}, 313 \mathrm{mg}$ (prepared from $1 \mathrm{mmol}$ imine), $78 \%$ yield. ${ }^{1} \mathrm{H}$ NMR (600 MHz, $\left.\mathrm{CDCl}_{3}\right) \delta 8.03(\mathrm{~m}, 2 \mathrm{H}), 7.82(\mathrm{~m}, 2 \mathrm{H}), 7.60(\mathrm{~d}, 2 \mathrm{H}, \mathrm{J}=7.8 \mathrm{~Hz}), 7.51$ (m, 1H), $7.45(\mathrm{~m}, 3 \mathrm{H}), 7.37(\mathrm{~m}, 2 \mathrm{H}), 7.32(\mathrm{t}, 2 \mathrm{H}, \mathrm{J}=7.2 \mathrm{~Hz}), 7.24(\mathrm{~m}, 1 \mathrm{H}), 5.13(\mathrm{t}, 1 \mathrm{H}$, $\mathrm{J}=9.6 \mathrm{~Hz}), 3.43(\mathrm{t}, 1 \mathrm{H}, \mathrm{J}=9 \mathrm{~Hz}), 2.20(\mathrm{~m}, 2 \mathrm{H}), 1.50(\mathrm{~m}, 2 \mathrm{H}), 1.35(\mathrm{~m}, 4 \mathrm{H}), 0.90(\mathrm{t}, 3 \mathrm{H}$, $\mathrm{J}=6.6 \mathrm{~Hz}) .{ }^{13} \mathrm{C}\left\{{ }^{1} \mathrm{H}\right\}$ NMR $\left(150 \mathrm{MHz}, \mathrm{CDCl}_{3}\right) \delta 141.0(\mathrm{~d}, \mathrm{~J}=4.5 \mathrm{~Hz}), 132.7(\mathrm{~d}, \mathrm{~J}=9.8$ Hz), 131.9 (d, J=7.5 Hz), 131.85 (d, J=9.8 Hz), 128.45 (d, J=3.6 Hz), 128.4, 127.7, 127.2, 86.3, 79.7 (d, J=6.2 Hz), 46.8, 31.1, 28.3, 22.2, 18.8, 14.0. HRMS [ESI(TOF)] for $\mathrm{C}_{26} \mathrm{H}_{29} \mathrm{NOP}\left[\mathrm{M}+\mathrm{H}^{+}\right]$: m/z: calcd for: 402.1987; found: 402.1971 .

$P, P$-diphenyl- $N$-(1-phenylnon-2-yn-1-yl)phosphinic amide, 1 e.<smiles>CC#CC(NP(=O)(c1ccccc1)c1ccccc1)c1ccccc1</smiles>

$1 e, 80 \%$

White solid, Mp $110-112{ }^{\circ} \mathrm{C}, 332 \mathrm{mg}$ (prepared from $1 \mathrm{mmol}$ imine), $80 \%$ yield. ${ }^{1} \mathrm{H}$ NMR (600 MHz, $\left.\mathrm{CDCl}_{3}\right) \delta 8.03(\mathrm{~m}, 2 \mathrm{H}), 7.82(\mathrm{~m}, 2 \mathrm{H}), 7.60(\mathrm{~d}, 2 \mathrm{H}, \mathrm{J}=8.4 \mathrm{~Hz}), 7.52$ (m, 1H), $7.46(\mathrm{~m}, 3 \mathrm{H}), 7.37(\mathrm{~m}, 2 \mathrm{H}), 7.32(\mathrm{t}, 2 \mathrm{H}, \mathrm{J}=7.2 \mathrm{~Hz}), 7.25(\mathrm{~m}, 1 \mathrm{H}), 5.13(\mathrm{t}, 1 \mathrm{H}$, $\mathrm{J}=9.6 \mathrm{~Hz}), 3.41(\mathrm{t}, 1 \mathrm{H}, \mathrm{J}=9 \mathrm{~Hz}), 2.20(\mathrm{~m}, 2 \mathrm{H}), 1.49(\mathrm{~m}, 2 \mathrm{H}), 1.38(\mathrm{~m}, 2 \mathrm{H}), 1.29(\mathrm{~m}$, 4H), $0.88(\mathrm{t}, 3 \mathrm{H}, \mathrm{J}=7.2 \mathrm{~Hz}) . \quad{ }^{13} \mathrm{C}\left\{{ }^{1} \mathrm{H}\right\} \mathrm{NMR}\left(150 \mathrm{MHz}, \mathrm{CDCl}_{3}\right) \delta 141.0(\mathrm{~d}, \mathrm{~J}=4.7$ 
Hz), 132.7 (d, J = 9.9 Hz), 131.9 (d, J = 7.4 Hz), 131.8 (d, J = 9.6 Hz), 128.5, $128.4(\mathrm{~d}$, $\mathrm{J}=12.8 \mathrm{~Hz}), 127.7,127.2,86.3,79.7(\mathrm{~d}, \mathrm{~J}=6.2 \mathrm{~Hz}), 46.8,31.3,28.6,28.5,22.5,18.8$, 14.0. HRMS [ESI(TOF)] for $\mathrm{C}_{27} \mathrm{H}_{31} \mathrm{NOP}\left[\mathrm{M}+\mathrm{H}^{+}\right]$: $\mathrm{m} / \mathrm{z}$ : calcd for: 416.2143 ; found: 416.2141.

$N$-(3-cyclopropyl-1-phenylprop-2-yn-1-yl)-P,P-diphenylphosphinic amide, 1 f.<smiles>O=P(C#CC1CC1)(c1ccccc1)c1ccccc1</smiles>

1f, $70 \%$

White solid, $\mathrm{Mp} 178-180{ }^{\circ} \mathrm{C}, 260 \mathrm{mg}$ (prepared from $1 \mathrm{mmol}$ imine), $70 \%$ yield. ${ }^{1} \mathrm{H}$ NMR (600 MHz, $\left.\mathrm{CDCl}_{3}\right) \delta 8.01(\mathrm{~m}, 2 \mathrm{H}), 7.80(\mathrm{~m}, 2 \mathrm{H}), 7.56(\mathrm{~d}, 2 \mathrm{H}, \mathrm{J}=7.8 \mathrm{~Hz}), 7.53(\mathrm{t}$, 1H, J=7.2 Hz), 7.47 (m, 3H), $7.38(\mathrm{~m}, 2 \mathrm{H}), 7.31(\mathrm{t}, 2 \mathrm{H}, \mathrm{J}=7.8 \mathrm{~Hz}), 7.25$ (t, 1H, J=5.4 Hz), $5.10(\mathrm{t}, 1 \mathrm{H}, \mathrm{J}=9.6 \mathrm{~Hz}), 3.38$ (t, 1H, J=8.4 Hz), $1.24(\mathrm{~m}, 1 \mathrm{H}), 0.74(\mathrm{~m}, 2 \mathrm{H}), 0.63$ (m, 2H). ${ }^{13} \mathrm{C}\left\{{ }^{1} \mathrm{H}\right\}$ NMR $\left(150 \mathrm{MHz}, \mathrm{CDCl}_{3}\right) \delta 140.9(\mathrm{~d}, \mathrm{~J}=4.7 \mathrm{~Hz}), 132.7(\mathrm{~d}, \mathrm{~J}=9.8$ Hz), 131.9 (d, J=8.7 Hz), 131.8 (d, J=9.8 Hz), 128.5, 128.4 (d, J=12.6 Hz), 127.7, $127.2,89.2,74.8(\mathrm{~d}, \mathrm{~J}=6 \mathrm{~Hz}), 46.8,8.1,-0.5$.

$N$-(3-cyclopentyl-1-phenylprop-2-yn-1-yl)-P,P-diphenylphosphinic amide, $1 \mathrm{~g}$.<smiles>O=[PH](NC(C#CC1CCCC1)c1ccccc1)c1ccccc1</smiles>

$1 \mathrm{~g}, 72 \%$

White solid, Mp $128-130{ }^{\circ} \mathrm{C}, 287 \mathrm{mg}$ (prepared from $1 \mathrm{mmol}$ imine), $72 \%$ yield. ${ }^{1} \mathrm{H}$ NMR (600 MHz, $\left.\mathrm{CDCl}_{3}\right) \delta 8.04(\mathrm{~m}, 2 \mathrm{H}), 7.80(\mathrm{~m}, 2 \mathrm{H}), 7.60$ (d, 2H, J=7.8 Hz), 7.52 
(m, 1H), $7.45(\mathrm{~m}, 3 \mathrm{H}), 7.37(\mathrm{~m}, 2 \mathrm{H}), 7.32(\mathrm{t}, 2 \mathrm{H}, \mathrm{J}=7.2 \mathrm{~Hz}), 7.24(\mathrm{~m}, 1 \mathrm{H}), 5.15(\mathrm{t}, 1 \mathrm{H}$, $\mathrm{J}=9.6 \mathrm{~Hz}), 3.42(\mathrm{t}, 1 \mathrm{H}, \mathrm{J}=9 \mathrm{~Hz}), 2.64(\mathrm{~m}, 1 \mathrm{H}), 1.88(\mathrm{~m}, 2 \mathrm{H}), 1.71(\mathrm{~m}, 2 \mathrm{H}), 1.57(\mathrm{~m}$, 4H). ${ }^{13} \mathrm{C}\left\{{ }^{1} \mathrm{H}\right\} \operatorname{NMR}\left(150 \mathrm{MHz}, \mathrm{CDCl}_{3}\right) \delta 141.0(\mathrm{~d}, \mathrm{~J}=4.4 \mathrm{~Hz}), 132.7$ (d, J=9.9 Hz), 131.9 (d, J=9.8 Hz), 131.7 (d, J=9.9 Hz), 128.4, 128.3 (d, J=11.9 Hz), 127.6, 127.3, 90.4, $79.2(\mathrm{~d}, \mathrm{~J}=6 \mathrm{~Hz}), 46.8,33.7(\mathrm{~d}, \mathrm{~J}=1.2 \mathrm{~Hz})$, 30.2, 24.9. HRMS [ESI(TOF)] for $\mathrm{C}_{26} \mathrm{H}_{27} \mathrm{NOP}\left[\mathrm{M}+\mathrm{H}^{+}\right]: \mathrm{m} / \mathrm{z}$ : calcd for: 400.1830; found: 400.1828 .

$N$-(3-cyclohexyl-1-phenylprop-2-yn-1-yl)-P,P-diphenylphosphinic amide, $1 \mathrm{~h}$.<smiles>O=P(NC(C#CC1CCCCC1)c1ccccc1)(c1ccccc1)c1ccccc1</smiles>

$1 \mathrm{~h}, 75 \%$

White solid, Mp $155-157^{\circ} \mathrm{C}, 310 \mathrm{mg}$ (prepared from $1 \mathrm{mmol}$ imine), $75 \%$ yield. ${ }^{1} \mathrm{H}$ $\operatorname{NMR}\left(600 \mathrm{MHz}, \mathrm{CDCl}_{3}\right) \delta 8.05(\mathrm{~m}, 2 \mathrm{H}), 7.81(\mathrm{~m}, 2 \mathrm{H}), 7.62(\mathrm{~d}, 2 \mathrm{H}, \mathrm{J}=7.8 \mathrm{~Hz}), 7.52$ (m, 1H), $7.47(\mathrm{~m}, 3 \mathrm{H}), 7.38(\mathrm{~m}, 2 \mathrm{H}), 7.32(\mathrm{t}, 2 \mathrm{H}, \mathrm{J}=7.2 \mathrm{~Hz}), 7.25(\mathrm{~m}, 1 \mathrm{H}), 5.15(\mathrm{t}, 1 \mathrm{H}$, $\mathrm{J}=9.6 \mathrm{~Hz}), 3.39(\mathrm{t}, 1 \mathrm{H}, \mathrm{J}=9 \mathrm{~Hz}), 2.42(\mathrm{~m}, 1 \mathrm{H}), 1.79(\mathrm{~m}, 2 \mathrm{H}), 1.70(\mathrm{~m}, 2 \mathrm{H}), 1.51(\mathrm{~m}$, 1H), $1.43(\mathrm{~m}, 2 \mathrm{H}), 1.31(\mathrm{~m}, 3 \mathrm{H}) .{ }^{13} \mathrm{C}\left\{{ }^{1} \mathrm{H}\right\}$ NMR $\left(150 \mathrm{MHz}, \mathrm{CDCl}_{3}\right) \delta 141.0(\mathrm{~d}, \mathrm{~J}=4.2$ Hz), 132.8 (d, J=9.9 Hz), 131.9 (d, J=10.1 Hz), 131.7 (d, J=9.8 Hz), 128.4, 128.3, 127.6, 127.3, 90.3, 79.6 (d, J=6.3 Hz), 46.8, 32.5, 29.1, 25.9, 24.8. HRMS [ESI(TOF)] for $\mathrm{C}_{27} \mathrm{H}_{29} \mathrm{NOP}\left[\mathrm{M}+\mathrm{H}^{+}\right]$: m/z: calcd for: 414.1987; found: 414.1982 .

$N$-(3-(Cyclohex-1-en-1-yl)-1-phenylprop-2-yn-1-yl)-P,P-diphenylphosphinic amide, 1 i.<smiles>O=P(NC(C#CC1=CCCCC1)c1ccccc1)(c1ccccc1)c1ccccc1</smiles>

$1 i, 82 \%$ 
White solid, Mp $154-156^{\circ} \mathrm{C}, 337 \mathrm{mg}$ (prepared from $1 \mathrm{mmol}$ imine), $82 \%$ yield. ${ }^{1} \mathrm{H}$ NMR (600 MHz, $\left.\mathrm{CDCl}_{3}\right) \delta 8.04(\mathrm{~m}, 2 \mathrm{H}), 7.81(\mathrm{~m}, 2 \mathrm{H}), 7.61(\mathrm{~d}, 2 \mathrm{H}, \mathrm{J}=7.2 \mathrm{~Hz}), 7.52$ (m, 1H), $7.46(\mathrm{~m}, 3 \mathrm{H}), 7.37(\mathrm{~m}, 2 \mathrm{H}), 7.32(\mathrm{~d}, 2 \mathrm{H}, \mathrm{J}=7.8 \mathrm{~Hz}), 7.25(\mathrm{~m}, 1 \mathrm{H}), 6.09(\mathrm{~s}$, 1H), $5.26(\mathrm{t}, 1 \mathrm{H}, \mathrm{J}=9.6 \mathrm{~Hz}), 3.46(\mathrm{t}, 1 \mathrm{H}, \mathrm{J}=9 \mathrm{~Hz}), 2.09(\mathrm{~d}, 4 \mathrm{H}, \mathrm{J}=6 \mathrm{~Hz}), 1.62(\mathrm{~m}$, 4H). ${ }^{13} \mathrm{C}\left\{{ }^{1} \mathrm{H}\right\} \operatorname{NMR}\left(150 \mathrm{MHz}, \mathrm{CDCl}_{3}\right) \delta 140.7(\mathrm{~d}, \mathrm{~J}=4.4 \mathrm{~Hz}), 135.1,132.8(\mathrm{~d}, \mathrm{~J}=$ $9.8 \mathrm{~Hz}), 131.9(\mathrm{~d}, \mathrm{~J}=7.8 \mathrm{~Hz}), 131.8(\mathrm{~d}, \mathrm{~J}=9.8 \mathrm{~Hz}), 128.5,128.4(\mathrm{~d}, \mathrm{~J}=12.8 \mathrm{~Hz})$, $127.8,127.3,120.2,87.4,86.0(\mathrm{~d}, \mathrm{~J}=6.3 \mathrm{~Hz}), 47.1,29.1,25.6,22.2,21.5 . \quad$ HRMS [ESI(TOF)] for $\mathrm{C}_{27} \mathrm{H}_{27} \mathrm{NOP}\left[\mathrm{M}+\mathrm{H}^{+}\right]$: m/z: calcd for: 412.1830; found: 412.1829 .

\section{$N$-(6-Chloro-1-phenylhex-2-yn-1-yl)-P,P-diphenylphosphinic amide, $\mathbf{1 j}$.}

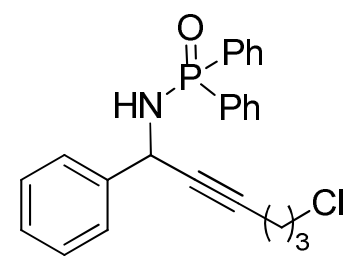

$1 \mathrm{j}, 90 \%$

White solid, Mp 107-109 ${ }^{\circ} \mathrm{C}, 366 \mathrm{mg}$ (prepared from $1 \mathrm{mmol}$ imine), $90 \%$ yield. ${ }^{1} \mathrm{H}$ NMR (600 MHz, $\left.\mathrm{CDCl}_{3}\right) \delta 8.00(\mathrm{~m}, 2 \mathrm{H}), 7.82(\mathrm{~m}, 2 \mathrm{H}), 7.56(\mathrm{~d}, 2 \mathrm{H}, \mathrm{J}=7.8 \mathrm{~Hz}), 7.52$ (m, 1H), 7.47 (m, 3H), $7.39(\mathrm{~m}, 2 \mathrm{H}), 7.33(\mathrm{t}, 2 \mathrm{H}, \mathrm{J}=7.8 \mathrm{~Hz}), 7.26(\mathrm{t}, 1 \mathrm{H}, \mathrm{J}=7.2 \mathrm{~Hz})$, $5.14(\mathrm{t}, 1 \mathrm{H}, \mathrm{J}=9.6 \mathrm{~Hz}), 3.61(\mathrm{t}, 2 \mathrm{H}, \mathrm{J}=6.6 \mathrm{~Hz}), 3.42(\mathrm{t}, 1 \mathrm{H}, \mathrm{J}=8.4 \mathrm{~Hz}), 2.39(\mathrm{~m}, 2 \mathrm{H})$, $1.92(\mathrm{~m}, 2 \mathrm{H}) .{ }^{13} \mathrm{C}\left\{{ }^{1} \mathrm{H}\right\} \operatorname{NMR}\left(150 \mathrm{MHz}, \mathrm{CDCl}_{3}\right) \delta 140.7(\mathrm{~d}, \mathrm{~J}=4.8 \mathrm{~Hz}), 132.5(\mathrm{~d}, \mathrm{~J}$ $=9.8 \mathrm{~Hz}), 132.0(\mathrm{~d}, \mathrm{~J}=6.9 \mathrm{~Hz}), 131.8(\mathrm{~d}, \mathrm{~J}=9.8 \mathrm{~Hz}), 128.6,128.4(\mathrm{~d}, \mathrm{~J}=12.6 \mathrm{~Hz})$, $127.9,127.1,84.1,80.8(\mathrm{~d}, \mathrm{~J}=5.6 \mathrm{~Hz}), 46.7,43.7,31.2,16.2 . \quad$ HRMS [ESI(TOF)] for $\mathrm{C}_{24} \mathrm{H}_{24} \mathrm{NOPCl}\left[\mathrm{M}+\mathrm{H}^{+}\right]$: m/z: calcd for: 408.1284 ; found: 408.1280 . 
$N$-(1,5-diphenylpent-2-yn-1-yl)-P,P-diphenylphosphinic amide, 1 k.<smiles>O=P(NC(C#CCCc1ccccc1)c1ccccc1)(c1ccccc1)c1ccccc1</smiles>

$1 \mathrm{k}, 75 \%$

White solid, Mp $148-150{ }^{\circ} \mathrm{C}, 326 \mathrm{mg}$ (prepared from $1 \mathrm{mmol}$ imine), $75 \%$ yield. ${ }^{1} \mathrm{H}$ $\operatorname{NMR}\left(600 \mathrm{MHz}, \mathrm{CDCl}_{3}\right) \delta 7.99(\mathrm{~m}, 2 \mathrm{H}), 7.81(\mathrm{~m}, 2 \mathrm{H}), 7.51(\mathrm{~m}, 3 \mathrm{H}), 7.45(\mathrm{~m}, 3 \mathrm{H})$ $7.38(\mathrm{~m}, 2 \mathrm{H}), 7.27(\mathrm{~m}, 5 \mathrm{H}), 7.20(\mathrm{~m}, 3 \mathrm{H}), 5.10(\mathrm{t}, 1 \mathrm{H}, \mathrm{J}=9.6 \mathrm{~Hz}), 3.39(\mathrm{t}, 1 \mathrm{H}, \mathrm{J}=9 \mathrm{~Hz})$ $2.80(\mathrm{~m}, 2 \mathrm{H}), 2.51(\mathrm{~m}, 2 \mathrm{H}) .{ }^{13} \mathrm{C}\left\{{ }^{1} \mathrm{H}\right\}$ NMR $\left(150 \mathrm{MHz}, \mathrm{CDCl}_{3}\right) \delta 140.8(\mathrm{~d}, \mathrm{~J}=4.8$ Hz), 140.6, 132.6 (d, J=9.8 Hz), 131.92 (d, J=7.7 Hz), 131.88 (d, J=9.6 Hz), 128.5 (d, $\mathrm{J}=1.7 \mathrm{~Hz}), 128.46,128.38,128.36,127.7,127.2,126.3,85.4,80.5$ (d, J=6 Hz), 46.8, 34.8, 20.9. HRMS [ESI(TOF)] for $\mathrm{C}_{29} \mathrm{H}_{27} \mathrm{NOP}\left[\mathrm{M}+\mathrm{H}^{+}\right]$: $\mathrm{m} / \mathrm{z}$ : calcd for: 436.1830; found: 436.1818 .

\section{General procedure for the gold-catalyzed hydration of the propargylic}

\section{$N$-(diphenylphosphinoyl) amines 1}

Under nitrogen, $\mathrm{NaAuCl}_{4}-2 \mathrm{H}_{2} \mathrm{O}(10 \mathrm{~mol} \%)$ was added to a dry flask. A solution of the propargylic $N$-(diphenylphosphinoyl) amine 1 (1 equiv) in $\mathrm{EtOH} / \mathrm{H}_{2} \mathrm{O} / \mathrm{DCM}$ (4:1:1, $3 \mathrm{~mL})$ was then added and the reaction mixture was stirred for $20 \mathrm{~h}$ at room temperature. The reaction was added with water $(3 \mathrm{~mL})$ an extracted with DCM $(3 \times 5$ $\mathrm{mL}$ ). The organic layer was dried with anhydrous $\mathrm{Na}_{2} \mathrm{SO}_{4}$, filtered and then concentrated by rotary evaporation. The crude mixture was purified by flash column chromatography on silica gel with hexanes/ethyl acetate $(1 / 1$ to $1 / 5)$ to give the $\beta$-amino ketone products 2 in $45-71 \%$ yields. 


\section{Characterization of the racemic $\beta$-amino ketone products 2}

$N$-(3-oxo-1-phenylheptyl)-P,P-diphenylphosphinic amide, 2 a.<smiles>CC(C)CC(NP(=O)(O)c1ccccc1)c1ccccc1</smiles>

$2 a, 62 \%$

White solid, Mp $155-157^{\circ} \mathrm{C}, 116.3 \mathrm{mg}$ (prepared from $0.465 \mathrm{mmol}$ amine), $62 \%$ yield. ${ }^{1} \mathrm{H}$ NMR $\left(600 \mathrm{MHz}, \mathrm{CDCl}_{3}\right) \delta 7.80(\mathrm{~m}, 4 \mathrm{H}), 7.43(\mathrm{~m}, 4 \mathrm{H}), 7.27(\mathrm{~m}, 7 \mathrm{H}), 4.58(\mathrm{~m}, 1 \mathrm{H})$, $4.47(\mathrm{~s}, 1 \mathrm{H}), 3.14(\mathrm{~m}, 2 \mathrm{H}), 2.24(\mathrm{~m}, 1 \mathrm{H}), 2.19(\mathrm{~m}, 1 \mathrm{H}), 1.36(\mathrm{~m}, 2 \mathrm{H}), 1.13(\mathrm{~m}, 2 \mathrm{H})$ $0.78(\mathrm{t}, 3 \mathrm{H}, \mathrm{J}=7.2 \mathrm{~Hz}) .{ }^{13} \mathrm{C}\left\{{ }^{1} \mathrm{H}\right\} \mathrm{NMR}\left(150 \mathrm{MHz}, \mathrm{CDCl}_{3}\right) \delta 210.2,142.4(\mathrm{~d}, \mathrm{~J}=7.2$ Hz), 132.5 (d, J=9.6 Hz), 131.8 (dd, J=6.3, 2.6 Hz), 131.6 (d, J=9.5 Hz), 128.5 (dd, $\mathrm{J}=12.5,9.3 \mathrm{~Hz}), 128.4,127.1,126.4,51.8,50.1,43.5,25.3,22.0,13.7$. HRMS [ESI(TOF)] for $\mathrm{C}_{25} \mathrm{H}_{29} \mathrm{NO}_{2} \mathrm{P}$ [M+H'] : m/z: calcd for: 406.1936; found: 406.1932 .

$N$-(3-oxo-1-(p-tolyl)heptyl)-P,P-diphenylphosphinic amide, 2 b.<smiles>Cc1ccc(C(CC(=O)O)NP(=O)(c2ccccc2)c2ccccc2)cc1</smiles>

$2 b, 60 \%$

White solid, Mp 151-153oC, $141 \mathrm{mg}$ (prepared from $0.563 \mathrm{mmol}$ amine), $60 \%$ yield. ${ }^{1} \mathrm{H}$ NMR $\left(600 \mathrm{MHz}, \mathrm{CDCl}_{3}\right) \delta 7.81(\mathrm{~m}, 4 \mathrm{H}), 7.43(\mathrm{~m}, 4 \mathrm{H}), 7.34(\mathrm{~m}, 2 \mathrm{H}), 7.15(\mathrm{~d}, 2 \mathrm{H}$, $\mathrm{J}=7.8 \mathrm{~Hz}), 7.08(\mathrm{~d}, 2 \mathrm{H}, \mathrm{J}=7.8 \mathrm{~Hz}), 4.55(\mathrm{~m}, 1 \mathrm{H}), 4.31(\mathrm{~m}, 1 \mathrm{H}), 3.13(\mathrm{~d}, 2 \mathrm{H}, \mathrm{J}=5.4 \mathrm{~Hz})$, $2.30(\mathrm{~s}, 3 \mathrm{H}), 2.25(\mathrm{~m}, 1 \mathrm{H}), 2.18(\mathrm{~m}, 1 \mathrm{H}), 1.37(\mathrm{~m}, 2 \mathrm{H}), 1.14(\mathrm{~m}, 2 \mathrm{H}), 0.79(\mathrm{t}, 3 \mathrm{H}$ $\mathrm{J}=7.2 \mathrm{~Hz}) .{ }^{13} \mathrm{C}\left\{{ }^{1} \mathrm{H}\right\}$ NMR $\left(150 \mathrm{MHz}, \mathrm{CDCl}_{3}\right) \delta 210.2,139.4(\mathrm{~d}, \mathrm{~J}=7.4 \mathrm{~Hz}), 136.7$, 132.5 (d, J=9.5 Hz), 131.8 (dd, J=4.4, 2.6 Hz), 131.6 (d, J=9.5 Hz), 129.1, 128.4 (dd, 
$\mathrm{J}=12.6,5.3 \mathrm{~Hz}), 126.2,51.5,50.2(\mathrm{~d}, \mathrm{~J}=2 \mathrm{~Hz}), 43.5,25.3,22.1,21.0,13.7$. HRMS [ESI(TOF)] for $\mathrm{C}_{26} \mathrm{H}_{31} \mathrm{NO}_{2} \mathrm{P}$ [M+H ${ }^{+}$]: m/z: calcd for: 420.2092; found: 420.2086 .

$N$-(1-(4-bromophenyl)-3-oxoheptyl)-P,P-diphenylphosphinic amide, 2 c.<smiles>CC(C)CC(NP(=O)(O)c1ccccc1)c1ccc(Br)cc1</smiles>

2c, $48 \%$

White solid, Mp 163-165oC, $114 \mathrm{mg}$ (prepared from $0.491 \mathrm{mmol}$ amine), 48\% yield. 1H NMR (600 MHz, $\left.\mathrm{CDCl}_{3}\right) \delta 7.81(\mathrm{~m}, 2 \mathrm{H}), 7.75(\mathrm{~m}, 2 \mathrm{H}), 7.43(\mathrm{~m}, 6 \mathrm{H}), 7.34(\mathrm{~m}$, 2H), $7.15(\mathrm{~d}, 2 \mathrm{H}, \mathrm{J}=8.4 \mathrm{~Hz}), 4.51(\mathrm{~m}, 1 \mathrm{H}), 4.46(\mathrm{~m}, 1 \mathrm{H}), 3.12(\mathrm{~m}, 2 \mathrm{H}), 2.27(\mathrm{~m}, 1 \mathrm{H})$, $2.19(\mathrm{~m}, 1 \mathrm{H}), 1.38(\mathrm{~m}, 2 \mathrm{H}), 1.15(\mathrm{~m}, 2 \mathrm{H}), 0.80(\mathrm{t}, 3 \mathrm{H}, \mathrm{J}=7.2 \mathrm{~Hz}) .{ }^{13} \mathrm{C}\left\{{ }^{1} \mathrm{H}\right\}$ NMR $(150$ $\left.\mathrm{MHz}, \mathrm{CDCl}_{3}\right) \delta 210.1,141.5(\mathrm{~d}, \mathrm{~J}=6.9 \mathrm{~Hz}), 132.3(\mathrm{~d}, \mathrm{~J}=9.6 \mathrm{~Hz}), 131.9(\mathrm{dd}, \mathrm{J}=5.6,2.7$ Hz), 131.6 (d, J=9.5 Hz), 131.5, 128.5 (dd, J=12.6, 7.5 Hz), 128.2, 121.0, 51.2, 49.7 (d, J=2.3 Hz), 43.5, 25.3, 22.1, 13.7. HRMS [ESI(TOF)] for $\mathrm{C}_{25} \mathrm{H}_{28} \mathrm{NO}_{2} \mathrm{PBr}\left[\mathrm{M}+\mathrm{H}^{+}\right]$: m/z: calcd for: 484.1041 ; found: 484.1028 .

$N$-(3-oxo-1-phenyloctyl)-P,P-diphenylphosphinic amide, $2 \mathrm{~d}$.<smiles>CC(C)CC(NP(=O)(O)c1ccccc1)c1ccccc1</smiles>

2d, $65 \%$

White solid, $\mathrm{Mp} 157-158^{\circ} \mathrm{C}, 158 \mathrm{mg}$ (prepared from $0.581 \mathrm{mmol}$ amine), $65 \%$ yield. ${ }^{1} \mathrm{H}$ NMR $\left(600 \mathrm{MHz}, \mathrm{CDCl}_{3}\right) \delta 7.83(\mathrm{~m}, 2 \mathrm{H}), 7.78(\mathrm{~m}, 2 \mathrm{H}), 7.46(\mathrm{~m}, 1 \mathrm{H}), 7.40(\mathrm{~m}, 3 \mathrm{H})$, $7.32(\mathrm{~m}, 2 \mathrm{H}), 7.27(\mathrm{~d}, 4 \mathrm{H}, \mathrm{J}=4.8 \mathrm{~Hz}), 7.20(\mathrm{~m}, 1 \mathrm{H}), 4.58(\mathrm{~m}, 1 \mathrm{H}), 4.45(\mathrm{~m}, 1 \mathrm{H}), 3.13$ $(\mathrm{d}, 2 \mathrm{H}, \mathrm{J}=5.4 \mathrm{~Hz}), 2.24(\mathrm{~m}, 1 \mathrm{H}), 2.16(\mathrm{~m}, 1 \mathrm{H}), 1.38(\mathrm{~m}, 2 \mathrm{H}), 1.17(\mathrm{~m}, 2 \mathrm{H}), 1.07(\mathrm{~m}$, 
2H), $0.79(\mathrm{t}, 3 \mathrm{H}, \mathrm{J}=7.2 \mathrm{~Hz}) .{ }^{13} \mathrm{C}\left\{{ }^{1} \mathrm{H}\right\}$ NMR $\left(150 \mathrm{MHz}, \mathrm{CDCl}_{3}\right) \delta 210.3,142.4(\mathrm{~d}$, $\mathrm{J}=7.2 \mathrm{~Hz}), 132.5$ (d, J=9.5 Hz), 131.8 (dd, J=6.3, 2.6 Hz), 131.6 (d, J=9.5 Hz), 128.5 (dd, J=12.5, $9 \mathrm{~Hz}), 128.4,127.1,126.4,51.7,50.0$ (d, J=2.1 Hz), 43.8, 31.1, 22.9, 22.3, 13.8. HRMS [ESI(TOF)] for $\mathrm{C}_{26} \mathrm{H}_{31} \mathrm{NO}_{2} \mathrm{P}\left[\mathrm{M}+\mathrm{H}^{+}\right]$: $\mathrm{m} / \mathrm{z}$ : calcd for: 420.2092; found: 420.2087 .

$N$-(3-oxo-1-phenylnonyl)-P,P-diphenylphosphinic amide, $2 \mathrm{e}$.<smiles>CC(C)CC(NP(=O)(O)c1ccccc1)c1ccccc1</smiles>

$2 \mathbf{e}, 60 \%$

White solid, Mp 143-145oC, $140.3 \mathrm{mg}$ (prepared from $0.54 \mathrm{mmol}$ amine), $60 \%$ yield. 1H NMR (600 MHz, CDCl3) $\delta 7.83(\mathrm{~m}, 2 \mathrm{H}), 7.78(\mathrm{~m}, 2 \mathrm{H}), 7.46(\mathrm{~m}, 1 \mathrm{H}), 7.40(\mathrm{~m}$, 3H), $7.33(\mathrm{~m}, 2 \mathrm{H}), 7.26(\mathrm{~d}, 4 \mathrm{H}, \mathrm{J}=4.2 \mathrm{~Hz}), 7.20(\mathrm{~m}, 1 \mathrm{H}), 4.57(\mathrm{~m}, 1 \mathrm{H}), 4.48(\mathrm{~s}, 1 \mathrm{H})$, $3.13(\mathrm{~d}, 2 \mathrm{H}, \mathrm{J}=5.4 \mathrm{~Hz}), 2.23(\mathrm{~m}, 1 \mathrm{H}), 2.18(\mathrm{~m}, 1 \mathrm{H}), 1.37(\mathrm{~m}, 2 \mathrm{H}), 1.19(\mathrm{~m}, 2 \mathrm{H}), 1.11$ $(\mathrm{m}, 4 \mathrm{H}), 0.81(\mathrm{t}, 3 \mathrm{H}, \mathrm{J}=7.2 \mathrm{~Hz}) .{ }^{13} \mathrm{C}\left\{{ }^{1} \mathrm{H}\right\} \mathrm{NMR}\left(150 \mathrm{MHz}, \mathrm{CDCl}_{3}\right) \delta 210.3,142.4(\mathrm{~d}$, $\mathrm{J}=7.2 \mathrm{~Hz}), 132.5$ (d, J=9.6 Hz), 131.8 (dd, J=6.3, 2.6 Hz), 131.6 (d, J=9.5 Hz), 128.5 (dd, J=12.3, 9.2 Hz), 128.4, 127.1, 126.4, 51.8, 50.1 (d, J=2.1 Hz), 43.8, 31.5, 28.6, 23.2, 22.4, 14.0. HRMS [ESI(TOF)] for $\mathrm{C}_{27} \mathrm{H}_{33} \mathrm{NO}_{2} \mathrm{P}\left[\mathrm{M}+\mathrm{H}^{+}\right]: \mathrm{m} / \mathrm{z}$ : calcd for: 434.2249; found: 434.2250 .

$N$-(3-cyclopropyl-3-oxo-1-phenylpropyl)-P,P-diphenylphosphinic amide, 2 f.<smiles>O=C(CC(NP(=O)(O)c1ccccc1)c1ccccc1)C1CC1</smiles>

2f, $71 \%$ 
White solid, Mp 174-176oC, $163 \mathrm{mg}$ (prepared from $0.59 \mathrm{mmol}$ amine), 71\% yield. ${ }^{1} \mathrm{H}$ NMR $\left(600 \mathrm{MHz}, \mathrm{CDCl}_{3}\right) \delta 7.83(\mathrm{~m}, 2 \mathrm{H}), 7.78(\mathrm{~m}, 2 \mathrm{H}), 7.46(\mathrm{~m}, 1 \mathrm{H}), 7.40(\mathrm{~m}, 3 \mathrm{H})$, $7.32(\mathrm{~m}, 2 \mathrm{H}), 7.27(\mathrm{~m}, 4 \mathrm{H}), 7.20(\mathrm{~m}, 1 \mathrm{H}), 4.60(\mathrm{~m}, 1 \mathrm{H}), 4.45(\mathrm{~s}, 1 \mathrm{H}), 3.30(\mathrm{~d}, 2 \mathrm{H}$, $\mathrm{J}=5.4 \mathrm{~Hz}), 1.76(\mathrm{~m}, 1 \mathrm{H}), 0.89(\mathrm{~m}, 1 \mathrm{H}), 0.76(\mathrm{~m}, 3 \mathrm{H}) .{ }^{13} \mathrm{C}\left\{{ }^{1} \mathrm{H}\right\}$ NMR $(150 \mathrm{MHz}$ $\left.\mathrm{CDCl}_{3}\right) \delta 209.6,142.5(\mathrm{~d}, \mathrm{~J}=6.9 \mathrm{~Hz}), 132.4(\mathrm{~d}, \mathrm{~J}=9.6 \mathrm{~Hz}), 131.8(\mathrm{dd}, \mathrm{J}=7.5,2.7 \mathrm{~Hz})$ $131.6(\mathrm{~d}, \mathrm{~J}=9.5 \mathrm{~Hz}), 128.5(\mathrm{~d}, \mathrm{~J}=11 \mathrm{~Hz}), 128.4,127.1,126.4,51.8,50.7$ (d, J=2.1 Hz), 21.5, 11.0. HRMS [ESI(TOF)] for $\mathrm{C}_{24} \mathrm{H}_{25} \mathrm{NO}_{2} \mathrm{P}\left[\mathrm{M}+\mathrm{H}^{+}\right]$: $\mathrm{m} / \mathrm{z}$ : calcd for: 390.1623; found: 390.1623 .

$N$-(3-cyclopentyl-3-oxo-1-phenylpropyl)-P,P-diphenylphosphinic amide, $2 \mathrm{~g}$.<smiles>O=C(CC(NP(=O)(O)c1ccccc1)c1ccccc1)C1CCCC1</smiles>

$2 g, 50 \%$

White solid, Mp $174-177^{\circ} \mathrm{C}, 114 \mathrm{mg}$ (prepared from $0.549 \mathrm{mmol}$ amine), $50 \%$ yield. ${ }^{1} \mathrm{H}$ NMR (600 MHz, $\left.\mathrm{CDCl}_{3}\right) \delta 7.84(\mathrm{~m}, 2 \mathrm{H}), 7.78(\mathrm{~m}, 2 \mathrm{H}), 7.47(\mathrm{~m}, 1 \mathrm{H}), 7.41(\mathrm{~m}, 3 \mathrm{H})$, $7.33(\mathrm{~m}, 2 \mathrm{H}), 7.27(\mathrm{~d}, 4 \mathrm{H}, \mathrm{J}=4.2 \mathrm{~Hz}), 7.20(\mathrm{~m}, 1 \mathrm{H}), 4.59(\mathrm{~m}, 2 \mathrm{H}), 3.18(\mathrm{~m}, 2 \mathrm{H}), 2.66$ (m, 1H), $1.51(\mathrm{~m}, 8 \mathrm{H}) .{ }^{13} \mathrm{C}\left\{{ }^{1} \mathrm{H}\right\}$ NMR $\left(150 \mathrm{MHz}, \mathrm{CDCl}_{3}\right) \delta 212.3,142.5(\mathrm{~d}, \mathrm{~J}=7.2$ Hz), $132.5(\mathrm{~d}, \mathrm{~J}=9.6 \mathrm{~Hz}), 131.8(\mathrm{dd}, \mathrm{J}=6.6,2.6 \mathrm{~Hz}), 131.6(\mathrm{~d}, \mathrm{~J}=9.5 \mathrm{~Hz}), 128.5$ (dd, $\mathrm{J}=12.5,9.3 \mathrm{~Hz}), 128.4,127.1,126.3,52.1,51.9,49.1,28.1(\mathrm{~d}, \mathrm{~J}=17.4 \mathrm{~Hz}), 25.8(\mathrm{~d}$, $\mathrm{J}=11.7 \mathrm{~Hz}$ ). HRMS [ESI(TOF)] for $\mathrm{C}_{26} \mathrm{H}_{27} \mathrm{NO}_{2} \mathrm{P}\left[\mathrm{M}+\mathrm{H}^{+}\right]$: m/z: calcd for: 400.1830; found: 400.1828 .

$N$-(3-cyclohexyl-3-oxo-1-phenylpropyl)-P,P-diphenylphosphinic amide, $2 \mathrm{~h}$.<smiles>O=C(CC(NP(=O)(O)c1ccccc1)c1ccccc1)C1CCCCC1</smiles>

$2 \mathrm{~h}, 53 \%$ 
White solid, Mp $159-162^{\circ} \mathrm{C}, 141 \mathrm{mg}$ (prepared from $0.617 \mathrm{mmol}$ amine), $53 \%$ yield. ${ }^{1} \mathrm{H}$ NMR $\left(600 \mathrm{MHz}, \mathrm{CDCl}_{3}\right) \delta 7.83(\mathrm{~m}, 2 \mathrm{H}), 7.78(\mathrm{~m}, 2 \mathrm{H}), 7.46(\mathrm{~m}, 1 \mathrm{H}), 7.41(\mathrm{~m}, 3 \mathrm{H})$, $7.32(\mathrm{~m}, 2 \mathrm{H}), 7.26(\mathrm{~d}, 4 \mathrm{H}, \mathrm{J}=4.8 \mathrm{~Hz}), 7.19(\mathrm{~m}, 1 \mathrm{H}), 4.56(\mathrm{~m}, 2 \mathrm{H}), 3.18(\mathrm{~m}, 2 \mathrm{H}), 2.10$ $(\mathrm{m}, 1 \mathrm{H}), 1.65(\mathrm{~m}, 3 \mathrm{H}), 1.56(\mathrm{~m}, 2 \mathrm{H}), 1.10(\mathrm{~m}, 5 \mathrm{H}) .{ }^{13} \mathrm{C}\left\{{ }^{1} \mathrm{H}\right\}$ NMR $\left(150 \mathrm{MHz}, \mathrm{CDCl}_{3}\right)$ $\delta 213.2,142.5$ (d, J=7.1 Hz), 132.5 (d, J=9.6 Hz), 131.8 (dd, J=6.2, $2.7 \mathrm{~Hz}), 131.6$ (d, $\mathrm{J}=9.6 \mathrm{~Hz}), 128.5(\mathrm{dd}, \mathrm{J}=12.5,9 \mathrm{~Hz}), 128.3,127.0,126.4,51.8,51.4,48.0,27.7$ (d, $\mathrm{J}=10.2 \mathrm{~Hz}), 25.7,25.4$. HRMS [ESI(TOF) $]$ for $\mathrm{C}_{27} \mathrm{H}_{31} \mathrm{NO}_{2} \mathrm{P}\left[\mathrm{M}+\mathrm{H}^{+}\right]$: $\mathrm{m} / \mathrm{z}$ : calcd for: 432.2092; found: 432.2089 .

$N$-(3-(cyclohex-1-en-1-yl)-3-oxo-1-phenylpropyl)-P,P-diphenylphosphinic amide, 2i.<smiles>O=C(CC(NP(=O)(O)c1ccccc1)c1ccccc1)C1=CCCCC1</smiles>

$2 \mathbf{i}, 65 \%$

White solid, Mp 115-118oC, $172 \mathrm{mg}$ (prepared from $0.616 \mathrm{mmol}$ amine), 65\% yield. ${ }^{1} \mathrm{H}$ NMR (600 MHz, $\left.\mathrm{CDCl}_{3}\right) \delta 7.84(\mathrm{~m}, 2 \mathrm{H}), 7.80(\mathrm{~m}, 2 \mathrm{H}), 7.45(\mathrm{~m}, 1 \mathrm{H}), 7.39(\mathrm{~m}, 3 \mathrm{H})$, $7.32(\mathrm{~m}, 2 \mathrm{H}), 7.28(\mathrm{~m}, 2 \mathrm{H}), 7.26(\mathrm{~m}, 2 \mathrm{H}), 7.18(\mathrm{t}, 1 \mathrm{H}, \mathrm{J}=7.2 \mathrm{~Hz}), 6.77(\mathrm{~s}, 1 \mathrm{H}), 4.62$ (m, 1H), $4.54(\mathrm{~m}, 1 \mathrm{H}), 3.43(\mathrm{dd}, 1 \mathrm{H}, \mathrm{J}=16.8,4.2 \mathrm{~Hz}), 3.34(\mathrm{dd}, 1 \mathrm{H}, \mathrm{J}=15.6,6 \mathrm{~Hz})$, $2.12(\mathrm{~m}, 2 \mathrm{H}), 2.04(\mathrm{~m}, 2 \mathrm{H}), 1.50(\mathrm{~m}, 4 \mathrm{H}) .{ }^{13} \mathrm{C}\left\{{ }^{1} \mathrm{H}\right\}$ NMR $\left(150 \mathrm{MHz}, \mathrm{CDCl}_{3}\right) \delta 199.7$, 142.7 (d, J=6.9 Hz), 141.1, 139.3, 132.4 (d, J=9.5 Hz), 131.8 (d, J=2.7 Hz), 131.7 (d, $\mathrm{J}=9.6 \mathrm{~Hz}), 128.4(\mathrm{dd}, \mathrm{J}=12.5,6.8 \mathrm{~Hz}), 128.3,126.9,126.5,52.3,44.7$ (d, J=2.3 Hz), 26.0, 22.7, 21.7, 21.3. HRMS [ESI(TOF)] for $\mathrm{C}_{27} \mathrm{H}_{29} \mathrm{NO}_{2} \mathrm{P}\left[\mathrm{M}+\mathrm{H}^{+}\right]$: $\mathrm{m} / \mathrm{z}$ : calcd for: 430.1936; found: 430.1938 . 
$N$-(6-chloro-3-oxo-1-phenylhexyl)-P,P-diphenylphosphinic amide, 2 j.<smiles>O=C(CC(NP(=O)(c1ccccc1)c1ccccc1)c1ccccc1)NCl</smiles>

$2 \mathrm{j}, 45 \%$

White solid, Mp 137-140oC, $172 \mathrm{mg}$ (prepared from $0.744 \mathrm{mmol}$ amine), $45 \%$ yield. ${ }^{1} \mathrm{H}$ NMR $\left(600 \mathrm{MHz}, \mathrm{CDCl}_{3}\right) \delta 7.82(\mathrm{~m}, 2 \mathrm{H}), 7.78(\mathrm{~m}, 2 \mathrm{H}), 7.43(\mathrm{~m}, 4 \mathrm{H}), 7.34(\mathrm{~m}, 2 \mathrm{H})$, $7.27(\mathrm{~m}, 4 \mathrm{H}), 7.22(\mathrm{~m}, 1 \mathrm{H}), 4.59(\mathrm{~m}, 1 \mathrm{H}), 4.31(\mathrm{~s}, 1 \mathrm{H}), 3.39(\mathrm{dt}, 2 \mathrm{H}, \mathrm{J}=6,1.8 \mathrm{~Hz})$ $3.16(\mathrm{~d}, 2 \mathrm{H}, \mathrm{J}=6 \mathrm{~Hz}), 2.47(\mathrm{~m}, 1 \mathrm{H}), 2.39(\mathrm{~m}, 1 \mathrm{H}), 1.87(\mathrm{~m}, 2 \mathrm{H}) .{ }^{13} \mathrm{C}\left\{{ }^{1} \mathrm{H}\right\}$ NMR $(150$ $\left.\mathrm{MHz}, \mathrm{CDCl}_{3}\right) \delta 208.5,142.2(\mathrm{~d}, \mathrm{~J}=7.1 \mathrm{~Hz}), 132.5$ (d, J=9.6 Hz), 131.9 (dd, J=6.5, 2.6 Hz), $131.6(d, J=9.3 \mathrm{~Hz}), 128.55,128.51$ (dd, J=8.9, $3.8 \mathrm{~Hz}), 127.3,126.3,51.7,50.5$ (d, J=2.1 Hz), 44.1, 40.4, 25.9. HRMS [ESI(TOF)] for $\mathrm{C}_{24} \mathrm{H}_{26} \mathrm{NO}_{2} \mathrm{PCl}\left[\mathrm{M}+\mathrm{H}^{+}\right]: \mathrm{m} / \mathrm{z}$ : calcd for: 426.1390; found: 426.1388 .

$N$-(3-oxo-1,5-diphenylpentyl)-P,P-diphenylphosphinic amide, 2 k.<smiles>O=C(CCc1ccccc1)CC(NP(=O)(O)c1ccccc1)c1ccccc1</smiles>

$2 \mathbf{k}, 58 \%$

White solid, Mp 147-149oC, $149 \mathrm{mg}$ (prepared from $0.568 \mathrm{mmol}$ amine), 58\% yield. ${ }^{1} \mathrm{H}$ NMR $\left(600 \mathrm{MHz}, \mathrm{CDCl}_{3}\right) \delta 7.82(\mathrm{~m}, 4 \mathrm{H}), 7.48(\mathrm{t}, 1 \mathrm{H}, \mathrm{J}=7.2 \mathrm{~Hz}), 7.41(\mathrm{~m}, 3 \mathrm{H})$, 7.34 (m, 2H), 7.23 (m, 7H), 7.14 (t, 1H, J=7.2 Hz), 7.02 (d, 2H, J=7.8 Hz), 4.59 (m, 1H), 4.38 (s, 1H), 3.15 (d, 2H, J=4.8 Hz), $2.73(\mathrm{t}, 2 \mathrm{H}, \mathrm{J}=7.2 \mathrm{~Hz}), 2.61(\mathrm{~m}, 1 \mathrm{H}), 2.52$ (m, 1H). ${ }^{13} \mathrm{C}\left\{{ }^{1} \mathrm{H}\right\}$ NMR $\left(150 \mathrm{MHz}, \mathrm{CDCl}_{3}\right) \delta 208.9,142.3(\mathrm{~d}, \mathrm{~J}=7.1 \mathrm{~Hz}), 140.6$, 132.5 (d, J=9.5 Hz), 131.9 (dd, J=5.9, 2.6 Hz), 131.6 (d, J=9.5 Hz), 128.56 (d, J=12.5 
$\mathrm{Hz}), 128.50,128.4,128.2,127.2,126.4,126.0,51.7,50.4,45.2,29.2$. HRMS [ESI(TOF)] for $\mathrm{C}_{29} \mathrm{H}_{29} \mathrm{NO}_{2} \mathrm{P}\left[\mathrm{M}+\mathrm{H}^{+}\right.$]: $\mathrm{m} / \mathrm{z}$ : calcd for: 454.1936; found: 454.1925 .

Characterization of the chiral $\beta$-amino ketone products $(R)-2$ a

(R)-N-(3-oxo-1-phenylheptyl)-P,P-diphenylphosphinic amide, $(R)-2$ a.<smiles>CC(C)CC(NP(=O)(O)c1ccccc1)c1ccccc1</smiles>

(R)-2a

$60 \%, 85 \%$ ee

White solid, Mp $155-157^{\circ} \mathrm{C}, 125.6 \mathrm{mg}$ (prepared from $0.517 \mathrm{mmol}$ amine), $60 \%$ yield. 85\% ee determined by HPLC analysis: CHIRALCEL OD-H column, 90:10 hexanes: ${ }^{i} \mathrm{PrOH}$, flow rate $=1.0 \mathrm{~mL} / \mathrm{min}, \lambda=230 \mathrm{~nm}$, retention time: $\mathrm{t}_{\text {major }}=7.9 \mathrm{~min}, \mathrm{t}_{\text {minor }}=$ $14.4 \min . \quad[\alpha]^{23}{ }_{\mathrm{D}}=-66.8\left(\mathrm{c}=1.45, \mathrm{CHCl}_{3}\right) .{ }^{1} \mathrm{H}$ NMR $\left(600 \mathrm{MHz}, \mathrm{CDCl}_{3}\right) \delta 7.80(\mathrm{~m}$, 4H), $7.43(\mathrm{~m}, 4 \mathrm{H}), 7.27(\mathrm{~m}, 7 \mathrm{H}), 4.58(\mathrm{~m}, 1 \mathrm{H}), 4.47(\mathrm{~s}, 1 \mathrm{H}), 3.14(\mathrm{~m}, 2 \mathrm{H}), 2.24(\mathrm{~m}$, 1H), $2.19(\mathrm{~m}, 1 \mathrm{H}), 1.36(\mathrm{~m}, 2 \mathrm{H}), 1.13(\mathrm{~m}, 2 \mathrm{H}), 0.78(\mathrm{t}, 3 \mathrm{H}, \mathrm{J}=7.2 \mathrm{~Hz}) .{ }^{13} \mathrm{C}\left\{{ }^{1} \mathrm{H}\right\} \mathrm{NMR}$ $\left(150 \mathrm{MHz}, \mathrm{CDCl}_{3}\right) \delta 210.2,142.4(\mathrm{~d}, \mathrm{~J}=7.2 \mathrm{~Hz}), 132.5(\mathrm{~d}, \mathrm{~J}=9.6 \mathrm{~Hz}), 131.8(\mathrm{dd}, \mathrm{J}=6.3$, $2.6 \mathrm{~Hz}), 131.6$ (d, J=9.5 Hz), 128.5 (dd, J=12.5, 9.3 Hz), 128.4, 127.1, 126.4, 51.8, 50.1, 43.5, 25.3, 22.0, 13.7. HRMS [ESI(TOF)] for $\mathrm{C}_{25} \mathrm{H}_{29} \mathrm{NO}_{2} \mathrm{P}\left[\mathrm{M}+\mathrm{H}^{+}\right]: \mathrm{m} / \mathrm{z}$ : calcd for: 406.1936; found: 406.1932 .

\section{Diastereoselective reduction of the racemic $\beta$-amino ketone $2 \mathrm{i}$}

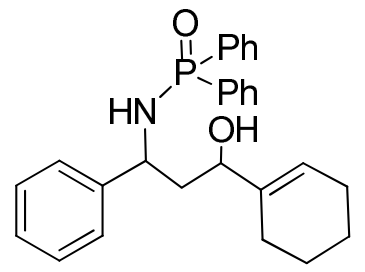

$3 \mathbf{i}, 86 \%, \mathrm{dr}=2.3: 1$ 
Under nitrogen, the $\beta$-amino ketone $2 \mathbf{i}(0.152 \mathrm{mmol}, 65.1 \mathrm{mg}, 1$ equiv) was dissolved in $2 \mathrm{~mL}$ THF and cooled to $-40{ }^{\circ} \mathrm{C} . \mathrm{Zn}\left(\mathrm{BH}_{4}\right)_{2}(0.76 \mathrm{mmol}, 0.3 \mathrm{M}$ in THF, $2.5 \mathrm{~mL}, 5$ equiv) was then added dropwise and the reaction mixture was stirred for $1 \mathrm{~h}$ at $-40{ }^{\circ} \mathrm{C}$. Then, the reaction was warmed to $0{ }^{\circ} \mathrm{C}$ and the stirring continued for another $1 \mathrm{~h}$. The reaction was quenched with the addition of water $(2 \mathrm{~mL})$ at $0{ }^{\circ} \mathrm{C}$ and extracted with dichloromethane $(3 \times 4 \mathrm{~mL})$. The organic phase was dried with anhydrous $\mathrm{Na}_{2} \mathrm{SO}_{4}$, filtered and then concentrated by rotary evaporation. The crude mixture was purified by flash column chromatography on silica gel with hexanes/ethyl acetate (1/1) to give the 1,3-amino alcohol $\mathbf{3 i}$ as colorless oil in $86 \%$ yield $(56.3 \mathrm{mg})$ and with 2.3:1 diastereomeric ratio. ${ }^{1} \mathrm{H} \mathrm{NMR}\left(600 \mathrm{MHz}, \mathrm{CDCl}_{3}\right) \delta$ $7.85(\mathrm{~m}, 2 \mathrm{H}), 7.70(\mathrm{~m}, 2 \mathrm{H}), 7.50(\mathrm{t}, 1 \mathrm{H}, \mathrm{J}=7.8 \mathrm{~Hz}), 7.42(\mathrm{~m}, 3 \mathrm{H}), 7.27(\mathrm{~m}, 5 \mathrm{H}), 7.13$ (d, 2H, J=7.2 Hz), $5.67(\mathrm{~s}, 1 \mathrm{H}), 4.42(\mathrm{~m}, 1 \mathrm{H}), 4.33$ (d, 1H, J=10.2 Hz), 3.45 (t, 1H, $\mathrm{J}=9.6 \mathrm{~Hz}), 1.97(\mathrm{~m}, 5 \mathrm{H}), 1.77(\mathrm{~m}, 1 \mathrm{H}), 1.53(\mathrm{~m}, 5 \mathrm{H}) .{ }^{13} \mathrm{C}\left\{{ }^{1} \mathrm{H}\right\}$ NMR $(150 \mathrm{MHz}$ $\left.\mathrm{CDCl}_{3}\right) \delta 144.3(\mathrm{~d}, \mathrm{~J}=6.2 \mathrm{~Hz}), 139.5,132.8(\mathrm{~d}, \mathrm{~J}=9.9 \mathrm{~Hz}), 132.0(\mathrm{dd}, \mathrm{J}=30.2,2.4 \mathrm{~Hz})$ $131.5(\mathrm{~d}, \mathrm{~J}=9.8 \mathrm{~Hz}), 128.5,128.4(\mathrm{dd}, \mathrm{J}=52.1,12.5 \mathrm{~Hz}), 126.9,126.0,121.7,70.8$, 52.3, 45.5, 24.9, 24.6, 22.7, 22.6. HRMS [ESI(TOF)] for $\mathrm{C}_{27} \mathrm{H}_{30} \mathrm{NO}_{2} \mathrm{PNa}\left[\mathrm{M}+\mathrm{Na}^{+}\right]$: m/z: calcd for: 454.1912; found: 454.1906 . 


\section{References}

1. (a) Havey, D. F.; Sigano, D. M. J. Org. Chem. 1996, 61, 2268-2272. (b) Arcadi, A.; Cacchi, S.; Cascia, L.; Fabrizi, G.; Marinelli, F. Org. Lett. 2001, 3, 2501-2504. (c) Yoon, T.; Shair, M. D.; Danishefsky, S. J.; Shulte, G. K. J. Org. Chem. 1994, 59, 3752-3754. (d) Fleming, J. J.; Bois, J. D. J. Am. Chem. Soc. 2006, 128, 3926-3927. (e) Shibasaki, M. ; Ishida, Y. ; Iwasaki, G. ; Limori, T. J. Org. Chem. 1987, 52, 3488-3489. (f) Hoepping, A.; Johnson, K. M.; George, C.; Flippen-Anderson, J.; Kozikowski, A. P. J. Med. Chem. 2000, 43, 2064-2071.

2. Zani, L. ; Bolm, C. Chem. Commun. 2006, 4263-4275.

3. (a) $\mathrm{Pu}, \mathrm{L}$. Tetrahedron 2003, 59, 9873-9886. (b) Pu, L.; Yu, H. -B. Chem. Rev. 2001, 101, 757-824. (c) Cozzi, P. G.; Hilgraf, R.; Zimmermann, N. Eur. J. Org. Chem. 2004, 4095-4105. (d) Trost, B.M.; Weiss, A.H. Adv. Synth. Catal. 2009, 351, 963-983. (e) Blay, G.; Monleón, A.; Pedro, J. R. Curr. Org. Chem. 2009, 13, 1498-1539.

4. Frantz, D. E.; Fässler, R.; Carreira, E. M. J. Am. Chem. Soc. 1999, 121, $11245-11246$.

5. Topić, D.; Aschwanden, P.; Fässler, R.; Carreira, E. M. Org. Lett. 2005, 7, 5329-5330.

6. Pinet, S.; Pandya, S. U.; Chavant, P. Y.; Ayling, A.; Vallee, Y. Org. Lett. 2002, 4, 1463-1466.

7. (a) Yan, W.; Mao, B.; Zhu, S.; Jiang, X.; Liu, Z.; Wang, R. Eur. J. Org. Chem. 
2009, 3790-3794; (b) Zhu, S.; Yan, W.; Mao, B.; Jiang, X.; Wang, R. J. Org. Chem. 2009, 74, 6980-6985. (c) Yan, W.; Li, P.; Feng, J.; Wang, D.; Zhu, S.; Jiang, X.; Wang, R. Tetrahedron: Asymmetry 2010, 21, 2037-2042.

8. Blay, G.; Ceballos, E.; Monleón, A.; Pedro, J. R. Tetrahedron 2012, 68, $2128-2134$.

9. Zani, L.; Alesi, S.; Cozzi, P. G.; Bolm, C. J. Org. Chem. 2006, 71, 1558-1562.

10. (a) Rudolph, J.; Rasmussen, T.; Bolm, C.; Norrby, P. -O. Angew. Chem. Int. Ed. 2003, 42, 3002-3005. (b) Rasmussen, T.; Norrby, P. -O. J. Am. Chem. Soc. 2003, 125, 5130-5138. (c) Rudolph, J.; Bolm, C.; Norrby, P. -O. J. Am. Chem. Soc. 2005, $127,1548-1552$.

11. (a) Alonso, F.; Beletskaya, I. P.; Yus, M. Chem. Rev. 2004, 104, 3079-3159. (b) Hintermann, L.; Labonne, A. Synthesis 2007, 1121-1150. (c) Kutscheroff, M. Chem. Ber. 1881, 14, 1540-1542.

12. (a) Ackermann, L.; Kaspar, L. T.; J. Org. Chem. 2007, 72, 6149-6153. (b) Halpern, J.; James, B. R.; Kemp, A. L. W. J. Am. Chem. Soc. 1961, 83, 4097-4098.

13. Kanemitsu, H. ; Uehara, K. ; Fukuzumi, S. ; Ogo, S. J. Am. Chem. Soc. 2008, 130, $17141-17147$

14. (a) Xu, C. ; Du, W. ; Zeng, Y. ; Dai, B. ; Guo, H. Org. Lett. 2014, 16, 948-951. (b) Shimada, T.; Bajracharya, G. B.; Yamamoto, Y. Eur. J. Org. Chem. 2005, 59-62; (c) Shimada, T.; Yamamoto, Y. J. Am. Chem. Soc. 2002, 124, 12670-12671.

15. (a) Hiscox, W.; Jennings, P. W. Organometallics 1990, 9, 1997-1999. (b) Baidossi, W.; Lahav, M.; Blum, J. J. Org. Chem. 1997, 62, 669-672. 
16. Easton, N. R.; Cassady, D. R.; Dillard, R. D. J. Org. Chem. 1965, 30, 3084-3088.

17. (a) Casado, R.; Contel, M.; Laguna, M.; Romero, P.; Sanz, S. J. Am. Chem. Soc. 2003, 125, 11925-11935. (b) Mizushima, E. ; Sato, K. ; Hayashi, T. ; Tanaka, M. Angew. Chem. Int. Ed. 2002, 41, 4563-4565. (c) Fukuda, Y.; Utimoto, K. J. Org. Chem. 1991, 56, 3729-3731.

18. Rajaram, A. R.; Pu, L. Org. Lett. 2006, 8, 2019-2021.

19. Wang, W.; Xu, B.; Hammond, G. B. J. Org. Chem. 2009, 74, 1640-1643.

20. Ghosh, N.; Nayak, S.; Sahoo, A. K. J. Org. Chem. 2011, 76, 500-511.

21. Ghosh, N.; Nayak, S.; Prabagar, B.; Sahoo, A. K. J. Org. Chem. 2014, 79, 2453-2462.

22. Pradhan, T. R.; Mendhekar, K. L.; Mohapatra, D. K. J. Org. Chem. 2015, 80, $5517-5531$.

23. Zhang, Z.; Wu, L.; Liao, J.; Wu, W.; Jiang, H.; Li, J.; Li, J. J. Org. Chem. 2015, 80, 7594-7603.

24. Gommermann, N.; Knochel, P. Tetrahedron 2005, 61, 11418-11426.

25. Dube, H.; Gommermann, N.; Knochel, P. Synthesis, 2004, 12, 2015-2025.

26. Gommermann, N.; Gehrig, A.; Knochel, P. Synlett, 2005, 18, 2796-2798.

27. Colombo, F.; Benaglia, M.; Orlandi, S.; Usuelli, F.; Celentano, G. J. Org. Chem. 2006, 71, 2064-2070.

28. Arend, M.; Westermann, B.; Risch, N. Angew. Chem. Int. Ed. 1998, 37, 1044-1070.

29. Miura, K.; Tamaki, K.; Nakagawa, T.; Hosomi, A. Angew. Chem. Int. Ed. 2000, 39, 
1958-1960.

30. Gomtsyan, A. Org. Lett. 2000, 2, 11-13. 


\section{Chapter 6. Attempted Research: Asymmetric Reformatsky Reaction Catalyzed by the $\mathrm{H}_{8}$ BINOL-based Ligands}

\subsection{Introduction}

The classical Reformatsky reaction, first introduced in 1887 , is a zinc-induced reaction between $\alpha$-halogenated esters and aldehydes or ketones, forming $\beta$-hydroxyesters. ${ }^{1-3}$ Currently, Reformatsky reactions are broadly defined as all the transformations that result from metal insertions of activated $\alpha$-halocarbonyl compounds and subsequent addition to various electrophiles.

The Reformatsky reaction is one of the most powerful methods for the formation of carbon-carbon bonds. It is an important alternative to the aldol reaction, generating $\beta$-hydroxy carbonyl compounds. Compared with the strong base or acid-induced aldol reaction, the Reformatsky reaction is performed under mild reaction conditions. Therefore, its excellent functional group tolerance has contributed to the success.

However, the asymmetric version of the Reformatsky reaction is rarely reported for more than a century after its discovery. ${ }^{4-5}$ Furthermore, suffered from moderate enantioselectivity, high loading amounts of ligands and tough conditions, its application in organic synthesis, especially total synthesis of natural products, was limited.

The major difficulty to develop catalysts for the asymmetric Reformatsky reaction is attributed to its heterogeneous character. In recent years, the introduction of $\mathrm{Me}_{2} \mathrm{Zn}$ and $\mathrm{Et}_{2} \mathrm{Zn}$ as zinc sources allowed the development of the homogeneous 
Reformatsky reaction and provided the possibilities to achieve high enantioselectivity. ${ }^{6-9}$

In 2006, Cozzi reported the first enantioselective Reformatsky reaction with ketones catalyzed by the chiral $\left[\mathrm{MnCl}\left(\right.\right.$ salen)] complex $\mathbf{6 . 1}$ and $\mathrm{Me}_{2} \mathrm{Zn} .{ }^{10}$ The zinc enolate was prepared in-situ from ethyl iodoacetate and $\mathrm{Me}_{2} \mathrm{Zn}$ under homogeneous conditions. The reaction proceeded at room temperature with moderate to good enantioselectivity for a broad range of ketones, including aromatic ketones $(69-86 \%$ ee), aliphatic ketones $(23-86 \%$ ee) and $\alpha, \beta$-unsaturated ketones (up to $75 \%$ ee). Addition of 4-phenylpyridine $\mathrm{N}$-oxide enhanced the enantioselectivity (Scheme 6.1).

Scheme 6.1. The $\mathrm{Me}_{2} \mathrm{Zn}$-mediated Reformatsky reaction catalyzed by [ $\left.\mathrm{MnCl}(\mathrm{salen})\right]$

6.1
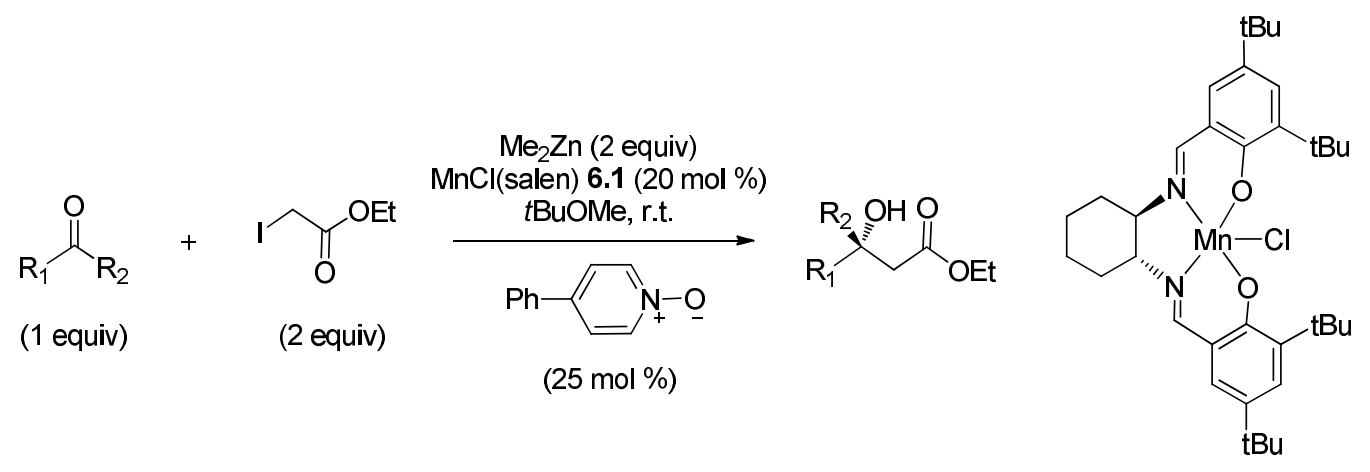

$\mathrm{MnCl}($ salen) 6.1

In the same year, Cozzi described the first catalytic, enantioselective, one-pot, three-component imino-Reformatsky reaction in the presence of $N$-methylephedrine 6.2 and $\mathrm{Me}_{2} \mathrm{Zn} .{ }^{11}$ The imines were prepared in-situ from the corresponding aldehydes and anilines, using $\mathrm{Me}_{2} \mathrm{Zn}$ as the dehydrating reagent. The admission of air into the mixture of an imine, ethyl iodoacetate, $\mathrm{Me}_{2} \mathrm{Zn}$ and $\mathrm{N}$-methylephedrine $\mathbf{6 . 2}$ promoted the Reformatsky reaction to give various $\beta$-amino esters with excellent yield (up to 
$92 \%$ ee) and enantioselectivity (83-94\%) (Scheme 6.2). ${ }^{11}$

Scheme 6.2. The enantioselective three-component imino-Reformatsky reaction

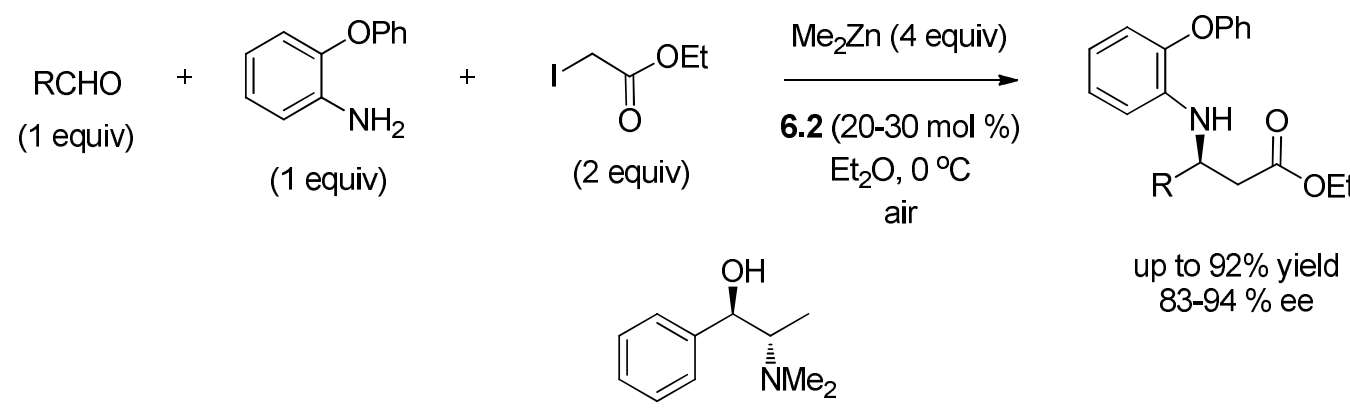

$N$-methylephedrine 6.2

A catalytic enantioselective Reformatsky reaction with aldehydes proved to be more challenging due to its higher reactivity. Only a few examples of enantioselective Reformatsky reaction with aldehydes have been reported to date. ${ }^{12-16}$

In 2008, Feringa developed the first catalytic enantioselective Reformatsky reaction with aldehydes which proceeded with good yield (60-87\%) and enantioselectivity (54-84\% ee) (Scheme 6.3). ${ }^{12}$ The 3, 3'-BINOL derivative ligand 6.3 was used to catalyze this reaction with the use of $\mathrm{Me}_{2} \mathrm{Zn}$ as the zinc source. The presence of air was found crucial to initiate a radical reaction with $\mathrm{Me}_{2} \mathrm{Zn}$, which promoted the reaction efficiently. Also, slow addition of aldehyde was required to obtain high enantioselectivity.

Scheme 6.3. The Reformatsky reaction of aldehydes catalyzed by the 3, 3'-BINOL derivative ligand 6.3

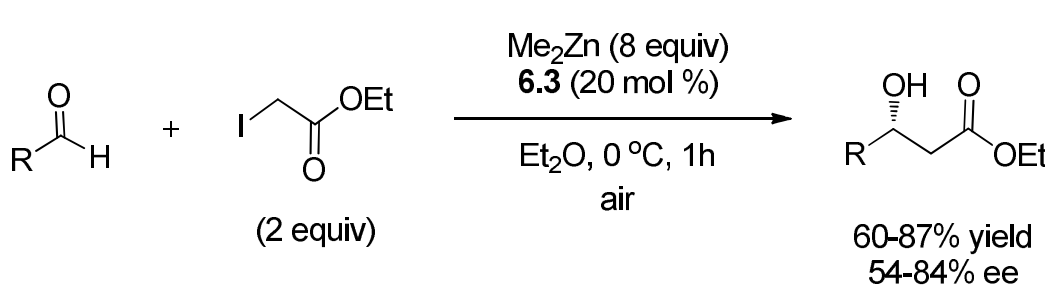<smiles>CC(C)(C)c1cc2ccccc2c(-c2c(O)c(S(C)(=O)=O)cc3ccccc23)c1O</smiles>

6.3

The authors proposed a radical mechanism to explain this air-promoted 
Reformatsky reaction (Scheme 6.4). In the presence of air, $\mathrm{Me}_{2} \mathrm{Zn}$ forms alkyl peroxides ( $\mathrm{ZnMeOOMe}$ ) that are able to initiate radical reactions, such as the formation of methyl radical, promoter of the catalytic cycle. ${ }^{17-20}$

Scheme 6.4. Proposed mechanism for the air-promoted Reformatsky reaction

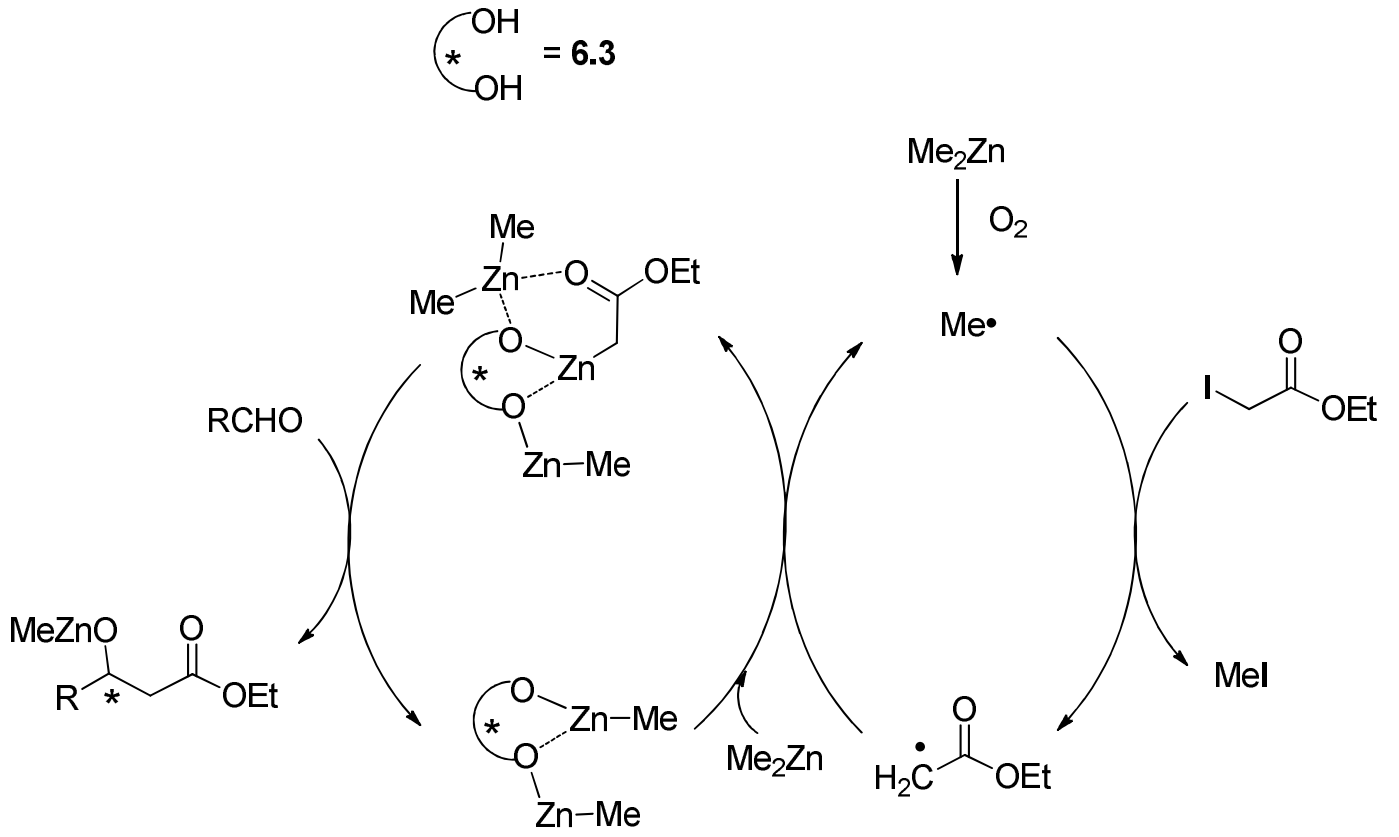

In 2011, Wolf reported the asymmetric Reformatsky reaction with aldehydes catalyzed by the chiral bisoxazolidine 6.4 (Scheme 6.5$).{ }^{15}$ In the presence of $10 \mathrm{~mol}$ $\%$ of 6.4, $\mathrm{Me}_{2} \mathrm{Zn}$ and air, the reaction with aromatic aldehydes gave the desired $\beta$-hydroxyl esters in excellent yield (up to $94 \%$ ) and with good enantioselectivity ( $75-80 \%$ ee). However, low to moderate enantioselectivity $(26-51 \%$ ee) was obtained in the reaction with aliphatic aldehydes. In their procedure, slow addition of aldehydes was required and 8 equiv of $\mathrm{Me}_{2} \mathrm{Zn}$ had to be added in two portions to achieve high conversion. 
Scheme 6.5. The Reformatsky reaction of aldehydes catalyzed by the chiral bisoxazolidine 6.4

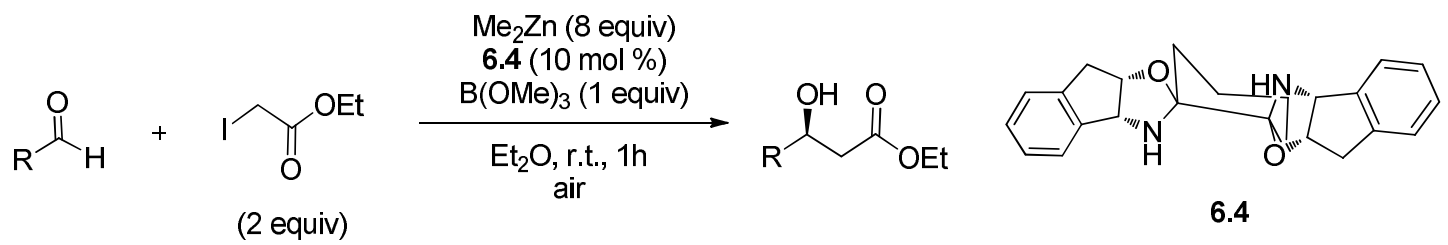

While Feringa and Wolf have developed the highly enantioselective Reformatsky reactions, these air-promoted reactions undergo a radical process which is very sensitive to unusual parameters such as the size of flask, the stirring rate and the timing of the exposure to air. These parameters are difficult to control and the results might not be easy to reproduce. In addition, the reactions require 8 equivalents $\mathrm{Me}_{2} \mathrm{Zn}$.

To avoid the use of air and better control the reaction, Cozzi reported a ${ }^{t} \mathrm{BuOOH}$-promoted enantioselective Reformatsky reaction in the presence of the aminoalcohol 6.5 and $\mathrm{Me}_{2} \mathrm{Zn}$ (Scheme 6.6). ${ }^{16} \mathrm{BuOOH}$ was employed to promote the halogen/zinc exchange. The reaction proceeded at $-25{ }^{\circ} \mathrm{C}$ with good yield (40-90\%) and enantioselectivity $(43-93 \%$ ee) for aromatic aldehydes but low to moderate enantioselectivity (40-52\% ee) for aliphatic aldehydes. The amount of $\mathrm{Me}_{2} \mathrm{Zn}$ was reduced to $1.5-2$ equiv, much less than those ( 8 equiv) in the air-promoted reactions.

Scheme 6.6. The ${ }^{t} \mathrm{BuOOH}$-promoted enantioselective Reformatsky reaction

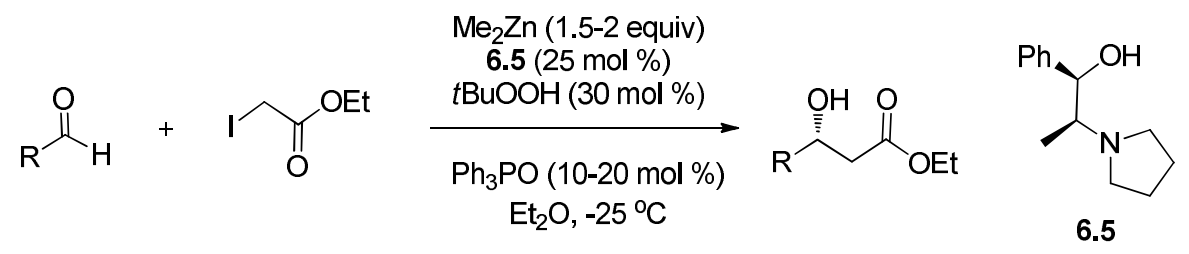

Although a few catalytic systems have been developed for the enantioselective 
Reformatsky reaction, there is still much room for improvement. The major drawbacks include: 1. A large amount of $\mathrm{Me}_{2} \mathrm{Zn}$ (8 equiv) is usually employed. 2 . The air-promoted reactions are not easy to control and reproduce. 3 . The substrate scope is limited. Besides, the asymmetric Reformatsky reaction with aliphatic aldehydes is a more challenging area and no catalytic system has been found efficient to date.

\subsection{Asymmetric reformatsky reaction catalyzed by the $\mathrm{H}_{8} \mathrm{BINOL-based} \mathrm{ligands}$}

In Feringa's work, it is assumed that the 3,3'-ditrimethylsilyl group of the ligand 6.3 serves as a blocking unit in the intermediate. ${ }^{12}$ Its size is crucial to the chiral induction. Most of our BINOL/ $\mathrm{H}_{8} \mathrm{BINOL}-$ based ligands have binding sites on the 3 , 3' positions. On the basis of the previous studies in our laboratory on the asymmetric alkyne addition to aldehydes, those substitutents contribute to the induction of enantioselectivity. The success on the catalytic asymmetric alkyne additions implies that these ligands may also have potential for use in the asymmetric Reformatsky reaction.

We have developed a series of the BINOL/ $\mathrm{H}_{8} \mathrm{BINOL}-$ based bifunctional ligands for highly enantioselective additions of alkyne, aryl and vinyl to aldehydes in the presence of zinc reagents. ${ }^{21}$ Bifunctional ligands contain both a Lewis acid center and a Lewis base center, which can activate nucleophiles and electrophiles simultaneously and control the stereochemical course of the reaction. Herein, we will describe our 
attempt to use the $\mathrm{BINOL} / \mathrm{H}_{8} \mathrm{BINOL}-$ based bifunctional ligands for the asymmetric Reformatsky reaction. We anticipate that with the use of our catalytic system, the enantioselectivity could be further improved. In addition, a large amount of zinc reagents and the use of a controlled amount of air could be avoided.

In our catalytic system, we assume that a ligand could efficiently bind both zinc-inserted haloester and aldehyde tightly, facilitate the reaction and induce the enantioselectivity. We chose ethyl iodoacetate and benzaldehyde as the substrates for initial screening of various chiral ligands. Dicyclohexylamine that has been proven very effective in the asymmetric alkyne addition to aldehydes was used as a Lewis base additive in this reaction. The experimental procedure is shown below.

In a $10 \mathrm{~mL}$ round bottom flask, THF (4 mL), a ligand (30 mol \%) and $\mathrm{Me}_{2} \mathrm{Zn}(2$ equiv) were added in dry box. The reaction mixture was stirred for $1 \mathrm{~h}$ at room temperature and then cooled to $0{ }^{\circ} \mathrm{C}$. Dicyclohexylamine (30 mol \%), ethyl iodoacetate ( 2 equiv) and benzaldehyde ( $0.35 \mathrm{mmol}, 1$ equiv) was sequentially added. The mixture was maintained at $0{ }^{\circ} \mathrm{C}$ for $24 \mathrm{~h}$.

A variety of the $\mathrm{BINOL} / \mathrm{H}_{8} \mathrm{BINOL}$-based bifunctional ligands L1-L9 were examined and the results are shown in Scheme 6.7. The reaction using $\mathbf{L} 1$ proceeded with good yield (70\%) and promising enantioselectivity $(60 \%$ ee) under this condition. No desired product was obtained when $\mathbf{L 5}$ was used. Other ligands gave very poor enantioselectivity. 
Scheme 6.7. The Reformatsky reaction by using the BINOL $/ \mathrm{H}_{8} \mathrm{BINOL}-$ based bifunctional ligands L1-L9

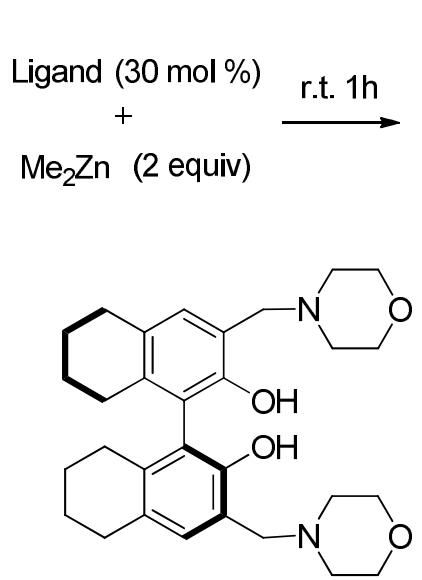

L1

$60 \%$ ee<smiles>O=Cc1cc2ccccc2c(-c2c(O)c(C=O)cc3ccccc23)c1O</smiles>

L4

$2 \%$ ee

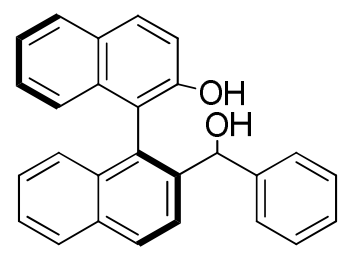

L7

$11 \%$ ee

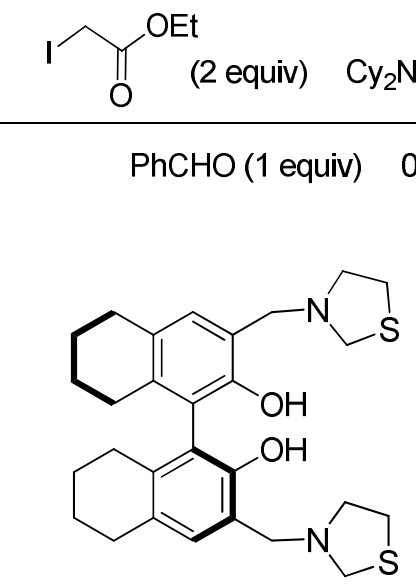

L2

$23 \% \mathrm{ee}$<smiles>O=C(c1cc2ccccc2c(-c2c(O)c(C(=O)C(F)(F)F)cc3ccccc23)c1O)C(F)(F)F</smiles>

L5 No Product<smiles>Oc1ccc2ccccc2c1-c1c(C(O)c2ccccc2)ccc2ccccc12</smiles>

L8 $7 \%$ ee<smiles>Oc1c(CN2CCCC2)cc2c(c1-c1c(O)c(CN3CCCC3)cc3c1CCCC3)CCCC2</smiles>

L3 racemic<smiles>O=C(c1ccccc1)c1cc2ccccc2c(-c2c(O)c(C(=O)c3ccccc3)cc3ccccc23)c1O</smiles>

L6 $13 \%$ ee<smiles>OCCN(c1ccccc1)c1ccc2ccccc2c1-c1c(O)ccc2ccccc12</smiles>

L9

It is hypothesized that the binding of a ligand to a zinc species is crucial before the addition of benzaldehyde. Therefore, we examined a new procedure consisting of three steps. In the first step, $\mathrm{Me}_{2} \mathrm{Zn}$ was mixed with the ligand and dicyclohexylamine to generate a zinc species. In the second step, ethyl iodoacetate was added and reacted with the zinc species to form a ligand-zinc-inserted ester complex. In the third step, 
the complex reacted with benzaldehyde to give the final addition product. The experimental procedure is shown below.

In a $10 \mathrm{~mL}$ round bottom flask, THF (4 mL), L1 (30 mol \%), $\mathrm{Me}_{2} \mathrm{Zn}$ (2 equiv) and dicyclohexylamine $(30 \mathrm{~mol} \%)$ were added in dry box. After the reaction mixture was stirred at room temperature for $1 \mathrm{~h}$ and then cooled to $0{ }^{\circ} \mathrm{C}$, ethyl iodoacetate $(2$ equiv) was added and the mixture was stirred at $0{ }^{\circ} \mathrm{C}$ for $1 \mathrm{~h}$. Benzaldehyde $(0.35$ mmol, 1 equiv) was then added and the stirring continued at $0{ }^{\circ} \mathrm{C}$ for $24 \mathrm{~h}$.

As shown in Scheme 6.8, the enantioselectivity was improved to $72 \%$ while the yield was reduced to $45 \%$. The low yield was attributed to the formation of the iodo-byproducts.

Scheme 6.8. A new procedure for the Reformatsky reaction catalyzed by $\mathbf{L 1}$

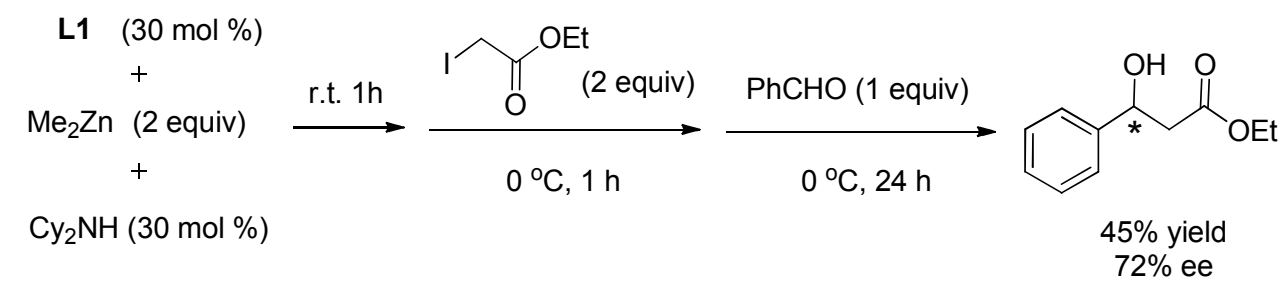

Encouraged by this result, we assume that extending the reaction time of step 1 and step 2 may promote the interaction of the ligand and the zinc-inserted ester to achieve higher enantioselectivity. When the reaction time of step 1 and step 2 was extended to $4 \mathrm{~h}$ and $6 \mathrm{~h}$, respectively, the enantioselectivity was slightly increased to $74 \%$ but the yield was significantly decreased to $10 \%$ due to the formation of more byproducts (Scheme 6.9). It indicates that in step 1 the ligand may react with ethyl iodoacetate to form the byproducts. 
Scheme 6.9. Extending the reaction time of step 1 and step 2

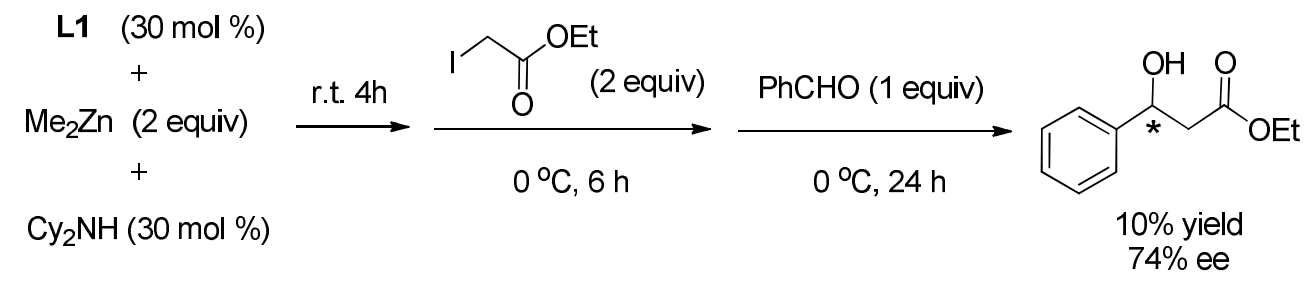

In order to avoid the formation of the iodo-byproducts and improve the yield of the desired product, the sequence for the addition of the reagents was further revised. Ethyl iodoacetate was added in step 1 and the ligand was added in step 2. The experimental procedure is shown below.

In a $10 \mathrm{~mL}$ round bottom flask, THF ( $4 \mathrm{~mL}$ ), ethyl iodoacetate (2 equiv), $\mathrm{Me}_{2} \mathrm{Zn}$ (2.6 equiv) and dicyclohexylamine (30 mol \%) were added in dry box. After the reaction mixture was stirred at room temperature for $1 \mathrm{~h}$ and cooled to $0{ }^{\circ} \mathrm{C}, \mathbf{L 1}(30$ mol \%) was added and the mixture was stirred at $0{ }^{\circ} \mathrm{C}$ for $1 \mathrm{~h}$. Benzaldehyde $(0.35$ mmol, 1 equiv) was then added and the stirring continued for $24 \mathrm{~h}$ at $0{ }^{\circ} \mathrm{C}$.

As shown in entry 1 of Scheme 6.10, good enantioselectivity (74\% ee) and high yield $(82 \%)$ were achieved by using the conditions as described above. Scheme 6.10 summarizes the screening of the reaction conditions. When benzaldehyde was added immediately after $\mathbf{L} 1$, the enantioselectivity was decreased to $60 \%$ while the yield was maintained (81\%) (entry 2). Extending the reaction time to $3 \mathrm{~h}$ in step 2 decreased the yield (34\%) but still preserved the good enantioselectivity ( $74 \%$ ee) (entry 3). Decreasing the temperature to $-10{ }^{\circ} \mathrm{C}$ in step 3 gave lower ee and yield (entry 4). Increasing to room temperature also diminished ee and yield (entry 5). When the reaction was performed at $10{ }^{\circ} \mathrm{C}$ in step $3,71 \%$ ee and $41 \%$ yield were 
observed (entry 6). Replacing $\mathrm{Me}_{2} \mathrm{Zn}$ with $\mathrm{Et}_{2} \mathrm{Zn}$ significantly reduced ee and yield with the formation of an alkyl addition byproduct (entry 7). When the alkylzinc reagents were mixed with $\mathbf{L} 1$ in step 2, lower ee and yield were obtained (entry 8,9). Increasing the amount of the solvent could also damage ee and yield (entry 10). The good enantioselectivity was preserved while the yield was decreased when the amount of the solvent was reduced (entry 11). When other solvents were used except dioxane, the ee and/or yield decreased (entries 12-16). Without the use of dicyclohexylamine as the additive, significantly reduced enantioselectivity (50\% ee) and yield (30\%) were observed (entry 17).

Scheme 6.10. Screening of the reaction conditions for the Reformatsky reaction catalyzed by $\mathbf{L} \mathbf{1}$

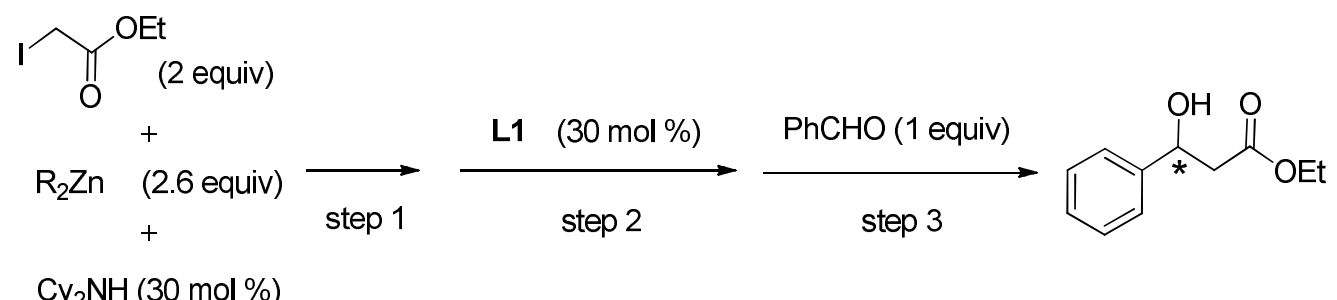

\begin{tabular}{|c|c|c|c|c|c|}
\hline entry & step 1 & step 2 & step 3 & $\begin{array}{l}\text { ee } \\
(\%)\end{array}$ & $\begin{array}{l}\text { yield } \\
(\%)\end{array}$ \\
\hline 1 & $\begin{array}{c}\text { Iodoethylacetate (2 eq) } \\
\mathrm{Me}_{2} \mathrm{Zn}(2.6 \mathrm{eq}), \mathrm{Cy}_{2} \mathrm{NH}(30 \%), \\
\text { r.t }(1 \mathrm{~h}), \mathrm{THF}(4 \mathrm{~mL})\end{array}$ & $\begin{array}{c}\text { Ligand } \\
(30 \%), 0{ }^{\circ} \mathrm{C}(1 \mathrm{~h})\end{array}$ & $\begin{array}{l}\text { Benzaldehyde } \\
(1 \text { eq }), 0{ }^{\circ} \mathrm{C}(24 \\
\text { h) }\end{array}$ & 74 & 82 \\
\hline 2 & $\begin{array}{l}\text { Iodoethylacetate (2 eq) } \\
\mathrm{Me}_{2} \mathrm{Zn}(2.6 \mathrm{eq}), \mathrm{Cy}_{2} \mathrm{NH}(30 \%), \\
\text { r.t }(1 \mathrm{~h}), \mathrm{THF}(4 \mathrm{~mL})\end{array}$ & \multicolumn{2}{|c|}{$\begin{array}{l}\text { Ligand (30\%), Benzaldehyde (1 eq), } \\
\qquad 0^{\circ} \mathrm{C}(24 \mathrm{~h})\end{array}$} & 60 & 81 \\
\hline 3 & $\begin{array}{c}\text { Iodoethylacetate (2 eq) } \\
\mathrm{Me}_{2} \mathrm{Zn}(2.6 \mathrm{eq}), \mathrm{Cy}_{2} \mathrm{NH}(30 \%), \\
\text { r.t }(1 \mathrm{~h}), \mathrm{THF}(4 \mathrm{~mL})\end{array}$ & $\begin{array}{c}\text { Ligand } \\
(30 \%), 0{ }^{\circ} \mathrm{C}(3 \mathrm{~h})\end{array}$ & $\begin{array}{l}\text { Benzaldehyde } \\
(1 \text { eq }), 0{ }^{\circ} \mathrm{C}(24 \\
\text { h) }\end{array}$ & 74 & 34 \\
\hline 4 & $\begin{array}{l}\text { Iodoethylacetate (2 eq) } \\
\mathrm{Me}_{2} \mathrm{Zn}(2.6 \mathrm{eq}), \mathrm{Cy}_{2} \mathrm{NH}(30 \%), \\
\text { r.t }(1 \mathrm{~h}), \mathrm{THF}(4 \mathrm{~mL})\end{array}$ & $\begin{array}{l}\text { Ligand } \\
(30 \%), 0{ }^{\circ} \mathrm{C}(1 \mathrm{~h})\end{array}$ & $\begin{array}{l}\text { Benzaldehyde } \\
(1 \text { eq }),-10^{\circ} \mathrm{C} \\
(24 \mathrm{~h})\end{array}$ & 60 & 31 \\
\hline 5 & $\begin{array}{l}\text { Iodoethylacetate (2 eq) } \\
\mathrm{Me}_{2} \mathrm{Zn}(2.6 \mathrm{eq}), \mathrm{Cy}_{2} \mathrm{NH}(30 \%), \\
\text { r.t }(1 \mathrm{~h}), \mathrm{THF}(4 \mathrm{~mL})\end{array}$ & $\begin{array}{l}\text { Ligand } \\
(30 \%), 0{ }^{\circ} \mathrm{C}(1 \mathrm{~h})\end{array}$ & $\begin{array}{l}\text { Benzaldehyde } \\
\text { (1 eq), r.t (24 h) }\end{array}$ & 62 & 40 \\
\hline
\end{tabular}




\begin{tabular}{|c|c|c|c|c|c|}
\hline 6 & $\begin{array}{l}\text { Iodoethylacetate (2 eq) } \\
\mathrm{Me}_{2} \mathrm{Zn}(2.6 \mathrm{eq}), \mathrm{Cy}_{2} \mathrm{NH}(30 \%), \\
\text { r.t }(1 \mathrm{~h}), \mathrm{THF}(4 \mathrm{~mL})\end{array}$ & $\begin{array}{c}\text { Ligand } \\
(30 \%), 0{ }^{\circ} \mathrm{C}(1 \mathrm{~h})\end{array}$ & $\begin{array}{l}\text { Benzaldehyde } \\
(1 \text { eq }), 10{ }^{\circ} \mathrm{C} \\
(24 \mathrm{~h})\end{array}$ & 71 & 41 \\
\hline 7 & $\begin{array}{c}\text { Iodoethylacetate (2 eq) } \\
\mathrm{Et}_{2} \mathrm{Zn}(2.6 \mathrm{eq}), \mathrm{Cy}_{2} \mathrm{NH}(30 \%) \\
\text { r.t }(1 \mathrm{~h}), \mathrm{THF}(4 \mathrm{~mL})\end{array}$ & $\begin{array}{c}\text { Ligand } \\
(30 \%), 0{ }^{\circ} \mathrm{C}(1 \mathrm{~h})\end{array}$ & $\begin{array}{l}\text { Benzaldehyde } \\
(1 \text { eq }),-10{ }^{\circ} \mathrm{C} \\
(24 \mathrm{~h})\end{array}$ & 18 & 10 \\
\hline 8 & $\begin{array}{l}\text { Iodoethylacetate ( } 2 \text { eq) } \\
\mathrm{Me}_{2} \mathrm{Zn}(2 \mathrm{eq}), \mathrm{Cy}_{2} \mathrm{NH}(30 \%), \\
\text { r.t }(1 \mathrm{~h}), \mathrm{THF}(4 \mathrm{~mL})\end{array}$ & $\begin{array}{l}\text { Ligand (30\%), } \\
\mathrm{Me}_{2} \mathrm{Zn}(0.6 \mathrm{eq}), 0 \\
{ }^{\circ} \mathrm{C}(1 \mathrm{~h})\end{array}$ & $\begin{array}{l}\text { Benzaldehyde } \\
(1 \text { eq }), 0{ }^{\circ} \mathrm{C}(24 \\
\text { h) }\end{array}$ & 52 & 49 \\
\hline 9 & $\begin{array}{l}\text { Iodoethylacetate }(2 \mathrm{eq}) \\
\mathrm{Me}_{2} \mathrm{Zn}(2 \mathrm{eq}), \mathrm{Cy} \mathrm{N}_{2} \mathrm{NH}(30 \%), \\
\text { r.t }(1 \mathrm{~h}), \mathrm{THF}(4 \mathrm{~mL})\end{array}$ & $\begin{array}{l}\text { Ligand (30\%), } \\
\mathrm{Et}_{2} \mathrm{Zn}(0.6 \mathrm{eq}), 0 \\
{ }^{\circ} \mathrm{C}(1 \mathrm{~h})\end{array}$ & $\begin{array}{l}\text { Benzaldehyde } \\
(1 \text { eq }), 0{ }^{\circ} \mathrm{C}(24 \\
\text { h) }\end{array}$ & 60 & 35 \\
\hline 10 & $\begin{array}{c}\text { Iodoethylacetate (2 eq) } \\
\mathrm{Me}_{2} \mathrm{Zn}(2.6 \mathrm{eq}), \mathrm{Cy}_{2} \mathrm{NH}(30 \%), \\
\text { r.t }(1 \mathrm{~h}), \mathrm{THF}(8 \mathrm{~mL})\end{array}$ & $\begin{array}{c}\text { Ligand } \\
(30 \%), 0{ }^{\circ} \mathrm{C}(1 \mathrm{~h})\end{array}$ & $\begin{array}{l}\text { Benzaldehyde } \\
(1 \text { eq }), 0{ }^{\circ} \mathrm{C}(24 \\
\text { h) }\end{array}$ & 32 & 27 \\
\hline 11 & $\begin{array}{l}\text { Iodoethylacetate (2 eq) } \\
\mathrm{Me}_{2} \mathrm{Zn}(2.6 \mathrm{eq}), \mathrm{Cy}_{2} \mathrm{NH}(30 \%), \\
\operatorname{r.t}(1 \mathrm{~h}), \mathrm{THF}(2 \mathrm{~mL})\end{array}$ & $\begin{array}{c}\text { Ligand } \\
(30 \%), 0{ }^{\circ} \mathrm{C}(1 \mathrm{~h})\end{array}$ & $\begin{array}{l}\text { Benzaldehyde } \\
(1 \text { eq }), 0{ }^{\circ} \mathrm{C}(24 \\
\text { h) }\end{array}$ & 74 & 20 \\
\hline 12 & $\begin{array}{l}\text { Iodoethylacetate (2 eq) } \\
\mathrm{Me}_{2} \mathrm{Zn}(2.6 \mathrm{eq}), \mathrm{Cy}_{2} \mathrm{NH}(30 \%), \\
\text { r.t }(1 \mathrm{~h}), \text { Dioxane }(4 \mathrm{~mL})\end{array}$ & $\begin{array}{c}\text { Ligand } \\
(30 \%), 0{ }^{\circ} \mathrm{C}(1 \mathrm{~h})\end{array}$ & $\begin{array}{l}\text { Benzaldehyde } \\
(1 \text { eq }), 0{ }^{\circ} \mathrm{C}(24 \\
\text { h) }\end{array}$ & 73 & 50 \\
\hline 13 & $\begin{array}{l}\text { Iodoethylacetate (2 eq) } \\
\mathrm{Me}_{2} \mathrm{Zn}(2.6 \mathrm{eq}), \mathrm{Cy}_{2} \mathrm{NH}(30 \%), \\
\text { r.t }(1 \mathrm{~h}), \mathrm{DCM}(4 \mathrm{~mL})\end{array}$ & $\begin{array}{c}\text { Ligand } \\
(30 \%), 0{ }^{\circ} \mathrm{C}(1 \mathrm{~h})\end{array}$ & $\begin{array}{l}\text { Benzaldehyde } \\
(1 \text { eq }), 0{ }^{\circ} \mathrm{C}(24 \\
\text { h) }\end{array}$ & 31 & 67 \\
\hline 14 & $\begin{array}{l}\text { Iodoethylacetate (2 eq) } \\
\mathrm{Me}_{2} \mathrm{Zn}(2.6 \mathrm{eq}), \mathrm{Cy}_{2} \mathrm{NH}(30 \%), \\
\text { r.t }(1 \mathrm{~h}), \text { Toluene }(4 \mathrm{~mL})\end{array}$ & $\begin{array}{c}\text { Ligand } \\
(30 \%), 0{ }^{\circ} \mathrm{C}(1 \mathrm{~h})\end{array}$ & $\begin{array}{l}\text { Benzaldehyde } \\
(1 \text { eq }), 0{ }^{\circ} \mathrm{C}(24 \\
\text { h) }\end{array}$ & 24 & 64 \\
\hline 15 & $\begin{array}{l}\text { Iodoethylacetate ( } 2 \text { eq) } \\
\mathrm{Me}_{2} \mathrm{Zn}(2.6 \mathrm{eq}), \mathrm{Cy}_{2} \mathrm{NH}(30 \%) \text {, } \\
\text { r.t }(1 \mathrm{~h}), \text { Hexanes }(4 \mathrm{~mL})\end{array}$ & $\begin{array}{c}\text { Ligand } \\
(30 \%), 0{ }^{\circ} \mathrm{C}(1 \mathrm{~h})\end{array}$ & $\begin{array}{l}\text { Benzaldehyde } \\
(1 \text { eq }), 0{ }^{\circ} \mathrm{C}(24 \\
\text { h) }\end{array}$ & 23 & 45 \\
\hline 16 & $\begin{array}{l}\text { Iodoethylacetate (2 eq) } \\
\mathrm{Me}_{2} \mathrm{Zn}(2.6 \mathrm{eq}), \mathrm{Cy}_{2} \mathrm{NH}(30 \%), \\
\text { r.t }(1 \mathrm{~h}), \mathrm{Et}_{2} \mathrm{O}(4 \mathrm{~mL})\end{array}$ & $\begin{array}{c}\text { Ligand } \\
(30 \%), 0{ }^{\circ} \mathrm{C}(1 \mathrm{~h})\end{array}$ & $\begin{array}{l}\text { Benzaldehyde } \\
(1 \text { eq }), 0{ }^{\circ} \mathrm{C}(24 \\
\text { h) }\end{array}$ & - & $<10$ \\
\hline 17 & $\begin{array}{c}\text { Iodoethylacetate (2 eq) } \\
\mathrm{Me}_{2} \mathrm{Zn}(2.6 \mathrm{eq}), \text { r.t (1 h), THF } \\
\text { (4 mL) }\end{array}$ & $\begin{array}{c}\text { Ligand } \\
(30 \%), 0{ }^{\circ} \mathrm{C}(1 \mathrm{~h})\end{array}$ & $\begin{array}{l}\text { Benzaldehyde } \\
(1 \text { eq }), 0{ }^{\circ} \mathrm{C}(24 \\
\text { h) }\end{array}$ & 50 & 30 \\
\hline
\end{tabular}

It was found that the reaction conditions of entry 1 in Scheme 6.10 were optimal for the use of L1. We tried to investigate the use of more $\mathrm{H}_{8} \mathrm{BINOL}$-based 
bifunctional ligands under the optimal conditions.

The study of $\mathbf{L 1}, \mathbf{L} 2$ and $\mathbf{L 3}$ indicates: 1. The additional hetero atoms in the cyclic amine groups of these compounds should play a role in the asymmetric induction. 2 . The ring size of the cyclic amine groups was crucial to the enantioselectivity. We thus designed a new type of catalysts for this reaction by incorporating an additional nitrogen atom into the cyclic amine substituents. These compounds were prepared from one-pot Mannich reactions of the corresponding $N$-substituted piperazines with $\mathrm{H}_{8} \mathrm{BINOL}$ and paraformaldehyde. The terminal nitrogen atom could be easily modified by using various $N$-substituents. This should allow us to systematically modify the steric and electronic properties of the ligands.

A series of the $\mathrm{H}_{8} \mathrm{BINOL-based} \mathrm{ligands} \mathrm{A1-A9} \mathrm{were} \mathrm{synthesized} \mathrm{and} \mathrm{examined}$ under the above optimal conditions (Scheme 6.11). When A1 was used, the reaction gave almost no enantioselectivity at all, which indicates that the substitution on the terminal nitrogen atom is necessary. The reaction using $N$-alkyl substituted ligands (A2-A4) proceeded with 47-64\% ee. For the $N$-acyl and $N$-Boc substituted ligands (A5, A6), 24\% and 65\% ee were obtained, respectively. The $N$-allyl substituted ligand A7 was employed to catalyze the reaction with $66 \%$ enantioselectivity. When phenyl groups were introduced as substituents $(\mathbf{A 8}, \mathbf{A 9})$, the enantioselectivity was improved to $73 \%$. 
Scheme 6.11. The Reformatsky reaction catalyzed by ligands A1-A9

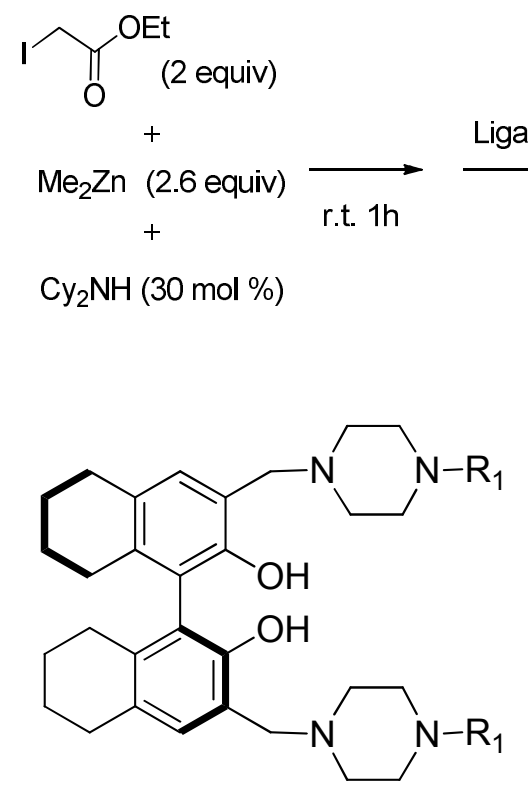

Ligand $\mathrm{R}_{1} \quad$ ee $\% \quad$ yield $\%$

$\begin{array}{llll}\text { A1 } & \mathrm{H} & 5 & 45\end{array}$

A2 Me $64 \quad 60$

A3 $\quad$ Et $\quad 64 \quad 61$

$\begin{array}{llll}\text { A4 } & \mathrm{iPr} & 47 & 50\end{array}$

A5 acyl $24 \quad 53$

A6 $\quad$ Boc $\quad 65 \quad 65$

A7 allyl $\quad 66 \quad 64$

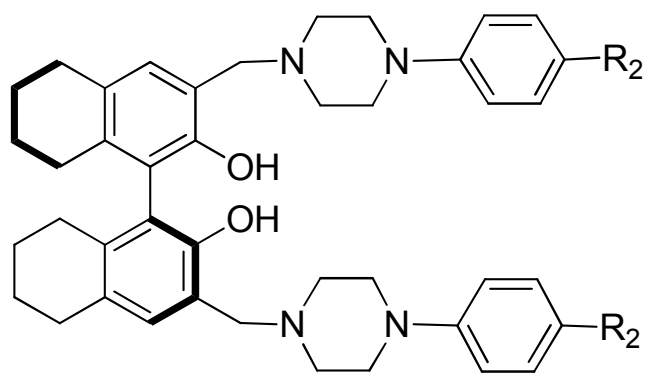

Ligand $R_{2} \quad$ ee $\% \quad$ yield $\%$

$\begin{array}{llll}\text { A8 } & \mathrm{H} & 73 & 62\end{array}$

$\begin{array}{llll}\text { A9 } & \mathrm{F} & 73 & 55\end{array}$

The study of A1-A9 indicates that the phenyl group at the terminal position can

enhance the asymmetric induction. Then, we designed and prepared a new type of the $\mathrm{H}_{8}$ BINOL-based ligands B1-B9 with $N$-benzyl substituents (Scheme 6.12). Either electron-donating (B1-B4) or electron-withdrawing groups substituted benzyl ligands 
(B5-B9) catalyzed the reaction with a range of $57-71 \%$ ee's. How the electronic properties of the substituents influence this reaction is not clear.

Scheme 6.12. The Reformatsky reaction catalyzed by ligands B1-B9

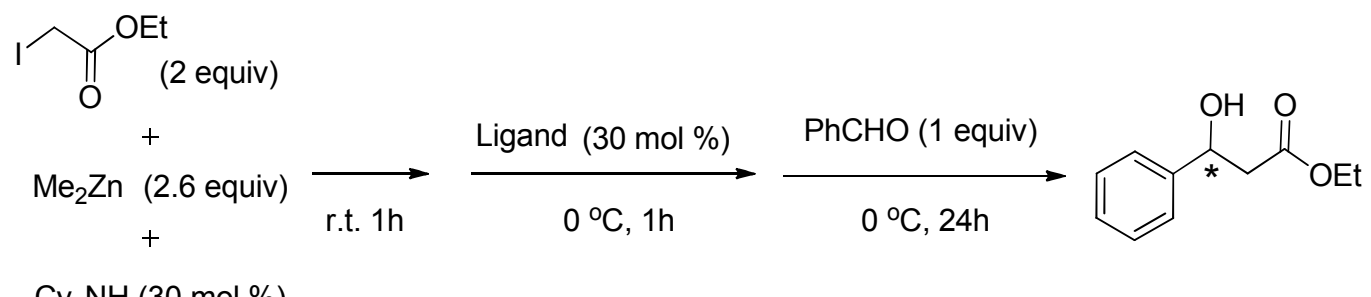

$\mathrm{Cy}_{2} \mathrm{NH}(30 \mathrm{~mol} \%)$

Ligand $R \quad$ ee $\% \quad$ yield $\%$<smiles>[R]c1ccc(CN2CCN(Cc3cc4c(c(-c5c(O)c(CN6CCN(Cc7ccc([R])cc7)CC6)cc6c5CCCC6)c3O)CCCC4)CC2)cc1</smiles>

B1 $\quad \mathrm{H} \quad 70 \quad 52$

$\begin{array}{lll}\text { B2 } & \mathrm{Cl} & 65\end{array}$

B3 $\mathrm{Br} \quad 70 \quad 63$

B4 $\quad \mathrm{CF}_{3} \quad 61 \quad 58$

B5 $\mathrm{Me} \quad 70 \quad 65$

B6 $\quad$ OMe $\quad 71 \quad 62$

B7 $\quad \mathrm{NMe}_{2} \quad 60 \quad 55$<smiles>Oc1c(CN2CCN(Cc3ccc4c(c3)OCO4)CC2)cc2c(c1-c1c(O)c(CN3CCN(Cc4ccc5c(c4)OCO5)CC3)cc3c1CCCC3)CCCC2</smiles>

B8, $71 \%$ ee, $67 \%$ yield<smiles>COc1cc(OC)c(CN2CCN(Cc3cc4c(c(-c5c(O)c(CN6CCN(Cc7c(OC)cc(OC)cc7OC)CC6)cc6c5CCCC6)c3O)CCCC4)CC2)c(OC)c1</smiles>

B9, $57 \%$ ee, $60 \%$ yield

To investigate the steric effects of the ligands, more groups were introduced to the 
terminal position. Ligands C1-C8 were prepared and examined under the above optimal conditions (Scheme 6.13). When ligand C1 containing a diphenylmethyl group at each of the terminal nitrogen atom was employed in the reaction, good enantioselectivity (78\% ee) and high yield (80\%) were achieved. However, the enantioselectivity was significantly decreased with the use of electron-withdrawing groups substituted diphenyl ligands $(\mathbf{C 2}, \mathbf{C 3})$. The Ligand $\mathbf{C 4}$ in which, the diphenyl groups are linked together gave reduced ee and yield. Replacing one phenyl group of the diphenyl groups with a methyl group dramatically diminished ee and yield (C5). In the presence of the ligand $\mathbf{C 6}$ with three phenyl groups, the enantioselectivity was decreased $(55 \%$ ee). These results imply that the flexible diphenyl ring is important for the stereo control. Both electronic and steric properties need to be considered to achieve high enantioselectivity.

The BINOL-based diphenyl ligand $\mathbf{C 7}$ and $\mathbf{C 8}$ were also tested and very low enantioselectivity was observed, indicating the framework of $\mathrm{H}_{8} \mathrm{BINOL}$ is important for the asymmetric induction. 
Scheme 6.13. The Reformatsky reaction catalyzed by ligands C1-C8

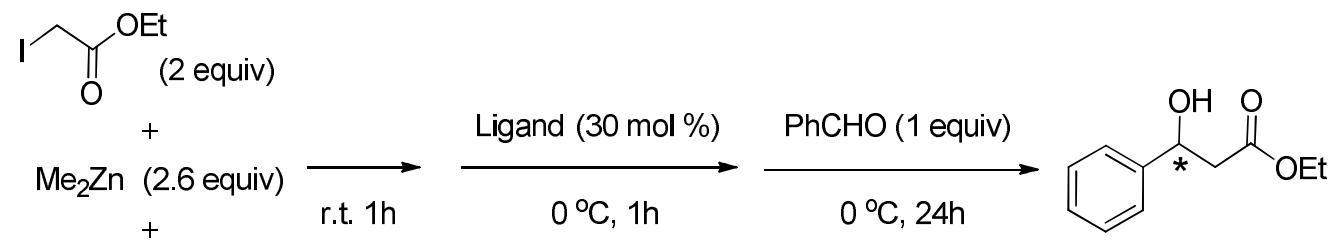
$\mathrm{Cy}_{2} \mathrm{NH}(30 \mathrm{~mol} \%)$<smiles>[R]N1CCN(Cc2cc3c(c(-c4c(O)c(CN5CCN([R])CC5)cc5c4CCCC5)c2O)CCCC3)CC1</smiles>

Ligand

$\mathrm{R}$

ee $\% \quad$ yield $\%$

C1<smiles>N#CC(c1ccccc1)c1ccccc1</smiles>

78

80

C2<smiles>CC([Al])(c1ccc(F)cc1)c1ccc(F)cc1</smiles>

43

56

C3<smiles>NC(c1ccccc1)c1ccc(Cl)cc1</smiles>

C4<smiles>NC1c2ccccc2-c2ccccc21</smiles>

58

38

C5<smiles>CC(C)c1ccccc1</smiles>

31

38

C6

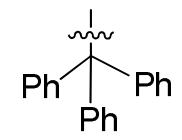<smiles>Oc1c(CN2CCN(C(c3ccccc3)c3ccccc3)CC2)cc2ccccc2c1-c1c(O)c(CN2CCN(C(c3ccccc3)c3ccccc3)CC2)cc2ccccc12</smiles>

C7, $15 \%$ ee, $68 \%$ yield<smiles>Oc1c(CN2CCN(C(c3ccccc3)c3ccccc3)CC2)cc2cc(Br)ccc2c1-c1c(O)c(CN2CCN(C(c3ccccc3)c3ccccc3)CC2)cc2cc(Br)ccc12</smiles>

C8, $18 \%$ ee, $62 \%$ yield

In addition, we also studied a series of the monomorpholinylmethyl substituted 
$\mathrm{H}_{8}$ BINOL-based ligands D1-D6 (Scheme 6.14). Disappointingly, Ligands D1-D5 gave almost no enantioselectivity at all. Low enantioselectivity ( $37 \%$ ee) was obtained with the use of D6.

Scheme 6.14. The Reformatsky reaction catalyzed by ligands D1-D6

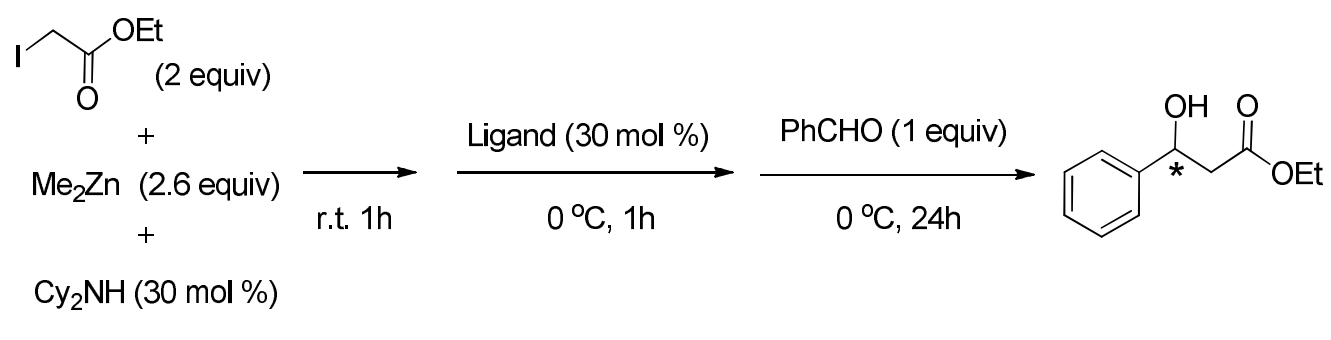

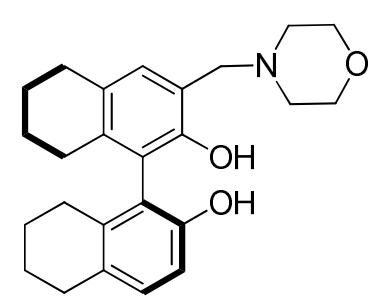

D1, 7\% ee

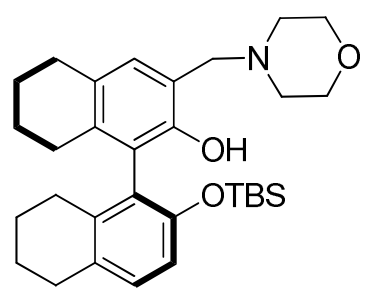

D4, 3\% ee

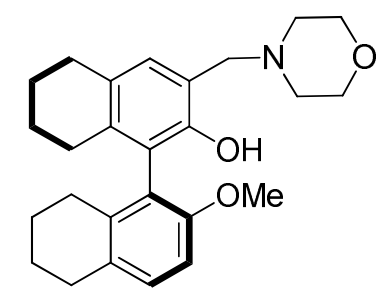

D2, 5\% ee<smiles>CCOC(=O)COc1ccc2c(c1-c1c(O)c(CN3CCOCC3)cc3c1CCCC3)CCCC2</smiles>

D5, $7 \%$ ee<smiles>COc1ccc2c(c1-c1c(O)c(CN3CCOCC3)cc3c1CCCC3)CCCC2</smiles>

D3, $12 \%$ ee<smiles>Oc1ccc2c(c1-c1c(CN3CCOCC3)ccc3c1CCCC3)CCCC2</smiles>

D6, $37 \%$ ee

Previously, it was found that dicyclohexylamine as an additive promoted the asymmetric reaction catalyzed by $\mathbf{L 1}$. Therefore, in the presence of the best diphenyl ligand C1, we also screened the use of a broad range of nitrogen-containing acyclic and cyclic bases as the additive, but they all gave lower enantioselectivity $(13-74 \%$ ee) under the optimal reaction conditions (Scheme 6.15). 
Scheme 6.15. Screening of nitrogen-containing additives

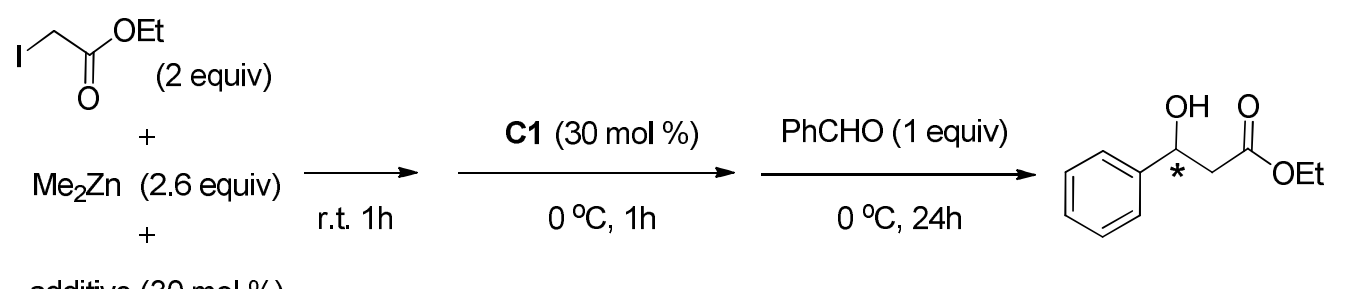

additive (30 mol \%)

secondary amines<smiles>C1CCC(NC2CCCCC2)CC1</smiles>

$78 \%$ ee<smiles>c1ccc(Nc2ccccc2)cc1</smiles>

$73 \%$ ee<smiles>O=C(O)c1ccccc1CNCc1ccccc1</smiles><smiles>CCCCCCNCCCCCC</smiles>

$74 \%$ ee<smiles>CC(C)CNCC(C)C</smiles>

$35 \%$ ee<smiles>CCNCC</smiles>

$32 \%$ ee<smiles>CCNCc1ccccc1</smiles>

$13 \%$ ee tertiary amines<smiles>CCN(CC)CC</smiles>

$72 \%$ ee<smiles>CCN(C(C)C)C(C)C</smiles>

$70 \%$ ee<smiles>CN(C)c1ccccc1</smiles>

$64 \%$ ee<smiles>CN(c1ccccc1)c1ccccc1</smiles>

$63 \%$ ee<smiles>CN(C)c1cccc2cccc(N(C)C)c12</smiles>

$72 \%$ ee

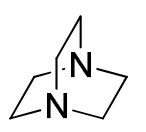

$34 \%$ ee aromatic amines<smiles></smiles><smiles>CC(C)(C)c1ccncc1</smiles>

$72 \%$ ee<smiles>c1ccnnc1</smiles>

$72 \%$ ee<smiles>c1c[nH]cn1</smiles>

$69 \%$ ee<smiles>Cn1ccnc1</smiles>

$65 \%$ ee<smiles>c1nc[nH]n1</smiles>

$32 \%$ ee

To explain the results obtained in this work, we have proposed a mechanism for our catalytic system in the asymmetric Reformatsky reaction (Scheme 6.16). In the presence of dicyclohexylamine and THF, the zinc-inserted ester complex $\mathbf{6 . 6}$ is 
formed when ethyl iodoacetate is treated with $\mathrm{Me}_{2} \mathrm{Zn}$. Then ligand $\mathbf{C 1}$ reacts with $\mathbf{6 . 6}$ to generate the ligand-zinc complex $\mathbf{6 . 7}$, which incorporates with benzaldehyde to give the intermediate 6.8. The nucleophilic attack of the ester species to benzaldehyde leads to the addition product.

Scheme 6.16. Proposed mechanism for the Reformatsky reaction catalyzed by $\mathbf{C} \mathbf{1}$

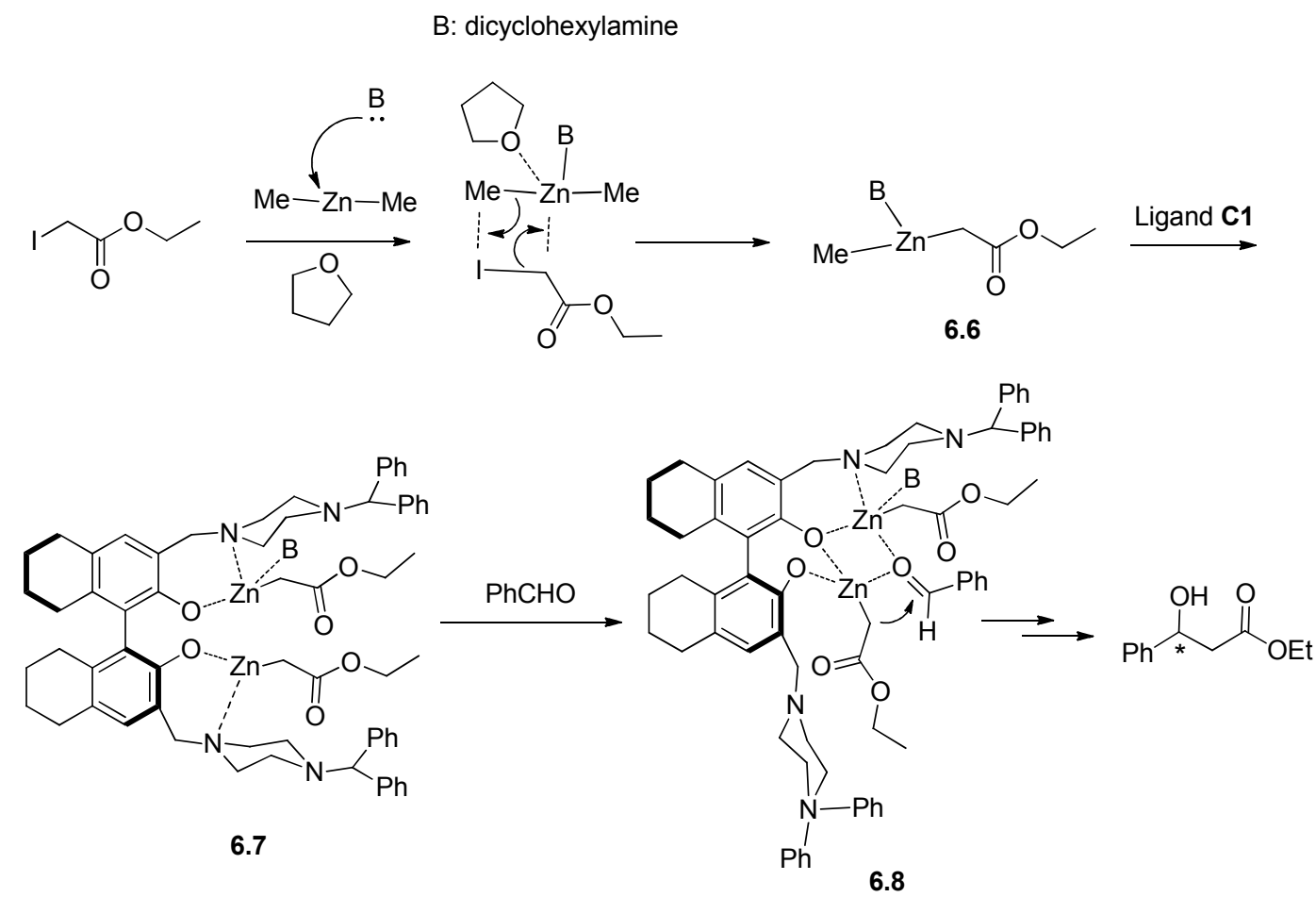

\subsection{Summary}

We have discovered that a 3,3'-di(1-diphenylmethylpiperazinyl)methyl $\mathrm{H}_{8} \mathrm{BINOL}$ compound $\mathbf{C 1}$ can catalyze the asymmetric reaction of ethyl iodoacetate with benzaldehyde in the presence of $\mathrm{Me}_{2} \mathrm{Zn}$ and dicyclohexylamine. The reaction proceeds in high yield ( $80 \%)$ and with good enantioselectivity $(78 \%$ ee). This method has advantages over the previous work including the use of a small amount of $\mathrm{Me}_{2} \mathrm{Zn}$ 
(2.6 equiv) and avoiding the use of air. Our study shows that the electronic and steric properties of the ligands can significantly affect the chiral induction.

To achieve higher enantioselectivity, further modification of both ligands and reaction conditions will be made in the future. More detailed mechanistic study is also needed in order to better understand this reaction and further improve the catalytic efficiency. 


\section{Experimental and Characterization}

\section{Analytical instruments}

NMR: Bruker $600 \mathrm{MHz}$.

HPLC: Water 600 Pump and Waters 486 Tunable Absorbance Detector, Chiralcel OD, OD-H, or Chiralpak AD, AD-H column.

Polarimeter: Jasco Digital Polarimeter P-2000.

High resolution mass spectra were obtained by EI [70-VSE(C)] or ESI (Q-TOf) analysis.

\section{General data}

Reactions were carried out under nitrogen. All commercial chemicals were used without further purification unless otherwise noted. Zinc reagents and catalysts were purchased and stored in dry nitrogen atmosphere. THF, toluene and 1,4-dionaxe were distilled over sodium and benzophenone under nitrogen. DCM, $\mathrm{Et}_{2} \mathrm{O}$ and hexanes were dried by passing through activated alumina columns under nitrogen. Benzaldehyde was distilled from $4 \AA$ molecular sieves prior to use. All the NMR spectra were obtained in $\mathrm{CDCl}_{3}$ unless indicated otherwise.

\section{Synthesis and characterization of ligands}

\section{a. Characterization of ligand L1}

Compound L1 was known compound and prepared according to the literature procedure. $^{21 \mathrm{~d}}$ 


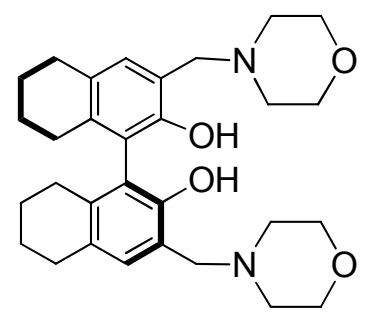

${ }^{1} \mathrm{H}$ NMR (600 MHz, $\left.\mathrm{CDCl}_{3}\right) \delta 10.34$ (s, 2H), 6.72 (s, 2H), 3.79 (d, 2H, J=13.8 Hz), $3.67(\mathrm{~s}, 8 \mathrm{H}), 3.58(\mathrm{~d}, 2 \mathrm{H}, \mathrm{J}=13.8 \mathrm{~Hz}), 2.70(\mathrm{~m}, 4 \mathrm{H}), 2.54(\mathrm{~s}, 8 \mathrm{H}), 2.32(\mathrm{~m}, 2 \mathrm{H}), 2.16$ $(\mathrm{m}, 2 \mathrm{H}), 1.68(\mathrm{~m}, 8 \mathrm{H}) .{ }^{13} \mathrm{C} \mathrm{NMR}\left(150 \mathrm{MHz}, \mathrm{CDCl}_{3}\right) \delta 152.0,135.9,128.7,127.6$, $123.9,117.7,66.7,61.9,52.9,29.2,27.0,23.2,23.1$.

\section{b. Synthesis and characterization of ligands A1-A9}

Ligands A1-A9 were prepared according to the similar procedure as ligand $\mathbf{C 1}$.

\section{A1}

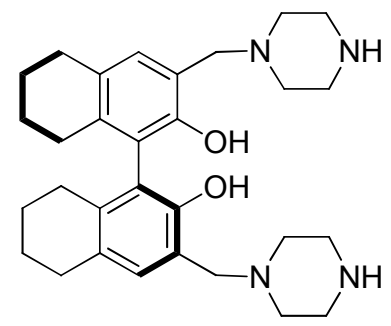

${ }^{1} \mathrm{H}$ NMR (600 MHz, $\left.\mathrm{CDCl}_{3}\right) \delta 10.50(\mathrm{~s}, 2 \mathrm{H}), 6.70(\mathrm{~s}, 2 \mathrm{H}), 3.76(\mathrm{~d}, 2 \mathrm{H}, \mathrm{J}=13.8 \mathrm{~Hz})$, $3.56(\mathrm{~d}, 2 \mathrm{H}, \mathrm{J}=13.8 \mathrm{~Hz}), 2.86(\mathrm{~m}, 8 \mathrm{H}), 2.70(\mathrm{~m}, 4 \mathrm{H}), 2.53(\mathrm{~m}, 8 \mathrm{H}), 2.32(\mathrm{~m}, 2 \mathrm{H}), 2.16$ $(\mathrm{m}, 2 \mathrm{H}), 1.70(\mathrm{~m}, 10 \mathrm{H}) .{ }^{13} \mathrm{C}\left\{{ }^{1} \mathrm{H}\right\} \mathrm{NMR}\left(150 \mathrm{MHz}, \mathrm{CDCl}_{3}\right) \delta 152.2,135.7,128.5$, $127.3,123.9,118.1,62.0,53.4,45.7,29.2,27.0,23.3,23.2$.

A2<smiles>CN1CCN(Cc2cc3c(c(-c4c(O)c(CN5CCN(C)CC5)cc5c4CCCC5)c2O)CCCC3)CC1</smiles> 
${ }^{1} \mathrm{H}$ NMR $\left(600 \mathrm{MHz}, \mathrm{CDCl}_{3}\right) \delta 6.69(\mathrm{~s}, 2 \mathrm{H}), 3.77(\mathrm{~d}, 2 \mathrm{H}, \mathrm{J}=13.2 \mathrm{~Hz}), 3.58(\mathrm{~d}, 2 \mathrm{H}, \mathrm{J}=$ $13.8 \mathrm{~Hz}), 2.70(\mathrm{~m}, 4 \mathrm{H}), 2.59-2.43(\mathrm{~m}, 16 \mathrm{H}), 2.36(\mathrm{~m}, 2 \mathrm{H}), 2.25(\mathrm{~s}, 6 \mathrm{H}), 2.15(\mathrm{~m}, 2 \mathrm{H})$, $1.69(\mathrm{~m}, 8 \mathrm{H}) .{ }^{13} \mathrm{C}\left\{{ }^{1} \mathrm{H}\right\} \operatorname{NMR}\left(150 \mathrm{MHz}, \mathrm{CDCl}_{3}\right) \delta$ 152.2, 135.7, 128.5, 127.3, 124.0, 118.2, 61.4, 54.7, 52.4, 45.8, 29.2, 27.0, 23.3, 23.2. HRMS [ESI(TOF)] for $\mathrm{C}_{32} \mathrm{H}_{47} \mathrm{~N}_{4} \mathrm{O}_{2}\left[\mathrm{M}+\mathrm{H}^{+}\right]:$m/z: calcd for: 519.3699; found: 519.3701 .

A3

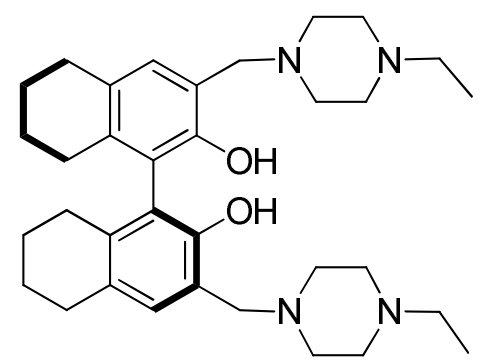

${ }^{1} \mathrm{H}$ NMR (600 MHz, $\left.\mathrm{CDCl}_{3}\right) \delta 10.04$ (s, 2H), 6.69 (s, 2H), 3.77 (d, 2H, J=13.2 Hz), $3.58(\mathrm{~d}, 2 \mathrm{H}, \mathrm{J}=13.8 \mathrm{~Hz}), 2.70(\mathrm{~m}, 4 \mathrm{H}), 2.59(\mathrm{~m}, 8 \mathrm{H}), 2.46(\mathrm{~m}, 6 \mathrm{H}), 2.36(\mathrm{~m}, 8 \mathrm{H}), 2.15$ $(\mathrm{m}, 2 \mathrm{H}), 1.70(\mathrm{~m}, 8 \mathrm{H}), 1.05(\mathrm{t}, 6 \mathrm{H}, \mathrm{J}=7.2 \mathrm{~Hz}) .{ }^{13} \mathrm{C}\left\{{ }^{1} \mathrm{H}\right\} \mathrm{NMR}\left(150 \mathrm{MHz}, \mathrm{CDCl}_{3}\right) \delta$ $152.3,135.6,128.4,127.2,124.0,118.2,61.5,52.45,52.40,52.1,29.2,27.0,23.3$ 23.2, 11.9.

A4

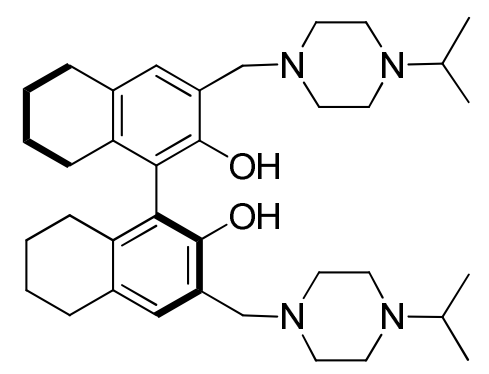

${ }^{1} \mathrm{H}$ NMR (600 MHz, $\left.\mathrm{CDCl}_{3}\right) \delta 10.66(\mathrm{~s}, 2 \mathrm{H}), 6.70$ (s, 2H), 3.78 (d, 2H, J=13.8 Hz), 
$3.56(\mathrm{~d}, 2 \mathrm{H}, \mathrm{J}=13.8 \mathrm{~Hz}), 2.58(\mathrm{~m}, 20 \mathrm{H}), 2.32(\mathrm{~m}, 2 \mathrm{H}), 2.15(\mathrm{~m}, 2 \mathrm{H}), 1.68(\mathrm{~m}, 8 \mathrm{H})$, $1.39(\mathrm{~m}, 2 \mathrm{H}), 0.99(\mathrm{t}, 12 \mathrm{H}, \mathrm{J}=6.6 \mathrm{~Hz}) .{ }^{13} \mathrm{C}\left\{{ }^{1} \mathrm{H}\right\} \mathrm{NMR}\left(150 \mathrm{MHz}, \mathrm{CDCl}_{3}\right) \delta$ 152.3, $135.6,128.4,127.2,124.0,118.2,61.5,58.4,54.3,52.8,48.2,29.2,27.0,23.2(\mathrm{~d}$, $\mathrm{J}=10.8 \mathrm{~Hz}), 18.4(\mathrm{~d}, \mathrm{~J}=14.6 \mathrm{~Hz})$.

A5

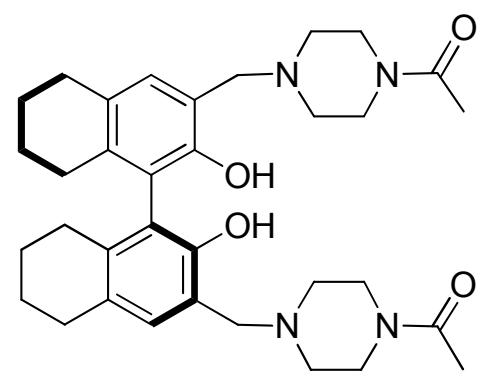

${ }^{1} \mathrm{H}$ NMR (600 MHz, $\left.\mathrm{CDCl}_{3}\right) \delta 9.88(\mathrm{~s}, 2 \mathrm{H}), 6.70$ (s, 2H), 3.79 (d, 2H, J=13.2 Hz), $3.59(\mathrm{~m}, 6 \mathrm{H}), 3.44(\mathrm{~m}, 4 \mathrm{H}), 2.70(\mathrm{~m}, 4 \mathrm{H}), 2.53(\mathrm{~m}, 8 \mathrm{H}), 2.33(\mathrm{~m}, 2 \mathrm{H}), 2.16(\mathrm{~m}, 2 \mathrm{H})$, $2.05(\mathrm{~s}, 6 \mathrm{H}), 1.69(\mathrm{~m}, 8 \mathrm{H}) .{ }^{13} \mathrm{C}\left\{{ }^{1} \mathrm{H}\right\} \mathrm{NMR}\left(150 \mathrm{MHz}, \mathrm{CDCl}_{3}\right) \delta 168.9,151.9,136.1$, $128.8,127.8,123.9,117.7,61.4,52.5,52.1,45.9,41.1,29.2,27.0,23.2,23.1,21.3$.

A6

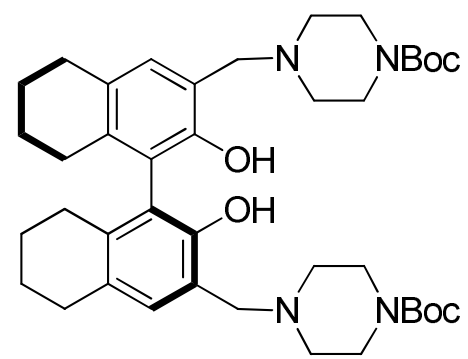

${ }^{1} \mathrm{H}$ NMR $\left(600 \mathrm{MHz}, \mathrm{CDCl}_{3}\right) \delta 10.10(\mathrm{~s}, 2 \mathrm{H}), 6.56(\mathrm{~s}, 2 \mathrm{H}), 3.66(\mathrm{~d}, 2 \mathrm{H}, \mathrm{J}=13.8 \mathrm{~Hz})$, $3.41(\mathrm{~d}, 2 \mathrm{H}, \mathrm{J}=14.4 \mathrm{~Hz}), 3.26(\mathrm{~m}, 8 \mathrm{H}), 2.56(\mathrm{~m}, 4 \mathrm{H}), 2.35(\mathrm{~m}, 8 \mathrm{H}), 2.19(\mathrm{~m}, 2 \mathrm{H}), 2.01$ $(\mathrm{m}, 2 \mathrm{H}), 1.53(\mathrm{~m}, 8 \mathrm{H}), 1.30(\mathrm{~s}, 18 \mathrm{H})$. 


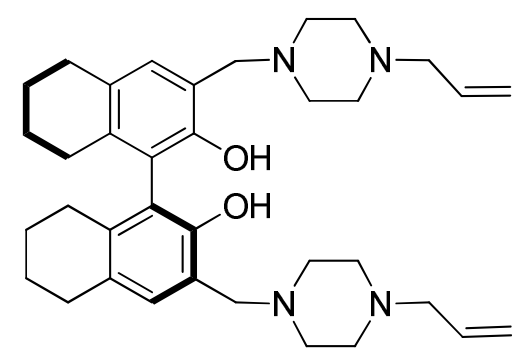

${ }^{1} \mathrm{H}$ NMR $\left(600 \mathrm{MHz}, \mathrm{CDCl}_{3}\right) \delta 10.57(\mathrm{~s}, 2 \mathrm{H}), 6.70(\mathrm{~s}, 2 \mathrm{H}), 5.81(\mathrm{~m}, 2 \mathrm{H}), 5.13(\mathrm{~m}, 4 \mathrm{H})$, 3.80 (d, 2H, J=13.8 Hz), 3.56 (d, 2H, J=13.2 Hz), 2.96 (m, 4H), 2.43 (m, 20H), 1.64 $(\mathrm{m}, 12 \mathrm{H})$

\section{A8}

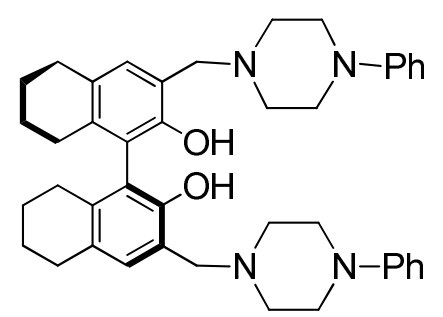

${ }^{1} \mathrm{H}$ NMR $\left(600 \mathrm{MHz}, \mathrm{CDCl}_{3}\right) \delta 10.45(\mathrm{~s}, 2 \mathrm{H}), 7.25(\mathrm{~m}, 4 \mathrm{H}), 6.89(\mathrm{~m}, 6 \mathrm{H}), 6.76(\mathrm{~s}, 2 \mathrm{H})$, $3.87(\mathrm{~d}, 2 \mathrm{H}, \mathrm{J}=13.8 \mathrm{~Hz}), 3.66(\mathrm{~d}, 2 \mathrm{H}, \mathrm{J}=13.8 \mathrm{~Hz}), 3.19(\mathrm{~s}, 8 \mathrm{H}), 2.74(\mathrm{~m}, 12 \mathrm{H}), 2.38$ (m, 2H), $2.19(\mathrm{~m}, 2 \mathrm{H}), 1.72(\mathrm{~m}, 8 \mathrm{H}) .{ }^{13} \mathrm{C}\left\{{ }^{1} \mathrm{H}\right\}$ NMR $\left(150 \mathrm{MHz}, \mathrm{CDCl}_{3}\right) \delta$ 152.2, $151.0,135.9,129.1,128.6,127.5,124.0,120.0,118.1,116.4,61.5,52.5,49.1,29.2$ 27.0, 23.3, 23.2. HRMS [ESI(TOF)] for $\mathrm{C}_{42} \mathrm{H}_{51} \mathrm{~N}_{4} \mathrm{O}_{2}\left[\mathrm{M}+\mathrm{H}^{+}\right]$: $\mathrm{m} / \mathrm{z}$ : calcd for: 643.4012; found: 643.4015 .

A9

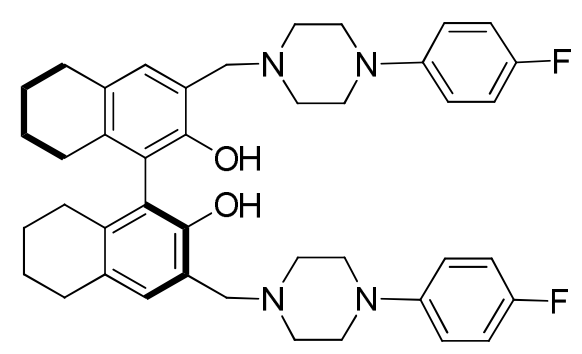


${ }^{1} \mathrm{H}$ NMR $\left(600 \mathrm{MHz}, \mathrm{CDCl}_{3}\right) \delta 10.42(\mathrm{~s}, 2 \mathrm{H}), 6.94(\mathrm{~m}, 4 \mathrm{H}), 6.83(\mathrm{~m}, 4 \mathrm{H}), 6.76(\mathrm{~s}, 2 \mathrm{H})$, 3.87 (d, 2H, J=13.2 Hz), 3.65 (d, 2H, J=13.8 Hz), 3.10 (m, 8H), 2.73 (m, 12H), 2.39 $(\mathrm{m}, 2 \mathrm{H}), 2.20(\mathrm{~m}, 2 \mathrm{H}), 1.69(\mathrm{~m}, 8 \mathrm{H}) .{ }^{13} \mathrm{C}\left\{{ }^{1} \mathrm{H}\right\}$ NMR $\left(150 \mathrm{MHz}, \mathrm{CDCl}_{3}\right) \delta$ 158.1, $156.6,152.2,147.7,135.9,128.6,127.5,124.0,118.2,118.16,115.6,115.5$.

\section{c. Synthesis and characterization of ligands B1-B9}

Ligands B1-B9 were prepared according to the similar procedure as ligand $\mathbf{C 1}$.

\section{B1}<smiles>Oc1c(CN2CCN(Cc3ccccc3)CC2)cc2c(c1-c1c(O)c(CN3CCN(Cc4ccccc4)CC3)cc3c1CCCC3)CCCC2</smiles>

${ }^{1} \mathrm{H}$ NMR $\left(600 \mathrm{MHz}, \mathrm{CDCl}_{3}\right) \delta 10.67(\mathrm{~s}, 2 \mathrm{H}), 7.30(\mathrm{~m}, 10 \mathrm{H}), 6.73(\mathrm{~s}, 2 \mathrm{H}), 3.83(\mathrm{~d}, 2 \mathrm{H}$, $\mathrm{J}=13.8 \mathrm{~Hz}), 3.59(\mathrm{~d}, 2 \mathrm{H}, \mathrm{J}=13.8 \mathrm{~Hz}), 3.48(\mathrm{~s}, 4 \mathrm{H}), 2.74-2.16(\mathrm{~m}, 28 \mathrm{H}), 1.72(\mathrm{~m}$, 8H). ${ }^{13} \mathrm{C}\left\{{ }^{1} \mathrm{H}\right\}$ NMR $\left(150 \mathrm{MHz}, \mathrm{CDCl}_{3}\right) \delta 152.3,138.0,135.6,129.0,128.4,128.2$, $127.2,127.1,124.0,118.2,62.8,61.5,52.7,52.5,29.2,27.0,23.3,23.2$. HRMS [ESI(TOF)] for $\mathrm{C}_{44} \mathrm{H}_{55} \mathrm{~N}_{4} \mathrm{O}_{2}\left[\mathrm{M}+\mathrm{H}^{+}\right]$: m/z: calcd for: 671.4325; found: 671.4324 .

B2

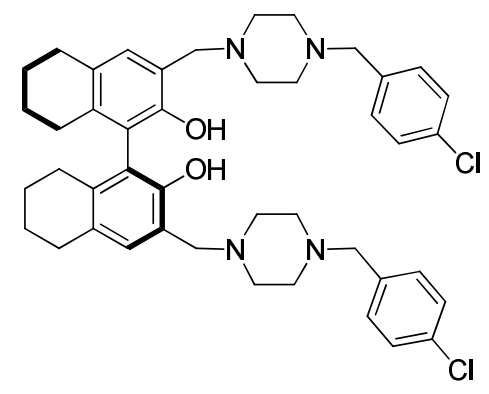


${ }^{1} \mathrm{H}$ NMR (600 MHz, $\left.\mathrm{CDCl}_{3}\right) \delta 10.60(\mathrm{~s}, 2 \mathrm{H}), 7.26(\mathrm{~d}, 4 \mathrm{H}, \mathrm{J}=7.8 \mathrm{~Hz}), 7.22$ (d, 4H, $\mathrm{J}=8.4 \mathrm{~Hz}), 6.71(\mathrm{~s}, 2 \mathrm{H}), 3.82(\mathrm{~d}, 2 \mathrm{H}, \mathrm{J}=13.8 \mathrm{~Hz}), 3.56(\mathrm{~d}, 2 \mathrm{H}, \mathrm{J}=13.8 \mathrm{~Hz}), 3.42(\mathrm{~s}, 4 \mathrm{H})$, $2.52(\mathrm{~m}, 22 \mathrm{H}), 2.15(\mathrm{~m}, 2 \mathrm{H}), 1.68(\mathrm{~m}, 8 \mathrm{H})$.

\section{B3}

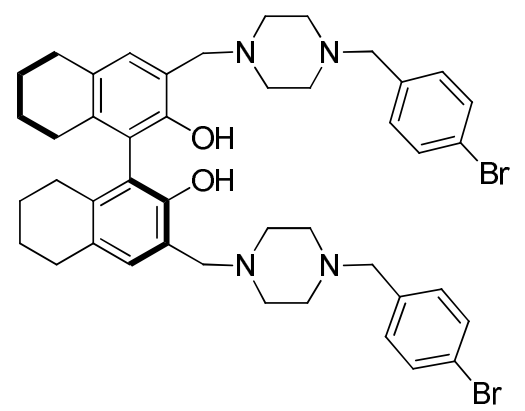

${ }^{1} \mathrm{H}$ NMR $\left(600 \mathrm{MHz}, \mathrm{CDCl}_{3}\right) \delta 10.60(\mathrm{~s}, 2 \mathrm{H}), 7.40(\mathrm{~d}, 4 \mathrm{H}, \mathrm{J}=8.4 \mathrm{~Hz}), 7.15(\mathrm{~d}, 4 \mathrm{H}$, $\mathrm{J}=8.4 \mathrm{~Hz}), 6.70(\mathrm{~s}, 2 \mathrm{H}), 3.810(\mathrm{~d}, 2 \mathrm{H}, \mathrm{J}=13.8 \mathrm{~Hz}), 3.54(\mathrm{~d}, 2 \mathrm{H}, \mathrm{J}=13.8 \mathrm{~Hz}), 3.39(\mathrm{~s}$, 4H), $2.46(\mathrm{~m}, 24 \mathrm{H}), 1.66(\mathrm{~m}, 8 \mathrm{H})$.

\section{B4}

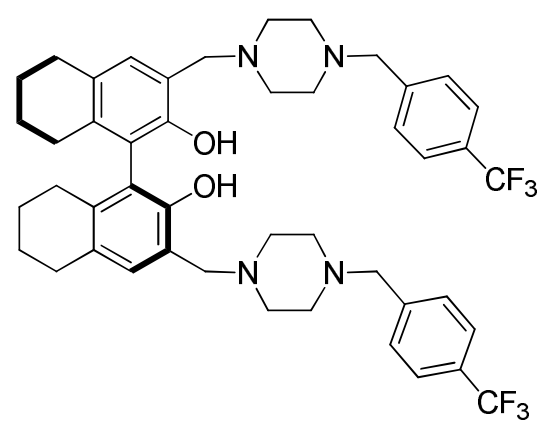

${ }^{1} \mathrm{H}$ NMR (600 MHz, $\left.\mathrm{CDCl}_{3}\right) \delta 10.58(\mathrm{~s}, 2 \mathrm{H}), 7.50(\mathrm{~d}, 4 \mathrm{H}, \mathrm{J}=7.8 \mathrm{~Hz}), 7.41(\mathrm{~d}, 4 \mathrm{H}$, $\mathrm{J}=7.8 \mathrm{~Hz}), 6.71(\mathrm{~s}, 2 \mathrm{H}), 3.83(\mathrm{~d}, 2 \mathrm{H}, \mathrm{J}=13.8 \mathrm{~Hz}), 3.56(\mathrm{~d}, 2 \mathrm{H}, \mathrm{J}=13.8 \mathrm{~Hz}), 3.51(\mathrm{~s}, 4 \mathrm{H})$, $2.52(\mathrm{~m}, 22 \mathrm{H}), 2.16(\mathrm{~m}, 2 \mathrm{H}), 1.69(\mathrm{~m}, 8 \mathrm{H})$. 


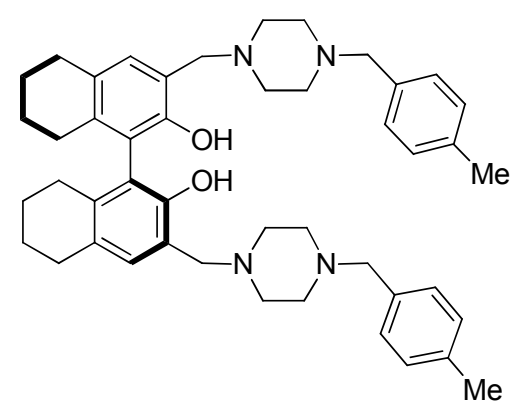

${ }^{1} \mathrm{H}$ NMR (600 MHz, $\left.\mathrm{CDCl}_{3}\right) \delta 10.66(\mathrm{~s}, 2 \mathrm{H}), 7.16(\mathrm{~d}, 4 \mathrm{H}, \mathrm{J}=7.2 \mathrm{~Hz}), 7.10(\mathrm{~d}, 4 \mathrm{H}$, $\mathrm{J}=7.8 \mathrm{~Hz}), 6.71(\mathrm{~s}, 2 \mathrm{H}), 3.80(\mathrm{~d}, 2 \mathrm{H}, \mathrm{J}=13.2 \mathrm{~Hz}), 3.60(\mathrm{~d}, 2 \mathrm{H}, \mathrm{J}=13.8 \mathrm{~Hz}), 3.43(\mathrm{~s}, 4 \mathrm{H})$, $2.54(\mathrm{~m}, 28 \mathrm{H}), 2.14(\mathrm{~m}, 2 \mathrm{H}), 1.70(\mathrm{~m}, 8 \mathrm{H})$.

\section{B6}

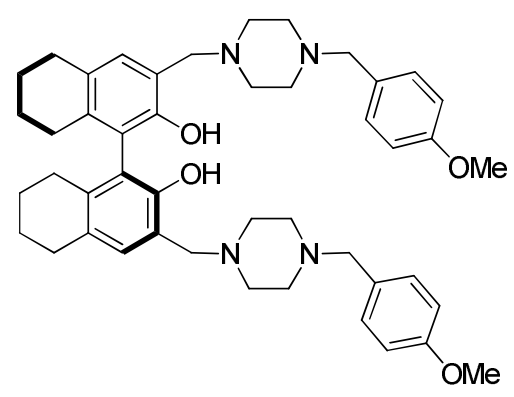

${ }^{1} \mathrm{H}$ NMR $\left(600 \mathrm{MHz}, \mathrm{CDCl}_{3}\right) \delta 7.16(\mathrm{~d}, 4 \mathrm{H}, \mathrm{J}=8.4 \mathrm{~Hz}), 6.81(\mathrm{~d}, 4 \mathrm{H}, \mathrm{J}=8.4 \mathrm{~Hz}), 6.68(\mathrm{~s}$, 2H), 3.78 (d, 2H, J=14.4 Hz), 3.76 (s, 6H), 3.53 (d, 2H, J=13.8 Hz), 3.38 (s, 4H), 2.42 $(\mathrm{m}, 24 \mathrm{H}), 1.70(\mathrm{~m}, 8 \mathrm{H})$.

B7

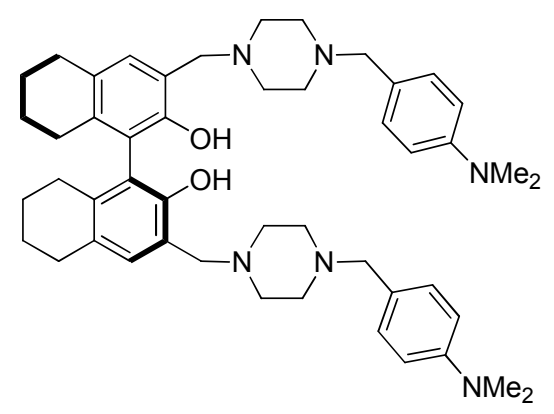


${ }^{1} \mathrm{H}$ NMR (600 MHz, $\left.\mathrm{CDCl}_{3}\right) \delta 10.75$ (s, 2H), 7.18 (d, 4H, J=8.4 Hz), 6.75 (s, 2H), $6.72(\mathrm{~d}, 4 \mathrm{H}, \mathrm{J}=9 \mathrm{~Hz}), 3.85(\mathrm{~d}, 2 \mathrm{H}, \mathrm{J}=13.8 \mathrm{~Hz}), 3.61$ (d, 2H, J=13.8 Hz), $3.42(\mathrm{~s}, 4 \mathrm{H})$, $2.96(\mathrm{~s}, 12 \mathrm{H}), 2.48(\mathrm{~m}, 24 \mathrm{H}), 1.74(\mathrm{~m}, 8 \mathrm{H})$.

\section{B8}<smiles>Oc1c(CN2CCN(Cc3ccc4c(c3)OCO4)CC2)cc2c(c1-c1c(O)c(CN3CCN(Cc4ccc5c(c4)OCO5)CC3)cc3c1CCCC3)CCCC2</smiles>

${ }^{1} \mathrm{H}$ NMR $\left(600 \mathrm{MHz}, \mathrm{CDCl}_{3}\right) \delta 10.63(\mathrm{~s}, 2 \mathrm{H}), 6.81(\mathrm{~d}, 2 \mathrm{H}, \mathrm{J}=1.2 \mathrm{~Hz}), 6.70(\mathrm{~m}, 6 \mathrm{H})$, $5.92(\mathrm{~s}, 4 \mathrm{H}), 3.80$ (d, 2H, J=13.8 Hz), 3.55 (d, 2H, J=13.8 Hz), 3.37 (s, 4H), 2.46 (m, 24H), $1.68(\mathrm{~m}, 8 \mathrm{H})$.

B9

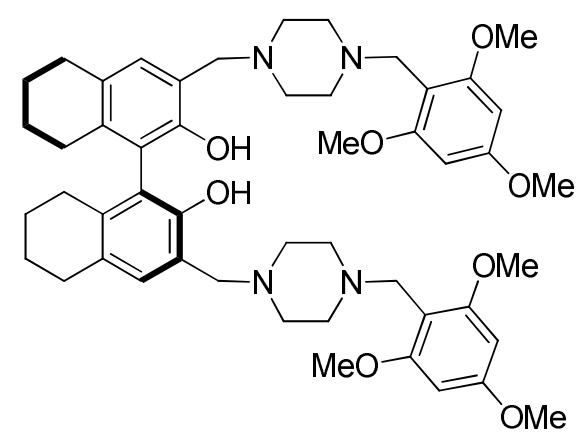

${ }^{1} \mathrm{H}$ NMR (600 MHz, $\left.\mathrm{CDCl}_{3}\right) \delta 10.77$ (s, 2H), 6.67 (s, 2H), 6.09 (s, 4H), $3.80(\mathrm{~s}, 6 \mathrm{H})$, 3.77 (d, 2H, J=13.2 Hz), 3.73 (s, 12H), 3.58 (s, 4H), 3.49 (d, 2H, J=13.8 Hz), 2.43 (m, 24H), $1.66(\mathrm{~m}, 8 \mathrm{H})$. 


\section{d. Synthesis and characterization of ligands C1-C8}

C1<smiles>Oc1c(CN2CCN(C(c3ccccc3)c3ccccc3)CC2)cc2c(c1-c1c(O)c(CN3CCN(C(c4ccccc4)c4ccccc4)CC3)cc3c1CCCC3)CCCC2</smiles>

Paraformaldehyde (23.8 mmol, $714.3 \mathrm{mg}, 4$ equiv) was added to a 2-neck round bottom flask fitted with condenser under nitrogen. The flask was then charged with dioxane $\left(20 \mathrm{~mL}\right.$, degassed), and the mixture was cooled to $0{ }^{\circ} \mathrm{C}$. 1-(diphenylmethyl)piperazine (23.8 mmol, $6.0 \mathrm{~g}, 4$ equiv) was added dropwise into the mixture over $20 \mathrm{~min}$. After the addition was completed, the ice bath was removed and the mixture was warmed to room temperature for $2 \mathrm{~h}$. It was then heated at $65^{\circ} \mathrm{C}$ for $18 \mathrm{~h}$. After the solution was cooled to room temperature, $(S)-\mathrm{H}_{8} \mathrm{BINOL}$ (6.0 mmol, $1.76 \mathrm{~g}, 1$ equiv) dissolved in dioxane $(10 \mathrm{~mL})$ was added, and the resulting solution was reheated to $65{ }^{\circ} \mathrm{C}$ for $18 \mathrm{~h}$. Upon completion of the reaction, the mixture was diluted with ethyl acetate $(20 \mathrm{~mL})$ and washed with saturated $\mathrm{NaHCO}_{3}(3 \times 20 \mathrm{~mL})$ and $\mathrm{H}_{2} \mathrm{O}(3 \times 20 \mathrm{~mL})$. The organic layer was then dried over anhydrous $\mathrm{Na}_{2} \mathrm{SO}_{4}$ and concentrated by rotary evaporation. The crude solid was washed with EtOH to give pure $\mathbf{C 1}$ as a white powder in 90\% yield $(4.44 \mathrm{~g}) .{ }^{1} \mathrm{H}$ NMR $\left(600 \mathrm{MHz}, \mathrm{CDCl}_{3}\right) \delta$ $10.46(\mathrm{~s}, 2 \mathrm{H}), 7.42(\mathrm{~m}, 8 \mathrm{H}), 7.28(\mathrm{~m}, 8 \mathrm{H}), 7.20(\mathrm{~m}, 4 \mathrm{H}), 6.74(\mathrm{~s}, 2 \mathrm{H}), 4.27(\mathrm{~m}, 2 \mathrm{H})$ $3.87(\mathrm{~d}, 2 \mathrm{H}, \mathrm{J}=13.8 \mathrm{~Hz}), 3.58(\mathrm{~d}, 2 \mathrm{H}, \mathrm{J}=13.8 \mathrm{~Hz}), 2.76-2.33(\mathrm{~m}, 22 \mathrm{H}), 2.17(\mathrm{~m}, 2 \mathrm{H})$, $1.72(\mathrm{~m}, 8 \mathrm{H}) .{ }^{13} \mathrm{C}\left\{{ }^{1} \mathrm{H}\right\} \operatorname{NMR}\left(150 \mathrm{MHz}, \mathrm{CDCl}_{3}\right) \delta$ 152.4, 142.6, 142.5, 135.6, 
$128.6,128.5,128.4,127.9,127.3,127.1,127.0,124.0,118.2,76.0,61.6,52.8,51.5$, 29.3, 27.0, 23.4, 23.3, $[\alpha]^{24}=16.5\left(\mathrm{c}=1.10, \mathrm{CHCl}_{3}\right) . \quad \mathrm{Mp} 182-185^{\circ} \mathrm{C} . \quad \mathrm{HRMS}$ [ESI(TOF)] for $\mathrm{C}_{56} \mathrm{H}_{63} \mathrm{~N}_{4} \mathrm{O}_{2}\left[\mathrm{M}+\mathrm{H}^{+}\right]$: m/z: calcd for: 823.4951; found: 823.4950 .

Ligands C2-C8 were prepared according to the similar procedure as ligand $\mathbf{C 1}$.

\section{$\mathrm{C2}$}

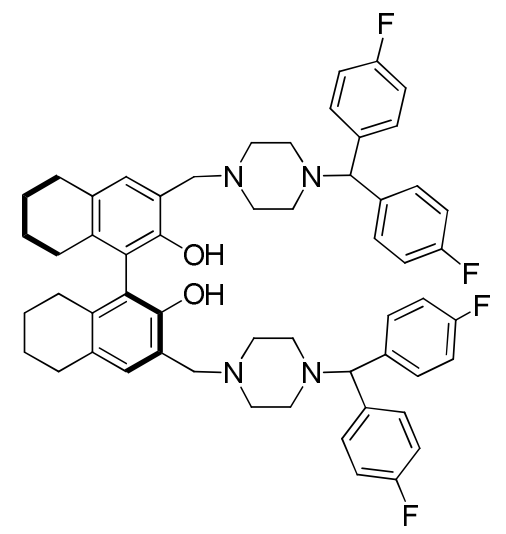

${ }^{1} \mathrm{H}$ NMR $\left(600 \mathrm{MHz}, \mathrm{CDCl}_{3}\right) \delta 10.54(\mathrm{~s}, 2 \mathrm{H}), 7.29(\mathrm{~m}, 8 \mathrm{H}), 6.94(\mathrm{~m}, 8 \mathrm{H}), 6.68(\mathrm{~s}, 2 \mathrm{H})$, $4.16(\mathrm{~s}, 2 \mathrm{H}), 3.85$ (d, 2H, J=13.8 Hz), 3.49 (d, 2H, J=13.8 Hz), $2.41(\mathrm{~m}, 24 \mathrm{H}), 1.63(\mathrm{~m}$, $8 \mathrm{H})$.

C3

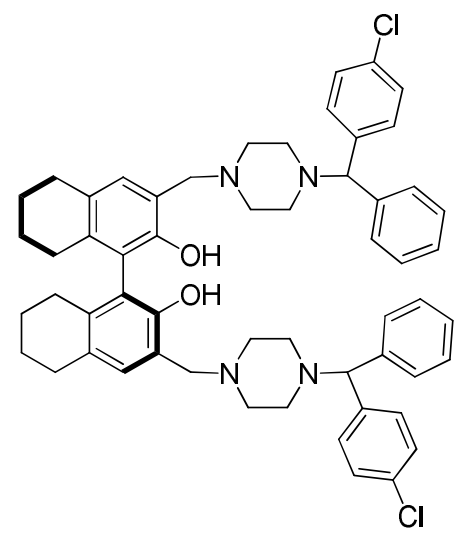

${ }^{1} \mathrm{H}$ NMR $\left(600 \mathrm{MHz}, \mathrm{CDCl}_{3}\right) \delta 10.58(\mathrm{~s}, 2 \mathrm{H}), 7.25(\mathrm{~m}, 18 \mathrm{H}), 6.68(\mathrm{~s}, 2 \mathrm{H}), 4.15(\mathrm{~s}, 2 \mathrm{H})$, $3.85(\mathrm{~d}, 2 \mathrm{H}, \mathrm{J}=13.8 \mathrm{~Hz}), 3.50(\mathrm{~d}, 2 \mathrm{H}, \mathrm{J}=13.8 \mathrm{~Hz}), 2.41(\mathrm{~m}, 24 \mathrm{H}), 1.63(\mathrm{~m}, 8 \mathrm{H})$. 


\section{C4}

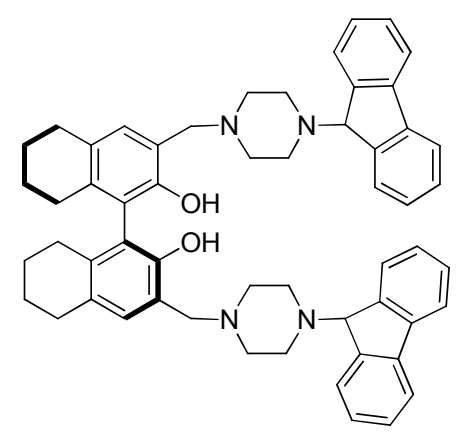

${ }^{1} \mathrm{H}$ NMR (600 MHz, $\left.\mathrm{CDCl}_{3}\right) \delta 10.54(\mathrm{~s}, 2 \mathrm{H}), 7.59$ (d, 4H, J=7.8 Hz), 7.55 (d, 2H, $\mathrm{J}=7.2 \mathrm{~Hz}), 7.42(\mathrm{~d}, 2 \mathrm{H}, \mathrm{J}=7.2 \mathrm{~Hz}), 7.35(\mathrm{t}, 2 \mathrm{H}, \mathrm{J}=7.8 \mathrm{~Hz}), 7.28(\mathrm{~m}, 4 \mathrm{H}), 7.13(\mathrm{t}, 2 \mathrm{H}$, $\mathrm{J}=7.2 \mathrm{~Hz}), 6.71(\mathrm{~s}, 2 \mathrm{H}), 4.79(\mathrm{~s}, 2 \mathrm{H}), 3.67(\mathrm{~s}, 4 \mathrm{H}), 2.60(\mathrm{~m}, 22 \mathrm{H}), 2.16(\mathrm{~m}, 2 \mathrm{H}), 1.69$ $(\mathrm{m}, 8 \mathrm{H})$.

\section{C5}

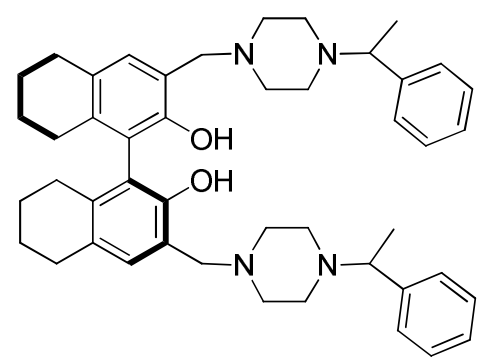

${ }^{1} \mathrm{H}$ NMR $\left(600 \mathrm{MHz}, \mathrm{CDCl}_{3}\right) \delta 10.66(\mathrm{~s}, 2 \mathrm{H}), 7.30(\mathrm{~m}, 10 \mathrm{H}), 6.72(\mathrm{~s}, 2 \mathrm{H}), 3.82(\mathrm{dd}$, 2H, J=21, $13.8 \mathrm{~Hz}), 3.57$ (dd, 2H, J=24, $13.8 \mathrm{~Hz}), 3.36$ (m, 2H), 2.45 (m, 24H), 1.67 (m, 8H), $1.35(\mathrm{~m}, 6 \mathrm{H})$.

\section{C6}

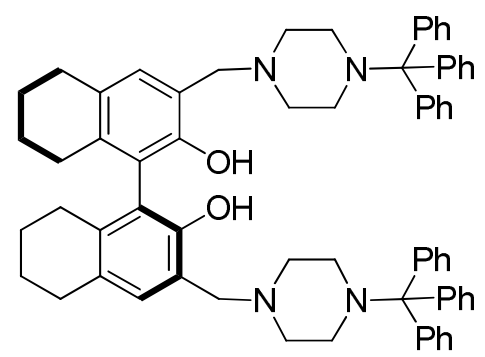

${ }^{1} \mathrm{H}$ NMR (600 MHz, $\left.\mathrm{CDCl}_{3}\right) \delta 10.25(\mathrm{~s}, 2 \mathrm{H}), 7.42(\mathrm{~m}, 14 \mathrm{H}), 7.16(\mathrm{~m}, 16 \mathrm{H}), 6.67(\mathrm{~s}$, 
2H), $3.71(\mathrm{~d}, 2 \mathrm{H}, \mathrm{J}=13.8 \mathrm{~Hz}), 3.61(\mathrm{~d}, 2 \mathrm{H}, \mathrm{J}=13.2 \mathrm{~Hz}), 2.46(\mathrm{~m}, 24 \mathrm{H}), 1.58(\mathrm{~m}, 8 \mathrm{H})$.

C7<smiles>Oc1c(CN2CCN(C(c3ccccc3)c3ccccc3)CC2)cc2ccccc2c1-c1c(O)c(CN2CCN(C(c3ccccc3)c3ccccc3)CC2)cc2ccccc12</smiles>

${ }^{1} \mathrm{H}$ NMR (600 MHz, $\left.\mathrm{CDCl}_{3}\right) \delta 11.39$ (s, 2H), 7.80 (d, 2H, J=7.8 Hz), 7.66 (s, 2H), $7.41(\mathrm{~m}, 8 \mathrm{H}), 7.27(\mathrm{~m}, 10 \mathrm{H}), 7.18(\mathrm{~m}, 6 \mathrm{H}), 7.11(\mathrm{~d}, 2 \mathrm{H}, \mathrm{J}=8.4 \mathrm{~Hz}), 4.18(\mathrm{~m}, 4 \mathrm{H}), 3.85$ $(\mathrm{d}, 2 \mathrm{H}, \mathrm{J}=13.8 \mathrm{~Hz}), 2.62(\mathrm{~m}, 16 \mathrm{H}) .{ }^{13} \mathrm{C}\left\{{ }^{1} \mathrm{H}\right\}$ NMR $\left(150 \mathrm{MHz}, \mathrm{CDCl}_{3}\right) \delta$ 153.6, $142.5,133.8,128.5,128.2,127.9,127.8,127.7,127.0,126.0,124.8,123.8,122.9$, $116.5,76.0,62.0,52.9,51.4$.

C8<smiles>Oc1c(CN2CCN(C(c3ccccc3)c3ccccc3)CC2)cc2cc(Br)ccc2c1-c1c(O)c(CN2CCN(C(c3ccccc3)c3ccccc3)CC2)cc2cc(Br)ccc12</smiles>

${ }^{1} \mathrm{H}$ NMR (600 MHz, $\left.\mathrm{CDCl}_{3}\right) \delta 11.59$ (s, 2H), 7.97 (s, 2H), 7.58 (s, 2H), 7.42 (m, 8H), $7.30(\mathrm{~m}, 10 \mathrm{H}), 7.21(\mathrm{~m}, 4 \mathrm{H}), 6.97(\mathrm{~d}, 2 \mathrm{H}, \mathrm{J}=9 \mathrm{~Hz}), 4.21(\mathrm{~s}, 2 \mathrm{H}), 4.15(\mathrm{~d}, 2 \mathrm{H}, \mathrm{J}=13.8$ $\mathrm{Hz}), 3.87(\mathrm{~d}, 2 \mathrm{H}, \mathrm{J}=13.8 \mathrm{~Hz}), 2.57(\mathrm{~m}, 16 \mathrm{H})$.

\section{e. Synthesis and characterization of ligands D1-D6}

Ligand D1 was prepared according to the similar procedure as ligand C1. 


\section{D1}<smiles>Oc1ccc2c(c1-c1c(CN3CCOCC3)cc3c(c1O)CCCC3)CCCC2</smiles>

${ }^{1} \mathrm{H}$ NMR $\left(600 \mathrm{MHz}, \mathrm{CDCl}_{3}\right) \delta 6.99(\mathrm{~d}, 1 \mathrm{H}, \mathrm{J}=8.4 \mathrm{~Hz}), 6.78(\mathrm{~m}, 2 \mathrm{H}), 3.69(\mathrm{~m}, 6 \mathrm{H})$, $2.75(\mathrm{~m}, 2 \mathrm{H}), 2.70(\mathrm{~m}, 2 \mathrm{H}), 2.55(\mathrm{~s}, 4 \mathrm{H}), 2.30(\mathrm{~m}, 2 \mathrm{H}), 2.15(\mathrm{~m}, 2 \mathrm{H}), 1.68(\mathrm{~m}, 8 \mathrm{H})$.

D2<smiles>COc1ccc2c(c1-c1c(CN3CCOCC3)cc3c(c1O)CCCC3)CCCC2</smiles>

(a) To a solution of $(S)-\mathrm{H}_{8} \mathrm{BINOL}\left(2.04 \mathrm{mmol}, 600 \mathrm{mg}, 1\right.$ equiv) and $\mathrm{K}_{2} \mathrm{CO}_{3}(10.2$ mmol, $1.4 \mathrm{~g}, 5$ equiv) in $20 \mathrm{~mL}$ THF was added MeI (2.04 mmol, $127.1 \mu \mathrm{L}, 1$ equiv) at room temperature under nitrogen. Then the reaction was heated to $50{ }^{\circ} \mathrm{C}$ and stirred for $24 \mathrm{~h}$. After cooled to room temperature, the mixture was quenched with water (10 $\mathrm{mL})$ and extracted with $\mathrm{CH}_{2} \mathrm{Cl}_{2}(3 \times 15 \mathrm{~mL})$. The organic layer was then dried over anhydrous $\mathrm{Na}_{2} \mathrm{SO}_{4}$ and concentrated by rotary evaporation. The crude mixture was purified by flash column chromatography on silica gel eluted with hexanes $/ \mathrm{CH}_{2} \mathrm{Cl}_{2}$ $(5 / 1)$ to give $O-\mathrm{Me}-(S)-\mathrm{H}_{8} \mathrm{BINOL}$ as a white powder in $70 \%$ yield $(440 \mathrm{mg})$.

(b) Paraformaldehyde (5.0 mmol, $150 \mathrm{mg}, 5$ equiv) was added to a 2-neck round bottom flask fitted with condenser under nitrogen. The flask was then charged with dioxane $(10 \mathrm{~mL}$, degassed $)$, and the mixture was cooled to $0{ }^{\circ} \mathrm{C}$. Morpholine $(5.0$ mmol, $431 \mathrm{uL}, 5$ equiv) was added dropwise into the mixture over $20 \mathrm{~min}$. After the addition was completed, the ice bath was removed and the mixture was warmed to 
room temperature for $2 \mathrm{~h}$. It was then heated at $65^{\circ} \mathrm{C}$ for $18 \mathrm{~h}$. After the solution was cooled to room temperature, $O-\mathrm{Me}-(S)-\mathrm{H}_{8} \mathrm{BINOL}(1.0 \mathrm{mmol}, 308 \mathrm{mg}, 1$ equiv) dissolved in dioxane $(5 \mathrm{~mL})$ was added, and the resulting solution was reheated to 95 ${ }^{\circ} \mathrm{C}$ for $20 \mathrm{~h}$. Upon completion of the reaction, the mixture was diluted with ethyl acetate $(15 \mathrm{~mL})$ and washed with saturated $\mathrm{NaHCO}_{3}(3 \times 15 \mathrm{~mL})$ and $\mathrm{H}_{2} \mathrm{O}(3 \times 15$ $\mathrm{mL}$ ). The organic layer was then dried over anhydrous $\mathrm{Na}_{2} \mathrm{SO}_{4}$ and concentrated by rotary evaporation. The crude mixture was purified by flash column chromatography on silica gel eluted with hexanes/ethyl acetate (20/1 to 10/1) to give pure D2 as a white powder in 65\% yield $(265 \mathrm{mg}) . \quad{ }^{1} \mathrm{H} \mathrm{NMR}\left(600 \mathrm{MHz}, \mathrm{CDCl}_{3}\right) \delta 10.31(\mathrm{~s}, 1 \mathrm{H})$, $7.12(\mathrm{~d}, 1 \mathrm{H}, \mathrm{J}=8.4 \mathrm{~Hz}), 6.87(\mathrm{~d}, 1 \mathrm{H}, \mathrm{J}=8.4 \mathrm{~Hz}), 6.81(\mathrm{~s}, 1 \mathrm{H}), 3.83$ (d, 1H, J = 13.8 $\mathrm{Hz}), 3.76(\mathrm{~m}, 7 \mathrm{H}), 3.70(\mathrm{~d}, 1 \mathrm{H}, \mathrm{J}=13.8 \mathrm{~Hz}), 2.83(\mathrm{~m}, 4 \mathrm{H}), 2.62(\mathrm{~s}, 4 \mathrm{H}), 2.38(\mathrm{~m}, 2 \mathrm{H})$, $2.20(\mathrm{~m}, 2 \mathrm{H}), 1.76(\mathrm{~m}, 8 \mathrm{H}) .{ }^{13} \mathrm{C}\left\{{ }^{1} \mathrm{H}\right\}$ NMR $\left(150 \mathrm{MHz}, \mathrm{CDCl}_{3}\right) \delta$ 154.8, 152.0, $136.5,136.2,129.6,129.0,128.6,127.5,125.7,124.3,117.7,109.2,66.7,61.9,56.1$ 53.0, 29.5, 29.3, 27.2, 27.1, 23.4, 23.35, 23.32, 23.2. HRMS [ESI(TOF)] for $\mathrm{C}_{26} \mathrm{H}_{34} \mathrm{NO}_{3}\left[\mathrm{M}+\mathrm{H}^{+}\right]: \mathrm{m} / \mathrm{z}$ : calcd for: 408.2539; found: 408.2536.

Ligand D3 was prepared according to the similar procedure as ligand D2.

\section{D3}<smiles>COc1ccc2c(c1-c1c(O)c(CN3CCOCC3)cc3c1CCCC3)CCCC2</smiles>

${ }^{1} \mathrm{H}$ NMR $\left(600 \mathrm{MHz}, \mathrm{CDCl}_{3}\right) \delta 10.21(\mathrm{~s}, 1 \mathrm{H}), 6.94(\mathrm{~d}, 1 \mathrm{H}, \mathrm{J}=7.8 \mathrm{~Hz}), 6.71(\mathrm{~s}, 1 \mathrm{H})$, $6.66(\mathrm{~d}, 1 \mathrm{H}, \mathrm{J}=8.4 \mathrm{~Hz}), 3.74(\mathrm{~d}, 1 \mathrm{H}, \mathrm{J}=13.2 \mathrm{~Hz}), 3.68(\mathrm{~s}, 4 \mathrm{H}), 3.57$ (d, 1H, J=13.2 Hz), 
$2.77(\mathrm{~m}, 2 \mathrm{H}), 2.70(\mathrm{t}, 2 \mathrm{H}, \mathrm{J}=6 \mathrm{~Hz}), 2.55(\mathrm{~s}, 4 \mathrm{H}), 2.45(\mathrm{~m}, 2 \mathrm{H}), 2.14(\mathrm{~m}, 2 \mathrm{H}), 1.68(\mathrm{~m}$, $8 \mathrm{H})$.

\section{D4}

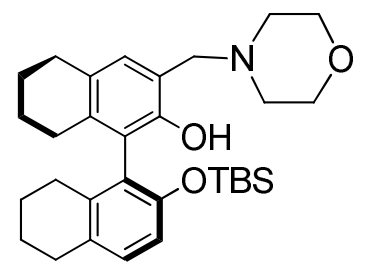

(a) To a solution of $(S)-\mathrm{H}_{8}$ BINOL (1.7 mmol, $500 \mathrm{mg}, 1$ equiv) in $10 \mathrm{~mL}$ THF was added $\mathrm{nBuLi}\left(2.0 \mathrm{mmol}, 2.5 \mathrm{M}\right.$ in hexanes, $0.8 \mathrm{~mL}, 1.2$ equiv) at $0{ }^{\circ} \mathrm{C}$ under nitrogen. The reaction was stirred for $20 \mathrm{~min}$. Then $\mathrm{TBSCl}(2.0 \mathrm{mmol}, 306 \mathrm{mg}, 1.2$ equiv) in 5 $\mathrm{mL}$ THF was added and the resulting solution was warmed to room temperature. After $20 \mathrm{~h}$, the reaction was quenched with saturated $\mathrm{NH}_{4} \mathrm{Cl}$ solution $(10 \mathrm{~mL})$ and extracted with $\mathrm{CH}_{2} \mathrm{Cl}_{2}(3 \times 15 \mathrm{~mL})$. The organic layer was then dried over anhydrous $\mathrm{Na}_{2} \mathrm{SO}_{4}$ and concentrated by rotary evaporation. The crude mixture was purified by flash column chromatography on silica gel eluted with hexanes/ $\mathrm{CH}_{2} \mathrm{Cl}_{2}(8 / 1$ to $5 / 1)$ to give $O$-TBS- $(S)-\mathrm{H}_{8}$ BINOL as a white powder in $74 \%$ yield $(512 \mathrm{mg})$.

(b) Paraformaldehyde (6.25 mmol, $188 \mathrm{mg}, 5$ equiv) was added to a 2-neck round bottom flask fitted with condenser under nitrogen. The flask was then charged with dioxane $\left(10 \mathrm{~mL}\right.$, degassed), and the mixture was cooled to $0{ }^{\circ} \mathrm{C}$. Morpholine $(6.25$ mmol, $548 \mathrm{uL}, 5$ equiv) was added dropwise into the mixture over $20 \mathrm{~min}$. After the addition was completed, the ice bath was removed and the mixture was warmed to room temperature for $2 \mathrm{~h}$. It was then heated at $65^{\circ} \mathrm{C}$ for $18 \mathrm{~h}$. After the solution was cooled to room temperature, $O$-TBS- $(S)-\mathrm{H}_{8} \mathrm{BINOL}(1.25 \mathrm{mmol}, 512 \mathrm{mg}, 1$ equiv) dissolved in dioxane $(5 \mathrm{~mL})$ was added, and the resulting solution was reheated to 95 
${ }^{\circ} \mathrm{C}$ for $20 \mathrm{~h}$. Upon completion of the reaction, the mixture was diluted with ethyl acetate $(15 \mathrm{~mL})$ and washed with saturated $\mathrm{NaHCO}_{3}(3 \times 15 \mathrm{~mL})$ and $\mathrm{H}_{2} \mathrm{O}(3 \times 15$ $\mathrm{mL}$ ). The organic layer was then dried over anhydrous $\mathrm{Na}_{2} \mathrm{SO}_{4}$ and concentrated by rotary evaporation. The crude mixture was purified by flash column chromatography on silica gel with hexanes/ethyl acetate $(25 / 1$ to $15 / 1)$ to give pure D4 as a white powder in 59\% yield (374 mg). ${ }^{1} \mathrm{H}$ NMR (600 MHz, $\left.\mathrm{CDCl}_{3}\right) \delta 10.21(\mathrm{~s}, 1 \mathrm{H}), 6.97(\mathrm{~d}$, 1H, J=8.4 Hz), $6.71(\mathrm{~m}, 2 \mathrm{H}), 3.79(\mathrm{~d}, 1 \mathrm{H}, \mathrm{J}=13.2 \mathrm{~Hz}), 3.70(\mathrm{~s}, 4 \mathrm{H}), 3.54(\mathrm{~d}, 1 \mathrm{H}$, $\mathrm{J}=13.8 \mathrm{~Hz}), 2.78(\mathrm{~m}, 2 \mathrm{H}), 2.71(\mathrm{~m}, 2 \mathrm{H}), 2.60(\mathrm{~m}, 4 \mathrm{H}), 2.48(\mathrm{~m}, 2 \mathrm{H}), 2.16(\mathrm{~m}, 2 \mathrm{H})$, $1.70(\mathrm{~m}, 8 \mathrm{H}), 0.70(\mathrm{~s}, 9 \mathrm{H}), 0.16(\mathrm{~s}, 3 \mathrm{H}),-0.01(\mathrm{~s}, 3 \mathrm{H}) .{ }^{13} \mathrm{C}\left\{{ }^{1} \mathrm{H}\right\} \mathrm{NMR}(150 \mathrm{MHz}$ $\left.\mathrm{CDCl}_{3}\right) \delta 152.1,150.1,137.0,136.4,129.6,128.8,128.08,128.06,127.5,124.7$ $117.6,116.0,66.7,61.9,52.9,29.5,29.4,27.3,27.0,25.3,23.4,23.33,23.30,23.2$, 17.7, -4.1, -4.8. HRMS [ESI(TOF)] for $\mathrm{C}_{31} \mathrm{H}_{46} \mathrm{NO}_{3} \mathrm{Si}\left[\mathrm{M}+\mathrm{H}^{+}\right]$: $\mathrm{m} / \mathrm{z}$ : calcd for: 508.3247; found: 508.3253 .

Ligand D5 were prepared according to the similar procedure as ligand D2.

\section{D5}<smiles>CCOC(=O)COc1ccc2c(c1-c1c(O)c(CN3CCOCC3)cc3c1CCCC3)CCCC2</smiles>

${ }^{1} \mathrm{H}$ NMR $\left(600 \mathrm{MHz}, \mathrm{CDCl}_{3}\right) \delta 7.01(\mathrm{~d}, 1 \mathrm{H}, \mathrm{J}=8.4 \mathrm{~Hz}), 6.74(\mathrm{~m}, 2 \mathrm{H}), 4.44(\mathrm{~d}, 1 \mathrm{H}$, $\mathrm{J}=16.8 \mathrm{~Hz}), 4.38(\mathrm{~d}, 1 \mathrm{H}, \mathrm{J}=16.2 \mathrm{~Hz}), 4.14(\mathrm{~m}, 2 \mathrm{H}), 3.69(\mathrm{~m}, 6 \mathrm{H}), 2.76(\mathrm{~m}, 2 \mathrm{H}), 2.70$ (m, 2H), $2.55(\mathrm{~s}, 3 \mathrm{H}), 2.47(\mathrm{~m}, 1 \mathrm{H}), 2.35(\mathrm{~m}, 1 \mathrm{H}), 2.15(\mathrm{~m}, 1 \mathrm{H}), 2.07(\mathrm{~m}, 1 \mathrm{H}), 1.67$ (m, 8H), $1.21(\mathrm{t}, 3 \mathrm{H}, \mathrm{J}=7.2 \mathrm{~Hz})$. 
Ligand D6 was prepared according to the literature procedure. ${ }^{22}$

\section{D6}

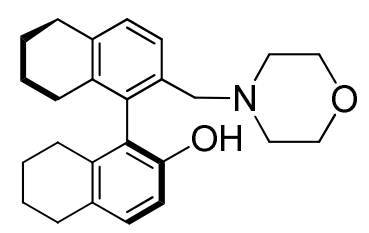

$[\alpha]^{22}=61.3\left(\mathrm{c}=3.0, \mathrm{CHCl}_{3}\right) .{ }^{1} \mathrm{H} \mathrm{NMR}\left(600 \mathrm{MHz}, \mathrm{CDCl}_{3}\right) \delta 8.97(\mathrm{~s}, 1 \mathrm{H}), 7.02(\mathrm{q}$, 2H, J=4.2 Hz), $6.97(\mathrm{~d}, 1 \mathrm{H}, \mathrm{J}=7.8 \mathrm{~Hz}), 6.87$ (d, 1H, J=8.4 Hz), $3.70(\mathrm{~m}, 2 \mathrm{H}), 3.59(\mathrm{~m}$, 2H), $3.32(\mathrm{~d}, 1 \mathrm{H}, \mathrm{J}=12 \mathrm{~Hz}), 2.96(\mathrm{~d}, 1 \mathrm{H}, \mathrm{J}=12 \mathrm{~Hz}), 2.80(\mathrm{~m}, 2 \mathrm{H}), 2.74(\mathrm{~m}, 2 \mathrm{H}), 2.57$ (m, 2H), $2.22(\mathrm{~m}, 2 \mathrm{H}), 2.17(\mathrm{~m}, 1 \mathrm{H}), 2.13(\mathrm{~m}, 1 \mathrm{H}), 2.05(\mathrm{~m}, 1 \mathrm{H}), 1.95(\mathrm{~m}, 1 \mathrm{H}), 1.68$ $(\mathrm{m}, 8 \mathrm{H}) .{ }^{13} \mathrm{C}\left\{{ }^{1} \mathrm{H}\right\}$ NMR $\left(150 \mathrm{MHz}, \mathrm{CDCl}_{3}\right) \delta 151.5,138.1,137.9,136.8,135.1$, $132.0,130.0,129.6,129.3,127.8,127.4,117.4,66.4,62.4,52.9,30.0,29.4,27.6,27.3$, $23.3,23.2,23.1,22.7$.

\section{Asymmetric Reformatsky reaction of benzaldehyde catalyzed by ligand C1}

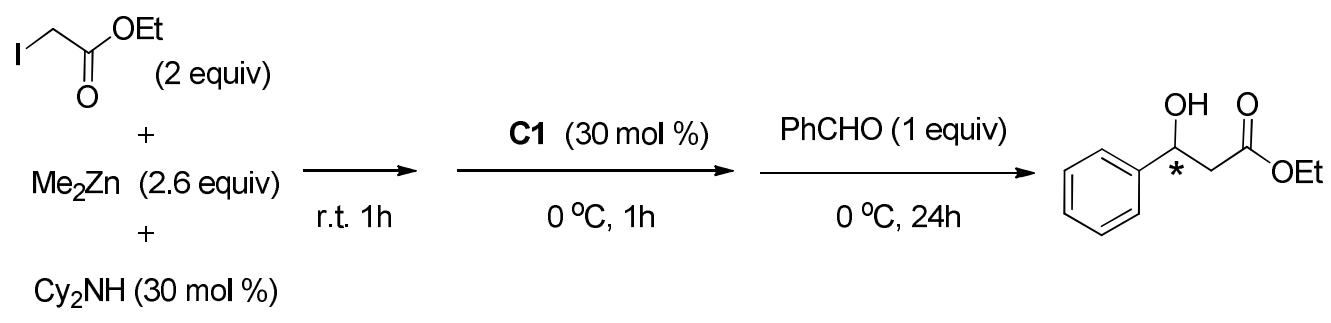

In a $10 \mathrm{~mL}$ round bottom flask, THF ( $4 \mathrm{~mL}$ ), ethyl iodoacetate (2 equiv), $\mathrm{Me}_{2} \mathrm{Zn}$ (2.6 equiv) and dicyclohexylamine (30 mol \%) were added in dry box. The reaction mixture was stirred for $1 \mathrm{~h}$ at room temperature and cooled to $0{ }^{\circ} \mathrm{C}, \mathbf{C 1}(30 \mathrm{~mol} \%)$ was added and the mixture was stirred for $1 \mathrm{~h}$ at $0{ }^{\circ} \mathrm{C}$. Benzaldehyde $(0.35 \mathrm{mmol}, 1$ equiv) was then added and the stirring continued for $24 \mathrm{~h}$ at $0{ }^{\circ} \mathrm{C}$. The reaction was quenched with $1 \mathrm{~mL}$ saturated $\mathrm{NH}_{4} \mathrm{Cl}$ aqueous solution and extracted with $\mathrm{CH}_{2} \mathrm{Cl}_{2}(3$ 
$\mathrm{mL} \times 3$ ). The combined organic layer was washed with brine, dried over $\mathrm{Na}_{2} \mathrm{SO}_{4}$ before concentrated on vacuo. The residue was purified by column chromatography (hexanes/EA=3:1) to give ethyl 3-hydroxy-3-phenylpropanoate as a colorless oil in 80\% yield. 78\% ee determined by HPLC analysis: CHIRALCEL OD column, 90:10 hexanes: ${ }^{i} \mathrm{PrOH}$, flow rate $=1.0 \mathrm{~mL} / \mathrm{min}, \lambda=220 \mathrm{~nm}$, retention time: $\mathrm{t}_{\text {major }}=8.5 \mathrm{~min}$, $\mathrm{t}_{\text {minor }}=10.5 \mathrm{~min} .{ }^{1} \mathrm{H}$ NMR $\left(300 \mathrm{MHz}, \mathrm{CDCl}_{3}\right) \delta 7.33(\mathrm{~m}, 5 \mathrm{H}), 5.13(\mathrm{~m}, 1 \mathrm{H}), 4.20(\mathrm{q}$, 2H, J=6 Hz), $3.29(\mathrm{~s}, 1 \mathrm{H}), 2.73(\mathrm{~m}, 2 \mathrm{H}), 1.26(\mathrm{t}, 3 \mathrm{H}, \mathrm{J}=9 \mathrm{~Hz})$. 


\section{References}

1. Reformatsky, S. Ber. Dtsch. Chem. Ges. 1887, 20, 1210-1211.

2. Ocampo, R.; Dolbier Jr., W. R. Tetrahedron 2004, 60, 9325-9374.

3. Cozzi, P. G. Angew. Chem. Int. Ed. 2007, 46, 2568-2571.

4. a) Yu, L. -T.; Ho, M. -T.; Chang, C. -Y.; Yang, T. -K. Tetrahedron: Asymmetry 2007, 18, 949-962. b) Orsini, F.; Sello, G.; Manzo, A. M.; Lucci, E. M. Tetrahedron: Asymmetry 2005, 16, 1913-1918. c) Grellepois, F. J. Org. Chem. 2013, 78, 1127-1137.

5. a) Cozzi, P. G.; Rivalta, E. Angew. Chem. Int. Ed. 2005, 44, 3600-3603. b) Kloetzing, R. J.; Thaler, T.; Knochel, P. Org. Lett. 2006, 8, 1125-1128. c) Fornalczyk, M.; Singh, K.; Stuart, A. M. Chem. Commun. 2012, 48, 3500-3502. d) Xu, X. -H.; Qiu, X. -L.; Qing, F. -L. Tetrahedron 2008, 64, 7353-7361.

6. Laroche, M. -F.; Belotti, D.; Cossy, J. Org. Lett. 2005, 7, 171-173.

7. Adrian Jr., J. C.; Snapper, M. L. J. Org. Chem. 2003, 68, 2143-2150.

8. Kanai, K.; Wakabayashi, H.; Honda, T. Org. Lett. 2000, 2, 2549-2551.

9. Dondoni, A.; Massi, A.; Sabbatini, S. Chem. Eur. J. 2005, 11, 7110-7125.

10. Cozzi, P. G. Angew. Chem. Int. Ed. 2006, 45, 2951-2954.

11. Cozzi, P. G. Adv. Synth. Catal. 2006, 348, 2075-2079.

12. Fernández-Ibánez, M. A.; Maciá, B.; Minnaard, A. J.; Feringa, B. L. Angew. Chem. Int. Ed. 2008, 47, 1317-1319.

13. Fernández-Ibánez, M. A.; Maciá, B.; Minnaard, A. J.; Feringa, B. L. Org. Lett. 
2008, 10, 4041-4044.

14. Tanaka, T.; Hayashi, M. Chem. Lett. 2008, 37, 1298-1299.

15. Wolf, C.; Moskowitz, M. J. Org. Chem. 2011, 76, 6372-6376.

16. Cozzi, P. G.; Benfatti, F.; Guiteras Capdevila, M.; Mignogna, A. Chem. Commun. 2008, 3317-3318.

17. Kitamura, M.; Suga, S.; Niwa, M.; Noyori, R. J. Am. Chem. Soc 1995, 117, $4832-4842$.

18. Lewínski, J.; Śliwińki, W.; Dranka, M.; Justiniak, I. ; Lipkowski, J. Angew. Chem. Int. Ed. 2006, 45, 4826-4829.

19. Yamada, K. -I.; Yamamoto, Y.; Maekawa, M.; Akindele, T.; Umeki, H.; Tomioka, K. Org. Lett. 2006, 8, 87-89.

20. Mileo, E.; Benfatii, F.; Cozzi, P. G.; Lucarini, M. Chem. Commun. 2009, 469-470.

21. (a) Liu, L.; Pu, L. Tetrahedron 2004, 60, 7427-7430. (b) Qin, Y. -C.; Pu, L. Angew. Chem. Int. Ed. 2006, 45, 273-277. (c) Qin, Y. -C.; Liu, L.; Sabat, M.; Pu, L. Tetrahedron 2006, 62, 9335-9348. (d) Turlington, M.; Pu, L. Org. Synth. 2010, 87, 59-67. (e) DeBerardinis, A. M.; Turlington, M.; Ko, J.; Sole, L.; Pu, L. J. Org. Chem. 2010, 75, 2836-2850. (f) DeBerardinis, A. M.; Turlington, M.; Pu, L. Angew. Chem. Int. Ed. 2011, 123, 2416 -2418. (g) Gu, S. -X.; Huang, W. -C.; Wu, X. -D.; Ying, J.; Pu, L. Syn. Comm. 2015, 45, 1541-1545. (h) Pu, L. Acc. Chem. Res. 2014, 47(5), 1523-1535.

22. Ko, D. -H.; Kim, K. H.; Ha, D. -C. Org. Lett. 2002, 4, 3759-3762. 
Appendix 


\section{Chapter 2}

${ }^{1} \mathrm{H}$ NMR and ${ }^{13} \mathbf{C}$ NMR Spectra (All the NMR spectra were obtained in $\mathrm{CDCl}_{3}$ unless indicated otherwise)

Chiral Propargylic Alcohols

${ }^{1} \mathrm{H}$ NMR of $(R)-\mathbf{1 a}$

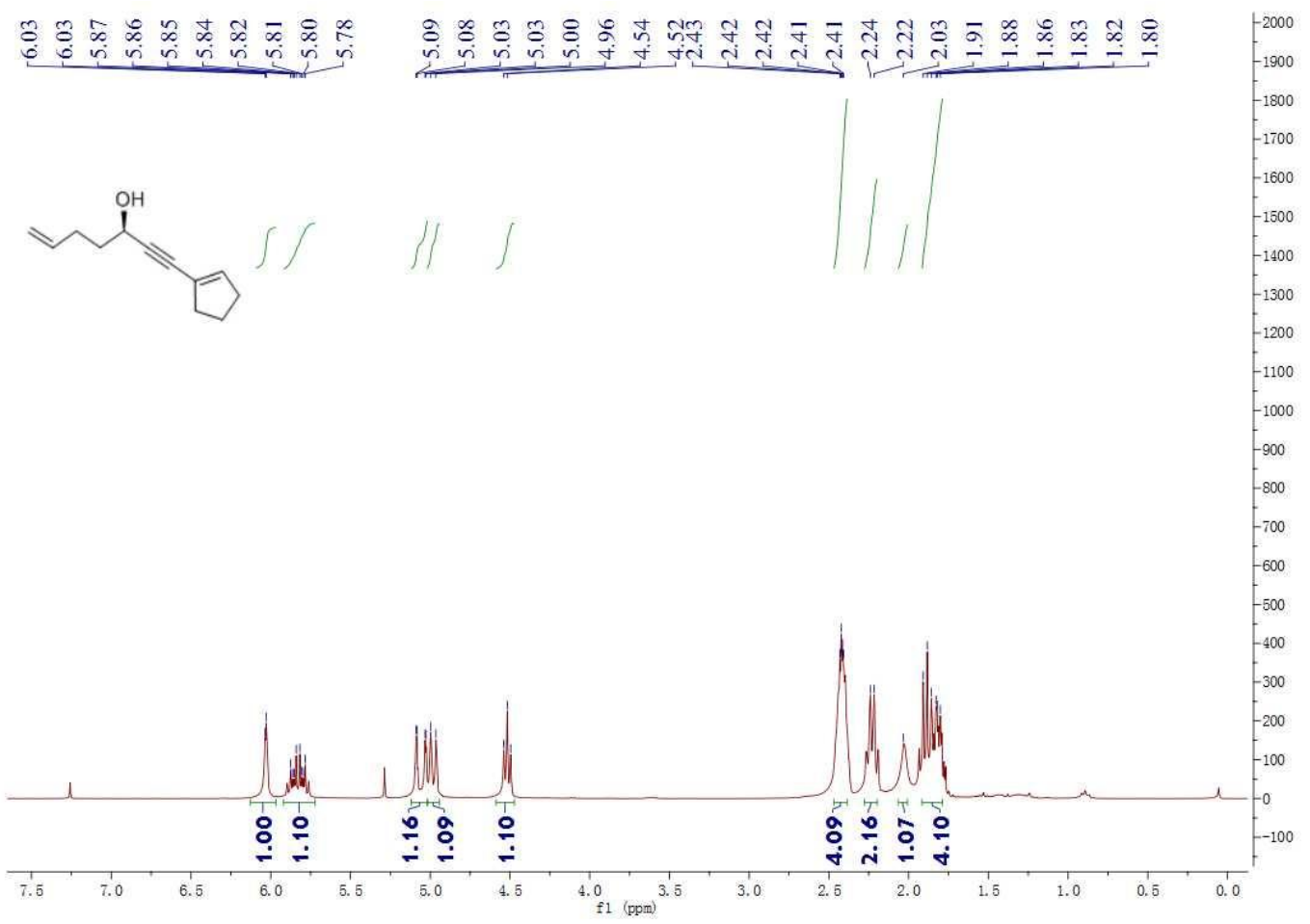

${ }^{13} \mathrm{C}$ NMR of $(R)-\mathbf{1 a}$

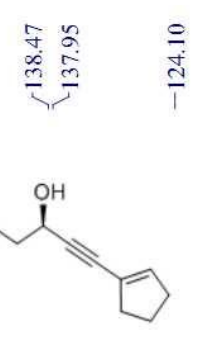

$\underset{\substack{\text { i } \\ i}}{\substack{\infty \\ i}}$

$n$
ช
1

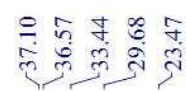

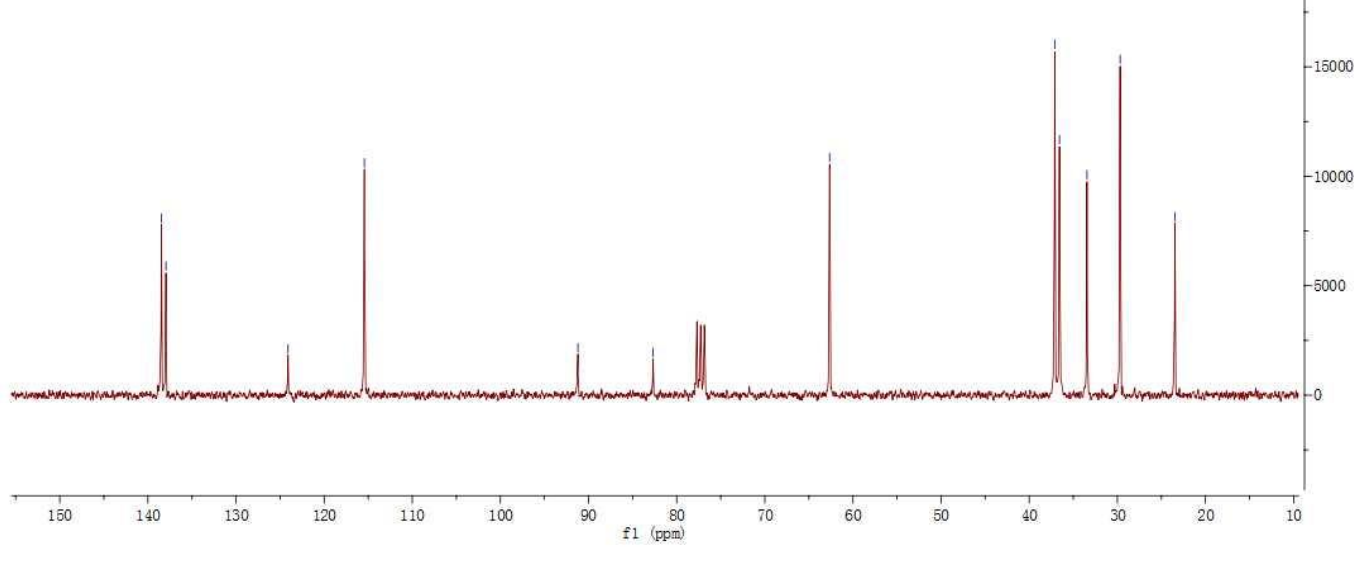


${ }^{1} \mathrm{H}$ NMR of $(R)-\mathbf{1 b}$

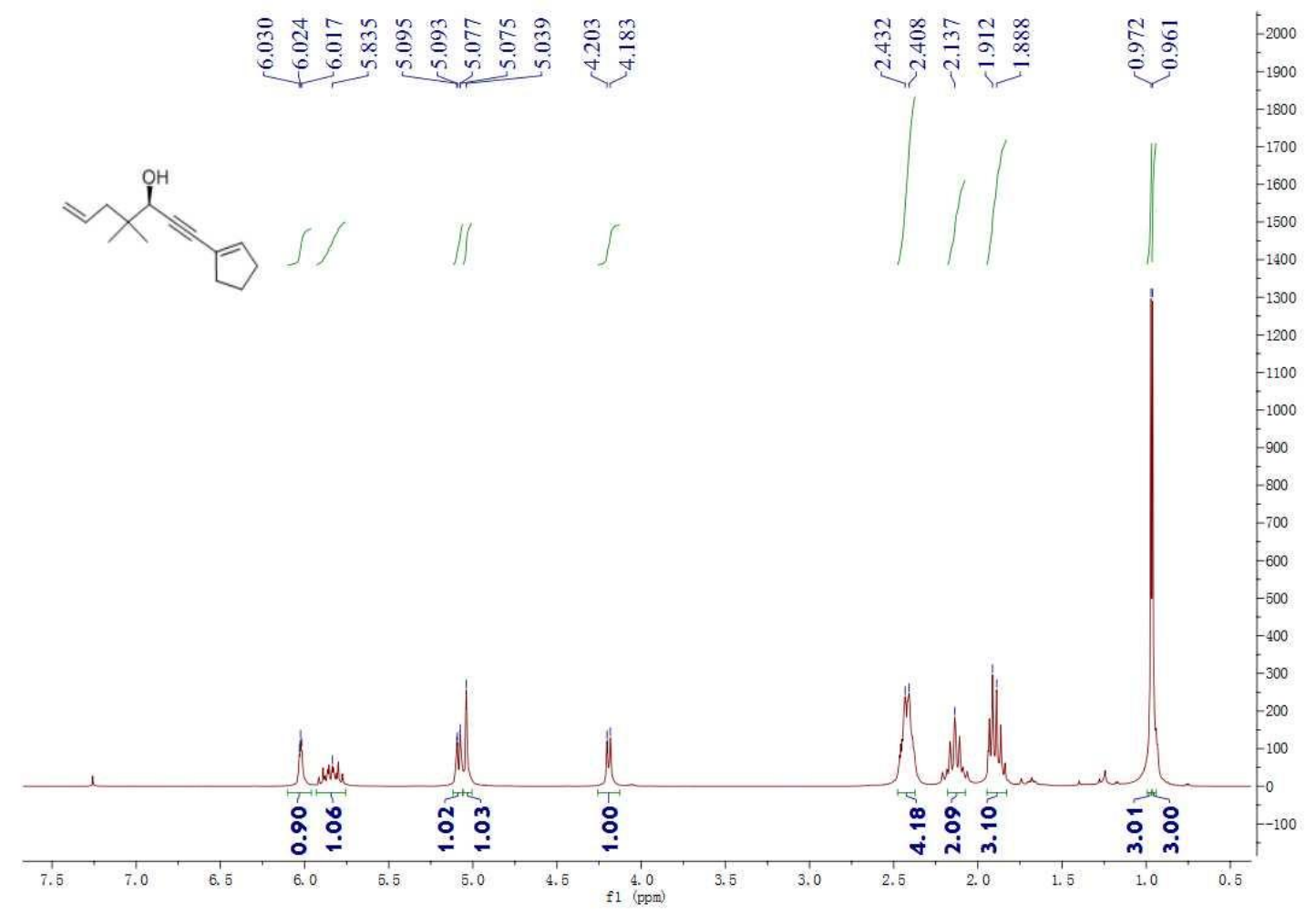

${ }^{13} \mathrm{C}$ NMR of $(R)-\mathbf{1 b}$

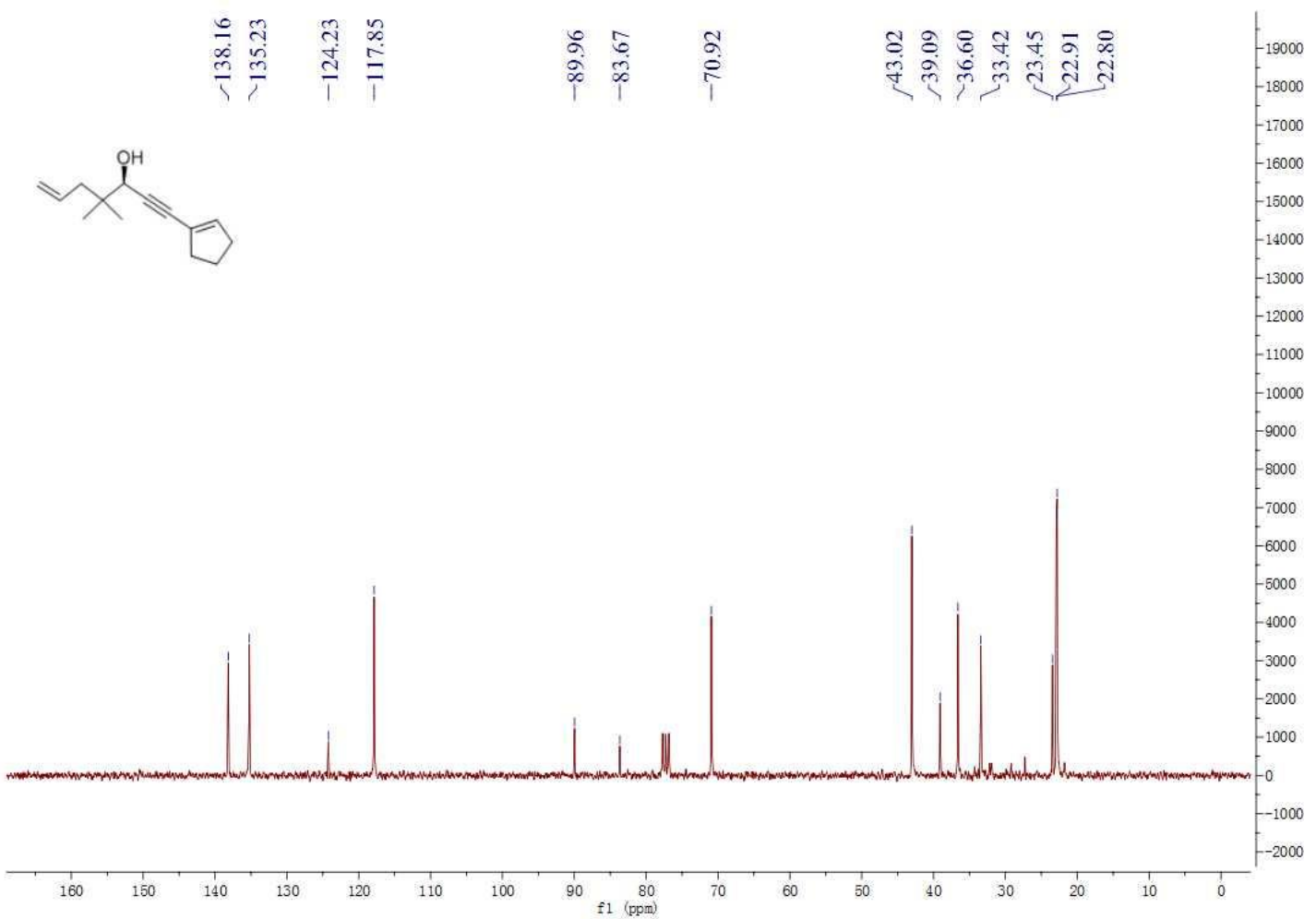


${ }^{1} \mathrm{H}$ NMR of $(R)-\mathbf{1 c}$

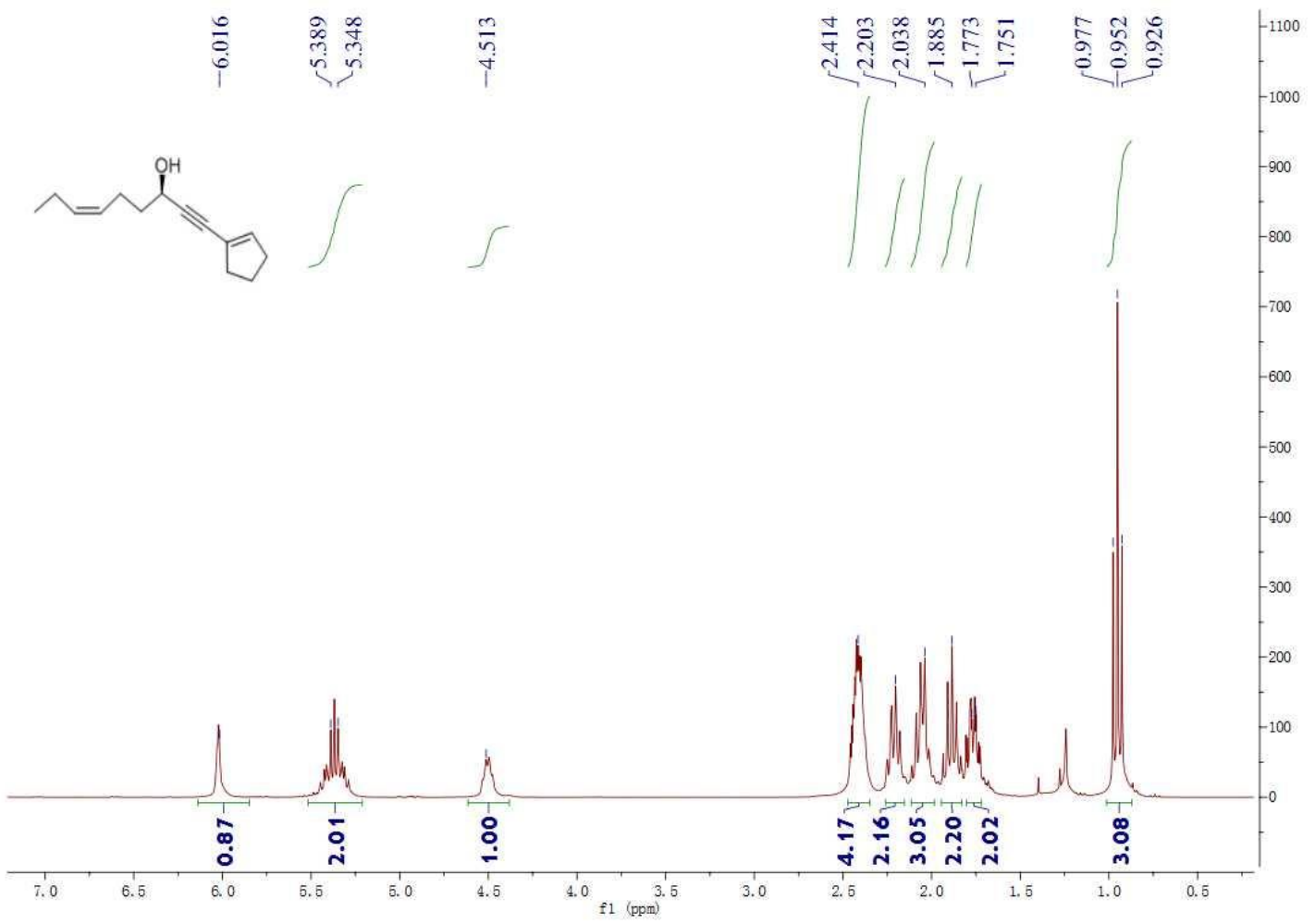

${ }^{13} \mathrm{C}$ NMR of $(R)-\mathbf{1 c}$

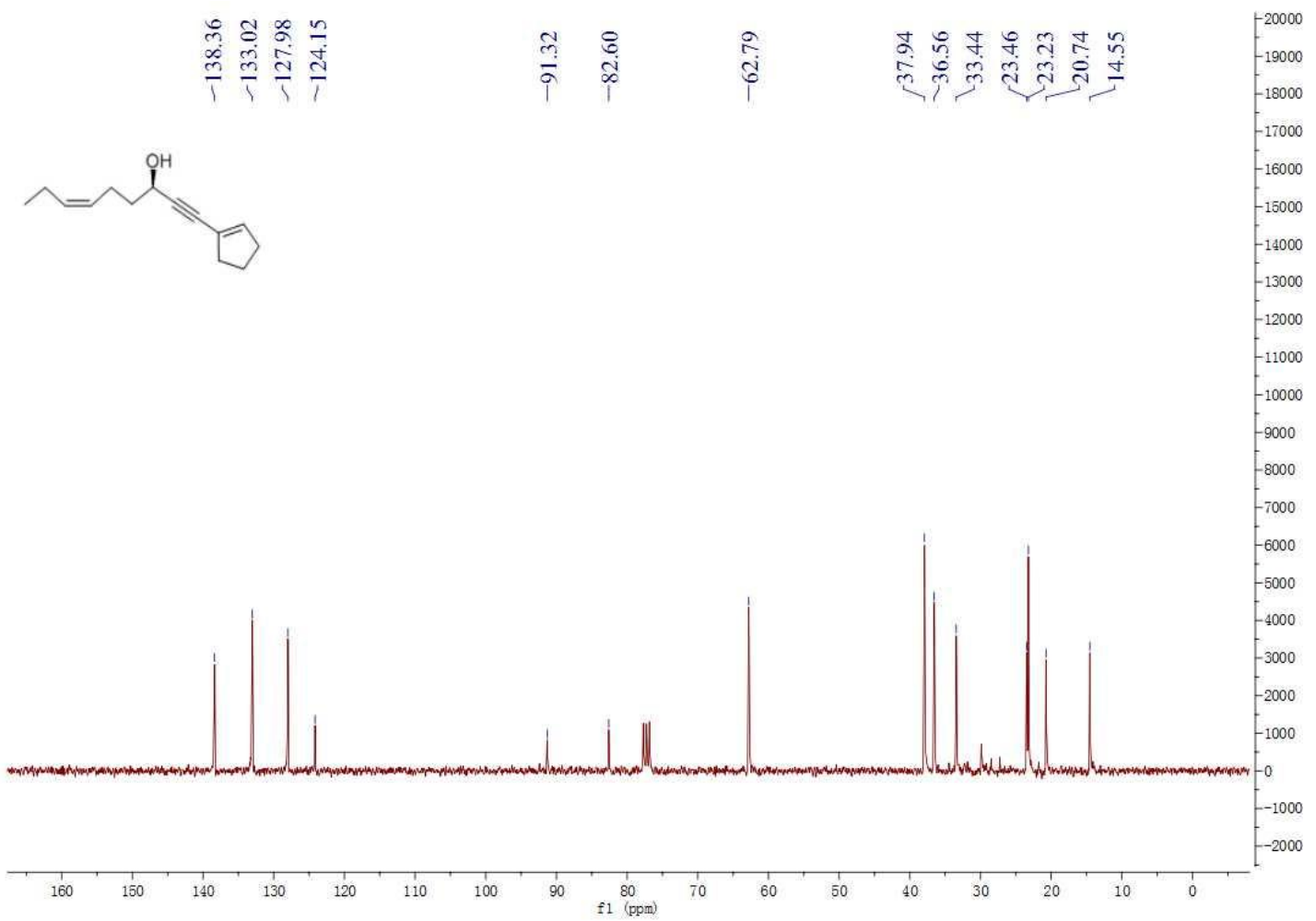


${ }^{1} \mathrm{H}$ NMR of $(R)-\mathbf{1 d}$

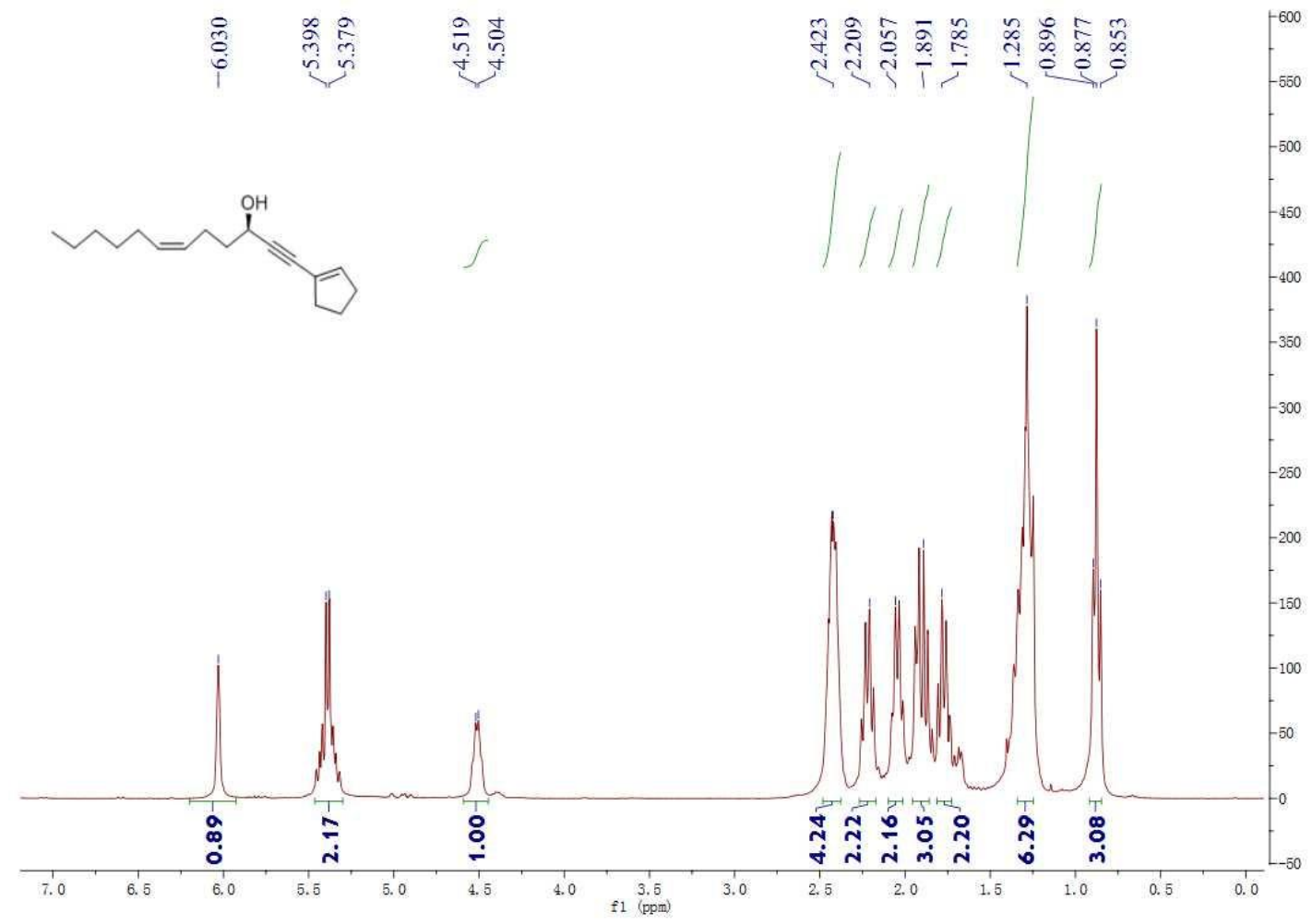

${ }^{13} \mathrm{C}$ NMR of $(R)-\mathbf{1 d}$

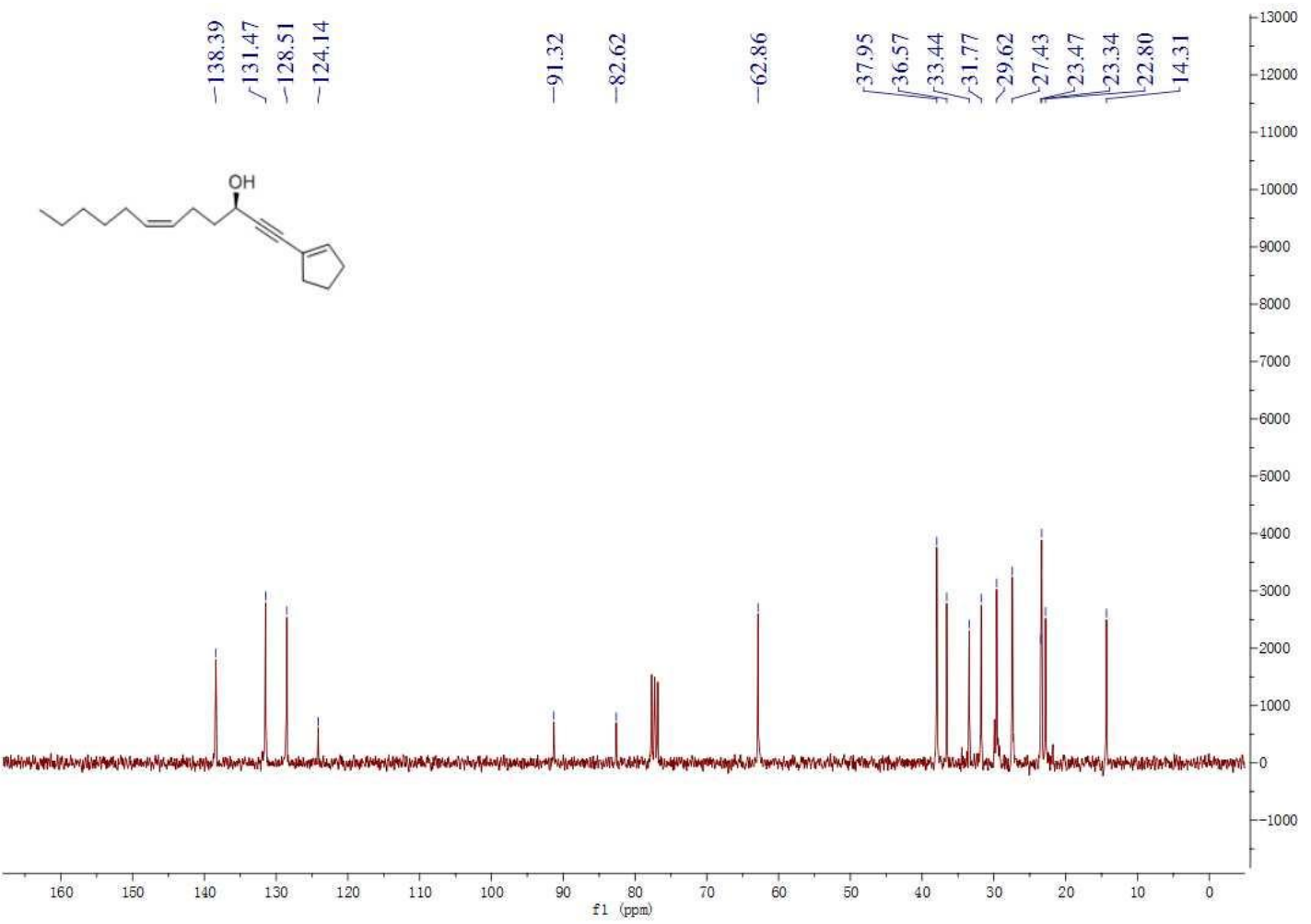


${ }^{1} \mathrm{H}$ NMR of $(R)-\mathbf{1 e}$

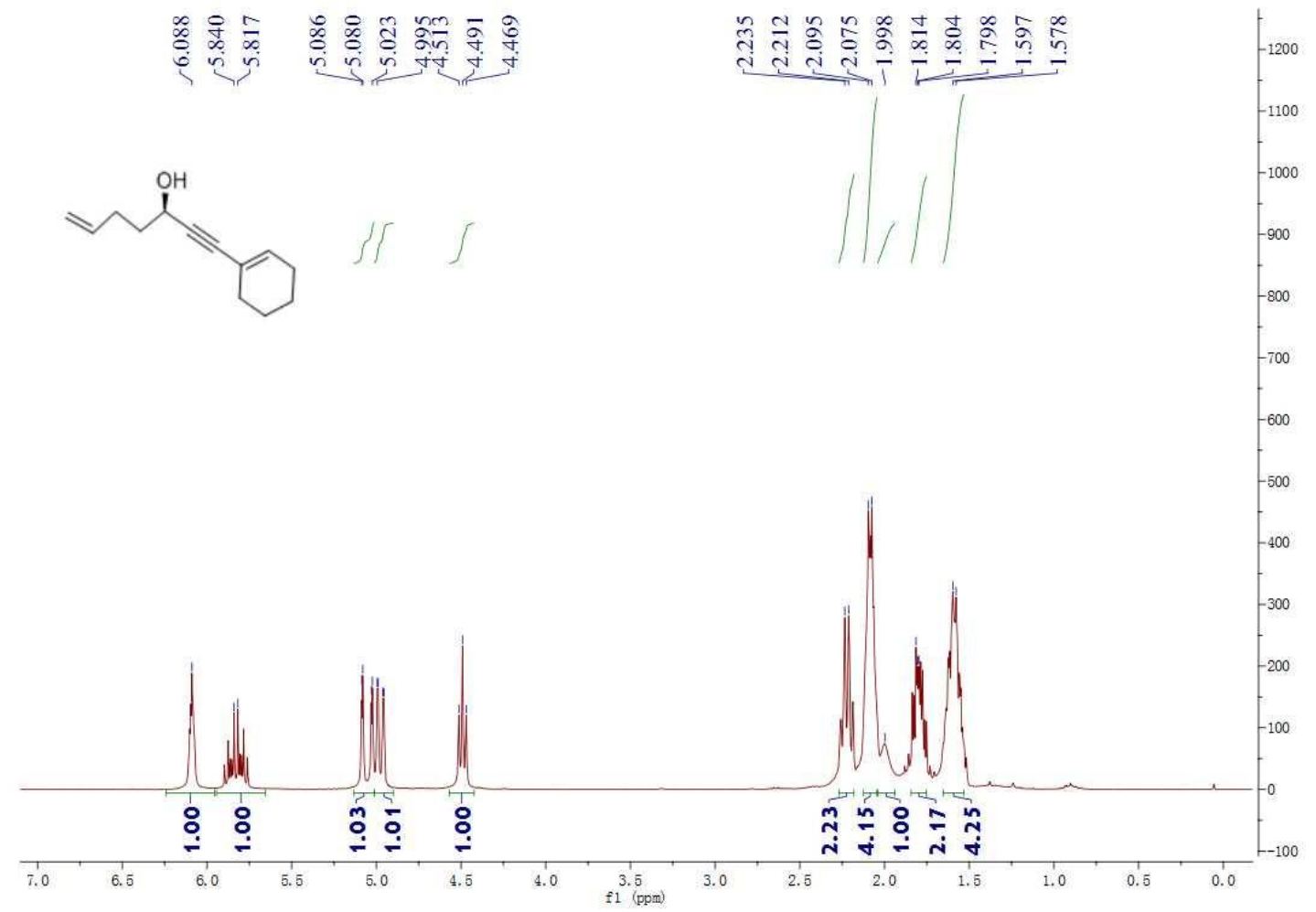

${ }^{13} \mathrm{C}$ NMR of $(R)-\mathbf{1 e}$

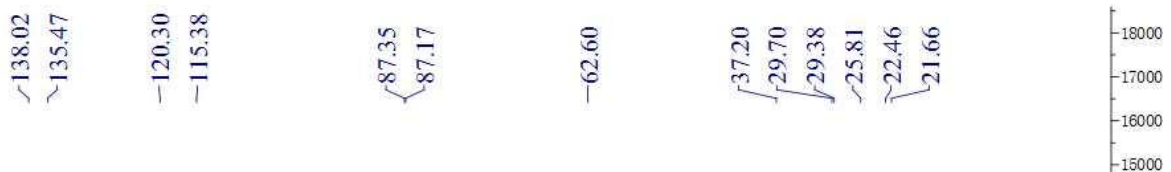<smiles>C=CCCC(O)C#CC1=CCCC1</smiles>

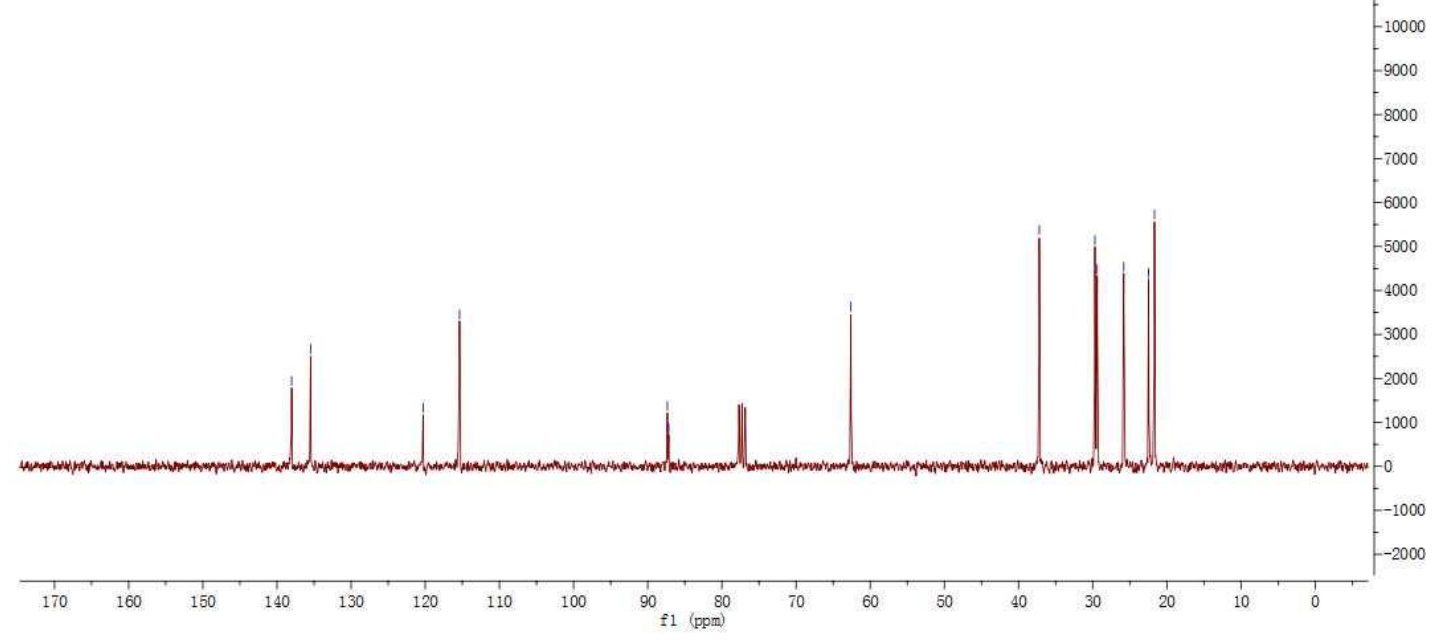


Racemic Propargylic Alcohols

${ }^{1} \mathrm{H}$ NMR of $\mathbf{1 f}$

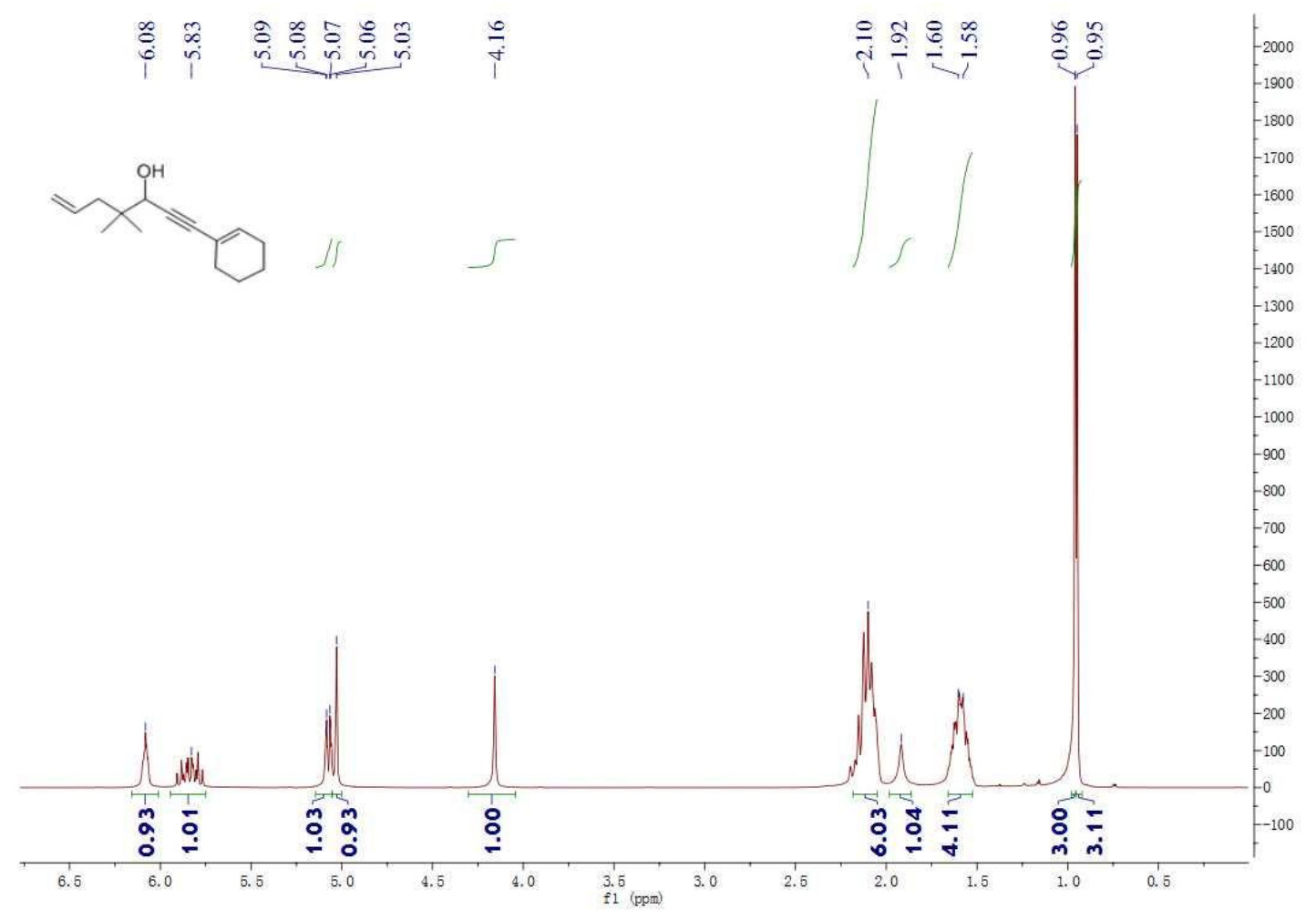

${ }^{13} \mathrm{C}$ NMR of $\mathbf{1 f}$

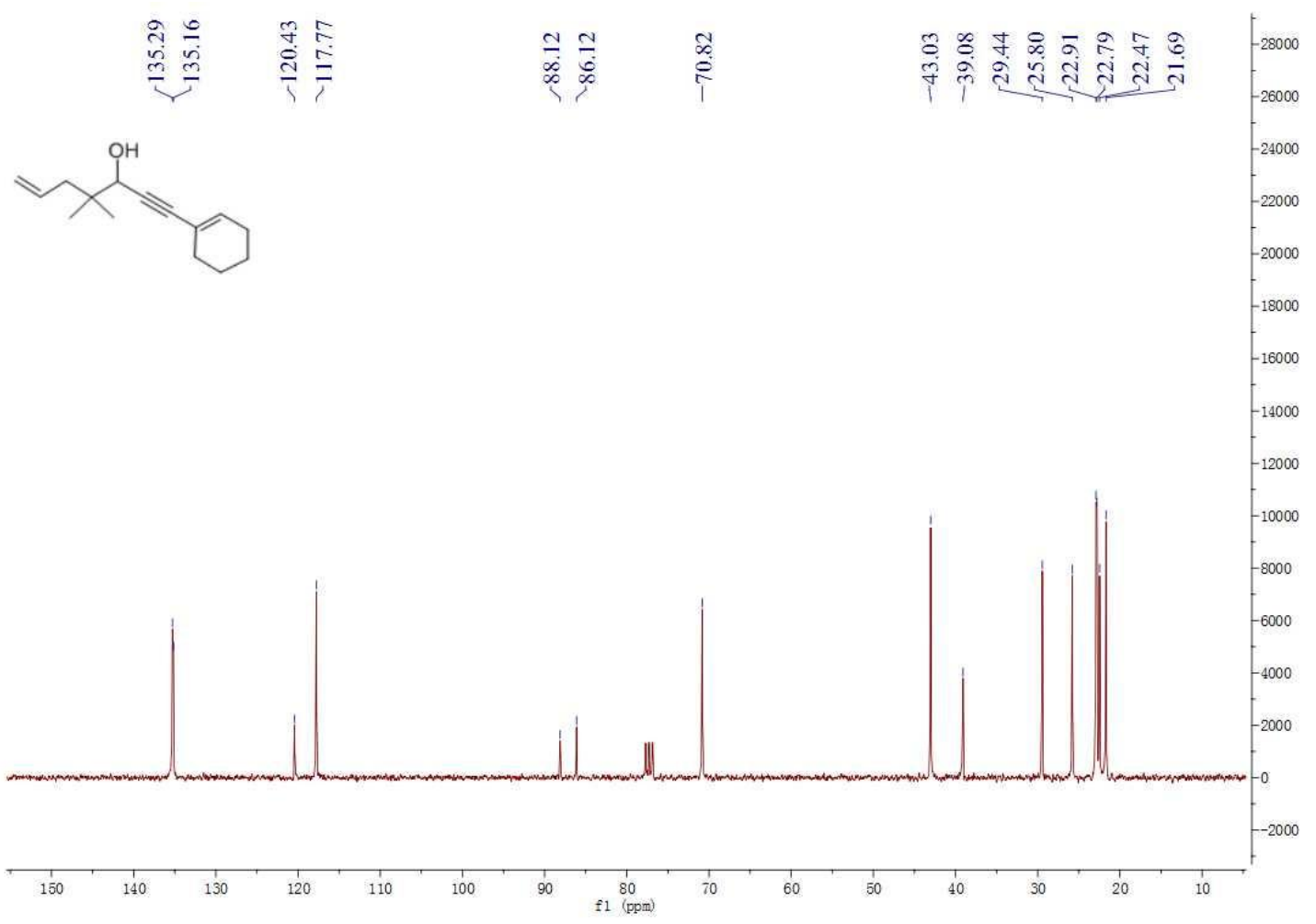


${ }^{1} \mathrm{H}$ NMR of $\mathbf{1 g}$

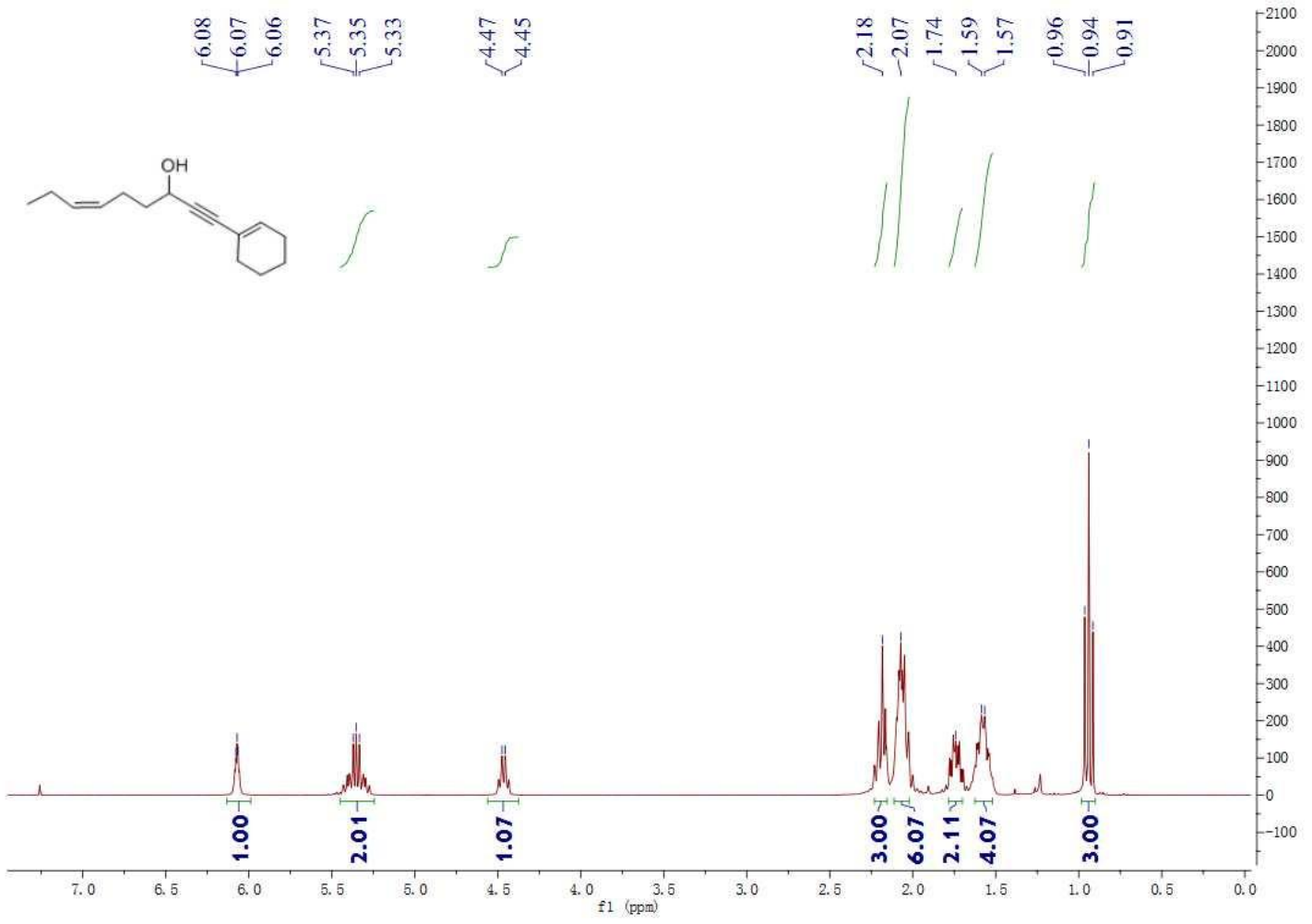

${ }^{13} \mathrm{C}$ NMR of $\mathbf{1 g}$

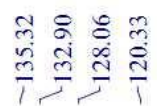

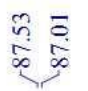

రి.

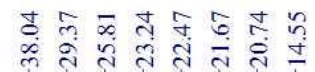

$-45000$

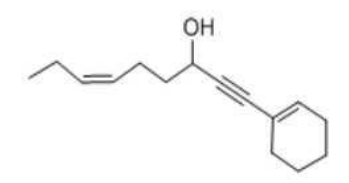

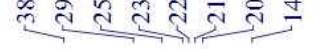

$-40000$

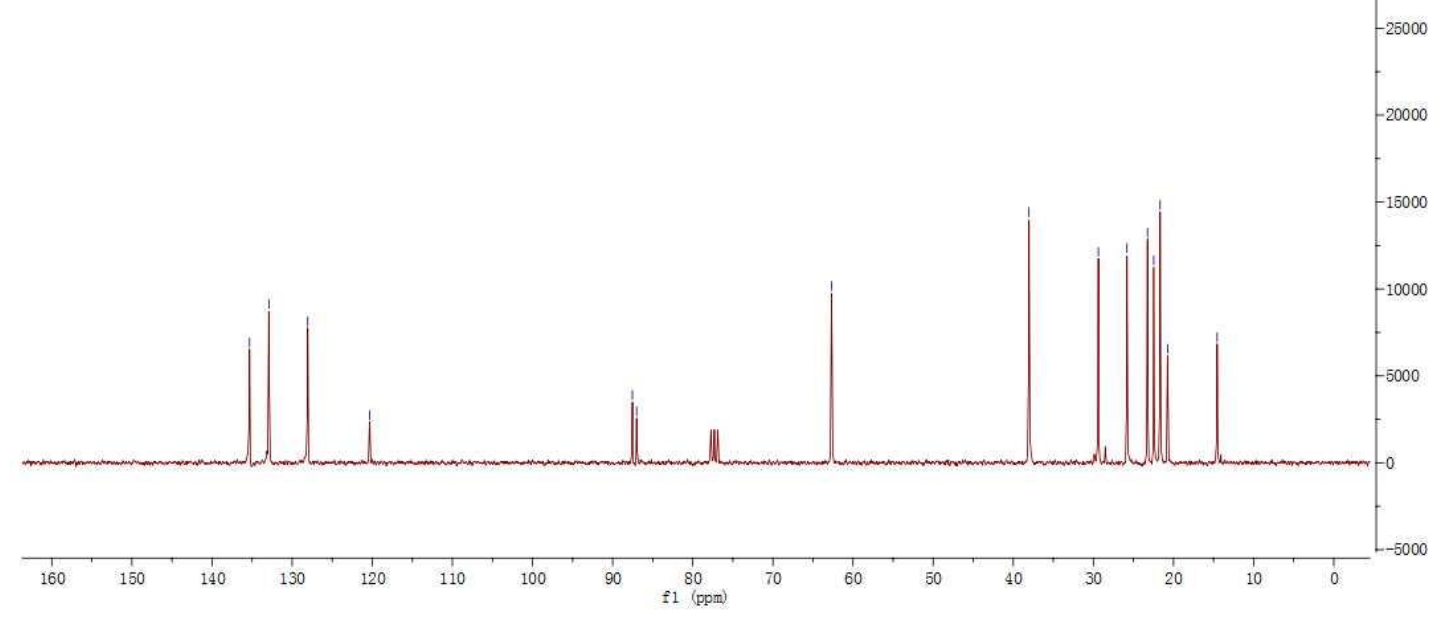


${ }^{1} \mathrm{H}$ NMR of $\mathbf{1 h}$

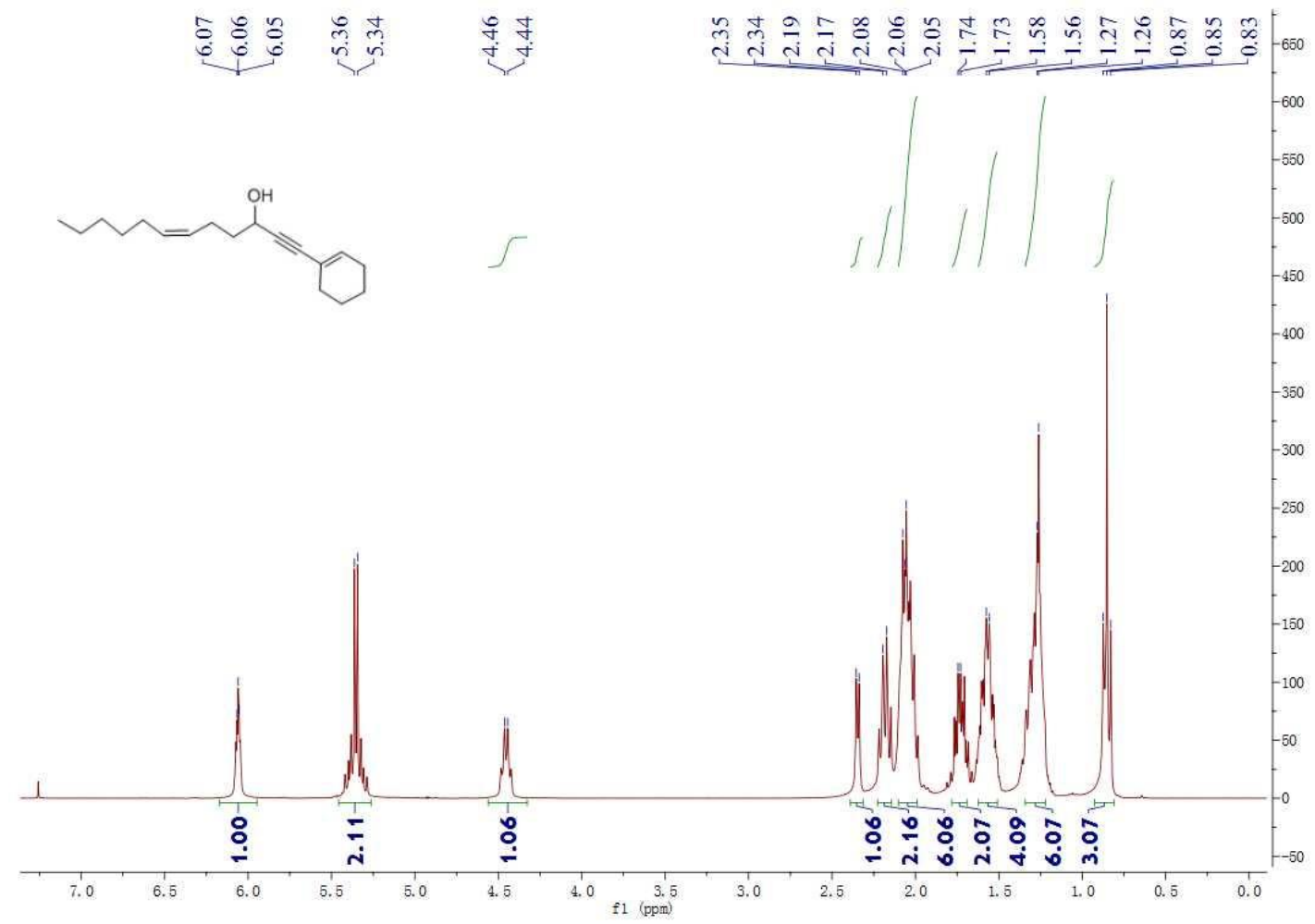

${ }^{13} \mathrm{C}$ NMR of $\mathbf{1 h}$

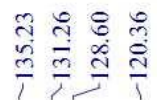

8
$\stackrel{8}{\infty}$
$\dot{\infty} \infty$

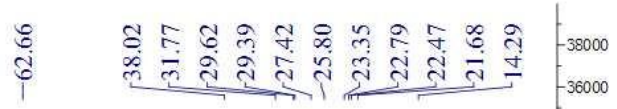

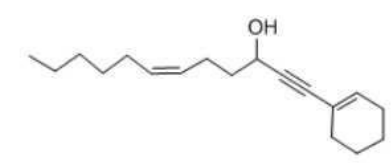

-34000
-32000

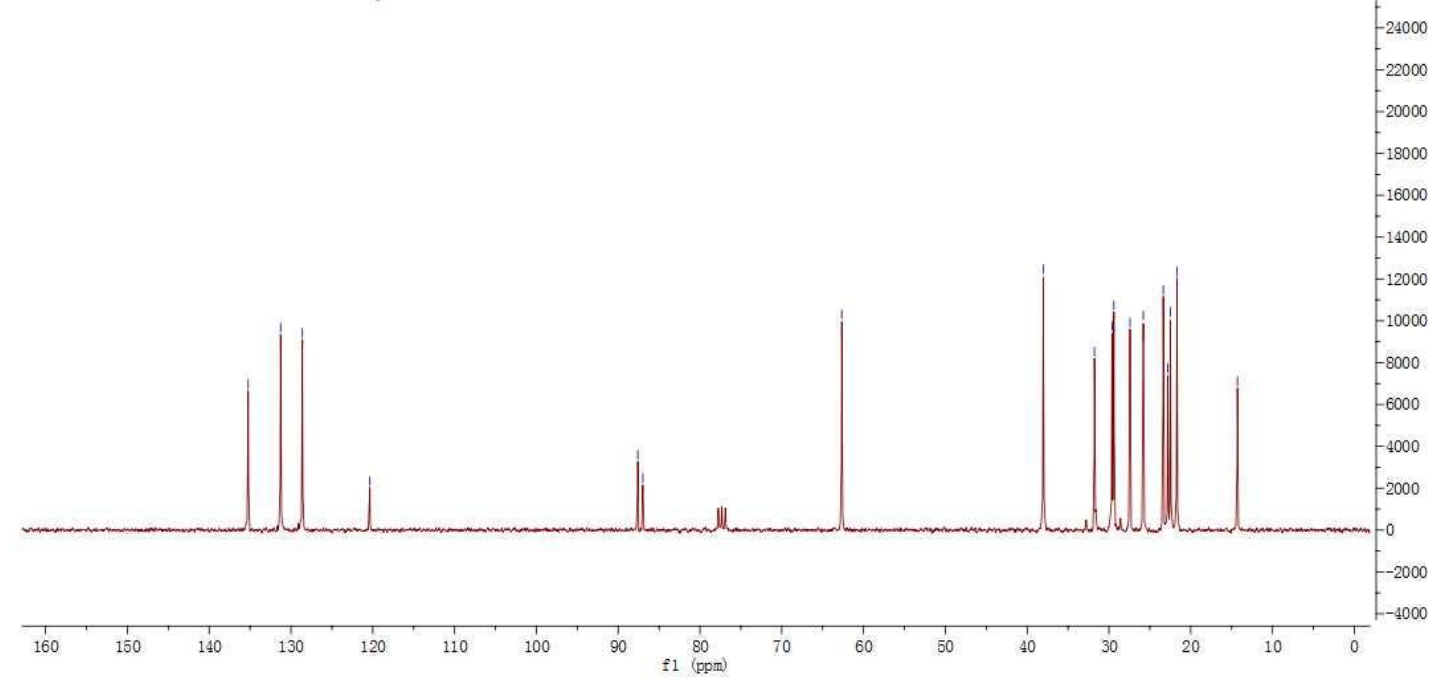




\section{Optically Active Triene-ynes}

${ }^{1} \mathrm{H}$ NMR of $(R)-\mathbf{2 a}$

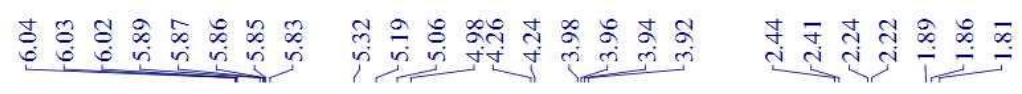

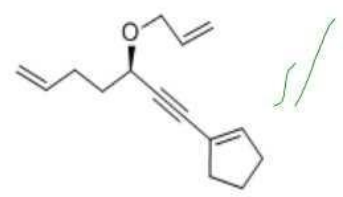

IIII
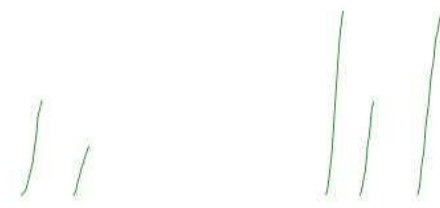

$-900$

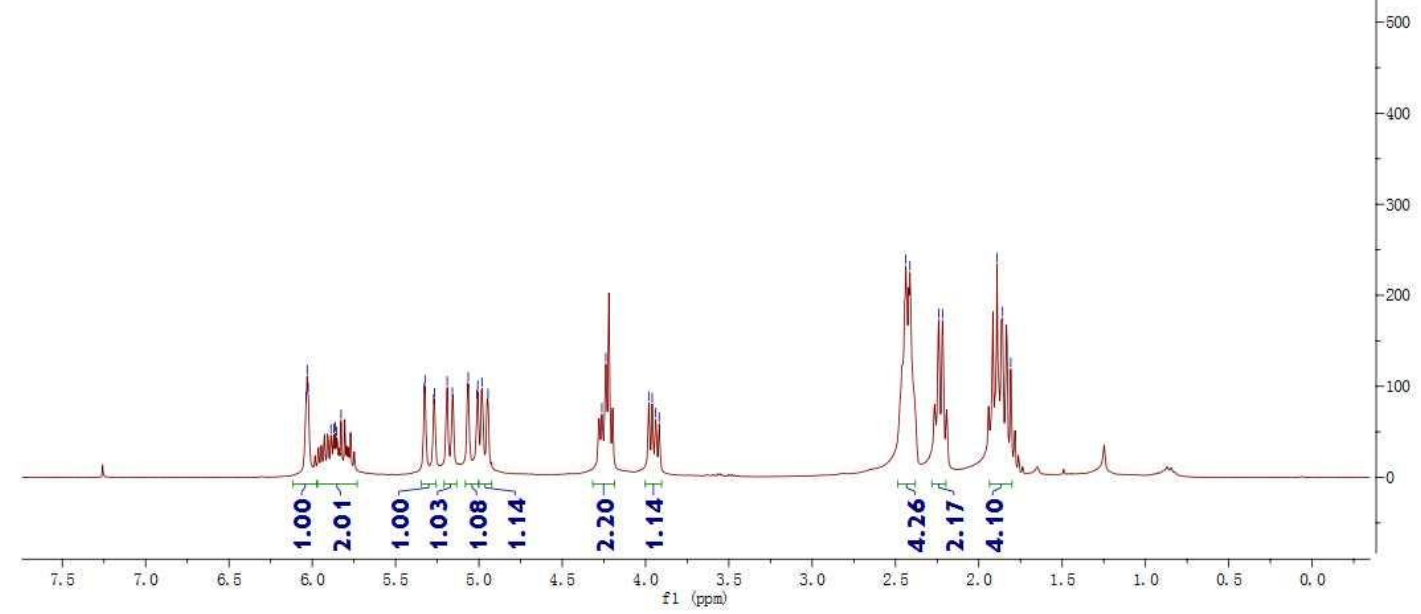

${ }^{13} \mathrm{C}$ NMR of $(R)-\mathbf{2 a}$
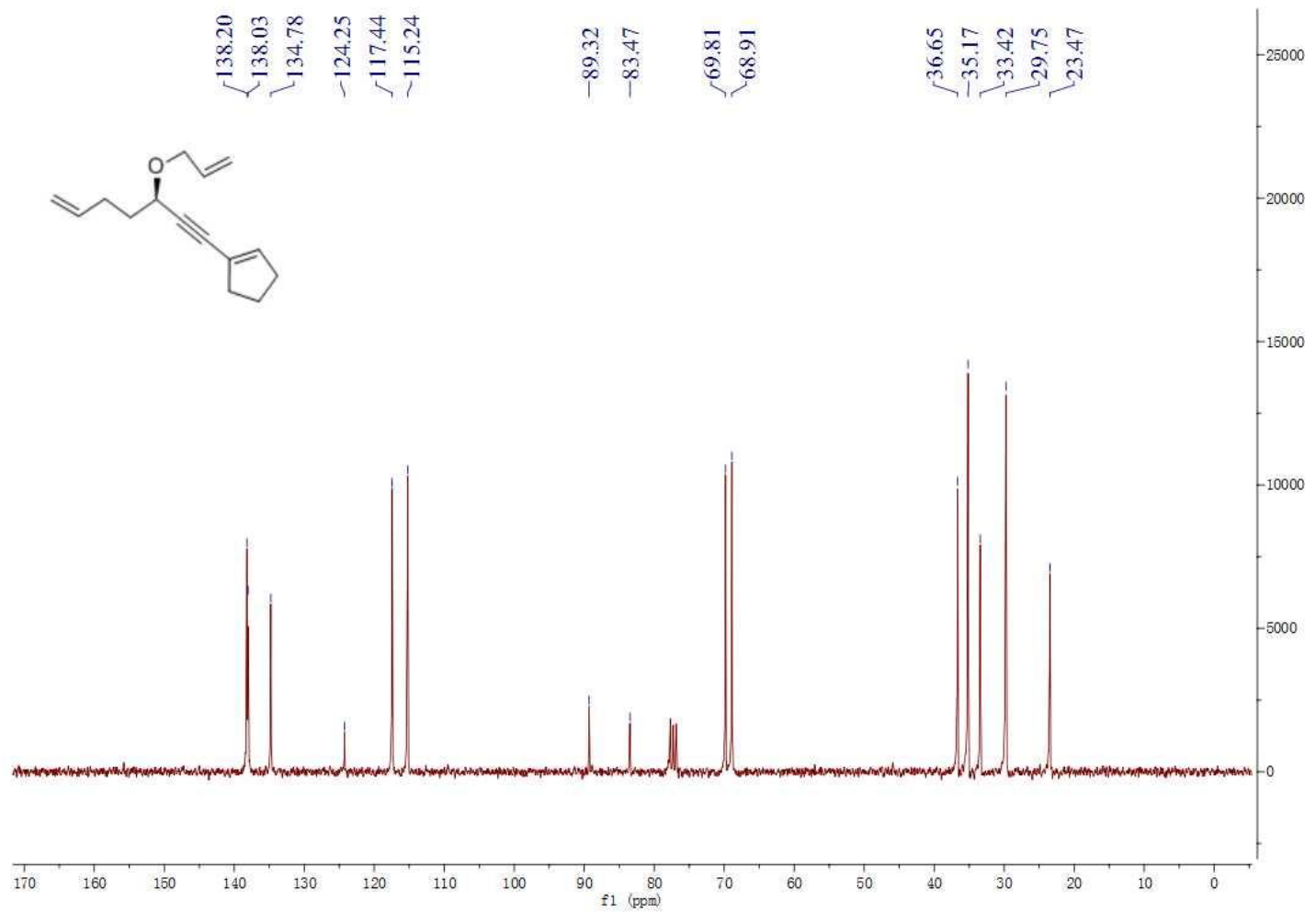
${ }^{1} \mathrm{H}$ NMR of $(R)-\mathbf{2 b}$

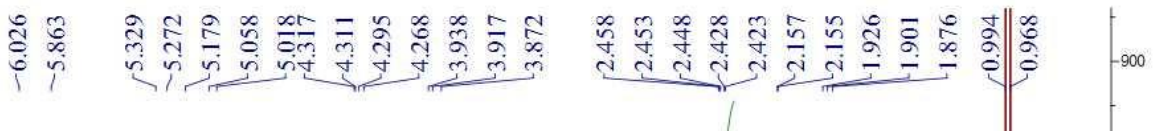<smiles>C=CCOC(C)C(C)(CC=C)CC1=CCCC1</smiles>

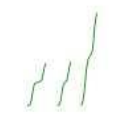

11

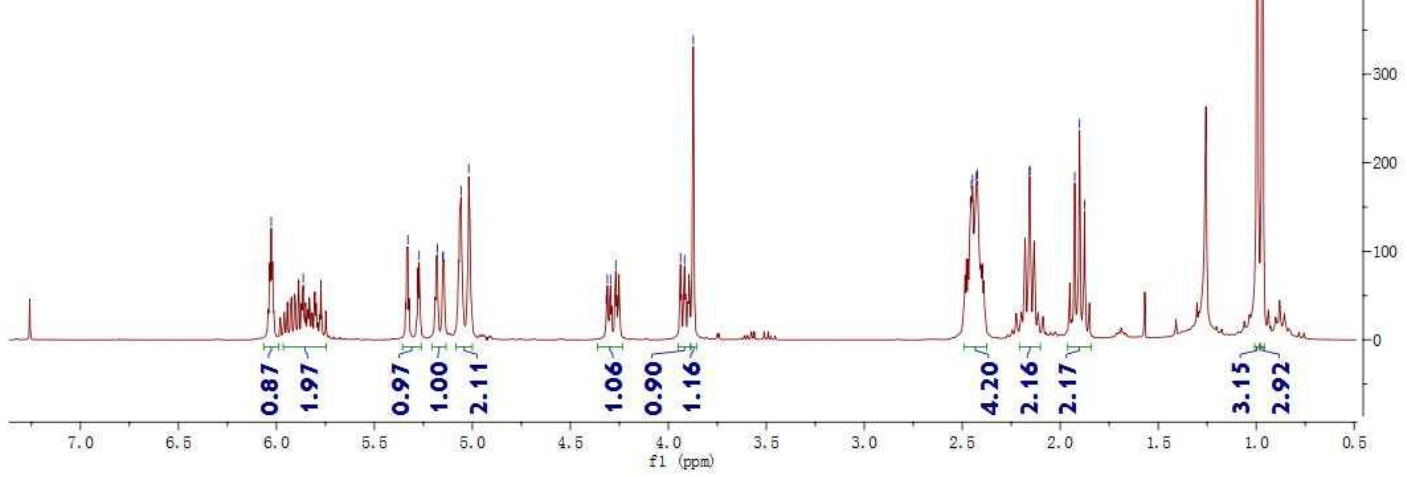

${ }^{13} \mathrm{C}$ NMR of $(R)-\mathbf{2 b}$

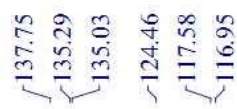

तु

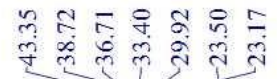

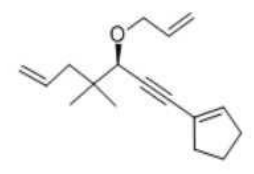

我䔁金? 
${ }^{1} \mathrm{H}$ NMR of $(R)-2 \mathbf{c}$

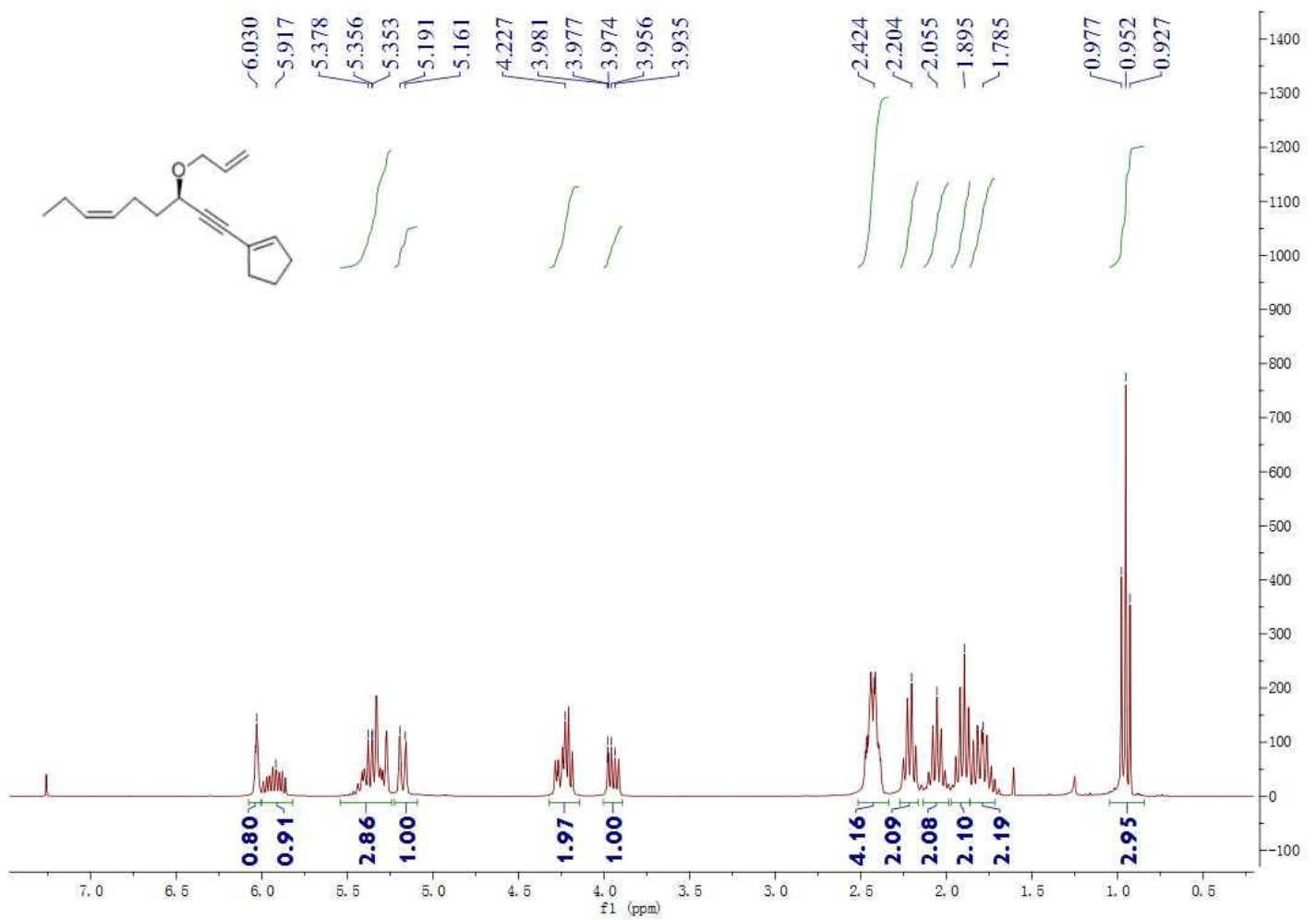

${ }^{13} \mathrm{C}$ NMR of $(R)-2 \mathbf{c}$

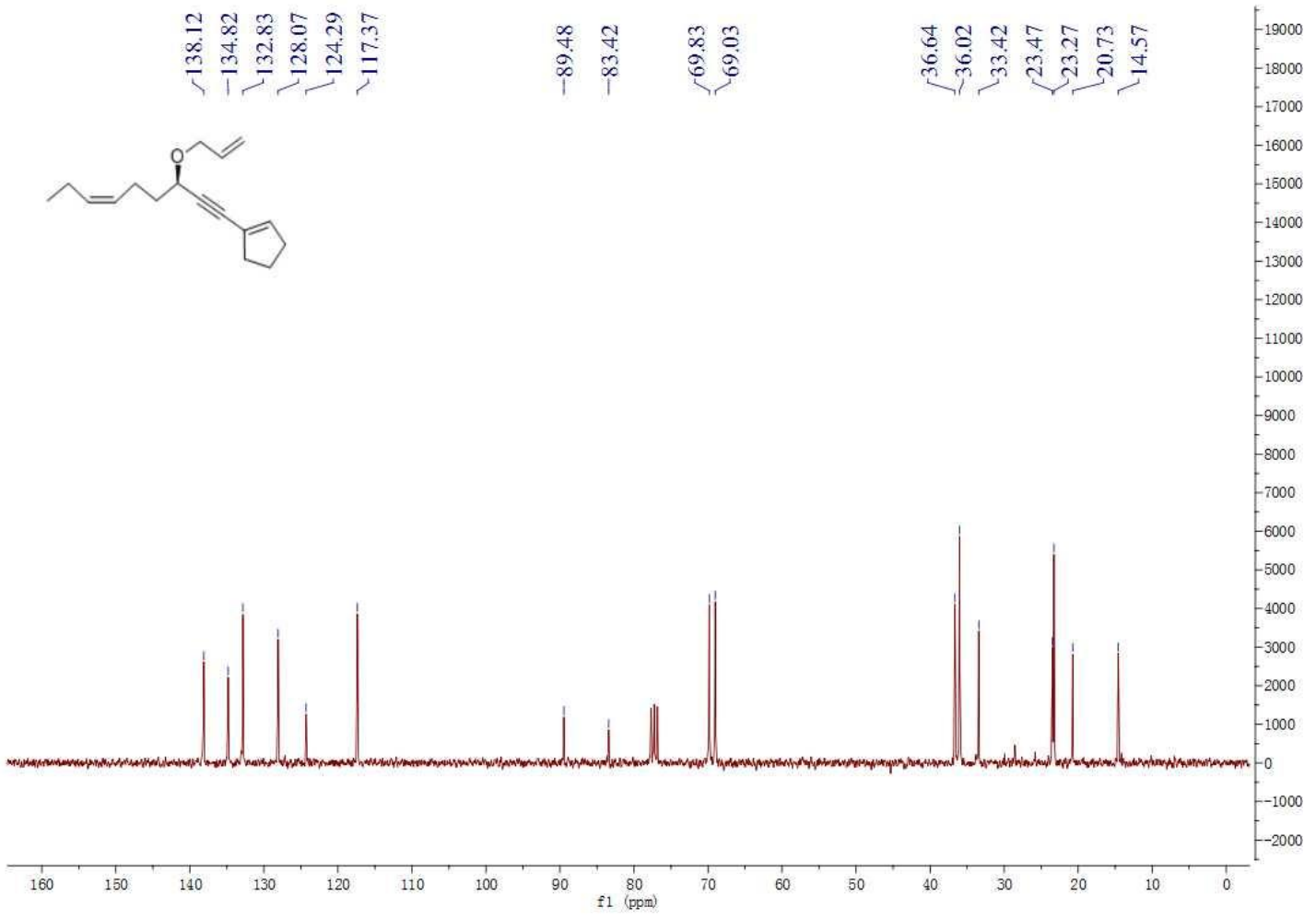


${ }^{1} \mathrm{H}$ NMR of $(R)-\mathbf{2 d}$

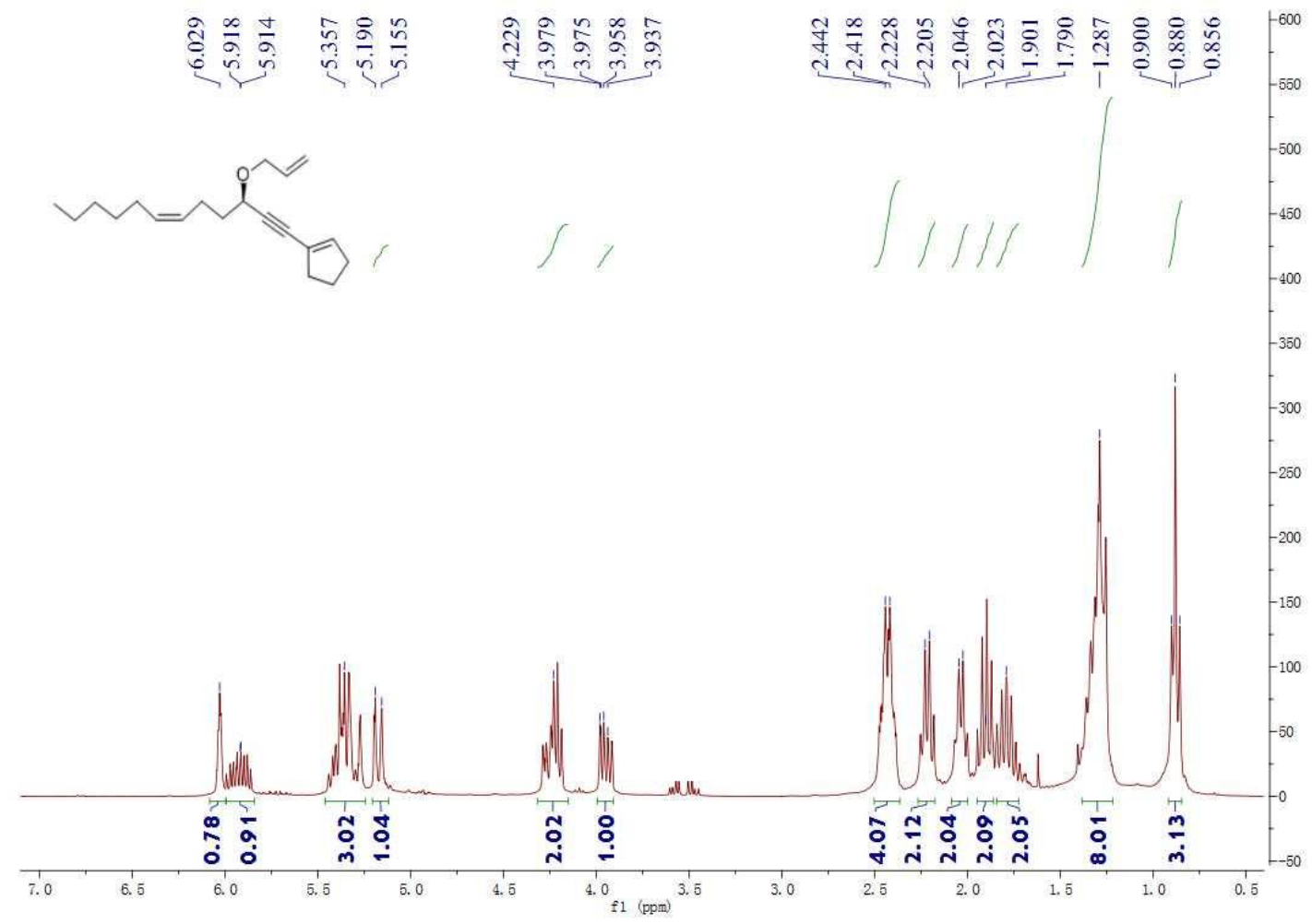

${ }^{13} \mathrm{C}$ NMR of $(R)-\mathbf{2 d}$

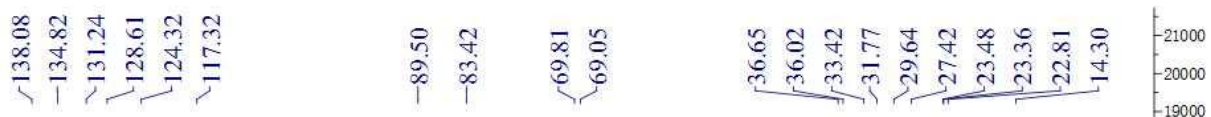<smiles>C=CCOC(C=CC1CCCC1)CC=CCCCC</smiles>

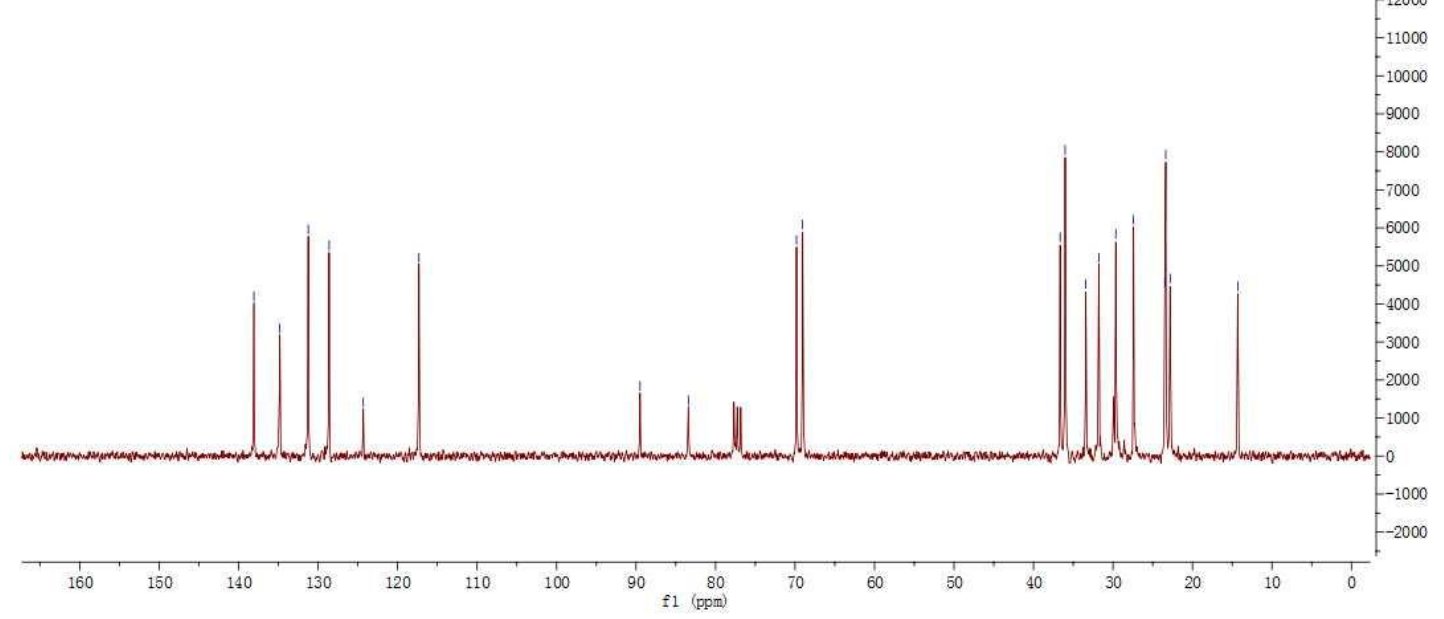


${ }^{1} \mathrm{H}$ NMR of $(R)-2 \mathbf{e}$

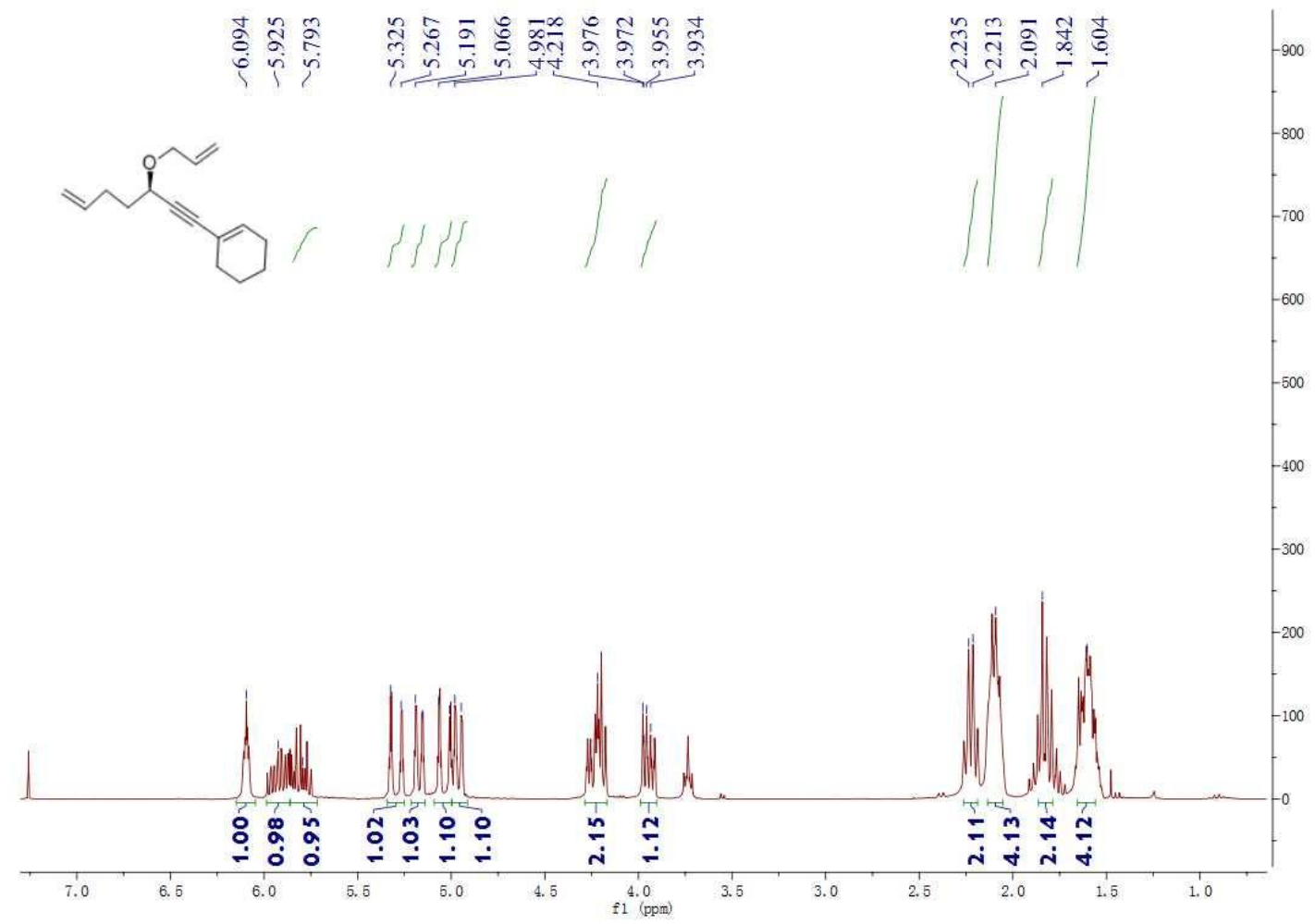

${ }^{13} \mathrm{C}$ NMR of $(R)-2 \mathbf{e}$
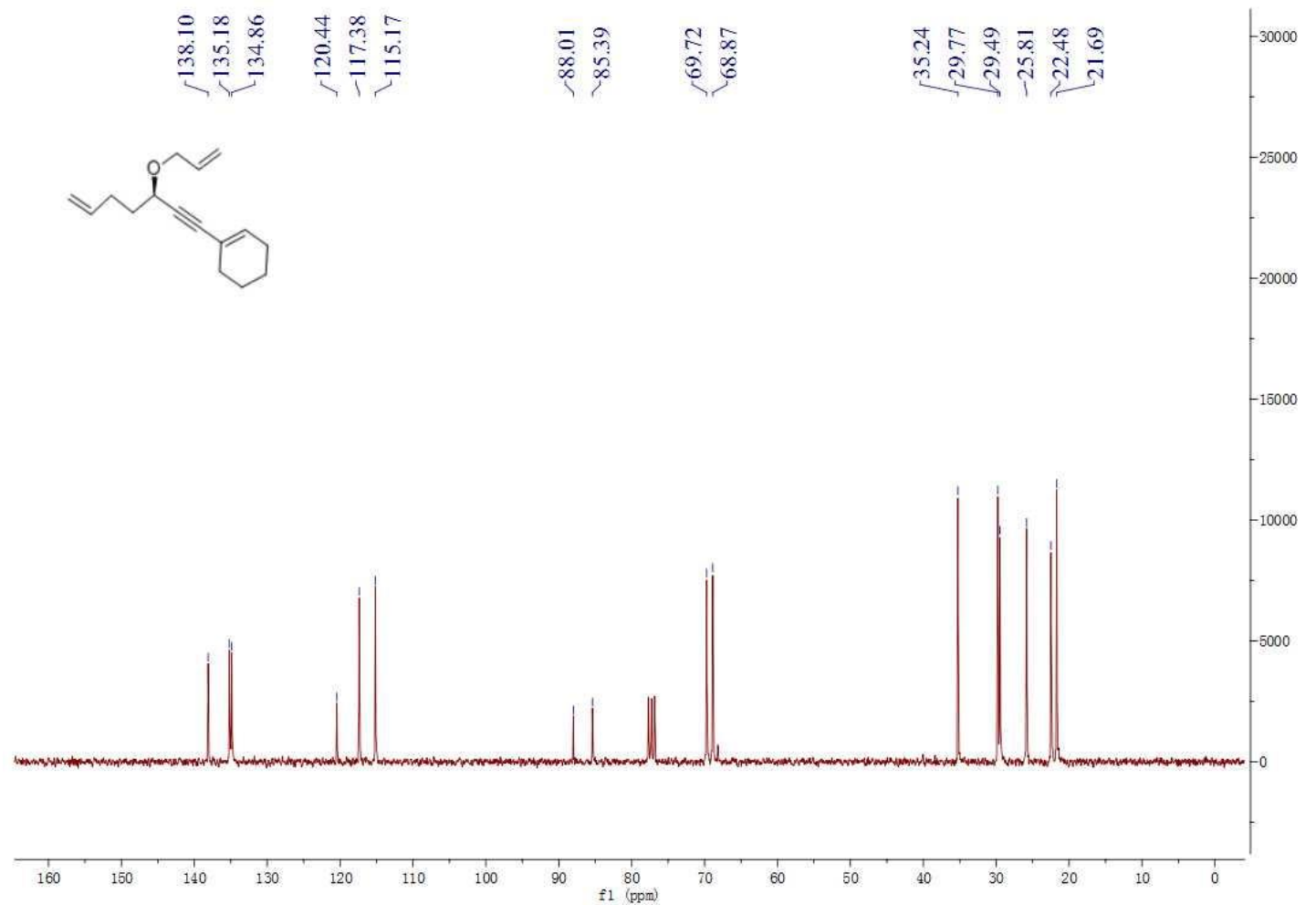


\section{Racemic Triene-ynes}

${ }^{1} \mathrm{H}$ NMR of $\mathbf{2 f}$

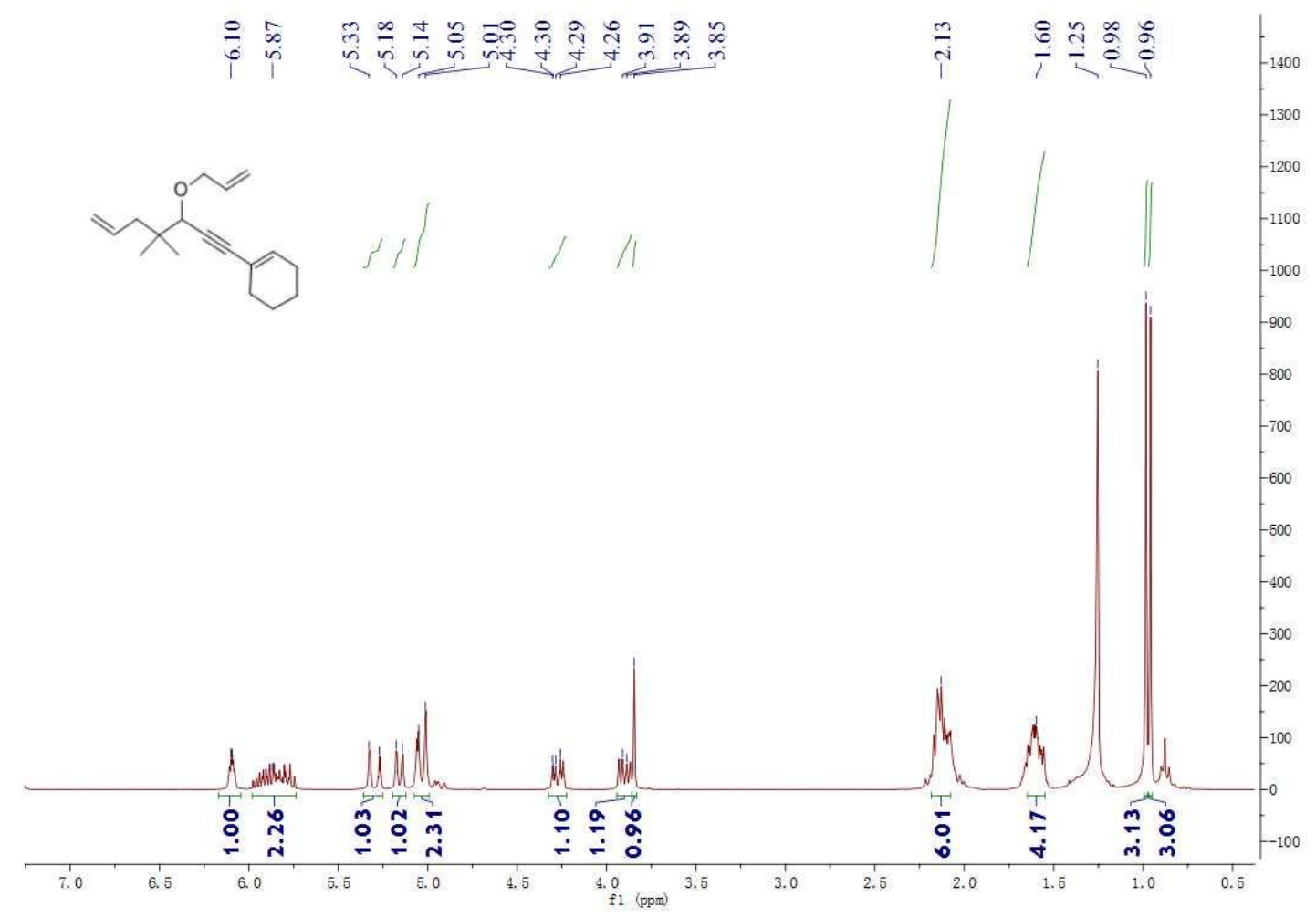

${ }^{13} \mathrm{C}$ NMR of $\mathbf{2 f}$

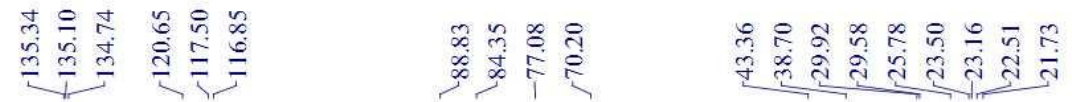

90000

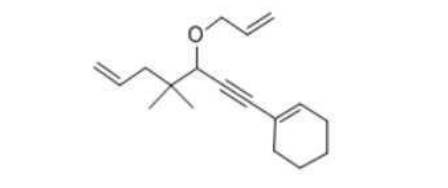

50000

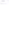

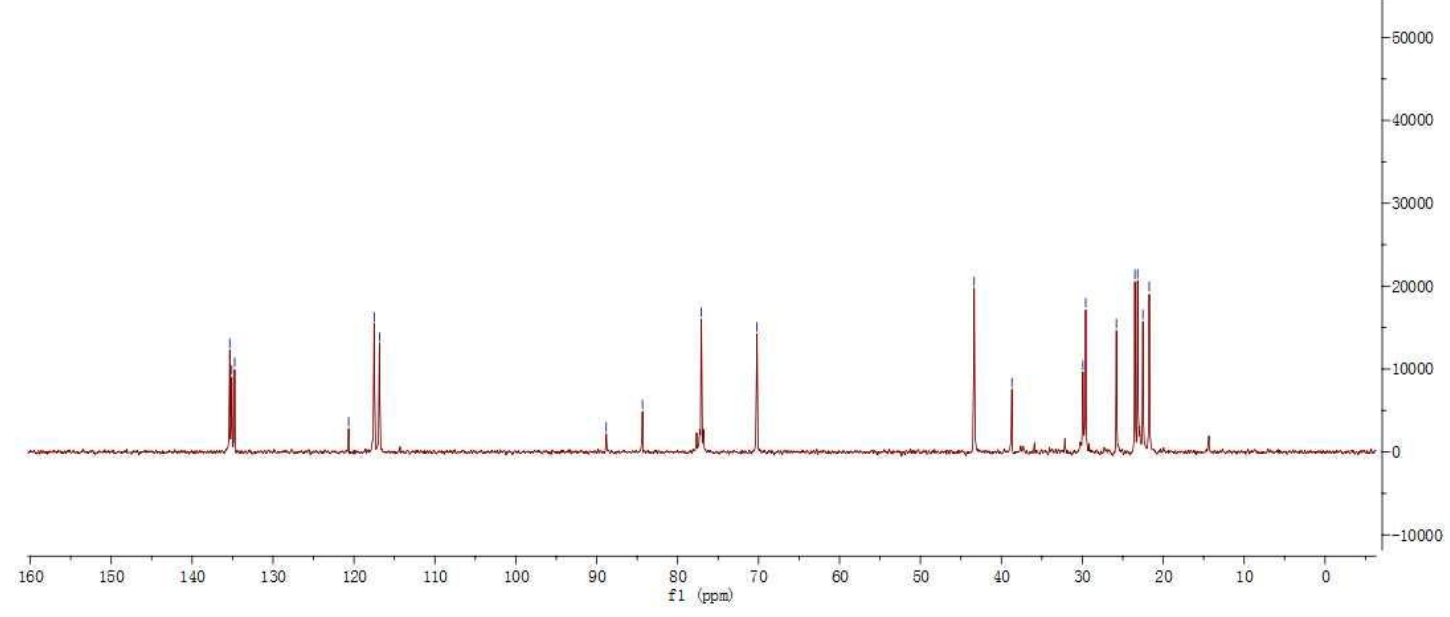




\section{${ }^{1} \mathrm{H}$ NMR of $\mathbf{2 g}$}

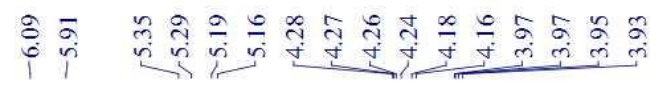

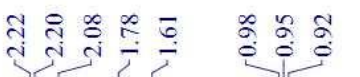
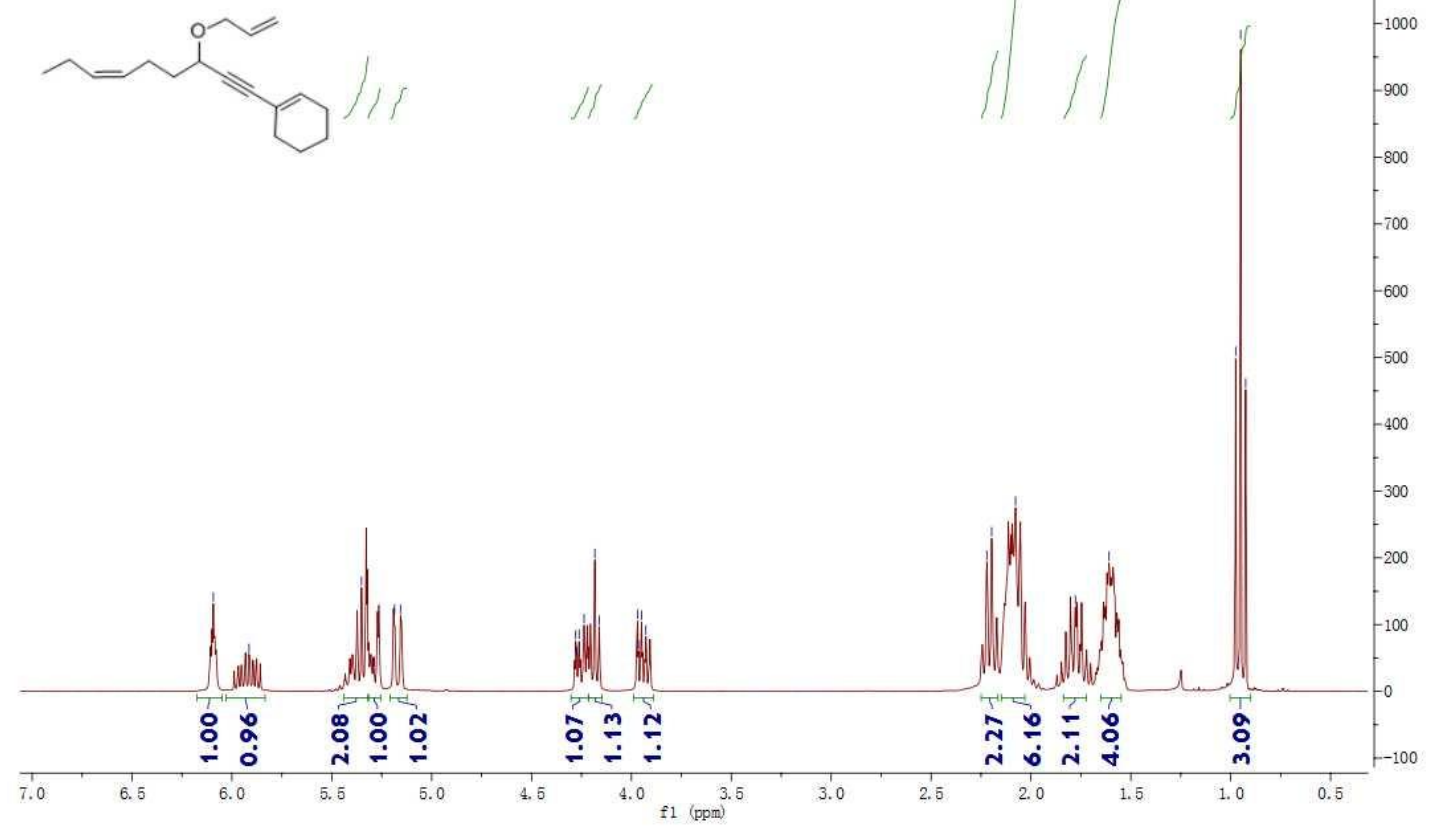

${ }^{13} \mathrm{C}$ NMR of $2 \mathrm{~g}$

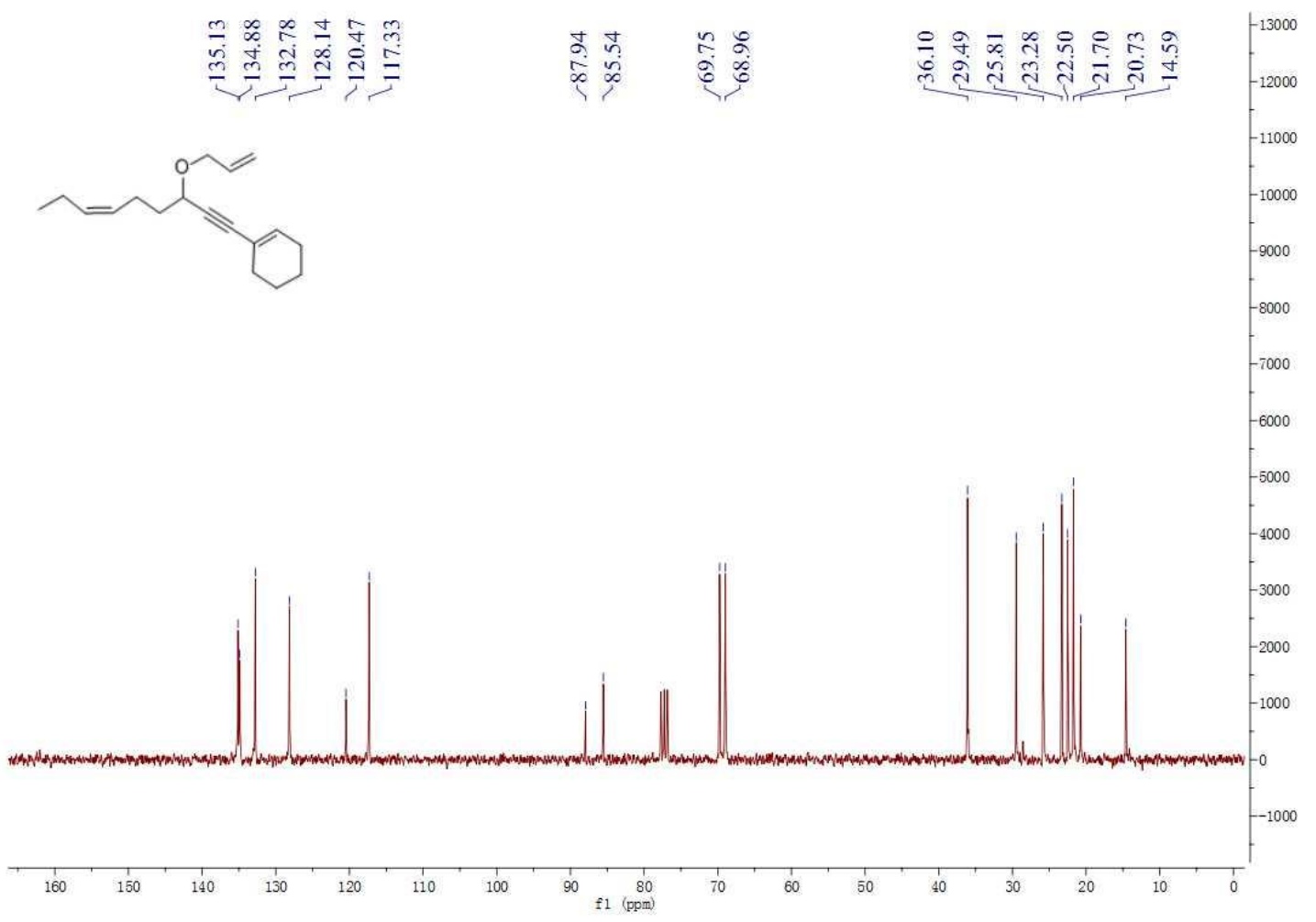


${ }^{1} \mathrm{H}$ NMR of $\mathbf{2 h}$

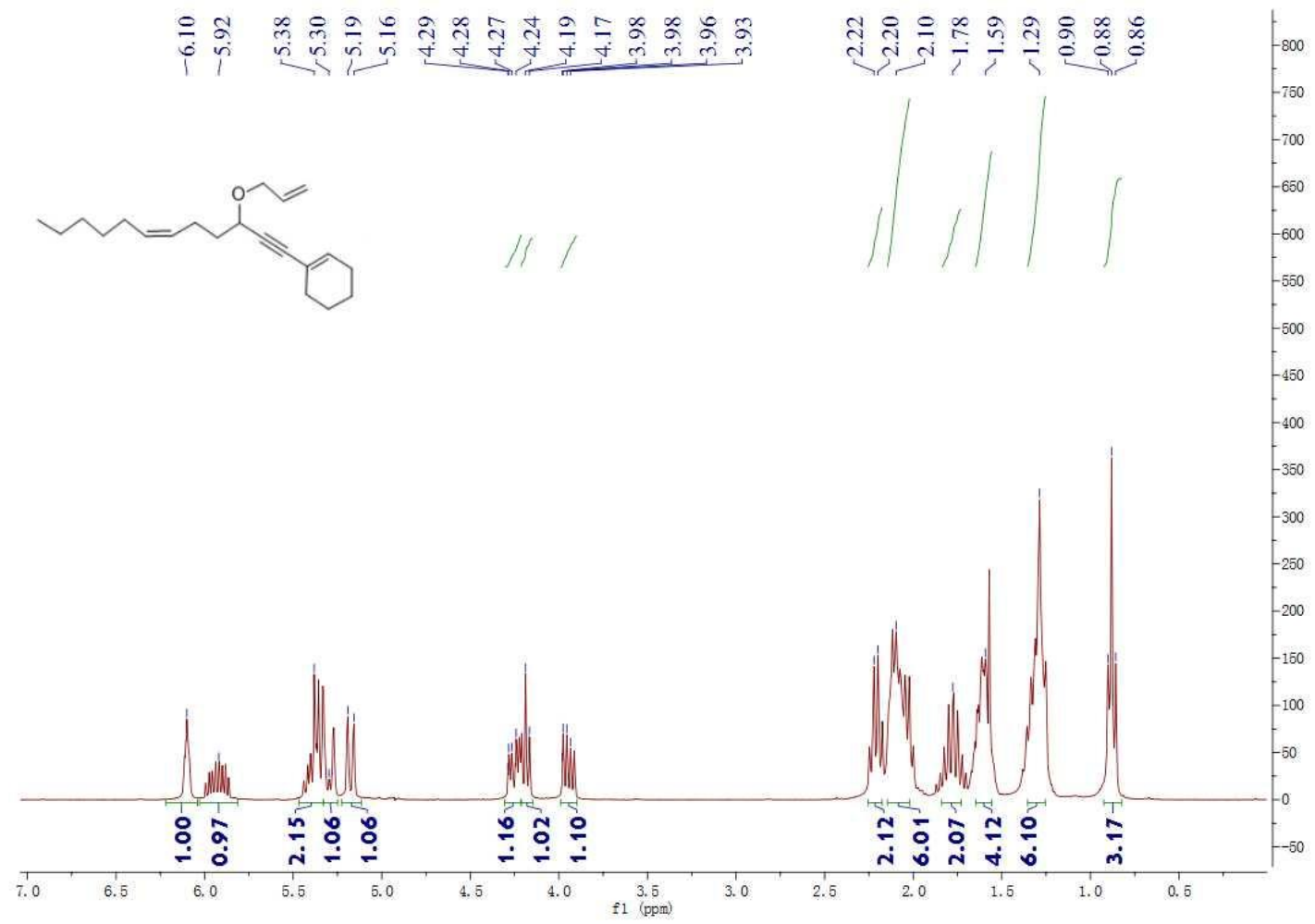

${ }^{13} \mathrm{C}$ NMR of $\mathbf{2 h}$

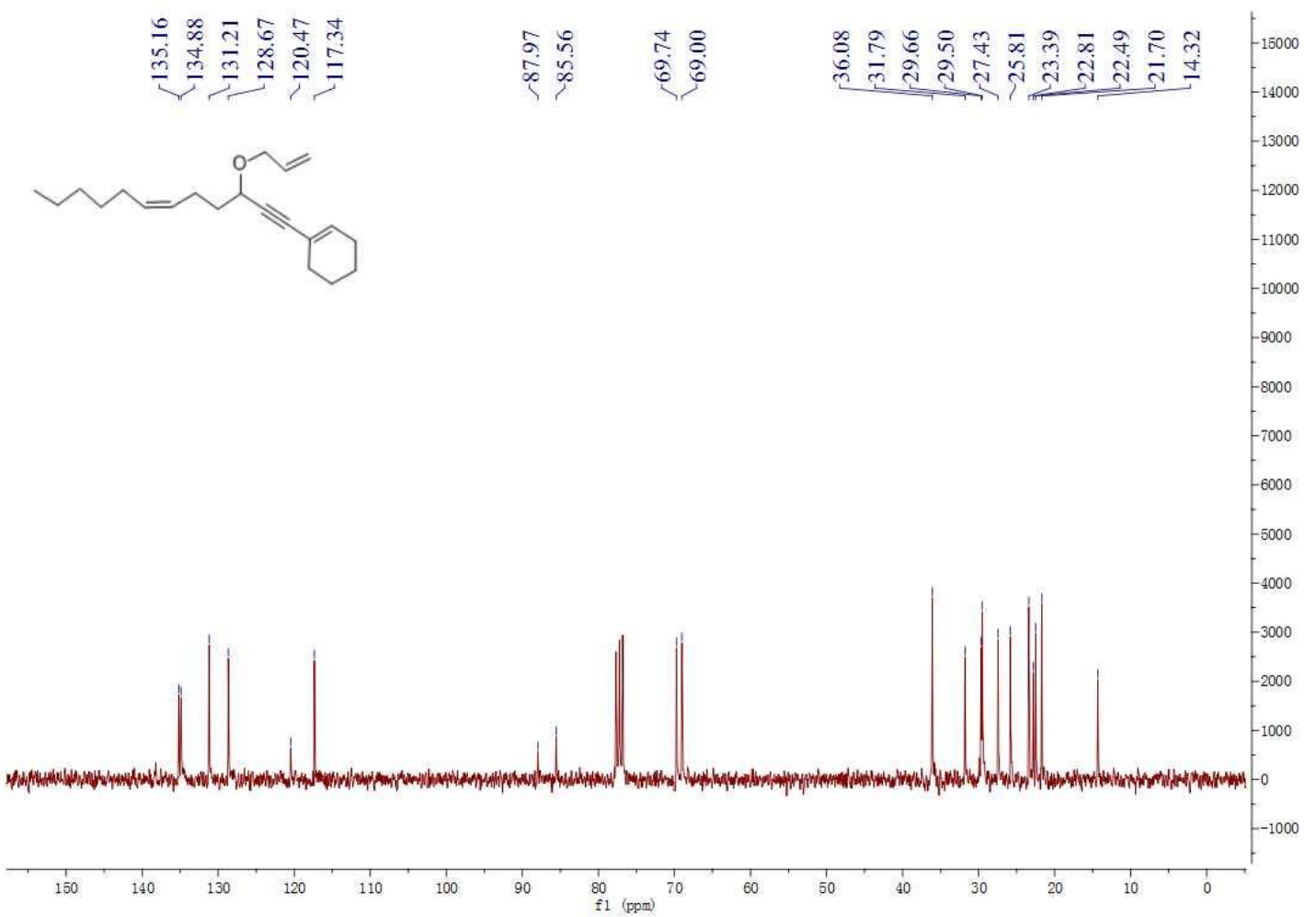


Optically active PK-DA Products

${ }^{1} \mathrm{H}$ NMR of compound 3a

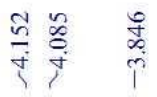

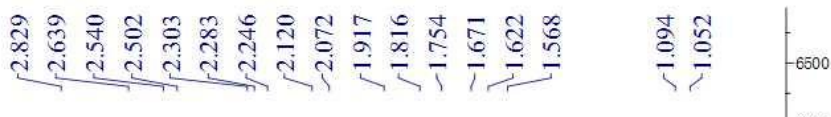

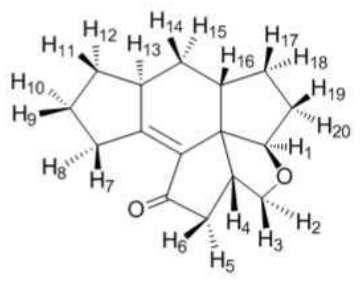

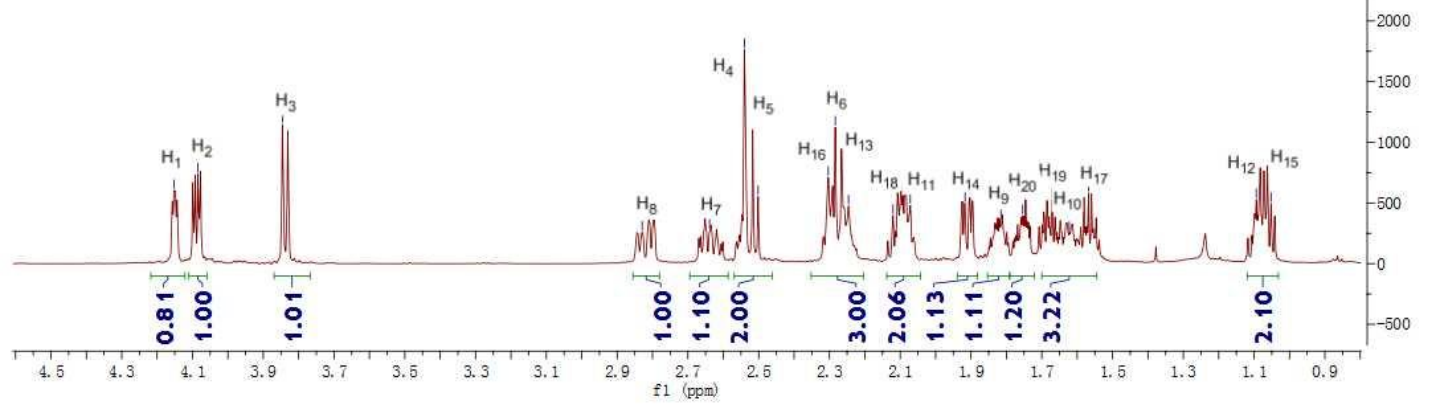

${ }^{13} \mathrm{C}$ NMR of compound 3a
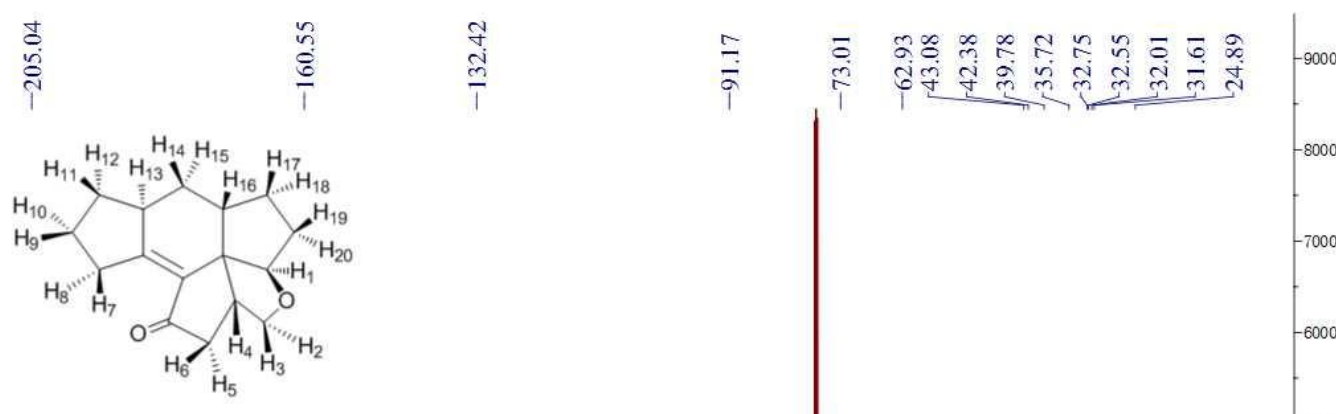
${ }^{1} \mathrm{H}$ NMR of compound $\mathbf{3 b}$

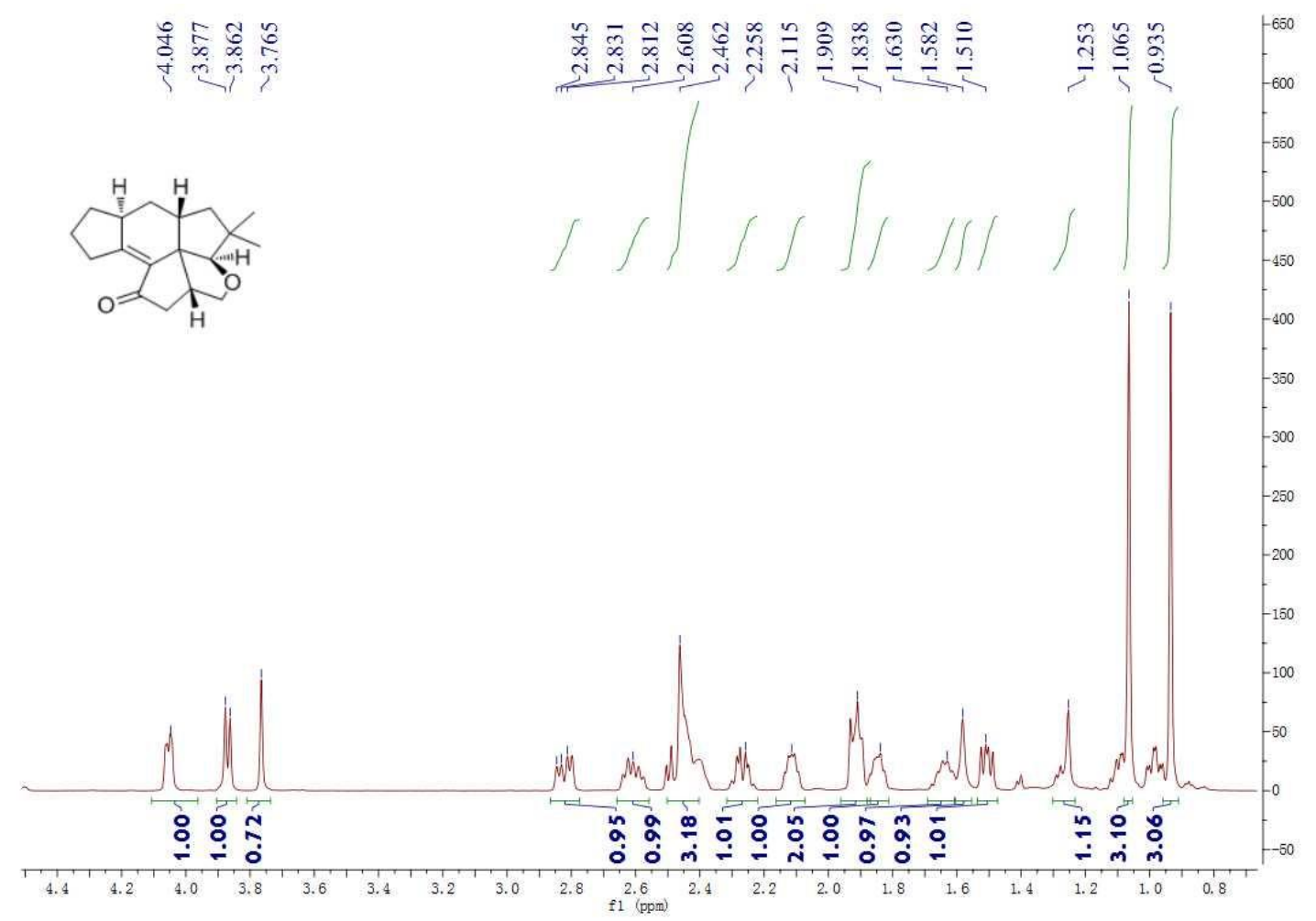

${ }^{13} \mathrm{C}$ NMR of compound $\mathbf{3 b}$
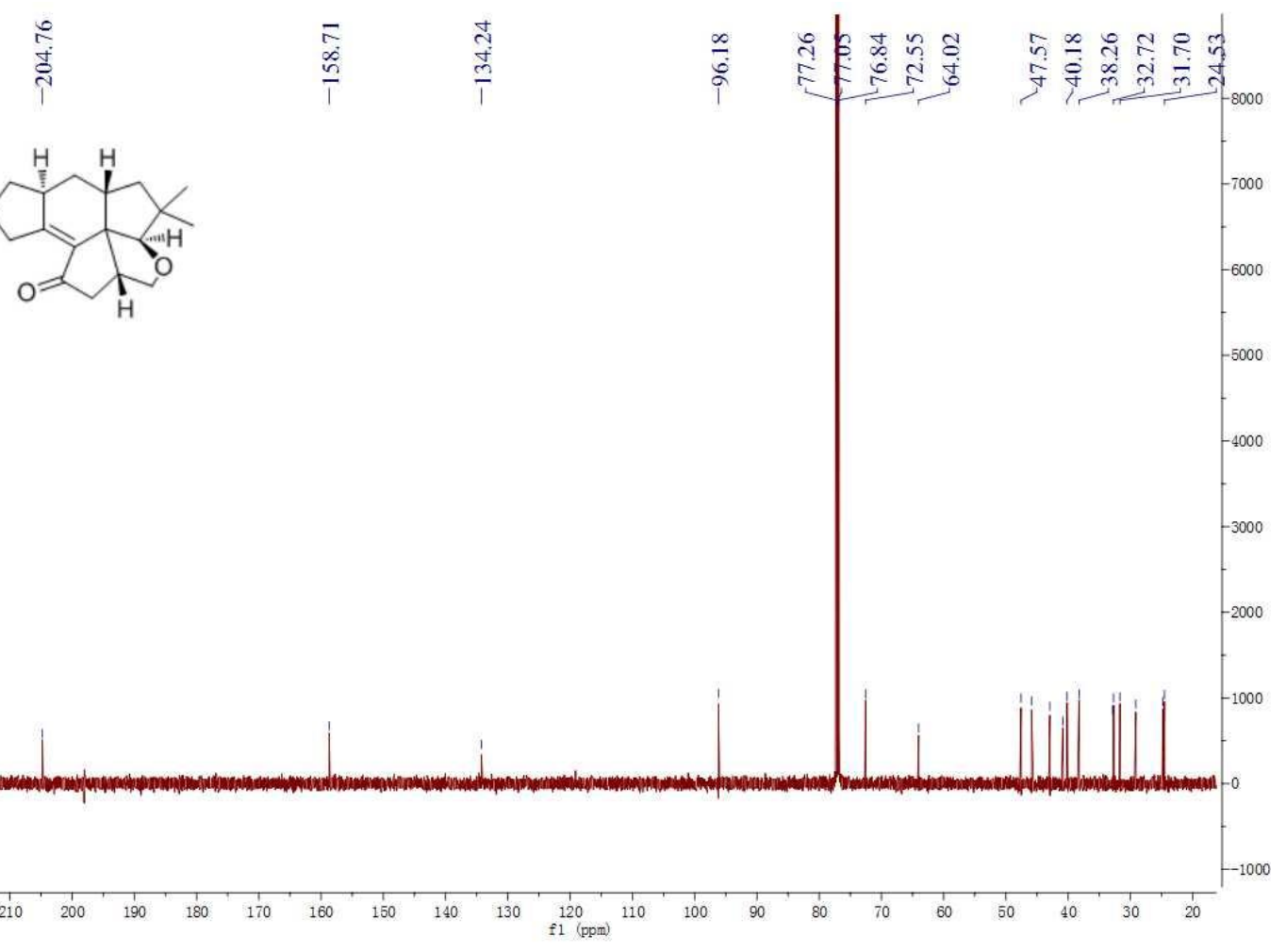
${ }^{1} \mathrm{H}$ NMR of compound $3 \mathrm{c}$

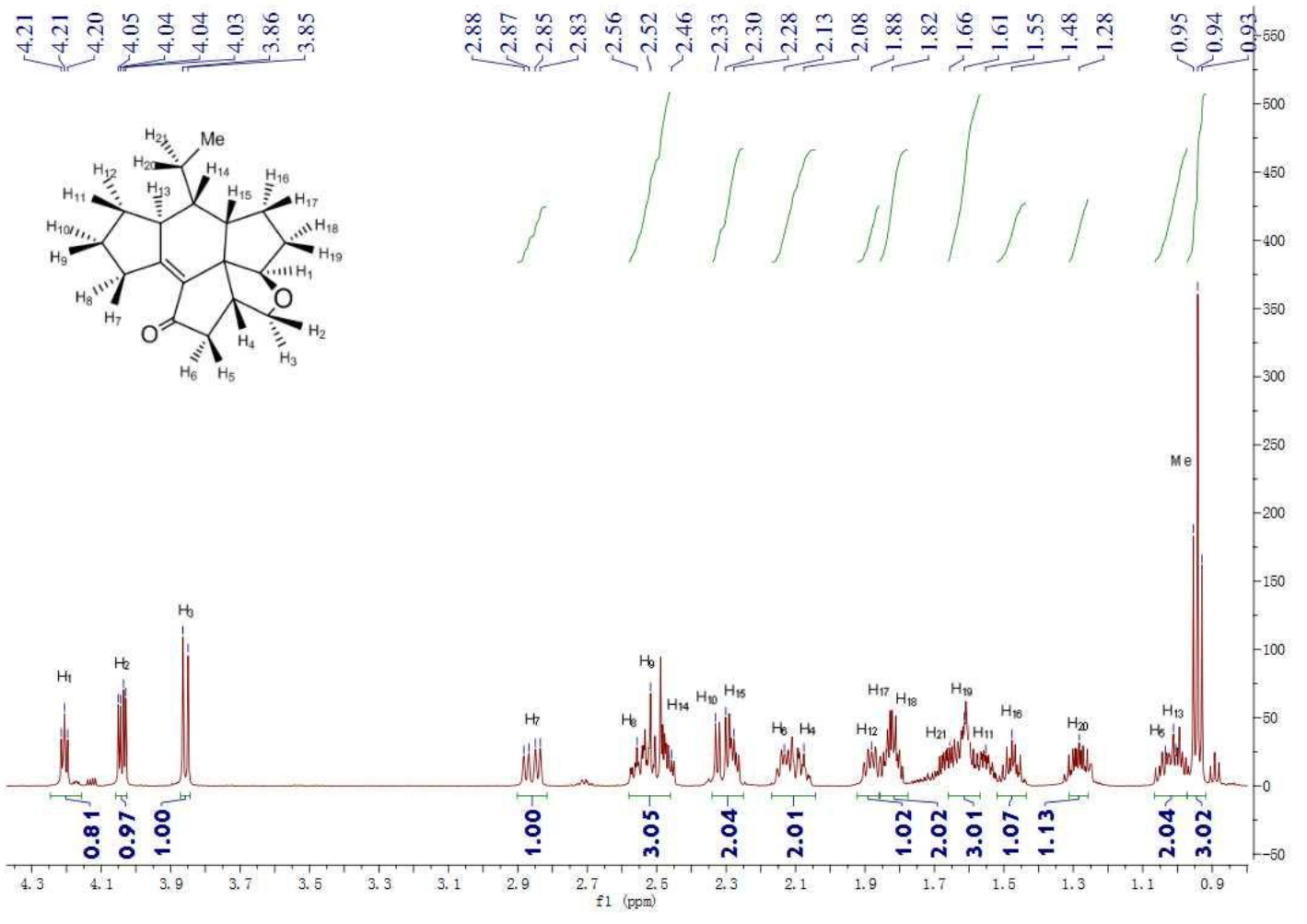

${ }^{13} \mathrm{C}$ NMR of compound $3 \mathrm{c}$

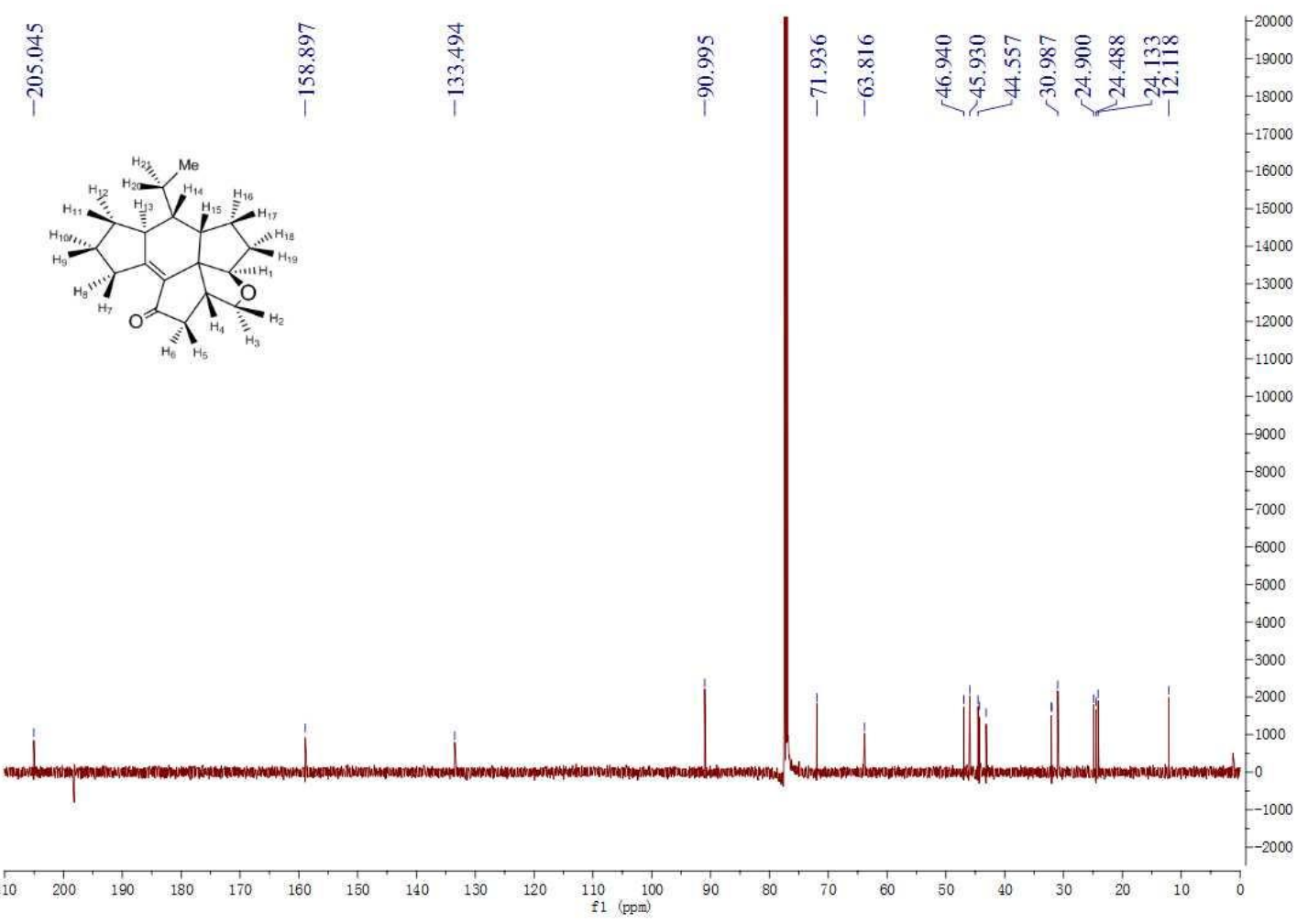


${ }^{1} \mathrm{H}$ NMR of compound 3d

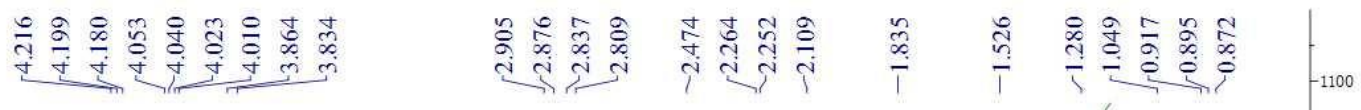

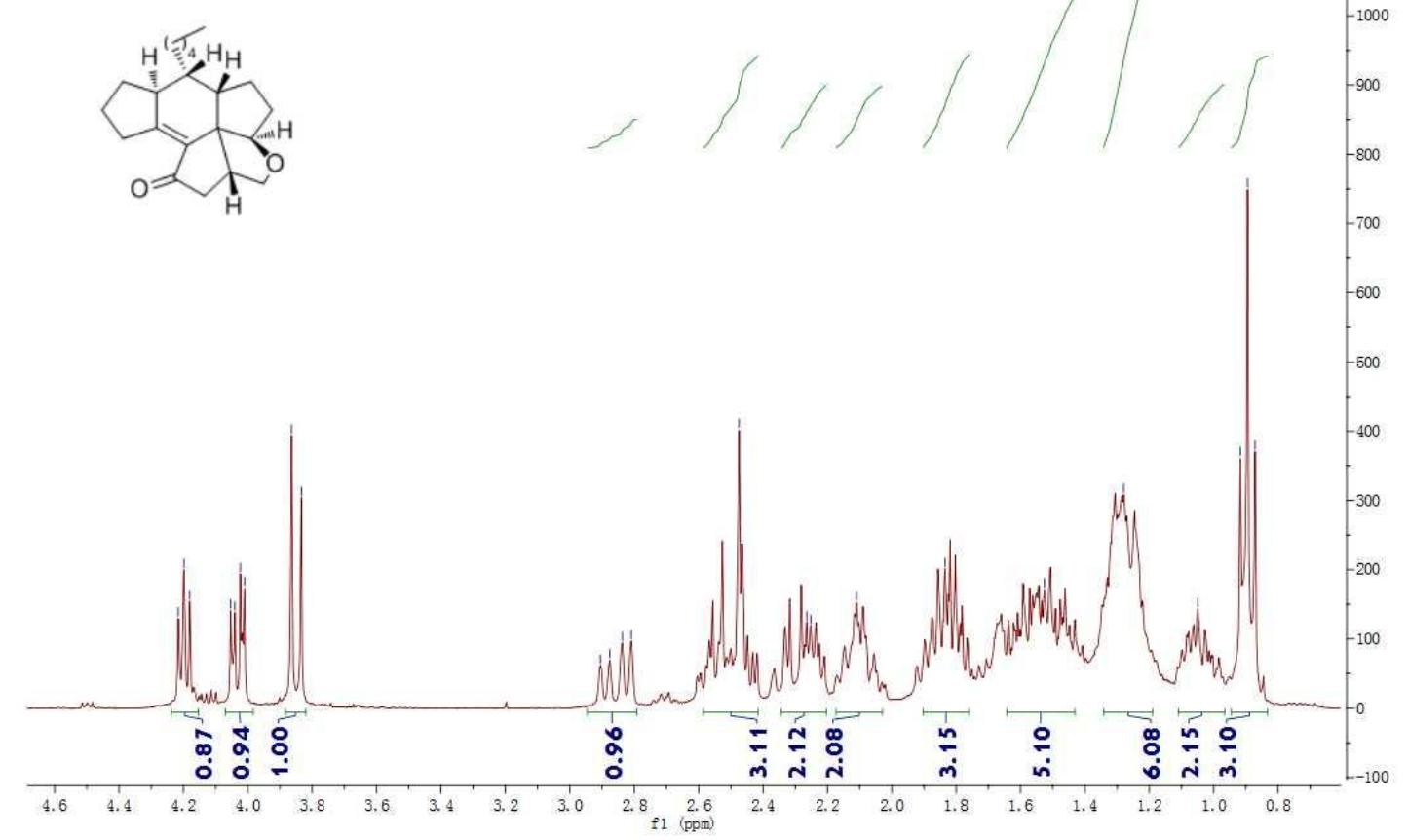

${ }^{13} \mathrm{C}$ NMR of compound 3d
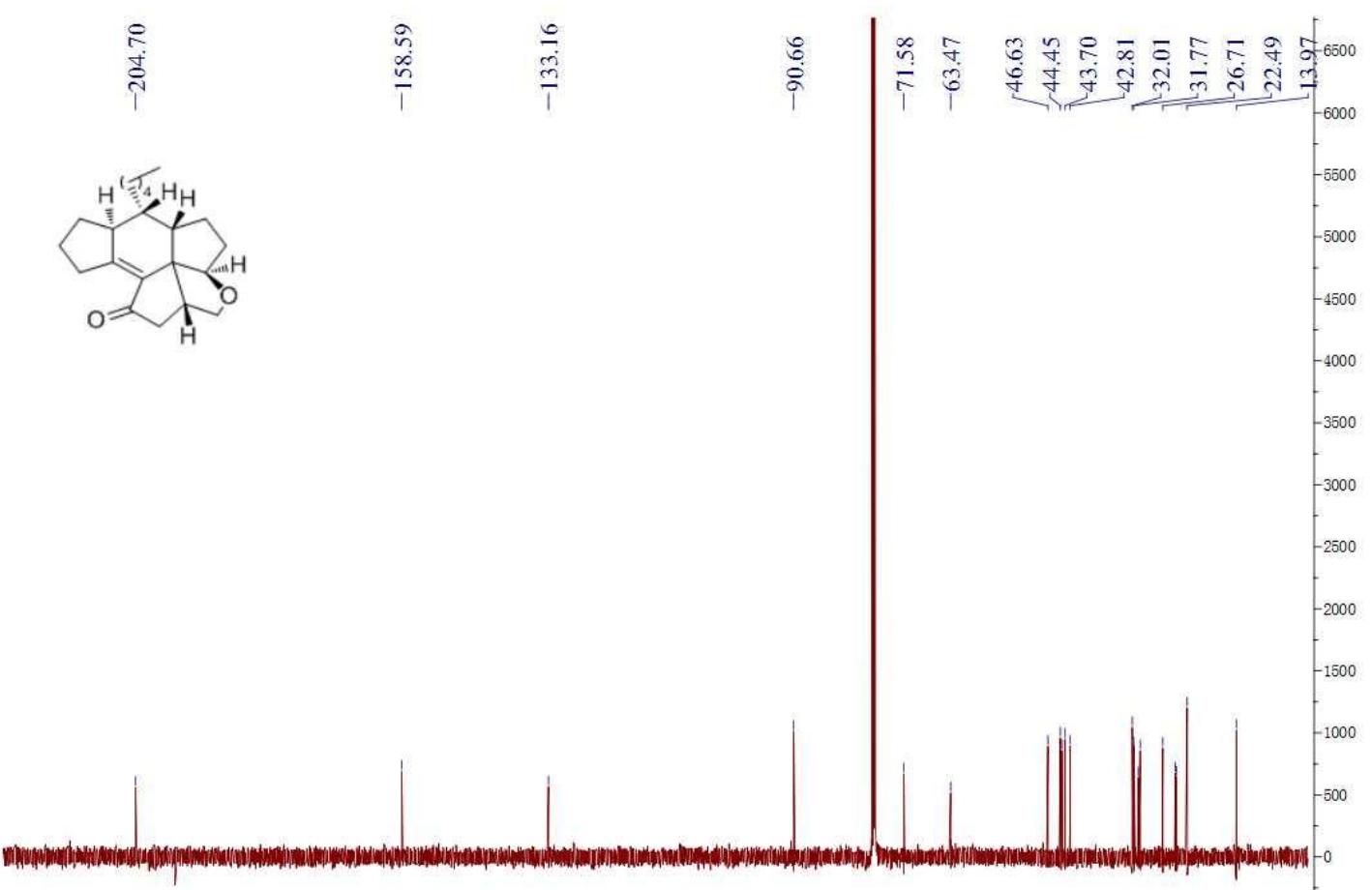

$\begin{array}{lllllllllllll}220 & 210 & 200 & 190 & 180 & 170 & 160 & 150 & 140 & 130 & 120 & 110 \\ f 1 & (\mathrm{ppm})\end{array}$ 
${ }^{1} \mathrm{H}$ NMR of compound $3 \mathbf{e}$

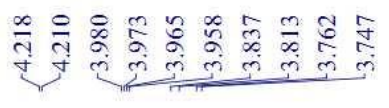

\%

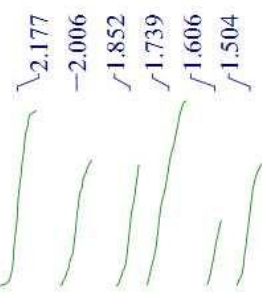

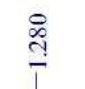

\begin{tabular}{c}
-800 \\
-750 \\
-700 \\
-650 \\
-600 \\
-550 \\
-500 \\
\hline-450 \\
-400 \\
\hline-350 \\
\hline-300 \\
\hline-250 \\
\hline-200 \\
\hline-150 \\
\hline-100 \\
\hline-50 \\
\hline-0 \\
\hline-50 \\
\hline
\end{tabular}

${ }^{13} \mathrm{C}$ NMR of compound $3 \mathrm{e}$
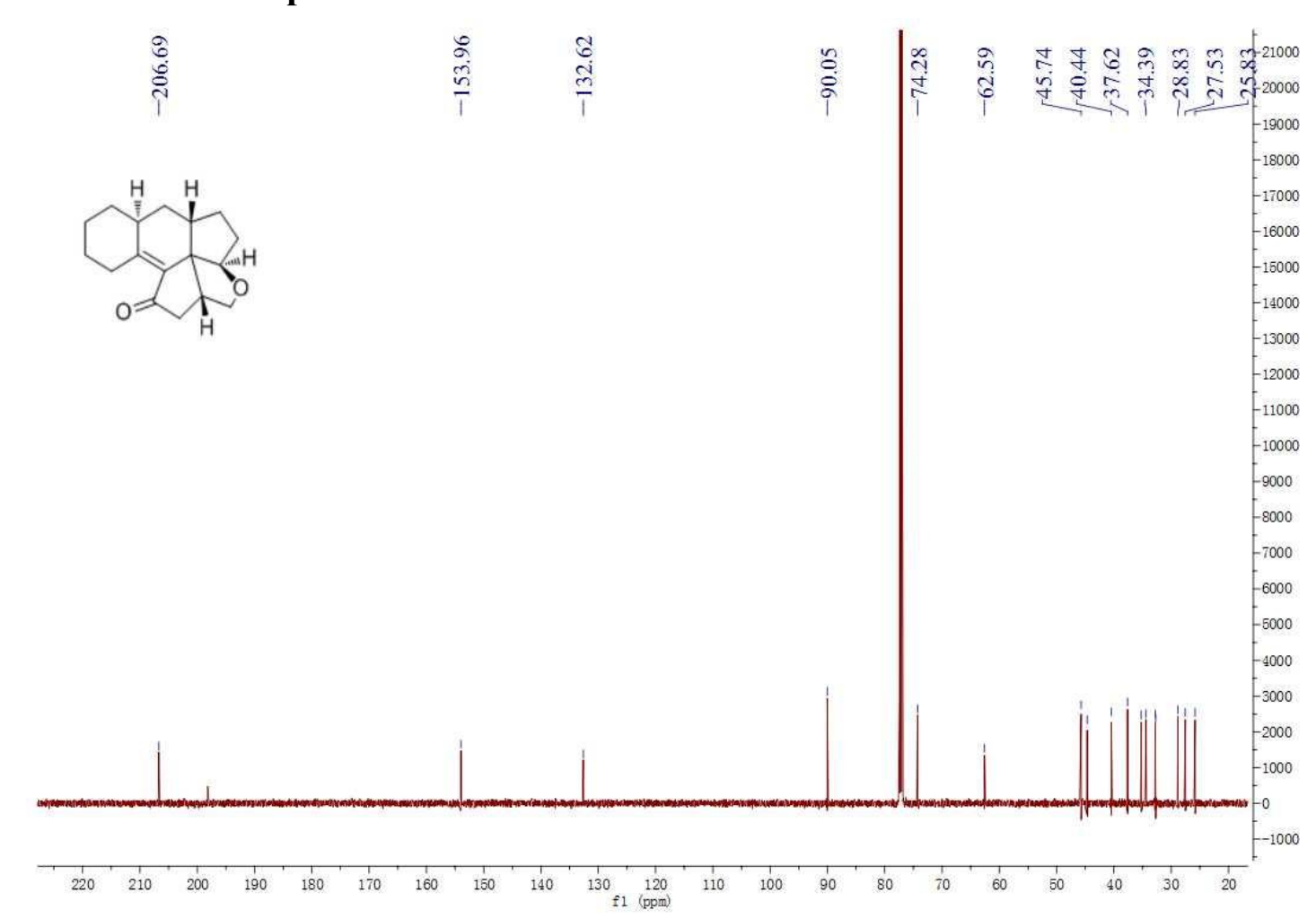

?.

๖ั 음 
Racemic PK Products, 3f-h

${ }^{1} \mathrm{H}$ NMR of $\mathbf{3 f}$

ईं

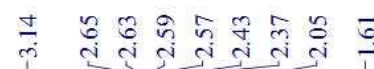

i.<smiles>C=CC(C)(C)C1(c2ccccc2)C(=O)CC2CCC1O2</smiles>

${ }^{13} \mathrm{C}$ NMR of $\mathbf{3 f}$

î

$\frac{\stackrel{2}{\circ}}{\frac{1}{2}}$

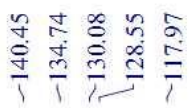

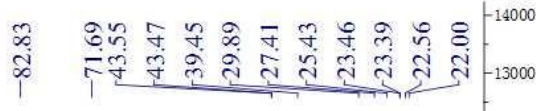<smiles>C=CCC(C)(C)C1OCC2CC(=O)C(C3=CCCCC3)=C21</smiles>

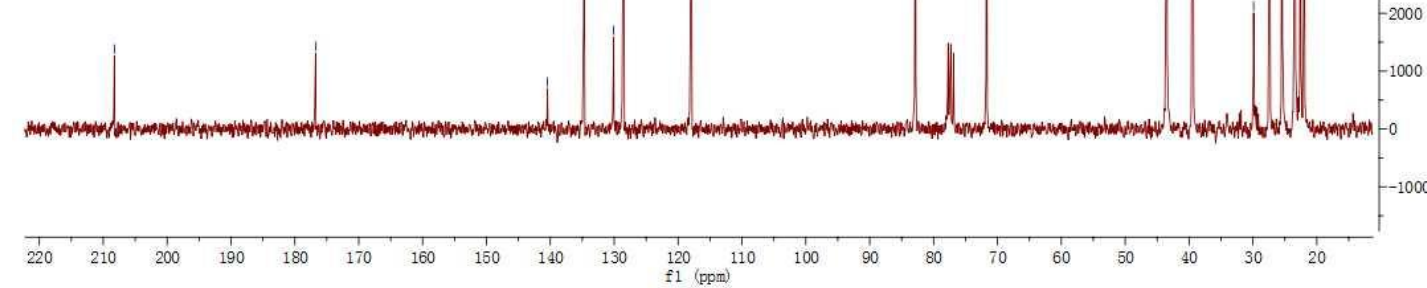




\section{${ }^{1} \mathrm{H}$ NMR of $\mathbf{3 g}$}

$\stackrel{5}{i}$ iे $\stackrel{+}{i}$ के

के<smiles>O=C1CC(C2=CCCCC2)=C2COCC2C1</smiles>

$\overrightarrow{3}$
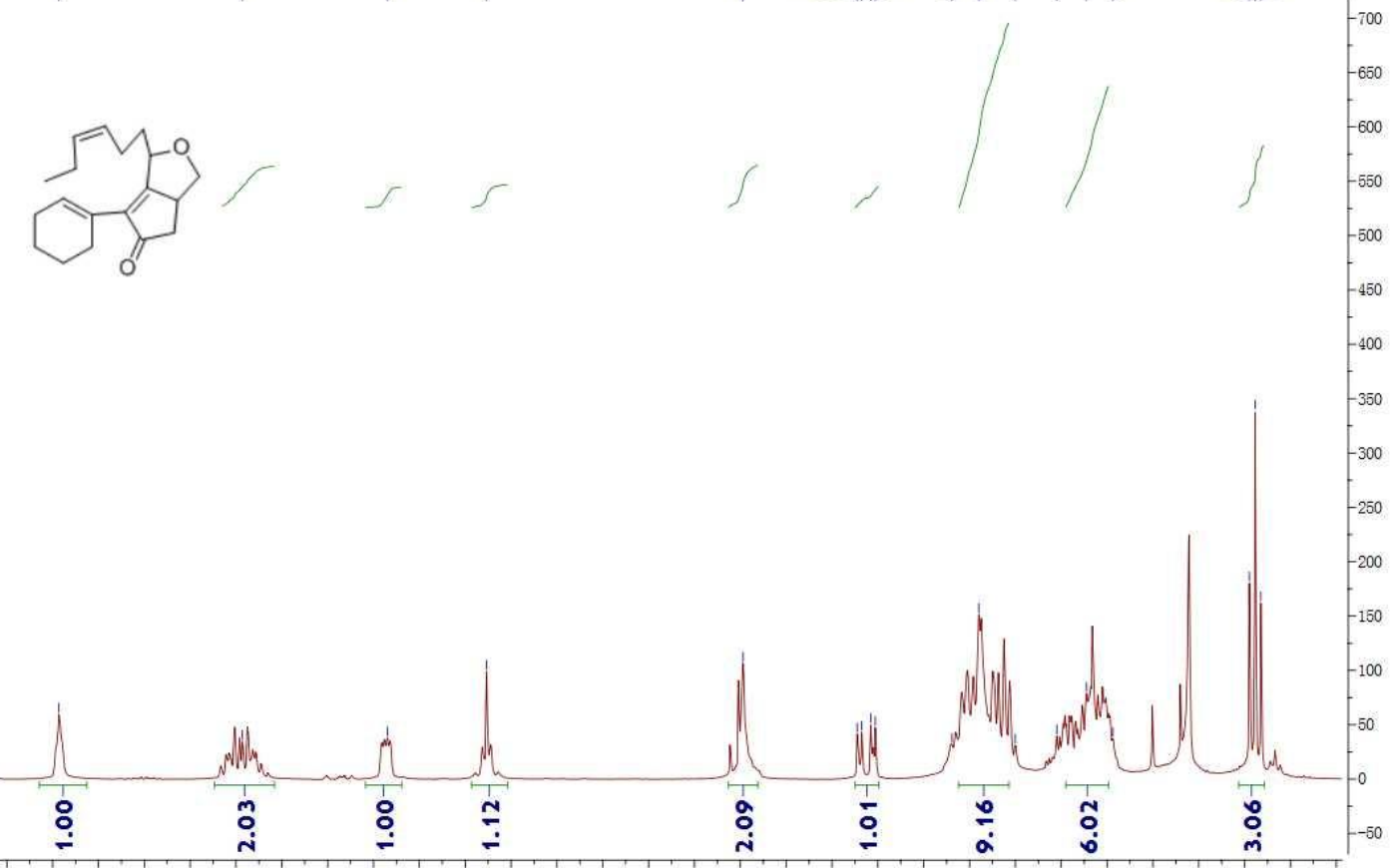

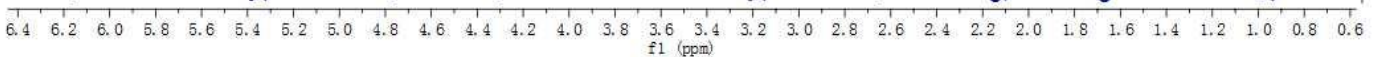

\section{${ }^{13} \mathrm{C}$ NMR of $3 g$}
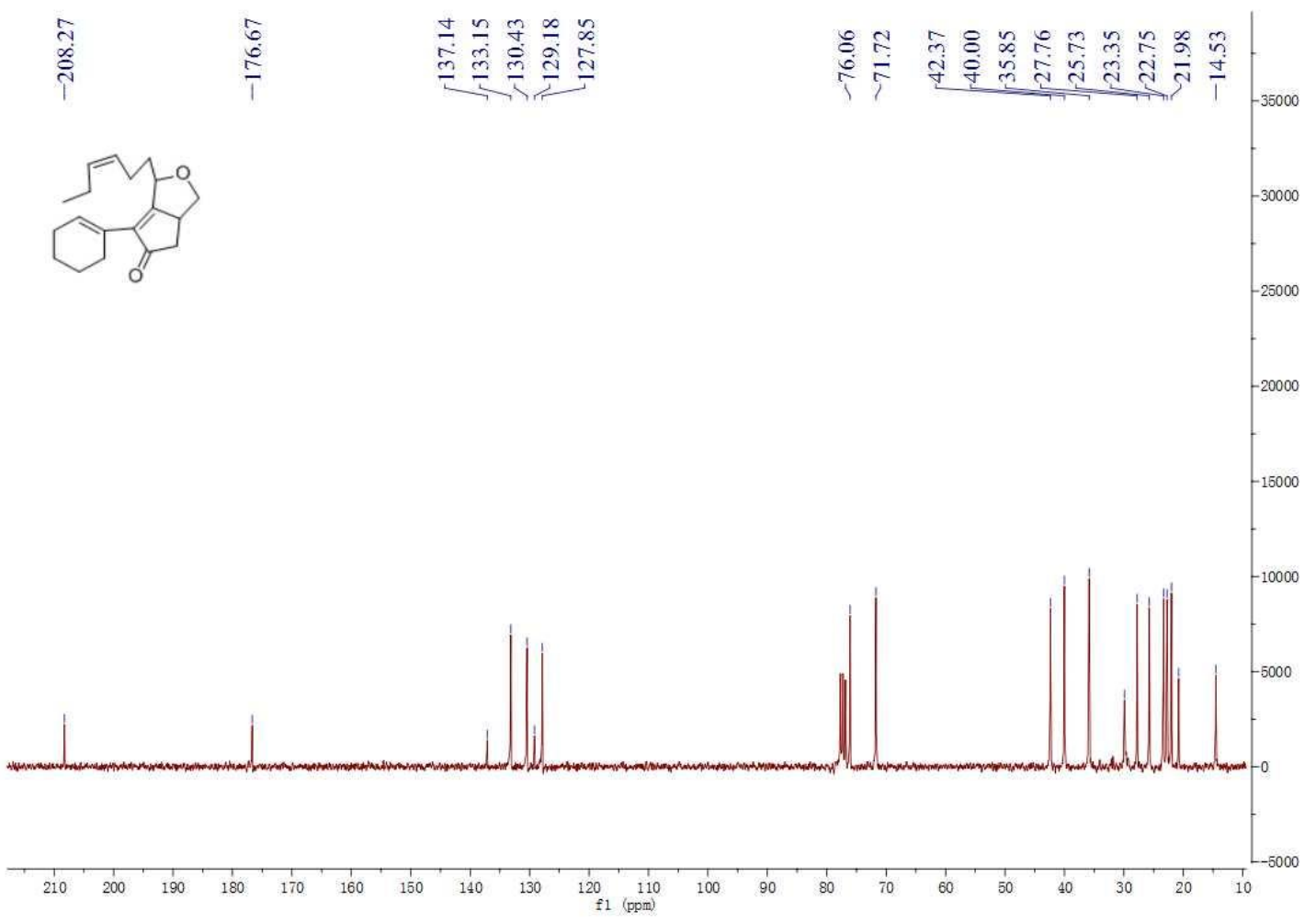
${ }^{1} \mathrm{H}$ NMR of $\mathbf{3 h}$

$\stackrel{\infty}{i}$ iे $\stackrel{i}{i} \frac{i}{i}$

के
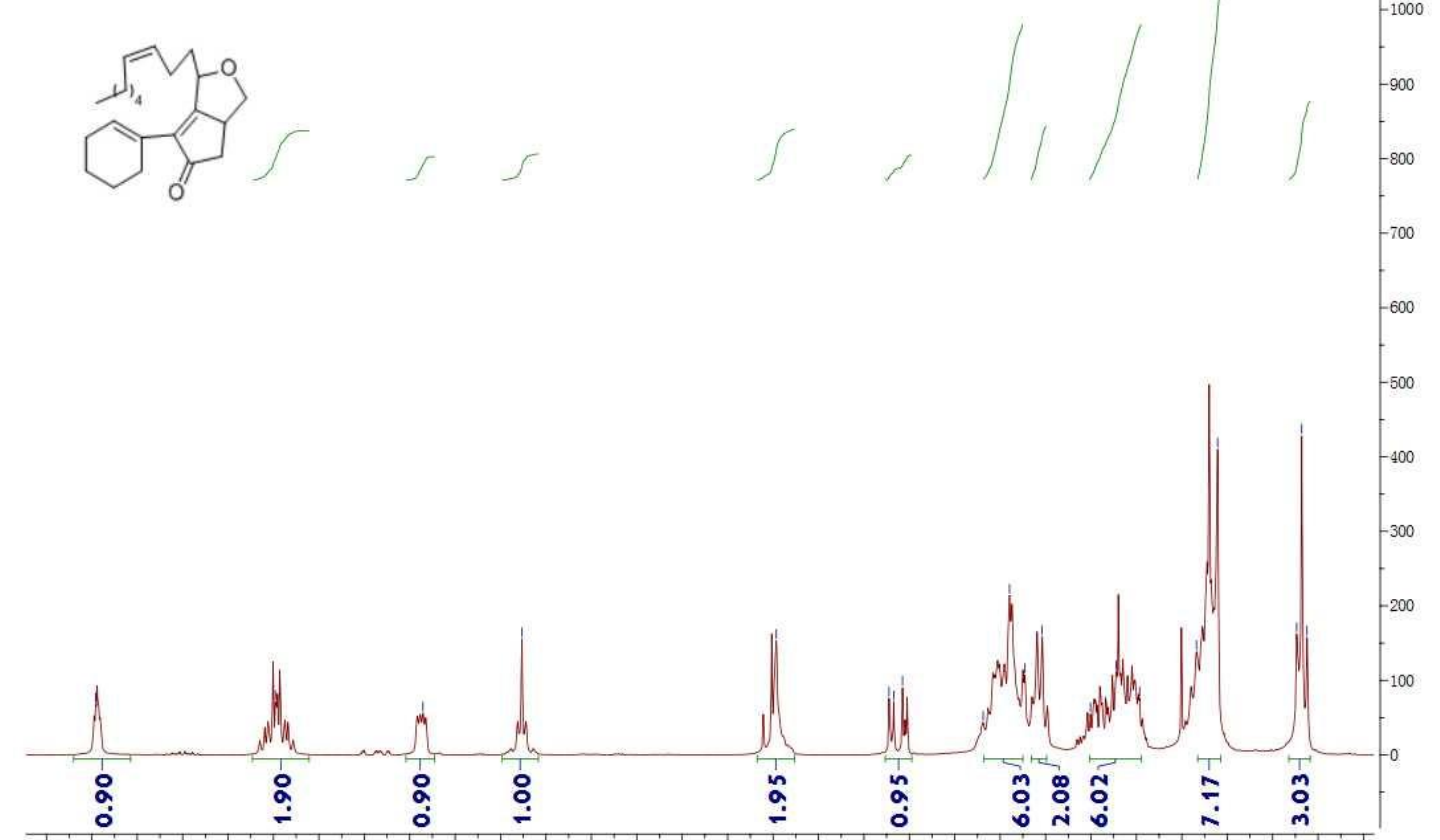

$\begin{array}{llllllllllllllllllllllllllllllllllllllll}6.4 & 6.2 & 6.0 & 5.8 & 5.6 & 5.4 & 5.2 & 5.0 & 4.8 & 4.6 & 4.4 & 4.2 & 4.0 & 3.8 & 3.6 & 3.4 & 3.2 & 3.0 & 2.8 & 2.6 & 2.4 & 2.2 & 2.0 & 1.8 & 1.6 & 1.4 & 1.2 & 1.0 & 0.8 & 0.6\end{array}$

\section{${ }^{13} \mathrm{C}$ NMR of $\mathbf{3 h}$}

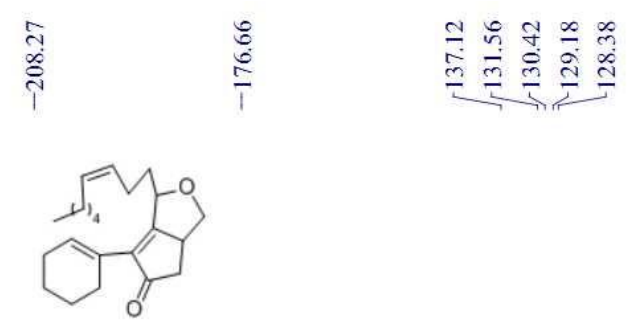

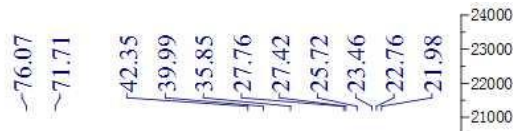

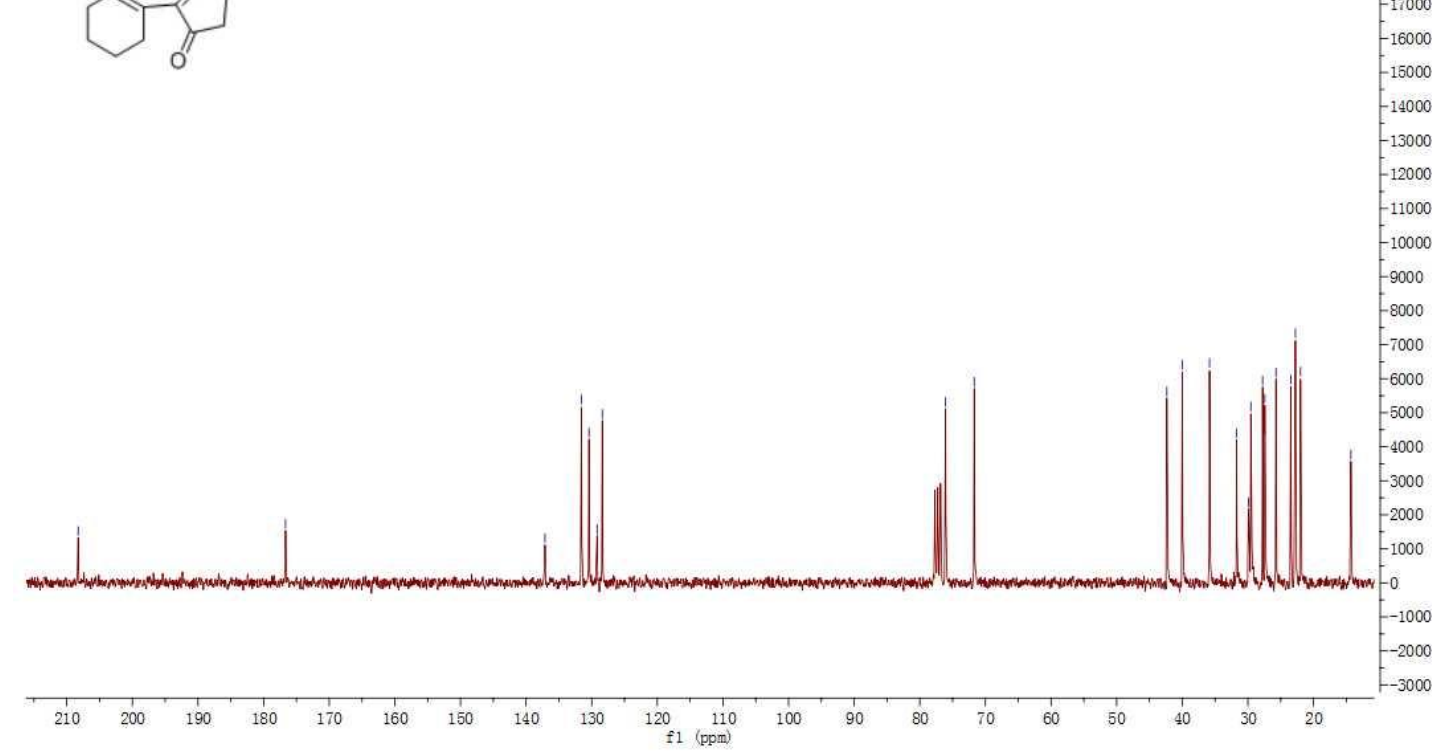


NMR Spectra for Determination of dr of Product 3d

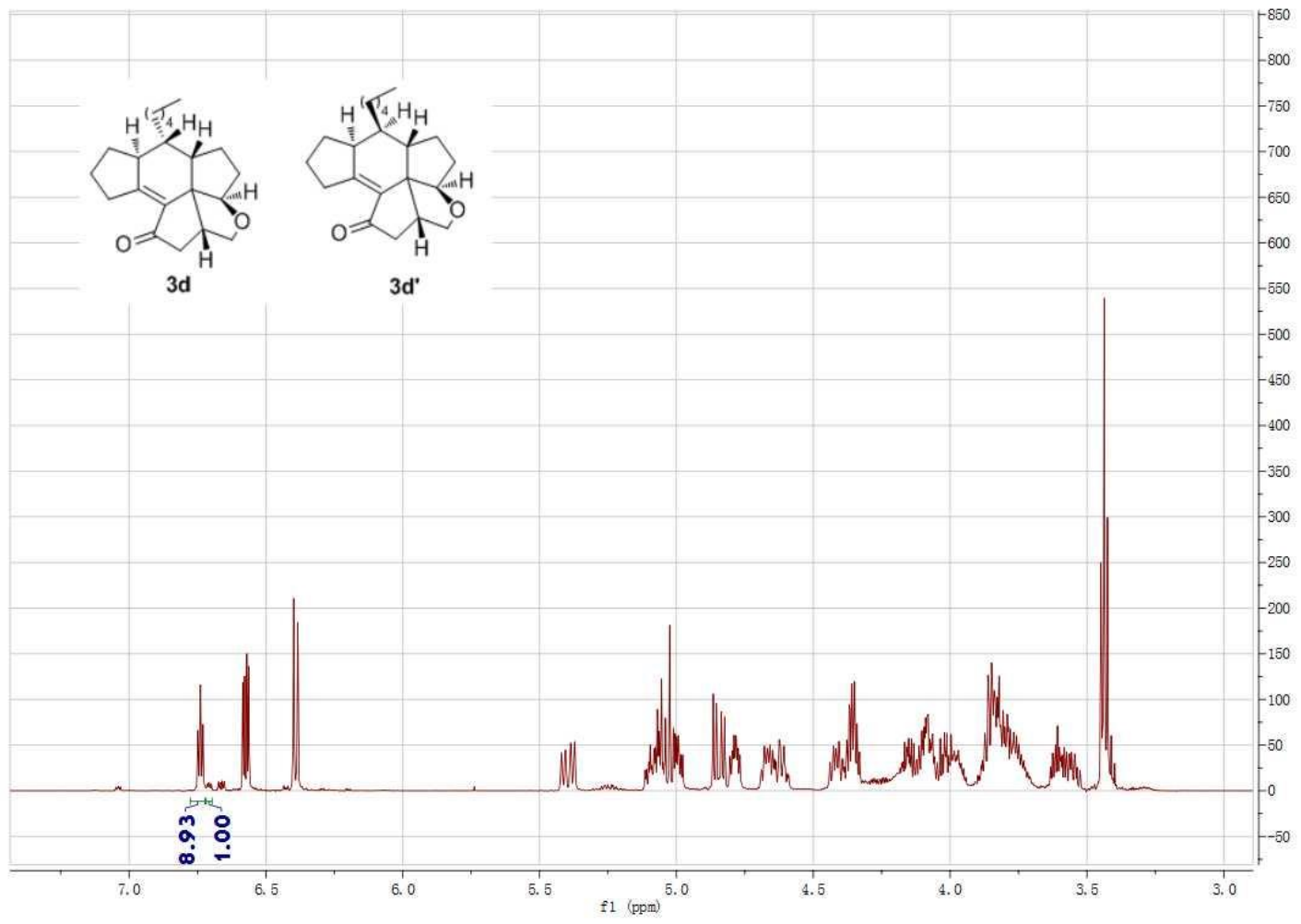

2D NMR Spectra of 3a and 3c

HSQC spectra of of compound 3a

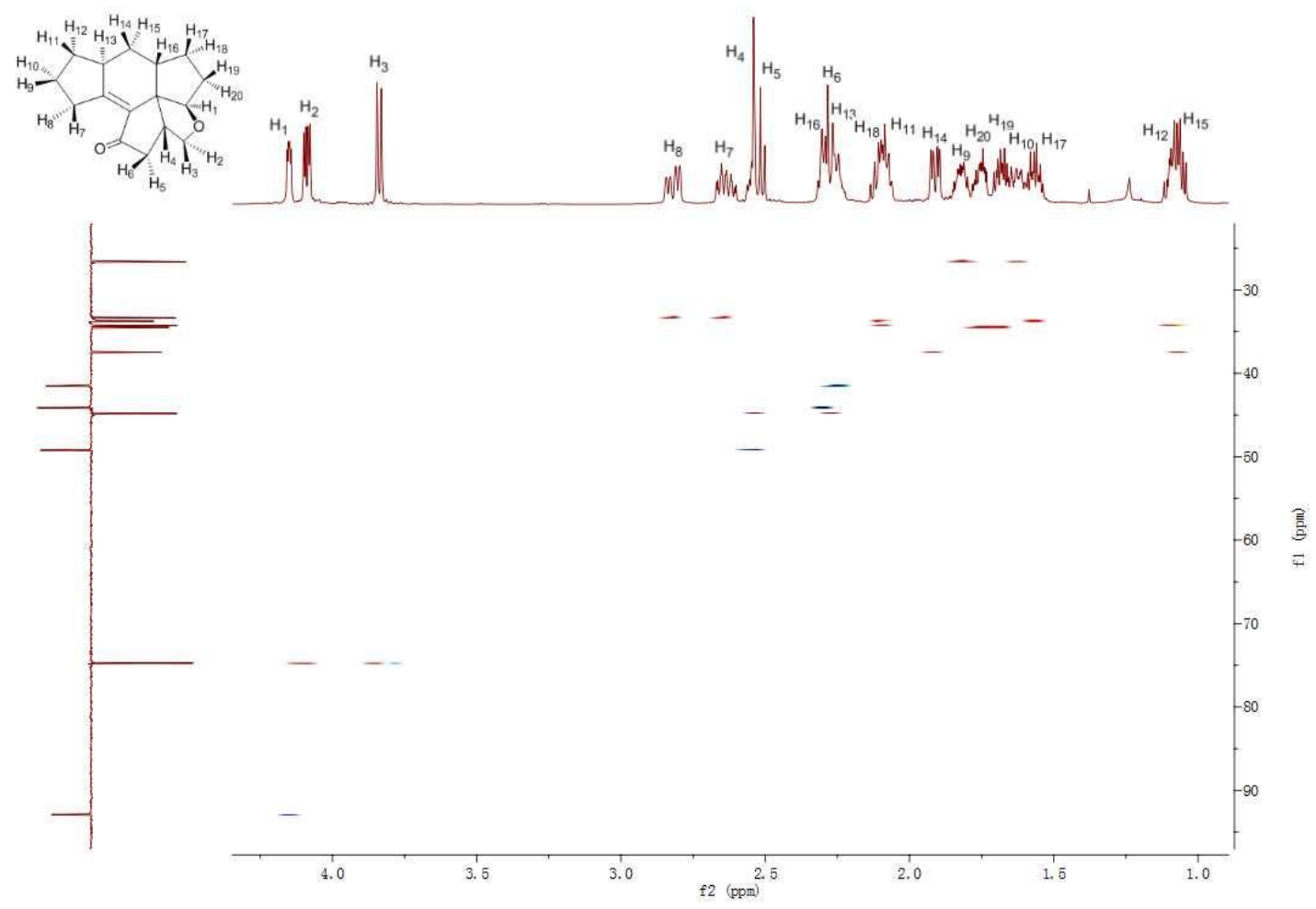


Comparison of DEPT-135 and ${ }^{13}$ C NMR of compound 3a

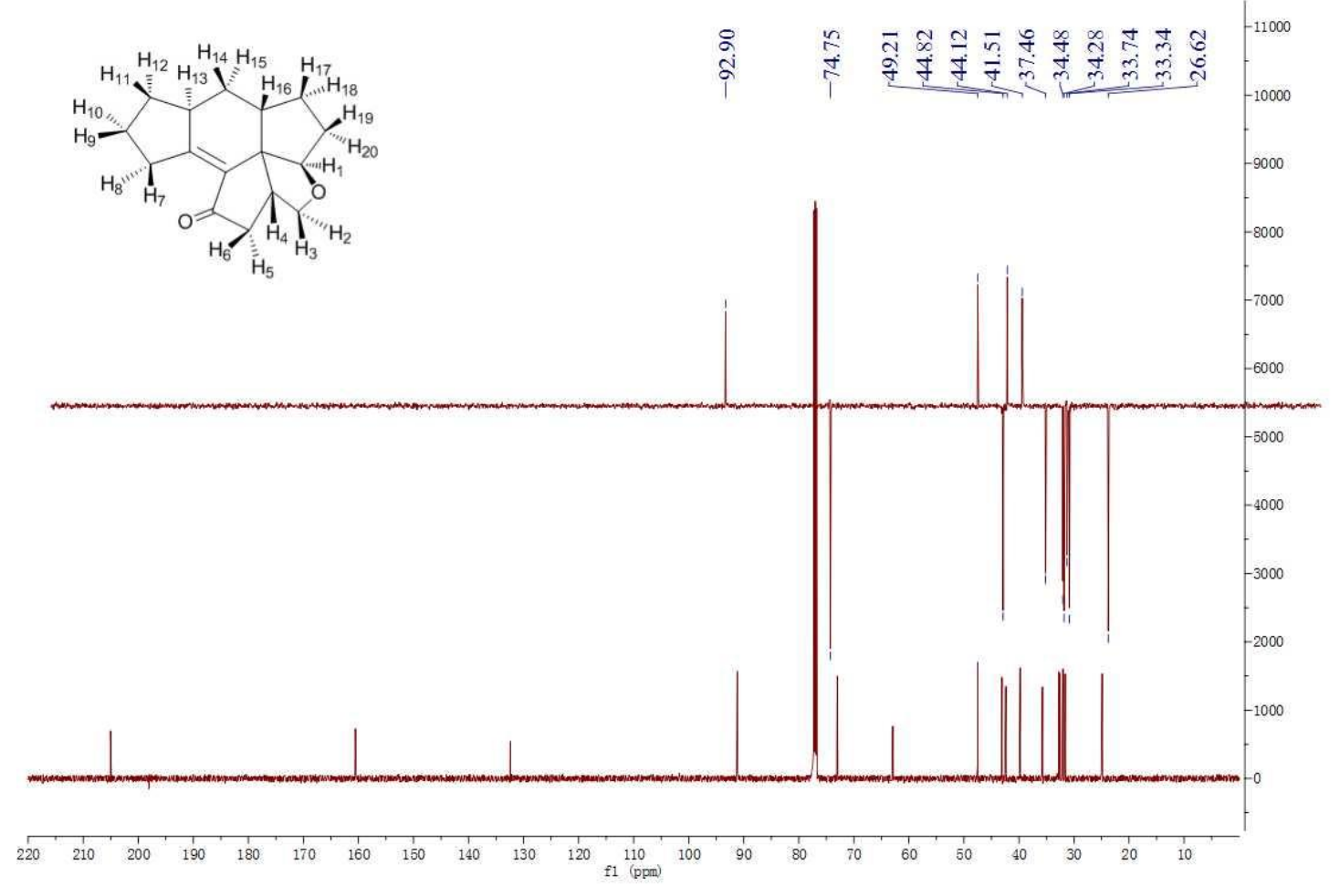

COSY spectra of compound 3a

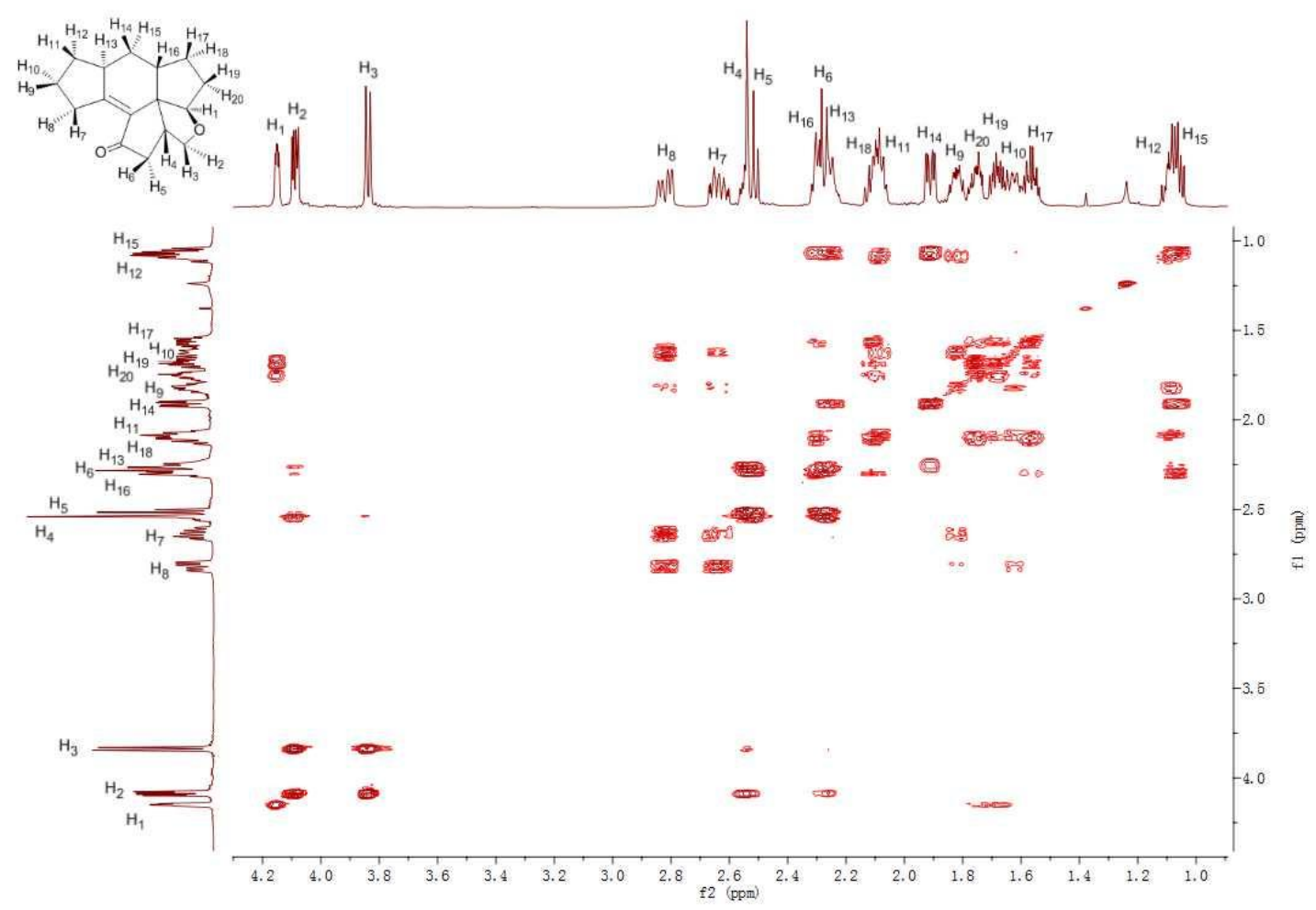


NOSEY spectra of compound 3a

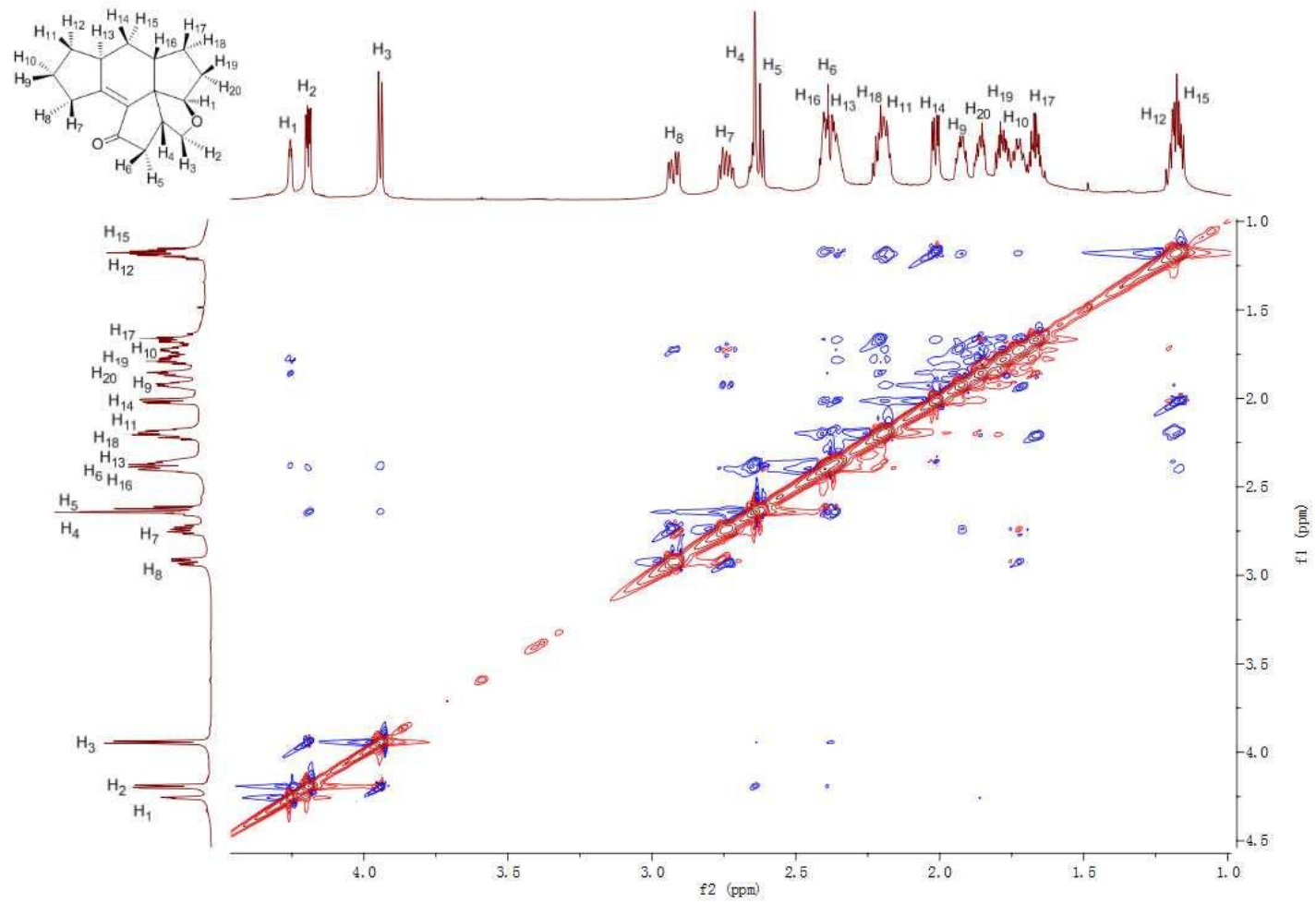

HSQC spectra of compound 3c

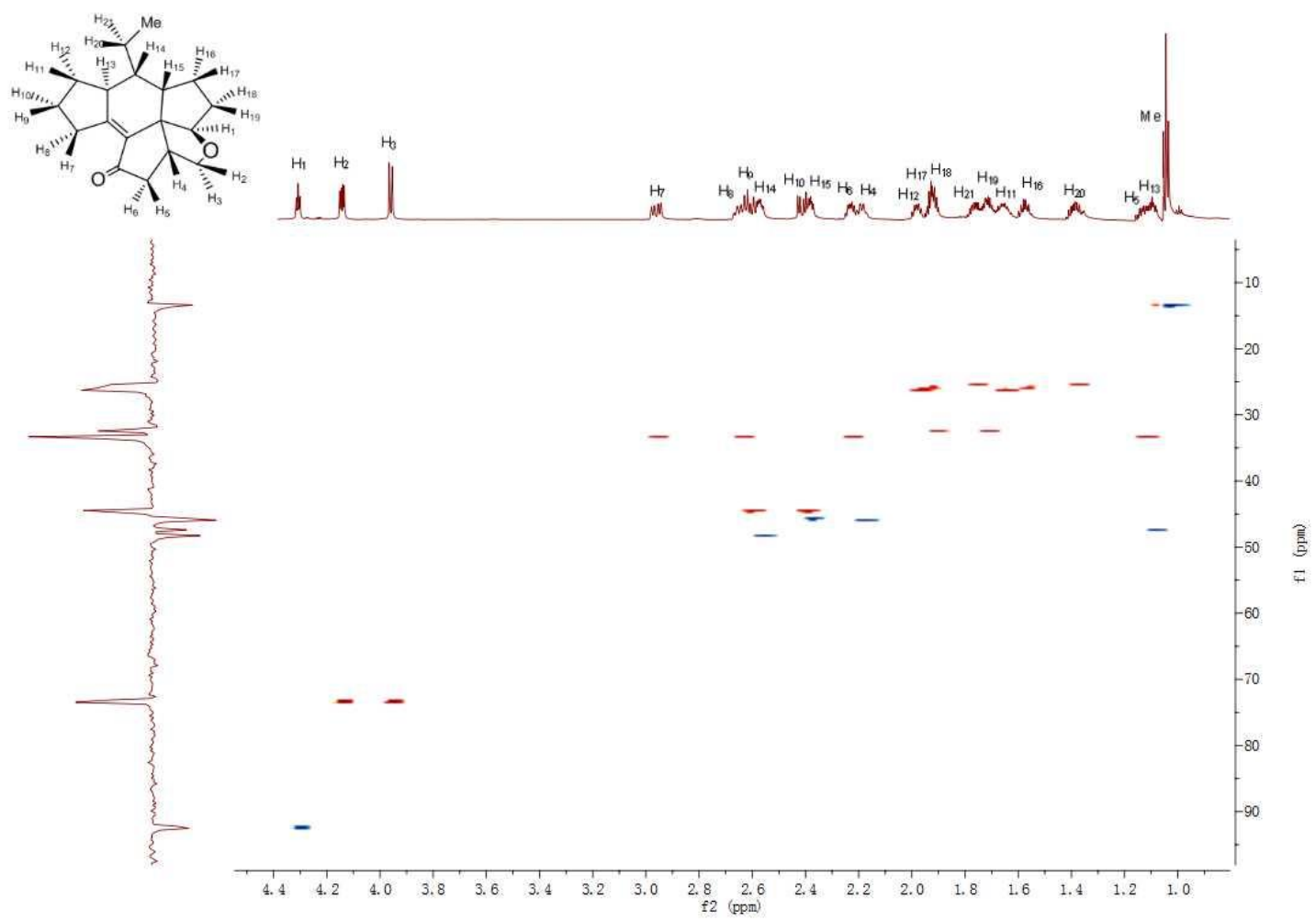


Comparison of DEPT-135 and ${ }^{13} \mathrm{C}$ NMR of compound 3c

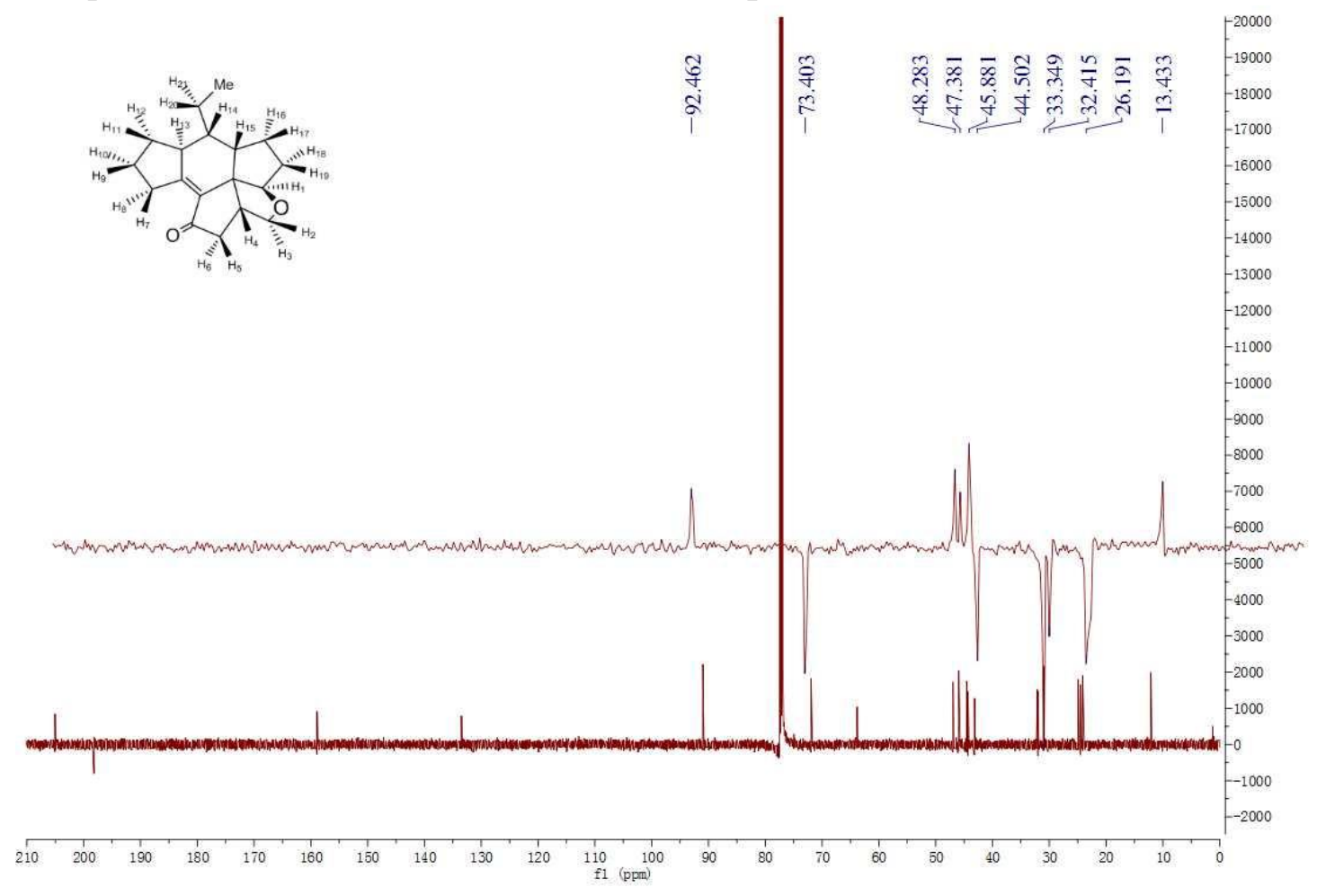

COSY spectra of compound 3c

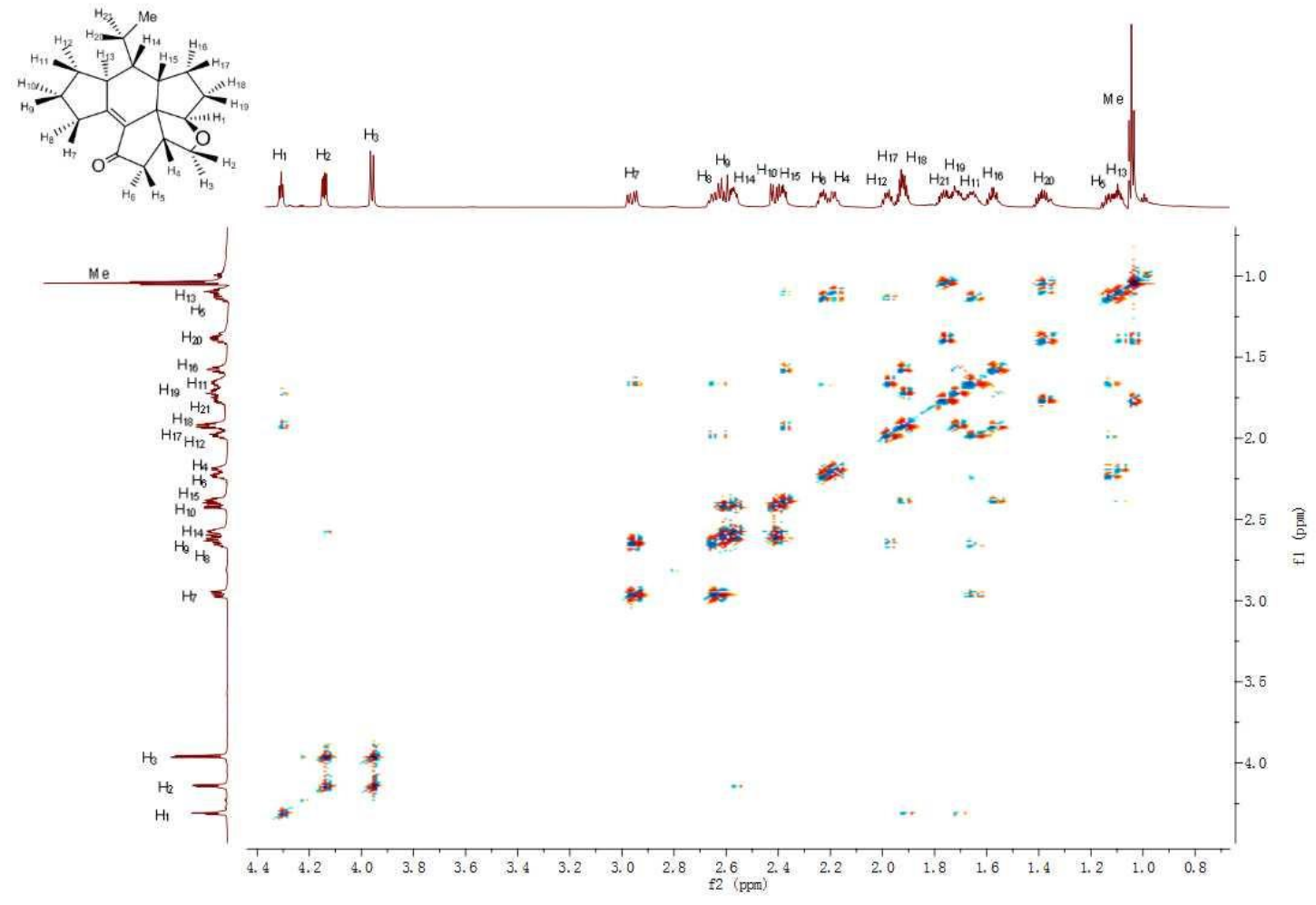


NOSEY spectra of compound 3c

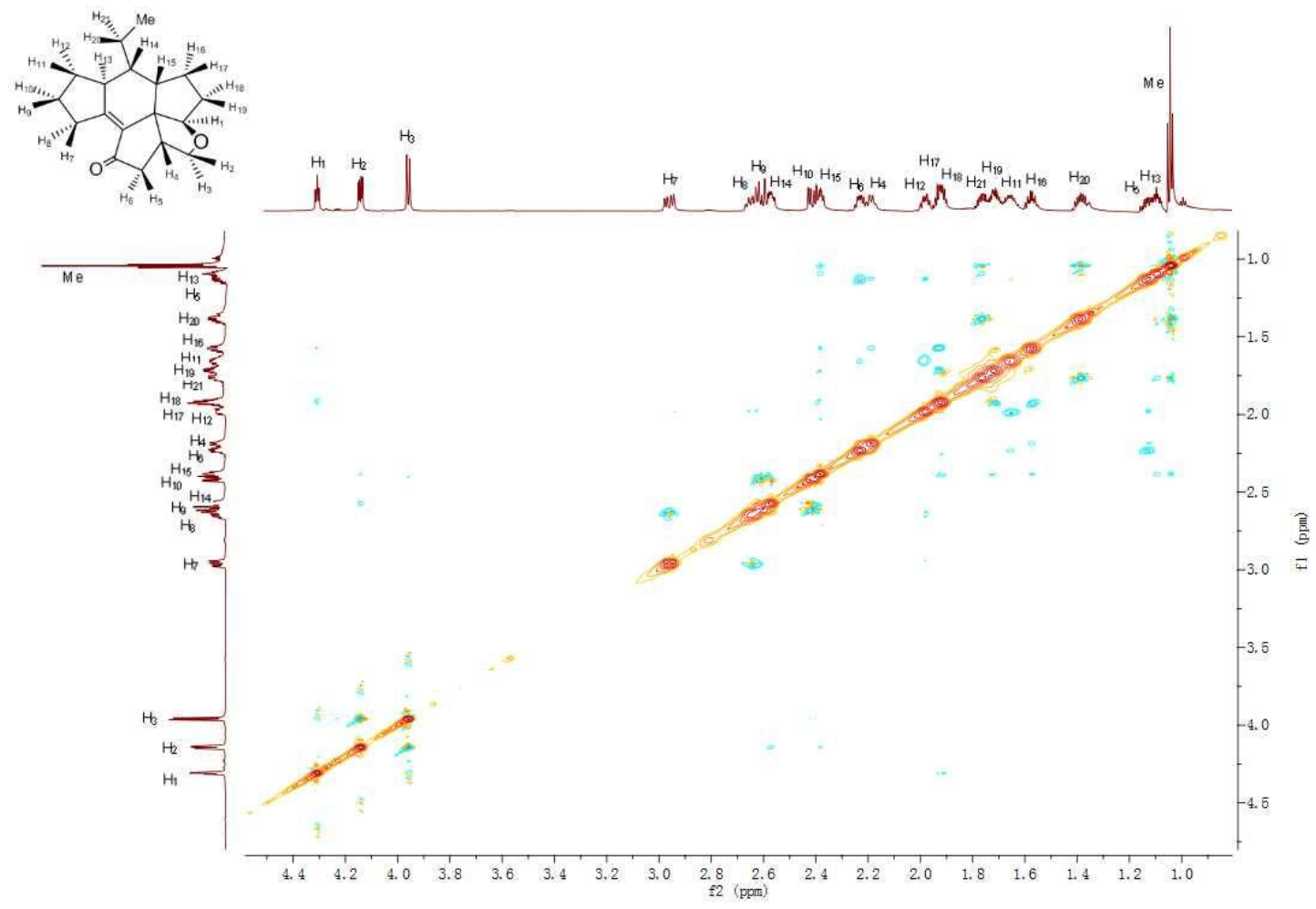

Other compounds

${ }^{1} \mathrm{H}$ NMR of $\mathbf{2 . 5 4}$

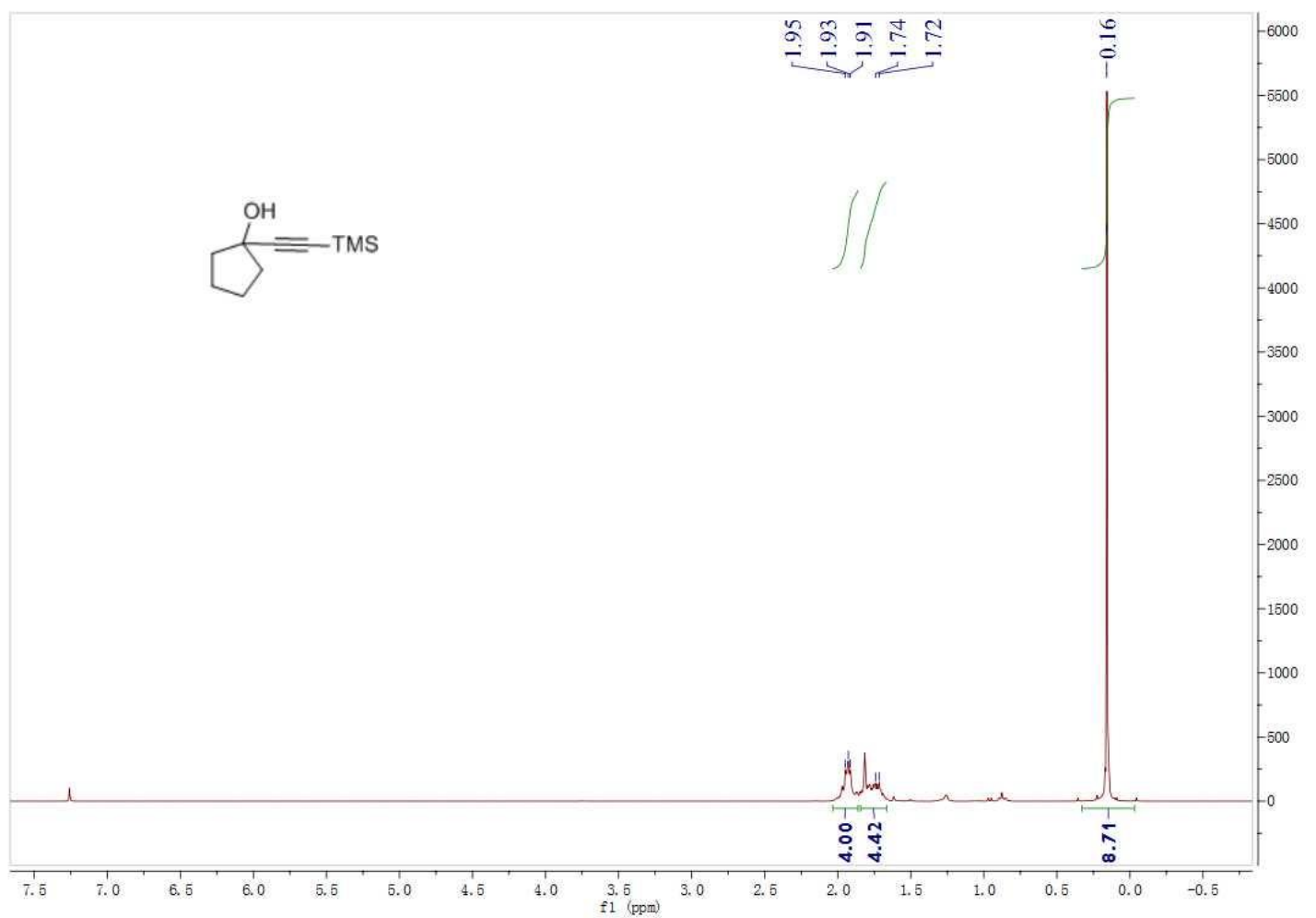


${ }^{13} \mathrm{C}$ NMR of $\mathbf{2 . 5 4}$

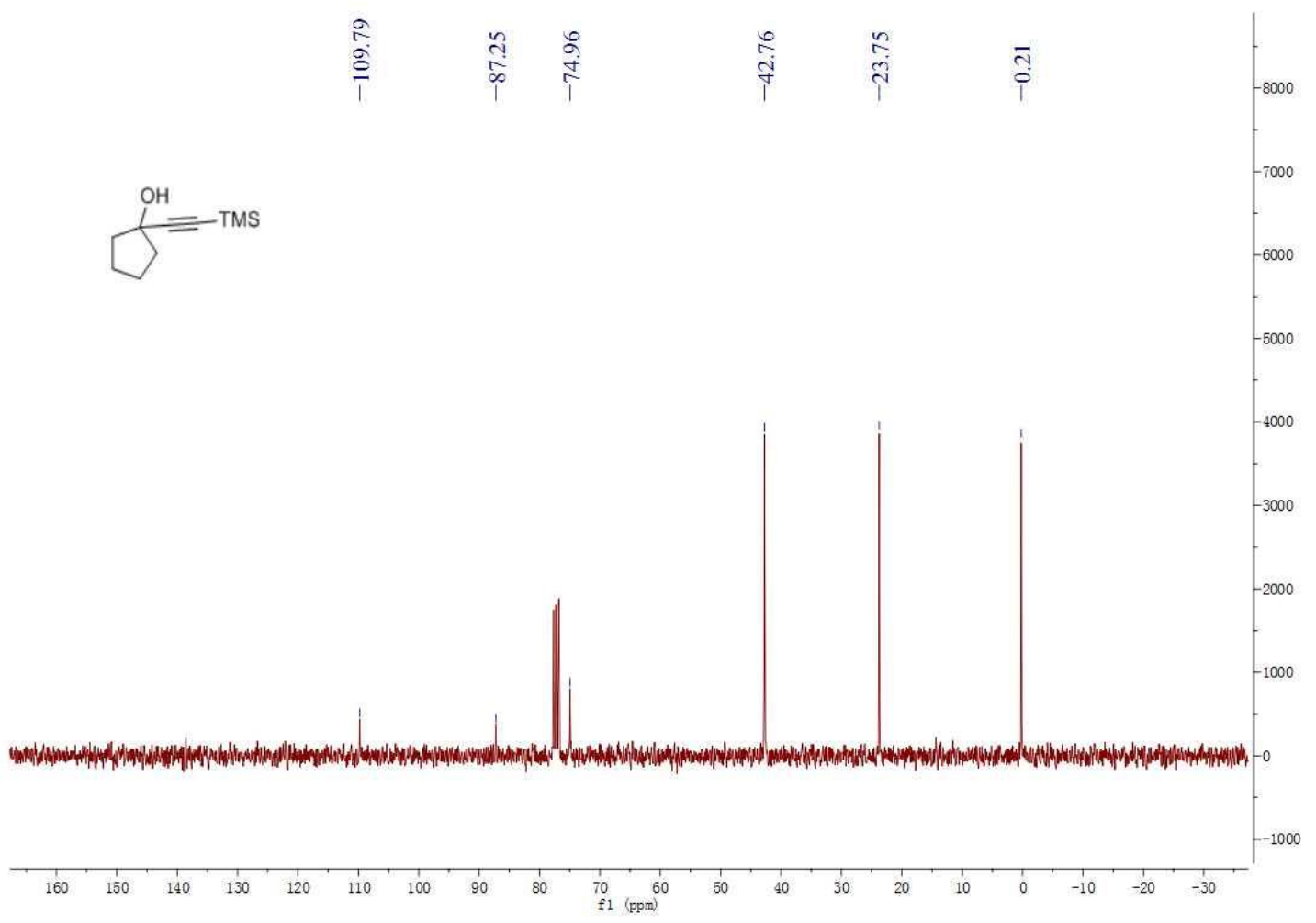

${ }^{1} \mathrm{H}$ NMR of $\mathbf{2 . 5 5}$

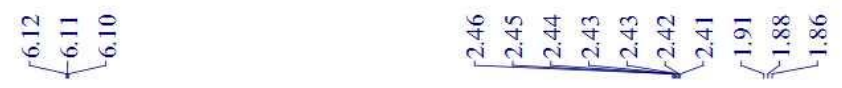

$y=\mathrm{TMS}$

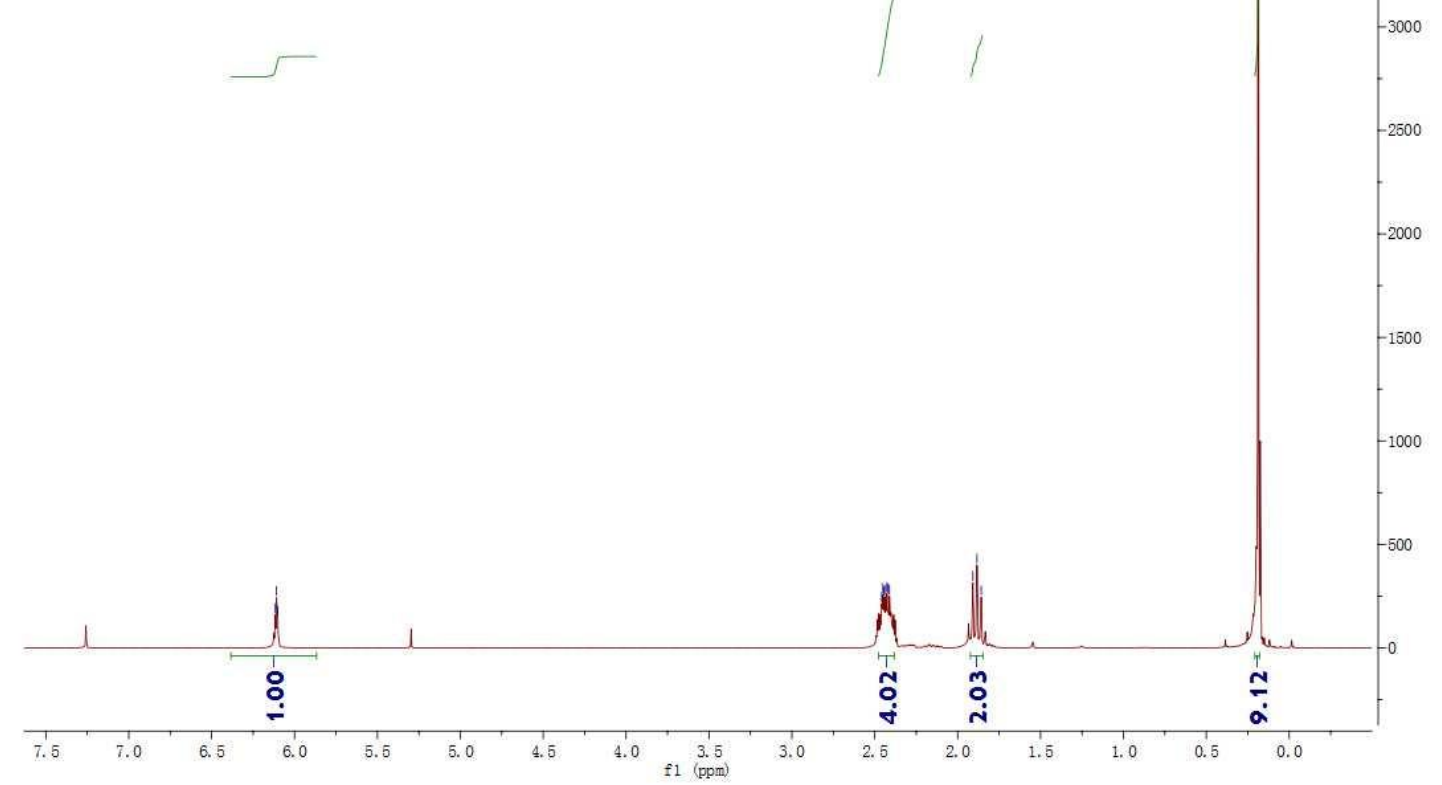


${ }^{13} \mathrm{C}$ NMR of $\mathbf{2 . 5 5}$

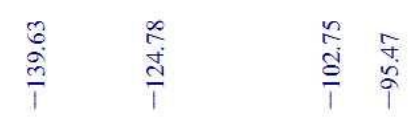

है.

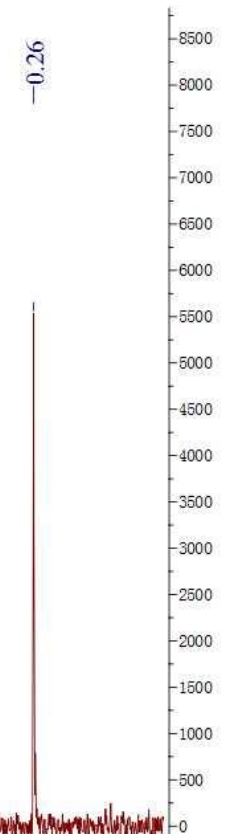

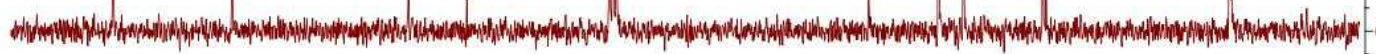

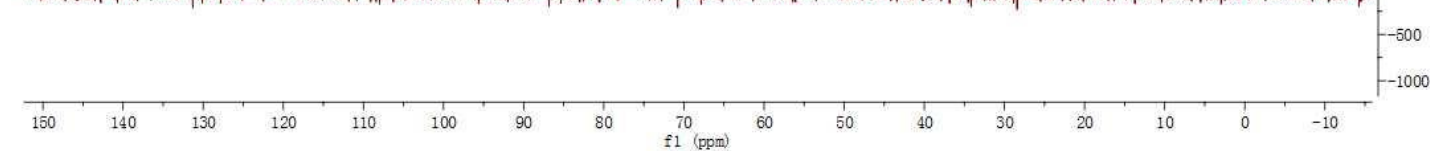

${ }^{1} \mathrm{H}$ NMR of $\mathbf{2 . 7 1}$

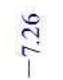

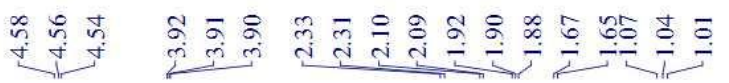

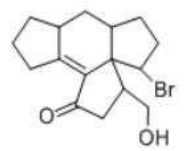

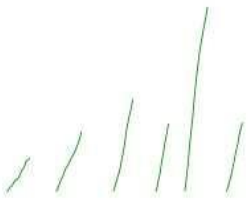

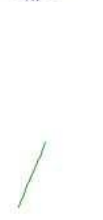

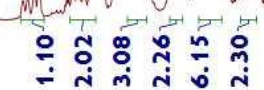

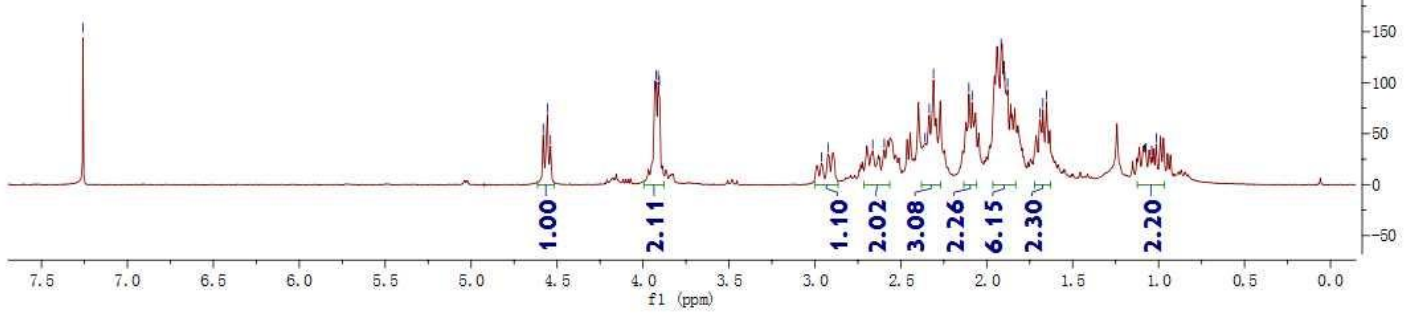


${ }^{13} \mathrm{C}$ NMR of 2.71

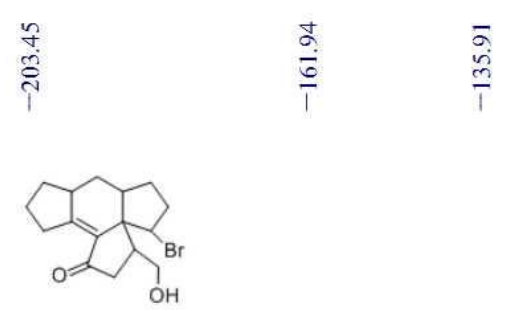

$\frac{a}{i}$

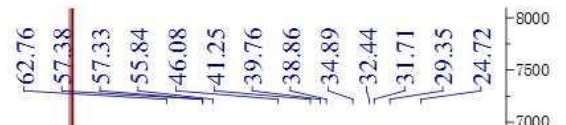

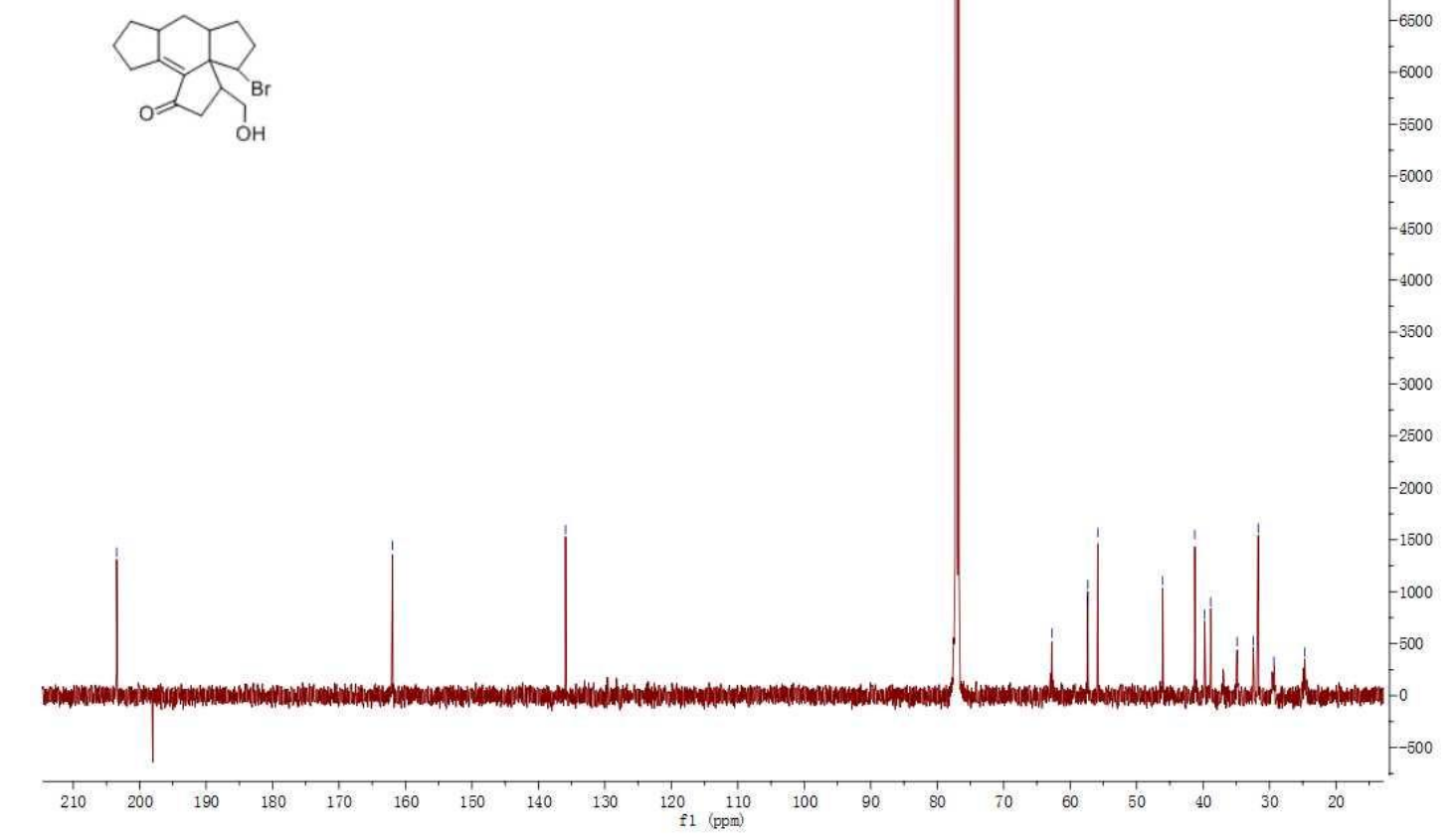

${ }^{13} \mathrm{C}$ NMR and DEPT-135 of $\mathbf{2 . 7 1}$

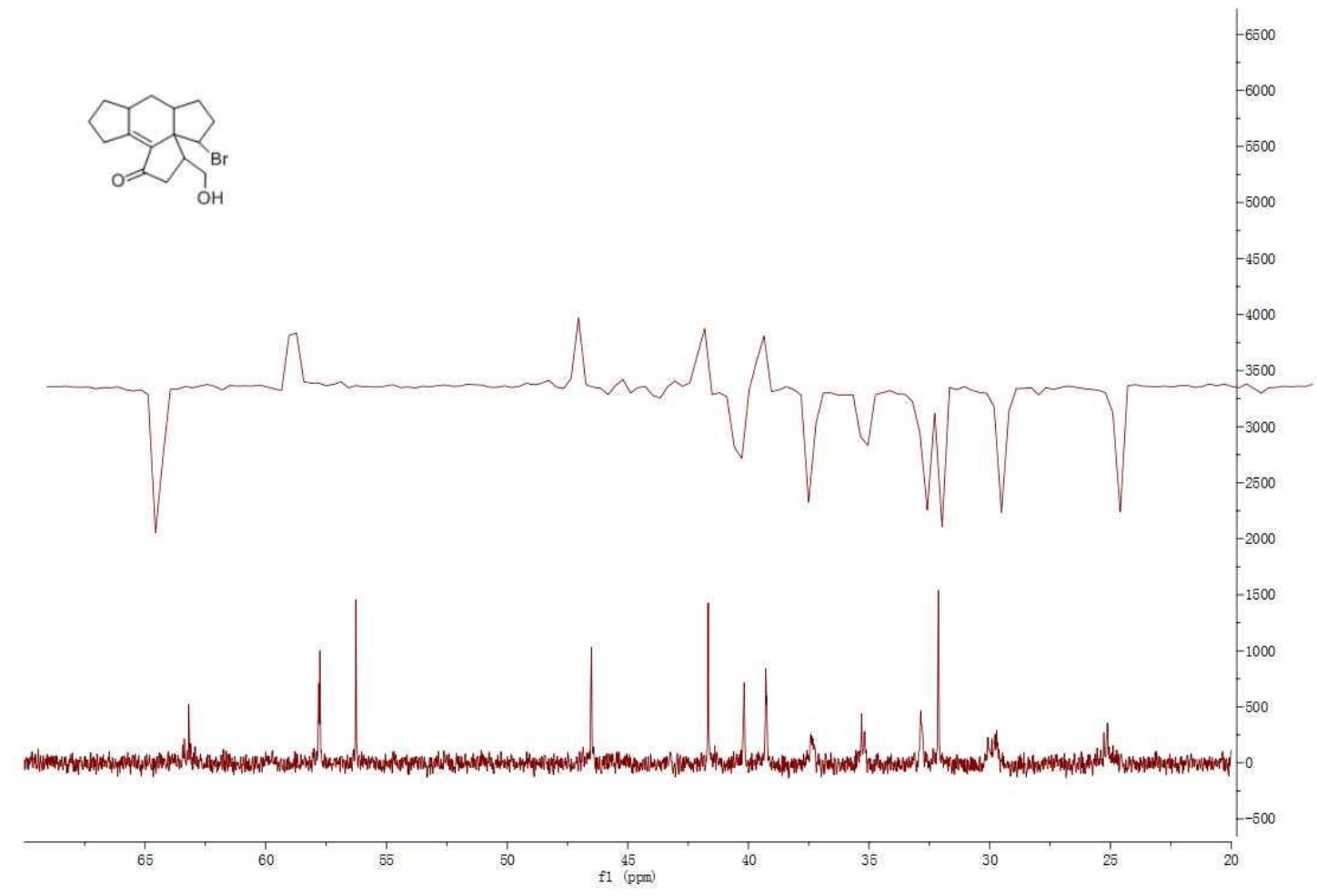


HSQC of $\mathbf{2 . 7 1}$

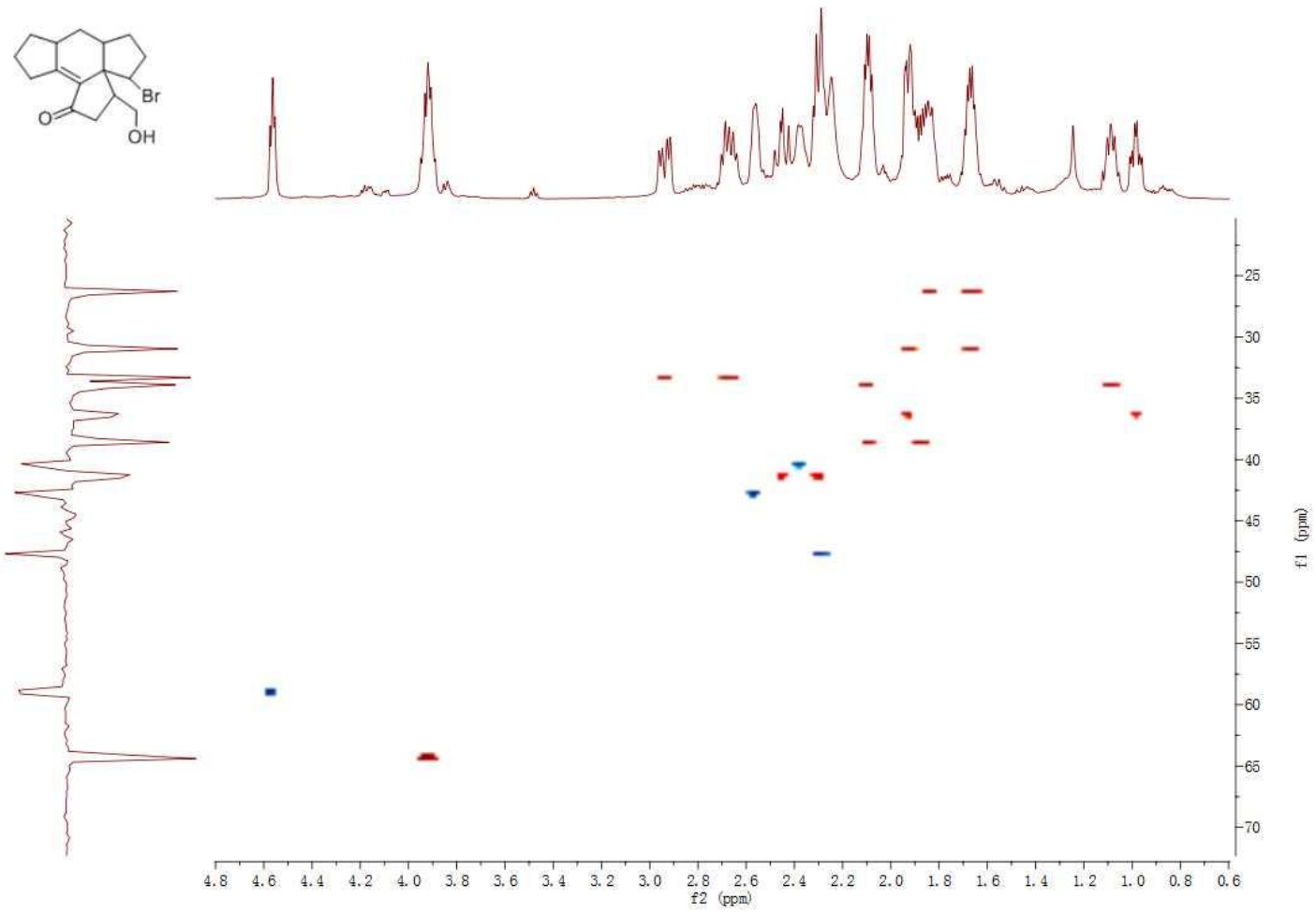

${ }^{1} \mathrm{H}$ NMR of $\mathbf{2 . 6 6}$

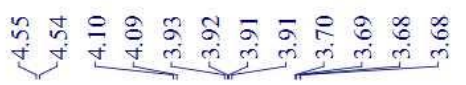

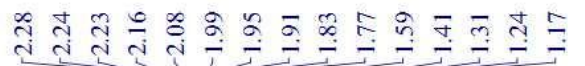
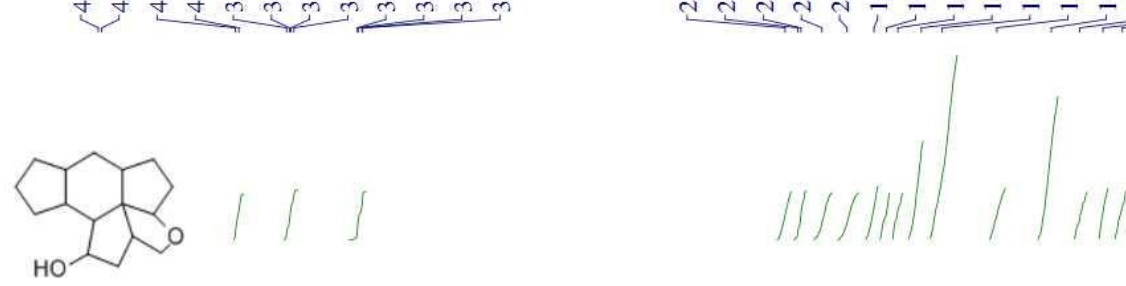

7500
-7000
-6500
-6000
-5500
-500

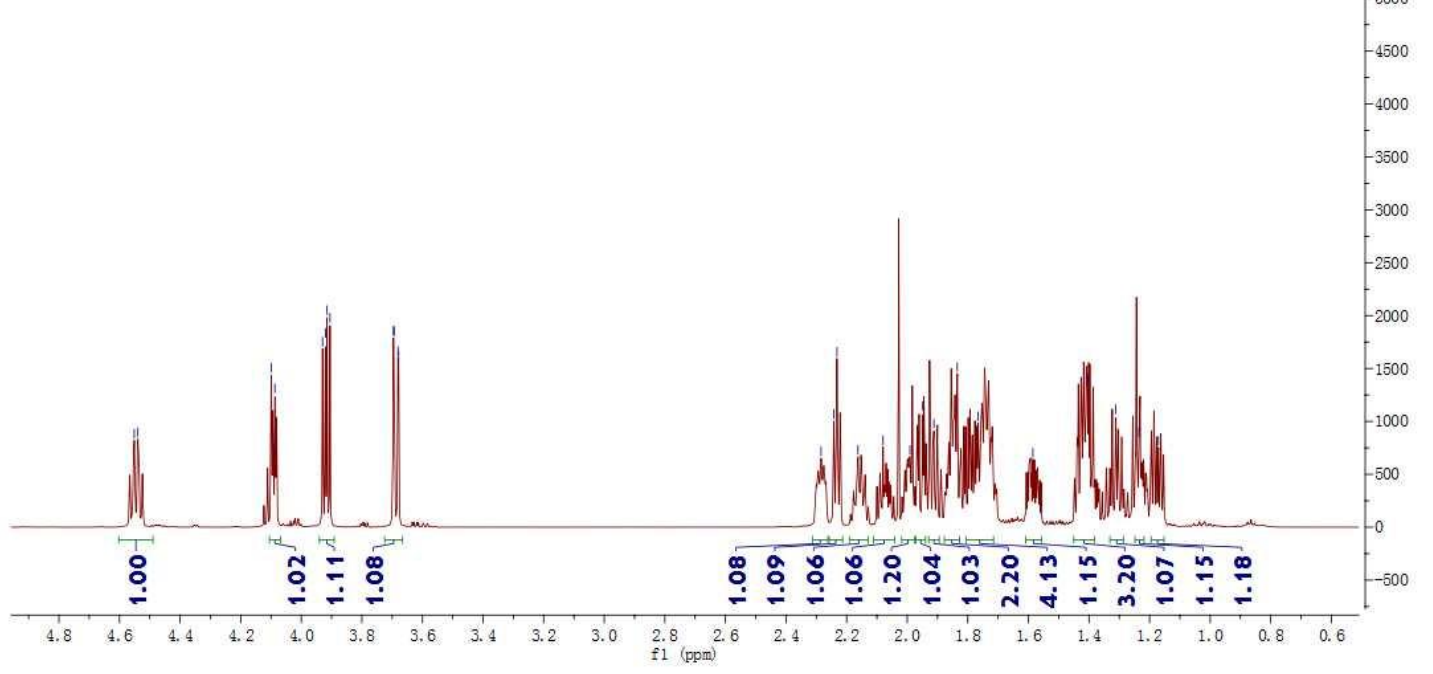


${ }^{13} \mathrm{C}$ NMR of $\mathbf{2 . 6 6}$

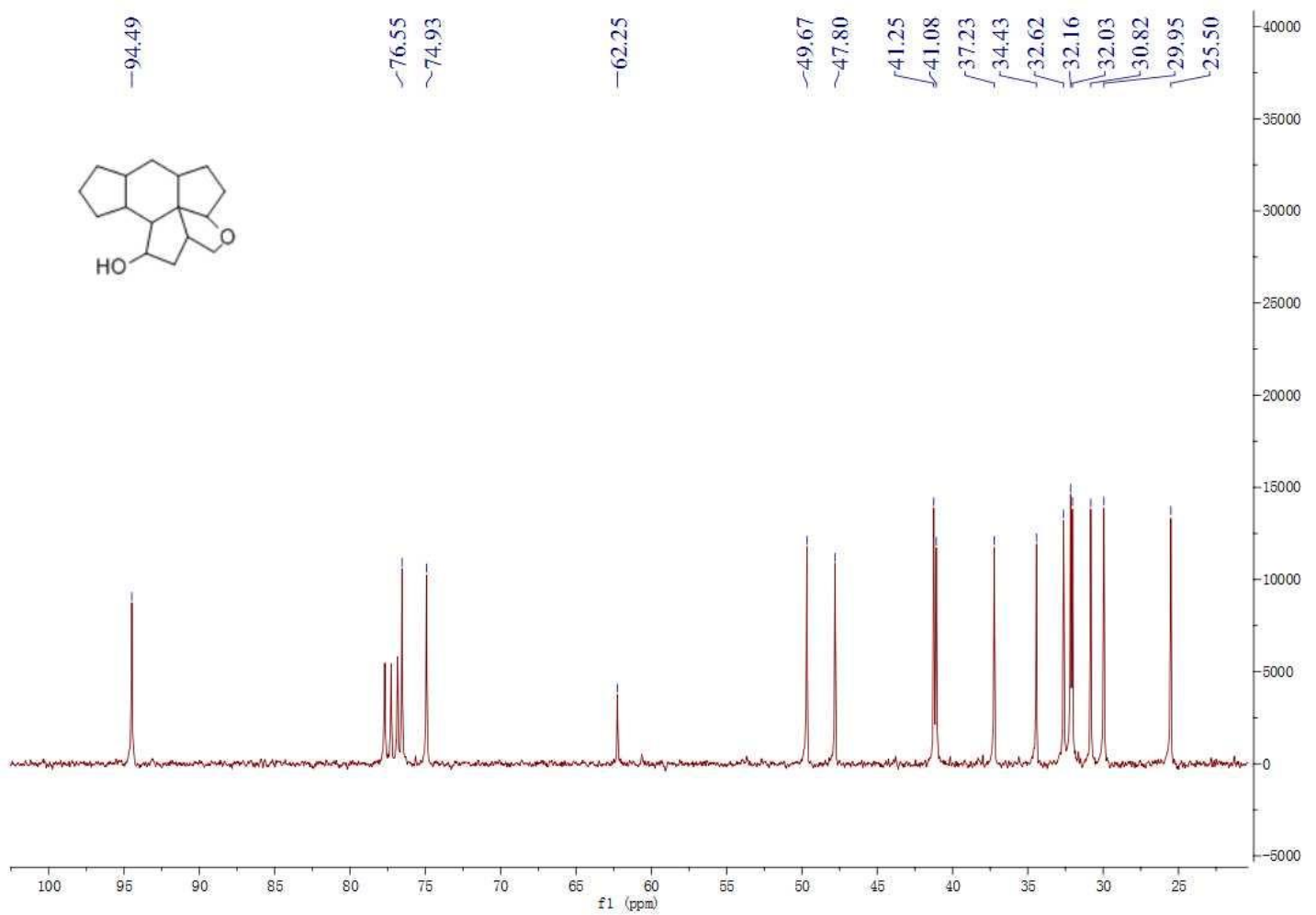

DEPT-135 of $\mathbf{2 . 6 6}$

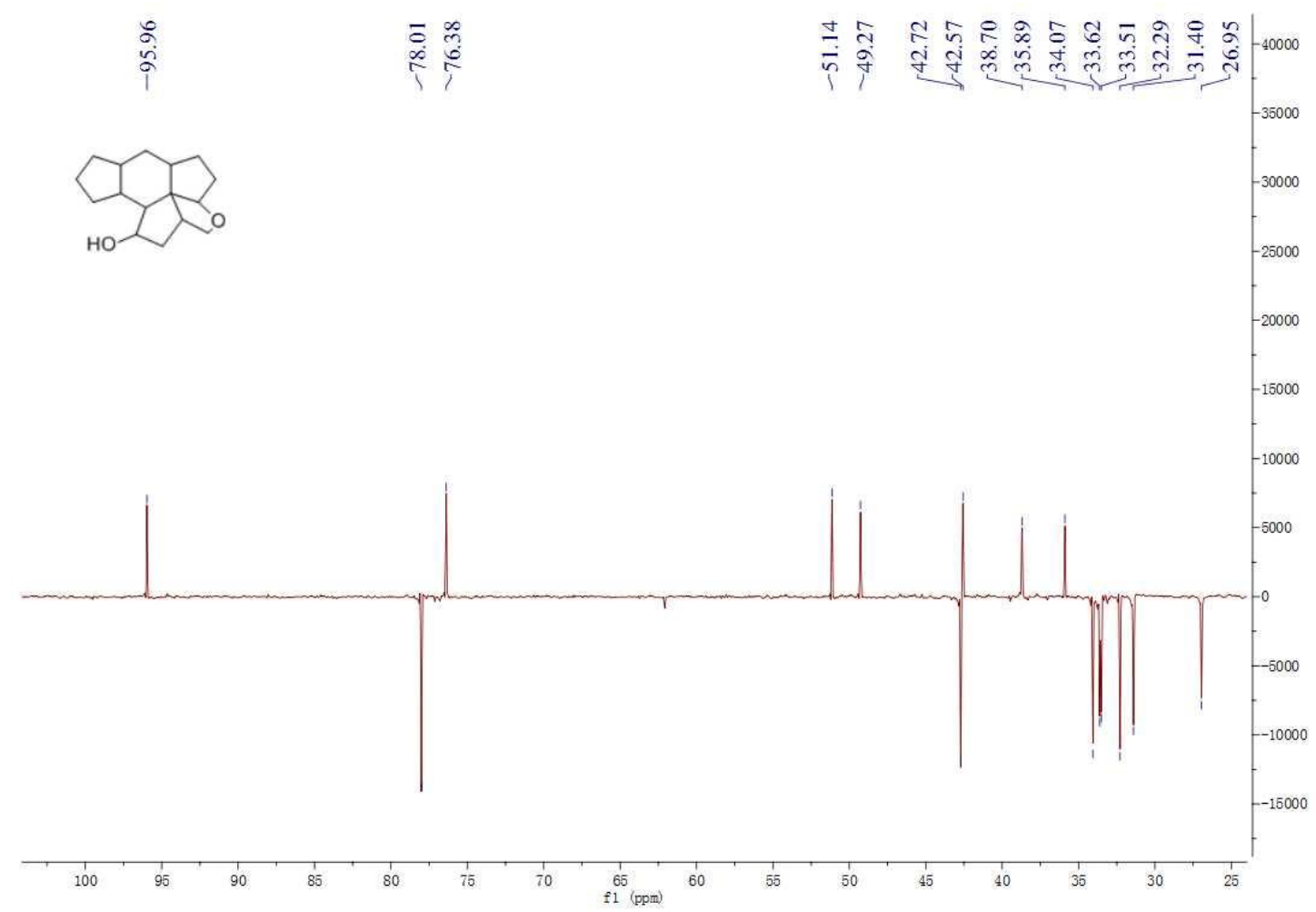


HSQC of $\mathbf{2 . 6 6}$
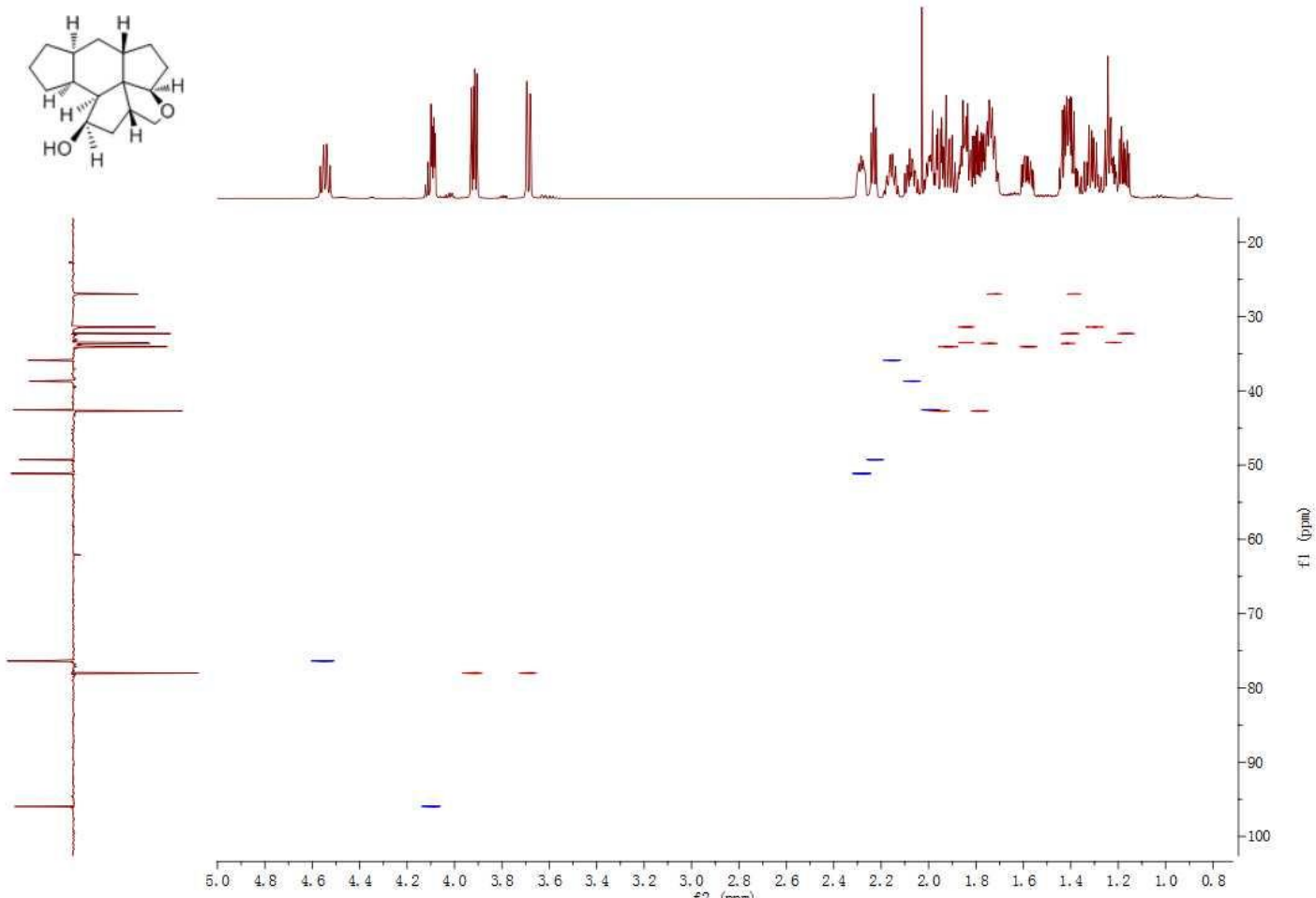

COSY of $\mathbf{2 . 6 6}$

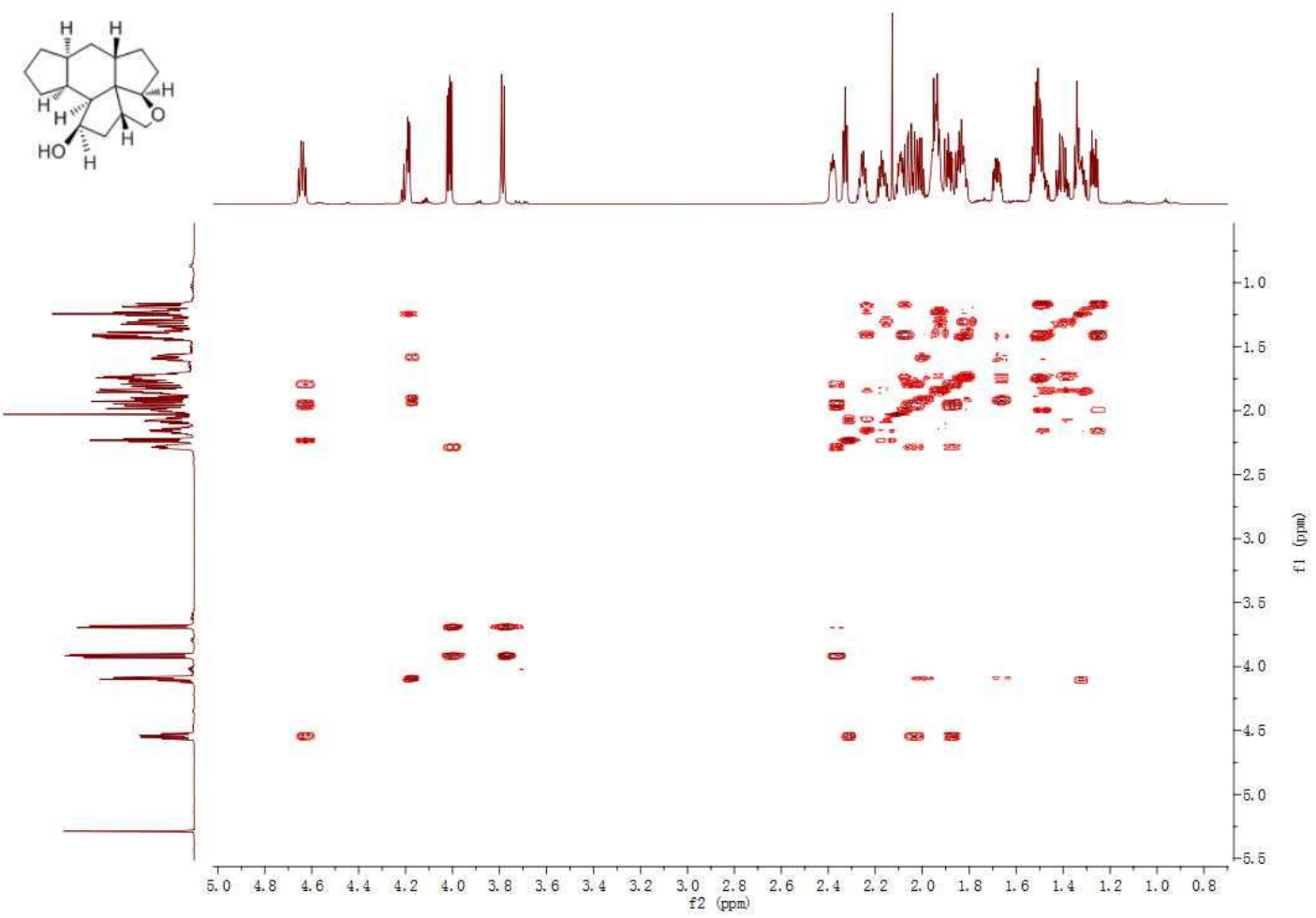


NOESY of $\mathbf{2 . 6 6}$

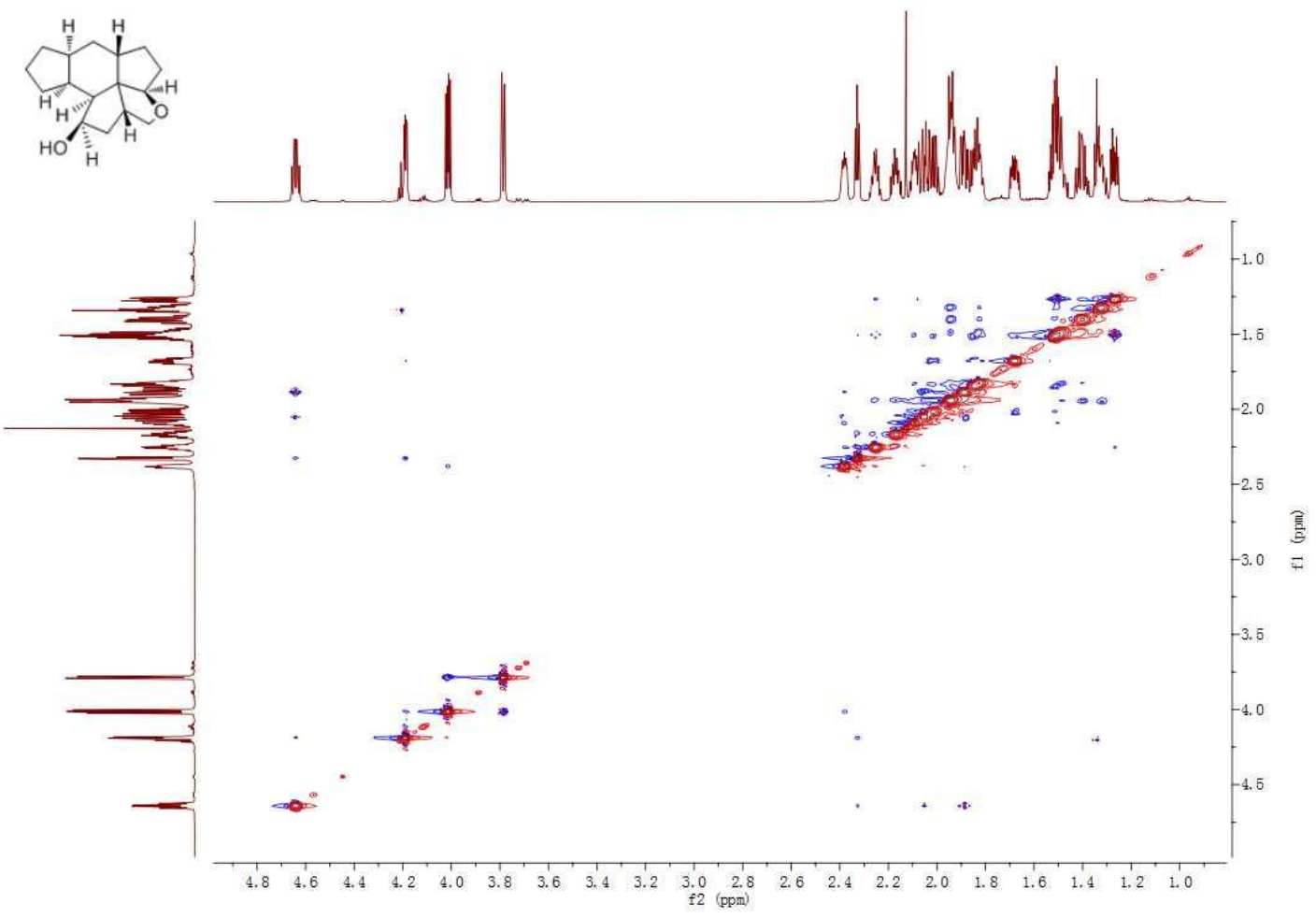

${ }^{1} \mathrm{H}$ NMR of $\mathbf{2 . 6 7}$

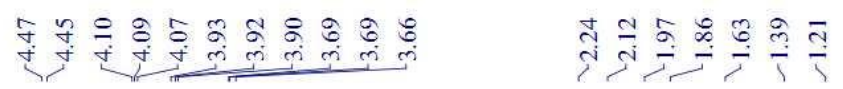
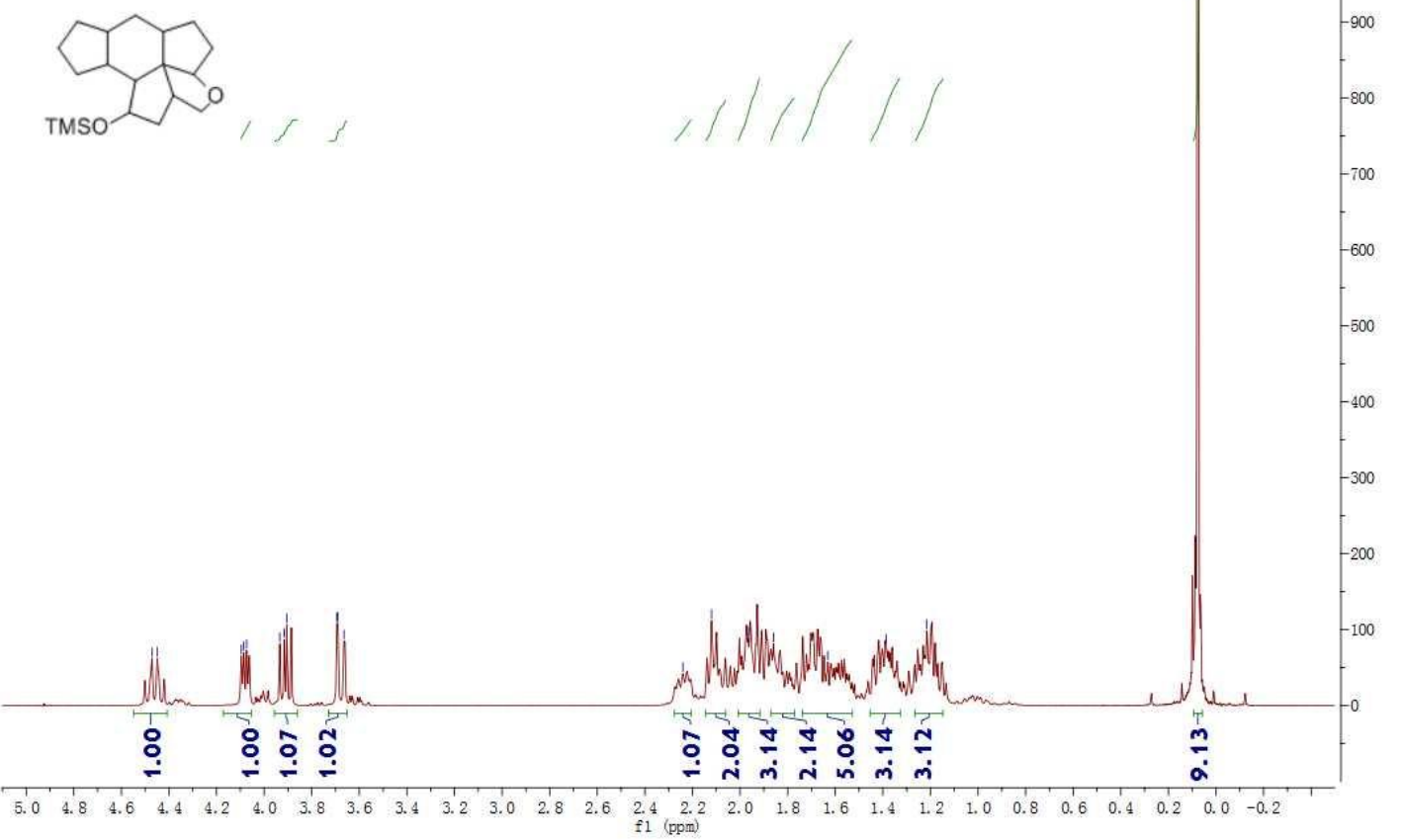
${ }^{13} \mathrm{C}$ NMR of $\mathbf{2 . 6 7}$

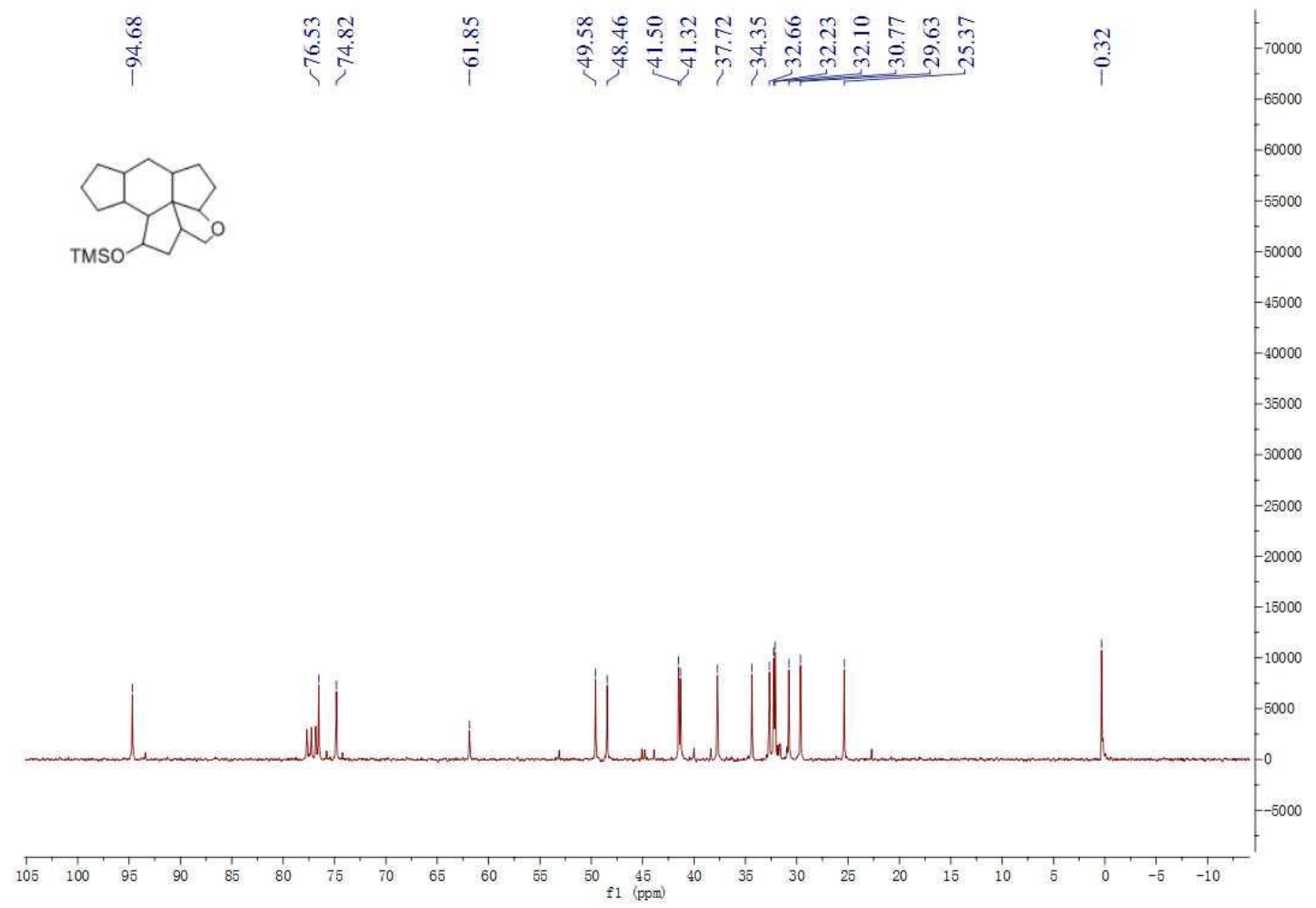

${ }^{1} \mathrm{H}$ NMR of $\mathbf{2 . 6 8}$

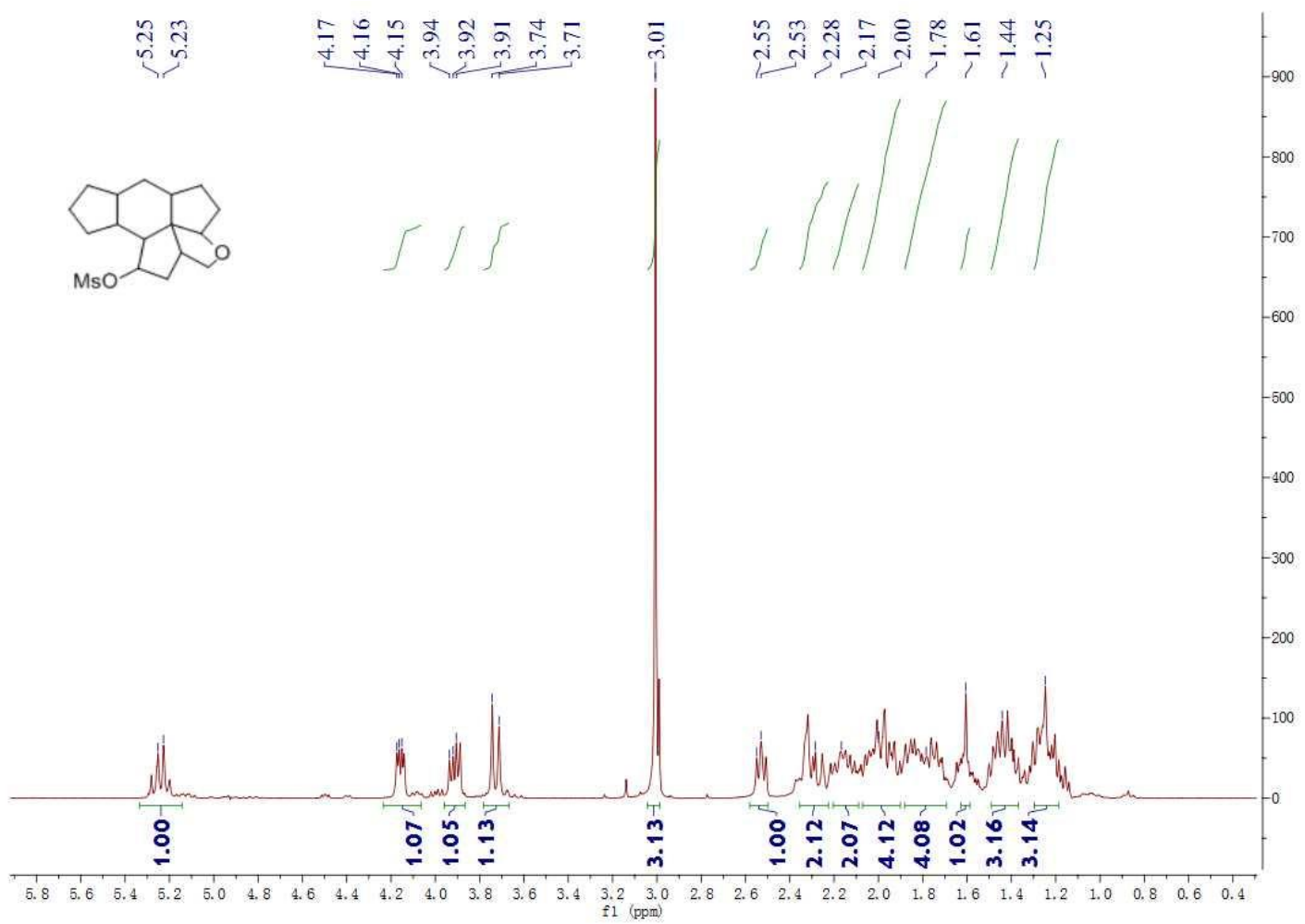


${ }^{13} \mathrm{C}$ NMR of $\mathbf{2 . 6 8}$

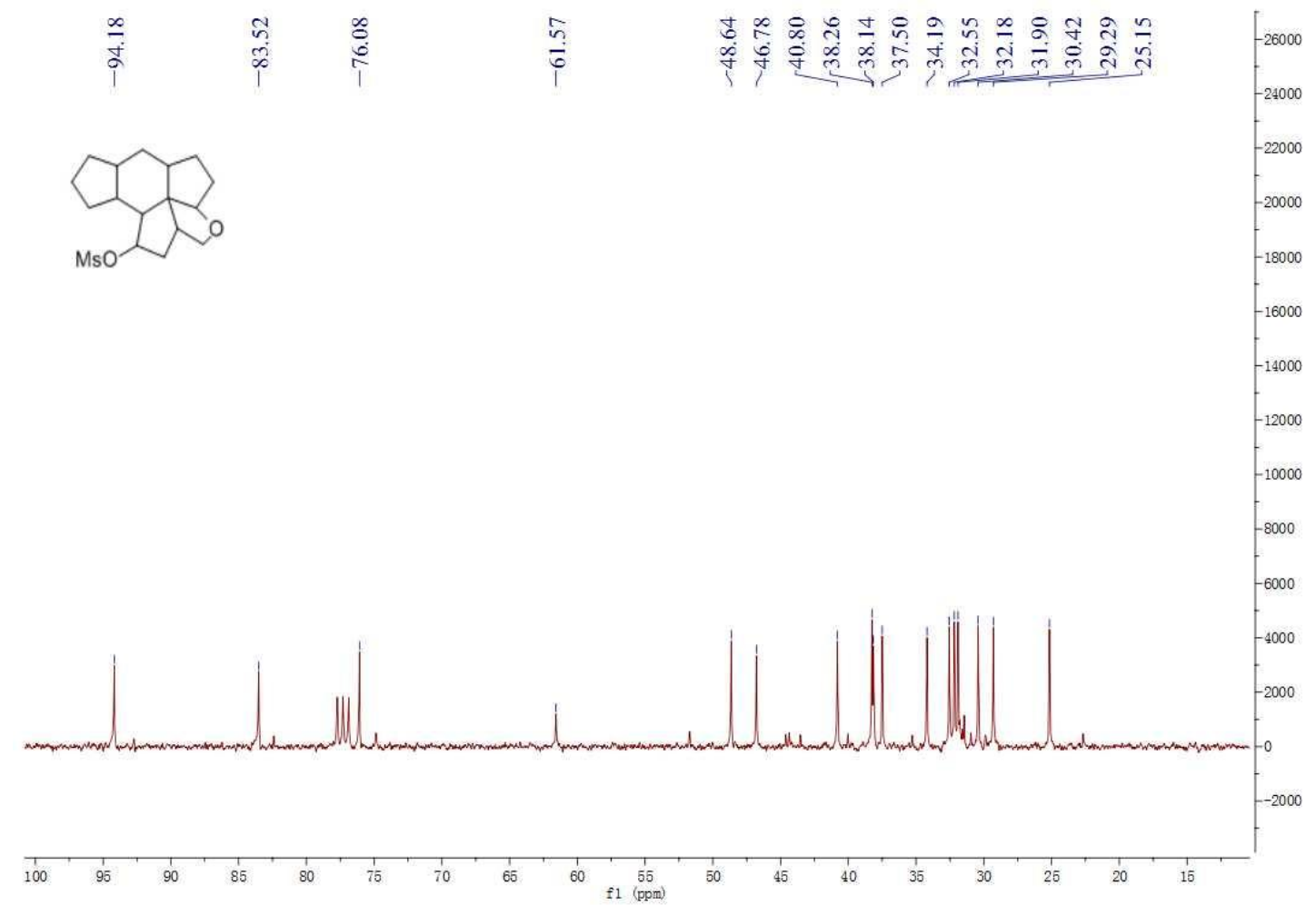

${ }^{1} \mathrm{H}$ NMR of $\mathbf{2 . 6 9}$

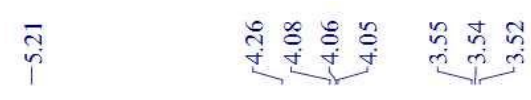

$\mathrm{CP}_{0}$

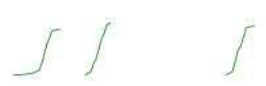

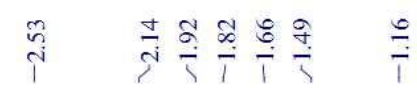
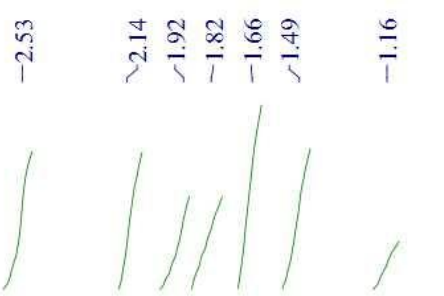

$-1100$

000 


\section{Chapter 3}

${ }^{1} \mathrm{H}$ NMR and ${ }^{13} \mathrm{C}$ NMR Spectra (All the NMR spectra were obtained in $\mathrm{CDCl}_{3}$ unless indicated otherwise)

Chiral Propargylic Alcohols $(R)-1$ a-g

${ }^{1} \mathrm{H}$ NMR of $(R)-\mathbf{1 a}$

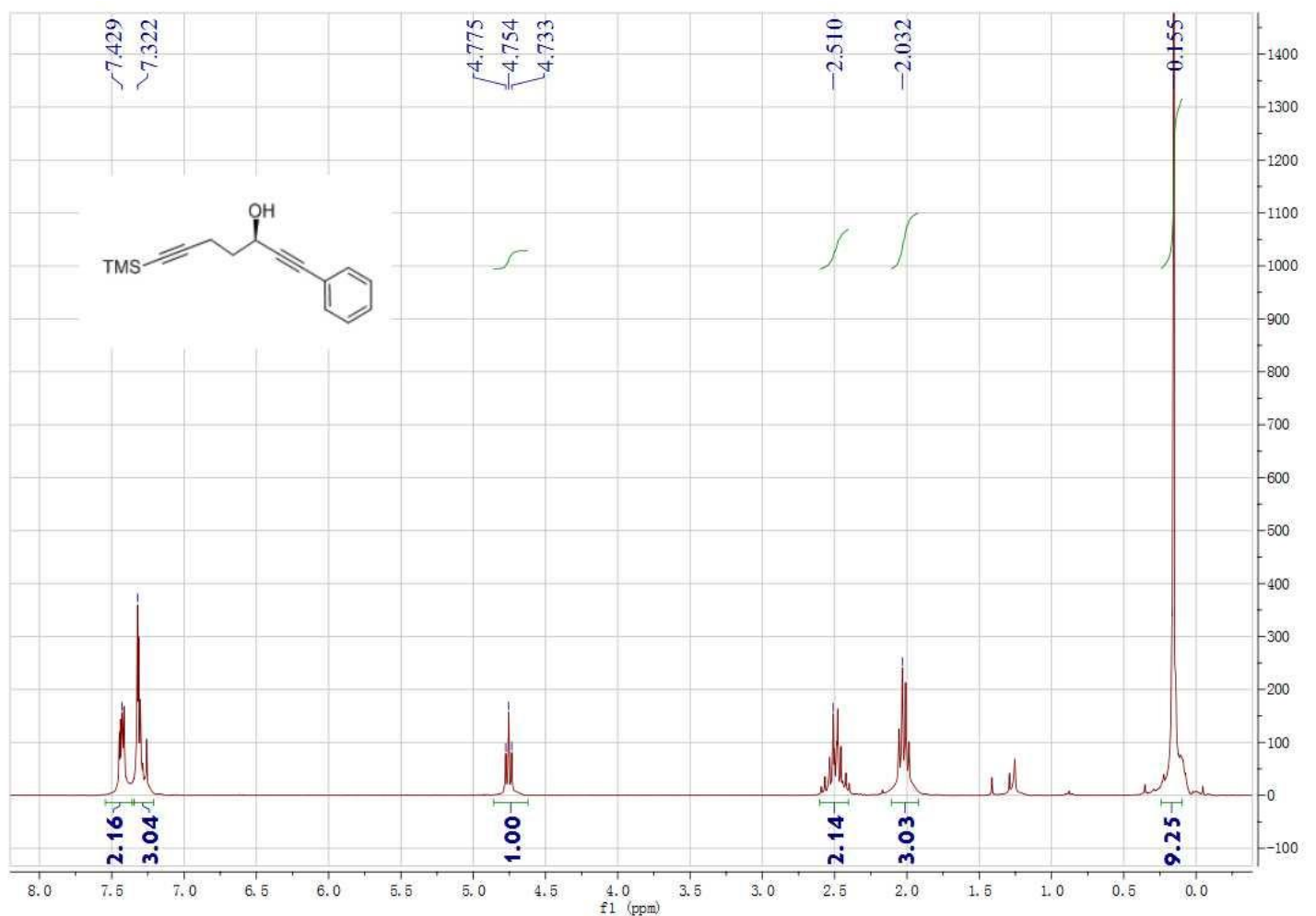

${ }^{13} \mathrm{C}$ NMR of $(R)-\mathbf{1 a}$

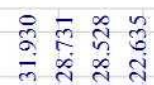

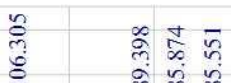

को $\infty$

ֻै

ส্ర

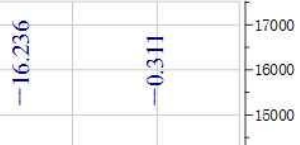

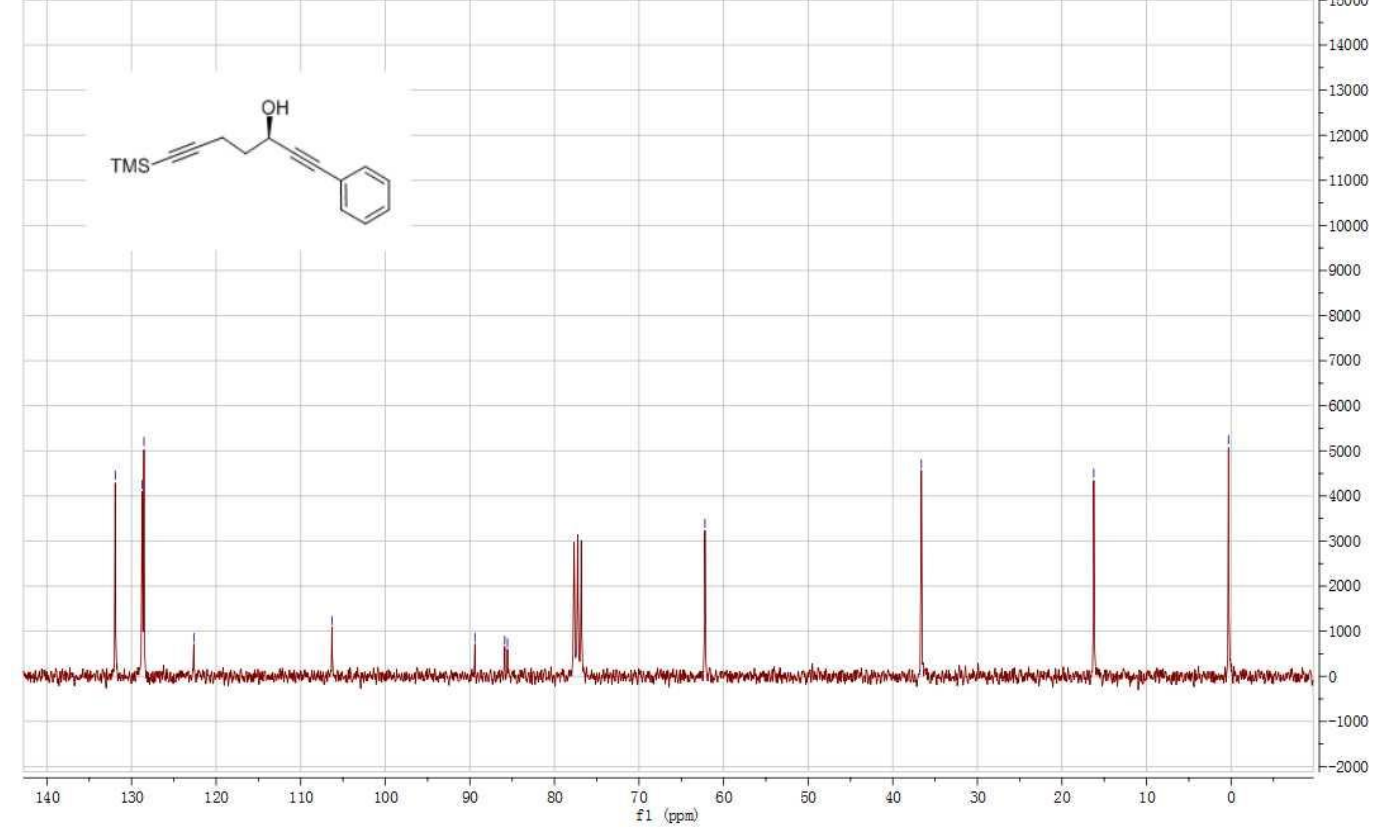


${ }^{1} \mathrm{H}$ NMR of $(R)-\mathbf{1 b}$

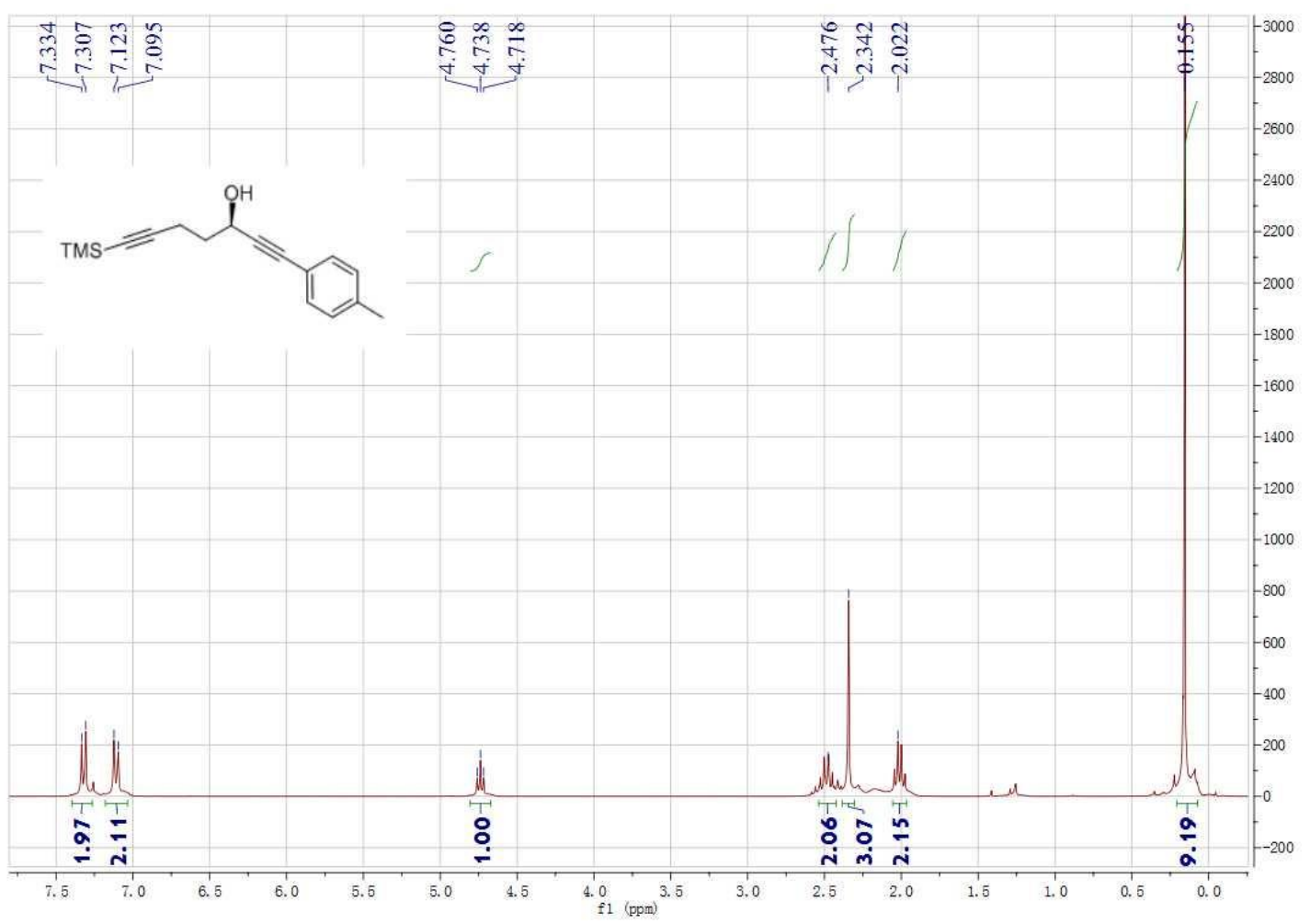

${ }^{13} \mathrm{C}$ NMR of $(R)-\mathbf{1 b}$

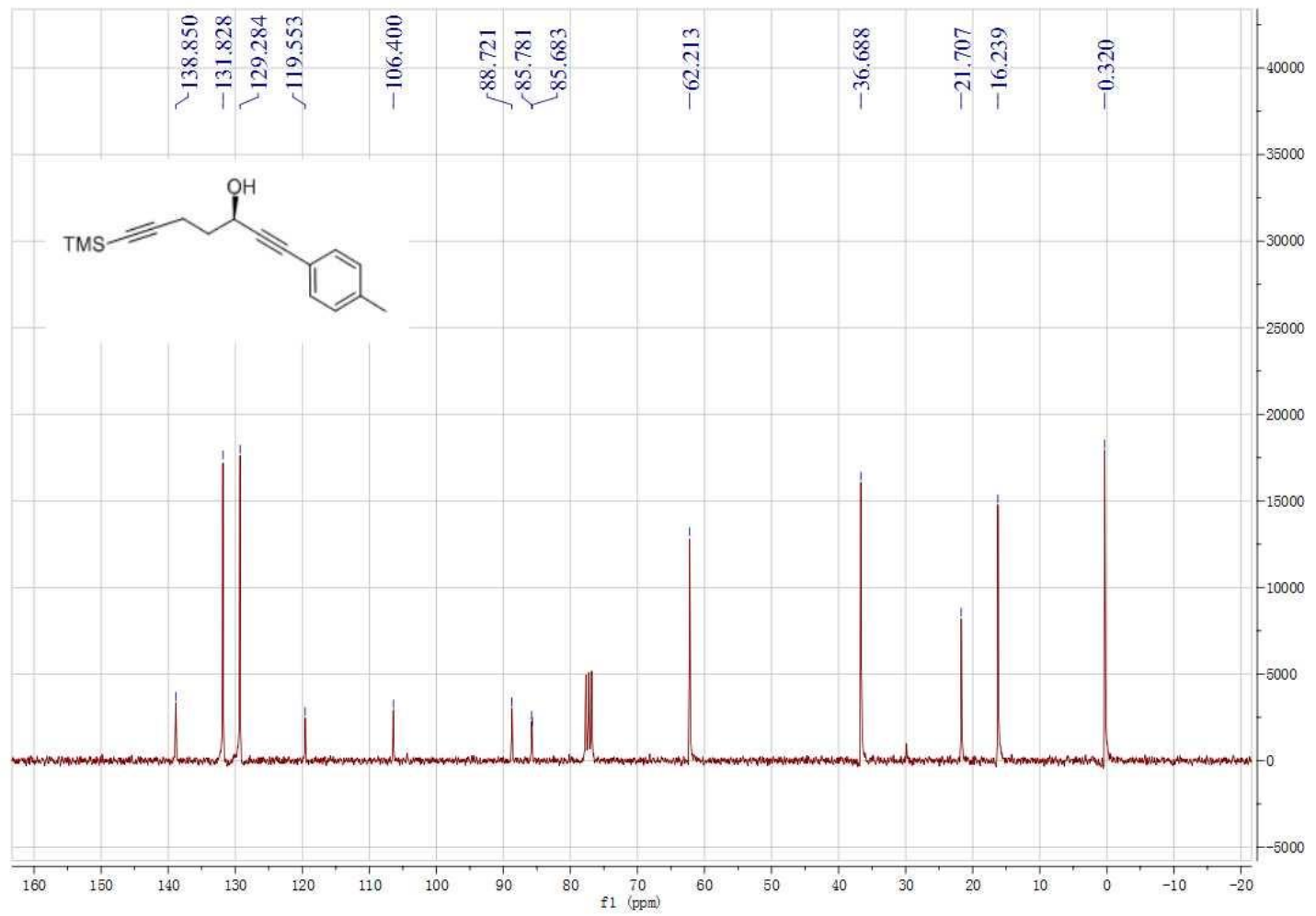


${ }^{1} \mathrm{H}$ NMR of $(R)-\mathbf{1 c}$

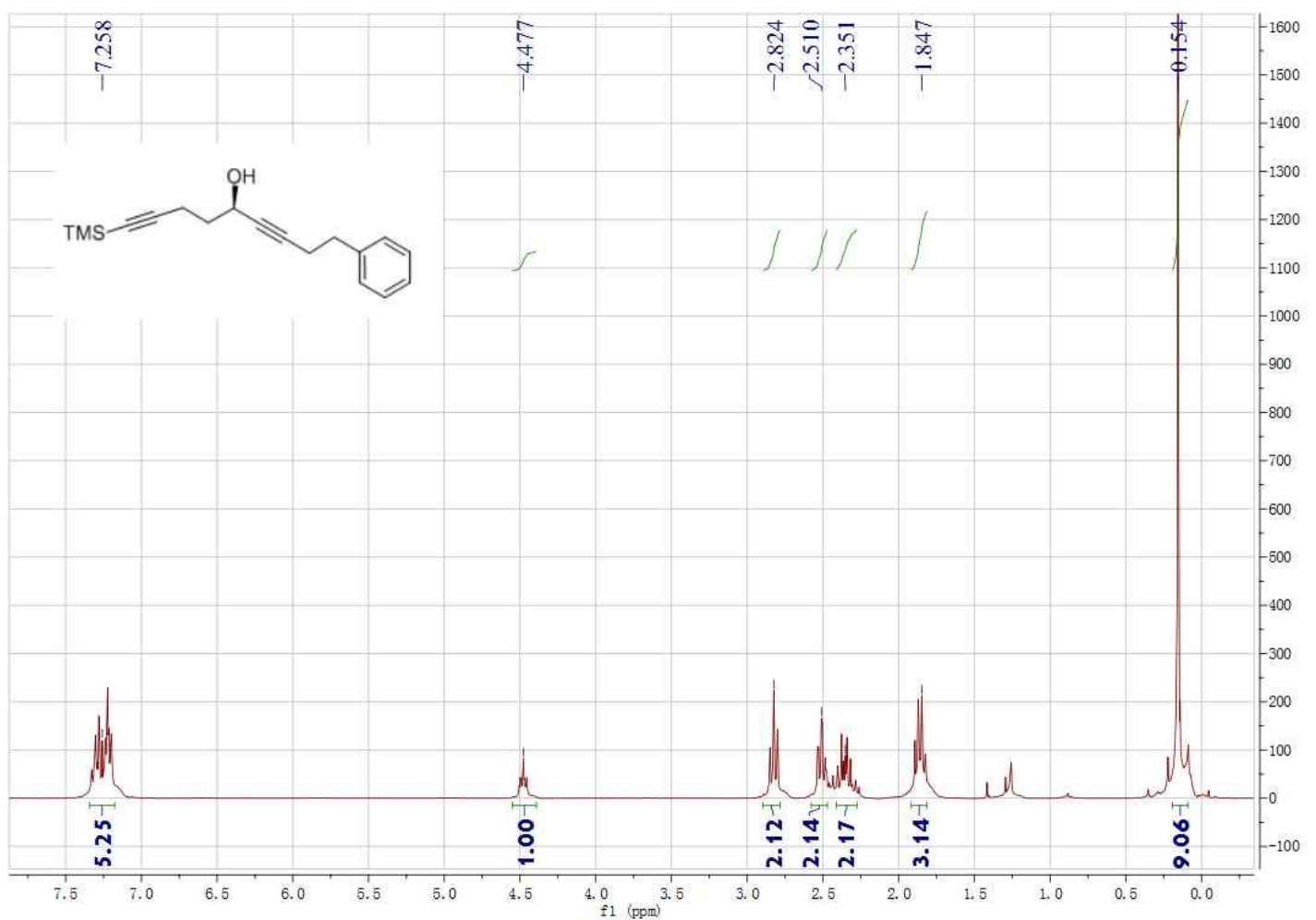

${ }^{13} \mathrm{C}$ NMR of $(R)-\mathbf{1 c}$

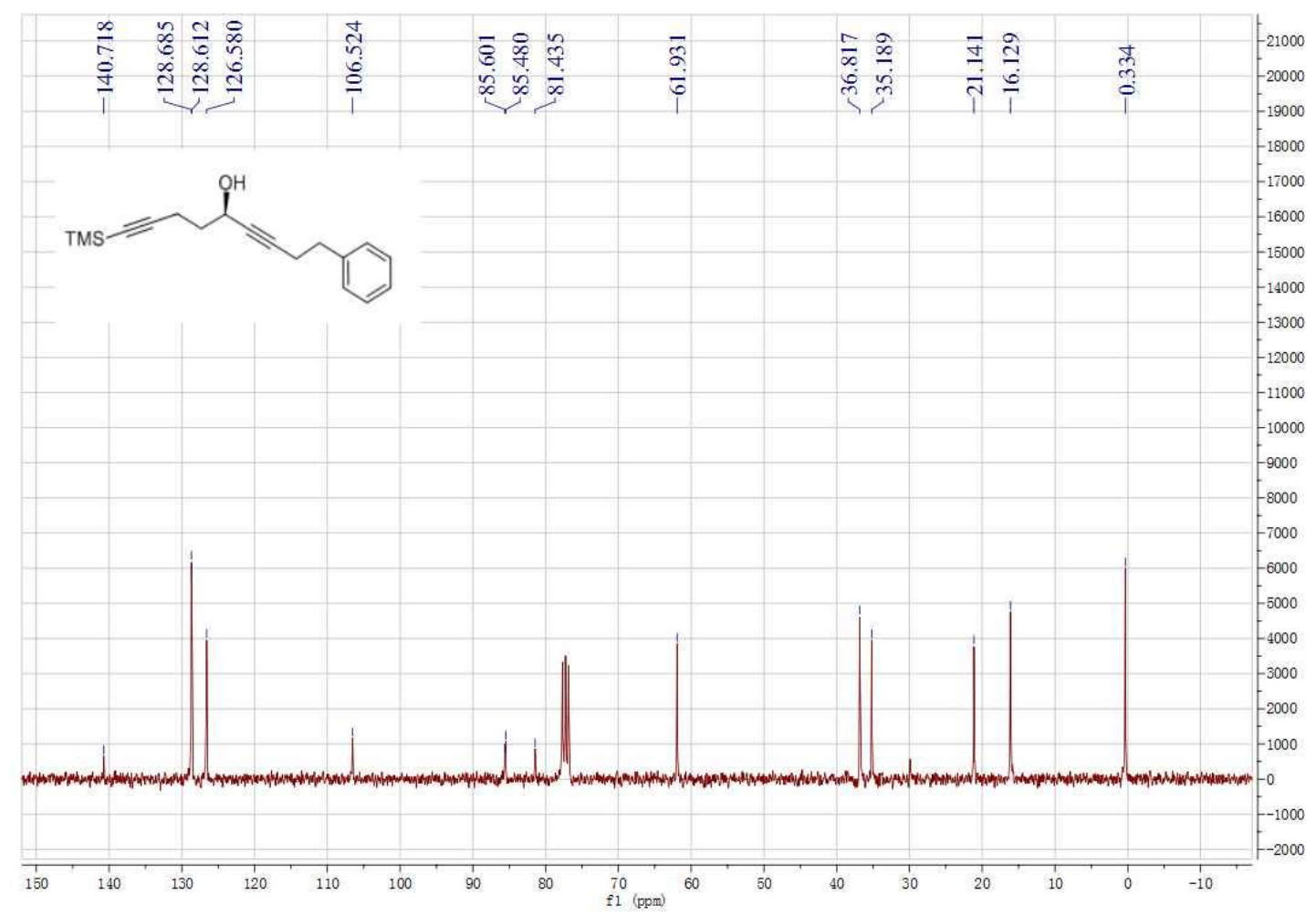


${ }^{1} \mathrm{H}$ NMR of $(R)-\mathbf{1 d}$

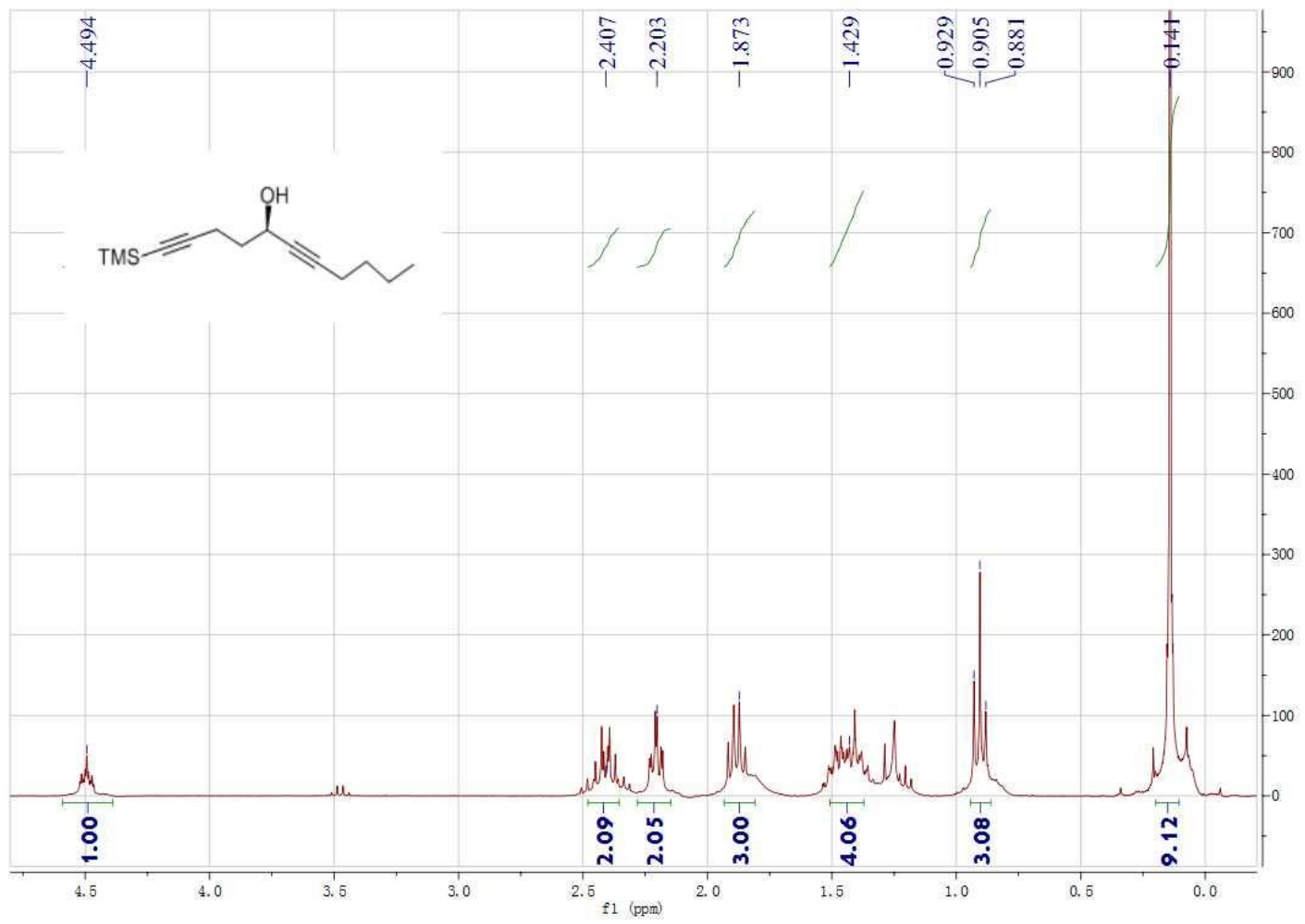

${ }^{13} \mathrm{C}$ NMR of $(R)-\mathbf{1 d}$

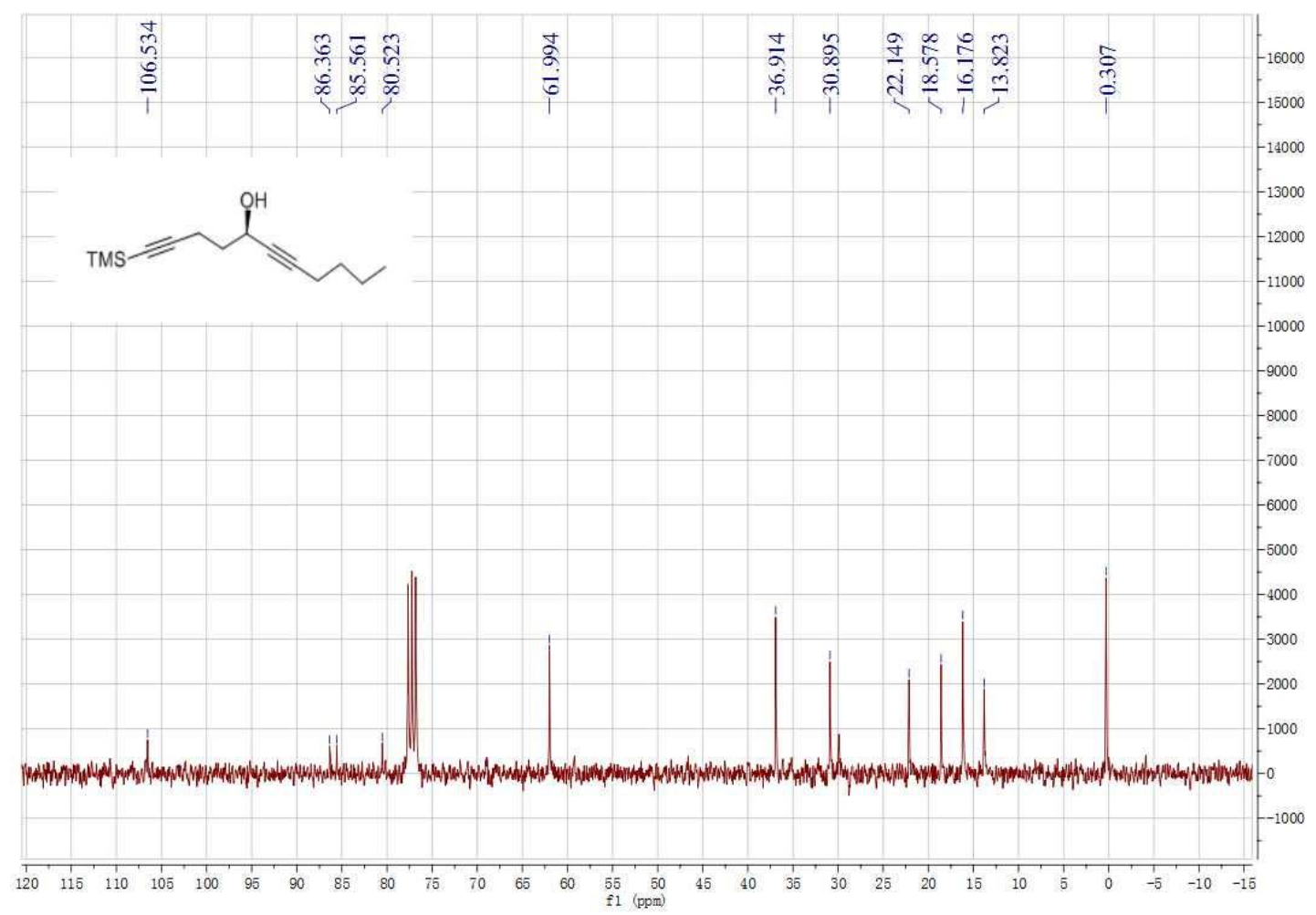


${ }^{1} \mathrm{H}$ NMR of $(R)-1 \mathbf{e}$

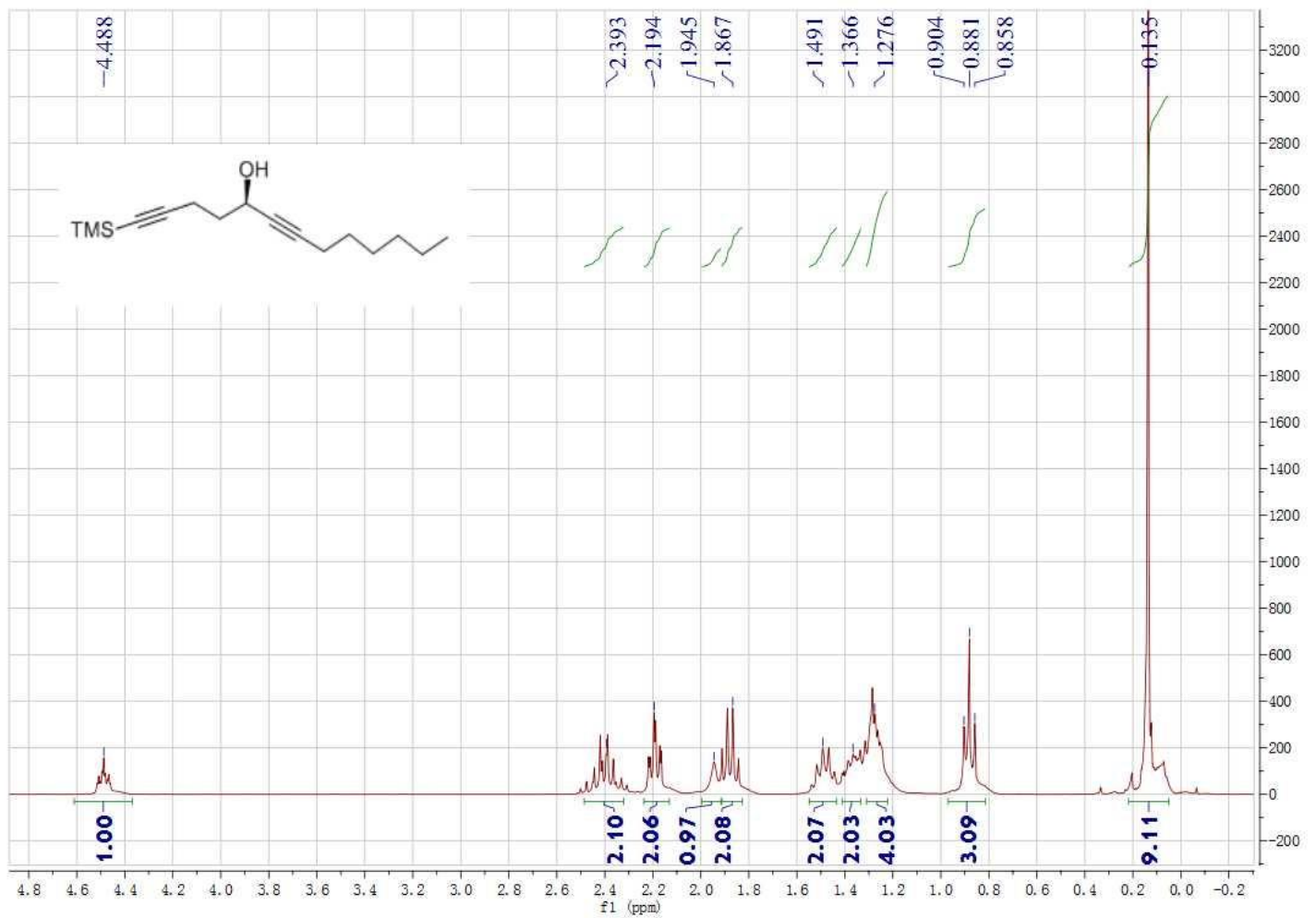

${ }^{13} \mathrm{C}$ NMR of $(R)-\mathbf{1 e}$

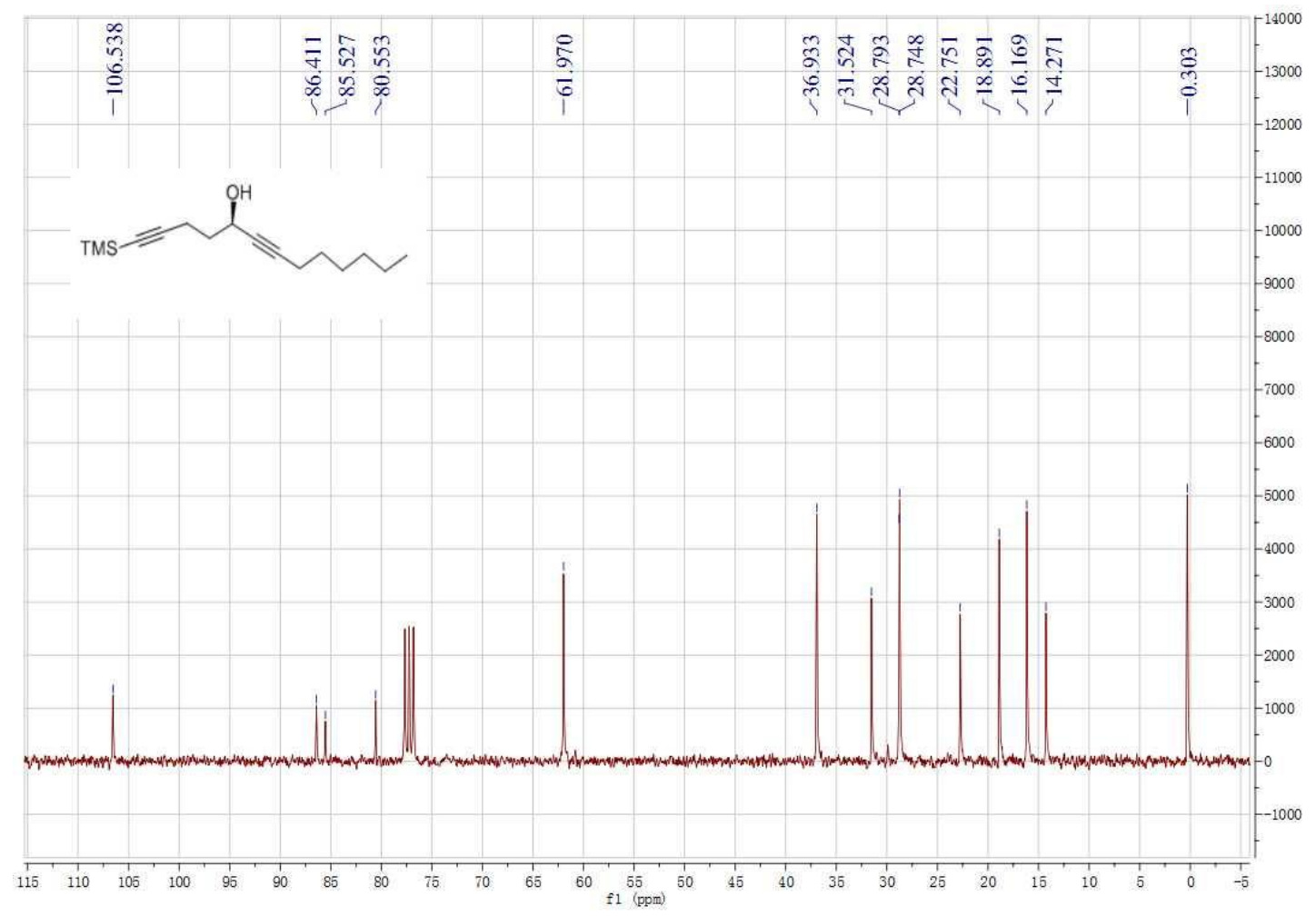


${ }^{1} \mathrm{H}$ NMR of $(R)-\mathbf{1 f}$

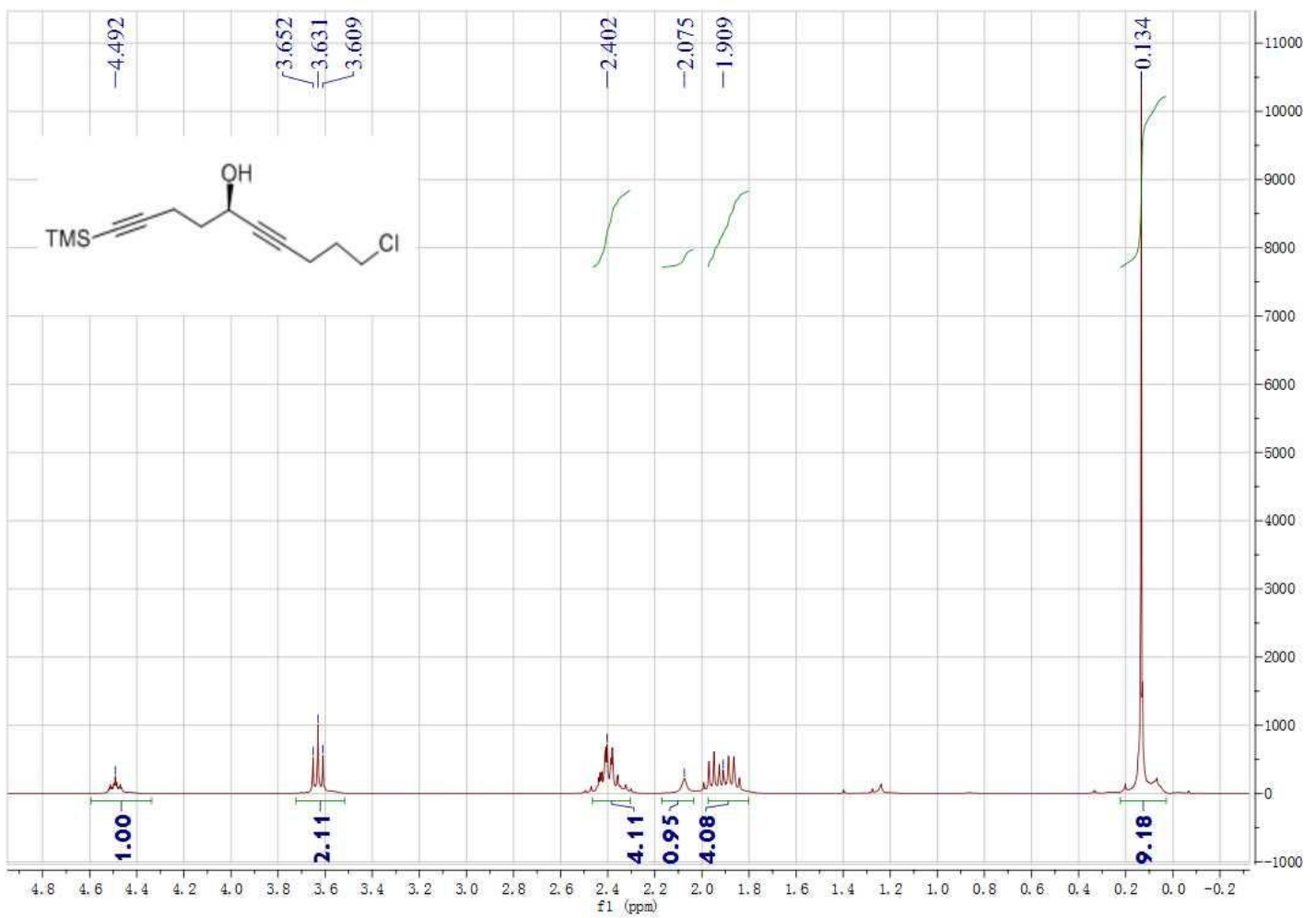

${ }^{13} \mathrm{C}$ NMR of $(R)-\mathbf{1 f}$

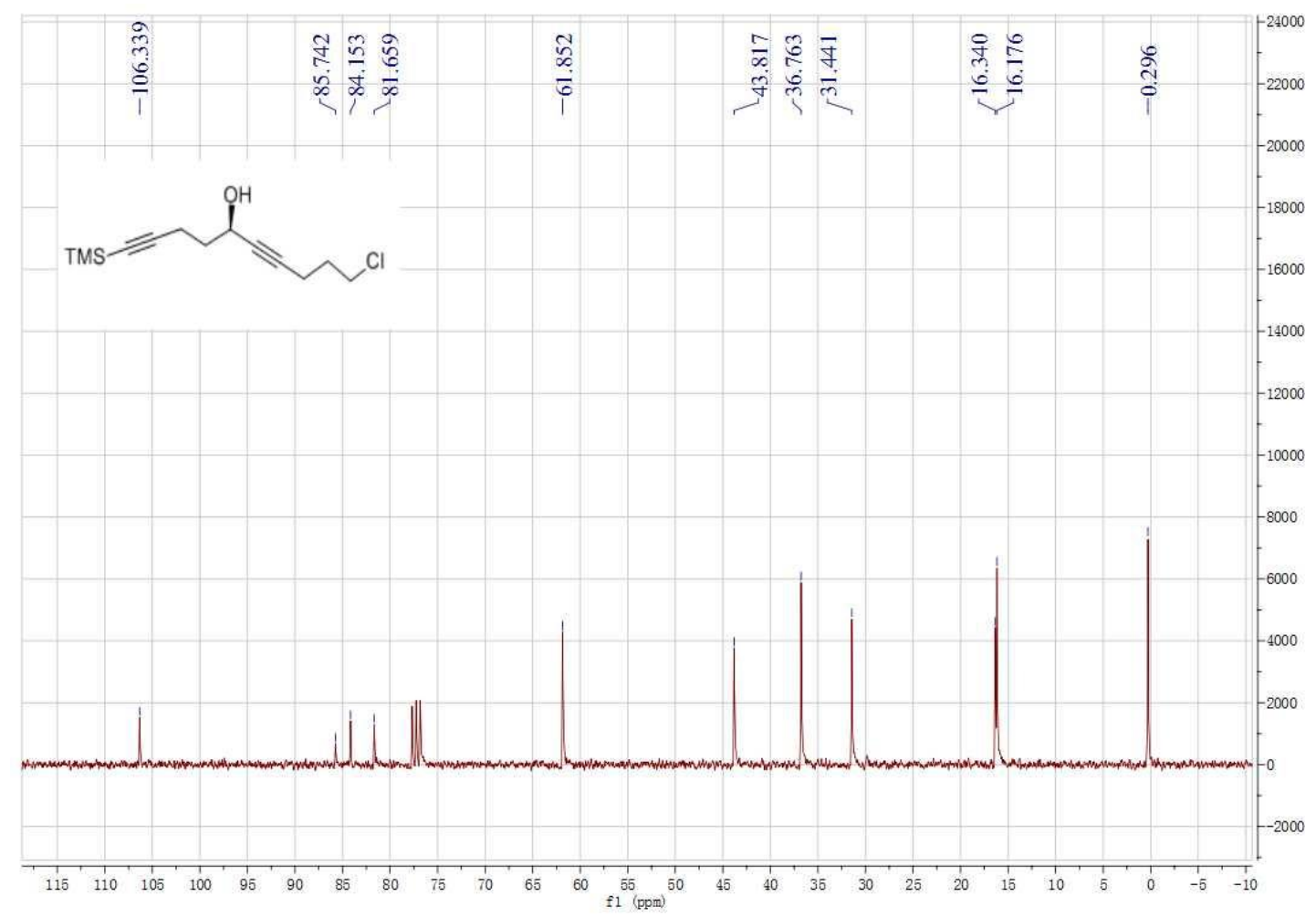


${ }^{1} \mathrm{H}$ NMR of $(R)-\mathbf{1 g}$

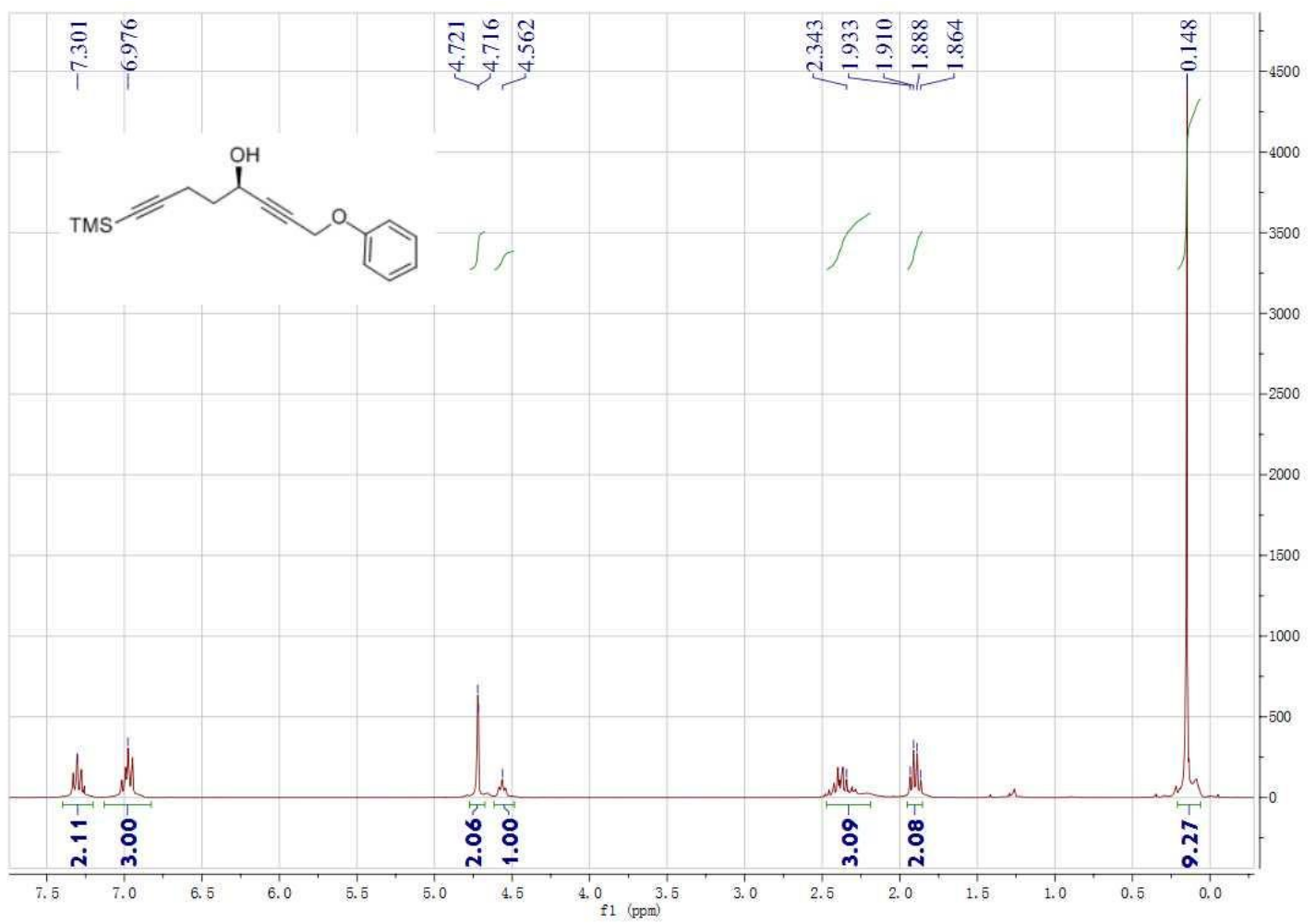

${ }^{13} \mathrm{C}$ NMR of $(R)-\mathbf{1 g}$

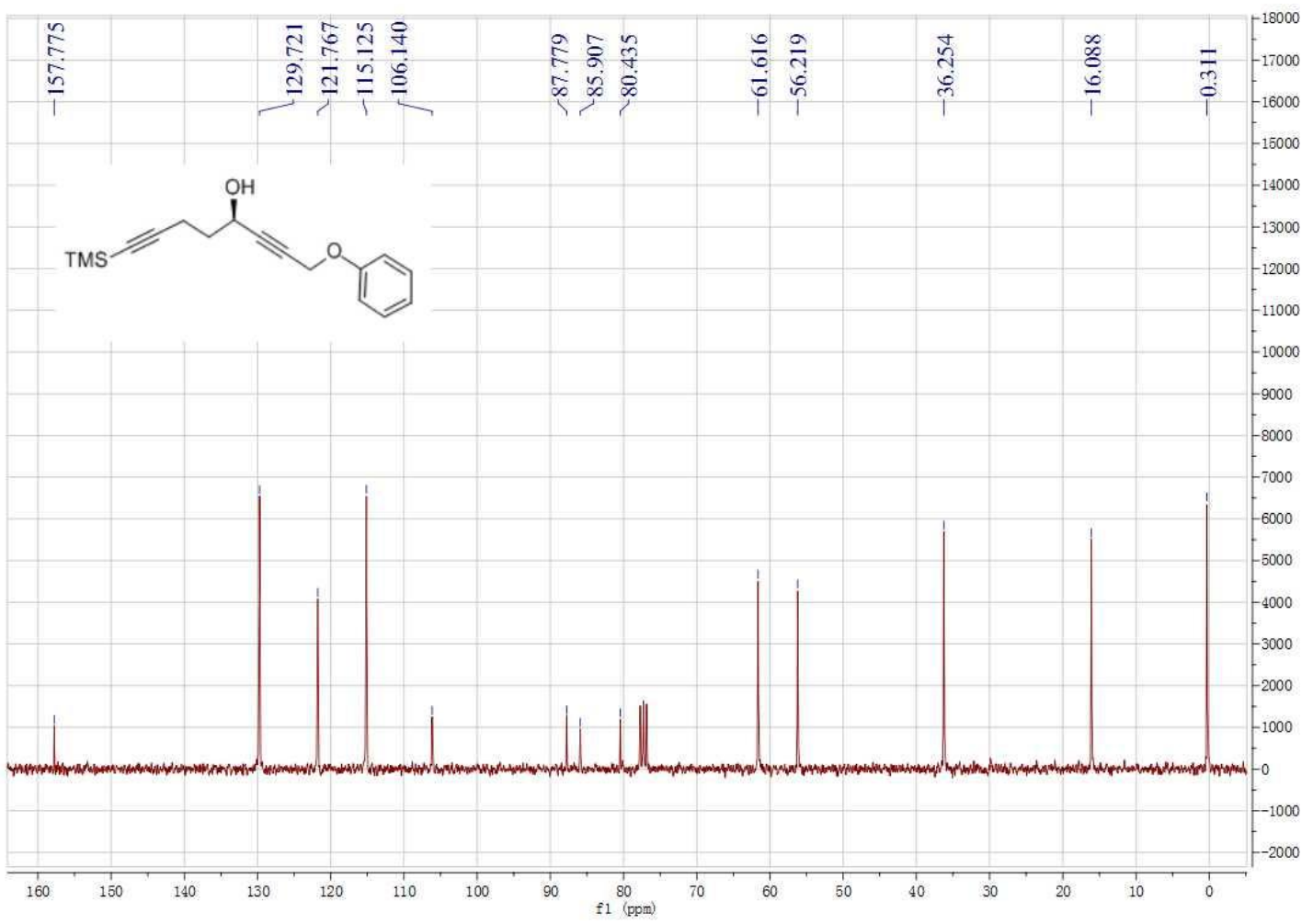


Chiral Unsubstituted Diene-diynes $(R)-2 a-g$

${ }^{1} \mathrm{H}$ NMR of $(R)-\mathbf{2 a}$

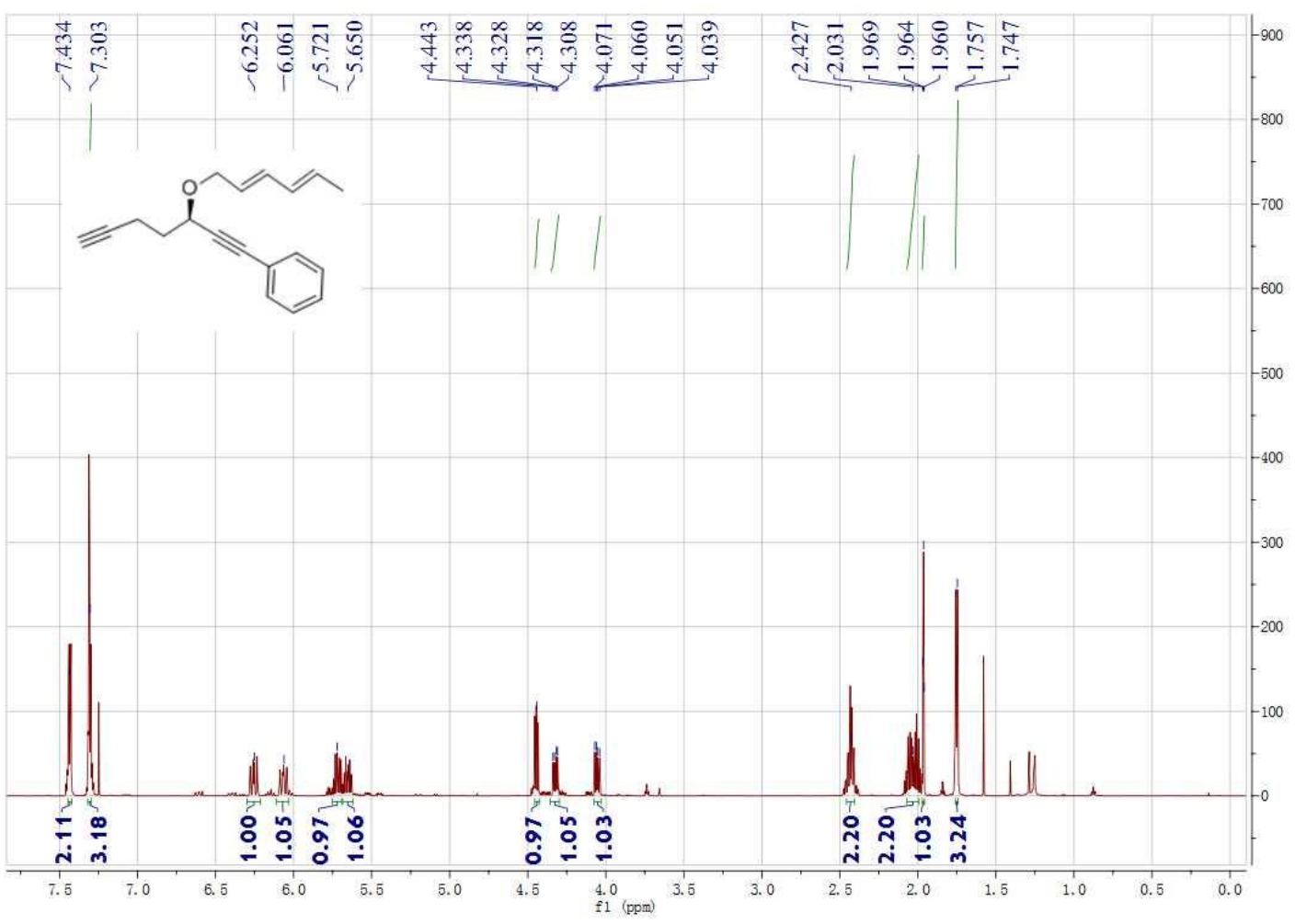

${ }^{13} \mathrm{C}$ NMR of $(R)-\mathbf{2 a}$

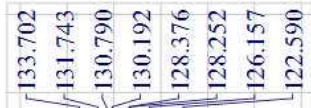

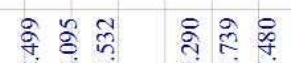

क⿺⿻一𠃋十

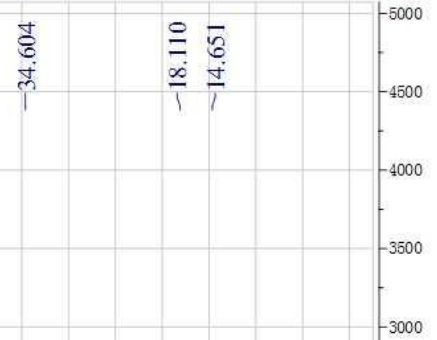

is

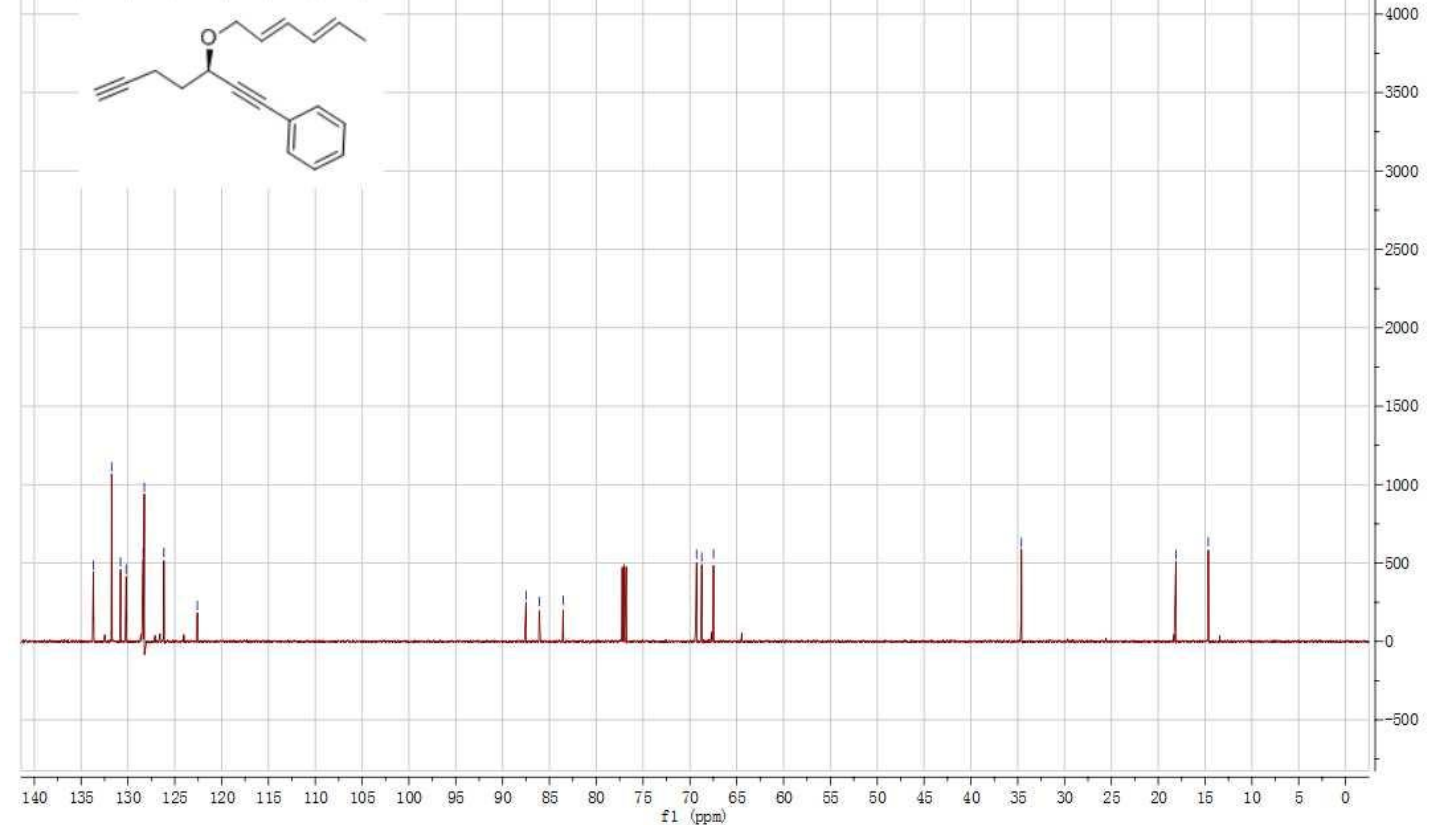


${ }^{1} \mathrm{H}$ NMR of $(R)-\mathbf{2 b}$

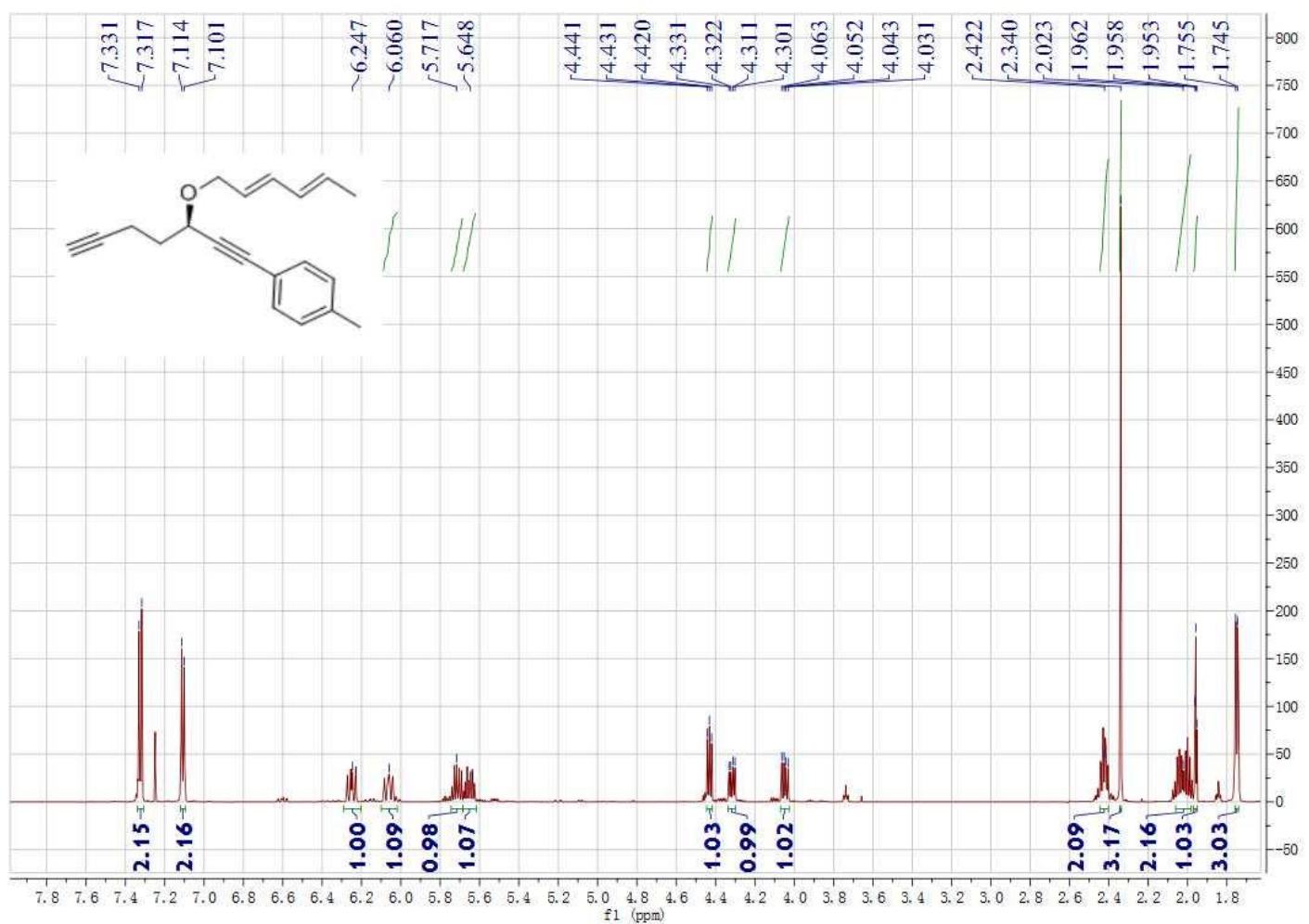

${ }^{13} \mathrm{C}$ NMR of $(R)-\mathbf{2 b}$

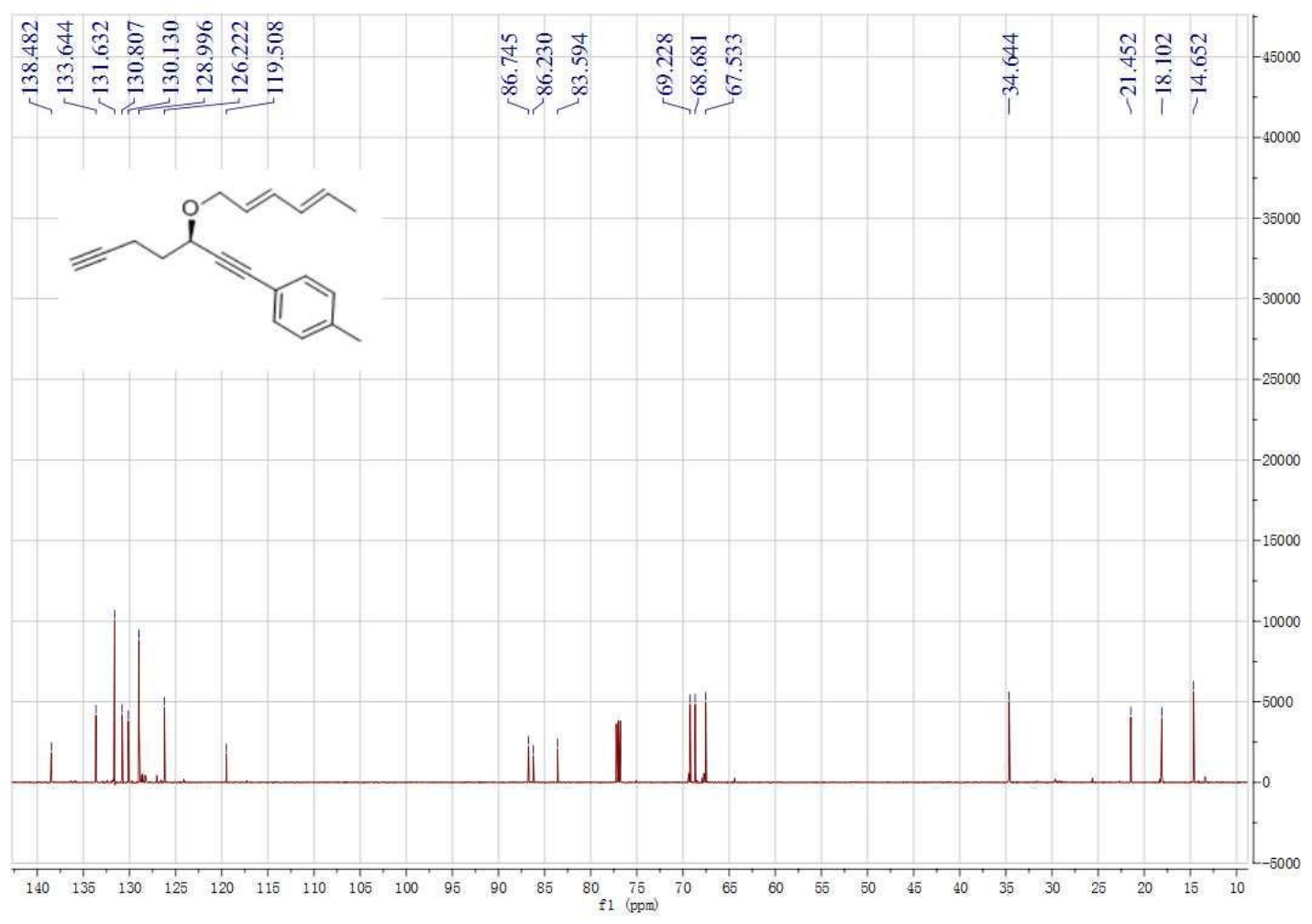


${ }^{1} \mathrm{H}$ NMR of $(R)-2 \mathrm{c}$

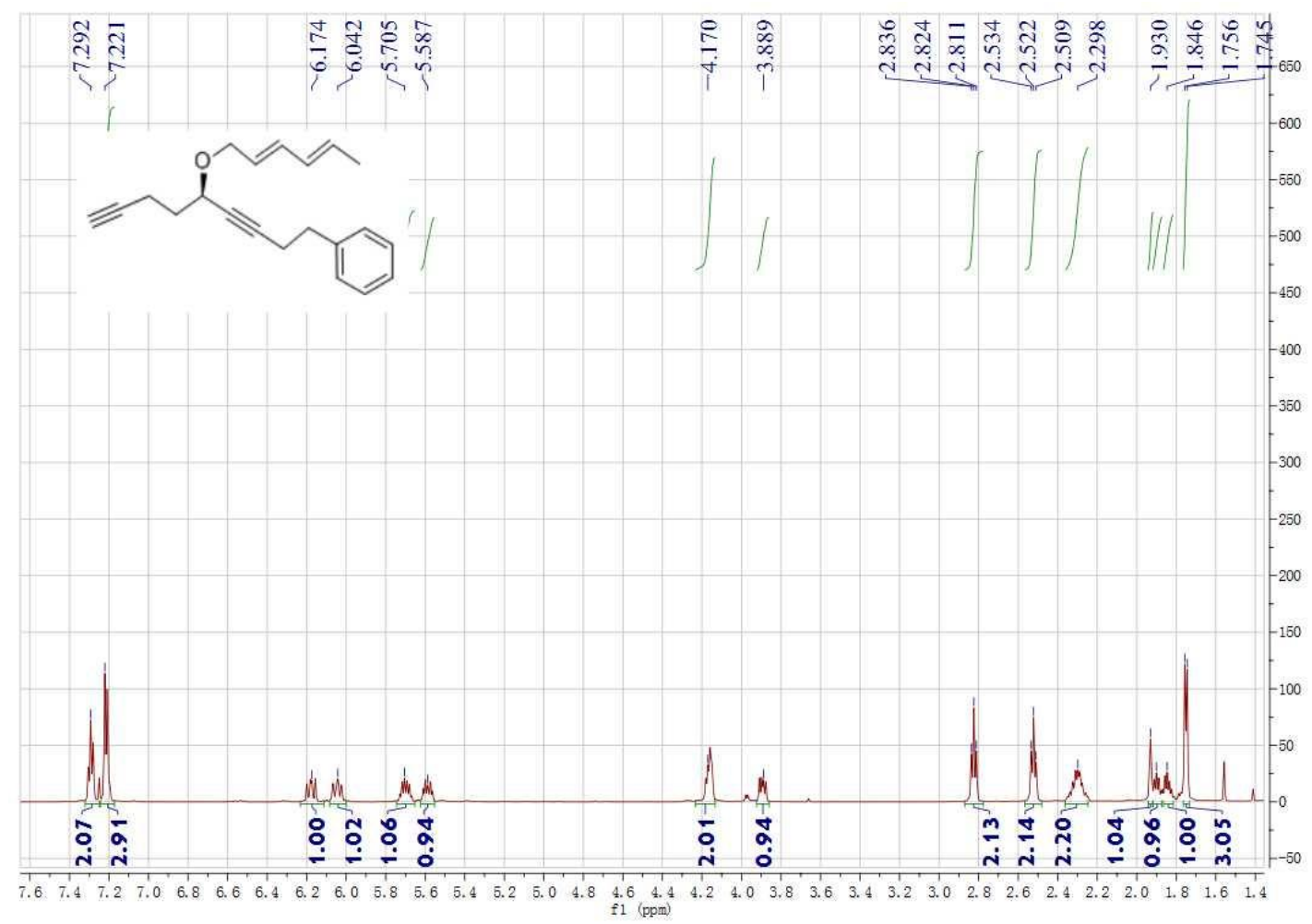

${ }^{13} \mathrm{C}$ NMR of $(R)-\mathbf{2 c}$

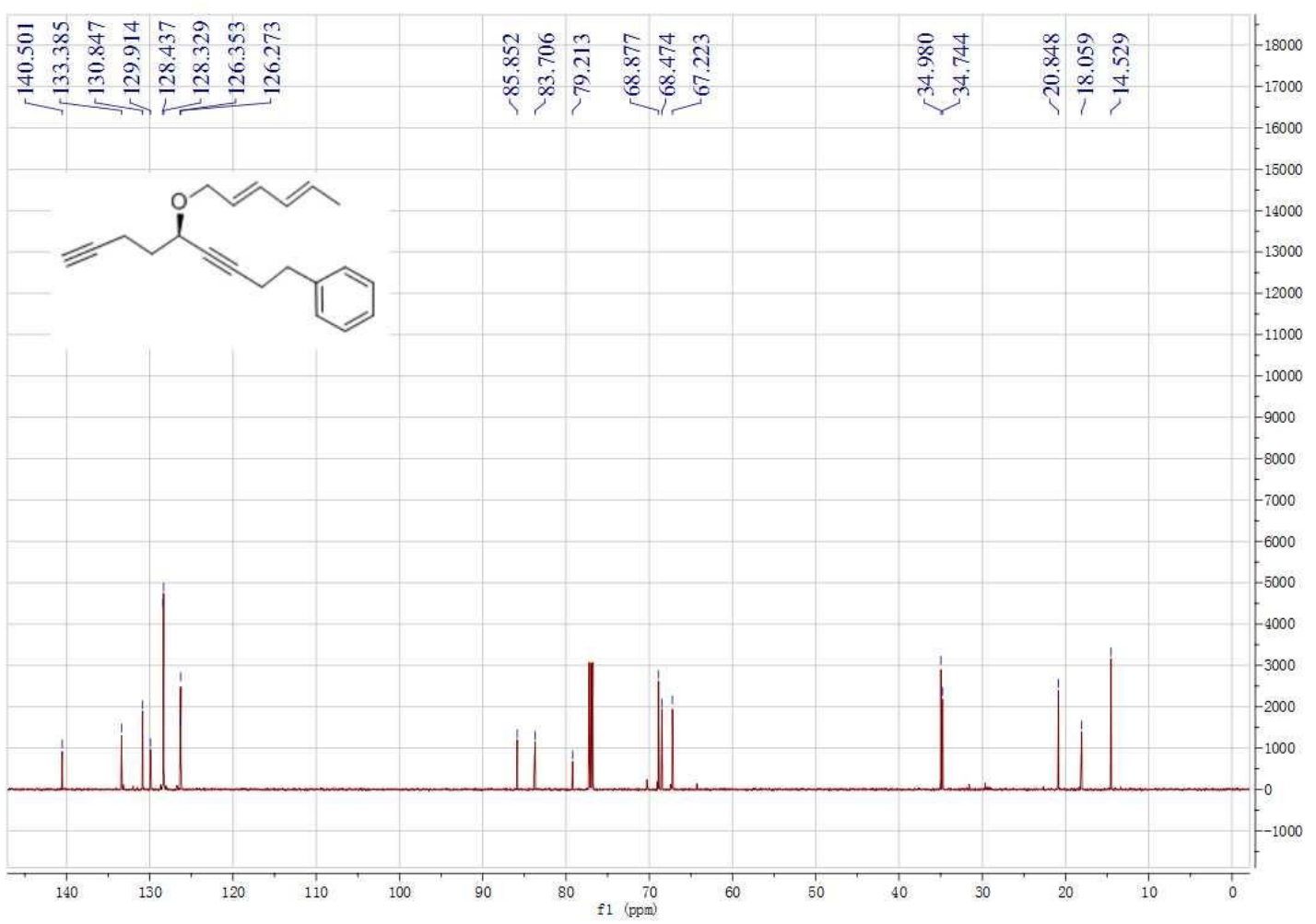


${ }^{1} \mathrm{H}$ NMR of $(R)-\mathbf{2 d}$

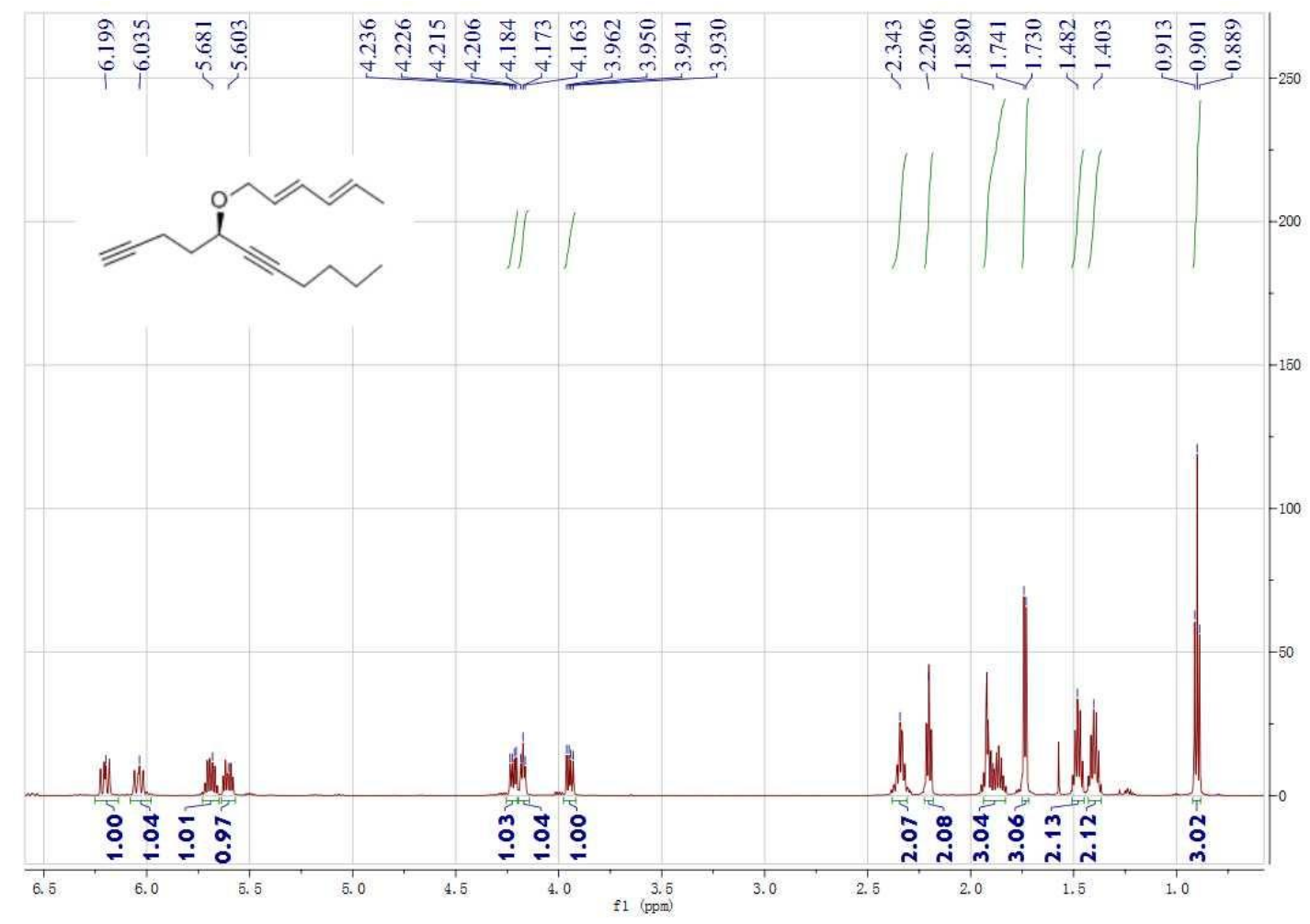

${ }^{13} \mathrm{C}$ NMR of $(R)-2 d$

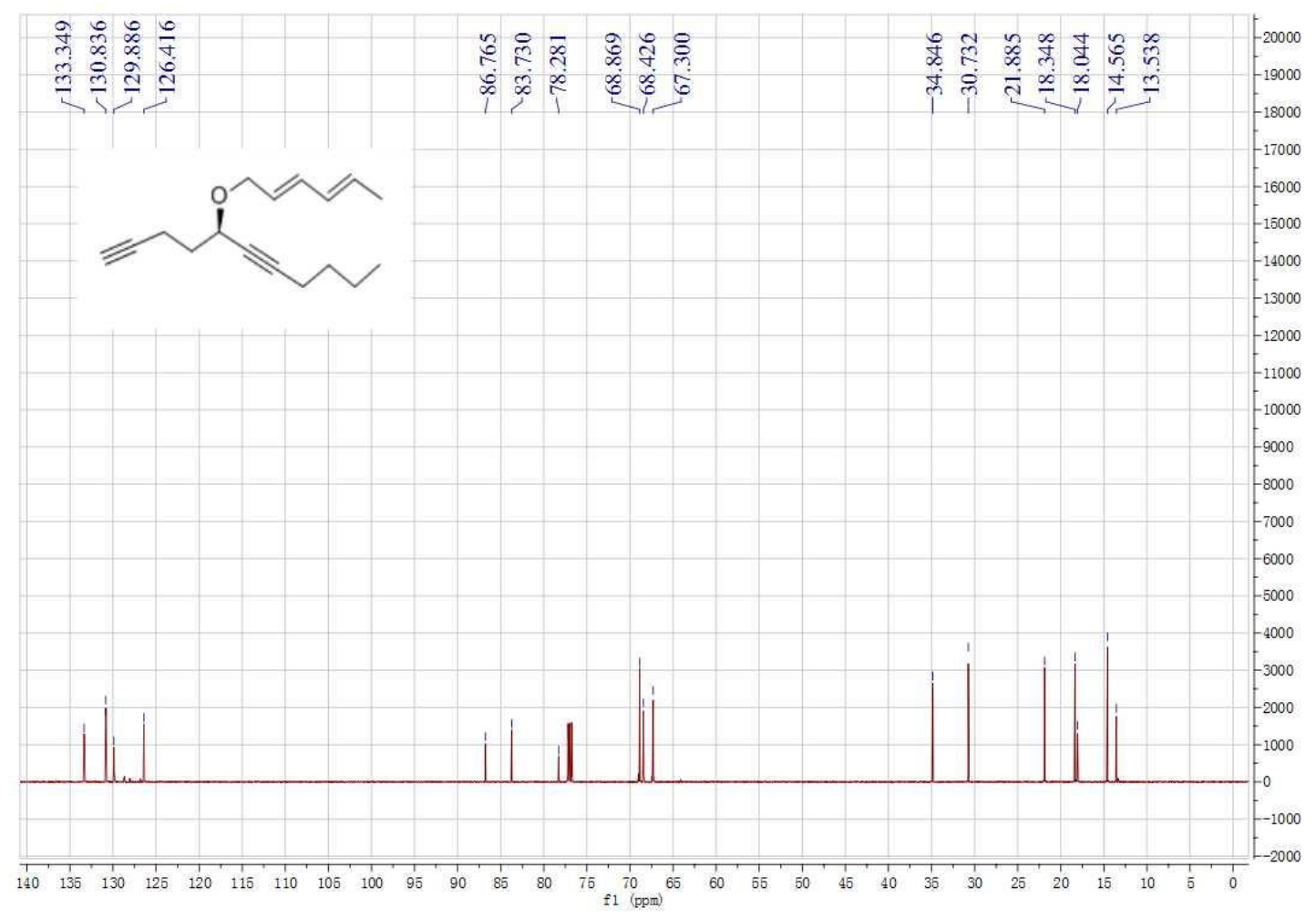


${ }^{1} \mathrm{H}$ NMR of $(R)-\mathbf{2 e}$

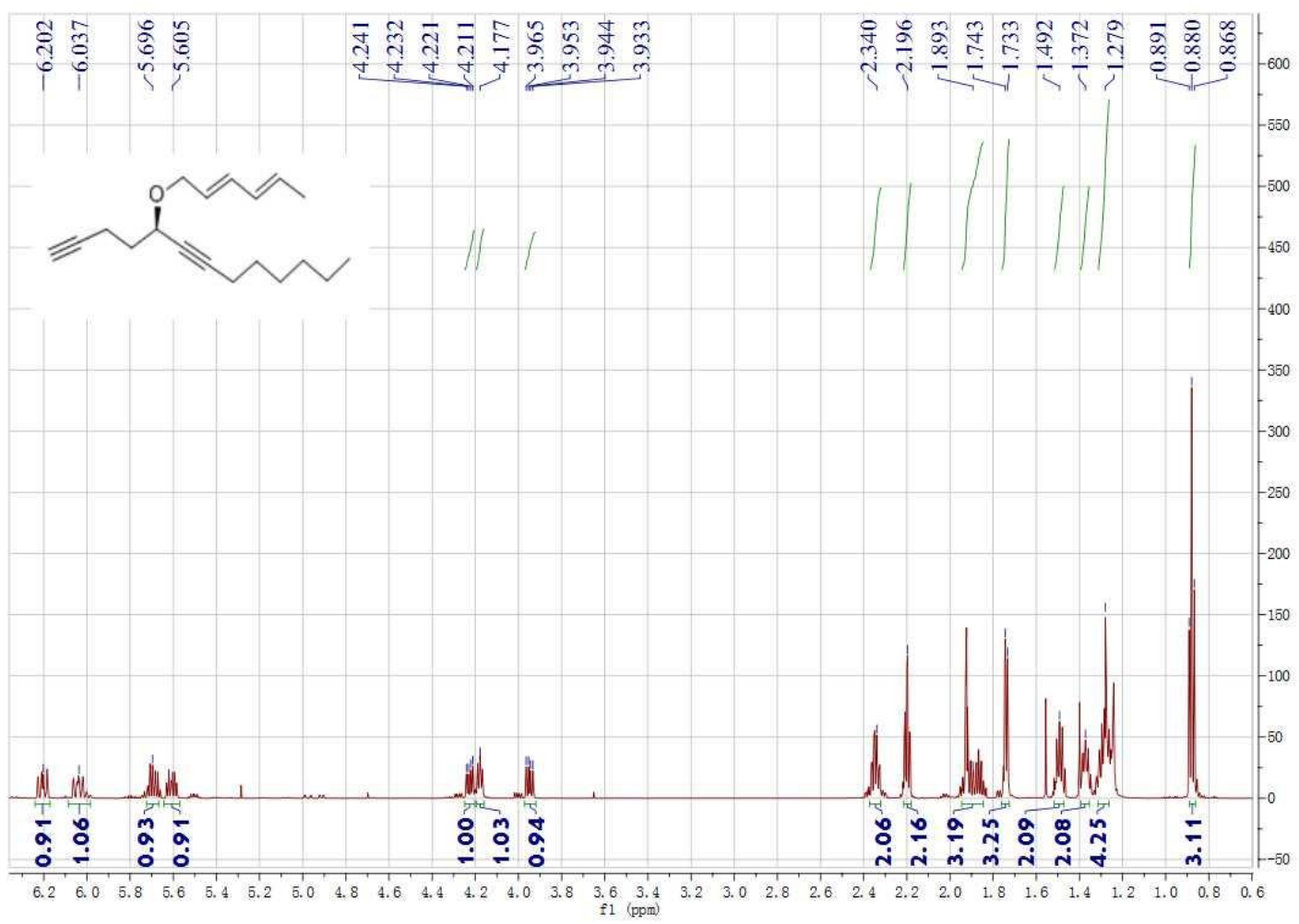

${ }^{13} \mathrm{C}$ NMR of $(R)-\mathbf{2 e}$

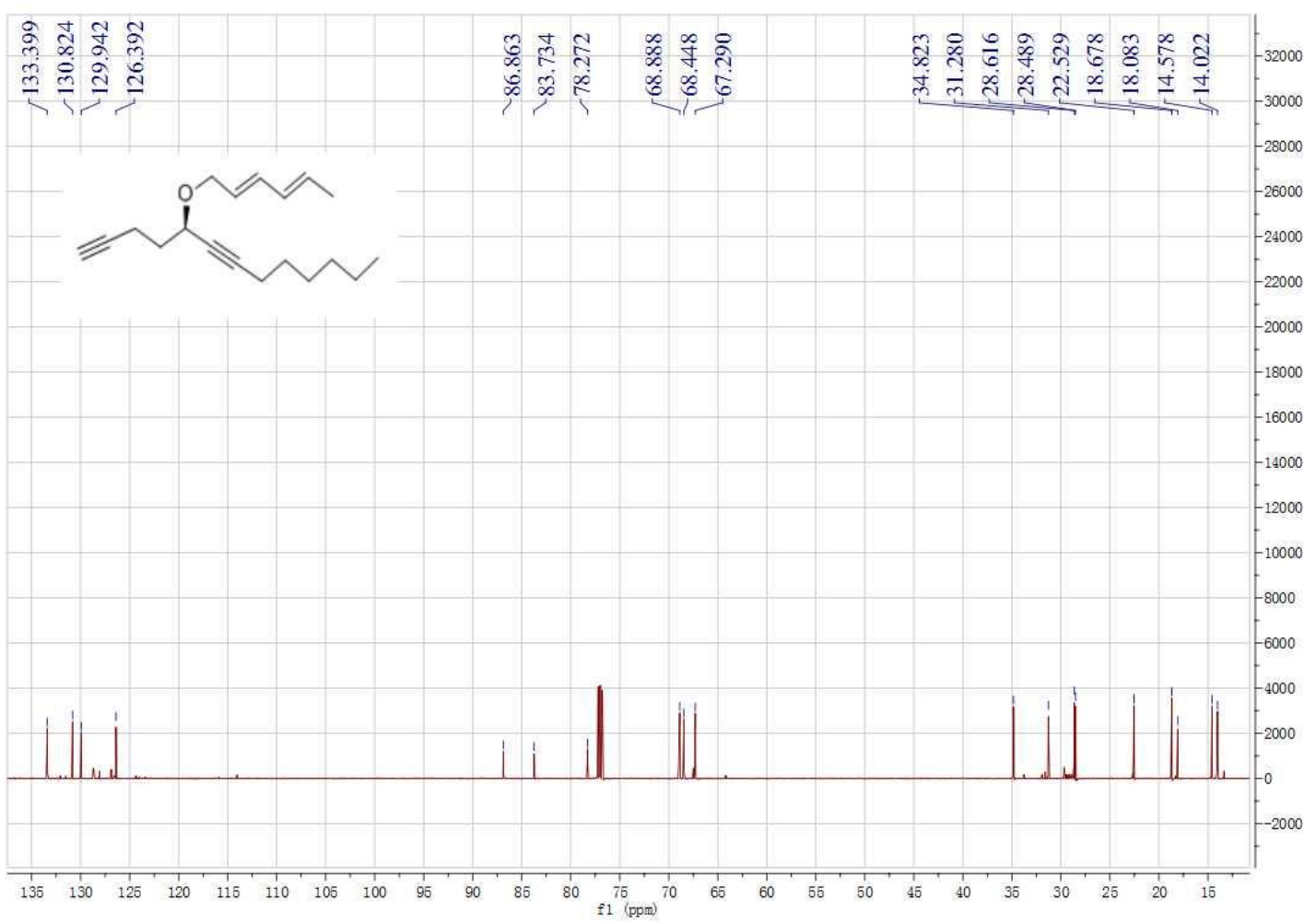


${ }^{1} \mathrm{H}$ NMR of $(R)-\mathbf{2 f}$

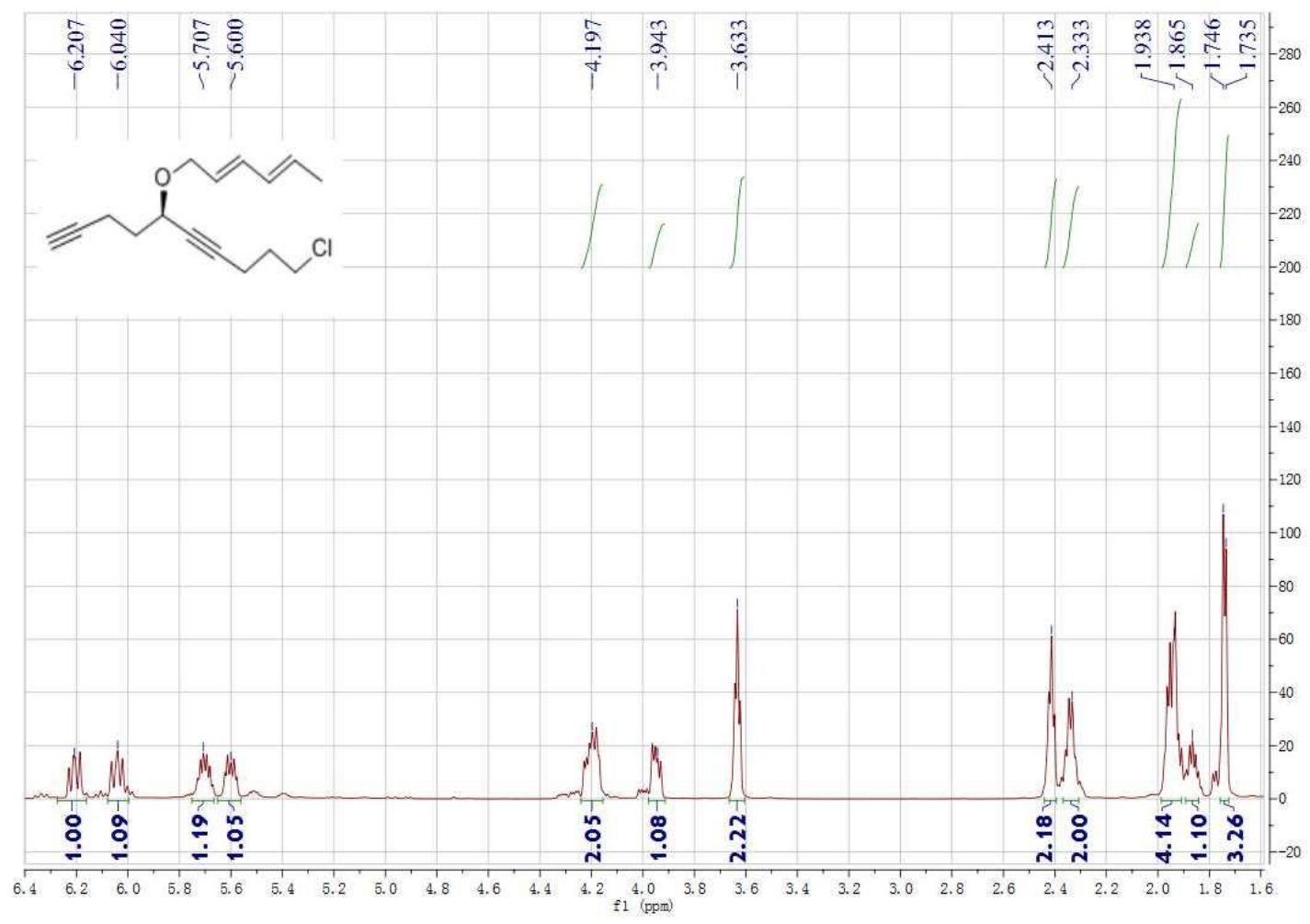

${ }^{13} \mathrm{C}$ NMR of $(R)-\mathbf{2 f}$

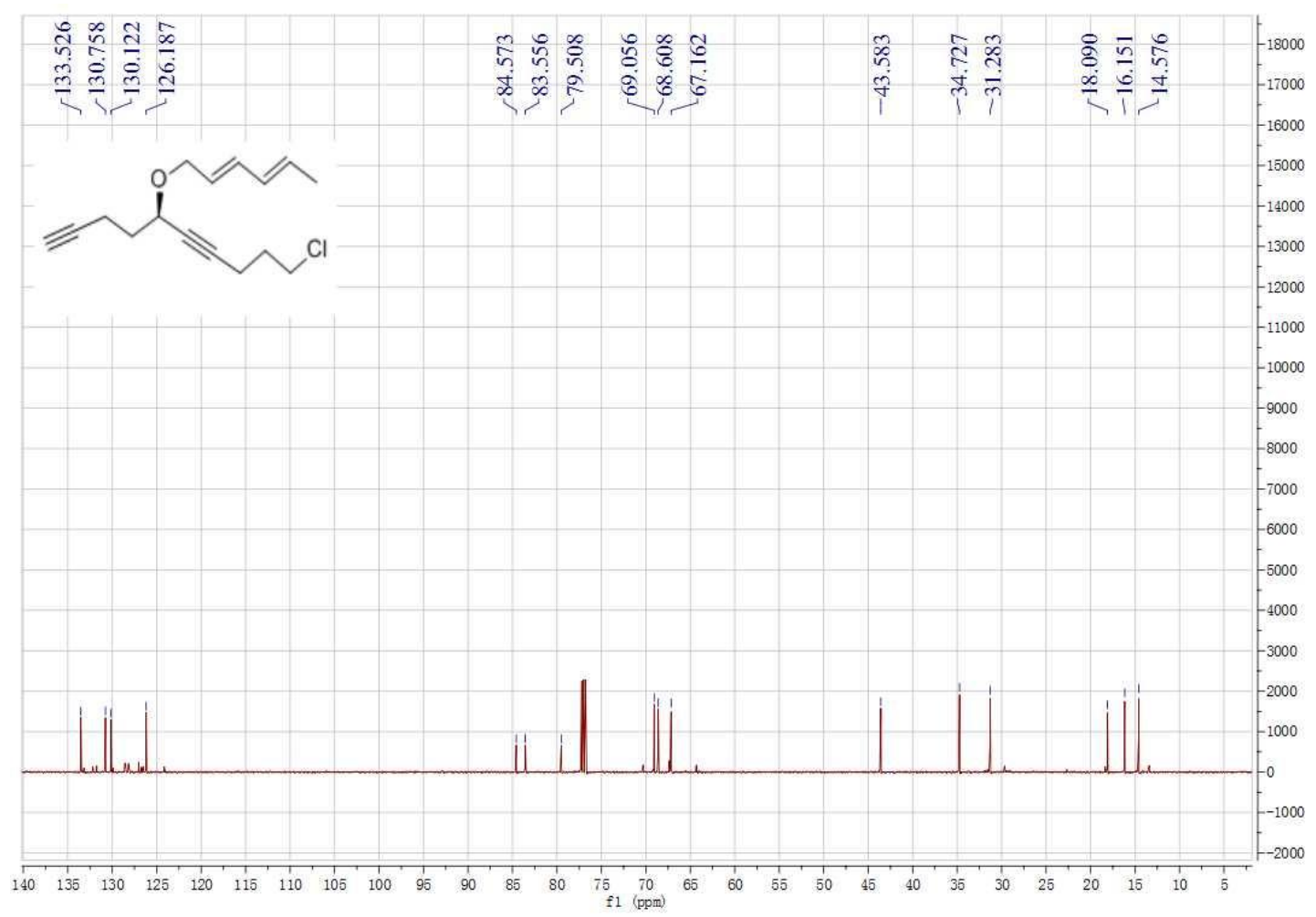


${ }^{1} \mathrm{H}$ NMR of $(R)-\mathbf{2 g}$

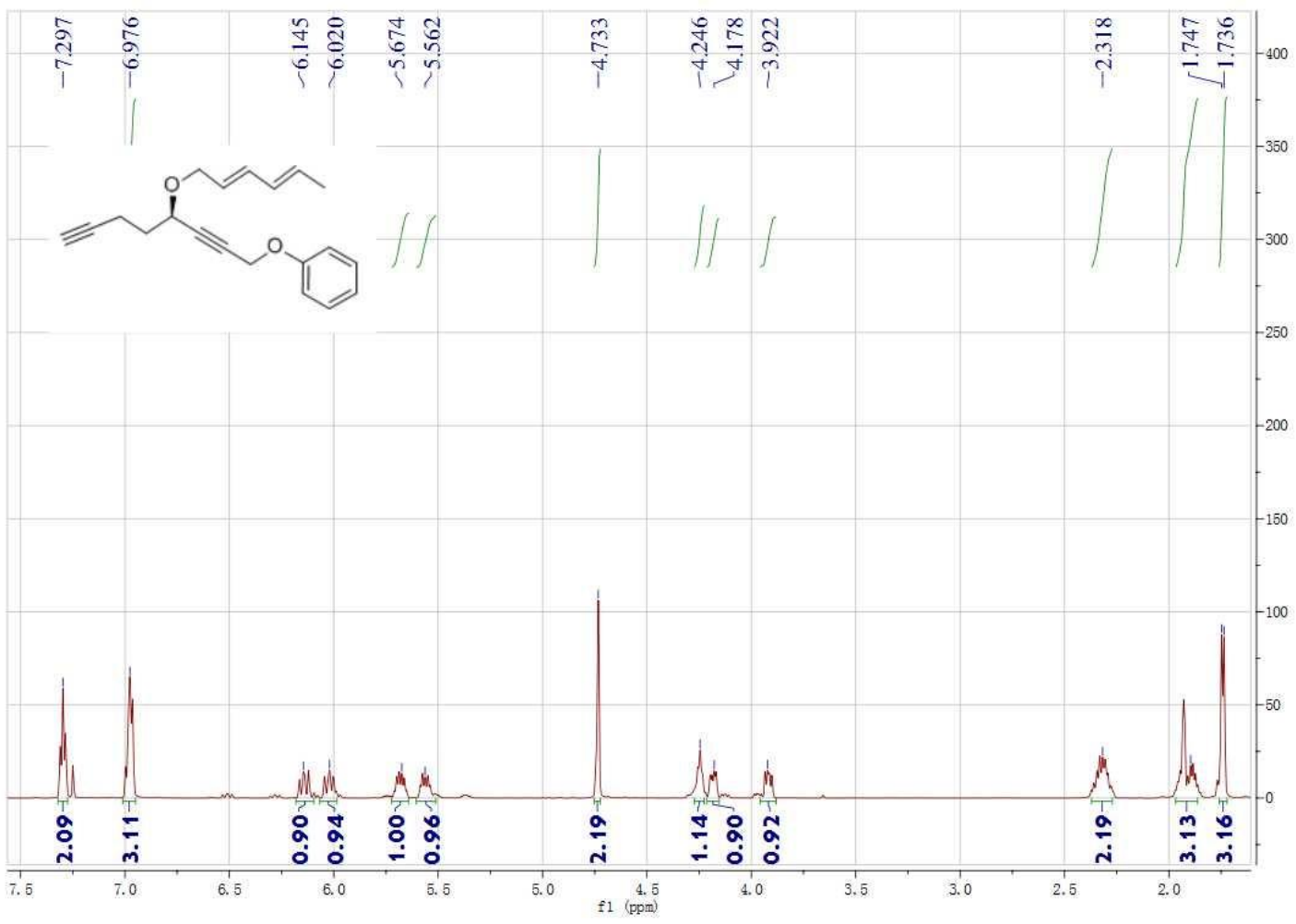

${ }^{13} \mathrm{C}$ NMR of $(R)-\mathbf{2 g}$

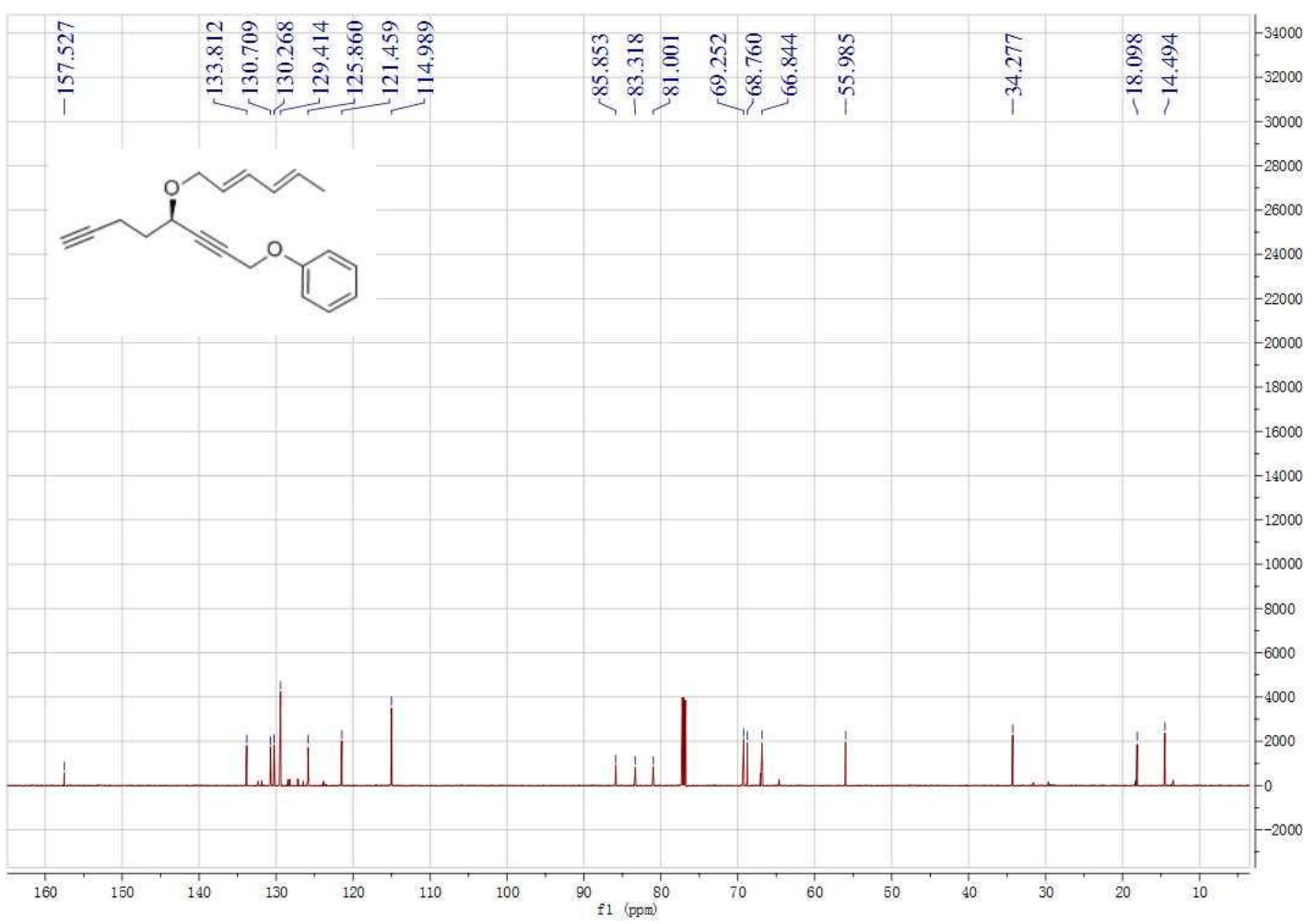


Optically Active Diene-diynes $(R)-3$

${ }^{1} \mathrm{H}$ NMR of $(R)-\mathbf{3 a}$

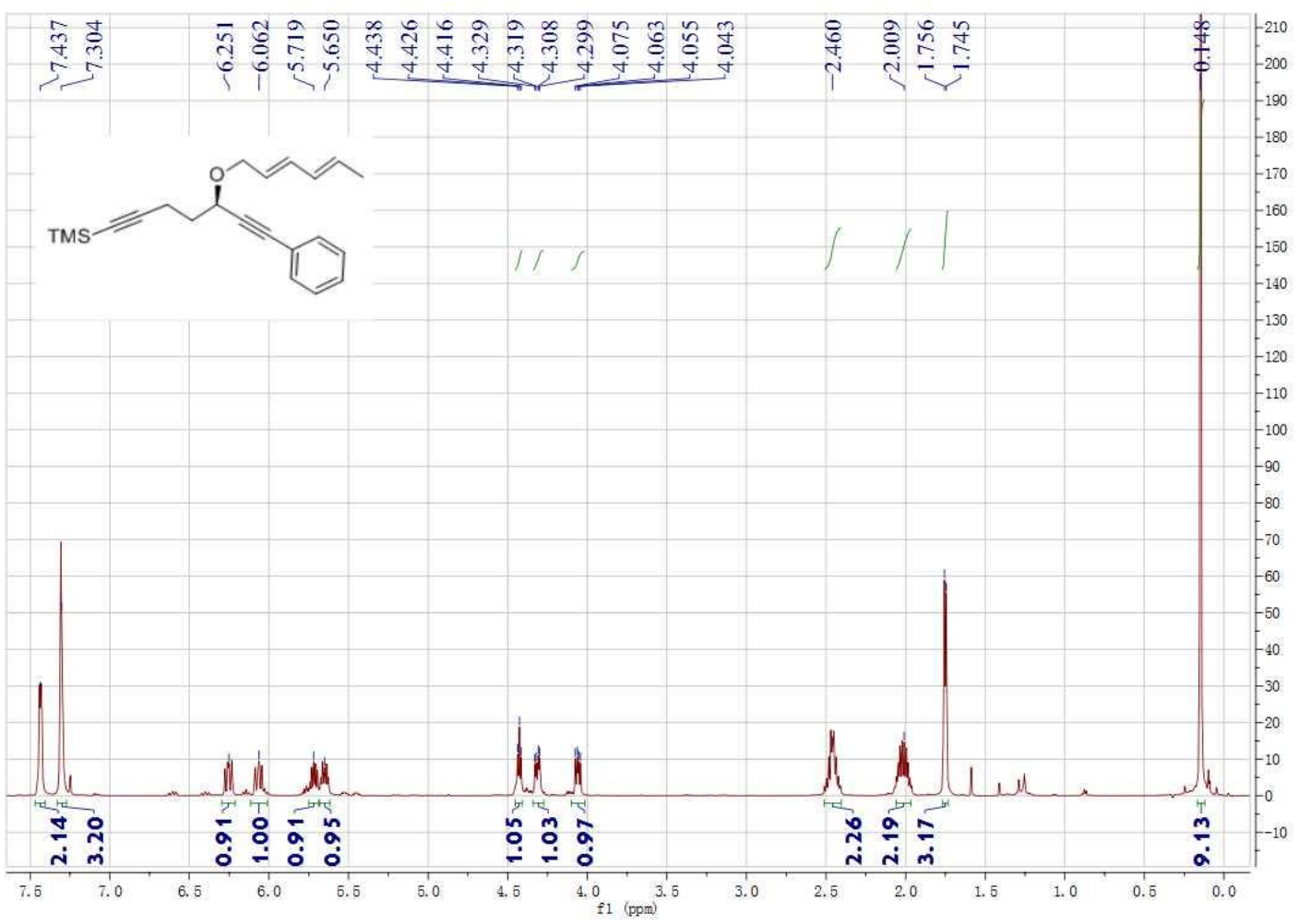

${ }^{13} \mathrm{C}$ NMR of $(R)-\mathbf{3 a}$

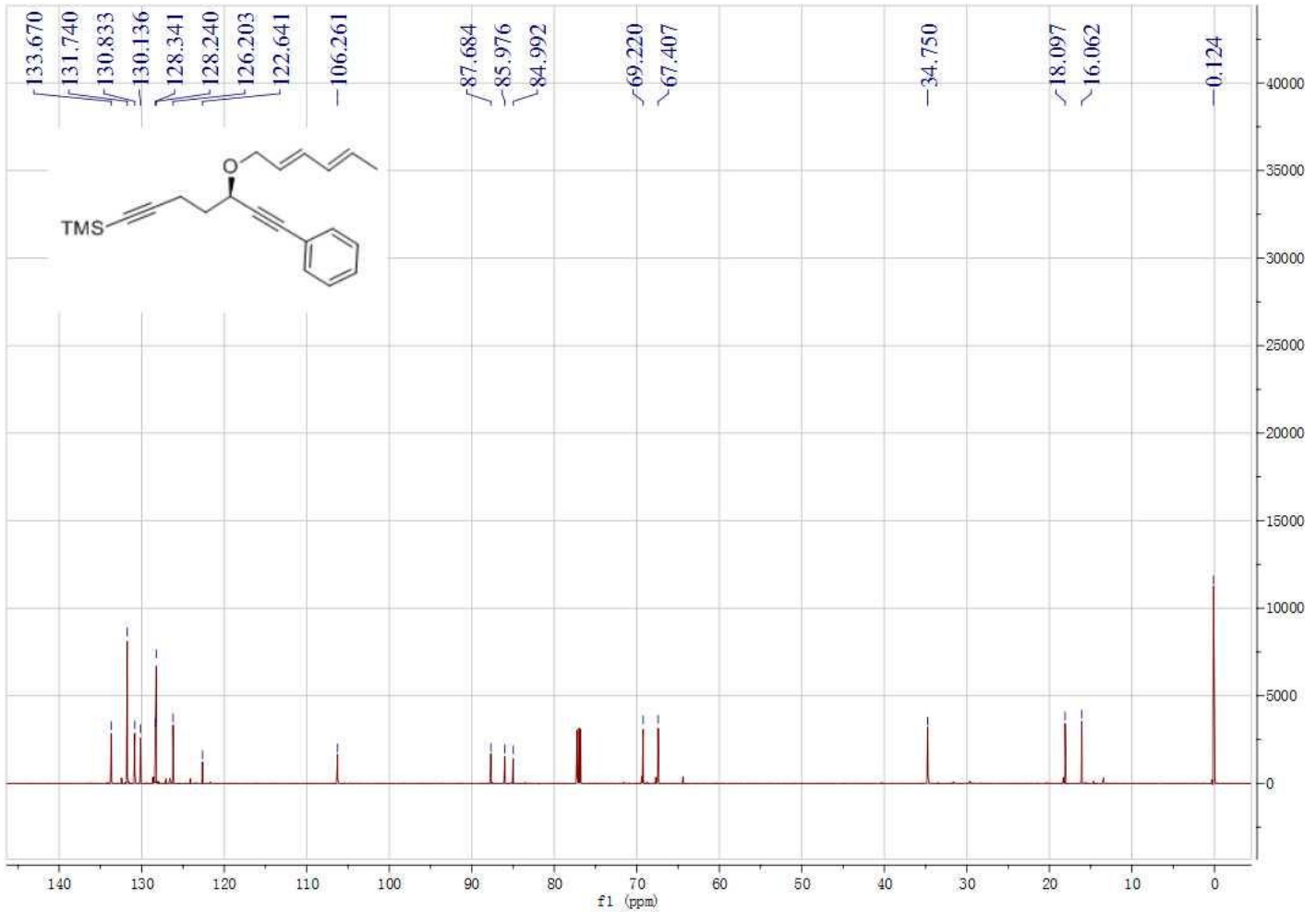


${ }^{1} \mathrm{H}$ NMR of $(R)-3-\mathrm{Me}$

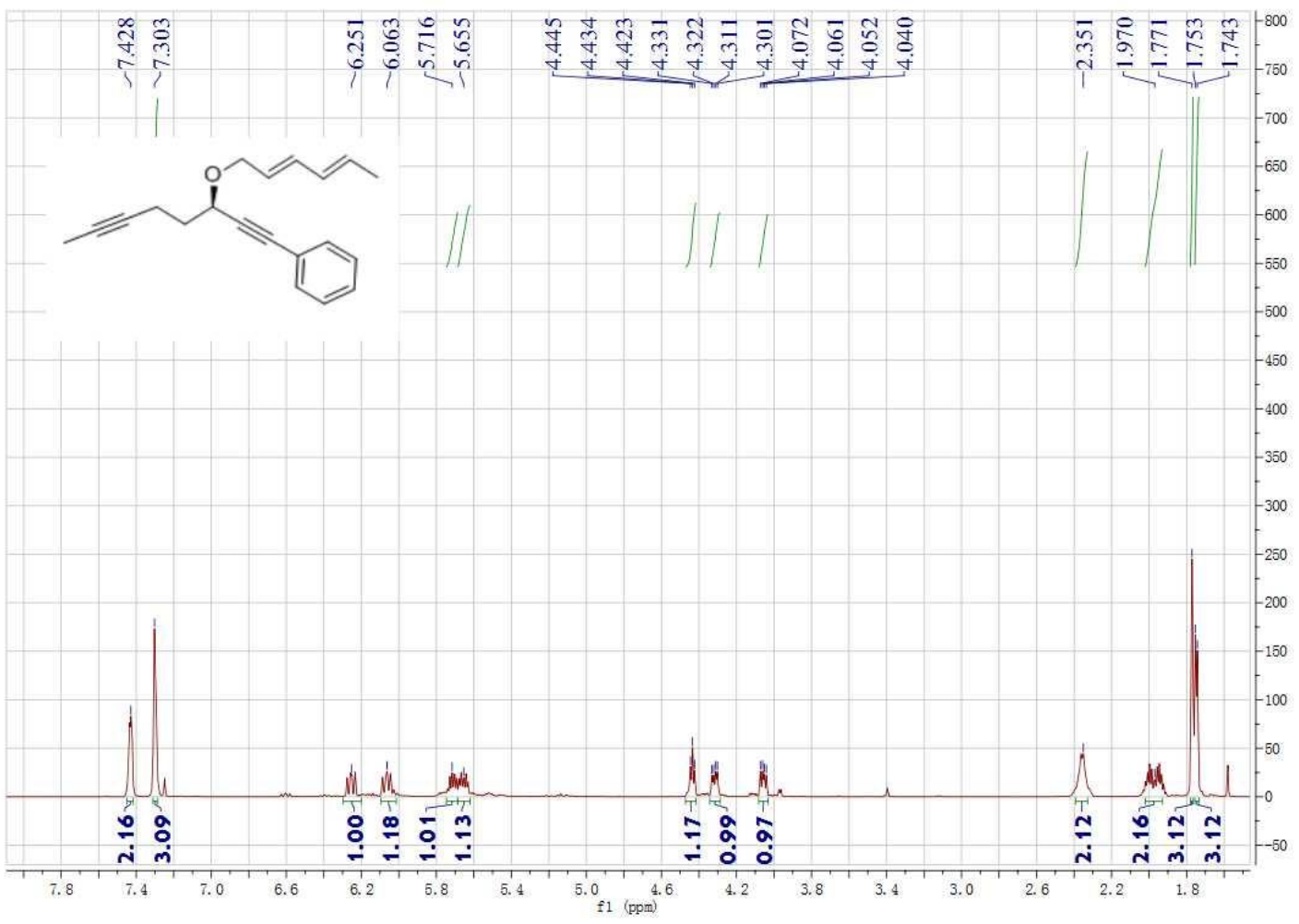

${ }^{13} \mathrm{C}$ NMR of $(R)-3-M e$

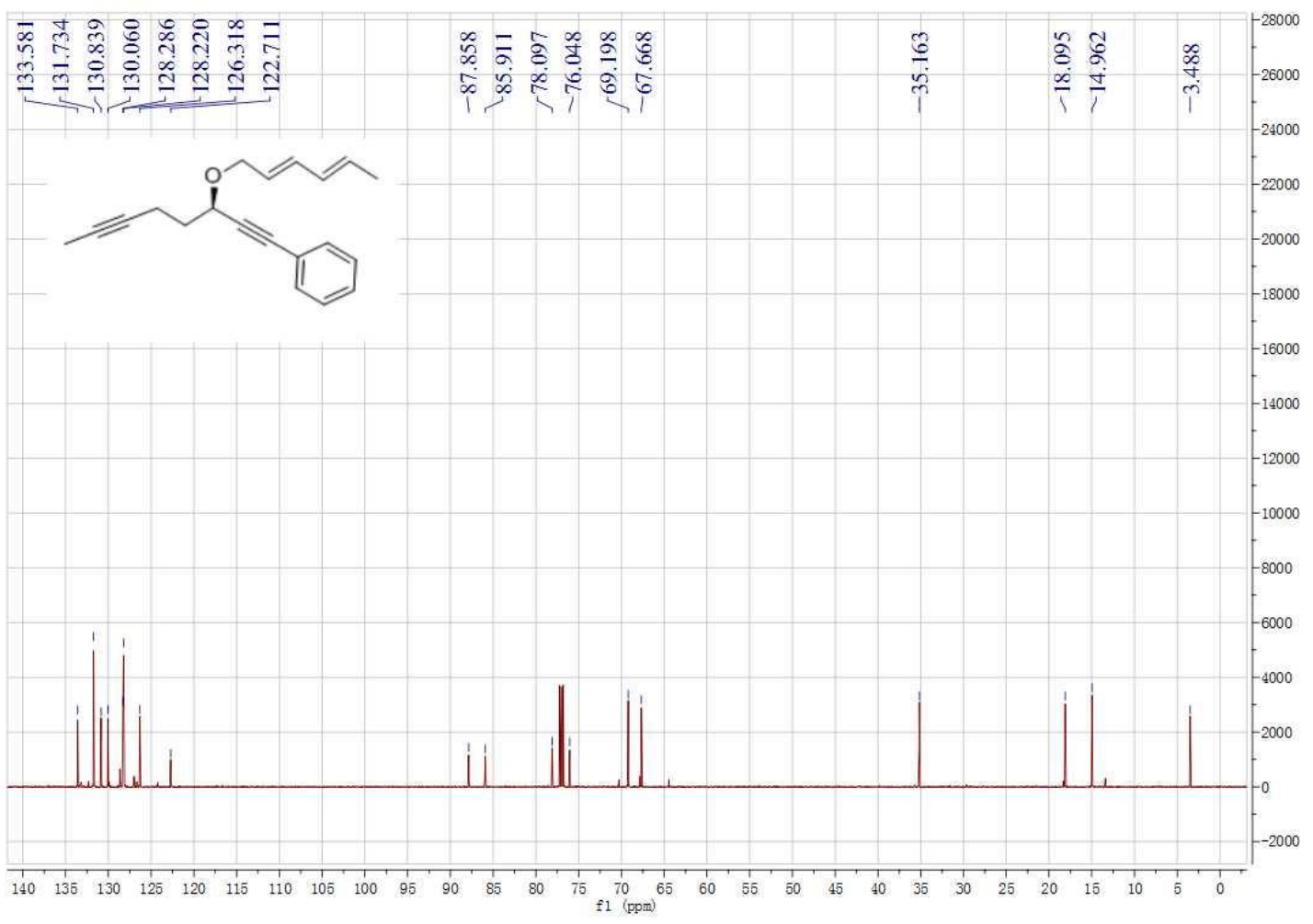


${ }^{1} \mathrm{H}$ NMR of $(R)-\mathbf{3 b}$

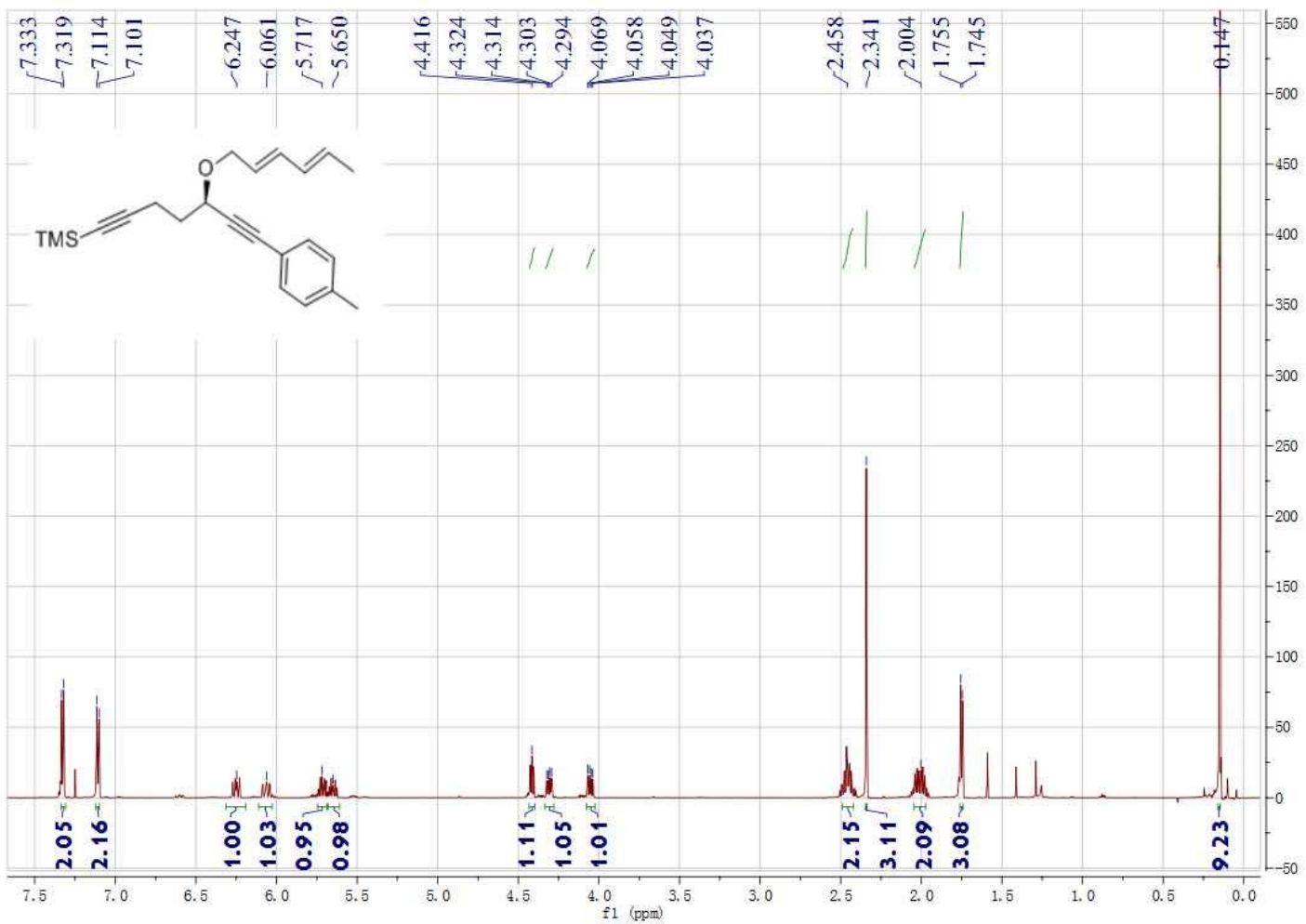

${ }^{13} \mathrm{C}$ NMR of $(R)-\mathbf{3 b}$

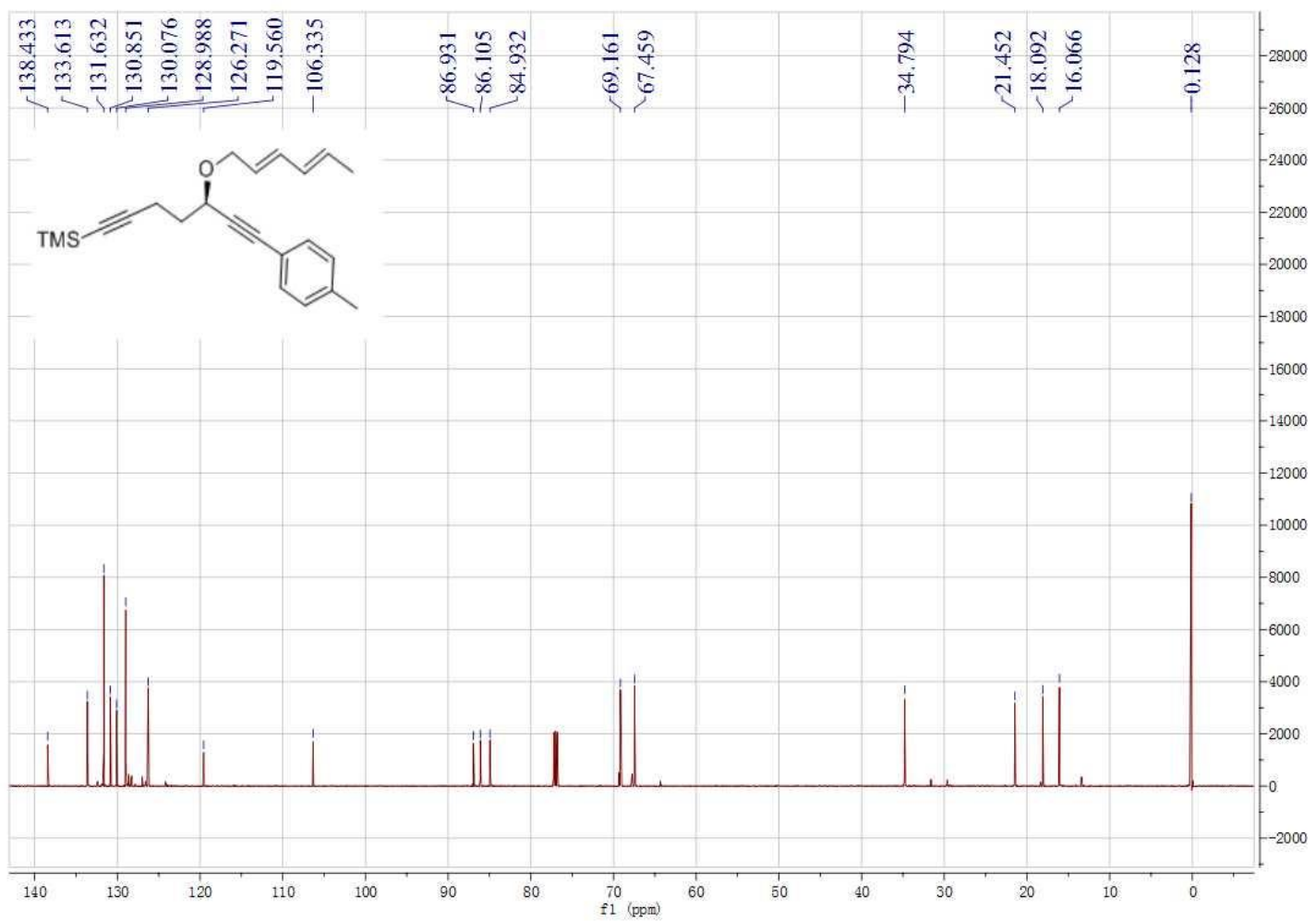


${ }^{1} \mathrm{H}$ NMR of $(R)-3 \mathbf{c}$

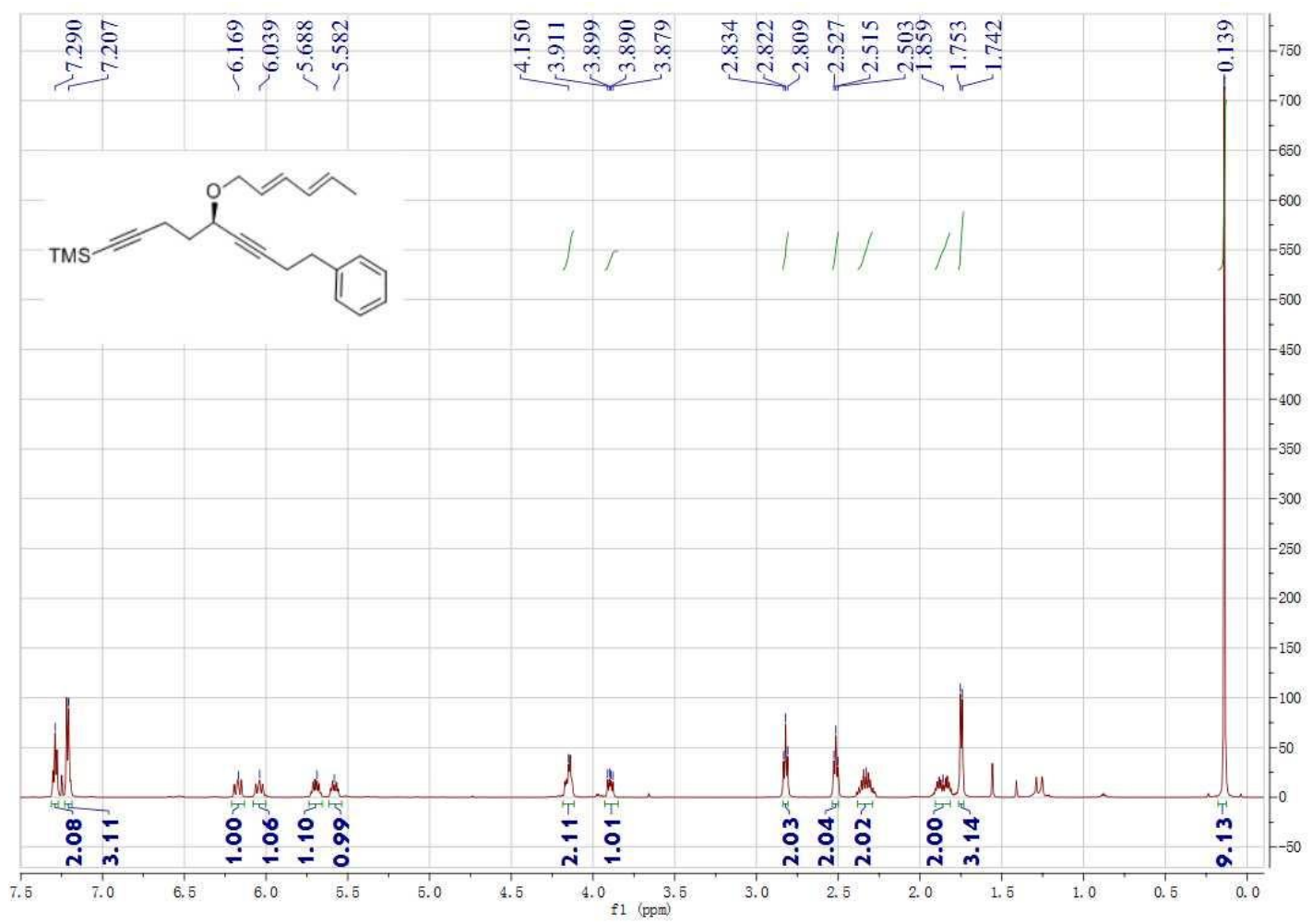

${ }^{13} \mathrm{C}$ NMR of $(R)-\mathbf{3 c}$

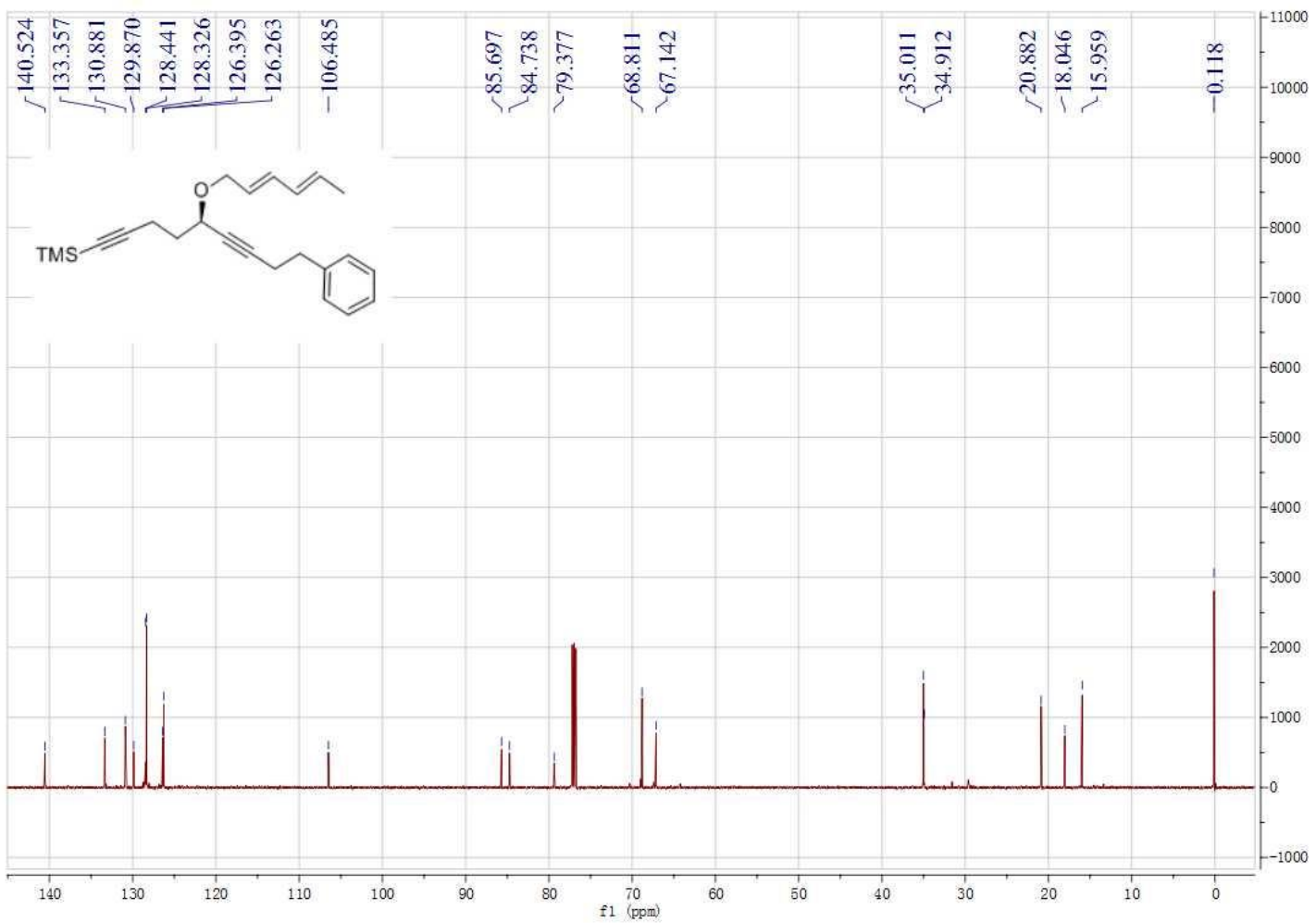


${ }^{1} \mathrm{H}$ NMR of $(R)-\mathbf{3 d}$

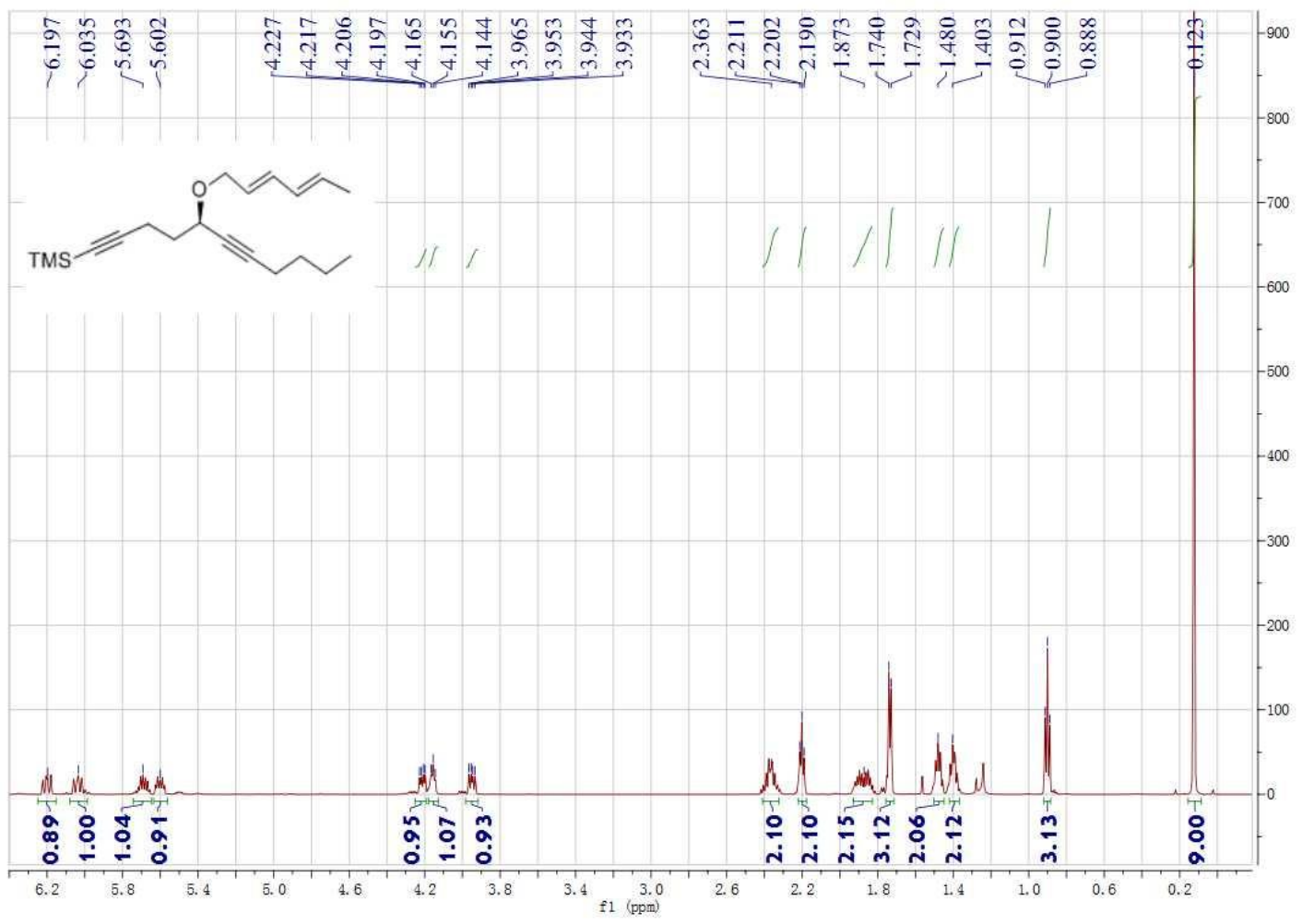

${ }^{13} \mathrm{C}$ NMR of $(R)-3 \mathbf{d}$

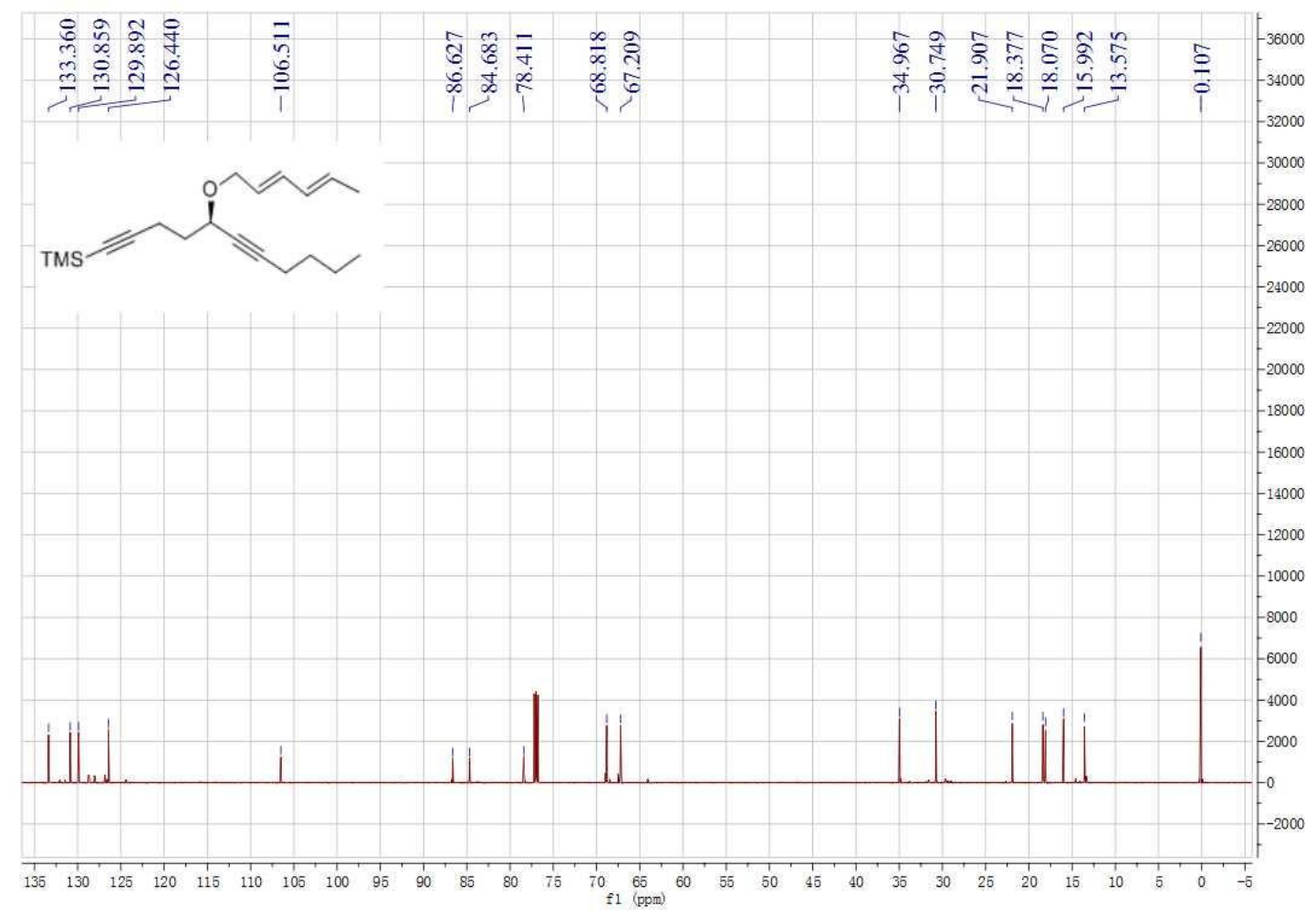


${ }^{1} \mathrm{H}$ NMR of $(R)-3 \mathbf{e}$

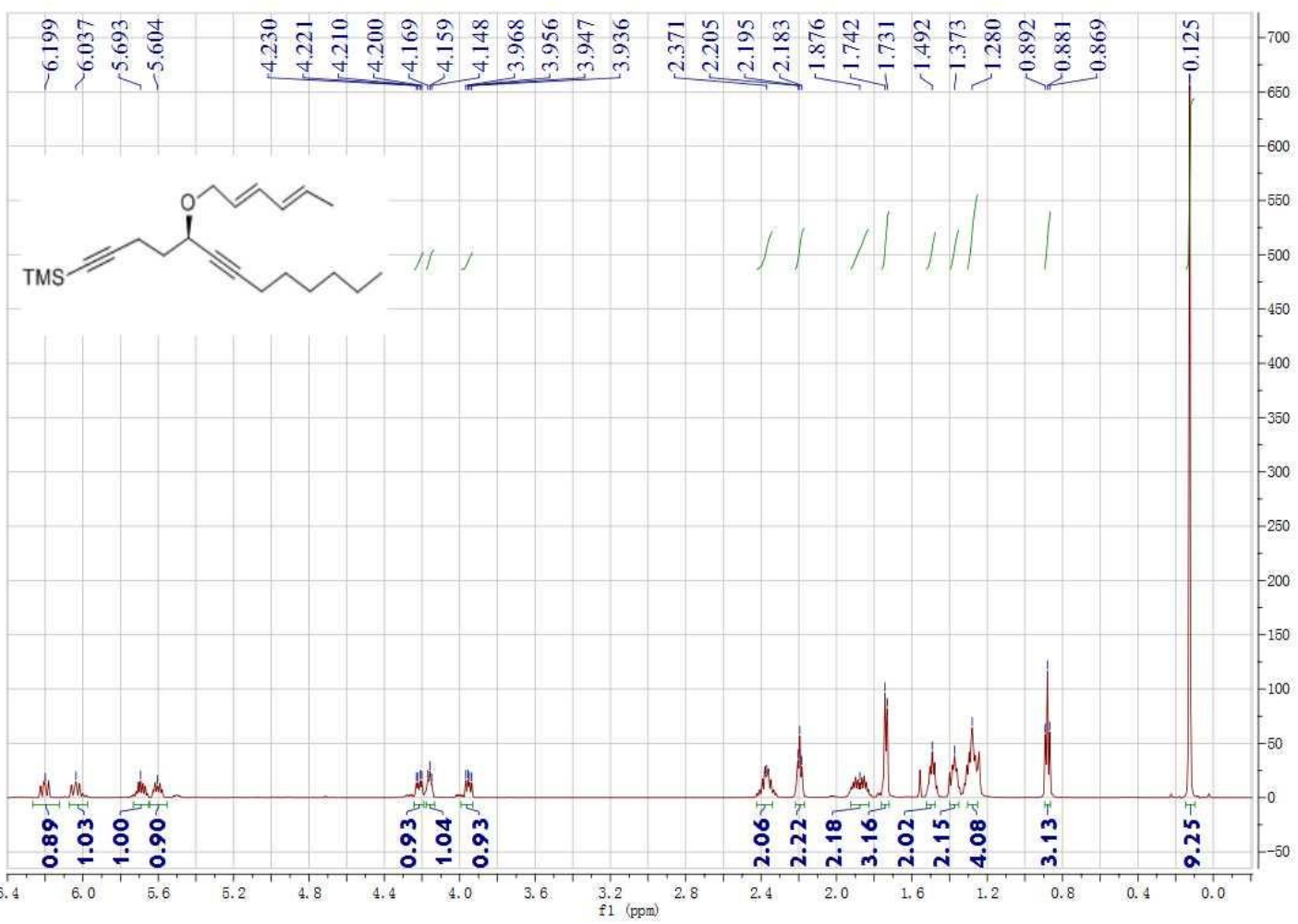

${ }^{13} \mathrm{C}$ NMR of $(R)-3 \mathbf{e}$

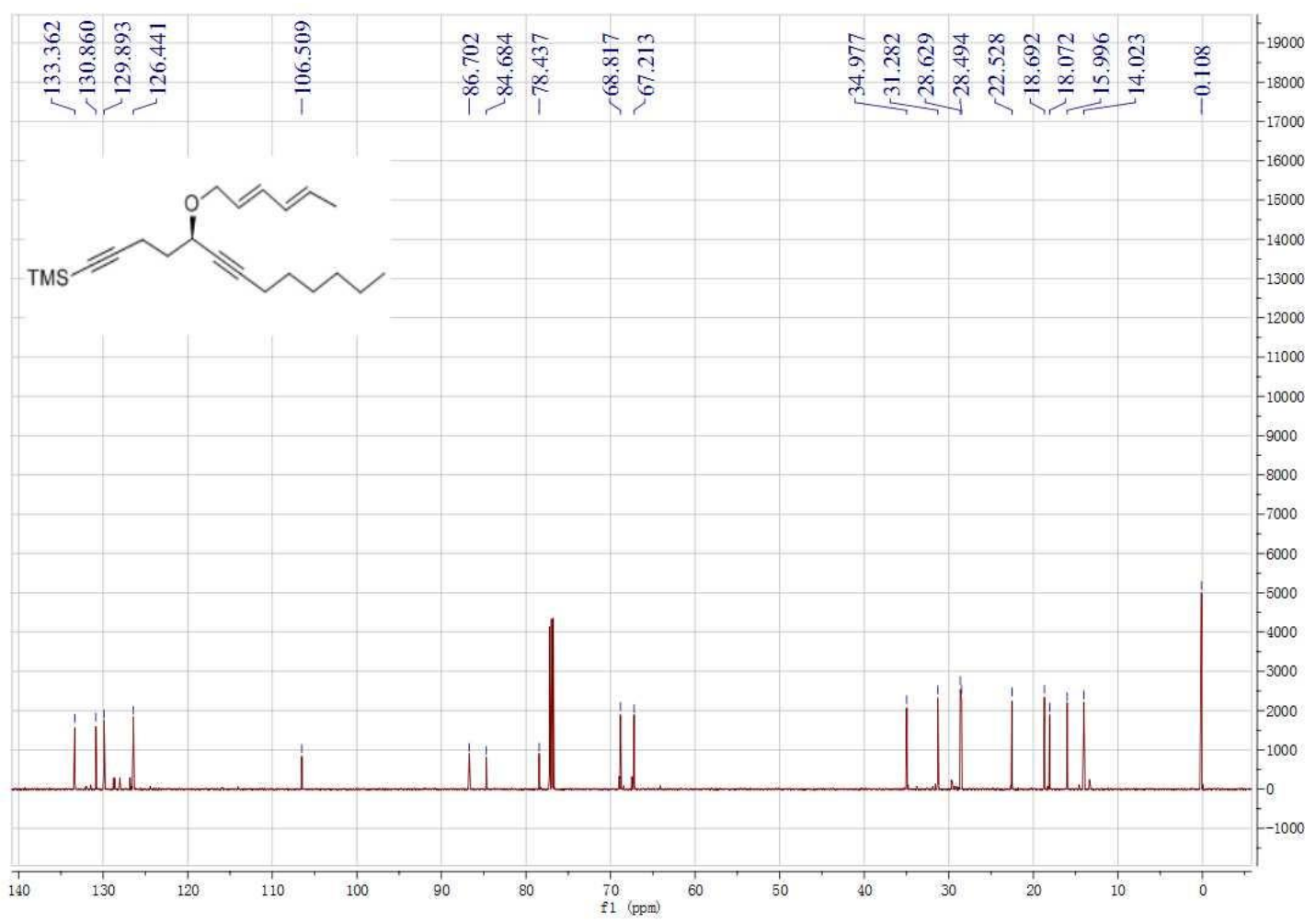


${ }^{1} \mathrm{H}$ NMR of $(R)-\mathbf{3 f}$

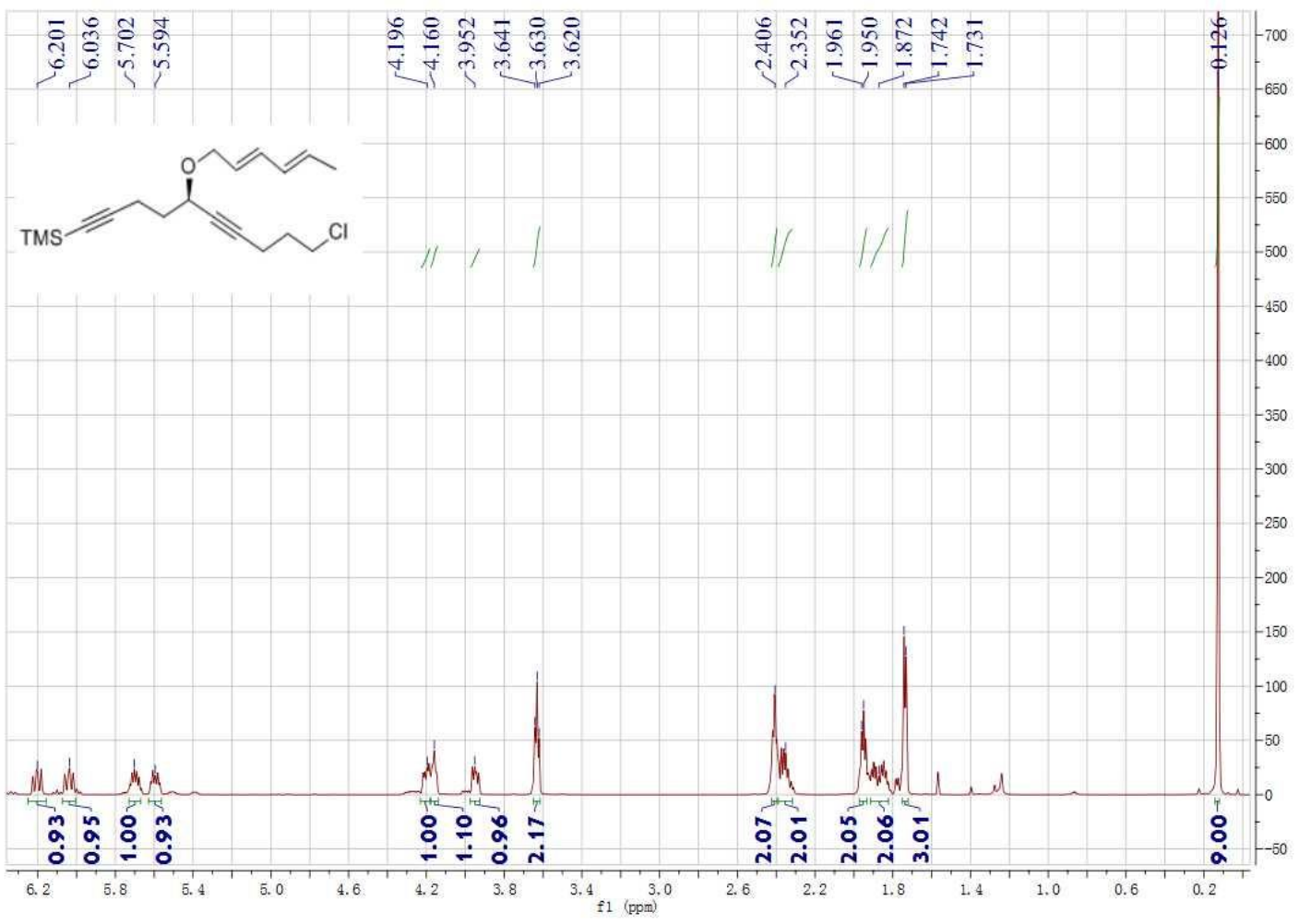

${ }^{13} \mathrm{C}$ NMR of $(R)-\mathbf{3 f}$

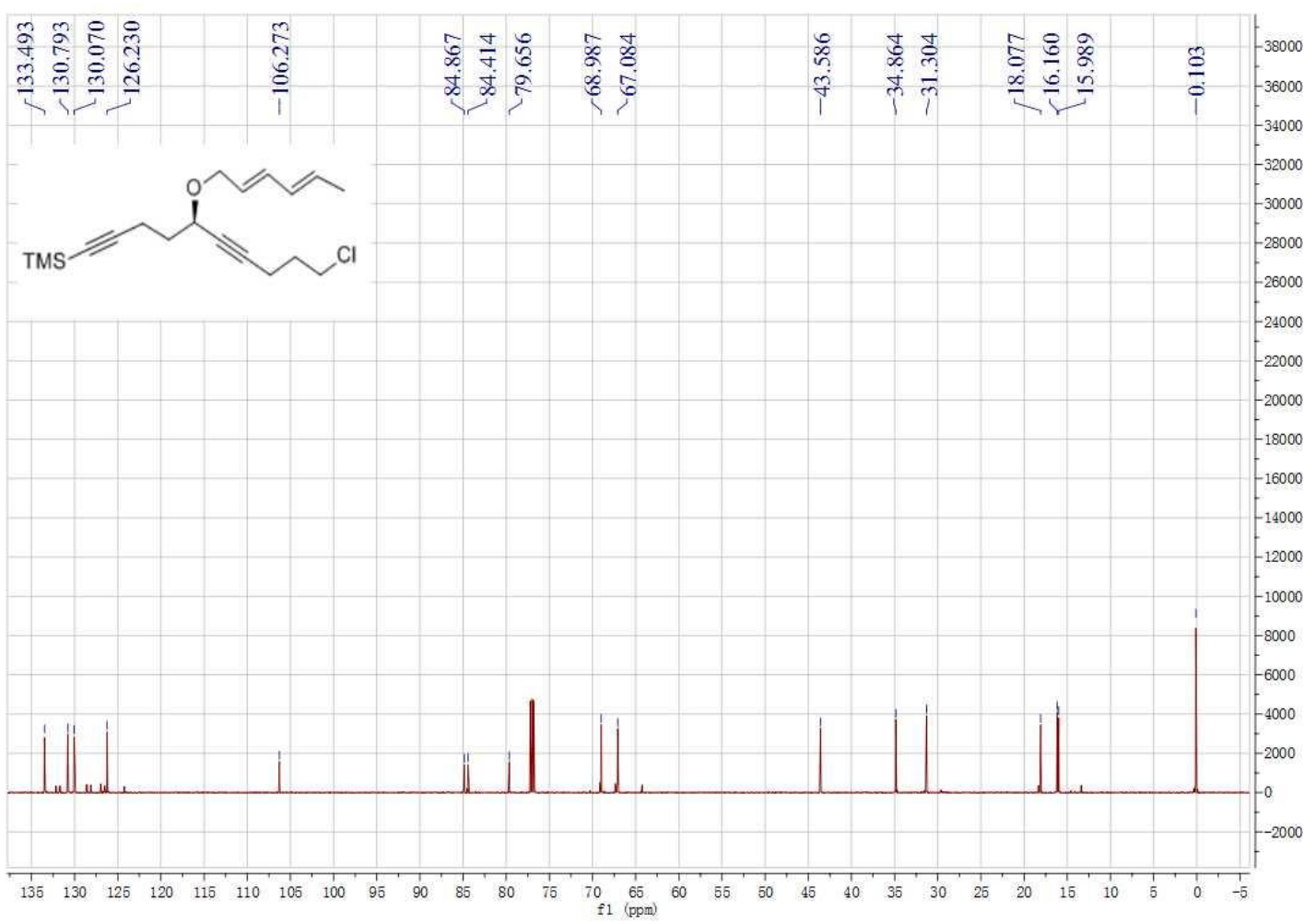


${ }^{1} \mathrm{H}$ NMR of $(R)-\mathbf{3 g}$

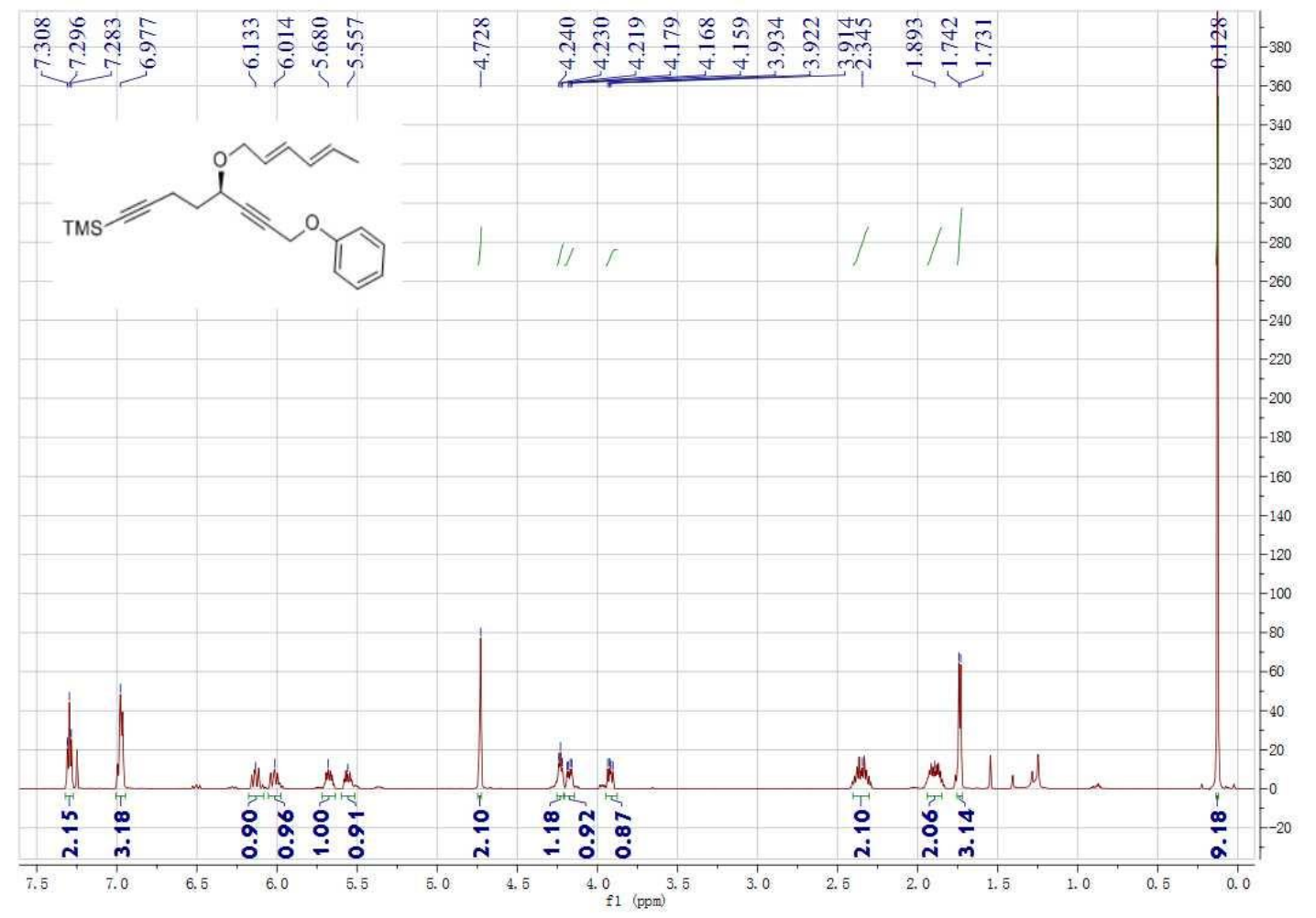

${ }^{13} \mathrm{C}$ NMR of $(R)-\mathbf{3 g}$

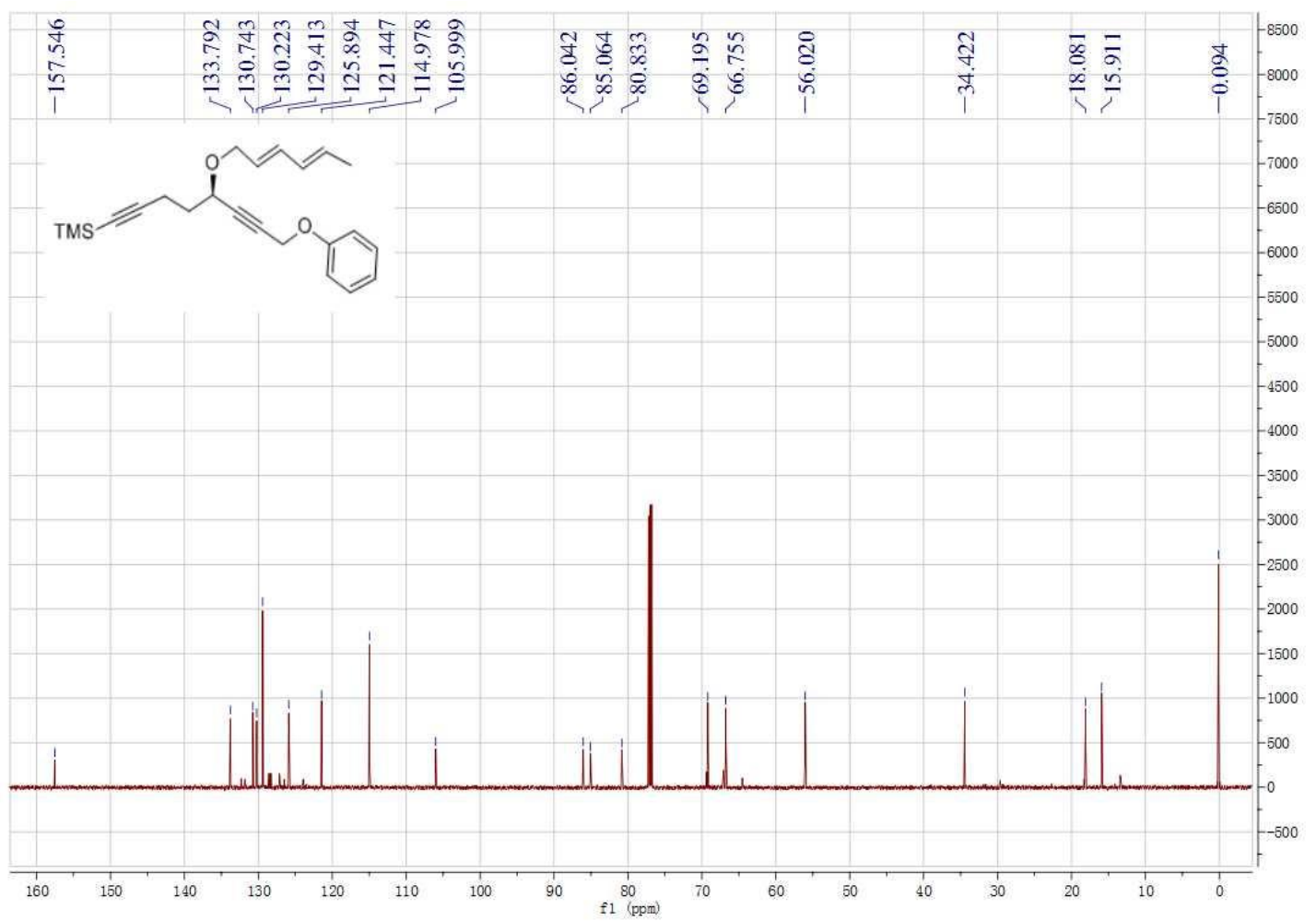




\section{Domino PK/DA Cycloaddition Products}

Compound 4a

${ }^{1} \mathrm{H}$ NMR of $\mathbf{4 a}$

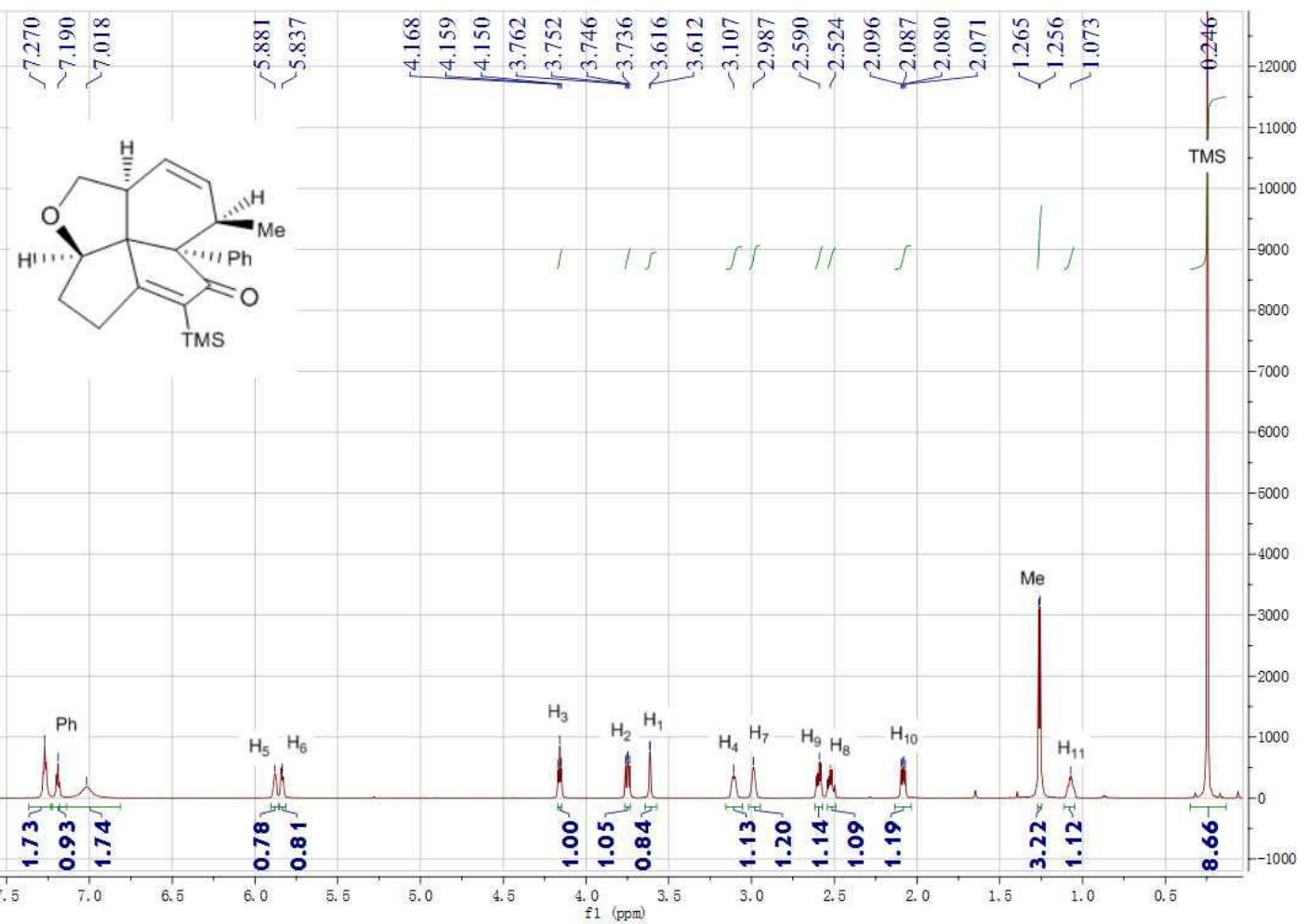

${ }^{13} \mathrm{C}$ NMR of $4 a$

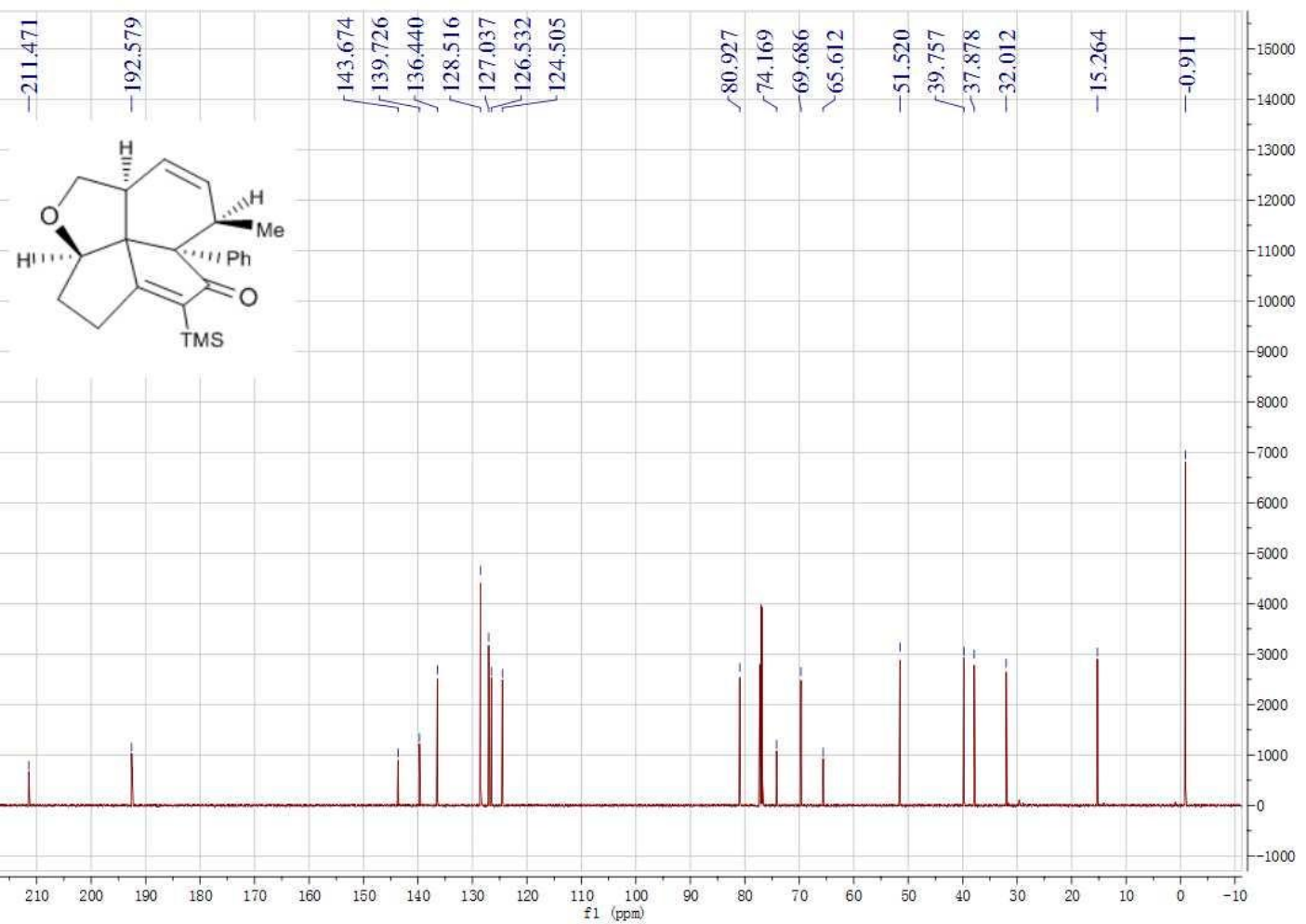




\section{Compound 4c}

${ }^{1} \mathrm{H}$ NMR of $4 \mathbf{c}$

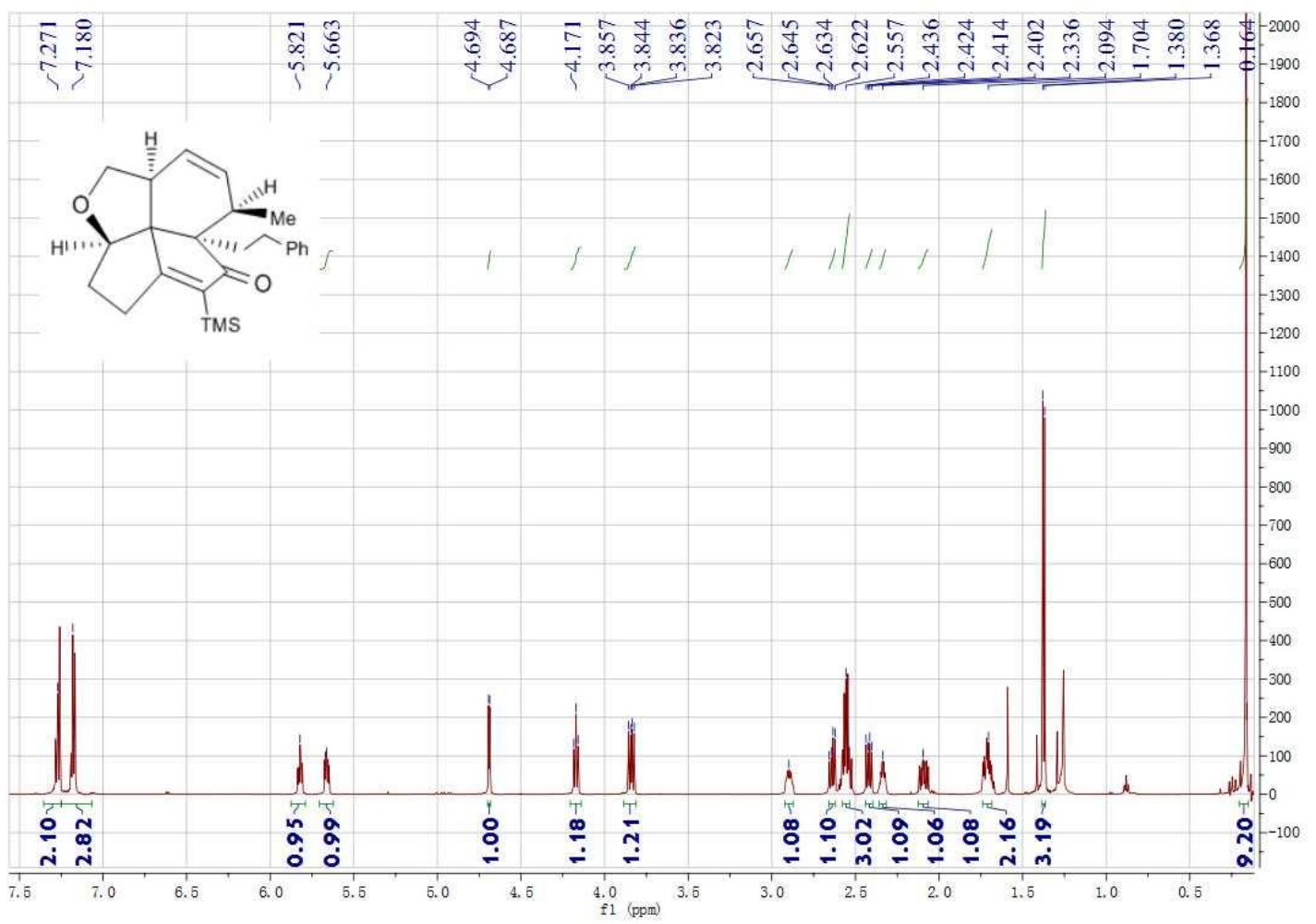

${ }^{13} \mathrm{C}$ NMR of $4 c$

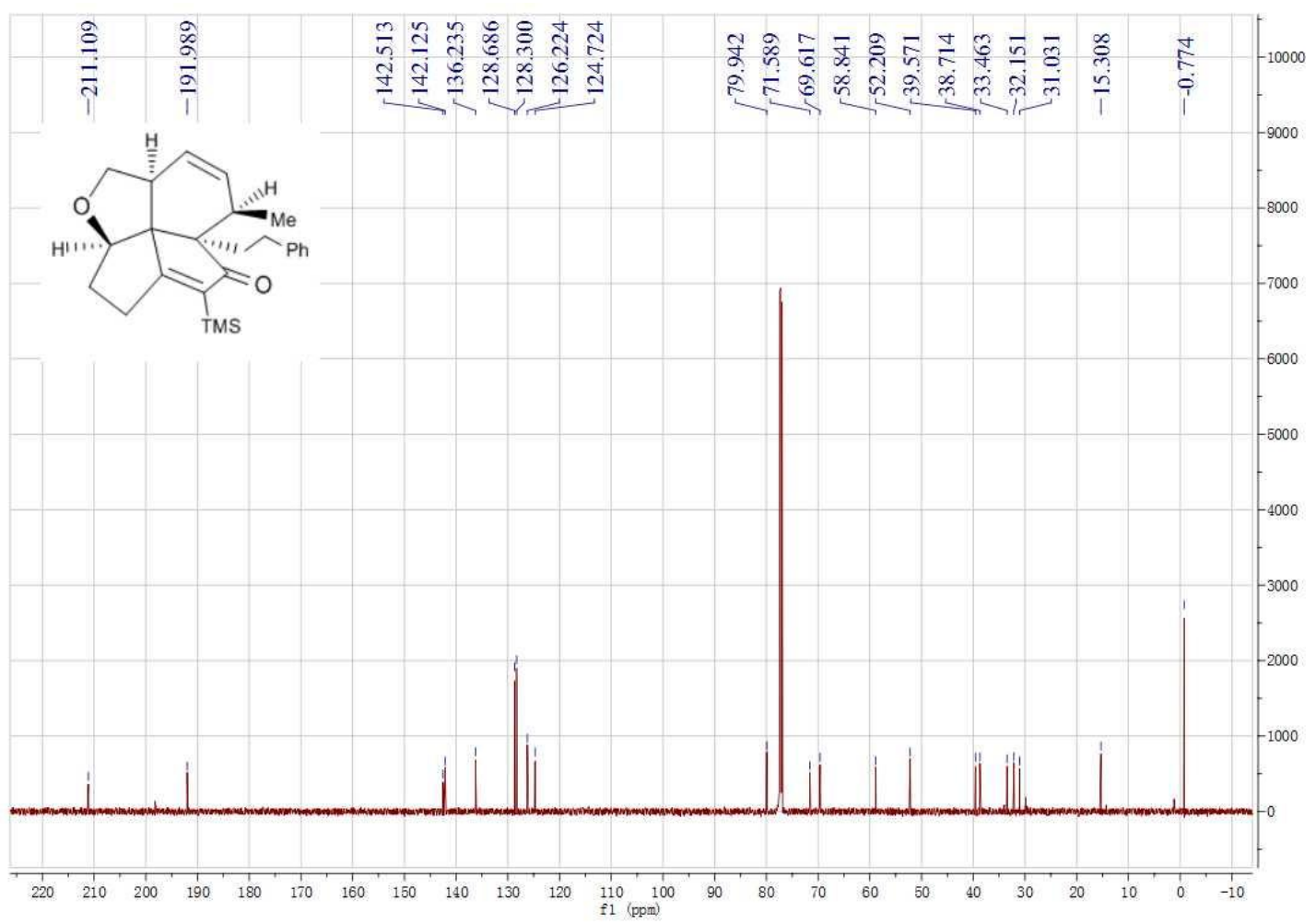


Compound 4-Me

${ }^{1} \mathrm{H}$ NMR of 4-Me

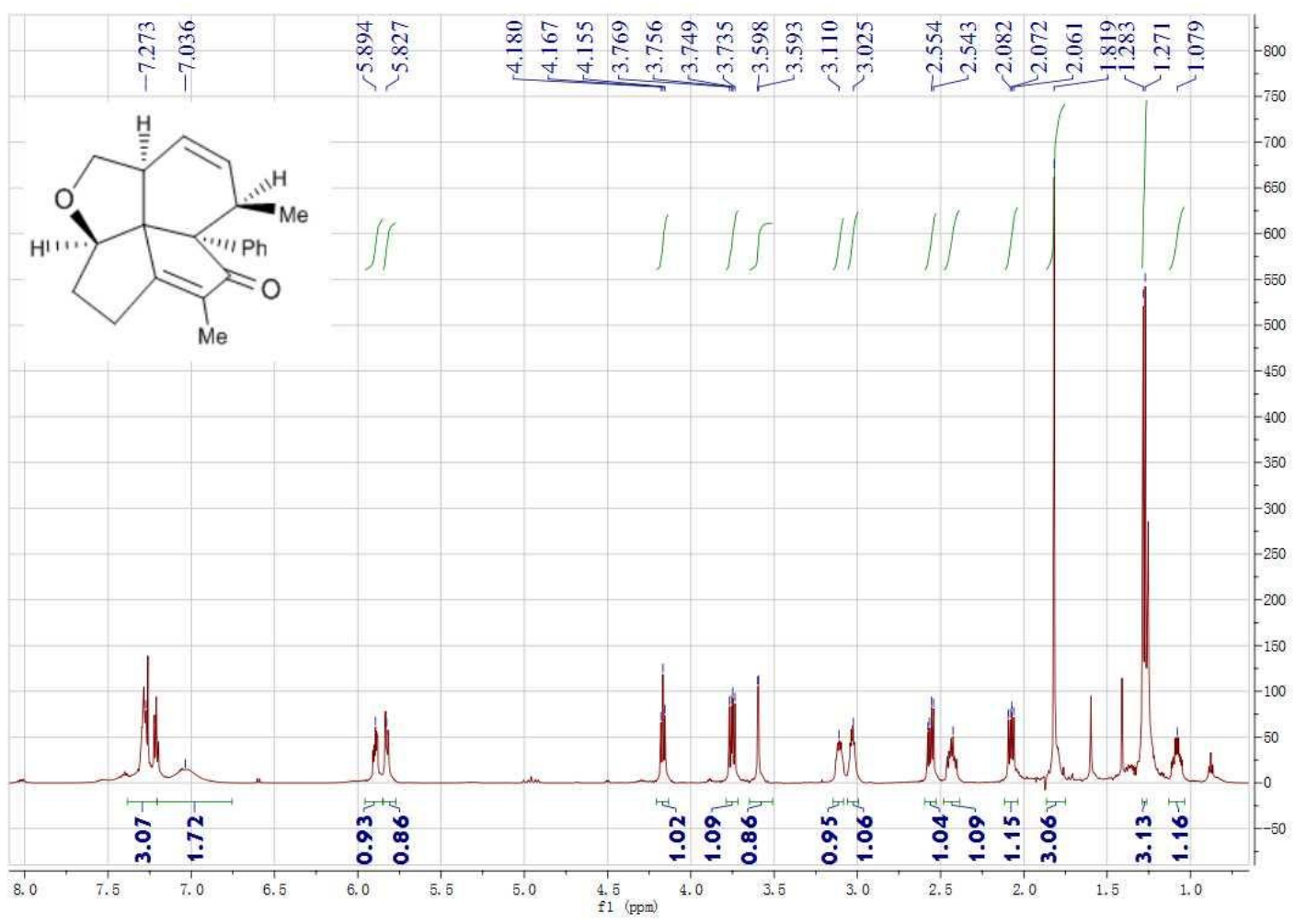

${ }^{13} \mathrm{C}$ NMR of $4-\mathrm{Me}$

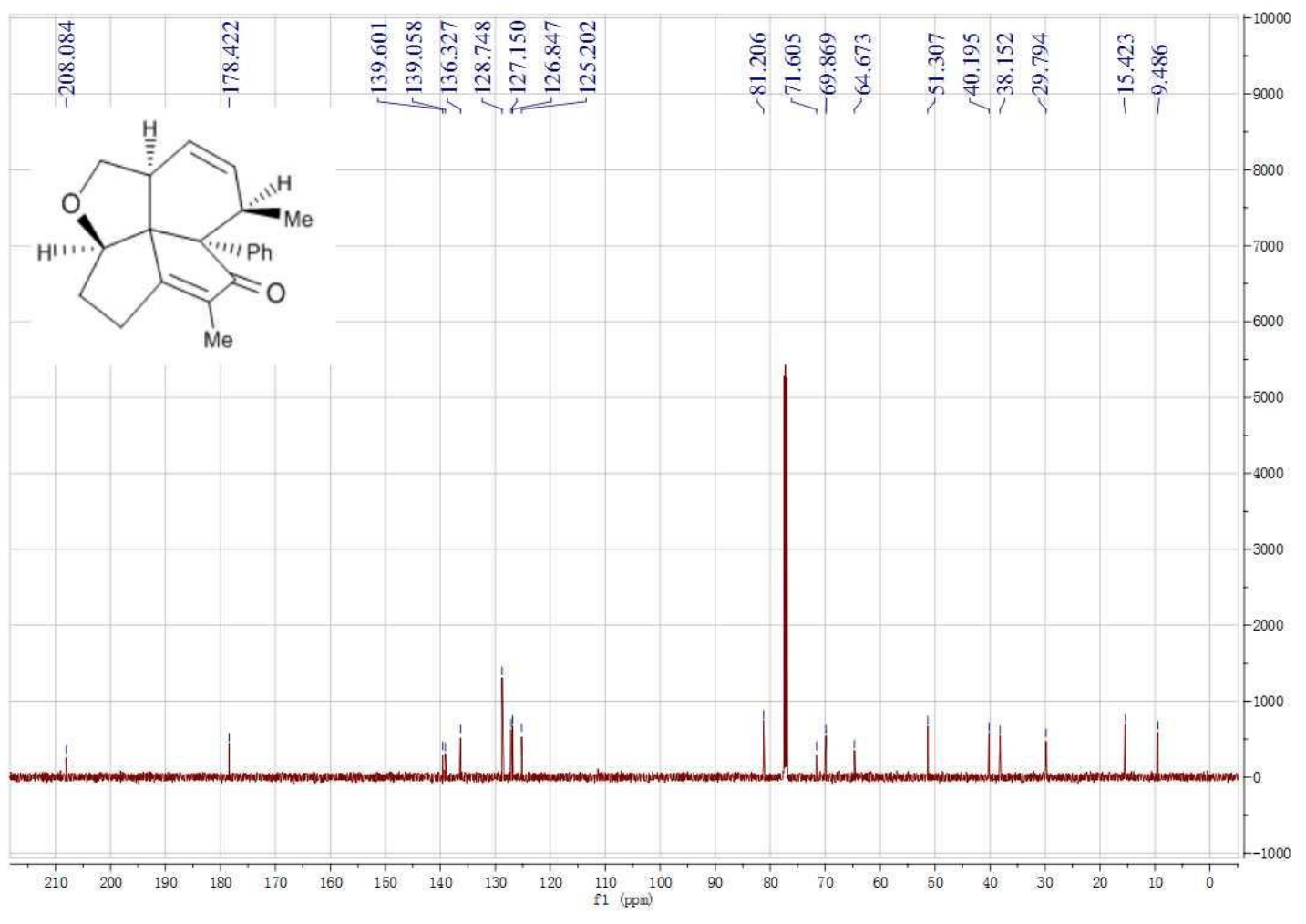




\section{Compound $4 b$}

${ }^{1} \mathrm{H}$ NMR of $\mathbf{4 b}$

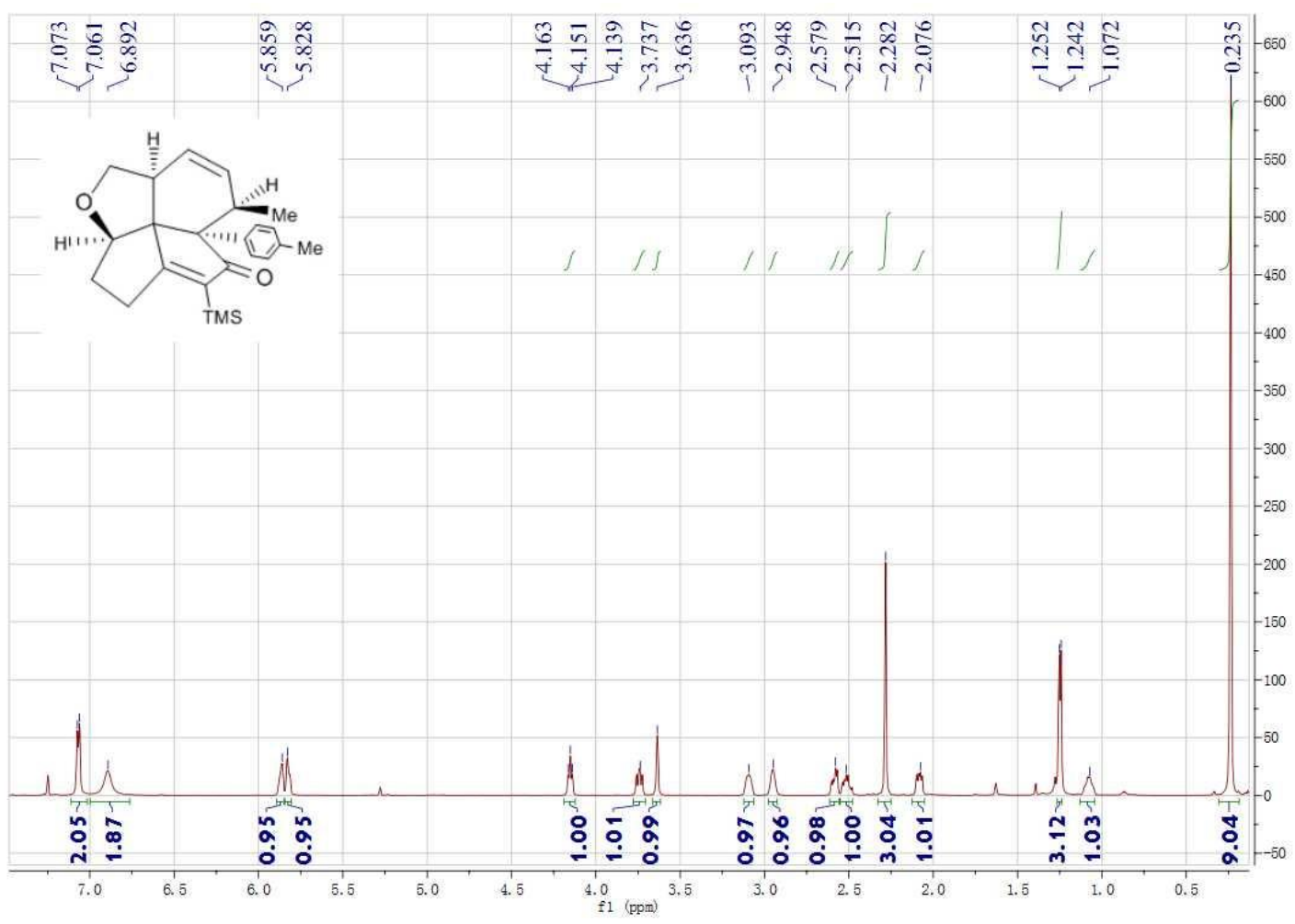

${ }^{13} \mathrm{C}$ NMR of $\mathbf{4 b}$

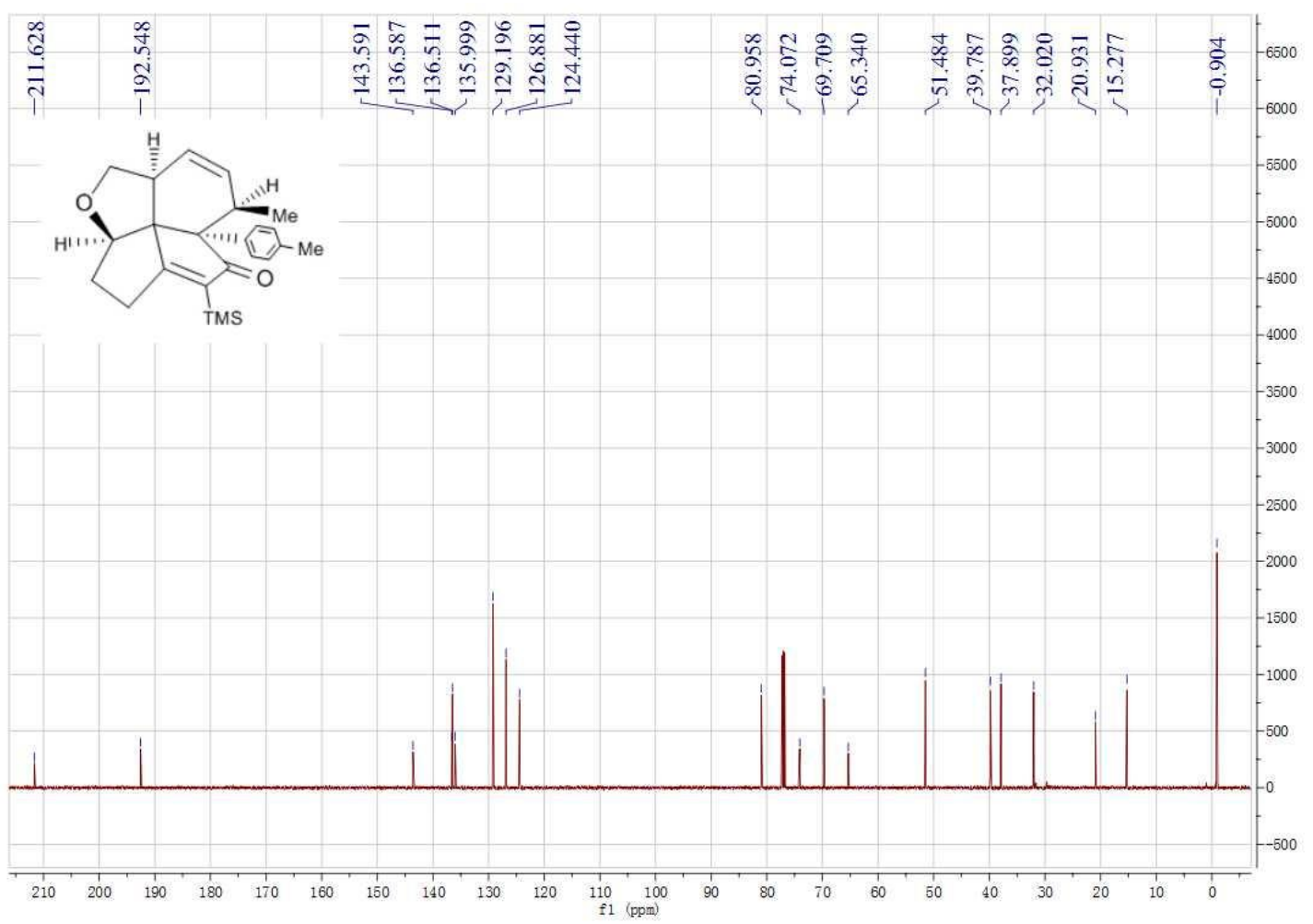




\section{Compound 4d}

${ }^{1} \mathrm{H}$ NMR of $\mathbf{4 d}$

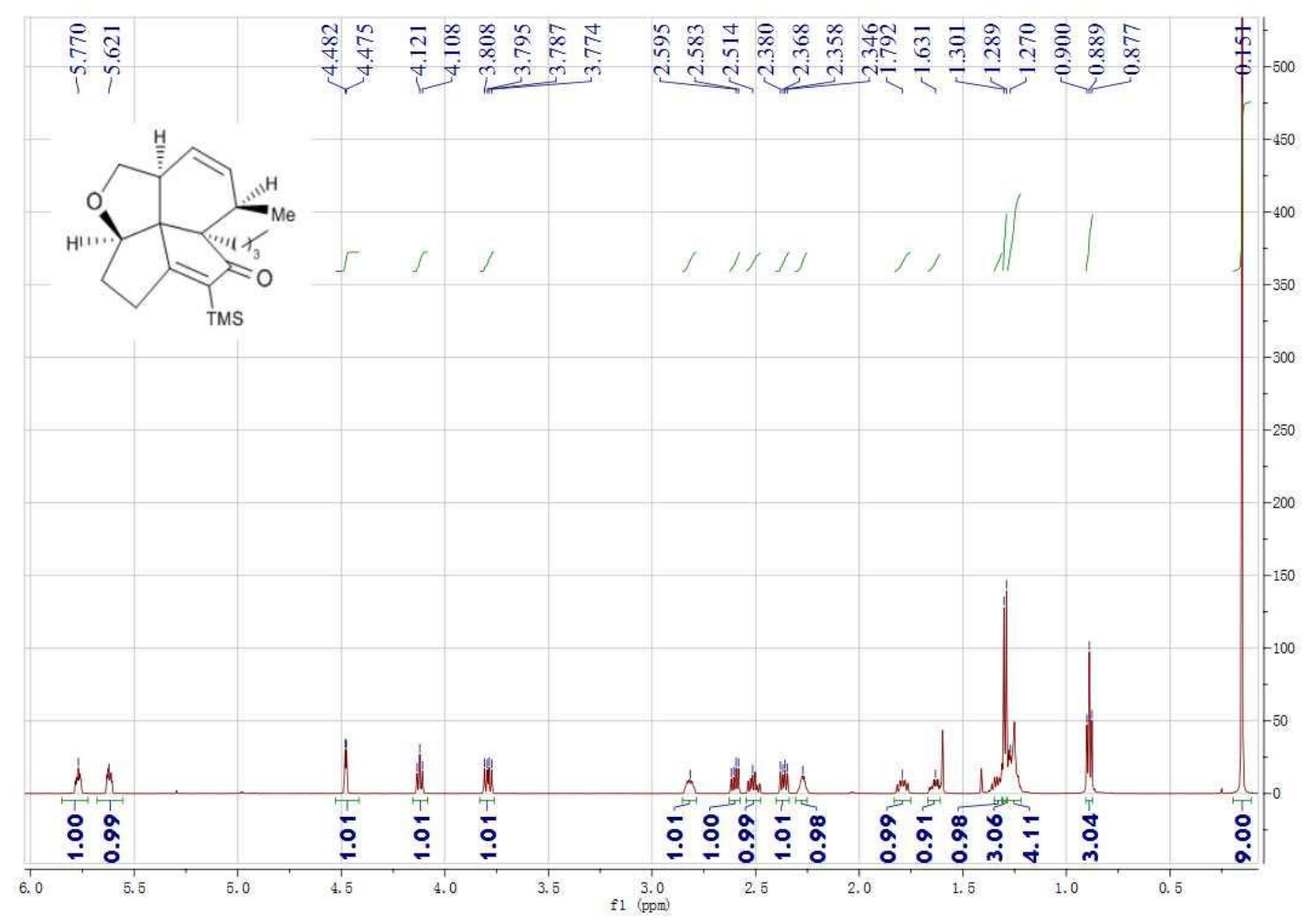

${ }^{13} \mathrm{C}$ NMR of $4 d$

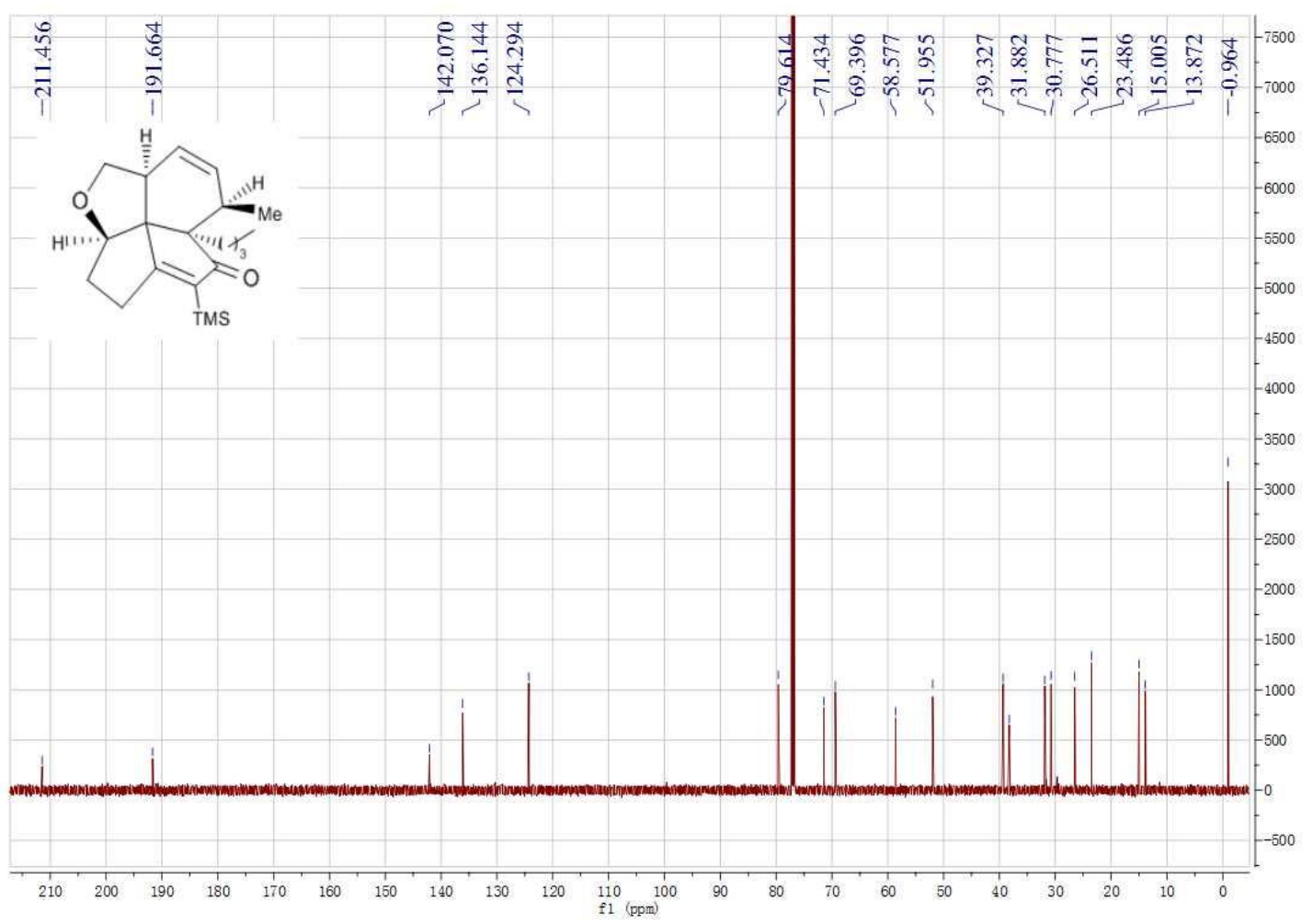




\section{Compound $4 \mathrm{e}$}

${ }^{1} \mathrm{H}$ NMR of $4 \mathbf{e}$

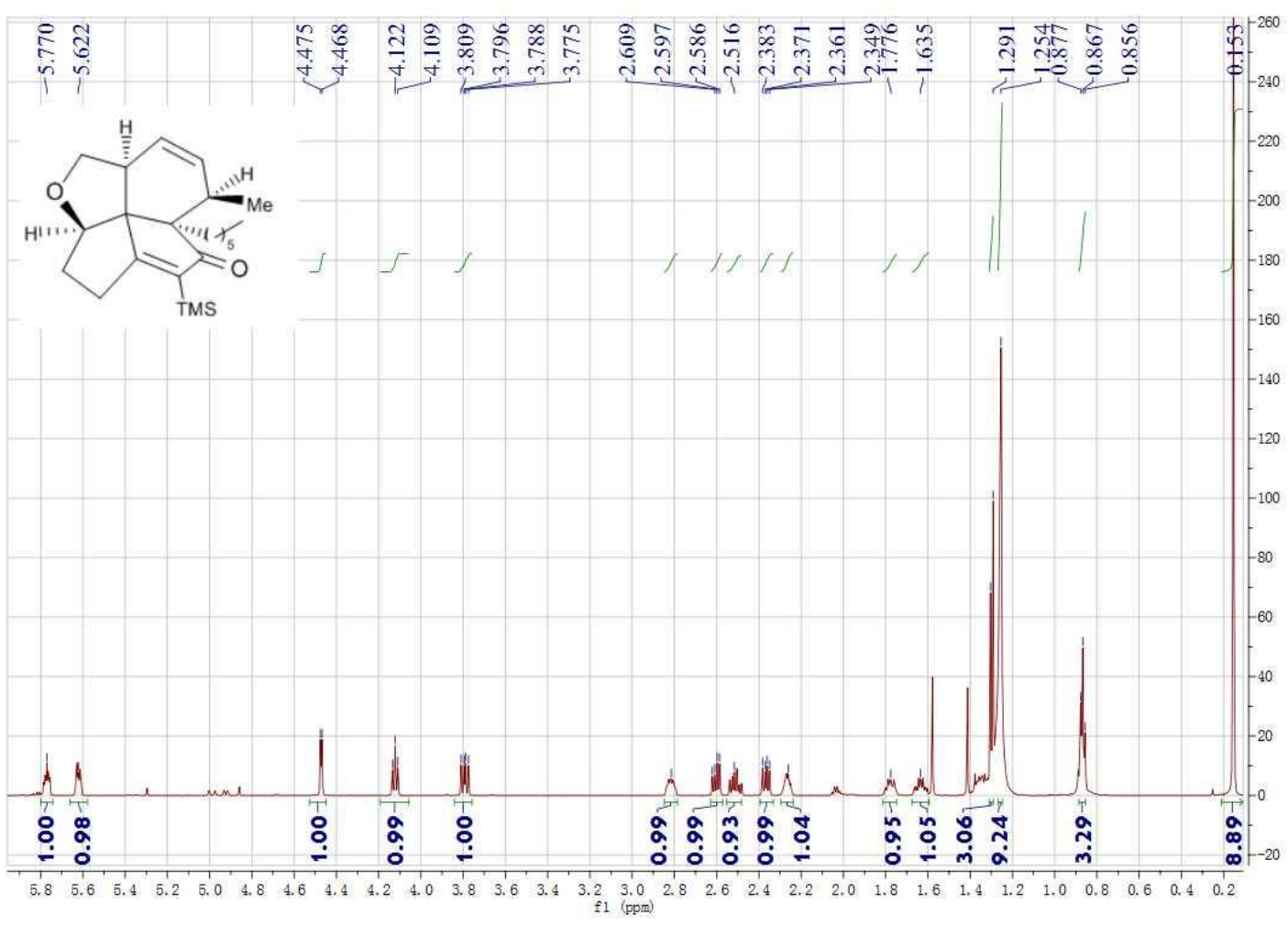

${ }^{13} \mathrm{C}$ NMR of $4 e$

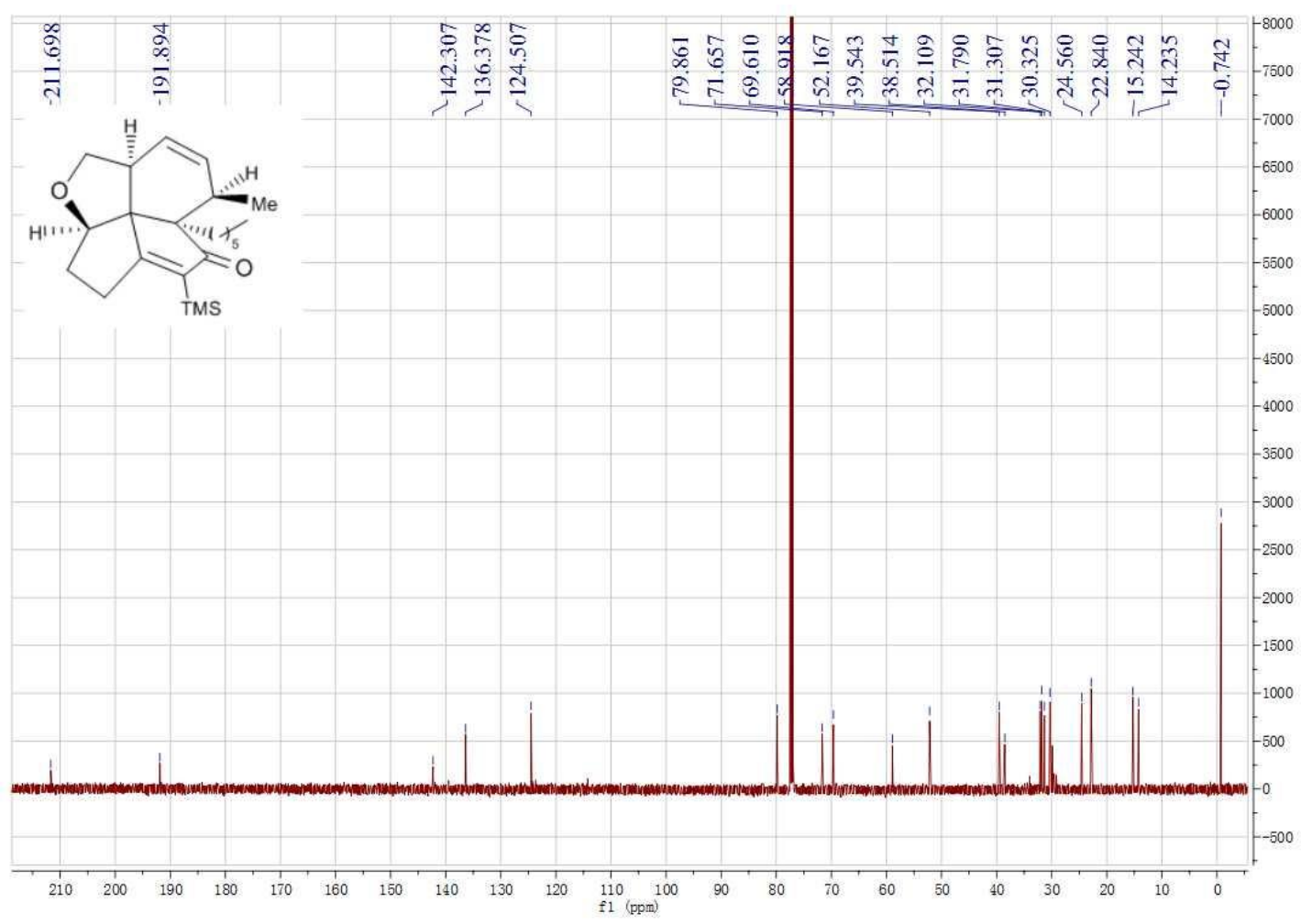




\section{Compound 4f}

${ }^{1} \mathrm{H}$ NMR of $\mathbf{4 f}$

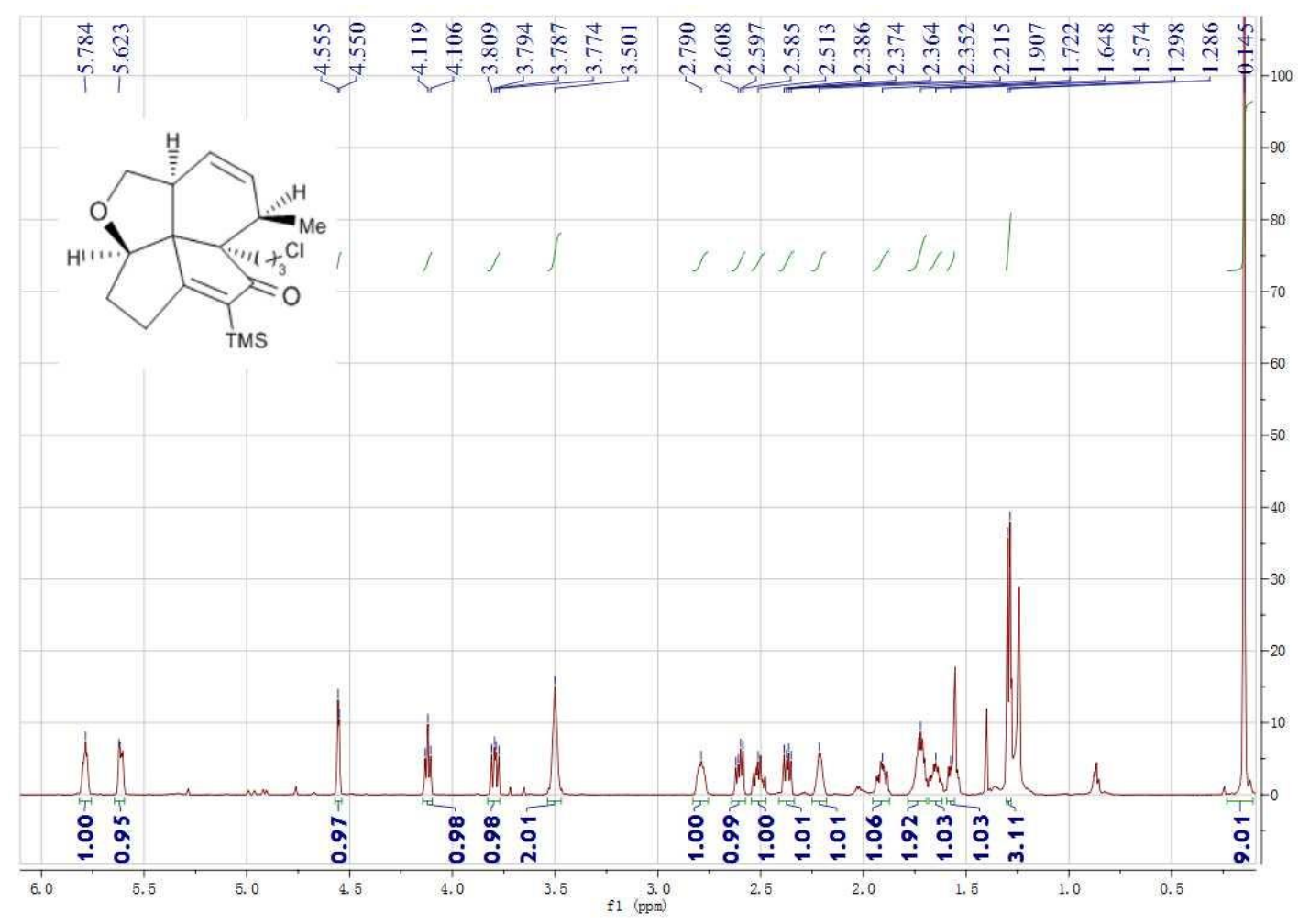

${ }^{13} \mathrm{C}$ NMR of $\mathbf{4 f}$

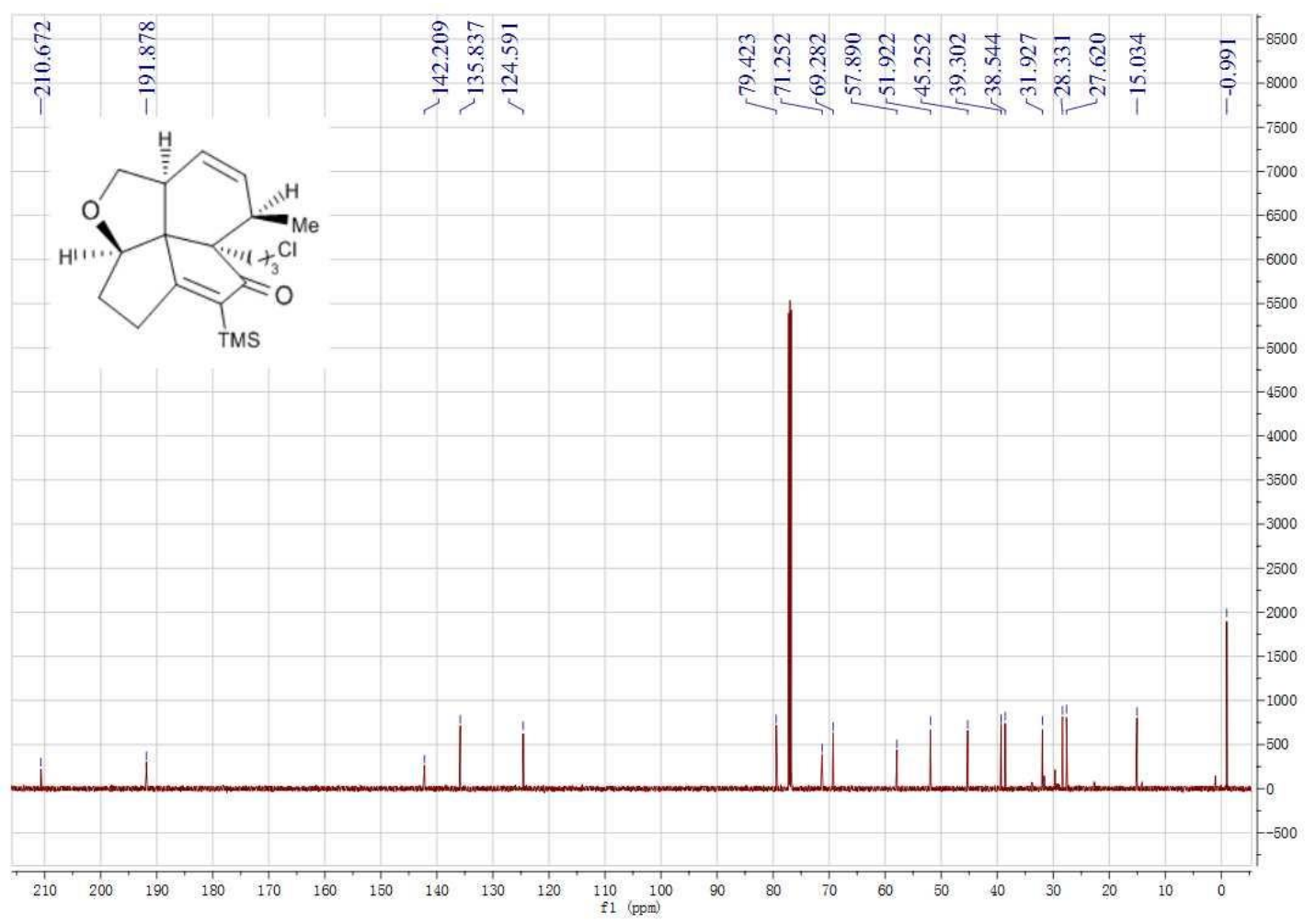




\section{Compound 4g}

${ }^{1} \mathrm{H}$ NMR of $\mathbf{4 g}$

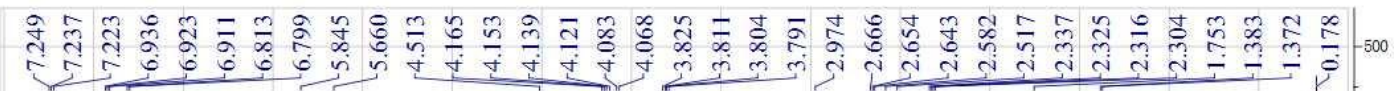

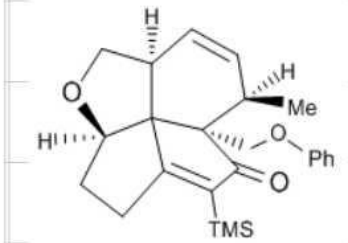

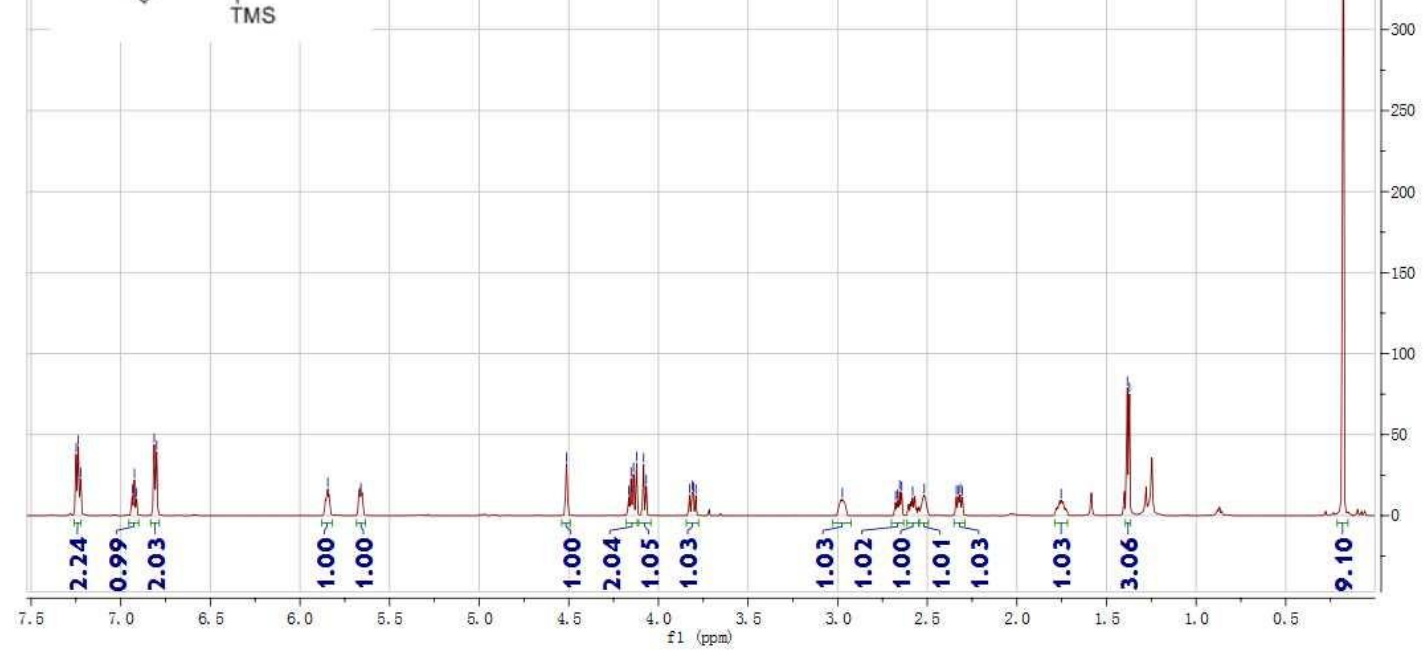

${ }^{13} \mathrm{C}$ NMR of $4 \mathbf{g}$
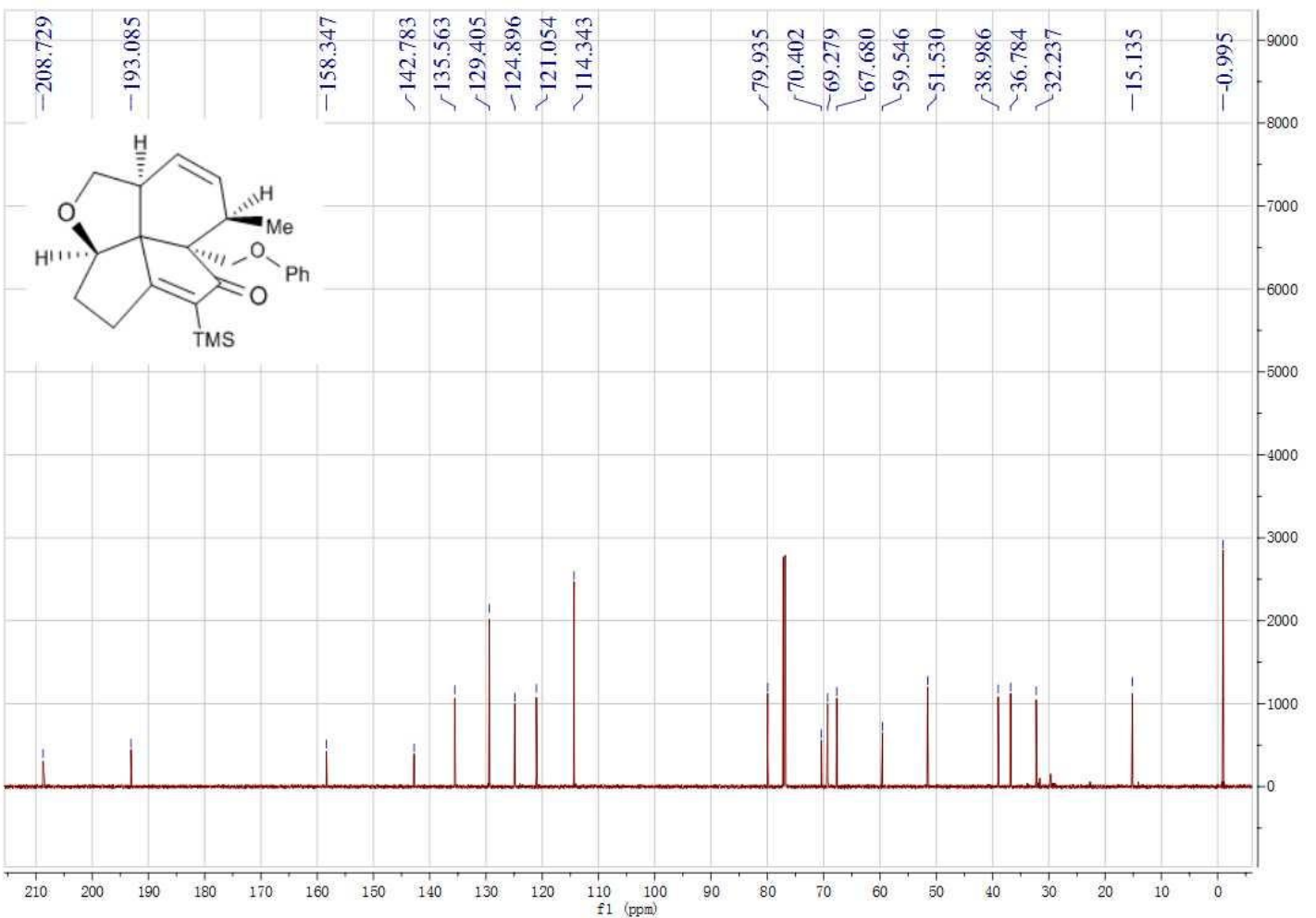
Additional Dienediyne Substrates and PK Product

Compound 3i

${ }^{1} \mathrm{H}$ NMR of $\mathbf{3 i}$

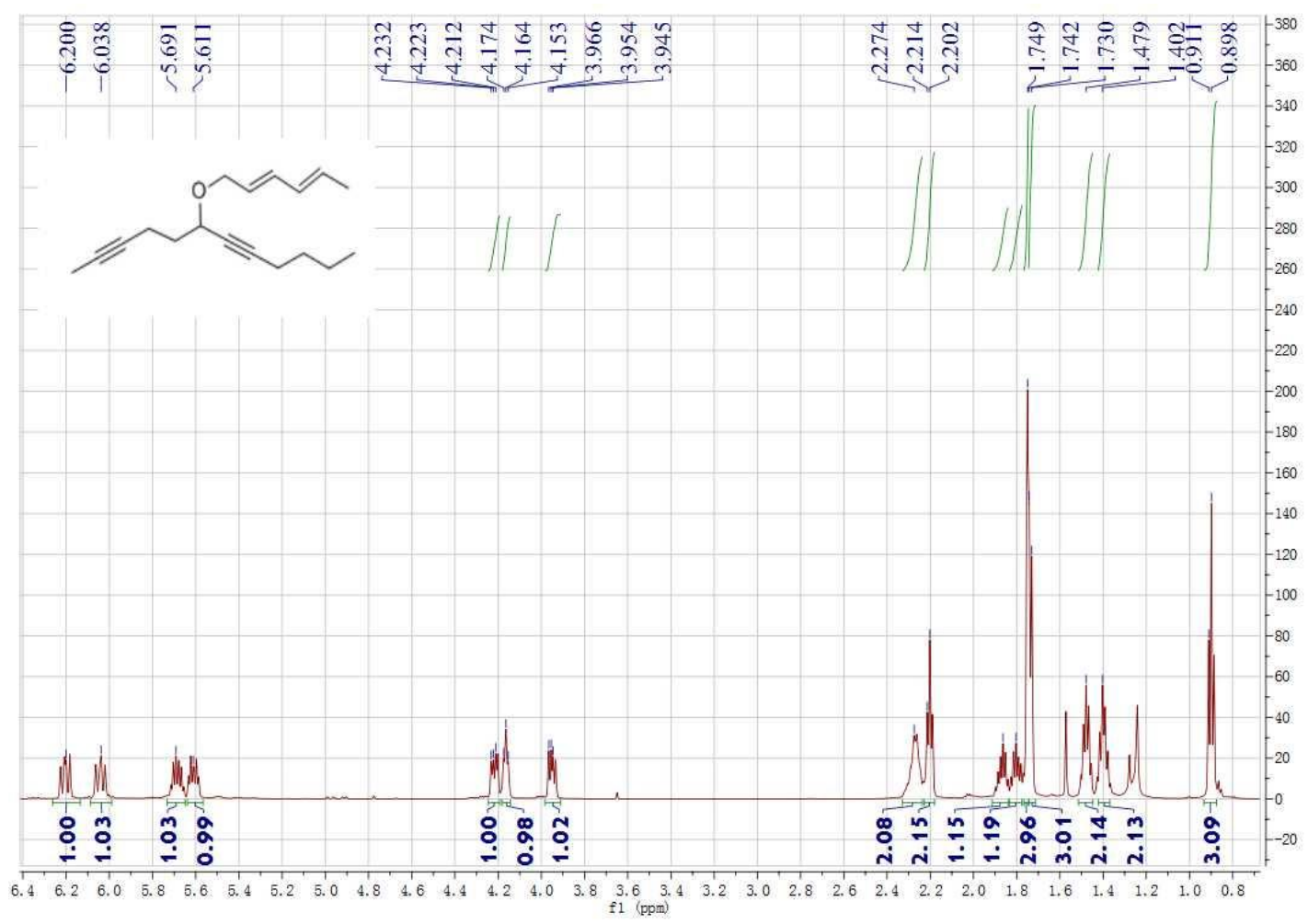

${ }^{13} \mathrm{C}$ NMR of $\mathbf{3 i}$

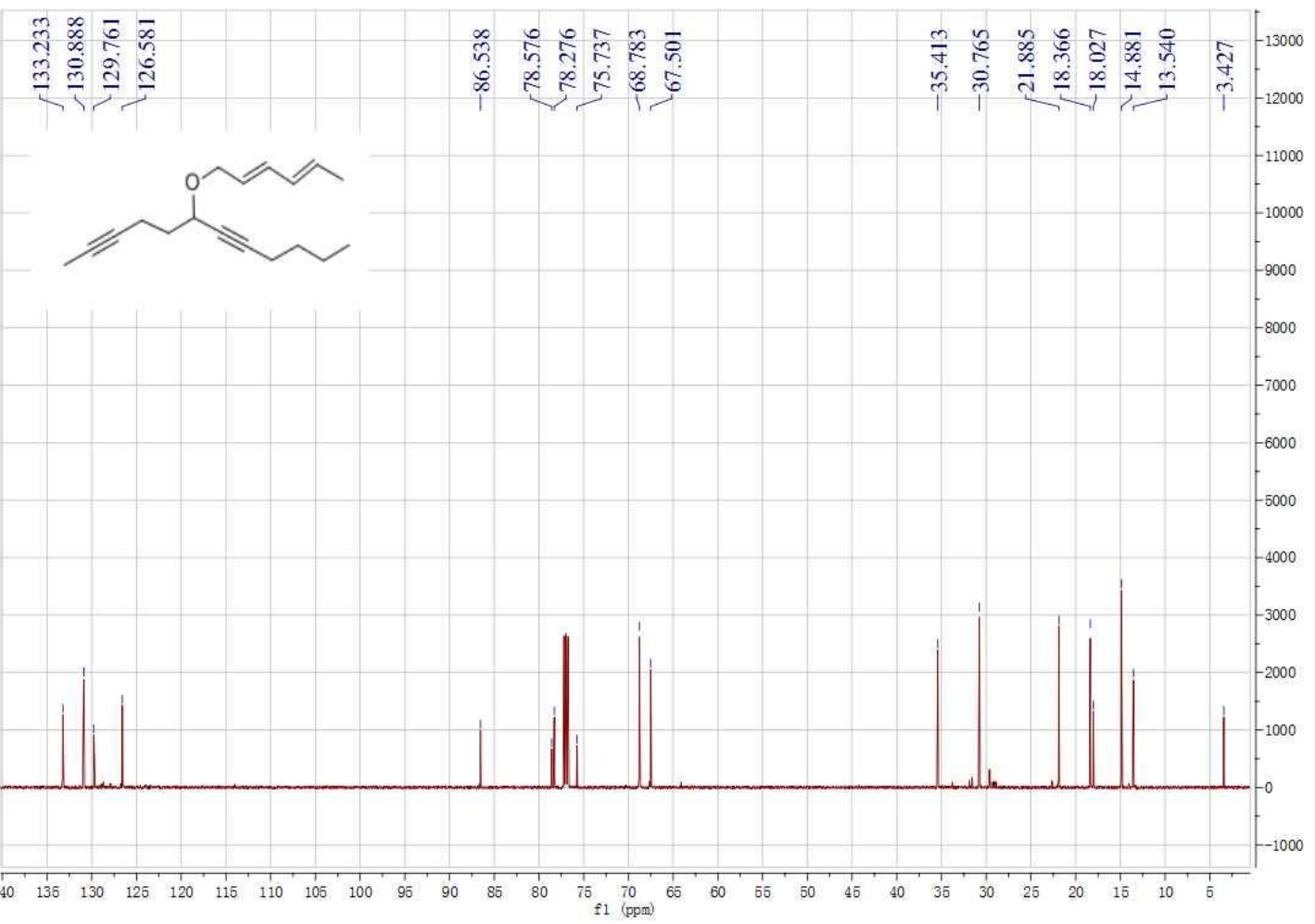


The mixture of two diastereomers in about 1.6:1 from PK-DA reaction of $\mathbf{3 i}$

HRMS [ESI(TOF)] for $\mathrm{C}_{19} \mathrm{H}_{27} \mathrm{O}_{2}\left[\mathrm{M}+\mathrm{H}^{+}\right]$: m/z: calcd for: 287.2011; found: 287.2014. ${ }^{1} \mathrm{H}$ NMR of two diastereomers

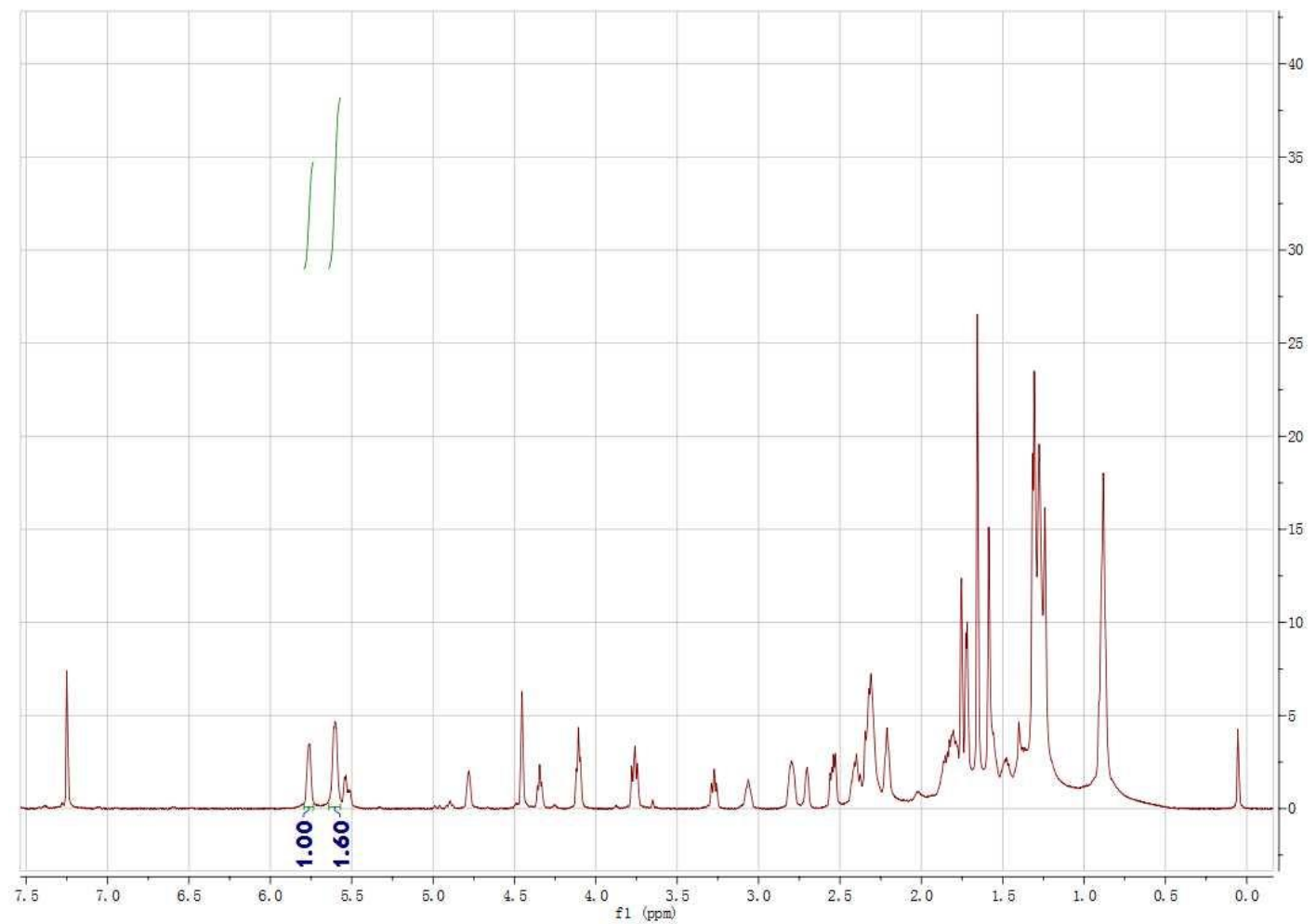

${ }^{13} \mathrm{C}$ NMR of two diastereomers

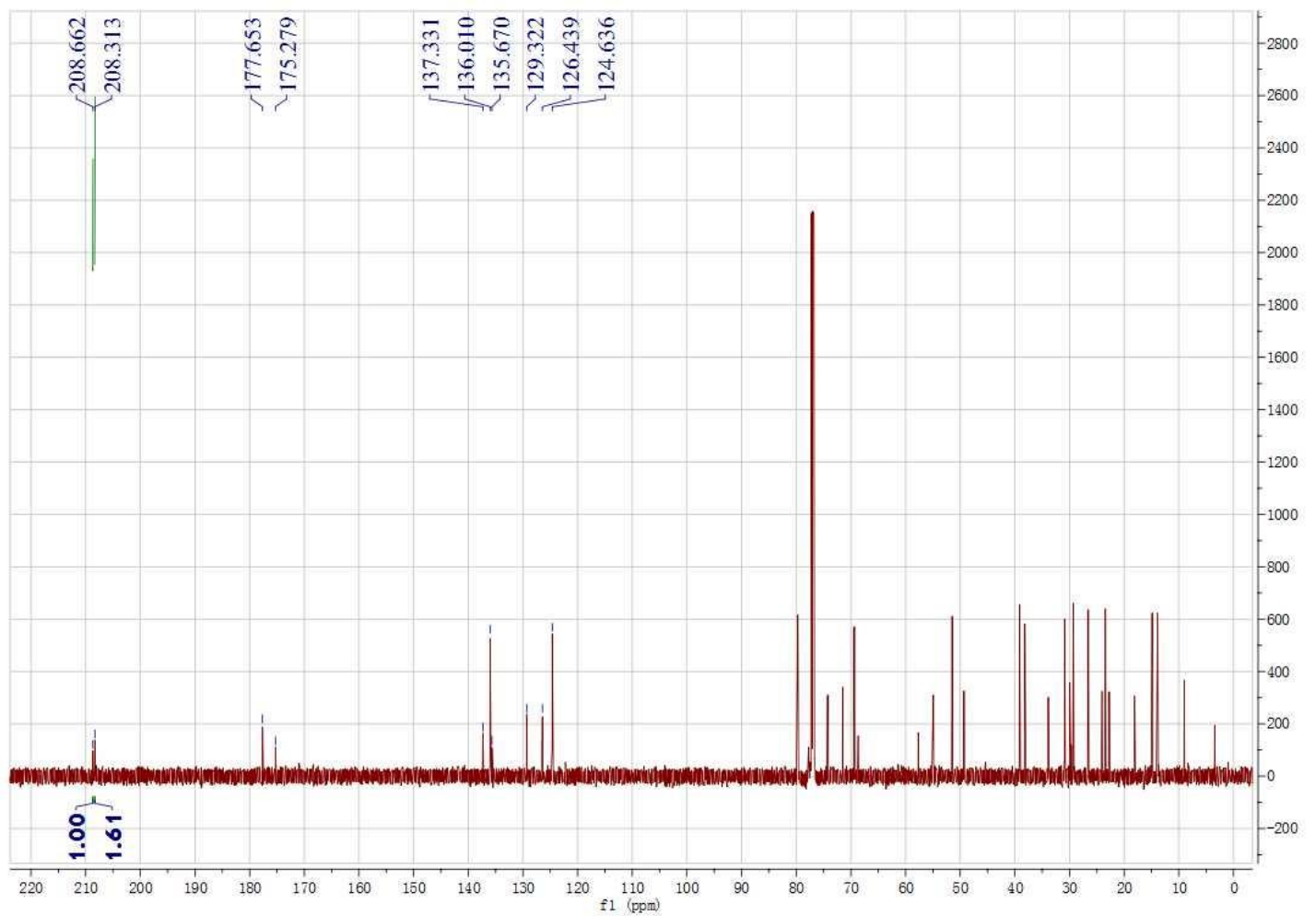




\section{Compound 3j}

${ }^{1} \mathrm{H}$ NMR of $\mathbf{3 j}$

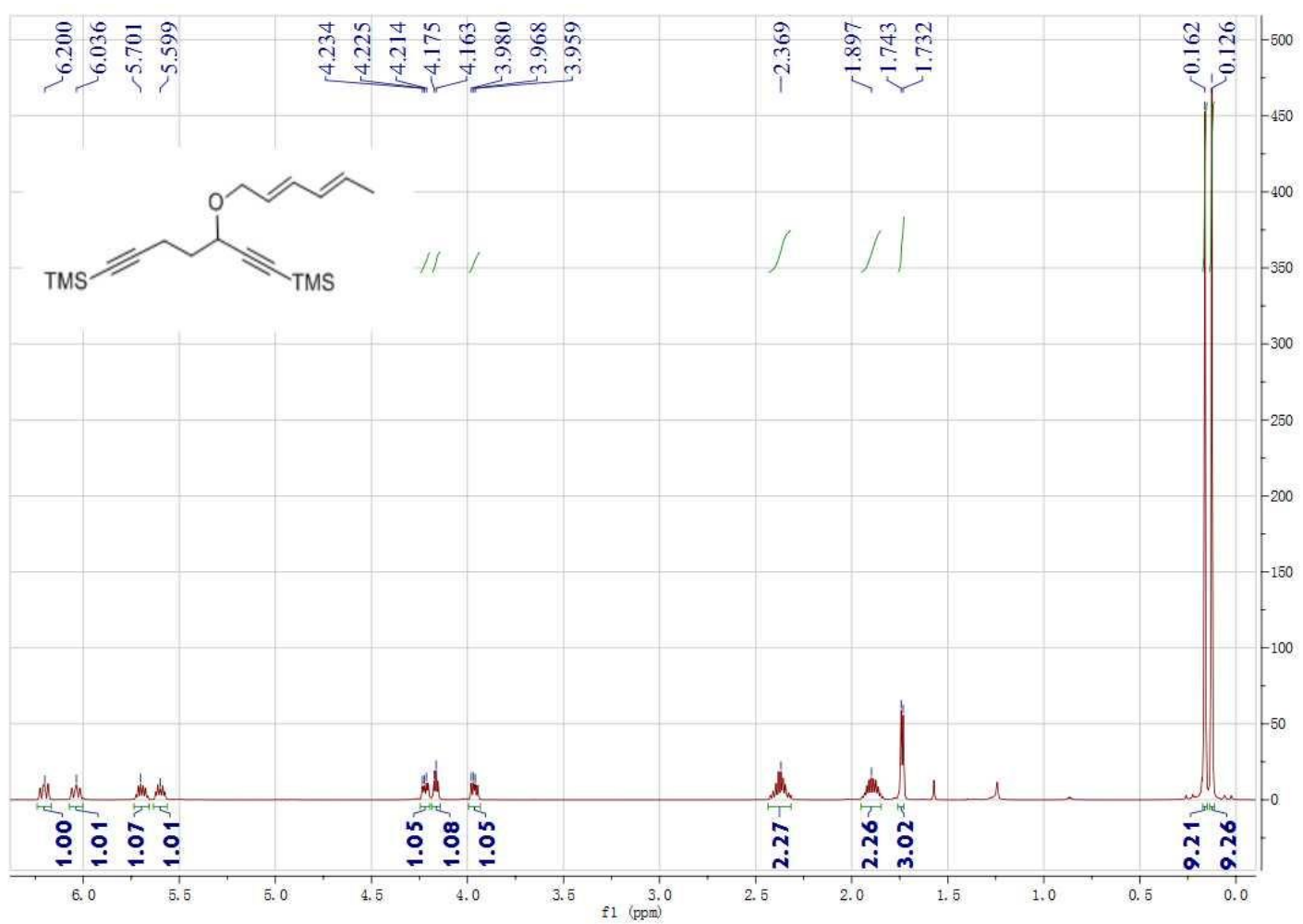

${ }^{13} \mathrm{C}$ NMR of $\mathbf{3 j}$

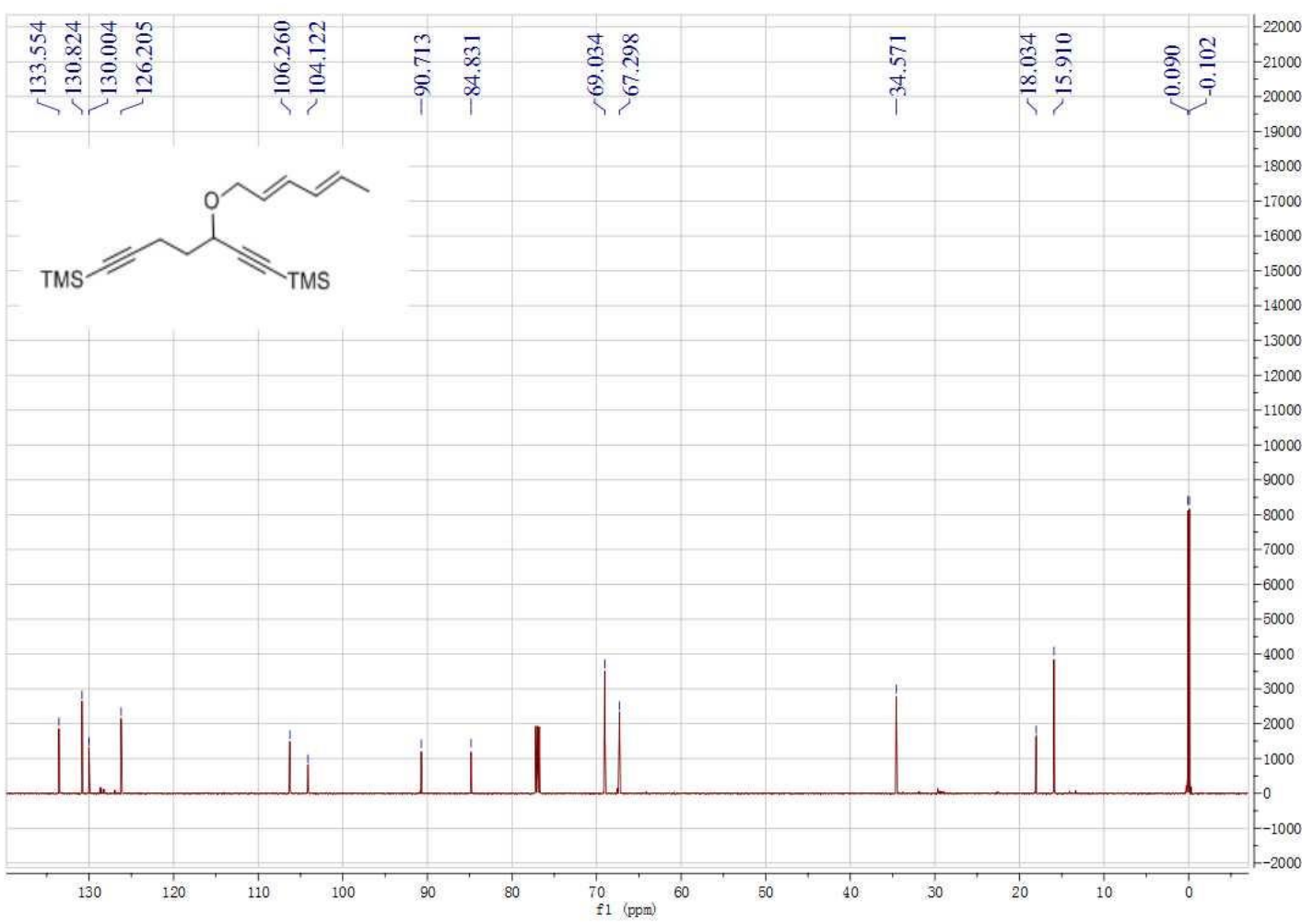




\section{Compound 4j}

${ }^{1} \mathrm{H}$ NMR of $\mathbf{4 j}$

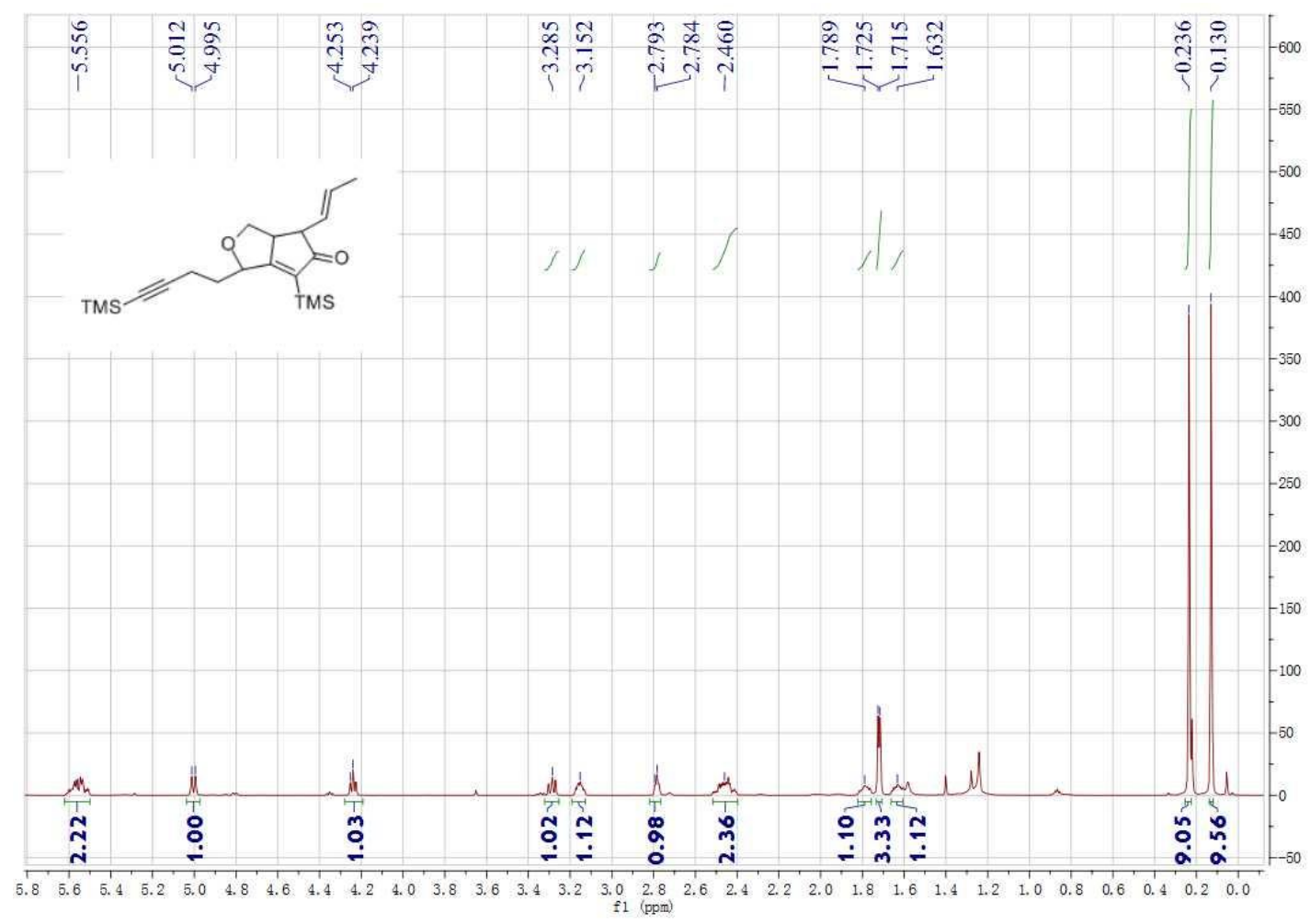

${ }^{13} \mathrm{C}$ NMR of $4 \mathbf{j}$

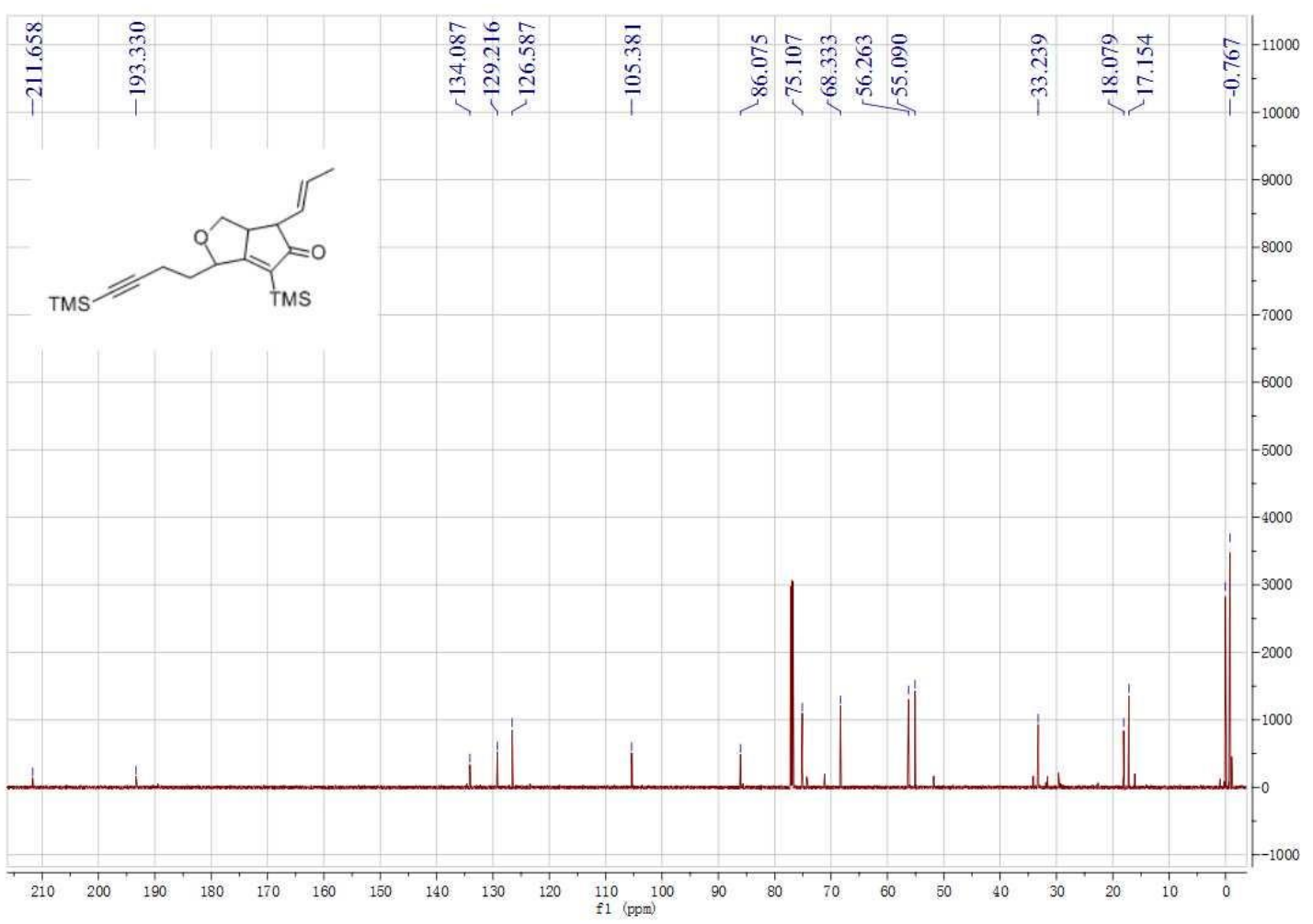


${ }^{1} \mathrm{H}$ NMR signal assignments of compound 4a

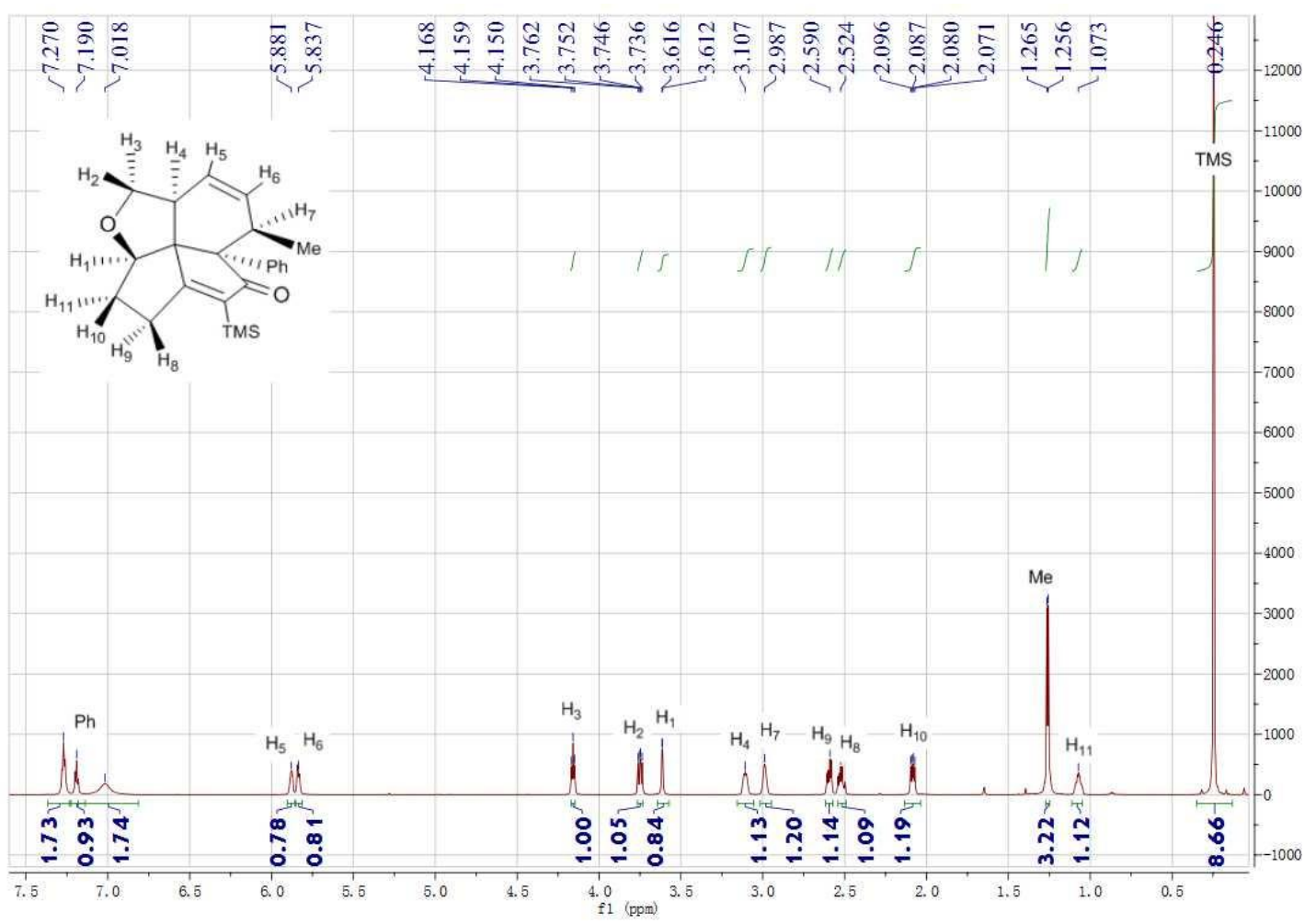

Comparison of DEPT-135 and ${ }^{13} \mathrm{C}$ NMR of compound $4 \mathbf{a}$

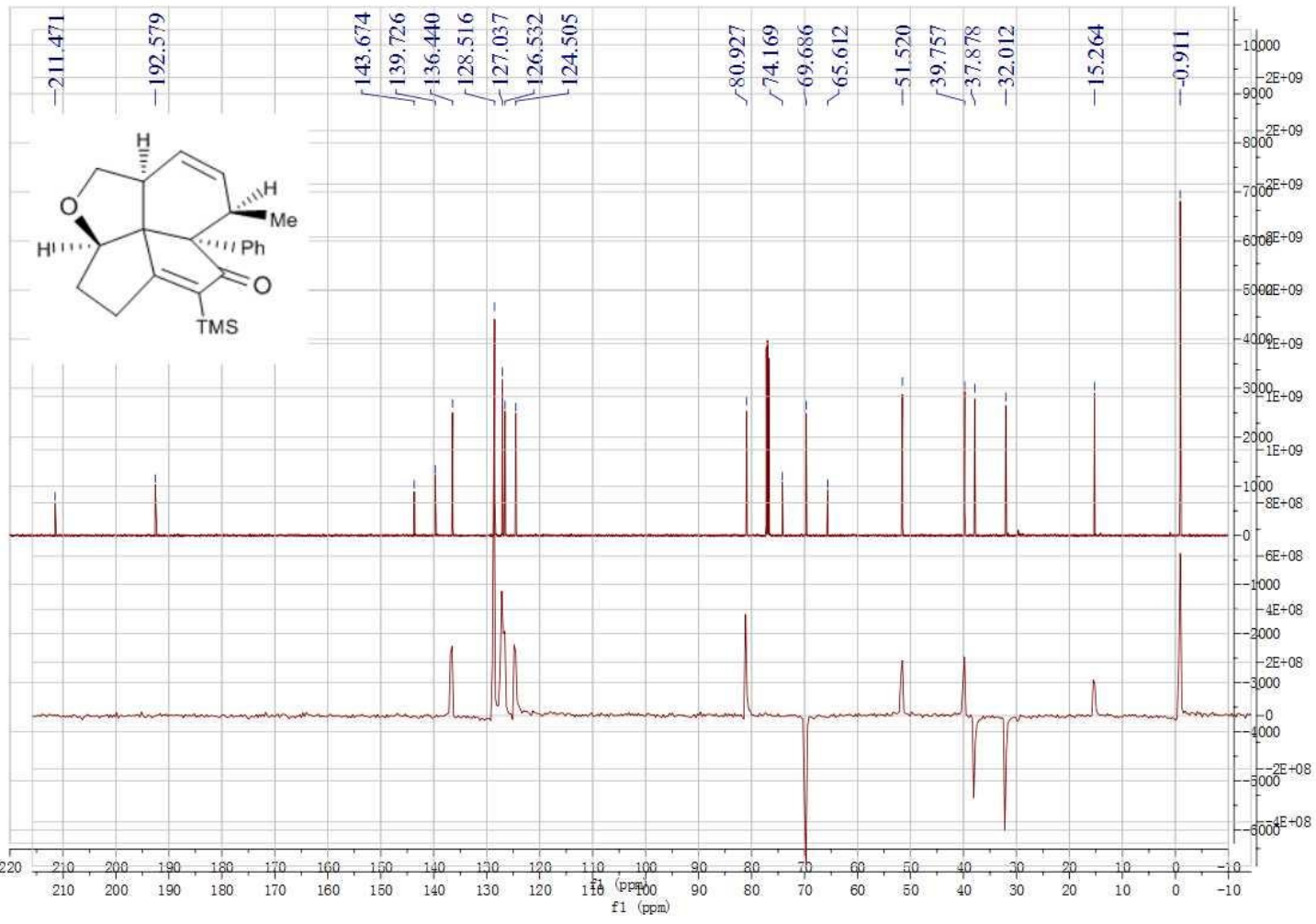


HSQC spectra of compound $\mathbf{4 a}$

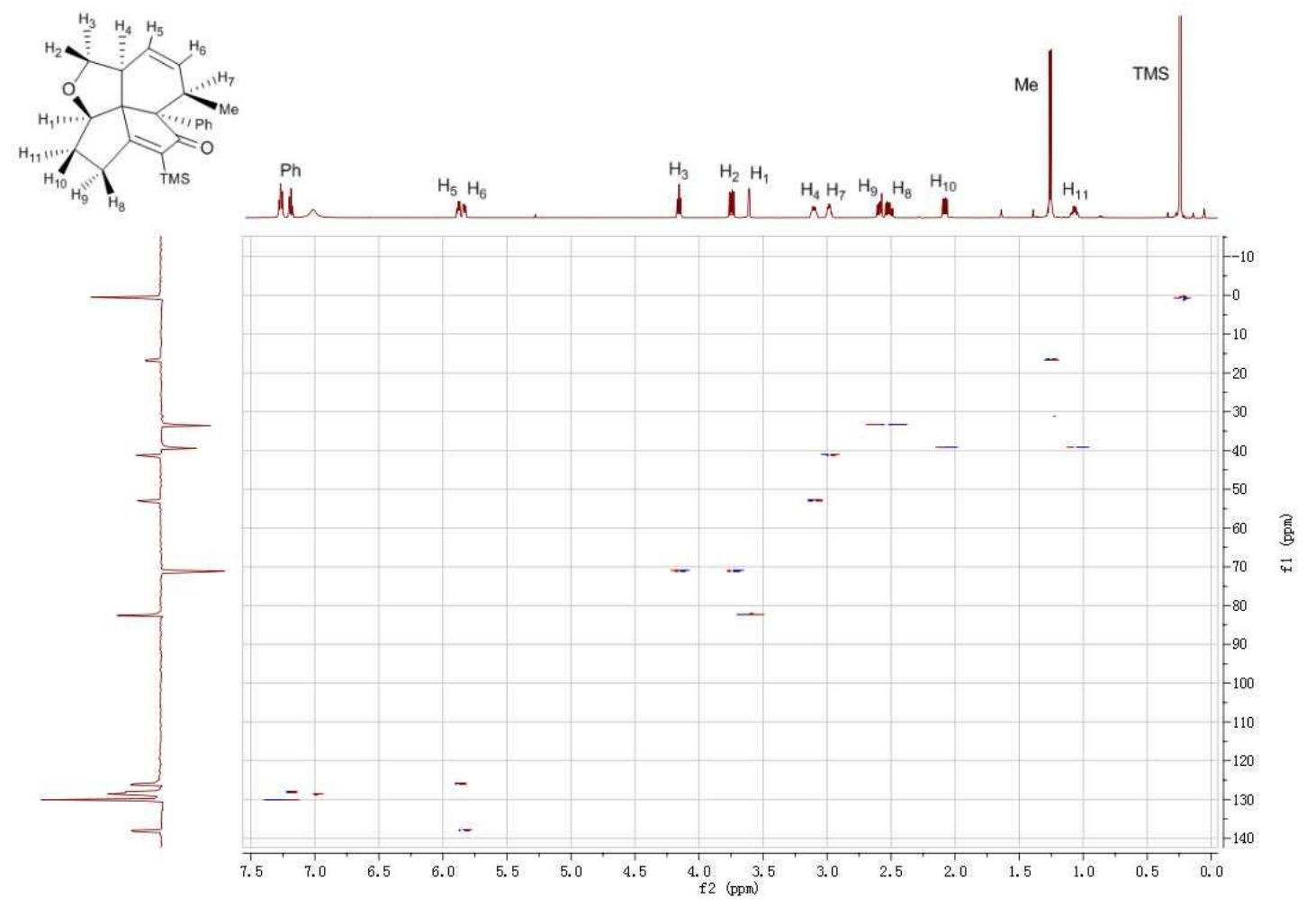

COSY spectra of compound $\mathbf{4 a}$

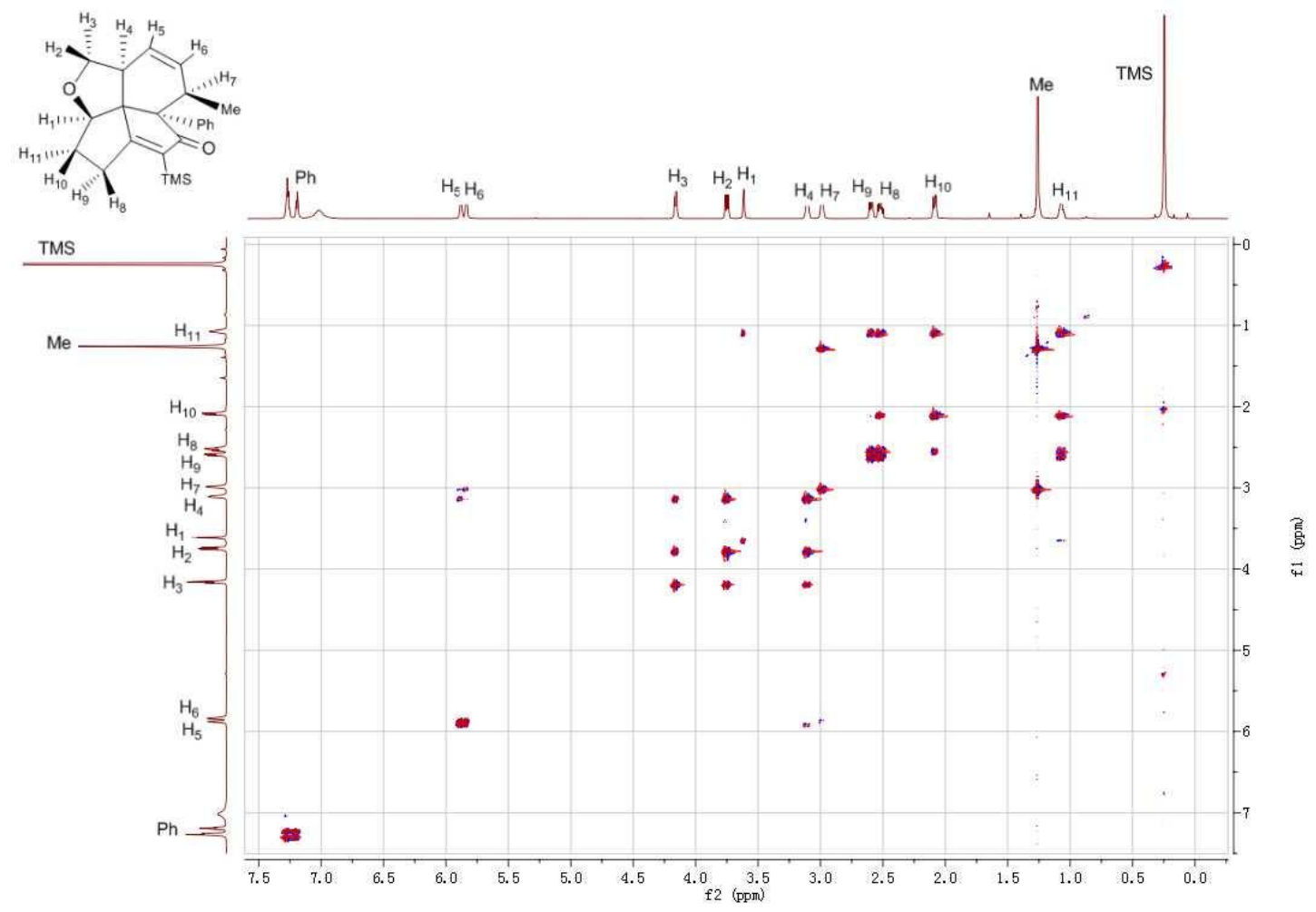


NOSEY spectra of compound $\mathbf{4 a}$

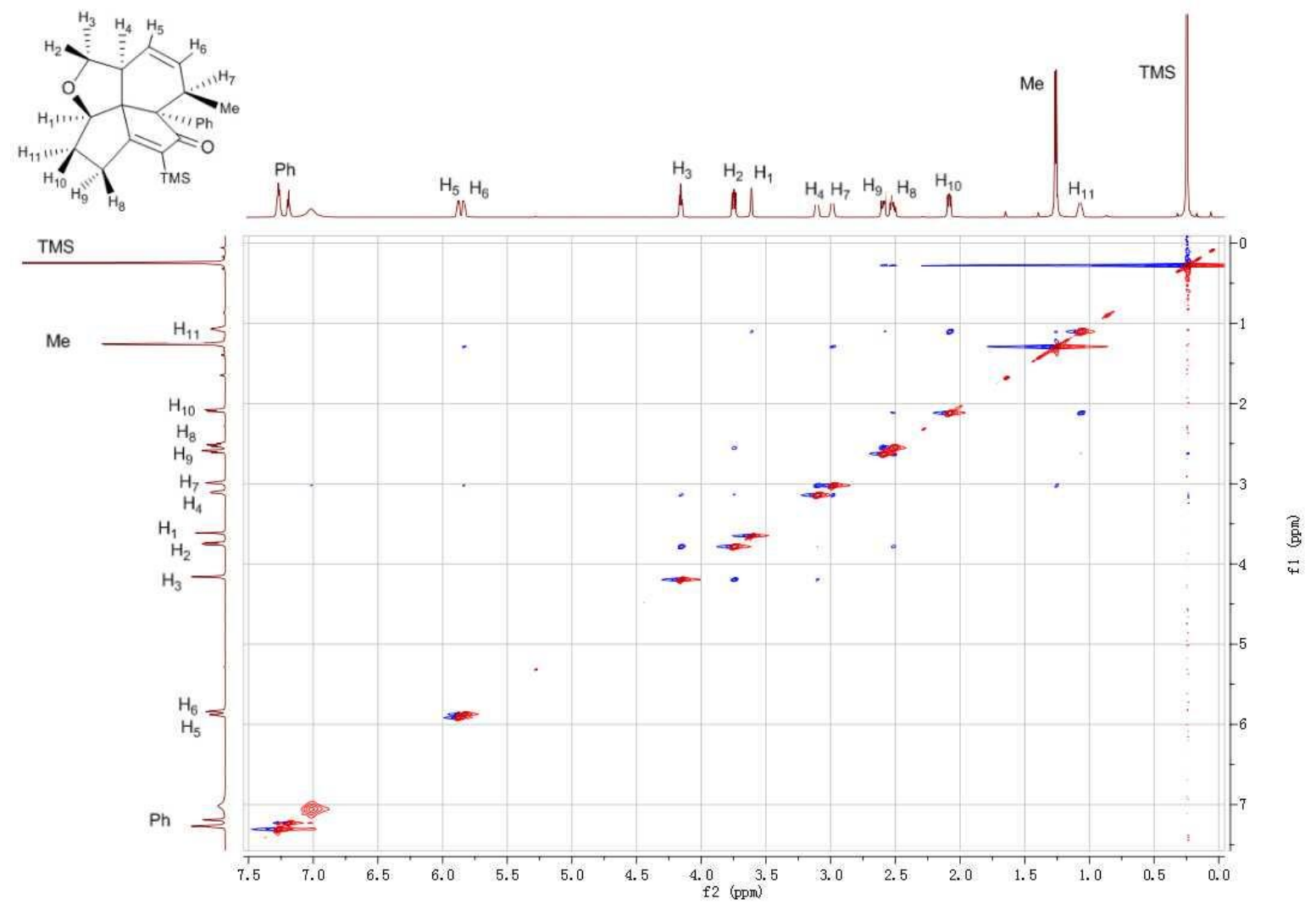

Signal enhanced NOSEY spectra of compound 4a

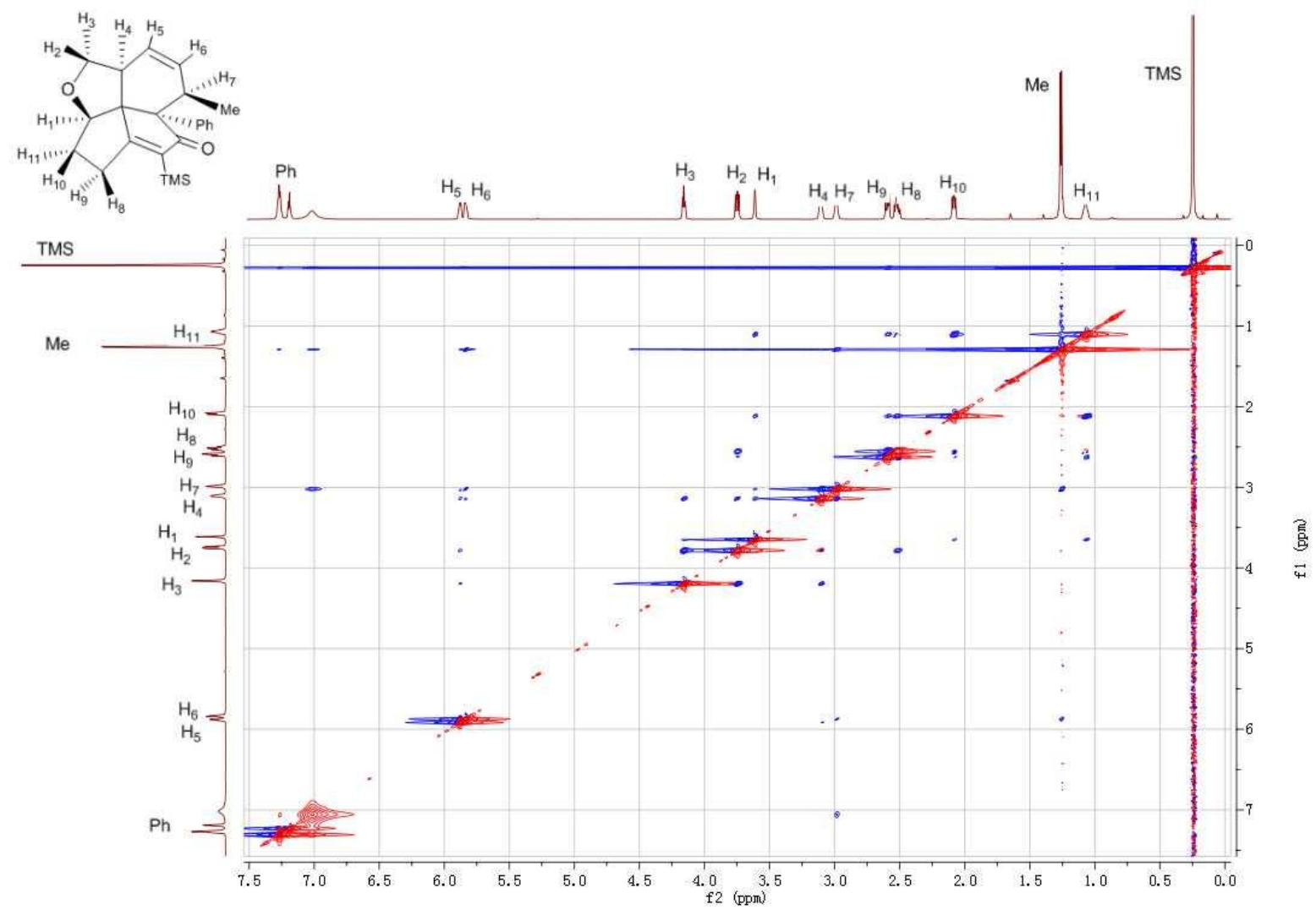




\section{X-Ray Analysis Data of Compound 4d}

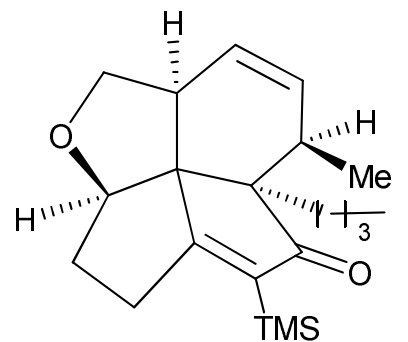

4d

Table 1. Crystallographic data for $\mathrm{C} 21 \mathrm{H} 32 \mathrm{O} 2 \mathrm{Si}$

Empirical formula

Formula weight

Temperature

Wavelength

Crystal system

Space group

Unit cell dimensions

Volume

$\mathrm{Z}$

Density (calculated)

Absorption coefficient

$\mathrm{F}(000)$

Crystal size

Theta range for data collection

Index ranges

Reflections collected

Independent reflections

Completeness to theta $=25.242^{\circ}$

Absorption correction

Refinement method

Data / restraints / parameters

Goodness-of-fit on $\mathrm{F}^{2}$

Final $\mathrm{R}$ indices $[\mathrm{I}>2 \operatorname{sigma}(\mathrm{I})]$

$\mathrm{R}$ indices (all data)

Largest diff. peak and hole
C21 H32 O2 Si

344.55

153(2) K

$0.71073 \AA$

Triclinic

P-1

$$
\begin{array}{ll}
\mathrm{a}=8.0904(10) \AA & \alpha=82.598(2)^{\circ} . \\
\mathrm{b}=9.9920(12) \AA & \beta=87.292(2)^{\circ} . \\
\mathrm{c}=13.4675(16) \AA & \gamma=68.4661(19)^{\circ} .
\end{array}
$$

1004.3(2) $\AA^{3}$

2

$1.139 \mathrm{Mg} / \mathrm{m}^{3}$

$0.127 \mathrm{~mm}^{-1}$

376

$0.460 \times 0.440 \times 0.380 \mathrm{~mm}^{3}$

3.314 to $35.718^{\circ}$.

$-12<=\mathrm{h}<=12,-16<=\mathrm{k}<=16,-22<=\mathrm{l}<=21$

24483

$8925[\mathrm{R}(\mathrm{int})=0.0204]$

$99.5 \%$

Empirical

Full-matrix least-squares on $\mathrm{F}^{2}$

8925 / 0 / 222

0.984

$\mathrm{R} 1=0.0638, \mathrm{wR} 2=0.1811$

$\mathrm{R} 1=0.0767, \mathrm{wR} 2=0.1976$

0.943 and -0.711 e. $\AA^{-3}$ 
Table 2. Atomic coodanates ( $\left.\times 10^{4}\right)$ and equivalent isotropic displacement parameters $\left(\AA^{2} \times 10^{3}\right)$ for $\mathrm{C} 21 \mathrm{H} 32 \mathrm{O} 2 \mathrm{Si}$. $\mathrm{U}(\mathrm{eq})$ is defined as one third of the trace of the orthogonalized $\mathrm{U}^{\mathrm{ij}}$ tensor.

\begin{tabular}{|c|c|c|c|c|}
\hline & $\mathrm{x}$ & $\mathrm{y}$ & $\mathrm{z}$ & $\mathrm{U}(\mathrm{eq})$ \\
\hline $\operatorname{Si}(1)$ & 8101(1) & $3872(1)$ & 1821(1) & $42(1)$ \\
\hline $\mathrm{O}(1)$ & 6037(1) & $-1302(1)$ & $1262(1)$ & $46(1)$ \\
\hline $\mathrm{O}(2)$ & $10117(2)$ & $1285(1)$ & $3534(1)$ & $60(1)$ \\
\hline $\mathrm{C}(1)$ & 7911(1) & $-378(1)$ & 2095(1) & $24(1)$ \\
\hline $\mathrm{C}(2)$ & 8943(2) & $-1516(1)$ & $1385(1)$ & $32(1)$ \\
\hline$C(3)$ & 10716(2) & $-1435(1)$ & $1110(1)$ & $38(1)$ \\
\hline $\mathrm{C}(4)$ & $11738(2)$ & $-1557(1)$ & $1890(1)$ & $38(1)$ \\
\hline$C(5)$ & $11007(2)$ & $-1748(1)$ & 2931(1) & $33(1)$ \\
\hline $\mathrm{C}(6)$ & 9110(1) & $-545(1)$ & $3020(1)$ & $26(1)$ \\
\hline $\mathrm{C}(7)$ & 9342(2) & $935(1)$ & 2922(1) & $32(1)$ \\
\hline $\mathrm{C}(8)$ & $8318(2)$ & $1919(1)$ & $2067(1)$ & $31(1)$ \\
\hline $\mathrm{C}(9)$ & 7414(2) & 1212(1) & $1674(1)$ & $28(1)$ \\
\hline $\mathrm{C}(10)$ & $5625(2)$ & 1797(1) & $1177(1)$ & $41(1)$ \\
\hline $\mathrm{C}(11)$ & 4680(2) & $986(2)$ & 1907(1) & $44(1)$ \\
\hline$C(12)$ & $6055(2)$ & $-541(1)$ & $2107(1)$ & $34(1)$ \\
\hline$C(13)$ & $7556(2)$ & $-1421(2)$ & $641(1)$ & $43(1)$ \\
\hline$C(14)$ & $12324(2)$ & $-1864(2)$ & $3751(1)$ & $51(1)$ \\
\hline$C(15)$ & $8216(2)$ & $-748(1)$ & $4032(1)$ & $33(1)$ \\
\hline$C(16)$ & $8180(2)$ & $-2260(2)$ & $4354(1)$ & $40(1)$ \\
\hline $\mathrm{C}(17)$ & 6891(3) & $-2271(2)$ & $5206(1)$ & $60(1)$ \\
\hline$C(18)$ & 6898(5) & $-3777(4)$ & $5577(2)$ & 101(1) \\
\hline$C(19)$ & $7479(6)$ & $4550(3)$ & $474(3)$ & $123(2)$ \\
\hline $\mathrm{C}(20)$ & 10283(3) & $4012(2)$ & 1947(3) & $95(1)$ \\
\hline$C(21)$ & 6473(7) & 4955(3) & 2643(4) & $177(3)$ \\
\hline
\end{tabular}


Table 3. Bond lengths and angles for $\mathrm{C} 21 \mathrm{H} 32 \mathrm{O} 2 \mathrm{Si}$.

\begin{tabular}{|c|c|}
\hline $\mathrm{Si}(1)-\mathrm{C}(21)$ & $1.804(3)$ \\
\hline $\operatorname{Si}(1)-C(20)$ & $1.839(2)$ \\
\hline $\mathrm{Si}(1)-\mathrm{C}(19)$ & $1.877(3)$ \\
\hline $\mathrm{Si}(1)-\mathrm{C}(8)$ & $1.8808(11)$ \\
\hline $\mathrm{O}(1)-\mathrm{C}(13)$ & $1.4310(19)$ \\
\hline $\mathrm{O}(1)-\mathrm{C}(12)$ & $1.4512(16)$ \\
\hline $\mathrm{O}(2)-\mathrm{C}(7)$ & $1.2165(14)$ \\
\hline$C(1)-C(9)$ & $1.5254(14)$ \\
\hline $\mathrm{C}(1)-\mathrm{C}(2)$ & $1.5533(14)$ \\
\hline$C(1)-C(12)$ & $1.5675(15)$ \\
\hline$C(1)-C(6)$ & $1.5689(14)$ \\
\hline $\mathrm{C}(2)-\mathrm{C}(3)$ & $1.4931(17)$ \\
\hline$C(2)-C(13)$ & $1.5092(18)$ \\
\hline $\mathrm{C}(3)-\mathrm{C}(4)$ & $1.3329(19)$ \\
\hline$C(4)-C(5)$ & $1.5125(17)$ \\
\hline$C(5)-C(14)$ & $1.5346(19)$ \\
\hline$C(5)-C(6)$ & $1.5745(15)$ \\
\hline$C(6)-C(15)$ & $1.5380(15)$ \\
\hline$C(6)-C(7)$ & $1.5465(14)$ \\
\hline $\mathrm{C}(7)-\mathrm{C}(8)$ & $1.4762(15)$ \\
\hline $\mathrm{C}(8)-\mathrm{C}(9)$ & $1.3514(15)$ \\
\hline $\mathrm{C}(9)-\mathrm{C}(10)$ & $1.5017(16)$ \\
\hline$C(10)-C(11)$ & $1.546(2)$ \\
\hline $\mathrm{C}(11)-\mathrm{C}(12)$ & $1.5216(19)$ \\
\hline$C(15)-C(16)$ & $1.5279(18)$ \\
\hline$C(16)-C(17)$ & $1.516(2)$ \\
\hline$C(17)-C(18)$ & $1.521(3)$ \\
\hline$C(21)-S i(1)-C(20)$ & 111.7(2) \\
\hline$C(21)-\operatorname{Si}(1)-C(19)$ & $111.0(3)$ \\
\hline$C(20)-\operatorname{Si}(1)-C(19)$ & $104.47(18)$ \\
\hline $\mathrm{C}(21)-\mathrm{Si}(1)-\mathrm{C}(8)$ & $110.81(11)$ \\
\hline $\mathrm{C}(20)-\mathrm{Si}(1)-\mathrm{C}(8)$ & $109.76(8)$ \\
\hline $\mathrm{C}(19)-\mathrm{Si}(1)-\mathrm{C}(8)$ & $108.94(10)$ \\
\hline $\mathrm{C}(13)-\mathrm{O}(1)-\mathrm{C}(12)$ & $110.19(9)$ \\
\hline $\mathrm{C}(9)-\mathrm{C}(1)-\mathrm{C}(2)$ & $116.62(8)$ \\
\hline $\mathrm{C}(9)-\mathrm{C}(1)-\mathrm{C}(12)$ & $101.12(8)$ \\
\hline
\end{tabular}




\begin{tabular}{|c|c|}
\hline $\mathrm{C}(2)-\mathrm{C}(1)-\mathrm{C}(12)$ & $99.97(8)$ \\
\hline$C(9)-C(1)-C(6)$ & $103.38(7)$ \\
\hline $\mathrm{C}(2)-\mathrm{C}(1)-\mathrm{C}(6)$ & $109.22(8)$ \\
\hline $\mathrm{C}(12)-\mathrm{C}(1)-\mathrm{C}(6)$ & $127.28(8)$ \\
\hline $\mathrm{C}(3)-\mathrm{C}(2)-\mathrm{C}(13)$ & $124.53(11)$ \\
\hline$C(3)-C(2)-C(1)$ & $111.53(9)$ \\
\hline $\mathrm{C}(13)-\mathrm{C}(2)-\mathrm{C}(1)$ & $103.75(10)$ \\
\hline $\mathrm{C}(4)-\mathrm{C}(3)-\mathrm{C}(2)$ & $114.34(11)$ \\
\hline$C(3)-C(4)-C(5)$ & $118.23(11)$ \\
\hline$C(4)-C(5)-C(14)$ & $112.34(11)$ \\
\hline$C(4)-C(5)-C(6)$ & 109.65(9) \\
\hline$C(14)-C(5)-C(6)$ & $114.77(10)$ \\
\hline$C(15)-C(6)-C(7)$ & $108.16(9)$ \\
\hline$C(15)-C(6)-C(1)$ & $113.41(9)$ \\
\hline$C(7)-C(6)-C(1)$ & $102.64(7)$ \\
\hline $\mathrm{C}(15)-\mathrm{C}(6)-\mathrm{C}(5)$ & $112.57(8)$ \\
\hline$C(7)-C(6)-C(5)$ & $107.62(9)$ \\
\hline$C(1)-C(6)-C(5)$ & 111.73(8) \\
\hline $\mathrm{O}(2)-\mathrm{C}(7)-\mathrm{C}(8)$ & $124.57(10)$ \\
\hline $\mathrm{O}(2)-\mathrm{C}(7)-\mathrm{C}(6)$ & $123.77(10)$ \\
\hline$C(8)-C(7)-C(6)$ & $111.24(9)$ \\
\hline $\mathrm{C}(9)-\mathrm{C}(8)-\mathrm{C}(7)$ & $106.59(9)$ \\
\hline$C(9)-C(8)-S i(1)$ & $130.20(8)$ \\
\hline$C(7)-C(8)-S i(1)$ & $122.23(8)$ \\
\hline $\mathrm{C}(8)-\mathrm{C}(9)-\mathrm{C}(10)$ & $129.75(10)$ \\
\hline $\mathrm{C}(8)-\mathrm{C}(9)-\mathrm{C}(1)$ & 115.21(9) \\
\hline $\mathrm{C}(10)-\mathrm{C}(9)-\mathrm{C}(1)$ & $111.31(9)$ \\
\hline $\mathrm{C}(9)-\mathrm{C}(10)-\mathrm{C}(11)$ & $98.45(10)$ \\
\hline $\mathrm{C}(12)-\mathrm{C}(11)-\mathrm{C}(10)$ & $103.98(10)$ \\
\hline $\mathrm{O}(1)-\mathrm{C}(12)-\mathrm{C}(11)$ & $107.73(10)$ \\
\hline $\mathrm{O}(1)-\mathrm{C}(12)-\mathrm{C}(1)$ & 106.61(9) \\
\hline $\mathrm{C}(11)-\mathrm{C}(12)-\mathrm{C}(1)$ & $106.33(10)$ \\
\hline $\mathrm{O}(1)-\mathrm{C}(13)-\mathrm{C}(2)$ & $102.51(10)$ \\
\hline$C(16)-C(15)-C(6)$ & $115.93(9)$ \\
\hline $\mathrm{C}(17)-\mathrm{C}(16)-\mathrm{C}(15)$ & $112.22(13)$ \\
\hline $\mathrm{C}(18)-\mathrm{C}(17)-\mathrm{C}(16)$ & $113.3(2)$ \\
\hline
\end{tabular}


Table 4,. Anisotropic thermal displacement $\left(\AA^{2} \times 10^{3}\right)$ for $\mathrm{C} 21 \mathrm{H} 32 \mathrm{O} 2 \mathrm{Si}$. The anisotropic displacement factor exponent takes the form: $\quad-2 \pi^{2}\left[\mathrm{~h}^{2} \mathrm{a}^{* 2} \mathrm{U}^{11}+\ldots \quad+2 \mathrm{hka} \mathrm{a}^{*} \mathrm{~b}^{*} \mathrm{U}^{12}\right]$

\begin{tabular}{|c|c|c|c|c|c|c|}
\hline & $\mathrm{U}^{11}$ & $\mathrm{U}^{22}$ & $\mathrm{U}^{33}$ & $\mathrm{U}^{23}$ & $\mathrm{U}^{13}$ & $\mathrm{U}^{12}$ \\
\hline $\operatorname{Si}(1)$ & $45(1)$ & $21(1)$ & $59(1)$ & $-2(1)$ & $-4(1)$ & $-12(1)$ \\
\hline $\mathrm{O}(1)$ & $45(1)$ & $50(1)$ & $55(1)$ & $-14(1)$ & $-4(1)$ & $-30(1)$ \\
\hline $\mathrm{O}(2)$ & $92(1)$ & $48(1)$ & $56(1)$ & $7(1)$ & $-39(1)$ & $-42(1)$ \\
\hline $\mathrm{C}(1)$ & $27(1)$ & $23(1)$ & $25(1)$ & $-3(1)$ & $-1(1)$ & $-11(1)$ \\
\hline $\mathrm{C}(2)$ & $37(1)$ & $28(1)$ & $33(1)$ & $-9(1)$ & $2(1)$ & $-14(1)$ \\
\hline$C(3)$ & $39(1)$ & $40(1)$ & $35(1)$ & $-10(1)$ & 11(1) & $-16(1)$ \\
\hline $\mathrm{C}(4)$ & $30(1)$ & $40(1)$ & $44(1)$ & $-8(1)$ & $7(1)$ & $-13(1)$ \\
\hline $\mathrm{C}(5)$ & $28(1)$ & $31(1)$ & $36(1)$ & $-2(1)$ & $-2(1)$ & $-7(1)$ \\
\hline$C(6)$ & $29(1)$ & $23(1)$ & $25(1)$ & $-1(1)$ & $-2(1)$ & $-10(1)$ \\
\hline $\mathrm{C}(7)$ & 41(1) & $26(1)$ & $33(1)$ & $-1(1)$ & $-9(1)$ & $-16(1)$ \\
\hline$C(8)$ & $37(1)$ & $22(1)$ & $32(1)$ & $-1(1)$ & $-6(1)$ & $-11(1)$ \\
\hline $\mathrm{C}(9)$ & $33(1)$ & $23(1)$ & $28(1)$ & $-1(1)$ & $-4(1)$ & $-10(1)$ \\
\hline $\mathrm{C}(10)$ & $40(1)$ & $34(1)$ & $45(1)$ & 2(1) & $-17(1)$ & $-9(1)$ \\
\hline $\mathrm{C}(11)$ & $28(1)$ & $50(1)$ & $50(1)$ & $-9(1)$ & $-3(1)$ & $-10(1)$ \\
\hline$C(12)$ & $32(1)$ & $40(1)$ & $35(1)$ & $-2(1)$ & $-1(1)$ & $-19(1)$ \\
\hline $\mathrm{C}(13)$ & $51(1)$ & $46(1)$ & $41(1)$ & $-18(1)$ & $-3(1)$ & $-24(1)$ \\
\hline$C(14)$ & $36(1)$ & $61(1)$ & $50(1)$ & $-2(1)$ & $-14(1)$ & $-8(1)$ \\
\hline$C(15)$ & $39(1)$ & $32(1)$ & $25(1)$ & $-3(1)$ & 2(1) & $-10(1)$ \\
\hline$C(16)$ & $48(1)$ & $40(1)$ & $34(1)$ & $5(1)$ & $3(1)$ & $-19(1)$ \\
\hline$C(17)$ & $68(1)$ & $84(1)$ & $44(1)$ & $-4(1)$ & 13(1) & $-48(1)$ \\
\hline$C(18)$ & $146(3)$ & $119(2)$ & $72(1)$ & $16(1)$ & $14(2)$ & $-99(2)$ \\
\hline$C(19)$ & $204(4)$ & $76(2)$ & $108(2)$ & $53(2)$ & $-76(2)$ & $-86(2)$ \\
\hline$C(20)$ & $69(1)$ & $46(1)$ & $172(3)$ & 21(1) & $-21(2)$ & $-34(1)$ \\
\hline$C(21)$ & $214(4)$ & $63(2)$ & $270(6)$ & $-83(2)$ & $188(5)$ & $-70(2)$ \\
\hline
\end{tabular}


Table 5. Hydrogen atom coordinates $\left(\mathrm{x} 10^{3}\right)$ and isotropic thermal displacement parameters $\left(\AA^{2} \mathrm{x} 10\right.$ 3) for $\mathrm{C} 21 \mathrm{H} 32 \mathrm{O} 2 \mathrm{Si}$.

\begin{tabular}{|c|c|c|c|c|}
\hline & $\mathrm{x}$ & $\mathrm{y}$ & $\mathrm{z}$ & $\mathrm{U}(\mathrm{eq})$ \\
\hline $\mathrm{H}(2)$ & 9208 & -2478 & 1798 & 38 \\
\hline $\mathrm{H}(3)$ & 11086 & -1307 & 436 & 45 \\
\hline $\mathrm{H}(4)$ & 12894 & -1525 & 1795 & 45 \\
\hline $\mathrm{H}(5)$ & 10833 & -2697 & 3003 & 39 \\
\hline $\mathrm{H}(10 \mathrm{~A})$ & 5688 & 1531 & 489 & 49 \\
\hline $\mathrm{H}(10 \mathrm{~B})$ & 5058 & 2862 & 1163 & 49 \\
\hline $\mathrm{H}(11 \mathrm{~A})$ & 4347 & 1441 & 2534 & 52 \\
\hline $\mathrm{H}(11 \mathrm{~B})$ & 3597 & 978 & 1599 & 52 \\
\hline $\mathrm{H}(12)$ & 5831 & -1060 & 2755 & 41 \\
\hline $\mathrm{H}(13 \mathrm{~A})$ & 7320 & -559 & 136 & 52 \\
\hline $\mathrm{H}(13 \mathrm{~B})$ & 7923 & -2301 & 294 & 52 \\
\hline $\mathrm{H}(14 \mathrm{~A})$ & 13416 & -2706 & 3688 & 77 \\
\hline $\mathrm{H}(14 \mathrm{~B})$ & 11792 & -1979 & 4410 & 77 \\
\hline $\mathrm{H}(14 \mathrm{C})$ & 12605 & -983 & 3679 & 77 \\
\hline $\mathrm{H}(15 \mathrm{~A})$ & 8839 & -503 & 4556 & 39 \\
\hline$H(15 B)$ & 6977 & -45 & 4002 & 39 \\
\hline $\mathrm{H}(16 \mathrm{~A})$ & 7837 & -2619 & 3774 & 48 \\
\hline $\mathrm{H}(16 \mathrm{~B})$ & 9388 & -2929 & 4565 & 48 \\
\hline $\mathrm{H}(17 \mathrm{~A})$ & 7198 & -1860 & 5771 & 73 \\
\hline $\mathrm{H}(17 \mathrm{~B})$ & 5676 & -1638 & 4981 & 73 \\
\hline $\mathrm{H}(18 \mathrm{~A})$ & 6541 & -4174 & 5031 & 151 \\
\hline $\mathrm{H}(18 \mathrm{~B})$ & 6062 & -3717 & 6136 & 151 \\
\hline $\mathrm{H}(18 \mathrm{C})$ & 8096 & -4411 & 5803 & 151 \\
\hline $\mathrm{H}(19 \mathrm{~A})$ & 6924 & 3945 & 212 & 184 \\
\hline $\mathrm{H}(19 \mathrm{~B})$ & 8549 & 4503 & 84 & 184 \\
\hline $\mathrm{H}(19 \mathrm{C})$ & 6640 & 5555 & 422 & 184 \\
\hline $\mathrm{H}(20 \mathrm{~A})$ & 10179 & 5023 & 1773 & 142 \\
\hline $\mathrm{H}(20 \mathrm{~B})$ & 11134 & 3405 & 1496 & 142 \\
\hline $\mathrm{H}(20 \mathrm{C})$ & 10699 & 3683 & 2640 & 142 \\
\hline$H(21 A)$ & 6827 & 4584 & 3341 & 266 \\
\hline $\mathrm{H}(21 \mathrm{~B})$ & 5312 & 4905 & 2524 & 266 \\
\hline $\mathrm{H}(21 \mathrm{C})$ & 6395 & 5964 & 2510 & 266 \\
\hline
\end{tabular}




\section{Chapter 4}

${ }^{1} \mathrm{H}$ NMR and ${ }^{13} \mathrm{C}$ NMR Spectra (All the NMR spectra were obtained in $\mathrm{CDCl}_{3}$ unless indicated otherwise)

${ }^{1} \mathrm{H}$ NMR of $(\boldsymbol{S})-4.1$

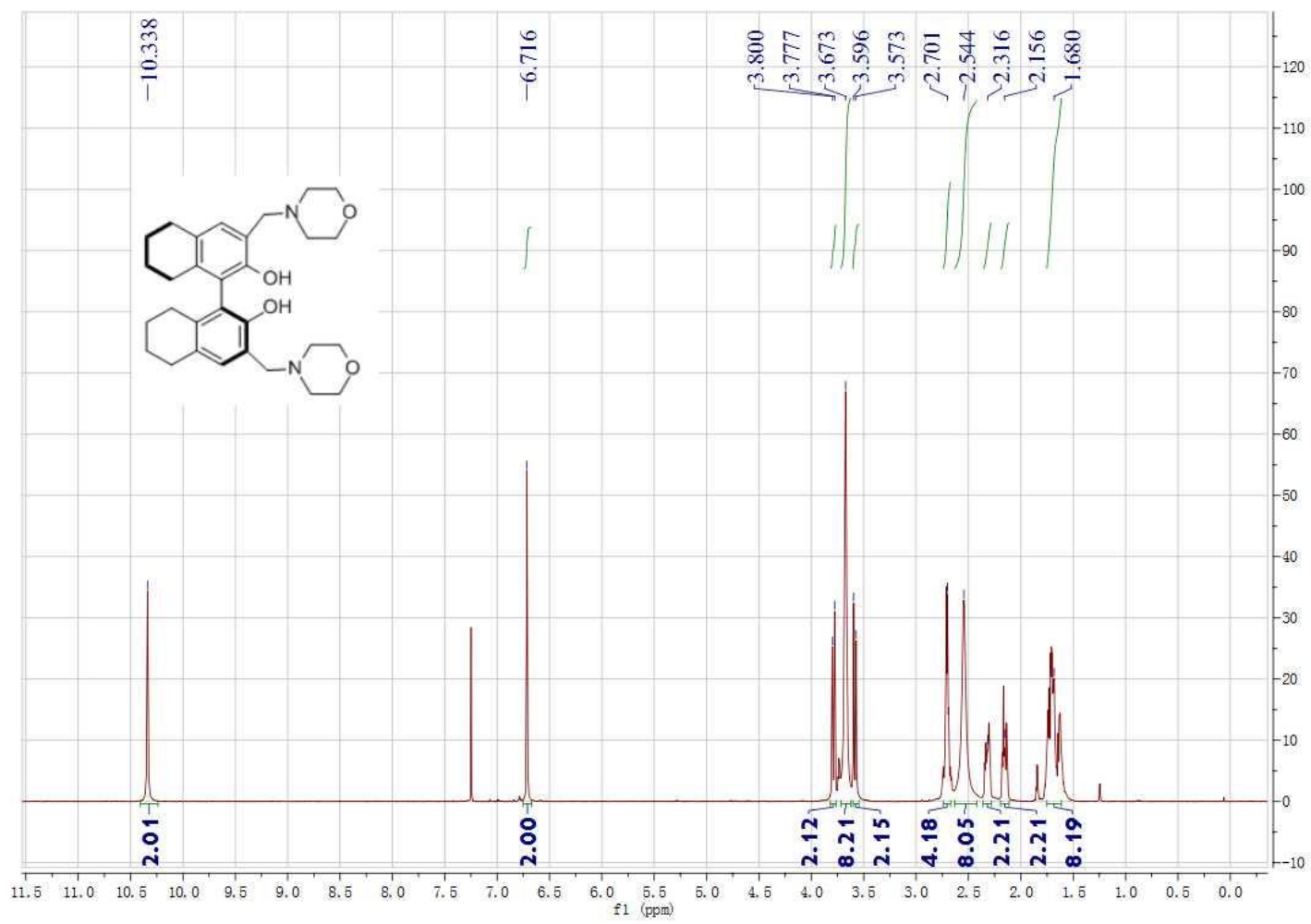

${ }^{13} \mathrm{C}$ NMR of $(\boldsymbol{S})-\mathbf{4 . 1}$

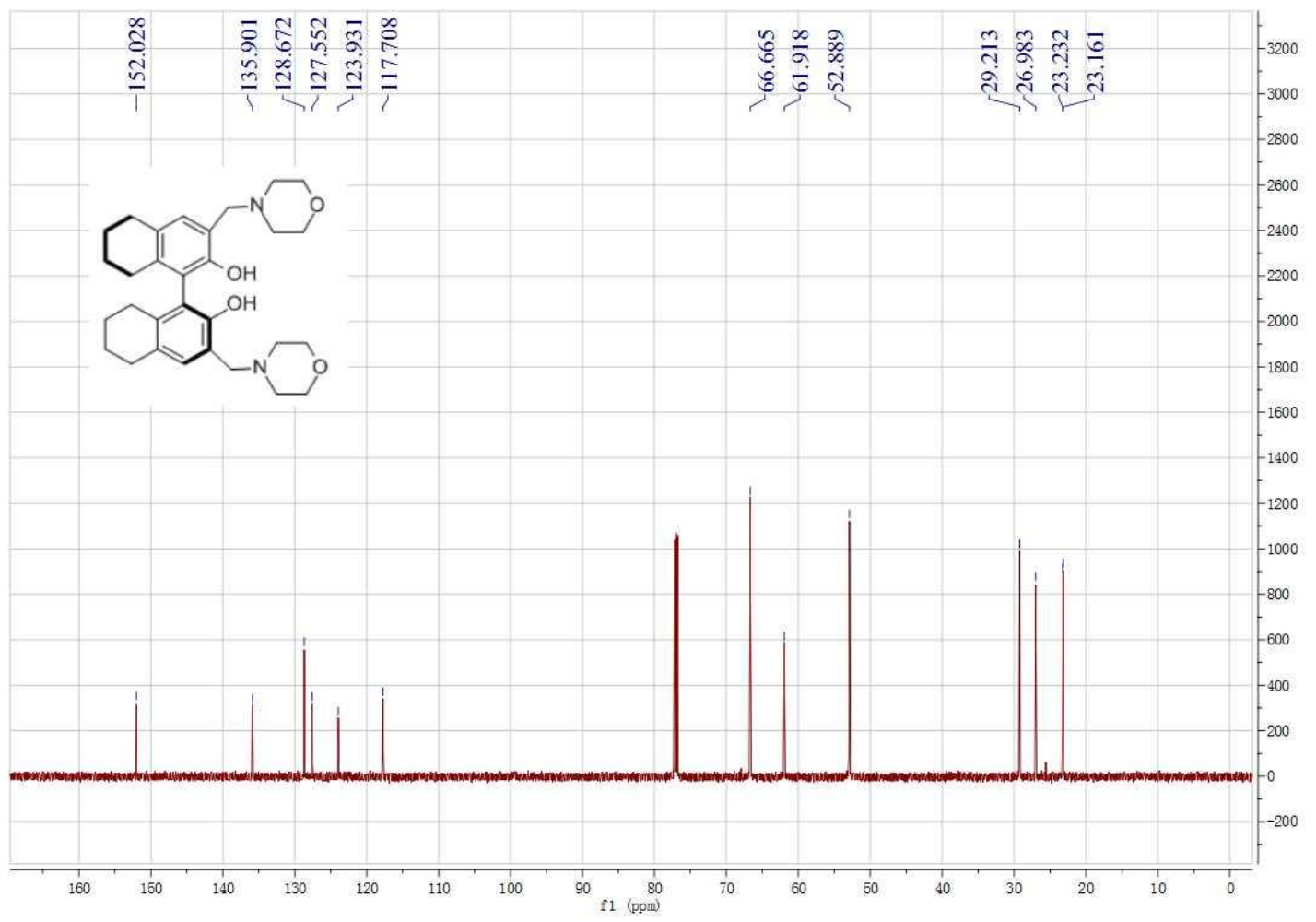


${ }^{1}$ H NMR of $(\boldsymbol{S})-4.2$

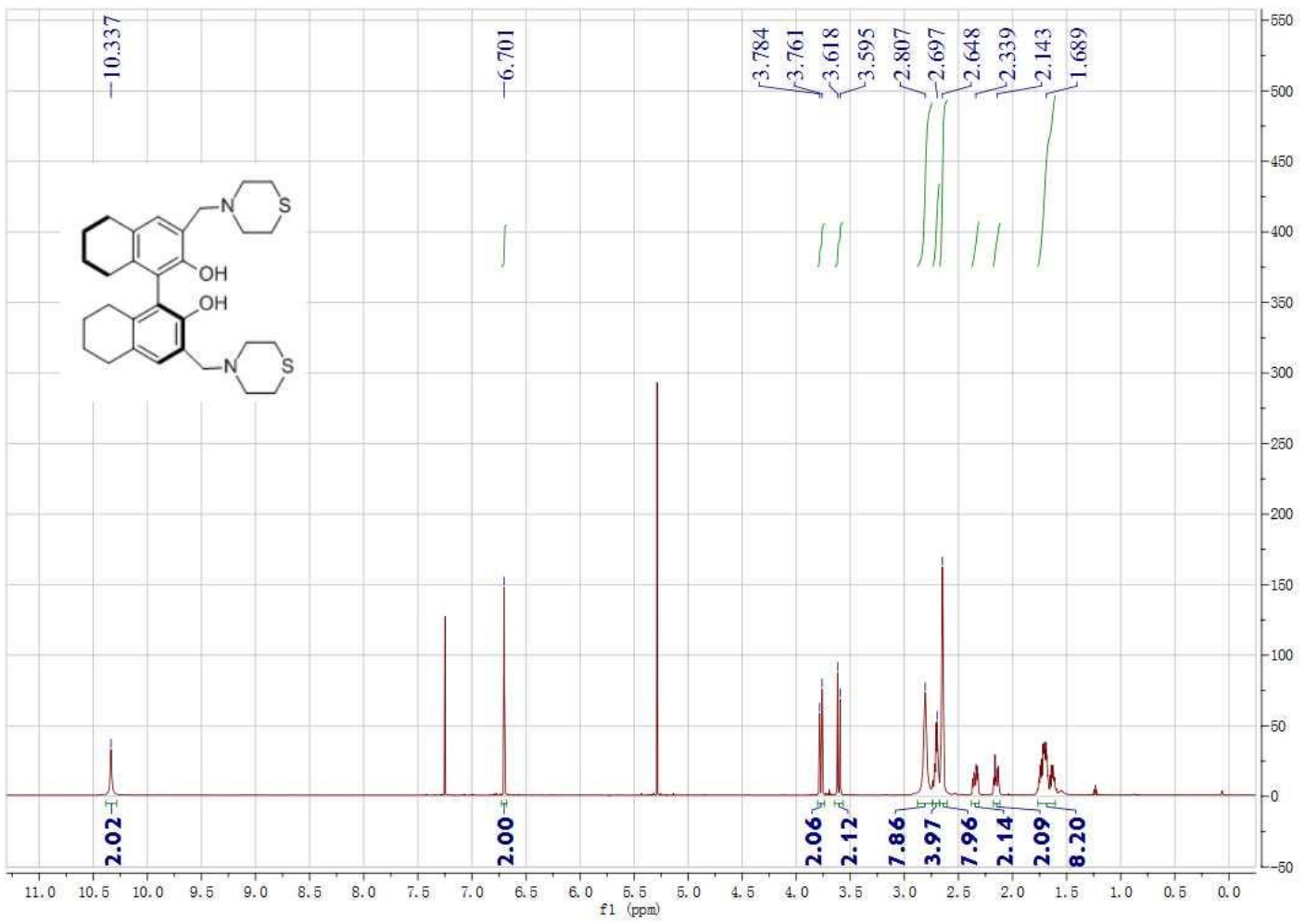

${ }^{13} \mathrm{C}$ NMR of $(\boldsymbol{S})-4.2$

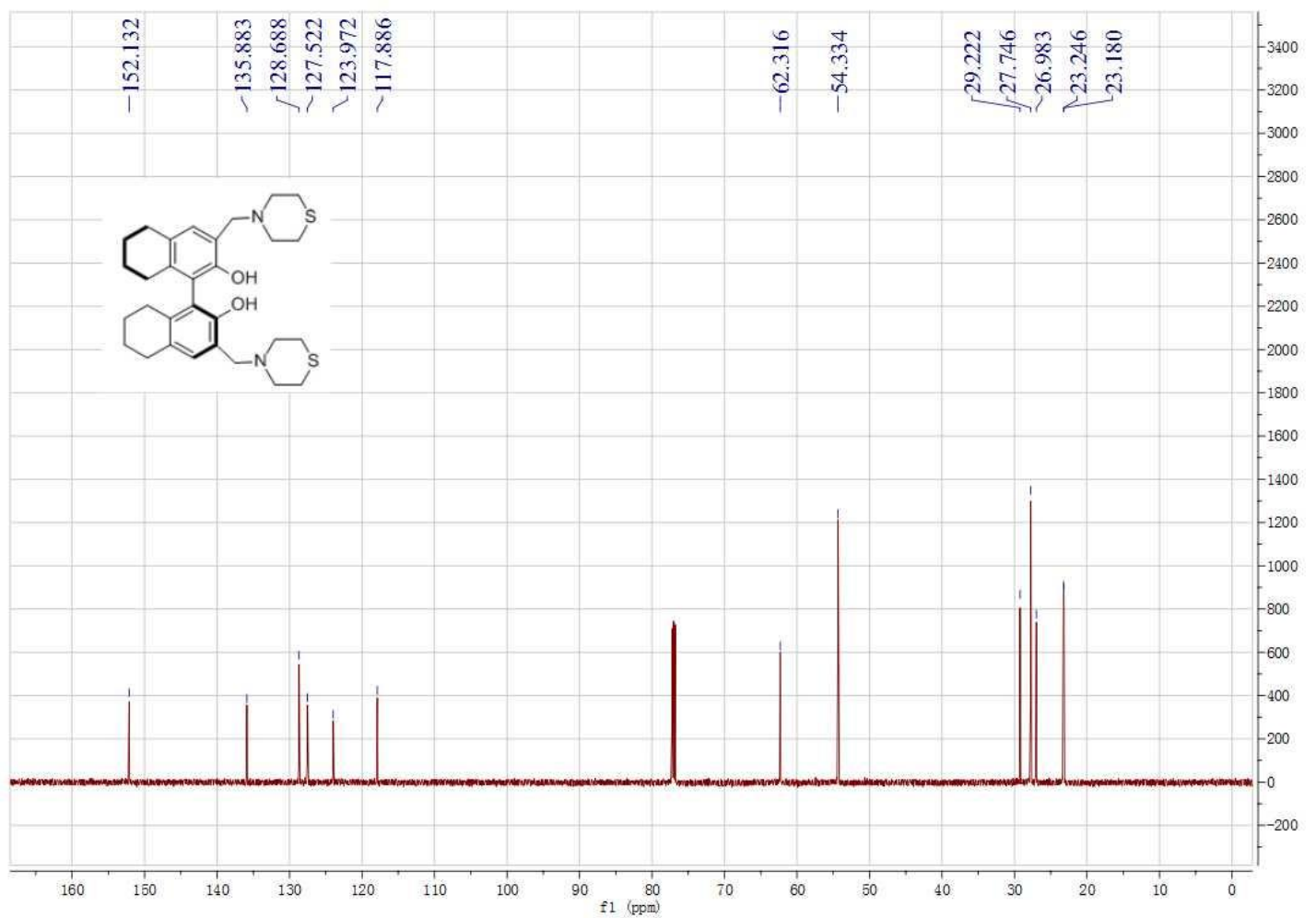


${ }^{1}$ H NMR of $(\boldsymbol{S})-\mathbf{4 . 3}$

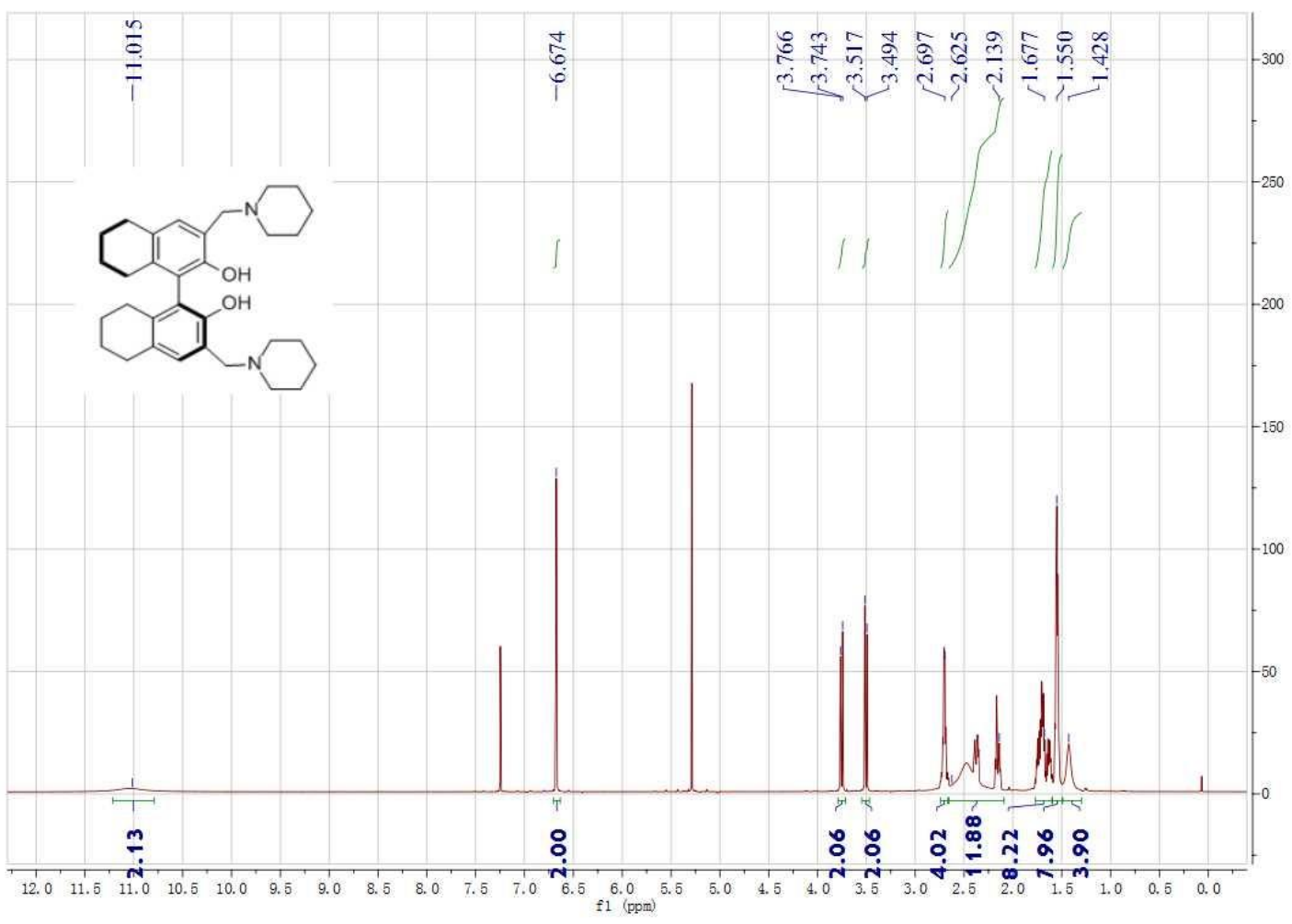

${ }^{13} \mathrm{C}$ NMR of $(\boldsymbol{S})-4.3$

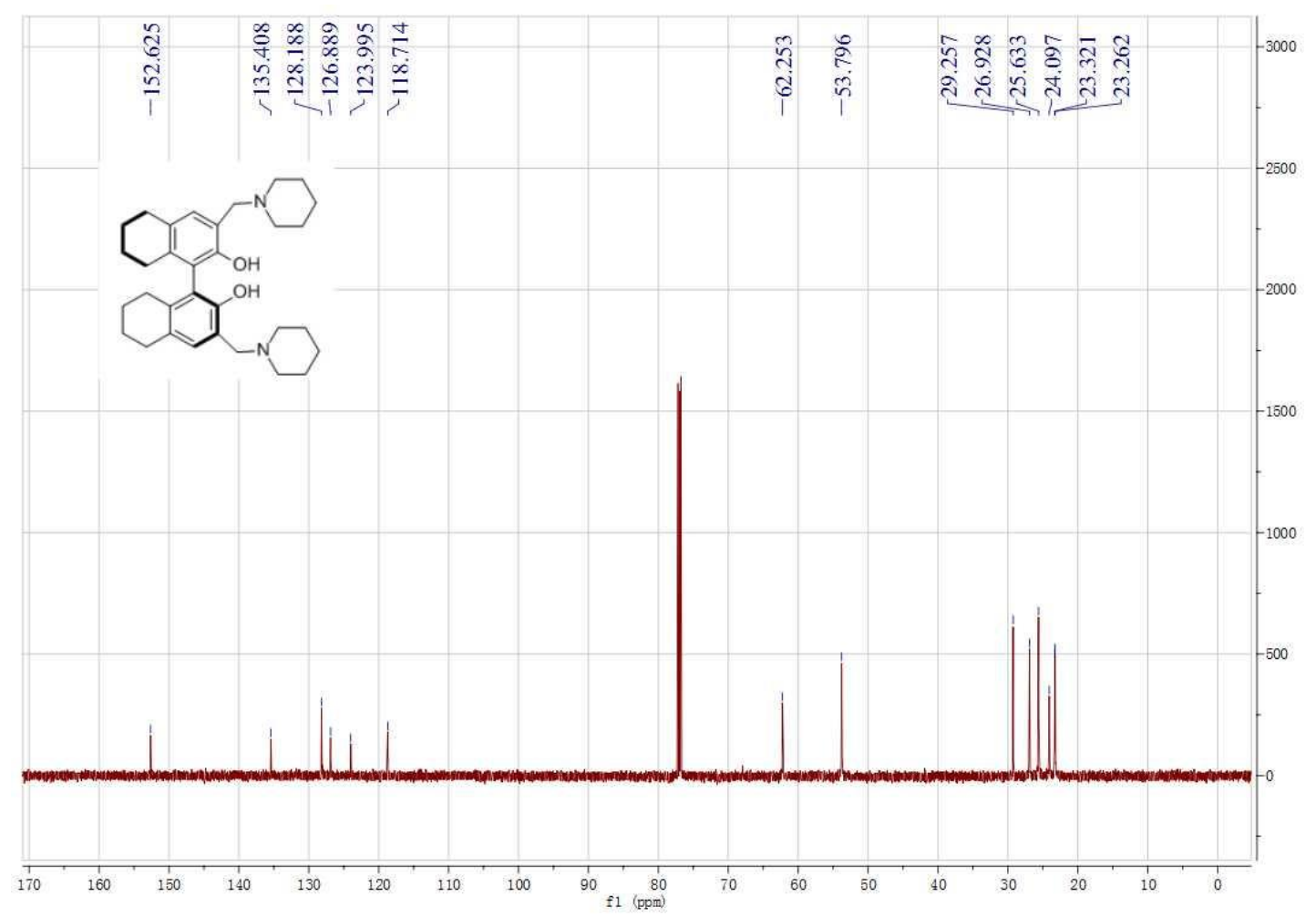


${ }^{1}$ H NMR of $(\boldsymbol{S})-4.4$

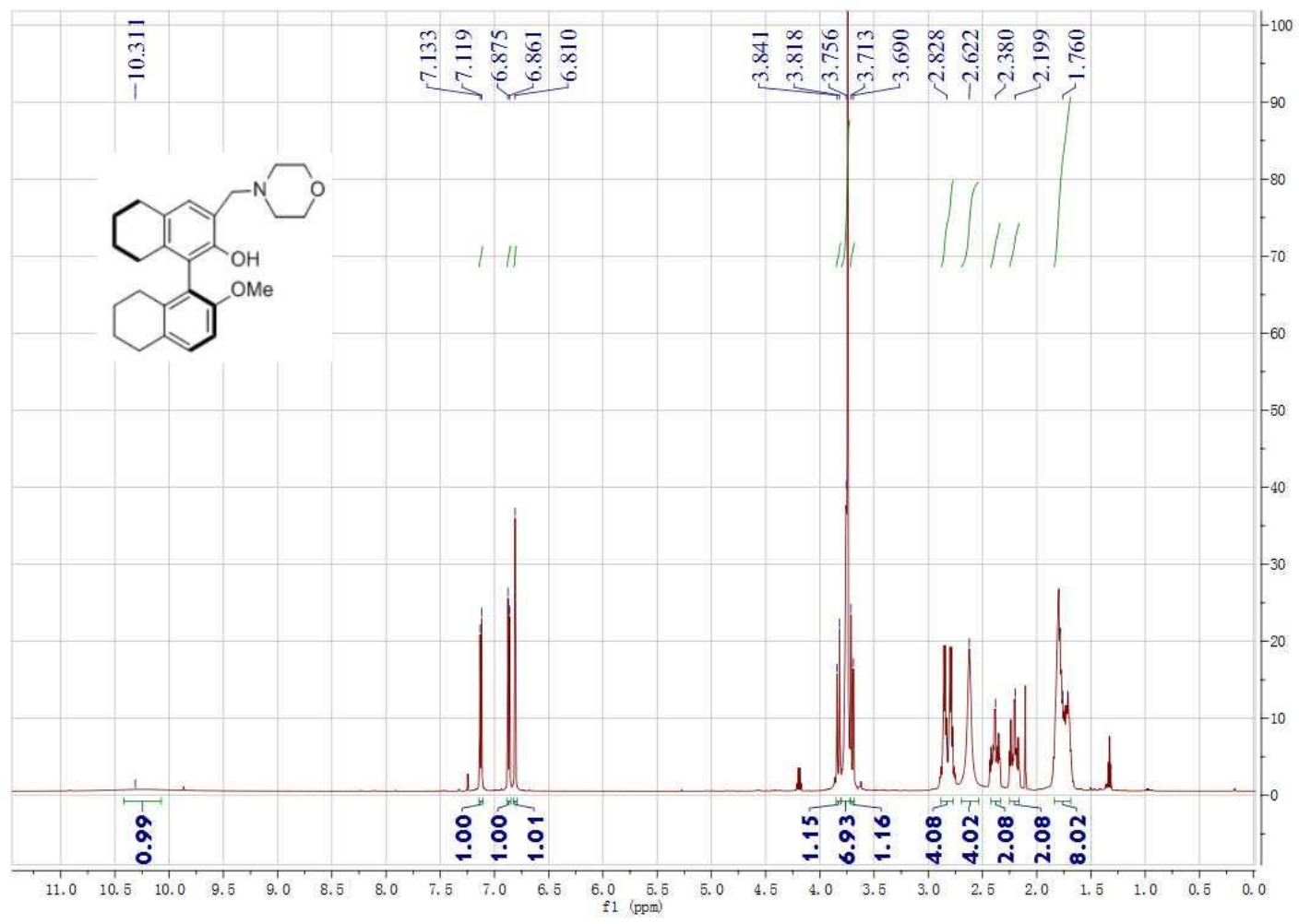

${ }^{13} \mathrm{C}$ NMR of $(\boldsymbol{S})-4.4$

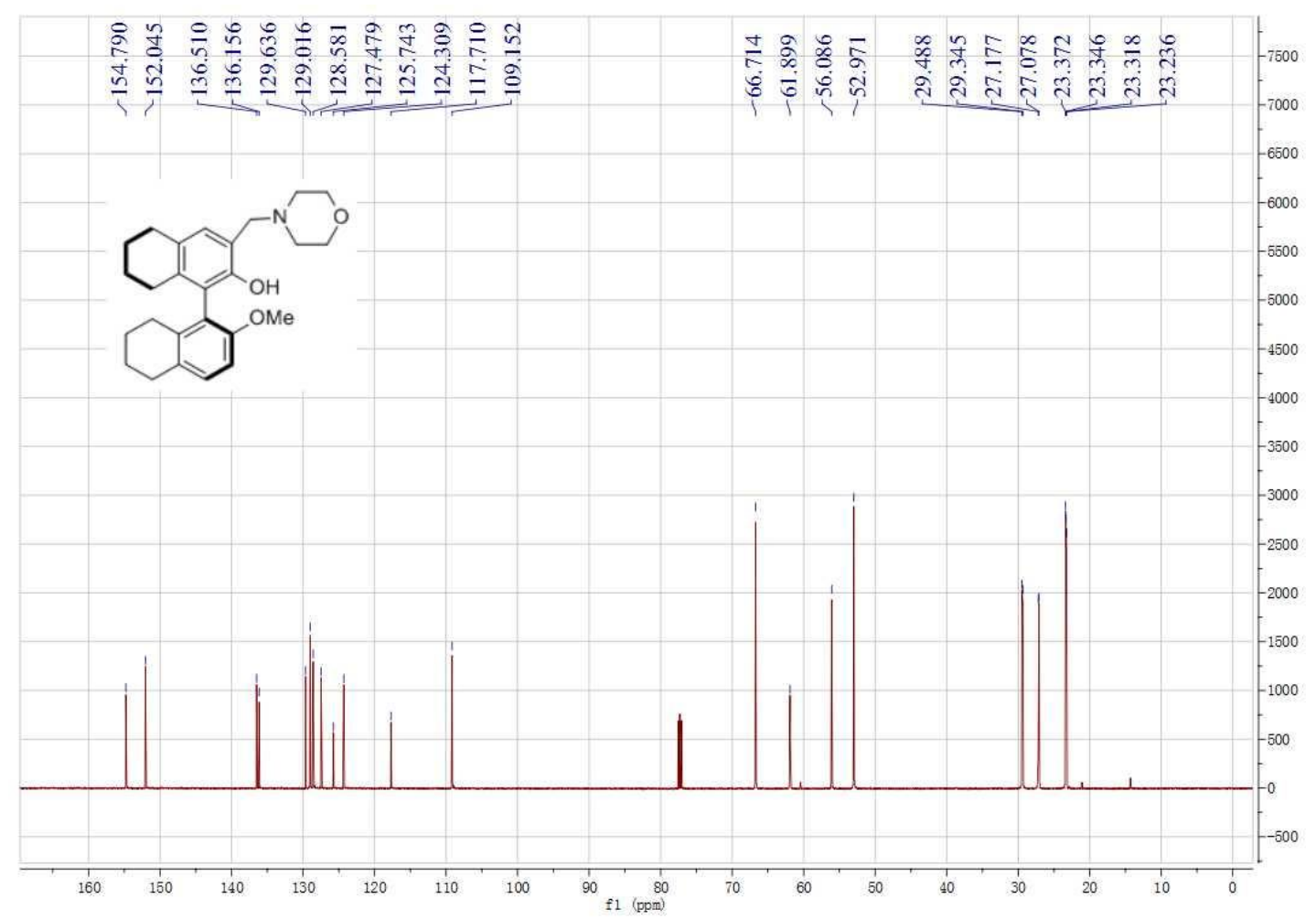


${ }^{1}$ H NMR of $(\boldsymbol{S})-4.5$

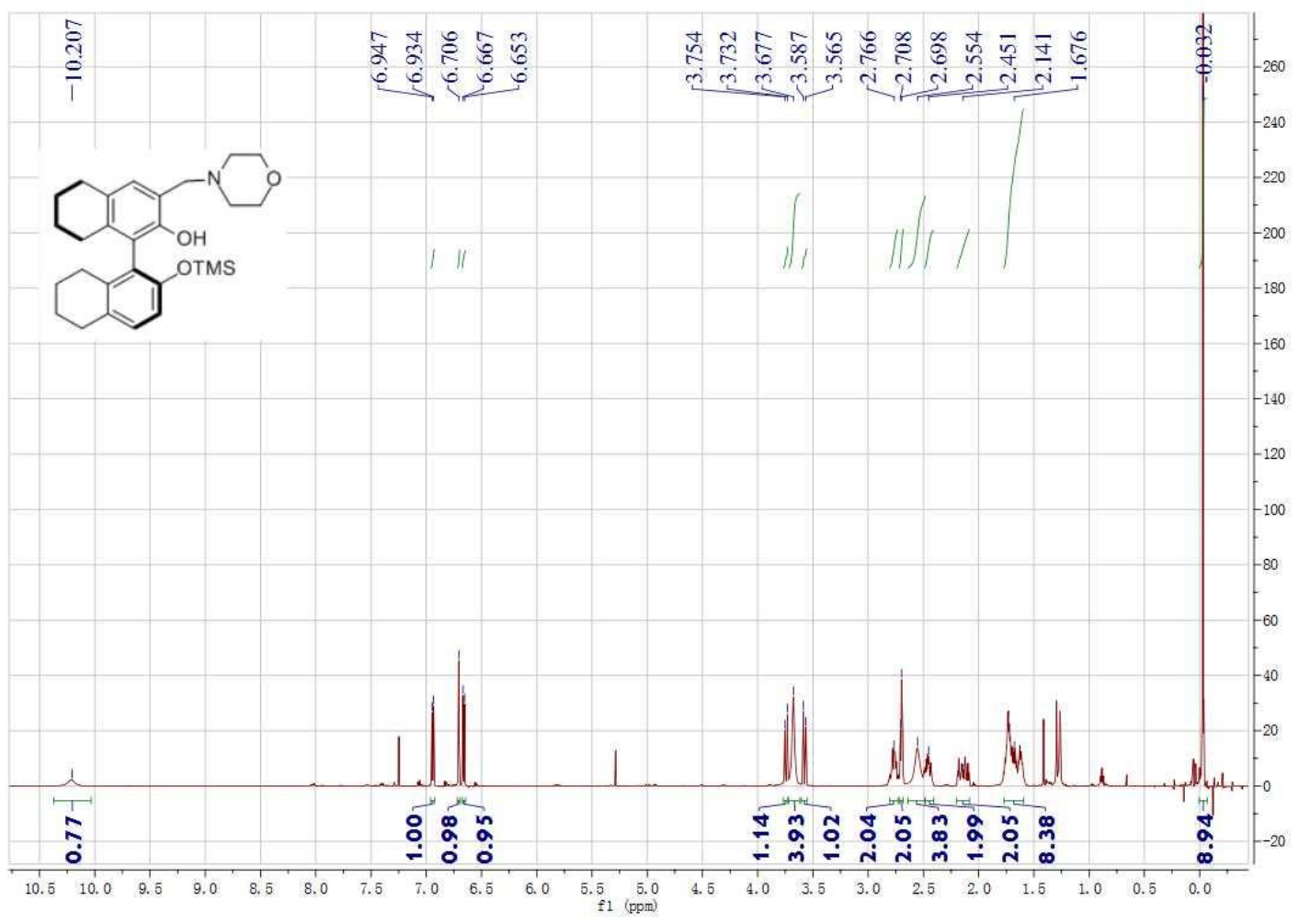


${ }^{1} \mathrm{H}$ NMR of $(\boldsymbol{S})-4.6$

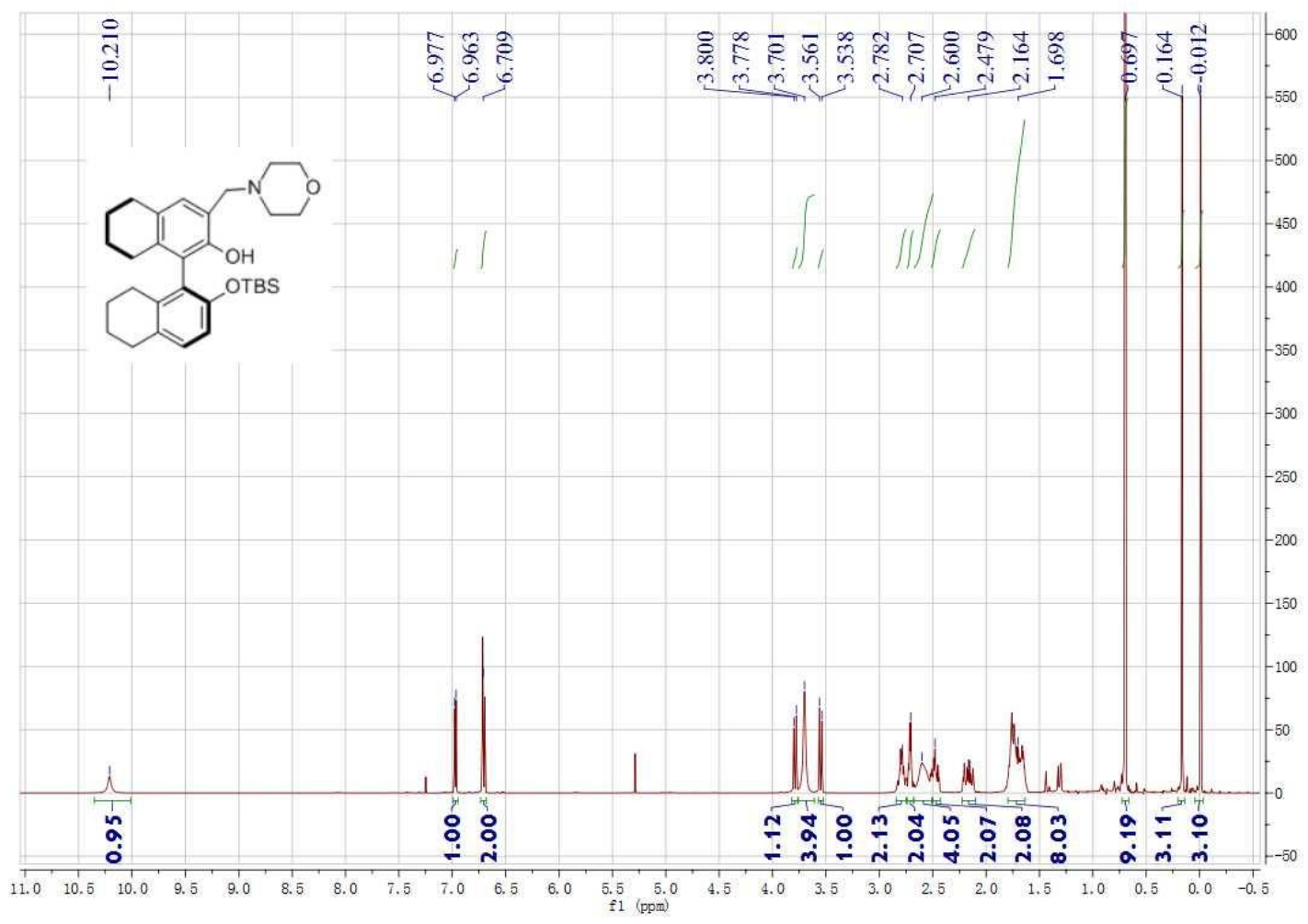

${ }^{13} \mathrm{C}$ NMR of $(\boldsymbol{S})-4.6$

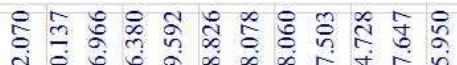

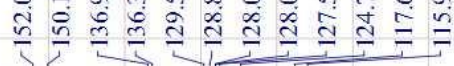

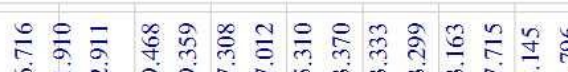

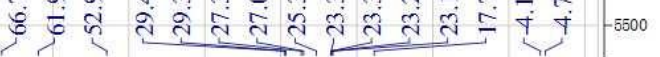

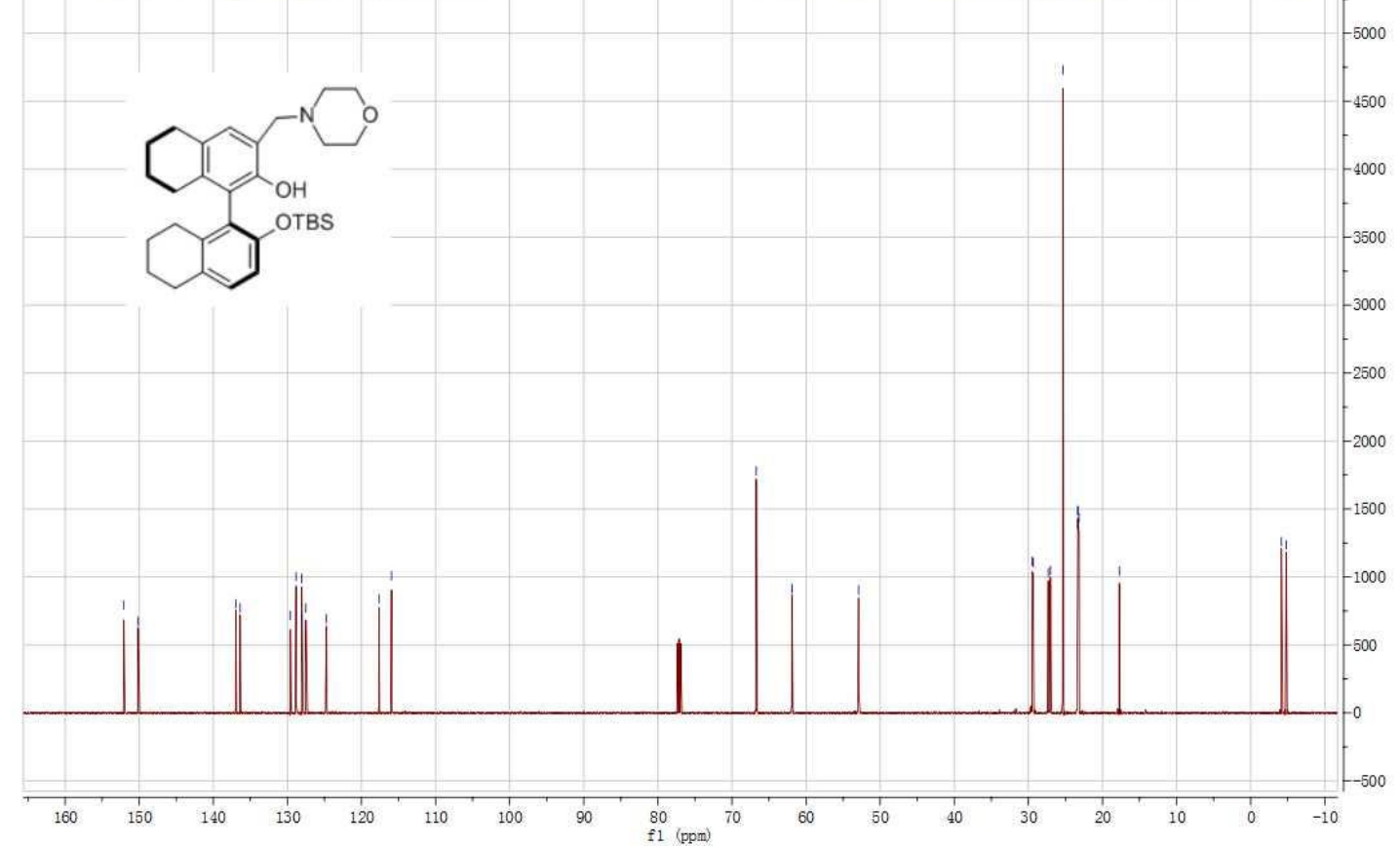


${ }^{1}$ H NMR of $(\boldsymbol{S})-4.7$

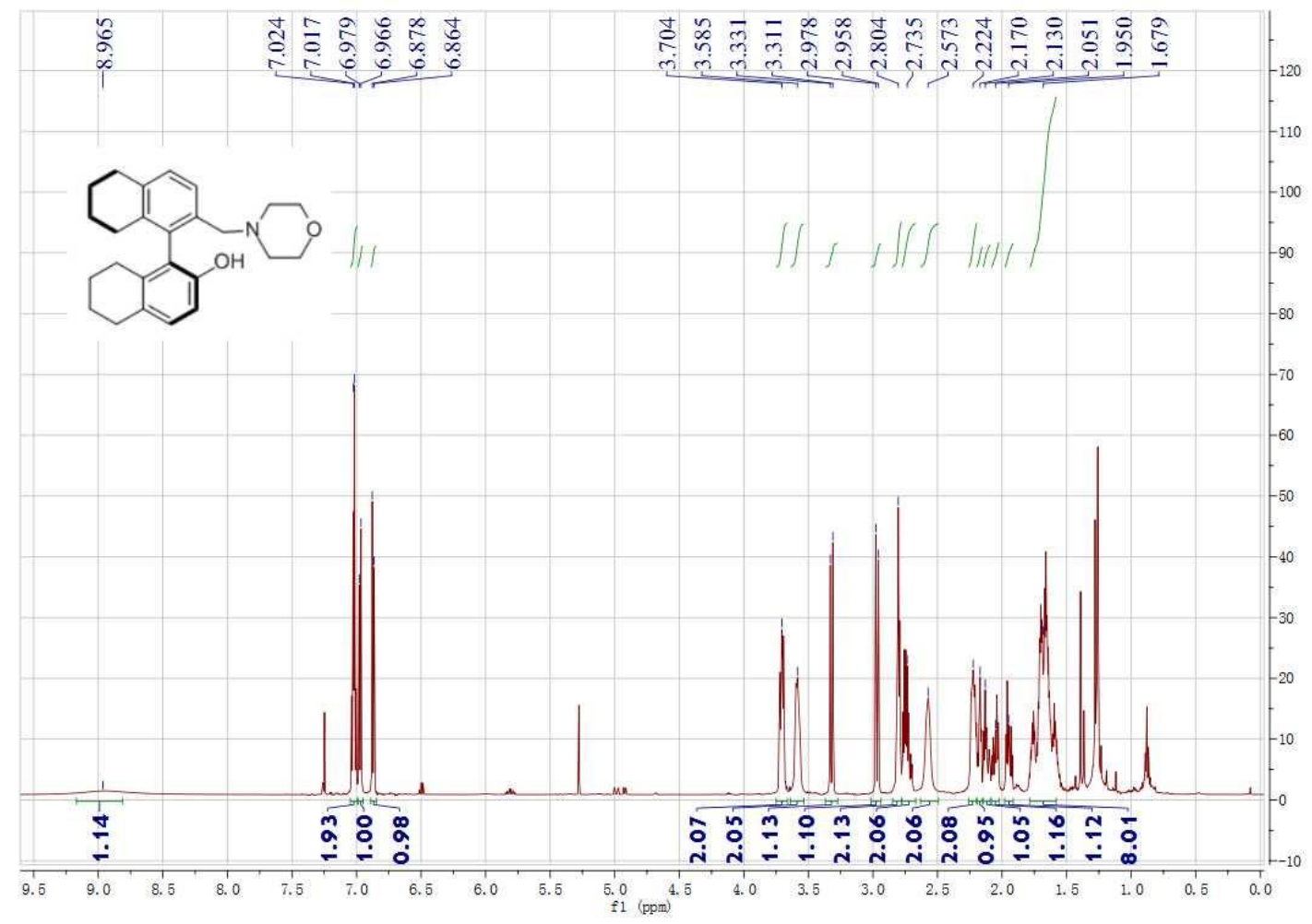

${ }^{13} \mathrm{C}$ NMR of $(\boldsymbol{S})-4.7$

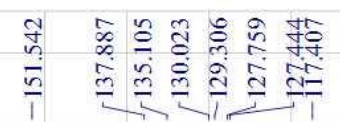

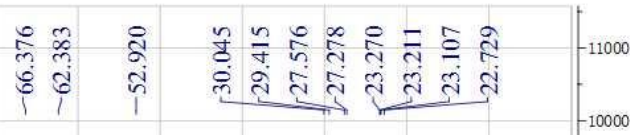<smiles>Oc1ccc2c3c1Cc1ccc4c(c1CN1CCOCC1)CCCC4CCC3CCC2</smiles>

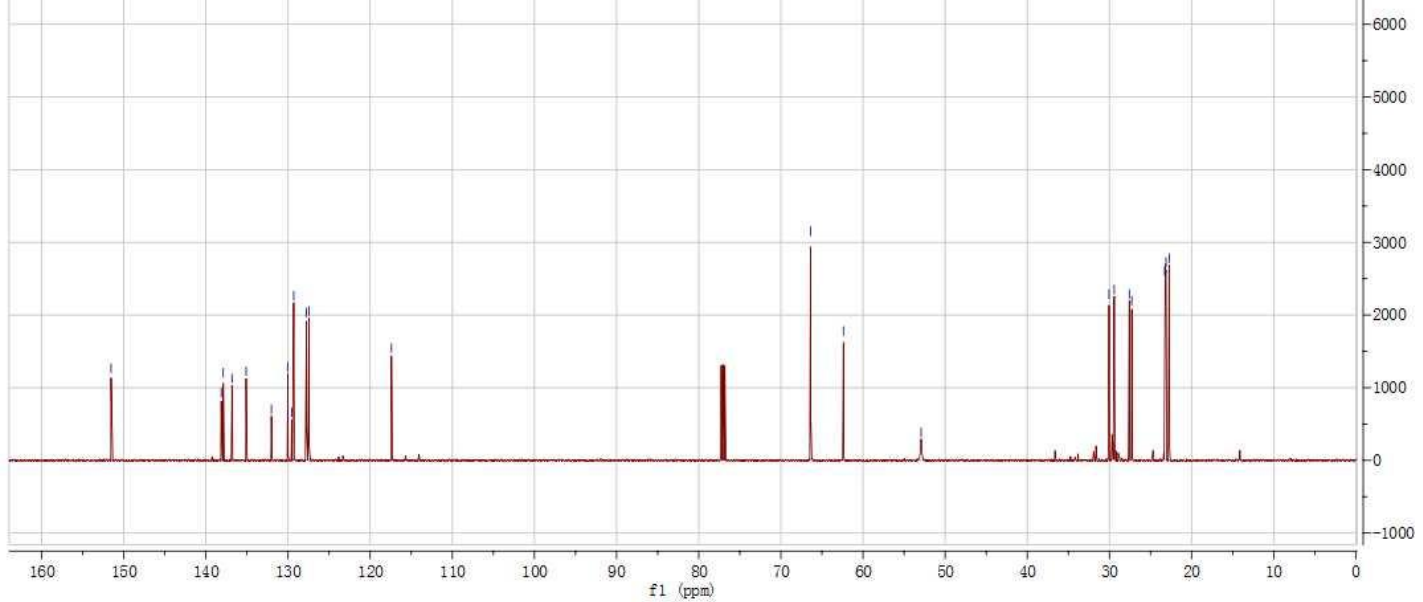


${ }^{1}$ H NMR of $(\boldsymbol{S})-4.8$

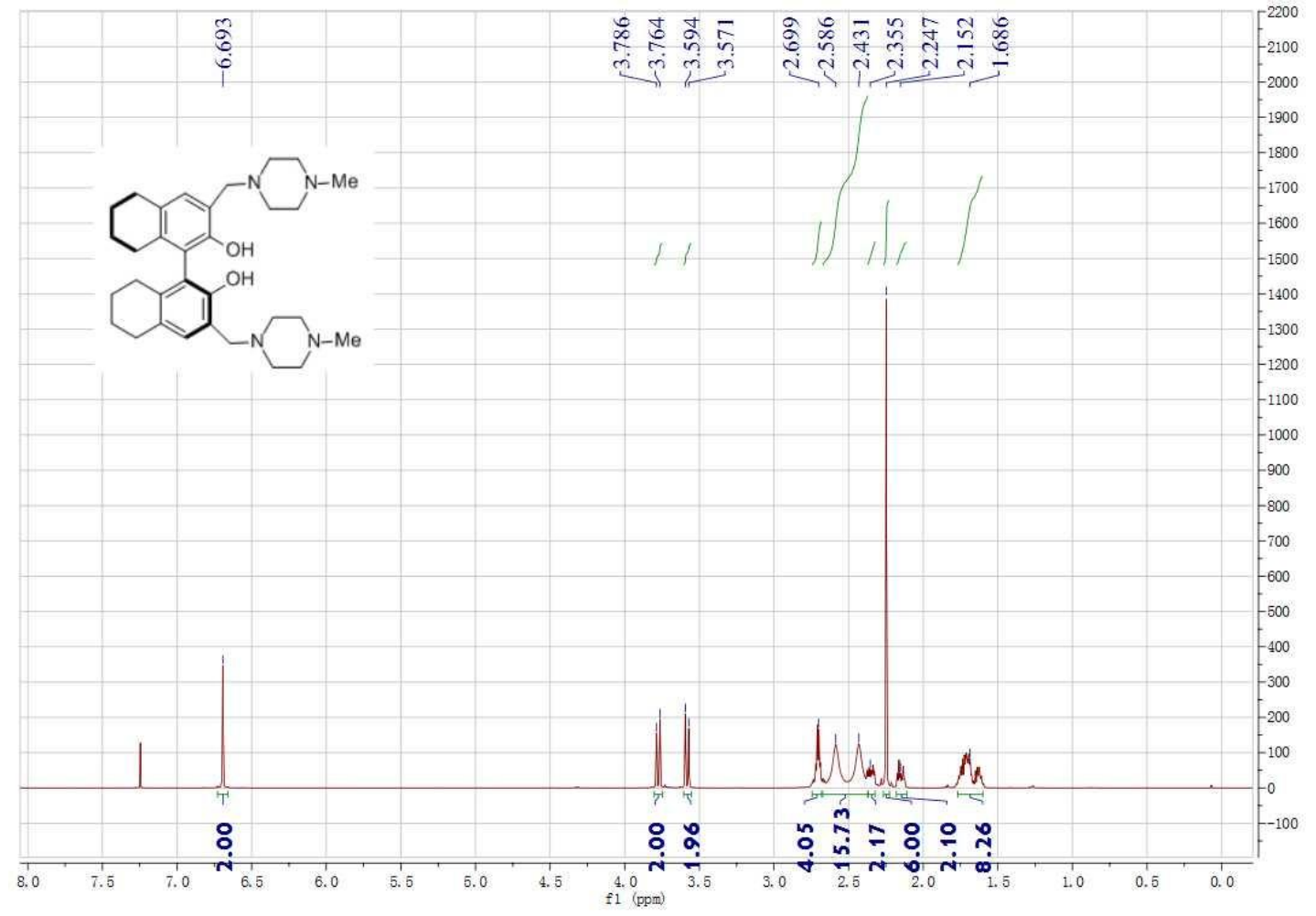

${ }^{13} \mathrm{C}$ NMR of $(\boldsymbol{S})-4.8$

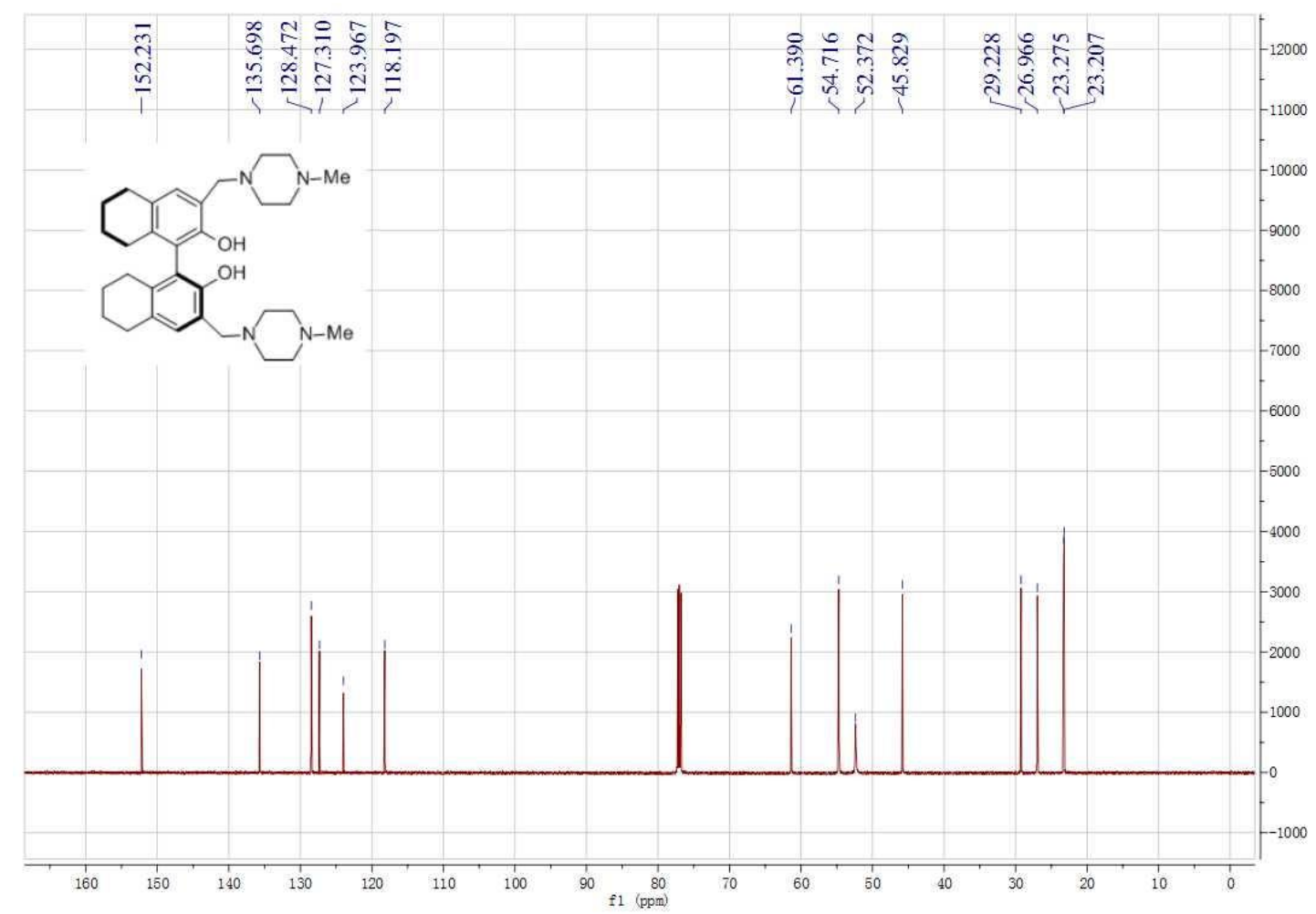


${ }^{1}$ H NMR of $(\boldsymbol{S})-4.9$

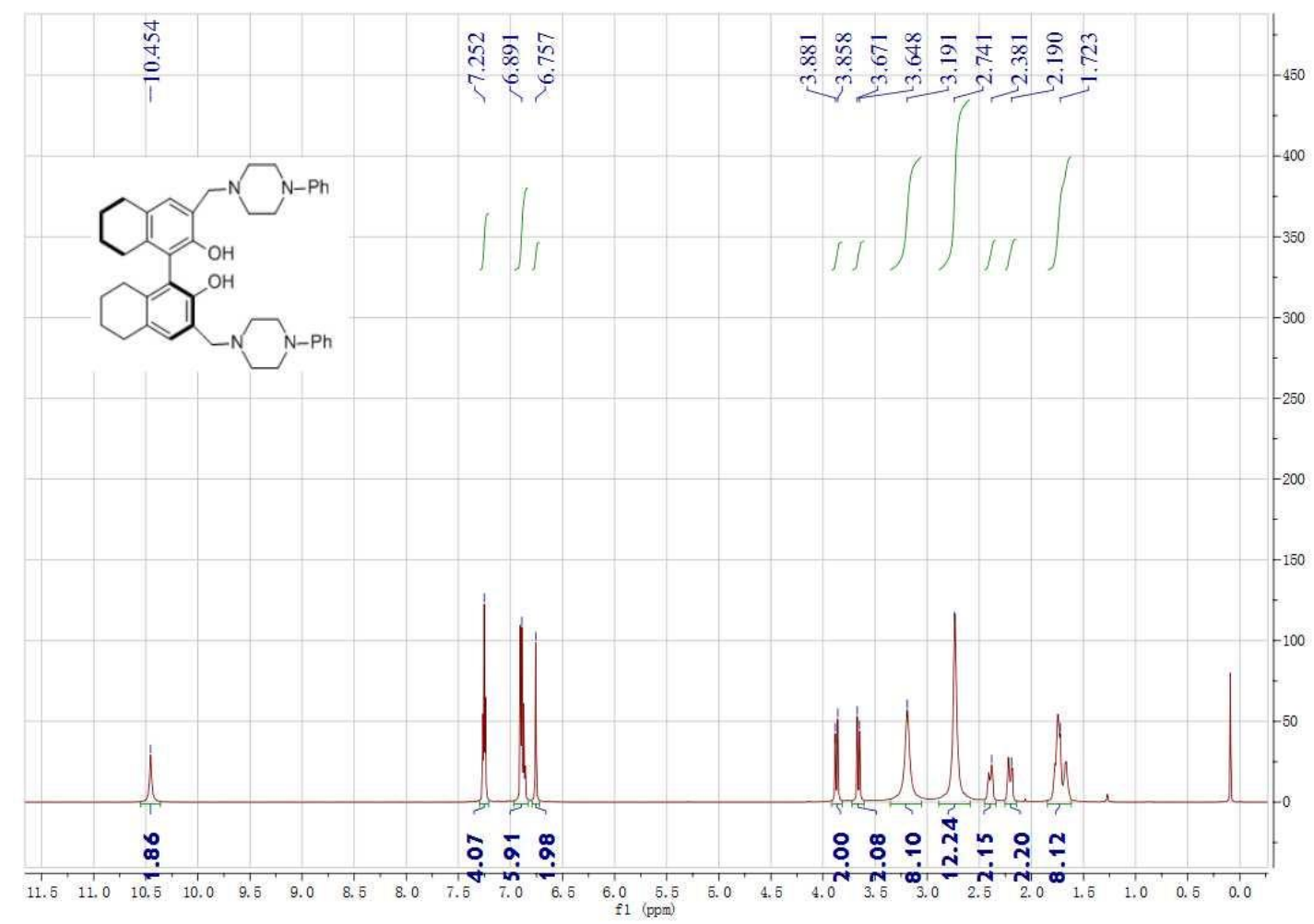

${ }^{13} \mathrm{C}$ NMR of $(\boldsymbol{S})-4.9$

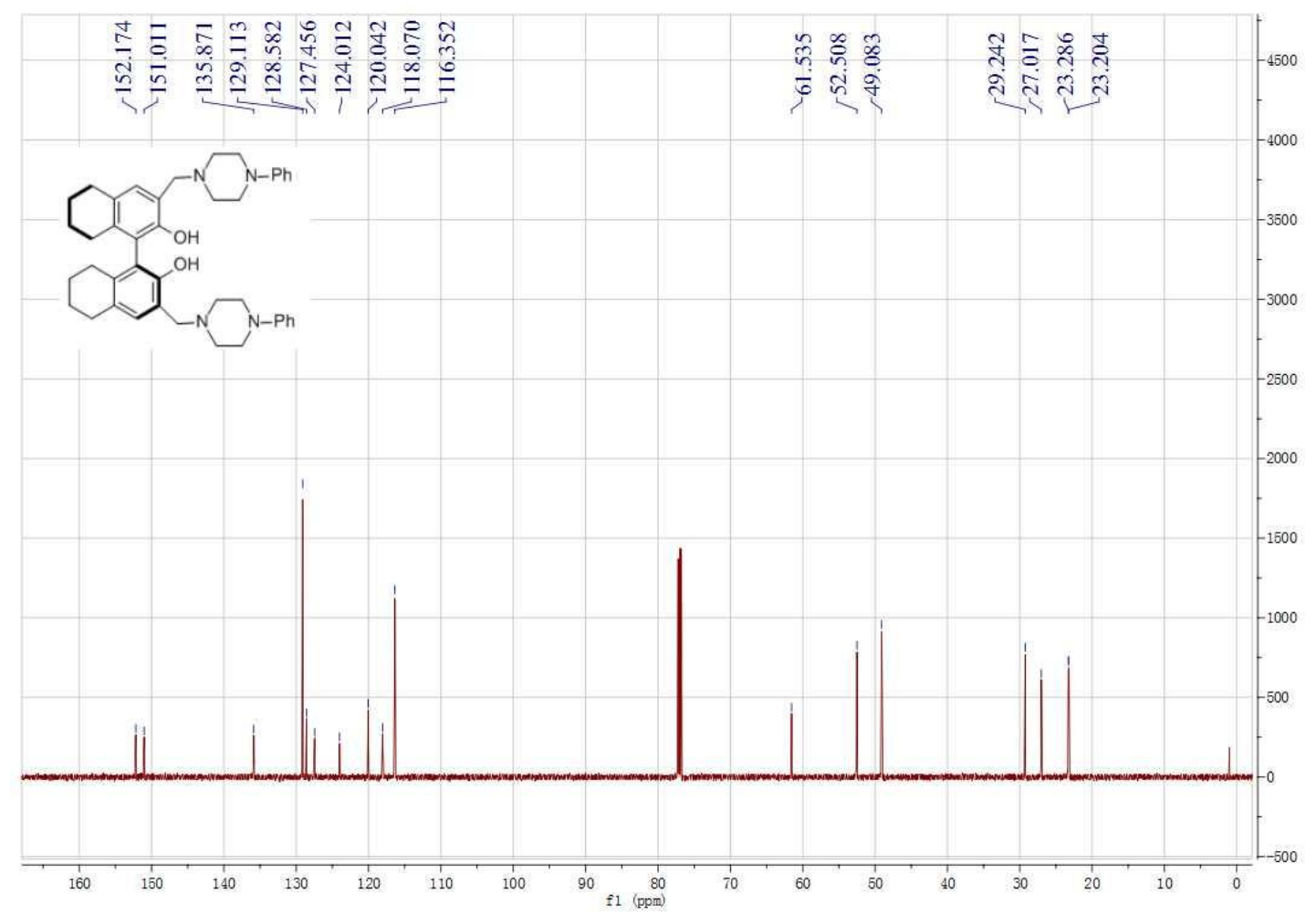


${ }^{1}$ H NMR of $(\boldsymbol{S})-\mathbf{4 . 1 0}$

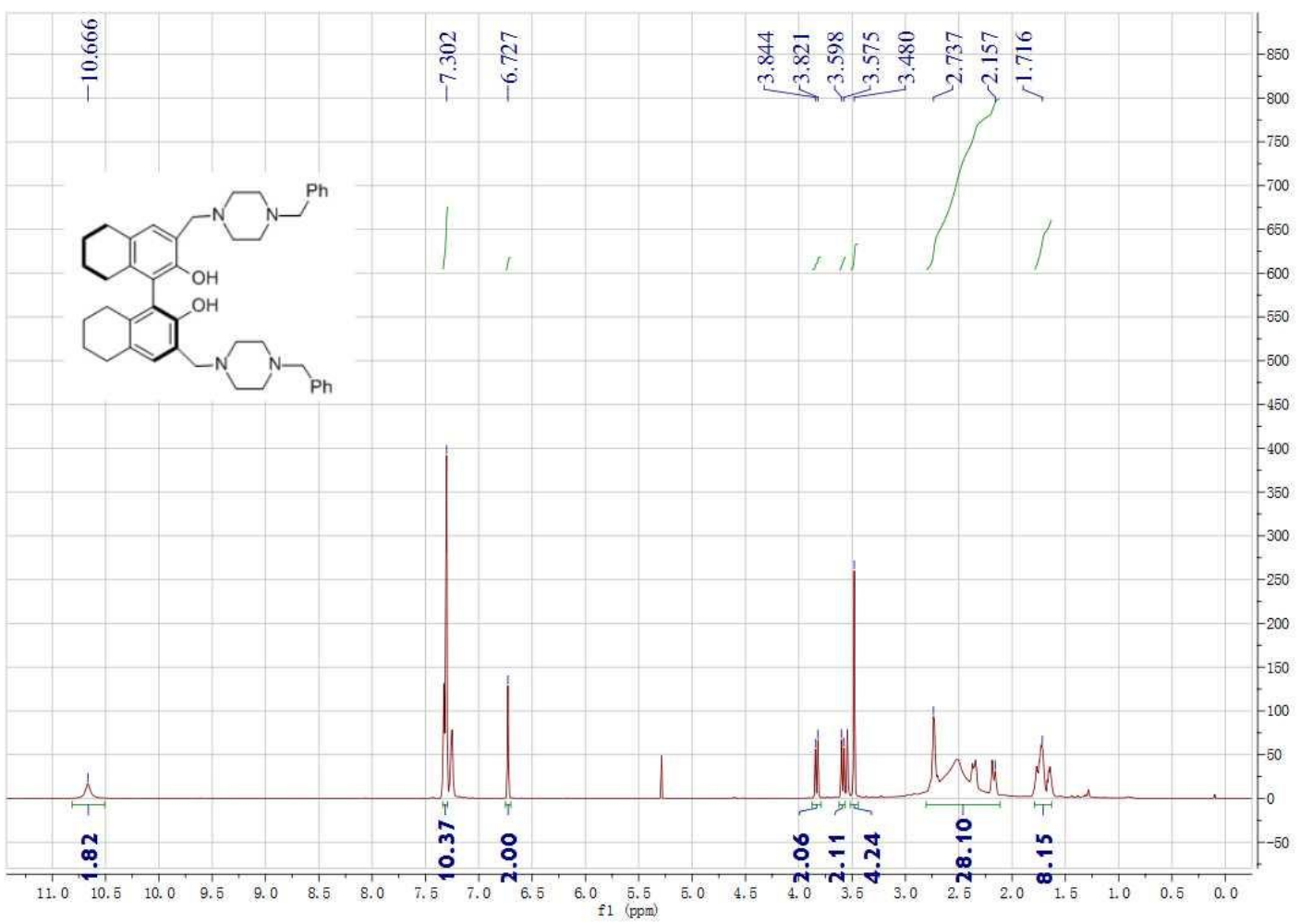

${ }^{13} \mathrm{C}$ NMR of $(\boldsymbol{S})-\mathbf{4 . 1 0}$

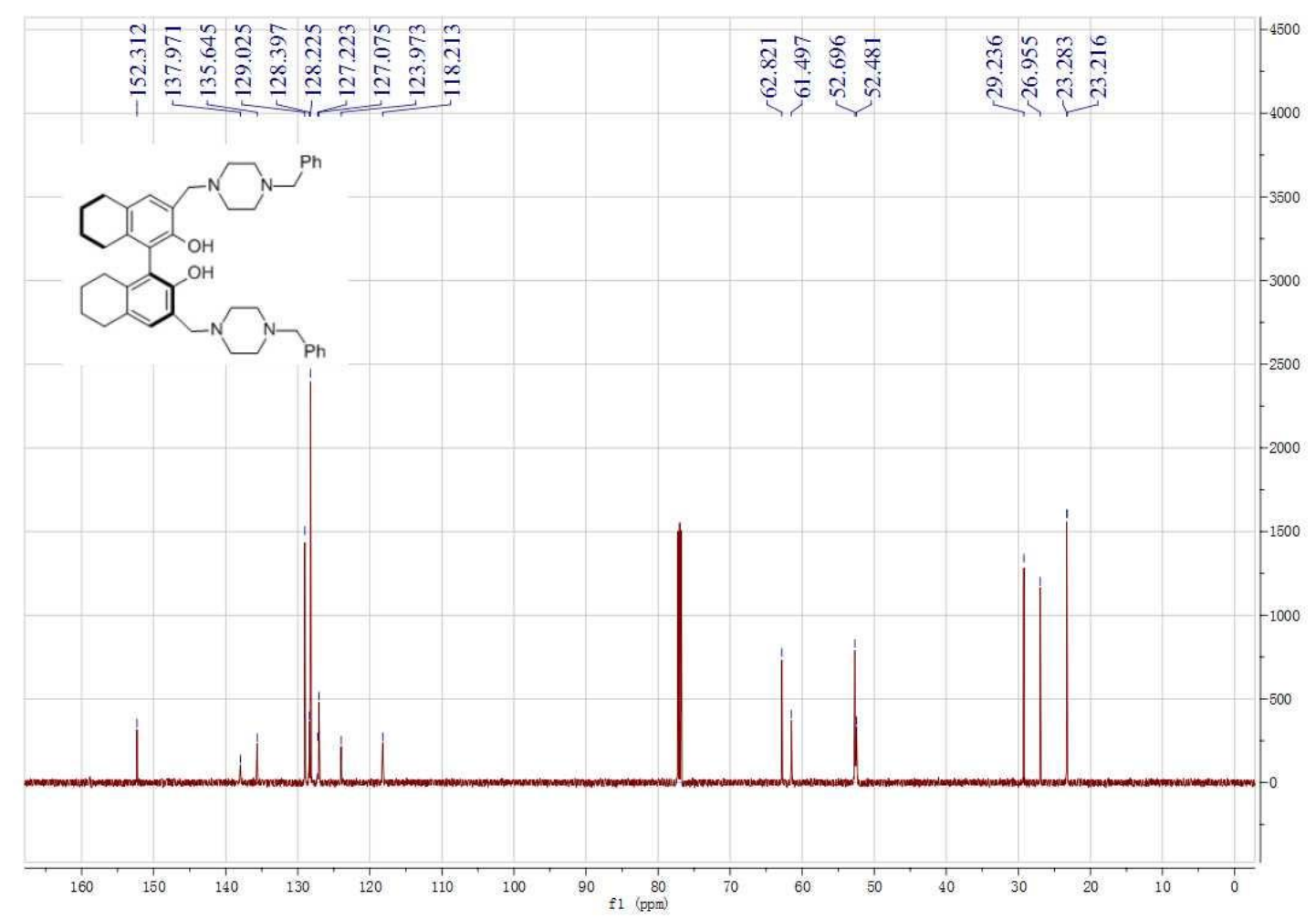


${ }^{1}$ H NMR of $(\boldsymbol{S})-\mathbf{4 . 1 1}$

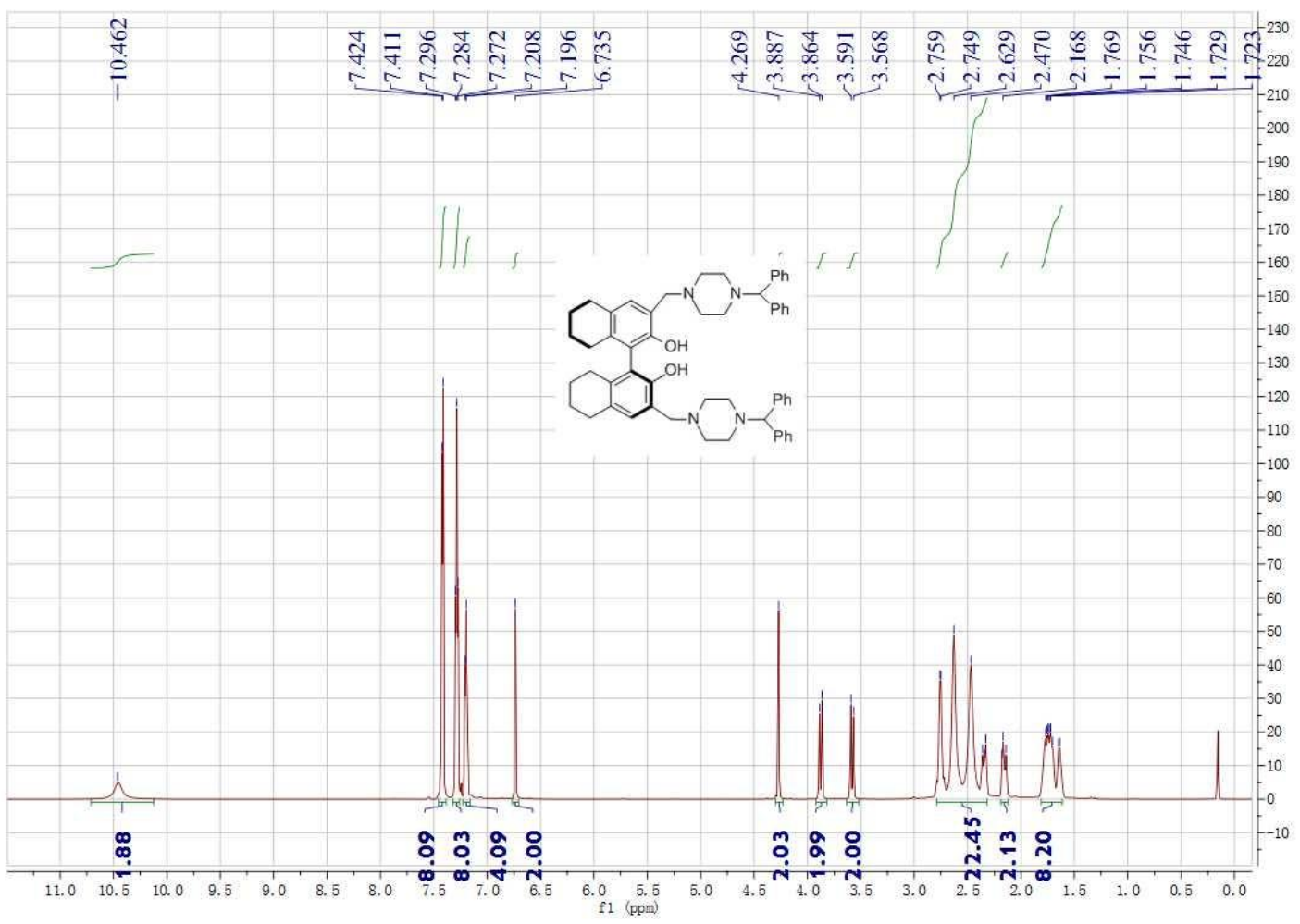

${ }^{13} \mathrm{C}$ NMR of (S)-4.11

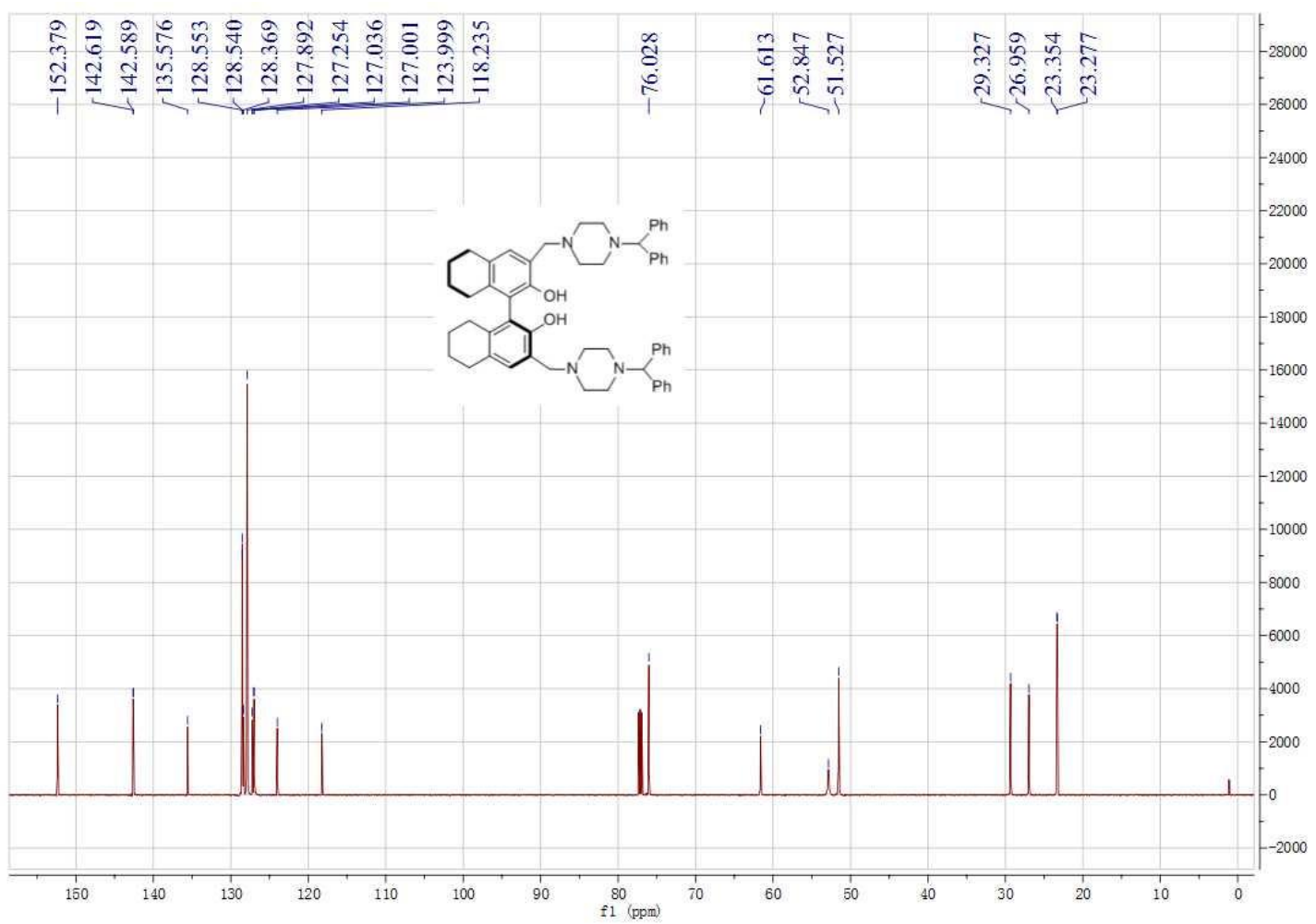


${ }^{1} \mathrm{H}$ NMR of $\mathbf{4 . 1 2}$

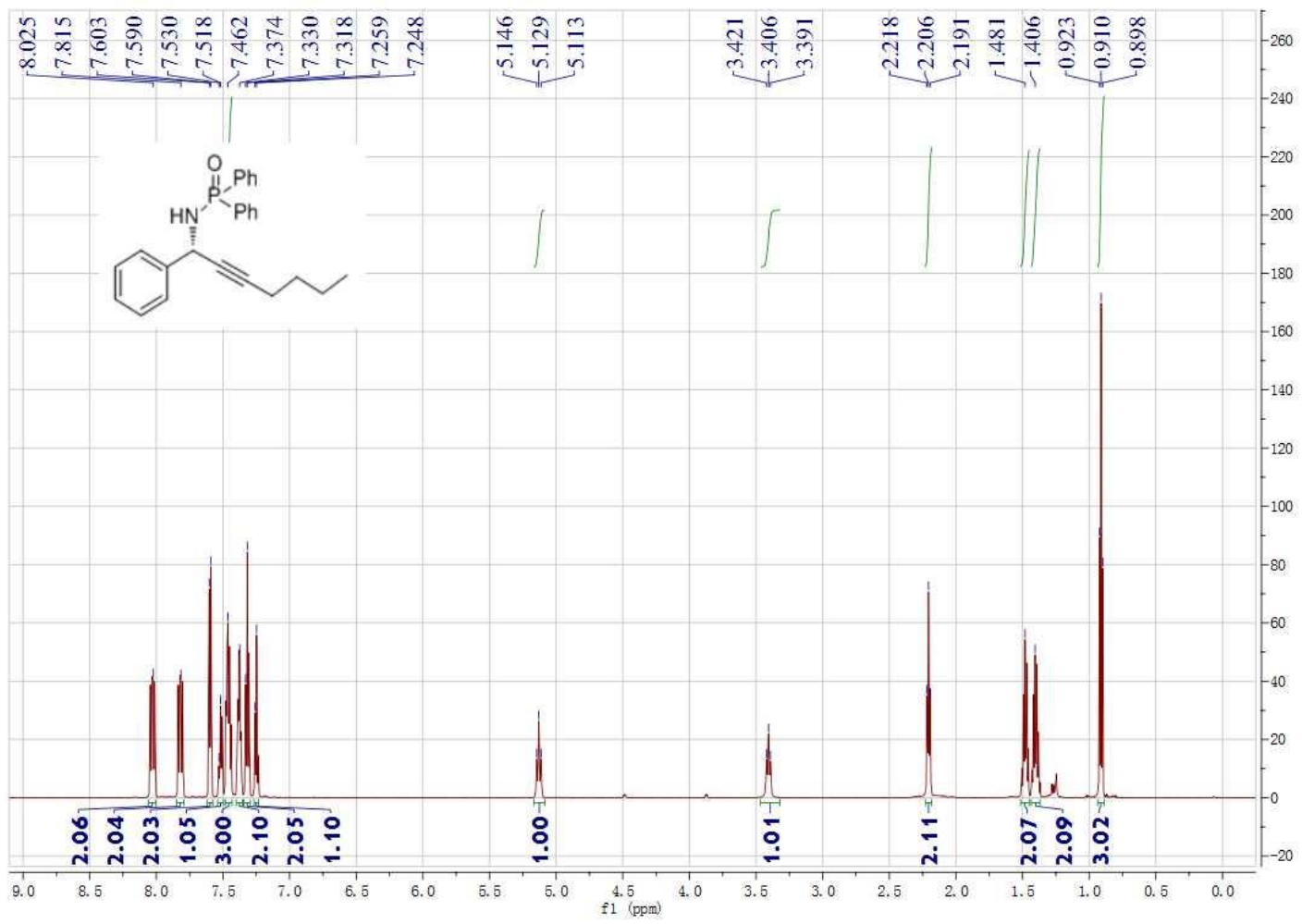

${ }^{13} \mathrm{C}$ NMR of $\mathbf{4 . 1 2}$

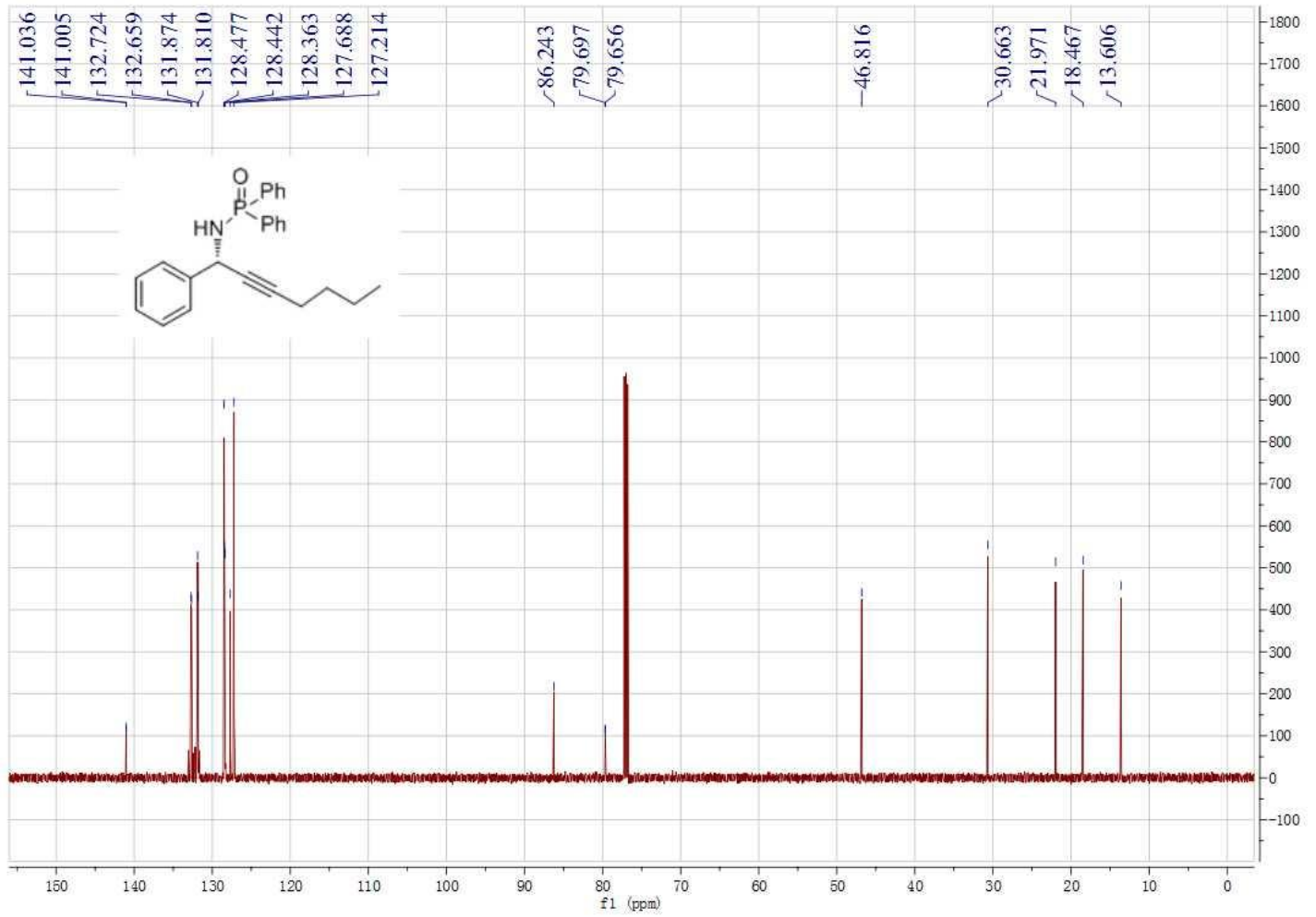


${ }^{1} \mathrm{H}$ NMR of 4.13

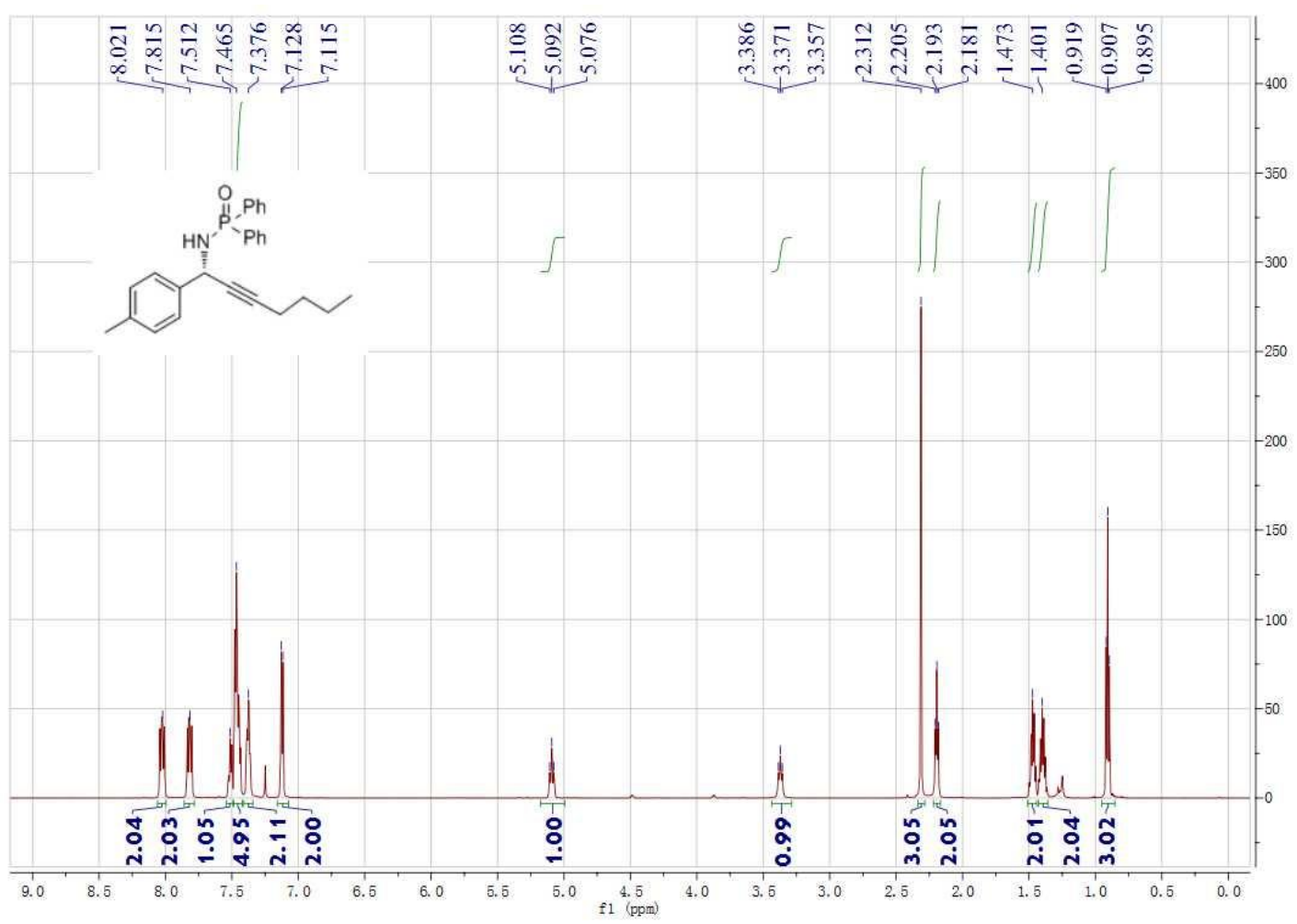

\section{${ }^{13} \mathrm{C}$ NMR of 4.13}

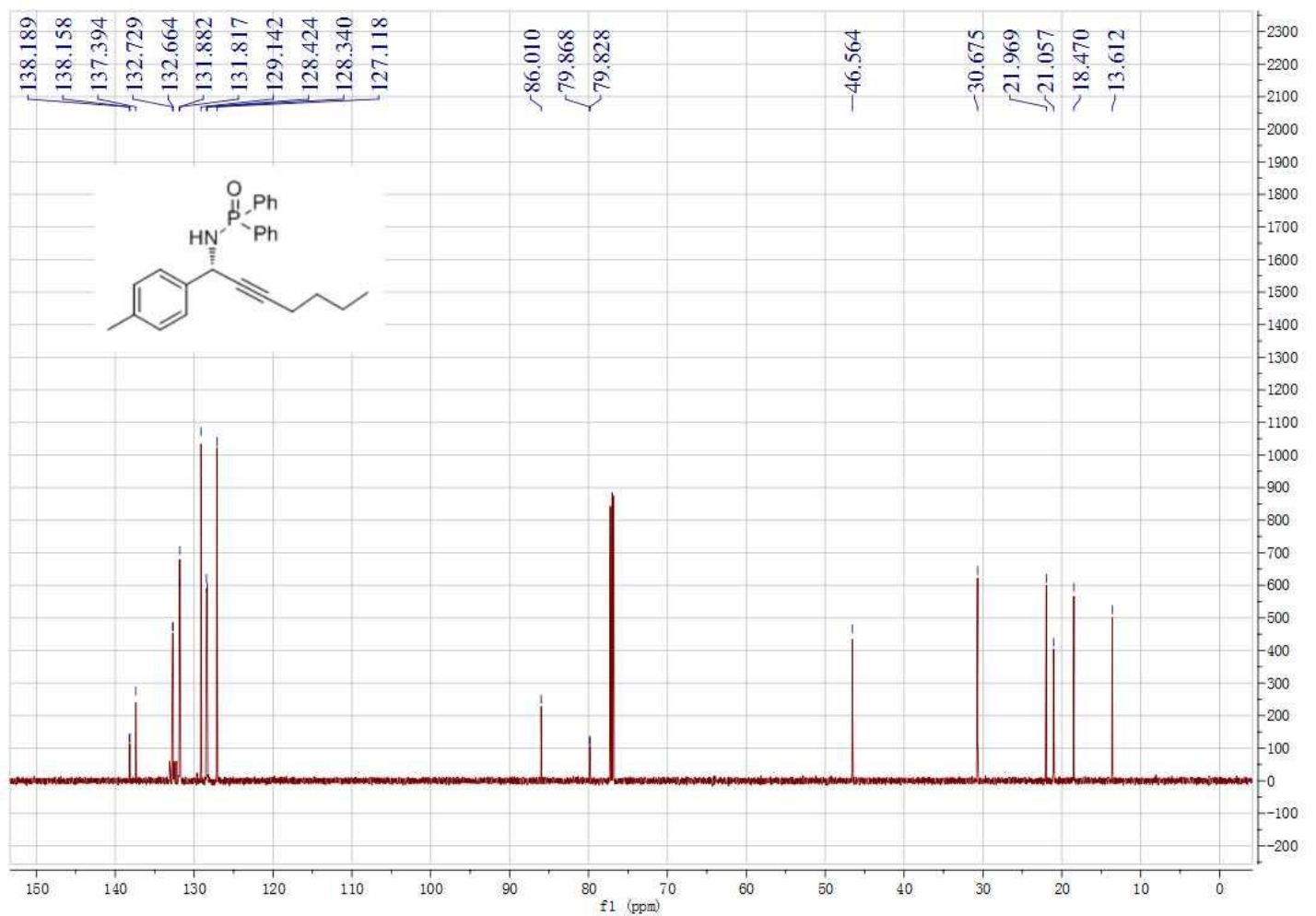


${ }^{1} \mathrm{H}$ NMR of 4.14

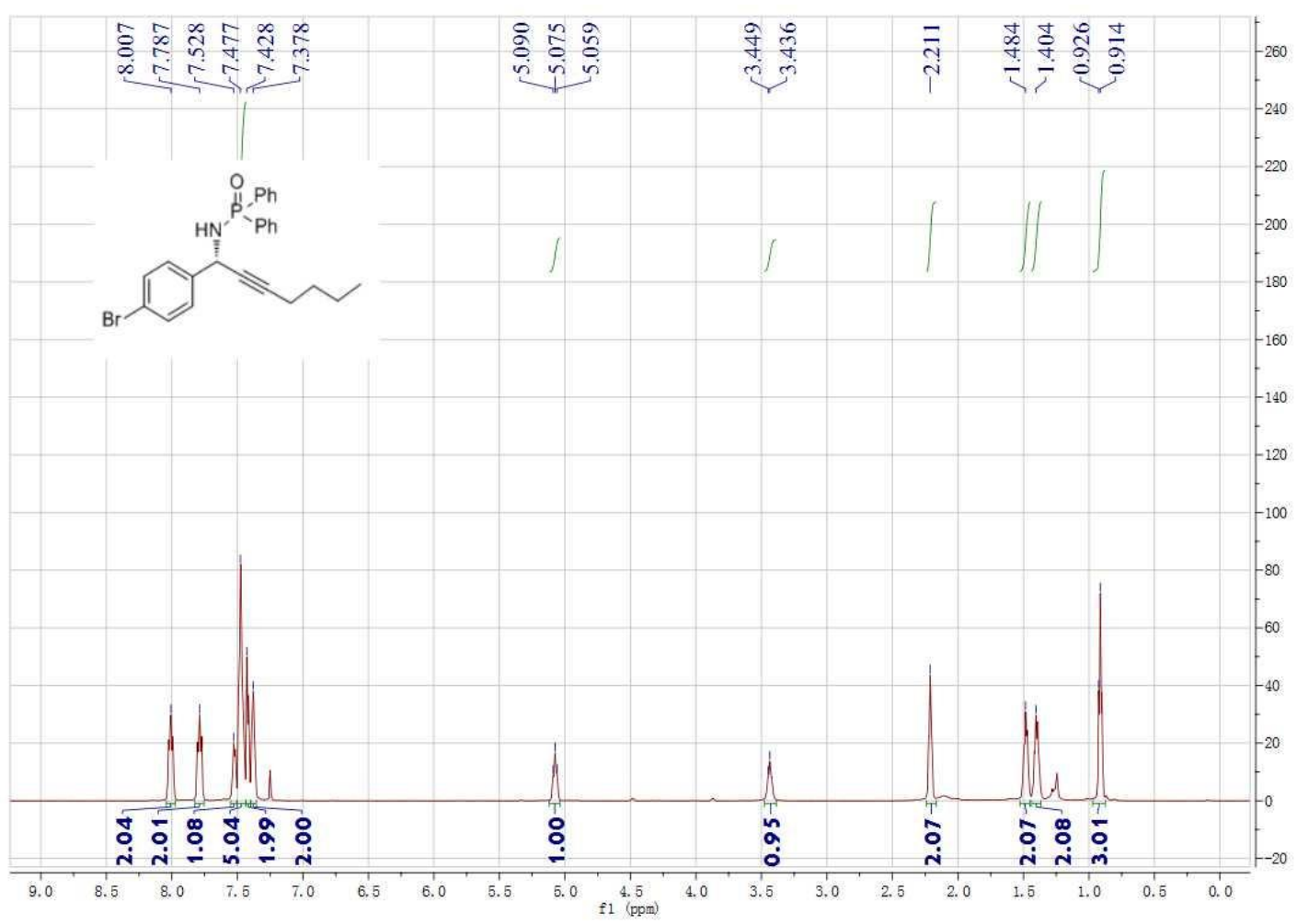

\section{${ }^{13} \mathrm{C}$ NMR of 4.14}

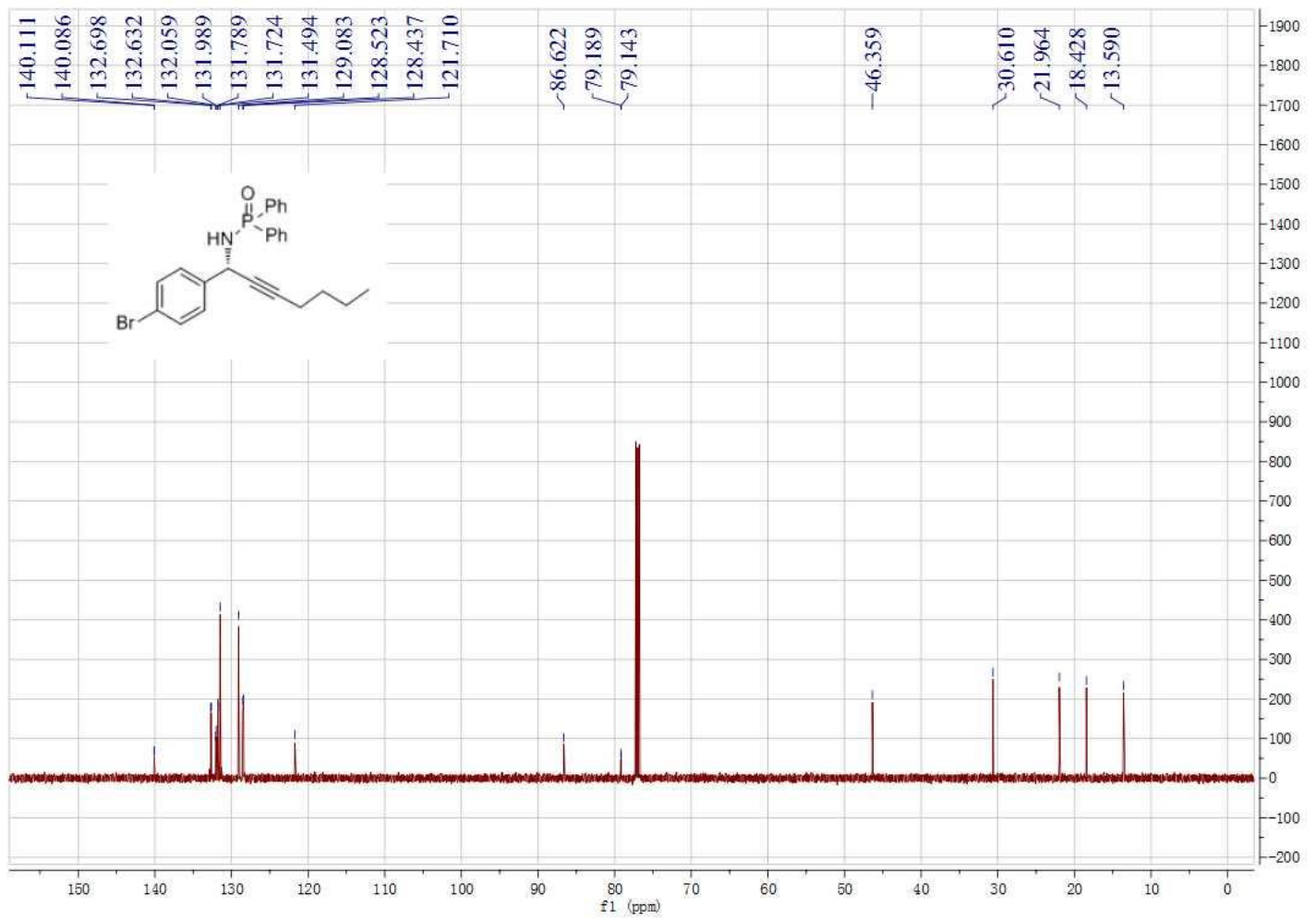


${ }^{1} \mathrm{H}$ NMR of 4.15

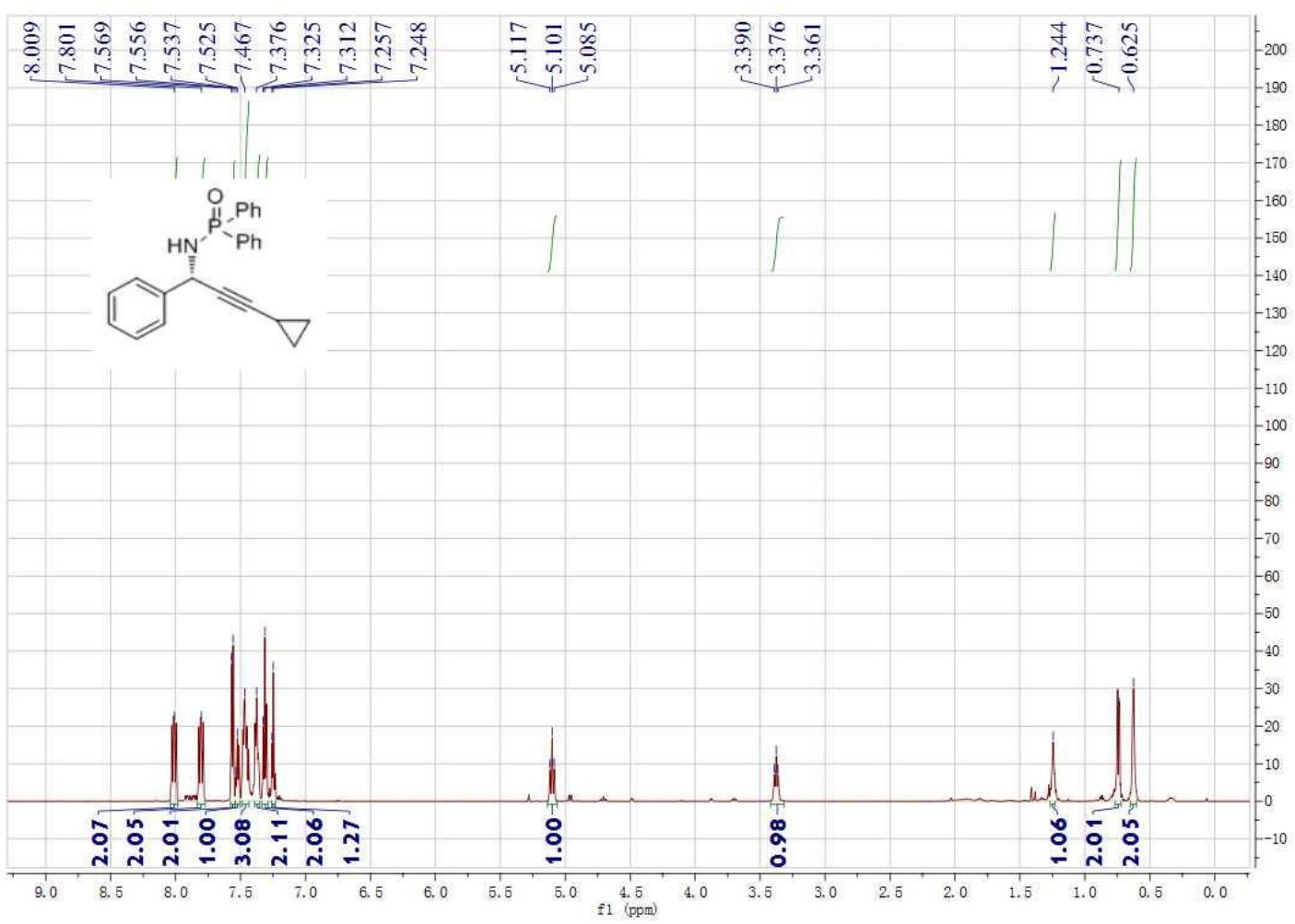

${ }^{13} \mathrm{C}$ NMR of 4.15

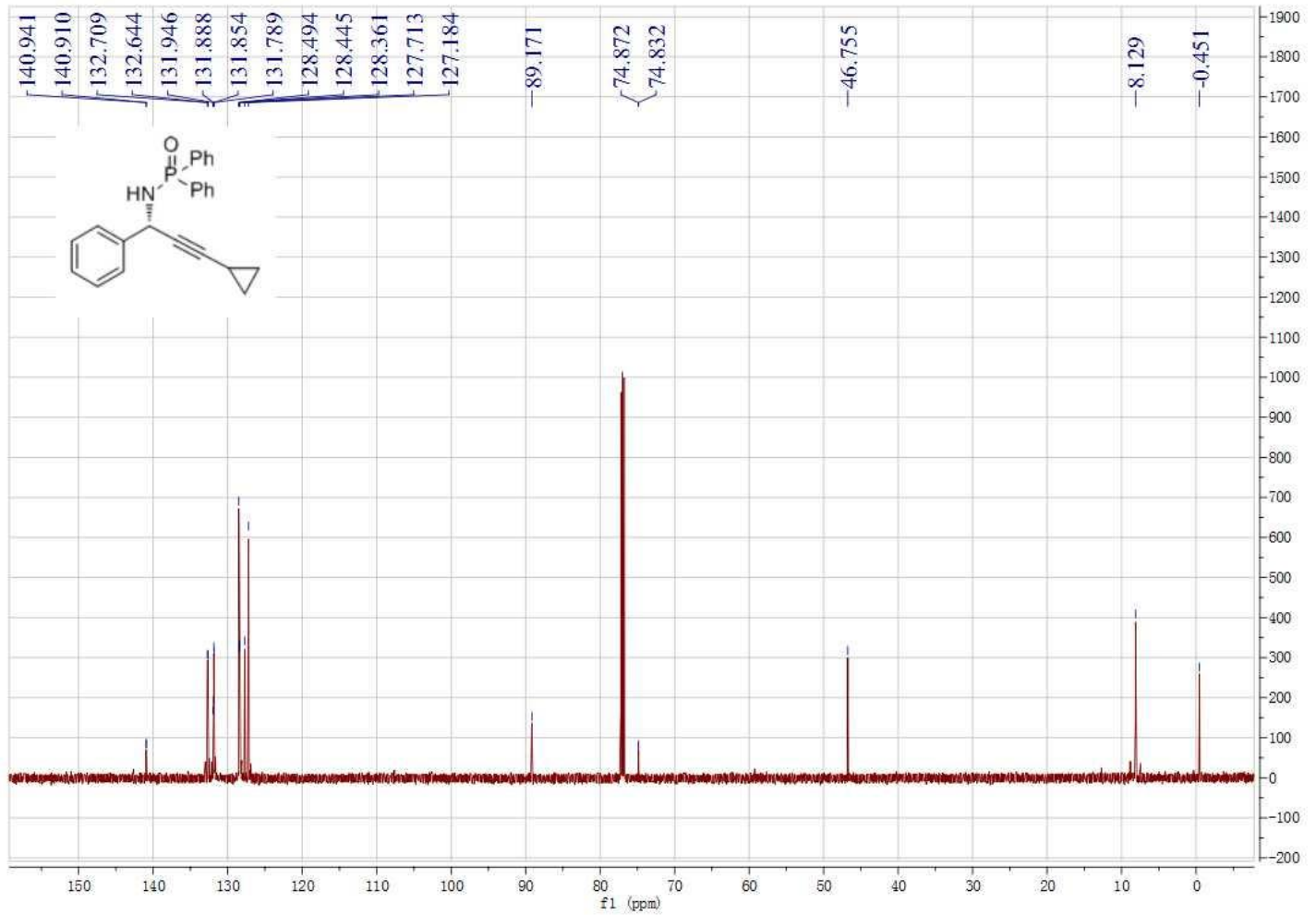


${ }^{1} \mathrm{H}$ NMR of 4.16

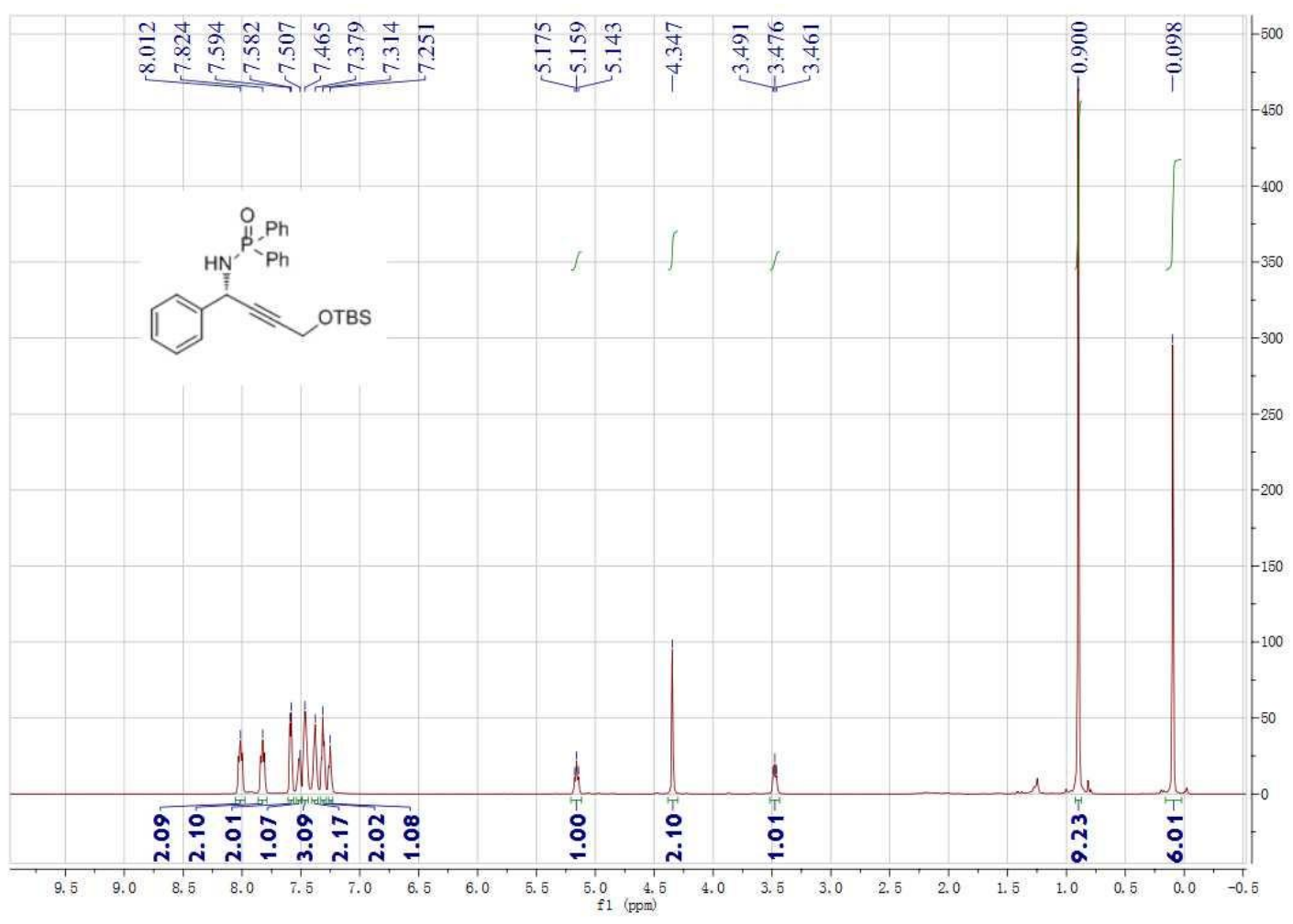

${ }^{13} \mathrm{C}$ NMR of $\mathbf{4 . 1 6}$

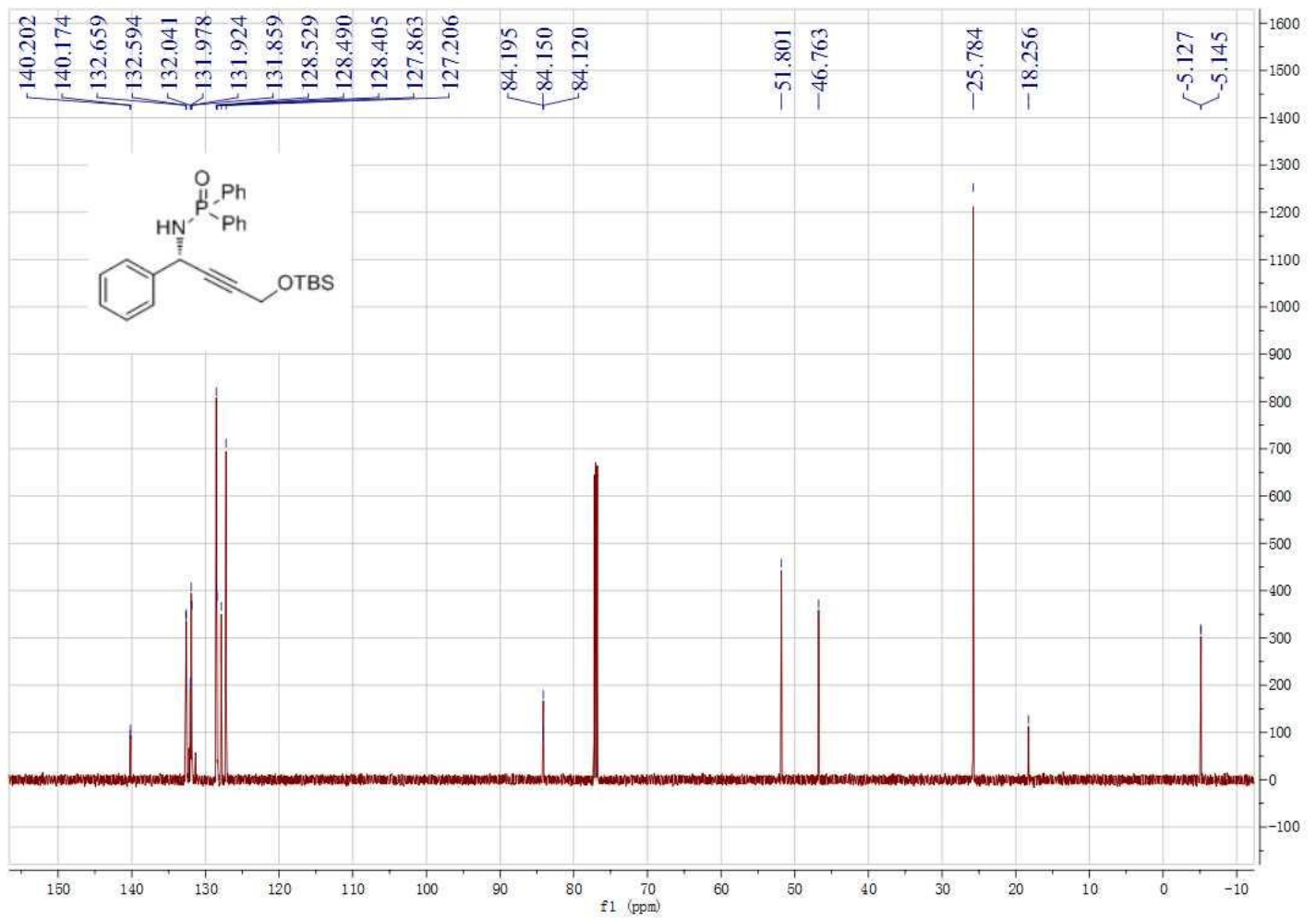


${ }^{1} \mathrm{H}$ NMR of 4.17

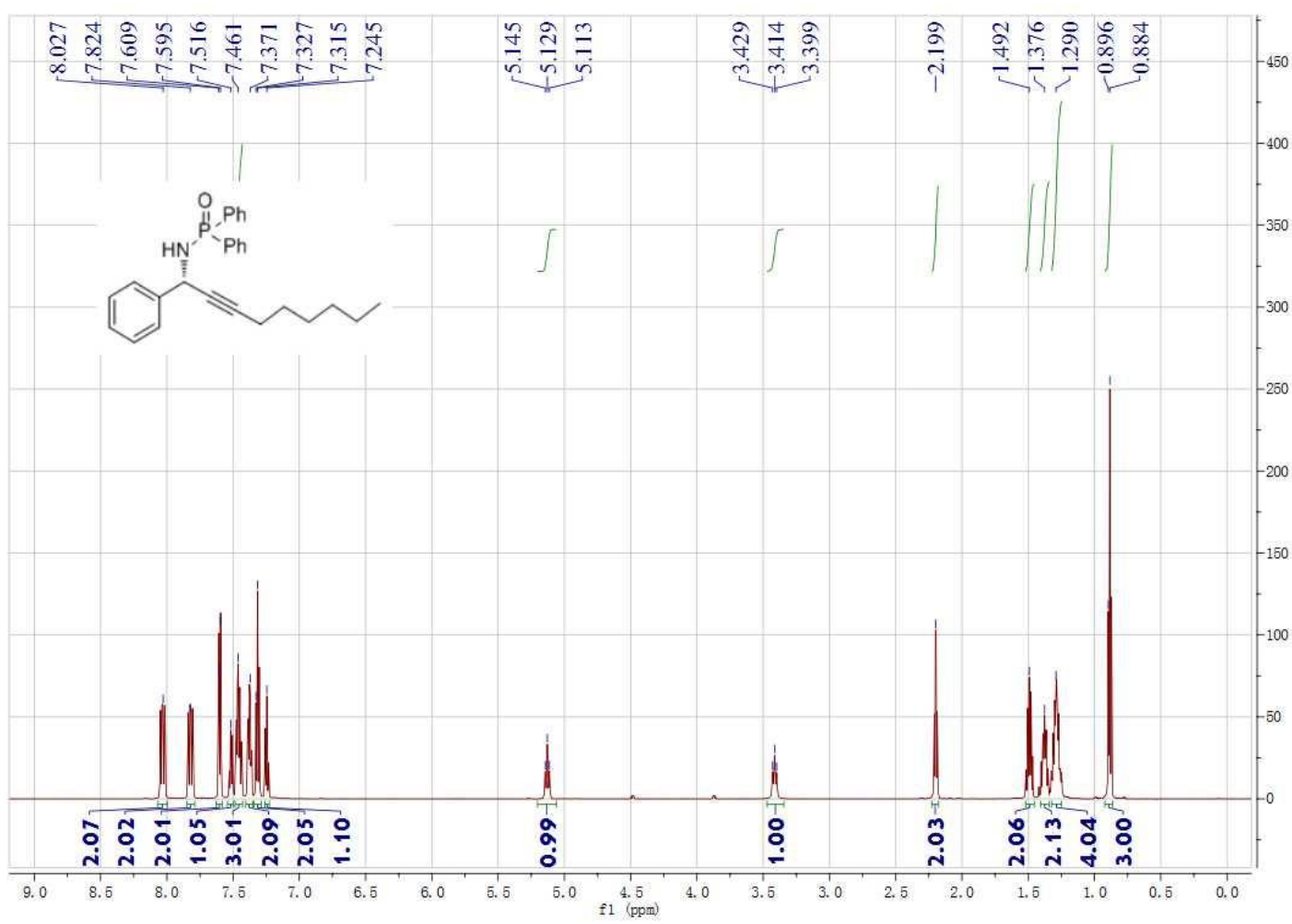

${ }^{13} \mathrm{C}$ NMR of 4.17

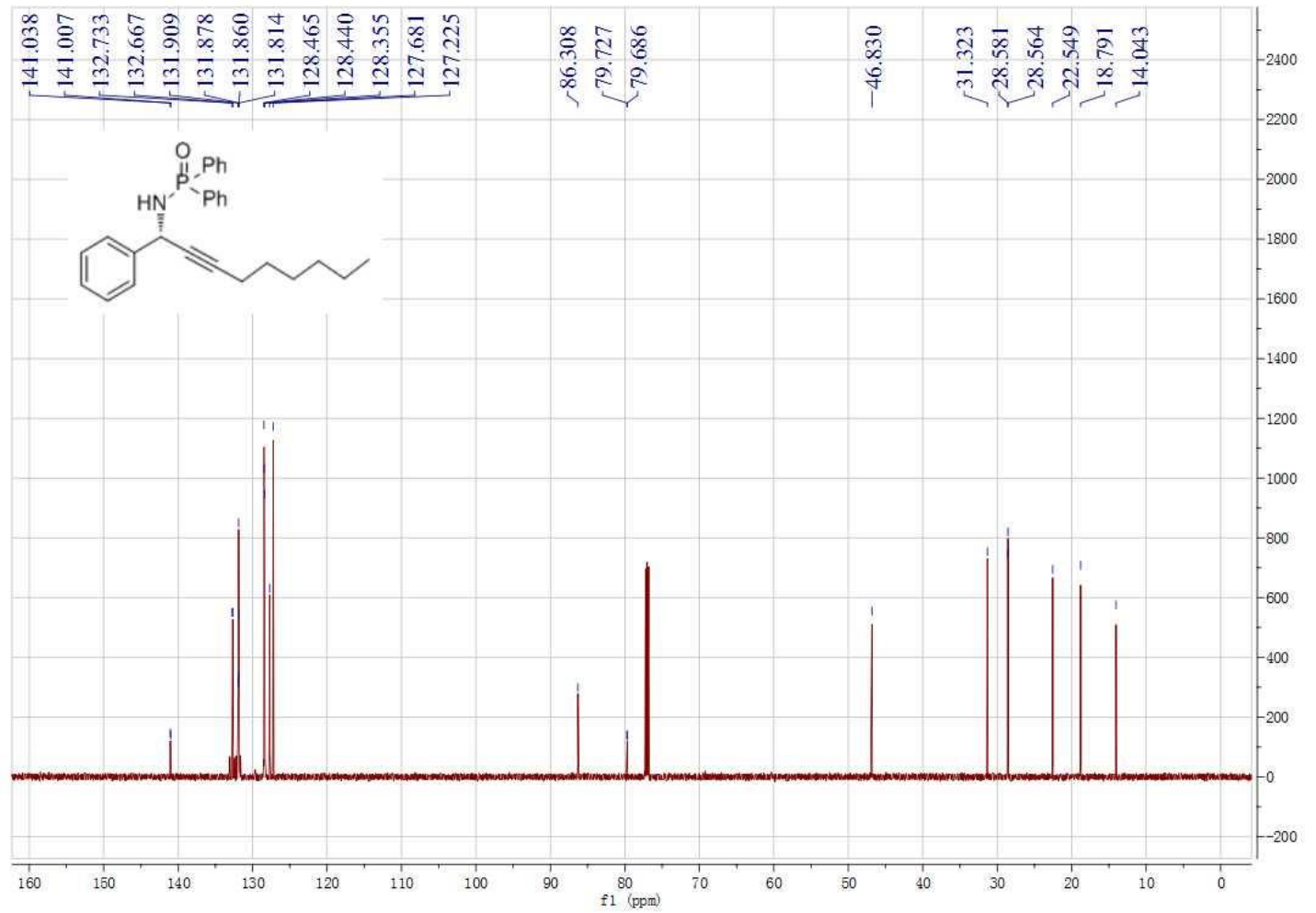


${ }^{1} \mathrm{H}$ NMR of 4.18

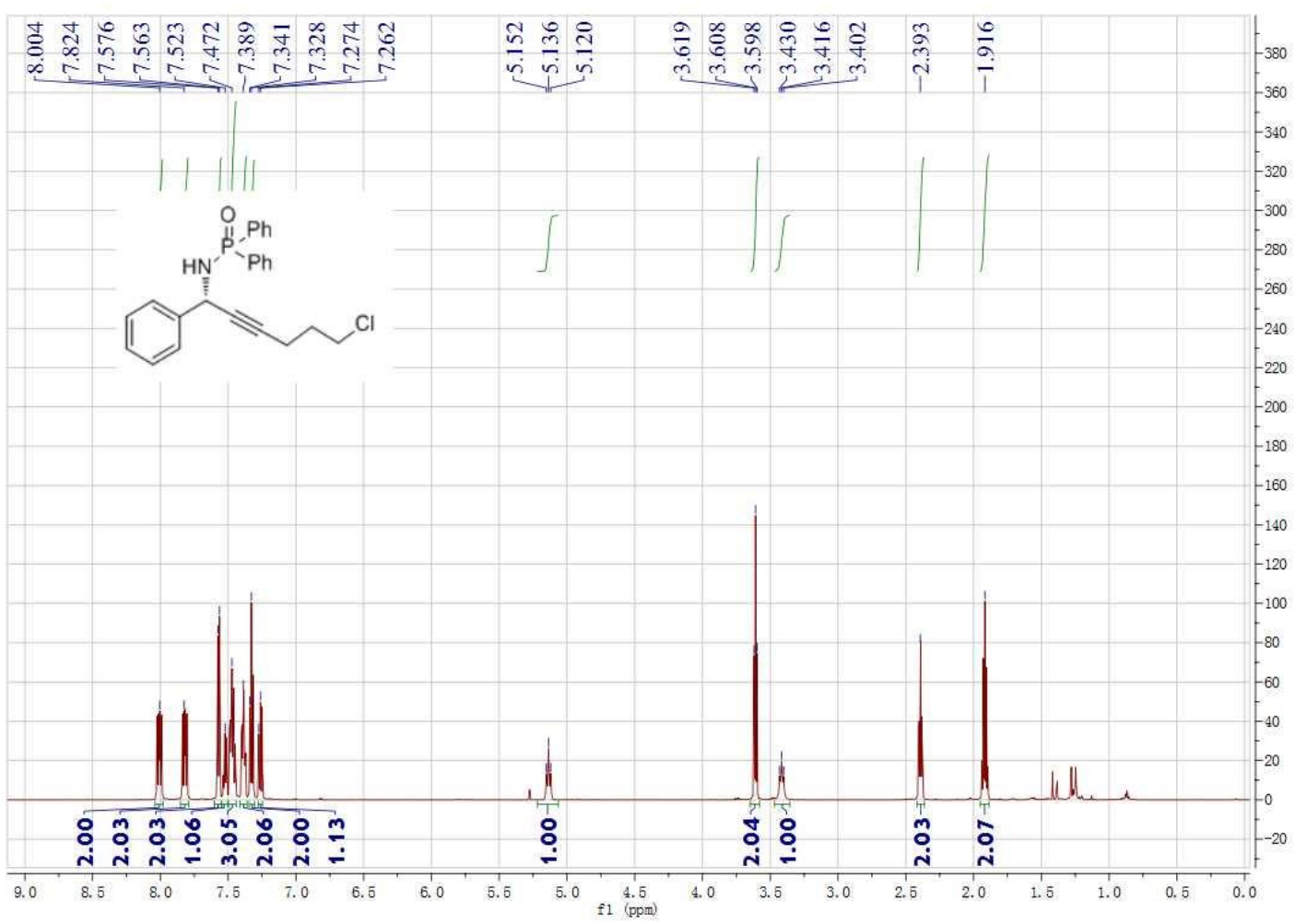

${ }^{13} \mathrm{C}$ NMR of 4.18

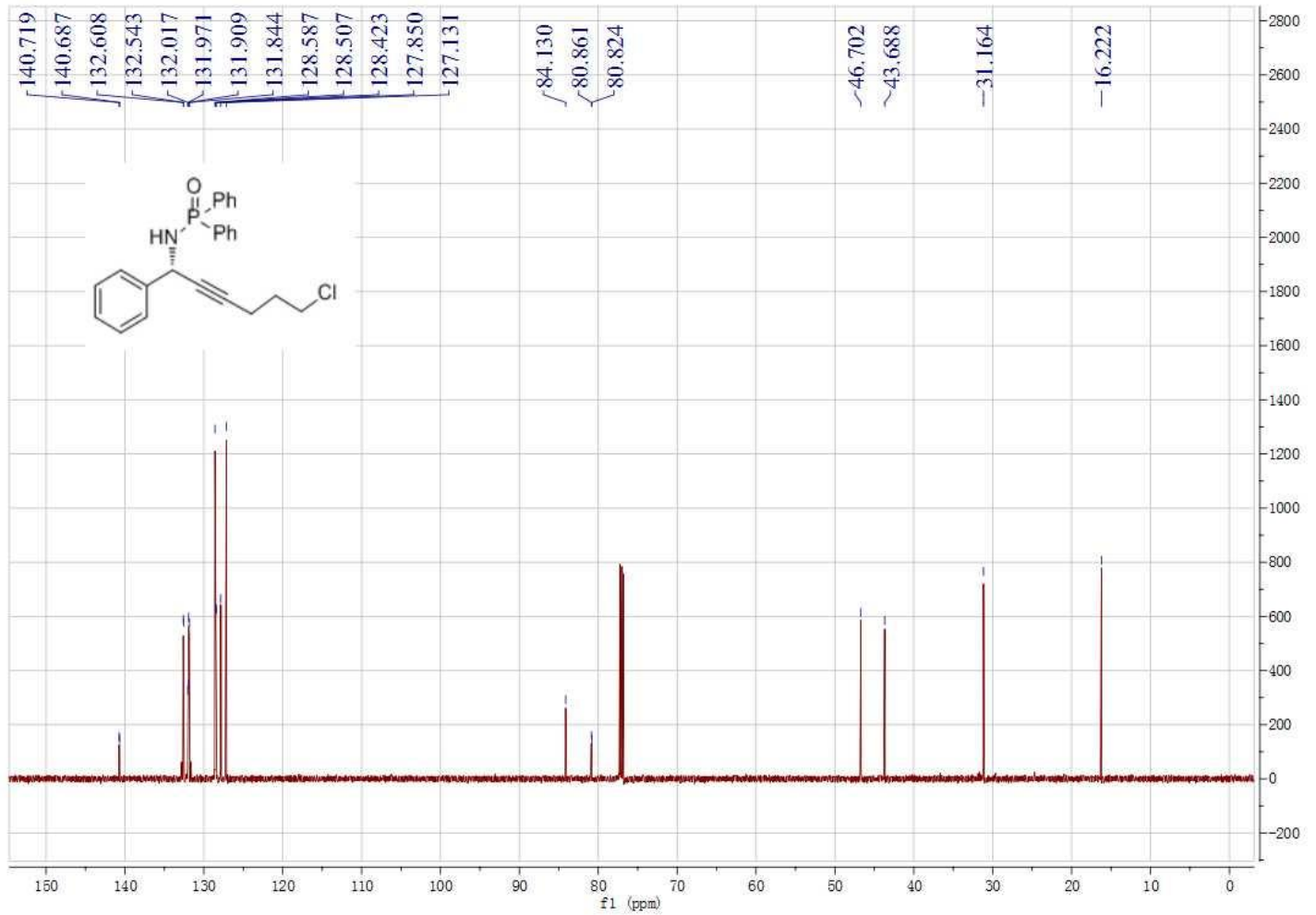


${ }^{1} \mathrm{H}$ NMR of 4.19

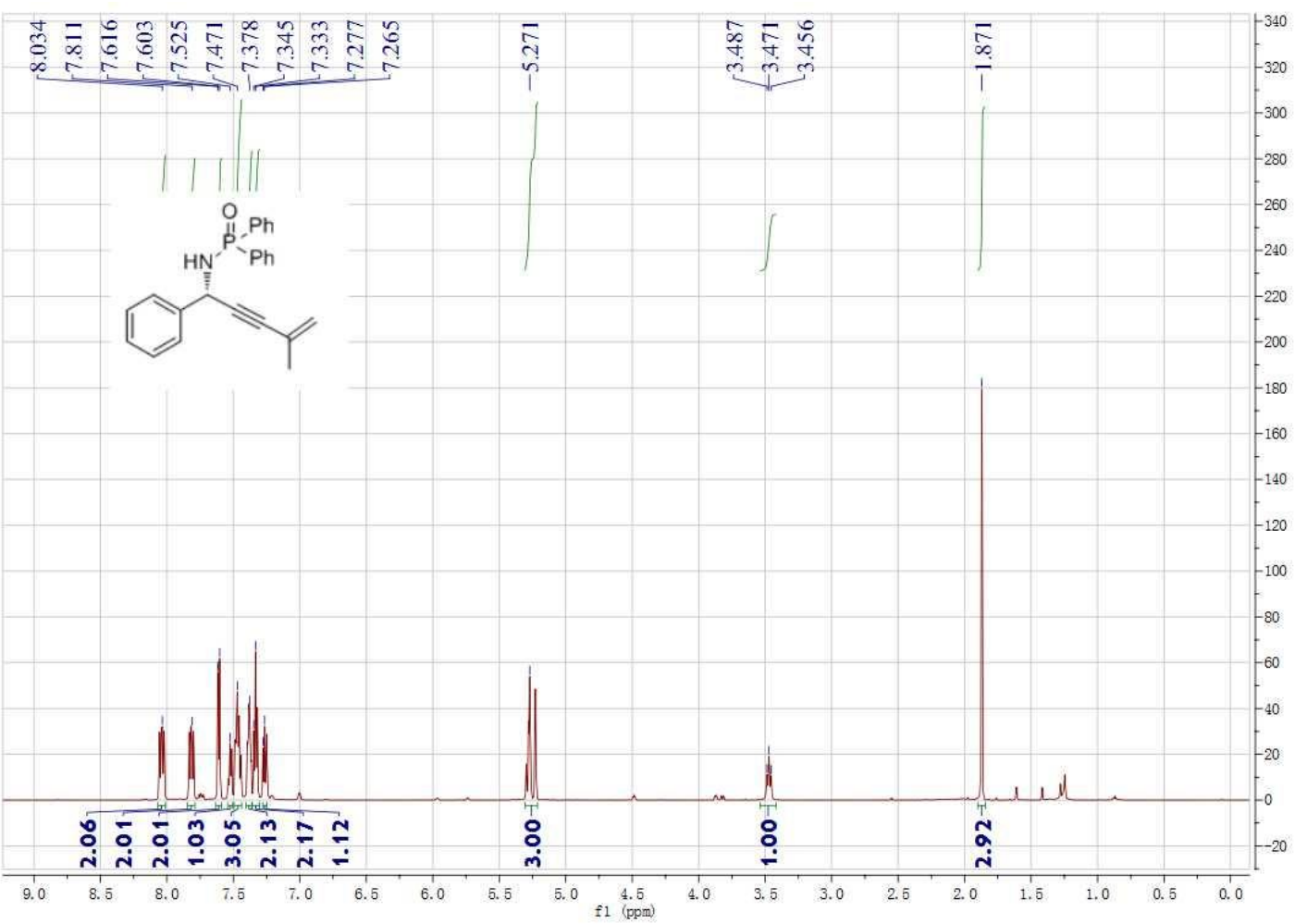

${ }^{13} \mathrm{C}$ NMR of 4.19

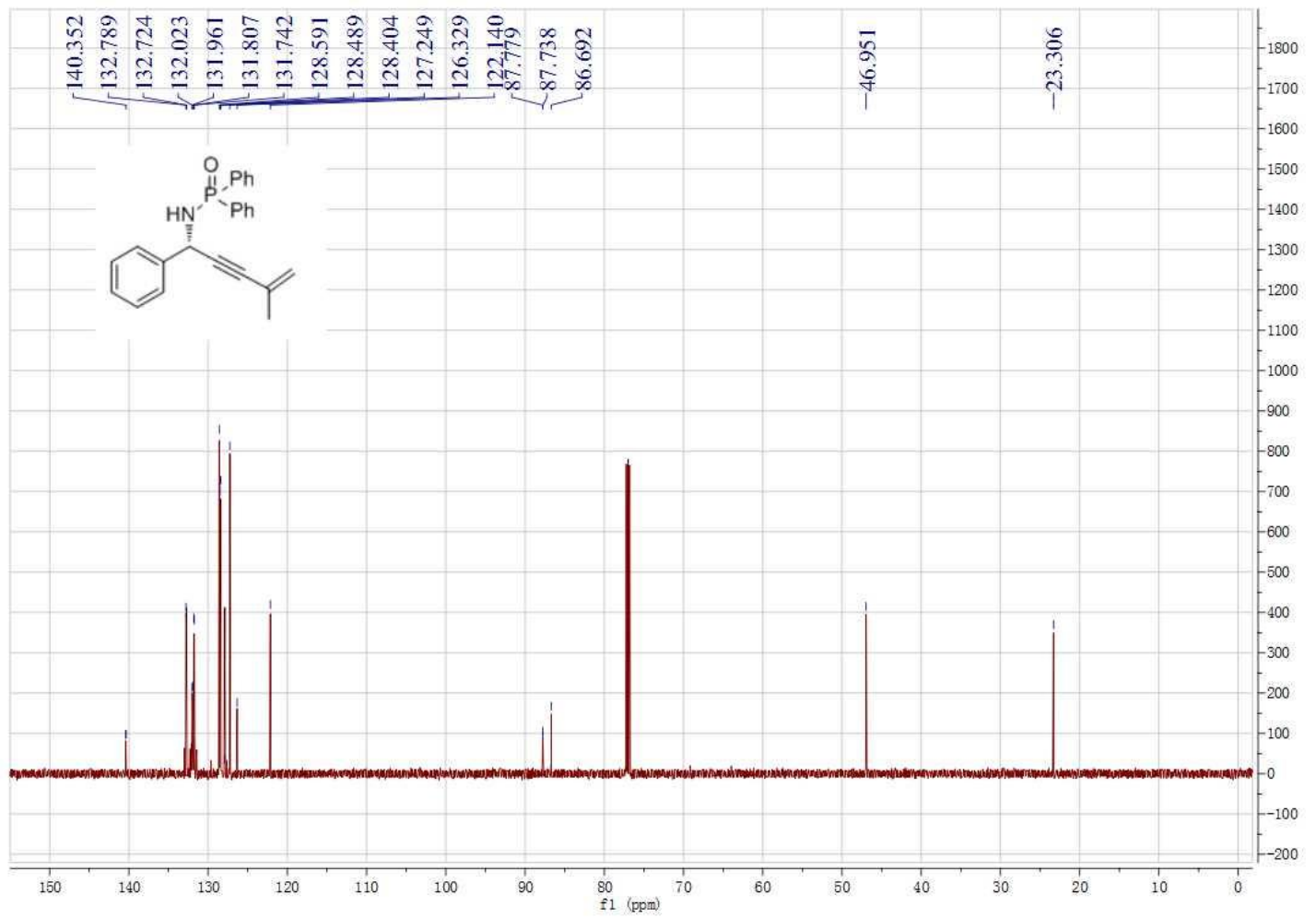


${ }^{1} \mathrm{H}$ NMR of 4.20

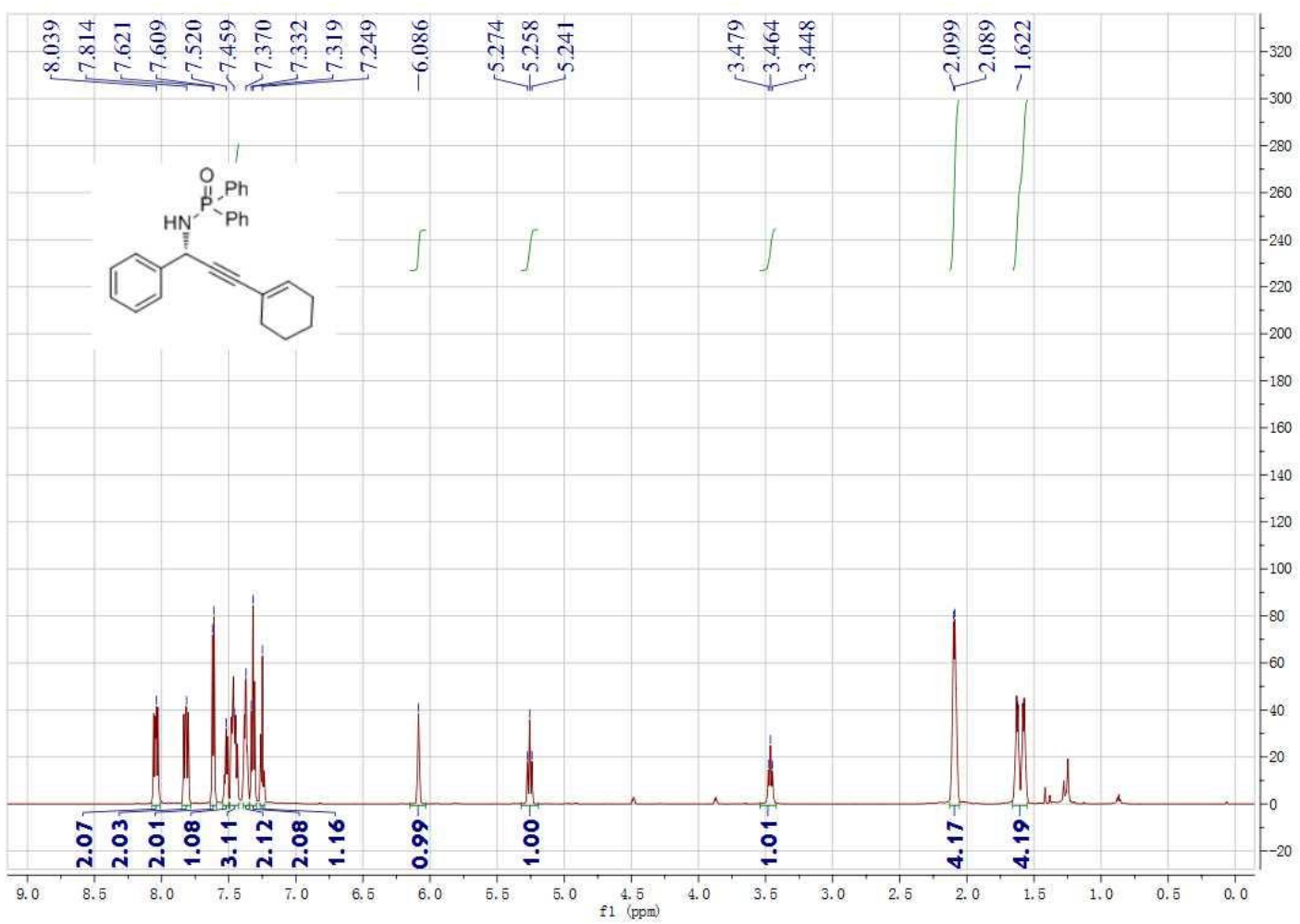

\section{${ }^{13} \mathrm{C}$ NMR of 4.20}

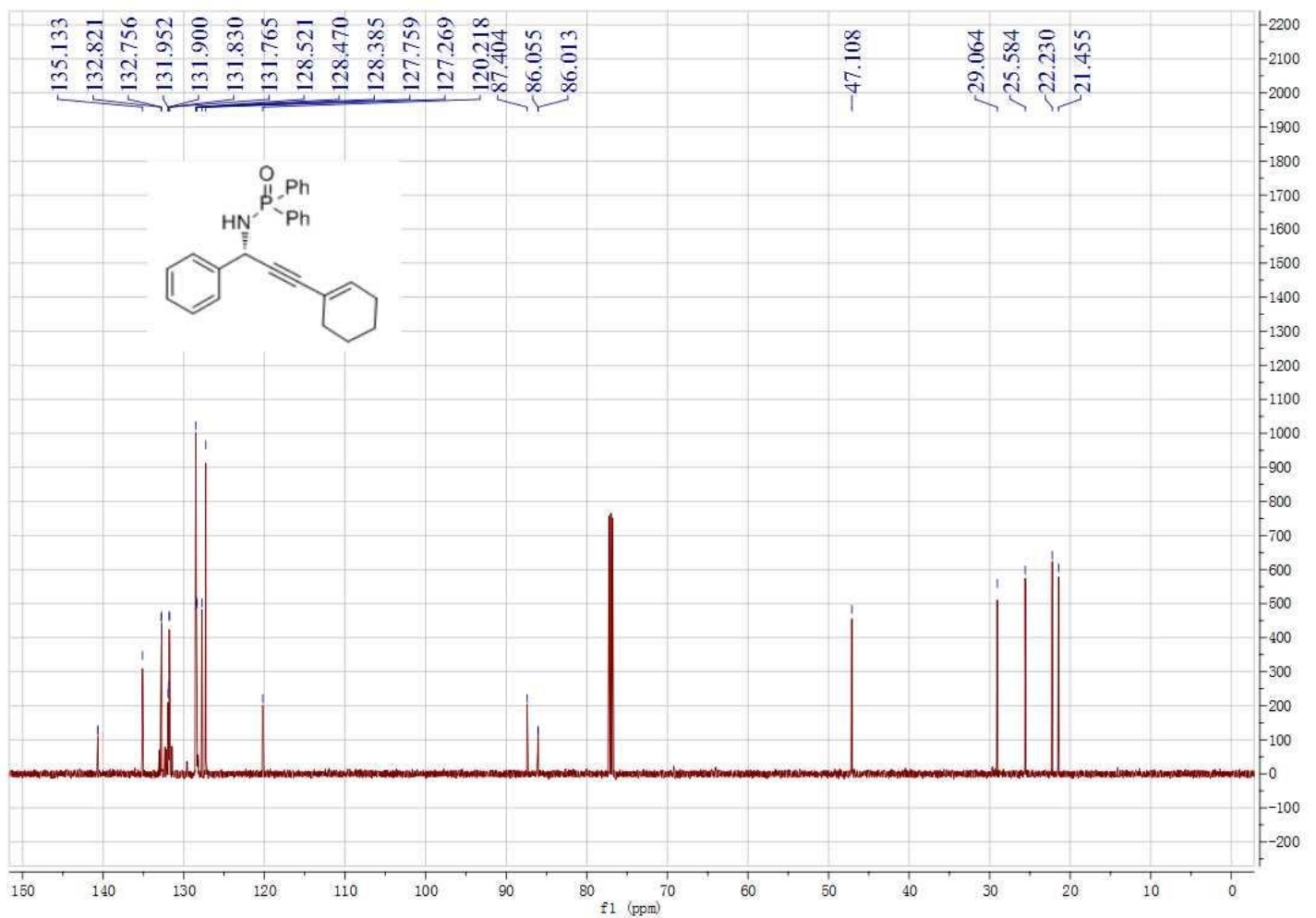


${ }^{1} \mathrm{H}$ NMR of 4.4

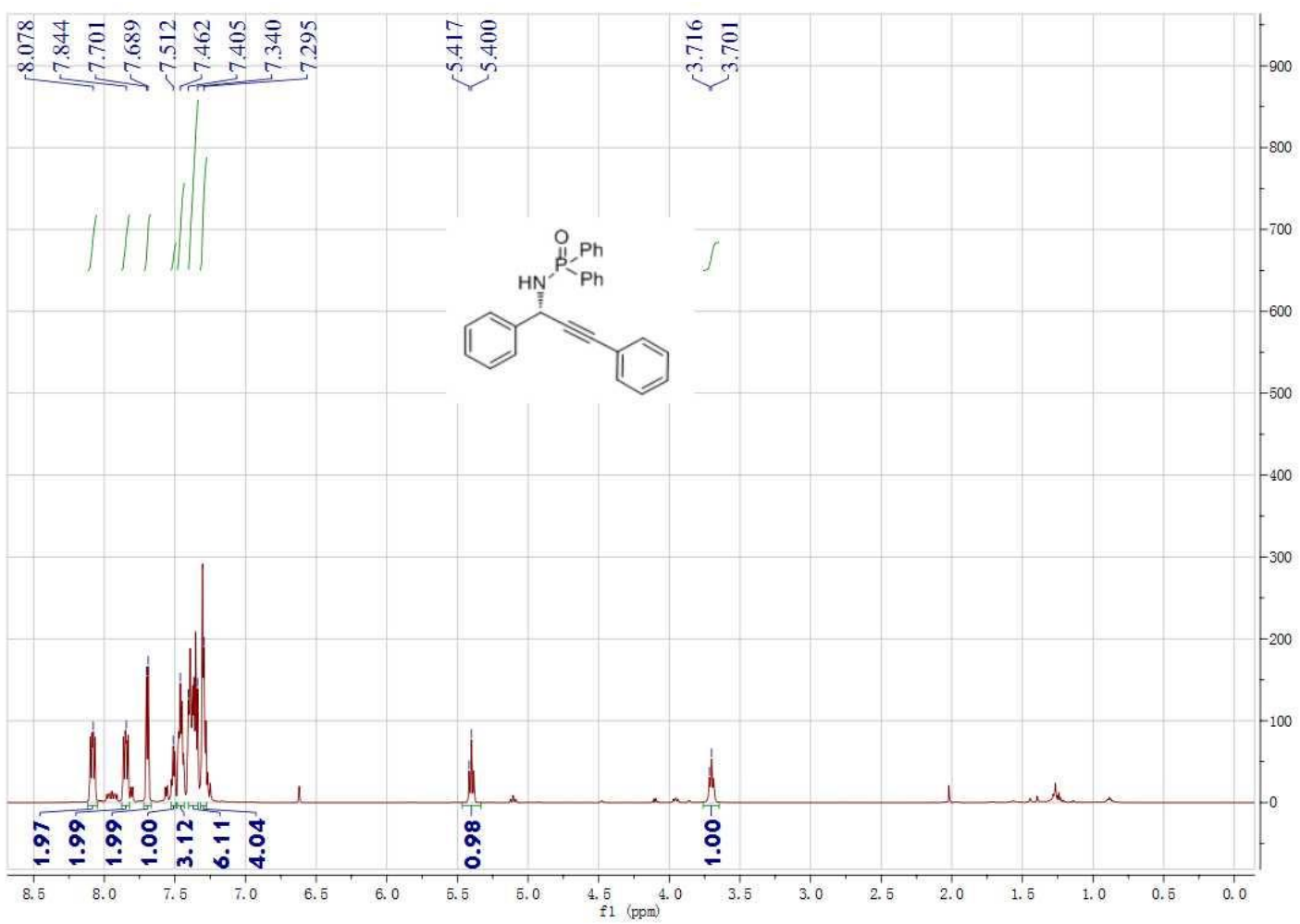

${ }^{13} \mathrm{C}$ NMR of 4.4

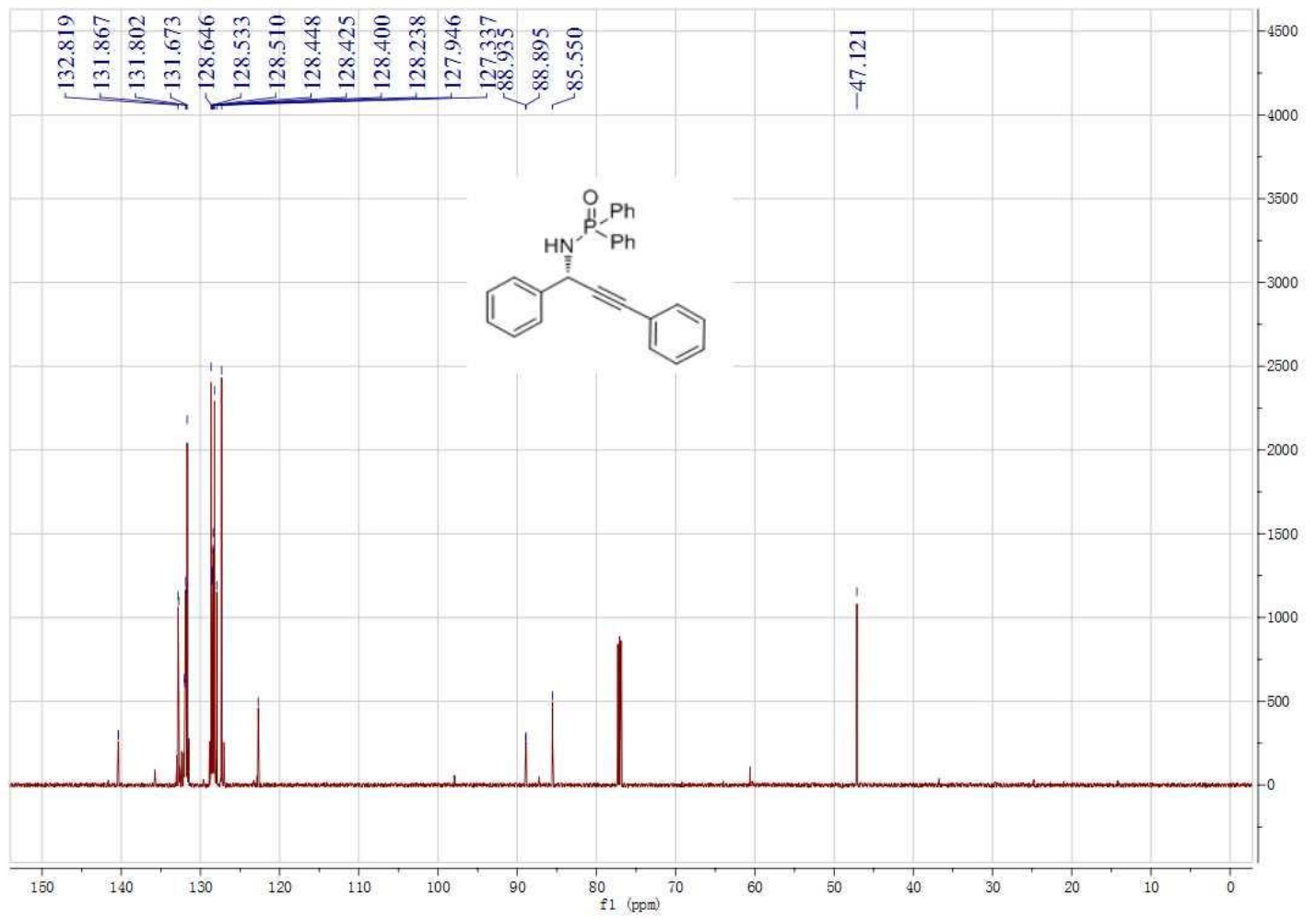




\section{${ }^{1} \mathrm{H}$ NMR of 4.21}

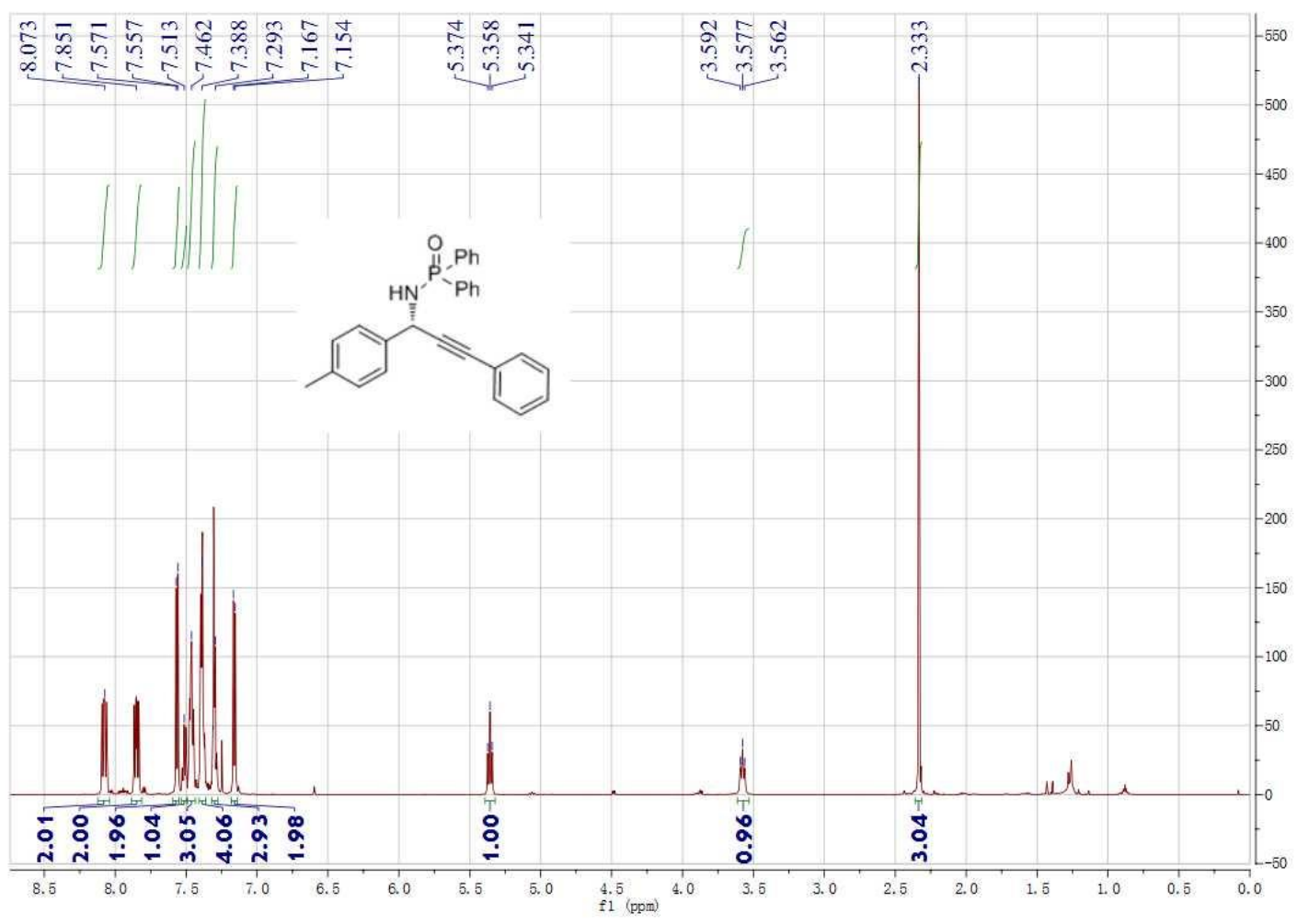

\section{${ }^{13} \mathrm{C}$ NMR of 4.21}

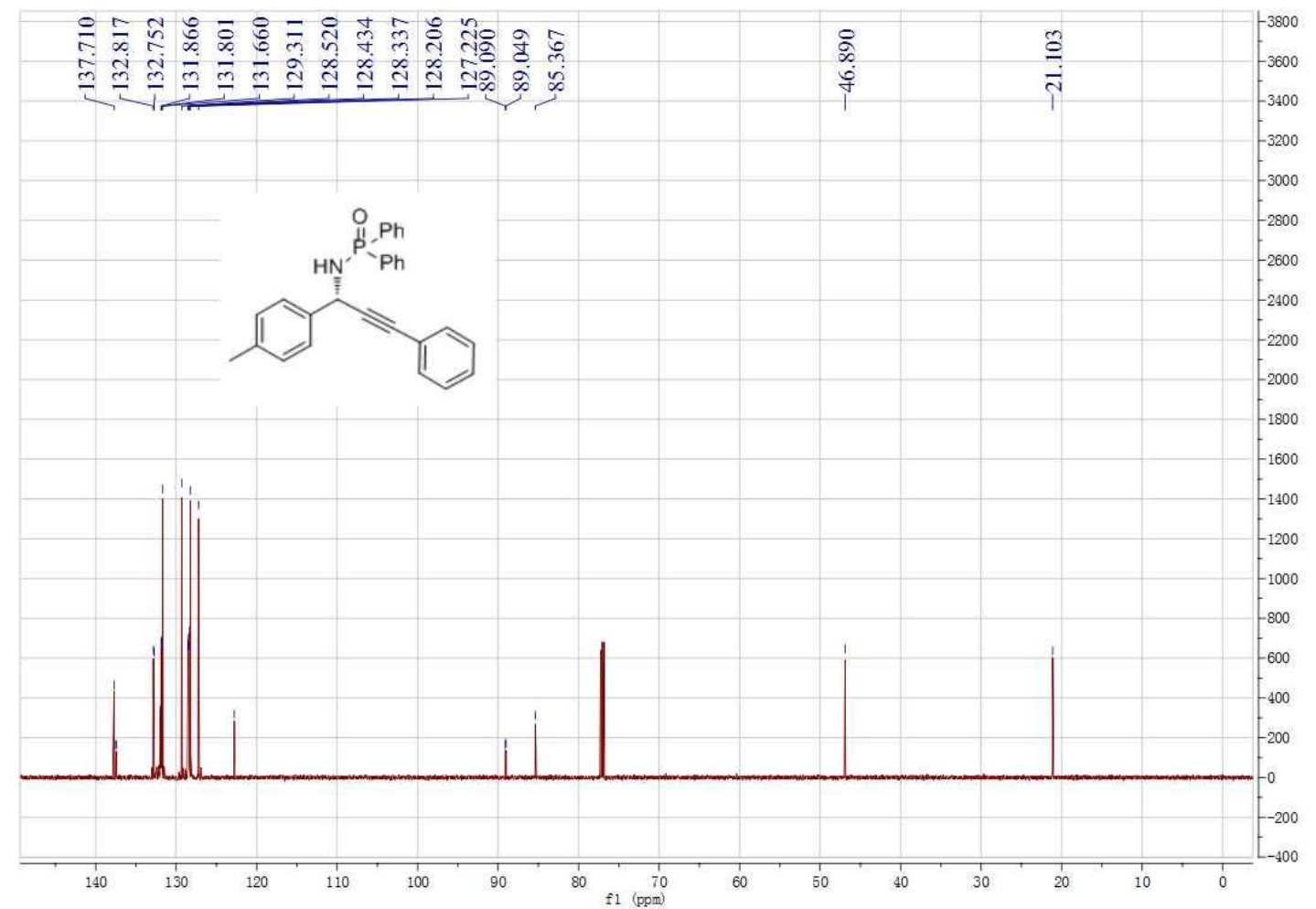


${ }^{1} \mathrm{H}$ NMR of 4.22

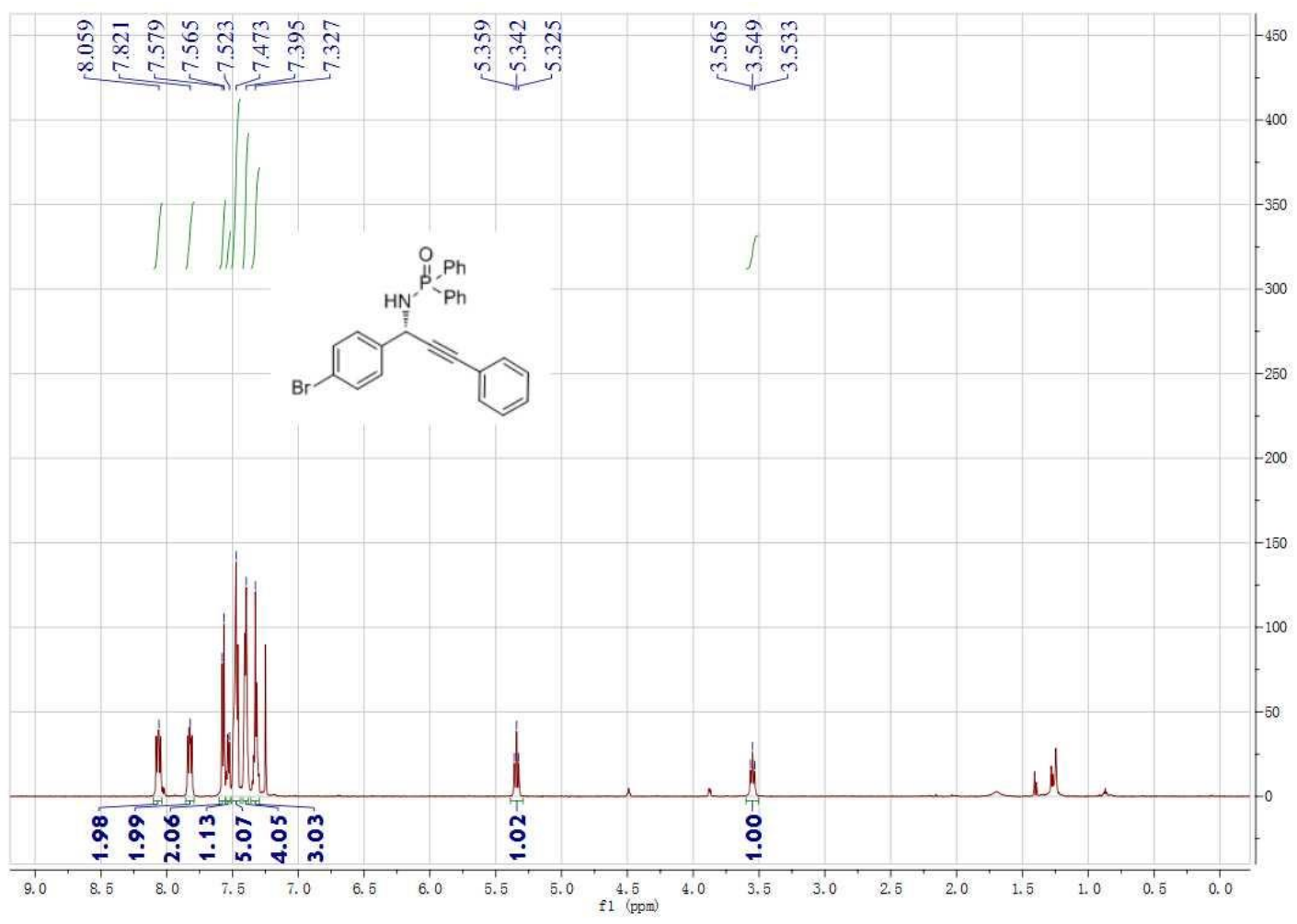

${ }^{13} \mathrm{C}$ NMR of 4.22

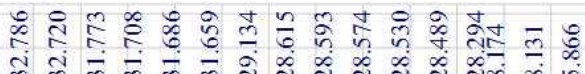

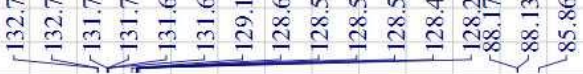

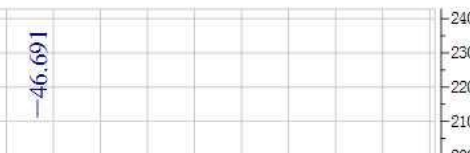<smiles>O=[PH](NC(=Cc1ccccc1)c1ccc(Br)cc1)c1ccccc1</smiles>
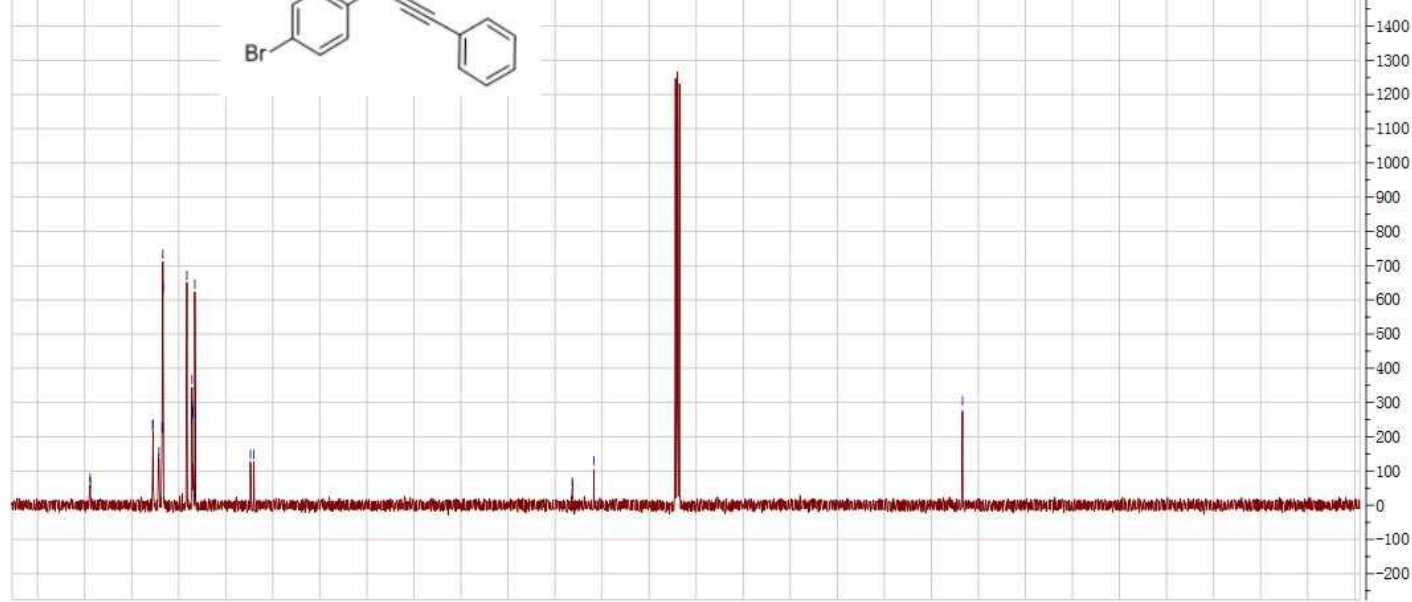

\begin{tabular}{llllllllllllllllllllllllllll}
145 & 140 & 135 & 130 & 125 & 120 & 115 & 110 & 105 & 100 & 95 & 90 & 85 & 80 & 75 & 70 & 65 & 60 & 55 & 50 & 45 & 40 & 35 & 30 & 25 & 20 & 15 & 10 \\
\hline
\end{tabular} 
${ }^{1} \mathrm{H}$ NMR of 4.23

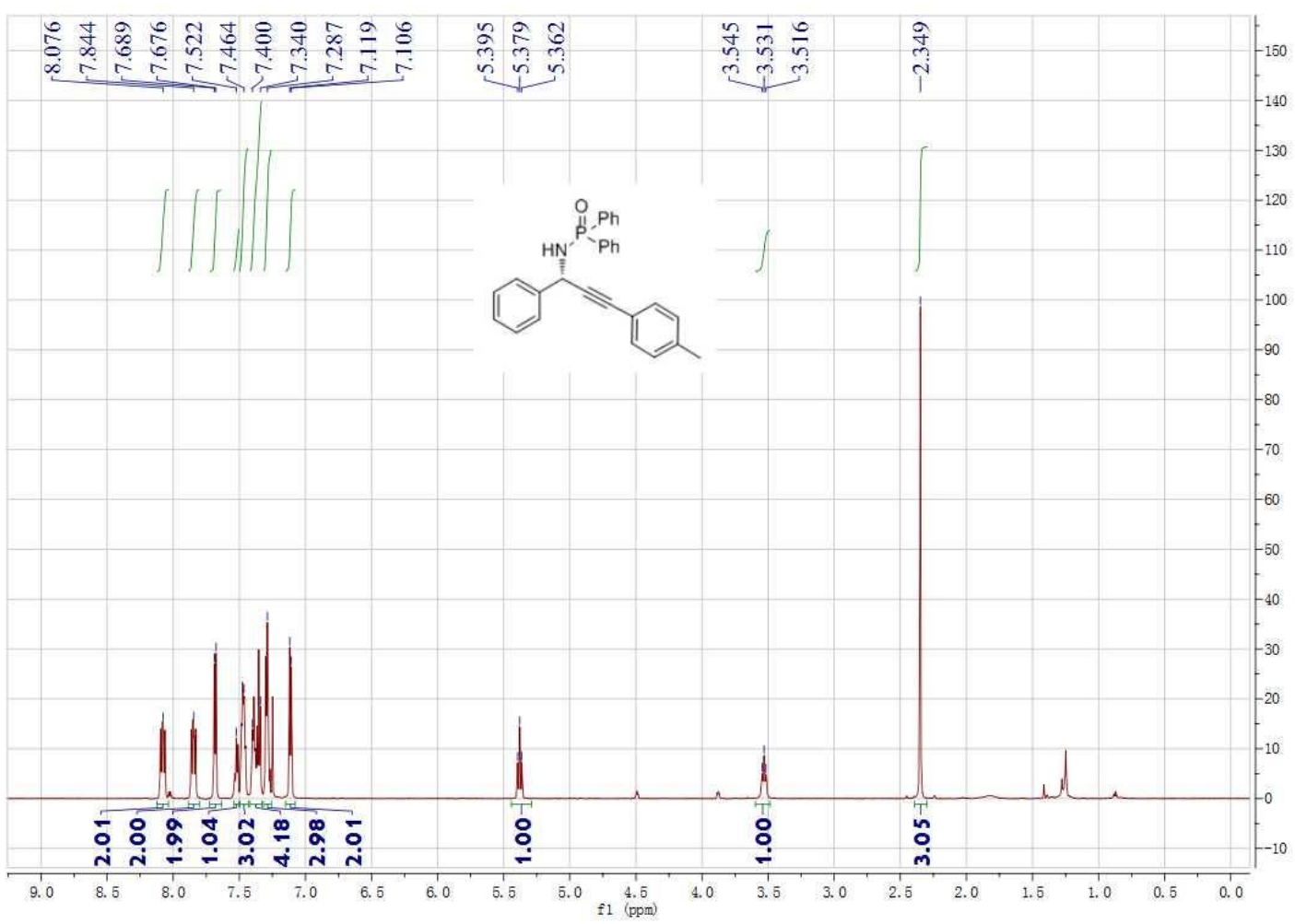

${ }^{13} \mathrm{C}$ NMR of 4.23

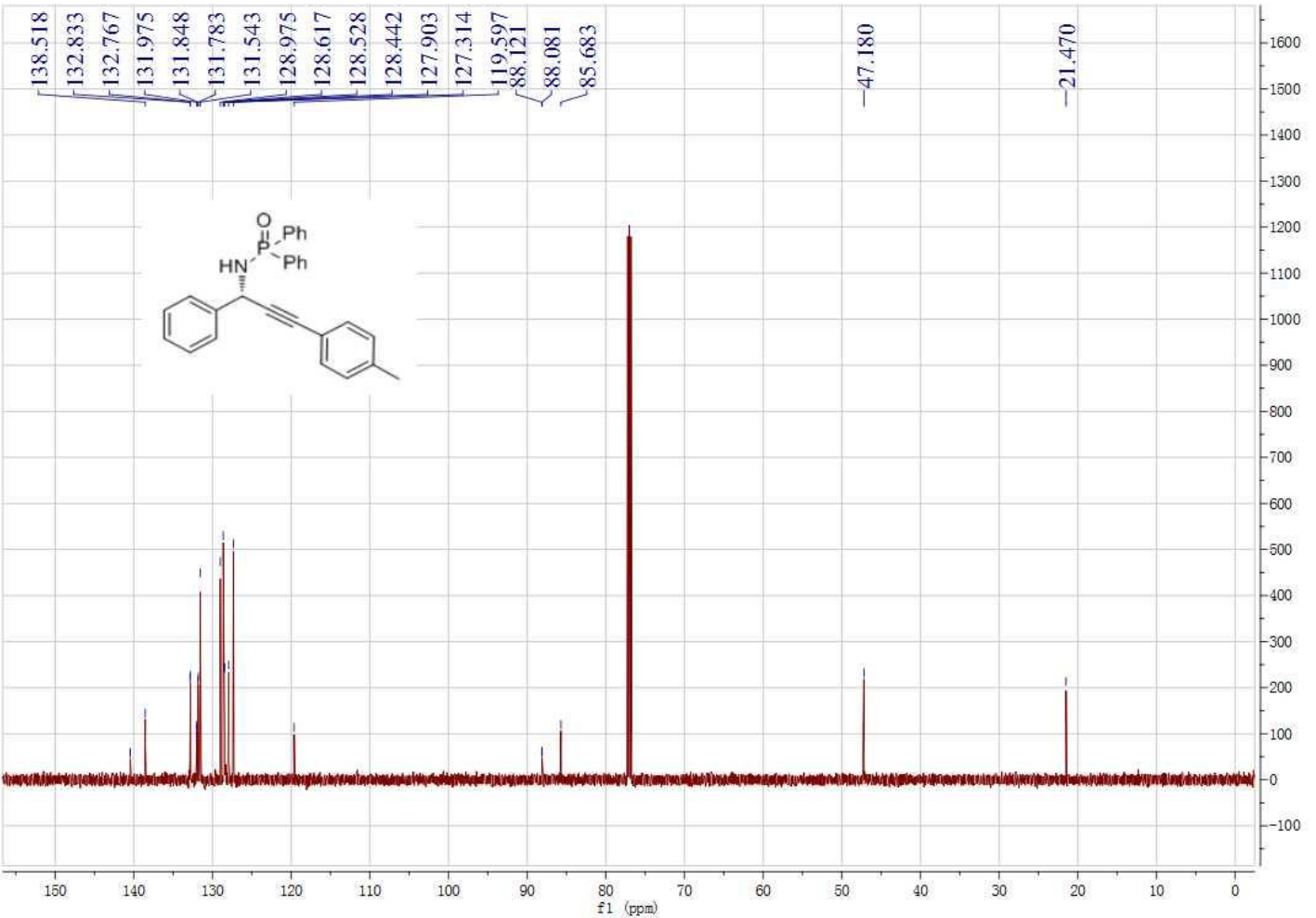


${ }^{1} \mathrm{H}$ NMR of $\mathbf{4 . 2 4}$

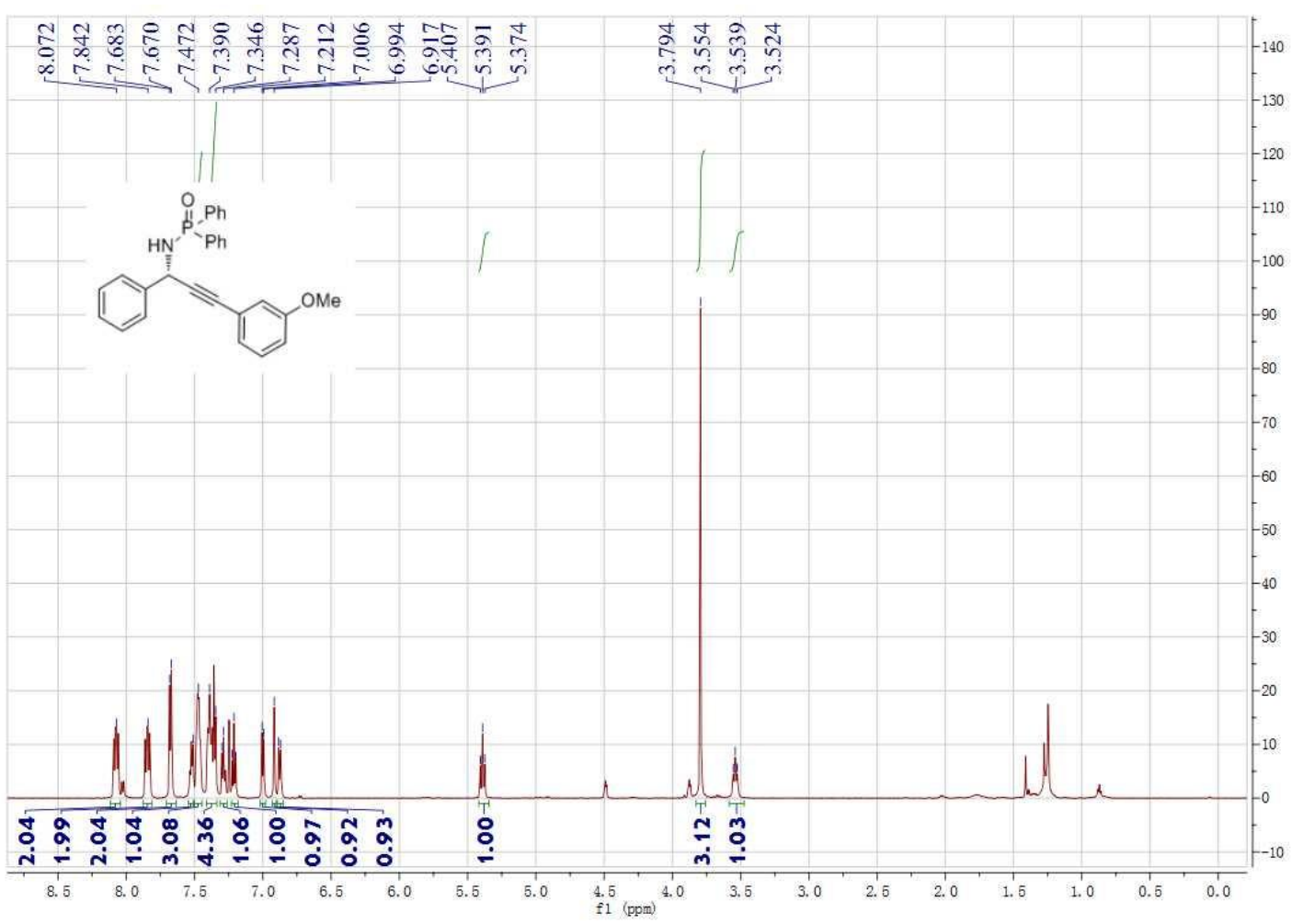

\section{${ }^{13} \mathrm{C}$ NMR of 4.24}

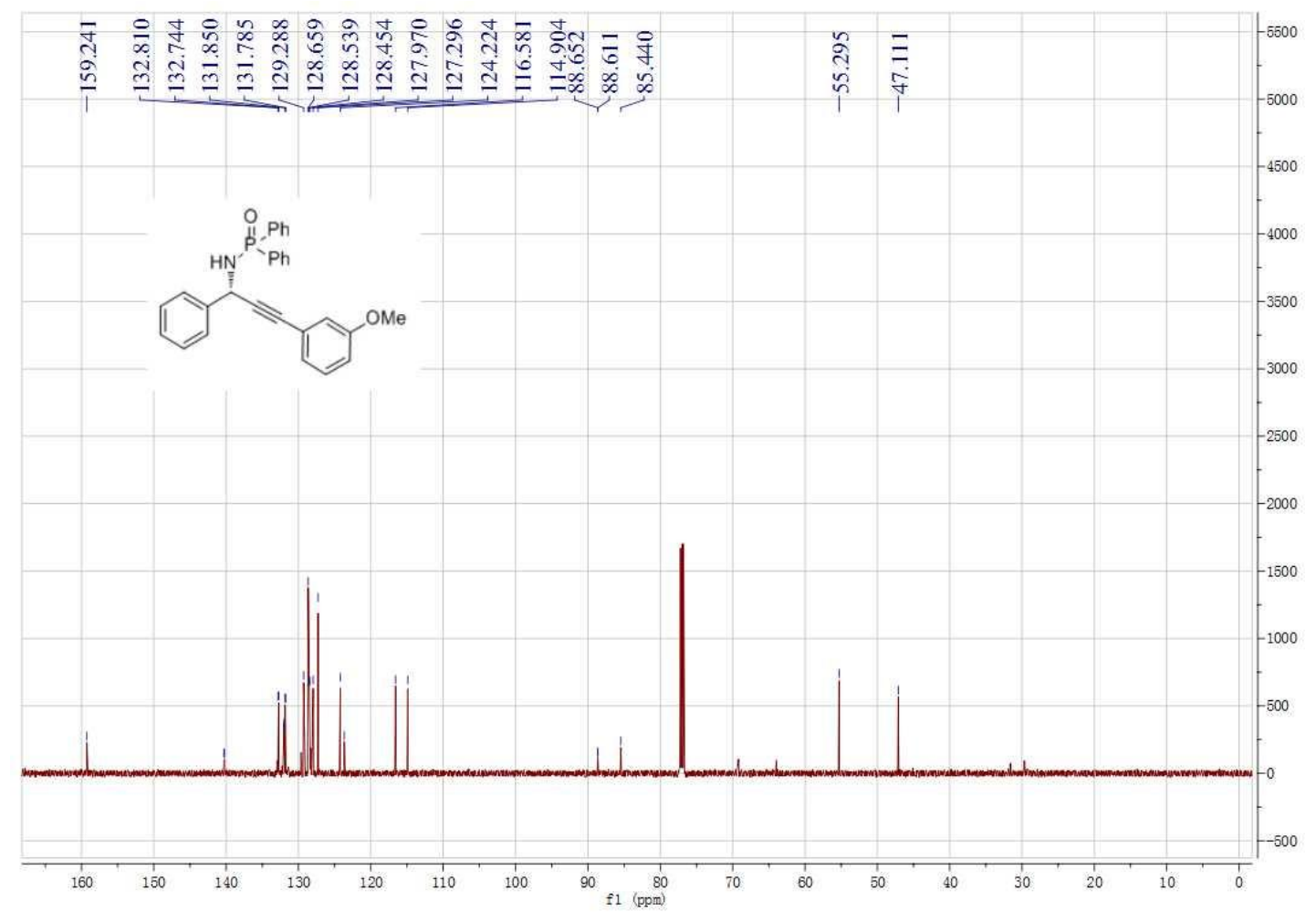


${ }^{1} \mathrm{H}$ NMR of 4.25

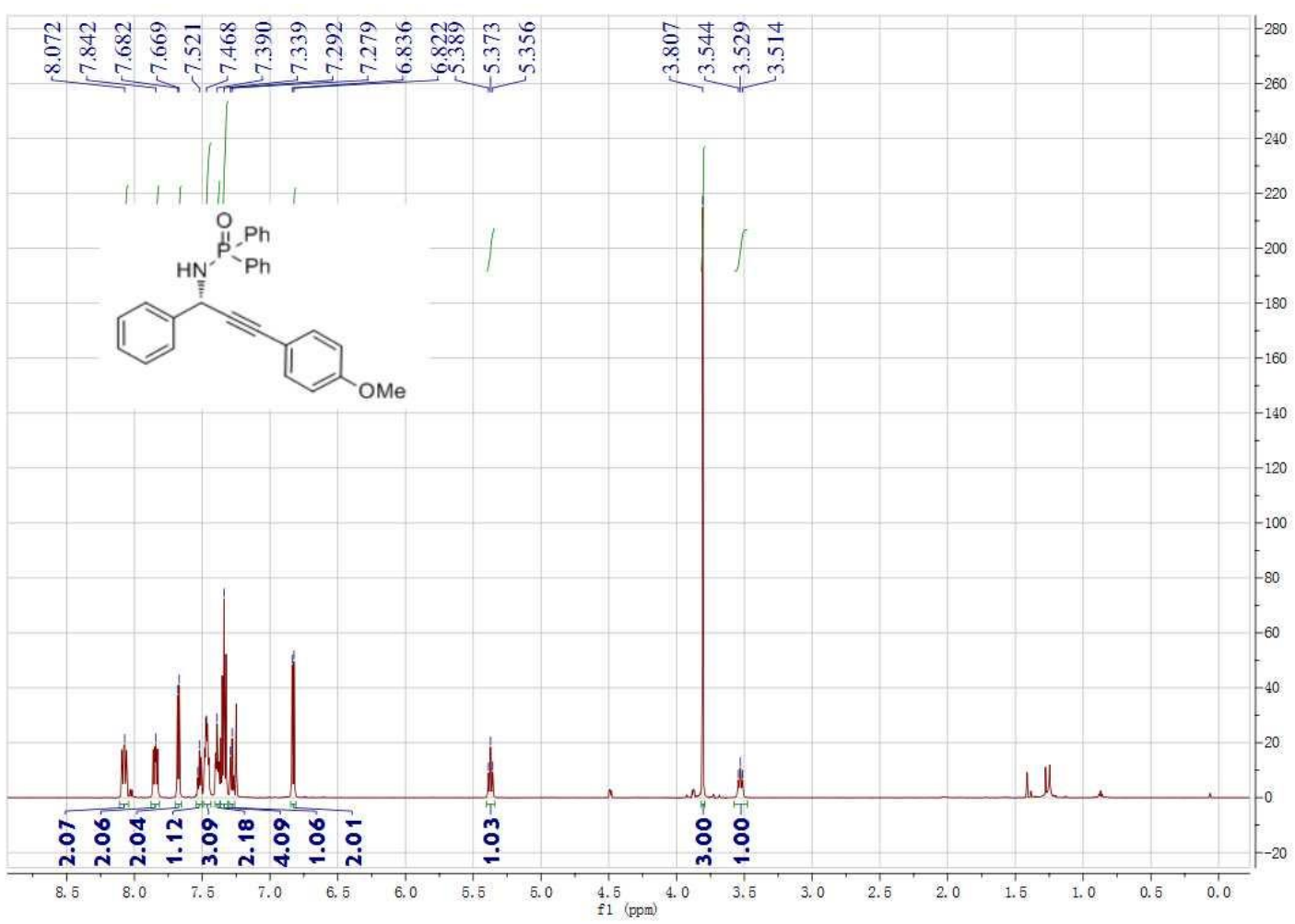

${ }^{13} \mathrm{C}$ NMR of 4.25

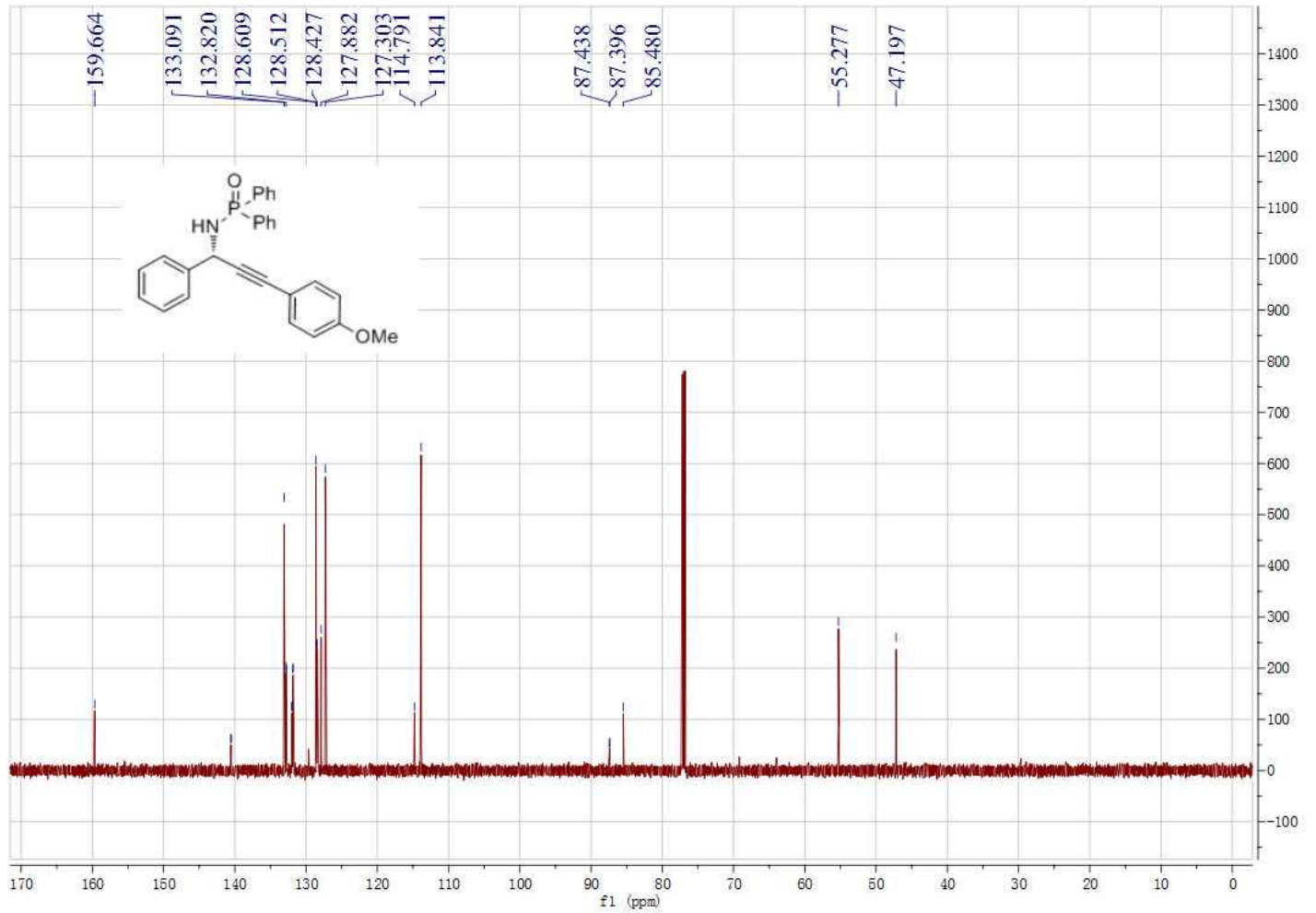


${ }^{1} \mathrm{H}$ NMR of $\mathbf{4 . 2 6}$

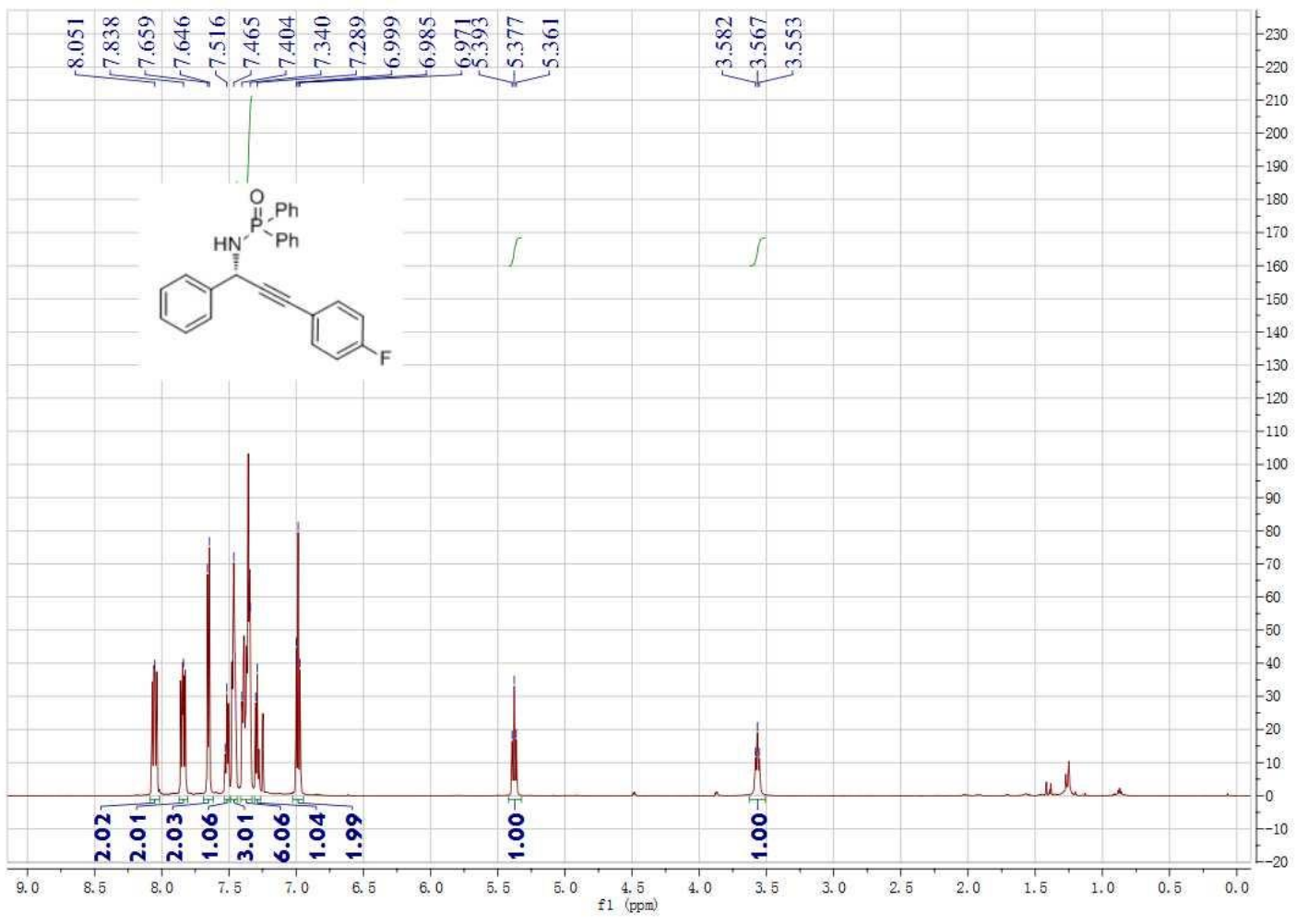

\section{${ }^{13} \mathrm{C}$ NMR of 4.26}

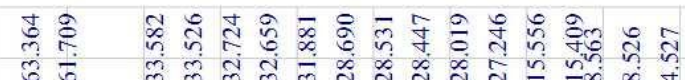

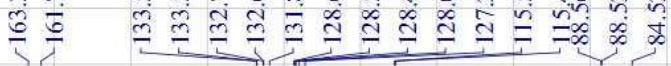
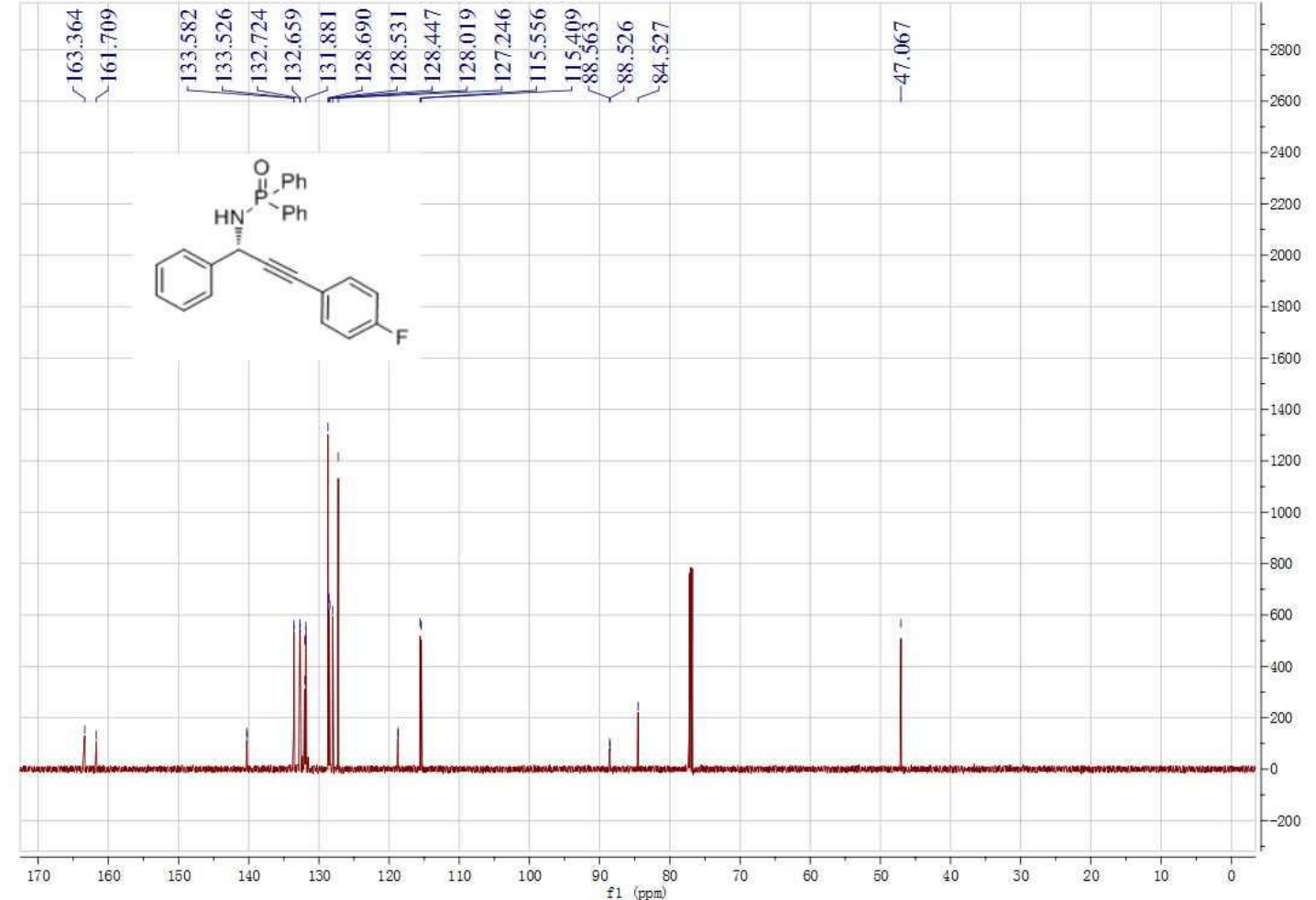
${ }^{1} \mathrm{H}$ NMR of 4.27

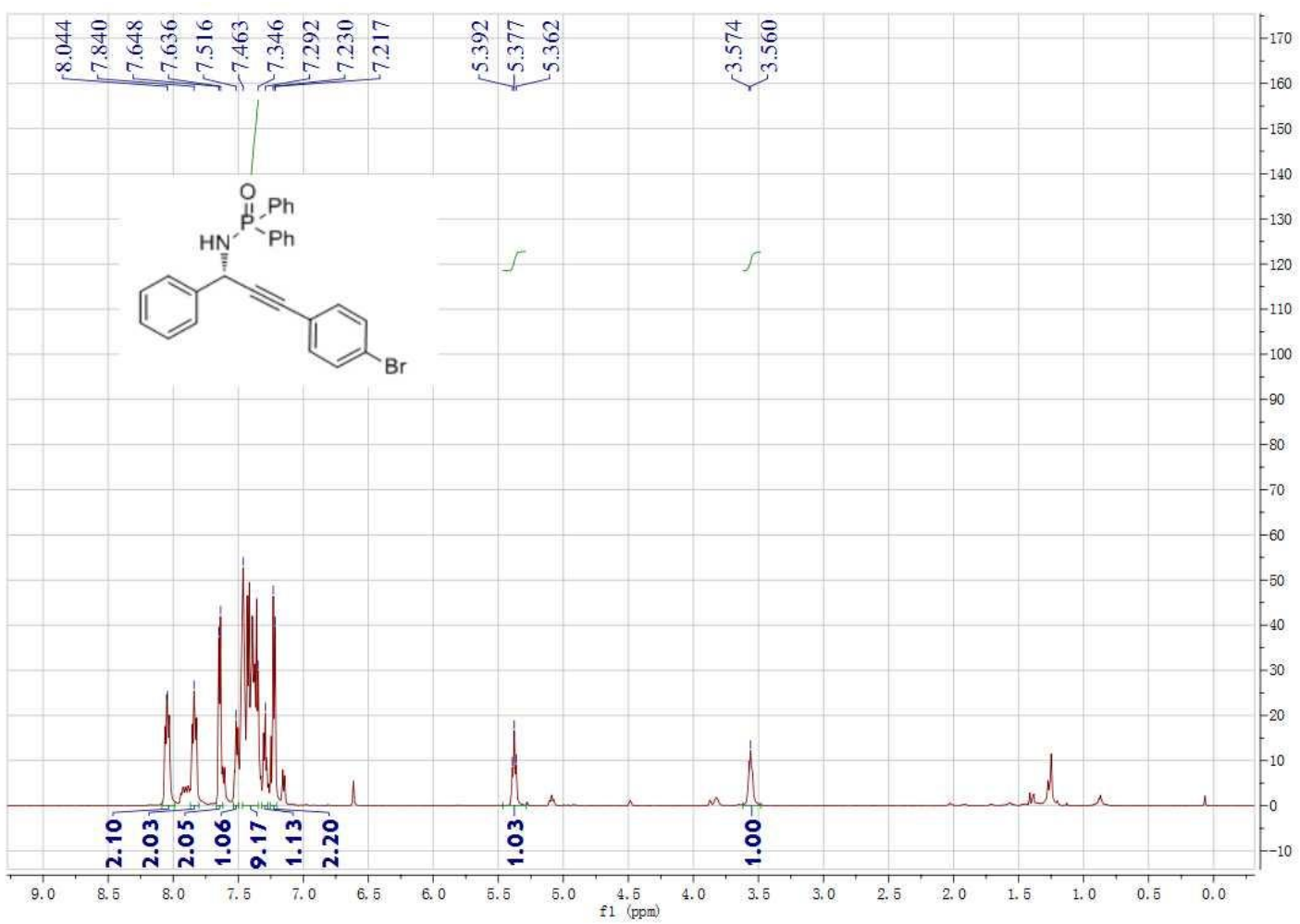

${ }^{13} \mathrm{C}$ NMR of 4.27

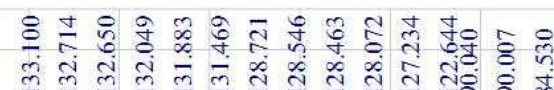

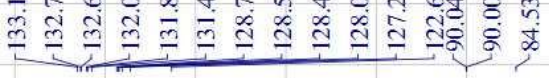<smiles>O=P(NC(C#Cc1ccc(Br)cc1)c1ccccc1)(c1ccccc1)c1ccccc1</smiles>

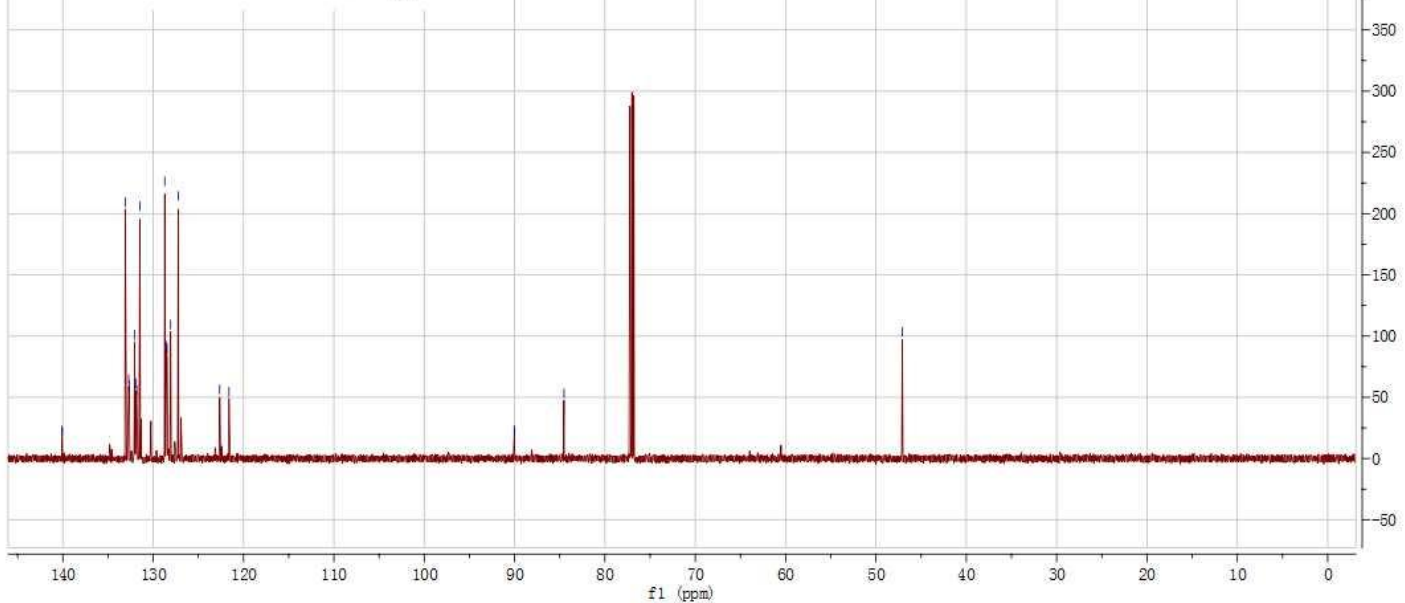




\section{Chapter 5}

${ }^{1} \mathrm{H}$ NMR and ${ }^{13} \mathbf{C}$ NMR Spectra (All the NMR spectra were obtained in $\mathrm{CDCl}_{3}$ unless indicated otherwise)

Compound 1a
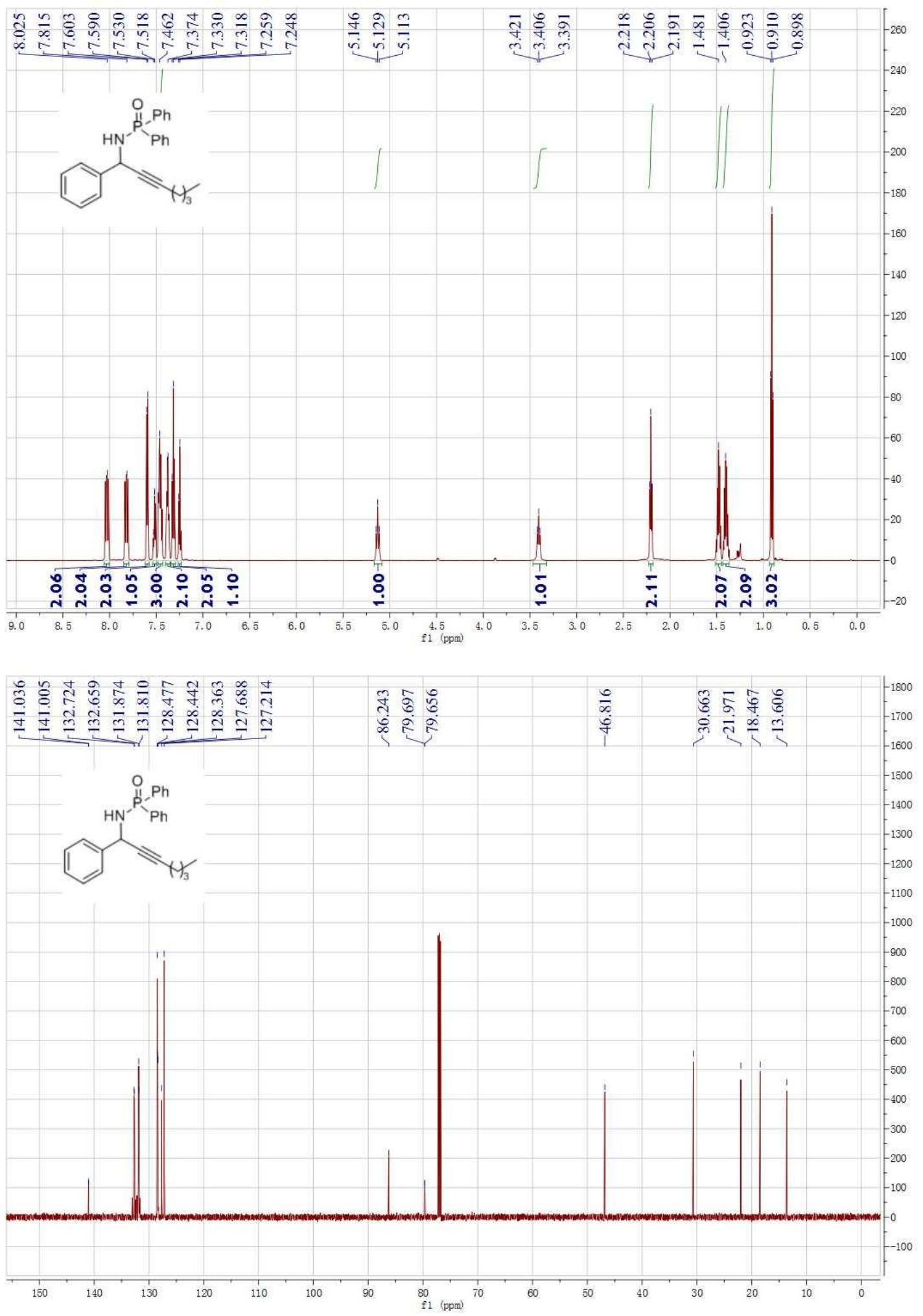


\section{Compound 1b}
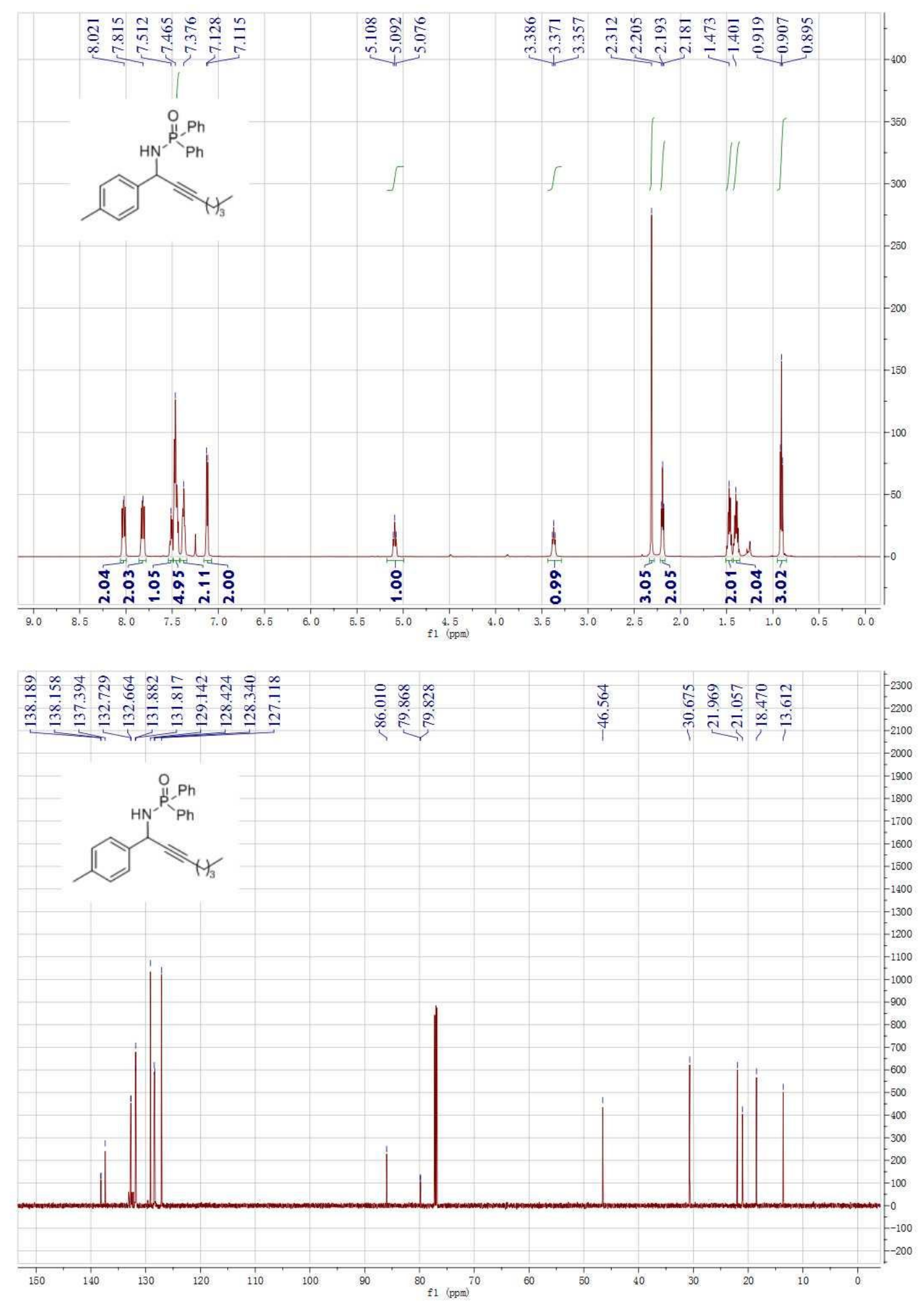


\section{Compound 1c}
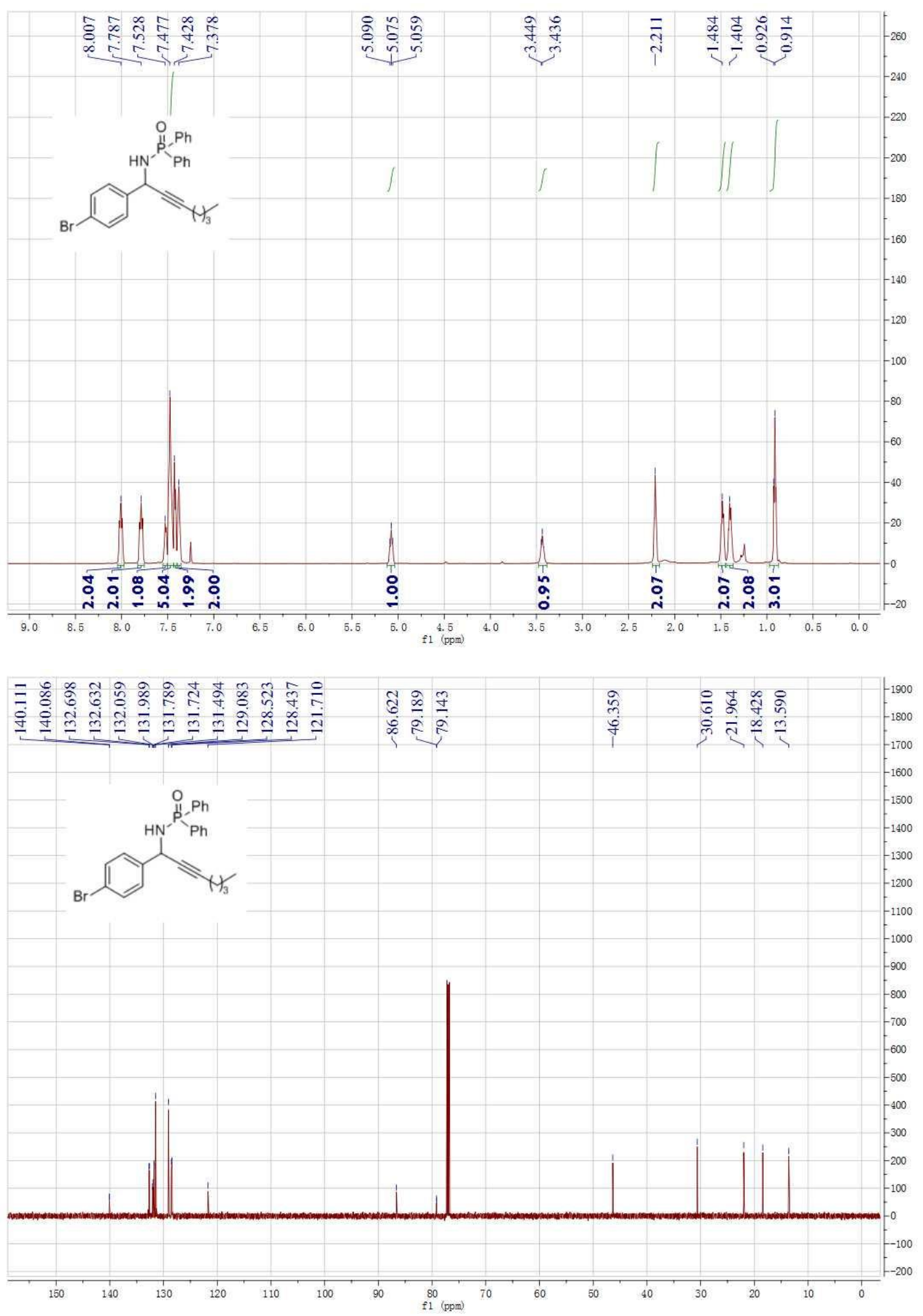


\section{Compound 1d}
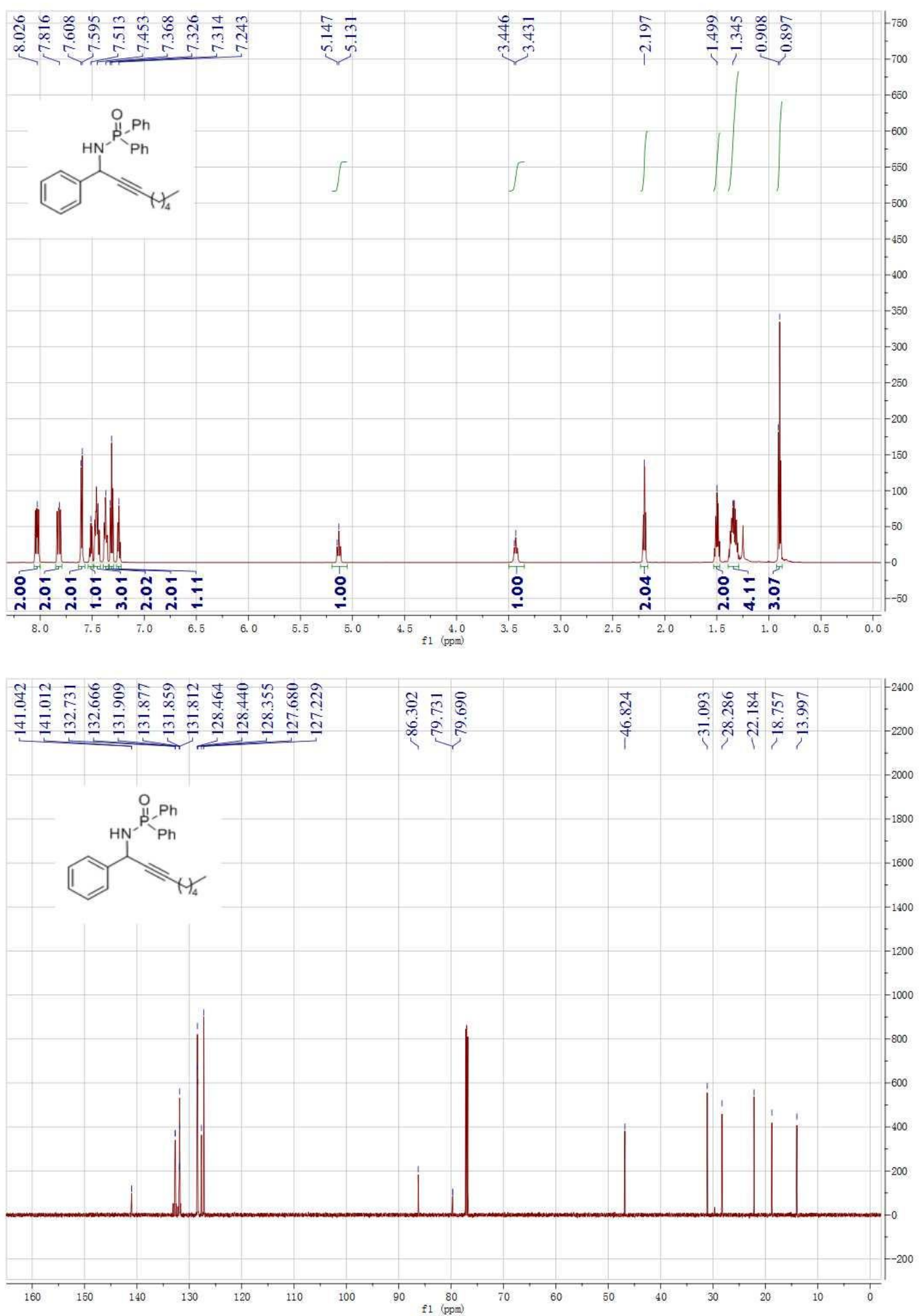


\section{Compound 1e}
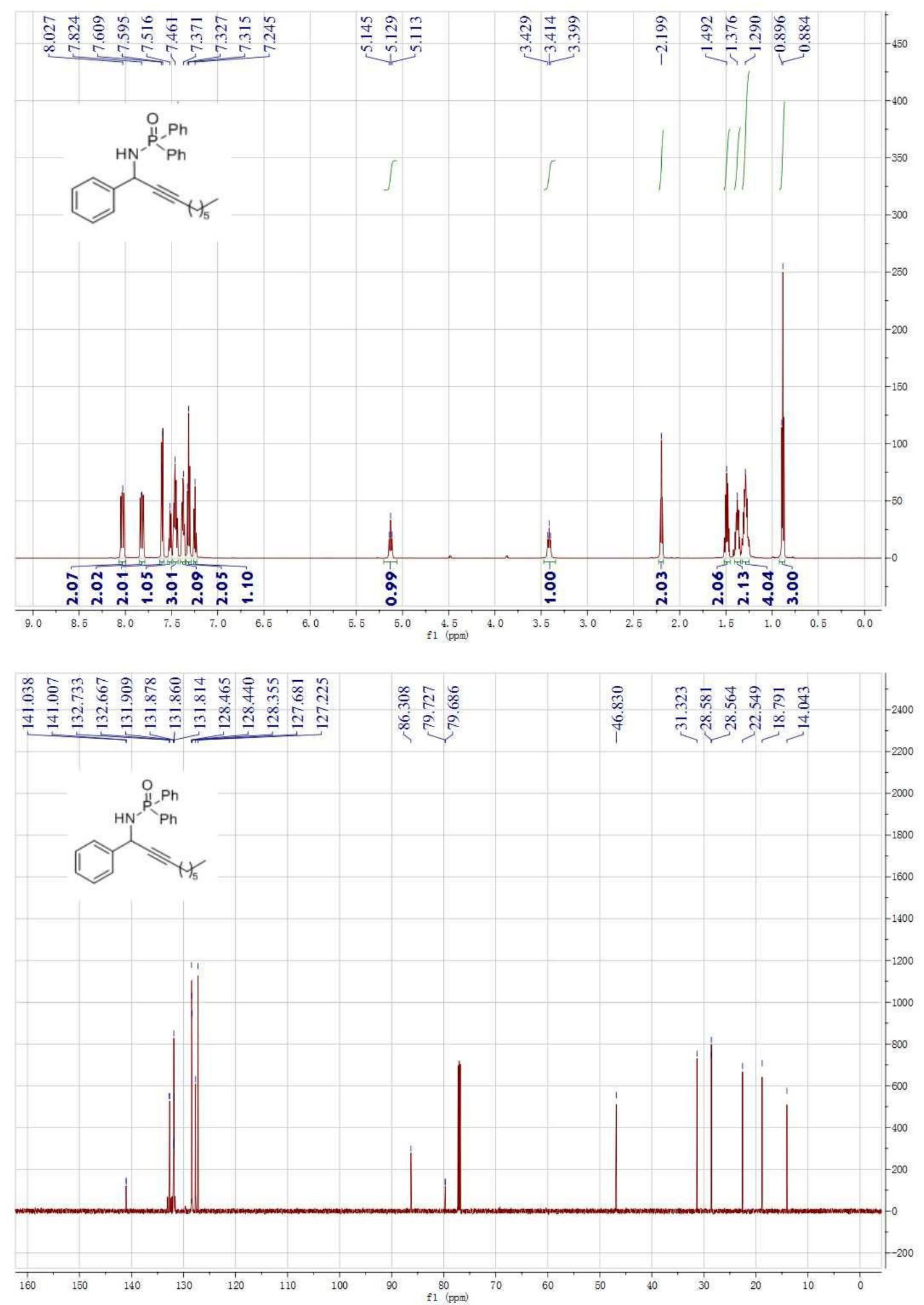


\section{Compound $1 \mathbf{f}$}
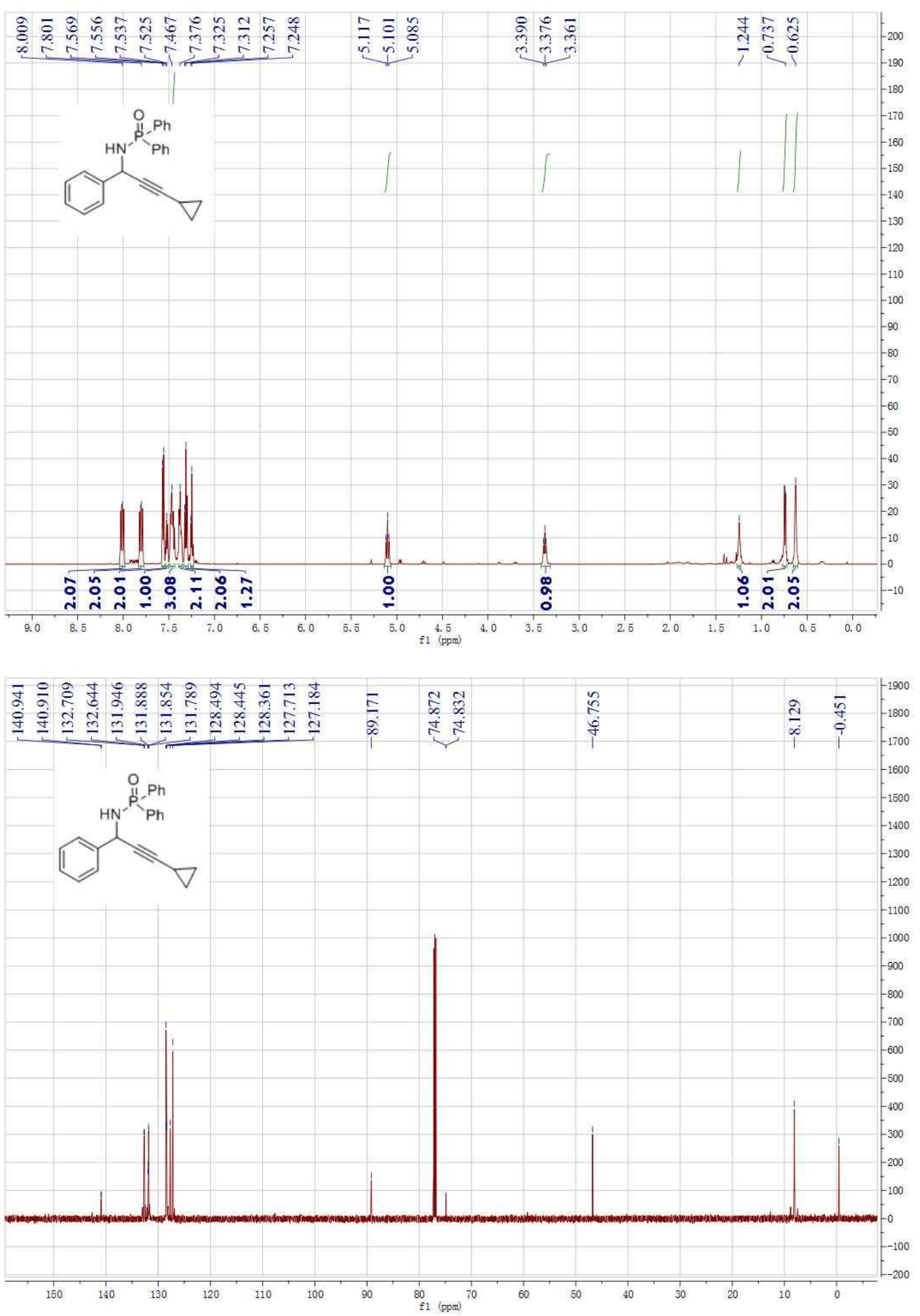


\section{Compound $1 \mathrm{~g}$}
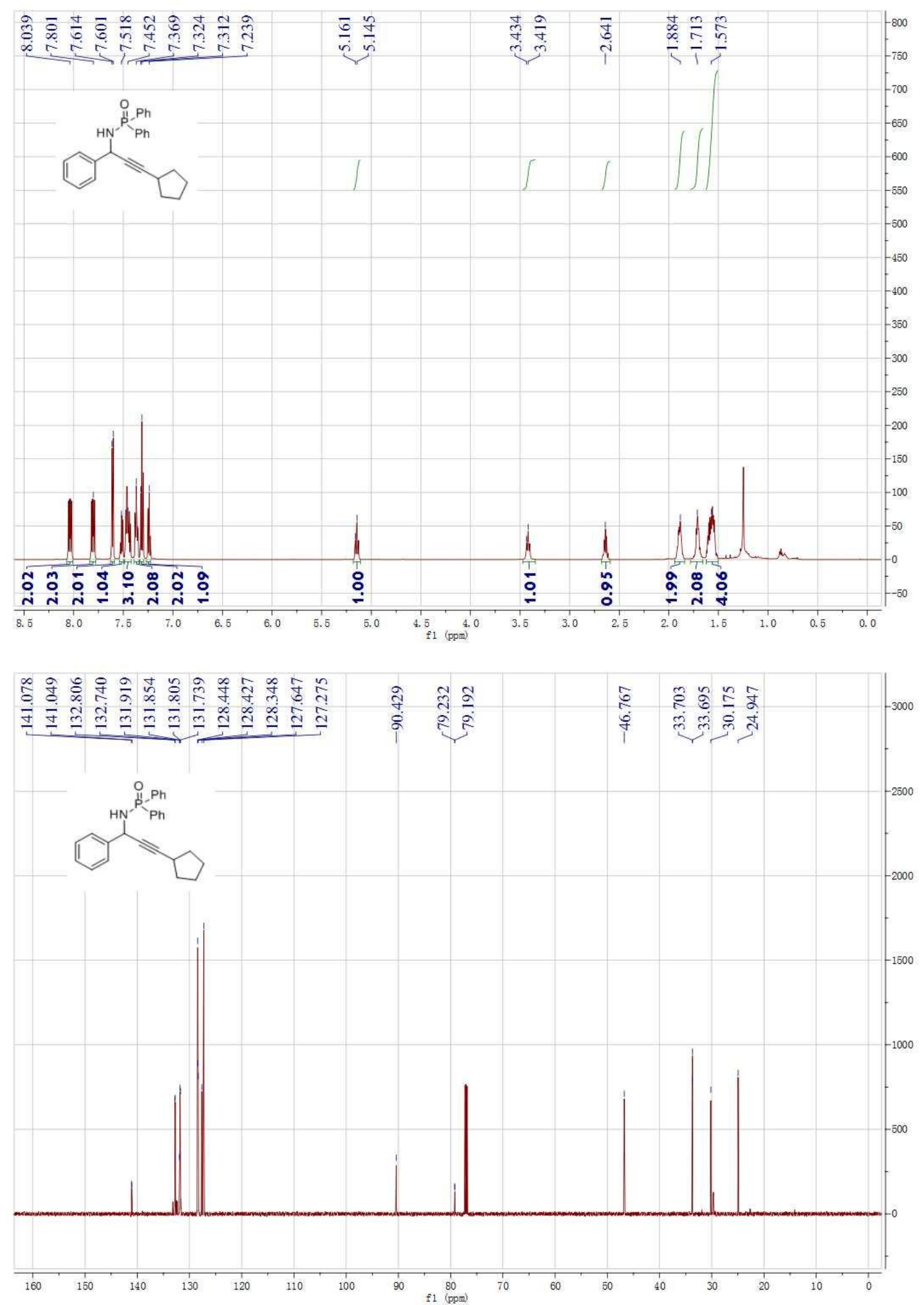


\section{Compound $\mathbf{1 h}$}
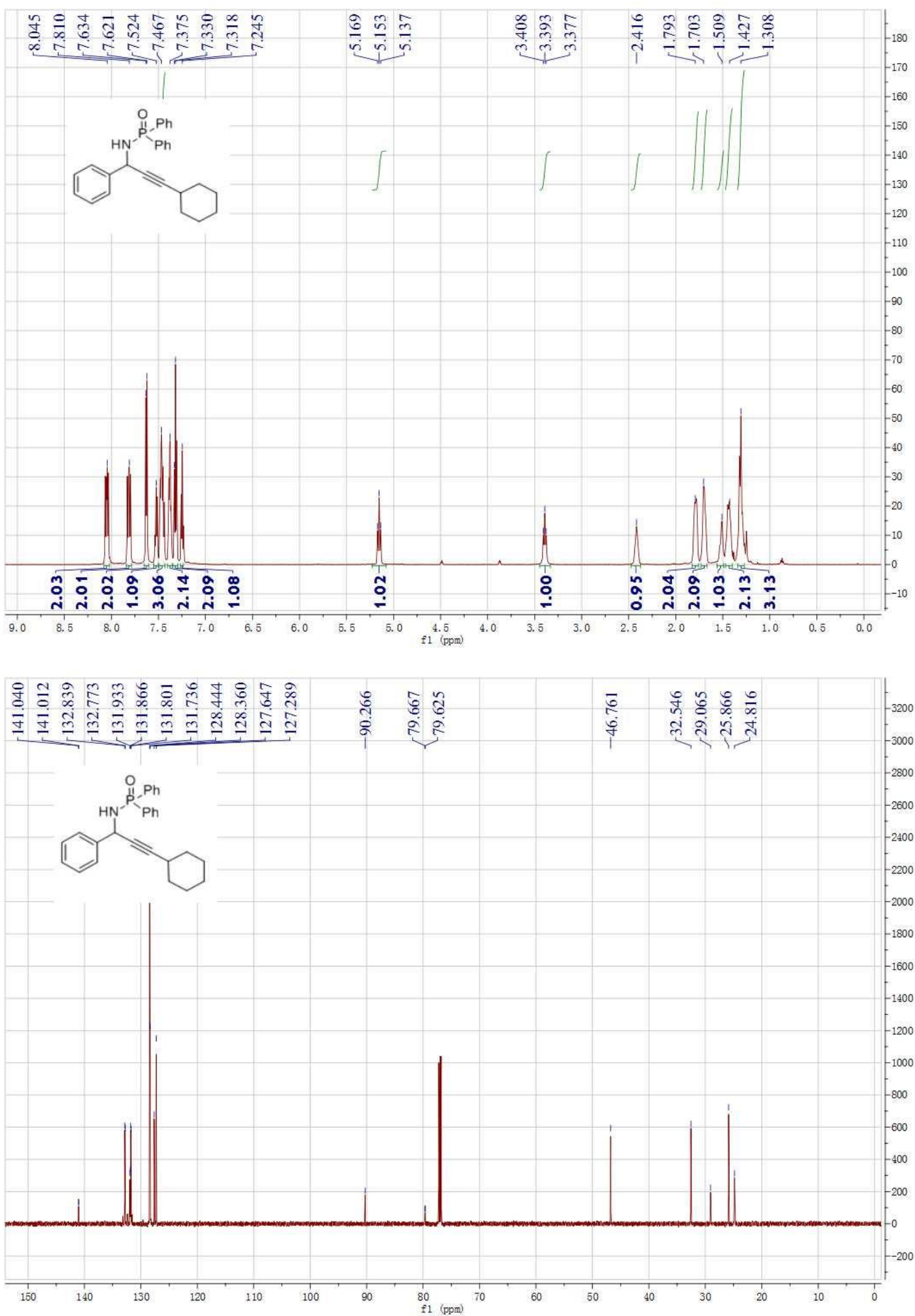


\section{Compound 1i}

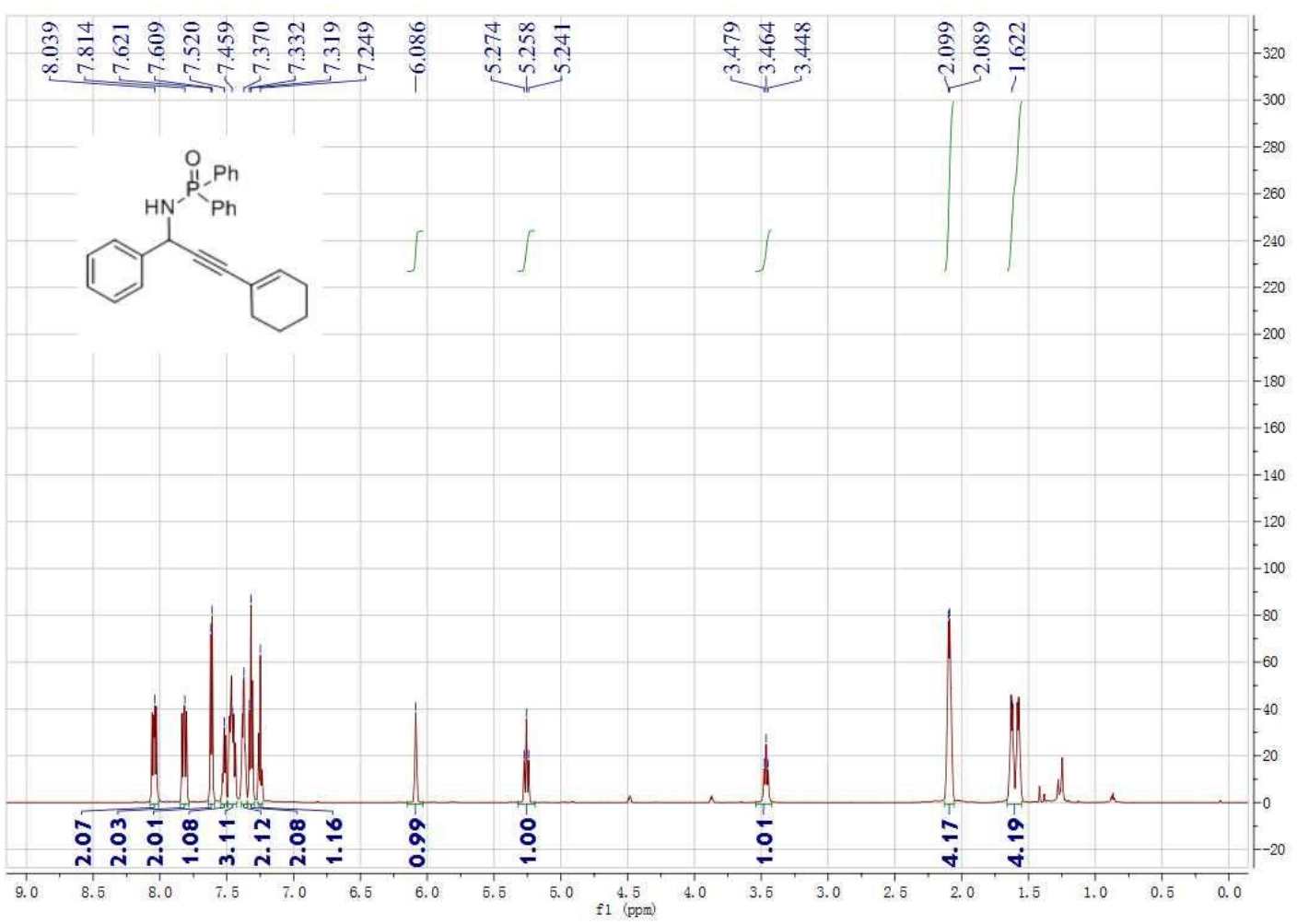

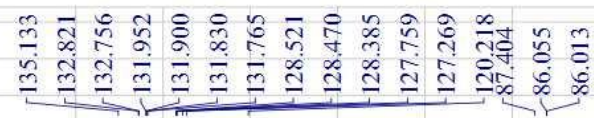
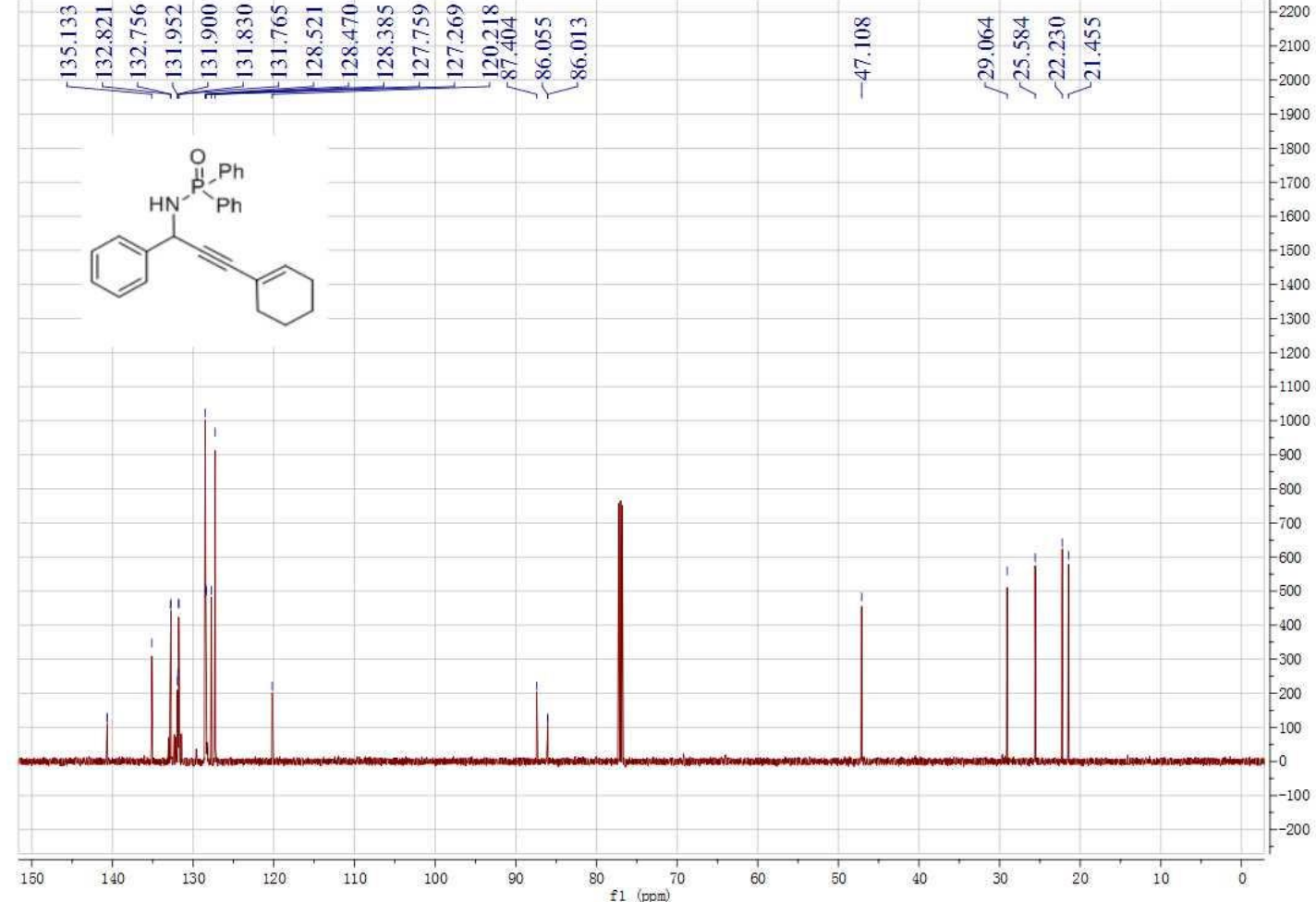


\section{Compound $\mathbf{1 j}$}
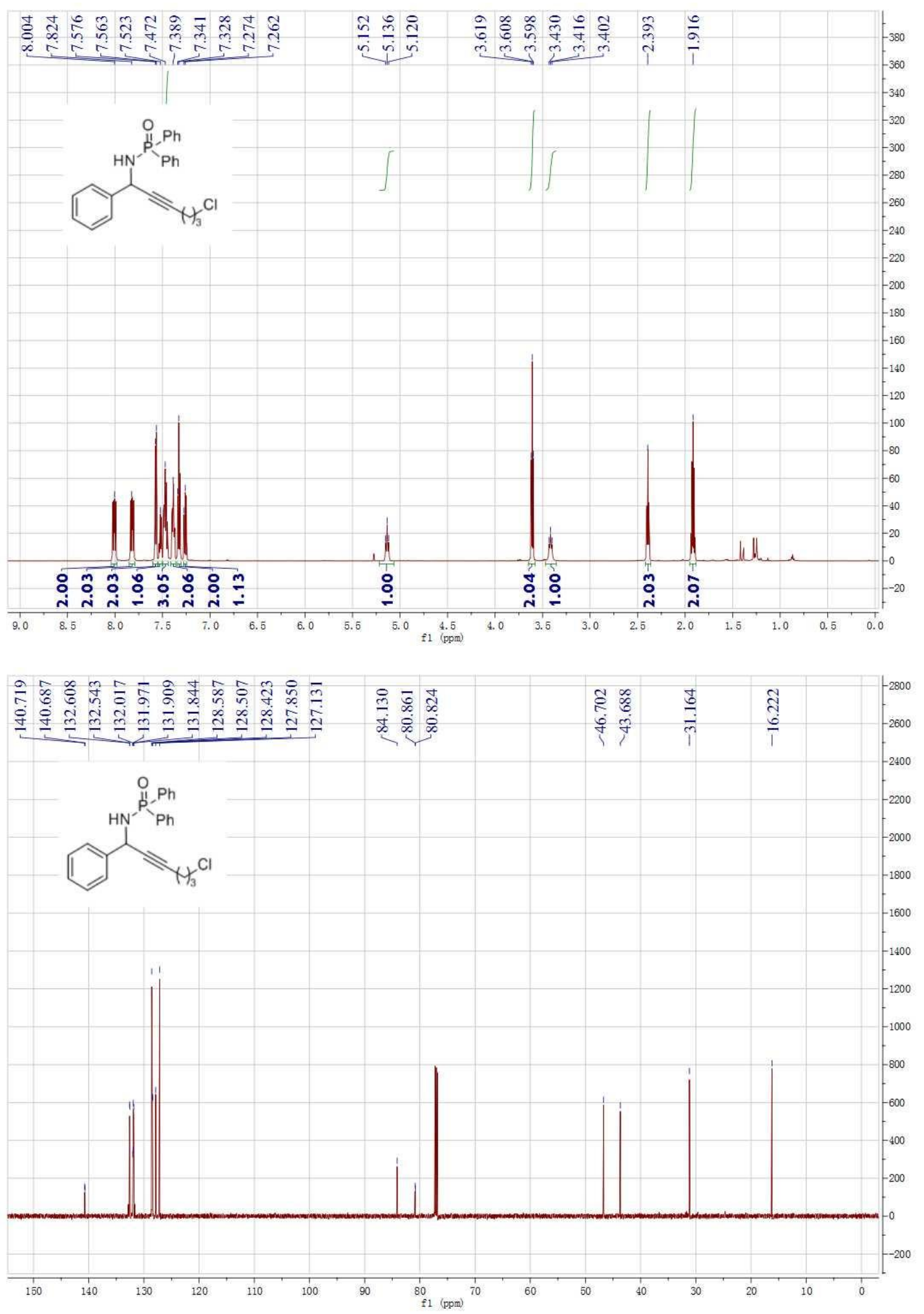


\section{Compound 1k}
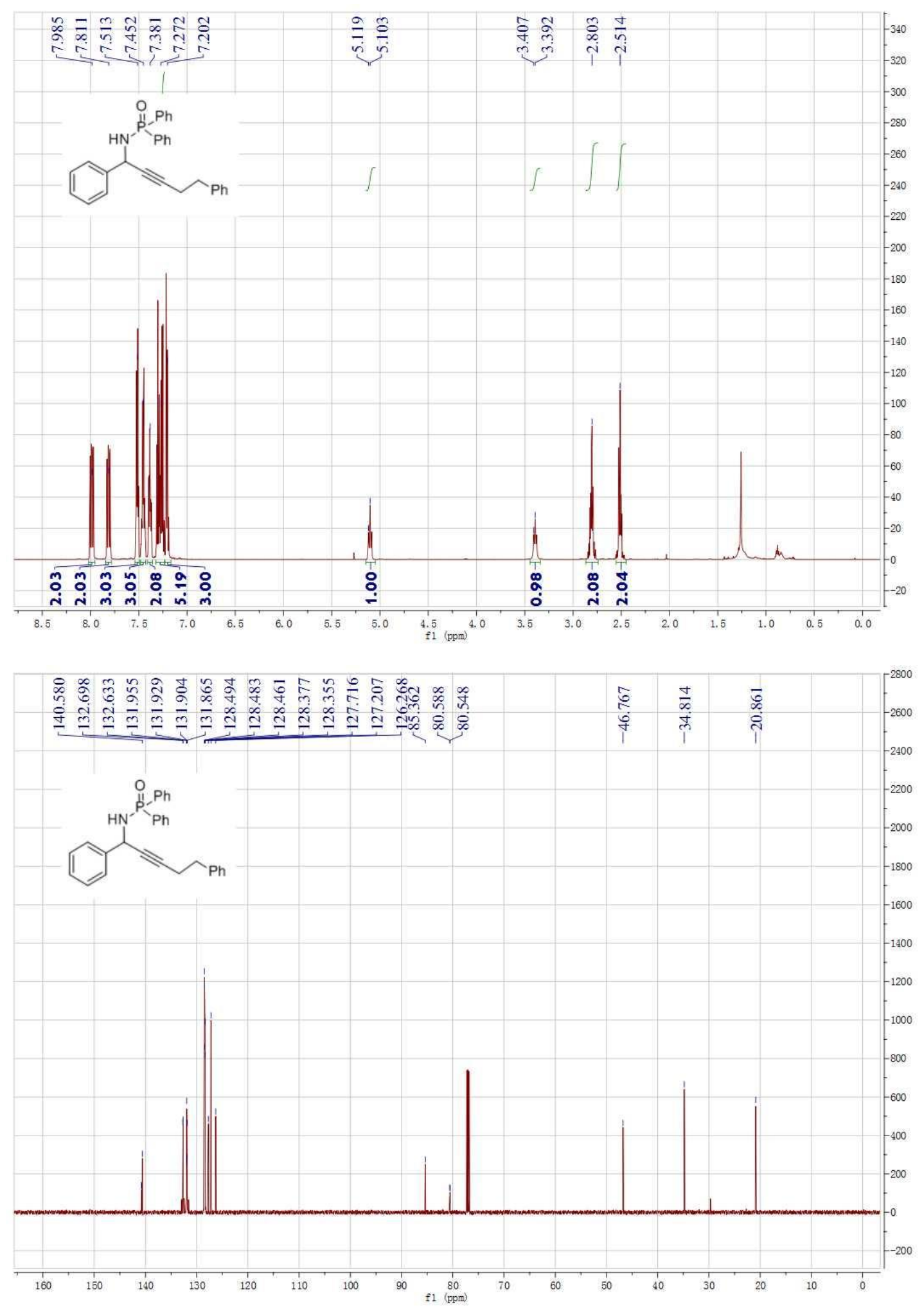
Compound 2a

${ }^{1} \mathrm{H}$ NMR (600 MHz, $\mathrm{CDCl}_{3}$ )

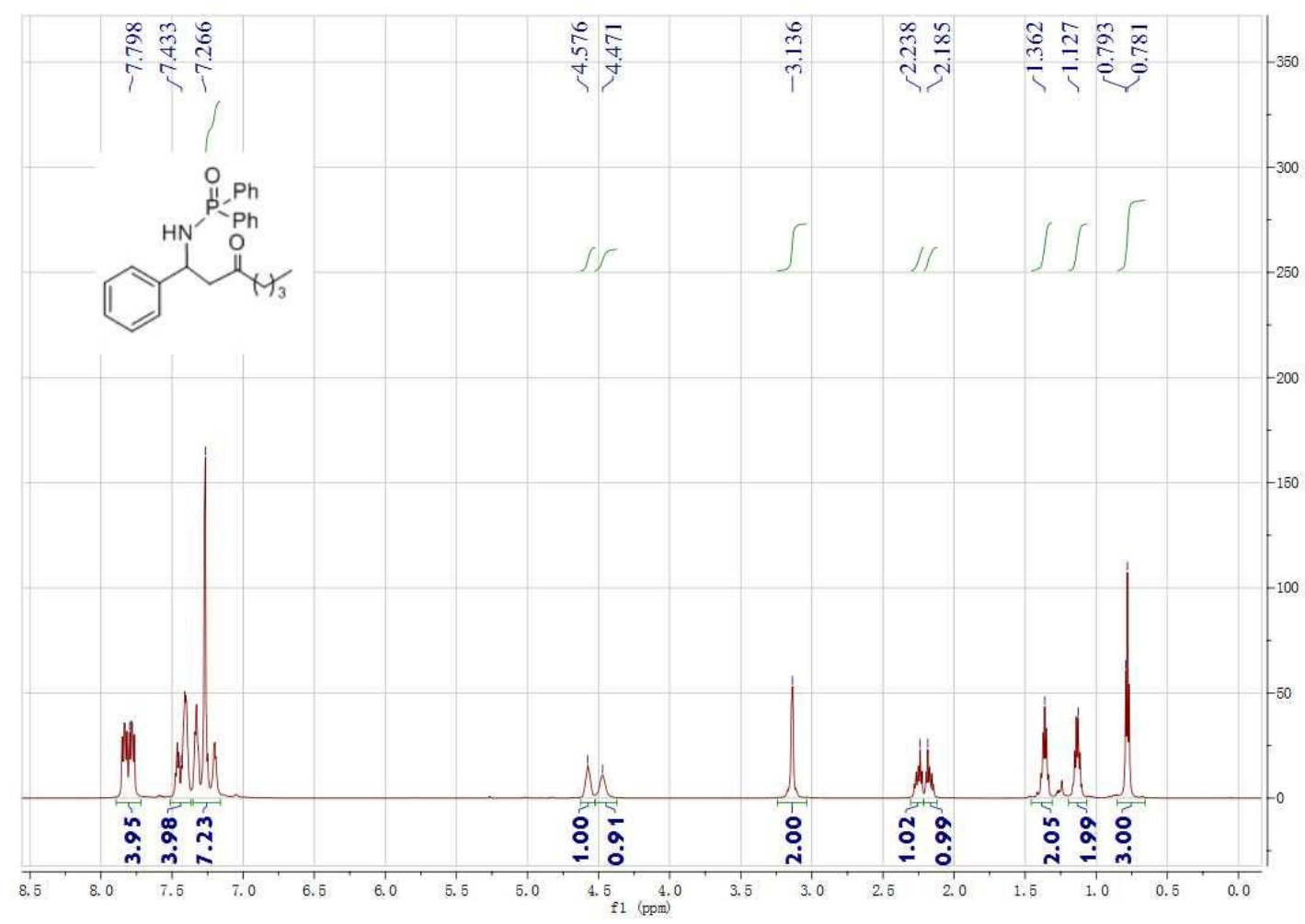

${ }^{1} \mathrm{H}$ NMR (600 MHz, benzene- $\mathrm{d}_{6}$ )

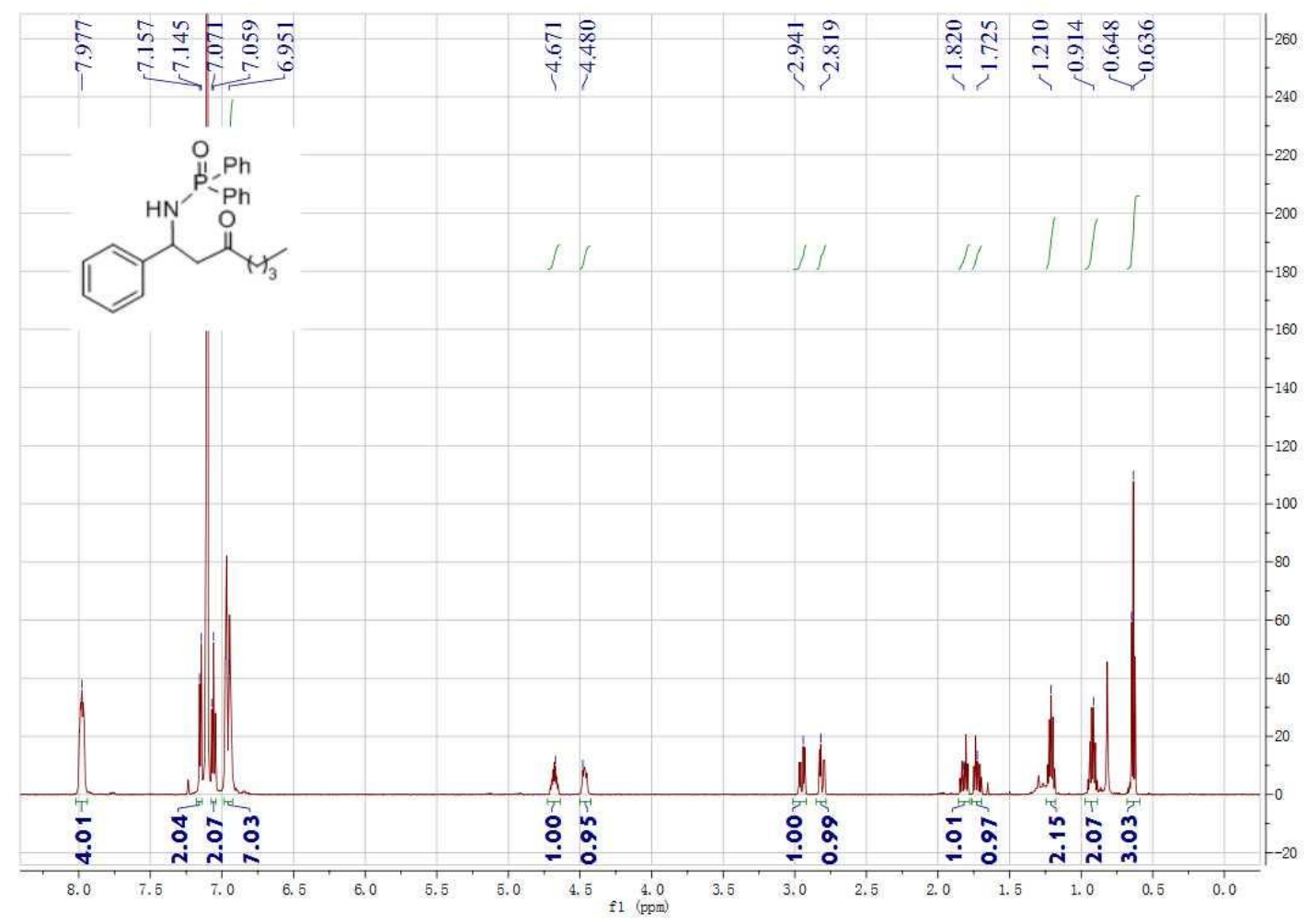


${ }^{13} \mathrm{C}\left\{{ }^{1} \mathrm{H}\right\}$ NMR $\left(150 \mathrm{MHz}, \mathrm{CDCl}_{3}\right)$

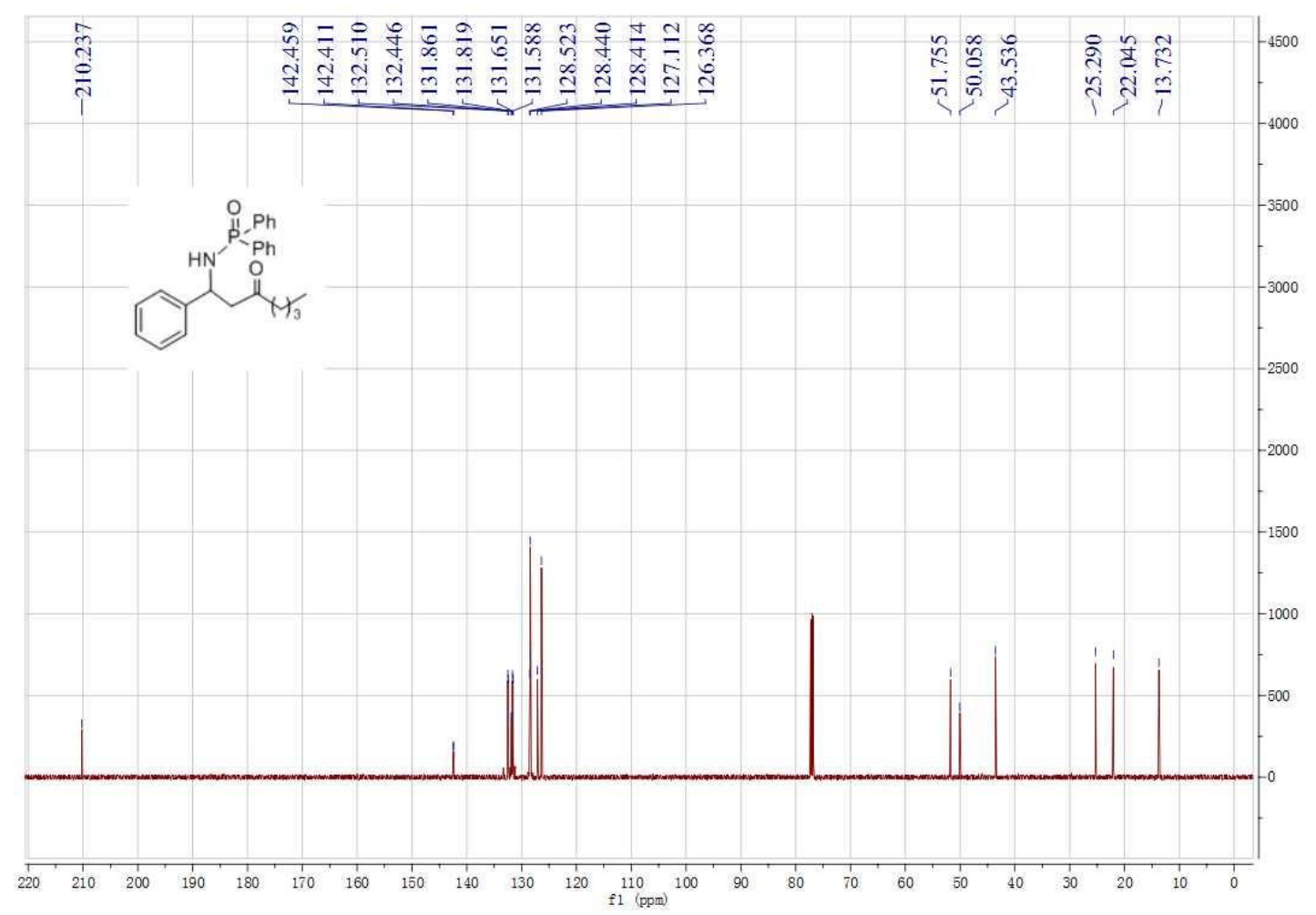

COSY (600 MHz, benzene- $\left.\mathrm{d}_{6}\right)$

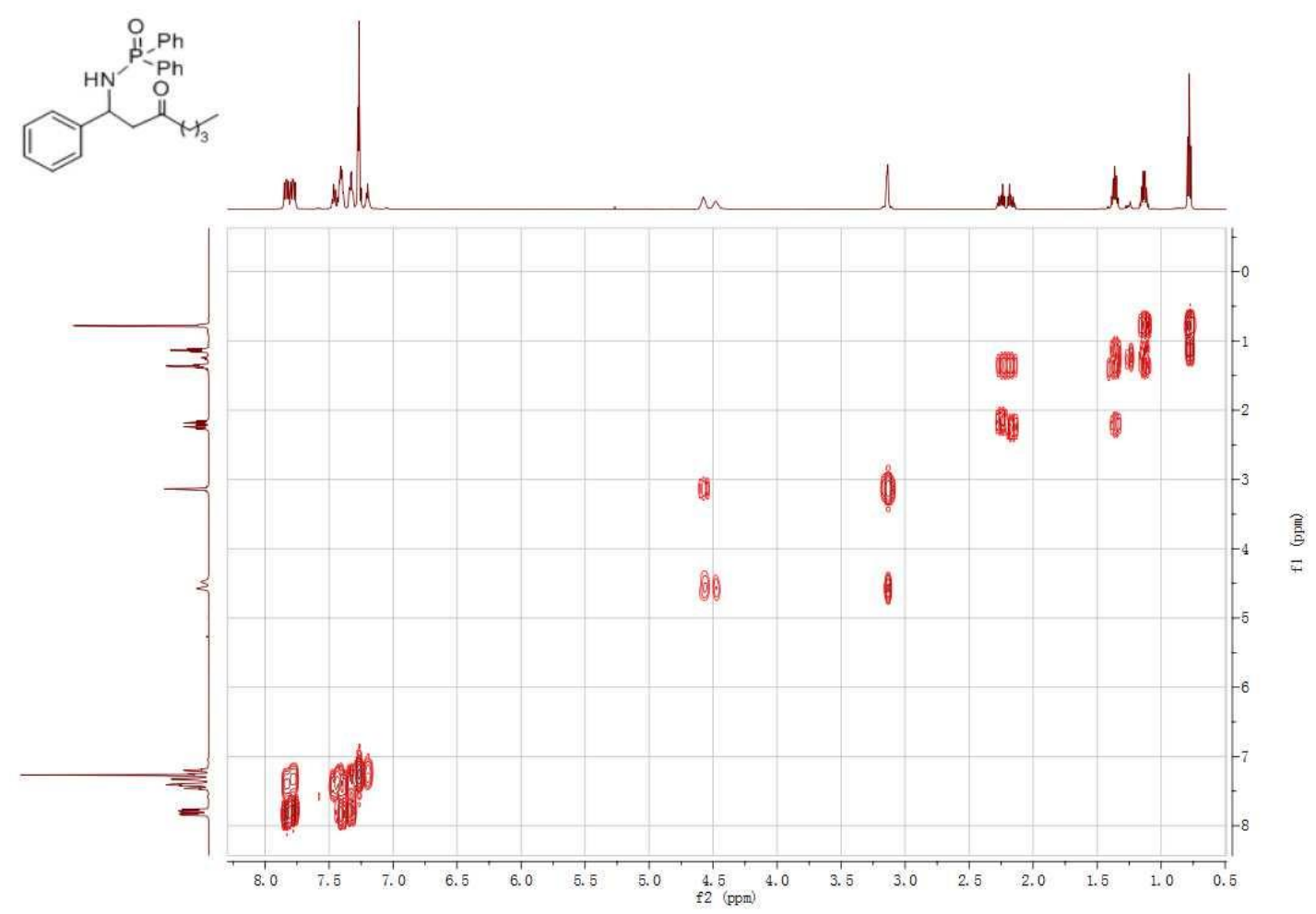




\section{Compound 2b}
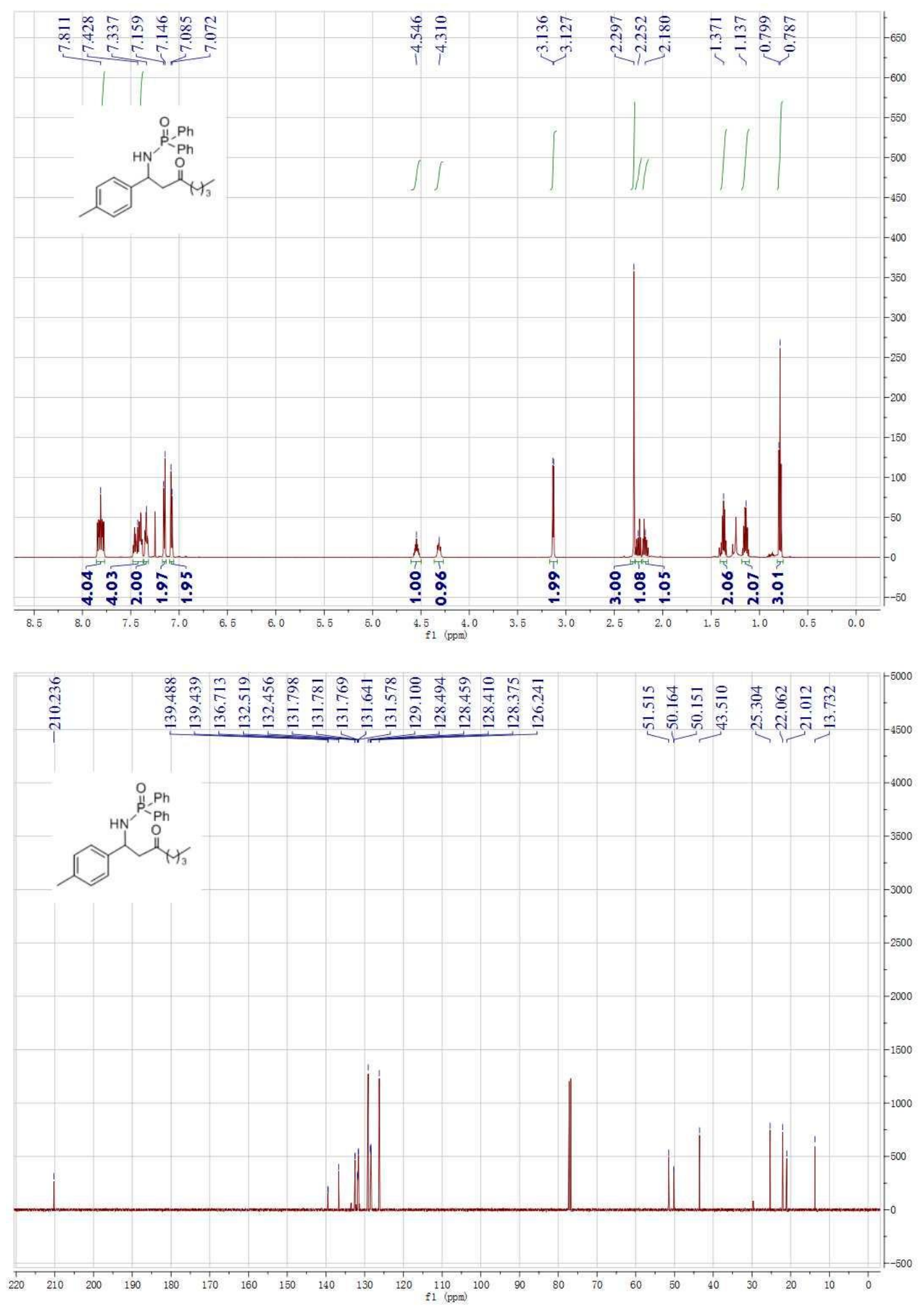


\section{Compound 2c}
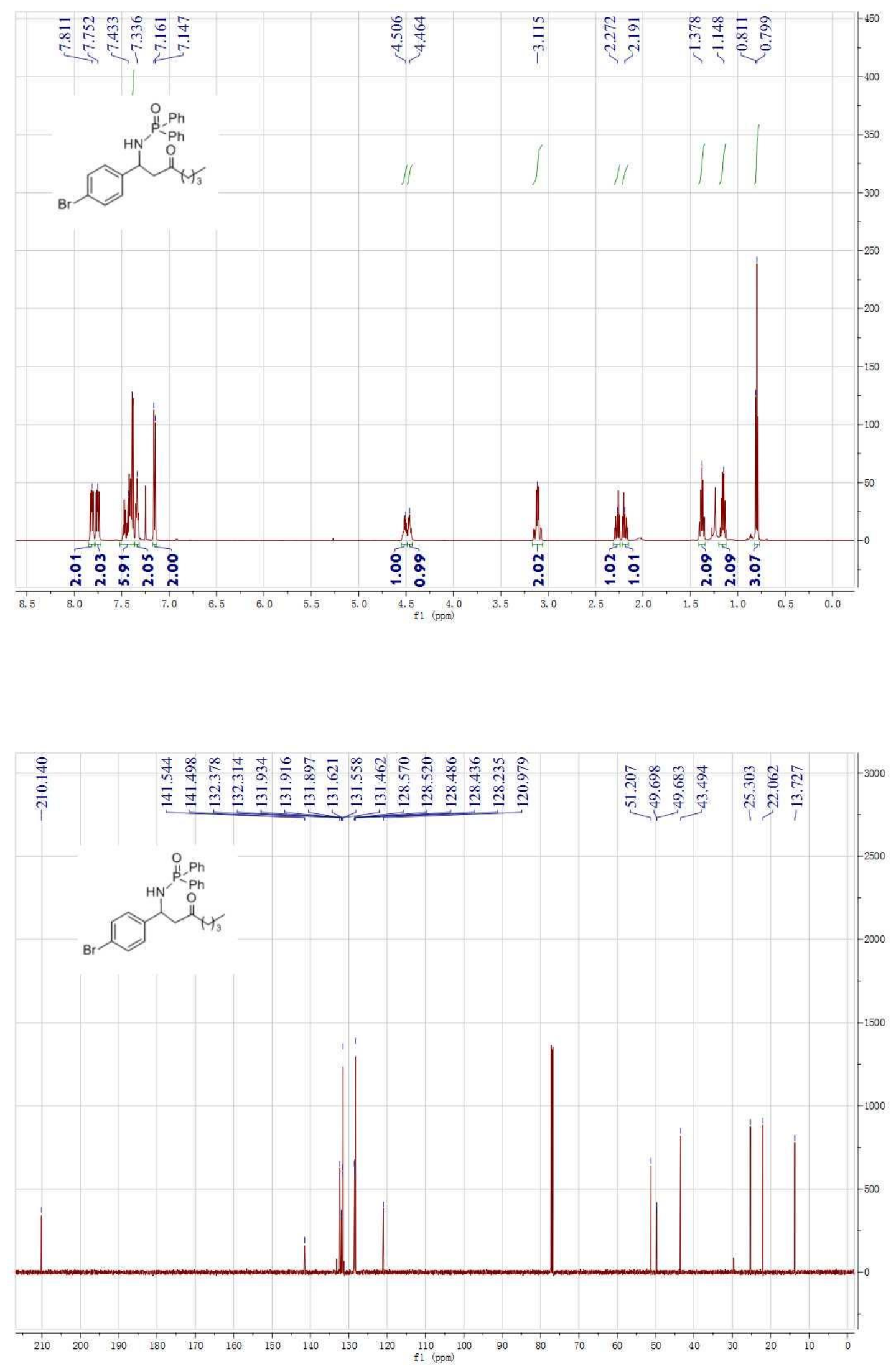


\section{Compound 2d}
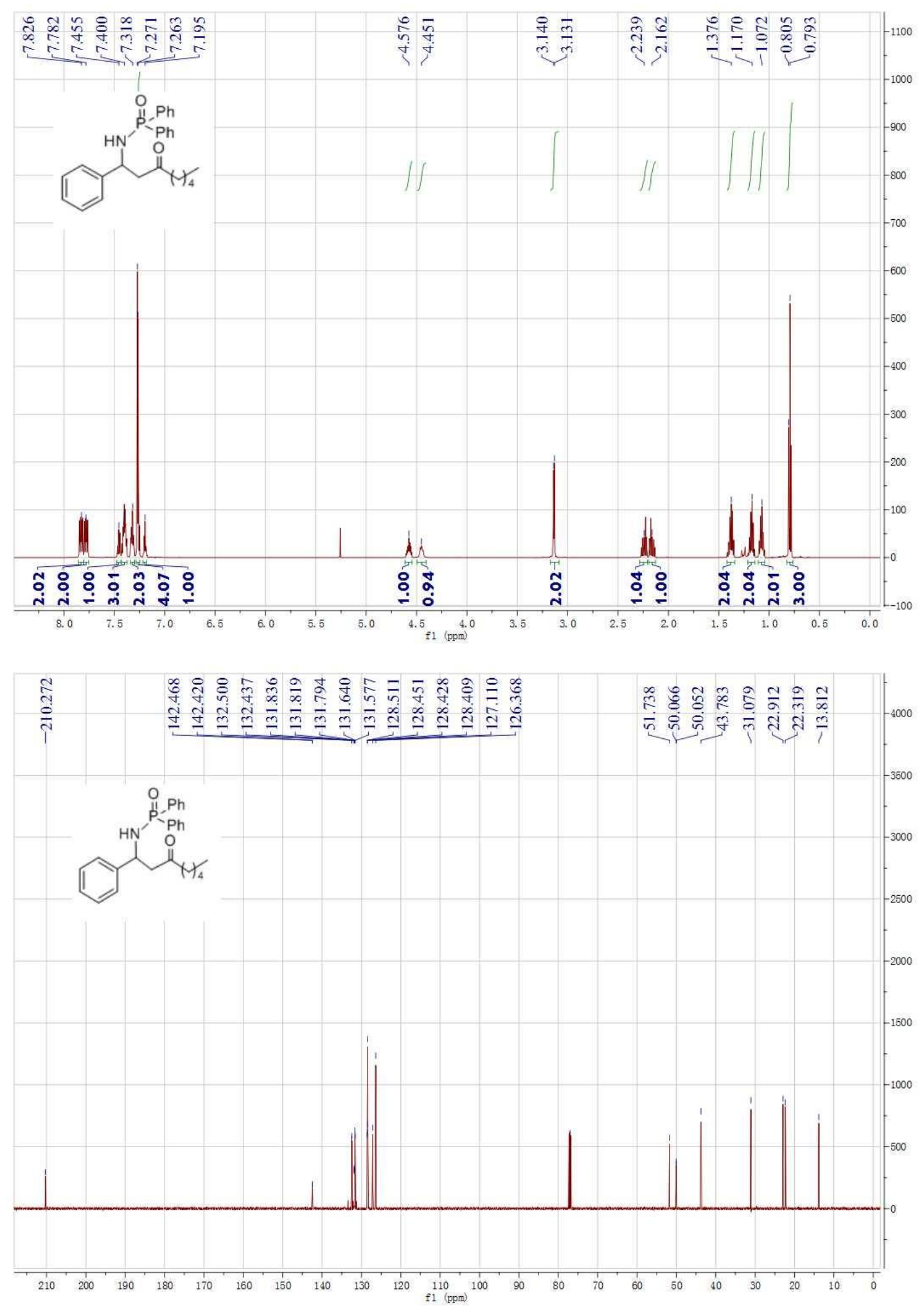


\section{Compound 2e}
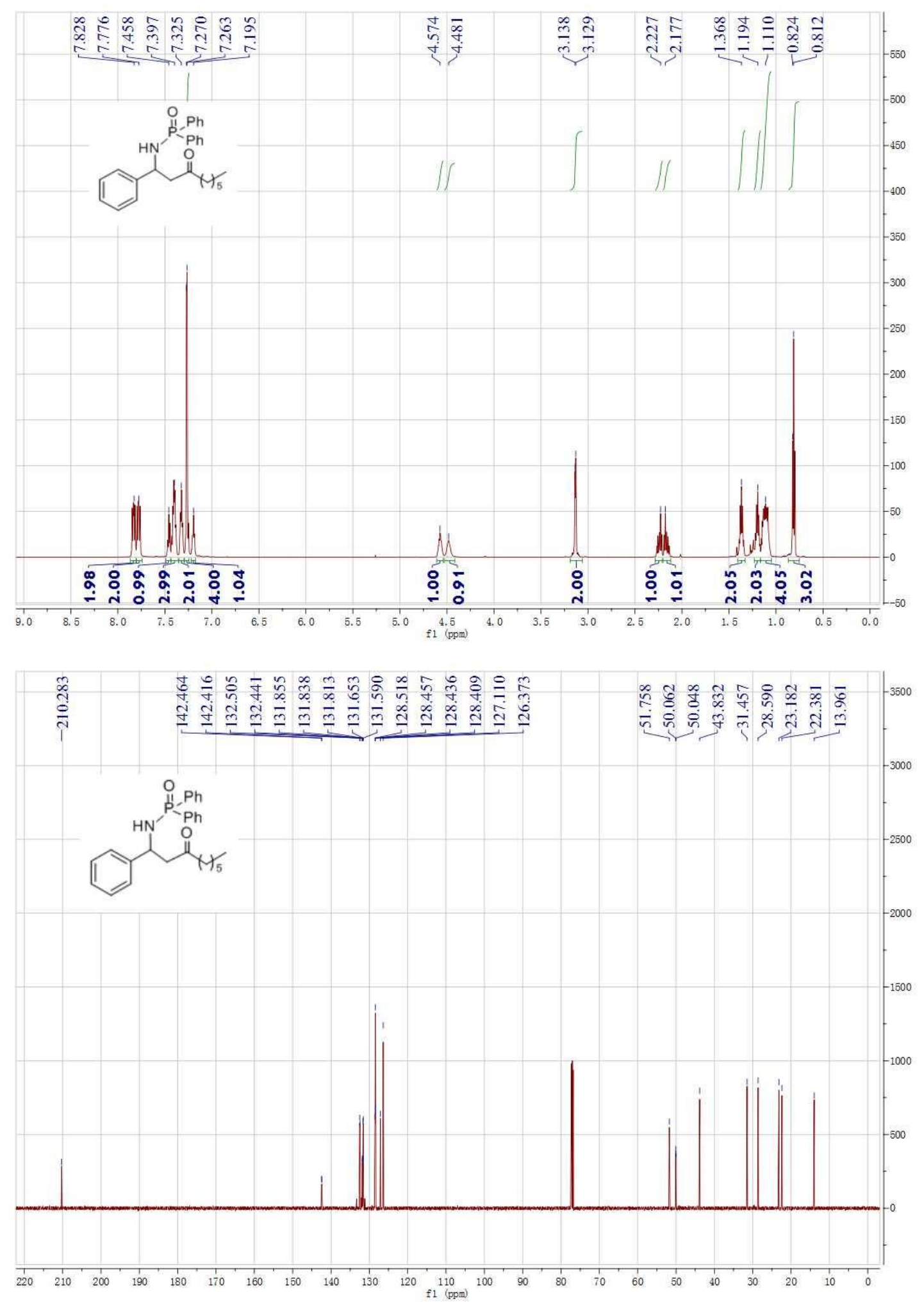


\section{Compound $2 \mathbf{f}$}
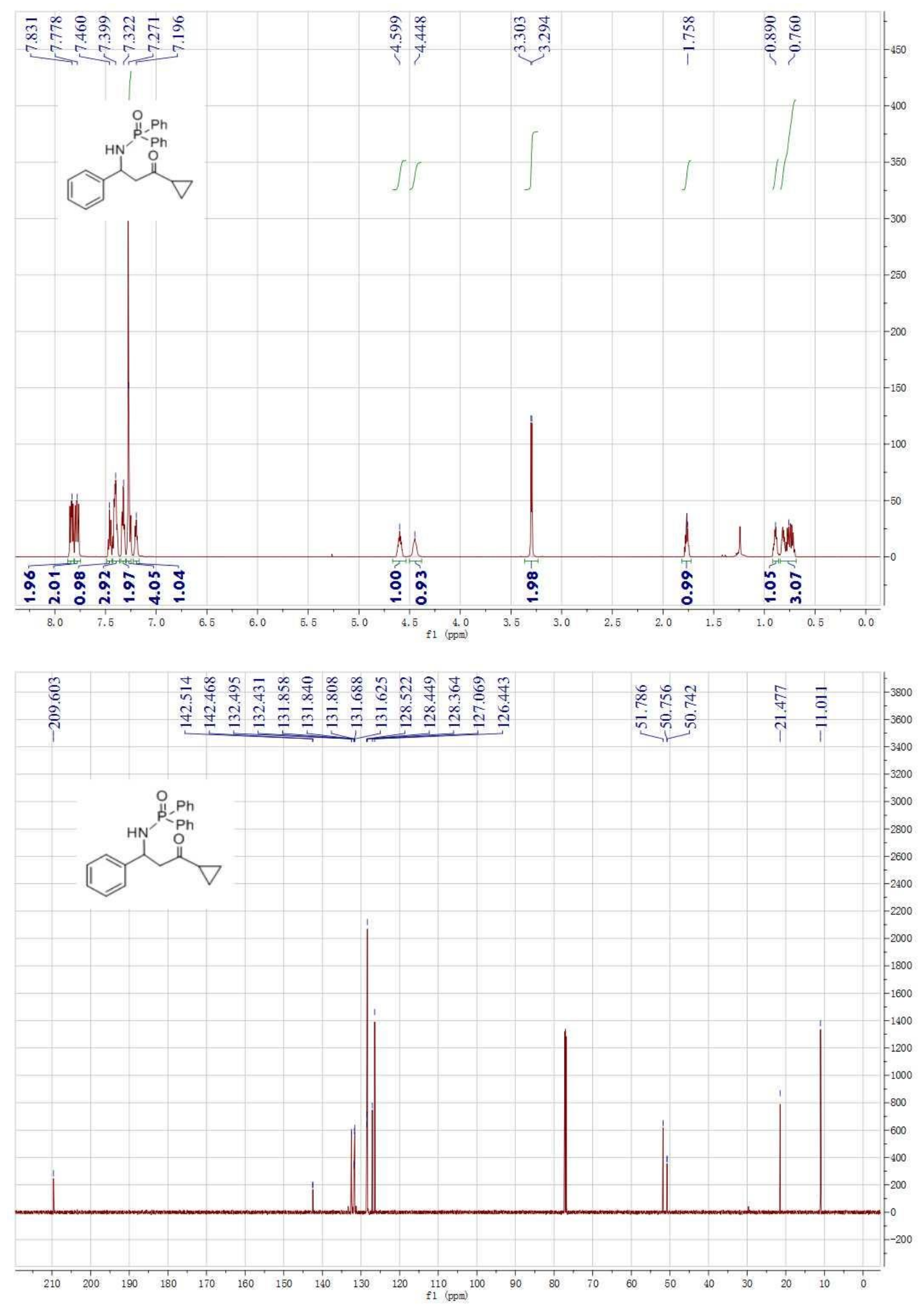


\section{Compound 2g}
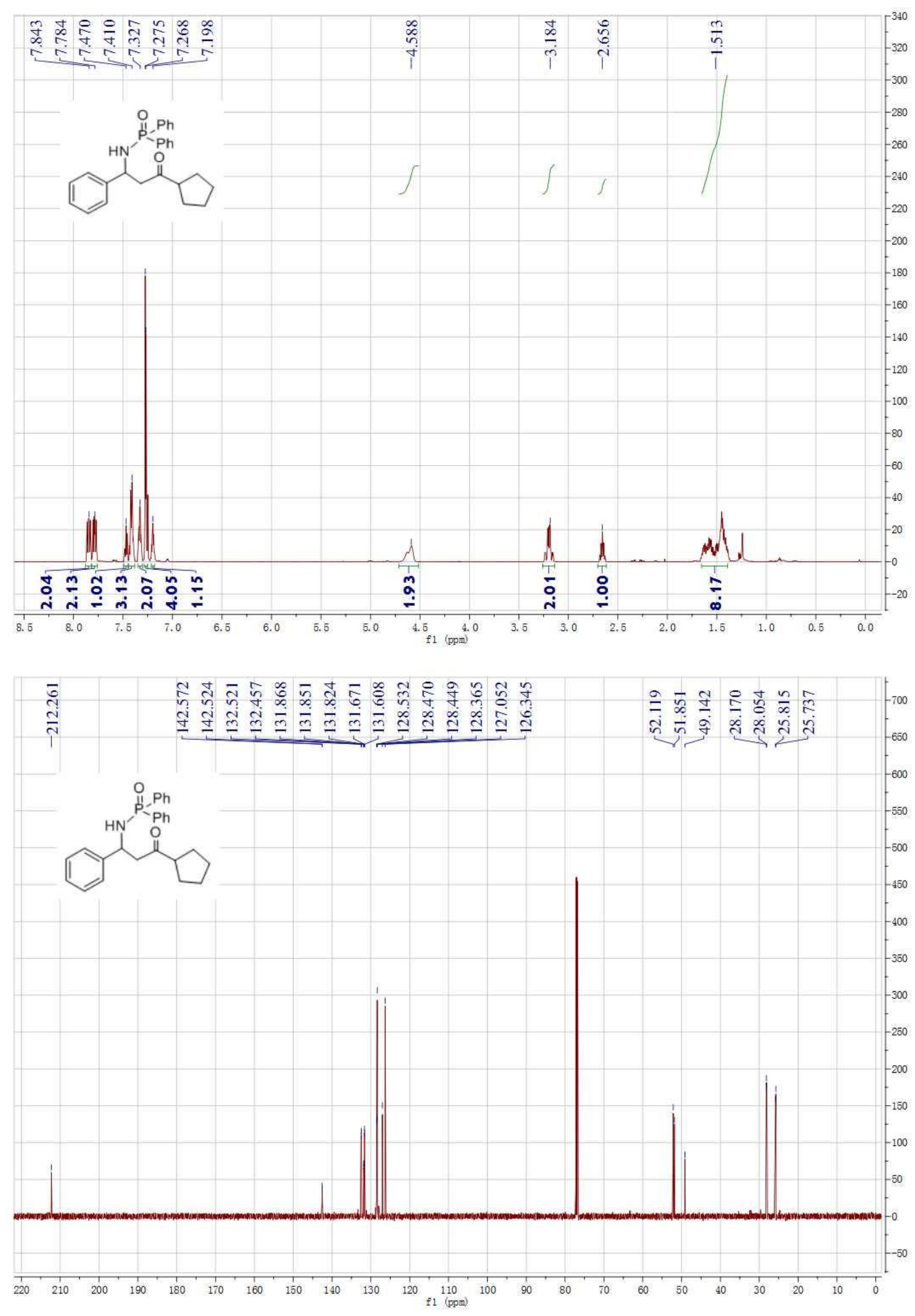
408

Compound ah
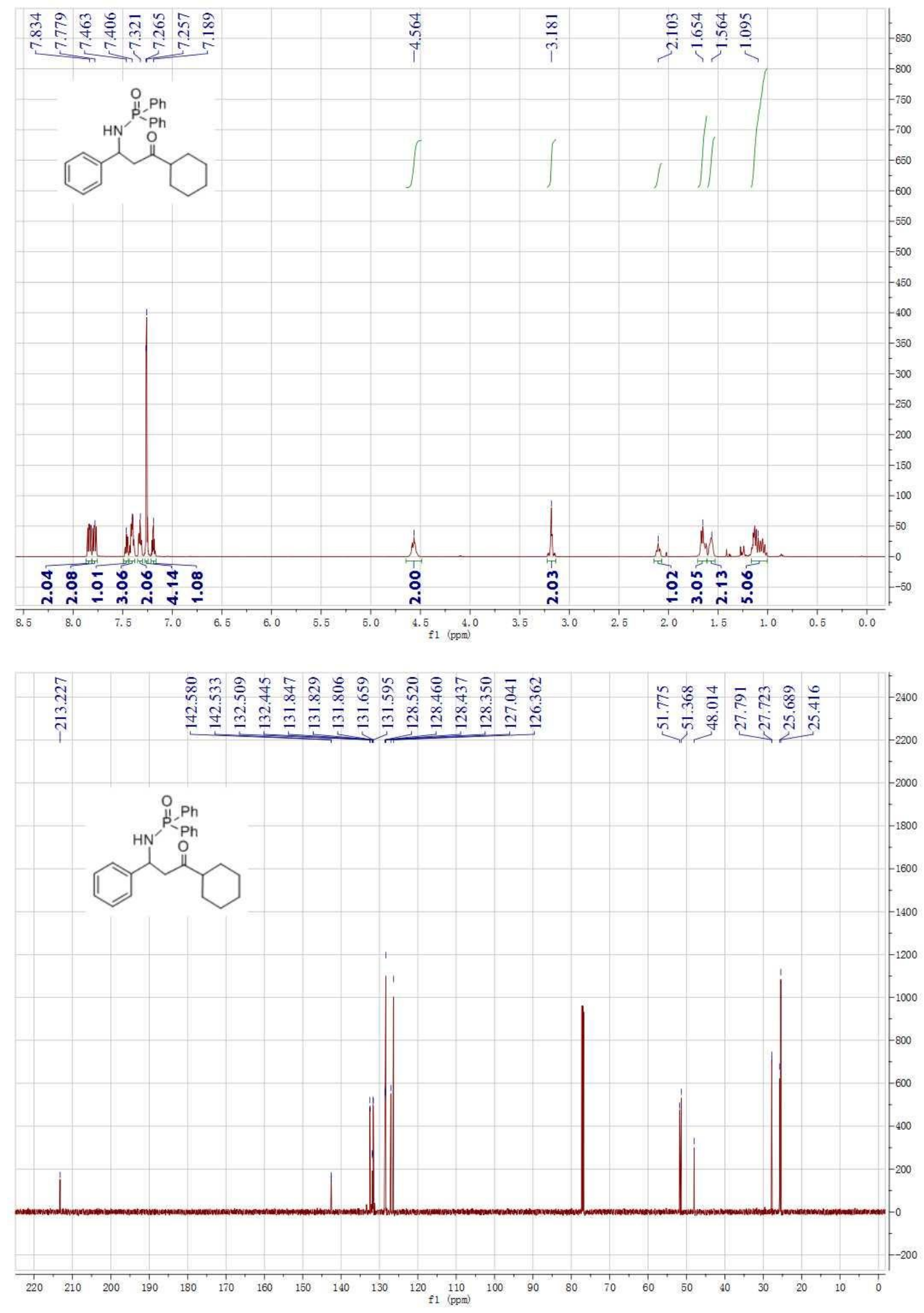


\section{Compound $\mathbf{2 i}$}

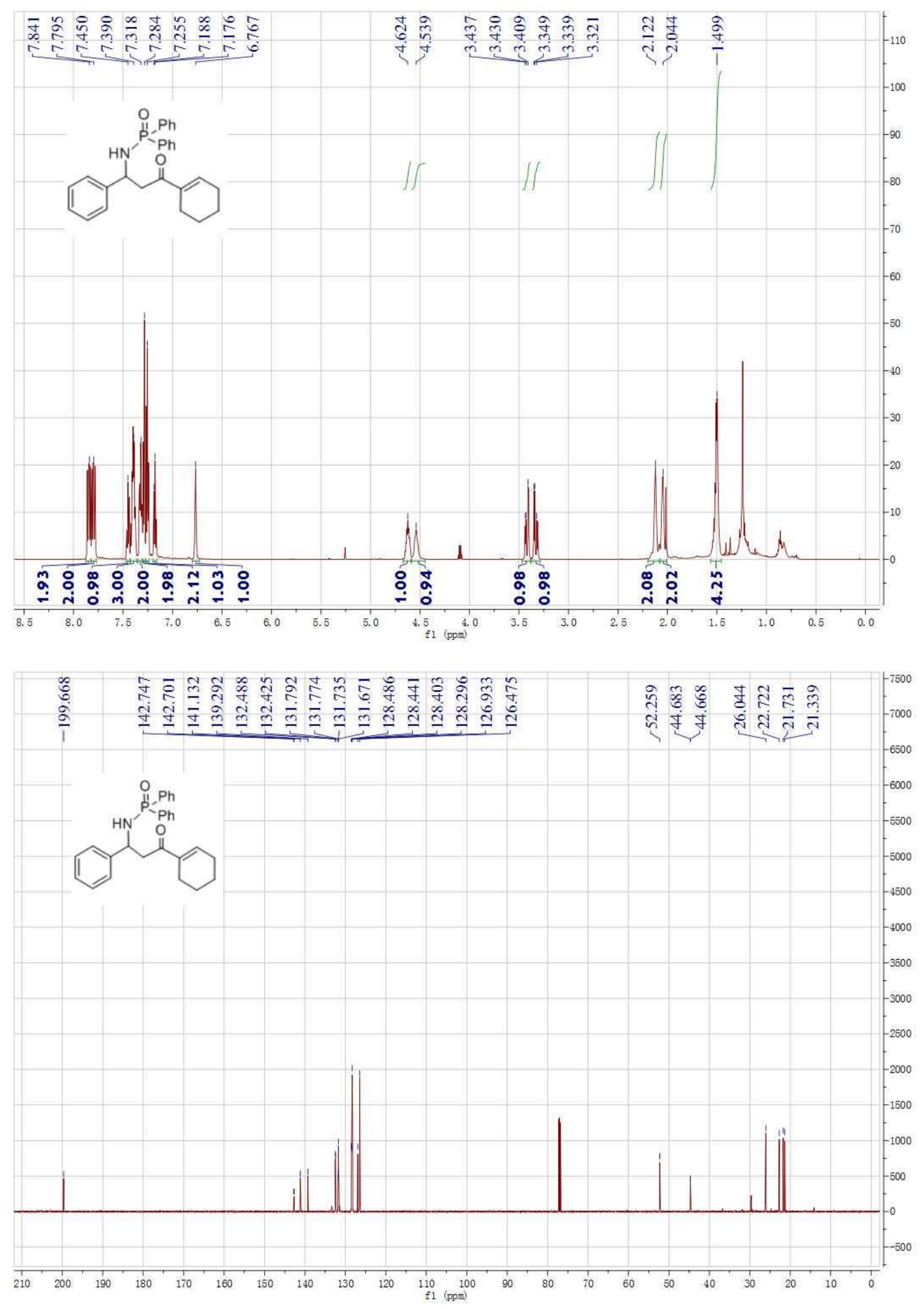




\section{Compound $\mathbf{2 j}$}
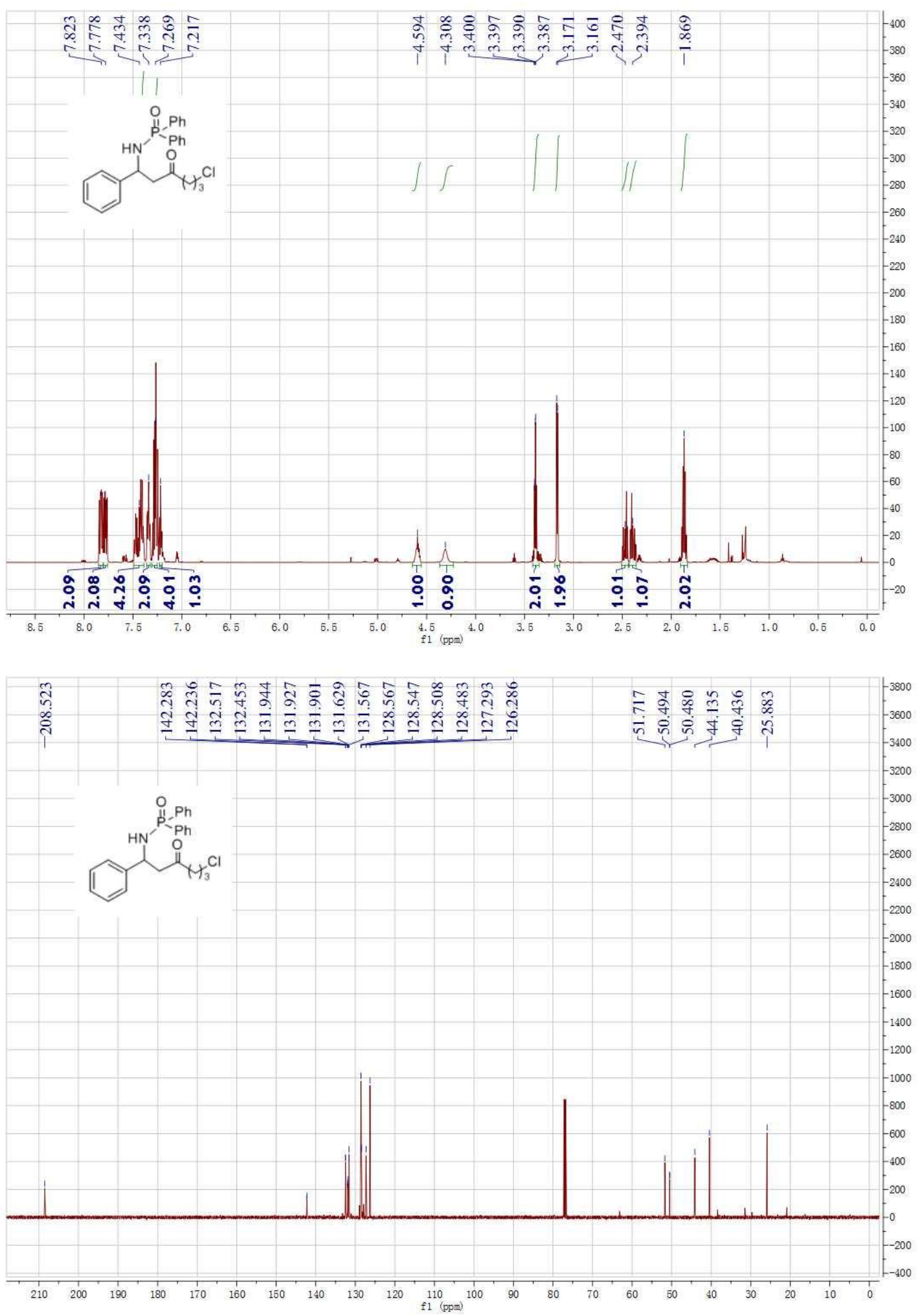


\section{Compound 2k}
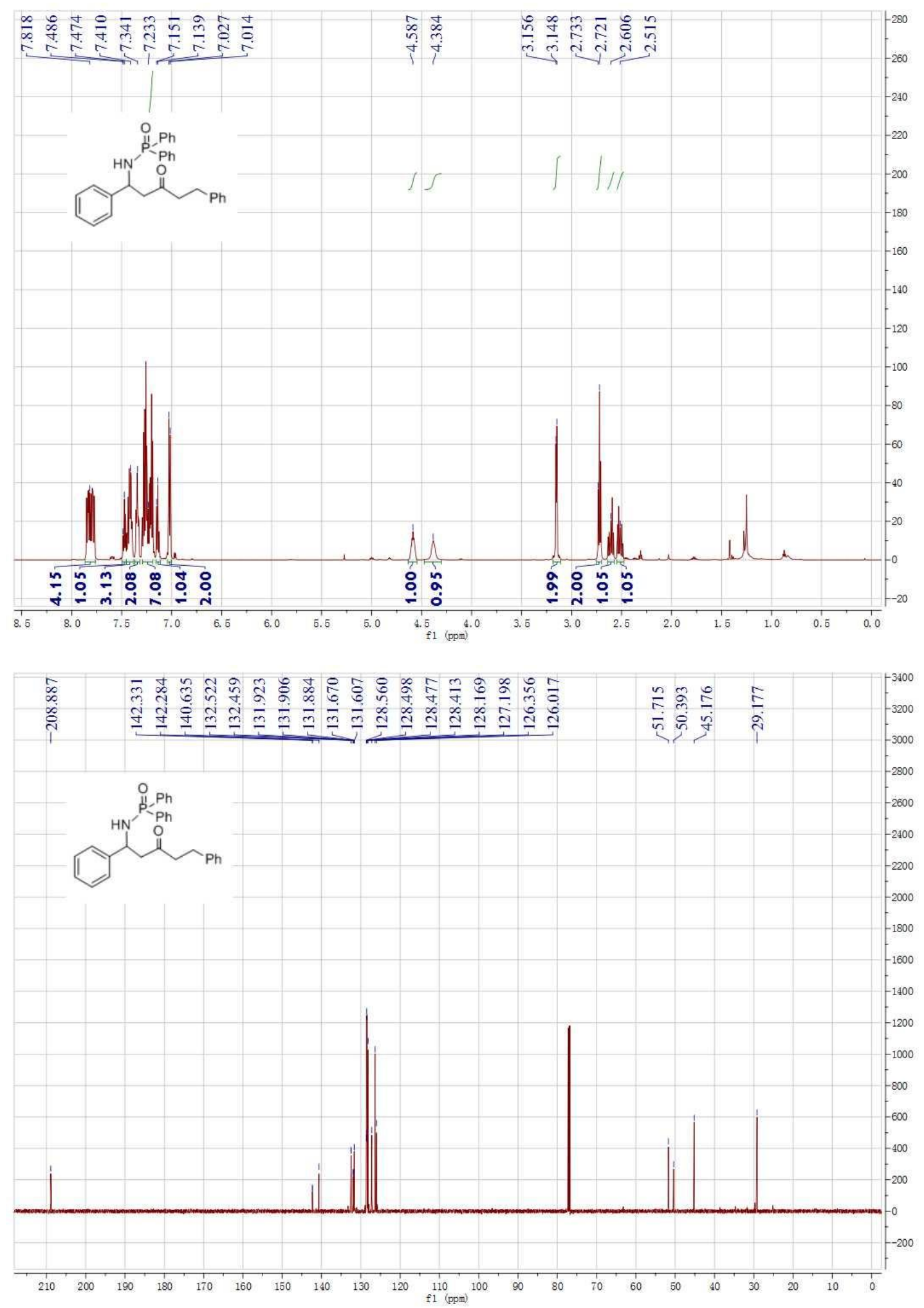
412

Compound Bi
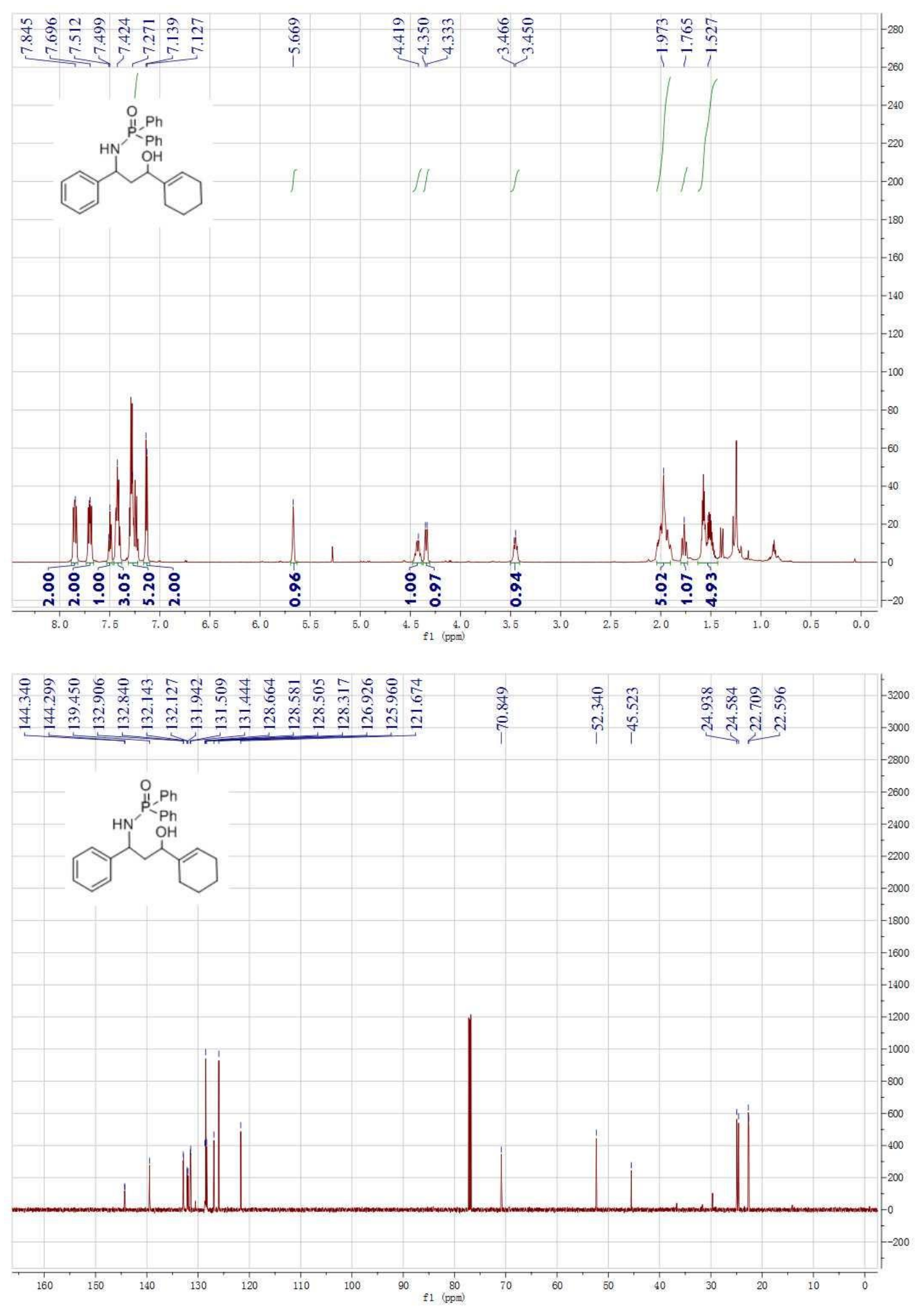
Diastereomeric ratio of compound $\mathbf{3 i}$

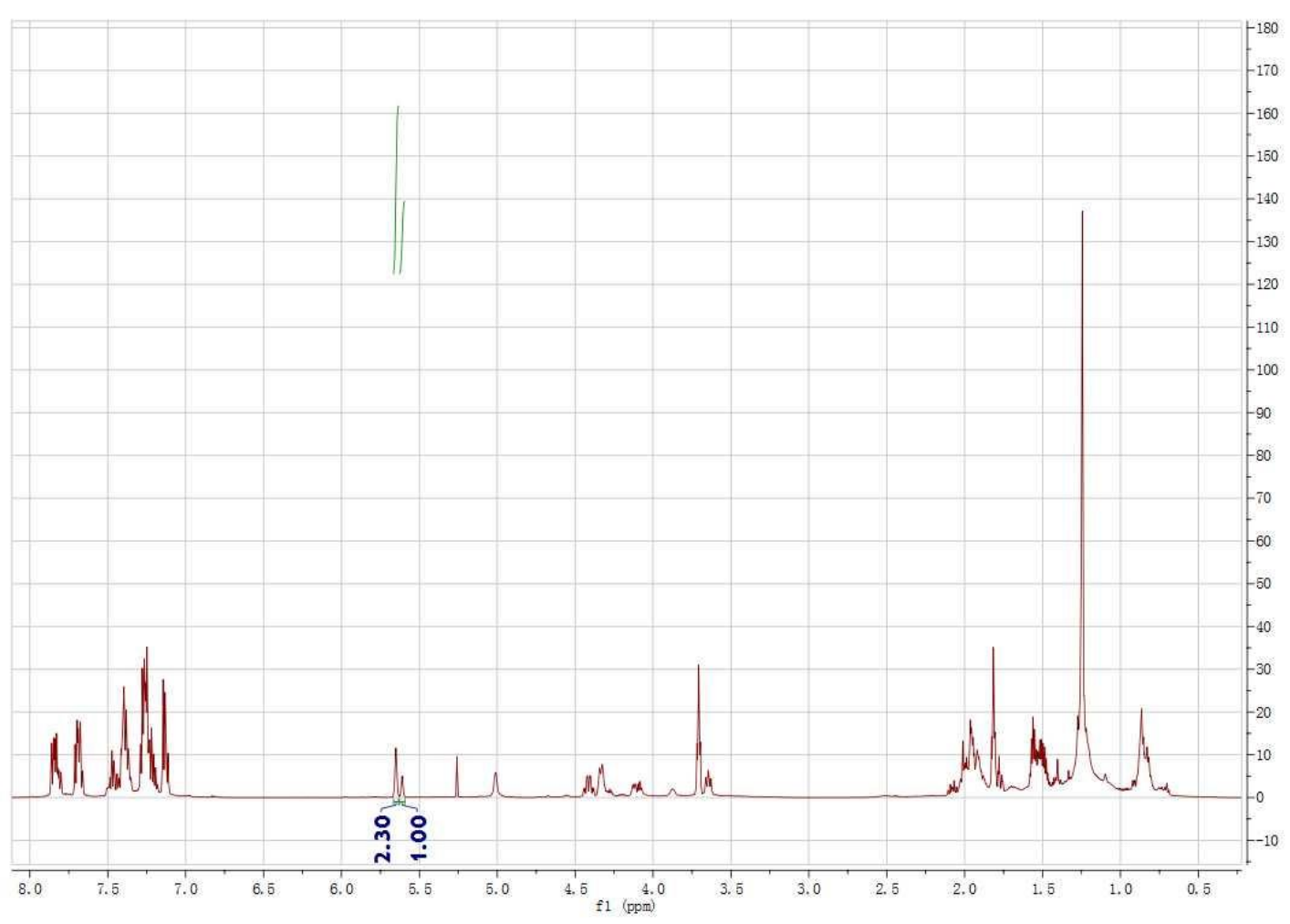




\section{Chapter 6}

${ }^{1} \mathrm{H}$ NMR and ${ }^{13} \mathrm{C}$ NMR Spectra (All the NMR spectra were obtained in $\mathrm{CDCl}_{3}$ unless indicated otherwise)

${ }^{1} \mathrm{H}$ NMR of $\mathbf{L 1}$

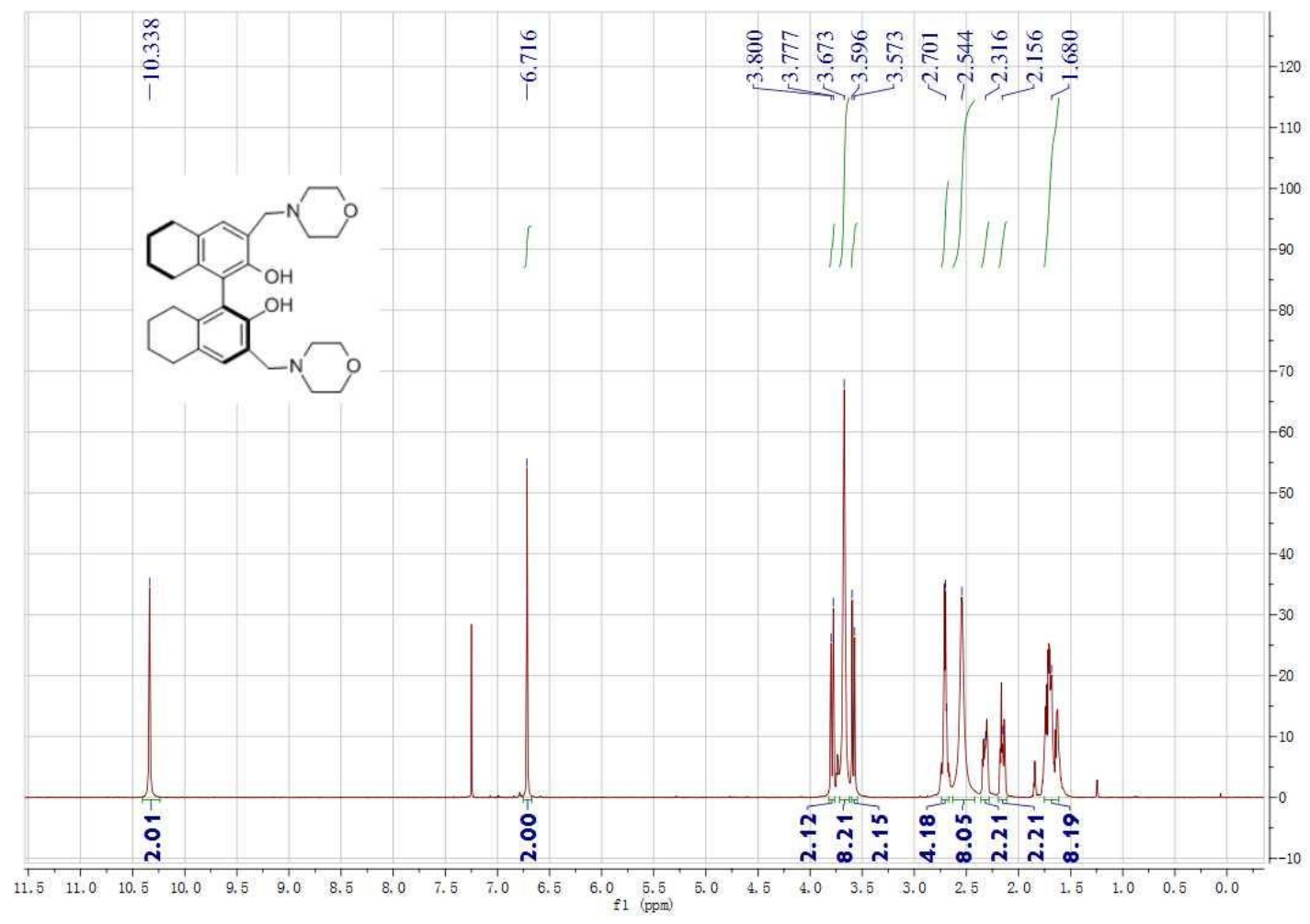

${ }^{13} \mathrm{C}$ NMR of $\mathbf{L 1}$

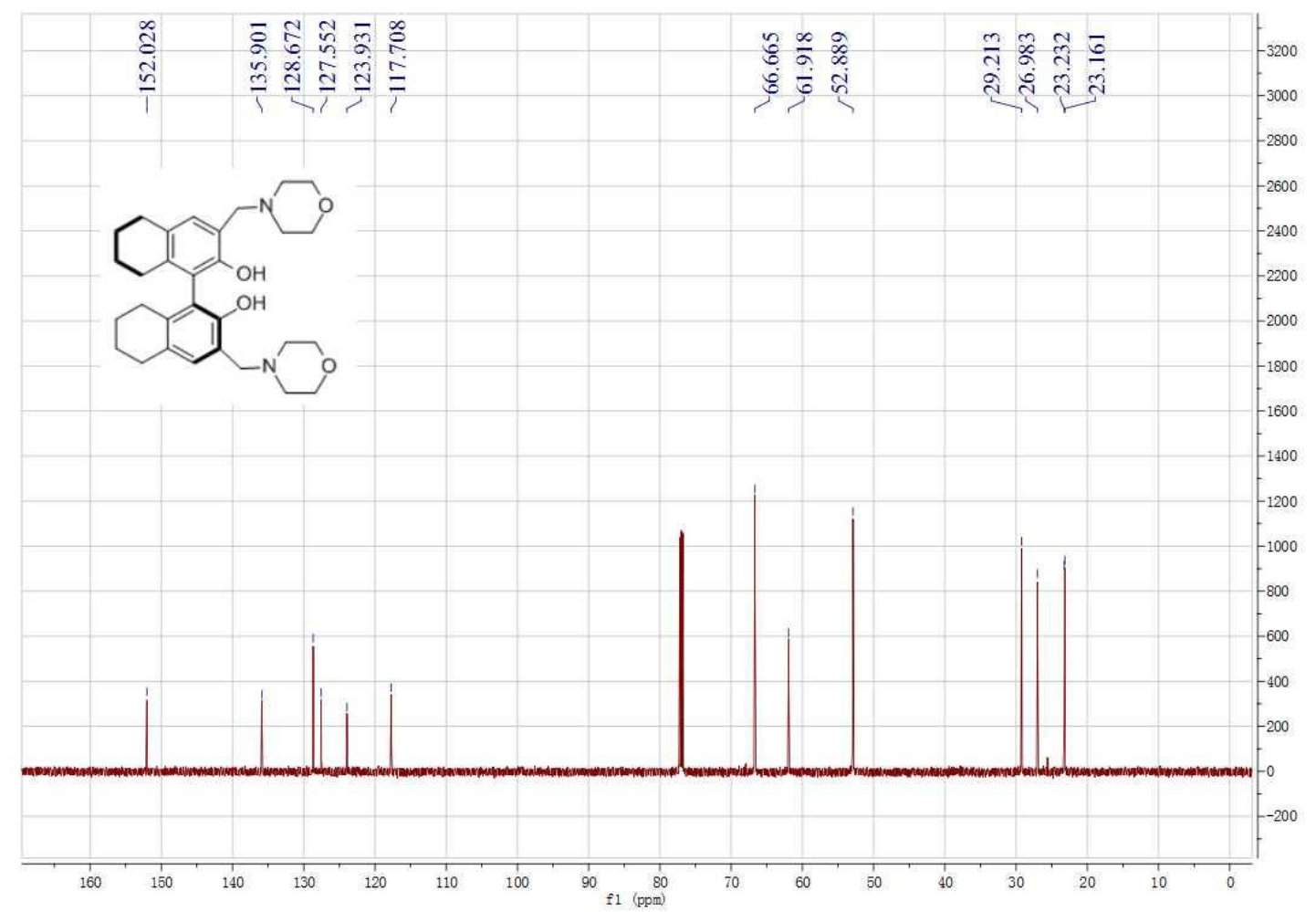


${ }^{1}$ H NMR of A1

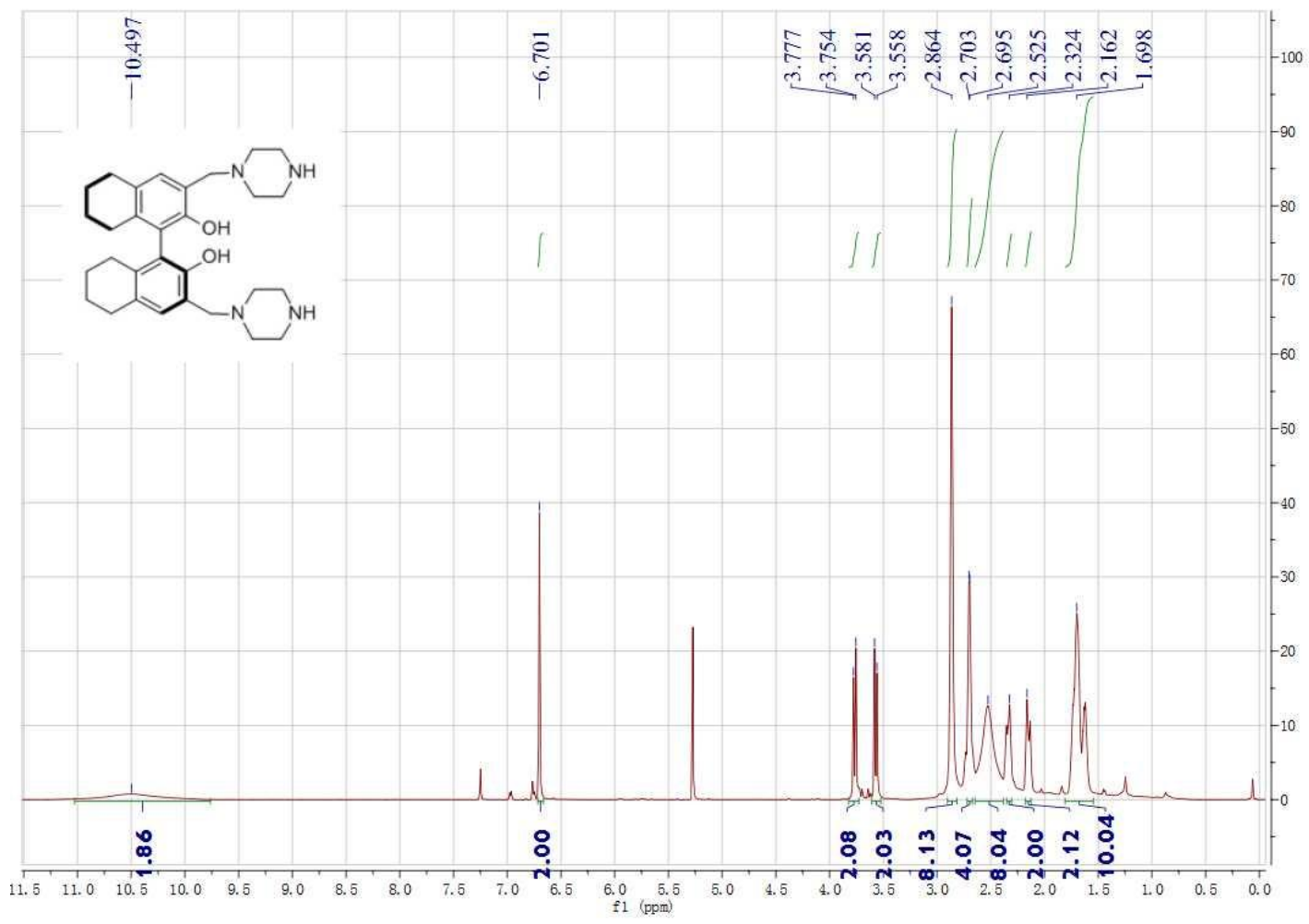

${ }^{13} \mathrm{C}$ NMR of $\mathbf{A} 1$

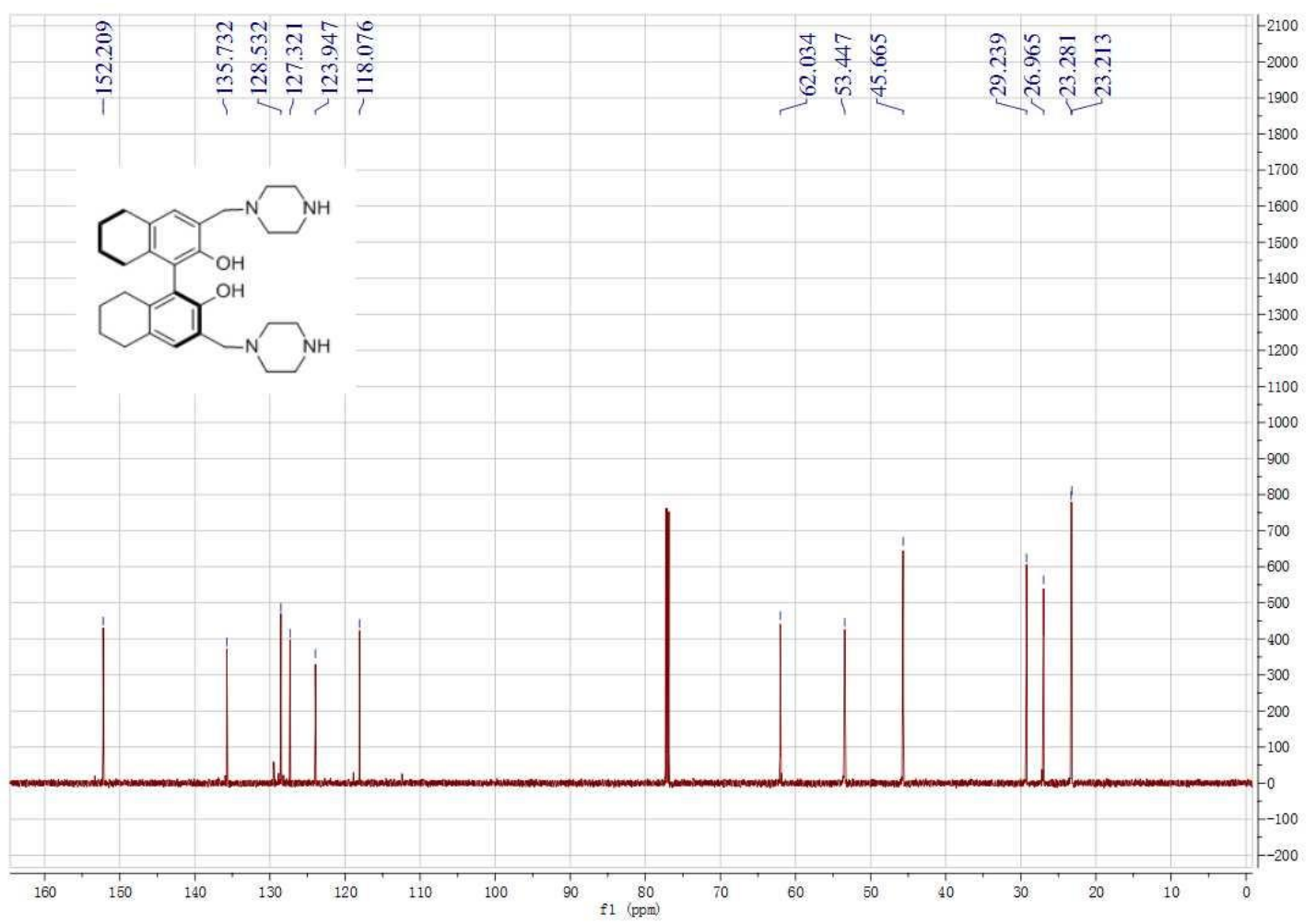


${ }^{1} \mathrm{H}$ NMR of $\mathbf{A 2}$

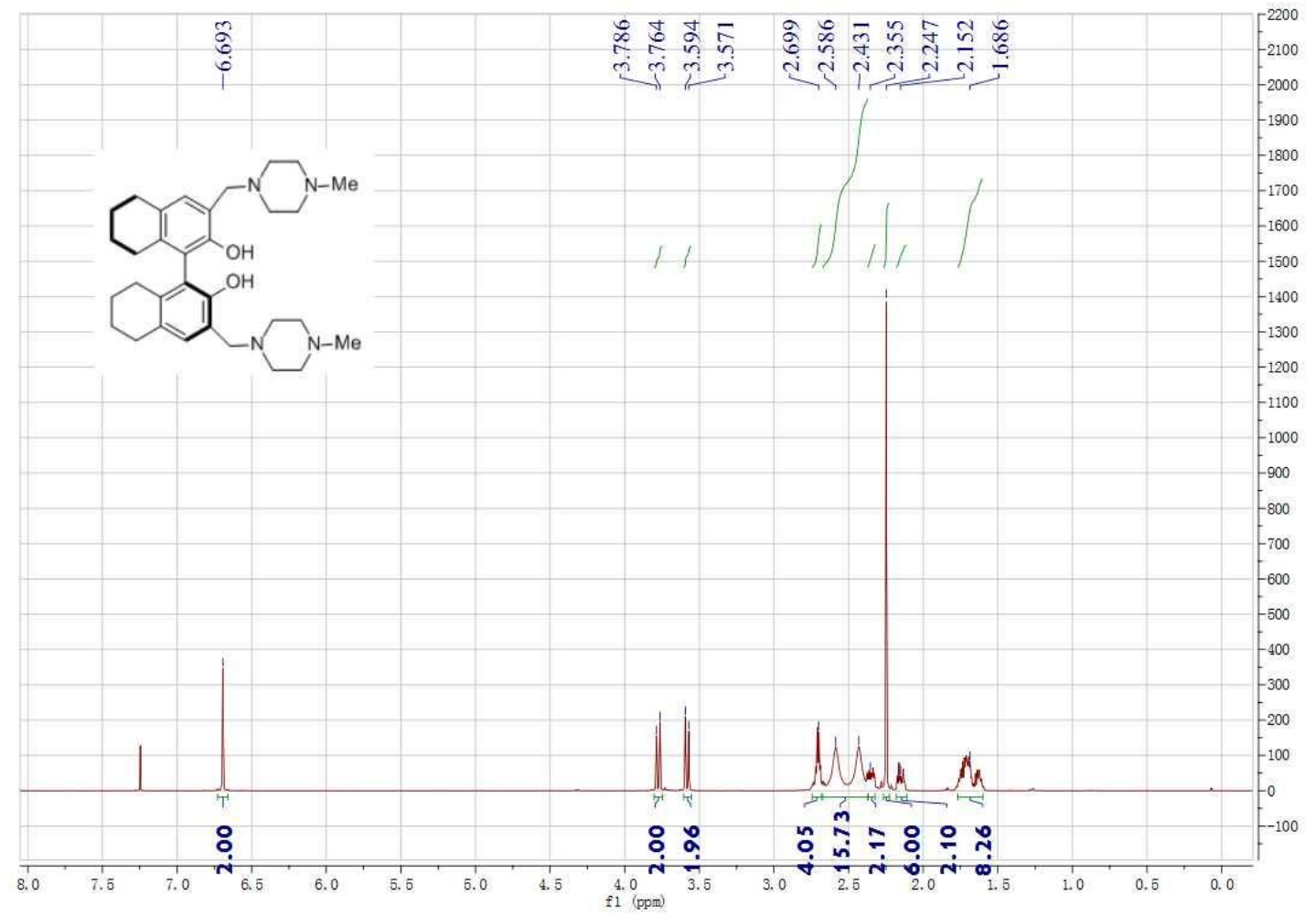

${ }^{13} \mathrm{C}$ NMR of A2

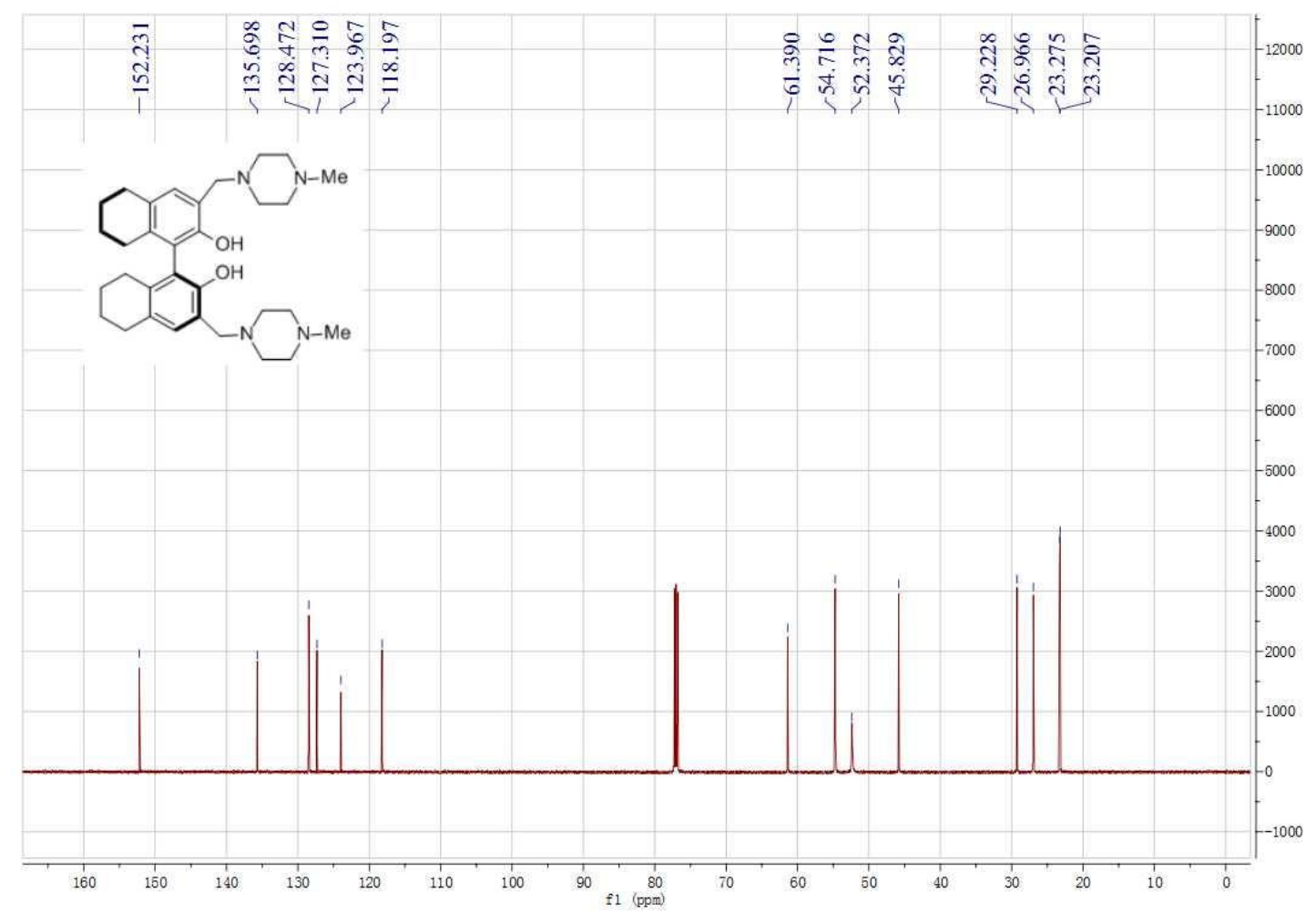


${ }^{1}$ H NMR of $\mathbf{A 3}$

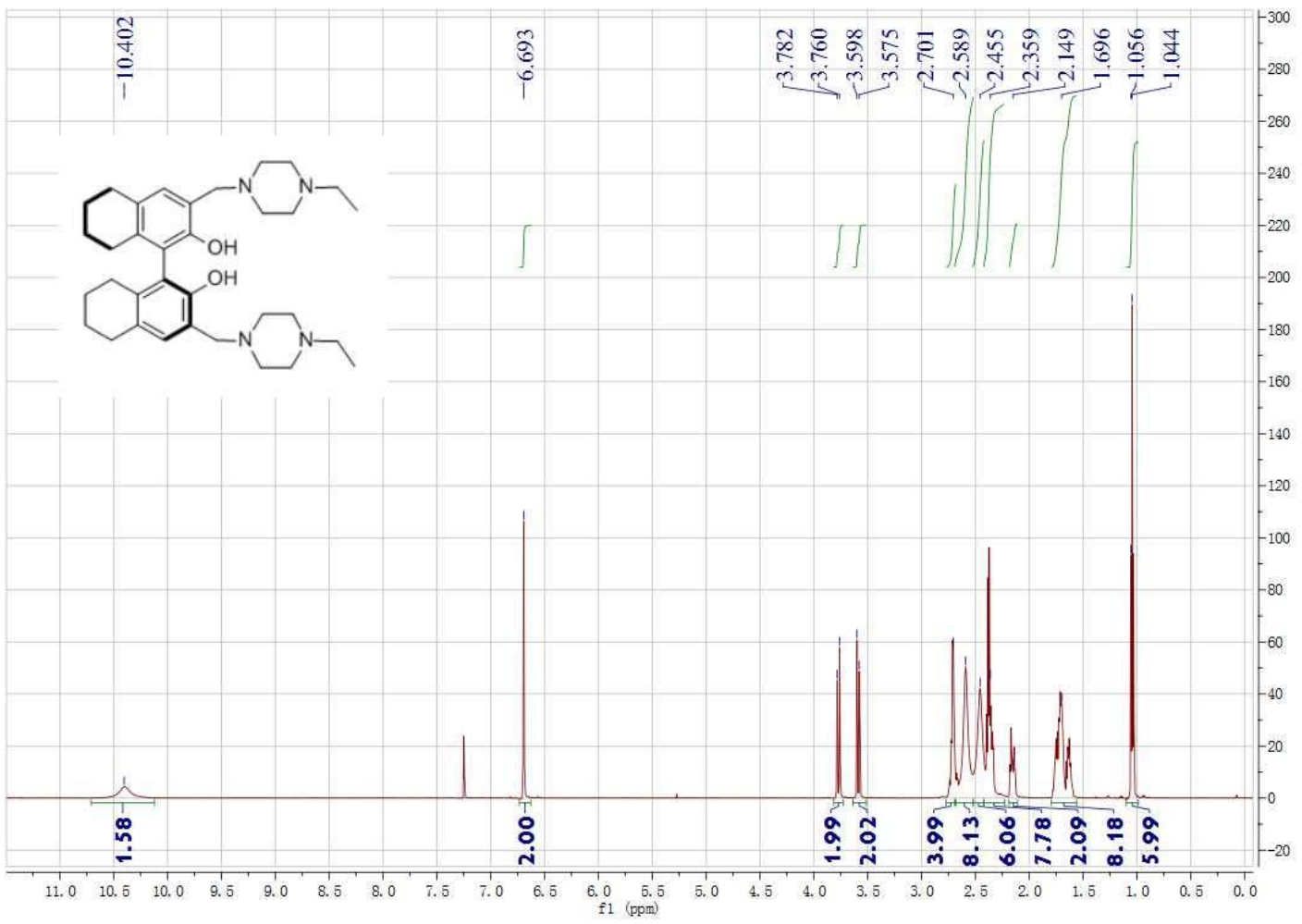

${ }^{13} \mathrm{C}$ NMR of $\mathbf{A 3}$

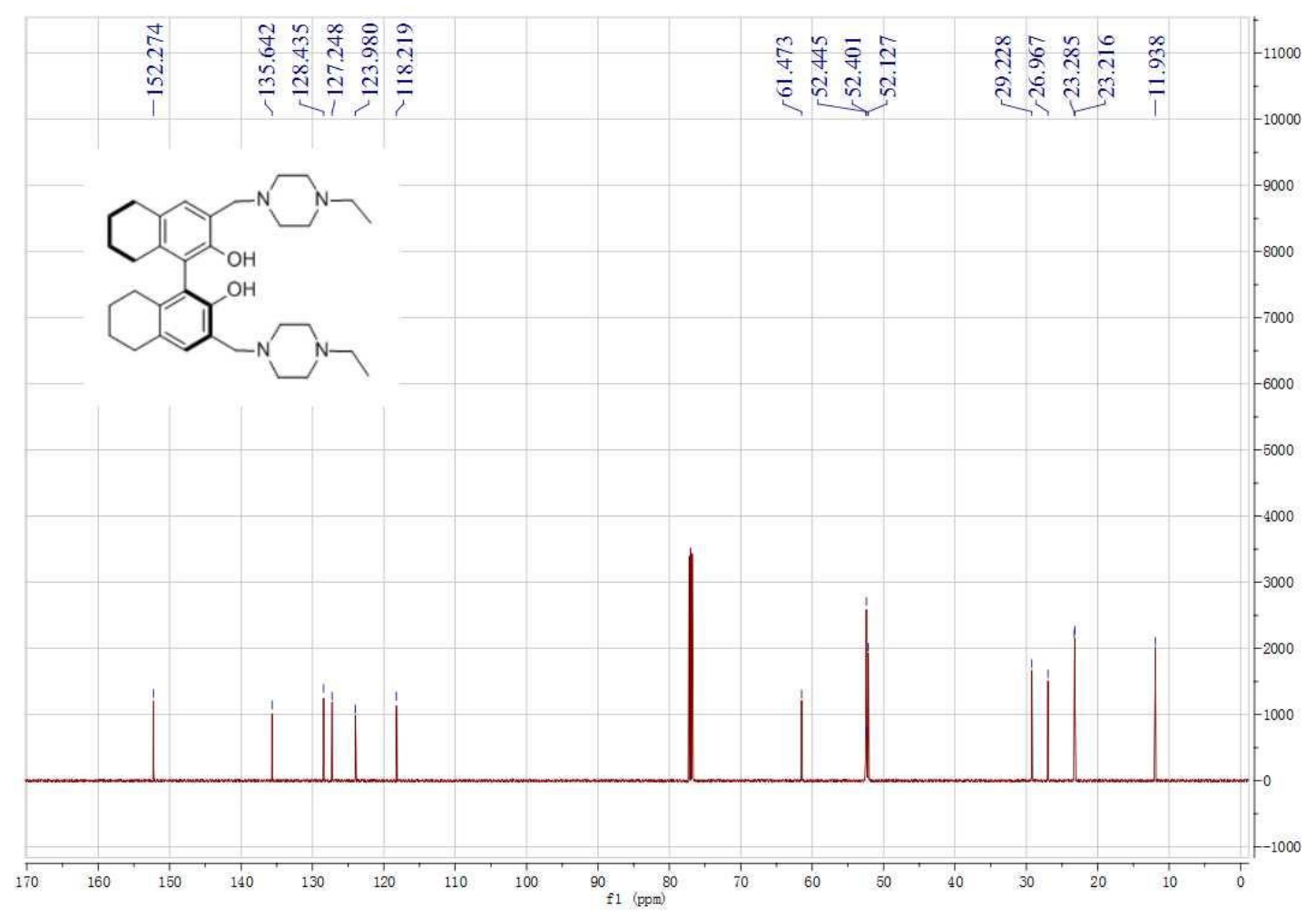


${ }^{1}$ H NMR of A4

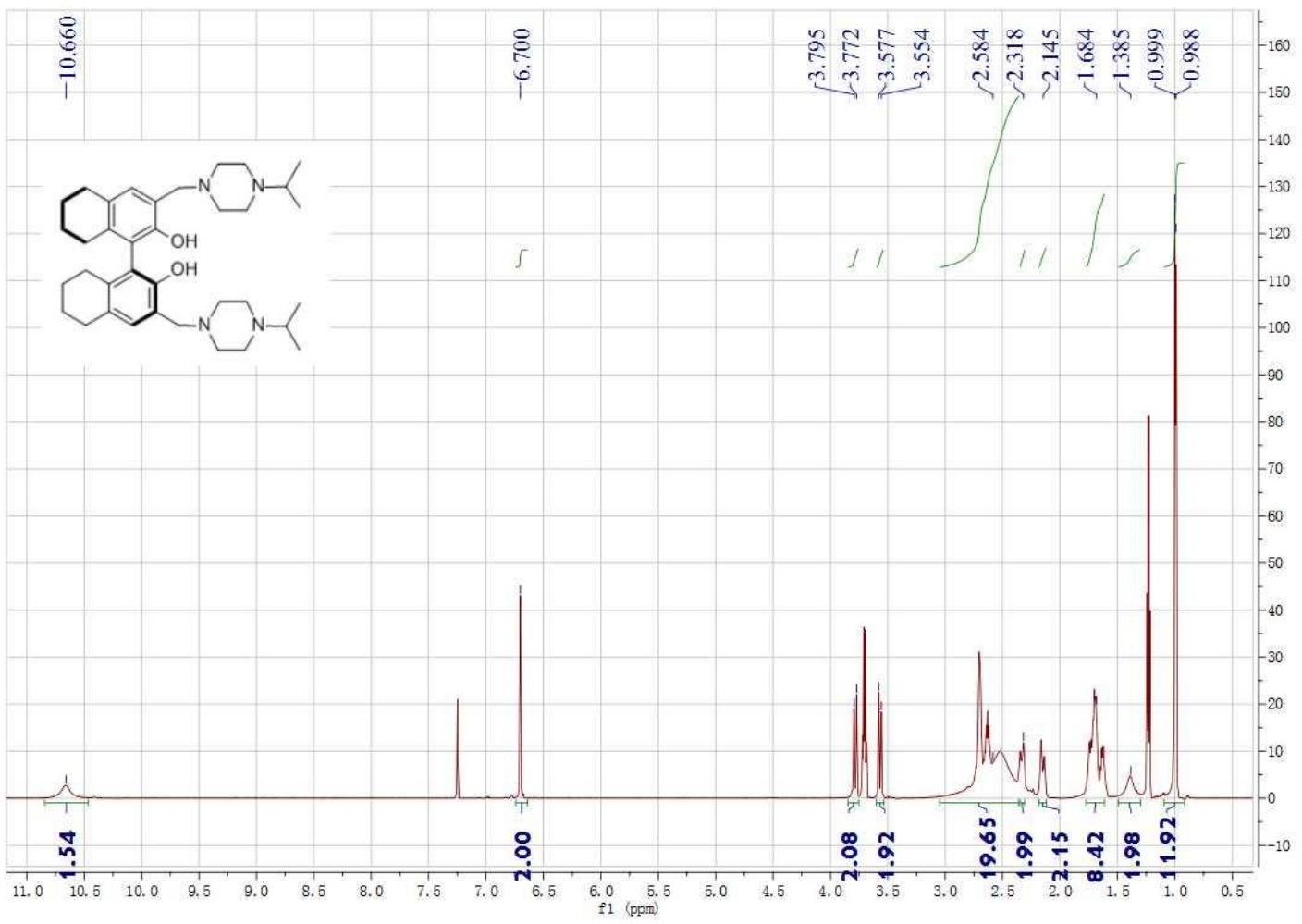

${ }^{13} \mathrm{C}$ NMR of $\mathbf{A 4}$

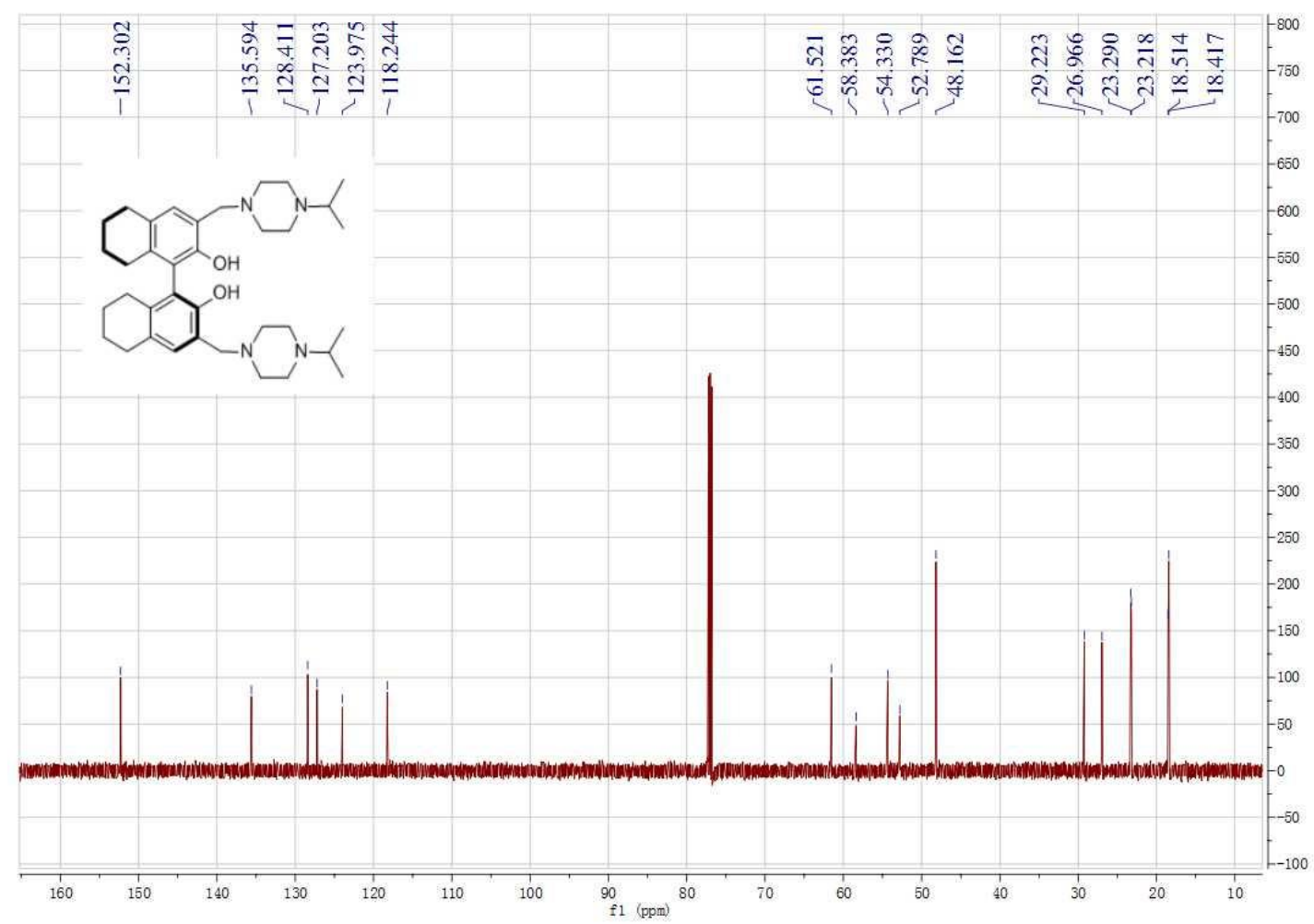




\section{${ }^{1} \mathrm{H}$ NMR of $\mathbf{A 5}$}

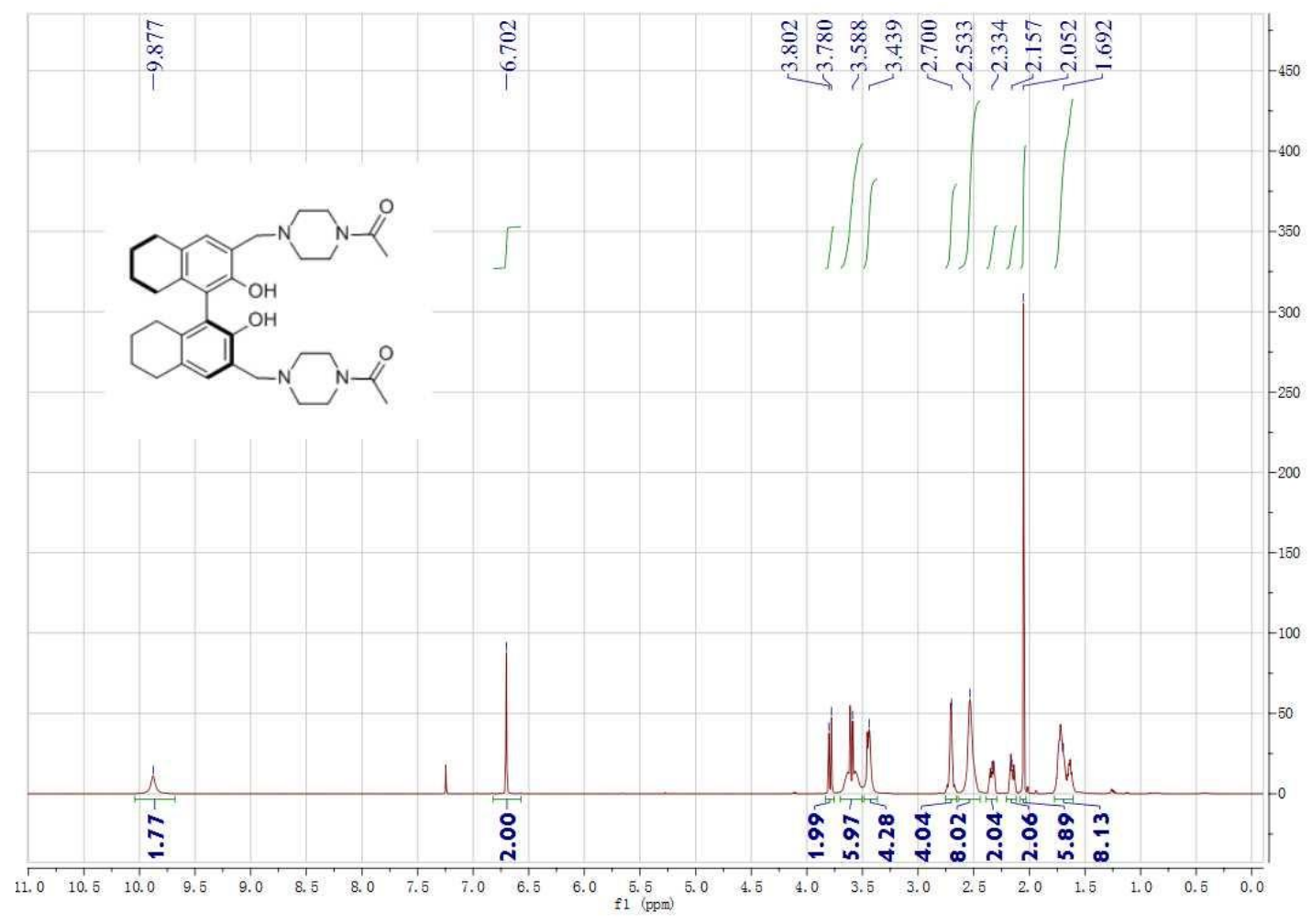

${ }^{13} \mathrm{C}$ NMR of $\mathbf{A 5}$

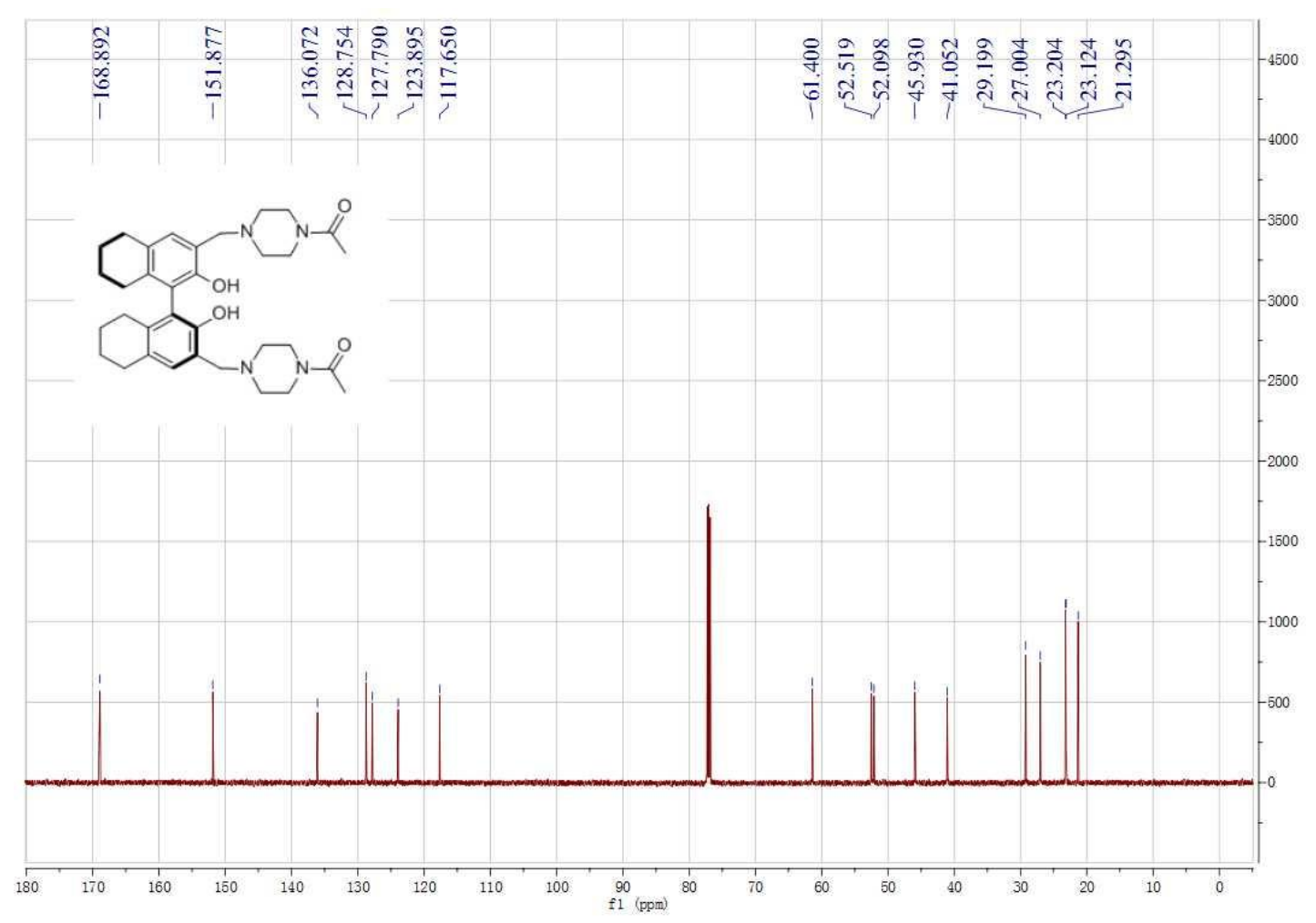


${ }^{1} \mathrm{H}$ NMR of $\mathbf{A 6}$

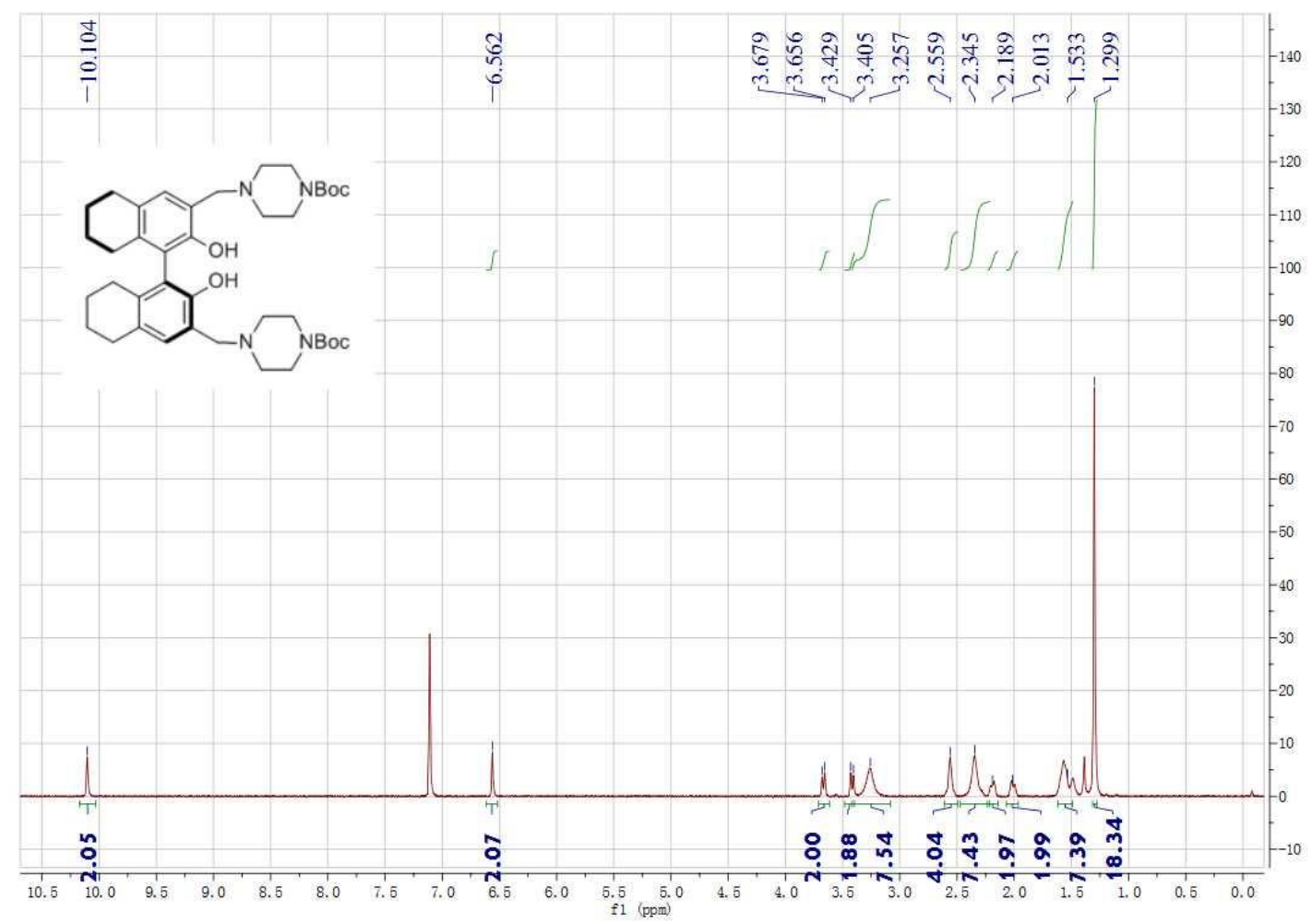

${ }^{1} \mathrm{H}$ NMR of A7

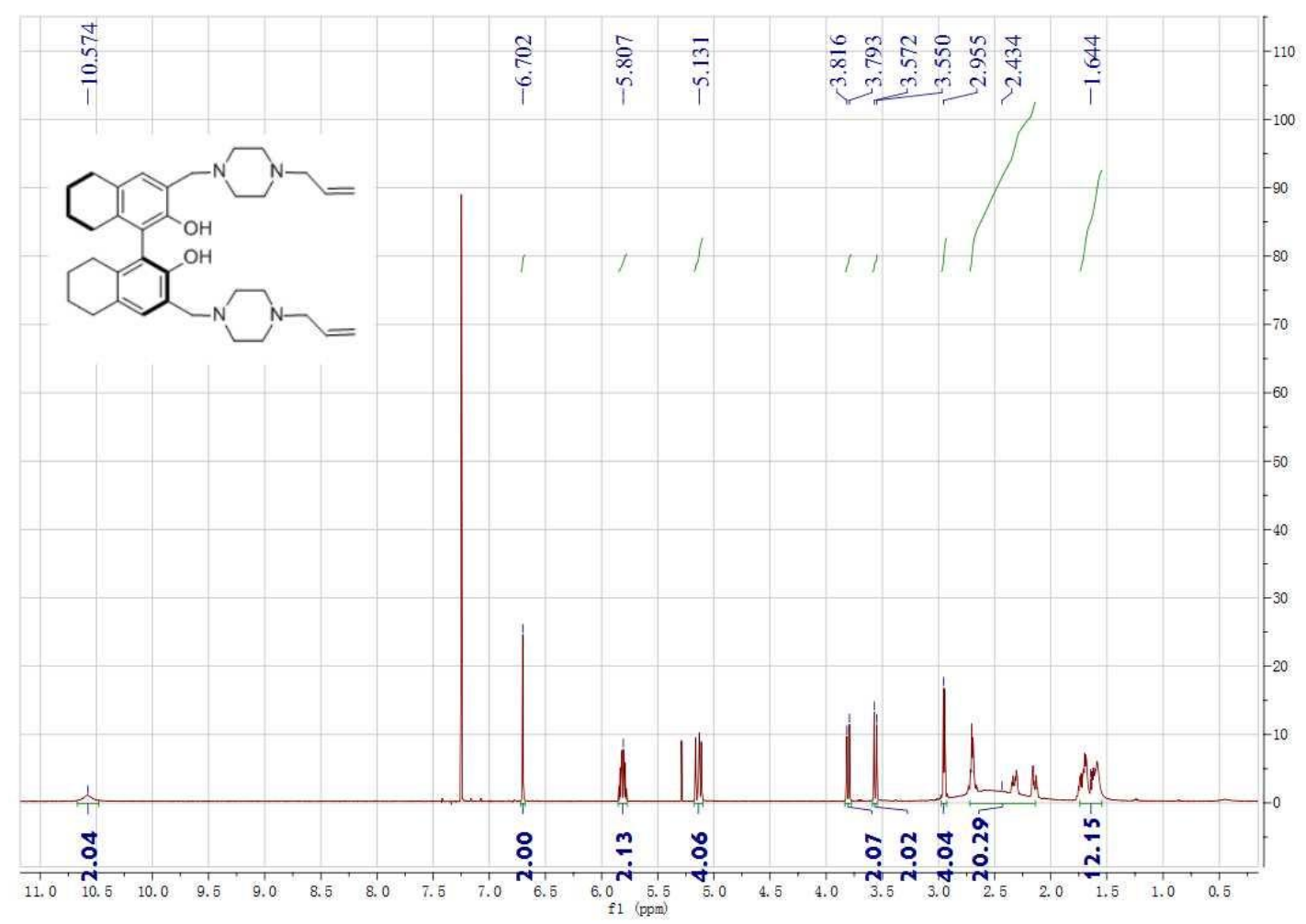


${ }^{1}$ H NMR of $\mathbf{A 8}$

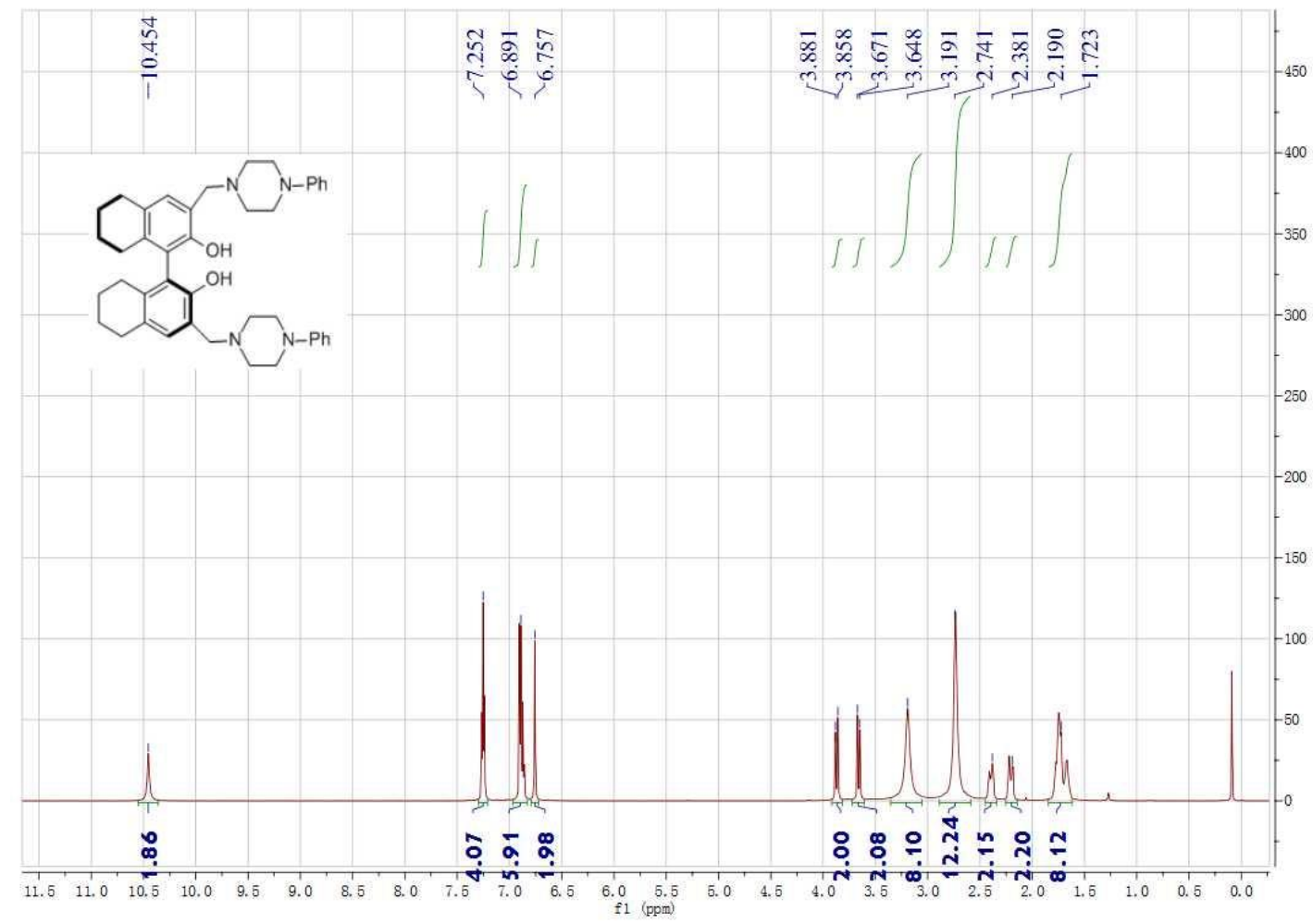

${ }^{13} \mathrm{C}$ NMR of $\mathbf{A 8}$

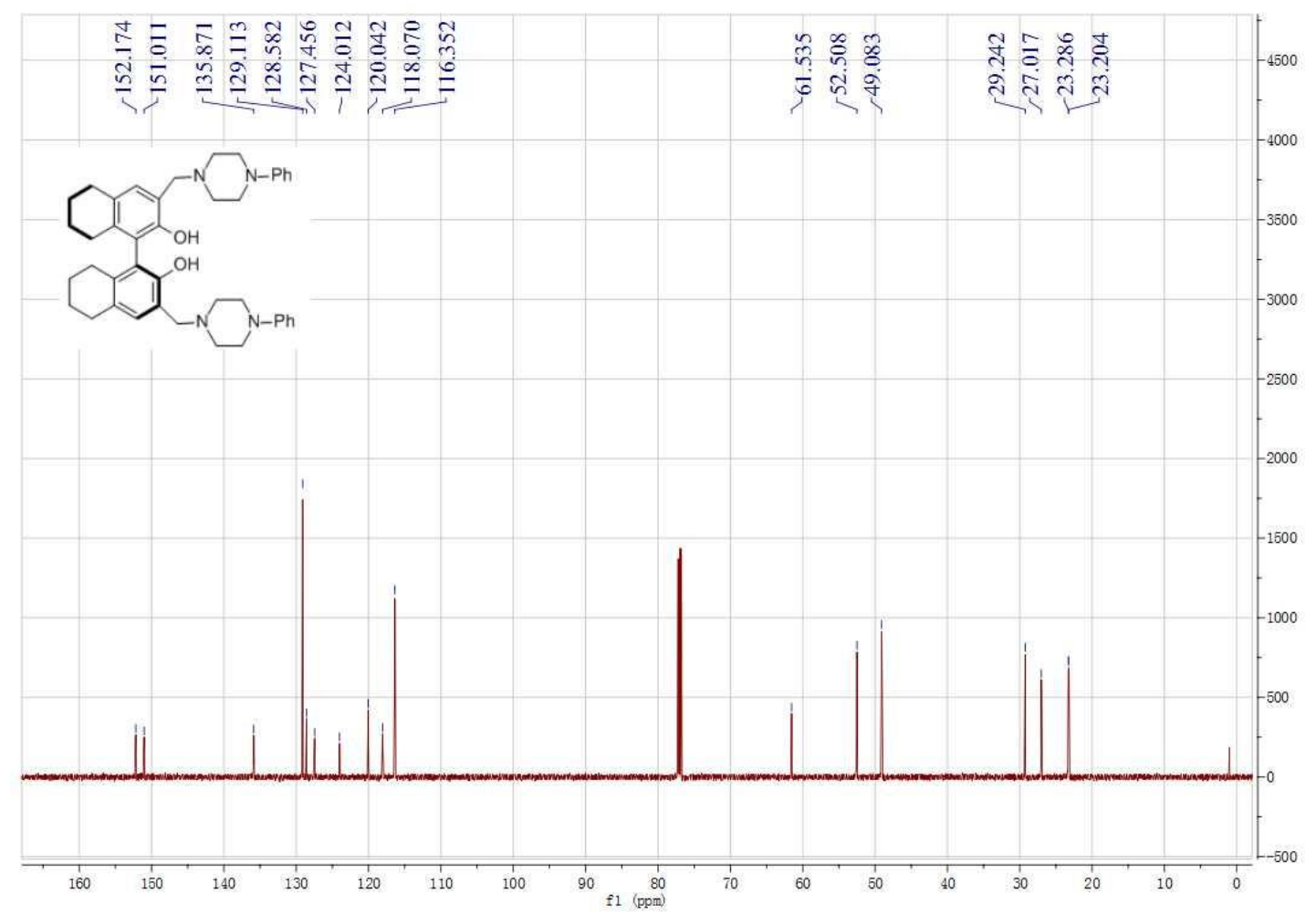


${ }^{1}$ H NMR of $\mathbf{A 9}$

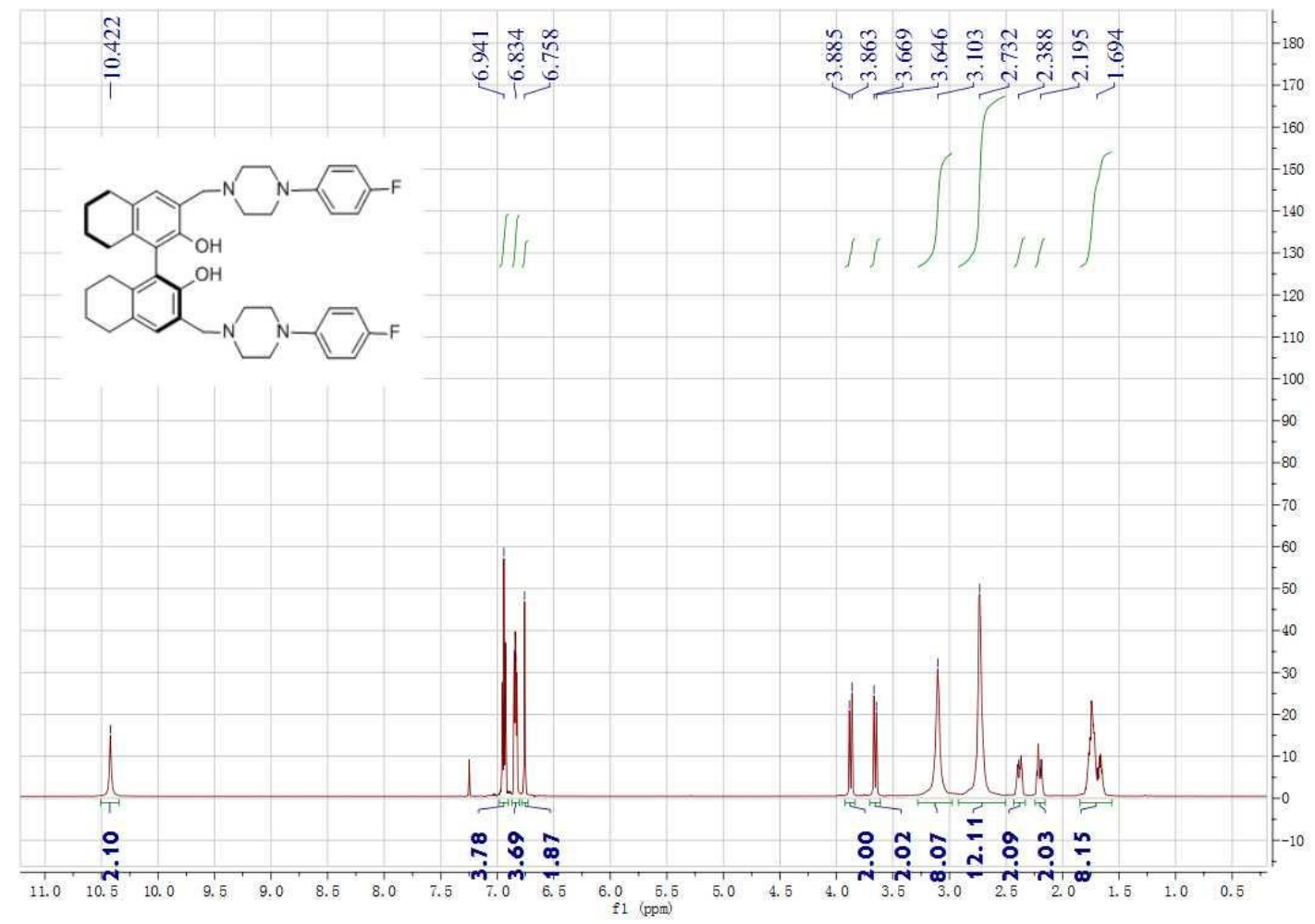

${ }^{13} \mathrm{C}$ NMR of $\mathbf{A 9}$

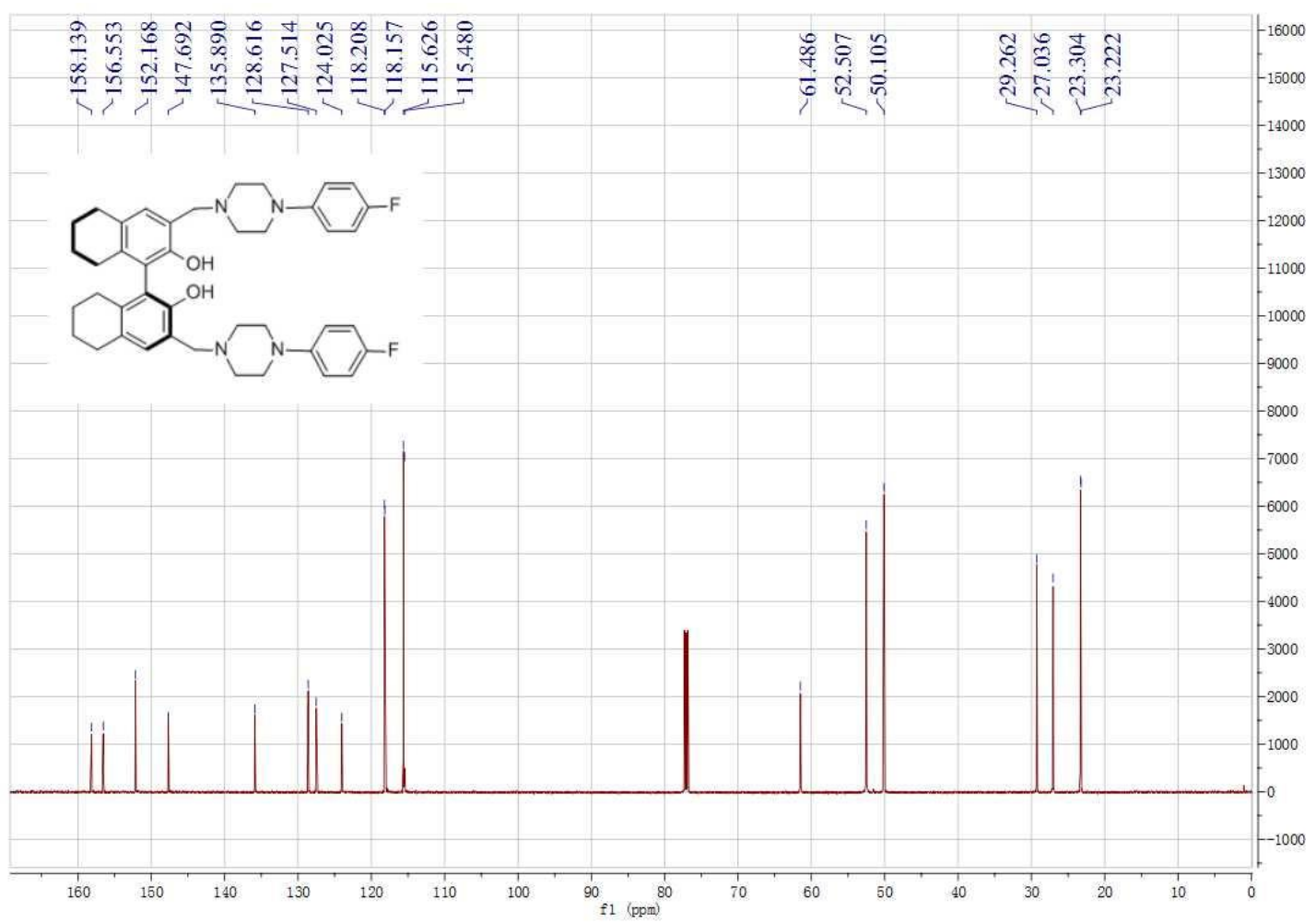


${ }^{1}$ H NMR of $\mathbf{B 1}$

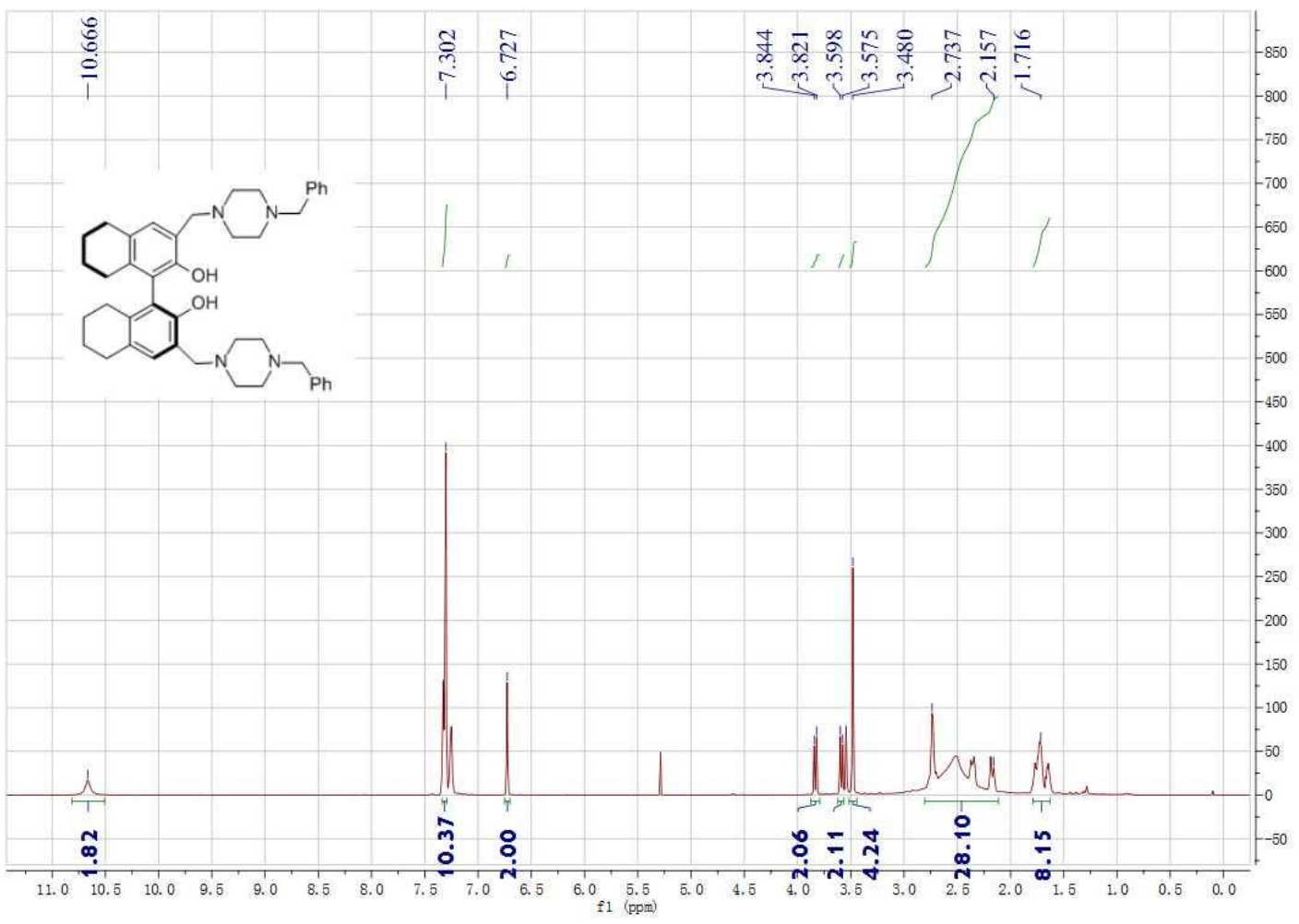

${ }^{13} \mathrm{C}$ NMR of $\mathbf{B} 1$

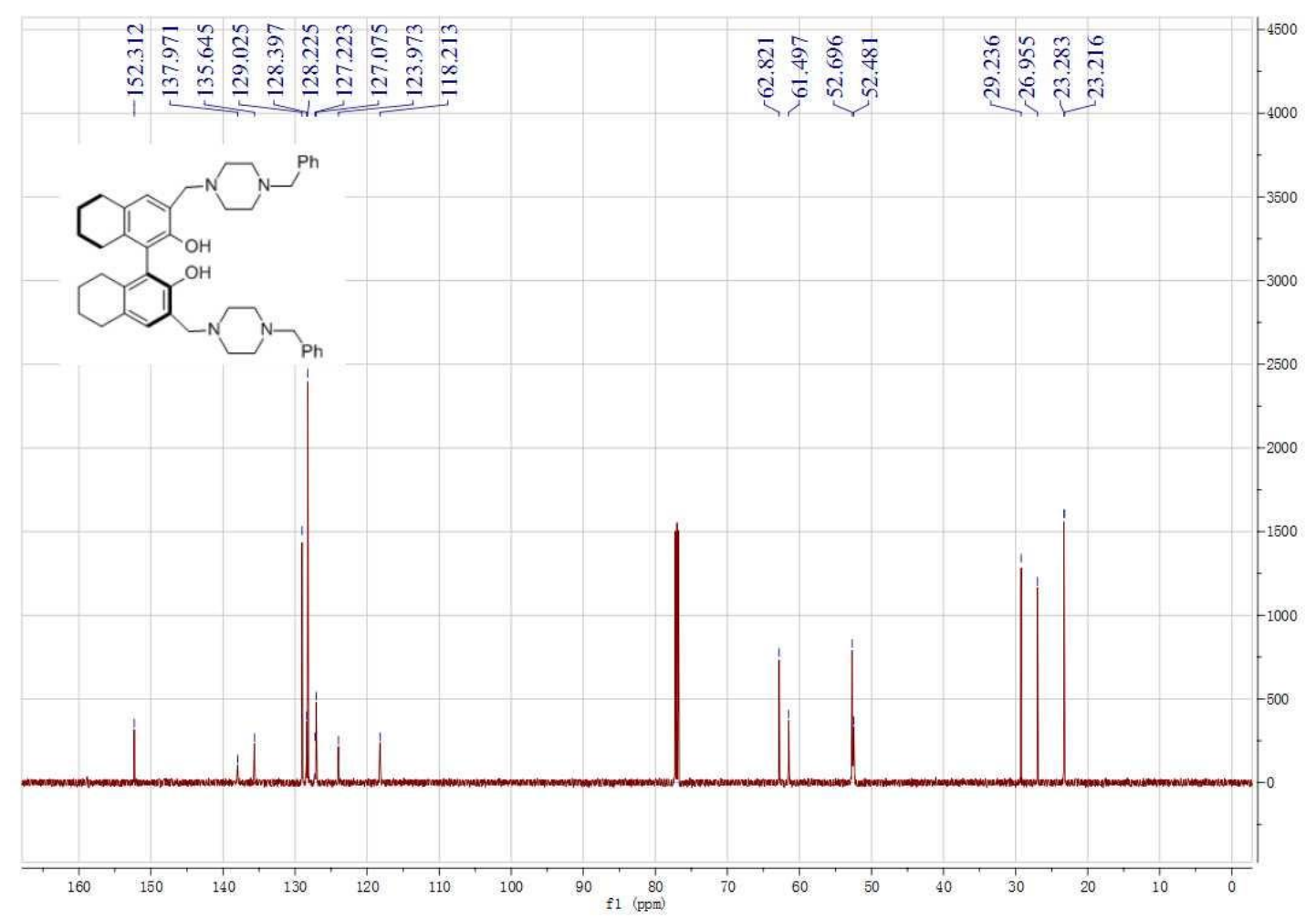


${ }^{1}$ H NMR of $\mathbf{B 2}$

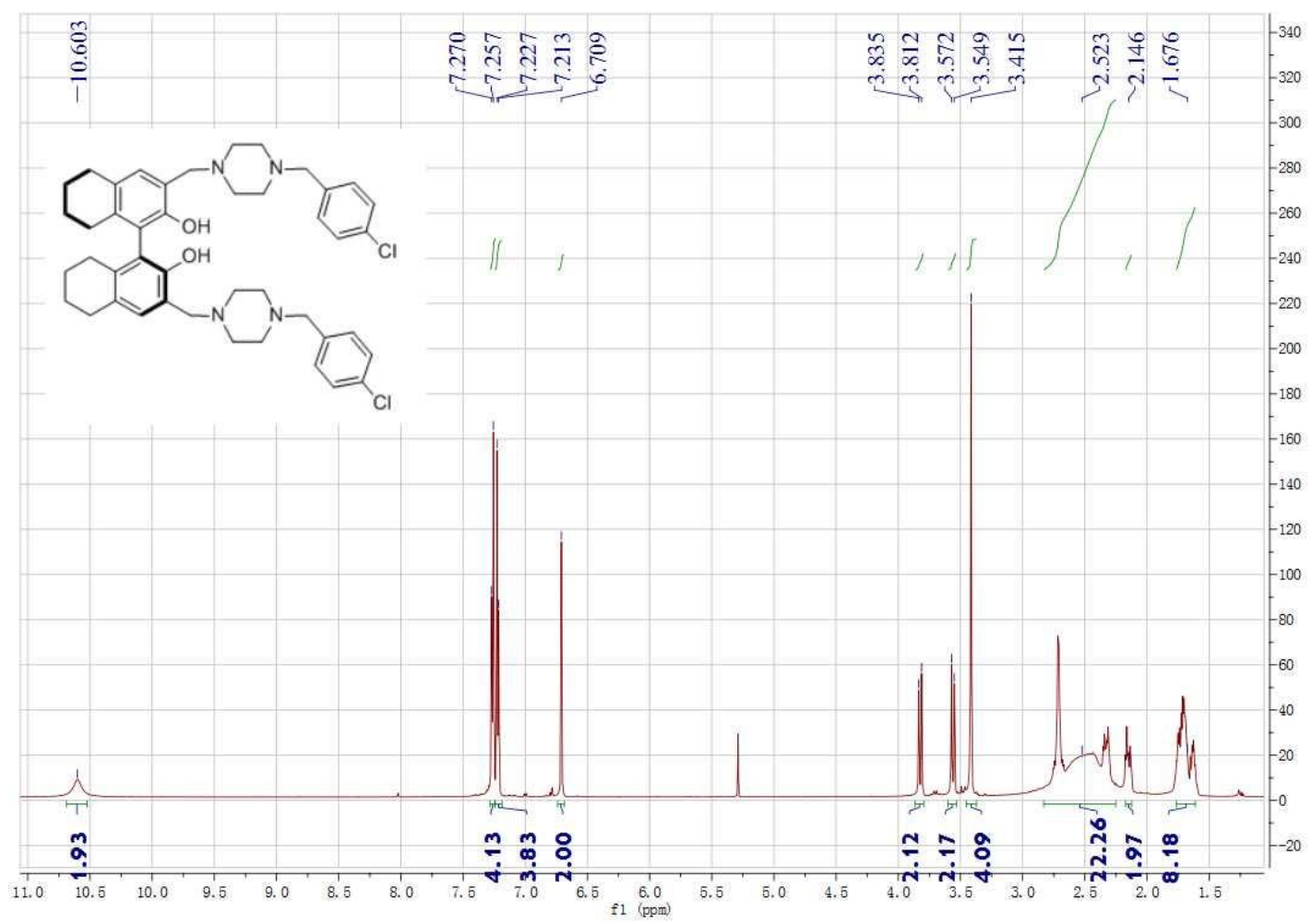

${ }^{1} \mathrm{H}$ NMR of $\mathbf{B 3}$

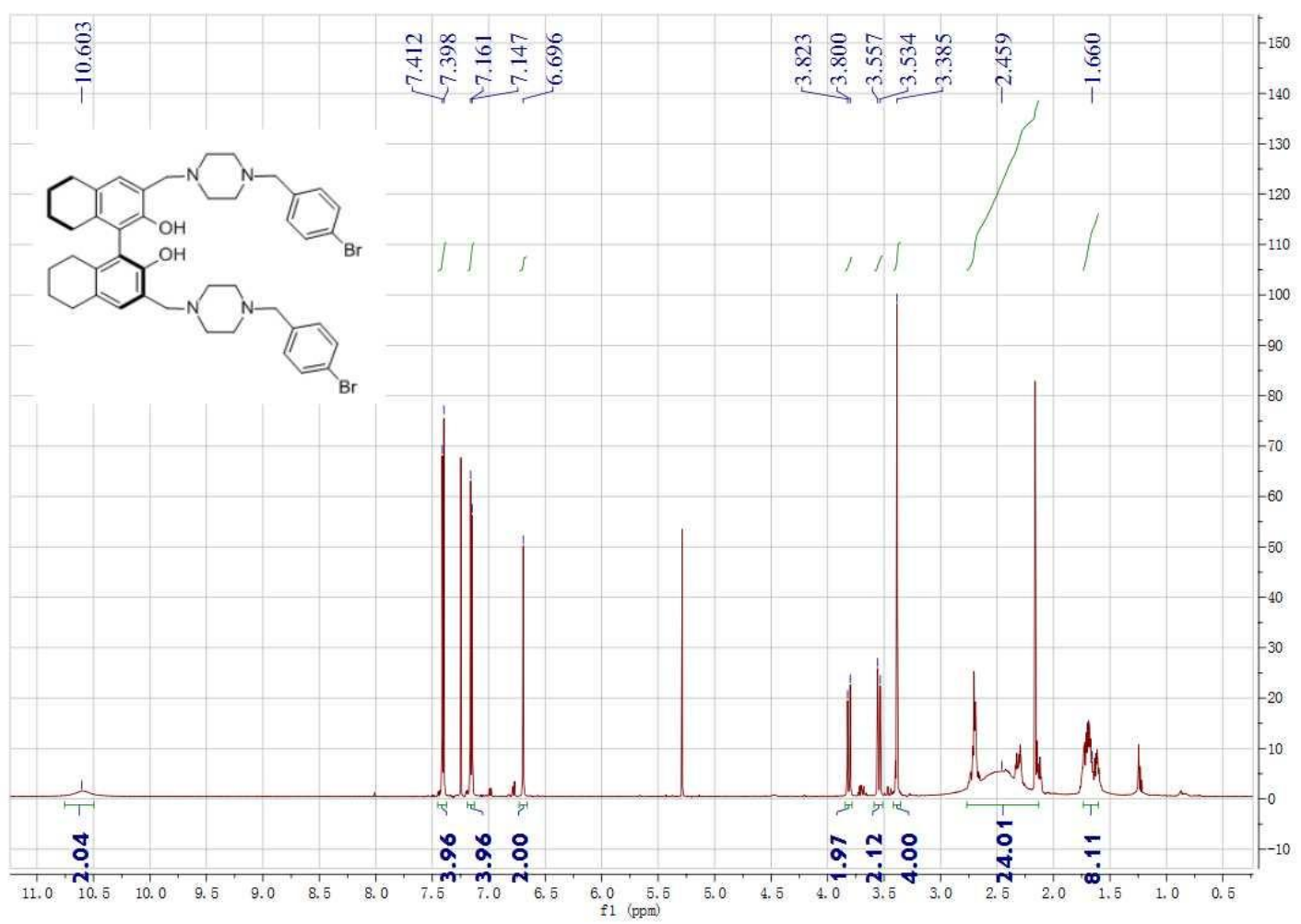


425

${ }^{1} \mathrm{H}$ NMR of $\mathbf{B} 4$

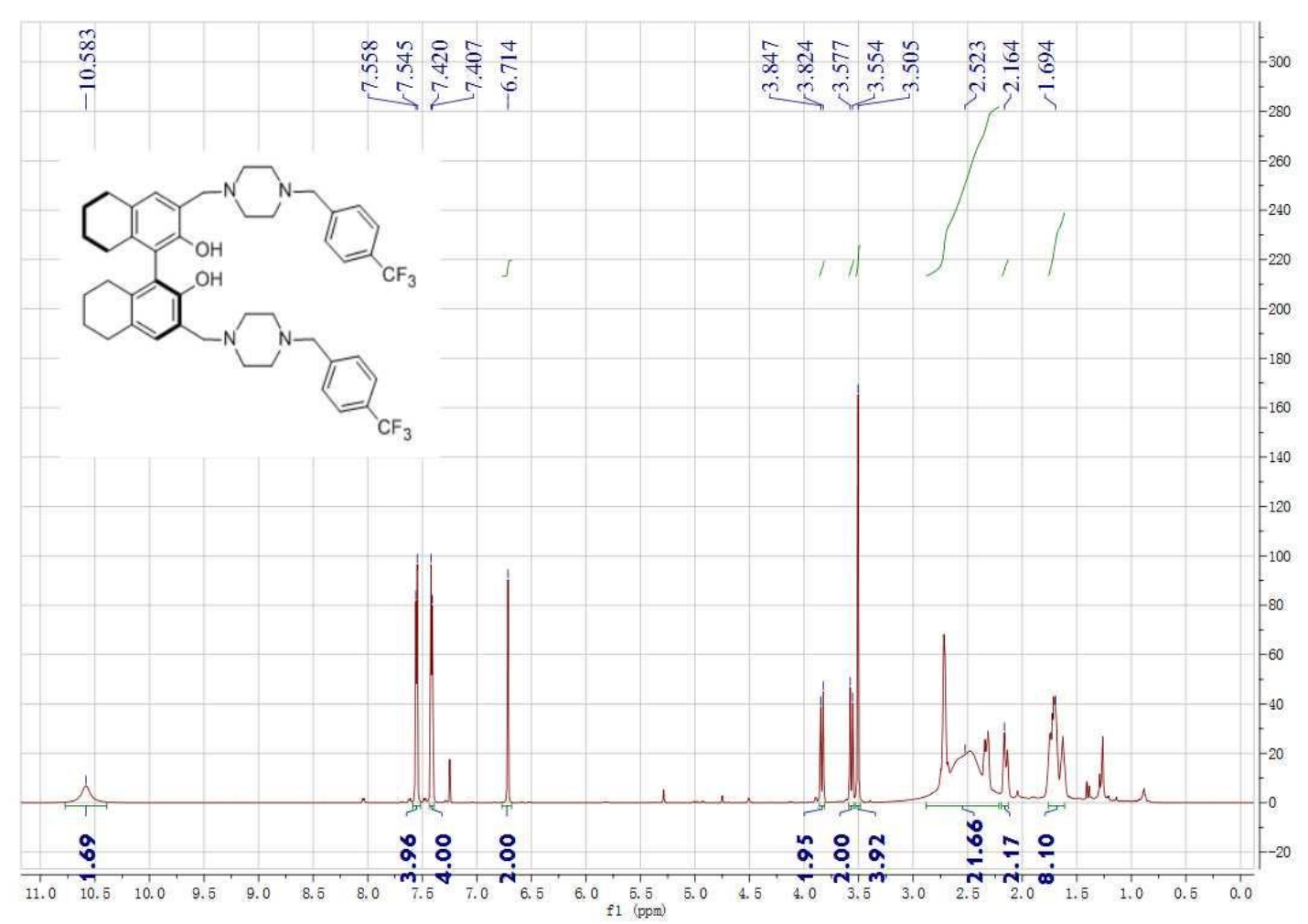

${ }^{1} \mathrm{H}$ NMR of $\mathbf{B 5}$

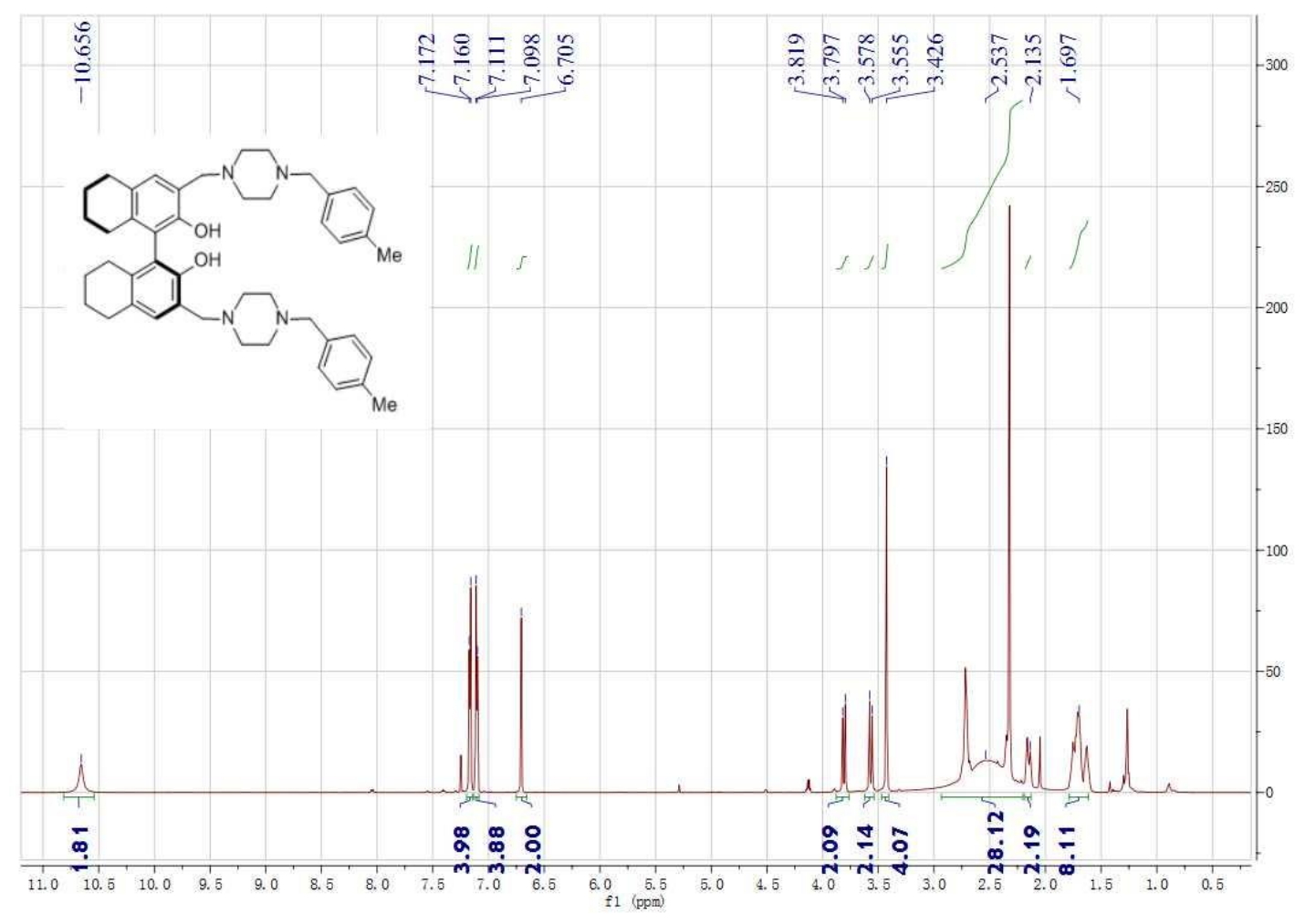


${ }^{1} \mathrm{H}$ NMR of $\mathbf{B 6}$

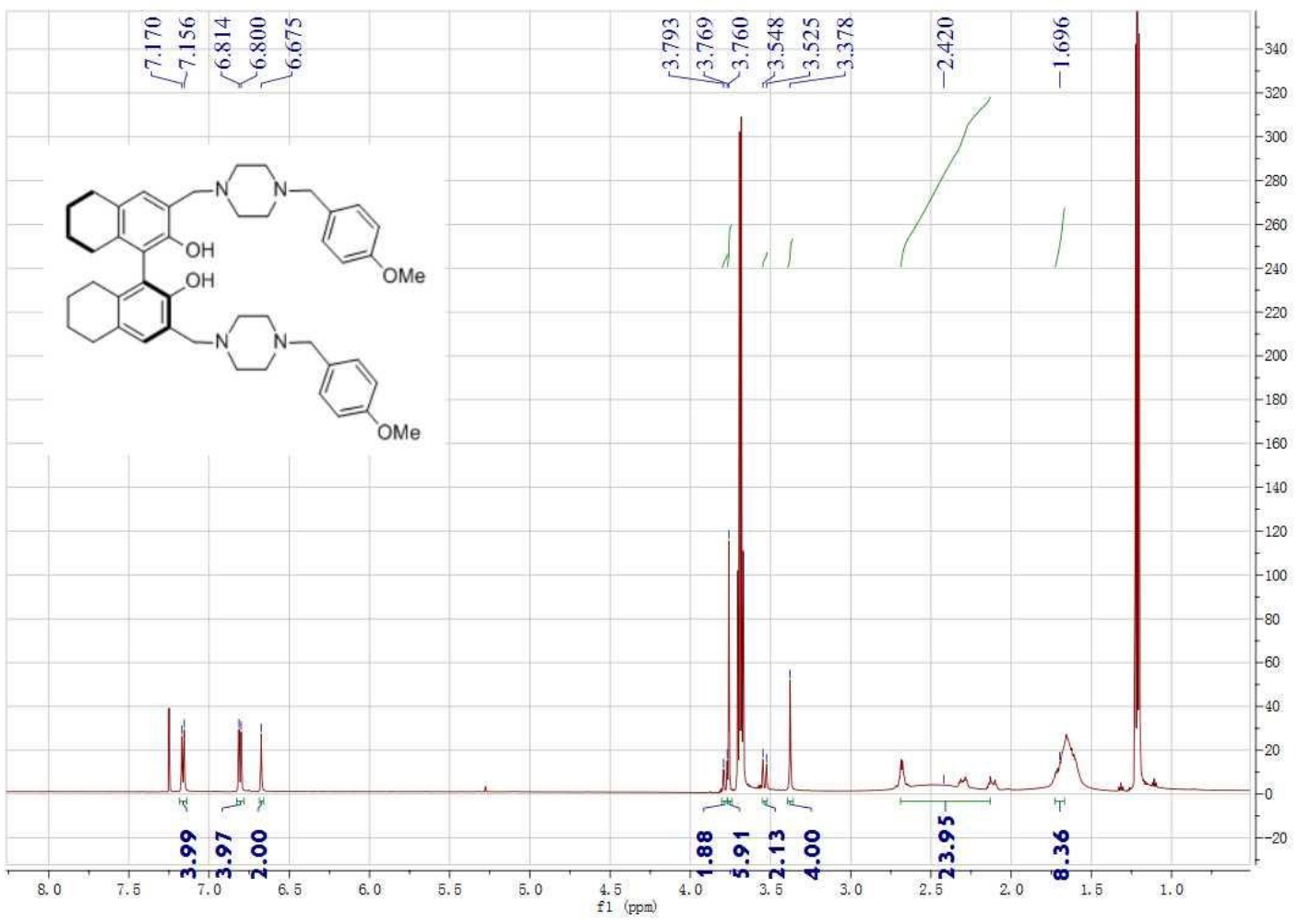

${ }^{1} \mathrm{H}$ NMR of $\mathbf{B} 7$

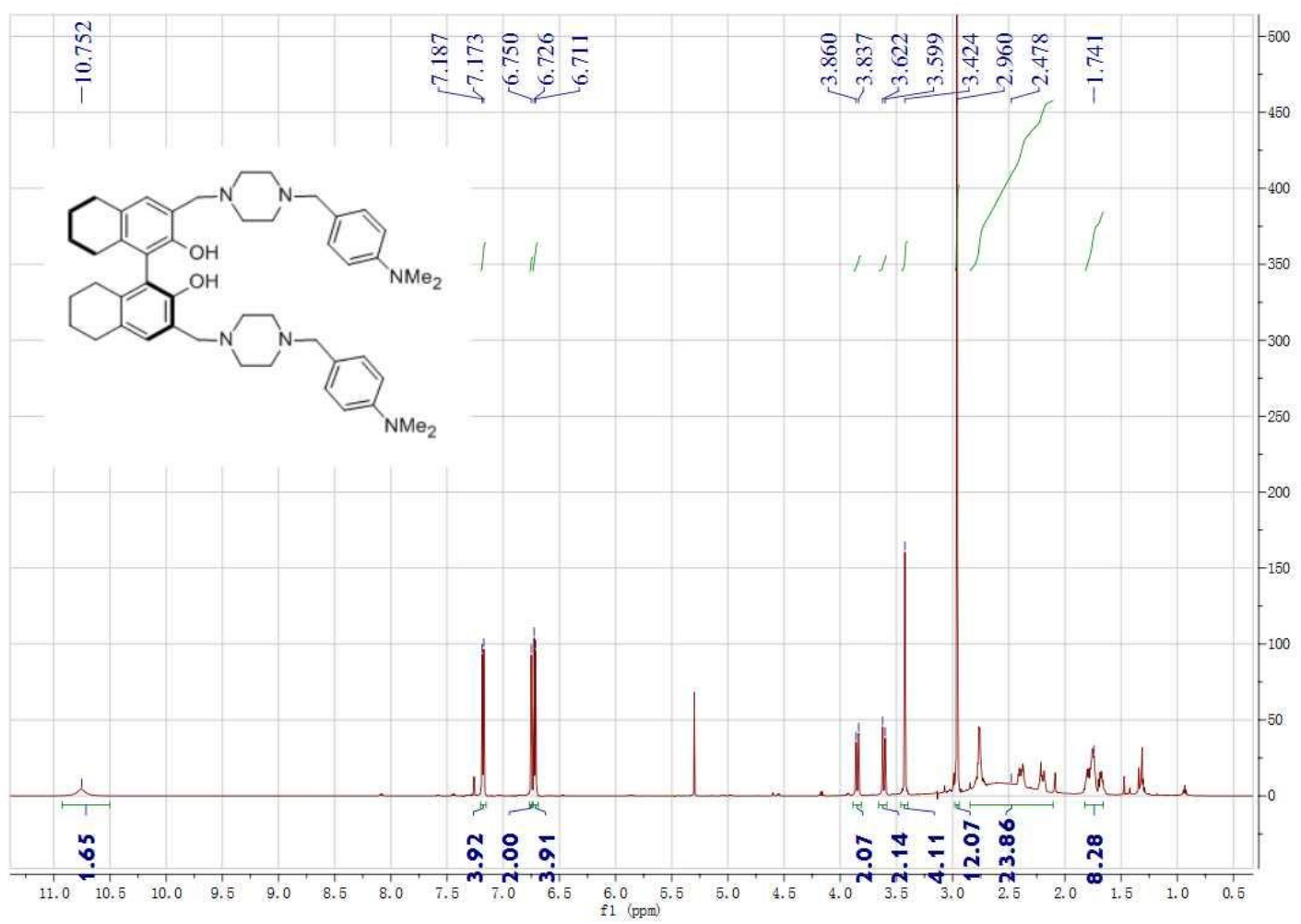


${ }^{1} \mathrm{H}$ NMR of $\mathbf{B 8}$

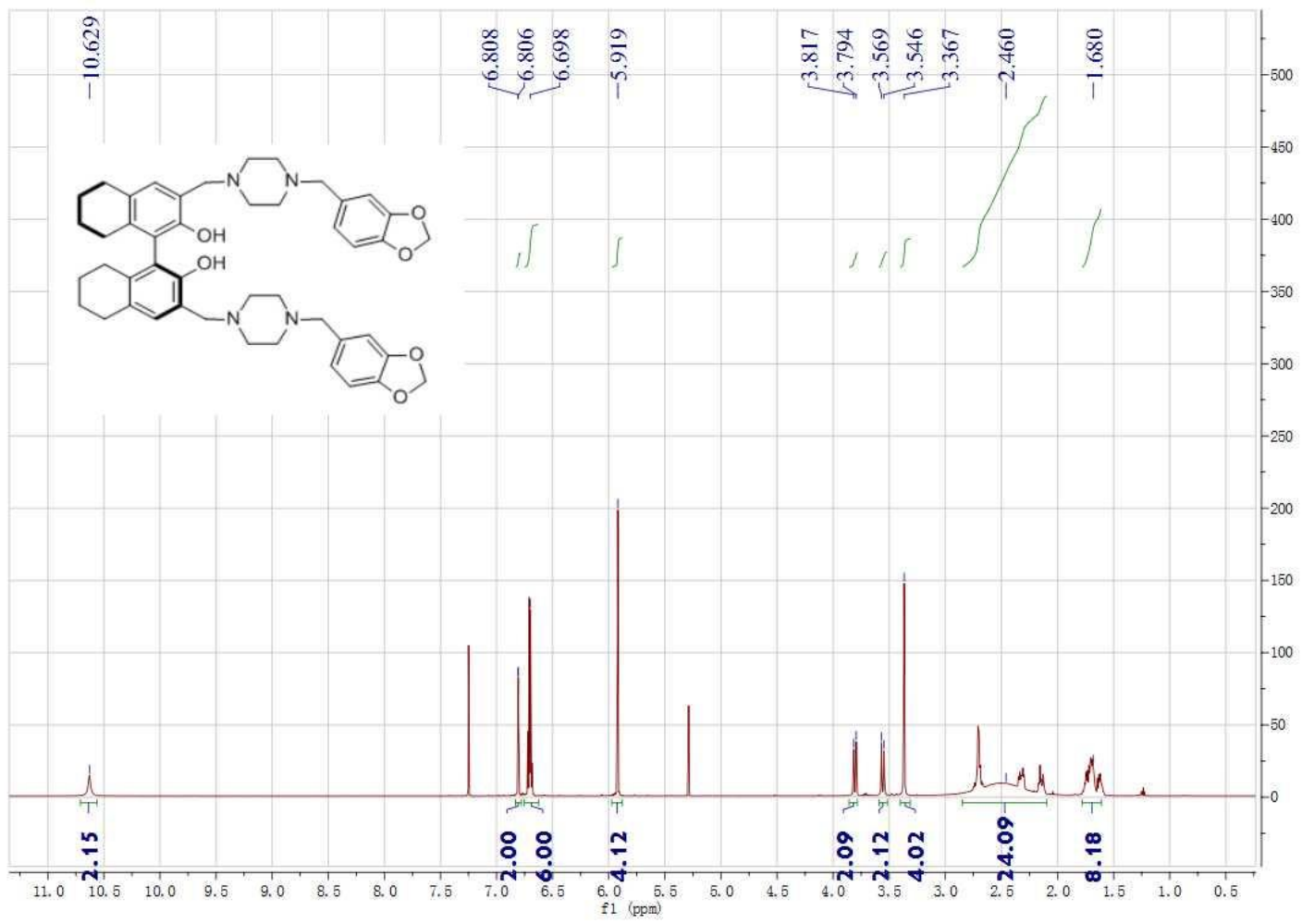

${ }^{1} \mathrm{H}$ NMR of $\mathbf{B 9}$

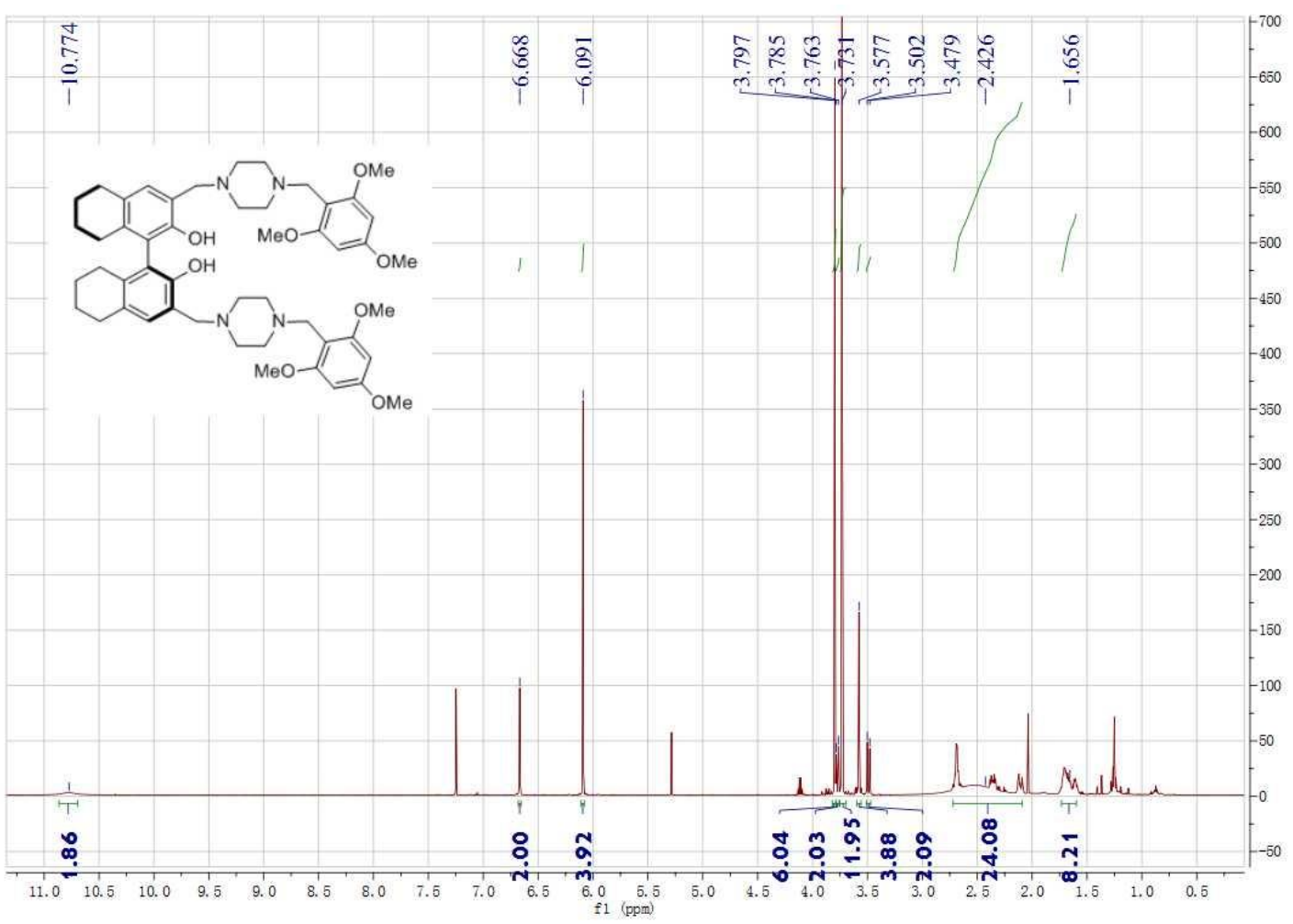


${ }^{1} \mathrm{H}$ NMR of $\mathbf{C 1}$

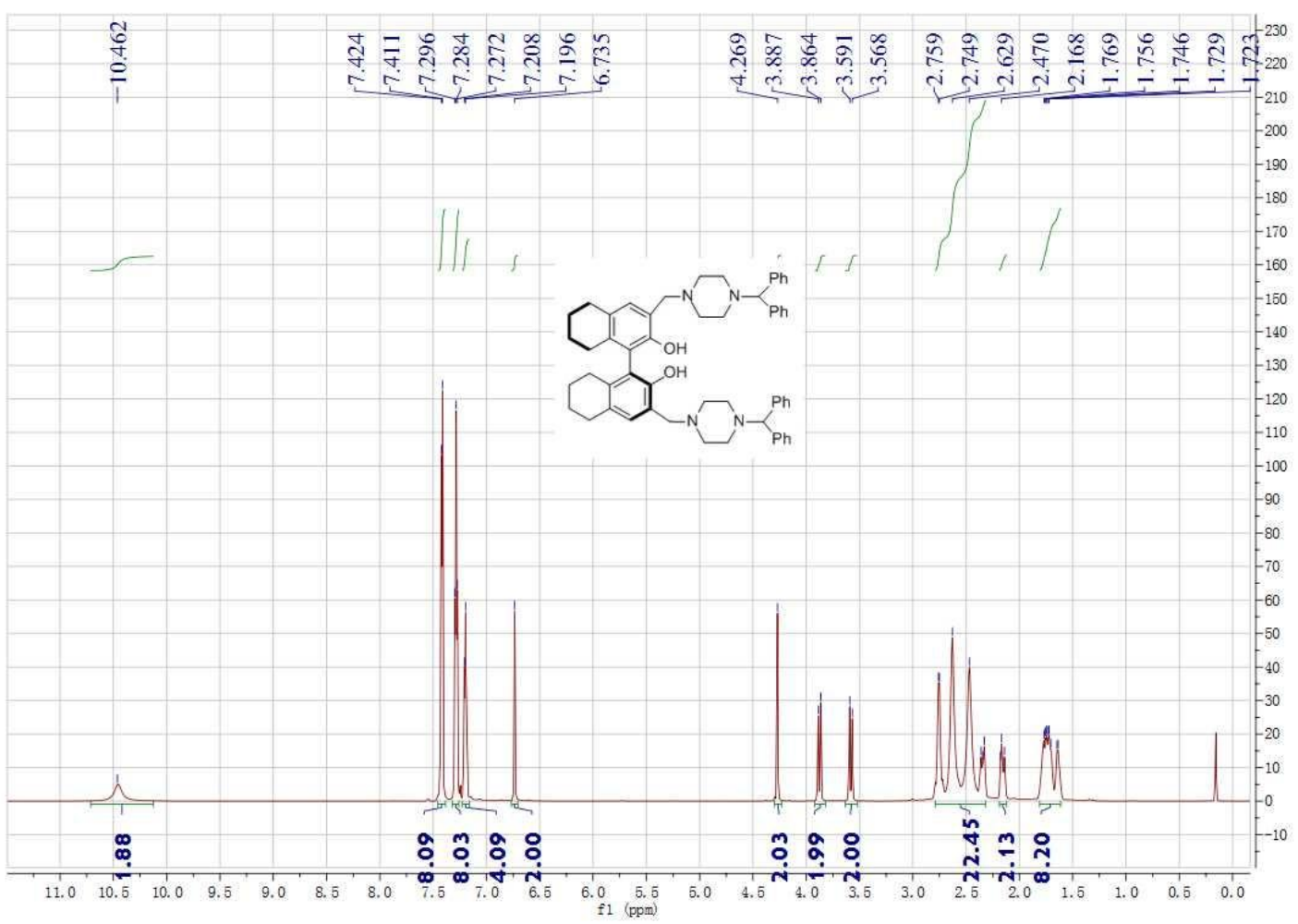

${ }^{13} \mathrm{C}$ NMR of $\mathbf{C 1}$

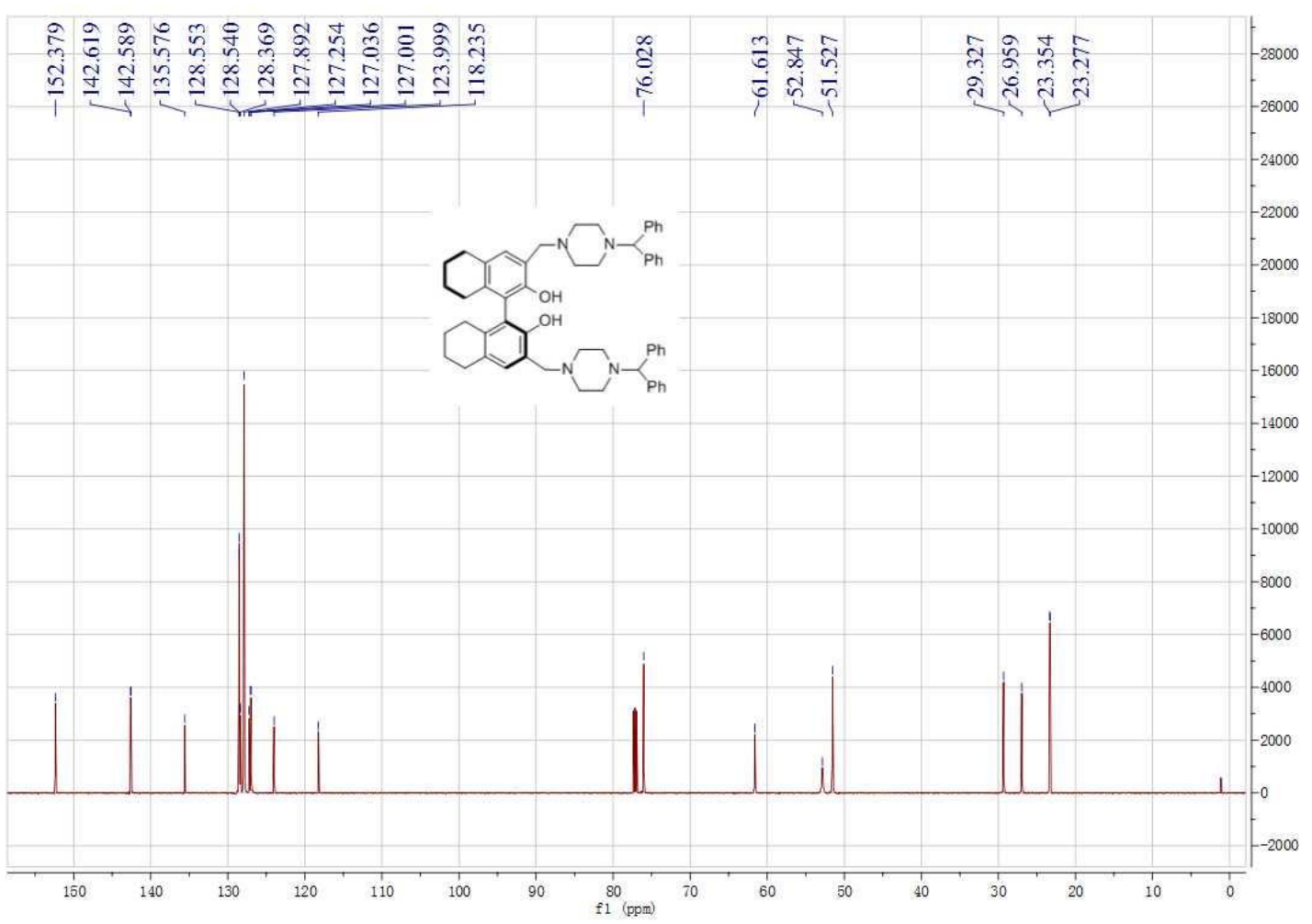


${ }^{1} \mathrm{H}$ NMR of $\mathbf{C 2}$

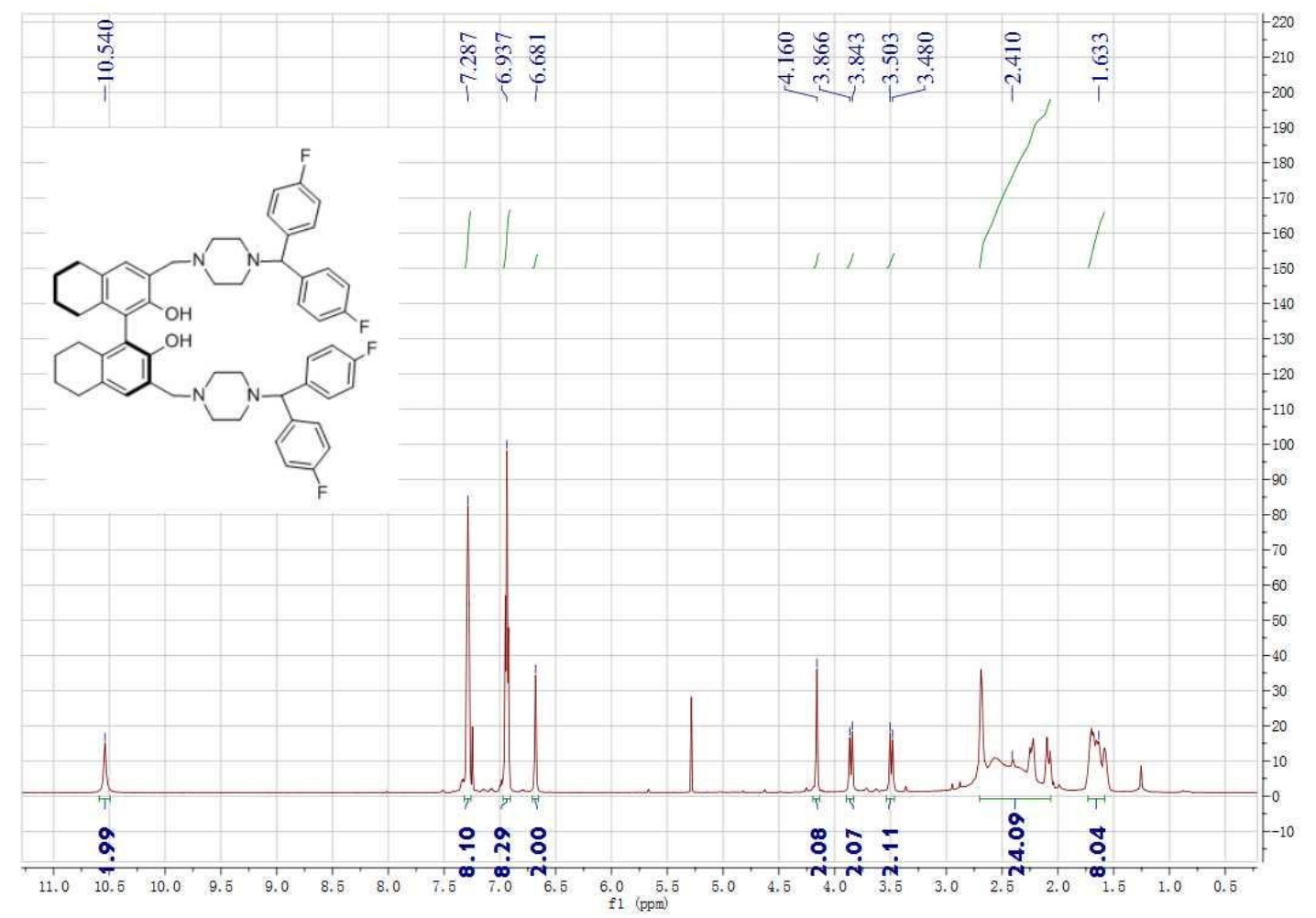

${ }^{1} \mathrm{H}$ NMR of $\mathbf{C 3}$

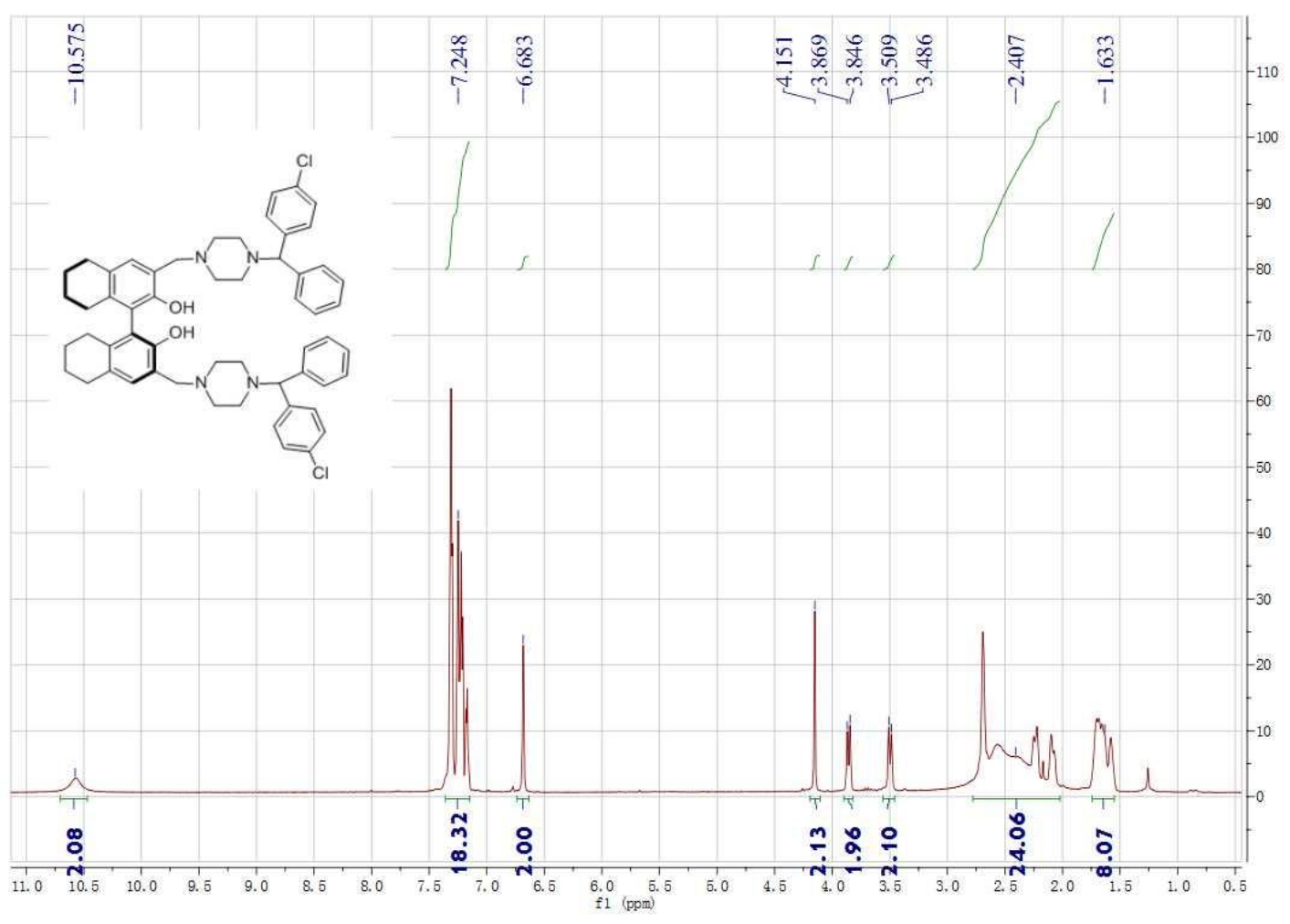


${ }^{1}$ H NMR of $\mathbf{C 4}$

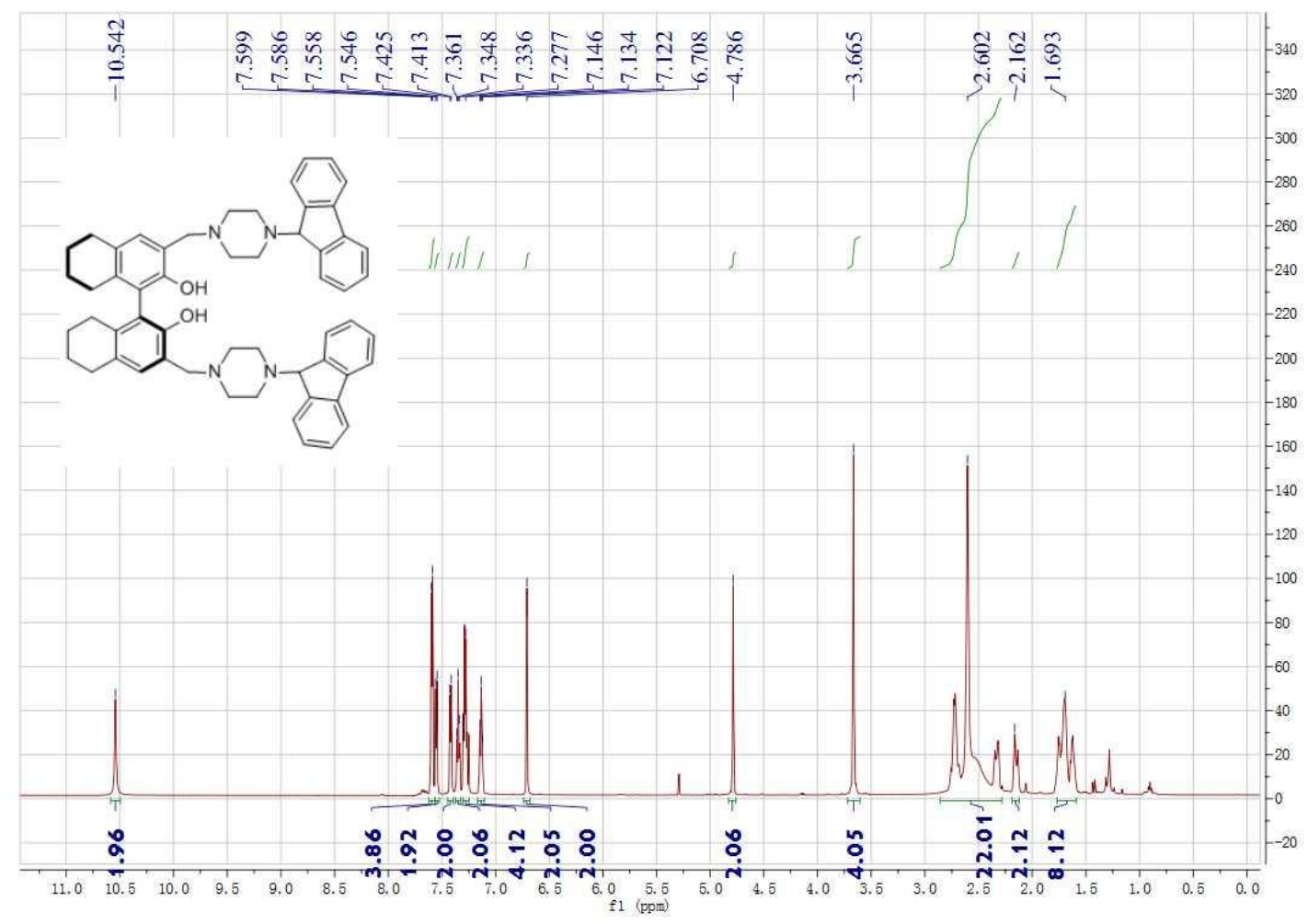

${ }^{1} \mathrm{H}$ NMR of $\mathbf{C 5}$

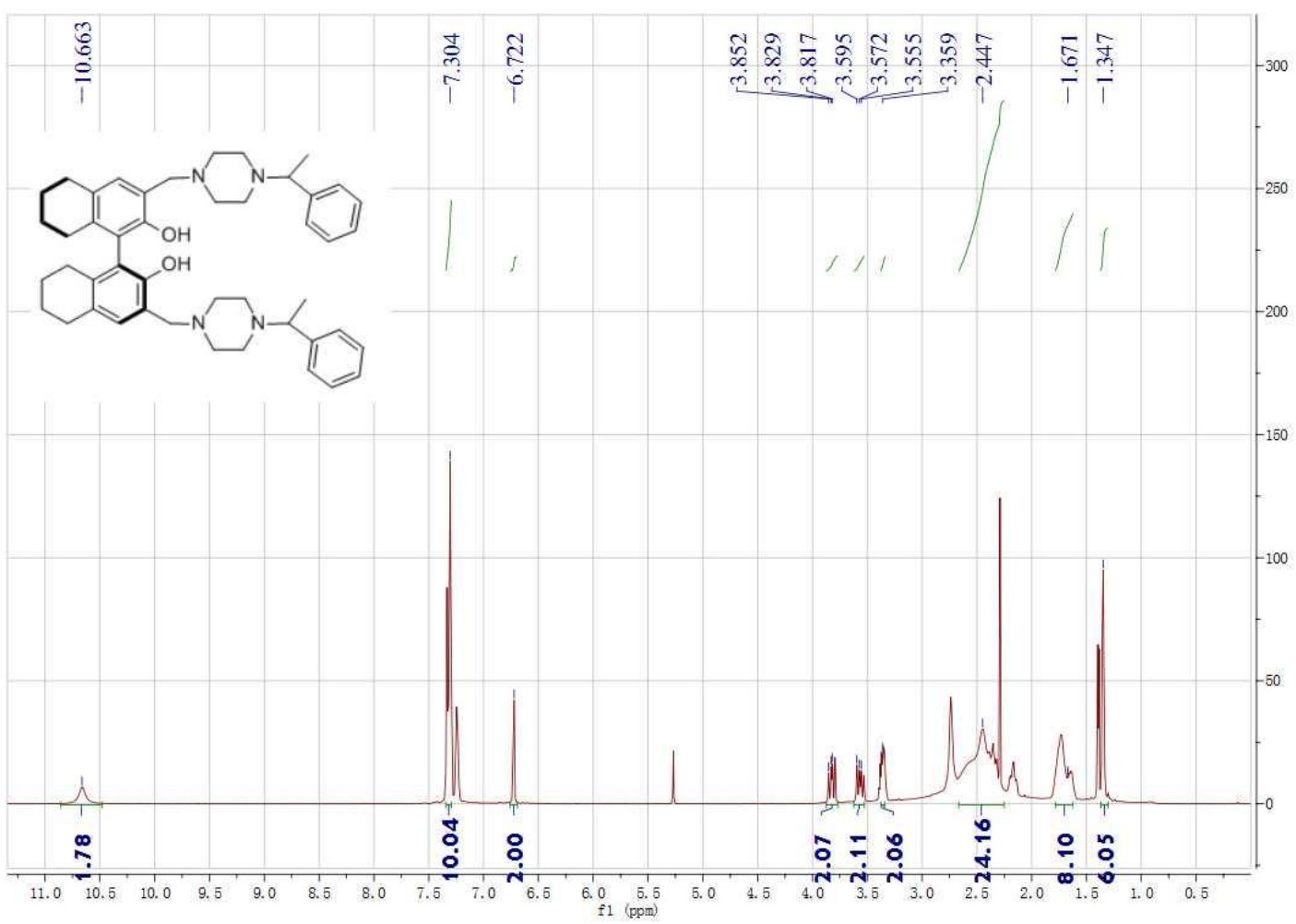


${ }^{1}$ H NMR of $\mathbf{C 6}$

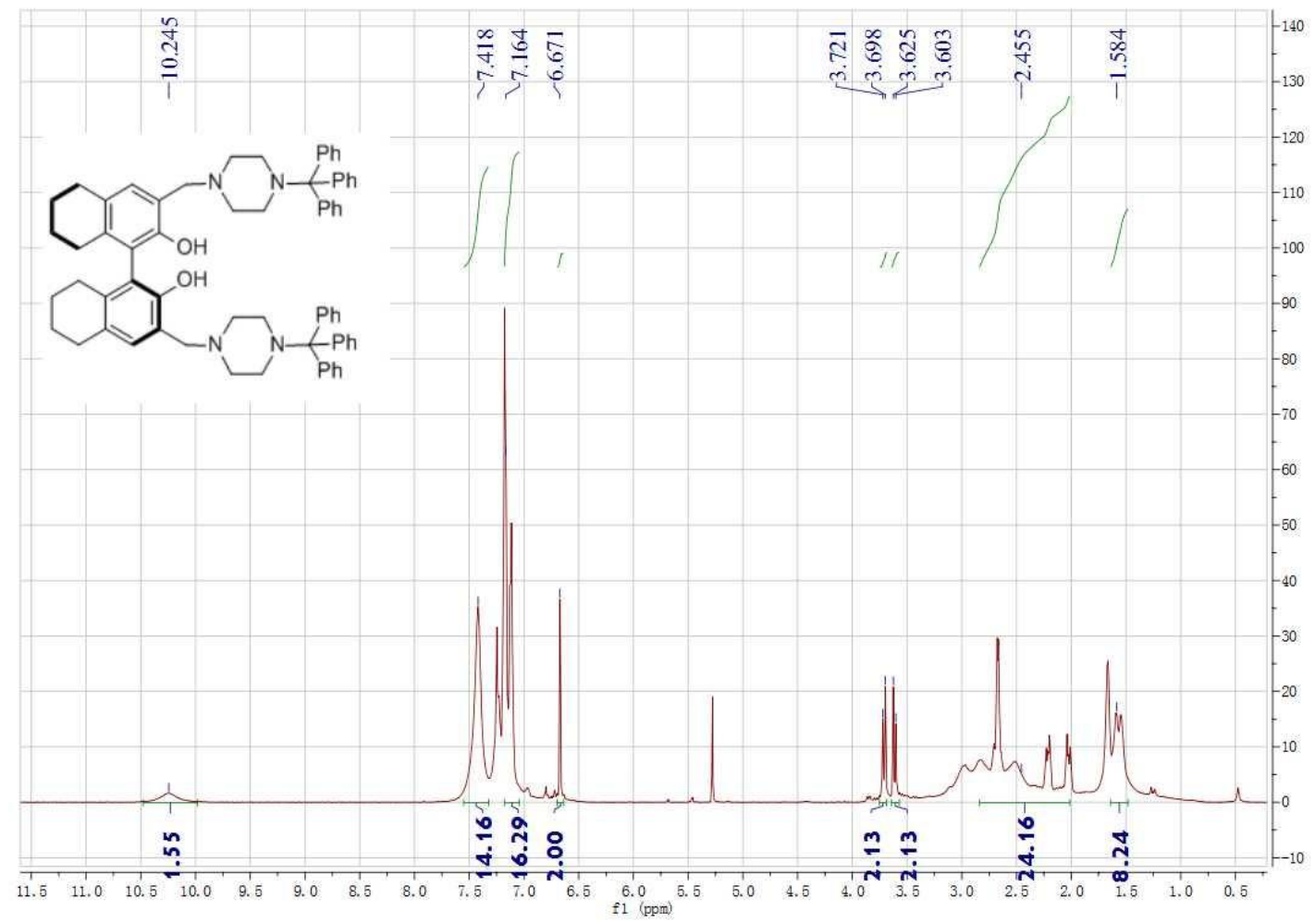

${ }^{1} \mathrm{H}$ NMR of $\mathbf{C 7}$

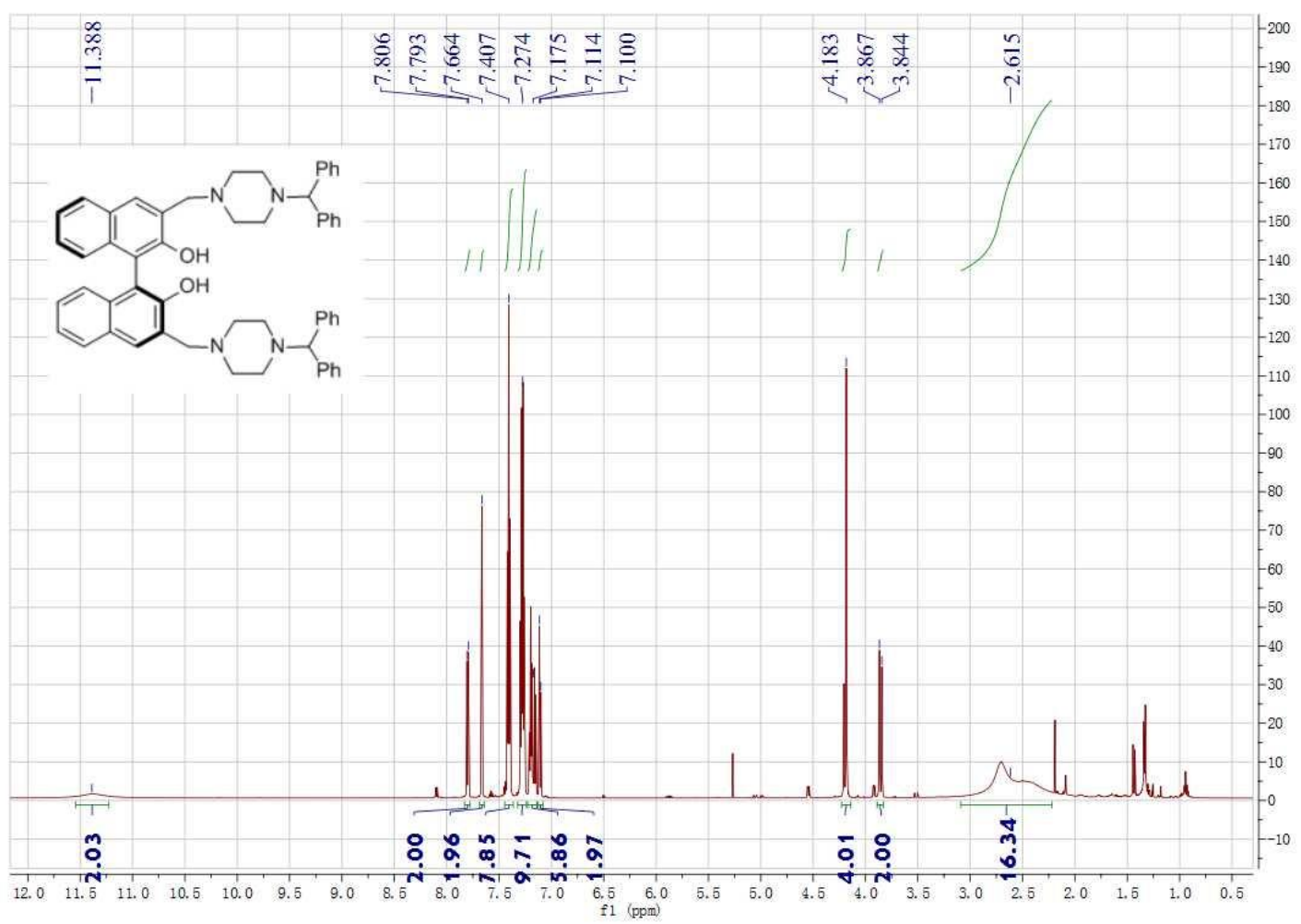


${ }^{13} \mathrm{C}$ NMR of $\mathrm{C} 7$

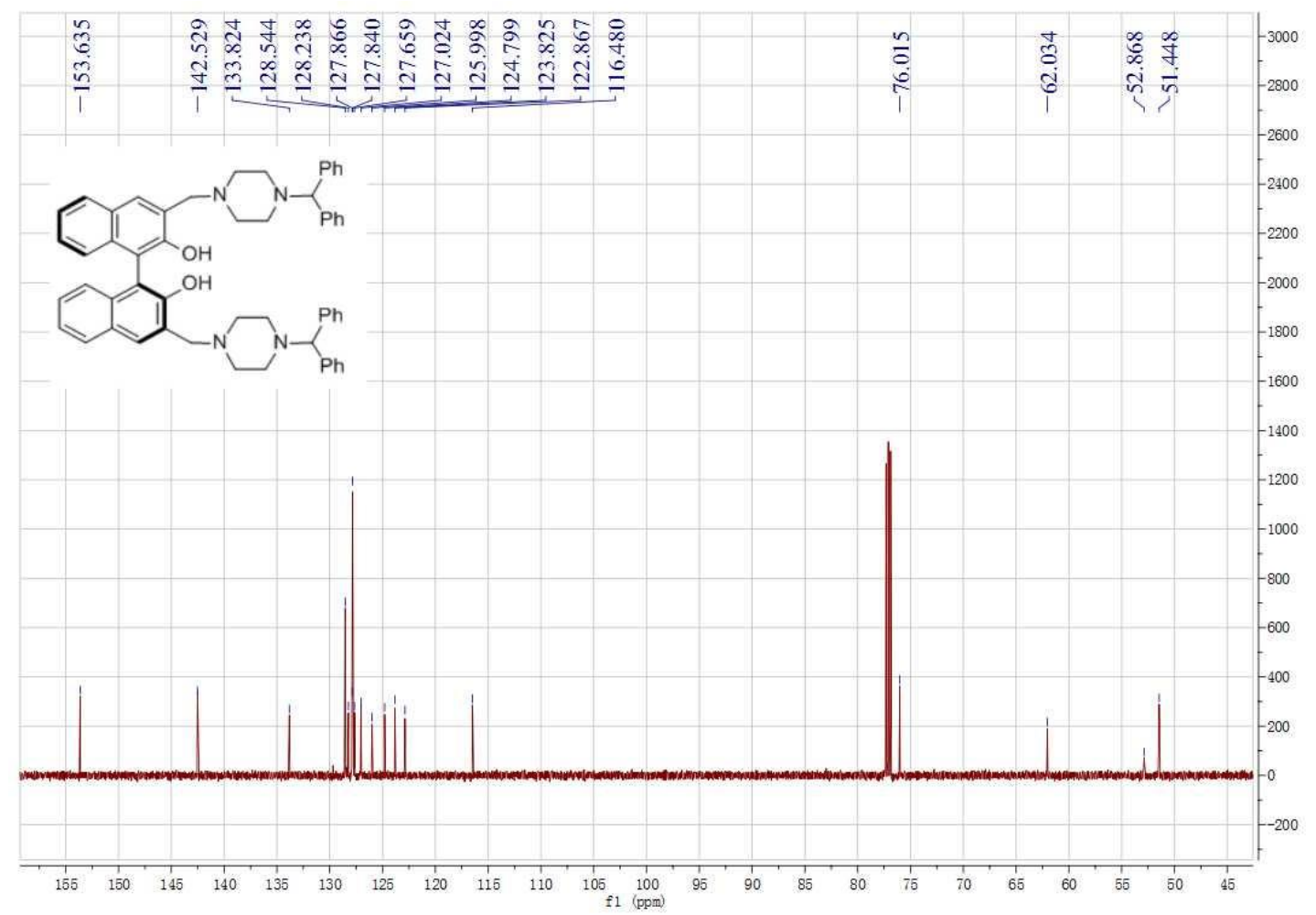

${ }^{1} \mathrm{H}$ NMR of $\mathbf{C 8}$

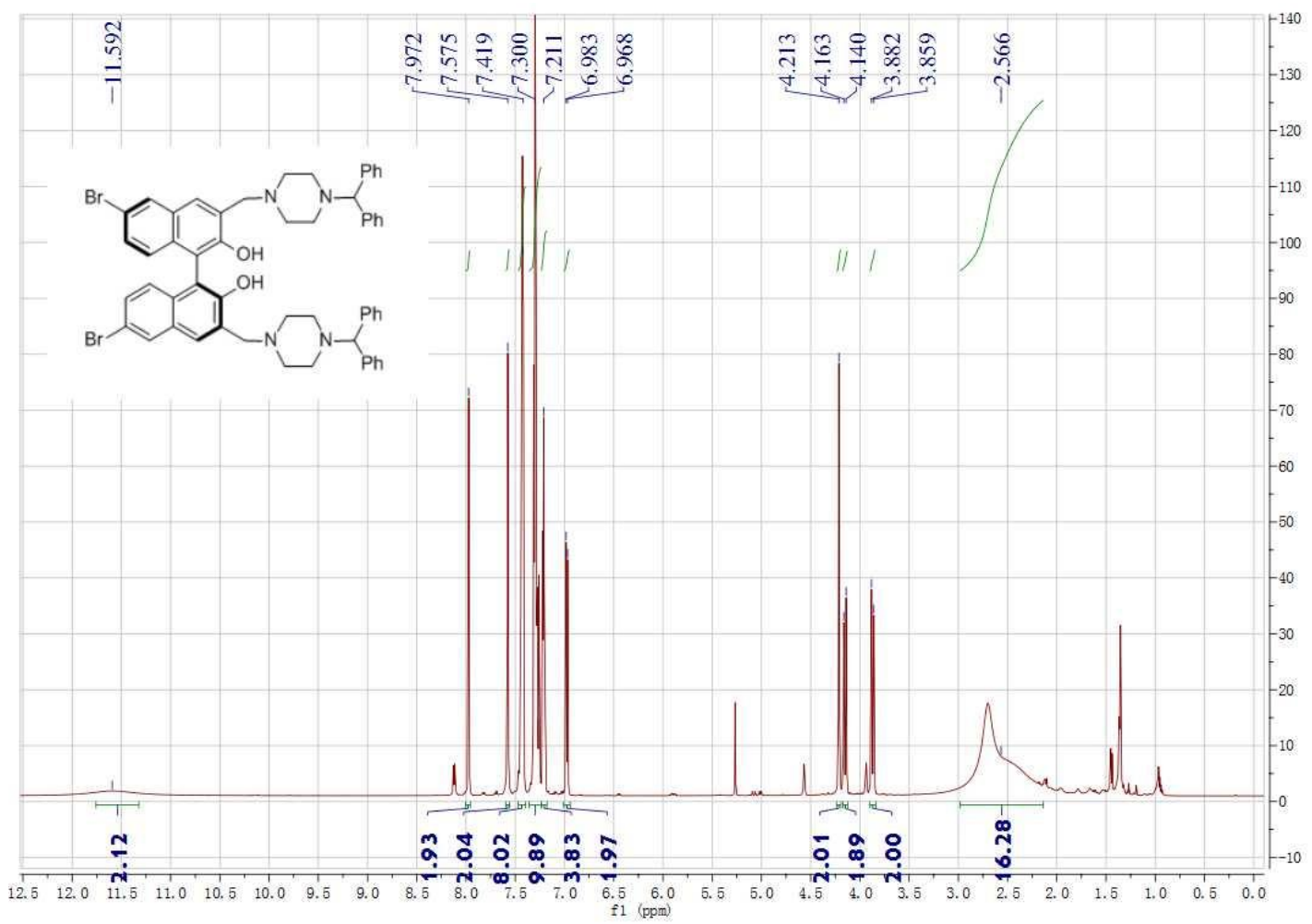


${ }^{1}$ H NMR of D1

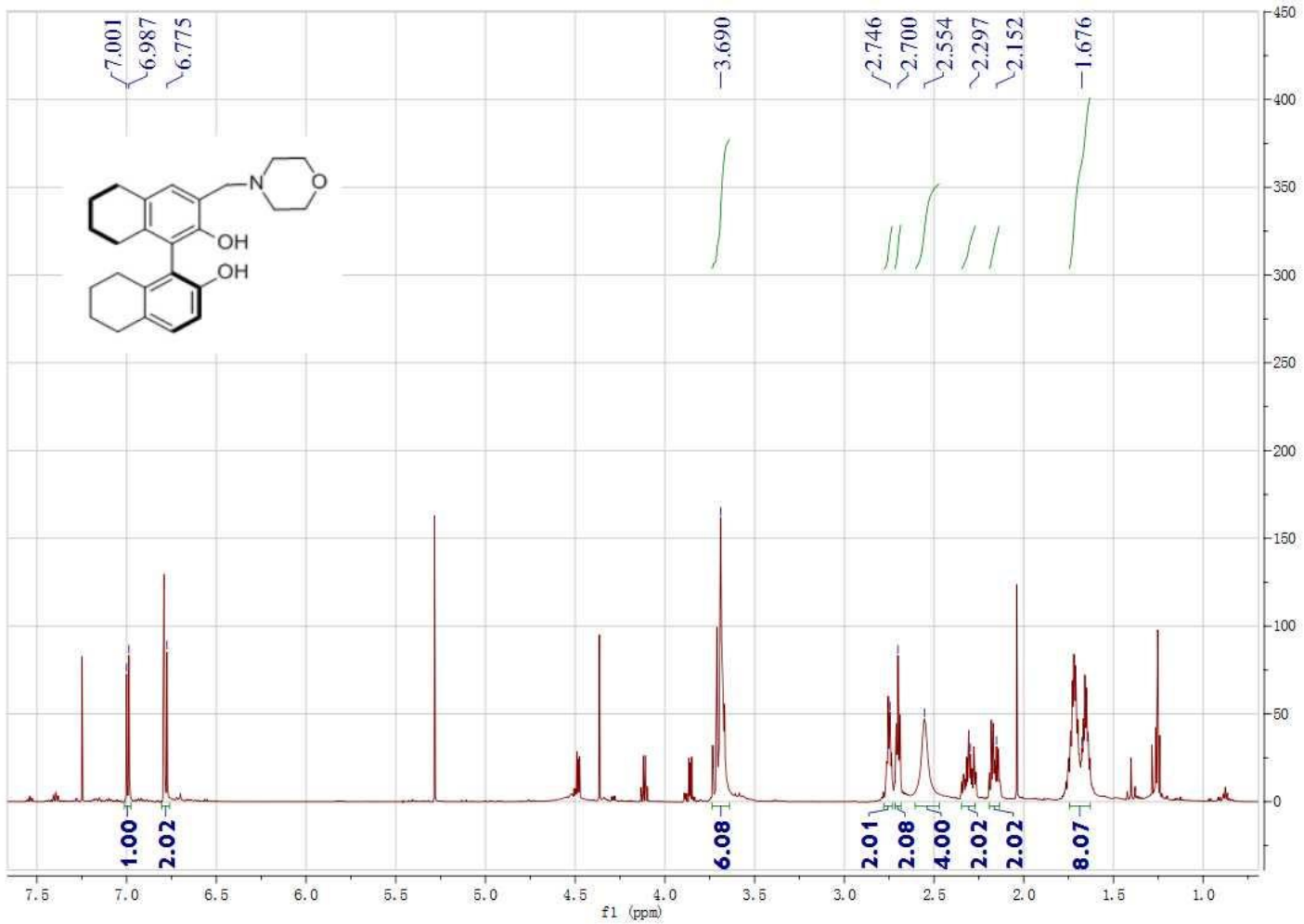

${ }^{1} \mathrm{H}$ NMR of D2

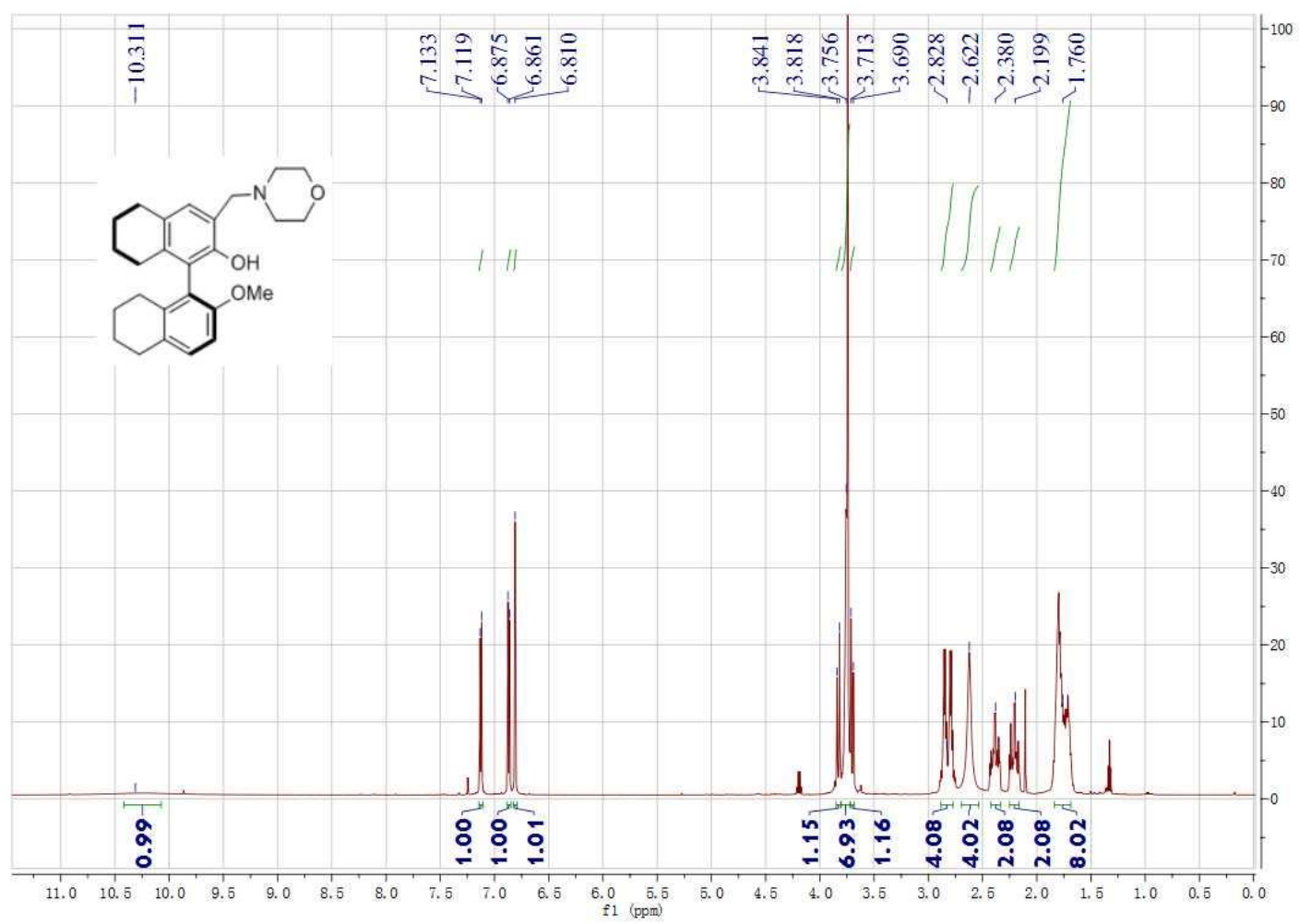


${ }^{13} \mathrm{C}$ NMR of $\mathbf{D 2}$

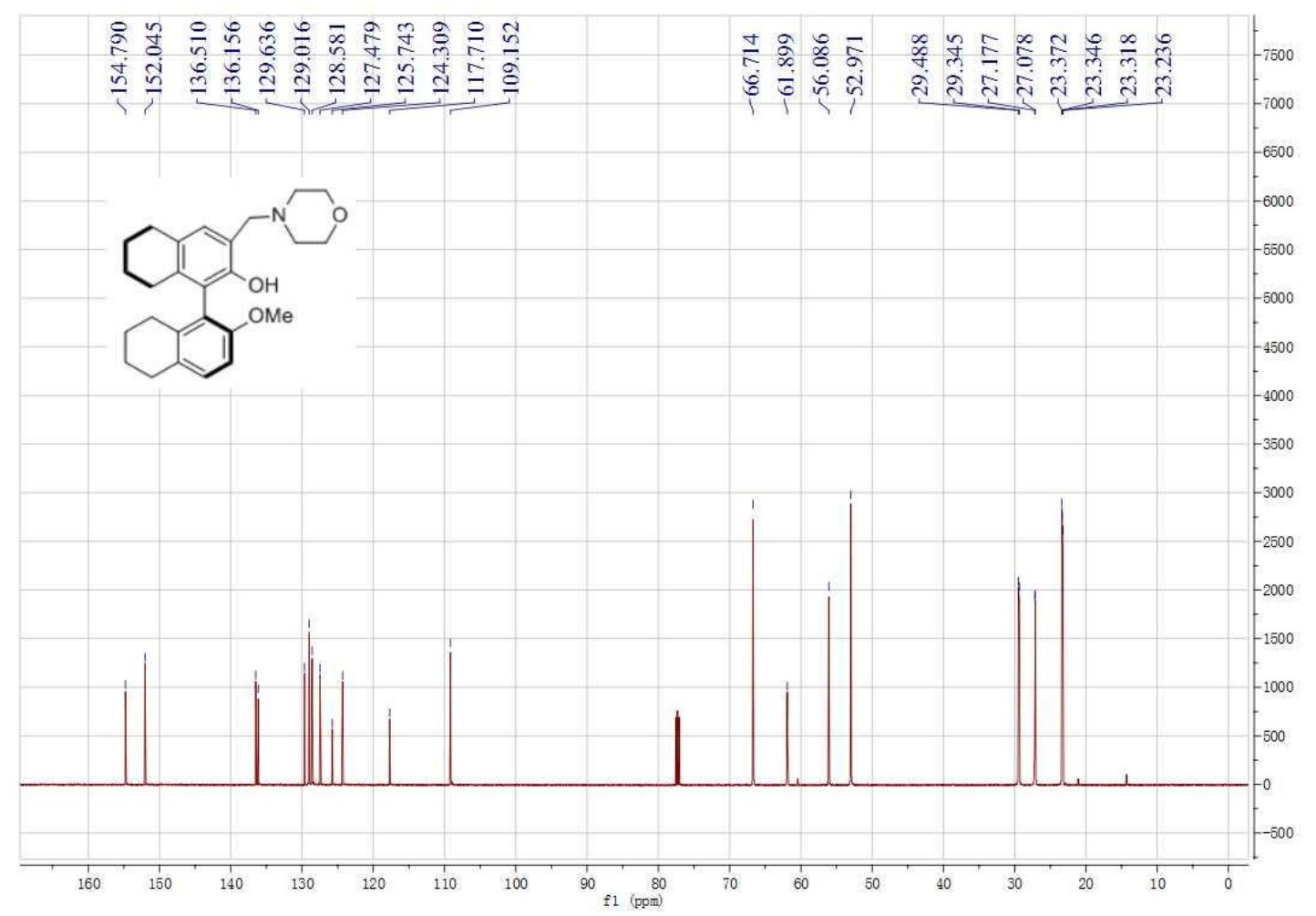

${ }^{1} \mathrm{H}$ NMR of D3

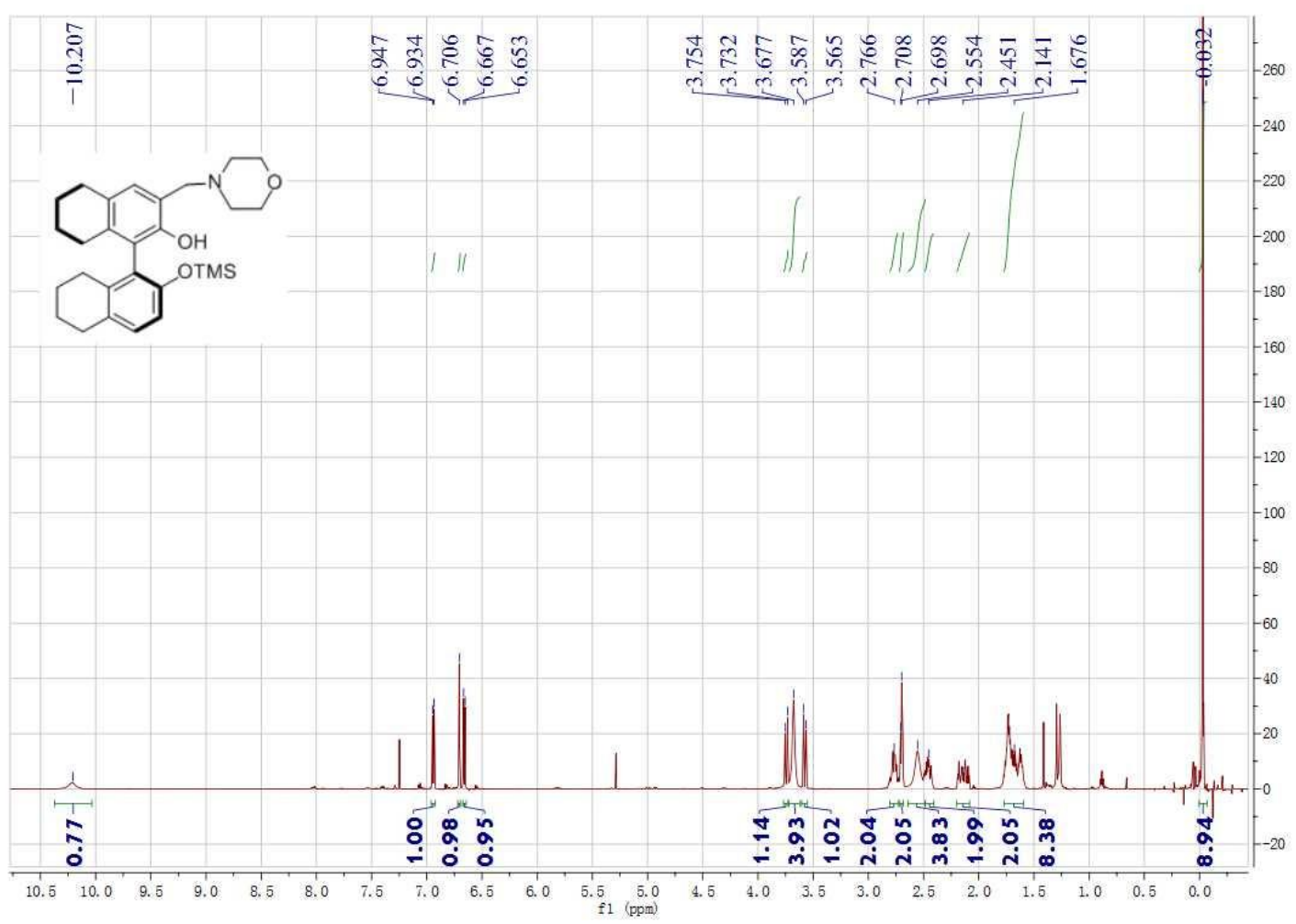


${ }^{13} \mathrm{C}$ NMR of $\mathbf{D 3}$

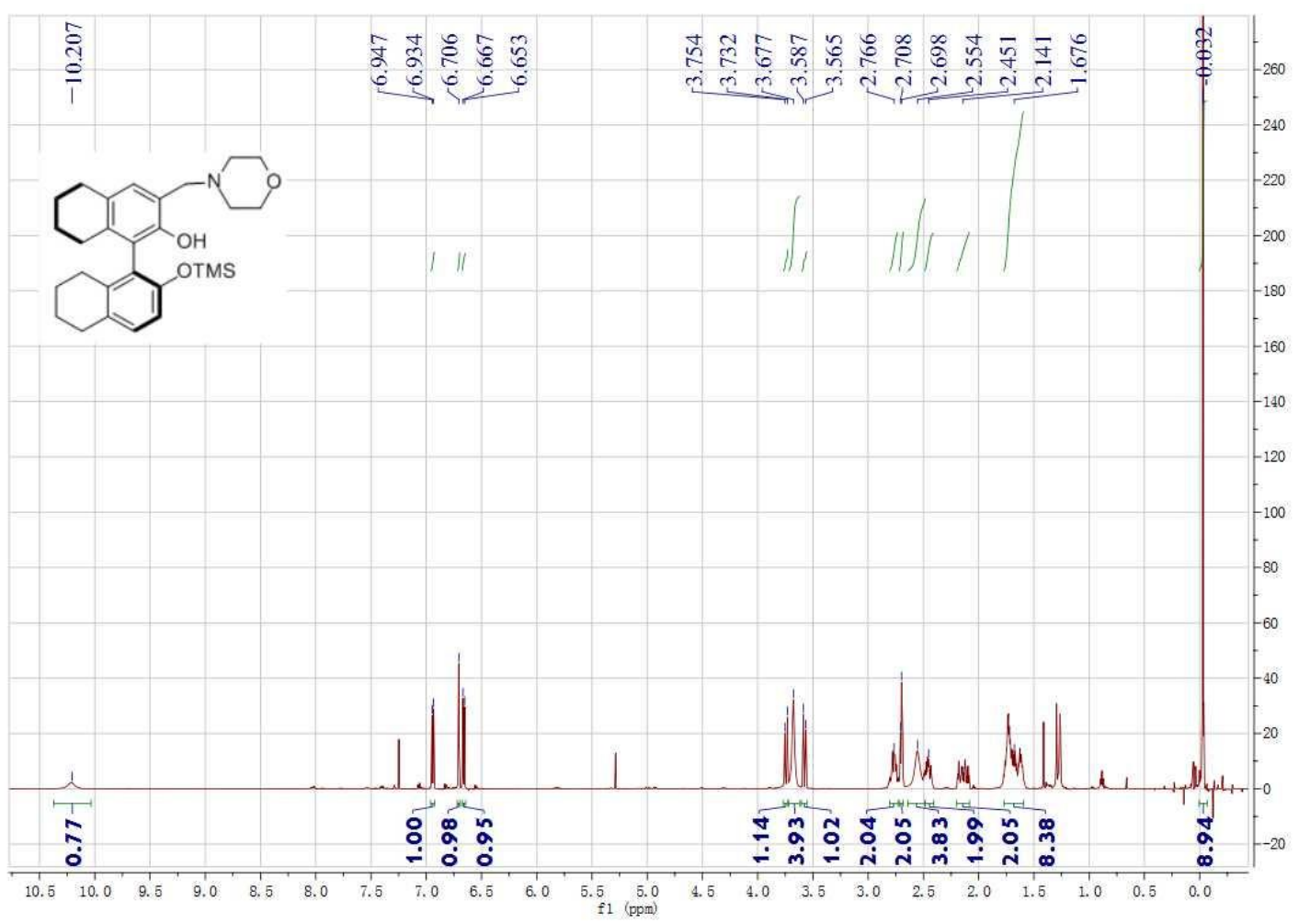

${ }^{1}$ H NMR of D4

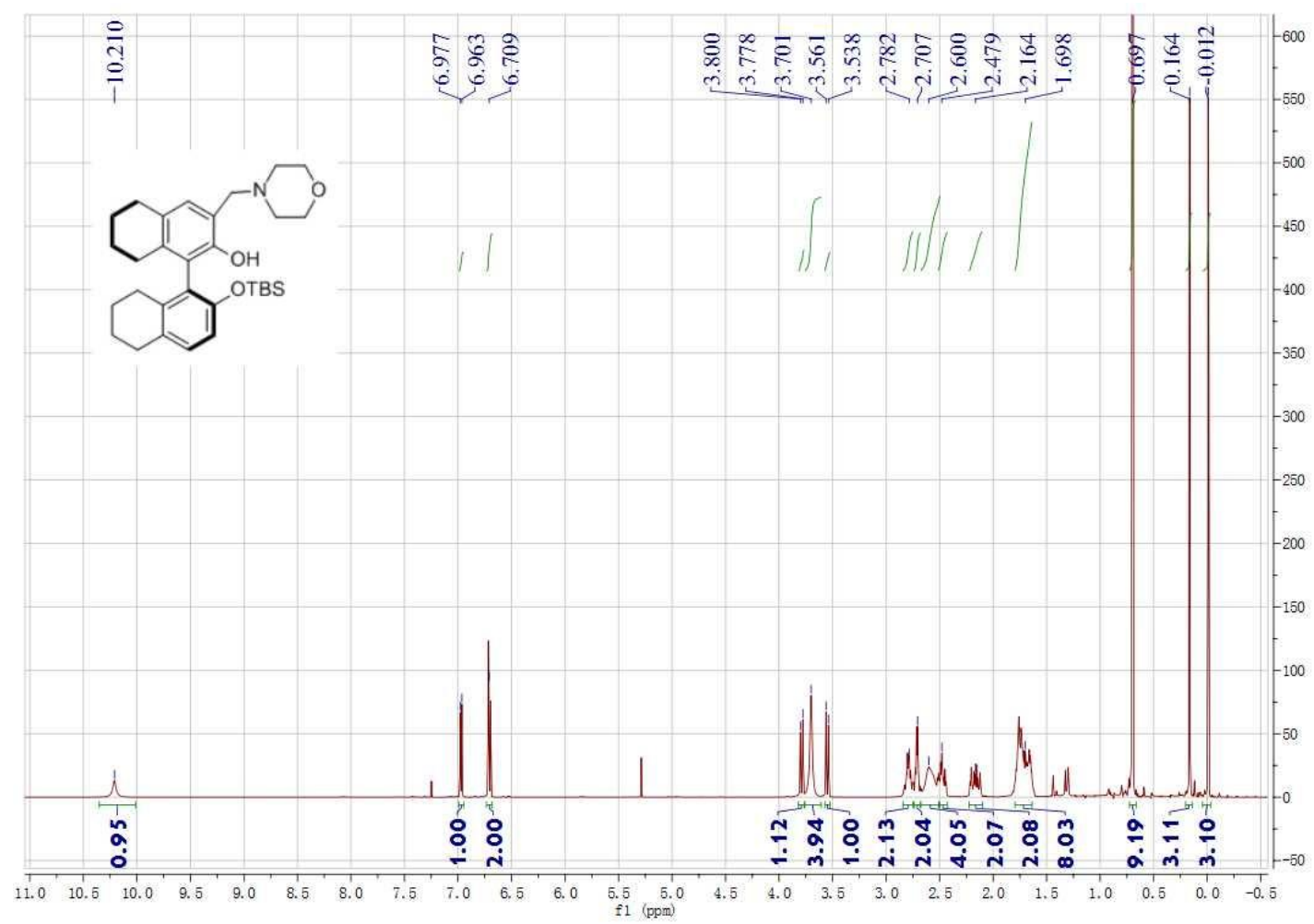




\section{${ }^{13} \mathrm{C}$ NMR of D4}

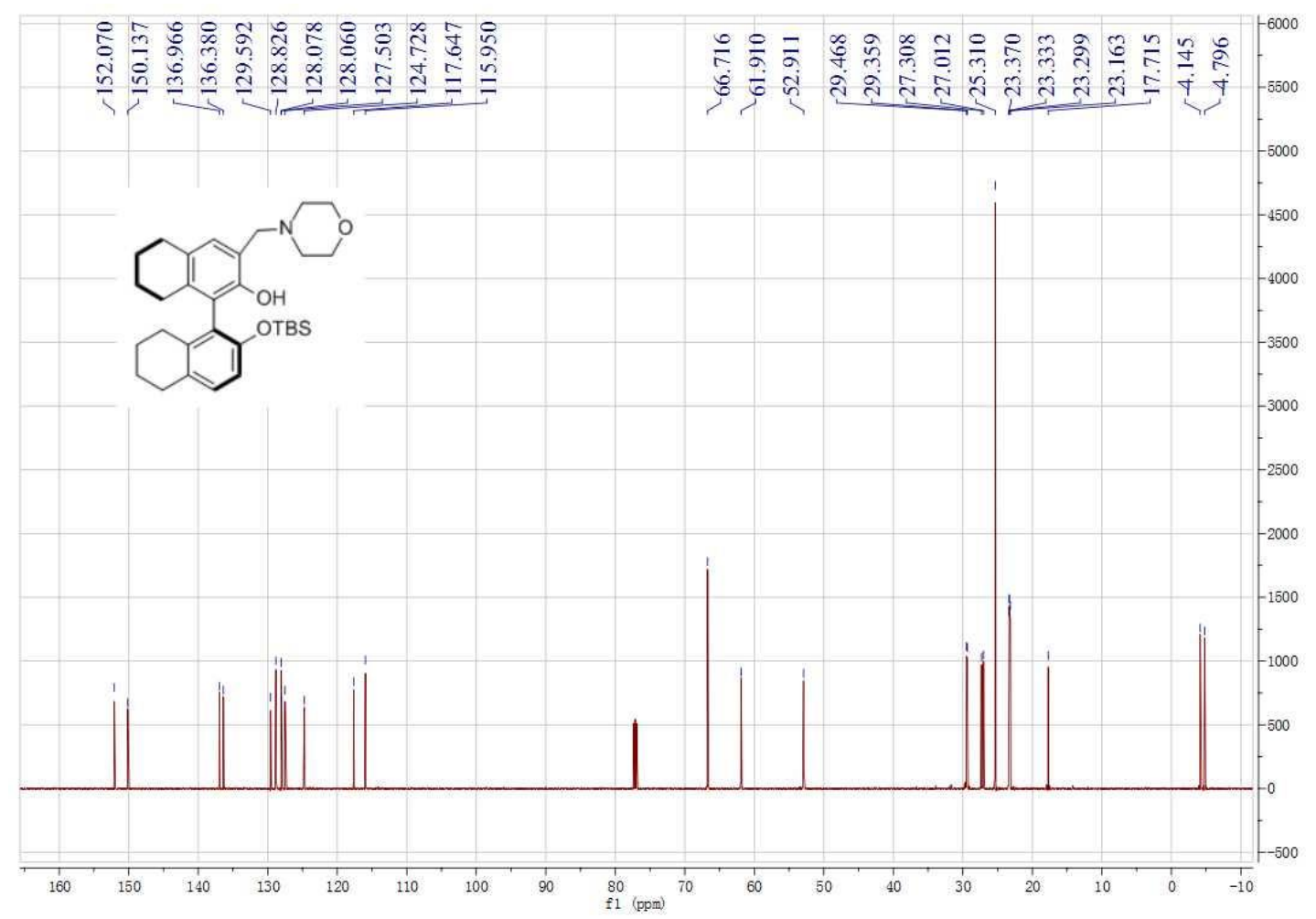

${ }^{1}$ H NMR of D5

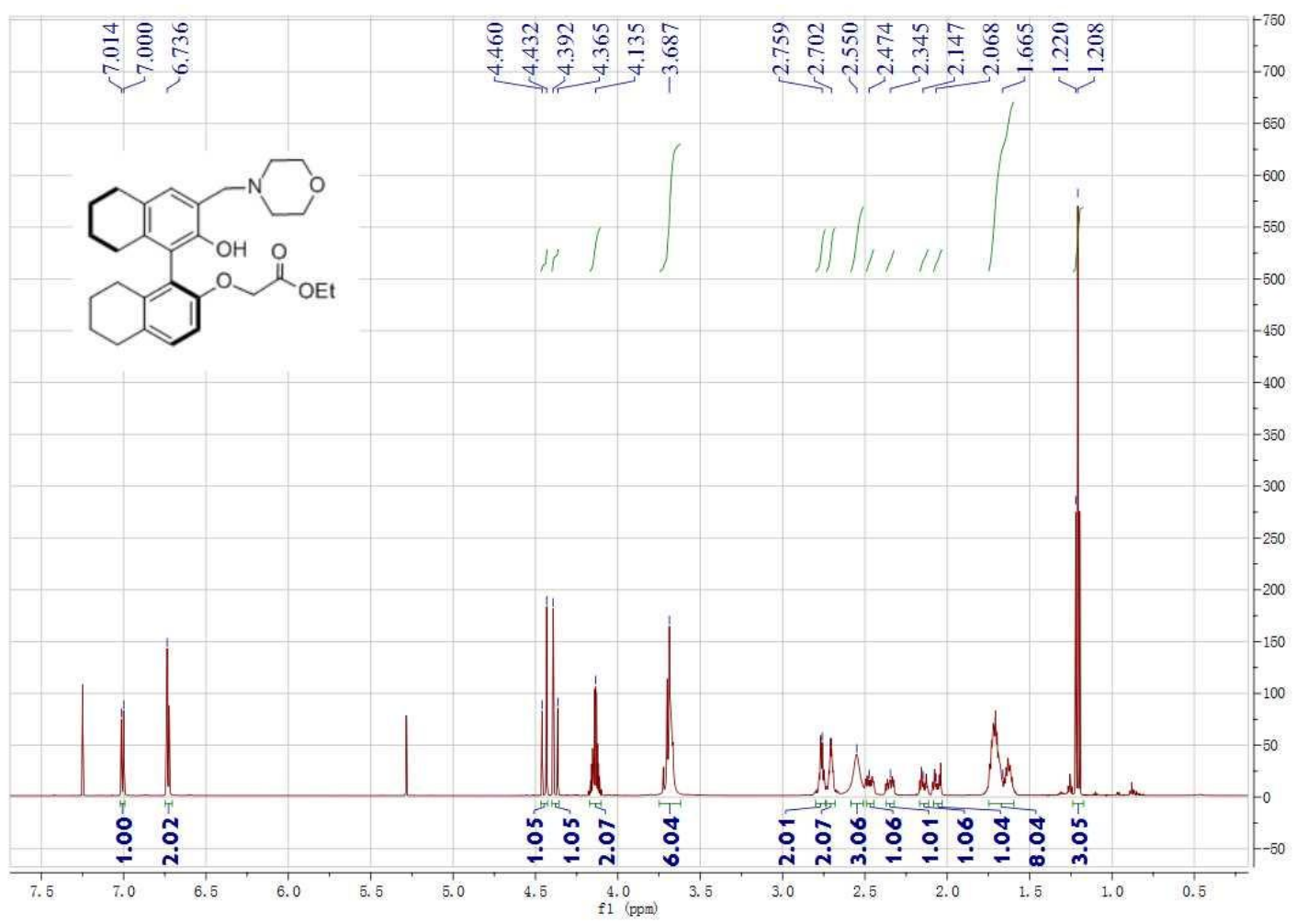


${ }^{1}$ H NMR of D6

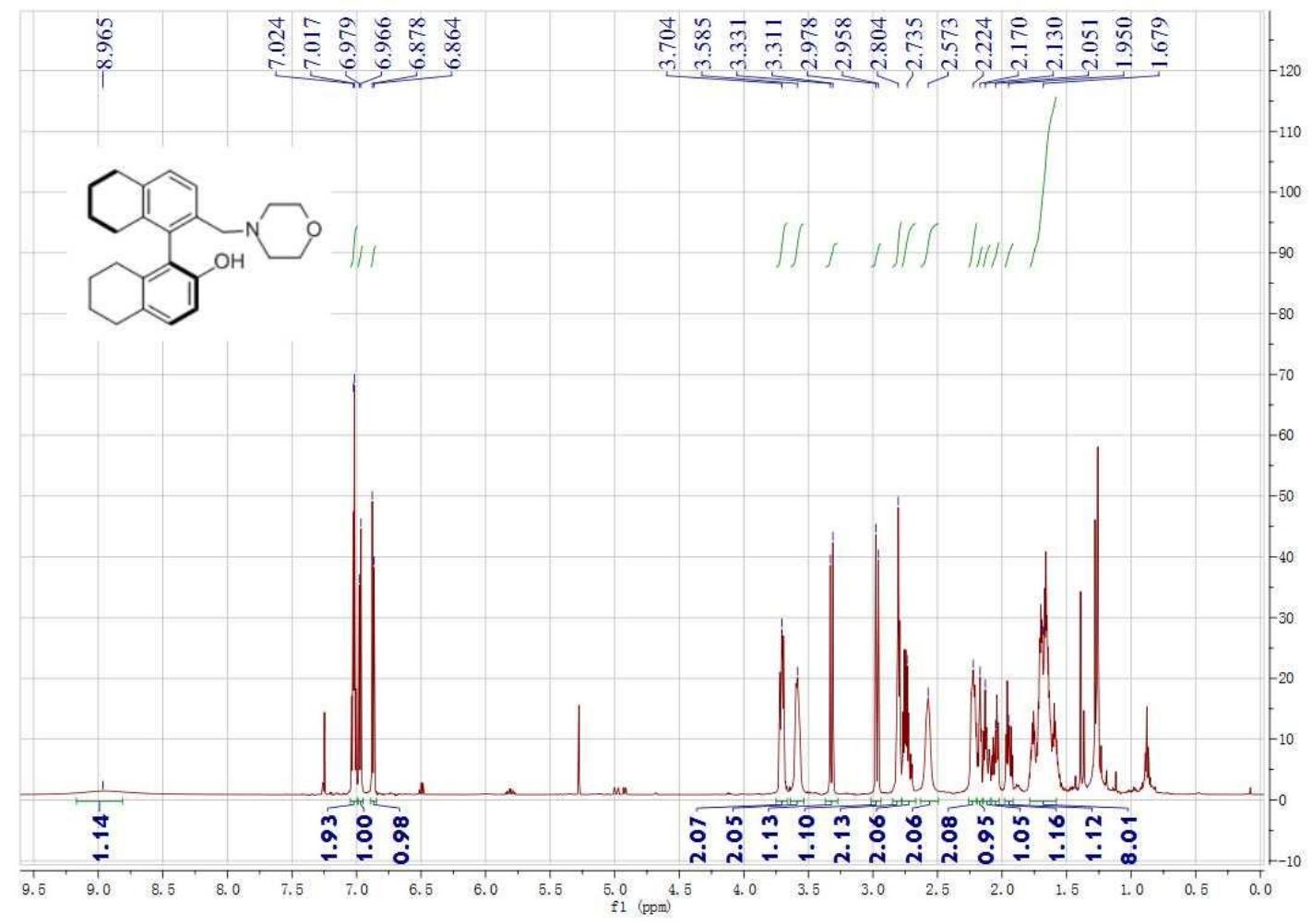

${ }^{13} \mathrm{C}$ NMR of D6

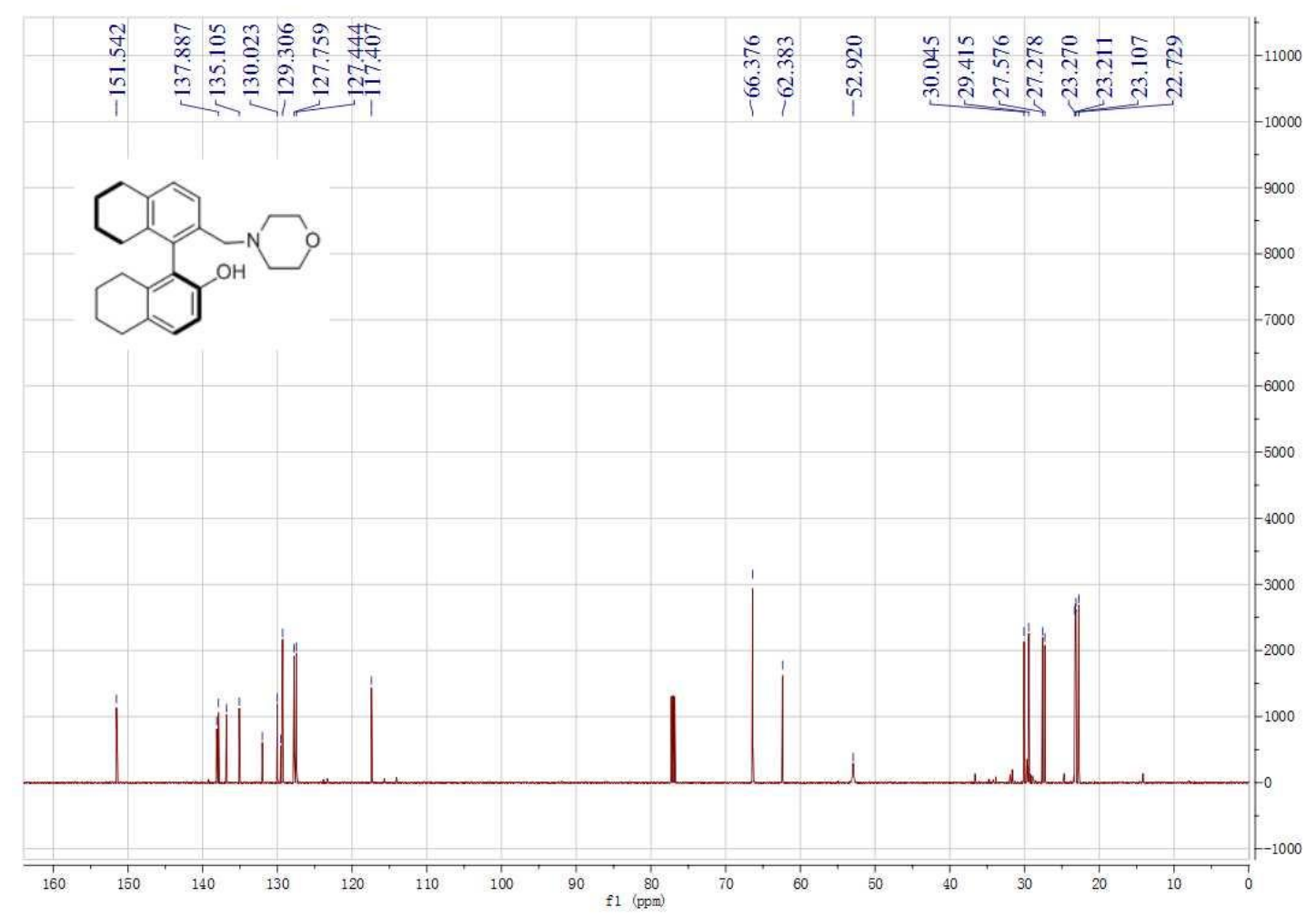


Reformatsky reaction product

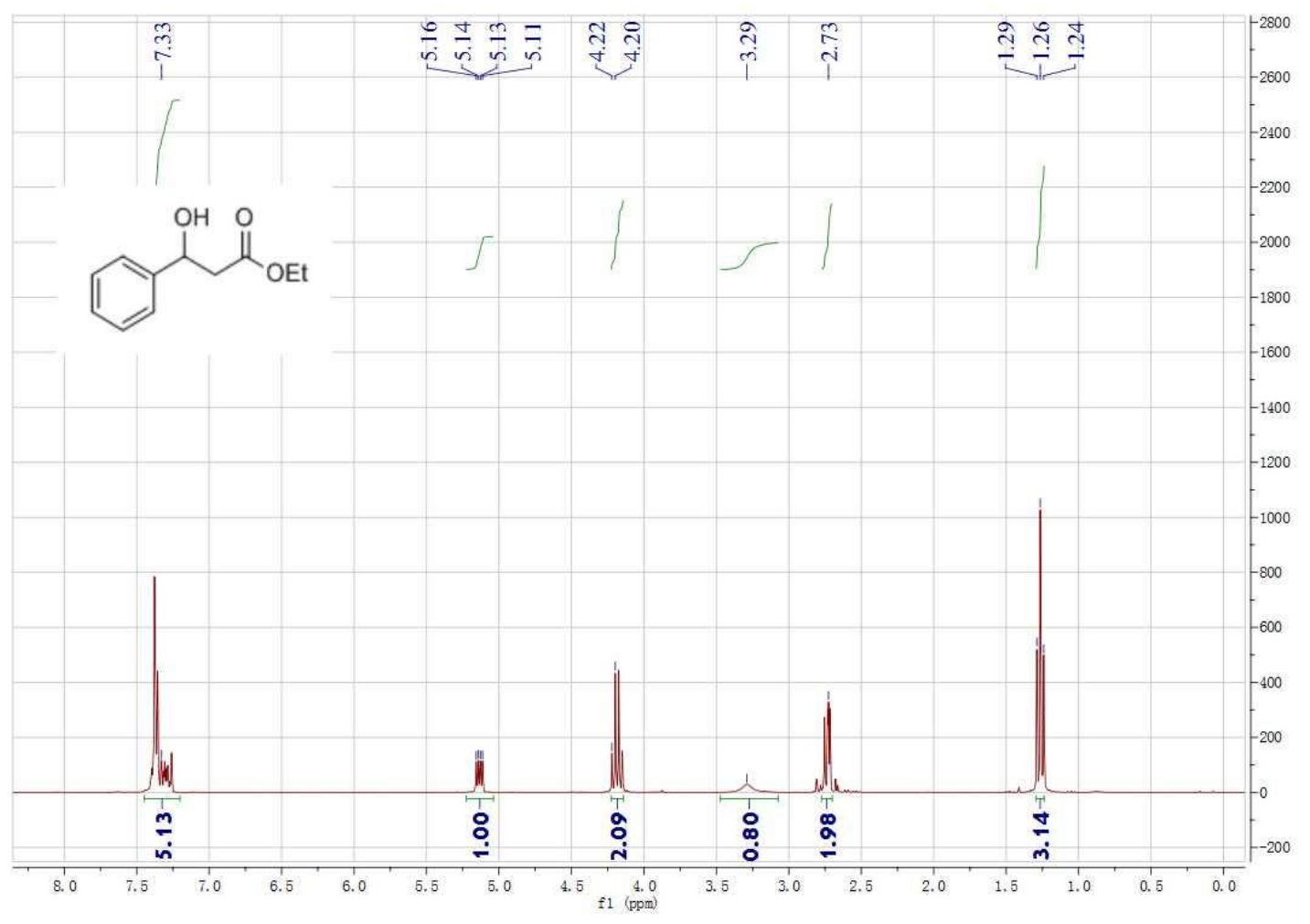

